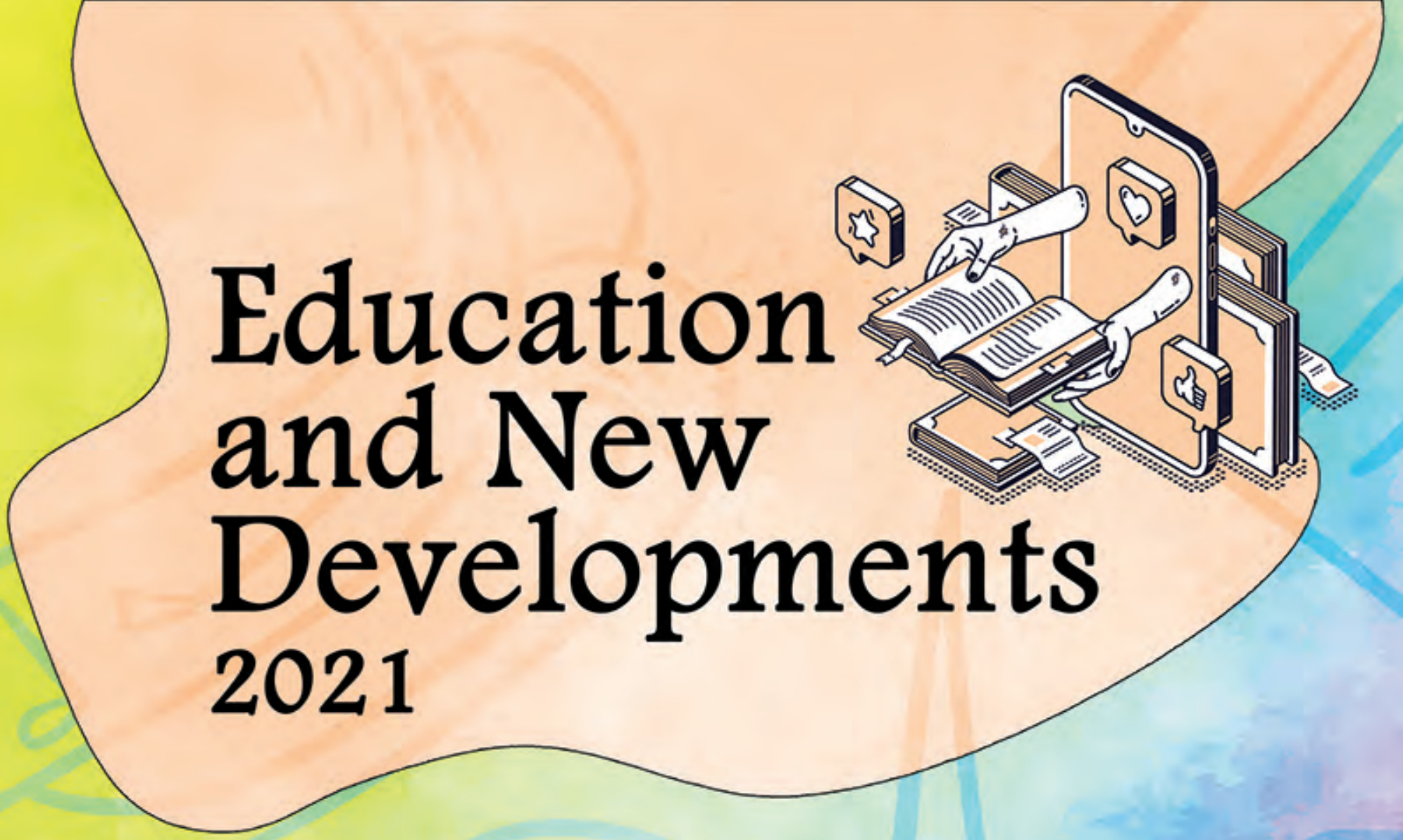

Edited by

Mafalda Carmo 


\section{Education and New Developments 2021}

Edited by

Mafalda Carmo 
Edited by Mafalda Carmo, World Institute for Advanced Research and Science (WIARS), Portugal

Published by inScience Press, Rua Tomas Ribeiro, 45, $1^{\circ} \mathrm{D}, 1050-225$ Lisboa, Portugal

\section{Copyright (C) 2021 inScience Press}

All rights are reserved. Permission is granted for personal and educational use only.

Commercial copying, hiring and lending is prohibited. The whole or part of this publication material cannot be reproduced, reprinted, translated, stored or transmitted, in any form or means, without the written permission of the publisher. The publisher and authors have taken care that the information and recommendations contained herein are accurate and compatible with the generally accepted standards at the time of publication.

The individual essays remain the intellectual properties of the contributors.

ISSN (electronic version): 2184-1489

ISSN (printed version): 2184-044X

ISBN: 978-989-54815-8-3

Legal Deposit: 428062/17

Printed in Lisbon, Portugal by GIMA - Gestão de Imagem Empresarial, Lda. 
Organizing and Scientific Committee

Keynote Lecture

Special Talk

xii

Index of Contents

xiii 



\section{FOREWORD}

This book contains the full text of papers and posters presented at the International Conference on Education and New Developments (END 2021), organized by the World Institute for Advanced Research and Science (W.I.A.R.S.), that this year had to be transformed into a fully Virtual Conference as a result of the Coronavirus (COVID 19) pandemic.

Education, in our contemporary world, is a right since we are born. Every experience has a formative effect on the constitution of the human being, in the way one thinks, feels and acts. One of the most important contributions resides in what and how we learn through the improvement of educational processes, both in formal and informal settings.

The International Conference seeks to provide some answers and explore the processes, actions, challenges and outcomes of learning, teaching and human development. The goal is to offer a worldwide connection between teachers, students, researchers and lecturers, from a wide range of academic fields, interested in exploring and giving their contribution in educational issues. We take pride in having been able to connect and bring together academics, scholars, practitioners and others interested in a field that is fertile in new perspectives, ideas and knowledge.

We counted on an extensive variety of contributors and presenters, which can supplement our view of the human essence and behavior, showing the impact of their different personal, academic and cultural experiences. This is, certainly, one of the reasons we have many nationalities and cultures represented, inspiring multi-disciplinary collaborative links, fomenting intellectual encounter and development.

END 2021 received 478 submissions, from more than 40 different countries, reviewed by a double-blind process. Submissions were prepared to take form of Oral Presentations, Posters and Workshops. The conference accepted for presentation 160 submissions (34\% acceptance rate), from which, 151 submissions are published in full text in this book.

The conference also includes:

- One Keynote presentation by Dr. Hava Vidergor $(\mathrm{PhD}$, senior lecturer of curriculum and instruction in the Graduate School at Gordon Academic College of Education, Israel).

- One Special Talk by Prof. Dr. Nazario Zambaldi (PhD General Pedagogy, Social Pedagogy, General Education and Subject Didactics at the Free University of Bolzano/Bozen, Italy)

We would like to express our gratitude to our invitees.

This conference addressed different categories inside the Education area and papers are expected to fit broadly into one of the named themes and sub-themes. To develop the conference program, we have chosen four main broad-ranging categories, which also covers different interest areas:

- In TEACHERS AND STUDENTS: Teachers and Staff training and education; Educational quality and standards; Curriculum and Pedagogy; Vocational education and Counselling; Ubiquitous and lifelong learning; Training programs and professional guidance; Teaching and learning relationship; Student affairs (learning, experiences and diversity; Extra-curricular activities; Assessment and measurements in Education.

- In PROJECTS AND TRENDS: Pedagogic innovations; Challenges and transformations in Education; Technology in teaching and learning; Distance Education and eLearning; Global and sustainable developments for Education; New learning and teaching models; Multicultural and (inter)cultural communications; Inclusive and Special Education; Rural and indigenous Education; Educational projects.

- In TEACHING AND LEARNING: Critical, Thinking; Educational foundations; Research and development methodologies; Early childhood and Primary Education; Secondary Education; Higher Education; Science and technology Education; Literacy, languages and Linguistics (TESL/TEFL); Health Education; Religious Education; Sports Education.

- In ORGANIZATIONAL ISSUES: Educational policy and leadership; Human Resources development; Educational environment; Business, Administration, and Management in Education; Economics in Education; Institutional accreditations and rankings; International Education and Exchange programs; Equity, social justice and social change; Ethics and values; Organizational learning and change, Corporate Education. 
This book contains the results of the research and developments conducted by authors who focused on what they are passionate about: to promote growth in research methods intimately related to teaching, learning and applications in Education nowadays. It includes an extensive variety of contributors and presenters, who will extend our view in exploring and giving their contribution in educational issues, by sharing with us their different personal, academic and cultural experiences.

We would like to express thanks to all the authors and participants, the members of the academic scientific committee, and of course, to our organizing and administration team for making and putting this conference together.

Hoping to continue the collaboration in the future,

Respectfully,

Mafalda Carmo

World Institute for Advanced Research and Science (WIARS), Portugal

Conference and Program Chair 


\title{
ORGANIZING AND SCIENTIFIC COMMITTEE
}

\author{
Organizer \\ World Institute for Advanced Research and Science (WIARS) \\ www.wiars.org \\ Conference and Program Chair \\ Mafalda Carmo \\ World Institute for Advanced Research and Science (WIARS), Portugal
}

\section{International Scientific Committee}

Aaron R. Deris, Minnesota State University, USA

Abdurrahman Guelbeyaz, Nagasaki University, School of Global Humanities and Social Sciences, Japan

Adrián Ponz Miranda, Zaragoza University, Spain

Ahmad Oueini, Lebanese American University, Lebanon

Alan Singer, Hofstra University, USA

Ali Baykal, Bahcesehir University, Turkey

Ali Yildirim, University of Gothenburg, Sweden

Alice Stephens, Clark Atlanta University, USA

Amir Dirin, Haaga-Helia University of Applied Science, Finland

Ana Conboy, College of Saint Benedict and Saint John's University, USA

Ana-Maria Bercu, Alexandru Ioan Cuza University of Iasi, Romania

Anca Draghici, Politehnica University of Timisoara, Romania

Andis Klegeris, University of British Columbia, Canada

Andrea Fiorucci, University of Salento, Italy

Andrea Hathazi, Babes-Bolyai University, Romania

Angela Piu, University of Valle d'Aosta, Italy

Anja María Mackeldey, Colegio Alemán Medellín / Universidad de Antioquia, Colombia

Antoni Kolek, University of Social Sciences, Poland
Aphrodite Ktena, National and Kapodistrian University of Athens, Greece

Aviva Dan, Ohalo Academic Education College, Israel

Beata Maślanka-Wieczorek, Polish-Japanese Academy of Information Technology, Poland

Beatriz Carrasquer Álvarez, Zaragoza University, Spain

Begoña Sampedro, University of Cordoba, Spain

Belkis Tekmen, Baskent University, Turkey

Binnur Yeşilyaprak, Ankara University, Turkey

Burcu Koç, Sakarya University, Turkey

Çağla Atmaca, Pamukkale University, Turkey

Carla Massoud, Saint-Joseph University

Beirut, France

Carolina Bodea Hategan, Babes-Bolyai University, Romania

Celia MacDonnell, University of Rhode Island and Brown University, USA

Cezar Scarlat, University "Politehnica" of Bucharest, Romania

Charalampos Karagiannidis, University of Thessaly, Greece

Charles Elkabas, University of Toronto, Canada

Cheng-Hsuan Li, National Taichung University of Education, Taiwan

Christian David Quintero Guerrero, Nueva Granada Militar University, Colombia

Christine Besnard, Glendon College, York University, Canada 
Christos Manasis, TEI of Sterea Ellada, Greece

Cory A. Bennett, Idaho State University, USA

Cristiano Luchetti, American University of Sharjah, United Arab Emirates

Daniel Madrid, University of Granada, Spain

Daniela Pasnicu, Spiru Haret University, Romania

David Aparisi, University of Alicante, Spain

David Nocar, Palacký University in Olomouc, Czech Republic

Denise Whitelock, The Open University, United Kingdom

Diane Boothe, Boise State University, USA

Dimitris Dranidis, The University of Sheffield International Faculty, CITY College, Greece

Donata Puntil, King's College London, United Kingdom

Dorina Anca Talas, Babeş-Bolyai University, Romania

Douglas Baleshta, Thompson Rivers University, Canada

Elena Polyudova, Defense Language Institute, USA

Elizabeth Sandell, Minnesota State University, USA

Ellen Whitford, Georgia Southern University, USA

Emre Erturk, Eastern Institute of Technology, New Zealand

Gilles Sagodira, University of Réunion Island, Reunion

Gina Chianese, University of Trieste, Italy

Giuditta Alessandrini, Università degli Studi Roma TRE, Italy

Gráinne Ní Dhomhnaill, University College Dublin, Ireland

Gyöngyi Bujdosó, University of Debrecen, Hungary

Harvey Oueijan, Notre Dame University, Lebanon

Hava Vidergor, Gordon Academic College of Education, Israel

Héctor Tronchoni, Florida Universitaria in Catarroja, Spain

Helena Skarupská, Tomas Bata University, Czech Republic
Helin Puksand, University of Tartu, Estonia

Henri Jacobs, Central University of Technology, Free State (CUT), South Africa

Huseyin Bicen, Near East University, Nicosia, Cyprus

Ilijana Čutura, University of Kragujevac, Serbia

Ilona Tandzegolskienė, Vytautas Magnus University, Lithuania

Ioana Velica, Babes-Bolyai University, Romania

Ioana Letiția Șerban, Babeş-Bolyai University, Romania

Iulia Mihalache, Université du Québec en Outaouais, Canada

Jacquelyn Baker-Sennett, Western Washington University, USA

Jana Mazancová, Czech University of Life Sciences Prague, Czech Republic

Janaina Cardoso, Rio de Janeiro State University, Brazil

Jeannette Jones, Texas Lutheran University, USA

Jitka Hloušková, University of Pardubice, Czech Republic

Joanna Paliszkiewicz, Warsaw University of Life Sciences, Poland

Jose Augusto Oliveira Huguenin, Universidade Federal Fluminense, Brazil

Juana Maria Sancho Gil, University of Barcelona, Spain

Judith Szerdahelyi, Western Kentucky University, USA

Julia Haba-Osca, University of Valencia, Spain

Karel Němejc, Czech University of Life Sciences Prague, Czech Republic

Karim Moustaghfir, Al Akhawayn University in Ifrane, Morocco

Katarína Slobodová Nováková, University of Ss. Cyril and Methodius in Trnava, Slovakia

Katerina Kabassi, Technological Educational Institute of the Ionian Islands, Greece

Kateřina Vitásková, Palacký University in Olomouc, Czech Republic

Khondkar R. Islam, George Mason University, USA 
Konstantinos Kalemis, National and Kapodistrian University of Athens / National Centre for Local Government and Public Administration, Hellenic Ministry of Education, Greece

Kyparisia Papanikolaou, School of Pedagogical and Technological Education, Greece

Ladário da Silva, Universidade Federal Fluminense (UFF), Brazil

Laura Rio, University of Bologna, Italy

Leela Ramsook, University of Trinidad and Tobago, Trinidad and Tobago

Lefkothea Kartasidou, University of Macedonia, Greece

Leila Kajee, University of Johannesburg, South Africa

Leona Stašová, University of Hradec Kralove, Czech Republic

Lina Kaminskienė, Vytautas Magnus University, Lithuania

Longzhi Yang, Northumbria University, United Kingdom

Loreta Chodzkiene, Vilnius University, Lithuania

Luis Gonzaga Roger Castillo, Universidad de Granada (UGR) / Centro de Estudios Bizantinos, Neogriegos y Chipriotas, Spain

Lukasz Tomczyk, Pedagogical University of Cracow, Poland

Luminita Cocarta, Al. I. Cuza University of Iasi, Romania

Maciej Dębski, University of Social Sciences, Poland

Magdalena Mądra-Sawicka, Warsaw University of Life Sciences, Poland

Magdolna Chrappán, University of Debrecen, Hungary

Małgorzata Cieciora, Polish-Japanese Academy of Information Technology, Polska

Maria Moundridou, School of Pedagogical and Technological Education (ASPETE), Greece

Maria Carme Boqué Torremorell, Ramon Llull University, Spain

Maria Luisa de Natale, Università Cattolica del Sacro Cuore, Italy

Marko Slavkovic, University of Kragujevac, Serbia
Marta Talavera, University of Valencia, Spain Maya Wizel, Middlebury College / Kibbutzim College, USA / Israel

Melissa Caspary, Georgia Gwinnett College, USA

Michael Reiner, IMC University of Applied Sciences Krems, Austria

Michele Lemos de Souza, Universidade Federal Fluminense, Brazil

Milan Kubiatko, University of Zilina, Slovakia

Napak-on Sritrakarn, Rajamangala University of Technology Isan, Thailand

Natalie Lavoie, University of Quebec in Rimousk, Canada

Nazario Zambaldi, Free University of Bolzano, Italy

Nella Mlsová, University of Hradec Králové, Czech Republic

Nihal Dogan, University of the Balearic Islands, Spain

Nilza Costa, University of Aveiro, Portugal

Paola Damiani, University of Turin, Italy

Pascal Marquet, University of Strasbourg, France

Paschalia Patsala, Arts and Humanities Research Council, United Kingdom

Pavel Brebera, University of Pardubice, Czech Republic

Pawel Topol, Adam Mickiewicz University in Poznań, Poland

Pedro Perera Méndez, Universidad de La Laguna, Spain

Petros Kefalas, University of York Europe Campus, Greece

Pule Phindane, Central University of Technology, South Africa

Rasa Nedzinskaitè-Mačiūnienè, Vytautas Magnus University, Lithuania

Remigijus Bubnys, Kaunas University of Technology, Lithuania

Rosanna Tammaro, University of Salerno, Italy

Rosemary Papa, Northern Arizona University, and Founder of Educational Leaders Without Borders, USA

Ryuichi Matsuba, Kumamoto University, Japan 
Sam Ramaila, University of Johannesburg, South Africa

Sandra Braun, Mount Royal University, Canada

Seppo Sirkemaa, University of Turku, Finland

Serhat Bahadir Kert, Yildiz Technical University, Turkey

Seweryn Spalek, Silesian University of Technology, Poland

Sharon Jaggernauth, The University of The West Indies, Trinidad \& Tobago

Sheryl Williams, Loughborough University, United Kingdom

Silvânia Alves de Carvalho, Universidade Federal Fluminense, Brazil

Silvia Nikolaeva, Sofia University, Bulgaria

Silvia Pokrivčáková, Trnava University, Slovakia

Simon Richir, Arts et Metiers Paristech (ENSAM), France

Soane Joyce Mohapi, University of South Africa, South Africa

Stefania Pinnelli, University of Salento, Italy

Stephanie Linek, ZBW - Leibniz Information Centre for Economics, Germany

Stephen Hughes, University of Granada, Spain

Susan Scott, Lakehead University, Canada

Suzie Savvidou, The University of Sheffield International Faculty, CITY College, Greece

Syed Ziaur Rahman, College of Applied Sciences-Ibri, Ministry of Higher Education, Sultanate of Oman, Oman

Tatjana Portnova, Russian Center of the University of Granada, Spain

Tena Velki, Josip Juraj Strossmayer University of Osijek, Croatia

Théodore Njingang Mbadjoin, University Lumière Lyon 2, France

Todd Brower, Western State College of Law, USA

Vanja Bevanda, Juraj Dobrila University of Pula, Croatia

Vashti Singh, Education Consultant and Independent Researcher, Trinidad and Tobago

Vicente J. Llorent, University of Cordoba, Spain

Wendy Setlalentoa, Central University of Technology, South Africa

Wiktor Bołkunow, Warsaw School of Economics, Poland

Yogesh Kumar Sharma, Government Shakamdhar PG College, Sambhar Lake, India

Youngsoon Kim, Inha University, South Korea

Yukiko Sawano, University of The Sacred Heart, Tokyo, Japan

Zoltán Rónay, Eötvös Loránd University, Hungary 


\title{
HYBRID LEARNING: KHAN ACADEMY PROMOTING PERSONALIZATION, INDEPENDENT LEARNING AND TEACHER-STUDENT RELATIONSHIP
}

\author{
Dr. Hava Vidergor \\ Graduate Studies, Gordon Academic College of Education, Haifa (Israel)
}

\begin{abstract}
Khan Academy (KA) is a useful platform for hybrid learning and especially learning math. However, little research has been conducted on how learners perceive using KA. The case study presented here examined the effectiveness of KA used by students at home combined with traditional face-to face learning in the class. Twenty-seven secondary school students $(\mathrm{N}=27)$ studying math filled in a reflective diary twice, and 18 of them consented to be interviewed. Main categories emerging from content analysis were the teacher, the student, teacher-student relations, subject and content, and learning environment. Main findings show: a. students perceived themselves as independent learners, investing in and aware of their functions as learners, more committed to the subject of math. b. Teachers using KA were perceived as more professional, dedicated, connected to students' needs, and innovative. c. KA was perceived as encouraging independence, available, and more interesting than books. d. Learning math via KA was more motivating and enjoyable. e. The teacher-student relationship was stressed by students as the most important component, being more valuable than the innovative learning environment. The main conclusion is that $\mathrm{KA}$ is effective in promoting personalization, independence, and innovative teaching-learning processes. However, the teacher's mediation of cognitive and emotional learning is crucial. Hence, teachers should use KA in math and other subjects available, while creating and maintaining direct lines of teacher-student interaction.
\end{abstract}

\section{Biography}

Dr. Hava Vidergor, $\mathrm{PhD}$, is a senior lecturer of curriculum and instruction in the Graduate School at Gordon Academic College of Education, Israel. She received an M.A. in educational leadership with distinction from University of Alabama at Birmingham, and a PhD in Education from Haifa University, Israel. Her research interests center on learning in hybrid environments, curriculum planning and design, innovative teaching-learning strategies, and gifted education. She has published numerous papers and presented widely in international conferences. She is the author or editor of several books: Applied Practice for Educators of Gifted and Able Learners (with Carole R. Harris), Innovative Teaching Strategies and Methods Promoting Lifelong Learning in Higher Education: From Theory to Practice (with Orly Sela) and Enhancing the Gift of Leadership (with Dorothy Sisk). She designed a new graduate program called Innovation in Education promoting teacher entrepreneurship in applying new pedagogies and creating and investigating blended learning environments. She serves on editorial board of reviewers of several international and local journals and experienced in editing special issues. Her Multidimensional Curriculum Model (MdCM) focusing on developing high order thinking and future thinking literacy in K-12 students was published in a book titled Multidimensional Curriculum Enhancing Future Thinking Literacy. 


\title{
POLIS: ARTS-BASED RESEARCH IN EDUCATION
}

\author{
Prof. Dr. Nazario Zambaldi \\ PhD General Pedagogy, Social Pedagogy, General Education and Subject Didactics, \\ Free University of Bolzano/Bozen (Italy)
}

\begin{abstract}
Starting from the $\mathrm{PhD}$ research Embodied Education through arts and theatre and from more than twenty years of artistic and theatrical research applied to education, the presented projects focus on the city as a metaphor and laboratory of practices. Introduced by a research and training experiences (LEA Languages Expression Arts and META Mediation Theatre Arts - shortly after 2000), a research in the psychiatric field is described (with the CRAT Centre of Research Art and Theatre and the direction of the CRATere festival, small review of arts, theatre and humanity - since 2005). A further area of arts-based research is related to inclusion and citizenship in the context of migration with the Theatre of Hospitality. Starting from these more recent projects, the Polis project is outlined: after the "end of the city", it affirms the need to reestablish communities through the re-appropriation of spaces and experiences - dialogue, ecology, memory - as well as through relationships and new alliances. The conclusions set out the developments of the Polis project, introducing an innovative methodological approach in the field of human rights, that is collocated between arts-based research and phenomenological videographic analysis.
\end{abstract}

Keywords: Arts, Theatre, Embodied Education, Arts-based research, Phenomenology, Videographic analysis, Human Rights

\section{Biography}

Nazario Zambaldi, PhD General Pedagogy, Social Pedagogy, General Education and Subject Didactics at the Free University of Bolzano/Bozen, Italy.

Theater director and visual artist, cultural operator, teacher of philosophy and human sciences in high school.

Topics of research and area of interest: Phenomenology, Arts-based research, Art, Theater, Embodiment, Ecology, Biopolitics, Human Rights.

www.metaart.it; nazario.zambaldi@gmail.com 


\section{ORAL PRESENTATIONS}

\section{$\underline{\text { Teachers and Students }}$}

The basis for a learning view - Education, experience and practice

Joar Sande

Designing teachers' training on adopting OERS in their teaching

Maria Perifanou, \& Anastasios A. Economides

The relations between musicianship and core competencies in professional music training-The TUT experience

Hua Hui Tseng

Early primary school teachers' perceptions about science and science process skills:

A framework to analyse the quality of ECEC services according to the child-centred culture

Paolo Sorzio, \& Caterina Bembich

Life sciences teachers' understanding, perceptions and adoption of inquiry-based science education in selected South African high schools Monde Kazeni, \& Nosipho Mkhwanazi

Teaching life sciences using second language: How do teachers cope? Amos Motloung, \& Lydia Mavuru

Cultural translation beyond an interdisciplinary exit, a meeting of knowledge Ana Hernández Espino

Life sciences teachers' conceptions about socioscientific issues in the topic evolution Mokgadi Relela, \& Lydia Mavuru

Spreadsheets and latex - A perfect union for the creation of testbanks for online assessment

Azam Beg, Manzoor Ahmed Khan, \& Maqsood Sandhu

Student mentor's ideal features: Peer choice

Madalena Cunha, \& Nuno Campos

The association between student engagement and creativity of undergraduates in China

Yanan Hu, \& Xiaotian Han

Using everyday language to support learners' access to mathematical content knowledge

Azwidowi Emmanuel Libusha

Free time and social relationships in a group of students from two high schools in Botosani County Adriana Albu, Mihaela Vlada, Adina Nechita, \& Florin Dima 
Teacher training for the prevention, reporting and addressing of violence against children

Elisabetta Biffi, \& Daniela Bianchi

Experiential learning processes using an e-diary in students' internship

Ilona Tandzegolskiené, \& Asta Lapéniené

A study on using game-based method to improve learning efficiency of junior

secondary school students

Timothy T.K. Wong, \& Yee Wan Kwan

Exploring South African preservice teachers' conceptual understanding

Sam Ramaila

How relationships impact sense of belonging in schools amongst female adolescents

Sonja Aicha Van Der Putten

Pedagogical practices adopted by teachers when teaching learners taking English as

first additional language in life sciences classrooms

Portia Seloma, \& Sam Ramaila

Building bridges: Bringing nonformal pedagogies into the classroom

Maya Wizel

Technology integration in natural sciences teaching and learning in South African township schools

Sam Ramaila

Pre-service teachers' preparedness and confidence in teaching life sciences topics:

What do they lack?

Lydia Mavuru, \& Oniccah Koketso Pila

A review of papers about block programming from the workshop on computing at school

Gilberto Amado de Azevedo Cysneiros Filho, Neiton Carvalho da Silva,

\& Barbara Silva Morais

Greek and Portuguese mathematics education and performance, through the

Prism of PISA

Eleni Nolka, \& Chryssa Sofianopoulou

Women faculty and scientific productivity in Latin American context:

Evidence from Chile

Geraldy Sepúlveda-Páez, \& Carmen Araneda-Guirriman

Identifying the effective teacher: The conceptions of pre-service assistant nurses

Katerina Kasimatis, Vasiliki Kontogianni, Andreas Moutsios-Rentzos, \& Varvara Rozou

Exploring information communications technology (ICT) infused microteaching module at a university of technology in South Africa

Paseka Patric Mollo

Perceptions and preferences of English student teachers on the assessment practices Pule Phindane

Transitioning architectural pedagogy into the virtual era via digital learning methods

Tatiana Estrina, Alvin Huang, Vincent Hui, \& Kristen Sarmiento 
Let's talk! Promoting meaningful communication through authentic teacher child dialogue

Barbara Shapir, Teresa Lewin, \& Samar Aldinah

Higher education institutions' need to initiate change to the accounting curriculum

during the fourth industrial revolution (4IR)

Shaun Peens

A reflection on gender achievement in sciences' rural school settings of multicultural

South Africa

Alice Mokoena, \& Gregory Alexander

Intercultural partnerships that foster cultural competence

Elizabeth J. Sandell, Katie Archer Olson, \& Maria-Renee Leonhardt Grigsby

The complexity of identity formation of black learners attending historically

white schools

Anthony Mpisi, \& Gregory Alexander

The portfolio of evidence in the competency-based educational model of the university

of Guanajuato

María Guadalupe Arredondo-Hidalgo, \& Diana del Consuelo Caldera González

Social science student teachers' awareness of the intertwiness of social science and social justice in multicultural school settings

Titus Williams, Gregory Alexander, \& Wendy Setlalentoa

Comparison of the first year learning outcomes of dual and nondual students in the light of the input competence survey

Róbert Pap-Szigeti, \& Erika Török

Ascertaining the use of extracurricular activities in promoting learners' holistic

development in multicultural school settings

Gregory Alexander, Sheila Matoti, \& Pieter Van Zyl

Initial and in-service training for secondary school teachers to implement projectbased learning (PBL)

Ana María Ortiz-Colón, Rafael Castellano-Almagro, Javier Rodríguez-Moreno,

\& Miriam Agreda Montoro

The interdisciplinarity of forensic sciences in the educational sphere: An analysis of this context in secondary school

Shirlene Carmo, Luís Souto, \& Carlos Silva

School-based in-service teacher training in literacy

Abha Gupta, \& Guang Lea Lee

Distance teaching and presence teaching towards a possible and useful integration Andrea Tarantino

Burnout prevention with psychoeducation in teachers

Mónika Veronika Szigeti

Investigating the use action learning approaches in civil engineering and construction studies: A case of skills centre

Khojane Geoffrey Mokhothu, Charles S Masoabi, \& Alfred H Makura

Pedagogical interactions in primary school reintegration processes: 
Reflective observations on the design and studio art programme at a university

Lebogang Nthejane

The importance of reflection-based strategies in training professionals working with MDVI children

Andrea Hathazi, \& Ioana-Letitia Serban

\section{Projects and Trends}

Game-based training: An effective method for reducing behavioral-finance biases

Digitally changing teaching practice environments: An exploration of concepts

Marloes de Munnik, \& Osama Al-Mahdi

Distance education and learning processes. A survey at university of Catania during the COVID-19 pandemic

Valeria Di Martino, \& Raffaella C. Strongoli

The plight of first-year teachers in public primary schools

Xiaotian Han

Instructional design of knowledge nuggets

Christian Ploder, Lisa Ehrhardt, Laura Gamper, \& Christoph Hazy

Change management: Experiences of private TVET college educators regarding virtual learning during COVID-19

Adebunmi Yetunde Aina, \& Ayodele Ogegbo

Impact of identity-oriented literature education on adolescents' insight into the self and the other

Peter Grandits

"Mind the gap": The transformative learning process of second language practitioners when becoming scholars

Dana Kaplan, \& Maya Wizel

University students' struggles with online learning during the COVID-19

Esther Chiner, Marcos Gómez-Puerta, Victoria E. García-Vera,

\& M. Cristina Cardona-Moltó

Escape room as a motivating tool in the English literature classroom

at tertiary education

Madalina Armie, José Francisco Fernández Sánchez, \& Verónica Membrive Pérez

Teaching in digital surroundings - Students opinion on digital tools and digital lectures

Marcin Fojcik, Martyna K. Fojcik, Lars Kyte, Bjarte Pollen, \& Jan Ove Rogde Mjånes

Students experiences on the use of google classroom: Case study of a university in Rwanda

Ayodele Ogegbo, \& Oyebimpe Adegoke

Teachers' attitudes in application of technology and effective teaching planning in primary school

Arjana Zhubi 
Identification of factors affecting elementary teachers' attitudes towards inclusion in

Kosovo: The role of demographic variables

Donika Koliqi, \& Naser Zabeli

Verification of affordance effect of HMI in the VR environment

Maki Arame, Junko Handa, Yoshiko Goda, Masashi Toda, Ryuichi Matsuba,

\& Tatsuru Daimon

A life-history case study on self-reliance experience of divorced migrant women

SooAn Choi, \& YoungSoon Kim

Digital storytelling and lifelong learning education in informal contexts:

The MEMEX project

Elisabetta Falchetti, Pascuala Migone, Cristina Da Milano, \& Maria Francesca Guida

An exploratory study on the research tendency of school counselors in South Korea

Sumin Kim, \& YoungSoon Kim

The impact of online activities on students' health and the importance

of time management

Carolina Bodea Hațegan, Dorina Talaș, \& Raluca Trifu

Use of social networks for the training of future teachers in early childhood education Mercedes Llorent-Vaquero, África M. Cámara-Estrella, Elena M. Díaz-Pareja,

\& Juana M. Ortega-Tudela

Participation to empower children and strengthen the community

Sabina Langer

Design thinking in future teachers training

Juana M. Ortega-Tudela, Elena M. Diaz-Pareja, África M. Cámara-Estrella,

\& Mercedes LLorent-Vaquero

The impact of COVID-19 on the school world

Rosanna Tammaro, Anna D’Alessio, Annamaria Petolicchio, \& Anna Iannuzzo

Massive open online courses camps: Before and during the pandemic

Janaina Cardoso

Storytelling and digital art as a means to improve multilingual skills

Véronique Delplancq, Ana Maria Costa, Cristina Amaro Costa, Emília Coutinho,

Isabel Oliveira, José Pereira, Patricia Lopez Garcia, Romain Gillain, Susana Amante,

Susana Fidalgo, \& Susana Relvas

4TH IR - Implications for higher education by looking at the use of mobile

teaching devices

Johannes Andreas Gerhardus Beukes

Reflections on offers and use of digital media for transferring knowledge in

teacher education

Susanne Schumacher, \& Ulrike Stadler-Altmann

Distributed intercultural project-based learning - A novel approach - Experiences

from a quadrilateral interdisciplinary collaboration

Manfred Meyer, Agung Nugroho, José Ochoa-Luna, Colin Stanley,

\& Heike Winschiers-Theophilus

The effect of a one-on-one dialogue-based mathematical intelligent tutoring system for learning equivalent fraction

Shu Chuan Shih, Hao Yu Tsai, \& Mei Ling Chen 
The good, the bad and the future - The challenges, positives and future strategies for higher education blended teaching

Monica Ward

Assessing the academic writing skills of final year English second language (ESL) educations students to determine their preparedness as language teachers:

A practical approach at a university of technology

Atrimecia Hass, \& Brigitte Lenong

Experiment D' - Serious game for the development of intercultural competences.

Concept, content, and experiences

Gala Rebane, \& Maik Arnold

Attitudes of grade one educators towards the implementation of inclusive education in classrooms at Botshabelo schools

Nomvuyo Joyce Mantshiyane, Wendy Setlalentoa, \& Pule Phindane

Challenges with the implementation of the admission policy for grades $R$ and 1 in the Motheo district in the Free State province of South Africa

Jaysveree M Louw

The role of communication as the drive for immigration: A case study in Finland

Zahra Hosseini, \& Sirkku Kotilainen

Education and technology during COVID-19 times

Daniel Nicolas Dominguez-Perez, \& Nicolas Dominguez-Vergara

Flipping a 700 student classroom

Peter Purgathofer, \& Kay Kender

Integration of pedagogy into technology: A practical paradigm

Zahra Hosseini, \& Jani Kinnunen

Development of health-promoting behaviour of a child as an educational goal in families of handicapped mothers with mental health disorders

Petra Hájková, \& Lea Květoňová

Online speech and language therapy. Focus-group based study

Carolina Bodea Hațegan, Dorina Talaș, \& Raluca Trifu

Upgrading MOOC students' engagement and participation in humanities-oriented online courses: The example of the MOOC based on the project "DETECt"

Jan Baetens, Roberta Pireddu, \& Frederik Truyen

Digital engineering: Competence acquisition and program development as an open co-creation process

Vanessa Mai, Susanne Wolf, Paul Varney, Martin Bonnet, \& Anja Richert

Analyzing indigeneity in academic and architectural frameworks

Tatiana Estrina, Shengnan Gao, Vivian Kinuthia, Sophie Twarog, Liane Werdina,

\& Gloria Zhou

Social skills teaching procedures in ASD-HF

Maria Carla Ricci, Francesca Di Carmine, Antonia Bosco, Agnese Lombardi,

\& Alessandro Frolli

Ensuring success in the flipped classroom when teaching on- line 
Virtual learning applying educational strategies in times of COVID-19; case of technology in military sciences

Flor Emperatriz Garcés Mancero, Magaly Margarita Narváez Ríos,

Luis Germánico Gutiérrez Albán, \& Víctor Danilo Lazo Alvarado

Service learning integrated with foreign languages learning:

Promoting transversal competencies

Dana Hanesová

\section{Teaching and Learning}

View of secondary technical school students on the paths and barriers to their professional development

Dana Vicherková, \& Josef Malach

Exploring the relationships between constructivist learning environment and critical thinking ability of secondary school students

Yee Wan Kwan

Online learning questionnaires based on renewable energy research equipment

F. Javier Maseda Rego, Itziar Martija López, Patxi Alkorta Egiguren,

Izaskun Garrido Hernández, \& Aitor J. Garrido Hernández

Educational initiatives to develop transversal skills in the management subject of master's degree in industrial engineering at Universitat Politécnica de Valéncia Mónica Martínez-Gómez, José Jabaloyes, \& Andrea Conchado Peiró

Analysing lesson-based interviews using the lesson activities map (LAMAP)

as a visual tool

Annamaria Savona

Pre-service teachers' critical reflection on the knowledge and skills learned in life sciences methodology module

Lydia Mavuru

Sleep quality and sleep habits in students

Beatriz Almeida, Carlos Albuquerque, Madalena Cunha, \& Anabela Antunes

A questionnaire for evaluating pupils' cognitive path about symmetry

at primary school

Simone Brasili, \& Riccardo Piergallini

Teachers experience with introducing programming in different courses for non-computer science students

Martyna K. Fojcik, \& Marcin Fojcik

Quality control tools in the analysis of COVID-19 caused problems

Nicolas Dominguez-Vergara, \& Daniel Nicolas Dominguez-Perez

The factors influencing the pedagogical orientations of the final year physical sciences pre-service teachers

Aviwe Sondlo, \& Umesh Ramnarain

Action research - Approach focused on the development of educational practice

Maja Domazet, \& Siniša Opić

Students' attitudes towards science: Where do we go from here 
Educational utilization of narrative medicine in Korean medical schools

Youngsub $\mathrm{Oh}$

Rethinking the other for multicultural education - Focused on the philosophy of

Buber and Levinas

Seungeun Choi

The teacher training during COVID-19 pandemic: An exploratory study about online laboratories quality

Rosanna Tammaro, Iolanda Sara Iannotta, \& Concetta Ferrantino

Theory and practice of storytelling with ScratchJr to develop early maths skills

Annarosa Serpe

Motivation in foreign language learning: The dynamic interactions of many factors

Christine Besnard

The development and piloting of an instrument to measure nature of science

(NOS) understanding

Tarisai Chanetsa, \& Umesh Ramnarain

Processability approaches to receptive third language acquisition: Implications for multilingual classrooms

Helen Forsyth

Cognitive and linguistic skills assessment protocol: Adaptation and validation for

Inês Martins, Cristiane Lima Nunes, Simone Aparecida Capellini, \& Graça S. Carvalho

Motivational power of gamification: The effect of playful learning on psychological needs of self-determination theory

Bahar Kutun, Alke Martens, \& Werner Schmidt

Teaching Setswana proverbs at the institution of higher learning in South Africa

Bridget Mangwegape

Faculty \& student retention: Keeping our HBCU-UDC alive during the

COVID-19 pandemic

Arlene King-Berry, \& Carolene Eslyn Charles

Student teachers' opinions about using authentic materials and tasks for acquiring

Estonian cultural history

Kristel Ruutmets, Evi Saluveer, \& Mari Niitra

Transfer effect of $N$-Back training: Mathematical implications in school-age children Selma Boz

\section{Organizational Issues}

Smart CV for lifelong qualifications certification based on blockchain

Anastasios A. Economides, \& Maria Perifanou

Knowing to empower: Study of the difficulties of the informal caregiver

Rosa Martins, Francisco Almeida, Susana Batista, \& Nélia Carvalho

Women in engineering, faculty of engineering in Bilbao

F. Javier Maseda Rego, Itziar Martija López, Patxi Alkorta Egiguren,

Izaskun Garrido Hernández, \& Aitor J. Garrido Hernández 
Creating lovemarks through students of public universities in Ireland

Javier Casanoves-Boix, Ana Cruz-García, \& Maurice Murphy

The impact of COVID-19 on residential care services for children:

A call for family-based approach in alternative care

Lucia Carriera, Chiara Carla Montà, \& Daniela Bianchi

Considerations of talent management in retention of academics in the National

601

University of Lesotho

Theressa Madzingesu Zengeya, Gregory Alexander, \& Desiree Pearl Larey

Higher education: Sustaining the future of students during a pandemic

Naziema Jappie

Enabling transformative inclusive learning pedagogies of preservice teachers in

610 multicultural higher learning contexts

June Palmer, Rantsie Kgothule, Gregg Alexander, \& Edwin de Klerk

Branding in private universities at EI Salvador: Brands that the public fall in love with Javier Casanoves-Boix, Ana Cruz-Garcia, Pablo Pinazo-Dallenbach,

\& José Ricardo Flores-Pérez

Transformative leadership in multicultural schooling contexts: A critical reflection of in-service teachers' practices and school managers' roles

Rantsie Kgothule, June Palmer, Gregg Alexander, \& Edwin De Klerk

Enhancing educators' credibility in intelligent learning environments

Mario Mallia Milanes, \& Matthew Montebello

Exploring the implementation of teacher leadership in Lesotho high schools

Lieketseng Lethole, June Palmer, \& Edwin de Klerk 


\section{POSTERS}

\section{$\underline{\text { Teachers and Students }}$}

The learnings of the basic education teacher

Joana Paulin Romanowski

What does a student of a teaching degree learn apart from subjects?

Interdisciplinary and intersectoral doctoral education designed to improve graduate employability

Tara Cusack, Nicola Mountford, Minna Isomursu, Guido Giunti Garcia, Dimitris Filos, \& Ioanna Chouvarda

\section{Projects and Trends}

Importance of digital competences and attitudes toward research in Mexican teachers Pedro José Canto Herrera, Hugo Salvador Flores Castro,

\& Sergio Humberto Quiñonez Pech

Self- and peer-assessment to enhance student engagement in undergraduate

group projects

Dermot Kerr, \& Sonya Coleman

MOOCS as a tool for virtual university orientation

Ilaria Merciai, \& Ruth Kerr

Heritage and art education through the screen. Filling the space by performative methodologies

Alessandra De Nicola

Creating a virtual study abroad experience to Russia

Jay Woodward, \& Michelle Kwok

New active methodologies for critical learning in the field of biochemistry

661 of human nutrition

Catharina Merchante, David Posé, Fernando Gallardo, Mar Quiñones,

Juan Antonio Gálvez, \& Beatriz Martínez-Poveda

Blueprints for change: What multicultural experience offers instructors of pre-service early education teachers

Michelle Henault Morrone, \& Yumi Matsuyama

School leadership and teachers' implementation of curriculum reform in Taiwan:

Mediating effect of teachers' orientation

Chun-Hung Cheng, \& Mei-Ju Chen

\section{Teaching and Learning}

A motor intervention to prepare learning to write

Natalie Lavoie, \& Émile Lebel

Organ donation: An educational pack for high school students 
A teaching micro-scenario

Anastasia Karamolegkou, Christina Diamantopoulou, Georgia Koutentaki,

\& Lefkothea-Vasiliki Andreou

\section{Organizational Issues}

Telecareer: Antecedents and consequences of strategic career behaviours on Iberian teleworkers

Joana Carneiro Pinto 


\section{WORKSHOPS}

\section{$\underline{\text { Teachers and Students }}$}

Radical present and reflexive connections. Didactical approaches to alienated spaces

Nushin Hosseini-Eckhardt, \& Leicy Esperanza Valenzuela Retamal

\section{Organizational Issues}

Principles for how we treat each other: Equitable conversations in our educational and personal spaces

Jennifer Sanguiliano Lonski, Laurinda Lott, \& Hank Van Putten 


\section{ORAL PRESENTATIONS}





\title{
THE BASIS FOR A LEARNING VIEW - EDUCATION, EXPERIENCE AND PRACTICE
}

\author{
Joar Sande \\ Western Norway University of Applied Sciences \\ Department of Computer science, Electrical engineering and Mathematical sciences (Norway)
}

\begin{abstract}
This article tells about my own experiences as a student and professor in technical education in Norway and USA in the 1980s and 90s, and economic education in Norway the academic year 2000-01. In technical education in Norway in the 1980s it was not necessary to put that much effort into your studies get a good grade. In the United States, on the other hand, students had two work hard to keep up to get good results. Norwegian higher education, however, has become more like American higher education after the Bologna process. A fresh university professor is nothing more than an advanced student, in the beginning one sticks to the textbook, and any deviation from the plan can cause light panic. As time goes by, the professor gains experience and growing self-confidence, and can start to experiment. My journey in teaching control engineering ended up with flipped classroom, based upon sociocultural learning, where both students and professors participate with the knowledge they have. Learning happens best if people interact and construct new knowledge together. The participants in the learning environment extend their closest (proximal) development zone by collaborating with others.
\end{abstract}

Keywords: Technical education, blended learning, flipped classroom, sociocultural learning, control engineering.

\section{Introduction}

-You are going to be a doctor, my grandmother told me. She said I had to bow to the medical secretary when I was at the doctor's office to get prescriptions for her. The medical secretary was the wife of the doctor. I did not bow, of course, because no one else did. Doctors were some of the finest grandma knew. There are many with higher education in my family for generations back, but no doctors. My conclusion was that there was one thing I should not become, and it was a doctor. I did not listen much to Grandma. The experiences I have from my own education have shaped me as a teacher. The teachers I have had have laid the foundation for my own educational and didactic approach to learning. Good, but also those perceived as bad teachers, have an approach to teaching that can be learned from. This article has two parts: In the first, I look at my own experiences as a student. The second section deals with my learning view, based on the subject area of control engineering which I have taught for over 20 years.

\section{Own experiences as a student}

After high school, I was in the Navy for one year, before I started at Bergen Engineering College in 1986, getting an engineering degree in automation technology. After that, I went on to the US for a 6-years master's degree in Electrical Engineering. I was dean of the Engineering Department at Sogn og Fjordane University College (SFIH) in the period from 1996 to 2000, and in my sabbatical leave after that, I pursued a degree in business economics at BI Norwegian Business School in Bergen the academic year 2000-01.

\subsection{Bergen college of engineering 1986-1989}

Bergen College of Engineering $(\mathrm{BIH})$ was one of the largest engineering education schools in Norway in the 1980 s, with traditions dating back to 1875 . The school, run by the county council, was taken over by the state and became a university college in 1977. The engineering programs went from being two-year to three-year in the early 80s. It was set up for teaching as in high school, with teaching in classrooms with the same schedule every week. The teachers did not have a common educational 
platform; they taught in their own way and had the same courses every year. There were assignments and laboratory exercises, but there were no particularly high demands on the students. The mathematics teacher took the students to the blackboard to show their calculations to the class, which meant that the students had to be well prepared for the lessons. The results in mathematics were therefore good. In some courses there were part-time professors, who came and did the job and not more than that. In any case, the students did not have the habit of visiting the professors at the office to ask for help. There were few and low requirements for the students, it was enough to read 14 days before the exam to get a decent grade. There were only written exams, usually of 5 hours, as final assessment. In one course we had a presentation, the only time we had to present something oral to the class. Most of the students probably had a feeling that they could not do anything practical after the education had finished, there were no subjects where we had gone into depth. This was the case in all engineering education in Norway in the 1980s and 1990s, the curriculum had many small courses that covered many different topics. The feeling was that no one was "good" in anything, but a foundation was laid anyway. If one was to study further and take a master's degree, it was the Norwegian Institute of Technology in Trondheim and the South Dakota School of Mines and Technology (SDSM\&T) in Rapid City, USA, which were the most relevant universities. BIH had a cooperation agreement with SDSM\&T, the course fit was approved beforehand, and therefore many went that way. Some went on to the Department of Physics at the University of Bergen (UiB), which offered a master's degree in physics.

\subsection{South Dakota school of mines and technology 1989-1992}

In American higher education there were many elements in the final assessment; assignments, laboratory exercises, tests, quizzes, and exams. This meant that the students had to work at a steady pace to keep up. You could typically achieve a final score of 700 points, where assignments and laboratory exercises counted 100 points each, tests 200 points, quizzes 100 points and the final exam 200 points. There were many oral presentations for the class, in the Senior Design Project there were five short reports with oral presentations underway, and a demonstration of the finished product in the end. Communication subjects and historical subjects were electives, and some were compulsory. To a small extent, there were project work where the students had to work in teams. We who came from Norway were used to working in teams and had more practical experience than the American students had. John Dewey's ideas on "learning by doing ", with a lot of group and project work, never really broke through in the United States (Dewey, 1962). The students from Asia were strong theoretical in mathematics and physics, but far less strong in practical subjects. Those from China, as an example, had just programmed on paper, without testing their programs on a computer.

A study at American universities in 1987 (Chickering \& Gamson, 1987) found that there were seven important factors that could help improve teaching. These seven factors are contact between students and professors, developing reciprocity and collaboration between students, using active learning techniques, providing quick feedback, emphasizes time on task, communicating high expectations and taking care of different talents and ways of learning.

Our education from Norway stood out well, compared to the education from other countries. The biggest difference was that we as students were "forced" to work hard, and it produced good results. It was also a short distance to the professor's office to ask for help. The students could enter a contract with the professor, one could choose to work towards an A and then receive clear feedback on what was expected. Otherwise, it was lessons in small classes, in some cases it went so fast that it seemed like the goal was to fill as many boards as possible in one class time. This meant that it was only time to write it down, and that the notes had to be reviewed afterwards. There was a lot of problem solving as homework, where emphasis was on repetition with solving many similar problems, until everyone understood the material. The exams were often multiple-choice, but those who already had a good A did not have to take it. The professor finally weighted the results after some sort of normal distribution, so that it was enough A and B. They decided everything that had to do with their courses. However, the department head gave clear notice if the grades were too bad. - I do not care what you do, but grades will have to be better!

\subsection{Norwegian business school $2000-2001$}

The first year at BI Norwegian Business School was the same for all fields of study, with lectures in large auditoriums with up to 300 students. Not all the material was reviewed, the lectures were mostly a guide on whether you succeeded in progression. The student group was composed of those coming from high school and adults who took further education or were on retraining. It was one group home exam, but there was no project work beyond that. There were no oral presentations, which can be difficult to have with such large student groups. The program worked well for them with a background from working life but made great demands on self-discipline. The students themselves had to make sure that they succeeded, and those who came straight from high school could easily fall out of the system. 
The biggest difference from technical education was that everything here centered on economy and economic returns. In a course, a spreadsheet should be prepared in connection with an analysis in accounting. You should make this spreadsheet yourself, but you could purchase it. One student had found a way to make money. It seemed legitimate to do so. The examination marks in the various courses were also weighted here, so that there was a normal distribution.

\subsection{The Bologna process}

The Bologna Process (Dahl \& Lindberg-Sand, 2009; Gornitzka, 2007), with the introduction of 3-year bachelor's degrees and 5-year master's degrees followed by 3-years doctoral degrees, has made Norwegian and European graduate education more like American graduate education. Globalization has meant that there are no longer national borders when it comes to education, and education must be comparable. The Quality Reform in Norway, which was introduced in the academic year 2003-04 (Fägerlind \& Strömqvist, 2004), made it possible to depart from the written examination as the only assessment element. It opened for so-called folder assessment, which can include tests and other student work. Closer follow-up of the students should prevent dropout.

\section{Control engineering}

\subsection{Introduction}

My learning view is essentially based on the sociocultural learning view, learning happens best if people interact and construct new knowledge together (Dysthe, 1999). The participants in the learning environment extend their closest (proximal) development zone (Vygotsky, 1978) by collaborating with others. The single student is a participant on par with everyone else, where everyone is equally important with the expertise and knowledge they have.

\subsection{Change of teaching program}

Professors plan forms of teaching they master, and students use learning strategies they are comfortable with. This can cause both parties to do more of what does not work. A new professor, newly graduated or experienced in the field of practice, needs to hang on to the teaching. In the beginning, it is a survival strategy, a bit in the same way as for fresh students. You must be confident about yourself, your colleagues and your students before you can give good teaching. Is there an introduction to the educational mindset of the university, and a common platform? It is difficult to organize the learning in any other way that is usual in the university. In the first year, notes or memorized content governs the teaching sessions. It is difficult to find room for activities that deviate from the planned arrangement.

I taught my first year as a professor at SFIH control engineering, also called technical cybernetics, which deals with automatic control of physical parameters such as speed, position, and temperature. Earlier subjects in mathematics and physics is the base. The program I followed was the textbook, traditionally laid out with theory teaching, computational exercises, and laboratory exercises. I did not have any educational education, and I made a program that I was used to as a student, and that was like my colleagues' plans. Control engineering was then two courses, Control Engineering 1 ( 6 credit points) and Control Engineering 2 ( 9 credit points). The content was the same that I had in my education, so I had a good overview of the learning material. I taught the subject, with some interruptions, until 2003.

In 2002, as a test scheme, I introduced a folder assessment, with one test and a submission that both accounted for $20 \%$ of the final assessment. Written exam was as before, but now with a weight of $60 \%$. Folder assessment became common with the introduction of the Quality Reform in 2003-04 (Fägerlind \& Strömqvist, 2004). The engineering programs in Norway received a new framework plan at the same time, and the two courses then merged into a course of 10 credits. I have had the course responsibility for that course since 2006.

Initially, it was 6 hours of classroom teaching every week, and with laboratory exercises that the students carried out on their own, but with access to guidance. There was a fixed schedule every week, for 14-15 weeks. It is not a very flexible arrangement, for neither students nor teachers. With the introduction of the new course in 2006, I transitioned to more problem solving than before, jointly with the students. The academic year 2013-14 I went to so-called blended learning (Picciano, Dziuban, \& Graham, 2013), where I made videos to support the review of most topics. The academic year 2017-18 was another step forward, with the transition to flipped classroom (inverted classroom). The students prepare themselves by watching videos beforehand, followed by up to 2 hours of blackboard teaching and 4 hours of self-activity with guidance every week. The videos are short cuts of $6-8$ minutes, which is a recommended length (Raths, 2014). I join the student group as a guide when they solve assignments and go through topics where I see that they have challenges. I also have made videos in theory they have had 
before in other subjects, and which is necessary in control engineering. I expect the students to have watched the videos before class. Spending time in teaching sessions on reviewing the videos is to punish those who have already watched them (Raths, 2014). Finally, the students write a reflection paper where they reflect on what they have learned in the course, and whether the expectations of themselves and others have been fulfilled. The reflection is included in the final assessment. Alternatively, they can record a video. It is important to go through the learning objectives and explain the educational program at the beginning of the course. Students want to know why they should learn this, and how relevant it is to working life. The learning objectives should be repeated throughout the semester. An expectation clearance at the start of the spring semester 2019 showed that the students will have distinct requirements, and they want to know what the expectations are.

\subsection{Flipped classroom and videos}

One way to prepare before class is to watch videos. I have prepared short videos with one single theme at a time. It is lot of research on flipped classroom and videos, and I will not repeat it here (Fyfield, Henderson, Heinrich, \& Redmond, 2019; Guo, Kim, \& Rubin, 2014). However, I checked on the use of videos in 2016 and 2017, when I made a transition from blended learning to flipped classroom. The results are shown in Table 1. In 2016 it was part of a study that investigated the differences in use of videos among engineering and nursing students (Sande, Leite, \& Kyte, 2020).

Table 1. Videos in control engineering.

\begin{tabular}{|l|l|l|}
\hline Question & $\mathbf{2 0 1 6}$ & $\mathbf{2 0 1 7}$ \\
\hline $\begin{array}{l}\text { The videos made it easier to understand } \\
\text { the subject matter. }\end{array}$ & 4,94 & 4,81 \\
\hline $\begin{array}{l}\text { The videos made me well prepared for } \\
\text { the learning sessions. }\end{array}$ & 3,68 & 3,93 \\
\hline $\begin{array}{l}\text { The model with videos and learning } \\
\text { sessions is more motivating than } \\
\text { lectures }\end{array}$ & 3,10 & 2,93 \\
\hline $\begin{array}{l}\text { The model with videos and learning } \\
\text { sessions gave me a greater learning } \\
\text { outcome than lectures. }\end{array}$ & 2,83 & 2,63 \\
\hline $\begin{array}{l}\text { The learning environment in the } \\
\text { learning sessions was good. }\end{array}$ & 4,36 & 4,50 \\
\hline $\begin{array}{l}\text { To what extent have you used the } \\
\text { videos before learning sessions. }\end{array}$ & 2,81 & 3,18 \\
\hline $\begin{array}{l}\text { To what extent have you used the } \\
\text { videos after learning sessions. }\end{array}$ & 3,29 & 4,56 \\
\hline
\end{tabular}

The questionnaire had a Likert scale: To very large degree 5, to a fairly large degree 4, to a fairly small degree 3, to a very small degree 2 and not at all 1. The number of participants in the survey were 21 in 2016 and 16 in 2017.

The students agree that videos made it easier to understand the subject matter. They also think the learning environment was good. In 2017, compared to 2016, more students watched videos after class. I still have a job to do to get flipped classroom work as intended. The Covid 19 situation and use of Zoom and Teams has given me more insight in distance learning and use of videos. My students have one clear recommendation: They want to meet on campus, and work together with other students. This is in accordance with my learning view and sociocultural learning, and together with the results in Table 1, probably means that a fully-fledged flipped classroom is not the way to go, blended learning is better.

\section{Closure}

In the old days, they built bridges with stone arching. The engineer stood under the arch when they removed the formwork, to show that he relied on the work done by himself and others. He (engineers were men of that time) knew that everyone, from those who laid the foundation to the one who placed the last stone that locked the arch, had done their job. The bridge was a result of collaboration between workers with different skills, and the engineer who people at that time believed had all the answers, was 
only one part of something bigger. These bridges are still standing today; those who built them had the necessary expertise.

Many of my ancestors in Hedmark County in Norway were wheel makers. They were not educated in mathematics and had never heard that the perimeter is $\pi$ times $d$, and that $\pi=3.14$. However, they knew that if you multiply the diameter $\mathrm{d}$ with a number slightly larger than three, the wheel would be round. The knowledge had gone from father to son for generations. The learning environment consisted of family members of three generations, with the advantages and disadvantages it could have.

\section{References}

Chickering, A. W., \& Gamson, Z. F. (1987). Seven principles for good practice in undergraduate education. AAHE bulletin, 3, 7.

Dahl, B. L., \& Lindberg-Sand, Å. (2009). Conformity or confusion? Changing higher education grading scales as a part of the Bologna Process: the cases of Denmark, Norway and Sweden. Learning and Teaching, 2(1), 39-79.

Dewey, J. (1962). The relation of theory to practice in education: Association for Student Teaching Cedar Falls, Iowa.

Dysthe, O. (1999). Ulike teoriperspektiv på kunnskap og læring. [Different theoretical perspectives on knowledge and learning]. Bedre skole, 3, 4-10.

Fägerlind, I., \& Strömqvist, G. (2004). Reforming higher education in the Nordic countries: studies of change in Denmark, Finland, Iceland, Norway and Sweden: UNESCO.

Fyfield, M., Henderson, M., Heinrich, E., \& Redmond, P. (2019). Videos in higher education: Making the most of a good thing. Australasian Journal of Educational Technology, 35(5), 1-7. doi:10.14742/ajet.5930

Gornitzka, Á. (2007). What is the use of Bologna in national reform? In Creating the European area of higher education (pp. 19-41): Springer.

Guo, P. J., Kim, J., \& Rubin, R. (2014, March). How video production affects student engagement: An empirical study of MOOC videos. Paper presented at the Proceedings of the first ACM conference on Learning@ scale conference.

Picciano, A. G., Dziuban, C. D., \& Graham, C. R. (2013). Blended learning: Research perspectives (Vol. 2): Routledge.

Raths, D. (2014). Nine video tips for a better flipped classroom. The Education Digest, 79(6), 15.

Sande, J., Leite, I., \& Kyte, L. (2020, June). Self-produced videos in flipped classroom for pre-course engineering students, engineering students and nursing students. Paper presented at the END conference.

Vygotsky, L. S. (1978). Mind in society: The development of higher mental process. In: Cambridge, MA: Harvard University Press. 


\title{
DESIGNING TEACHERS' TRAINING ON ADOPTING OERS IN THEIR TEACHING
}

\author{
Maria Perifanou, \& Anastasios A. Economides \\ SMILE lab, University of Macedonia (Greece)
}

\begin{abstract}
During the covid-19, it became apparent the imperative need for openly available digital educational resources to be used in education which has been shifted to Online Remote Teaching and Learning. It is important for teachers to be able to utilize Open Educational Resources (OERs) in education. This paper develops a framework for designing Teachers' Training programmes on how to integrate OERs in the teaching practice. The framework consists from six modules: 1) Introduction to OERs, 2) Exploring \& Evaluating existing OERs, 3) Using OERs, 4) Communicating \& Sharing OERs, 5) developing OERs, and 6) Open Educational Practices (OEPs). The paper also defines OERs \& OEPs competence. Finally, educational policy authorities may use this framework to design training programmes for teachers on how to integrate OERs in their teaching.
\end{abstract}

Keywords: Digital skills, inclusive education, lifelong learning, OERs skills, teachers professional development.

\section{Introduction}

During March and April 2020, more than 1.5 billion learners in most countries of the world were forced to attend online instead of face-to-face classes due to the COVID-19 social isolation restrictions (UNESCO, 2020). Almost all teachers and students participated in the online classes from home. However, it became clear that another form of discrimination is appearing. Not all teachers and students have the required digital infrastructure and digital skills to participate in such an Online Remote Teaching and Learning (ORTL). Furthermore, classes, teaching methods, and educational material (e.g. textbooks, case studies, assignments, projects, bibliographies) were not tailored to ORTL. Most educational material were in printed copyrighted form. Thus, it became apparent the imperative need for openly available digital educational resources to be used in ORTL. The adoption of Open Educational Resources (OERs) would be a solution.

OERs are digital educational material (e.g., full courses, educational modules, recorded lectures, assessments, case studies, textbooks, bibliographies, videos, photos, audio, multimedia, software, apps, tools, websites, learning management systems- LMS, social media) that are free (or with light copyright restrictions) to everyone to (http://www.opencontent.org/definition/):

- Retain - keep on a copy of the resource;

- Revise - adapt and modify (e.g., translate into another language) the resource;

- Remix - combine a copy of the resource with other material to produce something new;

- Reuse - use a copy of the resource;

- Redistribute - share a copy of the resource.

However, teachers usually do not have the knowledge and skills to use OERs or even know all about OERs. Also, many teachers would like to adapt the educational resources to their students' experiences, knowledge as well the local and current environment and context (e.g., Blomgren, 2018; Kimmons, 2015). Educators need new skills and knowledge to make the most of OERs and ORTL (OECD, 2020). According to TALIS (2018) survey, only 34\% of teachers in the European Union have participated in any online training in the past year. Thus, teachers (pre-service and in-service) need to be trained on utilizing OERs into their teaching practice. In fact, UNESCO (2019) stresses the need to train in-service and pre-service teachers on accessing, using, adapting, creating, and sharing OERs. 
There is an urgent need to design teachers' training programs and curricula to develop teachers' knowledge and skills on all phases of utilizing OERs into their teaching. Initially, it is important that teachers are able to find and use OERs. However, it is not easy to find OERs. They are scattered all over the places. Although there are serious efforts to gather and categorize them (e.g., Merlot, 2020; OER Commons, 2020), it is not an easy task. Therefore, a training program should give teachers the necessary knowledge and skills to find and evaluate appropriate OERs for their specific language, discipline, subject, educational level, student's age etc. (e.g., OPENLang Network Platform, 2020; OPENLang Network Project, 2020). Similarly, the training program should equip teachers with knowledge and skills to use and manage existing OERs as well to develop new ones. Furthermore, the teachers should be able to perform all educational activities using Open digital technologies. For example, the teachers should be able to communicate and teach students using open-source videoconferencing platforms (e.g., BigBlueButton) and open-source learning management systems (e.g. Moodle).

Next, this paper proposes a syllabus for Teachers' Training programmes on how to exploit Open Educational Resources (OERs) in the teaching practice.

\section{Methodology}

Inspired by the Open FASUCICESA - CPF Framework for MOOCs \& OERs (Economides \& Perifanou, 2018), this paper proposes a framework for a teachers' training syllabus. Among other issues, the Open FASUCICESA - CPF Framework describes the actions that a user can openly do on a MOOC and/or an OER without cost, anywhere, and anytime. These actions are the following:

- $\quad$ Openly Find (Seek, Locate, Discover);

- $\quad$ Openly Access (View, Watch, Read, Listen, Hear);

- Openly Store (Save, Retain, Download, Copy, Duplicate, Print);

- Openly Use (Control, Manage, Select);

- Openly Create (Design, Develop, Produce, Construct, Build, Calculate, Solve, Modify, Alter, Change, Adapt, Revise, Translate, Mix, Integrate, Combine);

- $\quad$ Openly Interact (Communicate);

- Openly Collaborate (Cooperate, Co-Create);

- $\quad$ Openly Evaluate (Assess, Review, Critique, Rank);

- Openly Share (Distribute, Teach, Publish, Display, Present, Present, Display, Show);

- Openly Abandon (Quit, Drop Out, Leave, Depart) without any penalties, charges, fines, obligations, punishments etc.;

under the following three dimensions of openness:

- Open Cost (allow anyone to participate at no cost);

- Open Place (allow anyone to participate from anywhere).

- Open Time (allow anyone to participate anytime);

Grouping together related actions, this paper proposes the following taxonomy of OERs skills: i) Exploring \& Evaluating existing OERs, ii) Using OERs, iii) Communicating \& Sharing OERs, and iv) Developing OERs using Open digital technologies (e.g., open data, open software, open hardware, and open networks). Of course, a training program on OERs skills should also include introductory issues about OERs as well as sections on Open Educational Practices (OEPs). So, we propose the following syllabus:

\section{Introduction to OERs}

- Open Education;

- OERs Definitions;

- OERs Types;

- Open Licenses, Intellectual Property Rights and Copyrights;

- OERs' Benefits \& Advantages;

- OERs' Weaknesses \& Challenges;

- $\quad$ OERs Costs (Production, Curation, Updating, Delivering etc.);

\section{Exploring \& Evaluating existing OERs}

- Search for OERs;

- $\quad$ Find (or locate, discover) OERs, and identify their Intellectual Property Rights; 
- Access (or view, watch, read, listen) OERs;

- Browse and navigate OERs;

- Evaluate (or assess, measure, compare, rank) OERs, and select (choose) the most appropriate ones;

\section{Using OERs}

- Store (or save, curate, archive) OERs on smart devices, LMSs, and Open Repositories;

- Download and install OERs (e.g., apps) on smart devices, LMSs, and Open Repositories;

- Copy (or duplicate, backup, curate) OERs on smart devices, LMSs, and Open Repositories;

- Analyse (or examine, investigate) OERs;

- Use (or operate) OERs in teaching and learning;

- Manage (or organize, plan, schedule) OERs;

- Terminate (or quit, withdraw, drop out, leave, depart, abandon, delete, dispose) OERs;

\section{Communicating \& Sharing OERs}

- Interact \& communicate (synchronously and asynchronously) with students and peers (or discuss, question-answer, argue, debate, negotiate) about OERs;

- Participate in Open Communities of peers about OERs;

- Collaborate \& cooperate with students and peers about OERs;

- Share (or disseminate, distribute, teach, publish, upload) OERs with students and peers in Open Communities and Repositories;

- Teach (or present, demonstrate, show, describe, explain) OERs to students and peers;

- Support (or guide, feedback, advise) students and peers with OERs;

- Evaluate (or assess, test) students using OERs;

\section{Developing OERs}

- Design OERs;

- Develop (or create, produce, write, edit, construct, build, generate) OERs;

- Code (or program) OERs;

- Execute OERs (e.g., run and parameterize software);

- Modify (or transform, convert, alter, change, adjust, adapt, revise, translate) OERs;

- Combine (or mix, synthesize, integrate, assemble) OERs;

- Correct (or repair, fix/solve problems in) OERs;

- Apply open licenses and copyrights to OERs;

- Protect students and peers using OERs and from inappropriate OERs.

\section{Open Educational Practices (OEPs)}

- Open Pedagogies;

- Open Teaching Methods \& Practices (e.g., Autonomous \& Self-Regulated Learning, Collaborative \& Social Learning, Discussions, Debates, Co-Creation);

- Open Assessment Methods (e.g., Peer Assessment, Collaborative Assessment, Problem-based Assessment, Project-based Assessment, e-Portfolio);

- Accessibility and Inclusion;

- OERs \& OEPs in specific disciplines (e.g., Languages, STEM, Economics, etc.);

- OERs \& OEPs in specific languages (e.g., English, Chinese, Hindi, Spanish, French, Arabic, etc.);

- OERs \& OEPs in Lifelong Learning;

- OERs \& OEPS Skills' Certification and Accreditation;

Module \#1 includes introductory material (definitions, types, benefits, challenges, and costs) about OERs as well as open licenses, intellectual property rights and copyrights issues. Regarding module $\# 2$, it is not a trivial task to find an OER suitable for a specific course, teacher, and students. Although important efforts have been made and are continuously made, there is not a comprehensive directory, meta-search engine, or repository (e.g., Merlot, 2020; OASIS, 2020; OER Commons, 2020; OpenDOAR, 2020) where a teacher can easily find an appropriate OER for his/her class on any subject at any educational level and language. So, it is important to train the teachers on the high variety of directories and repositories that contain open courses, educational modules, lesson plans, activities, assignments, assessment, textbooks, video lectures, podcasts, games and many other forms of educational material. 
A teacher should know the available OERs repositories, and be able to search them, locate appropriate OERs, explore candidate OERs, and understand their characteristics, properties and functionalities. In addition, the teacher should be able to identify the intellectual property rights of any OER.

It is also very important that the teacher should be able to evaluate the OER according to appropriate criteria (e.g., Economides \& Perifanou, 2018a, b; Perifanou et al., 2020). For example, a teacher should be able to evaluate the openness, authenticity, credibility, clarity, relevance, usefulness, ease-of-use, appearance, safety, and other characteristics of the OERs. Special attention should be given to the validity and reliability of the content since a lot of disinformation is circulated lately.

After selecting an appropriate OER, the teacher should be able to use it (module \#3). This includes downloading, storing, and curating it on various devices (e.g., mobile phone, laptop, desktop computer, LMS, institutional repository). Then the teacher should be able to schedule and use it in teaching and learning. Finally, if the OER becomes obsolete, the teacher should be able to withdraw and replace it with another appropriate OER. The teachers should not be locked in an inappropriate OER.

Regarding module \#4, the teacher should be able to openly interact, communicate, collaborate with students and peers using OERs. Also, the teacher should be able to share OERs with students and peers, as well as teach, support, and assess students using OERs.

Then, in module $\# 5$, the teacher should be able to modify, combine, and correct existing OERs. In addition, the teacher should be able to design, develop, and create new OERs. Finally, the teacher should be able to apply open licenses (e.g., Creative Commons) and copyrights to OERs as well as protect students and peers using OERs and from inappropriate OERs.

Finally, module \#6 contains material related to Open Educational Practices (OEPs). The teacher should be able to apply Open Pedagogies, Open Teaching and Assessment methods that are inclusive. Since different teachers teach different subjects (e.g., humanities, social sciences, natural sciences, law, medicine) in various languages, specific guidelines should be given to teachers according to the specific needs of the specific subject and language (as well socio-economic context).

Concluding, let define OERs \& OEPs competence to be the person's knowledge, skills and attitudes to 'efficiently' find, evaluate, use, create, and share OERs \& OEPs, as well as communicate and collaborate with others using open digital technologies, OERs \& OEPs in order to achieve specific goals. In other words, an OERs \& OEPs competent teacher should be able to find, evaluate, use, create, and share OERs \& OEPs, communicate and collaborate with students and peers using open digital technologies, OERs \& OEPs as well as utilize open pedagogies, teaching, and assessment methods.

\section{Conclusions and future research}

In order to not discriminate students regarding their access to educational resources that may cost a lot, educational authorities should develop educational policies and strategies of adopting Open Educational Resources (OERs) at all disciplines and levels of education. In order to efficiently integrate OERs \& OEPs in the teaching practice, pre-service and in-service teachers should be trained in utilizing OERs \& OEPs. This paper proposes a framework for teachers' training syllabus on OERs \& OEPs. Educational policy officials and training authorities may use this framework to design training programmes for teachers on how to integrate OERs in their teaching.

Features studies may investigate the impact of teachers' training programmes on teachers' competence to integrate OERs \& OEPs in their teaching practice. Also, investigation among different disciplines would shed light on the difficulties and obstacles that teachers of different disciplines face. For example, what is the level of difficulty in finding OERs for teaching economics, law, biology, Italian language, or philosophy?

\section{References}

Blomgren, C. (2018). OER awareness and use: The affinity between higher education and K-12, The International Review of Research in Open and Distributed Learning, Vol. 19 No. 2, doi: 10.19173/ irrodl.v19i2.3431.

Economides, A. A. \& Perifanou, M. (2018a). Dimensions of openness in MOOCs \& OERs. In: EDULEARN2018 Proceedings, 10th International Conference on Education and New Learning Technologies, pp. 3684-3693. 2-4 July, Palma Spain, IATED Digital library. DOI: $10.21125 /$ edulearn.2018.0942

Economides, A. A., \& Perifanou, M. A. (2018b). MOOC affordances model. In: 2018 IEEE Global Engineering Education Conference (EDUCON) (pp. 599-607). DOI: 10.1109/EDUCON.2018.8363285 
Kimmons, R. (2015). OER Quality and adaptation in K-12: Comparing teacher evaluations of copyright-restricted, open, and open/adapted textbooks. The International Review of Research in Open and Distributed Learning, 16(5). DOI: 10.19173/irrodl.v16i5.2341

Merlot (2020). Retrieved October 10, 2020 from: https://www.merlot.org/merlot/

OASIS (2020). Retrieved October 10, 2020 from: https://oasis.geneseo.edu/

OECD (2017). Giving knowledge for free: The emergence of Open Educational Resources. ISBN: $\quad 9789264032125 . \quad$ Retrieved June 10, 2019 from: http://www.oecd.org/education/ceri/38654317.pdf

OECD (2020). Lessons for education from COVID-19. A policy maker's handbook for more resilient systems. Retrieved June 10, 2019 from: http://www.oecd.org/education/lessons-for-educationfrom-covid-19-0a530888-en.htm

OER Commons (2020). Retrieved October 10, 2020 from: https://www.oercommons.org/

OpenDOAR (2020). Retrieved October 10, 2020 from: https://v2.sherpa.ac.uk/opendoar/

OpenLang Network Platform (2020). Retrieved October 10, 2020 from: https://openlangnetwork.kmi.open.ac.uk/

OpenLang Network Project (2020). Retrieved October 10, 2020 from: https:/www.openlangnet.eu/

Perifanou, M., Kosmas, P., Parmaxi, A. \& Economides, A.A. (2021). The challenge of creating the Openlang Network's online open database of 24 European language placements tests. In: 15th annual International Technology, Education and Development Conference (INTED) 2021, 8-9 March, IATED Publ.

TALIS (2018). The OECD Teaching and Learning International Survey. Retrieved October 10, 2020 from: https://www.oecd.org/education/talis/

UNESCO (2019). Recommendation on Open Educational Resources (OER). Retrieved October $\quad 10, \quad 2020 \quad$ from: $\quad$ http://portal.unesco.org/en/ev.php-

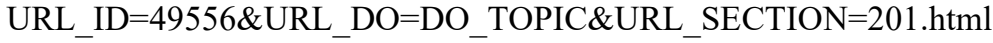

UNESCO (2020). COVID-19 Impact on Education. Retrieved October 10, 2020 from: https://en.unesco.org/covid19/educationresponse 


\title{
THE RELATIONS BETWEEN MUSICIANSHIP AND CORE COMPETENCIES IN PROFESSIONAL MUSIC TRAINING-THE TUT EXPERIENCE
}

\author{
Hua Hui Tseng \\ Tainan University of Technology (Taiwan)
}

\begin{abstract}
After being asked to respond to the Arts Education Act of 2015 by the Ministry of Education, Taiwan, concerning curricula and their impact on music education, what follows are some observations and reflections from the Tainan University of Technology (TUT), Taiwan, about its educators' experiences of teaching undergraduate music and music degrees. The idea put forward is that skills/knowledge competency reflects an emergent sensibility in contemporary music cultures, and this represents an opportunity for music educators to reconfigure and strengthen their pedagogical approaches. By recognizing the legitimacy of new and varied forms of musicianship and acknowledging the ways in which course curricula continue to grow in their range of practices and necessary literacies, strategies can be developed to support broader, cohesive, inclusive, diverse, meaningful, and useful experiences for music students.
\end{abstract}

Keywords: Curriculum, musician, core competencies.

\section{Introduction}

Contemporary society demands that people add value, and for musicians, it is no different. The demand implies offering holistic musical learning experiences that accommodate technology and allow musicians to add value to their communities. Kardos (2018) noted that artists and practitioners who generate influence and esteem in contemporary music might not look or sound like music students do, and the natural latency between curriculum development and the speed of life means higher music education programs that seek to reflect trends in contemporary cultures will inevitably lag behind. According to Abankwa and Mikkilä-Erdmann (2018), the lack of alternative programs for teacher training and the limited flexibility to obtain professional pedagogical qualifications as a musician is surprising because instrumental/vocal teachers need to have a broader understanding of their working responsibilities and possibilities and an understanding that goes beyond teaching artistry and embraces working on more general levels of music and art education (Abankwa \& Mikkilä-Erdmann, 2018). Berr (2016) noted that artistry first requires mastery of the basics because a skilled, knowledgeable, artistic and experienced musician acts as a source of inspiration for students in developing their own musicianship (Abankwa \& Mikkilä-Erdmann, 2018).

The concept of musicianship is usually thought of as part of a curriculum, and musicianship can permeate the classroom by handling most activities artistically (Berr, 2016). As stated in England's Action Ideal VIII by the Mayday Group (2018), ideally, music education makes important contributions to musical cultures (Kardos, 2018). This connection should be seen the manifest link between music research and the learning taking place in educational institutions. Kardos (2018) noted beyond issues of vocational viability of graduates, specializations can foster potentially crippling literacy issues, for example, music performance graduates who cannot operate technology or music technologists who cannot read music, etc. Conventional music curriculum creates boundaries between practices, which in the real world are becoming increasingly blurred and/or irrelevant. It is critical that professional music training provide a wide range of practical experiences in combination with professional musicianship and the cultivation of artistic personalities to indicate broader understanding of exciting music cultures and the possibility for inquiry-based learning.

The skills/knowledge competencies were recently adopted by Cole (2014) and Rohwer and Henry (2004), and the music teaching found herein continues to be relevant because of (a) the importance of skills/knowledge competencies; (b) the difficulty of acquiring skills/knowledge competencies; (c) the differences between the importance of teaching competency and acquisition ratings; (d) the benefits of university coursework; and (e) the potential improvements to coursework that are encompassed in three categories of skills/knowledge components, (teaching, personal, and musical skills and behaviors), each with individual competency items. 
Professional music training programs are challenged by major changes in the sociocultural and educational landscape. In response to Taiwan's societal challenges, such as current issues about music education policy, the Ministry of Education in Taiwan (1997) amended the Arts Education Act (AEA) that outlined the curriculum for study in the performing arts in 1997. The AEA of 1997 was related directly to Taiwan's art education reform (Lau \& Li, 2013). This new milestone provided a solid foundation in music education in Taiwan for all students (Ministry of Education, Taiwan, 1997). The TUT, Taiwan, Music Department's seven-year program from high school directly to a bachelor's degree in vocational education serves as an example for incorporating educational interventions based on Teachout's (1997) three categories of skills/knowledge components, namely, teaching, personal, and musical skills and behaviors as core competencies.

Recent curricular redesign at the TUT music department presented the opportunity to place greater emphasis on the three core competencies in the first two years of the music curriculum and transition basic Fundamentals (Ear and Mind) of Music courses into outcomes-based models. Introductory Ear-Training is one of several basic Fundamentals (Ear and Mind) of Music courses from the "old" curriculum that was completely revised. The Taiwan's Ministry of Education 2014 Curriculum Guidelines for the 12-Year Basic Education (covering elementary, junior high, and upper secondary school stages) core competencies drove the process of integrating first-year Theory, Harmony, Counterpoint, Sight Singing, Ear Training, Dictation, Form and Analysis Orchestration, Instrumentation, Keyboard Harmony, and Composition and related Theoretical/Aural skills into one course (Ministry of Education, Taiwan, 2014). As a result, an 18-week (720-contact-hour) hybrid didactic block given the title "Music Theory" was implemented. The course is comprised of more than 40 educational interventions that each target one or more core competencies.

\section{Relationships between musicianship and core competencies}

The aim of this research is to explore the assumed relationship between musicianship and core competencies (see Figure 1). It was assumed that musicianship, as naturally associated with knowing how to listen and think about music at the strategic level, is the category starting the relationship. The case of the TUT was examined. The main reasons for the choice are that the study has been ongoing over a number of years, it offers a seven-year program from high school directly to a bachelor's degree in vocational education, and artistry first requires mastery of the basics, suggesting that TUT is a leader in professional music training.

Figure 1. Relationships between musicianship, core competencies, and curriculum.

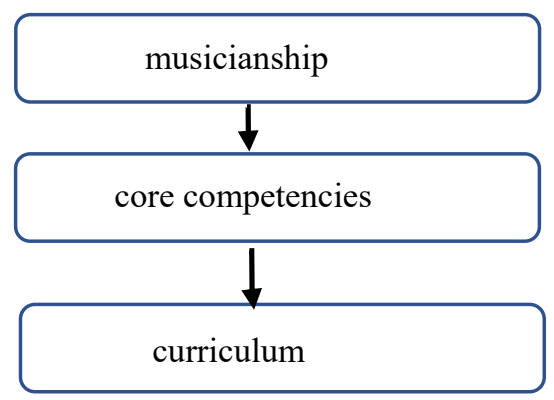

The curriculum falls into three main categories in the TUT's music department: Musicianship, Applied Studies and Ensembles, and Major Requirements. The primary focus of an integrated or holistic curriculum is not on the disciplines themselves but on the themes, the issues, or the phenomena (American Association for the Advancement of Science, 2000). A thematic approach is used to integrate curricular content by common topical areas or themes into interdisciplinary and multidisciplinary units of study (Merritt, 2019). In the 1930s, American educator and composer Randall Thompson, supported by the Carnegie Foundation, conducted a study to determine the extent to which musical education was an essential component of education as a whole (Nelson, 2005). Nelson (2005) concluded by discussing the significance of a critical, holistic approach for processes of acquired expertise to policy. The study was influential across the country in encouraging the integration of musical studies with other disciplines.

As an example, with respect to Integration in a chamber music class, the teacher might take time in class to dissect "Archduke Trio" as students rehearse the piece. For example, the teacher can alert students to what was going on in music history at the time that Beethoven composed this piece and discuss how it is similar or different to anything that audiences had heard before. Much like a college music theory lecture, the teacher can discuss with the students and raise awareness about how Beethoven uses triadic tonality and sonata-form in inventive ways. The teacher might also focus on stage presence and reflect on what worked 
and what did not work. The purpose of learning this piece goes beyond just playing good music well. It might incorporate an intentional introduction to new musical discourses and tools for students to add to their cognitive understanding of how music works (Table 1).

Table 1. Integrated curriculum, instruction/teaching, learning, related strategies, and the associated terminology.

\begin{tabular}{|l|l|}
\hline Curriculum & Instruction/Teaching \\
\hline $\begin{array}{l}\text { Chamber Music, for example, using Beethoven's - } \\
\text { Piano Trio Op. 97 "Archduke Trio." }\end{array}$ & $\begin{array}{l}\text { The Chamber Music requirements that are } \\
\text { integrated into the performance degree programs. }\end{array}$ \\
\hline Integrated & Integrated Curriculum \\
\hline $\begin{array}{l}\text { Incorporate Chamber Music into students' degree } \\
\text { curricula ("ensemble participation"). }\end{array}$ & $\begin{array}{l}\text { These include Sonata Classes, String \& Piano } \\
\text { Chamber Music, and The Intensive Quartet } \\
\text { Seminar. }\end{array}$ \\
\hline Integration & Learning \\
\hline $\begin{array}{l}\text { Regarding musicianship, instructors need to help } \\
\text { their students develop a confident, respectful, and } \\
\text { expressive stage presence. }\end{array}$ & $\begin{array}{l}\text { A certain level of body awareness is key as this } \\
\text { will assist in the students' expressive ability and } \\
\text { to use their physiology to support their musicality } \\
\text { and technical prowess. }\end{array}$ \\
\hline $\begin{array}{l}\text { Strategies } \\
\text { The didactic skills that can be cultivated } \\
\text { specifically through the study of Chamber Music } \\
\text { include (a) the ability to constructively self-assess } \\
\text { both as an individual and as a group, and (b) the } \\
\text { development of coaching, rehearsal, and basic } \\
\text { time management strategies and skills. }\end{array}$ & $\begin{array}{l}\text { The holistic instruction of performance and } \\
\text { pedagogy appeared as (a) modeling, (b) guided } \\
\text { thinking, (c) overt instruction of pedagogy, and } \\
\text { (d) experience. }\end{array}$ \\
\hline
\end{tabular}

\section{Application of skills/knowledge competencies in the music theory block}

The 2020 National Association of Schools of Music (NASM) Handbook provides access to the NASM standards and guidelines that include proposed revisions to NASM standards currently open for comment, including the Association's helpful Basic Competency Index by Discipline and Specialization for Undergraduate Degrees in Music (NASM, 2020). The NASM Handbook indicates standards applicable to all professional undergraduate music degrees. Expert status is established by these criteria: (a) common body of knowledge and skills, including performance, musicianship skills and analysis, composition/improvisation, history and repertory, and synthesis, (b) general studies competencies, and (c) recommendations for professional studies.

Each of the NASM core competencies is addressed below with descriptions of some of the specific educational interventions currently employed in the music theory block at the TUT Music department. This study's intent is not to evaluate the effectiveness of individual interventions but to create awareness about the variety of options for incorporating core competencies into the basic Fundamentals (Ear and Mind) of Music portion of undergraduate music curricula. For example, the ears perceive only what the knowing mind can understand. Thus, critical listening skills come from both knowing what is heard and for what to listen (Wang, 2017). For example, a teacher might encourage her students to listen to great performances that provide aural models that foster the cursory mind-ear connection (cognitive). Next, she could invite students to engage the ear to critically discriminate what is heard in performances and practice rooms in search of differing subtleties to help students gain clarity and form aesthetic concepts and opinions (emotional). Furthermore, the teacher may urge students to listen to the orchestral, chamber, vocal and solo instrumental works of the composers they study (spiritual). Table 2 at the end of the article lists the educational interventions possible. 
Table 2. Educational interventions in the music theory block targeting MOE core competencies.

\begin{tabular}{|c|c|}
\hline Personal & Musical knowledge \\
\hline $\begin{array}{l}\text { Students might be given comparative listening } \\
\text { projects; after being given the score, students } \\
\text { would evaluate two different performances of the } \\
\text { same short work or section of a piece. }\end{array}$ & $\begin{array}{l}\text { Three categories of skills/knowledge components } \\
\text { comprised of teaching, personal, and musical } \\
\text { skills and behaviors are included each with } \\
\text { individual competency items. }\end{array}$ \\
\hline $\begin{array}{l}\text { Faculty deal with Sight Singing in a number of } \\
\text { ways, including allowing students to choose a } \\
\text { method that seems comfortable for them (either } \\
\text { fixed Do, moveable Do, numbers, note names, } \\
\text { etc.) or using syllables for some exercises but not } \\
\text { for others. }\end{array}$ & $\begin{array}{l}\text { All undergraduate music majors must satisfy both } \\
\text { the written music theory and aural skills } \\
\text { requirements, which are team taught by } \\
\text { theory/composition teachers. }\end{array}$ \\
\hline $\begin{array}{l}\text { Emphasizing musical expression more and giving } \\
\text { students additional "hands-on" experiences; Ear } \\
\text { Training and Sight Singing classes (and music } \\
\text { theory) may more effectively awaken and develop } \\
\text { students' musicality and musicianship. }\end{array}$ & $\begin{array}{l}\text { Philosophical approaches are introduced by using } \\
\text { different musical tools to teach musical skills } \\
\text { (e.g., fixed or movable Do, La, or Do-based } \\
\text { minor) as corresponding to the purpose and need } \\
\text { for music theory instruction. }\end{array}$ \\
\hline Teaching & $\begin{array}{l}\text { An electronic audience response system is used } \\
\text { for daily formative feedback addressing } \\
\text { individual and group questions. }\end{array}$ \\
\hline $\begin{array}{l}\text { Music theory block runs concurrently with the } \\
\text { placement examination curriculum. }\end{array}$ & $\begin{array}{l}\text { A skills assessment (dictation, sight-singing, and } \\
\text { keyboard reading) and written theory assessment } \\
\text { (analysis, figured bass realization, etc.) are } \\
\text { evaluated by taking placement examinations in } \\
\text { both music theory and aural skills. }\end{array}$ \\
\hline $\begin{array}{l}\text { All undergraduate music majors must satisfy both } \\
\text { the written music theory and aural skills } \\
\text { requirements. }\end{array}$ & $\begin{array}{l}\text { Written theory may be better addressed primarily } \\
\text { by ear (e.g., meter, when to raise scale degree } 7 \text { in } \\
\text { minor keys, harmonic rhythm, resolving tendency } \\
\text { tones). } \\
\text { Aural skills include: } \\
\text { - hearing and adjusting intonation while playing } \\
\text { - } \quad \text { hearing the quality of a chord } \\
\text { - } \quad \text { hearing and recognizing pitches in a melody } \\
\text { - } \quad \text { tapping a rhythm that you have heard } \\
\text { - } \quad \text { singing a melody at sight from written music } \\
\text { without the aid of a piano or other instrument. }\end{array}$ \\
\hline $\begin{array}{l}\text { Introduction to music has students work } \\
\text { backwards using different kinds of musical } \\
\text { notation, melodic systems, harmonies, meters, and } \\
\text { rhythmic techniques with the goal of attaining basic } \\
\text { competence in the performance and creating music } \\
\text { to explore scale, mode, rhythm, meter, texture, } \\
\text { and form, with reference to a diverse range of } \\
\text { music. }\end{array}$ & $\begin{array}{l}\text { - Musical skills include chord analysis and } \\
\text { modulation. } \\
\text { - Chord analysis includes how a chord is related } \\
\text { to the key and to the other chords in a piece of } \\
\text { music. } \\
\text { - Modulation occurs when a longer succession } \\
\text { of chords emphasizes a new tonic, leading to } \\
\text { the perception of a new key. }\end{array}$ \\
\hline $\begin{array}{l}\text { Students develop their listening skills in the areas } \\
\text { that make music. }\end{array}$ & $\begin{array}{l}\text { How well can student scrutinize and analyze a } \\
\text { song? }\end{array}$ \\
\hline
\end{tabular}

\section{Conclusion}

Among the basic competencies by discipline and specialization in the TUT Music Department curriculum, Music Theory was the logical starting point for implementing competency-based education because the "often" or "always" included musical competencies (Robinson, 2019) already included essential standards; in addition, activities with those musical competencies and theory-based strategies were in place. It is possible that music theory is unique among the core music curriculum traditionally included in university coursework with its many opportunities to help students toward all three NASM core competencies. Future work is needed to integrate all essential competencies, experiences, and opportunities across disciplines to further connect them to professional practices and make them outcomes-based so that every learner develops the skills, expertise, and knowledge to survive and thrive in the twenty-first century. 


\section{References}

Abankwa, J., \& Mikkilä-Erdmann, M. (2018). Piano teacher education in Finland and Germany: Targeted competencies and respective learning environments of two cases. International Journal of Music Education, 36(4), 616-629 (C) The Author(s) 2018 Article reuse guidelines: sagepub.com/journalspermissions DOI: 10.1177/0255761418775130 journals.sagepub.com/home/ijm

American Association for the Advancement of Science. (2000). Designs for science literacy. New York, NY: Oxford University Press.

Berr, B. (2016). Musicianship rules. American Music Teacher. 65(6), 64-64.

Cole, M. R. (2014). An examination of cooperating teachers' observations of their student teachers in the areas of personal, teaching, and musical skills in the elementary classroom (Doctoral dissertation). Available from ProQuest Dissertations and Theses database. (UMI No. 3617588)

Hendrixson, C. (2015). Holistic education in a secondary band classroom. Retrieved from https://repository.tcu.edu/bitstream/handle/116099117/10343/Caleb_Hendrixson_Honors_Thesis.p df? sequence $=1 \&$ isAllowed $=y$

Kardos, L. (2018). Making room for 21st century musicianship in higher education. Action, Criticism, and Theory for Music Education, 17(1), 33-47. doi:10.22176/act17.1.33

Lewis, L. K. (2014). A model for developing a holistic collegiate curriculum for string performance and pedagogy (Doctoral dissertation). Available from ProQuest Dissertation and theses database. (UMI No. 3638399)

Merritt, R. D. (2019). Integrated curriculum. Research Starters Education, (4/1), 1.

Miksza, P., Roeder, M., \& Biggs, D. (2010). Surveying Colorado band directors' opinions of skills and characteristics important to successful music teaching. Journal of Research in Music Education, 57, 364-381. doi:10.1177/0022429409351655

Ministry of Education, Taiwan (2014). Curriculum guidelines of 12- year basic education. Retrieved from https://www.naer.edu.tw/ezfiles/0/1000/img/52/129488083.pdf

$\begin{array}{lllll}\text { Ministry of } & \text { Education, } & \text { Taiwan. } & \text { (1997). } & \text { Retrieved }\end{array}$ https://law.moj.gov.tw/ENG/LawClass/LawHistory.aspx?pcode=H0170037

National Association of Schools of Music (2020). National association of schools of music handbook 201920. Retrieved from https://nasm.arts-accredit.org/wp-content/uploads/sites/2/2020/01/M-2019-20Handbook-02-13-2020.pdf

Nelson, A. J. (2005). Cacophony or harmony? Multivocal logics and technology licensing by the Stanford University Department of Music. Industrial and Corporate Change, 14 (1), 93-118 doi:10.1093/icc/dth045

Nierman, G. E. (2017). Report from NAfME: The ISME national affiliate in the United States of America. Retrieved August 16, 2020, from https://www.isme.org/news/report-nafme-us

Robinson, E. (2019). An examination of North Carolina music educators' preferences of musical competencies (Master's thesis). Available from ProQuest Dissertation and Theses database. (UMI No. 27629154)

Rohwer, D., \& Henry, W. (2004). University teachers' perceptions of requisite skills and characteristics of effective music teachers. Journal of Music Teacher Education, 13(2), 18-27. doi:10.1177/10570837040130020104

Teachout, D. J. (1997). Preservice and experienced teachers' opinions of skills and behaviors important to successful music teaching. Journal of Research in Music Education, 45, 41-50. doi:10.2307/3345464

Wang, E. (2017). This and that. American Music Teacher, 66(6), 52-53. 


\title{
EARLY PRIMARY SCHOOL TEACHERS' PERCEPTIONS ABOUT SCIENCE AND SCIENCE PROCESS SKILLS: A CASE STUDY IN SOUTH AFRICA
}

\author{
Monde Kazeni \\ Science Education, University of the Witwatersrand (South Africa)
}

\begin{abstract}
Early primary school (grades R to 3 ) science education has been in the spotlight in recent years, as science education scholars are increasingly acknowledging the need to provide a strong foundation in science education, to motivate learners to study the subject in subsequent years. Literature suggests that most early primary school teachers lack the basic knowledge required to introduce young learners to science, and to motivate them in the study of science. Primary school teachers' limited knowledge of science and its processes could affect how they introduce and develop science concepts in early primary school learners. In the South African context, there is limited literature on early primary school teachers' knowledge of science and its processes, as well as on teachers' attitudes towards the teaching of science to early primary school learners. The purpose of the study was to investigate early primary school teachers' knowledge of the concepts of science and science process skills, and to determine their perceptions regarding the teaching of science in early primary school. The study involved four purposively selected early primary school teachers, in the Gauteng province of South Africa. Qualitative data were collected using semi-structured interviews, and the findings showed that the participating teachers had limited knowledge of the concepts of science and science process skills, and that they mostly had negative perceptions about the teaching of science in early primary school. These findings have implications on the training of early primary school teachers.
\end{abstract}

Keywords: Perception, knowledge, science process skills, primary school.

\section{Introduction}

For most people, primary school is the place where interest in science begins or ends. In other words, primary school science education forms the foundation for children's love, fear or the hate of science. If teachers do a bad job when teaching science to primary school children, it will be very difficult to get them interested and successful in science related subjects at secondary school or university levels. Early primary school children (5 to 9-year-olds) are naturally curious and want to explore the world around them, as they seek to integrate information about their surroundings (Jirout \& Klahr, 2012), which is precisely what scientist do. Early primary school (Grades R-3) science education therefore presents an opportunity to harness young people's curiosity, by directing it towards an understanding of science and its processes, with the purpose of developing scientifically minded individuals.

Early primary school teachers in South Africa are expected to introduce and motivate learners in the study of natural science and to develop science process skills (DBE, 2011). For early primary school teachers to teach science effectively, they need to have a basic understanding of what science entails, and the processes involved. In addition, they need to have positive attitudes towards the teaching of science. Science as a concept is broad, and it is defined differently by different scholars and disciplines. In the context of this study, science refers to the Natural science, taught in the Foundation phase (early primary school), in South Africa. In this study, I adopted the definition of science provided by the National Academy of Sciences (2008), which is; "The use of evidence to construct testable explanations and predictions of natural phenomena, as well as the knowledge generated through this process. p.10". Scientific knowledge is generated by scientists using specific science process skills, which are the processes used by scientists during their work, and the competencies displayed in solving scientific problems (Fugarasti, Ramli, Muzzazinah, 2019). According to Padilla (1990), science process skills are classified into basic and integrated process skills. The South African Foundation phase Curriculum and Assessment Policy Statement (CAPS) prescribes the development of basic science process skills, which include; observing, comparing, classifying, measuring, experimenting, and communicating (DBE, 2011). Explicit instruction of science process skills is considered effective in helping learners to gain skills that could enable them to approach science as scientists do, and it is necessary for mastering science content and to better prepare 
learners for careers in science (Coil, Wenderoth, Cunningham \& Dirks, 2010). It is therefore imperative for early primary school teachers to understand the essence of science and its processes.

Despite the advocacy in the South African CAPS to teach science and its processes at different educational levels, the performance of South African learners in science, including international science assessments, such as the Trends in International Mathematics and Science Study (TIMSS), has been consistently poor (Pretorius, 2014). While many factors could account for this poor performance, ineffective teaching of science in the Foundation phase could be a contributing factor (Shidiq \& Falkhmta, 2020). Unfortunately, most primary school teachers are not trained as science teachers or as scientists (Gerde, Pierce, Lee, \& Van Egeren, 2018), therefore lack science knowledge. For instance, a study conducted by Beni, Stears and James (2012), titled "Teaching natural sciences in the Foundation phase: Teachers' understanding of the natural science curriculum", found that Foundation phase teachers lacked the scientific knowledge that could enable them to teach science effectively. These researchers pointed out that teachers' lack of science content knowledge could affect their confidence to teach science, which could influence their attitudes towards the teaching of science, and the ways they teach it. In this regard, Ualesi and Ward (2018) found in their study on; Teachers' attitudes toward teaching science in a New Zealand Intermediate School, that teachers' attitudes determined the amount of effort they put in their lessons, as well as their willingness to go the extra mile. According to these researchers, the major contributor of negative attitude towards the teaching of science is teachers' lack of science knowledge.

The purpose of this study was to find out how early primary school teachers understand science and science process skills, and their perceptions regarding the teaching of science to early primary school learners. This investigation is particularly important because teachers' knowledge and perceptions about science could influence the way they introduce it to young learners (Abungu, Okere \& Wachanga, 2014).

\section{Objectives}

1. To determine early primary school teachers' understanding of science.

2. To establish early primary school teachers' knowledge of science process skills.

3. To explore teachers' perceptions about the teaching of science to early primary school learners.

\section{Conceptual framework}

As mentioned earlier, teachers' knowledge and perception of science could influence their confidence in teaching and guiding learners during science lessons, which could ultimately shape learners' interest, understanding and their decisions about future careers in science (Shidiq \& Falkhmta, 2020). This understanding is the basis of the Science, Technology, Engineering and Mathematics (STEM) conceptual framework used by Shidiq and Falkhmta (2020) in their study titled; "Exploring the relationship of teachers' attitudes, perceptions and knowledge, towards integrated STEM". The framework shows that teachers' cognitive, affective and self-efficacy influence their attitudes towards science, and these attitudes interact with perceptions and knowledge to ultimately influence teachers' integration of STEM in their teaching (Shidiq and Falkhmta (2020). This framework guided the investigation of early primary school teachers' knowledge of science and science process skills, and their perceptions about the teaching of science to young learners, in this study.

\section{Methodology}

A qualitative research approach, involving multiple case studies, was used to investigate early primary school teachers' knowledge of the concepts of science and science process skills, and perceptions about teaching science to early primary school learners. Four teachers purposively selected from different township (peri-urban) schools in Johannesburg, South Africa, participated in the study. All four participating teachers taught Foundation phase learners, and their profiles are provided under their narratives in the results section.

\section{Data collection and analysis}

Face-to-face semi-structured interviews were used to collect qualitative data. Interview items focused on teachers' description of science, their knowledge of science process skills, and their views regarding the teaching of science to early primary school learners. The interview schedule was piloted using two teachers who did not participate in the main study, to identify and revise items which were not clear to the interviewees. Data collected from interviews were transcribed, coded and sorted according to each participant's responses. 


\section{Study findings}

The profile of each participant, interview questions related to the objectives of the study and the responses provided by the participant are presented below.

\section{Teacher 1}

This participant was a female teacher, who held a Bachelors' degree in Business Management, and later obtained a Post-Graduate Certificate in Education (PGCE). She had 6 years' experience in Foundation phase teaching. She confessed, prior to the interview, that she has limited knowledge of science. The following were her responses to the interview questions.

i. How would you describe science as a concept, to someone who does not know what it is?

Response: "Science is more about solving problems using machines or medicine. I would say science is more technical, you know! Working with mixtures in the lab and finding cures. People who are science orientated solve things for themselves, because they do not trust God".

This teacher seemed to believe that science is all about finding cures, solutions to problems, and working in the lab, and that scientists do not trust God.

ii. What is your understanding of science process skills? Provide examples to clarify your response. Response: "(Coughs) Process skills you say? Like processes of what?" Are these process skills in the CAPS document or is it something from America or Europe?"

The interviewer informed her that they are in the CAPS document and provided an example of process skills (measuring). The teacher said that she does not know them.

iii. How do you feel about teaching science to early primary school learners?

Response: "From a religion point of view, it is a bit early to introduce science to Foundation phase learners. Science tends to be against Christianity, and learners at this age like to ask 'why' and finding out more about things. So, they can easily get confused and stop believing in God".

According to teacher 1, teaching science to young learners could confuse them and prevent them from accepting religious teachings.

\section{Teacher 2}

This was a male teacher who held a Bachelor of Education (B.Ed.) degree and had a 3-year Foundation phase teaching experience. The following texts display his responses to interview questions.

i. How would you describe science as a concept, to someone who does not know what it is?

Response: "Science is a way of life, it makes things easier for people. Science is innovation, changing the world and coming up with new technologies to make life easier and better. Science is everywhere, and it is in everything; in medicine, our food, our clothes, just about anything is made with science, even life".

This teacher seemed to know the benefits and products of science, but he did not refer to the nature of science and its processes, in his description of science.

ii. What is your understanding of science process skills? Provide examples to clarify your response. Response: "Skills are basically what you should be able to do, like read and write; and a process is a continuous thing, something that goes on. So, what they should always be able to do in science is to read, write, calculate and estimate. You know! The teacher appeared to have limited understanding of science process skills.

iii. How do you feel about teaching science to early primary school learners?

Response: I think science should be taught very early in school. I mean, look at the rest of the world; science is introduced to learners at a very young age. In places like China, they start in pre-school to make electric houses and cars, while our (South African) learners only really start to engage fully with science in grade 4, which disadvantages them a lot. If you only start to learn something at age 10, you won't really like it, as you will feel like it is just a subject that you need to learn to pass, and with science, your attitude determines your outcome.

The teacher seemed to advocate for early introduction of learners to science, to motivate them to love and appreciate it, as well as to perform well in the subject.

\section{Teacher 3}

The third participant was a female teacher holding a Teaching Diploma and an Advanced Certificate in Education (ACE). She had 10 years of primary school teaching experience, but she indicated that she is not a science person, therefore she was not sure whether she was the right person for the interview. Below are her responses to interview questions.

i. How would you describe science as a concept, to someone who does not know what it is?

Response: "Science as a concept is broad; it can be anything, which is why we have different sciences, such as; social sciences, financial sciences, medical sciences and even technological science. It depends on the context. If you are dealing with a sick person you need medical science to heal the person, but if you are battling with finances you also need financial science to help you". 
When requested to focus on the natural science taught in Foundation phase, she responded that; "Natural science is self-explanatory, it is about the science of natural things. So, it is about anything that is natural". She gave an example of plants as one of the natural things. Teacher 3 seemed to understand science broadly, as she could not provide a specific description of science.

ii. What is your understanding of science process skills? Provide examples to clarify your response. Response: "Science process skills? I'm not sure! Are they in the CAPS document? I only know processed materials". The teacher reiterated that she does not know science process skills, after the interviewer had clarified the question.

iii. How do you feel about teaching science to early primary school learners?

Response: "To be honest, I don't have any feelings about science teaching. The department says we must teach it, so I teach it, so that I can get my salary as a teacher. Besides, my learners do not really like studying science, as they prefer to go out on the ground to play".

When encouraged to provide her opinion regarding the teaching of science at early primary school, she said learners should learn science that is relevant to their daily lives, such as how to prevent influenza, how to farm, and traffic rules, instead of reciting what scientists discovered a long time ago.

\section{Teacher 4}

The fourth teacher held a Bachelor of Education (B.Ed.) degree in foundation phase teaching, with 6 years teaching experience. She was a head teacher in a Foundation phase programme, and she admitted that she lacked science knowledge. She responded to the interview questions as follows.

i. How would you describe science as a concept, to someone who does not know what it is?

Response: "Science as a concept? Mmmh, Eish! I'm not sure, but I would say science is something that is against religion. It is for independent thinkers and doers, who do not believe in the existence of God. It is for people who create things for themselves not depending on God. Science and religion are a total contradiction". This participant had very little understanding of science as implied by her response, and she also believed that science contradicts religion.

ii. What is your understanding of science process skills? Provide examples to clarify your response. Response: "Mmmmh! to be honest, I have no understanding of them. Are they in the CAPS document? Wait! Science skills are lab-based. I think mixing things and knowing the names of the mixtures".

The teacher did not know science process skills, and like the other teachers, she did not know that they are part of the Foundation phase science curriculum, which she is expected to implement.

iii. How do you feel about teaching science to early primary school learners?

Response: "Personally I think science in the Foundation phase should be taught, but should be kept to a minimum, because Foundation phase teachers are not taught science in depth or even the basics, in teacher training institutions, where much emphasis is placed on numeracy and literacy. Teachers are not miracle workers, they cannot teach what they do not know. In addition, she stated that; "Young kids are easily influenced. For example, when they watch a movie, they believe everything happening there, as they cannot differentiate between real life and fantasy or fiction. So, it's best to wait before teaching them too much science, which might confuse them". From her response, it could be assumed that teacher 4 equates science to fantasy or fiction and believes that it could mislead young learners.

\section{Discussion and conclusion}

Three main findings emerged from the study, the first is that the participating teachers had very little understanding of what science entails. They perceived science as something done by people who do not believe in God. Three of the teachers declared that they do not have science background, which is worrying since these teachers, who lack knowledge about science, are entrusted with the responsibility of introducing and motivating learners in the study of science (Coil, Wenderoth, Cunningham \& Dirks, 2010).

The second finding is that the participants had no or had little knowledge of science process skills, and they were not even aware that these skills are prescribed in the curriculum they were implementing. This is disturbing because science process skills are used in science to study natural phenomena. It is unlikely that teachers who are ignorant of these skills would develop them in their learners and use them to teach science effectively (Abungu, Okere \& Wachanga, 2014). Early primary school teachers' lack of science knowledge has been highlighted in literature both in South Africa (Beni, Stears \& James, 2012) and elsewhere (Wang, et al., 2011). This deficit might partly account for learners' lack of motivation to study science or their poor performance in science related subjects (Shidiq \& Falkhmta, 2020).

The third finding is that three of the participating teachers had negative attitudes towards the teaching of science in early primary school. This poses the pertinent question of whether these teachers introduce young learners to the study of science, adequately. Interestingly, the teachers seemed to believe that science contradicts religion, and that it could therefore negatively influence young people's belief in God. This view of science seems to emanate from the belief, by some religious sectors, that science and religion advocate conflicting positions on how reliable knowledge can be obtained (Billingsley, et al., 2016). 
The findings from this study are worrying, given the fact that early primary science is envisaged to lay the foundation for learning science at higher educational levels. If teachers have a poor understanding of science and its processes, and they have negative perceptions about the teaching of science to early primary school learners, then they are not likely to introduce science to learners adequately or to motivate them to study science and to take up science related careers in the future (Ualesi \& Ward, 2018). This could partly explain the poor performance of most South African learners in science assessments (Pretorius, 2014).

The findings from this study are important in view of the need to develop scientific skills and to motivate in young learners in the study of sciences. The findings have implications on the training of early primary school teachers, who might not be sufficiently prepared to effectively introduce young people to the study of science, and to prepare them for future science education and careers. However, the number of participants in this study was very small (four teachers) and all the participating teachers taught in peri-urban (township) schools. Therefore, the findings from the study might not be a true reflection of the ability and perceptions of early primary school teachers in Johannesburg or in South Africa as a country.

\section{Recommendations}

I recommend the inclusion or strengthening of science education programs in early primary school teacher training institutions. I further recommend regular professional development workshops for in-service primary school teachers, to enhance their understanding of the nature of science and science process skills. Furthermore, there is need to conduct similar large-scale studies, to either corroborate or nullify the findings from this study.

\section{References}

Abungu. H.E., Okere, M.I.O. \& Wachanga. S.W. (2014). The effect of science process skills teaching approach on secondary school students' achievement in chemistry in Nyando district, Kenya. Journal of Educational and Social Research, 4(6), 359-371. doi: 10.5901/jesr. 2014.v4n6p359.

Beni, S., Stears, M. \& James, A. (2012). Teaching natural sciences in the Foundation phase: Teachers' understanding of the natural science curriculum. South Africa: South African Journal of Childhood Education, 7 (1), 1-217.

Billingsley, B., Brock. R., Taber. K.S. \& Riga, F. (2016). How students view the boundaries between their science and religious education, concerning the origins of life and the universe. Science Education, 100(3), 459-482. https://doi.org/10.1002/sce.21213.

Coil, D., Wenderoth, M.P., Cunningham, M. \& Dirks, C. (2010). Teaching the Process of Science: Faculty Perceptions and an Effective Methodology. CBE Life Sci Educ. 9(4), 524-535.

Department of Basic Education. (2011). Curriculum and Assessment Policy Statement (CAPS): Life Skills for the Foundation Phase. Pretoria: Government Printer. doi: 10.1187/cbe.10-01-0005.

Fugarasti, H., Ramli, M, \& Muzzazinah. (2019). Undergraduate students' science process skills: A systematic review. AIP Conference Proceedings 2194, 020030(2019).

Gerde, H.K., Pierce, S.J., Lee, K. \& Van Egeren, L.A. (2018). Early childhood educators' self-efficacy in Science, Math, and Literacy instruction and science practice in the classroom. Early education and development, 29 (1), 70-90.

Jirout, J. \& Klahr, D. (2012). Children's scientific curiosity: In search of an operational definition of an elusive concept. Developmental Review, 32, 125-160. doi:10.1016/j.dr.2012.04.002.

National Academy of Sciences. (2008). Science, Evolution and Creationism. Washington, DC: NAS Press. https://doi.org/10.17226/11876.

Padilla, M. J. (1990). The science process skills. Research matters-To the science teacher (9004). Reston, VA: National Association for Research in Science Teaching (NARST). http://www.narst.org/publications/research/skill.cfm.

Pretorius, S. (2014). Educators' perceptions of school effectiveness and dysfunctional schools in South Africa. Journal of social science, 40(1), 51-64.

Shidiq, G. A. \& Faikhamta, C. (2020). Exploring the relationship of teachers' attitudes, perceptions, and knowledge towards integrated STEM. Ilkogretim Online - Elementary Education Online, 19(4), 2514-2531. doi:10.17051/ilkonline.2020.764619.

Ualesi, Y. \& Ward, G. (2018). Teachers' attitudes toward teaching science in a New Zealand Intermediate School. Australian Journal of Teacher Education, 43(6), 35-49.

Wang, H. H., Moore, T. J., Roehrig, G. H., \& Park, M. S. (2011). STEM integration: Teacher perceptions and practice. Journal of Pre-College Engineering Education Research 1(2), 1-13. 


\title{
A FRAMEWORK TO ANALYSE THE QUALITY OF ECEC SERVICES ACCORDING TO THE CHILD-CENTRED CULTURE
}

\author{
Paolo Sorzio, \& Caterina Bembich \\ DiSU, University of Trieste (Italy)
}

\begin{abstract}
In this contribution it is proposed a critical framework, based on Basil Bernstein's theory, for two aims. The first one is a critical reflection on some structural limits of the Indicator Frameworks used to evaluate the quality of Early Childhood Education and Care services (ECEC), since they rely mainly on measures of the structural and processual characteristics of the educational settings. As a consequence, the processual dimensions are reduced to their individual components, overlooking the complex and contingent interactions that create opportunities for learning. The second aim is to propose a framework, based on Basil Bernstein's theory to analyse the different child-centred approaches to ECEC.
\end{abstract}

Keywords: Child-centredness, quality of services, indicator frameworks, reflective practice.

\section{Introduction}

According to Chung and Walsh (2000), three major perspectives on child-centred practices have historically evolved: Romantic, Developmentalist and Democratic. Each identifies the child as at the centre of the educational professional practices, characterised by the identification of each child's needs, competencies, interests. However, each perspective proposes one's own declination of what the child is at the centre of (Romantic: her/his world; developmentalist: the curriculum; democratic: the community).

\section{Criticising the quality indicator frameworks methodology}

In developing a Quality Framework, Policy Institutions have usually identified some structural and processual indicators, in order to signal the level of achievement in specific and relevant dimensions, according to given benchmarks.

The focus of this contribution is to question the validity of measures of the interactional processes, as well as reflecting about the potentiality of the introduction of qualitative evidence to promote quality and child-centredness in the Early Childhood Education and Care services.

Table 1. Relevant features usually incorporated in the Quality indicator frameworks.

\begin{tabular}{|l|l|l|}
\hline Structural factors: & Organisational factors & Process factors \\
\hline Finances & Staff qualifications & Staff responsiveness \\
\hline indoor/outdoor spaces & Staff/children ratios & $\begin{array}{l}\text { Structure and complexity of } \\
\text { tasks }\end{array}$ \\
\hline playing materials and furniture & Health/food regulations & Quality of social interactions \\
\hline Impact over the community & Design/documentation strategies & Children's attendance \\
\hline & $\begin{array}{l}\text { In-service teacher training and } \\
\text { action-research }\end{array}$ & Relationships with families \\
\hline
\end{tabular}

Early Years educational settings are evaluated according to standards, on the basis of simple measures typically obtained by using rating scales. However, there are methodological limits in the analysis of the educational processes: for example, frameworks such as CLASS (Pianta, La Paro and Hamre, 2008) and ECERS-R (Harms, Clifford and Cryer, 2004) are intended to single out and measure the dimensions that characterise complex processes such as respect of children's rights, promotion of good relationships between adults and children; non-invasive care; autonomy, respect for children's interests and emotions, close listening, joint meaning making, prosocial behaviours. CLASS and 
ECERS-R schemes evaluate isolated dimensions as proxies of complex and dynamic processes, therefore, they can be interpreted differently in different contexts.

Although the systematicity and elegance of many Quality Frameworks are to be appreciated, there are two critical points:

a) the Frameworks tend to merge the concept of "indicator" and the concept of "measure" (Alexander, 2008). Some measures of quality can be easily assessed (Space per child; teacher/children ratios; health quality of food; daily schedules); however, rating scales do not suffice to evaluate the child-centredness and the opportunities for learning, since they single-out individual dimensions from complex and dynamic processes of interaction;

b) "the distance" of the singled-out dimensions from the direct experiences of practitioners, children and families in their everyday practices (Erickson, 2006; Hammersley, 1995).

By confounding measures and indicators, the complexity of the child-centred pedagogy is overlooked. The 'construct validity' of the Quality Indicator Frameworks needs to be assessed through educational theories, rather than relying only upon the accountability logic. Furthermore, practitioners develop their professional activities in a context characterised by the specificity of settings, tools, norms and people, which make the situated conditions for the development of the curricular activities. As a consequence, from the point of view of the practitioners, each setting is a unique context of practice. The ranking of specific dimensions is only an information that must be interpreted.

\section{Developing an alternative framework based on Basil Bernstein's work}

By applying the concepts proposed by Basil Bernstein $(1973 ; 1999)$ to analyse the process of schooling to the Early Years sector, we identify a pattern of possibilities that offers opportunity to understand how the professionals organise in practice the child-centred perspective (implicit theories) in terms of the curriculum, interaction and documentation. This approach may complement the more established model of standard measures to evaluate the quality of ECEC services. dimensions:

According to Bernstein, the practices of schooling can be identified by intersecting three

a) Classification (the degree of insulation an element has in relation to others, for example: experiences in-school and out-of-school; the degree of separation of activities in the same educational practice). The higher the classification, the stronger is the instructional approach;

b) Framing: the degree of adult's control of the interaction; the higher the control of discourse by the adults is, the stronger is the teacher's voice; the higher the opportunities of children's contribution, the stronger the children's voices are valued;

c) Vertical and horizontal discourse is a dimension that can highlight some differences within the child-centred approach. The socio-constructivist approach, such as the Reggio Approach promotes a vertical discourse, since it is based not only on child-initiated activities and children interests, but also on higher order thinking strategies, such as planning, revision, communication.

Democratic and constructivist approaches in early childhood education are characterised by children's interests and inquiries, an exploratory talk, in which the adults extend the children's thoughts and contributions. Democratic approaches to child centred education give value to a variety of children's contributions through different sign systems (should they be verbal language, visual, dance, musical, etc) to make children participant in the ongoing dialogue of society and the authors of their own individual contribution to the conversation. In these contexts, the professionals adopt practices based on the principles of "children as active constructors of knowledge. In classrooms consistent with this theory, teachers provide direction and guidance as they assist children in developing their knowledge, but they also provide opportunities for children to direct their own explorations of objects and academic topics" (Stipek, 2004, p. 550). Characteristically, spaces are integrated and children can move freely, in order to overcome differences in gender, different abilities, ethnicity and to some extent in age. Each organised space can create the opportunity for children's initiative, rather than fragmenting curricular activities in simple and repetitive exercises (Low classification). Interactions tend to promote children's genuine contributions to joint activities, to emphasize democratic dialogue, reflection and metacognition, rather than imposing an instructional script (Low framing). Romantic and constructivist Child-centredness tend to diverge in the role of adults: the constructivist approach, such as in the Reggio Emilia experience, the teachers' questions are oriented to extend the children's thinking processes, in order to achieve more clarity and systematicity during the joint curricular activities aimed at the production of an artefact (Vertical discourse). In the Romantic perspective, adults let the children play and express their personal feelings and interests. 
Table 2. Different educational approaches according to Bernstein's theory.

\begin{tabular}{|c|c|c|c|}
\hline Educational approach: & Instructional & $\begin{array}{l}\text { Romantic Child- } \\
\text { centredness }\end{array}$ & constructivist \\
\hline classification & strong & weak & weak \\
\hline Principles & $\begin{array}{l}\text { Focus on the acquisition } \\
\text { of behaviour. Children } \\
\text { are not considered } \\
\text { competent in setting up } \\
\text { their own objectives and } \\
\text { strategies }\end{array}$ & $\begin{array}{l}\text { Variety of children's } \\
\text { behaviour is the object } \\
\text { of development. Not a } \\
\text { prescriptive scheme of } \\
\text { behaviour }\end{array}$ & $\begin{array}{l}\text { focus on promoting } \\
\text { personal growth rather } \\
\text { than on instructing } \\
\text { children. Children are } \\
\text { considered accountable } \\
\text { for selecting their own } \\
\text { projects and for } \\
\text { self-regulation }\end{array}$ \\
\hline Metaphor of learning & Learning as acquisition & Learning as exploration & $\begin{array}{l}\text { Learning as } \\
\text { construction }\end{array}$ \\
\hline Goals of education & $\begin{array}{l}\text { Children master } \\
\text { procedures for external } \\
\text { tasks. Focus on } \\
\text { correctness }\end{array}$ & $\begin{array}{l}\text { Well-being and } \\
\text { self-regulation }\end{array}$ & $\begin{array}{l}\text { Metacognitive } \\
\text { dispositions; higher } \\
\text { order thinking and } \\
\text { understanding }\end{array}$ \\
\hline Teaching/education & $\begin{array}{l}\text { A piecemeal approach } \\
\text { to learning. The } \\
\text { activities relate to } \\
\text { isolated elements of } \\
\text { learning. repetition; } \\
\text { memorization. }\end{array}$ & $\begin{array}{l}\text { Children conducted } \\
\text { global activities: they } \\
\text { set goals; select tools } \\
\text { and strategies }\end{array}$ & $\begin{array}{l}\text { Project-based learning; } \\
\text { children set up their } \\
\text { own goals and } \\
\text { collaborate; teachers } \\
\text { promote }\end{array}$ \\
\hline \multirow[t]{3}{*}{ Framing } & Strong/visible & Weak/invisible & Weak/visible \\
\hline & $\begin{array}{l}\text { Instructional script; } \\
\text { children's contributions } \\
\text { should be filled in a } \\
\text { prescriptive scheme; } \\
\text { they are predictable; the } \\
\text { expected answer }\end{array}$ & $\begin{array}{l}\text { less directive approach; } \\
\text { children are expected to } \\
\text { regulate peer group } \\
\text { relationships and } \\
\text { individual behaviour }\end{array}$ & $\begin{array}{l}\text { High variety of } \\
\text { scaffolding strategies, } \\
\text { since the children's } \\
\text { thinking processes are } \\
\text { the centre of the } \\
\text { educational practice }\end{array}$ \\
\hline & $\begin{array}{l}\text { The teacher models the } \\
\text { activity and has an } \\
\text { expected behaviour in } \\
\text { mind }\end{array}$ & $\begin{array}{l}\text { The teacher supports the } \\
\text { child-initiated activities; } \\
\text { gives freedom and } \\
\text { monitors behaviour }\end{array}$ & $\begin{array}{l}\text { The teacher: expands } \\
\text { children's activities; } \\
\text { promotes dialogue; } \\
\text { privileges meaningful, } \\
\text { that is goal-based } \\
\text { activities, in which } \\
\text { some relevant aspects } \\
\text { are highlighted in order } \\
\text { to promote learning }\end{array}$ \\
\hline Role of the teacher & Visible and directive & Invisible & Visible and dialogical \\
\hline
\end{tabular}

This approach may complement the evaluative model based on fixed standards with the practitioners' critical reflection about their practices. Qualitative analysis and documentation (Erickson 1987) may offer an evidentiary basis for:

- Recognising the specific conditions that hinder the children's participation and learning according to the child-centred practice, especially the constraints to the recognition of children's voices, rights and agency;

- Promoting collaborative design of educational activities, in order to encourage children's exploration, dialogue and thinking processes;

- Conducting action-research projects within the services, in order to promote joint reflection among practitioner, to enhance the professional resources in the service.

\section{Integrating the measurement approach with the insiders' reflective accounts}

The measurement approach can be considered conducted by a detached subject who applies standardised instruments to gather data which represent the magnitude of specific dimensions in a setting, in order to compare them with given standards. This distant evaluative look can be complemented with in-depth professionals' accounts in narrative terms. 
In Pastori and Pagani's research (2017), the introduction of Quality Frameworks tools offers a pattern of information that can guide the practitioners in a joint analysis of the interactional dynamics in the educational setting. The use of standardised tools can be considered as a trigger for educators' reflection, narrative accounts and change. Subsequently, Pastori and Pagani conducted a participatory action-research with professionals (2020), by introducing the Classroom Assessment Scoring System (CLASS - Pianta et al., 2008), with the aim of engaging the participants in a critical discussion of their practice. Participants reported some positive aspects in the use of the framework, such as the centrality of the educator-child relationship in defining the quality of the service and the focus on the emotional dimension of learning. On the other hand, there are some shortcomings: the framework lacks a deep focus on the interactional competence of children; it emphasizes productivity ("doing something"), rather than the opportunities for learning emerging during the educational activities (that is, posing the questions: "which are the meaningful, rich experiences for children?", "Why do some activities become learning experiences?").

\section{Conclusion}

The Quality Frameworks are useful tools to register a great amount of information about the magnitude of relevant dimensions of the Early Years educational settings. However, their usefulness relies in understanding their implicit rationales and as an opportunity to empower the practitioners, who are the principal agents to improve the internal quality of the setting. Through reflective documentation, practitioners can evaluate the quality of their child-centred practice, by recognising potential boundaries to the children's participation, the degree of control of the communication between adults and children, the opportunities for learning created by the curricular design, dialogic communication and meaningful experiences.

\section{References}

Alexander, R. (2008). Education for All, The Quality Imperative and the Problem of Pedagogy. CREATE Pathways to Access. Research Monograph n. 20. Institute of education, University of London

Bernstein, B. (1977). Class, Codes and Control, Vol. III: Towards a theory of educational transmissions. London: Routledge \& Kegan Paul.

Bernstein, B. (1999). "Vertical and horizontal discourse: An essay", in British Journal of Sociology of Education, 20 (2), 157-173.

Chung, S. and Walsh, D.J. (2000). "Unpacking child-centredness. A history of meanings", in Journal of Curriculum Studies, 32, (2), pp. 215-234.

Erickson, F. (1987). "Qualitative methods in research on teaching”, in M. C. Wittrock (ed.), Handbook of Research on Teaching, Macmillan, New York.

Erickson, F. (2006). "Studying side by side: Collaborative action ethnography in educational research", in G. Spindler, L. Hammond (eds.), Innovations in Educational Ethnography. Theory, Methods, and Results, Psychology Press, New York.

Hammersley, M. (1995). "Theory and evidence in qualitative research", in Quality and Quantity, 29, pp. 55-66.

Harms, T., Clifford, R.M. and Cryer, D. (2004). Early Childhood Environment Rating Scale. Revised. NY: Teachers College Press.

Pastori, G.G. and Pagani, V. (2017). "Is validation always valid? Cross-cultural complexities of standard based instruments migrating out of their context", in European Early Childhood Education Research Journal, 25 (5), pp. 682-697.

Pastori, G., \& Pagani, V. (2020). "Coniugare valutazione standardizzata e approccio partecipativo-riflessivo. Un'esperienza di ricerca collaborativa nei servizi per l'infanzia italiani”. https://boa.unimib.it/retrieve/handle/10281/276214/424926/6.\%20Valentina\%20Pagani\%2c\%20Gi ulia\%20Pastori.pdf [last consultation January the $7^{\text {th }} 2021$ ].

Pianta, R. C., La Paro, K. M. and Hamre, B. K. (2008). Classroom Assessment Scoring System Pre-K Manual. Baltimore: Brookes Publishing. 


\title{
LIFE SCIENCES TEACHERS' UNDERSTANDING, PERCEPTIONS AND ADOPTION OF INQUIRY-BASED SCIENCE EDUCATION IN SELECTED SOUTH AFRICAN HIGH SCHOOLS
}

\author{
Monde Kazeni, \& Nosipho Mkhwanazi \\ Science Education, University of the Witwatersrand (South Africa)
}

\begin{abstract}
In recent years, Inquiry-Based Science Education (IBSE) has emerged as one of the most effective and beneficial science teaching practices for developing science concepts in learners and for motivating them in the study of science subjects. IBSE is a pedagogical practice that allows learners to develop key scientific ideas and to understand the natural world, using skills employed by scientists. Like most science school curricula around the world, the South African life sciences national curriculum (referred to as Curriculum and Assessment Policy Statement - CAPS), advocates for the adoption of IBSE. Despite the growing consensus about the cognitive and motivational benefits of IBSE, this pedagogical approach is seldom implemented by life science teachers, due to various factors. This qualitative research, involving a case study, explored the knowledge, perceptions, and adoption of IBSE by four life sciences high school teachers, conveniently selected from public schools around Johannesburg, in South Africa. Data were collected using semi-structured interviews, and the findings show that participating teachers have substantial knowledge and positive perceptions of IBSE. However, they are less inclined to adopting IBSE in their life science classrooms due to inhibiting factors. We recommend the training of life sciences teachers in effective way of abating the constraints of implementing IBSE effectively.
\end{abstract}

Keywords: Inquiry-based, science education, perceptions, knowledge.

\section{Introduction}

Recently, there has been increasing consensus among science education scholars, regarding the importance of Inquiry Based Science Education (IBSE) in enhancing the learning of science subjects (Ramnarain \& Hlatswayo, 2018). IBSE was defined by Ramnarain $(2014$, p.66) as “.... teaching approach that allows learners to develop key scientific ideas, through learning how to investigate, and building their knowledge and understanding of the world, using skills employed by scientists', such as, asking questions, collecting data, reasoning, reviewing evidence and drawing conclusions". Researchers (Hodgetts, et al, 2015; Ramnarain \& Hlatswayo, 2018; Ramnarain \& Schuster, 2014) have identified several benefits of IBSE, which include: Understanding of scientific concepts and phenomena; development of critical thinking skills, rational decision-making, problem-solving skills; enhancement of learners' acquisition of scientific practices; and motivation of learners to study science, and to pursue science related careers. In acknowledgment of the importance of IBSE, many countries have established educational projects and programs (Scientix in Belgium, Fibonacci in France, SiS Catalyst in the United Kingdom, and Primas in Germany, as listed by Rundgren [2018]) that promote the IBSE pedagogy.

In South Africa, the national curriculum (Curriculum and Assessment Policy Statement - CAPS) advocates for the adoption of IBSE in science classrooms (Department of Basic Education - DBE, 2011). In the life sciences CAPS document, advocacy for the adoption of IBSE is reflected in specific aim number 2 of the curriculum, which relates to; "Investigating Phenomena in Life Sciences (DBE, 2011, p.15)". This aim requires learners to "...be able to plan and carry out investigations, as well as to solve problems that require some practical ability. p. 15). According to the life sciences CAPS, “...this ability is underpinned by an attitude of curiosity and interest in wanting to find out how the natural world and the living things in it, work. p.15". The need to investigate natural phenomena and to arouse learners' curiosity and interest in the study of science is characteristic of the IBSE pedagogy. Adoption of IBSE in life science classrooms could enhance learners' understanding of life sciences concepts and processes, as well as develop pertinent cognitive and practical skills in learners. 
Despite growing consensus among researchers about the learning benefits of IBSE and the advocacy to adopt the learning approach in science classrooms, this teaching approach is rarely adopted in South African science classrooms (Ramnarain \& Hlatshwayo, 2018). Studies on the adoption of IBSE elsewhere have also identified a similar trend. For example, a study conducted by Kang and Keinonen (2016), involving 184 Finland and 143 Korean teachers, showed limited adoption of IBSE in science classrooms. In cases where IBSE is adopted, one sees a diversity of inquiry-based learning methods, which impacts on its comprehension by teachers (Kang \& Keinonen, 2016; Ramnarain \& Schuster, 2014). The adoption of IBSE is especially scarce in life sciences education, where learners often learn facts, terminologies, theories and process, which they often just memorize, without the need for investigations (Wilson, 2017), making IBSE seem unnecessary in this subject.

Teachers' reluctance to adopt IBSE could also be partly explained by their lack of knowledge and negative attitudes towards the teaching approach, as well as contextual teaching constraints (Wilkins, 2008). In this respect, Wilkins (2008) suggested a theoretical model, which relates teachers' knowledge, attitudes, and beliefs to their choices of instructional practices. Similarly, Sikko, Lyngved and Pepin (2012) stated that teachers' beliefs about science, the nature of science, teaching and learning, and beliefs about inquiry-based approaches, could influence their decisions and choices of pedagogical strategies. Furthermore, Hutchins and Friedrichsen (2012) found out that teachers with positive attitude towards inquiry instruction could use inquiry practice better. If teachers' core beliefs conflict with inquiry practices, they could act as a hindrance to their choice of inquiry, as a pedagogical strategy (Binns \& Popp, 2013).

Literature also presents counter-arguments about assertions that beliefs influence practice. For instance, a study conducted by Saad and Boujaoude (2012) in Lebanon, involving 34 teachers showed that holding positive beliefs about IBSE does not necessarily translate into implementation in the classroom. Considering the varied views about the relationship between knowledge, attitudes and practice, an exploration of life science teacher's knowledge, perceptions and practices of IBSE became necessary to understand life science teachers' reluctance to implement IBSE in their classrooms. This information could be useful in the revision of life sciences teacher training curricula and educational policy to emphasize training of teachers in the implementation of this germane pedagogy.

\section{Objectives}

The objectives of the study were to:

1. Determine life science in-service teachers' knowledge of IBSE.

2. Establish life science in-service teachers' perceptions about IBSE.

3. Investigate the adoption of IBSE by life science in-service teachers.

\section{Conceptual framework}

The study was guided by the "strongly simplified model of the relationship between attitude, intentions and practice", proposed by Hofer and Lembens (2019). According to the proponents of the model, knowledge and skills, affective factors, and beliefs interact in complex ways to influence teachers' attitudes, which determine their intentions (plans, resolutions, prospects) and may consequently influence their practice (Hofer \& Lembens, 2019). Figure 1. illustrates these interactions and their outcomes.

Figure 1. A strongly simplified model of the relationship between attitude, intentions and practice: Adopted from Hofer and Lembens (2019).

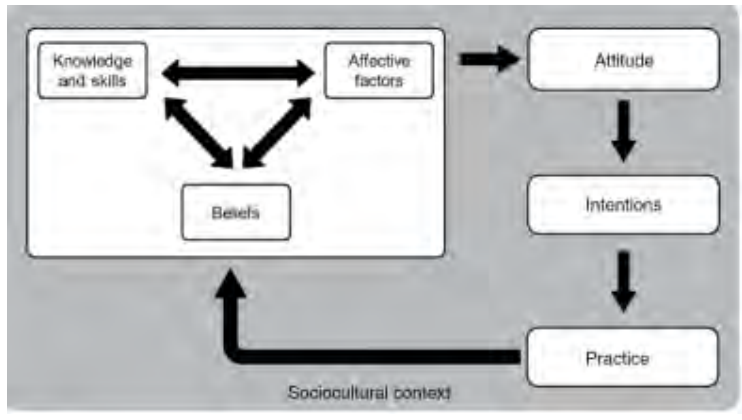


In the study reported here, attributes related to the three dimensions of Hofer and Lembens (2019)'s the model; knowledge and skills, affective factors and beliefs, in relation to attitudes, intentions and practice, were explored. The assumption in this study was that the three dimensions of Hofer and Lembens (2019)'s model mutually interact with each other to influence teachers' attitudes and consequently their decision (intention) to either adopt IBSE in their classrooms or not (Hofer \& Lembens, 2019). In this study, the dimension of knowledge and skills involved the determination of participating teachers' understanding of the concept of IBSE. The affective factors and beliefs dimensions were established by exploring teachers' perceptions of the pedagogical approach. Teachers' attitudes, intentions and practices were explored by obtaining their views about the adoption of IBSE.

\section{Methodology}

A qualitative research approach, involving a case study design, was used to collect data from four life sciences teachers, with the aim of gaining insights into their knowledge and perceptions about IBSE, and the adoption of IBSE in their classrooms.

\subsection{Population and sample}

The population of the study comprised of secondary school life sciences teachers in Johannesburg, South Africa. A convenient purposive sampling method was used to select the four teachers who participated in the study. Table 1 shows the demographics of the study participants.

Table 1. Demographic information of participants.

\begin{tabular}{|c|c|c|c|c|c|c|c|c|c|c|}
\hline Teacher & \multicolumn{2}{|l|}{ Gender } & \multicolumn{3}{|l|}{ Age (in years) } & \multicolumn{2}{l|}{ Qualification (Degree) } & \multicolumn{2}{l|}{$\begin{array}{l}\text { Teaching } \\
\text { experience (in } \\
\text { years) }\end{array}$} \\
\cline { 2 - 13 } & Female & Male & $25-30$ & $30-35$ & $35+$ & $\begin{array}{l}\text { Bachelor of } \\
\text { Education }\end{array}$ & Honours & $0-2$ & $2-4$ & $4+$ \\
\hline 1 & $\sqrt{ }$ & - & - & - & $\sqrt{ }$ & - & $\sqrt{ }$ & - & - & $\sqrt{ }$ \\
\hline 2 & $\sqrt{ }$ & - & - & $\sqrt{ }$ & - & $\sqrt{ }$ & - & - & $\sqrt{ }$ & - \\
\hline 3 & $\sqrt{ }$ & - & $\sqrt{ }$ & - & - & $\sqrt{ }$ & - & $\sqrt{ }$ & - & - \\
\hline 4 & $\sqrt{ }$ & - & $\sqrt{ }$ & - & - & $\sqrt{ }$ & - & $\sqrt{ }$ & - & - \\
\hline
\end{tabular}

\subsection{Data collection and analysis}

Qualitative data were collected using 30-minute semi-structured interviews, after obtaining ethics clearance and relevant permissions from stakeholders. The interview schedule was piloted using two life sciences teachers who did not participate in the main study. Data collected from interviews were analysed using a thematic data analysis method, where video recorded interviews were transcribed and coded. The following codes were used: $\mathrm{A}$ ' $\mathrm{T}$ ', followed by a number represented a participant (for example, T2 represented teacher two), lower case roman numerals represented themes (i, ii, iii), and lower-case letters (a, b, c, d...) represented interview items. For example, 'T1ai' represents a response provided by teacher ' 1 ', for interview item ' $a$ ', under theme ' $i$ '. Coded statements were categorized into the pre-determined themes: Teachers' knowledge of IBSE, their perceptions about IBSE, and their adoption IBSE. Emerging patterns were used to make inferences and conclusions about the study findings.

\section{Discussion of findings}

Participants' knowledge of IBSE was determined by establishing their; definition of IBSE, understanding of the features of IBSE, and the difference between IBSE and practical work. The findings from the study indicated that teachers have adequate knowledge of IBSE, in the sense that they were all able to provide satisfactory definitions of IBSE, and that they were able to cite some of the characteristics of IBSE, such as; questioning, investigating, collecting data, formulating hypothesis, and making inference based on evidence from collected data. These features have been identified in literature (Mashita, Ramli \& Karyanto, 2017; Ramnarain, 2014; Suduc, Bizoi \& Gorghiu, 2015) as characteristic of the IBSE pedagogy. Regarding the difference between IBSE and practical work, the participating teachers were conversant of the difference between the two instructional approaches. They associated IBSE with discovery, research, problem-solving, collection of evidence, and reasoning, and they related practical work to following instructions, a set of rules, or a prescribed method(s) for conducting experiments. The 
finding that teachers are knowledgeable about IBSE seems to conflict with some perception in literature (Binns \& Popp, 2013; Yoon et al., cited in Kang \& Keinonen, 2016) that most science teachers are not knowledgeable about IBSE. Large scale studies that investigate teacher knowledge of IBSE may be necessary to confirm or invalidate the findings from this study.

Participating teachers' perceptions about IBSE were determined by obtaining their views regarding the; necessity of adopting IBSE in their life sciences classrooms, the feasibility of teaching IBSE explicitly, and their opinions regarding the ability of IBSE to enhance learners' understanding of life science concepts. From the interview responses, it became clear that participants have positive attitudes towards IBSE. All participants affirmed the need to implement IBSE in life science classrooms, citing the benefits of IBSE, such as: Learner engagement in the learning process; opportunity to apply learnt content; motivation to learn life sciences; enhancement of learners' knowledge and understanding of abstract life science concepts; and the enhancement of creativity, as reasons for the need to implement IBSE. Researchers (Mashita, Ramli \& Karyanto, 2017; Ramnarain, 2014; Ramnarain \& Hlatshwayo, 2018; Suduc, Bizoi \& Gorghiu, 2015) have also highlighted similar benefits of IBSE. For instance, Ramnarain and Hlatshwayo (2018) pointed out that IBSE develops learners' experimental skills, it makes science more enjoyable, and it leads to increased scientific knowledge and understanding. When teachers were asked whether inquiry skills can be explicitly taught to learners or they automatically acquire them through participation in inquiry activities, three of the four participating teachers said they can be acquired through both direct teaching and participation in inquiry activities, while one teacher only agreed with the latter. Regarding the role of IBSE in enhancing learners' understanding of life sciences concepts. All teachers responded in the affirmative, which is a stance held by many scholars (Hodgetts, et al., 2015; Ramnarain \& Hlatshwayo, 2018). These findings offer a beacon of hope for the adoption of IBSE in South African life sciences classrooms, if contextual constraints are abated.

Finally, the adoption of IBSE in life sciences classrooms was explored by determining; the frequency with which participants implemented IBSE activities in their classrooms, participants' opinions regarding the adoption of IBSE by other life sciences teachers, effective ways of implementing IBSE in life sciences classrooms, and the challenges of implementing IBSE. Three of the four teachers were less inclined to implementing IBSE in their classrooms, citing constraining factors as reasons for their reluctance. One teacher indicated that she uses IBSE to teach certain topics, as the approach is not applicable to all topics. The teacher cited genetics, excretion, the endocrine system and the History of life on Earth, as examples of life sciences topics that cannot be easily taught through IBSE, while evolution and environmental studies were mentioned as examples of topics that could be taught through IBSE. Binns and Popp (2013) also attested to fact that some teachers seem to believe that not all topics are suited for inquiry-based learning, especially in biology. Furthermore, all teachers felt that other life sciences teachers are not likely to implement IBSE in their classrooms adequately, because of the same challenges experienced by participating teachers. This finding resonates with findings from similar studies, which found that science teachers seldom implement IBSE in their classrooms, due to contextual factors (Kang \& Keinonen, 2016; Ramnarain \& Schuster, 2014).

As alluded to earlier, some scholars (Hofer \& Lembens, 2019; Sikko, Lyngved \& Pepin, 2012) found a link between knowledge, affective factors, beliefs and practice. Contraly, the finding from this study seems to suggest a lack of correlation between teachers' understanding and perceptions about IBSE, and their classroom practice. This phenomenon was also observed by other researchers (Ramnarain \& Hlatshwayo, 2018; Saad \& BouJaoude, 2012) who found a negative correlation between teachers' beliefs and the implementation of IBSE. It appears that although the participants support the implementation of IBSE, pedagogical challenges prevent them from adopting the teaching approach in their classrooms.

Regarding the challenges of implementing IBSE, participating teachers highlighted: Limited time to implement IBSE, due to curriculum overload; lack of teaching resources; large class sizes, prescription of teaching and learning materials by the curriculum; and learners' lack of capacity to engage in IBSE activities. Ramnarain and Schuster (2014) identified similar constraints in their study titled "The pedagogical orientations of South African Physical Sciences teachers toward inquiry or direct instructional approaches". If the implementation of IBSE is an objective in science education programs in South Africa, the challenges experienced by teachers need to be mitigated.

\section{Limitations of the study}

The limited number and the homogeneity of participants in study reported here dictates that the findings cannot be generalized to the population of life sciences teachers in Johannesburg and in South Africa, as a country. In addition, since only female life science teachers participated in the study, the findings do not reflect the IBSE knowledge and perspectives of male life science teachers. 


\section{Conclusions and recommendations}

The results from this study show that participating teachers have adequate knowledge and positive perceptions of IBSE. However, they are less inclined to adopting or implementing IBSE in their classrooms because of constraining contextual factors. Based on these findings, I recommend the explicit training of pre-service and in-service teachers in effective ways of abating constraints to the adoption and implementation of IBSE in life science classrooms.

\section{References}

Binns, I. C. \& Popp. S. (2013). Learning to teach science through inquiry: Experiences of pre-service teachers. Electronic Journal of Science Education, 17(1), 1-24. Retrieved on October 19, 2020, from: https://files.eric.ed.gov/fulltext/EJ1188484.pdf.

Department of Basic Education (DBE). (2011). Curriculum Assessment Policy Statement

(CAPS), Grades 10-12: Life Sciences. Pretoria: Government Printers.

Hodgetts, K., Fouskaki, M., Siakavara, K., Moschochoritou, R. \& Chaniotakis, N. (2015). Student and Teacher Perceptions of Inquiry Based Science Education in Secondary Education in Greece. American Journal of Educational Research, 3(8), 968-976. doi: 10.12691/education-3-8-4.I

Hofer, E. \& Lembens, A. (2019). Putting inquiry-based learning into practice: How teachers changed their beliefs and attitudes through a professional development program. Chemistry Teacher International. 2019(2018003), 1-11. https://www.researchgate.net/deref/http\%3A\%2F\%2Fdx.doi. org\%2F10.1515\%2Fcti-2018-0030

Hutchins, K. L. \& Friedrichsen, P. J. (2012). Science Faculty Belief Systems in a Professional Development Program: Inquiry in College Laboratories. Journal of Science and Teacher Education, 23(8), 869-887. doi.org/10.1007/s10972-012-9294-Z

Kang, J. \& Keinonen, T. (2016). Examining factors affecting implementation of inquiry-based learning in Finland and South Korea. Problems of Education in the 21st Century, 74, 31-48. ISSN 1822-7864.

Mashita, C., Ramli, M. \& Karyanto, P. (2017). Practices of Inquiry-based Science Education: Case Study of Thailand's Junior High School. Pertanika Journal of social science \& humanities, 25 (S), $51-72$.

Ramnarain, U. \& Schuster, D. (2014). The pedagogical orientations of South African Physical Sciences teachers toward inquiry or direct Instructional Approaches. Research in Science Education, 44(4), 627-650.

Ramnarain. U. \& Hlatshwayo, M. (2018). Teacher Beliefs and Attitudes about Inquiry-Based Learning in a Rural School District in South Africa. South Africa Journal of Education, 38(1), 1-10. doi.org/10.15700/saje.v38n1a1431.

Ramnarain. U. (2014). Teachers' perceptions of inquiry-based learning in urban, suburban, township and rural high schools: The context-specificity of science curriculum implementation in South Africa. South Africa Journal of Education, 38, 65-75. doi.10.1016/j.tate.2013.11.003

Rundgren, C-J. (2018). Implementation of inquiry-based science education in different countries: some reflections. Cultural Studies of Science Education, 13, 607-615. doi.org/10.1007/s11422-016-9787-8

Saad, R. \& BouJaoude, S. (2012). The Relationship between Teachers' Knowledge and Beliefs about Science and Inquiry, and Their Classroom Practices. Eurasia Journal of Mathematics, Science \& Technology Education, 8(2), 113-128. doi.org/10.12973/eurasia.2012.825a

Sikko, S.A, Lyngved, R \& Pepin, B. (2012). Working with mathematics and science teachers on inquiry-based learning (IBL) approaches: teacher belief. Acta Didactica Norge, 6(1), 1-18.

Suduc, A.M, Bizoi, M, Gorghiu,G. (2015). Inquiry-Based Science Learning in Primary Education. Procedia - Social and Behavioral Sciences, 205(2015), 474-479. doi.10.1016/j.sbspro.2015.09.044

Wilkins, J. M. (2008). The relationship among elementary teachers' content knowledge, attitude, belief, and practices. Journal of Math Teacher Education, 11(2), 139-164. ISSN: ISSN-1386-4416.

Wilson, J. S. (2017). Promoting Critical Thinking in General Biology Courses: The Case of the White Widow Spider. Journal on Empowering Teaching Excellence, 1(2), 53-61. doi.org/10.26077/jmb7-zh62. 


\title{
TEACHING LIFE SCIENCES USING SECOND LANGUAGE: HOW DO TEACHERS COPE?
}

\author{
Amos Motloung, \& Lydia Mavuru \\ Department of Science and Technology Education, University of Johannesburg (South Africa)
}

\begin{abstract}
Language plays a pivotal role in science teaching and learning as it serves as both the medium through which the teachers and learners think and also communicate in the classrooms. Science and Life sciences in particular comprises of a unique scientific language register with a lot of technical words and terms borrowed from other languages other than English. Previous researchers acknowledged the difficulty teachers face when teaching science in a language different from their own and that of the learners. Consequently, the current study explored the various ways in which English-second-language Life Sciences teachers taught Life Sciences in order to mitigate language difficulties for themselves and those of their learners. The study was guided by the research question: how does English as a second language influence teacher practices when teaching Life Sciences to grade 12 learners? Using a qualitative research design, six Life Sciences teachers with various levels of teaching experience, two novices, two relatively experienced and two very experienced teachers, were purposefully selected from six different schools. The assumption was that teachers at various levels of experience may have different experiences of teaching the subject in a second language. Each teacher was observed once whilst teaching the same topic to grade 11 Life Sciences learners to establish their teaching practices. Incidences of learner engagement with the content, teacher-learner and learner-learner interactions were captured and scored using the Reformed Teaching Observation Protocol rubric. Lesson observations were suitable for data collection as they allowed the researcher to examine even non-elicited behaviour as it happened. The findings indicated that language difficulties were prevalent and affected both teachers and learners in engaging with the concepts at hand. For instance, most of the teachers whether experienced or not, struggled to explain and elaborate vital Life Sciences concepts in a comprehensible manner due to lack of proficiency in the language of instruction. The teachers mostly utilised code-switching as it enabled them to explain and elaborate scientific terms and processes in both English and their home languages. Because learners were allowed to express themselves in their home languages, the level of interaction also increased. In addition, teachers used transliteration and demonstrations as teaching strategies that also reduced the challenges of using English as a medium of instruction. The study informs both pre-service and in-service teacher development programmes.
\end{abstract}

Keywords: Life sciences, English-second-language-speakers, teacher practices, code switching.

\section{Introduction}

Language plays a very important role in both teaching and learning. Through language, communication can occur which allows for the transmission of knowledge. However, in South African township schools it is difficult to foster educational goals due to the language constraints that are faced by English-second-language (ESL) speakers. Hence, it is imperative that ESL teachers deploy strategies that allow them to cope with the language demands in such schools. In addition, Life Sciences is characterised by a variety of scientific terms, which are unfamiliar to both English-first-language speakers (EFL) and ESL speakers (Ferreira, 2011; Oyoo, 2004). ESL learners experience difficulties in acquiring the main concepts or themes addressed in science classes and therefore it is important that language use in Life Sciences classrooms is addressed (Gudula, 2017; Feez \& Quinn, 2017; Oyoo, 2004). The reason for such difficulties is that the teaching of sciences involves not only teaching the content but also teaching the scientific language.

\section{Literature review}

The nature of this study was to establish teachers' experiences in teaching Life Sciences in English, a second if not a third language to most of the township teachers. A large body of research on language issues in science learning reveals that ESL teachers are at the centre of all issues arising from 
teaching sciences in the second language (Feez \& Quinn, 2017; Gudula, 2017; Prinsloo, Rodgers, \& Harvey, 2018). One of the most prominent issues that arises from these studies is the acquisition of scientific concepts by learners. Most learners from township schools are ESL speakers and therefore find it difficult to comprehend some of the scientific concepts because they are foreign to them (Prinsloo et al., 2018). Hence, it is vital to explore the strategies that Life Sciences teachers employ to combat such issues.

Setati (2002) emphasised the significance of teacher language proficiency in science classes. While most ESL teachers are proficient in using English whilst teaching, they still prefer to clarify some difficult science concepts using their home languages. This highlights the need for township teachers to be proficient in more than one language and it also highlights the importance of code-switching when explaining science concepts (Feez \& Quinn, 2017). However, code switching tends to be problematic because some science concepts are watered down in the process, and therefore learners fail to engage meaningfully with such concepts. In addition, studies by Ferreira (2011), Gudula (2017) and Oyoo (2004) posited the need for science teachers to effectively use scientific language in portraying scientific themes. Therefore, it is vital to explore how teachers cope in teaching Life Sciences using their second language. The usage of code-switching in township science classes can be regadered as a way in which ESL teachers cope with the language demands presented by Life Sciences.

\subsection{Code-switching}

In South African classrooms, code-switching is one of the widely applied strategies to give meaning to science concepts (Ferreira, 2011). Code-switching involves teaching the same concept in English and then in another language (Oyoo, 2004). This implies that teachers should be multilingual and fluent in more than one language (Setati, 2002). Furthermore, Mthiyane (2016) asserted that using the learners' home language has the potential to convey powerful meanings to abstract science concepts. In addition, Oyoo (2017) emphasised that code-switching serves as a bridge between the learners' home language though it tends to water down some of the fundamental science concepts. Because code-switching is against the South African language policy, some teachers are reluctant to engage learners in their home languages (Ferreira, 2011). Oyoo (2017) confirmed that the language teachers use in a science class is constrained by the requirement of the content to be taught and learnt, thus teachers may feel reluctant to engage learners in their home language.

Township schools are generally multicultural schools, and since learners in these schools are mostly ESL speakers, Life Sciences teachers resort to code switching as a way of fostering scientific concepts that are mostly problematic to learners (Alhamami, 2019; Feez \& Quinn, 2017; Mthiyane, 2016; Prinsloo et al., 2018; Probyn, 2016). Studies reveal that code-switching is the preferred method applied by Life Sciences teachers and they also show that code-switching is used to facilitate communication and interaction between teachers and learners. However, some studies show that, though regarded a fruitful process, code-switching can also contribute to science language problems that occur in the classrooms (Boateng, 2019; Oyoo, 2017). Such problems can include the inability of teachers to speak all the different languages that are represented in that particular class. Learners in a Life Sciences class have different linguistic backgrounds and, because of this, teachers may only explain some concepts to learners who speak the same language they speak, and thus disadvantage those who speak a different language. Since code-switching involves moving from one language to the next (Prinsloo et al, 2018), it is unlikely that teachers are proficient in all 11 official South African languages. Hence, it can be difficult to accommodate all learners from different cultural backgrounds.

\section{Methodology}

\subsection{Research design}

This study followed a qualitative approach in determining how teachers teach Life Sciences using their second language. Creswell (2011) pointed out that a qualitative research design allows for the investigation of the phenomenon within its real life context. The design was suitable for this study because data was collected from Life Sciences teachers in real classrooms in township schools. Similarly, a qualitative approach makes it possible to study "things in their natural settings, attempting to make sense of or interpret phenomena in terms of the meanings people bring to them" (Denzin \& Lincoln, 2005, p. 3).

\subsection{Sampling}

Purposive and convenience sampling was used (Patton, 1990) to select six teachers who were ESL speakers from six township schools for the study. According to Patton (1990), purposive sampling allows for the selection of information-rich cases, where the researcher can obtain a great deal of data regarding the matter at hand, and in this case, how teachers teach Life Sciences using English. 
Furthermore, Etikan, Musa and Alkassim (2016) maintained that purposive sampling allows for the selection of participants that provide a distinctive and information-rich value to the study. The Life Sciences teachers had different teaching experiences: two novice teachers (N), Zanele and Mulalo, (zero to two years); two relatively experienced teachers (RE), Koali and Sizwe, (three to five years); and two very experienced (VE) teachers, Phale and Shilubane, (six years and above). The assumption was that teachers at various levels of experience may have different experiences in teaching Life Sciences using English as their second language. Denzin and Lincoln (2005) claimed that those involved in a qualitative research should be directly linked or affected by the problem researched, hence the involvement of these participants.

\subsection{Data collection}

Data collection involved observing each of the six teachers once to gain insights into how they teach grade 11 Life Sciences using English, which is their second language. A revised Reformed Teaching Observation Protocol (RTOP) was used to capture the level of each teacher and their learners' involvement during the lessons (Sawada, Piburn, Falconer, Turley, Benford, Bloom, \& Judson, 2000). See Table 1 for the categories in RTOP. Incidents of learner engagement with the content, teacher-learner and learner-learner interactions were captured and scored using the RTOP rubric. The lessons were video-recorded with permission from the participants. Mills (2011) pointed out that observations allow the researcher to examine non-elicited behaviour as it happens. Hence, this was significant in obtaining a holistic experience on how language is used in the classroom. In the same vein, Creswell (2011) inferred that, observations provide a more complete description of the phenomenon that would be impossible by analysing interview documents.

\subsection{Data analysis}

The lesson observations showing evidence of teacher and learners' involvement during the lessons were coded and analysed using an interpretive approach (Fontana \& Frey, 2003). The information was broken down into smaller units and each response was thoroughly interpreted, explained and analysed to make meaningful cohesion between participants' classroom observations (Cohen, Manion, $\&$ Morrison, 2000). Trends between the participants' observations were examined for any emerging themes. A correlation between themes and the research question was formulated and interpreted.

\subsection{Reliability, validity and transferability}

To ensure validity and reliability of the data from observations, the first and second author read the RTOP scores repeatedly and reviewed any emerging patterns and trends. The interpretations were further validated by checking with the participant teachers on any emerging themes.

\section{Findings}

In determining answers to the research question which sought to explore how teachers teach 1 Life Sciences in their second language, lesson observations were done. Each of the six teachers was observed once and scored using the RTOP scoring rubric. Table 1 shows teachers' scores for each of the RTOP categories.

Table 1. Teachers' scores in the different RTOP categories.

\begin{tabular}{|l|c|c|c|c|c|c|}
\hline & \multicolumn{6}{|c|}{ Teachers' scores with RTOP categories (out of 100) } \\
\cline { 2 - 7 } $\begin{array}{l}\text { Teachers' } \\
\text { pseudonyms }\end{array}$ & $\begin{array}{c}\text { Lesson design } \\
\text { and } \\
\text { implementation }\end{array}$ & $\begin{array}{l}\text { Propositional } \\
\text { knowledge }\end{array}$ & $\begin{array}{l}\text { Procedural } \\
\text { knowledge }\end{array}$ & $\begin{array}{l}\text { Communicative } \\
\text { interactions }\end{array}$ & $\begin{array}{c}\text { Learner- } \\
\text { Teacher } \\
\text { relationships }\end{array}$ & $\begin{array}{c}\text { Average } \\
\text { scores }\end{array}$ \\
\hline Phale & 60 & 65 & 35 & 55 & 70 & 57 \\
\hline Shilubane & 65 & 60 & 45 & 80 & 75 & 65 \\
\hline Koali & 80 & 85 & 55 & 90 & 80 & 78 \\
\hline Zanele & 60 & 70 & 50 & 60 & 65 & 61 \\
\hline Mulalo & 50 & 65 & 55 & 50 & 55 & 55 \\
\hline Sizwe & 70 & 65 & 60 & 65 & 65 & 65 \\
\hline Average scores & 64 & 71 & 50 & 67 & 68 & 64 \\
\hline
\end{tabular}

The findings revealed that though the participants taught in similar contexts, they did not experience the same. This is prominent in the variances between their RTOP scores. It is notable that teachers struggled with the language demands in the Life Sciences classes at all levels of experiences. Very experienced teachers and novice teachers struggled in the same way to cope with the scientific language demands. Hence some participants resorted to code-switching as a way of ensuring that science concepts are grasped by the learners. 
The total scores of the six teachers show a big difference and therefore share light on the way in which these teachers experienced the teaching of Life Sciences using their second language. For instance, Phale (VE) managed to get an average score of $57 \%$, which is very low. In this case, it shows that experience does not necessarily mean that a teacher will be effective in the classroom. For example, throughout the lesson, Phale only focused on delivering the content, and although he would code switch every now and then, it was not effective because the code-switching occurred in Sesotho. Since some of the learners were not Sotho speaking, there was a breakdown in communication. Some learners would make the following remarks: "Asisizwa isiSotho" which means they do not understand the Sesotho language. This illustrates that language plays a vital role in the teaching and learning of science concepts. It also highlights the need for township teachers to be proficient in more than one language. Shilubane (VE) had a fair average of $65 \%$, and although he had 16 years of experience, he did not score the highest. However, it is notable that during his lesson the language of instruction was mostly used. There was some code-switching that occurred effectively, because the learners were able to interact and engage meaningfully in the lesson.

Koali (RE) had the highest average score of $78 \%$ compared to other participants. One aspect that typified Koali's class was the teacher-learner interaction. This resulted from the usage of the Sesotho and IsiZulu language throughout the lesson. Though most of the lesson took place in the teacher's and learners' home language(s), it was noted that the level of engagement was high, and learners were able to participate effectively in the lesson, since they were not confined to using English. Mavuru and Ramnarain (2019) described the importance of familiarising science concepts to the learners so that they easily relate to them. This is significant in ensuring conceptual change.

Zanele (N) managed to obtain an average score of $61 \%$, she was one of the least experienced teachers with only two years of teaching experience. When teaching the respiratory diseases, she would play some videos that kept learners engaged in the lesson. However, because she mostly taught in English and hardly code switched, it was notable that some learners were disoriented in the lesson.

Mulalo (N) had the lowest average of 55\%. He was in his second year of teaching; hence some of the difficulties that arose in his classroom were directly linked to his inexperience. For instance, during the lesson he mostly used English, which would account for the lack of engagement of learners. Furthermore, the mispronunciation of some terms showed that he also lacks proficiency in the scientific language, which would explain the lower score. On the contrary, Sizwe (RE) managed to obtain 65\%, which was the same total score obtained by one of the most experienced teachers, Shilubane. Sizwe's scores on the RTOP items were mostly consistent, and during the lesson observation, it was established that he showed a great level of proficiency in the language of instruction. This impacted positively on the learners as the level of interaction in the classroom was fairly normal.

\subsection{Discussion of findings from lesson observations}

The findings indicate a very important aspect, that is, language difficulties in science classes are prevalent and ESL speakers struggle to cope with the language demands in these classes. This can be seen through the low scores that both experienced and inexperienced teachers obtained. This confirms Oyoo's (2017) findings, that ESL teachers struggle to meet the demands of not only the language of instruction but the scientific language too. The low average scores of experienced teachers like Phale and Shilubane, serve as evidence to show that language difficulties are experienced by all. Ferreira (2011) highlighted the need for ESL teachers to regularly code-switch when explaining some of the difficult concepts in Life Sciences. The findings in this study revealed that teachers used code-switching more frequently as a way of coping with the difficult language demands in Life Sciences Life Sciences classes. In this case, it is important to note that code-switching was not used only as a teaching method to try simplify difficult science concepts, rather it was also used as a way in which teachers tried to cope with the difficult scientific register. This affirms Probyn (2016), that code-switching for ESL speakers is not only a teaching aid, but rather a coping mechanism for both the language of instruction and the scientific language.

\section{Conclusion and implications}

This study explored how teachers teach Life Sciences using their second language and the means in which they use to cope with the language demands. In order to cope with the language difficulties, teachers used code switching. Previous studies have also advocated for the use of a language that is familiar to both teachers and learners to combat the constraints that are often paused by the use of the second language in science classes. The emphasis in this case, is that teachers' use of language in science classes influences their teaching, which eventually will affect learners' acquisition of scientific concepts. For instance, the RTOP scores obtained by teachers, especially with regard to teacher-learner interactions and communicative practices, showed that the teachers who scored the highest often practised 
code-switching. And in interpreting why such findings were obtained, factors such as proficiency in both the home language and English were raised, as some teachers, especially those that were not proficient in the learners' home languages, struggled to convey some of the vital concepts to learners. The researchers believe that Life Sciences is strongly affected by the language policy and, therefore, Life Sciences teachers in township schools should be aware of the difficulties and challenges that are faced by both teachers and learners.

\section{References}

Alhamami, A. (2019). Language of instructional science programs: science university students' voices. Journal Pendidikan IPA Indonesia, 8(10), 110-118.

Boateng, P. (2019). Managing transitions from mother tongue instruction to English as the medium of instruction. United Kingdom: UK Department for International Development and other Government departments.

Cohen, L., Manion, L., \& Morrison, K. (2000). Research methods in education. London: Routledge Falmer.

Creswell, J. W. (2011). Educational research: Planning, conducting, and evaluating quantitative and qualitative approaches to research $\left(4^{\text {th }}\right.$ ed). Upper Saddle River: Person Education.

Denzin, N. K., \& Lincoln, Y. S. (2005). The Sage handbook of qualitative research. Thousand Oaks, CA: Sage.

Etikan I., Musa S. A., \& Alkassim, R. S. (2016). Comparison of convenience sampling and purposive sampling. American Journal of Theoretical and Applied Statistic, 5(1), 1-4. doi: $10.11648 /$ j.ajtas.20160501.11

Feez, S., \& Quinn, F. (2017). Teaching the distinctive language of science: an integrated and scaffolded approach for pre-service teachers. Teaching and Teacher Education, 65, 192-204. doi: https:doi.org/10.1016/j.tate.2017.03.019

Ferreira, J. G. (2011). Teaching life sciences to English second language learners: what do teachers do? South African Journal of Education, 31, 102-113. doi: 10.15700/saje.31n1a409

Fontana, A., \& Frey, J. H. (2003). The interview: from structured questions to negotiated text. In N. Denzin and Y. S. Lincoln (Eds). Collecting and interpreting qualitative materials, 2nd Edition. (pp. 61-106). Thousand Oaks, CA: Sage.

Gudula, Z. (2017). The influence of language on the teaching and learning of natural sciences in Grade 7. MEd dissertation. Bellville, South Africa: University of Western Cape.

Mavuru, L., \& Ramnarain, U. (2019). Language affordances and pedagogical challenges in multilingual grade 9 natural sciences classrooms in South Africa. International Journal of Science Education, doi: 10.1080/09500693.2019.1655177

Mills, G. E. (2011). Action research: A guide for the teacher researcher (4th ed.). Boston, MA: Pearson.

Msimanga, A., \& Lelliot, A. (2013). Talking science in multilingual contexts in South Africa: Possibilities and challenges for engagement in learners' home languages in high school classrooms. International Journal of Science Education, 10(14), 1-25. doi: 10.1080/09500693.2013.851427

Mthiyane, N. (2016). Pre-service teachers' beliefs and experiences surrounding the use of language in science classrooms: A South African case study. Nordic Journal of African Studies, 25(2), $111-129$.

Oyoo, S. O. (2004). Effective teaching of science: the impact of physics teachers' classroom language. PhD thesis. Victoria, Australia: Monash University.

Oyoo, S. O. (2017). Learner outcomes in science in South Africa: role of the nature of learner difficulties with the language for learning and teaching science. Journal of Science Education, 47, 783-804. doi:10.1007/s11165-016-9528-8

Patton, M. Q. (1990). Qualitative evaluation and research methods. 2nd ed. Newbury Park, CA: Sage.

Prinsloo, C. H., Rodgers, S. C., \& Harvey, J. C. (2018). The impact of language factors on learner achievement in science. South African Journal of Education, 38(1), 1-12. doi: $10.15700 /$ sajev38n1a1431

Probyn, G. (2016). Language and opportunity to learn science in bilingual classroom in the Eastern Cape. Cape Town: University of Cape Town.

Sawada, D., Piburn, M. D., Falconer, R., Turley, J., Benford, R., Bloom, I., \& Judson, E. (2000). Reformed teaching observation protocol (RTOP) training guide. Phoenix, AZ: Arizona Board of Regents.

Setati, M. (2002). Researching mathematics education and language in multilingual South Africa. The Mathematics Educator, 12(2), 6-20. 


\title{
CULTURAL TRANSLATION BEYOND AN INTERDISCIPLINARY EXIT, A MEETING OF KNOWLEDGE
}

\author{
Ana Hernández Espino \\ Research group SIEP and PhD in education, Autonomous University of Madrid/PhD candidate (Spain) \\ PhD in social sciences, National University of Entre Rios/PhD candidate (Argentina) \\ Atlántida technical school, University of Labor of Uruguay/ Teacher (Uruguay)
}

\begin{abstract}
In a context of intercultural conflicts, of exclusive educational policies, it is necessary to create inclusive perspectives, enabling coexistence between different cultures. A Latin American educational framework rooted in neoliberal policies restricts creative gazes. Two doctoral researches carried out with a perspective of Popular Education, one in Mexico, Costa Rica, Argentina and Uruguay and another on a specific experience in Uruguay show the potential of the emancipatory component. His socio-historical analyzes link the educational proposals with the historical evolution of their problems in relation to their contexts. Cultural translation is presented as one of the potentialities, where weighted popular knowledge is rescued by groups. Some socio-community referents have skills to know, understand and translate the demands. A training obtained from the analysis of the experience and knowledge of the groups stimulates decolonization processes.
\end{abstract}

Keywords: Cultural translation, popular education, Mesoamerica, southern cone.

\section{Introduction}

The main objective of this presentation is to present some approaches to cultural translation in Popular Education experiences in spaces in countries such as Mexico, Costa Rica, Argentina and Uruguay. Within the framework of two doctoral investigations with critical qualitative methodology and a gender approach, at the Autonomous University of Madrid and at the National University of Entre Ríos.

\section{State of the art}

The cultural translation from different meanings presents scenarios with common points in a global perspective. From a significance of the translation in a synchronous analysis of a culture as a synonym of country culture, it is presented as a passage from one nation or country culture to another. From another place, the translation is investigated from documentary analysis, looking for common signs of a common culture. Literary translation behaves in a similar way, in a specific field it tries to translate translation without being linked to culture, something that is inevitable. The hybrid tries to take place in some of these investigations, but they do not support sociohistorical analysis. In a third place, we look at cultural translation from the contribution of De Sousa $(2006,2007)$ and Benjamin (1971), culture is a social construction and therefore, its translation is inseparable from its object.

\section{Perspective}

The research works carry out an ethical translation of the meanings of the Popular Education experiences (Hernández, 2019a), considering the meanings of the participants. Benjamín (1971) and de De Sousa $(2006,2007)$ present cultural translation and its professionalization. In a first analysis, translation is presented as the search for authenticity and for equality between the original and the translated code, viewed from various categories. The problematization between the original standardized code, the instituting product of the Popular Education perspective, and the translated product of research reflection tend to differ. It sets out the interests of each one of the issuing agents or translators. Through a qualitative methodology with a critical and participatory gaze, the stories of the participants are detected. 


\section{Methodology}

In a qualitative methodology with a gender perspective, the gazes of the participants in their space, time and territory, signify their world, offering their knowledge. The researcher with a previous academic coding tries to question these experiences, for this they must first recognize themselves in that coding. This first moment provides information on the official or reproduced accounts and their own accounts (Hernández, 2019b). In a second moment, the criticality and analysis of these stories based on the selected categories brings to the scene a differentiation.

\section{Approaches}

Cultural translation presents encoding and decoding concretions linked to the voluntary or involuntary political intention of the translators (Hernández, 2020). The problematizations of the categories by the researcher, when bringing together the binding meanings, develops an overlap between the research-translating gaze and the participants' own original and the reproduced one.

The "computer codes" (Foucault, 1997, p. 6) are emulated by passing from their original codes to reproduced computers. The power exercised by the researcher or by the official account exercised in the experiences reinstitute what was instituted or decolonize the official account. This exercise requires training.

The cultural translation of the investigative gaze, the connivance of the popular and scientific world makes its borders (Duschatzky, 1999) indiscernible. By setting up a confrontational exercise between the researcher's gaze and the investigated field, she takes a distance to look again. By looking in if you, the cultural translation exercised in the investigation becomes manifest. The participant's story and the researcher's gaze mediated by the Popular Education perspective are exposed in the analysis.

\section{References}

Benjamin, W. (1971). The task of the translator. Barcelona: Edhasa. Retrieved 1-4-2021 from https://programaddssrr.files.wordpress.com/2013/05/la-tarea-del-traductor-walter-benjamin.pdf

De Sousa Santos, B. (2006). Knowing from the South: For an emancipatory political culture. Lima: Editorial Fund of the Faculty of Social Sciences / Postgraduate Unit, Universidad Nacional Mayor de San $\quad$ Marcos. $\quad$ Retrieved 1-4-2021 from http://www.boaventuradesousasantos.pt/media/Conocer\%20desde\%20el\%20Sur_Lima_2006.pdf

De Sousa Santos, B. (2007). Knowing from the South: For an emancipatory political culture. 2nd ed. La Paz: CLACSO, CIDES - UMSA, Plural editores. Retrieved 1-4-2021 from https://www.google.com/url?sa=t\&rct=j\&q=\&esrc=s\&source=web\&cd=\&ved=2ahUKEwj45rP8m oPuAhWnIrkGHThCCwwQFjAAegQIAhAC\&url=http\%3A\%2F\%2Fwww.ceapedi.com.ar\%2Fim agenes\%2Fbiblioteca\%2Flibreria\%2F181.pdf\&usg=AOvVaw3YbKnXRYrlarxN9_dUP9TF

Duschatzky, S. (1999). The school as a frontier: reflections on the school experience of youth from popular sectors. Buenos Aires: Paidós.

Foucault, M. (1997). Words and things: an archeology of the human sciences. 26th ed. Mexico: XXI century.

Hernández, A. (2019a). Ethical perspective of Popular Education and its concretion in the exercise of the human rights of the citizenship of the XXI century. Simpósio 41 Inclusões, Equidade E Reflexões Pedagógicas. Cenários Vulneráveis E Direitos Humanos - Perspetiva Interculturalidade E Análise $\mathrm{G}$ Gender. From October 16 to 18 Coimbra, Portugal. 2019. University of Coimbra. ISSN No. 2595-2773. Paper summary retrieved 1-4-2021 from https://152fe815-3c89-4d82-ac2d8d755e680c6d.filesusr.com/ugd/8f3de9_82b6e790f875492898ee44fb0f8e5504.pdf

Hernández, A. (2019b). Education versus Emancipation: Is a liberating educational story possible?, 16, pp. 405-415, RIDECTEI 2019 - Education, science, technology and innovation, June 2019, ISBN: 978-1-945570- 96-4. Retrieved 1-4-2021 from https://redipe.org/editorial/ridectei-2019educacion-ciencia-tecnologia-e-innovacion/

Hernández, A. (in press). Educations or trainings, similar looks of different conceptualizations of themselves and themselves. Involuntary reproduction or political intentionality? Journal of Modern Education Review. New York: Academic Star Publishing Company.

Villasante, T. (2002). Subjects in Motion: Networks and creative processes in social complexity. Building Citizenship / 4. Montevideo: Nordan Community. 


\title{
LIFE SCIENCES TEACHERS' CONCEPTIONS ABOUT SOCIOSCIENTIFIC ISSUES IN THE TOPIC EVOLUTION
}

\author{
Mokgadi Relela, \& Lydia Mavuru \\ Department of Science and Technology Education, University of Johannesburg (South Africa)
}

\begin{abstract}
The goal of science education is emphatically positioned on promoting science literacy. The rationale is learners should not only learn about scientific knowledge and processes but also on how to apply the knowledge when making decisions about heterogenous societal and personal issues. Previous research has indicated that by addressing socioscientific issues (SSIs) when teaching controversial science topics, it provides a suitable context for developing scientific literacy in learners. Scientifically literate learners are well-informed citizens with regards to the social, ethical, economic, and political issues impacting on contemporary society. The theory of evolution is one such Life Sciences topic deeply embedded with SSIs. Teachers are conflicted when teaching this topic due to the controversy surrounding the theory as they view the teaching of evolution as a way of negating the legitimacy of their religious and cultural convictions. It is against this background that the study sought to answer the research question: How do Life Sciences teachers conceptualise socioscientific issues embedded in the topic evolution? In an explanatory mixed method approach, a questionnaire with both quantitative and qualitative questions was administered to 28 randomly selected grade 12 Life Sciences teachers. Data was analysed and descriptive statistics were obtained, and themes generated. The findings showed that all the participants were knowledgeable about the SSIs embedded in the topic evolution. In justifying their conceptions $61 \%$ of the teachers perceived SSIs as important in improving learners' reasoning and argumentative skills; developing learners' critical thinking skills; and in informing learners in decision making. There were however $11 \%$ of the teachers who pointed out that SSIs as too sensitive to deal with hence not suitable to teach young learners. Though the teachers were knowledgeable about the SSIs embedded in the theory of evolution, it does not mean that they could address them when teaching the various concepts of evolution. The main source of the controversy rose from the evolution of humankind versus the Christian belief in the six-day special creation. The participants (25\%) indicated that evolution challenges peoples' religious and cultural convictions, which conflicts both the teachers and learners to question or go against their religious beliefs. Several teachers pointed out that some of the concepts on evolution such as 'living organisms share common ancestry (18\%) and 'the formation of new species from existing species' $(11 \%)$, undermine the superiority of human beings over other organisms. The findings have implications for both pre-and in-service teacher professional development.
\end{abstract}

Keywords: Evolution, life sciences, socioscientific issues.

\section{Introduction}

Achieving science literacy is a fundamental objective in the advancement of science education. Science literacy can be achieved by engaging learners in debates, dialogues, discussion, and argumentation, which requires learners to justify the claims they make with reasons and evidence (Zeidler, 2014). Such achievements can be done through the integration of science and society whilst teaching topics that are entangled with controversial issues (Janasoff, 2010). Topics such as the theory of evolution, climate change and cloning are spelled out as being embedded with socioscientific issues (SSIs) (Janasoff, 2010). Addressing SSIs has been positioned as an effective way for learners to contextualize their science learning within a challenging social and political background (Hancock, Friedrichen, Kinslow, Sadler, 2019). To date research has clearly indicated that by addressing SSIs when teaching controversial science topics provides a well-suited approach for developing science literacy (Hancock et al., 2019). The theory of evolution is a topic embedded with SSIs and, if adequately addressed in the manner which is commensurate with its significance as a fundamental building block of life and its overall explanatory power in the Life Sciences classrooms, it can increase learners' levels of science literacy needed to prepare them for careers in Science, Technology, Engineering, and Mathematics (STEM) (National Science Teachers' Association, 2013).

Previous researchers have documented the antagonism between religious and cultural views and the theory of evolution as the main stumbling block in the teachers' and learners' willingness to engage with the concepts on the theory of evolution in the Life Sciences/Biology classrooms. The argument is that science instruction on the theory of evolution has the tendency to a certain extent to impact 
negatively on learners' socio-cultural values as it compels them to invalidate their indigenous values (Deniz \& Borgerding, 2018). As such, Weiland (2015) advocates for culturally relevant pedagogy which affords learners with modalities designed to ensure the maintenance of their cultural identity whilst ensuring that they are achieving goals academically during the teaching and learning of the theory of evolution. In their arguments for endorsement of the theory of evolution, Berta, Pobiner, Beardsley and Watson (2019) argued that learners may opt to deny the theory of evolution due to their religious and cultural backgrounds, but to be scientifically literate, it is necessary that the Life Sciences learners understand how and why scientists consider the theory of evolution to be the basic building block in Life Sciences. In agreement, Reiss (2019) pointed out that the pivotal role of the Life Sciences teachers is not to convert learners who do not accept the theory of evolution to accept the theory, but to build a sensitive multicultural classroom environment that aims to promote those learners who are most uncomfortable with the theory of evolution to engage in the topic on their own free will. Of utmost importance is for all Life Sciences learners to discover and acknowledge the theory of evolution in a classroom atmosphere that does not compel them to choose between science and their religious and cultural convictions. From this perspectives, pervious science research has advocated for the need to teach the theory of evolution in a classroom atmosphere that acknowledges the religious and cultural controversies surrounding the topic, with the aim of focusing on an increased scientific understanding as opposed to the endorsement of the theory of evolution (Berta et al., 2019; Reiss, 2019).

Religious and cultural discontentment are not the only impediment endangering the teaching and learning of the theory of evolution, the other is teachers' incapacitation to address the socioscientific controversy surrounding the theory (Sutherland \& L'Abbe, 2019). Teachers' capacity to exchange views about socioscientific issues in topics such as the theory of evolution in an efficient approach while at the same time being respectful and sensitive of learners' religious and cultural convictions forms the backbone of democracy (Sutherland \& L'Abbe, 2019).

Chikoko, Gilmour, Harber and Serf (2011) reported that Life Sciences teachers are not capacitated to manage the discussion of controversial issues in their classrooms. Similarly, in a study conducted by Mavuru (2018), findings indicated that Life Sciences teachers expressed their inability to properly address the socioscientific issues surrounding the theory, notably when faced with learners from different socio-cultural and religious convictions, which are perceived as antagonistic to the theory of evolution. Teachers are conflicted when teaching this topic as they view the teaching of evolution as a way of negating the legitimacy of their religious and cultural beliefs. It is against this background that the study sought to answer the research question: How do Life Sciences teachers conceptualise socioscientific issues embedded in the topic evolution?

\section{Literature review}

Several researchers in science education advocate that for the greater benefit of educating future citizens who are familiar with the scientific way of thinking by engaging learners in dialogues, discussion, debate, and argumentation (Zeidler, 2014). This would make learners realise the connections between science and their lives and to make well-informed decisions (Han-Tosunoglu \& Lederman, 2016). This suggests that science teachers are not only required to prepare learners for educational achievement, but to provide an education that nurtures science learners to become citizens who are cognisant of ethical, cultural, political, and economic aspects of the contemporary society (Han-Tosunoglu \& Ledermann, 2016). However, numerous studies on the teaching of controversial topics reported that science teachers find the addressing of SSIs challenging (Han-Tosunoglu \& Irez, 2017). In particular, science teachers are reluctant to use SSIs approach due to the concerns regarding classroom management and their own abilities (Tidemand \& Nielsen, 2017); time constraints linked to the curriculum coverage (Tidemand \& Nielsen, 2017); parental reaction, administrative pressures, and feelings of inadequacy in content areas (Greer \& Glaze, 2016). This is especially true with the most controversial topic in the history of science, which is the theory of evolution. According to Ogunleye (2009), the controversy surrounding the theory of evolution is deeply ingrained in the individuals' perceived antagonism between scientific understanding of the theory and the internal worldviews the individual is affiliated to. Glaze (2018) contends that it is the issue of evolution of humankind, and the emergence of new species, that causes the greatest antagonism among the public.

\section{Methodology}

The study employed an explanatory mixed methods research design (Creswell, 2014). This design was appropriate in combining the strength of both quantitative and qualitative research methods thereby compensating for their individual limitations (Pluye \& Hong, 2014). A group of 28 Life Sciences teachers from diverse socioeconomic and cultural background in terms of race, ethnicity religion was randomly selected. These included 14 teachers from township schools, 8 teachers from suburban schools, 2 from independent schools and four from Christian schools. Of the 28 participants 16 were Christians, 3 were Muslims and 9 identified themselves as following Traditional African religion. The sample was 
suitable for this study due to the high levels of diversity amongst teachers and learners in the schools in terms of values, culture, and ethnicity, which could influence the SSIs teachers hold. The assumption was that the teachers' and learners' religious and cultural backgrounds were likely to influence their instructional practices during the teaching and learning of the theory of evolution.

Data collection involved the administration of an adopted and adapted questionnaire for assessing the Pedagogical Content Knowledge for Biological Socio-scientific Issues (PCK-BSSIs) (Han-Tosunoglu \& Lederman, 2016). The questionnaire consists of two sections, A and B. Section A of the questionnaire required teachers' background information, which is science teaching orientation, while section B of the questionnaire focuses on teachers' understanding/beliefs about SSIs. Teachers' responses of the questionnaire were analysed using a rubric developed by Han-Tosunoglu and Lederman (2016) and descriptive statistics were obtained. The rubric helped to accommodate the responses for each question in one of three different categories: Inadequate understanding, eclectic understanding, and reform-based understanding, that indicate the degree to which participants are familiar with each of the given statements or not. Reform-based understanding indicates an in-depth understanding, or deep knowledge, of the teaching and learning of the theory of evolution. Eclectic understanding signifies that the participants showed some degree of understanding about the teaching and learning of the theory of evolution. While inadequate understanding shows that the participants are not knowledgeable with regards to the teaching and learning of the theory of evolution. In this study, we present the result of Section B of the instrument which is related to teachers' conceptions about the socioscientific issues in the topic evolution.

\section{Research findings}

Teachers' conceptions of socioscientific issues in the topic evolution was measured by five items of Section B of PCK- BSSIs questionnaire. Figure 1 that follows presents findings on the distribution of the participants' conceptions.

Figure 1. Teachers' conceptions about socioscientific issues embedded in the topic evolution.

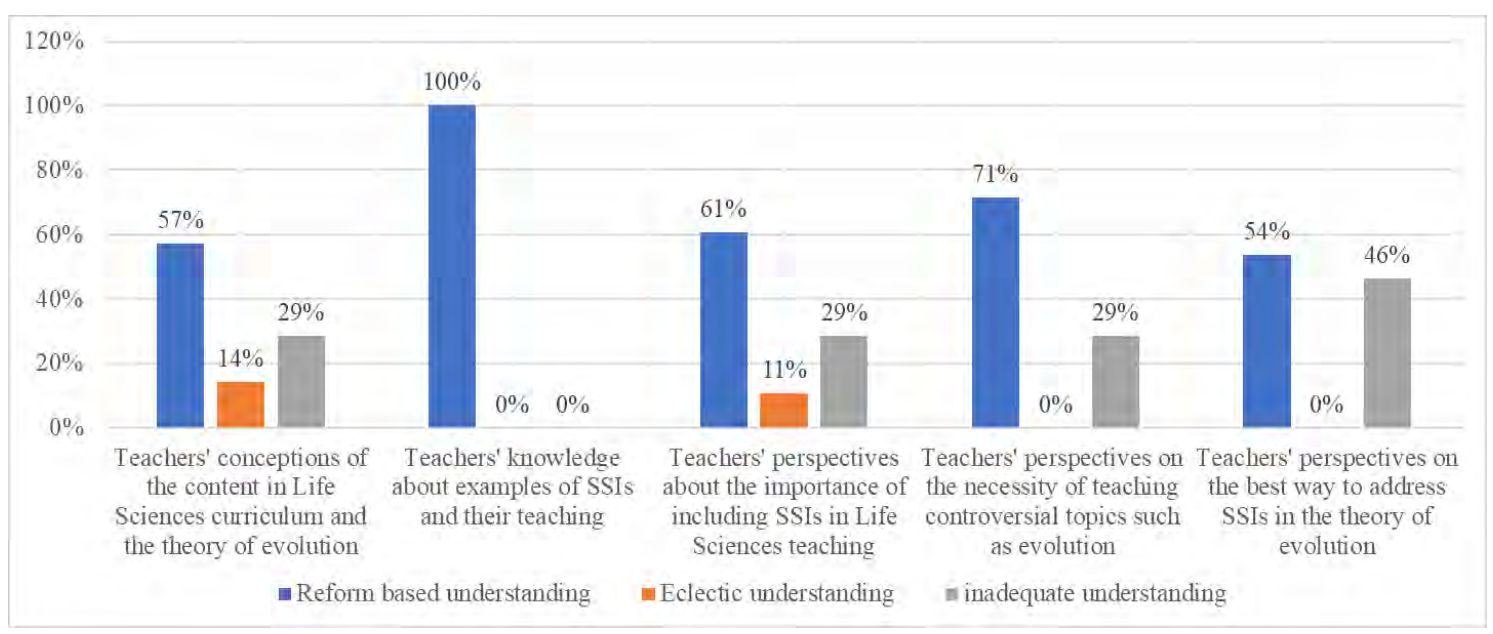

From Figure 1, in the first item which asked the participants about their perspective of the inclusion of the theory of evolution in the Life Sciences curriculum and whether there is potential for conflict between their personal beliefs and scientific beliefs, more than half $(57 \%)$ of the participating teachers perceived themselves as not having any personal conflict with the theory of evolution. As such, they recommended the inclusion of the theory of evolution in the Life Sciences curriculum. The participants' arguments in favour of the inclusion of the theory of evolution in the Life Sciences curriculum were that evolution is the only convincing theory that explains the existence of all living organisms on earth. As deduced from their justification, despite their familiarity with both scientific and religious beliefs, teachers in this category were not concerned that their beliefs about the theory are somehow antagonistic towards their religious beliefs about the special creation, and as such they still felt the topic should be included in the curriculum. On the other hand, $14 \%$ of the participants indicated that the evolution of humankind was inappropriate, hence should not be included as part of the evolution content in the grade 12 Life Sciences curriculum. These teachers particularly pointed out that the evolution of humankind was their bone of contention as it undermines the learners' and their religious and cultural convictions. The teachers in this category in a way indicated that they could easily embrace and acknowledge the fundamental ideas of the theory of evolution, on condition that those ideas are not applicable to the evolution of humankind. About a third $(29 \%)$ showed a lack of understanding about the theory of evolution. This was evident in their reasoning for not supporting the inclusion of the theory in 
the Life Sciences curriculum, which centred on the theory influencing the religious beliefs of the teenagers (grade 12 learners) who are still immature in making decisions for themselves.

All the teachers indicated that they had an in-depth knowledge and understanding of the socioscientific issues surrounding the theory of evolution and the teaching there of as indicated in item 2 . The second item was aimed at revealing teachers' awareness, recognition, and acknowledgement of their learners' socio-cultural background. Teachers' familiarity with the socioscientific issues embedded in the theory of evolution is envisioned to enable them to plan their lessons in a manner that provides learning opportunities relevant and sensitive to their learners' religious and cultural backgrounds. As deduced from their responses, it is the evolution of humankind versus special creation that emerged as the source of most socioscientific controversy surrounding the theory of evolution.

The third item was on the participants' perspectives on the need to address SSIs in their Life Sciences, (not specifically the theory of evolution). The analysis of data showed that more than half of the participants $(61 \%)$ stated that teaching learners about SSIs was crucial. In justifying their conceptions, teachers conceived SSIs as important in improving learners' reasoning and argumentative skills; developing learners' critical thinking skills; and in informing learners in decision making. Teachers in this category showed a reform-based understanding by virtue of acknowledging the values of addressing the SSIs during teaching and learning as a key principle for science literacy. Such a stance is particularly fitting for the South African curriculum, which supports equipping learners with the skills and values necessary for self-fulfillment and, meaningful participation in society as citizens of a free country (Department of Basic Education [DBE], (2011). From that same third item, 11\% of teachers had mixed views, indicating that some of the SSIs should be included while others are overly sensitive to deal with in the Life Sciences classrooms. These participants displayed an eclectic understanding, which means they showed some degree of understanding the need to address the SSIs. These teachers mentioned that the teaching of topics such as the theory of evolution, abortion, stem cell research, and HIV/AIDS, can stir emotions in their learners. In justifying their stance, the teachers pointed out that learners come from diverse sociocultural and religious backgrounds, which makes it difficult to address the diverse SSIs brought in by the learners. $29 \%$ of the teachers showed lack of understanding.

The fourth item was on teachers' conceptions on the need to address controversial and debatable issues on the topic of evolution in Life Sciences classrooms. Analysis of data revealed that most participants $(71 \%)$ presented reform-based understanding in acknowledging that addressing controversial and debatable topics in the Life Sciences classrooms was worth the effort and time. Teachers' reasons for advocating for the address of SSIs were based on the fact that addressing controversial issues would go a long way in developing science literacy among learners. The reason most of the teachers in this category gave for supporting the addressing of SSIs was that learners would become well informed citizens who could reason and argue about any matter at hand. They pointed out that in such a classroom environment, learners are given opportunities to recognize and appreciate different perspectives from their peers during the process of argumentation and debating. Though the teachers acknowledged and advocated for addressing controversial and debatable issues in their Life Sciences classrooms, there were however $11 \%$ of the $71 \%$ who indicated their inability to create learning environments conducive for debate and argumentation in their classrooms. The fear of losing control was the main reason pointed out by these teachers as classroom management is problematic in most South African classrooms in public schools.

Quite the opposite, the findings indicated that $29 \%$ of teachers showed that they lacked knowledge and understanding in addressing SSIs. The lack of understanding is evident in one of the participants who wrote, "debating controversial topics is for Life Orientation classes, not Life Sciences, here we are dealing with content, only." This view is contrary to the vision of science education postulated by Sadler (2004) that learners should not only learn about conceptual knowledge of the subject matter and scientific processes, but also how to use this knowledge for making decisions about complex societal and personal issues learners encounter in their daily lives. Some teachers who showed inadequate understanding argued that "evolution is just a theory", insinuating the theory of evolution as questionable and discreditable.

The last item (fifth item) sought teachers' perspectives on the best way to address the SSIs embedded in the theory of evolution. The item was aimed at revealing the pedagogical strategies employed by Life Sciences teachers during the teaching and learning of concepts in the theory of evolution. The analysis of data showed that there were two main school of thought, regarding the integration of SSIs embedded in the theory of evolution, namely: the first school of thought was categorised by teachers who engage learners in the socioscientific controversy surrounding the theory of evolution and the second school of thought was categorised by teacher who do not engage learners in the socioscientific controversy surrounding the theory of evolution. In this item more than half (54\%) of the participants engaged their learners in controversial activities that develop learners' critical, argumentative, and analytical thinking skills. The participants' reasons for engaging learners in controversy is that it allows their learners to become independent thinkers who are well informed. The participants indicated that this approach allows their learners to explore and establish a relationship between their existing knowledge and the new scientific knowledge. They also indicated that no learner would be left out or 
marginalized as their ideas would be embraced and acknowledged during discussions. Teachers also pointed out that misconceptions that may arise, will be addressed accordingly.

In this item, $46 \%$ of teachers indicated that they do not engage their learners in the discussions of socioscientific controversy surrounding the topic. These teachers pointed out that such discussions create conflict with their learners' religious and cultural backgrounds. This implies that these teachers were not well capacitated to facilitate discussions of the socioscientific issues in their classrooms. An important point raised by these teachers was that the topic is too long, and the time allocated for the teaching and learning of the theory is too little to allow discussions. Failure to complete the teaching of this topic would compromise learners' performance in their final examinations as the topic constitutes $44 \%$ of the marks in Paper 2.

\section{Discussion}

The findings showed that majority of the Life Sciences teachers categorised as having reform-based understanding, were deeply knowledgeable of their own as well as the learners' religious and cultural backgrounds. They accommodated and embraces in their pedagogical instructions. This is in accord with Berta et al. (2019) assertion that for most learners, acknowledging religious and cultural challenges associated with the theory is an effective classroom strategy for creating supportive classroom atmosphere. Previous studies (e.g. Berta et al., 2019; Reiss, 2019) underscore that in Life Sciences classrooms where learners hold religious and cultural worldviews that may interfere with the understanding of the theory of evolution, learners are highly unlikely to understand the theory until such time that their religious and cultural concerns are addressed.

\section{Conclusion and implications}

The findings of this study reinforce the need for Life Sciences teachers to consider the goals of science education which are aimed at producing science literate learners who are well-informed citizens by addressing SSIs embedded in topics such as the theory of evolution. Some of the teachers indicated that they address SSIs by engaging learners in debates, dialogues, discussion, and arguments. There were teachers who showed a lack of understanding of the importance of addressing SSIs as their focus was on completing the curriculum and preparing learners for examinations. There were some who did not support the inclusion of the theory of evolution in the curriculum arguing that the theory undermines the learners sociocultural and religious beliefs, particularly the evolution of humankind.

\section{References}

Bertka, C.M., Pobiner, B., Beardsley, P., \& Watson, W.A. (2019). Acknowledging students' concerns about evolution: a proactive teaching strategy. Evolution: Education and Outreach, 12(1), 3.

Chikoko, V., Gilmour, J.D., Harber, C. \& Serf, J. (2011). Teaching controversial issues and teacher education in England and South Africa. Journal of Education for Teaching, 37(1), 5-19.

Deniz, H. and Borgerding, L.A. (2018). Evolutionary theory as a controversial topic in science curriculum around the globe. In Evolution education around the globe (3-11). Springer, Cham.

Glaze, A. (2018). From worldviews to classrooms: Framing evolution acceptance in pre-service science teachers in the southeastern United States. Georgia Educational Researcher, 14(2), 1-12.

Greer, K. and Glaze, A. (2016). Socio-Scientific Argumentation as a Driver for Science Learning. New Perspectives in Science Education 5. 10.13140/RG.2.2.14176.28160.

Hancock, T. S., Friedrichsen, P. J., Kinslow, A. T., \& Sadler, T. D. (2019). Selecting socio-scientific issues for teaching. Science \& Education, 28(6-7), 639-667.

Han-Tosunoglu, C., \& Lederman, N. G. (2016). The development of an instrument for assessing pedagogical content knowledge for socioscientific knowledge (PCK-SSI). National Association for Research in Science Teaching (NARST). Baltimore, USA.

Mavuru, L. (2018). Teaching Evolution to Grade 12 Learners: Teachers' views and pedagogical practices. In M. Carmo (Ed.) Education Applications \& Developments IV: Advances in Education and Educational Trends Series (pp. 148-158). Portugal: In Science Press. http://hdl.handle.net/10210/274375

National Science Teachers Association (2012). NSTA standards for science teacher preparation.

Reiss, M. J., 2019. Evolution education: treating evolution as a sensitive rather than a controversial issue. Ethics and Education, 14(3), 351-366.

Sutherland, C. \& L'Abbé, E.N. (2019). Human evolution in the South African school curriculum. South African Journal of Science, 115(7-8), 1-7.

Tidemand, S. \& Nielsen, J.A. (2017). The role of socioscientific issues in biology teaching: From the perspective of teachers. International Journal of Science Education, 39(1), 44-61.

Zeidler, D.L. (2014). Socioscientific issues as a curriculum emphasis. Theory, research, and practice. In NG Lederman \& SK Abell (Eds.). Handbook of research on science education, 2, 697-726. 


\title{
SPREADSHEETS AND LATEX - A PERFECT UNION FOR THE CREATION OF TESTBANKS FOR ONLINE ASSESSMENT
}

\author{
Azam Beg ${ }^{1}$, Manzoor Ahmed Khan ${ }^{1}, \&$ Maqsood Sandhu ${ }^{2}$ \\ ${ }^{1}$ College of Information Technology, United Arab Emirates University (United Arab Emirates) \\ ${ }^{2}$ College of Business \& Economics, United Arab Emirates University (United Arab Emirates)
}

\begin{abstract}
The current COVID-19 pandemic forced an instant shift in teaching from the traditional classrooms to an online format. While it was relatively easy to switch the teaching to online mode, the assessment process presents bigger challenges. Specifically, the assessment quality is compromised because during an online test, most students are able to seek help from their fellow test-takers as well as from different online sources. One way of discouraging the students' tendency to share the answers among themselves is to inform them they will be given different questions than their peers. In this paper, we propose to use spreadsheets to create test questions in Latex format, thus making it easy to present each student with a 'unique' question-set during a test. The uniqueness of the testbank questions comes from randomly generated variable values in numerical questions. The spreadsheet also produces the answers to the questions to help automate the grading process. Such testbanks are suitable not only for normally sized courses, but also for the larger massive open online courses. We have successfully used such testbanks for multiple courses in our university's Computer Engineering program. Originally, we had used the testbanks for in-class assessment. After the classes shifted online, we ported the testbanks to our learning management system to enable online assessment.
\end{abstract}

Keywords: Automated assessment, testbank generation, spreadsheet, massive open online course, learning management system (LMS).

\section{Introduction}

A challenge faced by an online course, especially a massive open online course (MOOC) is its 'non-equivalence' to an in-person course (Banks \& Mienert 2016). A reason for the non-equivalence is the credibility of the online assessment (Ip et al. 2019, Cross et al. 2019, De Rosa \& Pistolese 2019). A few companies (for example, ProctorU, Examity, ProctorFree, etc.) offer online/video-based solutions for test proctoring. However, the scalability and the cost of such solutions make virtual proctoring unfeasible for widespread use.

The ongoing COVID-19 pandemic has adversely affected the assessment quality, whether formative and/or summative, for normally sized classes. Not having enough confidence in the online assessment has led many universities worldwide, to assign pass or fail grades, instead of the usual letter grades to the courses.

The testbanks for online assessment need to be created differently than the traditional paper versions. Conventionally, all students in a class were presented single version of a test. However, this approach is not suitable when the students are taking an online test. It is simply because it is now possible, more than ever, for the test-takers to get assistance from their peers and/or other online sources. However, making the students aware that each one of them is getting a 'unique' set of questions, is expected to discourage them from seeking peer help; this will in turn improve the assessment credibility and quality. Generally, for any course that relies on calculations (mathematics, statistics, algebra, etc.), a large testbank comprising unique questions can be created easily. It also implies that such testbanks can be used not only for conventionally sized classes with a dozen to a few hundred students, but also for MOOCs with several thousand students (Anon 2021, Uda 2021). Understandably, the MOOC attendees may vary widely in terms of knowledge, experience, cultural backgrounds, etc., so the testbanks have to be tailored accordingly (Hao \& Huiyan 2018). 
A few techniques for improving the credibility of online/ unsupervised tests include (Petrovic et al. 2017, Yanes et al. 2020): (a) limiting the time a test is available online, (b) randomizing the question sequence in a test, (c) randomizing answers in multiple choice questions, and (d) presenting each test-taker with the questions that are different from the other test-takers. While the common learning management systems (LMSs) allow the randomization of question sequence and multiple-choice answers, the responsibility of creating testbanks that are large enough to present somewhat if not completely unique tests still lies with the course instructors.

In this paper, we propose a spreadsheet-driven method for creating randomized sets of questions in Latex format. (It is well-known that Latex enables the creation of properly formatted text, equations and diagrams). Such questions are suitable for the testbanks for both the traditional paper-based tests and the online tests. Note that our method does not require any special setup, i.e., online databases, data servers, etc. The questions generated by this method can be readily used with an LMS.

The organization of this paper is as follows: Section 2 provides a brief literature review related to assessment and testbanks. Section 3 includes the details of the proposed spreadsheet-driven approach for automatically creating questions and answers for testbanks. Section 4 explains how to utilize the testbanks for course assessment. Section 5 concludes the paper.

\section{Literature review}

An academic assessment involves the creation of test questions, most of which are created manually. However, there are alternatives, for example: static test generation based on integer linear programming using multiple assessment variables (Nguyen \& Fong 2013), or semantic-based method (Miranda et al. 2013). The dynamic approach of test creation uses the bi-proportional matrix scaling technique (Paul and Pawar 2013). Yuan-Bin and Jie (2012) proposed a fishnet algorithm for automatically generating test sheets for the Examination System of Electrical Energy Measurement. Herman and Handzik (2010) and Herman and Loui (2011) introduced concept inventory for digital logic courses, but they mentioned question creation sans any details. They also did not mention how the answers to the questions would be produced. An adaptive learning approach for creating customized learning paths can be used for the students in the MOOCs or the traditional courses. The learning paths can be tailored using common artificial intelligence techniques, such as data mining, machine learning and predictive analytics (Lu et al. 2018). Ahmed et al. (2018) utilized cosine similarity scores for grading students' text-based answers. They used similarity scores for correct answers and keywords or phrases in the students' answers. Oliveira et al. (2018) proposed the use of online peer assessment using rubrics. This was to evoke motivation and creativity among the students. Beg and Beg (2018) proposed using Latex for generating diagrams for an electrical circuit analysis course. Beg (2020) also proposed using Latex for generating the questions with digital logic diagrams. Both papers relied on Octave-based scripting for generating the Latex code, which meant the test-taker had to have sufficient programming knowledge.

No published literature known to the authors reports using spreadsheets for the purpose of generating Latex-based questions and answers for the testbanks for different fields of study (e.g., business/finance, engineering, science, etc.) - and hence the motivation for this work.

\section{Creating test questions and answers using spreadsheets}

Our proposed method of using a spreadsheet to generate unique sets of Latex-formatted questions and answers is novel. This method does not require any commercial software or any elaborate setup of database servers, etc. To create the questions, the knowledge of a few spreadsheet functions is sufficient in most cases, and no scripting or programming skills are required.

Our method can be utilized for generating questions that involve numerical calculations, such as, in the fields of engineering, science, business, finance, etc. The method requires the use of two common applications: a spreadsheet (for example, the open-source Libre Office Calc or MS-Excel) and a Latex compiler. If needed, the same compiler can be used to generate image files containing the questions in the desired graphics format, e.g., .PNG, .JPG, etc.

The proposed method of generating questions and answers entails the following steps:

- Generate questions using spreadsheet formulae and pre-defined parameter ranges

- Create randomized diagrams (using Latex-Tikz) if needed

- Generate single answers for the fill-in-the-blank questions or multiple answers for the multiple-choice questions

- Randomize the order of the answers or choices, if using multiple choices

- Generate readily usable Latex code for questions and- answers. 
We have used this method to create fully formatted Latex questions of different types: text-only, text with equations, and text with diagrams. The examples below show two test questions for a digital logic course. The first question involves the creation of text and equations, whereas the second question requires the generation of both text and graphics. For the image, the spreadsheet's RANDBETWEEN ( ) and LOOKUP () functions randomly specify the logic gates. The gates are inter-connected and then the labels are placed in their proper locations.

Minimize the following function using Boolean theorems:

$$
\bar{A} \bar{B} \bar{C}+\bar{A} \bar{B} C+A \bar{B} C
$$

Choose one of the following answers:
(a) $\bar{B}$
(b) $A \bar{B}$
(c) $\bar{C}$
(d) $\bar{B} C+\bar{A} \bar{B}$

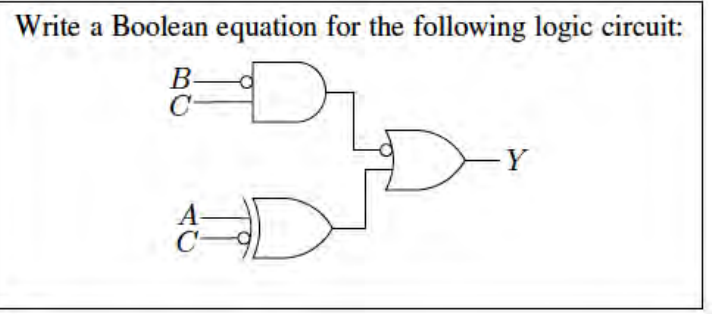

The proposed method can be used for many fields of study. As examples, we have arbitrarily chosen three questions from the fields of computer engineering, physics, and finance. The explanation of each question's creation in Latex format using a spreadsheet is provided.

Example 1: A typical question involving the number system conversion of a mixed number in a digital logic design course may look like this:

$$
\begin{aligned}
& \text { Convert the following decimal mixed number into binary } \\
& \text { format: } 26 \frac{15}{16}
\end{aligned}
$$

Table 1 shows how the question and answer are generated. The question requires three integer values (integer, numerator and denominator) within different ranges. These values are generated using the RANDBETWEEN () function. The values are embedded within the question text to form a Latex command. A correct answer is automatically generated by using the DEC2BIN ( ) function in cell A6.

Example 2: A typical question on mechanics in a physics course may look like this:

Calculate the distance travelled by a car in 4.9 seconds, if the initial velocity $\left(V_{i}\right)=8 \mathrm{~m} / \mathrm{s}$ and the acceleration (a) $=3 \mathrm{~m} / \mathrm{s}^{2}$.

The above question is based on this formula:

$$
S=V_{i} t+\frac{1}{2} a t^{2},
$$

where $S$ is the travelled distance, $V_{\mathrm{i}}$ is the initial velocity, a is the acceleration, and $t$ is travel time of a moving object.

Table 2 shows how the question is created and formatted using a spreadsheet. This question uses three randomly assigned parameter values within the specified ranges, utilizing the RANDBETWEEN () function. These numerical values are used inside the Latex formatted question text. A correct answer is calculated using basic arithmetic operations in cell A5.

Example 3: In a course on finance, a typical question may require the calculation of present value (PV), as shown below:

Calculate the present value $(P V)$ with compounding, if future value $(F V)=1000$, interest rate $(r)=2.5$, number of periods $(n)=5$, and compounding frequency $(m)=$ 0.5 .

The PV is calculated using this formula:

$$
P V=\frac{F V}{\left(1+\frac{r}{m}\right)^{n-m}},
$$


where FV is the future value, $\mathrm{r}$ is the interest rate, $\mathrm{n}$ is the number of periods, and $\mathrm{m}$ is the compounding frequency.

Table 3 shows the details of the question creation. The four parameter values are assigned random values based on the specified ranges using the RANDBETWEEN () function. The question text and the numerical values are properly combined into Latex format. The correct answer comes from the arithmetic operations in the cell A6.

\section{Using the spreadsheet-generated questions and answers for assessment}

We have used the proposed method for creating formative and assessment tools, i.e., tests and examinations. The assessment covered three undergraduate courses offered by our university's Department of Computer \& Network Engineering.

In the years 2017-2019, we had used our method for creating testbanks for paper-based assessment. After the current pandemic struck, we uploaded the testbanks comprising hundreds of questions into our university's LMS (Blackboard). In the Spring-2020 and Fall-2020 semesters, we successfully used the testbanks to administer LMS-based tests and examinations.

The format of the questions depended on the topics. The questions that were entirely text-based were uploaded in the LMS purely in plain-text format, whereas the questions that included equations and diagrams were uploaded as image files.

\section{Conclusions}

Our proposed method of generating testbanks for questions can be used in the assessment of a variety of courses. This method has been used in paper-based and LMS-based assessment in our Computer Engineering program. For us, the next task is to use this method in assessing the students in business and finance courses offered by our university's College of Business \& Economics. Yet another planned task is to scale the assessment for a MOOC.

Table 1. Creating a question and answer for number system conversion in a digital logic design course.

\begin{tabular}{|c|c|c|c|}
\hline Cell No. & Formula & Parameter values and Latex output & Comments \\
\hline A1 & $=$ RANDBETWEEN $(20,50)$ & 26 & Integer \\
\hline A2 & $=$ RANDBETWEEN $(4,6)$ & 4 & Fraction - $\log _{2}$ of denominator \\
\hline A3 & $=2^{\wedge} \mathrm{A} 2$ & 16 & Fraction - denominator \\
\hline A4 & $\begin{array}{l}=2 \star \text { RANDBETWEEN }(3, \mathrm{~A} 3 / 2)-1 \\
=" \text { Convert the following decimal mixed }\end{array}$ & 15 & Fraction - numerator (an odd number) \\
\hline A5 & 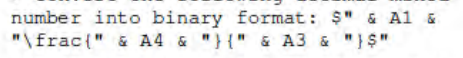 & $\begin{array}{l}\text { Convert the following decimal mixed number into bi- } \\
\text { nary format: } 26 \frac{15}{16}\end{array}$ & Question \\
\hline A6 & $=\operatorname{DEC} 2 \operatorname{BIN}(\mathrm{A} 1,6) \& " \| \operatorname{dDEC} 2 \mathrm{BIN}(\mathrm{A} 4, \mathrm{~A} 2)$ & 011010.1111 & Answer \\
\hline
\end{tabular}

Table 2. Creating a question and answer for speed calculation in a physics/mechanics course.

\begin{tabular}{|c|c|c|c|}
\hline Cell No. & Formula & Parameter values and Latex output & Comments \\
\hline A1 & $=$ RANDBETWEEN $(2,5)$ & 3 & Acceleration (a) \\
\hline A2 & $=$ RANDBETWEEN $(2,10)$ & 8 & Initial velocity $\left(V_{i}\right)$ \\
\hline A3 & $\begin{array}{l}=\text { RANDBETWEEN }(20,100) / 10 \\
=" \text { Calculate the distance travelled by } \\
\text { a car in " \& } 33 \text { \& seconds, if its }\end{array}$ & 4.9 & Time $(t)$ \\
\hline A4 & $\begin{array}{l}\text { initial velocity } \$ \mathrm{~V}_{-} \text {is is " \& A2 \& } \\
\mathrm{m} / \mathrm{s} \text { and the acceleration is " \& A1 \& } \\
\text { "m/s hat }\{12 \text {. }\end{array}$ & $\begin{array}{l}\text { Calculate the distance travelled by a car in } 4.9 \text { seconds, } \\
\text { if its initial velocity } V_{i} \text { is } 8 \mathrm{~m} / \mathrm{s} \text { and the acceleration is } \\
3 \mathrm{~m} / \mathrm{s}^{2} \text {. }\end{array}$ & Question \\
\hline A5 & $=\mathrm{A} 2 * \mathrm{~A} 3+0.5 * \mathrm{~A} 1 * \mathrm{~A} 3 * \mathrm{~A} 3$ & 75.215 & Answer \\
\hline
\end{tabular}

Table 3. Creating a question and answer for present value calculation in a finance course.

\begin{tabular}{|c|c|c|c|}
\hline Cell No. & Formula & Parameter values and Latex output & Comments \\
\hline A1 & $=$ RANDBETWEEN $(2,5) * 1000$ & 4000 & Future value $(F V)$ \\
\hline A2 & $=$ RANDBETWEEN $(3,10) / 2$ & 2 & Interest rate $(r)$ \\
\hline A3 & $=$ RANDBETWEEN $(3,10)$ & 6 & Number of periods $(n)$ \\
\hline A4 & $\begin{array}{l}=\text { RANDBETWEEN }(3,10) / 2 \\
=" \text { Calculate the present value (PV) } \\
\text { with compounding, if future value }\end{array}$ & 4 & Compounding frequency $(m)$ \\
\hline A5 & $\begin{array}{l}(\mathrm{FV})=" \& \mathrm{~A} 1 \& " ; \text { interest rate }(\mathrm{r}) \\
=" \& \mathrm{~A} 2 \& " ; \text { number of periods }(\mathrm{n})= \\
" \& \text { A } \& " ; \text { and compounding frequency } \\
(\mathrm{m})=" \& \text { A \& } \approx "\end{array}$ & $\begin{array}{l}\text { Calculate the present value (PV) with compounding, if } \\
\text { future value }(\mathrm{FV})=4000 \text {; interest rate }(\mathrm{r})=2 \text {; number } \\
\text { of periods }(\mathrm{n})=6 \text {; and compounding frequency }(\mathrm{m})= \\
4 \text {. }\end{array}$ & Question \\
\hline A6 & $=\mathrm{A} 1 /(1+\mathrm{A} 2 / \mathrm{A} 4)^{\wedge}(\mathrm{A} 3-\mathrm{A} 4)$ & 1777.8 & Answer \\
\hline
\end{tabular}




\section{References}

Ahmed, B., Kagita, M., Wijenayake, C. A., \& Ravishankar, J. (2018). Implementation guidelines for an automated grading tool to assess short answer questions on digital circuit design course. Proceedings of 2018 IEEE International Conference on Teaching, Assessment, and Learning for Engineering (TALE), 1142-1145, 2018.

Anon (2021). Earn College Credit from 6 Free Online Classes. Retrieved from http://blog.learningadvisor.com/earncollege- credit-6-free-online-classes.

Banks, C. \& Mienert E. (2016). The acceptability of MOOC certificates in the workplace. Proceedings of International Association for Development of the Information Society (IADIS) International Conference on e-Learning, 419-423, July 2016.

Beg, A. \& Beg, A. (2018). Using open technologies for automatically creating question-and-answer sets for engineering MOOCs. Computer Applications in Engineering Education, 26(3), 617-625, May 2018.

Beg, A. (2020). An enabling tool for enhancing the automated assessment of engineering/science courses. The International Journal of Electrical Engineering and Education, 1-14, October 2020.

Cross, J. S., Keerativoranan, N., Carlon, M. K. J., Tan, Y. H., Rakhimberdina Z., \& Mori H. (2019). Improving MOOC quality using learning analytics and tools. Proceedings of 2019 IEEE Learning with MOOCS (LWMOOCS), 174-179, 2019.

De Rosa, A. \& Pistolese, M. (2019). Evolution, education and massive open online courses: A multiverse proposal. Proceedings of 2019 IEEE Learning with MOOCS (LWMOOCS), 191-195, 2019.

Geoffrey, L. H., \& Handzik J. (2010) A preliminary pedagogical comparison study using the digital logic concept inventory. Proceedings of 2010 IEEE Frontiers in Education Conference (FIE), F1G-1-F1G-6, Washington, DC, USA, 2010.

Hao, W. \& Huiyan L. Research on blended teaching reform and innovation strategy based on MOOC education. Proceedings of 2018 13th International Conference on Computer Science \& Education (ICCSE), 1-4, 2018.

Herman, G. L., \& Michael C. L. (2011). Administering a digital logic concept inventory at multiple institutions. Proceedings of 2011 ASEE Annual Conference \& Exposition, 1-12, Vancouver, BC, Canada, 2011.

Ip, H. H. S., Li, C., Leoni, S., Chen, Y., Ma, K., Wong, C. H., \& Li Q (2019). Design and evaluate immersive learning experience for massive open online courses (MOOCs). IEEE Transactions on Learning Technologies, 12(4), 503-515, 2019.

Lu M., Zhao, H., Guo, Y., Wang, K., \& Huang K. (2018). A review of the recent studies on MOOCs. Proceedings of 2018 13th International Conference on Computer Science \& Education (ICCSE), $1-5,2018$.

Miranda, S., Mangione, G.R., Orciuoli, F., Gaeta, M., \& Loia, V. (2013). Automatic generation of assessment objects and remedial works for MOOCs. Proceedings of 2013 12th International Conference on Information Technology Based Higher Education and Training (ITHET), 1-8, Antalya, Turkey, 2013.

Nguyen, M. L. \& Fong, A. C. M. (2013). Large-scale multiobjective static test generation for web-based testing with integer programming. IEEE Transactions of Learning Technologies, 6(1), 46-59, 2013. ISSN 1939-1382.

Oliveira, T. de, Stringhini, D., \& Corrêa, D. G. M. (2018). Online peer assessment and scoring rubric to produce better digital systems designs in an undergraduate computer engineering curriculum. Proceedings of 2018 XIII Latin American Conference on Learning Technologies (LACLO), 393-399, 2018.

Paul, D. V., \& Pawar, J. D. (2013). Dynamic Question Paper Template Generation Using Bi-proportional Scaling Method. Proceedings of 2013 IEEE Fifth International Conference on Technology for Education (t4e 2013), 80-83, Kharagpur, India, 2013.

Petrovic, J., Vitas, D., \& Pale, P. (2017). Experiences with supervised vs. unsupervised online knowledge assessments in formal education. Proceedings of 2017 International Symposium ELMAR, 255-258, 2017.

Udacity (2021). Retrieved from https://www.udacity.com.

Yanes, N., Mostafa, A. M., Ezz, M., \& Almuayqil, S. N. (2020). A machine learning-based recommender system for improving students learning experiences. IEEE Access, 1, 2020.

Yuan-Bin, C., \& Jie, D. (2012) Design on algorithm of automatic test papers generation for examination system of electric energy measurement. Proceedings of 2012 International Conference on Computer Science and Service System, 1397-1400, Nanjing, China, 2012. 


\title{
STUDENT MENTOR'S IDEAL FEATURES: PEER CHOICE
}

\author{
Madalena Cunha ${ }^{1}, \&$ Nuno Campos ${ }^{2}$

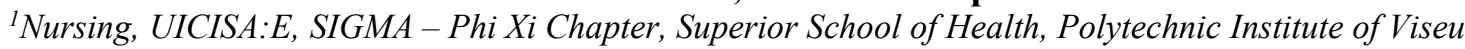 \\ and to the CIEC, University of Minho (Portugal) \\ ${ }^{2}$ Superior School of Health, Polytechnic Institute of Viseu (Portugal)
}

\begin{abstract}
Introduction: A student mentor is someone who shares his or her knowledge with a less experienced colleague in order to help the other developing his or her full academic potential by providing him/ her with the right guidance and support during his learning, social and academic integration processes.

Objective: To assess the features higher education students consider to be the most effective characteristics their Student Peer Mentor should possess.

Method: A descriptive-exploratory study, with a cross-sectional focus, involving a sample of 306 higher education health students, with a mean age of $21.15( \pm 3,540)$ years. $81.7 \%$ of the participants are female. Data collection was achieved using Cunha's Ideal Mentor Faces Scale (2017) with images adapted from Botas, Gabriel \& Welling, (1997/1998).

Results: Results show that $61.8 \%$ of the students surveyed would like to be student mentors and that most participants (54.2\%) look at their ideal mentor as someone who possesses positive features, while $12,1 \%$ of the participants would choose for their ideal mentor a student whose features might suggest the existence of a risk profile. Finally, and paradoxically, $33.7 \%$ of them would choose a student mentor who tends to exhibit certain negative features.

Positive characteristics were granted the highest mean values. Those values ranged between Satisfied (68\%), Tranquil (78.1\%); Optimistic (85\%); Confident (88.2\%) and Interested $(87.9 \%)$.

Conclusions: Results suggest that higher education students value the existence of student mentors with positive features/characteristics and realize that their existence is of great pedagogical importance. Therefore, there is now a greater need to ask higher education students to participate in Mentoring programs implemented with the support of second or third year Student Mentors who, on a voluntary basis, using their experiences and academic experiences can supervise incoming first year students (Mentee Students) in order to facilitate their integration and their adaptation to the different dimensions (pedagogical, scientific, social and any other) of the academic environment.
\end{abstract}

Keywords: Students, higher education, features, student mentor.

\section{Introduction}

The transition to higher education is regarded as a facilitating factor for new experiences. It is an early stage of a life project that may provoke confusing feelings that could cause students to behave differently. It is clearly a moment that requires adjustments and adaptations so that students can have a good academic performance. The shift from secondary education to higher education causes challenges for students which will have an impact on the way existing roles, routines, interpersonal relationships are transformed and on the way they perceive themselves and perceive their new. In order for students' adaptation to all the changes that are part of higher education to be effective, they must gain skills that will enable them to mobilize their personal resources and contexts. Among those resources, the importance of self-efficacy, a complex concept that explains the ability to cope with the surrounding environment, should be highlighted. This is a personal perspective through which the student tries to cope with the academic community and that will allow him to have an optimistic and positive emotional state (Carr, Perrell \& Recchia, 2016).

This is the right context for the student mentor to emerge as a type of student who can assist other students so they may develop their self-efficacy and find the right coping strategies, for if students do not have these skills, they may find it difficult to adapt to new and challenging events or situations they will have to face in the academic environment.

Mentor is the term generally used to describe a more experienced individual who is responsible for guiding and advising (Karkowska, 2015). "Mentoring" is a term generally employed to describe a relationship between a less experienced person, called mentee or protégé, and a more experienced person 
known as a mentor. Traditionally, mentoring was viewed as a dyadic, face-to-face, long-term relationship between a supervisory adult and a novice student that fosters the mentee's professional, academic or personal development (Karkowska, 2015).

In the context of education, the role of the student mentor can become an excellent tool for the mentee's personal and academic growth, as well as an effective means that will help them adapt to their academic life (Carr, Perrell \& Recchia, 2016). That way, the same authors report that mentorship is based on a short-term collaborative relationship between two students achieved through the development of a relationship between an experienced student and a student who has just joined a higher education institution. The student mentor can negotiate with his mentee an action plan whose aims are to provide him with the right interpersonal skills and to provide him the right human, academic, social and pedagogical support. A study conducted in 2014 by Jay, Park, Deirdre \& Doug (2016) with undergraduate medical students from the University of Calgary's Cumming School of Medicine indicates that students who were assigned a mentors show a greater sense of well-being and greater satisfaction with their academic life compared to students who are not mentees. The study also revealed that $58 \%$ (54 of 93) of the students reported having an informal mentor. Supporting coping strategies seems to be an effective predictor of higher education students' well-being. (Cunha, Duarte, André, Sequeira, Castro-Molina, Mota et al, 2017).

In view of the above, this article presents the results of the study, bearing in mind the following objective: to evaluate the ideal features that mentees consider their mentor students should possess.

\section{Methods}

The current cross-sectional descriptive-exploratory study involving a sample of 306 higher education health students.

\subsection{Participants}

Non-probability sampling was the sampling technique used in this study. The participants' age (they should be 18 or older) and the fact that they had to be higher education students were the criteria designed for the sample. The participants ' ages ranged between 18 years old and 42 years old, with a mean age of $21.15( \pm 3.540)$ years. $81.7 \%(n=250)$ of the participants were female.

\subsection{Data collection instruments}

The data collection instrument used was Cunha's Ideal Mentor Faces Scale (2017) with images adapted from Botas, Gabriel \& Welling (1997). The Ideal Mentor Faces Scale figures were coded as follows: from 1 to 30, in which 1 stands for aggressive, 2 for anxious, (...) 30 stands for self-conscious. The code designed for each image is as follow: 1-aggressive; 2-anxious; 3-shy; 4-arrogant; 5-tranquil; 6-bored; 7-confident; 8-euphoric; 9-enraged; 10-desperate; 11-exhausted; 12-frustrated; 13-guilted; 14-hangovered; 15-hysterical; 16-indifferent; 17-naive; 18- Interested 19-intoxicated; 20-lonely; 21-in love; 22-meditative; 23-miserable; 24-negative; 25-optimistic; 26-satisfied; 27-grumpy; 28-excited; 29-disgusted; 30- self-conscious). (Cf. Figure 1).

The faces participants considered more positive were: 5-tranquil; 7-confident 18-interested; 25 - optimistic; 26-satisfied. The Student Mentors' most appropriate profile mirrors situations in which the participants have selected 4 or 5 of the pictures with more positive features; risk profiles reflect situations in which the participants have selected only 2 to 3 figures they consider to be positive; negative profiles are represented by situations where the participants selected 0 or 1 picture among those they consider positive.

\subsection{Procedures}

The study obtained a favorable opinion from the Ethics Committee ( ${ }^{\circ}$ 3/2017) of the Higher Education Institution involved and the collection of data was authorized by the Presidents of the different schools that represent the functional units of a polytechnic Institute located in the northern region of Portugal. The students have participated voluntarily and, after they were provided with all the information they needed on the research project and the research protocols, gave their informed consent.

Statistical treatment of the data was performed using the Statistical Package for Social Sciences (SPSS) version 24.0.

\section{Results}

The results for the overall sample obtained using Cunha's Ideal Mentor Faces Scale (EFMI), (2017) show the mean values calculated for each feature selected as being the most suited for the students' ideal student mentor. These are the mean values found: 1 - aggressive $(0.3 \%)$; 2 -anxious $(1.3 \%)$; 3-shy $(0.3 \%)$; 4-arrogant $(0.3 \%)$; 5-tranquil $(78,1 \%)$; 6-bored $(0.3 \%)$; 7-confident $(88.2 \%)$; 8 -euphoric $(3.3 \%)$; 9-enraged $(0.3 \%) ; 10$-desperate $(0.3 \%) ; 11$-exhausted $(0.3 \%) ; 12$-frustrated $(0.3 \%)$; 13 - guilted $(0.3 \%)$; 14-hangovered $(0.3 \%) ; 15$-hysterical $(0.3 \%) ; 16$-indifferent $(0.7 \%)$; 17-naive $(0.7 \%)$; 
18 -interested $(87.9 \%) ; 19$-intoxicated $(0.3 \%) ; 20$-lonely $(0.7 \%) ; 21$-in love $(11.8 \%) ; 22$-meditative $(10.1 \%) ; 23$-miserable $(0.3 \%) ; 24$-negative $(0.3 \%) ; 25$-optimistic $(85.0 \%) ; 26$-satisfied $(68.0 \%)$; 27-grumpy $(0.3 \%)$; 28 -excited $(7.5 \%) ; 29$-disgusted $(0.3 \%) ; 30$-self-conscious $(0.1 \%)$.

Figure 1. Cunha's ldeal Mentor Faces Scale (2017).
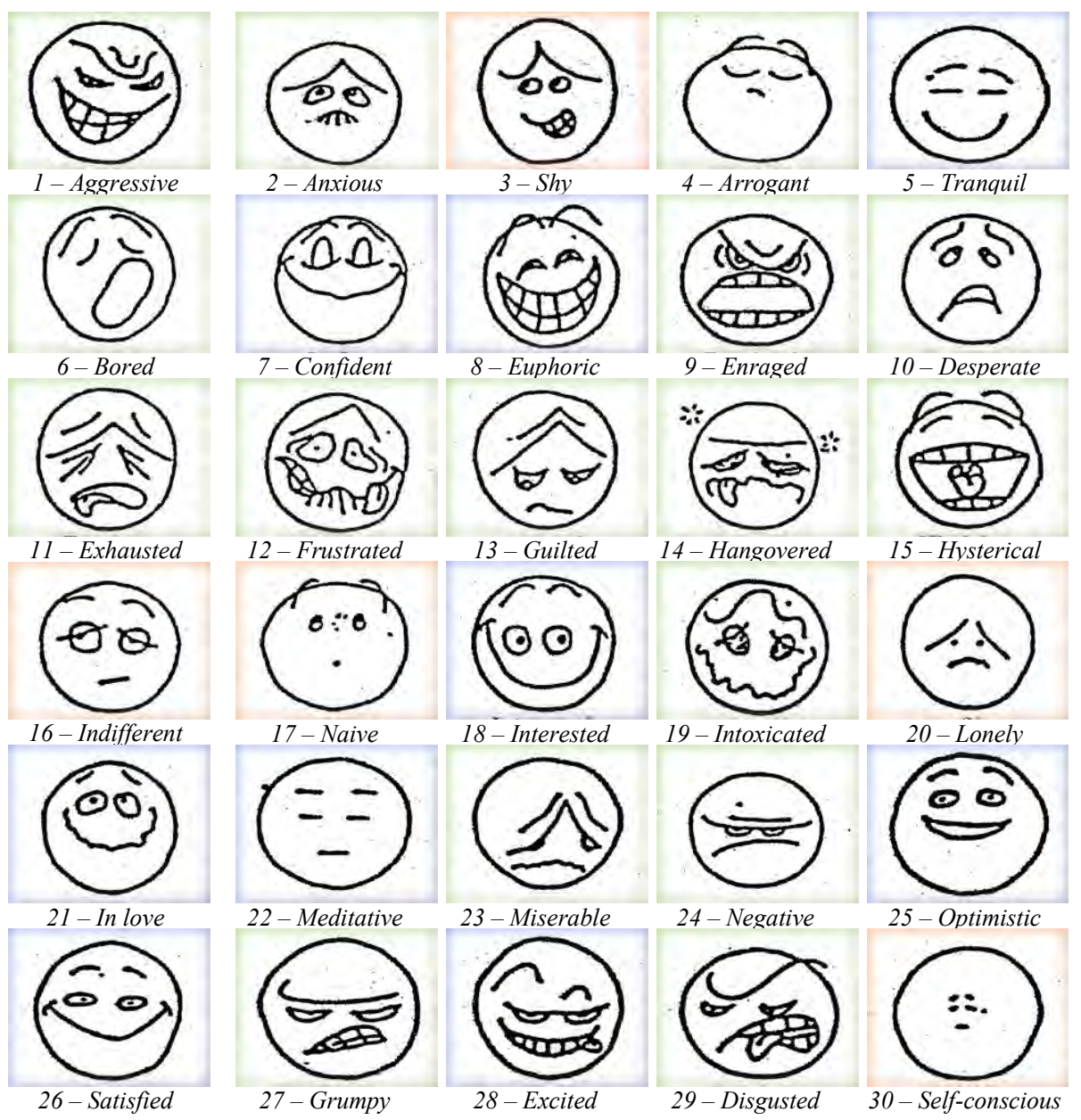

The features/profiles considered positive were granted the highest mean values that ranged between: (68.0\%) 26-satisfied; (78.1\%) 5-tranquil; (85.0\%) 25-optimistic; $(88.2 \%)$ 7-confident and (87.9\%) 18-interested. Most students (54.2\%) selected positive features as the best suited for their ideal student mentor. Both genders made similar choices $(54.4 \%$ for female students and $53,6 \%$ for male students). As far as student mentors' ideal features are concerned, evidence clearly showed that the choice of highly suitable features prevails among a large percentage of the participants, whether they are female or male $(54.2 \%)$. $54 \%$ of this overall value corresponds to a choice among female students while $53.6 \%$ reflect male students' choice. $12.1 \%$ of the students assign suitable features to their hypothetical mentor. This situation relates especially to female participants $(12.4 \%)$. Finally, $33.7 \%$ of the participants have selected poorly suited features for their ideal mentor. $33.2 \%$ of those students were female and $35.7 \%$ were male. However, there are no statistically significant differences between genders when it comes to choose the right features for their ideal mentor (Cf. Table 1).

Table 1. Features students consider the most suitable for their ideal mentor according to participants.

\begin{tabular}{|c|c|c|c|c|c|c|c|c|c|c|}
\hline Gender & \multicolumn{2}{|c|}{ Female } & \multicolumn{2}{|c|}{ Male } & \multicolumn{2}{|c|}{ Total } & \multicolumn{2}{|c|}{ Residual } & \multirow[b]{2}{*}{$\mathbf{X}^{2}$} & \multirow[b]{2}{*}{$\mathbf{p}$} \\
\hline Ideal Mentor features & $\begin{array}{c}n^{0} \\
(25)\end{array}$ & $\begin{array}{c}\% \\
(\mathbf{8 1 . 7}) \\
\end{array}$ & $\begin{array}{c}n^{\circ} \\
(56)\end{array}$ & $\begin{array}{c}\% \\
(18.3) \\
\end{array}$ & $\begin{array}{c}n^{0} \\
(306)\end{array}$ & $\begin{array}{c}\% \% \\
(100.0) \\
\end{array}$ & 1 & 2 & & \\
\hline $\begin{array}{l}\text { Inadequate features/ negative } \\
\text { profile }(0 \leq 1 \text { positive picture } \\
\text { chosen })\end{array}$ & 83 & 33,2 & 20 & 35,7 & 103 & 33,7 &,- 4 &, 4 & \multirow{3}{*}{0,199} & \multirow{3}{*}{0,905} \\
\hline $\begin{array}{l}\text { Poorly adequate/ Risk profile } \\
\text { ( } 2 \text { or } 3 \text { positive pictures selected) }\end{array}$ & 31 & 12,4 & 6 & 10,7 & 37 & 12,1 &, 3 &,- 3 & & \\
\hline $\begin{array}{l}\text { Highly adequate features/ Positive } \\
\text { profile ( } 4 \text { to } 5 \text { positive pictures } \\
\text { selected) }\end{array}$ & 136 & 54,4 & 30 & 53,6 & 166 & 54,2 &, 1 &,- 1 & & \\
\hline
\end{tabular}


In order to complement the study, a multivariate analysis procedure, called multivariate decision trees, was performed. In such analysis, the CHAID algorithm, an acronym for Chi-Square Automatic Interaction Detector was used ( $c f$. Figure 2). The explanatory variables (also known as independent variables) used to design decision Tree 1, hereinafter represented, were the importance of assigning a Student Mentor to each student of an undergraduate course and the students' age. The Ideal Mentor's features were taken into account as a response variable (aka dependent variable).

The results exhibited in the decision tree show that there are 2 levels of depth whose variables are statistically significant in explaining the Ideal Mentor's features.

In the first box that represents node 0, or root node, the information about the Ideal Mentor's adequate features is highlighted. This level corresponds to the choice of $39.5 \%$ of the participants. However, and since the mean value assigned to the Ideal Mentor's poorly adequate features is approximately $33.0 \%$, there is evidence of a large proximity between both representative values.

At the first level of the depth of the decision tree, more precisely in relation to root node 1 , there is information about the participants' level of agreement with the importance of assigning a Student Mentor to each student of any undergraduate course. The CHAID method is used to highlight the adequate features of the ideal mentor student. $39.2 \%$ of the participants have selected the features they consider the best suited for their hypothetical student mentor. For participants who do not attach any sort of importance to the assignment of a student mentor to undergraduate students, root node 2, the CHAID method highlights the ideal mentor's inappropriate features. This position represents $43.9 \%$ of the participants' opinions and, therefore, reflects a statistically significant difference $\left(X^{2}=7,724 ; \mathrm{p}=0.021\right)$.

The second level of the depth of the decision tree, more specifically in root node 3 , includes the participants who are 19 or younger. The CHAID method highlights the percentage of participants who have favored a more appropriate profile for their Ideal Mentor, with a representativeness of $45.7 \%$. In root node, that expresses the preferences of participants who were 19 or older, the mean value concerning the inappropriate features of the Ideal Mentor is highlighted. This value represents $36.5 \%$ of the participants' responses and shows the existence of statistical significance between the two age groups $\left(X^{2}=9,440 ; \mathrm{p}=0.018\right)$.

Figure 2. CHAID tree 1-ideal mentor's features versus the assignment of a Student Mentor to each undergraduate student.

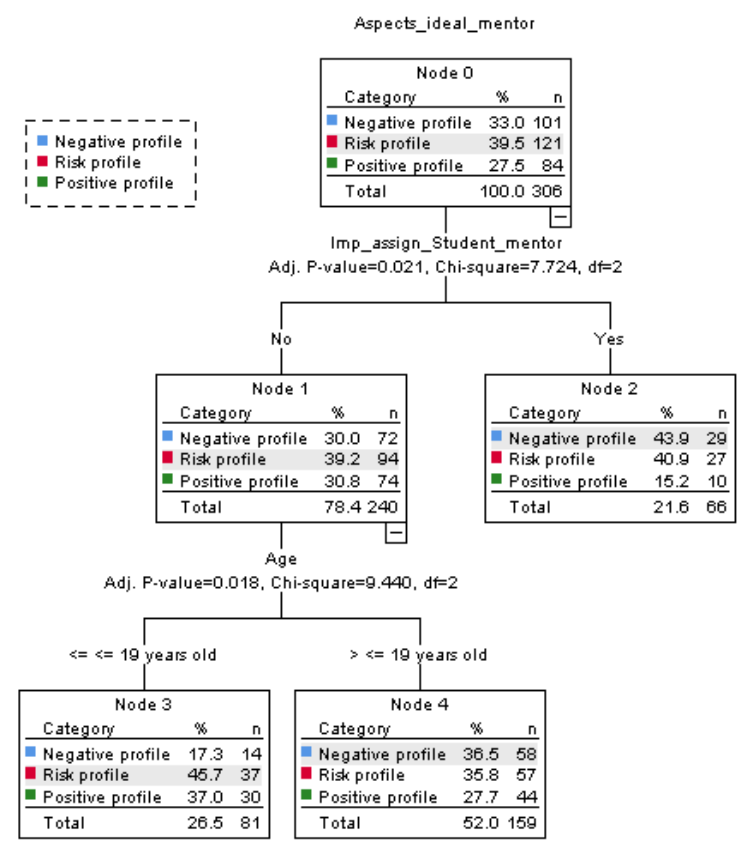

\section{Discussion}

Results confirm the importance of Student Mentors, older students who can help younger or first year higher education students so they are able to develop a sense of self-efficacy and find coping strategies that will help them minimize any negative feelings/emotions experienced during their first school days or during the whole course. As Carr, Perrell \& Recchia (2016) have pointed out, if students do not possess these skills, they may have problems adapting to the new and challenging events or situations they will have to face in their academic context. They same authors also emphasize that Student Mentors can negotiate with their Mentees an action plan whose aim will be to support the development of interpersonal skills, to provide them with human, academic, social and pedagogical support that will 
surely help them overcome any negative feelings/emotions caused by the demands of this new academic context. According to Karkowska (2015), the Student Mentor is a more experienced individual who is responsible for guiding and advising and who will foster the mentee's professional, academic or personal development. The study conducted by Jay, Park, Deirdre \& Doug (2016) is in agreement with what has been addressed before, for it claims that students with mentors show greater well-being and greater satisfaction with their academic life compared to students who are not mentees and who, consequently, do not have the support of a student mentor.

\section{Conclusions}

Findings revealed that the assignment of a Student Mentor to each undergraduate student is considered, as a whole, an important strategy. In addition, the participants in favor of such assignment claimed that it should take place in the 1 st year of the course $(47.1 \%)$. It was concluded that most participants, regardless of their gender, chose positive characteristics and a positive profile for their Ideal Mentor (54.2\%). The following features are considered to be the most positive: Satisfied (68\%), Tranquil (78.1\%); Optimistic (85\%); Confident (88.2\%) and Interested $(87.9 \%)$.

Results suggest the need for intervention programs that will implement concrete actions about the Student Mentors' role in the first year of the course so that students can understand how mentoring processes work and so they can figure the educational, pedagogical and social gains they can achieve if they are assigned a Student Mentor.

This initiative constitutes a personalized human support suited to respond to each student's uniqueness as it supports and encourages their interpersonal relationship with other colleagues and provides them with the chance to share relevant experiences, minimizing the newcomers' adjustment difficulties when they first arrive at a higher education institution. This kind of support will foster more positive emotions/feelings throughout the whole course. The existence of training programs to become a Student Mentor is another concern that has to be solved since those students will have to be prepared to be able to properly play the role they have been assigned: to act as catalysts for new students' integration, agents who will promote a culture of inclusion among higher education students and who will, therefore, contribute to the students' personal, academic and social, individual and collective well-being and whose action can, eventually, contribute to the mentees' good academic performance and to help prevent school failure and dropout in higher education.

\section{Acknowledgements}

The current project was funded by the FCT (Portuguese Foundation for Science and Technology) as part of the project "SuperES", Ref: PROJ/ CI\&DETS/ CGD/0005). We would like to express our sincere gratitude to the FCT, Superior School of Health, Polytechnic Institute of Viseu, Portugal.

\section{References}

Botas, A.L., Gabriel, G.\& Welling, H. (1997). Manual da Formação MENTORADO 1997/1998. SAP-IST.

Carr, J., Pitt, M., Perrell, E., \& Recchia, N. (2016). Mentoring students: exploring and managing incivil behaviour in community nursing placements. British Jour. of Community Nursing, 21(4), 203-207.

Cunha, M. (2017). Escala de Faces do Mentor Ideal. In M. Cunha (Coord.), Projeto supervisão e mentorado no ensino superior: Dinâmicas de sucesso (SuperEs). (Ref : Proj/CI\&DETS/CGD/005). Retrieved from http://www.ipv.pt/ci/projci/5.htm

Cunha, M. (Coord.). (2017). Projeto supervisão e mentorado no ensino superior: Dinâmicas de sucesso SuperES. (SuperEs). (Ref ${ }^{\mathrm{a}}$ : Proj/CI\&DETS/CGD/005). Retrieved from http://www.ipv.pt/ci/projci/5.htm

Cunha, M., Duarte, J., André, S., Sequeira, C., Castro-Molina, F.-J., Mota, M., ... \& Freitas, S. (2017). Bem-estar em estudantes do ensino superior. Millenium, 2 (ed espec 2), 21-38. https://doi.org/10.29352/mill0202e.02.

Jay, J.H., Park, P.A., Deirdre, D., \& Doug, M. (2016). The medical students' perspective of faculty and informal mentors: a questionnaire study. BMC Medical Education, 16, 4, 1-7.

Karkowska, M. (2015). MENTOR - Mentoring between teachers in secondary and high schools. Project number - 2014-1-PL01-KA200-003335. Retrieved from http://edu-mentoring.eu/handbook /supplement.pdf 


\title{
THE ASSOCIATION BETWEEN STUDENT ENGAGEMENT AND CREATIVITY OF UNDERGRADUATES IN CHINA
}

\author{
Yanan Hu, \& Xiaotian Han \\ School of Primary Education, Shanghai Normal University Tianhua College (China)
}

\begin{abstract}
The purpose of the study aimed to: (a) determine to what extent undergraduates expect their college courses; (b) measure the degree to what extent what degree undergraduates engage in their college courses; (c) measure the degree to what extent undergraduate feel their capability of creativity; and (d) examine the degree to which student engagement and their creativity are associated. The study applied a non-experimental, correlational design and used survey responses from 431 randomly selected undergraduates to address the research questions. The findings are as follows. First, the majority of the students have high expectation on their courses and they put feedback as their first priority. Second, most of the Chinese students still attach great importance to their homework. However, the low percentage in reflection shows that the students still lack the habit of doing self-reflection. Third, Chinese undergraduates have fair creativity ability and the students scored their creativity on behavior highest and the creativity on knowledge system lowest. Fourth, student engagement has a positive relation to their creativity on knowledge system, creativity on behaviors, creativity on personalities and creativity on innovative thinking. Among which, the students' enhanced engagement has a most direct impact on their creativity on behaviors.
\end{abstract}

Keywords: Higher education, student engagement, creativity, undergraduates.

\section{Introduction}

The development of students' creative thinking is imperative for college students in China. Previous research has demonstrated students' active engagement as a facilitator to creative thinking development for Chinese college students (Shen 2003; Yuan \& Yan, 2009). However, the great enthusiasm stands in sharp contrast to the limited research in this field. In China, the relevant study is still at a primary stage and there is a great need for in-depth quantitative analysis. Therefore, this study is conducted to fill the methodology gap and to provide a deeper understanding in this field.

This paper has four research questions listed as follows. Research questions 1 to 3 are descriptive questions. Research question 4 aims to find out the association between two variables, student engagement and their creativity.

Research Question 1 (RQ1): To what extent do undergraduates expect their college courses?

Research Question 2 (RQ2): To what degree do undergraduates engage in their college courses?

Research Question 3 (RQ3): To what extent do undergraduate feel their capability of creativity? creativity?

Research Question 4 (RQ4): Is there an association between student engagement and their

\section{Literature review}

One of the most important fundamental theoretical frameworks on creativity is the Four $\mathrm{P}$ framework which focus on the Four Ps, namely, person, product, process and press (environment). In 2007, Four C framework has been developed based on the previous theory. This theory were proposed by Beghetto and Kaufman (2007) who distinguished the little $\mathrm{C}$ with the Big $\mathrm{C}$ with the former referring to the everyday creativity and the latter means the eminent creativity. In 2009, Beghetto and Kaufman added Pro-C to their framework and supported the idea that years of hard-working and practice could sharpen one's creative abilities and therefore lifted him or her to the position of experts. This process echoes Richard Paul's critical thinking theory which illustrates the way from a "unreflective thinker", "challenged thinker", "beginning thinker", "practicing thinker", to "advanced thinker" to the “accomplished thinker" (Paul \& Elder, 2009, p. 20). 
As for the key ingredients necessary for creativity, Amabile and Pratt (2016) point out the Componential Model of Creativity, which includes three interconnected variables, namely domain-relevant skills, creativity-related process and intrinsic and extrinsic motivation. Besides studying the key components to creativity, others have researched the driving force for people to become creative (Forgeard \& Mecklenburg, 2013; Gruber, 1998). According to Csikszentmihalyi (1996), one of the most important motivator to creative is Flow which refers to achieving sense of fulfillment just by doing the things.

In terms of the assessment of creativity, Guilford's Presidential address marks the beginning of the scientific research of creativity. Since then, many assessments have been developed to test the participants' creativity skill and creative personality. Among the instruments of creativity, Getzels and Johnson's (1962) DT test, Guilford's structure of Intellect (SOI) divergent production tests and Torrance's $(1974,2008)$ Test of Creative Thinking (TTCT) stand out. For the reliability for the SOI, TTCT, and TTCT are quite convincing. Getzels and Johnson's DT test (1962) requires the participants to give multiple responses and their answers would be valued based on fluency, originality, flexibility and elaboration. In other words, the number, the uniqueness and the extension of ideas matter a lot in the test. In a reanalysis of Torrance data found the DT tests were 3 times better than the IQ test for predicting the creativity ability.

As for the students' engagement, there are many variables affecting to students' engagements, such as age (Finn, 1989); gender (Finn \& Cox, 1992); scores (Zen, 2001); teachers (Shen, 1994) and etc. As to age, researchers in China have found one interesting fact that might contrast to the previous findings of Finn (1989) who proposed that the level of students' engagement would increase according to their age. In 2009, Tsinghua University has introduced and modified the NSSE. Scholars have proved the reliability and validity of the Chinese version of NSSE based on Classical Test Theory (CTT), Item Response Theory (IRT) and Confirmatory Factor Analysis (CFA) (Guo, Tu, \& Shi, 2013). Studies have found that the more time and energy students are willing to put in their academic study, the more likely they will get satisfactory results.

\section{Methodology}

\subsection{Research design}

The study applied a non-experimental, correlational design and used survey responses from undergraduates to address the research questions. The target population was undergraduates (including freshmen, sophomores, juniors, and seniors) in education major in Shanghai universities. Due to practical constraints, convenience sample was employed.

\subsection{Instrumentation}

A web-based survey was used to collect the data for this non-experimental study. The contents of the survey included four sections: (a) demographic information (i.e., gender, grade level, and birthplace); (b) students' course expectation (i.e., expectation of course planning, class delivering, formative assessment, and summative assessment); (c) student engagement; and (d) students' capability of creativity.

The scale of students' course expectation was developed by the authors and is based on a powerful and meaningful learning cycle. The scale aimed to assess to what extent that students expect the provided college courses. The scale used a 5-point response option for each item.

The student engagement scale was also developed by the authors to assess the extent to which students would like to participate in the courses: (1) previewing course content, (2) concentration in lectures, (3) responding questions in class, (4) group discussions, (5) peer work, (6) homework, (7) reflection, and (8) call for assistance in office hours. The scale used a 4-point response option for each item, with anchors at 1-not at all, 2-seldom, 3-sometimes, and 4-often. Higher scores corresponded to higher class engagement.

The scale of undergraduate capability of creativity was based on Zhu, Li, and Zuo's (2010) study. The scale aimed to examine the extent to which undergraduates perceived their capabilities of creativity. This scale includes four subscales: (1) system of knowledge, (2) characteristics of behaviors, (3) personalities, and (4) innovative thinking (see Table 1 for details). The scale applied a 5-point response option for each item, with anchors at 1-not at all, 2-seldom, 3-sometimes, 4-often, and 5-always. High scores corresponded to higher perceptions of creativity ability.

\subsection{Data analysis and presentation}

Descriptive analyses provided information as to students' expectations on their college course, student engagement, and undergraduate creativity ability. The study also used correlational analysis 
methods to identify whether student engagement were associated with each aspect of undergraduate creativity ability. SPSS 25.0 was used to analyze the collected data using an alpha level of .05 for identifying statistically significant results.

\section{Results}

The study applied a non-experimental, correlational design and collected 431 survey responses from undergraduates in China to answer the research questions. The target population was undergraduates (including freshmen, sophomores, juniors, and seniors) in Shanghai, China. Demographic information regarding the respondents reveal that the ratio of females and males were nearly $91.88 \%$ to $8.12 \%$, respectively. The respondents' ages were in the range of 18 to 22 . The percentage of freshmen, sophomores, juniors, and seniors was $33.41 \%, 29.23 \%, 23.67 \%$, and $13.69 \%$ respectively.

\subsection{Research question 1 (RQ1): Description of undergraduates' expectation to their college courses}

RQ1 determines to what extent undergraduates expect their college courses. Table 1 below shows the descriptive statistics for the measure of undergraduates' expectation mean and its sub scales.

Table 1. Descriptive statistics for the overall scores and subscales of the measures of undergraduate's expectation.

\begin{tabular}{|c|c|c|c|c|}
\hline & $M$ & $S D$ & Min & Max \\
\hline Undergraduate's expectation (Average) & 4.23 & .71 & 1 & 5 \\
\hline Planning (item1, 2) & 3.99 & .86 & 1 & 5 \\
\hline Delivery (item 4, 7) & 4.04 & .73 & 1 & 5 \\
\hline Assessment (item 5) & 3.99 & .65 & 1 & 5 \\
\hline Feedback (item 3, 6, 8) & 4.06 & .71 & 1 & 5 \\
\hline
\end{tabular}

\subsection{Research question 2 (RQ2): Description of student engagement}

RQ2 examines to what degree undergraduates engage in their college courses. Table 2 below shows the descriptive statistics for the measure of student engagement mean and its subscales.

Table 2. Descriptive statistics for the overall scores and subscales of student engagement.

\begin{tabular}{|c|c|c|c|c|c|}
\hline & Cronbach's Alpha & $M$ & SD & Min & Max \\
\hline Student engagement (8-item mean) & .79 & 3.17 & .40 & 1 & 4 \\
\hline Item 1: Preview & - & 2.80 & .71 & 1 & 4 \\
\hline Item 2: Concentration in lectures & - & 3.05 & .70 & 1 & 4 \\
\hline Item 3: Responding questions in class & - & 3.38 & .65 & 1 & 4 \\
\hline Item 4: Group discussions & - & 2.90 & .71 & 1 & 4 \\
\hline Item 5: Peer work & - & 3.53 & .54 & 1 & 4 \\
\hline Item 6: Homework & - & 3.88 & .35 & 1 & 4 \\
\hline Item 7: Reflection & - & 2.93 & .65 & 1 & 4 \\
\hline Item 8: Call for assistance in office hours & - & 2.92 & .67 & 1 & 4 \\
\hline
\end{tabular}

\subsection{Research question 3 (RQ3): Description of undergraduates' creativity}

RQ3 measures the degree to what extent undergraduates' capability of creativity. Table 3 below shows the descriptive statistics for the measure of undergraduates' self-reported creativity mean and its subscales.

Table 3. Descriptive Statistics for the Subscales of Undergraduate's Creativity.

\begin{tabular}{|c|c|c|c|c|c|c|}
\hline Undergraduates' creativity & Cronbach's Alpha & $M$ & SD & Min & Max & Numbers of Items \\
\hline Knowledge System & .865 & 3.16 & .78 & 1.00 & 5.00 & 4 \\
\hline Behavioral Characteristics & .923 & 3.59 & .69 & 1.25 & 5.00 & 8 \\
\hline Personalities & .889 & 3.49 & .76 & 1.50 & 5.00 & 6 \\
\hline Innovative Thinking & .935 & 3.41 & .73 & 1.16 & 5.00 & 6 \\
\hline
\end{tabular}

\subsection{Research question 4 (RQ4): The association between student engagement and undergraduate's creativity}

Student engagement was significantly correlated to each subscale of undergraduate creativity: knowledge system $(\mathrm{r}=.311)$, behavioral characteristics $(\mathrm{r}=.405)$, personalities $(\mathrm{r}=.350)$, and innovative thinking $(\mathrm{r}=.373)$. The overall student engagement was regressed on the subscale rating they gave regarding the undergraduate creativity across four components (knowledge system, behavioral characteristics, personalities, and thinking characteristics). 
Table 4. Descriptive statistics and Pearson correlations between key variables in the regression models.

\begin{tabular}{|l|l|l|l|l|}
\hline & Correlations & \\
\hline Variables & 2 & 3 & 4 & 5 \\
\hline 1. Student Engagement & $.311^{* *}$ & $.405^{* *}$ & $.350^{* *}$ & $.373^{* *}$ \\
\hline 2. Creativity-Knowledge System & & $.648^{* *}$ & $.451^{* *}$ & $.560^{* *}$ \\
\hline 3. Creativity-Behavioral Characteristics & & & $.719^{* *}$ & $.736^{* *}$ \\
\hline 4. Creativity-Personalities & & & & $.798^{* *}$ \\
\hline 5. Creativity-Innovative Thinking & & & & \\
\hline$* \mathrm{p}<.05 ; * * \mathrm{p}<.01$ & & & \\
\hline
\end{tabular}

In linear regression model, the undergraduate's creativity on knowledge system, behavioral characteristics, personalities, and creative thinking was respectively regressed on the total rating of student engagement across eight components in which they participated. The full model was statistically significant.

Table 5 reveals regarding student engagement explained $9.6 \%$ additional variance, $\mathrm{F}(1,430)=45.789, \mathrm{p}<.001, \Delta \mathrm{R} 2=.096$, and was statistically significant and is considered to be a medium effect. When student engagement rating increased by a value of one point, their creativity on knowledge system would increase by .603 point $(b=.603, p<.001)$.

Table 5. Summary of linear regression results predicting creativity on knowledge system from student engagement.

\begin{tabular}{|l|l|l|l|l|l|}
\hline & $\mathrm{b}$ & $\mathrm{SEb}$ & $\beta$ & $\mathrm{t}$ & $\mathrm{p}$ \\
\hline Predictor Variable: & & & & & \\
\hline Student Engagement & .603 & .089 & .311 & 6.767 & .000 \\
\hline
\end{tabular}

$* \mathrm{p}<.05 * * \mathrm{p}<.01$ Note: $\mathrm{R}=.311, \mathrm{R} 2=.096, \mathrm{~F}(1,430)=45.789, \mathrm{p}<.001$

Table 6 reveals regarding student engagement explained $16.4 \%$ additional variance, $\mathrm{F}(1,430)=83.95, \mathrm{p}<.001, \Delta \mathrm{R} 2=.164$, and was statistically significant and is considered to be a large effect. When student engagement rating increased by a value of one point, their creativity on behaviors would increase by .693 point $(b=.693, p<.001)$.

Table 6. Summary of linear regression results predicting creativity on behavioral characteristics from student engagement.

\begin{tabular}{|l|l|l|l|l|l|}
\hline & $b$ & $S E_{b}$ & $\beta$ & $t$ & $p$ \\
\hline Predictor Variable: & & & & & \\
\hline Student Engagement & .693 & .076 & .405 & 9.162 & .000 \\
\hline
\end{tabular}

$* p<.05 * * p<.01$ Note: $R=.405, R^{2}=.164, F(1,430)=83.950, p<.001$

Table 7 reveals regarding student engagement explained $12.1 \%$ additional variance, $\mathrm{F}(1,430)=59.928, \mathrm{p}<.001, \Delta \mathrm{R} 2=.121$, and was statistically significant and is considered to be a medium effect. When student engagement rating increased by a value of one point, their creativity on personalities would increase by .659 point $(b=.659, \mathrm{p}<.001)$.

Table 7. Summary of linear regression results predicting creativity on personalities from student engagement.

\begin{tabular}{|l|l|l|l|l|l|}
\hline & $\mathrm{b}$ & $\mathrm{SEb}$ & $\beta$ & $\mathrm{t}$ & $\mathrm{p}$ \\
\hline Predictor Variable: & & & & & \\
\hline Student Engagement & .659 & .085 & .350 & 7.741 & .000 \\
\hline
\end{tabular}

$* \mathrm{p}<.05 * * \mathrm{p}<.01$ Note: $\mathrm{R}=.350, \mathrm{R} 2=.123, \mathrm{~F}(1,430)=59.928, \mathrm{p}<.001$

Table 8. Summary of linear regression results predicting creativity on innovative thinking from student engagement.

\begin{tabular}{|l|l|l|l|l|l|}
\hline & $b$ & $S E_{b}$ & $\beta$ & $t$ & $p$ \\
\hline Predictor Variable: & & & & & \\
\hline Student Engagement & .679 & .082 & .373 & 8.321 & .000 \\
\hline
\end{tabular}

$* \mathrm{p}<.05 * * \mathrm{p}<.01$ Note: $\mathrm{R}=.373, \mathrm{R}^{2}=.139, \mathrm{~F}(1,430)=69.231, \mathrm{p}<.001$

Table 8 reveals regarding student engagement explained $13.7 \%$ additional variance, $\mathrm{F}(1,430)=69.231, \mathrm{p}<.001, \Delta \mathrm{R} 2=.137$, and was statistically significant and is considered to be a large effect. When student engagement rating increased by a value of one point, their creativity on innovative thinking would increase by .679 point $(b=.679, \mathrm{p}<.001)$. 


\section{Discussion}

As for RQ1, "To what extent do undergraduates expect their college courses", results show the majority of the students have high expectation on their courses and their highest expectation is on the feedback.

In terms of students' various forms of engagement in classroom, we have find that almost all students could complete and submit the assignments on time and over $90 \%$ of participants reported they "often" participate in responding questions and peer work. Findings show that the majority of the Chinese students still put the first priority on their scores, and therefore, attach great importance to the homework. However, the low percentage in reflection shows that the students still lack the habit of doing self-reflection, which might hinder them from achieving greater results in their future academic study.

As for the description of their self-reported creativity, we have found that across the four sections of undergraduate's creativity, the mean is above 3.16, which reveals that undergraduates had fair creativity. the lowest one for creativity on knowledge system $($ mean $=3.16)$. This finding echoes with the previous research that a solid knowledge foundation is the prerequisite to creativity (Li \& Tang, 2016).

Regarding the associate between student engagement and undergraduate's creativity, we have found that When student engagement rating increased by a value of one point, their creativity on knowledge system would increase by .603 point $(b=.603, p<.001)$, their creativity on behaviors would increase by .693 point $(b=.693, p<.001)$, their creativity on personalities would increase by .659 point and their creativity on innovative thinking would increase by .679 point.

\section{References}

Barron, F. (1999). All creation is a collaboration. In A. Montuori \& R. Purser (eds.), Social creativity (Vol. 1, pp. 49-59). Cresskill, NJ: Hampton Press.

Beghetto, R. A. \& Kaufman, J. C. (2007). Toward a broader conception of creativity: A case for "mini-c" creativity. Psychology of Aesthetics, Creativity, and the Arts, 1, 73-79.

Csikszentmihalyi, M. (1988). Society, culture, and person: A systems view of creativity. In R. Sternberg (ed.), The nature of creativity: Contemporary psychological perspectives (pp. 325-339). Cambridge: Cambridge University Press.

Davis, G. A. (1992). Creativity is forever (3rd ed.). Dubuque, IA: Kendall/Hunt.

Getzels, J. W. \& Jackson, P. W. (1962). Creativity and intelligence: Explorations with gifted students. New York: Wiley.

Glaveanu, V. P. (2010). Principles for a cultural psychology of creativity. Culture and Psychology, 16, $147-163$.

Gruber, H. E. (1988). The evolving systems approach to creative work. Creativity Research Journal, 1, 27-51.

Guo, F. F., Shi, J. H., \& Tu, D.(2013)A Metric Study on NSSE-China. Fudan Education Forum, (11): 55-62.

He,Q.S., Ying, T. S., Huang, S.Y., \&Liu, H. P. (1999). Some suggestions on the education reform of foreign majors. Foreign Language Teaching and Research Press, (1):24-28.

Hong. L. (2017). Research on the current situation and long-term mechanism construction of China's graduate students' innovation ability. Time Education, (1) : 10-11.

McMillan, J., \& Schumacher, S. (2010). Research education: Evidence-based inquiry. New Jersey: Pearson Education.

Pace, C. R (1984). Measuring the Quality of College Student Experiences: An Account of the Development and Use of the College Student Experiences Questionnaire. Los Angeles: Higher Education Research Institute.

Paul, R., \& Elder, L. (2009c). A glossary of critical thinking terms and concepts. Dillion Beach, CA: Foundation for Critical Thinking.

Stephen, B. (2005). 100 Ideas for Teaching Creativity. London: Continuum.

Torrance, E. P. (1974). Torrance Tests of Creative Thinking: Norms-technical manual. Bensenville, IL: Scholastic Testing Service.

Wallas, G. (1926). The art of thought. London: Watts \& Co.

Zen. Q. (2001). A study on the structure and characteristics of primary school students' classroom participation Psychological Science, (2),160-162. 


\title{
USING EVERYDAY LANGUAGE TO SUPPORT LEARNERS’'ACCESS TO MATHEMATICAL CONTENT KNOWLEDGE
}

\author{
Azwidowi Emmanuel Libusha \\ Department of Childhood Education, University of Johannesburg (South Africa)
}

\begin{abstract}
The language of mathematics can hinder the development of some learners' conceptual understanding of mathematics. Language as a whole plays a crucial role in the teaching and learning of mathematics as it serves as the medium in which the teachers and learners think and communicate in the classroom. Ball, Thames and Phelps (2008) argue that the demands of teaching mathematics require specialized mathematical knowledge that only pertains to mathematics teaching and is not required in other mathematics professions. The role of the teacher is to use resources available to them to support learners in accessing mathematical content knowledge. Previous researchers acknowledged the difficulty learners face when trying to interpret the formal language of mathematics in order to access mathematical content knowledge. Consequently, the current study explored the various ways in which the language of learning and teaching can be utilized by teachers to mitigate language difficulties their learners may experience. The study was guided by the research question: What is the informal mathematical language that Grade 10 teachers use to inform effective instruction when teaching functions? This paper aims to describe how teachers use informal mathematical language to teach inequalities and functions. The research is qualitative and the descriptive method was employed, with the researcher serving as the main instrument. The required data was collected by observing two teachers teaching inequalities and functions. The findings indicate that the use of transliteration and demonstrations as teaching strategies reduced the challenges of using English as a medium of instruction to interpret mathematical symbolic language and that the use of everyday language makes a difference in the learning of functions and inequalities. The study informs both pre-service and in-service teacher development programmes.
\end{abstract}

Keywords: Mathematics, mathematical language, teacher practice, functions, inequalities.

\section{Introduction}

Teaching mathematics effectively depends on how well the teacher can communicate mathematical concepts. According to Lampert and Cobb (2003), communication and language are the most basic elements that are involved in the teaching and learning of mathematics. The content knowledge possessed by the teacher and how the teacher communicates that knowledge using a particular language are vital when learners are learning mathematics. A study by Nomlomo (2010) revealed that learners struggle to access mathematical content knowledge because of a failure to understand the language of learning and teaching. The language of learning and teaching needs to be made simpler and accessible in order for learners to understand what is being communicated to them.

The Curriculum and Assessment Policy Statement (CAPS) (Department of Basic Education, 2011) defines mathematics as a language that makes use of symbols and notations to describe numerical, geometric and graphical relationships. This implies that understanding the language of mathematics is the key ingredient in supporting learners to access mathematical content knowledge. How well learners understand the language of learning and teaching depends on their background and the environment in which they live. To some, English is their second language and they do not use it at home; to some it is their first language and to others it is a language they are still learning. It is imperative that both teachers and learners communicate at the same level while learners progress to a higher level of mathematics influenced by the mathematical language required for that particular level. De Villiers (2010) argues that learners struggle with mathematics because teachers teach it using language that is above the level of the learners.

This paper seeks to determine the language used by teachers to teach to teach the section on functions of mathematics in the curriculum effectively. This study draws from Pimm's (1991) hypothesis that good teaching entails extensive subject matter knowledge and an understanding of alternative ways 
of presenting such knowledge to learners using language. The study was guided by the research question: What is the informal mathematical language that Grade 10 teachers use to inform effective instruction when teaching functions? The paper aims to describe how teachers use informal mathematical language to teach inequalities and functions.

\section{Literature review}

Clarkson (2009) discusses globalization and how it has affected the way mathematics is being taught in different countries. Due to globalization, language affects the teaching of mathematics in the multilingual classroom. In an ideal classroom, learners are assumed to be proficient in the language of learning and teaching and their proficiency should not affect how they learn mathematics. However, when the language of learning and teaching is not the learners' first language, the way in which mathematics is communicated and understood in the classroom is affected.

Clarkson (2009) argues that the first language of the teacher and that of the learners together with the common language that is used in a normal conversation, which may not be the official teaching language, must be considered in the mathematics classroom when learners are communicating about mathematical ideas. While the mathematics used at a high school level and primary school level is not synonymous with the mathematics used in other domains of practice such as engineering, one has to understand that the mathematics taught by teachers in school classrooms is critically important (Adler, 2005), because a firm understanding of this level of mathematics opens doors for the mathematics used in other professions.

In Johannesburg, where the study was conducted, one usually finds multilingual teachers teaching multilingual students in English, which is not the first language of the teacher or of most students in the classroom (Hooijer \& Fourie, 2009). For example, you may find learners who are fluent in English but not fluent in mathematical English. In this instance, learners must first communicate their mathematical understanding in plain English and so develop mathematical English before they can understand the mathematical content knowledge. Tikunoff (1985) asserts that learners learn most effectively in the language they understand the best. However, sometimes the language that learners understand the best is not their first language but rather the local street language combined with slang. As a result, learners are encouraged to use the language they know or their daily language to communicate their mathematical ideas. Once they understand informal mathematical language, it will lead them to understand formal mathematical language, and they will be in a position to do mathematics.

\section{Theoretical framework}

The study used code switching as a learning resource or a mechanism for learning that teachers can use to enable learners to gain access to the mathematical content or the language of mathematics. The language teachers use to support learners, the method of teaching (pedagogical content knowledge) and the knowledge of how to bridge the gap between the language of learning and teaching (English), mathematical language and the mathematical content knowledge constitute specialized subject knowledge that a teacher should possess (Adler, 2006; Ball \& Bass, 2000; Shulman, 1986). The researcher adopted Pimm's (1981) notion of the importance of understanding the mathematical register. According to Pimm (1981), the aim of mathematical language or register is to help construct, express and communicate mathematical meanings, because when written mathematics is understood and mathematical terms or the register is well understood, it will enable a learner to make sense of mathematical concepts.

\section{Methodology}

The description is based on the qualitative research method. The required data was collected by observing two teachers teaching inequalities and functions. The research is qualitative; the method is descriptive and the researcher is the main instrument of this research.

\subsection{Selection of participants}

Using the purposive sampling technique, two mathematics teachers from the same school in Gauteng province were selected. The purposive sampling is when researchers thoroughly think through how they will establish a sample population, even if it is not statistically representative of the greater population at hand (Creswell, 2005). These teachers had taught Grade 10 mathematics for more than five years and mathematical functions is one of the topics included in the curriculum. Within five years of teaching functions, teachers should have developed and established the competency to teach the topic. 
Teacher A was a white woman and English was her first language; Teacher B was an African male and English was not his first language.

\subsection{Data collection and analysis}

Two methods of data collection were used to ensure methodological triangulation (Creswell, 2005). The non-participant observation method was appropriate as it allowed the researcher to observe the teachers" practices in "real life" classroom contexts (Golafshani, 2003). Each teacher was interviewed once using a semi-structured interview schedule to gain clarity on the issues the researcher did not understand during classroom observations and also to determine their conceptual understanding of range and domain when doing functions. The data analysis involved descriptive coding of data from interviews and lesson observations using Henning, Gravett and Van Rensburg's (2005) manual.

\section{Findings}

\subsection{Teacher A}

During the interview, the teacher was asked how she would explain the concepts of range and domain to someone who is hearing the terms for the first time. Teacher A defined a domain as "looking at the space the function covers from left to right focusing on the x-axis, and the range is looking at the space the function covers from the bottom to the top focusing on the y-axis."

During the classroom observation, Teacher A explained the effect of a on the graph of hyperbolas that have the equation $\mathrm{y}=\mathrm{a} / \mathrm{x}$. The teacher explained how to determine the range and domain when the value of a is greater than zero. The teacher started by explaining that the value of a determines the space the function will occupy on the Cartesian plane. The teacher pointed on the graph that was drawn on the board and explained to the learners that when the value of a is positive, the graph will curve towards the top right corner and bottom left corner (see Figure 1). This means the functions will occupy the first and third quadrants of the Cartesian plane.

\section{Figure 1. $f(x)=a / x$ when the value of a is positive.}

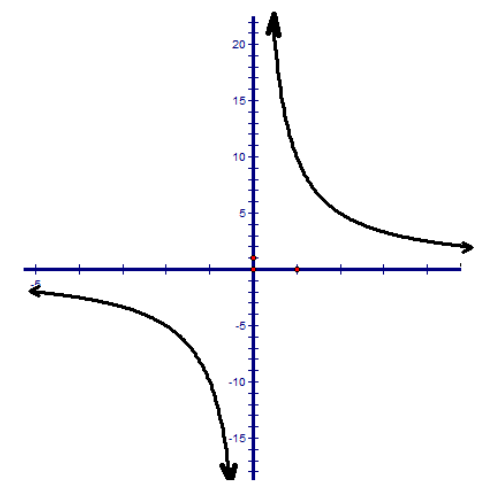

The teacher proceeded to explain that when looking at the function from left to right, the function will start from negative infinity and curve towards the $y$-axis and from the $y$-axis to positive infinity; looking at the function from the bottom to the top, the function will start from negative infinity and move towards the $x$-axis and from the $x$-axis to positive infinity. Teacher $\mathrm{A}$ then explained the concept using informal mathematical language and included mathematical terms. Thereafter, Teacher A explained that when $a$ is greater than 0 , the domain of the graph will be greater than zero and less than zero with a range that is greater than zero and less than zero. The last part of the explanation incorporated mathematical symbolic language as she wrote the statement in symbolic form for the students: for example, when $a>0$, then $0<x<0$ and $0<y<0$.

\subsection{Teacher B}

During the interview, Teacher B explained the range and domain as follows: "The domain is the $\mathrm{x}$-values and the range is the $\mathrm{y}$-values; basically, finding the range and domain is all about finding all the $\mathrm{x}$-values and all the $\mathrm{y}$-values when a function is given."

During the classroom observation, Teacher B started by explaining the domain and range using the concept of inputs and outputs when drawing a function using the table method. Based on the teacher's explanation, the inputs are the x-values, which are the domain, and the outputs are the $y$-values, which are the range. Teacher $\mathrm{B}$ explained that regardless of how many $\mathrm{x}$-values you take, you will always get the corresponding $\mathrm{y}$-values. Teacher $\mathrm{B}$ then reminded the learners of continuous functions and discontinuous 
functions. Drawing from the understanding of discontinuous functions, the concept of the asymptote was explained. Based on this concept, the domain and range were explained using the table method and learners were instructed to also use a zero, which gave an undefined answer. The teacher then said the function was not continuous because it was undefined when the value of $\mathrm{x}$ was zero. He then said that the domain is represented by the set of real numbers except when $\mathrm{x}$ is equal to zero.

\section{Discussions}

Nomlomo (2010) writes about the progression from informal language to formal mathematical language in a situation where learners are either bilingual or multilingual. She argues that teachers must be in a position to move learners from predominantly informal spoken language - the kind that learners use in their everyday life to express mathematical thinking-to formal written mathematical language. Teacher A managed to do this. To understand how to interpret the symbolic form, one has to move from everyday English to formal mathematical English and understand how mathematical English can be transformed into symbols. In Teacher A's class, the use of common language or the language used to explain mathematical terms can be regarded as informal mathematical language. For example, consider the teacher's explanation: "when looking at the function from left to right, the function will start from negative infinity to the y-axis without touching the y-axis and from the y-axis to positive infinity and looking at the function from the bottom to the top, the function will start from negative infinity to $\mathrm{x}$-axis without touching the $\mathrm{x}$-axis and from the $\mathrm{x}$-axis to the positive infinity."

The statement above can be regarded as informal mathematical language. However, in formal mathematical language, one would say the following: if the value of a is less than zero, the graph will possess a maximum turning point and if the value of a is greater than zero the graph will possess a minimum turning point. The difference between the two sentences is that the one has mathematical terms and the other one has English terms used on a daily basis. Look at the following words:

Table 1. English language vs mathematical language.

\begin{tabular}{|l|l|l|}
\hline To the right & - & Positive infinity \\
\hline From the left & - & Negative infinity \\
\hline $\begin{array}{l}\text { From } x \text {-axis without } \\
\text { touching the } x \text {-axis }\end{array}$ & - & Greater than zero \\
\hline $\begin{array}{l}\text { To the } x \text {-axis without } \\
\text { touching the } x \text {-axis }\end{array}$ & - & Less than zero \\
\hline
\end{tabular}

Even though the statements on the left and those on the right are both in English, there is a difference in the usage. Learners can be encouraged to move between the three forms of language. They can move from informal language to mathematical language, and then progress from formal mathematical language to symbolic mathematical language. This will be easier if the informal language is the language of learning and teaching compared to a different language, because informal mathematical language will contain mostly English words. Understanding the language of learning and teaching in the context of a learner's daily language can make a difference in how a learner understands mathematical content knowledge (Setati, 2006).

In his lesson, Teacher $\mathrm{B}$ focused on mathematical language. For a learner to be able to understand Teacher B, their understanding of the mathematical register must be intact. Teacher B used formal mathematical language to get learners to access mathematical content knowledge, which in this case was to understand the domain and the range of the hyperbola function. Although the teaching approaches differed, both teachers did get the message across. The only challenge would be the audience the lesson is intended for: learners who have a good understanding of the mathematics register or learners who are still learning the register. As Pimm (1991) points out, the teacher should realise that part of learning mathematics is gaining control over the language of mathematics so that one is able to communicate mathematics-related concepts with fluency and understanding. However, mathematics as a subject is difficult enough as it is, and failing to understand the language of mathematics can result in failing to understand the mathematical content knowledge.

\section{Conclusion}

The study explored the various ways in which the language of learning and teaching can be utilized by teachers to mitigate language difficulties their learners experience when learning mathematical functions in Grade 10. The findings indicate that the use of transliteration and demonstrations as teaching strategies reduced the challenges of using English as a medium of instruction to interpret mathematical 
symbolic language and that the use of everyday language makes a difference in the learning of functions and inequalities.

Although both teachers have an understanding of the mathematical content, using everyday English words, as illustrated by Teacher A, enabled some of the learners to understand the mathematical content knowledge. This was recognized by the responses learners gave when asked to provide explanations on the board. The use of mathematical terms without explaining them thoroughly with the use of everyday language has caused learners to lack confidence in the mathematics classroom. This was observed when there were no learners willing to explain their own understanding. This study concludes that the use of everyday language or common language plays an important role in the teaching of mathematics. The common language is a resource that can be used to inform effective instruction when teaching mathematical inequalities and functions.

\section{References}

Adler, J. (2005). Mathematics for teaching: What is it and why is it important that we talk about it? Pythagoras, 62, 2-11. doi:10.4102/pythagoras.v0i62.109

Adler, J. B. (2006). Teaching mathematics in multilingual classrooms (Vol. 26). Cham: Springer.

Ball, D. L., \& Bass, H. (2000). Interweaving content and pedagogy in teaching and learning to teach: Knowing and using mathematics. In J. Boaler (Ed.), Multiple perspectives on the teaching and learning of mathematics (pp. 83-104). Westport, CT: Ablex.

Ball, D. L., Thames, M. H., \& Phelps, G. (2008). Content knowledge for teaching: What makes it special? Journal of Teacher Education, 59(5), 389-407. doi:10.1177/0022487108324554

Clarkson, P. C. (2009). Potential lessons for teaching in multilingual mathematics classrooms in Australia and Southeast Asia. Journal of Science and Mathematics Education in Southeast Asia, 32(1), 1-17.

Creswell, J. W. (2005). Educational research: Planning, conducting, and evaluating quantitative and qualitative research (2nd ed.). Upper Saddle River, NJ: Pearson Education.

De Villiers, M. (2010, June). Some reflections on the Van Hiele theory. Paper presented at the 4th congress of teachers of mathematics of the Croatian Mathematical Society, Zagreb. Retrieved from https://www.researchgate.net/publication/264495589_Some_Reflections_on_the_Van_Hiele_ theory

Department of Basic Education. (2011). Curriculum and assessment policy statement: Life sciences; Further education and training phase Grade 10-12. Pretoria: Author.

Golafshani, N. (2003). Understanding reliability and validity in qualitative research. The qualitative report, 8(4), 597-607.

Henning, E., Gravett, S., \& Van Rensburg, W. (2005). Finding your way in academic writing. Pretoria: Van Schaik Publishers.

Hooijer, E., \& Fourie, J. (2009). Teacher's perspective of multilingual classrooms in a South African school. Education as Change, 13(1), 135-151. doi:10.1080/16823200902943304

Lampert, M., \& Cobb, P. (2003). Communication and language. In J. Kilpatrick, W. G. Martin, \& D. Schifter (Eds.), A research companion to principles and standards for school mathematics (pp. 237-249). Reston, VA: National Council of Teachers of Mathematics.

Nomlomo, V. (2010). Classroom interaction: Turn-taking as a pedagogical strategy. Per Linguam: A Journal of Language Learning / Tydskrif vir Taalaanleer, 26(2), 50-66. doi:10.5785/26-2-21

Pimm, D. (1981). Metaphor and analogy in mathematics. For the Learning of Mathematics, 1(3), 47-50.

Pimm, D. (1991). Communicating mathematically. In K. Durkin \& B. Shire (Eds.), Language in mathematical education (pp. 17-23). Milton Keynes: Open University Press.

Setati, M. (2006). Access to mathematics versus access to the language of power. In J. Novotná, H. Moraová, M. Krátká, \& N. Stehlíková (Eds.), Proceedings of the 30th Conference of the International Group for the Psychology of Mathematics Education (Vol. 5, pp. 97-104). Prague: PME.

Shulman, L. S. (1986a). Those who understand: Knowledge growth in teaching. Educational researcher, 15(2), 4-14. doi:10.3102/0013189X015002004

Shulman, L. S. (1986b). Those who understand: A conception of teacher knowledge. American Educator, $10(1), 9-15$.

Tikunoff, W. J. (1985). Developing student functional proficiency for LEP students. Portland, OR: Northwest Regional Educational Laboratory. 


\title{
FREE TIME AND SOCIAL RELATIONSHIPS IN A GROUP OF STUDENTS FROM TWO HIGH SCHOOLS IN BOTOSANI COUNTY
}

\author{
Adriana Albu ${ }^{1}$, Mihaela Vlada ${ }^{2}$, Adina Nechita ${ }^{1}$, \& Florin Dima ${ }^{2}$ \\ ${ }^{1}$ Grigore T. Popa University of Medicine (Romania) \\ ${ }^{2}$ Vaslui Public Health Department (Romania)
}

\begin{abstract}
Introduction: it is necessary to assess the way students spend their free time in the final years of high school due to the poor results that have appeared recently in the baccalaureate exams. Methods: the study was carried out using a group of 202 students from the 11th and 12th grades from a National College (117 pupils) and a High School (85 pupils) from the city of Dorohoi, Botosani County. The young people filled in a questionnaire with questions about leisure activities and social relationships. The results were processed using Pearson's chi-squared test. Results and discussions: The time allocated daily for physical activity is mostly $15-30$ minutes $(23.76 \%)$ with significant differences between the two schools $(\mathrm{p}<0.05)$. The time spent watching TV is mostly $0.5-1$ hours (35.64\%) with insignificant differences between grades ( $>0.05)$. Most students $(44.05 \%)$ do not sit at the computer, the calculated differences being statistically insignificant $(\mathrm{p}>0.05)$. When looking at social relationships we take into account friends, where in the majority of cases (32.4\%) students have „one” true friend. This is a usual result because in this period of the adolescent's life the role the group of friends plays decreases, with significant differences between school years $(\mathrm{p}<0.05)$. In their free time, they go out into town, mostly $2-3$ evenings per week $(28.71 \%)$, but there are also $31.68 \%$ negative answers. Parents are less concerned about school activity ("never" answers $-34.15 \%$ ) with significant differences between grades $(\mathrm{p}<0.01)$. Parents are also less concerned with the way their children spend their free time ("never" answers $-34.65 \%$ ) with significant differences between school years $(\mathrm{p}<0.05)$. Conclusions: there is a series of situations that guide us towards a modest concern for the future, both from students and their parents.
\end{abstract}

Keywords: Free time, social relationships.

\section{Introduction}

In recent years, we have witnessed in Romania a drastic reduction in the percentage of students who finish high school. It is necessary to evaluate some factors that may explain the causes of this result. We focused on the elements represented by leisure activities and social relationships because they can be quite demanding.

Sports activities are a healthy way to spend your free time. There is an interesting result for students with anemia in Damanhur that should attract the attention of specialists. Those with anemia admit to exercising in a percentage of $44.2 \%$ and those without anemia in a proportion of $78.5 \%$ with significant differences (Naglaa \& Marwa, 2018). Daily physical activity contributes to the support of cardiac function, the development of motor and cognitive skills, to metabolic improvement (Haapala, 2013). Unfortunately, most young people do not pay attention to this way of spending their free time. Their favorite activities are watching TV shows and playing computer games. Such activities are also preferred by young women in Damanhour with and without anemia, but there are no significant differences, so it represents the same way of spending free time (Naglaa \& Marwa, 2018).

Adolescents in the Philippines recognize the constant watching of television programs as a main way of spending free time, while exercise is practiced "sometimes" or "often" (Yap, 2017).

Special attention should be paid to the time spent at the computer because currently, the literature describes the term "digital addiction" as highlighting the situations in which a person uses the computer intensely, uncontrolled, in a pathological way (Baciu, 2020). It also describes internet addiction present in people who use the internet in a pathological sense, being unable to use it constructively. Unfortunately, we reach a situation of social isolation, the appearance of stress reactions, and depressive states (Baciu, 2020). 
Social isolation can be associated with the orientation towards alcohol consumption, some drugs, and even with the emergence of ideas of suicide or self-aggression (Endo, Ando, Shimodera, Yamasaki, Usami, Okazaki, Sasaki, Richards, Hatch \& Nishida, 2017). Starting from these elements, special attention must be paid to body appearance and diets that are uncontrolled and performed only according to the recommendations obtained from the Internet. Serious eating problems can occur due to lack of control from family and low support from friends (Arseniev-Koehler, Lee, McCormick, Moreno, 2016; Haynos, Watts, Loth, Pearson \& Neumark-Stzainer, 2016).

In Romania, we pay special attention to food because we face a strong anchoring in the traditions of families. Sometimes there are deficient eating habits that will persist throughout life, which will affect the health of young people (Albu, Moraru \& Hodorcă, 2015). All these aspects must be in the attention of parents and preventive medical services. Specialized intervention is needed to address issues related to alcohol and drug use, unprotected sex, nutrition, and physical activity. Risky behaviors are becoming more common with age, so the role of preventive services is becoming increasingly important (Harris, Aalsma, Weitzman, Garcia-Huidobro, Wong, Hadland, Santelli, Park \& Ozer, 2017).

The objectives of the study: evaluation of the daily time allotted to physical activity; assessment of the daily time spent watching TV and especially on the computer; the presence of friends and the time spent with them outside the school program, which will allow for showing the presence of social isolation tendencies; parents' interest for school work and leisure taking into account the fact that adolescents want to become independent but still need guidance and support from the family.

\section{Method}

The study was carried out in Dorohoi, a small city in Botosani County. The studied group consists of 202 students from the 11th and 12th grades from a National College (high school - 117 young people) and a School Group (high school - 85 young people). 98 students from the 11th grade and 104 from the 12th grade were interviewed. Students completed a questionnaire with questions about how they spend their free time and their social relationships.

o Leisure was studied using three questions:

- How much sports or other physical activities do you practice per day (in minutes)?: under 15; 15-30; 30-45; 45-60; over 60 minutes.

- How many hours a day do you spend watching TV?: none; 0.5-1 hour; 2-3 hours; 4-5 hours.

- How many hours a day do you spend on the computer?: none; 0.5-1 hour; 2-3 hours; 4-5 hours.

o Social relationships were assessed using four questions:

- How many true friends do you have?: none; one; two, three, or more.

- In general, how many times per week do you go out with friends after school?: 0 times; 1 time, 2-3 times: 4-5 times; 6-7 times.

- Do parents (at least one of them) have time available to help you prepare your homework?: always; often; rarely; never.

- Do your parents have time to organize your free time?: always; often; rarely; never.

The processing of the results was done in between school years out of the desire to try to understand the disastrous results that have appeared lately in high school final exams.

The statistical interpretation was performed using Pearson's chi-squared test.

\section{Results}

The study focuses on two main directions represented by leisure time and social relationships.

When looking at free time activities, we will insist on physical exercise, watching television and using the computer. Sustained physical activity (over $60 \mathrm{~min}$.) is recognized by $19.30 \%$ of young people, the dominant response is $15-30 \mathrm{~min}$. $(23.76 \%)$ or $30-45 \mathrm{~min}(23.26 \%)$. Students in the 12 th grade do fewer sports, an easy situation to understand considering the time needed to prepare for the graduation exams, thusly the calculated differences are significant $\left(\mathrm{p}<0.05 ; f=4 ; \chi^{2}=10.213\right)$ (Table 1$)$.

Table 1. "How much sports or other physical activities do you practice per day?".

\begin{tabular}{|c|c|c|c|c|c|}
\hline & under 15 minutes & $15-30$ minutes & $30-45$ minutes & $45-60$ minutes & over 60 minutes \\
\hline 11th grade & 15 & 24 & 31 & 10 & 18 \\
\hline 12th grade & 30 & 24 & 16 & 13 & 21 \\
\hline Total & 45 & 48 & 47 & 23 & 39 \\
\hline$\%$ & 22.27 & 23.76 & 23.26 & 11.38 & 19.30 \\
\hline
\end{tabular}


Another leisure activity is watching television programs or playing computer games. Television programs are watched mainly 30 min-1 hour daily (35.64\%). There are also $32.67 \%$ young people who mark the "none" answer. There are $26.73 \%$ of teenagers who sit 2-3 hours a day in front of the TV screen and $4.95 \%$ who mark the "4-5 hours" answer. The calculated differences are statistically insignificant ( $\left.>0.05, f=3, \chi^{2}=3.076\right)$ an unexpected result in young people in the final years of high school who should be preoccupied with preparations for the graduation exams.

The situation is even more interesting in terms of time spent on the computer because $44.05 \%$ of students choose the "none" option. We must not overlook the $16.33 \%$ of students who mark the "4-5 hours" result which is difficult to understand especially for students in the 12th grade (Table 2).

Table 2. "How many hours per day do you spend watching TV/using the computer?".

\begin{tabular}{|c|c|c|c|c|}
\hline & None & $0.5-1$ hour & 2-3 hours & 4-5 hours \\
\hline & \multicolumn{4}{|c|}{ Television } \\
\hline 11 th grade & 32 & 40 & 22 & 4 \\
\hline 12 th grade & 34 & 32 & 32 & 6 \\
\hline Total & 66 & 72 & 54 & 10 \\
\hline \multirow[t]{2}{*}{$\%$} & 32.67 & 35.64 & 26.73 & 4.95 \\
\hline & \multicolumn{4}{|c|}{ Computer } \\
\hline 11 th grade & 40 & 22 & 19 & 17 \\
\hline 12 th grade & 49 & 22 & 17 & 16 \\
\hline Total & 89 & 44 & 36 & 33 \\
\hline$\%$ & 44.05 & 21.78 & 17.82 & 16.33 \\
\hline
\end{tabular}

The calculated differences are statistically insignificant $\left(\mathrm{p}>0.05 ; f=3 ; \chi^{2}=0.791\right)$ and draw attention to the young people in the final year who have time to sit at the computer, to socialize or play games.

In adolescents, social relationships diversify, being necessary to assess the existence of the group of friends but also the relationships with the parents. The group of friends is essential until the age of 14-15, after which its importance decreases, with restricted, selective friendships being preferred.

In the students in the studied group, the group of friends is still present in $28.21 \%$ of situations, but the calculated differences are statistically significant $\left(\mathrm{p}<0.05 ; f=3 ; \chi^{2}=8.33\right)$ which leads to the reduction of its role in young people in the final years of high school. The "none" answers in $10.89 \%$ of cases are worrying, which leads us to the situation of dangerous social isolation in this age group (Table 3).

Table 3. "How many true friends do you have?".

\begin{tabular}{|c|c|c|c|c|}
\hline & None & One & Two & Three or more \\
\hline 11th grade & 8 & 24 & 37 & 29 \\
\hline 12th grade & 14 & 39 & 23 & 28 \\
\hline Total & 22 & 63 & 60 & 57 \\
\hline$\%$ & 10.89 & 31.18 & 29.70 & 28.21 \\
\hline
\end{tabular}

The presence of the group of friends also means the existence of time spent with them outside of school. The result obtained is interesting because $31.68 \%$ of students mark the " 0 times" answer. Being a small town, there are not many possibilities to spend time somewhere with friends where teenagers will find it interesting (Table 4).

Table 4. "How many times per week do you go out with friends after school?".

\begin{tabular}{|c|c|c|c|c|c|}
\hline & 0 times & 1 time & $2-3$ times & $4-5$ times & $6-7$ times \\
\hline 11th grade & 35 & 24 & 24 & 8 & 7 \\
\hline 12th grade & 29 & 27 & 34 & 8 & 6 \\
\hline Total & 64 & 51 & 58 & 16 & 13 \\
\hline$\%$ & 31.68 & 25.24 & 28.71 & 7.92 & 6.43 \\
\hline
\end{tabular}

We can see that $7.92 \%$ of young people marked the " $4-5$ times" answer and $6.43 \%$ marked the "6-7 times" answer. The calculated differences are statistically insignificant ( $\left.\mathrm{p}>0.05 ; f=4 ; \chi^{2}=2.325\right)$ a result difficult to understand for young people in the final year of high school. These results require further study with the assessment of the parents' interest for the students' school activity.

In most cases $(34.15 \%)$ parents are not at all concerned about school activity. At the opposite pole are placed $13.36 \%$ of families in which this concern is permanent (Table 5). 
Table 5. "Do parents have time to help you with your homework? / Do parents have time to organize your free time?".

\begin{tabular}{|c|c|c|c|c|}
\hline & Always & Often & Rarely & Never \\
\cline { 2 - 5 } & \multicolumn{4}{|c|}{ Homework } \\
\hline 11th grade & 6 & 23 & 38 & 31 \\
\hline 12th grade & 21 & 18 & 67 & 38 \\
\hline Total & 27 & 41 & 32.17 & 34.15 \\
\hline$\%$ & 13.36 & 20.29 & 25 & 32 \\
\hline \multicolumn{5}{|c|}{ Free time } \\
\hline 11th grade & 7 & 34 & 27 & 38 \\
\hline 12th grade & 19 & 20 & 52 & 70 \\
\hline Total & 26 & 54 & 25.74 & 34.65 \\
\hline$\%$ & 12.87 & 26.73 & & \\
\hline
\end{tabular}

The calculated differences are statistically significant $\left(\mathrm{p}<0.01 ; f=3 ; \chi^{2}=11.375\right)$ and draw attention to the parents of pupils in the 12th grade who are more interested with preparing their homework.

Leisure activity is not supervised by $34.65 \%$ of parents; there are also $12.87 \%$ of families where there is permanent supervision. However, the significant differences calculated $\left(\mathrm{p}<0.05 ; f=3 ; \chi^{2}=9.125\right)$ are encouraging because they focus on the higher percentage of parents of students in the final high school year who are interested in this aspect.

\section{Discussion}

The focus is mainly on students in the 12th grade who will take the graduation exam. It is an important exam because it allows you to continue your studies at a college or a post-secondary school. Solving this problem requires in-depth study that leads to the minimization of free time.

Systematic physical activity is recommended for any age group. According to WHO recommendations, young people (5-17 years old) need at least 60 minutes of sustained activity per day, and adults (18-64 years old) need 150 minutes of moderate activity per day (WHO, 2017a; WHO, 2017b). Unfortunately for students in the studied group, such an answer appears only in $19.30 \%$ of situations, a result present in other studies carried out on adolescents from a high school in Iasi $(15.8 \%)$ who were not in the final year of high school (Albu, Onose, Negrea, Crăcană \& Hodorcă, 2015).

The modest time allotted for physical activity is recognized by most students, being present in $60.6 \%$ of young people in the USA (Miller, Sliwa, Brener, Park \& Merlo, 2016). Instead, these young people spend more than 3 hours per day watching television programs $(33.2 \%)$ or using the computer $(40.3 \%)$.

In Ghana, many young people have a $\mathrm{TV}$ in their room, which is turned on during their homework (27.6\%), have a personal computer/laptop (41.7\%) and even a gaming console (38.1\%) in their room, so they have all the conditions to spend too much time in front of the television or computer (Gaa, Apprey, Annan, Mogre \& Dzogbefia, 2019).

For students in the studied group, the result is interesting because there are many negative answers for both television programs (32.67\%) and computers (44.05\%). The study carried out on students from different high schools in Iasi highlights $22.78 \%$ negative answers for watching television programs and $11.81 \%$ for computer use (Albu, Hodorcă, Onose, Negrea \& Crăcană, 2016).

Adolescents in southeastern Iran respond negatively in $9.03 \%$ of situations for watching television programs and in 49.34\% of situations for computer use (Shahraki-Sanavi, Rakhshani, Ansari-Moghaddam \& Mohamad, 2017). At the same time, the daily physical activity that lasts 60 minutes is recognized by only $4.19 \%$ of girls. It is necessary to carry out in-depth studies related to students' habits of spending free time. These assessments are especially important for final high school years and students in large cities, but also in small cities where leisure activities are less numerous or tempting (Baciu, 2020).

Social relationships become essential for the evolution of young people. In the studied group there is an interesting situation represented by maintaining the group of friends ( 3 or more friends) after the age of $14-15$ years $(28.21 \%)$ which demonstrates a later maturation of students in the studied group. Unfortunately, there are many negative responses (I do not spend time outside of school with friends) which raises some worries related to the trend of isolation.

Parents still have an important role to play. They must closely monitor the student's school and leisure activities. We obtained an important result because the parents of the 12th-grade students are much more concerned with these aspects, however, permanent supervision is present in about $10 \%$ of families.

These are important issues because they can often be associated with inappropriate behavior. In England, lack of parental supervision (never/rarely) is associated with smoking (1.5\%), alcohol consumption (10.4\%), antisocial behaviors (18.5\%), behavioral problems (19.4\%) (Zilanawala, Sacker \& Kelly, 2017). 


\section{Conclusion}

Leisure activities must be closely supervised by parents as they can easily become tiring and disruptive for the sustained study required to complete high school. Sustained sports activity is not a concern of most students. There are many negative answers for watching television programs but also for computer activity, a special situation for high school students.

Social relationships are present in most cases but there is still a group of friends even in the $12^{\text {th }}$ grade which indicates a rather slow social evolution.

Parents of students who are in their final high school years are more interested in school and leisure activities of students because they are preoccupied with securing their future.

Such studies are important because they allow us to account for some factors that can be considered a risk in ensuring the future of young people.

\section{References}

Albu, A., Hodorcă, R. M., Onose, I., Negrea, M., \& Crăcană, I. (2016). The evaluation of the scholar fatigue phenomen and some causative factors in a group of teenagers from Iasi. Global Journal of Sociology: Curent Issues, 6(2), 44-49.

Albu, A., Moraru, C. E., \& Hodorcă, R. M. (2015). The evaluation of some eating habits at a group of teenagers studying at Dimitri Catemir highschool in Iasi. Procesia Social and Behavioral Sciences, 197, 1947-1951.

Albu, A., Onose I., Negrea M., Crăcană I., \& Hodorcă R. M. (2015). Correlation between physical development diagnostic and exercise in a group of teens from Garabet Ibrăileanu high school in Iasi. The European Proceedings of Social \& Behavioural Sciences, XI, 273-279.

Arseniev-Koehler, A., Lee, H., McCormick, T., \& Moreno, M. (2016). Proana:Pro-eting disorders socialization on Twitter. Journal of Adolescent Health, 58, 659-664.

Baciu, A. (2020). Digital addiction - an anthropological phenomenon of the preseent century. In Antropologia Mileniului III, București: Ed. Academiei Romane.

Baciu, A. (2020). Medical and social consequences of digital addiction. Medical Anthropology, The Publishing House of the Romanian Academy, 22(3), 141-147.

Endo, Ando, Shimodera, Yamasaki, Usami, Okazaki, Sasaki, Richards, Hatch, \& Nishida (2017). Preference for solitude, social isolation, suicidar ideation and self-harm in adolescents. Journal of Adolescent Health, 61, 187-191.

Gaa, P., Apprey, C., Annan, R., Mogre, V., \& Dzogbefia, V. P. (2019). The home and school environment, physical activity levels and adiposity indice of school-age children. International Journal of Public Health Science, 8,(1), 82-92.

Haapala, E. (2013). Cardiorespiratory firness and motos skills in relation to cognition and academic performance in children- a review. Journal of Human Kinetics, 36, 55-68.

Harris, S., Aalsma, M., Weitzman, E., Garcia-Huidobro, D., Wong, C., Hadland, S., Santelli, J., Park, J., \& Ozer, E. (2017). Research on clinical precentive services for adolescents and young adults:where are we and where do we need to go?. Journal of Adolescent Health, 60, 249-260.

Haynos, A., Watts, A., Loth, K., Pearson, C., \& Neumark-Stzainer, D. (2016). Factor predicting an escalation of restrictiv eating during adolescence. Journal of Adolescent Health, 59, 391-396.

Miller, G., Sliwa, S., Brener, N., Park, S., \& Merlo, C. (2016). School district policies and adolescents'soda consumption. Journal of Adolescent Health, 59, 17-23.

Naglaa, K. A. H., \& Marwa, M. A. O. (2018). Life style risk factors of iron deficiency anemia among adolescents'girls. International Journal of Nursing Didactics, 8(10), 18-28.

Shahraki-Sanavi, F., Rakhshani, F., Ansari-Moghaddam, A. \& Mohamad M. (2017). Association of physical activity and sedentary behavior with dietary behavior among mid-adolescent female students in southest of Iran. Medical Communication, bioscience biotechnology Research communication, 10(4), 739-745.

WHO, 2017a. Physical activity and adults. Recommended levels of physical activity for adults aged 18-64 years.

WHO, 2017b. Physical activity and young people. Recommended levels of physical activity for children aged 5-17 years.

Yap, R. A. (2017). Weight management: it's effect in the prevention of obesity related illness. International Journal of Physycal Education, Fitness and Sports, 6(4), 20-25.

Zilanawala, A., Sacker, A., \& Kelly, Y. (2017). Longitudinal latent cognitive profiles and psychosocial well-being in early adolescence. Journal of Adolescent Health, 61, 493-500. 


\title{
TEACHER TRAINING FOR THE PREVENTION, REPORTING AND ADDRESSING OF VIOLENCE AGAINST CHILDREN
}

\author{
Elisabetta Biffi, \& Daniela Bianchi \\ "Riccardo Massa" Department of Human Sciences for Education, University of Milano-Bicocca (Italy)
}

\begin{abstract}
Each year an estimated one billion children (one out of two children worldwide) suffer some form of physical, sexual or psychological violence or neglect (Hillis, Mercy, Amobi, \& Kress, 2016). Being a victim of violence in childhood has lifelong impacts on education, health, and well-being. Exposure to violence can lead to poor academic performance due to cognitive, emotional, and social problems (WHO, 2019). The right of the child to freedom from all forms of violence is affirmed by the United Nations Committee on the Rights of the Child, in its General Comment No. 13 (UNCRC, 2011). Moreover, the Sustainable Development Goals contain a clear call to eliminate violence against children, most explicitly in Target 16.2 (UN, 2015).

Many efforts have been made globally to achieve these goals. Schools have been identified as one of the crucial contexts for conducting violence prevention efforts. They offer an important space where children, teachers and educators can learn and adopt pro-social behaviors that can contribute to preventing violence (WHO, et al., 2016). Teachers can play a key role, helping to build a "violence-free world" (UNESCO, WHO, UNICEF, End Violence Against Children, 2020), both by promoting positive relationships and by identifying signs of violence early. In fact, while international strategies provide a necessary framework for the promotion and protection of children's rights, it is the people who can make a difference in the prevention and detection of violence against children (Biffi, 2018).

Based on these premises, the paper will focus on how teacher training can help prevent, report and address violence against children. Teachers are often not trained on this: some of them know the contents, but have doubts about how to deal with certain situations. Teachers should learn what to do with students who have gone through a traumatic experience because children choose someone who can see and recognize them (Miller, 1979, En. transl. 1995; Miller, 1980, En. transl. 1983). To be able to really recognize the child, a training course with teachers is necessary, to raise awareness and help them see the signals that children send (The Alliance for Child Protection in Humanitarian Action, End Violence Against Children, UNICEF, WHO, 2020). This paper, through literature and presentation of a training course with teachers in Italy, will offer a pedagogical reflection on teacher training in the prevention, reporting and addressing of violence against children, in order to start building a common shared strategy.
\end{abstract}

Keywords: Teacher training, violence against children, prevention, rights of the child, Italy.

\section{Violence against children: Prevention starts at school}

In accordance with the definition provided by the World Health Organization, violence is «The intentional use of physical force or power, threatened or actual, against oneself, another person, or against a group or community, that either results in or has a high likelihood of resulting in injury, death, psychological harm, maldevelopment or deprivation» (Krug, Mercy, Dahlberg, \& Zwi, 2002, p. 5).

The right of the child to freedom from all forms of violence is affirmed by the United Nations Committee on the Rights of the Child, in its General Comment No. 13 (UNCRC, 2011). Moreover, the Sustainable Development Goals contain a clear call to eliminate violence against children, most explicitly in Target 16.2 (UN, 2015). Although children's rights are formally recognized, each year an estimated one billion children (one out of two children worldwide) suffer some form of physical, sexual or psychological violence or neglect (Hillis, Mercy, Amobi, \& Kress, 2016).

Being a victim of violence in childhood has lifelong impacts on education, health, and well-being. Exposure to violence can lead to poor academic performance due to cognitive, emotional, and social problems (WHO, 2019). It has been reported that children who have experienced violence display 
difficulties at school, in terms of deficits or delays in their skills development and knowledge acquisition (McKee, \& Dillenburger, 2009).

Schools have been identified as one of the crucial contexts for conducting violence prevention efforts. They offer an important space where children, teachers and educators can learn and adopt pro-social behaviours that can contribute to preventing violence (WHO, 2016). Teachers and educators are in a position to contribute to the early identification of maltreatment and family violence in general, although it is a complex task (Walsh, et al., 2008). At the same time, teachers and educators have a professional relationship with families that allows them to support parents and promote a positive parental attitude. Indeed, several studies have underlined the role of schools (Baginsky, 2003; 2007) and demonstrated that, if child protection is to be effective, it is crucial for teachers and educators «to be clear and confident about their own pastoral role with regard to sensitive issues of child protection, especially when collaborating in multidisciplinary child protection work» (McKee, \& Dillenburger, 2009, p. 3). Teachers can play a key role, helping to build a "violence-free world" (UNESCO, WHO, UNICEF, End Violence Against Children, 2020), both by promoting positive relationships and by identifying signs of violence early. In fact, while international strategies provide a necessary framework for the promotion and protection of children's rights, it is the people who can make a difference in the prevention and detection of violence against children (Biffi, 2018).

\section{The teacher-child relationship}

In the relationship with the child there is an issue of ambiguity, with respect to what is legitimate to act on him/her. Children choose someone who can see and recognize them (Miller, 1980, En. transl. 1983). It is therefore necessary to learn to be aware of how one is in relationship with a child who is living or has gone through a traumatic experience. In order to really recognize the child, a training course with teachers is necessary, to raise awareness and help them see the signals that children send (The Alliance for Child Protection in Humanitarian Action, End Violence Against Children, UNICEF, WHO, 2020).

Teachers should learn to stay in the classroom with children who have experienced a traumatic experience on their skin, because, among the many consequences, it is an aspect that has an incredible impact on learning. In order to achieve this goal, it becomes important to work on themselves and understand which resources to activate. It is necessary to know how to stay in relationships with their students, in particular with children with difficult life stories (Bertolini, Caronia, 1993). Learn to stay inside the uncomfortable stories, to stay inside the fatigue. Even when faced with a child with a tough story, the difficulty lies with the adult because it is he/she who perceives it as such. It is therefore necessary to take charge of the relationship for what it is, with one's own difficulties and with those of the child, which must be recognized and understood. It is not possible to work immediately on the child's behavior, which should instead be seen as a sign of discomfort. Stopping at the symptom risks being counterproductive because it could prevent teachers from understanding what lies behind that particular behavior. So before acting on the student and his/her family it is necessary to work on themselves. To do this, a relationship of trust is needed, not only with the individual child, but with the whole community of the school, the family, the territory. Only in this way will it be possible to open a new horizon for the child and focus on his/her well-being. If teachers are able to make their students feel good at school, children can be given the opportunity to know that school can be a positive place, a place where they can feel good. This should be the primary goal of teachers and of the entire school community.

\section{A training course for teachers in Italy for the prevention of violence against children}

With these premises, the contribution aims to explore teacher training on the prevention of violence against children through the presentation of a course for teachers in Italy. The course started from a specific need of the territory and the teachers to receive training on the prevention and reporting of violence against children, following some episodes that occurred with their students. The training course was promoted by a Municipality of a suburban area of North Italy and the University of Milano-Bicocca and involved some schools in the area, from kindergarten to high school.

The purpose of the course was to facilitate the identification and treatment of children in situations of prejudice and severe discomfort with preventive and guidance effectiveness. Furthermore, through the course teachers have been made more aware of the dimensions on which they most need to strengthen themselves both as individuals and as services. The training course has also contributed to the knowledge of the child protection services in the area, promoting better networking between schools and the Municipality. 
At the end of the training, the path will continue in schools, where the trained teachers will become reference points for the entire school, with a view to sustainability.

Due to the COVID-19 restrictions in Italy, the course had to be held remotely, but took place in laboratory mode encouraging activities in small groups. During the first meeting the expectations and needs of the teachers involved were explored. From the dialogue with them it emerged that they do not receive specific training on the prevention of violence against children and even if they know the contents, they say they do not feel confident about how to deal with certain difficult situations. The teacher's doubts are mainly summarized in the inability to see a need and, once identified, in not knowing how to manage it. It was therefore necessary to build sharing strategies to know how to deal with situations of violence against children, which teachers could witness or see their signals, also promoting prevention thanks to early and shared actions. During the training, the teachers were able to learn to recognize a situation, to deal with it and to activate the resources around them, with a view to continuous collaboration with the social workers of the Municipality.

Starting from the needs identified by the teachers, the course was developed according to different objectives: to help teachers "see" and "hear" the children in their school, to orient themselves with respect to their own way of being at school and to network with territorial protection services. In fact, it is important to prepare the personal ground for understanding how to be predisposed to feel the risk of violence with the children they work with. Furthermore, at school there is often the risk that some modalities that are used in the daily educational relationship may become echoes for those who have experienced violence. Those who live in a difficult story have a high sensitivity with respect to some modes of relating. Although there are differences between children's age groups, some words (Biffi, 2020) or gestures, such as that of the teacher to approach the child's body, are never neutral. With children who are victims of violence this gesture becomes even more meaningful. The educational relationship passes through the body and the teacher must be even more aware of it when the child experiences suffering. Another fundamental aspect is networking with local services: it is necessary to work as a team to have a complete vision of the child's life and to be able to deal with any uncomfortable situations in the best way for the child and his/her family. The training course therefore wanted to give teachers and the protection services of the Municipality a space to reflect on their experiences and professional skills, in order to understand what resources are already there and what skills must be refined to better live the relationship with students and families and to deal with any difficult situations.

To achieve these objectives the course was based on experts' presentations, discussion of critical cases, plenary discussion sessions, narrative writing, use of images and videos. The intention was to create an informal space for the teachers involved, based on T-group method (Lewin, 1947) and Sensitive Group approach (Rogers, 1970), in order to make them reflect on their stereotypes and prejudices, on their experiences with children at school and on how to deal with hypothetical future situations. This is because there is no objective dimension when it comes to the relationship between teachers and students. Teachers cannot rely on the objectivity of the experts or on their own objectivity. In educational relationships there is always a subjectivity, which makes the role of teachers more strategic in preventing violence against children, but at the same time makes their task even more complex. It was therefore essential not to provide teachers with a pre-filled vademecum, but to build together with them a common strategy to make them more aware of the necessary steps and of the people they could ask for help. Collaboration with child protection services was fundamental, providing teachers with useful information on the reporting process in the event of childhood violence, and was also useful in terms of building a future work network. Both talked and tried to understand each other's needs, in order to build a common and shared working strategy.

Through group work, some concerns were clarified and resources that already exist within the school were discovered. This confirms that, unfortunately, there is still a lack of dialogue within the school today. Teachers expressed the desire and the need to repeat this training course cyclically to give the opportunity also to new teachers to participate and to refresh their memory regularly. Very often it is assumed that the teacher knows all the services in the territory and all the people who work within them. The risk is to pass information only to those responsible and not to involve the entire school community in the process of preventing violence against children.

The training course made it possible to bring out three aspects in particular: it is important to recognize and understand how to use the resources that are already present within the school; increase the level of sensitivity in general in order to have a "trained look" with which it will be less difficult to see certain situations; a child who is unwell does not learn, or if she/he learns it uses it as a mask to hide a discomfort. The collaboration between teachers and social workers then highlighted the need for greater dialogue and mutual trust and the importance of finding an effective communication channel, a common language for better teamwork. Both expressed the need to have a constant and regular moment of dialogue between the various services. Being able to create routines helps a lot of different services to work together, there is a need for regularity. A network intervention works if the nodes are solid and interconnected with each other, otherwise families risk falling into the holes in the net. 


\section{Conclusion}

Reflecting on violence against children is fundamental because in the teacher-child relationship patterns of the parent/adult-child relationship are repeated. It is therefore essential to consider these situations with a broader view. Teachers and educators should also help each other to reflect on some practices and styles that take place within the school and that have an impact on children. In fact, it is not always possible to read how the words and gestures of teachers can have an effect on the personal stories of their students. For this reason teachers should observe both the children and themselves in the relationship with them, continually questioning themselves. By building reflections on their actions they will be able to connect with children because what they do at school is related to what happens in the whole life of the child.

The first factor of prevention is the knowledge of the child, knowing how to recognize him (Miller, 1979, En. transl. 1995), so that any violence against the child can be recognized early. The key tools that teachers and educators should equip themselves are observation and listening, which also depend on how spaces and times are managed at school. It is therefore important to create a school culture capable of putting children at the center. This listening and observing attitude is always useful, not only in cases of violence. If the relationship is missing, learning also fails. Teachers and educators should be able to listen empathically to children, so that they will feel free to ask for their help if necessary. Signs of maltreatment and violence are often little or no visible and can only be identified by paying close attention to the child's behavior. Furthermore, teachers are required to have knowledge of the official procedures as, once the risk factors are identified, it is necessary to know exactly which steps to follow (Biffi, 2018).

To do this, it is necessary to learn not to work alone and to have spaces and times for sharing with colleagues within the school, with the experts who supervise them, with the families and with the territory by creating a strong alliances. At the same time, it is also important to work on the whole class because if a student has a discomfort the whole class will suffer.

The goal is to guarantee children the right to protection against violence, focusing on the best interests of the child (UN General Assembly, 1959; 1989). Childhood is a common good and for this reason it must be protected.

\section{References}

Baginsky, M. (2003). Newly qualified teachers and child protection. Child Abuse Review, 12, 119-127. Baginsky, M. (2007). Schools, social services and safeguarding children. Leicester: NSPCC.

Bertolini P., Caronia L. (1993). Ragazzi difficili. Pedagogia interpretativa e linee di intervento, Firenze: La Nuova Italia.

Biffi, E. (2018). Training Teachers to Prevent Violence Against Children: The First Line Against Family Violence. In K. Trimmer, R. Dixon, \& Y. Stewart Findlay (Eds.), The Palgrave Handbook of Education Law for Schools (pp. 519-532). PALGRAVE MACMILLAN.

Biffi, E. (2020). When educational words become violent. The risk of hate speech within the educational relationship, MeTis, 9(2), pp. 101-117.

Hillis, S., Mercy, J., Amobi, A., \& Kress, H. (2016). Global Prevalence of Past-Year Violence against Children: A Systematic Review and Minimum Estimates. Pediatrics, 137, e20154079. https://doi.org/10.1542/peds.2015-4079

Krug E.G., Mercy J.A., Dahlberg L.L., \& Zwi A.B. (2002) The World Report on Violence and Health. Switzerland: World Health Organization. Retrieved 18.02.2021 from: https://apps.who.int/iris/bitstream/handle/10665/42495/9241545615_eng.pdf;jsessionid=2F9F6BB 450AF91E897BD80F5AC6B9B20?sequence=1

Lewin K (1947) Frontiers in group dynamics: Concept, method and reality in social science; equilibrium and social change. Human Relations, 1(1), pp. 5-41.

McKee, B.E., \& Dillenburger, K. (2012). Effectiveness in child protection training for pre-service early childhood educators. International Journal of Educational Research, 53, 348-359.

Miller A. (1979): The Drama of Being a Child: The Search for the True Self, En. Transl. London: Virago, 1995.

Miller A. (1980): For Your Own Good: Hidden Cruelty in Child-Rearing and the Roots of Violence, En. Transl. New York: Farrar Straus Giroux, 1983.

Rogers, C. (1970). Encounter Groups, New York: Harper and Row; London: Penguin. 
The Alliance for Child Protection in Humanitarian Action, End Violence Against Children, UNICEF, WHO (2020). COVID-19: Protecting Children from Violence, Abuse and Neglect in the Home. Retrieved 18.02.2021

from: https://www.alliancecpha.org/en/system/tdf/library/attachments/technical_note_covid19_and_its_implicationhs_for_protecting_children_from_violence_in_the_home_v1_0.pdf?file $=1$ \&type $=$ node $\&$ id $=38088$

UNESCO, WHO, UNICEF, End Violence Against Children (2020). Global status report on preventing violence against children. Retrieved 18.02.2021 from: https://www.who.int/publications/i/item/9789240004191

United Nations (2015): Transforming our World: the 2030 Agenda for Sustainable Development. Retrieved

from: https://sustainabledevelopment.un.org/post2015/transformingourworld/publication

UN Committee on the Rights of the Child (2011). General comment No. 13 - The Right of the Child to Freedom from all Forms of Violence.

UN General Assembly (1959). Resolution adopted by the General Assembly. 1386 (XIV). Declaration of the Rights of the Child. A/RES/14/1386.

UN General Assembly (1989). Convention on the Rights of the Child. 20 November 1989, United Nations, Treaty Series, vol. 1577.

Walsh, et al. (2008). Case, teachers and school characteristics influencing teachers' detection and reporting of child physical abuse and neglect: Results from an Australian survey. Child Abuse \& Neglect, 32(10), 983-993.

World Health Organization, et al. (2016). INSPIRE: Seven strategies for ending violence against children. Luxembourg: World Health Organization. Retrieved 18.02.2021 from: file://C:/Users/user/Downloads/9789241565356-eng.pdf

World Health Organization (2019). School-based violence prevention. A practical handbook. Switzerland: World Health Organization. Retrieved 18.02.2021 from: https://apps.who.int/iris/bitstream/handle/10665/324930/9789241515542eng.pdf? sequence $=1 \&$ isAllowed $=y$ 


\title{
EXPERIENTIAL LEARNING PROCESSES USING AN E-DIARY IN STUDENTS' INTERNSHIP
}

\author{
Ilona Tandzegolskienè, \& Asta Lapėnienè \\ Academy of Education, Vytautas Magnus University, Kaunas (Lithuania)
}

\begin{abstract}
The article/presentation analyses data from e-diary taken by 88 students from three groups of pedagogical programs who were studying in the following school years: 2018-2019 and 2019-2020. As part of the internship tasks, the diary had to be written regularly weekly (for a total of 20 or 22 weeks). According to the provided half-standardised e-diary form, every week, the research participants had to document the most significant/successful/problematic situation in their school internship and raise any questions. The database on an e-diary basis contains 1962 situations of internship pedagogical activity. The data presented in the article is general for the whole group of research participants. The data analysis is based on six stages: access to the data, data coding, finding topics, revision of the topics, a summary of the topics and preparation of the report.

The article presents how the e-diary was designed and how the e-diary stimulates the metacognitive capacity to reflect upon thinking capacities. The thematic analysis of the entries in e-diary has been conducted according to the following three aspects: emotional, cognitive, and the change in internship activity. The thematic analysis's emotional aspect (which was revealed in the e-diary notes) has been reflected by the dynamics of satisfaction from the professional activity. The intellectual aspect has been revealed by the dynamics of changes in students' self-estimation, attitude towards learning, and the teaching profession. The diaries provided the opportunity to analyse the learning situations via descriptions in the e-diary and the participant's self-reflections on their gained internship experience.
\end{abstract}

Keywords: Experiential learning, diary structure, electronic diary, case study.

\section{Introduction}

Experiential learning is essential for the $21^{\text {st }}$ century. Experience can reshape the learner's future if it creates the possibility for conscious engagement. A connection between teachers' self-reflection and the metacognition of future teachers has been made clear. Self-reflection and metacognition provide important learning tools for building confidence and interpersonal skills since metacognitive knowledge enables future teachers to consciously apply learning strategies, develop effective work habits, and evaluate their performance (Desautel, 2009).

Nowadays, technologies are an integral part of the educational environment. The development of smart technologies and their integration into the teaching/learning process provides many perspectives and encourages the learner to reflect and think about the processes during student internships (Clipaa et al., 2012). E-diary is one of the most effective innovative tools for teachers to develop their teaching/learning practices and stimulates the metacognitive capacity (Clipaa et al., 2012; Bartlett \& Milligan, 2015). E-diary discloses realistic pictures of everyday school life and functions as a collection of 'instantaneous information in the authentic environment, which allows daily encounters to be captured and recorded during the internship. Therefore, the study based on the e-diary method is designed and organised only in collaboration with the study participants. This design requires the active involvement of research participants, which is essential to empower learners to be reflective teachers at the end of the internship. It also unites teachers as reflexive and self-supported technicians and responsible practitioners (Clipaa et al., 2012).

This article aims to reveal the benefits of constructing an electronic diary as an educational tool focusing on the observation and reflection of learning experiences.

Electronic diaries as a learning tool applied during organised pedagogical internships correlate with a constructivist approach to the study. The cognitive structure is constantly evolving and improving due to constructivism (Binkley \& Minor, 2020). A didactic attitude based on constructivism's principles emphasises learning as individual knowledge based on personal experience. Primary (ordinary, 
spontaneous) perception plays a mediator between the learner's knowledge and the totality of thinking structures (Bertran, 1995). The initial structure of perception constantly reforms itself to incorporate new knowledge into the learner's already existing cognitive structure. This new information is always affected and concurrently analysed according to the initial perception model and changing it (Binkley \& Minor, 2020). The purpose of constructivist learning is not to transmit and receive information, but to promote the learners' understanding and activity (Howard \& Brady, 2015), as learners independently construct and gather their knowledge base and become jointly responsible for the teaching content, which is inseparable from everyday life and experience. In response to this provision, an e-learning space is created with the help of an e-diary, where learners, while presenting their internship situations, have an opportunity to update gained internship experience and create new meanings based on it.

The E-diary design was based on Kolb's experiential learning model (Kolb, 1984; McLeod, 2017) by establishing connections between experience, learning environment, and pedagogical changes during the internship period. The essence of learning from experience is that learning and development are greatly facilitated by an integrated learning process based on the experiment, and it consists of the following crucial stages:

- $\quad$ here-and-now experience;

- data collection and naming, which includes observation and reflection;

- $\quad$ analysis and conceptualisation of the received information;

- $\quad$ concept verification process.

The learning specifics of using an e-diary are characterised by the fact that the emerging collaborative relationships strongly influence the transition from one stage to another based on this model in the e-learning space. Kolb and Fry (1975), emphases the main idea of the learning process, that is accompanied by tension and conflict. To obtain the four areas of the learning model is to gain new knowledge, abilities and skills. The experiential learning model is based on dialectical tension between the four types of interactions with the environment, which are the following: 1) During the first situation, direct experience an impression is formed, which enables the student to set certain during internship activity situations apart from the general stream of activities. Such experiences are usually caused by situations that contradict the established procedures in practical and intellectual activities. It depends on each specific situation, whether the experience is painful or pleasant. 2) In the second situation (observation and identification), the student records important internship activity experiences in the e-diary. It allows the student to look at his/her activity process as the observer reflecting over past events. In this situation, by describing his/her activity procedure, the student switches from the performer's position to a new activity observer position. 3) In the third situation (reflective activity assessment), the teacher/consultant, reacting to the described situation, mediates and helps the student reflect on his/her activity. 4) In the fourth situation, activity consultations during internships aim to search for deliberate activity prospects, and there is an attempt to foresee the alternatives to a specific activity.

These four teaching/learning situations create the prospect and the system of a consistent transition from direct experience to the planned activity, while each new teaching/learning situation enriches and expands previously gained experience. As a learning tool, e-diary allows students to perform various tasks and share their daily experiences and discoveries, which are later analysed and discussed. The description of problematic situations creates the preconditions for internship participants to move to the reflective assessment level to avoid the same mistakes in the future.

\section{Design/methodology}

For conducting this research were chosen participants from the Pedagogical Program. It is a one-year program that provides the qualification for successful graduates to start practising as teachers. The research was conducted in the following school years: 2018-2019 and 2019-2020. Research participants within the program have qualified to teach a particular subject (chemistry, physics, biology, languages, information technologies, mathematics, music, art, history, geography etc.) and complete their teacher qualification during the pedagogical studies.

Data were collected from 88 research participants (76 women and 12 men) who were part of the pedagogical program. For the most part, students in these studies already have pedagogical experience because they work in non-formal education or have started working in schools for the first academic year. E-diary was provided to the Lithuanian student participants who are part of the pedagogical program as school internships was a compulsory part of their study program. E-diary is the perfect tool for learners to teach and learn from it. In this research, the age and gender of research participants were not considered of distinct important. Research emphasises the analysis of the situation of internship activities of the research participants. The language of the research was Lithuanian, and all participants were participating in their native language. Since it plays an important role in constructing practitioners' identity and working on native language, they helped research participants reflect on themselves better (Kavaliauskienė et al., 2010). 
E-diary as a system of measures reflects two learning opportunities: Practice-functional and reflexive-conceptual, and its purpose during the pedagogical internships is twofold:

- For the beginner teachers - to capture internship activity situations and learn from them.

- To provide operative consulting support to study organisers for the novice educator.

E-diary function is divided into several stages. In the first stage, student participants were given access to the Moodle system and can fill in the e-diary questions for the whole week. Logged e-diary content can still be altered during the same week; however, e-diary content cannot be changed from the previous week.

In the second stage, the supervising teacher reads the participants' e-diaries from the specific week of their student participants' internship and note their supervisor comments and answers any noted questions. Comments can be written in the system only by the supervising teachers.

In the third stage, the data set collected based on the e-diary is analysed based on a set of semi-standardised thematic themes by the students themselves. Participating students independently analyse their described scenario of pedagogical activities during their internship. This process makes it possible to capture first-year teachers' activity regularities, which summarise the pedagogical internship experiences.

As part of the internship tasks, the diary had to be written regularly weekly (for a total of 20 or 22 weeks). Every week the student participants of the internship, according to the provided half-standardised e-diary form, had to describe in their opinion the most significant/successful/problematic situation in their school internship and to ask the questions they had. The questions were answered by the teachers working in that program. The students' mentors were involved in cases of specific problems. As a result, the system encourages research participants to record and analyse internship activity situations where and when developing in schools.

The e-diary entries were only available to a defined circle of users: the student and the teacher-consultant. Other students could only follow the entry if it were posted in a general discussion. The database on an e-diary basis contains 1962 situations of internship pedagogical activity. The data presented in the article are general for the whole group of research participants. The data analysis is based on six stages: access to the data, data coding, finding topics, revision of the topics, a summary of the topics and preparation of the report.

The thematic analysis of the entries in e-diary has been conducted according to the following three aspects: emotional, cognitive, and the change in internship activity. The emotional aspect of the thematic analysis- which was revealed in the e-diary notes- has been reflected as dynamics of satisfaction from the professional activity. The intellectual aspect has been revealed by the changing dynamics of the student's self-estimation, attitude towards learning, and the teaching profession. The internship experience side has been revealed by analysing the learning situations described in the e-diary and the student's reflections on the gained experience.

\section{The core experience of the interaction of structural elements}

The experiential learning situations showed certain personal, professional, and emotional aspects of development and how these aspects changed during the pedagogical internships in an e-diary (Figure 1).

Figure 1. Interaction of experience structure elements.

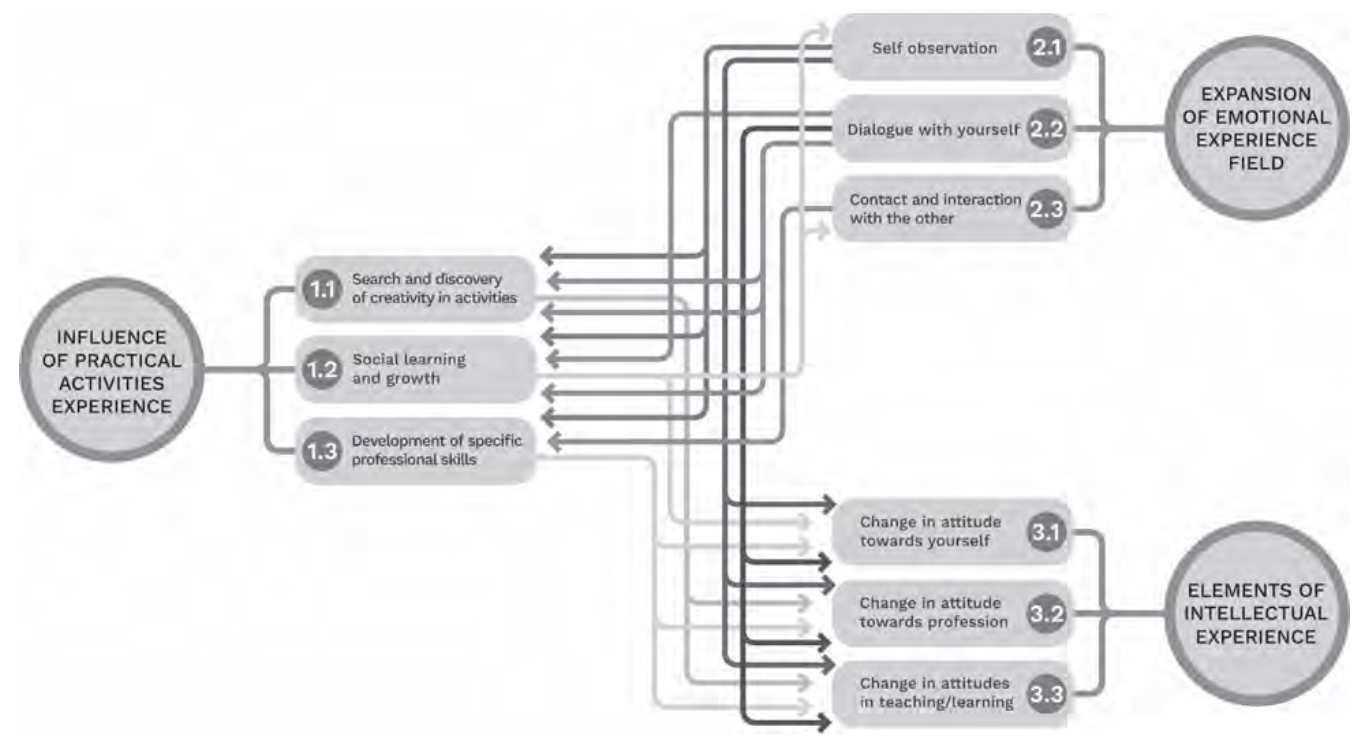


The main themes presented in the article also showed the interfaces and process flow. It is important to note that recorded and described activities during the internship raised awareness of ongoing processes. During the study, an individual's attitudes affected performance and learning. Situations containing rapid changes stimulate the student participants' emotions, which importantly links the learners' emotions to their learning experiences. As emotions fade with time and with the supervising mentors' supporting guidance, student participants' self-reported changes occur in both attitude and practice.

"In the first part of the internship, the observation was holistic. I observed and recorded everything that caused thoughts or questions. Now the observation does not feel like an acquired structure. I did not plan this deliberately, but I noticed the records improved organizationally" (Lina).

The review of results is an important stage in the development of an e-diary. Reflection and discussion with a mentor provided the opportunity to interact with others about one's experience and allow an educator to develop the knowledge and professional skills applicable to their profession. It shows that activity develops specific professional skills, and learners improve their communication skills.

"I am very happy with my mentor, thanks to whom I gained more self-confidence; I got acquainted with teaching methods she uses in lessons; I was able to learn new techniques of artistic expression; I was able to communicate and collaborate amicably. My mentor was always finding time with me to reflect on the subject. She has always been a kind, warm, and creative person" (Gintare).

During the research, e-diary's data was analysed and observed by study participants while describing problematic situations. They move to the reflexive assessment level independently, and this taught the young educators to develop a self-reflection algorithm and not repeat the same mistakes in the future. Knowledge gained during the internship also leads to personal growth, professional development, and the adoption of teaching/learning paradigms.

"The success, in my opinion, is that each week I was improving more and more during the internship. I started to notice my own mistakes and what I was seeking to change and improve, and I concluded each lesson with new demands made on myself. (Monika).

The e-diary questionnaire also aims to social learning and growing. It is achieved by observing and interpreting new experiences. Thus, its benefits alter the understanding of attitudes toward learning and professional change. Reading and analysing an e-diary showed that interns' physical, emotional, social, and intellectual environment was important.

"The most important thing in learning is to use existing knowledge, to formulate problems correctly, to organise one's own and students' work, to understand the goals and perspectives of one's work. What is more important for students is to assess their progress in educational activities." (Jurate).

Analysis of the situations presented in the documents showed that it was not always possible to move to the level of self-reflection. It required extensive guidance through the mentors' remarks to help trainee teachers respond and reflect on their observed and e-diary logged situations. The form created by the e-diary provides a quick response to the situation or problem that arises; the tool helps the student participant to gain a sense of discussion and constant support. Discussions in the e-diary platform aim not to provide an answer but to encourage the search for alternative solutions. For example, it has been suggested to observe other teachers' activities in the same problematic classrooms to exchange practices and consult one another. It has been demonstrated that discussion and peer collaboration construct new knowledge and experience, leading to personal development, professional growth, and pedagogical image building.

"I would like to ask what to do, for example, if a student misbehaves during a lesson, speaks out, does not do tasks, etc., and when you tell him or her, that after the lesson he or she will go to the principal to write an explanation, but he or she stubbornly says he or she will not go. What should teachers do in this case?" (Edita)

Using an e-diary as a tool helped the student participants capture emotions, insights, and experience elements during their internship. It prevents the loss of important details and enabled a deeper discussion and analysis of existing complex experiences and emotions. It is important to emphasise that both positive and negative emotions promote change in teachers practice work and intellectual change in attitudes. It inspires a mundane change in oneself as a personality and a professional activity that becomes more creative, planned, and analysed based on the didactic aspect.

\section{Discussion}

The e-diary becomes an important learning platform to capture real-life pictures of specific moments or individual and personalised descriptions of the daily routine. For consistency and completeness, it is essential to log both specific situations and to describe daily experience daily, so important emotional considerations are noted. Moreover, e-diary allows organic data to be collected by 
taking note of instant information. Based on this experience, we can conclude that an electronic diary is a good tool for retrieving pedagogical curriculum data and situations. Another advantage of e-diary documentation is that it allows submitting both texts for analysis and photos and visual samples. It can be assumed that the e-diary, as an independent tool, can also become a methodological tool and a special technique for researching and capturing educational processes in a specific research field.

\section{Conclusion}

1. The experiential learning model was implemented by creating a system of measures for newly qualified teachers, aiming to systematically record, reflectively, observe and analyse specific situation during internship activities. This system of measures comprises an e-diary form, support-consulting system and online half standardised form of e-diary analysis. This system's relevance has become especially evident when qualifying face new, unusual internship activity situations and when the existing experience is insufficient, nor is there enough knowledge to deal with them.

2. E-diary, as the system of learning tools, has presents opportunities to systematically cover all experiential learning stages: observation and identification of the experienced situation; reflective assessment of the activity and the change in internship activity. Identification of problematic situation often contributed to finding solutions for them. The analysis of the situations recorded in the e-diary has made it possible to identify event development tendencies and forecast the practitioner's behaviour changes. Reacting to the experiences recorded in the e-diary, the future teacher encourages reflecting, searching for alternative solutions and foreseeing possibilities of changes in a specific professional activity, which leads to growth as a professional.

\section{References}

Bartlett, R. \& Milligan, Ch. (2015). What is Diary Method? London: Bloomsbury Academic.

Bertran, I. (1995). Contemporary Theories and Practice in Education. Madison: Atwood Publishing.

Binkley, E., E. \& Minor, A. J. (2020). Constructivist Pedagogy to Promote Cultural Learning in Counselor Education. Journal of Creativity in Mental Health, 1-12.

Braun, V., Clarke, V. \& Terry, G. (2014). Thematic analysis. In P. Rohleder \& A. Lyons (Eds.) Qualitative research in clinical and health psychology. Basingstoke: Palgrave MacMillan.

Clipaa, O., Ignata, A. \& Stansiub, M. (2012). Learning diary as a tool for metacognitive strategies Development. Published by Elsevier B.V. Selection and/or peer-review under responsibility of PSIWORLD2011, 905-909.

Desautel, D. (2009). Becoming a Thinking Thinker: Metacognition, Self-Reflection, and Classroom Practice. Teachers College Record, Vol. 111(8), 1997-2020.

Dewey, J. (1959). Art as Experience and Nature. New York: Capricorn. Dewey on education: selections. New York: Teachers College Press.

Dobos, A. (2014). Experiential learning for professional development in the civil service. Procedia-Social and Behavioral Sciences, Vol. 116, 5085-5090.

Howard, C. \& Brady, M. (2015) Teaching social research methods after the critical turn: challenges and benefits of a constructivist pedagogy, International Journal of Social Research Methodology, Vol.18(5), 511-525.

Jyi-Yeon, Y. (2008). The Use of Diaries as a Qualitative Research Method to Investigate Teachers` Perception and Use of Rating Schemes. Journal of Pan-Pacific Association of Applied Linguistics, Vol. 12(1), 1-10.

Kavaliauskienė G., Mažeikienė V., \& Valūnaitė-Oleškevičienė G. (2010). Role of native language in learning English. Filologija. Edukologija, Vol. 18 (2).

Kolb, D., A. (1984) Experiential Learning. Experience as the Source of Learning and Development. New Jersey: Prentice-Hall.

Kozulin, A. \& Rand, Y. (Ed.) (2000). Experience of Mediated Learning. An Impact of Feuerstein's Theory in Education and Psychology. Amsterdam: Pergamon.

McLeod, S. A. (2017). Kolb - learning styles and experiential learning cycle. Simply Psychology. https://www.simplypsychology.org/learning-kolb.html.

Rutkauskienè, D., Lenkavičius, A., Targamadzè, A., Volunevičienè, A, Pociūtè, E., Dėmenienè, A. \& Kelmenienè, V. (2007). Nuotolinio mokymosi dėstytojo vadovas. Mokomoji knyga. Kaunas: Technologija.

Schitz, B., Klug, J. \& Schmidt, M. (2011). Assessing Self-Regulated Learning Using Diary Measures with University Students Handbook of Self-Regulation of Learning and Performance. New York and London: Routledge, $251-259$.

Žydžiūnaitė, V. \& Sabaliauskas, S. (2017). Kokybiniai tyrimai: principai ir metodai. Vilnius: Vaga, 207-228. 


\title{
A STUDY ON USING GAME-BASED METHOD TO IMPROVE LEARNING EFFICIENCY OF JUNIOR SECONDARY SCHOOL STUDENTS
}

\author{
Timothy T.K. Wong ${ }^{1}$, \& Yee Wan Kwan ${ }^{2}$ \\ ${ }^{1}$ Hong Kong University Graduate Association College (Hong Kong SAR) \\ ${ }^{2}$ University of St. Joseph (Macau SAR)
}

\begin{abstract}
Game-based approaches aim at improving participants' engagement and satisfaction, they might have great advantages in solving the issues of students demotivated and uninvolved in learning activities. However, there are few studies on using games elements in education and examining to what extent game-based educational approaches enhance learning. To bridge this research gap, the objective of this study is to examine whether game-based method improves students' academic performance in the school subject Life and Society.

A total of four classes of Grade Seven students and two teachers participated in the study in Hong Kong. Three classes $(n=75)$ were assigned to the experimental groups and one class $(n=30)$ were assigned to the control group. The experimental group participated in class sessions where they learned the timeline, major events, and factors affecting economic development of Hong Kong by a group-based card game, while the control group were taught by lecture-based method. Using a pre- \& post-tests design, data were collected by a tailor-made survey including 9 fact-based questions to assess the learning outcomes. The contents of the survey were judged two experienced teachers and one panel head.

Paired samples t-tests and two-way ANOVA were used to compare the possible changes, group differences and interaction effects. Results showed that both the experimental group and control group significantly increased their academic performance in the post-tests, indeed the average post-test scores of experimental groups were higher than that of the control group. Only one among three classes in the experimental group showed a significant increase in post-test scores, indicating a possibility of teacher difference. Boys in the experimental groups significantly improved in the post-test while girls did not differ significantly from pre-test scores. Both students with low and middle ability levels improved significantly in their post-test scores, while students with high ability level did not reach statistical significance. The interaction effect between gender and student ability level was statistically significant, indicating that the influence of student ability level on pre-test scores depended on their gender. Finally recommendations, implications, and limitations to the study are discussed.
\end{abstract}

Keywords: Game-based approaches, card game method, academic performance, junior secondary students.

\section{Introduction}

Recently, game-based approaches are suggested helpful in improving students' cognitive engagement and satisfaction, solving issues of demotivated and uninvolved in learning activities (Surendeleg, Murwa, Yun, \& Kim, 2014). As a matter of fact, a related term "gamification" appeared in digital media industry starting from early 2000 which advertisers in marketing used it to attract consumers (Plass, Homer, \& Kinzer, 2015; Jett, 2020). The success of gamification in the marketplace has drawn educators' attention to transfer this strategy into learning and classroom context (Surendeleg, et al., 2014).

In Hong Kong, frontline teachers make use of game-based learning to enhance students' learning engagement and effectiveness. In 2018/19, two awardees were awarded the Chief Executive's Award for Teaching Excellence. They transformed daily lesson tasks in Life and Society and Chinese History to board and card games, and it successfully grasped students' attention and fostered student-student interaction and self-directed learning when compared to traditional lessons (Education Bureau, 2018).

However, there is little local empirical research on whether game-based learning could improve students' learning effectiveness, such as any gains in academic assessment tasks which aligned with the learning contents in textbook. This action research would fill in this research gap by implementing a timeline card game in the seventh grade of a school in Hong Kong. 


\section{Study objectives \& significance}

As reported earlier, there are few studies on using games elements in classroom and examining to what extent game-based educational approaches enhance school subject learning. To bridge this research gap, the objective of this study is to examine whether game-based method improves students' academic performance in the school subject Life and Society. With this in mind, the current study was conceptualized with the aim of investigating:

1. What are the effects of game-based approach in Life and Society on academic performance?

2. Are the effects of game-based approach on academic performance in Life and Society different in students' gender and academic ability?

\section{Literature review}

\subsection{Game-based approaches in education}

The concepts of gamification and game-based learning share similar features and have been used interchangeably (e.g., Jett, 2020; Nah, Zeng, Telaprolu, Ayyappa, \& Eschenbrenner, 2014). The former emphasizes the use of actual games to facilitate learning, they are in digital mode usually, but it's not a must. While the latter highlights the process of applying game elements to the design of instruction (Alsawaier, 2018; Jett, 2020). In this case, teachers in game-based learning might re-design the activities, using artificial conflict and rules of play, to make activities more interesting and attractive (Plass et al., 2015). In this paper, game-based learning is used as a broad concept, including the use of actual games and game elements to address specific learning objectives.

Game-based approaches could be used in any of these three directions: using serious games (games designed with a purpose), repurposing commercial games in educational contexts, and having students create their own games (van Eck, 2006). Plass et al. (2015) summarized four functions of these approaches: 1) Preparation for later learning activities, 2) Teach new knowledge and skills, 3) Practice and reinforce existing knowledge and skills, and 4) Develop 21 st-century skills. Teachers could select these functions with reference to their learning goals of the lesson.

\subsection{Game-based teaching and students' performance}

After a systematic literature review on studies of game-based learning from 2003 to 2013, Jabbar and Felicia (2015) concluded that there is insufficient empirical evidence on the relationship between game design and learning outcomes. They reported that more than half of the studies were in primary education, only around $15 \%$ of them were on secondary education. Besides, current empirical findings on the impacts of game-based learning on students' motivation and academic performance are inconsistent.

First, the impacts of game-based learning on students' intrinsic motivation were mixed (Dichev \& Dicheva, 2017; Jett, 2020). The elements of social aspects such as competition and collaborations positively affected intrinsic motivation (e.g., Surendeleg, et al., 2014). However, Dichev \& Dicheva (2017) reviewed that factors like students' negative perceptions of competition, some game elements undermining feeling of competence, and short duration of the approach negatively influenced intrinsic motivation, in particular for students with low ability. In Christy and Fox (2015)'s study, they found that female participants performed negatively because of stereotype and social comparison. These indicate game design and student individual differences might affect the impacts on motivation.

Similarly, the impacts on academic performance are inconclusive also. Some studies (e.g., Hwang, Wu, Huang, \& Huang, 2012; Tan, Goh, Ang, \& Huan, 2013) found that game-based learning is effective in students' knowledge acquisition because of the opportunities of repeated practice. A meta-analysis study by Sailer and Homner (2020) reported that cognitive learning outcomes gain across various studies. However, these positive impacts were not found across all types of cognitive assessment tasks (Jett, 2020). For example, it found that high school chemistry students enjoyed the game, but their final exam scores did not significantly improve (Hanus \& Focx, 2015).

In sum, the impacts of game-based learning on motivation and academic performance were mixed, and most of these studies targeted at games in digital mode. They also showed that students' characteristics make a difference on the outcomes. These uncertain findings urged more empirical studies, particularly on secondary students should be conducted to inform the uses of games in classroom setting. Thus, this study would focus on the impacts of a card game on the academic performance of junior secondary school students.

\section{Study design \& methods}

\subsection{Context}

The study participants comprised of seventh grade students (or Secondary 1 students in Hong Kong context) studying Life and Society (L\&S). The school is a Direct Subsidy School (DSS) in Hong 
Kong, which allows ample opportunities and flexibilities in curriculum development and resource allocation. The seventh grade consists of six classes. Two L\&S teachers oversee the curriculum implementation, each takes up three classes. The author, a third-year teacher, takes up the high, middle and low achiever classes. He is also the seventh grade L\&S form coordinator who provides support and collaborative lesson planning with a first-year L\&S colleague who also oversees another batch of high, middle and low achiever class.

Life and Society (L\&S) is one of the strands under the Personal, Social and Humanities Education (PSHE) Key Learning Area in Hong Kong secondary schools. The curriculum covers the understanding of oneself and ways to facilitate one's interpersonal relationships and cultivates students' sensitivity in local, national and global issues (Curriculum Development Council, 2010).

\subsection{Game design and implementation of the study}

The subject topic chosen for this study is about Hong Kong economy. Prior the study, students across the whole form were assigned to design the game in October, and the best game sets in terms of content knowledge and aesthetic design were selected and used for this current study in November.

The game aimed to enable students to understand different major events that affect the economy of Hong Kong and to identify Hong Kong is an externally oriented economy. It is a card game based on the timeline game consisting of 20 cards, consisting four to five players. This game was being carried out in understanding the economic performance of Hong Kong. Students had the prior knowledge of the indicators measuring economic performance of an economy previously. When the game was about to hold, the teacher did a warm-up in hinting students the said game objectives and recalled the past economic transformation of Hong Kong (i.e., Hong Kong has transformed itself from primary industry to tertiary industry). Students were also instructed to recall the indicators measuring economic performance.

\subsection{Method, participants, and analysis}

Using a pre- \& post-tests design, a total of four classes of Grade Seven students and two teachers participated in the study. The experimental group participated in class sessions where they learned the timeline, major events, and factors affecting economy development of Hong Kong by a group-based card game, while the control group were taught by lecture-based method.

The academic performance was measured by a tailor-made survey including 9 fact-based questions relating different major events of Hong Kong that affect its economy and factors affecting the city's economic performance, which are in line with the game and lesson objectives. The range of the possible scores is from 0 to 20 . The contents of the survey were judged by three experts consisting of two experienced teachers and one panel head. Students finished the online pre-test and post-test survey consisting the same set of questions at the beginning and the end of the card game respectively. The study planning and implementation are also supervised by the Head of Department, who oversees Life and Society in seventh to ninth grade and Liberal Studies in tenth and twelfth grade respectively.

\section{Study results}

\subsection{Effects of card game on academic performance}

Table 1 presented descriptive statistics for mean academic performance scores at pre- and post-tests for experimental $(n=75)$ and control groups $(n=30)$ using paired samples t-tests. Results showed that both the experimental group and control group significantly increased their academic performance in the post-test, indeed the average post-test scores of experimental groups $(\mathrm{M}=14.21)$ were higher than that of the control group ( $M=14.03)$. Only one (Experimental group 3: $M=16.70)$ among three classes in the experimental groups showed a significant increase in post-test scores, indicating a possibility of teacher difference. Both the control group and experimental group 3 were taught by the same teacher while other two experimental groups were taught by another teacher.

Table 1. Paired Samples t-tests comparing pre-post test scores on academic performance.

\begin{tabular}{|c|c|c|c|c|}
\hline \multicolumn{1}{|c|}{ Group } & Pretest: Mean (SD) & Posttest: Mean (SD) & $t$ value & $p$ value \\
\hline Control group (N=30) & $13.03(3.46)$ & $14.03(3.41)$ & -2.76 & 0.00 \\
\hline Experimental groups (N=75) & $13.17(3.44)$ & $14.21(3.79)$ & -3.48 & 0.01 \\
\hline Experimental group 1 (n=30) & $10.53(2.73)$ & $11.13(3.69)$ & 1.52 & 0.14 \\
\hline Experimental group 2 $(\mathrm{n}=25)$ & $15.60(2.68)$ & $15.92(2.18)$ & -0.74 & 0.47 \\
\hline Experimental group 3 $(\mathrm{n}=20)$ & $14.10(2.51)$ & $16.70(1.95)$ & -3.77 & 0.00 \\
\hline
\end{tabular}




\subsection{Effects of game-based approach on academic gains students by gender and academic ability}

As indicated in tables 2 and 3, paired-samples t-tests were conducted to evaluate the impacts of gender and academic ability levels on academic gains. Boys $(\mathrm{M}=15.15, \mathrm{SD}=3.00)$ in the experimental groups significantly improved in the post-test while girls $(\mathrm{M}=13.44, \mathrm{SD}=4.21)$ did not differ significantly from pre-test scores.

Students were divided into three academic ability / knowledge levels according to their pre-test scores (Low: 11 scores or below; Middle: $>11-16$ scores; High: $>16$ scores). Both students with low $(\mathrm{M}=10.63, \mathrm{SD}=4.00)$ and middle $(\mathrm{M}=15.04, \mathrm{SD}=2.32)$ ability levels improved significantly in their post-test scores, while students with high ability level $(\mathrm{M}=16.96, \mathrm{SD}=1.49)$ did not.

Table 2. Paired Samples t-tests comparing pre-post test scores of the experimental groups on academic performance by gender as conducted to evaluate the impact.

\begin{tabular}{|l|c|c|c|c|}
\hline \multicolumn{1}{|c|}{ Experimental Group } & Pretest: Mean (SD) & Posttest: Mean (SD) & $t$ value & $p$ value \\
\hline Boys (N=30) & $13.61(3.19)$ & $15.15(3.00)$ & -3.07 & 0.00 \\
\hline Girls (N=41) & $12.80(3.65)$ & $13.44(4.21)$ & -1.81 & 0.08 \\
\hline
\end{tabular}

Table 3. Paired Samples t-tests comparing pre-post test scores of the experimental groups on academic performance by student ability level.

\begin{tabular}{|l|c|c|c|c|}
\hline \multicolumn{1}{|c|}{ Experimental Group } & Pretest: Mean (SD) & Posttest: Mean (SD) & $t$ value & $p$ value \\
\hline Low $(\mathrm{n}=24)$ & $9.13(1.41)$ & $10.63(4.00)$ & -2.26 & 0.03 \\
\hline Middle $(\mathrm{n}=28)$ & $13.39(1.23)$ & $15.04(2.32)$ & -3.42 & 0.00 \\
\hline High $(\mathrm{n}=23)$ & $17.13(1.32)$ & $16.96(1.49)$ & 0.75 & 0.46 \\
\hline
\end{tabular}

To further explore the impact of gender and student ability level on their academic gains, a two-way ANOVA was conducted. There was a statistically significant main effect for ability level, $F(2,69)=26.63, p=0.00$. The main effect for gender, $F(1,69)=3.53, p=0.06$, did not reach statistical significance. The interaction effect between gender and student ability level was statistically significant, $F(2,69)=4.82, p=0.01$. The results indicated that the influence of student ability level on pre-test scores interacted with their gender.

\section{Discussion, implications and conclusion}

The major findings showed that both the experimental group and control group significantly increased their academic performance in the post-tests. Among the three experimental groups, only one showed a significant increase in post-test scores. Boys and students with low and middle ability/knowledge levels significantly gained in academic performance using this game-based method.

The game-based approach had positive impacts on students' academic gains. These findings are consistent with some studies (e.g., Jett, 2020; Yildirim, 2017), indicating this approach could increase students' knowledge acquisition. As a matter of fact, games could give students repeated opportunity to practice skills and apply knowledge, helping them transfer their learning in later situations such as homework and assessment tasks (Plass et al., 2015).

The impacts of game-based learning on students were varied, such as difference in gender and existing knowledge level. The challenges and conflicts in game-based learning environment can be enjoyable and motivating on one hand, on the other hand might generate frustration in some cases. Students' engagement was found depending on the availability of clear goals, unambiguous feedback, and a good fit with students' knowledge levels and skills (Hwang, Wu, Huang, \& Huang, 2012; Tan, Goh, Ang, \& Huan, 2013). In addition, boys performed better than girls in this study might because girls likely prefer a well-structured and systematic summary of learning objectives and modules. Learning through sorting a series of cards might not fit their learning preference. This gender difference is also raised by Christy and Fox (2015). These individual differences might explain the impacts of game-based learning are mixed among students with different characteristics and readiness.

A number of possible factors affects the impacts of game-based learning. The findings of this study also indicated a possibility of teacher difference on students' learning outcomes. Indeed, scaffolding in terms of feedback and support from teachers and game mates is important to maintain the enjoyment and progress throughout the game (Jabbar \& Felicia, 2015). Like other teaching approaches, timely feedback, feedback on progression toward goals and feedback on the state of the game from teachers are essential to achieve educational objectives (Killi, 2005). These feedbacks might carry out differently among teachers and in turn affect students' learning outcomes. Teachers need to respond to the players' in-game actions to provide guidance and feedback appropriately (Plass, et al., 2015). 
The current study provided empirical data on the impacts of game-based approach on students' academic gains in Hong Kong secondary school students in particular. Findings in this study indicated that students' characteristics and readiness contribute to their gains in game-based learning environment, informing the possible factors affecting the implementation of game-based approach. As this study focused on Grade 7 (Secondary 1) students who learnt the contents in a card game, further research is recommended to focus on students with other characteristics, examine the impacts of various game designs on academic gains and motivation. Besides, to understand the experiences of game-based approach on learning in depth, qualitative feedback from students could be included in future studies.

In conclusion, the present study has contributed to the literature by exploring the impacts of game-based approach on secondary school students' academic gains in a school subject by providing empirical evidence, which filled research gaps in previous research. Positive impacts of game-based approach on academic performance were observed, and it was different by students' gender and existing ability or knowledge level. These results can inform those teachers who are interested in using game-based approach in engaging learning process and improving learning outcomes in classroom settings.

\section{References}

Alsawaier, R. S. (2018). The effect of gamification on motivation and engagement. International Journal of Information and Learning Technology, 35(1), 56-79.

Christy, K. R., \& Fox, J. (2014). Leaderboards in a virtual classroom: A test of stereotype threat and social comparison explanations for women's math performance. Computers \& Education, 78, 66-77.

Curriculum Development Council. (2010). Life and Society Curriculum Guide (Secondary 1-3) [Program of studies]. https://www.edb.gov.hk/attachment/en/curriculum-development/kla/pshe/l\&s_ curriculum guide eng.pdf

Dichev, C., \& Dicheva, D. (2017). Gamifying education: What is known, what is believed and what remains uncertain: A critical review. International Journal of Educational Technology in Higher Education, 14(1), 1-36.

Education Bureau. (2018). Personal, Social and Humanities Education Key Learning Area: Teaching practices presented with the Award. Retrieved April 2, 2021, from https://www.ate.gov.hk/tchinese/doc/CEATE1819_Compendium_list_teaching_practices_award_P SHE.pdf

Hanus, M. D., \& Fox, J. (2015). Assessing the effects of gamification in the classroom: A longitudinal study on intrinsic motivation, social comparison, satisfaction, effort, and academic performance. Computers \& Education, 80, 152-161.

Hwang, J.-P., Wu, T.-T., Huang, Y.-M., \& Huang, Y.-M. (2012). Development and evaluation of peer feedback in the English quiz game design in social network. Paper presented at the proceedings of the 12th IEEE International Conference on Advanced Learning Technologies.

Jabbar, A. I. A. \& Felicia, P. (2015). Gameplay engagement and learning in game-based learning: A systematic review. Review of Educational Research, 85(4), 740-779.

Jett, M.B. (2020). Leveling up instruction: Action research evaluating the impact of gamification on the intrinsic motivation and academic performance of students disaffected from high school English language arts. Doctoral thesis, University of South Carolina, U.S.

Killi, K. (2005). Digital game-based learning: Towards an experiential gaming model. Internet and Higher Education, 8, 13-24.

Nah, F. F.-H., Zeng, Q., Telaprolu, V. R., Ayyappa, A. P., \& Eschenbrenner, B. (2014). Gamification of education: A review of literature. In F. F.-H. Nah (Ed.), HCI in Business (pp. 401-409). Springer International Publishing.

Plass, J.L., Homer, B.D., \& Kinzer, C.K. (2015). Foundations of game-based learning. Educational Psychologist, 50(4), 258-283.

Sailer, M., \& Homner, L. (2020). The gamification of learning: A meta-analysis. Educational Psychology Review, 32(1), 77-112.

Surendeleg, G., Murwa, V., Yun, H.K., \& Kim, Y.S. (2014). The role of gamification in education - a literature review. Contemporary Engineering Sciences, 7, 1609-1616.

Tan, L. J., Goh, H.-L. D., Ang, P. R., \& Huan, S. V. (2013). Participatory evaluation of an educational game for social skills acquisition. Computers \& Education, 64, 70-80.

van Eck, R. (2006, March/April). Digital game-based learning: It's not just the digital natives who are restless. EDUCAUSE Review, 41(2), 16-30.

Yildirim, I. (2017). The effects of gamification-based teaching practices on student achievement and students' attitudes towards lessons. The Internet and Higher Education, 33, 86-92. 


\title{
EXPLORING SOUTH AFRICAN PRESERVICE TEACHERS' CONCEPTUAL UNDERSTANDING OF LIGHT PHENOMENA
}

\author{
Sam Ramaila \\ Department of Science and Technology Education, University of Johannesburg (South Africa)
}

\begin{abstract}
The wave and particle nature of light poses considerable instructional challenges to both teachers and learners in diverse educational settings. Developing a meaningful conceptual understanding of the wave and particle nature of light is a key requirement for demystifying the complex nature of various optical phenomena. The study adopted an exploratory descriptive survey design and involved purposively selected South African preservice Physical Sciences as participants. Preservice Physical Sciences teachers' conceptual understanding of light phenomena was explored through the administration of the Light Phenomena Conceptual Assessment (LPCA) inventory. The key findings of the study revealed that preservice Physical Sciences teachers exhibited conceptual hurdles in relation to light phenomena such as reflection, refraction, total internal reflection and light scattering. The prevalence of these conceptual hurdles can partly be attributed to pervasive knowledge gaps manifested as a result of deficient instructional strategies adopted to demystify complex nature of light phenomena. Theoretical implications for initial teacher education are discussed.
\end{abstract}

Keywords: Teacher education, light phenomena, instructional strategies.

\section{Introduction}

Development of meaningful conceptual understanding is a key requirement for adequate remediation of prevailing misconceptions associated with complex scientific phenomena. The wave and particle nature of light poses considerable instructional challenges to both teachers and learners in diverse instructional settings. Research has demonstrated that students may know about theories of light but still fail to interpret the interference that results from the wave nature of light (Sengoren, 2010). The navigation of these instructional challenges requires teachers to adopt nuanced and innovative pedagogic approaches to demystify the complex nature of light phenomena. Commensurate with this key strategic imperative, this study explored South African preservice Physical Sciences teachers' conceptual understanding of light phenomena with a view to glean insight into the nature of their baseline knowledge of various optical phenomena.

\section{Methodology}

South African preservice Physical Sciences teachers' conceptual understanding of light phenomena was explored through the administration of the Light Phenomena Conceptual Assessment (LPCA) inventory developed by Ndihokubwayo, Uwamahoro, Ndayambaje and Ralph (2020) as part of a survey. The empirical investigation involved 50 purposively selected $4^{\text {th }}$ year Bachelor of Education preservice Physical Sciences teachers. The cohort had already completed a physics module when the LPCA inventory was administered. In addition, the participants had been afforded opportunities to perform work integrated learning at schools during the preceding years of their professional training.

\section{Results}

Table 1 below provides participants' responses to the various items of the LPCA inventory. 
Table 1. Participants' responses to the various items of the LPCA inventory.

\begin{tabular}{|c|c|c|c|c|}
\hline & $\mathrm{A}(\%)$ & B (\%) & $\mathrm{C}(\%)$ & $\mathrm{D}(\%)$ \\
\hline 1 & & & 79 & 21 \\
\hline 2 & 5 & 69 & 26 & \\
\hline 3 & 11 & 42 & 32 & 15 \\
\hline 4 & 26 & 58 & 16 & \\
\hline 5 & 5 & 79 & 11 & 5 \\
\hline 6 & 11 & 32 & 37 & 21 \\
\hline 7 & 26 & 37 & 16 & 21 \\
\hline 8 & 37 & 26 & 21 & 11 \\
\hline 9 & 37 & 32 & 21 & 11 \\
\hline 10 & 21 & 42 & 26 & 11 \\
\hline 11 & & 32 & 53 & 16 \\
\hline 12 & 11 & 26 & 47 & 11 \\
\hline 13 & 16 & 37 & 37 & 11 \\
\hline 14 & 16 & 26 & 37 & 21 \\
\hline 15 & 16 & 47 & 11 & 26 \\
\hline 16 & 42 & 21 & 11 & 26 \\
\hline 17 & 11 & 21 & 37 & 32 \\
\hline 18 & 21 & 32 & 16 & 32 \\
\hline 19 & 16 & 37 & 37 & 11 \\
\hline 20 & 26 & 26 & 21 & 26 \\
\hline 21 & 16 & 37 & 26 & 21 \\
\hline 22 & 32 & 42 & 5 & 16 \\
\hline 23 & 21 & 21 & 32 & 26 \\
\hline 24 & 21 & 21 & 16 & 32 \\
\hline 25 & 11 & 42 & 32 & 16 \\
\hline 26 & 21 & 21 & 26 & 32 \\
\hline 27 & 21 & 21 & 32 & 26 \\
\hline 28 & 32 & 16 & 32 & 21 \\
\hline 29 & 11 & 53 & 37 & \\
\hline 30 & 11 & 53 & 5 & 32 \\
\hline
\end{tabular}

Participants' distribution of responses to the questionnaire is depicted in Figure 1 below. The preservice teachers provided a variety of responses which painted a grim picture about their conceptual understanding and baseline knowledge of light phenomena. Optics is a vast conceptual area in physics and the need to foster meaningful conceptual understanding to promote preservice teachers' mastery experiences is paramount. This key imperative is also applicable to other concomitant conceptual areas in physics as a key knowledge domain.

Figure 1. Distribution of responses.

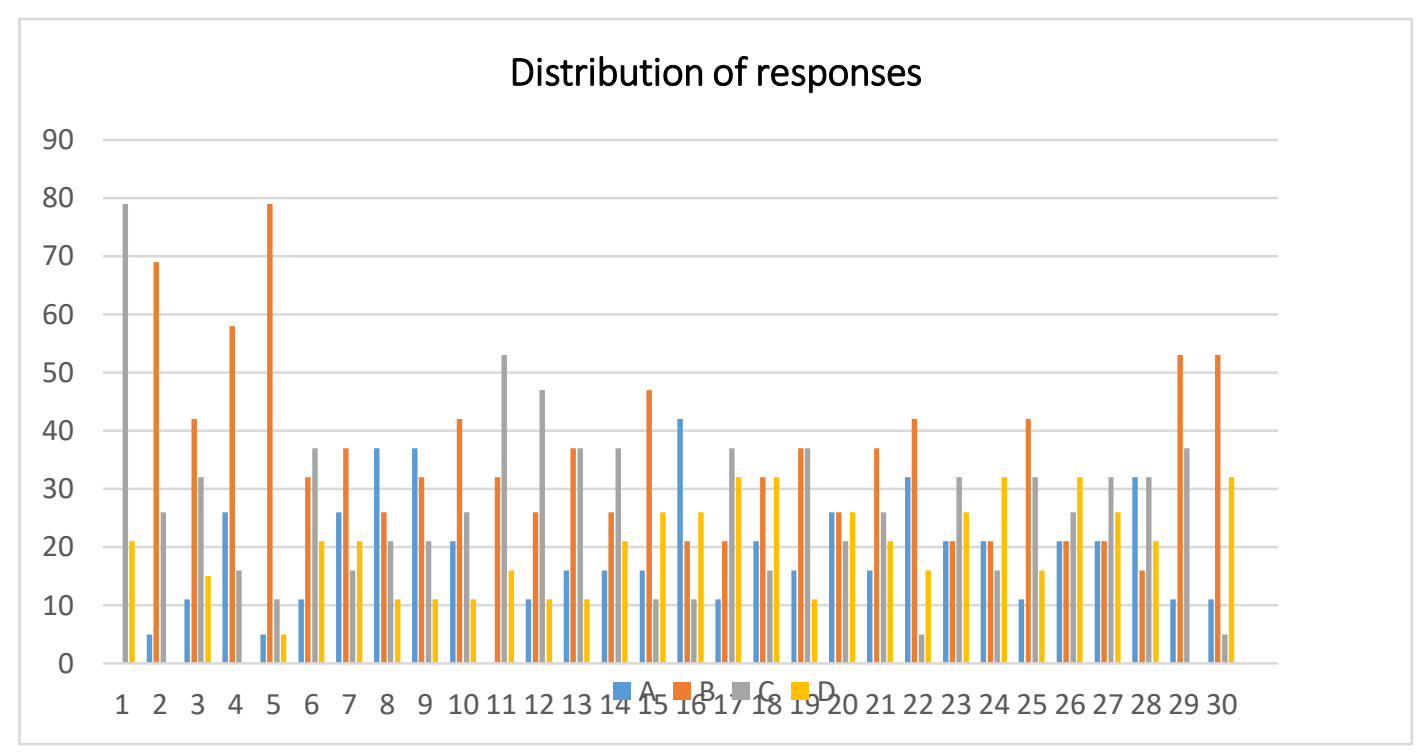


The participants' overall performance on each question is illustrated in Figure 2 below. Satisfactory overall performance was demonstrated in relation to items 1, 2, 5, 29 and 30. 79\% of the respondents provided the correct answer (C) for item 1 ("Why do we see things"). 69\% of the respondents provided the correct answer (B) for item 2 ("Why can we not see things in the dark of night"). 79\% of the respondents provided the correct answer (B) for item 5 ("Sunlight can be used to tell time. How would your image appear at 12:00 0' clock when standing outside the classroom on a hot day?"). The participants demonstrated dismal overall performance in other items pertaining to the LPCA inventory which evaluated conceptual understanding of light phenomena such as reflection, refraction, total internal reflection and light scattering.

Figure 2. Overall performance on each item of the LPCA inventory.

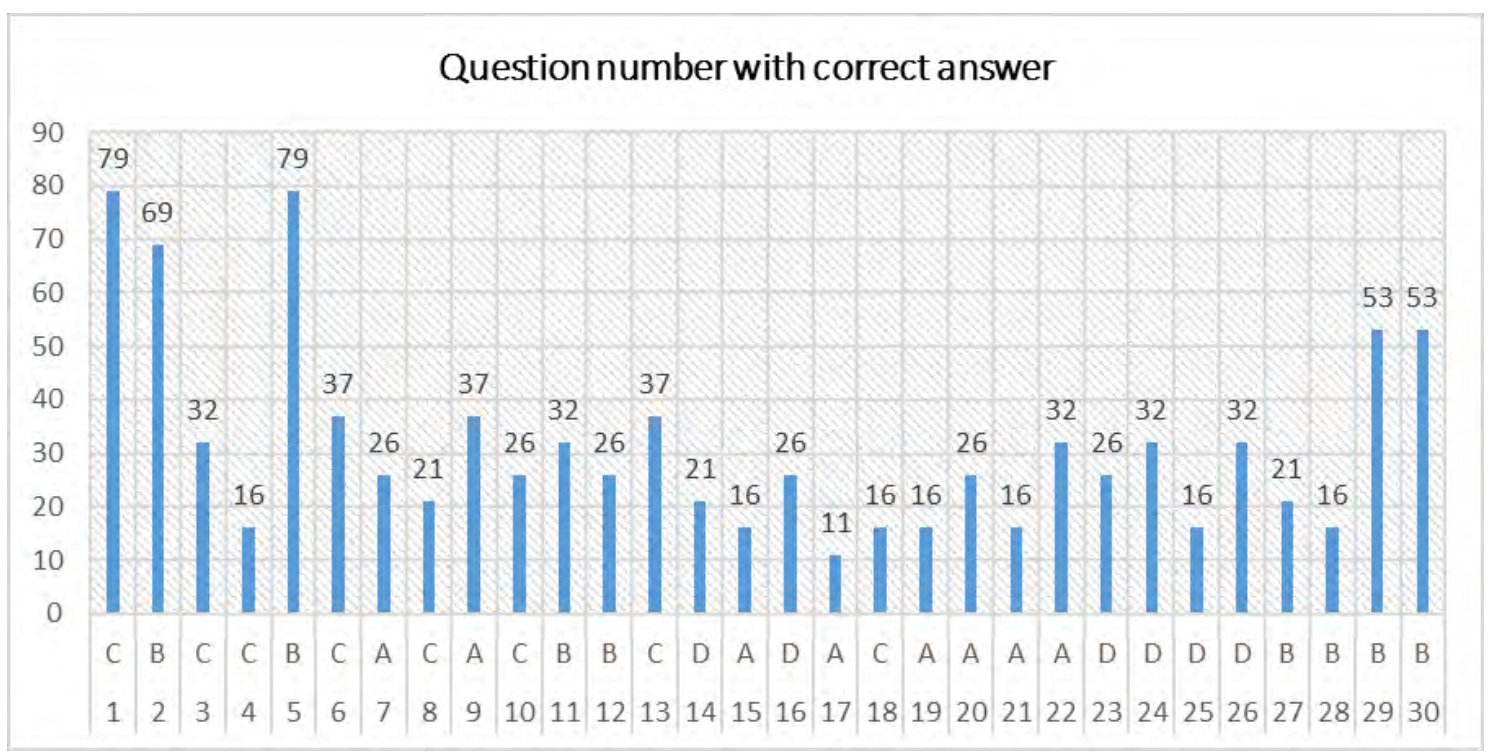

\section{Discussion}

Meaningful enhancement of human capital development requires teachers to be reflective practitioners with requisite innovative capacity and adequate pedagogical content knowledge. However, preservice teachers who participated in this empirical investigation demonstrated inadequate conceptual understanding of light phenomena. Inadequate conceptual understanding is underpinned by pervasive knowledge gaps which essentially serve to hamper teacher professional practice and meaningful enactment of innovative pedagogic approaches to demystify the complex nature of scientific phenomena. The key findings of the study revealed that preservice Physical Sciences teachers exhibited conceptual hurdles in relation to light phenomena such as reflection, refraction, total internal reflection and light scattering. The prevalence of these conceptual hurdles can partly be attributed to pervasive knowledge gaps manifested as a result of deficient instructional strategies adopted in an attempt to demystify the complex nature of light phenomena. It has been established that students tend to exhibit conceptual difficulties with virtual images even after instruction (Kaewkhong, Mazzolini \& Emarat, 2010). In addition, student misconceptions associated with plane mirrors, spherical mirrors and lenses are connected to the mode of instruction used by teachers (Kaltakci-Gurel, Eryilmaz \& Mcdermott, 2016). This study demonstrated that preservice teachers exhibited inadequate conceptual understanding of the wave and particle nature of light. In support of this notion, research has demonstrated that students find it increasingly difficult to draw a good model of the wave and particle nature of light (Özcan, 2015). There is a critical need to develop preservice teachers' conceptual understanding of complex scientific phenomena as part of their professional training with a view to enhance their professional competence and meaningful development of pedagogical content knowledge. This is certainly a significant step towards progressive realization of the improvement of the quality of science education in its broadest sense within the broader South African context. 


\section{Conclusion}

The development of preservice teachers' conceptual understanding of complex scientific phenomena is central to meaningful enhancement of their pedagogical content knowledge. Concerted efforts have to be made to ensure optimal provision of teacher professional training geared towards holistic development of teachers as reflective practitioners.

\section{References}

Kaewkhong, K., Mazzolini, A., \& Emarat, N. (2010). Thai high-school students' misconceptions about and models of light refraction through a planar surface. Physics Education, 45, 95-107.

Kaltakci-Gurel, D., Eryilmaz, A., \& Mcdermott, L. C. (2016). Identifying pre-service physics teachers' misconceptions and conceptual difficulties about geometrical optics. European Journal of Physics, 37,045705 .

Ndihokubwayo, K., Uwamahoro, J., Ndayambaje, I., \& Ralph, M. (2020). Light phenomena conceptual assessment: An inventory tool for teachers. Physics Education, 55, 035009.

Özcan, Ö. (2015). Investigating students' mental models about the nature of light in different contexts. European Journal of Physics, 36, 065042.

Sengoren, S.K. (2010). How do Turkish high school graduates use the wave theory of light to explain optics phenomena? Physics Education, 45, 253-256. 


\title{
HOW RELATIONSHIPS IMPACT SENSE OF BELONGING IN SCHOOLS AMONGST FEMALE ADOLESCENTS FROM REFUGEE BACKGROUNDS
}

\author{
Sonja Aicha Van Der Putten \\ Faculty of Education, Simon Fraser University (Canada)
}

\begin{abstract}
Education is believed to play an essential role in creating a sense of belonging amongst adolescents from refugee backgrounds. This narrative inquiry study set out to better understand the influence that relationships formed in one Canadian school community played in the development of a sense of belonging amongst female adolescent students from refugee backgrounds. Study participants were from Middle Eastern and East African origin and had been living in Canada for two-years or less. Data were collected over a five-month period through two sets of interviews, and a series of observations. Findings indicated the students from refugee backgrounds sense of belonging in school was strengthened by strong relationships with teachers from whom they perceived a genuine sense of support and care, which resulted in higher academic achievement. The study also conveyed that students felt that their Canadian-born peers largely ignored them in class, which resulted in increased feelings of social isolation and lack of belonging. The female student experience was further influenced by additional familial obligations and responsibilities.
\end{abstract}

Keywords: Refugees, education, belonging, females, students.

\section{Introduction}

Children and adolescents under the age of 18 years old make up over half of all individuals from refugee backgrounds worldwide (Children, n.d.). These children and adolescents have endured untold hardships, and the risk of abuse, neglect, violence, exploitation, trafficking or military recruitment, does not end upon resettlement (Children, n.d.). Host countries have a responsibility to consider the unique cognitive, social and emotional needs of developing children and adolescents being resettled in their communities, and one way to do so is through education (UNHCR, 2015). Education acts as a stabilizing force in the lives of children and adolescents from refugee backgrounds by protecting them from recruitment into armed groups, sexual exploitation and child marriage; by creating community resilience; by empowering them with the skills and knowledge necessary to live meaningful lives; and by enlightening them to learn about themselves and the world they live in (Education, n.d.).

This study set out to investigate the impact school communities play on adolescents from refugee backgrounds' sense of belonging. This research examined three fundamental questions. First, the study analyzed what it meant for female adolescent students from refugee backgrounds to experience a sense of belonging in their school (SOBIS). Second, it explored the impact of teacher and peer relationships on student sense of belonging; and third it sought to answer how the services available in one Canadian secondary school system influenced student sense of belonging.

Education plays an essential role in creating a sense of belonging and preserving hope amongst adolescents from refugee backgrounds (Hoot, 2011). To feel a sense of belonging in school (SOBIS) is to feel connected to a particular group, to feel accepted by peers, supported by teachers and to feel supported by the school community (2015). Students' sense of belonging is determined by their level of attachment to their school, their compliance with school rules and expectations, their involvement in academics and extracurricular activities, and their belief in the values of their school (Kia-Keating and Ellis, 2007). A strong sense of belonging is related to positive academic, behavioural and psychological outcomes, including improved self-efficacy, motivation and reduced social-emotional distress (Kia-Keating and Ellis, 2007).

This study conveyed that students from refugee backgrounds are not just an addition to the school, but rather are a part of the school community. Yet, to truly feel a sense of belonging within a school community, efforts should be made, both by the schools and communities, as well as by the newcomers 
themselves. Students from refugee backgrounds were genuinely happy to arrive at school, excited to commence their learning, or pick up where they left off in their academic studies. The study participants showed great determination and effort in their learning, and conveyed a strong sense of hope that their Canadian education could help improve the lives of themselves and their families. The stronger relationships they were able to develop with their teachers and peers, the greater sense of belonging they felt. However, barriers posed by language skills, poverty, mental health and gendered expectations, were a constant source of challenge in their lives.

\section{Method}

\subsection{Participants}

Study participants were chosen through a selective or purposive sampling process, which narrows down the participants to a select group of people who fit a particular profile (Connelly \& Clandinin, 1999). In consultation with the English Language Learner teachers, participants were selected who were female, from refugee backgrounds, have been in Canada two years or less and who maintained a working knowledge of the English language.

Females were chosen as focal participants in this study because female adolescents from refugee backgrounds often have different experiences both during conflict and post-conflict than their male counterparts. During times of conflict, female and male children and adolescents who are directly involved in the conflict (often through deliberate strategic targeting), have many different experiences, ranging from sexual violence, to economic exploitation, to forced recruitment as combatants (Women's Commission for Refugee Women and Children, 2000). The study uses narrative inquiry to focus specifically on female adolescents and to give voice to their unique experiences.

\subsection{Research design}

This study collected data from student participants and English language learner (ELL) teacher interviews, classroom and school community observations, and a field note journal. Students were interviewed to allow them the opportunity to explain their stories in their own voices. ELL teachers were interviewed to better understand the influence of the classroom community on the student participants' experiences of belonging. Interviews were semi-structured and were guided by a set of general questions related to the study's core sense of belonging questions (Merriam \& Tisdell, 2016).

Observations were conducted to better understand the influence of the school community on students' sense of belonging. Observations allowed the researcher to record first-hand accounts of participant experiences in their classrooms, in the wider school community (e.g. school performances and events), at relevant meetings, on the sports-field and at club gatherings. Observations also allowed the researcher to observe the students in a variety of school community settings. Field notes were recorded from these observations in a field note journal in which the researcher used description, quotations and comments to describe situations.

The study took place at a large inter-city Secondary school located in a sub-urban neighbourhood in a large metropolitan community in British Columbia, Canada. The student population intermixes with the reality of the high levels of poverty, criminal activity, and opioid usage in this neighbourhood daily.

The stories being shared throughout this narrative inquiry were those of changing identities and the discovery of the self, as the participants evolved and matured, as adolescents, as students, as young women and as new Canadians. The stories they share link together different parts of their lives, public and private, and connect their pasts to their futures, shaping a story about who they are (Connelly \& Clandinin, 1999, p. 5).

\subsection{Data analysis}

The data analysis for this study involved collected, coding (both open and axial), and organizing data into themes. From these themes, categories are then created which represented the data and formed an interpretation of them (Creswell, 2011, p. 179). Concepts were identified, labelled, and categories were created based on the similarities and differences, as well as patterns and structures, amongst concepts (Basit, 2003).

To begin the analysis, open coding was applied to the first set of interviews and observations. Once all the raw data had been collected from the first round of interviews, and observations, a second interview was held. Upon completion of the second phase of data collection the new quotes, comments, notes and stories were again coded, and applied to the categories that had emerged in the first round of data collection - where relevant. A new document with new categories based on the study's core questions was created, from which the process of axial coding commenced, and an attempt to relate the main codes to each other, and to the core questions being asked was made (Creswell, 2011, p.184). The first two rounds 
of data were used to sort into the core question categories. The data was then divided into naturally emerging thematically based categories, core question categories and outliers, which were data that did not seem to fit in any category. Finally, codes, categories and core questions, were sorted and compared, to look for themes and patterns, a third time, in an attempt to make better sense of them.

Throughout the narrative inquiry process, the researcher employed reflection and reflexivity as important elements of the process which help to keep in check bias perspectives and assumptions (Marshall \& Reason, 2008). Guarding against personal bias was further reinforced by the development of categories that were supported by multiple pieces of data that shared similar themes, and were not just bits and pieces of information. Furthermore, participants were frequently consulted with that their voices were being expressed accurately and that the analysis and theories that emerged were consistent with their views and experiences. Participants were asked to read over their interviews, and to expand upon certain situations that had arisen during the observation periods, both in and around the school community.

\subsection{The impact of positive relationships on sense of belonging in school (SOBIS)}

Students from refugee backgrounds SOBIS was strengthened by strong and positive relationships with teachers from whom they perceived a genuine sense of support and care (Demanet \& Van Houtte, 2012; Hattie \& Anderman, 2013; Hoot, 2011; Wentzel, 1998). Study participants explained that teachers who asked them about their day, inquired if they looked unwell or simply greeted them upon arriving to class, were "nicer" than other teachers. "Nicer" teachers were perceived as being easier to talk to, kinder and more accepting. The study found that in classrooms where the students perceived their teacher as being kind and helpful, the study participants were better able to self-advocate and seek out help when they needed it in their learning. Their sense of belonging was developed as being part of a learning community, in which questions were encouraged and mistakes inevitable, as opposed to being the one isolated student who did not understand the lesson. These students did better academically in supportive teachers' classes. Unfortunately, the study participants identified on average only three teachers (of the eight-to-ten they may learn from in any given year), with whom they felt a supportive relationship. These teachers were generally the Learning Support or English Language Learner (ELL) teacher and one or two other specific teachers in the entire school, which the study participants identified as being supportive. ELL teacher Priya conveys the desire she has to get to know her students on an individual level, but the frustrations that emerge in simply trying to connect with students and their families.

Getting to know the students' backgrounds and knowing they're refugees, I wanted to know more about them...I often wish I could just pick up the phone and call [parents] but we always need multicultural workers and sometimes it takes weeks for them to get back to me...I wish we had a multicultural worker in the school who was always around...we need translators...before we can have a dialogue to get to the point of [even a simple] situation.

(Priya, Interview I, April 4, 2017)

In addition, adolescents' attitudes, choices of activities and emotional well-being are closely linked to that of their peer groups, and sense of belonging largely depends on the acceptance attained by peer groups (Brown \& Larson, 2009). The study participants from families that provided the most support and encouragement for them to explore their new communities, were more involved in the school and wider community, and generally had more friends and acquaintances outside the ELL classroom. Furthermore, their level of English was stronger than that of their newcomer peers, which can be attributed to more time spent with native English speakers through the clubs, teams, organizations and jobs in which they participated. The study also conveyed that students felt that their Canadian-born peers largely ignored them in class discussions, in group work and in the hallways. They believed this to be a related to their language abilities and the fact that their peers had difficulty understanding them. As a result, study participants were more reluctant to speak up in class and often withheld their opinions for fear of their peers whispering about them, even if only to clarify what they had to say.

\section{Conclusion}

In the secondary setting, sense of belonging is not so straightforward for newcomer or Canadian-born students alike either. Constantly shifting and changing senses of identity and self-concept amongst all adolescents, convey that many students in the secondary school settings, whether newcomer or Canadian-born, do not feel a strong connection to, or belonging in, their high school generally (Connelly \& Clandinin, 1999, p. 94). Adolescence poses developmental and social challenges regardless of background, ethnicity and personality. Future studies that compare the level of sense of belonging amongst Canadian-born students to the level of sense of belonging experienced by students from refugee 
backgrounds would provide greater insight into our general understanding of the development of adolescent students' SOBIS.

Connecting and Acceptance: Whether students from refugee backgrounds develop a sense of belonging in school depends on how connected and accepted they feel in their school. This is conveyed by how welcoming the school is to them as demonstrated by the closeness of the relationships they form with their teachers and peers, and the supports that are available to help them achieve success in their school. The daily stressors that continue in the lives of students from refugee backgrounds after their arrival to their new country are persistent. Poverty, low language skills, disjointed families, and mental health concerns, all contribute to poor academic achievement and social isolation, requiring students from refugee backgrounds to have a great deal of stamina and endurance to persevere. While getting involved and actively contributing to the school and community environment are proactive measures that students from refugee backgrounds can take to start to build trusting relationships with teachers and peers, females are further challenged with gendered expectations in their homes that may pose barriers to their school and community participation.

Continued Challenges: The challenges faced by students and families of refugee backgrounds do not stop upon their arrival in their host country, and Canada is no exception. The study participants made frequent comments throughout the interviews about the high cost of living in Canada, including the cost of food, transportation and housing. Addressing ways to better support families financially as well as providing them with skills and language training, would enable parents to better care for their children and alleviate much of the stress on their children.

\section{Study significance}

Schools and communities that are able to foster a positive sense of belonging amongst students from refugee backgrounds increase their pro-social outcomes and decrease their negative well-being outcomes. The positive academic, behavioural and psychological outcomes of students who feel a strong sense of SOBIS, results in improved self-efficacy, motivation and reduced social-emotional distress (Kia-Keating and Ellis, 2007). However, in order for this to occur, skills and language training, affordable housing, increased minimum wages to reflect the cost of living and affordable day-care, is required to better support families and subsequently students from refugee backgrounds. Presently, Canada does not spend enough money on language services, skills accreditation and on training for newcomers (Grubel \& Grady, 2011). The Canadian government could significantly reduce the costs to taxpayers of paying for social services and welfare programs of newcomers, if they were to put in place the proper training and resources to better support these families upon arrival to Canada (Grubel \& Grady, 2011). Future studies would benefit from examining the provision of more equitable support for students from refugee backgrounds. Many students stated that they felt treated unfairly because they believed themselves to be working equally as hard or harder than their peers, yet their grades were not reflective of their efforts. A future study which examines how to provide equitable access to opportunities, such as post-secondary education, while recognizing practical limitations such as language barriers, knowledge gaps (from interrupted educations), and financial barriers, is required to help students feel that their new society is supportive and a fair one that they want to positively contribute to.

Children and adolescents from refugee backgrounds are ordinary people, who have been met with extraordinary circumstances. They are capable of enhancing and strengthening the social fabric of our society, and as we continue to welcome thousands of people from refugee backgrounds to Canada annually, we have a responsibility to commit to helping support them upon arrival and throughout the settlement process, both for their well-being and for the health of our society.

\section{References}

Anderman, E. M. (2002). School effects on psychological outcomes during adolescence. Journal of educational psychology, 94(4), 795-797.

Basit, T. (2003). Manual or electronic? The role of coding in qualitative data analysis. Educational research, 45(2), 143-154.

Brown, B. B., \& Larson, J. (2009). Peer relationships in adolescence. In Brown, B.B. \& Larson, J. (Eds.), The Handbook of adolescent psychology (74-100). USA: Wiley Online Library.

Children. (n.d.). United Nations High Commissioner on Refugees. Retrieved September $28^{\text {th }}$ n.d., from https://www.unhcr.org/children-49c3646c1e8.html

Clandinin, D. J., \& Connelly, F. M. (1996). Teacher's professional knowledge landscapes: Teacher stories - stories of teachers - school stories - stories of schools. Educational Researcher, 25(3), 24-30. 
Connelly, M. F., \& Clandinin, J. D. (1999). Shaping a professional identity: Stories of educational practice. New York, USA: Teachers College Press.

Convention on the Rights of the Child. (2015, August 18), United Nations Human Rights Office of the High Commissioner. $\quad$ Retrieved September $28^{\text {th }}, \quad$ n.d. from http://www.ohchr.org/en/professionalinterest/pages/crc.aspx

Creswell, J. W. (2011). Educational research: Planning, conducting, and evaluating quantitative and qualitative research (4th $e d$.). NC, USA: Merrill.

Demanet, J., \& Van Houtte, M. (2012). School belonging and school misconduct: The differing role of teacher and peer attachment. Journal of Youth and Adolescence, 41(4), 499-514.

Education. (n.d.). United Nations High Commissioner on Refugees. Retrieved September $28^{\text {th }}$ n.d., from https://www.unhcr.org/education.html

Ferede, M. K. (2012). Structural factors associated with higher education access for first-generation refugees in Canada: An agenda for research. Refuge: Canada's Journal on Refugees, 27(2), 79-88.

Figures at a Glance. (2019). United Nations High Commissioner on Refugees. Retrieved September $28^{\text {th }}$ n.d., from https://www.unhcr.org/ph/figures-at-a-glance

Frater-Mathieson, K. (2004). Resilience. In R. Hamilton \& D. Moore (Eds.), Educational Interventions for Refugee Children (53-63). London, UK: Routledge Falmer Publishers.

Grubel, H. \& Grady, P. (2011). Immigration and the Canadian Welfare State. The Fraser Institute. Retrieved from https://www.fraserinstitute.org/sites/default/files/immigration-and-the-canadianwelfare-state-2011.pdf

Guo, Y., Maitra, S., \& Guo, S. (2019). "I belong to nowhere": Syrian refugee children's perspectives on school integration. Journal of Contemporary Issues in Education, 14(1), 89-105.

Hattie, J., \& Anderman, E. M. (2013). Introduction. In J. Hattie, \& E.M. Anderman, (Eds.), International Guide to Student Achievement (xix-xxii). NY, USA: Routledge.

Hoot, J. L. (2011). Working with very young refugee children in our schools: Implications for the world's teachers. Procedia-Social and Behavioral Sciences, 15, 1751-1755.

Kia-Keating, M., \& Ellis, B. H. (2007). Belonging and Connection to School in Resettlement: Young Refugees, School Belonging, and Psychosocial Adjustment. Clinical Child Psychology and Psychiatry, 12(1), 29-43.

Libbey, H. P. (2007). School connectedness: Influence above and beyond family connectedness. (Published doctoral dissertation). University of Minnesota, MN, USA.

Marshall, J., \& Reason, P. (2008). Taking an attitude of inquiry. Towards quality improvement of action research: Developing ethics and standards, 61-82.

Merriam, S., \& Tisdell, E. (2016). Qualitative research: A guide to design and implementation (4th ed.). San Francisco, USA: Jossey-Bass.

Qin-Hilliard, D. B. (2003). Gendered Expectations and Gendered Experiences: Immigrant Students' Adaptation in Schools. New Directions for Student Leadership, 2003(100), 91-109.

Wentzel, K.R. (1998). Social Relationships and Motivation in Middle School: The Role of Parents, Teachers, and Peers. Journal of Educational Psychology, 90(2), 202-209

Women's Commission for Refugee Women \& Children. (2000, January 1). Untapped Potential: Adolescents Affected by Armed Conflict. United Nations International Children's Emergency Fund. Retrieved from http://www.unicef.org/emerg/files/adolescents_armed_conflict.pdf 


\title{
PEDAGOGICAL PRACTICES ADOPTED BY TEACHERS WHEN TEACHING LEARNERS TAKING ENGLISH AS FIRST ADDITIONAL LANGUAGE IN LIFE SCIENCES CLASSROOMS
}

\author{
Portia Seloma, \& Sam Ramaila \\ Department of Science and Technology Education, University of Johannesburg (South Africa)
}

\begin{abstract}
This study examined pedagogical practices adopted by teachers when teaching learners taking English as First Additional Language in Life Sciences classrooms. The inquiry adopted a generic qualitative design located within the interpretivist paradigm and involved purposively selected Life Sciences teachers and grade 10 learners from South African township schools as participants. Qualitative data was collected through semi-structured interviews and classroom observations. The empirical investigation is underpinned by the Cognitive Academic Language Proficiency (CALP) as the underlying theoretical framework. The study uncovered a myriad of instructional challenges facing Life Sciences teachers and learners associated with the use of English as a medium of instruction while it is taken as a First Additional Language by the learners. In particular, the terminology used in Life Sciences as a key knowledge domain posed fundamental instructional challenges in relation to meaningful development of enhanced learners' conceptual understanding of scientific phenomena. Theoretical implications for meaningful science teaching and learning are discussed.
\end{abstract}

Keywords: Pedagogical practices, first additional language, life sciences.

\section{Introduction}

Language diversity renders classroom environment a complex and dynamic terrain for both teachers and learners. The complex and dynamic nature of classroom environment requires teachers to adopt nuanced and innovative pedagogic approaches that are responsive to the challenges posed by language diversity. Language has been identified as one of the causes of learners' poor performance in science within the South African context (Cleghorn \& Rollnick, 2002; Mji \& Makgato, 2006). Both teachers and learners bring their own diverse languages to the classroom as South Africa is a multilingual country. This study is inspired by the desire to understand how teachers teach Life Sciences content in a manner that is responsive to the language diversity of both teachers and learners. English is a medium of instruction in South African schools through which learners are expected to develop a firm grasp of scientific concepts. Yet, English is taken as First Additional Language by a substantial number of learners at South African township schools.

\section{Background}

The teaching of Life Sciences as a key knowledge domain poses enormous challenges to both teachers and learners. Learners who are taught in English as their mother tongue have an accumulated advantage in Life Science classrooms over those who are English second language speakers (Oyoo, 2014). There are various teaching strategies that can be employed by English second language teachers in Life Sciences classrooms such as the use of investigations and practical work, analogies, code switching and classroom communication (Ferreira, 2011). Wellington and Osborne (2001) point out that science has its own peculiar language and hence every science lesson is a language lesson especially in a context where the language of instruction is different from the learner's home language. The problem is exacerbated by the fact that science language is both technical and non-technical by its very nature. Technical terms are specific scientific words and non-technical terms refer to non-scientific words used in everyday life (Oyoo, 2015). Learners' acquisition and understanding of scientific concepts is often compromised by the language of instruction being different from their home language (Lee, 2001). Smith-Walters et al. (2016) identified three challenges of associated with language in science learning, namely: specialised vocabulary, the speed at which new terms are introduced in science and the 
difficulties learners face as they learn the language of science. Teachers face the key imperative to understand the language of science and how they can encourage science language acquisition within their learners (Smith-Walters, Mangione \& Bass, 2016). It is against this background that the study examined pedagogical practices adopted by teachers when teaching learners taking English as First Additional Language in Life Sciences classrooms. The empirical investigation was guided by the following research question:

What pedagogical practices are adopted by teachers when teaching learners taking English as First Additional Language in Life Sciences classrooms?

\section{Theoretical framework}

The study is underpinned by the Cognitive Academic Language Proficiency (CALP) as the underlying theoretical framework. CALP refers to the ability to manage language necessary for cognitively challenging tasks and is required for accelerated cognitive and academic growth (Laija-Rodriquez, Ochoa \& Paker, 2006). CALP is invoked as a theoretical lens to provide insightful elucidation into the nature of pedagogical practices adopted by teachers when teaching learners taking English as First Additional Language in Life Sciences classrooms.

\section{Purpose of the study}

The study examined pedagogical practices adopted by teachers when teaching learners taking English as First Additional Language in Life Sciences classrooms. The empirical investigation was underpinned by the following objectives.

- To identify pedagogical practices adopted by teachers when teaching learners taking English as First Additional Language in Life Sciences classrooms.

- To identify language barriers that impede meaningful delivery of instruction in Life Sciences classrooms.

\section{Research design and methodology}

The inquiry adopted a generic qualitative design located within the interpretivist paradigm and involved purposively selected Life Sciences teachers and grade 10 learners from South African township schools. Qualitative data was collected through semi-structured interviews and classroom observations.

\section{Research findings}

The study involved Life Sciences teachers and learners at South African township schools as participants. The demographic profile of the participants is provided in Table 1 below.

Table 1. Demographic profile of the participants.

\begin{tabular}{|l|l|c|c|c|c|l|}
\hline & Gender & $\begin{array}{c}\text { Teaching } \\
\text { experience }\end{array}$ & Grade & $\begin{array}{c}\text { Number of } \\
\text { learners }\end{array}$ & $\begin{array}{c}\text { Teacher's native } \\
\text { language }\end{array}$ & $\begin{array}{c}\text { Learners' native } \\
\text { languages }\end{array}$ \\
\hline Teacher A & Female & 3 years & 10 & 30 & IsiZulu & IsiZulu, Sepedi, Sotho \\
\hline Teacher B & Female & 5 years & 10 & 20 & IsiXhosa & Zulu, Sotho \\
\hline Teacher C & Female & 7 years & 10 & 25 & IsiZulu & Zulu, Sotho \\
\hline
\end{tabular}

Research findings were clustered according to the key themes that emerged during data analysis, namely: instructional challenges and pedagogical strategies.

\section{Theme 1: Instructional challenges}

The teachers encountered a myriad of instructional challenges when teaching learners taking English as First Additional Language in Life Sciences classrooms as reflected in the following excerpt.

The challenge that I find is that I constantly have to use second language to explain some of the concepts then I always have to translate some of the words because learners do not have a full understanding of some words, so I have to teach them language first and then teach concepts which is a bit more difficult and it takes more time than it normally should.

Language diversity appeared to pose enormous instructional challenges for the teachers when implementing code switching as a pedagogical strategy as encapsulated in the following excerpt. 
The other challenge is that me and my learners do not speak the same home language, I am Zulu, teaching kids who are Pedi's and Sotho's and Xhosa's, and these languages I am not that much good at, yet I try to speak them. Although sometimes it is difficult since I do not always know some words in their home languages which I might happen to know in my own home language, which is IsiZulu.

Other instructional challenges were related to the nature of science language used in Life Sciences as a key knowledge domain as demonstrated by the following excerpt.

Science has its own terminology. This terminology is not easy for learners to grasp let alone to pronounce some words, and this includes myself. To deal with the challenges of science language firstly is to recognise that there are some science words which are easily explainable to learners such as plants and animals since they can also be found in their homes and they can easily visualise them when they are mentioned. For example, if I say to learners, today we are going to learn about plants and animals, their minds form ideas of plants and animals they know, therefore, I use analogies using real life examples. Nonetheless, words like the xylem, phloem and epidermis, are new to them, to their minds. In this case, I use pictures to show how the plant tissue appear and ensure that I constantly assess them. I have sometimes noticed that it is not necessarily that my kids do not understand the subject life sciences, but it is its language, that is, its difficulty. So, my kids are struggling to grasp the English in the life science and also getting the science of the words that we use because life science is a very technical subject with its own language and it is little use bit far from the normal English that we use, that they are used to.

\section{Theme 2: Pedagogical strategies}

The teachers adopted various pedagogical strategies in an attempt to navigate fundamental challenges associated with the provision of instruction to learners taking English as First Additional Language in Life Sciences classrooms. Table 2 below depicts pedagogical strategies adopted by the teachers.

Table 2. Pedagogical strategies adopted by the teachers.

\begin{tabular}{|c|}
\hline Code switching \\
Use of pictures \\
Use of analogies \\
Use of video clips \\
\hline
\end{tabular}

\section{Discussion}

Teaching learners taking English as First Additional Language in Life Sciences classrooms appeared to be an extremely difficult and complex undertaking for teachers. Language proficiency plays a pivotal role in demystifying the nature of scientific knowledge. The teachers' Cognitive Academic Language Proficiency (CALP) affects the instructional process as teachers' English proficiency influences learners' acquisition of the concepts to be learned (Nel \& Muller, 2010). The vocabulary load presented in most science textbooks continues to be high and may contribute to misconceptions, lack of understanding and avoidance of the subject (Pearson, Hiebert \& Kamil, 2007). The teachers adopted various pedagogical strategies when navigating fundamental challenges associated with the provision of instruction to learners taking English as First Additional Language in Life Sciences classrooms within the context of this study. However, meaningful implementation of adopted pedagogical strategies required enhanced professional competence on the part of teachers. Barriers that served to impede meaningful delivery of instruction in Life Sciences classrooms included language diversity, terminology used in Life Sciences as a key knowledge domain and general lack of essential resources. There is a critical need for teachers as key agents of educational change to fully embrace contemporary teaching approaches such as inquiry-based learning to demystify the nature of scientific knowledge. As an innovative pedagogic approach, inquiry-based learning can serve to augment pedagogical strategies such as code switching and the use of analogies to ensure immense pedagogical benefits for the learners. 


\section{Conclusion}

Teaching learners taking English as First Additional Language in Life Sciences classrooms appears to be a daunting task for teachers. Teacher professional training ought to make provision for meaningful development of language proficiency with a view to build professional capacity required to demystify the nature of scientific knowledge.

\section{References}

Cleghorn, A., \& Rollnick, M. (2002). The role of English in individual and societal development: A view from African classrooms. Tesol Quarterly, 36(3), 347-372.

Ferreira, J. G. (2011). Teaching life sciences to English second language learners: What do teachers do? South African Journal of Education, 31(1), 102-113.

Laija-Rodriguez, W., Ochoa, S.H., \& Paker, R. (2006). The Cross-linguistic role of Cognitive Academic Language Proficiency on reading growth in Spanish and English. Bilingual Research Journal, 30(1), 87-106.

Lee, O. (2001). Culture and language in science education: What do we know and what do we need to know? Journal of Research in Science Teaching, 38(5), 499-501.

Mji, A., \& Makgatho, M. (2006). Factors associated with high school learners' performance: A spotlight of Mathematics and Physical Sciences. South African Journal of Education, 26, 253-266.

Nel, N., \& Muller, H. (2010). The impact of teachers limited English proficiency on the English second language in South Africa. South African Journal of Education, 30, 635-650.

Oyoo, S.O. (2014). Language of Instruction and Science Learning in African Science Classrooms, In Daniel O. Orwenjo, Martin C. Njeroge, Ruth W. Ndung'u and Phyllis W. Mwangi (Eds.); Multilingualism and Education in Africa: The State of the state of the Art, (pp. 24-49). Cambridge: Cambridge Scholars Publishing.

Oyoo, S.O. (2015). Why language is so important in science teaching. World Economic forum.

Pearson, Hiebert, E.H., \& Kamil, M.L. (2007). Theory and research into practice: A vocabulary assessment: What we know and what we need to learn. Reading Research Quarterly, 42(2). 282-296.

Smith-Walters, C., Mangione, A.K., \& Bass, S.A. (2016). Science language special issue: Challenges in preparing preservice teachers for teaching science as a second language. Electronic Journal of Science Education, 20(3), 60-71.

Wellington, J., \& Osborne, J. (2001). Language and literacy in science education. Buckingham: Open University Press. 


\title{
BUILDING BRIDGES: BRINGING NONFORMAL PEDAGOGIES INTO THE CLASSROOM
}

\author{
Maya Wizel \\ Middlebury College (USA) \\ Bar-Ilan University (Israel)
}

\begin{abstract}
Education systems worldwide have long sought ways to engage and support learners to become self-directed and develop 21 st-century skills. This became even more relevant-and crucial-with the COVID-19 pandemic restrictions. Solutions to help formal education systems establish innovative pedagogies and methods to organize learning can be found in places as unpredictable as nonformal education settings. In this study, I interviewed educators with backgrounds in nonformal education to better understand that system's qualities and how they can be transferred into formal settings. Findings regarding practices include teachers prioritizing instructional choice (voluntarism); addressing social-emotional aspects through diverse teaching methods that emphasize students' active learning and real-life experiences (classroom as a social group); and excelling in dialogue and teamwork to sustain solid interpersonal relationships with students and colleagues (relationships and dialogue). Educators working in nonformal settings often know they have a unique collection of difficult-to-articulate abilities. This research presents the voices of youth movement leaders in Israel, who nonformally have been doing what formal educators worldwide are trying to figure out; defines some of their skills; and explores how those skills can be applied in formal settings. This study has been published as a book in Hebrew in 2020. This paper embodies a few aspects of the study and will benefit formal education leaders and practitioners who seek to incorporate methods from nonformal pedagogies.
\end{abstract}

Keywords: Choice, educational change, nonformal pedagogies, youth movement, teaching.

\section{Introduction}

\subsection{1st-century education challenges}

In the past two decades, there has been continuous worldwide conversation regarding the future of public education systems. One of the leading terms discussed is 21st-century competencies (Organization for Economic Co-operation and Development, 2018), which encompasses the education system's need to help students develop the knowledge, skills, values, and attitudes, including personal, social, and global perspectives, needed in this century. These recommended skills relate to citizenship, being part of the workforce, and living in a world that is digital and continually changing. Relevant skills include adaptiveness and flexibility, creative thinking, teamwork, communication, critical thinking, and social awareness. In considering this broad range of recommendations and the challenges that education systems face worldwide, it becomes clear that some answers do not need to be reinvented. They can simply be adopted from nonformal education systems that have succeeded in those areas for decades. This sort of nonformal education has received far less attention from academic researchers than has its formal counterpart (Cohen, 2015). The aim of this research is to enhance awareness of this often-overlooked source of relevant and inspiring educational practices.

\subsection{Distinction between formal and nonformal education}

The literature uses various terms used to describe and distinguish educational activities that occur inside and outside of schools. Smith (2002) and Silberman-Keller (2003) termed the lifelong learning and development of values, knowledge, and skills as informal education. This sort of learning comes with exposure to experiences within the family or environment, for example, learning through play or from day-to-day life experiences. Nonformal education refers to an organized system of learning and development with specific goals and methodologies, such as community sports teams or music bands. Juxtaposed with those definitions are ones that use an organizational framework and others that emphasize educational aspects, such as pedagogy (Shmida \& Romi, 2008). Although these definitions offer some framework for nonformal education, other scholars suggested that any attempt to define nonformal 
education contradicts the essence of this type of education, which is characterized by flexibility and diversity. It is impossible and even not worthy to contain it to one narrowing definition (Smith, 2002). In this paper, I use the term nonformal education and nonformal pedagogies to describe types of practices common in youth movements.

Silberman-Keller (2003) focused on how learning and teaching happen in nonformal education settings. According to her, nonformal pedagogy relates to the participants' background, and learning is "situated"-it happens while experiencing social and cultural activities and will change accordingly. She also described nonformal learning as related to dialogue and conversation; thus, it is less expected and predicted. Kahane (1997), an Israeli researcher who unpacked the qualities of nonformal education, made significant contributions to the concept and to the field overall. Decades of field research led Kahane to create a set of eight structural components of informality, each representing a distinct aspect of the concept. He named the structural components, defined them, and described the effects each could be expected to have on participants' worldviews, social behaviors, and interactions among the group (Cohen, 2015, p. 224). In the following sections, I explain those components relevant to this paper: voluntarism, multiplicity, and symmetry. Although I offer some definitions and distinctions between nonformal and formal education, some scholars describe educational activities as more of a line, or a bridge, than as two sides of a wall (Michaeli, 2013; Smith, 2002).

\subsection{Nonformal educators}

Most Israeli children join a youth movement (similar to a youth club or camp in the United States), attend at least two activities per week, and build strong social ties that extend far beyond the confines of formal programming. "Youth movements can play an important role in adolescents' process of identity development, offering a venue for experimentation and exploration of new roles, ideas, and values" (Cohen, 2015 , p. 225). Teens take active roles as counselors in the many youth movements in Israel. They volunteer in educational settings that are distinctly different from schools-nonformal educational settings using nonformal pedagogies. The leaders of such organizations carry roles with unique and complex responsibilities that require varying organizational and pedagogical skills. Through this role, some leaders find their passion for education, complete their certifications, and enter the formal education system as classroom teachers and school principals.

Internationally, some educators in the formal Kindergarten-through-12th-grade $(\mathrm{K}-12)$ system, have backgrounds in nonformal education as well, for instance as counselors or instructors at summer camps. They reported that those early experiences as young educators pushed them to choose teaching careers (Wizel, 2018) and continue to serve them in the formal system. One goal of the current research was to explore bridges that educators build while using values, skills, and knowledge and applying methods from nonformal pedagogy in the formal education setting, schools, and classrooms.

\subsection{Research goal}

This study aims a magnifying glass on the opportunities that can happen when educators who are experienced in nonformal settings continue their career paths into the formal education system, becoming teachers and principals of schools. The research goal was to explore qualities and practices from the youth movements that can be brought successfully into the formal education system.

\section{Methods}

This qualitative study, which explores such educators, is part of a research collection conducted for the Council of Youth Movements (a registered nonprofit association), which is the umbrella organization for all the youth movements in Israel. Ten educators were recruited through social media, all had employment experience of 2 to 15 years in youth movements and currently worked in the $\mathrm{K}-12$ public education system in Israel. Seven participants worked as teachers, and three as school principals. The participants were diverse in terms of which youth movement they had attended or led, their years of experience, and the formal school subjects they taught. I interviewed (and recorded) participants at their schools for approximately one hour each. I then transcribed the interview recordings and used those transcriptions in a qualitative coding process. Participants often described the interview process as a reflective one that helped them understand their educational backgrounds, motives, and practices.

\section{Discussion}

Several themes emerged from the qualitative coding of the interviews. In this short paper, I discuss three themes related to differences between nonformal and formal education and the pedagogical bridges educators created in their actions. These themes related to voluntarism, the classroom as a social group, and relationships and dialogue. 


\subsection{Bridge 1: Voluntarism}

Kahane (1997) described voluntarism as a relatively constraint-free pattern of choice (of goals, means, and affiliations) in which the cost of changing one's mind is minimal. This was the main difference between nonformal and formal education systems that participants described. Simply stated, students are required to attend school, but they can choose whether to attend, which, and their level of engagement with a youth movement. One participant described that in the nonformal youth movement, "I spoke enthusiastically with 200 teenagers, and they all listened. Here [formal school], I enter a class of 30 sixth graders, and I need to fight with them regarding everything."

Participants connected this issue of choice in schools with other challenges, such as discipline, motivation, self-efficacy, student engagement, and self-directed learning. Some attempted to enhance choice in their classrooms, in what can be termed instructional choice. That is, these educators made efforts to give learners autonomy to choose among age- or ability-appropriate options, for example, choosing between tasks or selecting a topic for assignments. One teacher described giving choices for a final project by allowing learners to write a paper, record a podcast, or film a videoclip, as well as to choose between independent or small-team work.

Encouraging more choice must be done thoughtfully: It needs to be relevant to the learners and their strategies and ability to choose (Beymer \& Thomson, 2015). The choice must be managed (Katz \& Assor, 2007). For example, because it is difficult-sometimes intimidating - to choose among endless possibilities, the choice can be managed by offering fewer options. In addition, social, cultural, and personal differences regarding choice must be carefully considered. Finally, the conversation about choice for students at the class or school level must consider aspects of teachers' choice, as well.

\subsection{Bridge 2: The classroom as a social group}

Is any group of students a social group? In nonformal pedagogy, learning occurs in a group and involves a social context. Development of the individual connects with development of the group (Silberman-Keller, 2003): the individuals develop inside the group, and the group develops due to the development of the individuals. Unsurprisingly, study participants raised this issue. They discussed how, in nonformal pedagogy, the concept of the group is central; becoming part of a like-minded peer group emerged as a main attraction for youth to join youth movements. This social element allows reciprocal relationships and opportunities to experiment with behaviors and values. The group is perceived as an educational resource and functions like a family and community.

Raviv (2016) offered a relevant distinction between content and process, explaining that content relates to the "what"-academic goals such as the topic or the subject and learning new knowledge. He defined process as the "how," which mostly goes unrevealed. It includes processes that appear in the social group, such as the phases the group goes through, and personal and interpersonal processes, such as group conflicts and dynamics.

Similarly, teachers and principals who have a background in nonformal educational settings stressed their crucial role in leading a dynamic group. They highlighted the broader meaning of teachers' roles, including maintaining relationships, organizational culture, and group norms. They described these as teaching skills to address and give time and energy to things that happen in the peer group. One participating teacher stated that this is his expertise: "I make a circle. We sit in a circle and talk and discuss." Some participants expressed tension in the formal education setting between what teachers must accomplish according to the curriculum and study plan and what is happening right now in the classroom and needs attention.

This prioritization relates to the nonformal term, situated learning, reacting to the current situation as a learning opportunity and being adaptive and flexible. One teacher described, "If kids come back from recess and are occupied with the conflict that was raised, I acknowledge this conflict, and I devote time to it even if I know I have a teaching goal." This time dedicated to social interactions also relates to social-emotional learning. To benefit from the advantages of the class as a group, teachers should prioritize transforming the classroom into a group and encourage learning that involves social interactions. Educational systems, at the same time, need to structure more time so that educators will not need to face the tension between curriculum and social aspects. They then could use the social group to promote both learning and emotional health.

\subsection{Bridge 3: Relationships and dialogue}

One characteristic of a nonformal educational setting is symmetry in personal relationships (Kahane, 1997). "Symmetry, in reference to a relationship, is based on three interrelated elements: actors, who have fairly equivalent resources; exchanges which are balanced reciprocally; and, therefore, expectations which the actors tend mutually to accommodate" (Bekerman \& Keller, 2004, p. 6). Symmetry is about relationships that have more equality and less one-sided power than often seen in formal educational settings. In youth movements, even more key than acquiring knowledge and skills is the 
relationship with the young group-leader educator (often only 2 to 3 years older than the peer members). This leader is a meaningful adult with close bonds to the group members. The leader finds the balance between having authority and friendly relationships and easily learns to move between those roles in a flexible, adaptive manner. The counselors' authority in youth movements is based on eye-level communication. Another important term is dialogue - an educational conversation that includes trust, honesty, and openness from all involved. Freire's (1970) educational philosophy stressed the vital role of dialogue and called for cancellation of the distinction between a teacher and his or her students.

Research participants with nonformal backgrounds were skilled in creating interpersonal dialogue connections with students. They perceived the dialogue as central to other aspects. One teacher said, "We are partners in this. Tell me what you want, what you dream, what you care about, what you're passionate about, and we will structure our learning around this." Another teacher used the term intimacy. She stated that it was hard for her to reach the same level of intimacy with students as she had in nonformal settings due to her lack of time and the large number of students in her classroom.

Just as the other bridges interconnected, this bridge connects to changes in the teachers' rolefrom one of being the source of knowledge to one of an adult who, through conversation and communication, supports and facilitates learning and development.

Educators found creative ways to invest in personal relationships, often during recess times, while structuring independent work, or when incorporating meeting times during classes. A school principal gave an excellent example of how she uses existing organizational structures to promote communication: "If there is a conversation in my room with the guidance counselor and a few adults from the team and the student, I will ask the student to summarize the conversation. This way, I can learn what he heard, what we meant, and what the gaps are."

\subsection{Other bridges}

Other bridges arose in the research but are only summarized here because they are beyond the scope of this short paper. One such theme regarded flexibly in using diverse teaching methods-games, group work, outdoor learning, and other practices that serve the learning goals - and other priorities, such as the group. In general, it seemed that educators with nonformal educational backgrounds tended to use progressive teaching methods that also required a shift in their role as teachers.

Another bridge related to developing self-directed learners. This relevant challenge received particular attention during the COVID-19 pandemic. Participants shared the ways in which they gave students more responsibility and successfully enhanced their engagement. One straightforward method was to do less as adults and authentically trust the students to do their share. This challenge also related to choice and the ability to take risks and fail in a blame-free environment with trust and confidence.

A third theme regarded the world outside the school. Teachers used the curriculum as a platform to address social justice issues and to encourage discussions of values and activism, making their education actions relevant and significant.

\section{Conclusion: Questions and vision}

The formal education system desires to develop students' 21 st-century skills. Nonformal educational settings such as clubs, sports groups, and, in the case of this study, youth movements successfully address those skills. Despite the differences between settings, educators have ways to carry some nonformal pedagogy into the formal education system. Those teaching methods support students to develop as self-directed learners and address students' social-emotional needs by envisioning the classroom as a social group and fostering dialogue and eye-level relationships.

What can formal settings do to help this entrance of nonformal pedagogy into schools? Schools can accept more teachers with nonformal backgrounds and encourage these educators to transfer the skills they learned in nonformal setting into the school. One study participant described taking 3 years to understand that it was allowed and acceptable for her to play games with her students, as she had in the youth movement. Schools can recognize behaviors and habits connected to nonformal pedagogies and encourage all teachers, regardless of their backgrounds, to adopt appropriate methods and ways of working. In addition, they must address obstacles to doing so, such as the classroom size or the school-day structure.

The formal education system is often described as strict. However, in this study, I experienced the system's elasticity and witnessed many educators lead nonformal-style education inside the formal education system: teachers who continually adapted their teaching and had meaningful personal connections with their students, and school leaders who led an organizational culture devoted to creating open communication that then transfers to students. These practices are not in themselves innovative; their value is in their authenticity as educators use them to bridge the life experiences and perspectives necessary for 21 st-century schooling. Those efforts encourage new ways to look at what we already know and answer the call for more bridges than walls. 


\section{References}

Bekerman, Z., \& Keller, D. S. (2004). Non-formal pedagogy epistemology rhetoric and practice. Education and Society, 22, 45-65.

Beymer, P. N., \& Thomson, M. M. (2015). Effects of choice in the classroom. Support for Learning, 30, $105-120$.

Cohen, E. H. (2015). Changes among Israeli youth movements: A structural analysis based on Kahane's code of informality. Cambridge Journal of Education, 45, 223-243.

Freire, P. (1970). Pedagogy of the oppressed. New York: Seabury.

Kahane, R. (1997). The origins of postmodern youth: Informal youth movements in a comparative perspective. New York: Walter de Gruyter.

Katz, I., \& Assor, A. (2007). When choice motivates and when it does not. Educational Psychology Review, $19,429-442$.

Michaeli, N. (2013). There is a different education already. Hed Hchinuch, 5, 78-79.

Organisation for Economic Co-operation and Development. (2018). The future of education and skills: Education 2030. https://www.oecd.org/education/2030/E2030\%20Position\%20Paper\%20 (05.04.2018).pdf

Raviv, A. (2016). Content and process: Working with groups in the nonformal education. Oranim College, Israel.

Shmida, M., \& Romi, S. (2008). Non-formal education in changing reality. Hebrew University Magnes Press.

Silberman-Keller, D. (2003). Toward the characterization of non-formal pedagogy. Paper presented at the Annual Meeting of the American Educational Research Association, Chicago, IL.

Smith, M. K. (2002). Informal, non-formal and formal education: A brief overview of different approaches. Encyclopedia of informal education. https://infed.org/mobi/informal-non-formal-and-formaleducation-a-brief-overview-of-some-different-approaches/

Wizel, M. (2018). Preparing educational hackers. In Y. Weinberger and Z. Libman (Eds.), Contemporary pedagogies in teacher education and development (pp. 101-118). London: IntechOpen. 


\title{
TECHNOLOGY INTEGRATION IN NATURAL SCIENCES TEACHING AND LEARNING IN SOUTH AFRICAN TOWNSHIP SCHOOLS
}

\author{
Sam Ramaila \\ Department of Science and Technology Education, University of Johannesburg (South Africa)
}

\begin{abstract}
This study examined technology integration in Natural Sciences teaching and learning in South African township schools. A mixed method approach was adopted as part of an exploratory descriptive survey design. Data was collected through semi-structured interviews, classroom observations as well as administration of open-ended survey questionnaire. The study involved purposively selected grade 9 Natural Sciences teachers and learners as participants. The empirical investigation is underpinned by technological pedagogical content knowledge (TPACK) as the underlying theoretical framework. The participants demonstrated a positive disposition about technology integration in Natural Sciences teaching and learning. In particular, technology integration was perceived to provide opportunities for the enhancement of meaningful Natural Sciences teaching and learning in township schools. Digital resources were largely viewed as essential educational tools that can be deployed to demystify abstract scientific concepts with a view to enhance scientific literacy. Theoretical implications for technology-enhanced teaching and learning are discussed.
\end{abstract}

Keywords: Technology integration, TPACK, technology-enhanced learning, digital resources.

\section{Introduction}

The advent of the Fourth Industrial Revolution provides meaningful opportunities for embracing pedagogic innovation as an integral part of digital transformation. However, there is a crucial need to bridge the digital divide between under-resourced and well-resourced schools within the broader South African context. Challenges stifling meaningful integration of technology in teaching and learning include poor literacy of educators (Johnson, Jacovina, Russell \& Soto, 2016). Bozkurt (2014) posits that teachers do not have knowledge about technology and technological pedagogical content knowledge (TPACK) as a whole. Costley (2014) asserts that technology has become a common tool that most people use in their households and schools. Technology integration has the potential to transform teacher-centred environments into learner-centred environments. Learner-centred environments provide opportunities for learners to become more flexible and to take charge of their learning (Keser, Uzunboylu \& Ozdamli, 2012). In support of this notion, Miller (2011) posits that learners develop their technological abilities through sustained practice and involvement in teaching and learning.

\section{Background}

Meaningful information and communication technology (ICT) integration in the classroom is hampered by a myriad of factors. These factors include lack of time (Assan \& Thomas, 2012), lack of clarity regarding the e-Education Policy (Vandeyar, 2015), lack of support both in terms of infrastructure and policy (Vandeyar, 2015), lack of skills (Msila, 2015) and more focus on the technical aspects as opposed to the pedagogical and theoretical frameworks (Tamim et al., 2015). ICT integration in teaching and learning remains a key focus area across the globe. Many companies are investing in ICT infrastructure, equipment and professional development in order to improve teaching and learning in schools (Buabeng-Andoh, 2012). The current belief is that ICT is an important catalyst and tool for encouraging educational reforms that transform students into productive knowledge workers (Pelgrum, 2001). Technology is a powerful and flexible tool for learning as it has also become an important part of student lives' beyond and within the classroom (Rabah, 2015). In addition, Rabah (2015) further argues that the 
primary goal of educational technology within a pedagogical context is to facilitate the teaching and learning process. There is a critical need to examine the complexity of barriers impeding ICT integration in teaching and learning with a view to foster pedagogic innovation within the broader South African context.

\section{Research design and methodology}

This study adopted a mixed method approach as part of exploratory descriptive survey design located within the interpretivist paradigm. Exploratory descriptive survey design makes provision for the determination and description of the situation and comparing how sub-groups view a certain issue (Gay, Mills, \& Airasian, 2011). According to Burns and Bush (2006), exploratory research design provides opportunities for gathering information in an informal and unstructured manner. Exploratory research helps a researcher to build understanding about the problem of the research. In addition, exploratory research design is not limited to one specific paradigm as it may use either qualitative or quantitative approaches. Data was collected through semi-structured interviews, classroom observations as well as administration of open-ended survey questionnaire. The study involved purposively selected grade 9 Natural Sciences teachers and learners as participants.

\section{Research findings}

Table 1 below provides participants' level of proficiency associated with various competencies. While the participants demonstrated moderate levels of proficiency in relation to various competencies, they demonstrated a positive disposition about technology integration in Natural Sciences teaching and learning. In particular, technology integration was perceived to provide opportunities for the enhancement of meaningful Natural Sciences teaching and learning in township schools. Digital resources were largely viewed as essential educational tools that can be deployed to demystify abstract scientific concepts with a view to enhance scientific literacy.

Table 1. Participants' level of proficiency associated with various competencies.

Competency

Level of proficiency

Learning how to use a new application

Moderate

Acting as a guide to learners when teaching using the internet

Satisfactory

Troubleshooting problems that occur when using technology

Moderate

Using technology to differentiate technology

Moderate

Table 2 below depicts participants' opinions about technology integration in Natural Sciences teaching and learning. While the participants expressed varied opinions about technology integration in Natural Sciences teaching and learning, they expressed fundamental appreciation of the key pedagogical affordances of technology integration. Access to technological resources remained a pervasive challenge for teachers and learners in township schools. Harnessing the affordances of technology integration requires provision of adequate resources. In addition, there is a need to provide training for teachers on technology integration in order to strengthen their professional competence to fully embrace technology-enhanced teaching and learning. 
Table 2. Participants' opinions about technology integration in Natural Sciences teaching and learning.

\begin{tabular}{|c|c|c|c|c|}
\hline Statement & $\begin{array}{l}\text { Strongly } \\
\text { Agree }\end{array}$ & Agree & Disagree & $\begin{array}{l}\text { Strongly } \\
\text { Disagree }\end{array}$ \\
\hline \multicolumn{5}{|l|}{ When using the internet... } \\
\hline $\begin{array}{l}\text { Learners create products that show higher } \\
\text { levels of learning }\end{array}$ & 15 & 28 & 10 & 7 \\
\hline Learners are more motivated & 25 & 20 & 10 & 5 \\
\hline There is more student collaboration & 20 & 15 & 15 & 10 \\
\hline $\begin{array}{l}\text { The abundance of unreliable sources is } \\
\text { disturbing }\end{array}$ & 2 & 58 & 0 & 0 \\
\hline \multicolumn{5}{|l|}{ I think... } \\
\hline $\begin{array}{l}\text { Electronic media will replace printed text } \\
\text { within five years }\end{array}$ & 10 & 20 & 20 & 10 \\
\hline $\begin{array}{l}\text { Learners are more knowledgeable than I am } \\
\text { when it comes to technology }\end{array}$ & 10 & 50 & 0 & 0 \\
\hline $\begin{array}{l}\text { Technology is a good tool for } \\
\text { collaboration with other teachers when } \\
\text { building unit plans }\end{array}$ & 2 & 58 & 0 & 0 \\
\hline Technology is unreliable & 15 & 35 & 5 & 5 \\
\hline
\end{tabular}

\section{Discussion}

While the participants expressed positive disposition about technology integration in Natural Sciences teaching and learning, access to essential resources remained a pervasive challenge. The participants demonstrated moderate levels of proficiency in relation to various competencies. Teachers are often overwhelmed by heavy teaching loads which do not make provision for training opportunities (Sabaliauskas, Ghavifekr et al., 2016). According to Laabidi and Laabidi (2016), there is a critical need to enhance professional competence of teachers through skills training to ensure that learners are adequately prepared for a technological society. Teachers who have little or no confidence to apply technologies in their occupation will try to escape from those occupations altogether (Laabidi \& Laabidi, 2016). The teachers acknowledged the fact that learners were more knowledgeable than them when it comes to technology use. Technology was perceived to be a good tool for collaboration with other teachers when building unit plans. However, the teachers bemoaned the fact that technology can often be unreliable. There is a crucial need to enhance teachers' technological pedagogical content knowledge with a view to foster meaningful ICT integration in teaching and learning (Cox et al, 1999).

\section{Conclusion}

Technology integration can serve as an innovative catalyst to foster pedagogic innovation in Natural Sciences teaching and learning in township schools. There is a crucial need to enhance teacher professional competence on technology integration with a view to enable them to fully embrace digital transformation.

\section{References}

Bozkurt, E. (2014). TPACK levels of physics and science teacher candidates: Problems and possible solutions. Asia-Pacific Forum on Science Learning and Teaching, 15(2), Article 5, p.1

Buabeng-Andoh, C. (2012). Factors Influencing Teachers' Adoption and Integration of Information and Communication Technology into Teaching: A Review of the Literature. International Journal of Education and Development using Information and Communication Technology (IJEDICT), 8, 136-155.

Burns, A.C. \& Bush, R.F. (2006). Marketing Research ( $5^{\text {th }}$ edition). New Jersey: Prentice Hall.

Costley. K. C., (2014). The positive effects of technology on teaching and student learning. Arkansas Tech University.

Cox, M., Preston, C., Cox, C. (1999). What factors support or prevent teachers from using ICT in the primary classroom. Paper presented at the British Educational Research Association Annual Conference. University of Sussex at Brighton. (September 2-5 1999). 
Gay, Mills, \& Airasian (2011). Educational research: Competencies for analysis and applications (10th edition).

Johnson, A. M., Jacovina, M. E., Russell, D. G., \& Soto, C. M. (2016). Challenges and solutions when using technologies in the classroom. In Adaptive educational technologies for literacy instruction (pp. 13-30). Routledge.

Keser, H., Uzunboylu, H., and Ozdamli, F. (2012). The trends in technology supported collaborative learning studies in 21 st century. World journal on educational technology, 3(2), 103-119.

Laabidi, Y., \& Laabidi, H. (2016). Barriers Affecting Successful Integration of ICT in Moroccan Universities. Journal of English Language Teaching and Linguistics, 1(3). doi: 10.21462/jeltl.v1i3.29

Miller, S. (2011). Student voice for change. Learning and leading with technology, 38(8), 20-23.

Msila, V. (2015). Teacher readiness and Information and Communications Technology (ICT) use in classrooms: A South African case study. Creative Education, 6(18), 1973-1981.

Pelgrum, W. (2001). Obstacles to the integration of ICT in education: results from a worldwide educational assessment. Computers \& Education, 37(2), 163-178.

Rabah, J. (2015). Benefits and challenges of Information and Communication Technologies (ICT) Integration in Quebec English Schools. The Turkey online Journal of Educational Technology, 14(2), 24-31.

Sabaliauskas, T., \& Pukelis, K. (2004). Barriers to integration of information and communication technologies into the teaching and learning process. Presentation, European Conference on Educational Research, University of Crete., 22-25, September 2004.

Tamim, R., Borokhovski, E., Pickup, D., Bernard, R. (2015). Large-scale, government-supported educational tablet initiatives. Burnaby, BC: Commonwealth of Learning.

Vandeyar, T. (2015). Policy intermediaries and the reform of e-Education in South Africa. British Journal of Educational Technology, 46, 344-359. 


\title{
PRE-SERVICE TEACHERS' PREPAREDNESS AND CONFIDENCE IN TEACHING LIFE SCIENCES TOPICS: WHAT DO THEY LACK?
}

\author{
Lydia Mavuru, \& Oniccah Koketso Pila \\ Department of Science and Technology Education, University of Johannesburg (South Africa)
}

\begin{abstract}
Pre-service teachers' preparedness and confidence levels to teach is a topical subject in higher education. Previous studies have commented on the role of teacher in-service training in preparing teachers for provision of meaningful classroom experiences to their learners, but many researchers regard pre-service teacher development as the cornerstone. Whilst teacher competence can be measured in terms of different variables e.g. pedagogy, knowledge of the curriculum, technological knowledge etc., the present study focused on teacher competency in terms of Life Sciences subject matter knowledge (SMK). The study was framed by pedagogical content knowledge (PCK). The study sought to answer the research question: How do preservice teachers perceive their levels of preparedness and confidence in teaching high school Life Sciences topics at the end of their four years of professional development? In a qualitative study, a total of 77 pre-service teachers enrolled for the Methodology and Practicum Life Sciences course at a university in South Africa participated in the study. Each participant was tasked to identify topic(s)/concept(s) in Life Sciences they felt challenged to teach, provide a critical analysis of the reasons for that and map the way forward to overcome the challenges. This task was meant to provide the pre-service teachers with an opportunity to reflect and at the same time evaluate the goals of the learning programme they had gone through. Pre-service teachers' perspectives show their attitudes, values and beliefs based on their personal experiences which therefore help them to interpret their teaching practices. The qualitative data was analysed using content analysis. The findings showed that whilst pre-service teachers were competent to teach other topics, the majority felt that they were not fully prepared and hence lacked confidence to teach the history of life on earth and plant and animal tissues in grade 10; excretion in animals particularly the functions of the nephron in grade 11; and evolution and genetics in grade 12. Different reasons were proffered for the lack of preparedness to teach these topics. The participants regarded some of these topics as difficult and complex e.g. genetics. Evolution was considered to be antagonistic to the participants' and learners' cultural and religious belief systems. Hence the participants had negative attitudes towards them. Some of the pre-service teachers indicated that they lacked interest in some of the topics particularly the history of life on earth which they considered to be more aligned to Geography, a subject they did not like. As remedies for their shortcomings in the content, the pre-service teachers planned to co-teach these topics with colleagues, and others planned to enrol for content enrichment programmes. These findings have implications for teacher professional development programmes.
\end{abstract}

Keywords: Teacher confidence, Life Sciences, preparedness, pre-service teachers.

\section{Introduction}

For meaningful teaching to occur in the classrooms, teachers need to be fully prepared and be confident to teach the subject matter. In as much as previous studies have commented on the role of teacher in-service training and experience in preparing teachers for provision of meaningful classroom experiences to their learners (e.g. Harris \& Saas, 2011), many researchers regard pre-service teacher development as the cornerstone (e.g. Yildirim \& Kalman, 2017). Teachers are required to possess different knowledge domains such as contextual knowledge, curriculum knowledge, knowledge of the learners, pedagogical content knowledge and the subject matter knowledge. It is imperative for teachers to exhibit these differentiated yet integrated knowledge domains to effectively guide the learning process (Botha \& Reddy, 2011). Teacher education programmes should equip the pre-service teachers with these knowledge domains as this helps pre-service teachers to shape their teaching approaches and in developing their teacher identity. Chang-kredl and Kingsley (2014) identified confidence to teach as one of the crucial elements of pre-service teachers' self-identity.

A study by Cimer (2012) confirmed the difficulties associated with the teaching and learning of some of the biological concepts. A point to note is that many pre-service teachers experienced some challenges when learning some of the Life Sciences concepts during their high school years, thus these challenges have also persisted throughout their professional development journey. Thus said, Chang-kredl and Kingsley (2014) acknowledged prior experiences as another aspect which forms teacher identity. 
Inadequate mastery of the subject content negatively affects the pre-service teachers' teaching (Botha \& Reddy, 2011), therefore, the current study sought to establish the pre-service teachers' confidence and preparedness to teach Life Sciences towards the end of their teacher education programme. The rationale for this study comes from the argument that the teaching of content to pre-service teachers should not be done in isolation to the teaching of representations to be used and the teaching strategies if teacher preparation is to be successful. The context of the teacher development programme that these pre-service teachers were enrolled in was split between two faculties where the subject matter was taught in the Faculty of Science and the education courses were taught in the Faculty of Education. The present study sought to answer the research question: How do pre-service teachers perceive their levels of preparedness and confidence in teaching high school Life Sciences topics at the end of their four years of professional development? An honest reflection of one's abilities is crucial in self-development (Kayapinar, 2016) as it helps one to gain self-efficacy.

\section{Literature review}

Previous research has shown that Life Sciences topics such as protein synthesis, transport in plants, genetics, mitosis and meiosis, hormonal regulation, gaseous exchange, respiration, are considered to be complex (Cimer, 2012). Cimer (2012) attributes this complexity to the abstract nature of science, the overloaded biology curricular, and the difficulty in the concepts and processes. It is unfortunate that due to these identified challenges Life Sciences learning is sometimes based on the memorisation of concepts rather than understanding of the content. The teaching approaches teachers employ tend to contribute to learners' inability to understand the content (Cimer, 2004). There is a need for teachers to be well equipped with the subject matter knowledge, skills, values, principles, teaching and learning approaches and how such approaches can be implemented in a Life Sciences classroom. Teacher education programmes are called to develop pre-service teachers with the relevant knowledge and skills to teach their learners meaningfully. Whilst pre-service teachers are considered to be at their infant stage of the teaching profession, considerable effort to develop them fully for their role in the classrooms is imperative. It was however found that pre-service teachers battle to apply the knowledge which they have learned during teacher development programmes due to the lack of knowledge regarding the realities in schools (Coetzee (2012). As a result pre-service teachers lack confidence and are not well prepared to teach some of the Life sciences topics.

At the end of their teacher development programme, pre-service teachers are expected to be well grounded with the necessary knowledge and skills to teach and manage the diverse classroom contexts. Thus, if they indicate elements of incompetence it means they are not well developed, and as such they become less confident to teach when they become qualified teachers (Botha \& Reddy, 2011). Teachers' lack of confidence and preparedness to teach the subject they are trained in raises concerns on how that could impact negatively on the performance of the learners. In a study conducted by Setlalentoa (2018) learners expressed the difficulties they experienced in understanding the Life sciences concepts such as genetics and inheritance, meiosis and mitosis, emphasising the many vocabularies that accompany the subject matter and the limited time which they have to learn the content. The learners became disinterested to continue studying the subject citing the teachers' lack of subject matter knowledge and pedagogical content knowledge as some of the factors causing the challenges learners were facing (Setlalentoa, 2018).

The manner in which Life Sciences content is taught contributes to learners' failure to realise the value and meaning of the concepts taught. To this, Cimer (2004) bemoaned that in most cases, Biology teaching is teacher-centred which demotivates learners from attentively listening and engaging during the teaching and learning process. Lack of resources is also perceived as a factor which forces the teachers to engage in the teacher-centred approach (Cimer, 2012). Pre-service teachers are not well equipped with ideas of how to approach certain Life Sciences topics in a context with no relevant teaching resources, and this affects their competency in teaching the particular subject matter. Language of learning and teaching has also been found to be a factor which impedes learners and teachers alike to understand and explain science terminologies and processes (Mavuru \& Ramnarain, 2020). Considering the many Latin and Greek words which are embedded in the Life Sciences terminology and processes, learners and pre-service teachers alike, find these terms challenging.

In an attempt to expose pre-service teachers to the realities of the school and classroom contexts, the teacher education programmes allocate time which pre-service teachers spend in schools teaching (Dias-Lacy \& Guirguis, 2017). This provides an opportunity for the pre-service teachers to interpret and articulate the school curriculum and utilise the knowledge and skills they learn in university and as such, they get to realise their capabilities and shortcomings.

\section{Conceptual framework}

This study is underpinned by Pedagogical Content Knowledge (PCK) as the conceptual framework as proposed by Shulman (1986). PCK is a special type of knowledge which amalgamates the 
content knowledge and the pedagogical knowledge. In essence, PCK is an essential aspect of teaching and learning and holds the potential to stimulate an effective learning environment. Whilst Shulman stipulates that teachers should not only be knowledgeable about the subject matter but also strategies to teach the content to the learners, the present study focuses on the teacher development of subject matter knowledge, a domain within PCK. The importance of subject matter knowledge in PCK was demonstrated in a study by Rollnick et al. (2008) where a teacher was found to display powerful PCK due to his nuanced subject matter knowledge.

\section{Research methodology}

This study followed a qualitative research design using a case study approach (Merriam, 2009). Qualitative research seeks to establish the manner in which individuals interpret their experiences (Merriam, 2009). This approach allowed for an in-depth establishment of the pre-service teachers' preparedness and confidence to teach particular Life Sciences topics.

\subsection{Selection of the participants}

77 pre-service teachers enrolled for a Life Sciences methodology and practicum course at a South African University were purposively selected to participate in the study. These pre-service Life Sciences teachers were in their final year of a four year teacher development programme. The nature of the teacher development they went through was that they learned the Life Sciences subject matter in the Faculty of Science during the first three years. All the education courses were offered in the Faculty of Education. The pre-service teachers were also involved in the actual classroom teaching of Life Sciences (work integrated learning) at different schools throughout their teacher development.

\subsection{Data collection and analysis}

To collect data, each pre-service Life Sciences teacher was tasked to do the following: 1. To identify a topic/concept in Life Sciences they were not confident to teach; 2 . To critically present reasons for such a discomfort and map the way forward on how they could develop the knowledge and skills to teach it. The task allowed pre-service teachers to intensively engage with the Life sciences content and reflect on their experiences during classroom practice. Each pre-service teacher then submitted a report. Data was analysed using content analysis (Marshall \& Firth, 2017) wherein codes and categories were identified leading to relational analysis.

\section{Findings}

The findings showed that whilst pre-service teachers were competent to teach other topics, the majority felt that they were not fully prepared and hence lacked confidence to teach some topics. Most of these pre-service teachers articulated their lack of confidence in teaching topics such as history of life on earth and plants and animal tissues in grade 10; excretion in grade 11; and evolution and genetics in grade 12. The pre-service teachers' reasons for their lack of confidence and preparedness to teach these topics were attributed to factors related to the complexity and difficulty of the subject matter, and attitudes towards the topics.

Some of the pre-service teachers indicated that they lacked interest in some of the topics particularly the history of life on earth which they considered to be more aligned to Geography, a subject they did not like. Because of such negative attitudes, the participants failed to engage with this content meaningfully and did not give it the attention it deserved. Thus said, the pre-service teachers' capabilities to teach this topic was compromised. This has implications on the learning experiences grade 10 learners will have considering that the CAPS document stipulates that the topic requires a total of 6 weeks of teaching which translates to 24 hours of engagement, to show the importance placed on the topic. The following is one of the pre-service teacher's comment regarding this topic:

Participant 1: The main reason I am not confident to teach the topic of history of life on earth is that I fail to have perspective into the millions of years ago.

Considering the participant's sentiments, it shows that such teacher feelings or attitudes towards the topic will prevent the teacher from even enriching one's content knowledge and let alone acquire necessary skills to teach the topic meaningfully to the learners.

In the case of the topic evolution, the pre-service teachers considered it to be antagonistic to their cultural and religious belief systems and those of the learners. They indicated that when teaching this topic particularly the evolution of humankind, it felt as if they would be challenging the belief systems which learners have been taught to believe in from an early age and continue upholding such beliefs in their homes. They considered the topic as having a lot of controversy which makes is sensitive to some learners. One participant indicated, "I am very uncomfortable hence not prepared and confident to teach this topic because I fear that learners along with their parents might think I am challenging their faith"

The pre-service teachers attributed their lack of confidence to teach topics such as genetics and excretion to the abstract nature and complexity of the concepts. These participants also mentioned that 
there are specialised terminologies used in these topics, which make it difficult for one to understand them. As such, those pre-service teachers indicated that they also found it difficult to explain the concepts and processes involved considering that they themselves lack the required level of subject matter knowledge.

In addition to some of the personal reasons pre-service teachers mentioned with regards to their lack of preparedness and confidence to teach some topics, they identified profound contextual factors which limited their horizons to teach the topics. Firstly, some of the participants placed the blame on their high school Life Sciences teachers and their university lecturers who failed to demonstrate adequate knowledge and skills when teaching them some of the topics. This is encapsulated in one of the participants' report.

Participant 2: Regarding the topic tissues, I am not one hundred percent confident to teach and it stems from my time as a learner in high school. My teacher was boring as she would just sit by her desk and read information in the textbook.

This shows that a vicious cycle of incompetency has been created, which will have a ripple effect at so many levels if not addressed. In this kind of reflection, some of the pre-service teachers deeply reflected on the situation they found themselves in which in a way helped them to take responsibility of their predicament. An example is one of the participants who pointed out that whilst he could trace the root of his lack of preparedness to teach some topics to his high school teacher, he however realised that he could have taken responsibility and made an effort to self-study and do more research since he was not satisfied with the experiences in the classroom. Some of the general reasons given by the pre-service teachers for their failure and discomfort in teaching particular topics was drawn from the lack of adequate resources. An example was given by one of the participants who reported the following:

Participant 3: There are concepts which make it difficult for one to teach without resources, particularly the abstract concepts.

Specific to this problem, these pre-service teachers were referring to both plant and animal tissues which made it difficult for them to explain the concepts meaningfully to the learners without using microscopes. These pre-service teachers had had an experience of teaching such concepts during work integrated learning in schools hence they indicated how difficult it was to accommodate learners who preferred seeing and touching. Some of the pre-service teachers elaborated on the issue of resource unavailability where their teachers did not use videos, slides, other than simply reading from the textbook and expected them as learners to discern the important knowledge and skills to be mastered.

In their reports the pre-service teachers made an undertaking by mapping the way forward on how they could develop the knowledge and skills to teach the topics they found themselves not confident and less prepared to teach. Most of these pre-service teachers indicated their willingness to initiate collaborative teaching with fellow teachers in a process referred to as team teaching. Their justifications were that if one is strong in teaching certain concepts, the individual should be able to teach the other colleagues' classes. Through this way, no learner would be disadvantaged because of the teachers' lack of competency. Collaboration with fellow teacher remains one of the crucial elements of teacher development, especially engaging with experienced in-service teachers considering that the developmental process occurs when the mentor is more knowledgeable than the other, hence mentorship between in-service and pre-service teachers is recommended.

Some of the pre-service teachers indicated that they were willing to enrol in content enrichment programmes specific for the topics they struggled in. They indicated that they would utilise technology to enrich their knowledge. Some of the pre-service teachers also pointed out that navigating through technology would assist them to obtain resources, encourage them to become innovative in their teaching, a skill needed in the $4^{\text {th }}$ industrial revolution.

\section{Discussions}

Pre-service teachers identified different topics which they were not confident to teach which were influenced by factors such as lack of content knowledge, contradiction with one's beliefs and religion, former high school teacher's approach when teaching the topic, and lack of interest in the topic. As a result of these factors, pre-service teachers struggled to apply robust teaching approaches when teaching those topics. Considering the difficulties mentioned by the pre-service teachers, it shows that they did not only impact on their subject matter knowledge but also on their pedagogical knowledge to teach the topics. Thus said, teachers' topic specific PCK is underdeveloped. This is so because an early study by Rollnnick et al. (2008) identified the role of subject matter knowledge in the teachers' PCK and that the lack of subject matter knowledge is problematic and is an issue of concern in South Africa.

Being well knowledgeable and passionate about the subject matter raises the potential of the teacher to implement innovative strategies to support learners' learning. The topic evolution has proved to be challenging to both teachers' and learners' religious beliefs, thus the pre-service teachers indicated their discomfort and lack of confidence thereof to teach such a controversial topic particularly human evolution. This therefore influences in a negative way the manner in which teachers would teach such concepts to their learners because Mavuru and Ramnarain (2020) found that the learners' socio-cultural 
backgrounds which includes their belief systems influences how they learn or engage with the concepts taught. Notably, it was also found that ignoring learners' worldviews in the teaching and learning process, impacts negatively on learners' conceptual understanding (Mavuru \& Ramnarain, 2020).

\section{Conclusions}

The study focused on answering the research question: How do pre-service teachers perceive their level of preparedness and confidence in teaching high school Life Sciences topics at the end of their four years of teacher professional development? Pre-service Life Sciences teachers were not entirely confident and prepared to teach particular topics. One major identified factor is the lack of the subject matter knowledge which had an effect on the pre-service teachers' PCK. The participants indicated that some of the Life Sciences content is complicated and complex not only to the learners but also to the teachers. The topics identified by the pre-service teachers identified which they felt not prepared and not confident to teach ranged from grade 10 to grade 12 which included the history of life on earth; and plants and animal tissues in grade 10; excretion in grade 11; and evolution and genetics in grade 12. The teachers proffered various reasons for their lack of preparedness which included the poor learning experiences in high school; and the poor university preparation in the content area. The findings have implications on the teacher professional development and informs the future studies which may focus on the initiatives of the teacher education developmental programmes to assist pre-service teachers.

\section{References}

Agbo, S.A. (2003). A learning community model for professional development and transformational teacher education. In: Preston DS (ed.). The Idea of Education. Amsterdam, NY:Radopi.

Botha, M.L \& Reddy, C.P.S. (2011). In-service teachers' perspectives of pre-service teachers' knowledge domains in science. South African Journal of Education, 31, 257-274.

Chang-kredl, S. \& Kingsley, S. (2014). Identity expectations in early childhood teacher education: Pre-service teachers' memories of prior experiences and reasons for entry into the profession. Teaching and Teacher Education, 43, 27-36.

Cimer, A. (2004). A study of Turkish biology teachers' and student's views of effective teaching in schools and teacher education. EdD Dissertation. The University of Nottingham, Nottingham: UK.

Cimer, A. (2012). What makes biology learning difficult and effective: Students' views. Education Research and Reviews, 7(3), 61-71.

Coetzee, A. (2012). Presentation: NSC to CAPS by the Gauteng Department of Education. Paper presented in seminar on NCS to CAPS. Kgorong Hall: UNISA.

Dias-lacy, S.L, \& Guirguis, R.V. (2017). Challenges for new teachers and ways of coping with them. Journal of Education and Learning, 6(3), 265-271.

Harris, D.N. \& Sass, T.R. (2011). Teacher training, teacher quality and student achievement. Journal of Public Economics, 95(7-8), 798-812. https://doi.org/10.1016/j.jpubeco.2010.11.009

Kayapinar, U. (2016). A study on reflection in in-service teacher development: Introducing reflective practitioner development model. Educational Sciences: Theory \& Practice, 16(5), 1671-1691. https://doi.org/10.12738/estp.2016.5.0077

Marshall, M. \& Firth, S. (2017). My revision notes: AQA A level psychology. London: Hodder Education.

Mavuru, L. \& Ramnarain, U. (2020). Language affordances and pedagogical challenges in multilingual grade 9 Natural Sciences classrooms in South Africa. International Journal of Science Education, 42(14), 2472-2492. https://doi.org/10.1080/09500693.2019.1655177

Mavuru, L., Ramnarain, U. (2020). Learners' socio-cultural backgrounds and science teaching and learning: a case study of township schools in South Africa. Cultural Studies of Science Education, 15(4), 1067-1095. https://doi.org/10.1007/s11422-020-09974-8

Merriam, S.B. (2009). Qualitative research: A guide to design and implementation ( $2^{\text {nd }}$ ed). San Francisco, CA: Jossey-Bass.

Rollnick, M., Bennett, J., Rhemtula, M., Dharsey, N., \& Ndlovu, T. (2008). The place of subject matter knowledge in pedagogical content knowledge: A case study of South African teacher. International Journal of Science Education, 30 (10),1365-1387. https://doi.org/ $10.1080 / 09500690802187025$

Setlalentoa, W. (2018). Experiences of pre-service teachers on Life Sciences topics and learning. What makes learning difficult and effective? 40th International Academic Conference, 219-229

Shulman, L. (1986). Those who understands: Knowledge growth in teaching. Educational Researcher, 15 (2), 4-14.

Yildirim, I \& Kalman, M. (2017). The validity and reliability study of the Turkish version of the preparedness to teach scale. Kastamonu Education Journal, 25 (6), 2311-2326. 


\title{
A REVIEW OF PAPERS ABOUT BLOCK PROGRAMMING FROM THE WORKSHOP ON COMPUTING AT SCHOOL
}

\author{
Gilberto Amado de Azevedo Cysneiros Filho, Neiton Carvalho da Silva, \\ \& Barbara Silva Morais \\ Universidade Federal Rural de Pernambuco (UFRPE), Departamento de Estatística e Informática \\ (DEINFO), Street Manuel de Medeiros, s/n-neighborhood: Dois Irmãos, city: Recife - UF: PE, \\ ZIP CODE 52171-900 (Brazil)
}

\begin{abstract}
This paper describes a survey to identify how Block Programming is being used in Brazilian schools. The motivation of this research is to provide us with data and insights to support the research project on Block Programming and Computational Thinking in Schools whose goal is to investigate and create a proposal for how Block Programming can be inserted into the school curriculum. The relevance of this research is that the school should prepare the students for the skills (creativity, programming, problem solving, abstraction and innovation) demanded by the job market and for further education (e.g. university courses and qualification courses). In particular, in Brazil the curriculum of schools is governed by a normative document called the Common National Curricular Base (Base Nacional Comum Curricular - BNCC). The BNCC defines that the school curriculum should enable the student to have the following competencies: (1) knowledge; (2) scientific, critical, and creative thinking; (3) cultural repertoire; (4) communication; (5) digital culture; (6) work and life project; (7) argumentation; (8) self-knowledge and self-care; (9) empathy and cooperation; and (10) responsibility and citizenship. Some of these skills can be achieved by learning Block Programming aligned with Computational Thinking instruction. The importance of learning programming in school is justified by the increased use of technology in modern society and the need to be prepared to create and use technological solutions that involve programming and computing. The BNCC highlights that the skills developed by students should be organized by offering different curricular arrangements, according to the relevance to the local context and the possibilities of the education systems. This can be applied in a multidisciplinary way through block programming based on computational thinking in basic education. A literature review was conducted of papers published in the area of block programming at the Workshop on Informatics at School (WIE) between the years 2016 to 2019. The choice of this event is due to the fact that it has been standing out over the years as a forum for discussions where works in the area of digital technologies of information and communication (TDIC) in formal and non-formal spaces of education have been disseminated. During this period we identified papers that describe the use of several environments of Block Programming (e.g. Scratch) and several experiences and proposals of how to insert Block Programming in the students' education.
\end{abstract}

Keywords: Block programming, computational thinking, BNCC, workshop of computing at school, workshop de informática na escola (WIE).

\section{Introduction}

In modern society, the growing use of technologies proves the importance of learning programming at school. In this context, we have the Brazilian educational planning that outlines strategies for the insertion of programming in basic education. This strategic planning was introduced in the reformulation of the Common National Curricular Base in the year 2018, as we have the insertion of the term Computational Thinking (CP) in basic education. According to [Wing, 2006] the term CP is broadly defined as a methodology of problem solving, systems development through basic concepts of Computer Science, such as logical reasoning.

Given this, it was verified that the teaching of programming for basic education through playful and attractive approaches needs to be taken into consideration. In this context, Visual Programming Languages (VPL), that is, languages that include visual expressions" [Burnett, 1999]. Using this paradigm many tools have developed artifacts for teaching visual programming by "plug-in blocks" with the objective 
of facilitating the teaching-learning process. Since then, block programming discusses fundamental approaches that result in the development of the PC skills addressed in the BNCC. And according to [Silva, Freitas, 2021], the 10 competencies of the BNCC are interrelated, targeting the curricular components of all basic education in Brazil, and interconnecting with the construction of knowledge and skills in the student's academic and professional training.

This work aimed to identify strategies developed by block programming used in the teaching-learning process that stimulate the development of PC through a Systematic Literature Mapping (SLM) as methodology. It aimed to clarify the following research question: How does block programming contribute to the teaching of programming by stimulating PC development through different tools.

\section{Related papers}

Several papers present studies that seek to identify how CP skills can be developed with the teaching of visual programming. According to Bombasar et al. (2015) conducted a systematic review of the literature with the aim of identifying the main tools that have been used to address the development of PC teaching from 2006 to 2015 .

According to (Morais, 2020), many students have difficulties in learning to program and the scientific community has been developing several proposals to overcome this challenge. And as a result it was indicated that the main tools used are those that use visual programming.

\section{Methodology}

According to [Petersen et al. 2015] the methodological procedure of systematic literature mapping (SLM) is a method that allows categorizing primary studies seeking results on the state of the art of a given subject. To identify the strategies developed by block programming used in the teaching-learning process in Brazil, the SLM method was adopted.

\subsection{Search strategy}

The data collection was carried out from October 29, 2020 to January 15, 2021, and it was used as a base the papers published in the Workshop on Informatics at School (WIE), this national base gathers numerous publications on Informatics in Education from Brazil from all years available at: $<$ https://br-ie.org/pub/index.php/wie/issue/archive $>$.

\subsection{Inclusion and exclusion criteria}

Papers published between the years 2016 to 2019 were defined as inclusion criteria, as in previous surveys identified a scarcity of papers detailing block programming teaching in previous years. Another criterion to be considered were papers with technological descriptors parallel to the teaching of computing with approaches linked interdisciplinarily using block programming containing keywords such as: computational thinking, App Inventor, Scratch, Scratch Jr, inclusive education, pedagogical practices in teaching computing, teacher training and BNCC. Two stages were performed: the first stage of screening the papers were chosen through the title and abstract as shown in Table 1.

Table 1. Stage 1 - Proceedings of the Workshop on Computing at School from 2016 to 2019.

\begin{tabular}{|c|c|}
\hline Year(all) & DOI \\
\hline 2016(4) & 10.5753/cbie.wie.2016.359;10.5753/cbie.wie.2016.436;10.5753/cbie.wie.2016.786; 10.5753/cbie.wie.2016.958 \\
\hline $2017(9)$ & $\begin{array}{l}\text { 10.5753/cbie.wie. } 2017.402 ; 10.5753 / \text { cbie.wie. } 2017.362 ; 10.5753 / \text { cbie.wie. } 2017.1159 ; 10.5753 / \text { cbie.wie. } 2017.382 ; \\
10.5753 \text { /cbie.wie. } 2017.432 ; 10.5753 \text { /cbie.wie. } 2017.538 ; 10.5753 \text { /cbie.wie. } 2017.805 ; 10.5753 / \text { cbie.wie. } 2017.1119 ; \\
10.5753 \text { cbie.wie. } 2017.1174\end{array}$ \\
\hline $2018(2)$ & $10.5753 /$ cbie.wie. $2018.41 ; 10.5753 /$ cbie.wie.2018.195 \\
\hline 2019(14) & 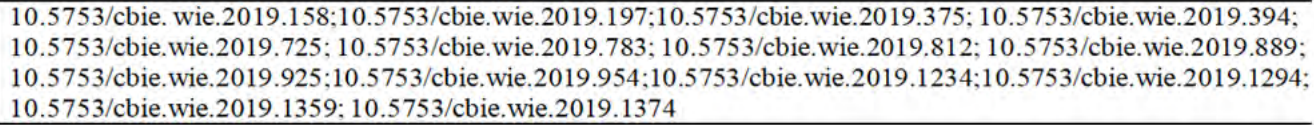 \\
\hline
\end{tabular}

The other step was data extraction whereby the papers were fully analyzed considering the research question against the validation criteria as shown in Table 2. 
Table 2. Criteria used for data extraction in the selected papers.

\section{Criteria for data extraction}

Tool used; PC skills developed; Pedagogical Approaches; Other Information (Place, Year, Teaching Level, Teaching Unit, etc.)

In the end a total of 29 papers were analyzed, and among it significant works were revealed relating block programming to cross-cutting themes such as: Therapy of Psychiatric Patients [Leal, 2019]; Teaching robotics with indigenous people [Segundo, 2019] in basic education in Brazil; Several papers dealing with combating school dropout [Santos, 2019] as an example; Building a humanoid [Amorim, 2016] in a public school in Recife; Financial education with block programming [Oliveira Farias, 2019].

\section{Results and discussion}

Despite the expansion of the term CP as of 2006, we found that the BNCC only addresses the insertion of CP in 2018, leaving a 12-year gap in the knowledge about programming in elementary education. In this context, we observed that from 2019 we had a significant increase in works that inserted programming in blocks in basic education units using different tools that developed PC skills, as shown in Table 1.

Given the filter of criteria selected in Table 2, we observed that the skills addressed in the PC pillars, such as pattern recognition, logical reasoning, abstraction, etc., are being worked on through block programming, because works with different educational modalities and different pedagogical approaches are taking advantage of block programming to expand these skills. Reports of the works that dealt with: inclusive education, indigenous education, and regular basic education performing practices using tools with block programming, propagate the importance of programming for the development of PC.

Another important piece of data deals with the research question through which we analyzed the tools used, as shown in Graph 1. It is possible to see that $48 \%$ of the developed activities used the tool Scratch 1 and $29 \%$ from App Inventor ${ }^{2}$ tool. In this context, it was observed that these two tools were considered strategies that contributed to the teaching of block programming, as it was categorized from digital games to multidisciplinary projects such as: products for financial education in mathematics teaching, resulting from the scope of the learning developed through these tools.

Figure 1. Main Tools Used in Basic Education with Block Programming.

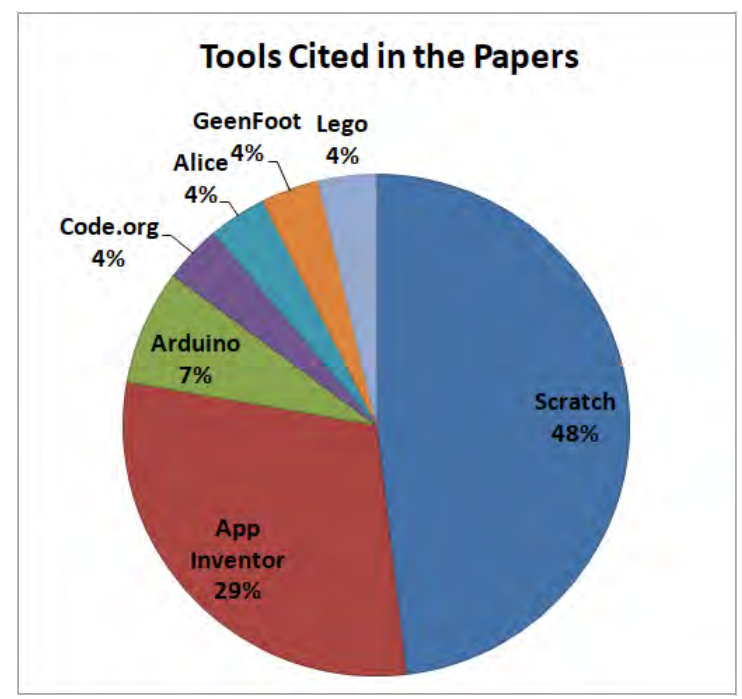

In its totality we obtained a total of 29 mapped papers, among which it was observed, as shown in Table 3, that most of the works were developed in the northeast region.

\footnotetext{
${ }^{1}$ Scratch is a programming language created in 2007 by MIT's Medium Lab. Since 2013 Scratch2 has been available online and as an application for Windows, OS X, and Linux. The source code for version 1.x is under the GPLv2 license. Available at: https://scratch.mit.edu.

${ }^{2}$ MIT App Inventor, also known as App Inventor for Android, is an open-source application originally created by Google, and currently maintained by Massachusetts Institute of Technology (MIT). It allows computer programming newcomers to create software applications for the operating system Android. Available at: https://appinventor.mit.edu.
} 
Table 3. Number of papers per region in Brazil.

\begin{tabular}{c|c|c|c|c}
\hline Regions & North & Northeast & Southeast & South \\
\hline All & 3 & 17 & 4 & 5 \\
\hline
\end{tabular}

We did not verify dated reasons why this phenomenon occurred, however, we can point out that most of the works involved partnerships between universities and schools. This finding also reveals that even though the BNCC deals with the insertion of the PC in basic education, the movement within the school is still considered small. This analysis leads to reflection on the subject that still generates much discussion about teacher training for the teaching of PC, and the practices that will be developed as a result of their knowledge with programming. In this context, the most used tools according to the data were indispensable for being free and considered easy to use in the reports described in the mapped works.

\section{Final considerations}

The result of the mapping considering the criteria of data extraction and the two most used tools, we conclude that free tools are artifacts that facilitate the activities, and that to meet the BNCC on PC in elementary school, block programming can be considered a primary strategy for the development of PC and an important methodology for the basic teaching of programming even in approaches with cross-cutting themes and different educational modalities, considering that the BNCC directs the PC to be inserted in elementary school in a multidisciplinary way.

\section{Future Work}

As a recommendation, we propose an expansion of the researched base by checking other bases (journals and events) not covered by the research, in order to increase the selection of studies, because in SLM we highlight the strategies used through tools that use block programming to develop educational practices. Thus, the block programming offer can be scaled both with digital tools and in the form using unplugged computing, as it covers all the competencies foreseen in the BNCC in accordance with the PC.

\section{References}

Amorim, Jadson et al. Integrating the App Inventor and Arduino Platforms in the Construction of a Humanoid. In: Annals of the Workshop of Computing in School. 2016. p. 786.

Bombasar, James et al. Tools for teaching-learning computational thinking: where is Alan Turing? In: Brazilian Symposium on Computers in Education (Simpósio Brasileiro de Informática na Educação-SBIE). 2015. p. 81.

Brasília, D. (2018). Base Nacional Comum Curricular. Available at: http://basenacionalcomum.mec.gov.br/images/BNCC_EI_EF_110518_versaofinal_site.pdf.

Brazil. Law of Directives and Bases of National Education. Law no. 9.394, of December $20,1996$.

Burnett, Margaret; Sheretov, Andrei; Rothermel, Gregg. Scaling up a" what you see is what you test" methodology to spreadsheet grids. In: Proceedings 1999 IEEE Symposium on Visual Languages. IEEE, 1999. p. 30-37.

Da Silva, Mozart Linhares; De Freitas, Josí Aparecida. A Base Nacional Comum Curricular and the Neoliberal Art of Governing Education In Brazil. Revista Educativa-Revista de Educação, v. 23, n. 1, p. 8097, 2021.

Leal, Lucas; Aita, Keylla Maria Sá Urtiga; Silva, Aline. Experience with the use of the Scratch Tool in the Therapy of Psychiatric Patients. In: Proceedings of the Workshop on Computing in School. 2019. p. 954-963.

Morais, Ceres Germanna Braga; Neto, Francisco Milton Mendes; Osório, António José Meneses. Difficulties and challenges of the algorithms and programming learning process in higher education: a systematic literature review. Research, Society and Development, v. 9, n. 10, p. e9429109287-e9429109287, 2020.

Oliveira Farias, Fernando Lucas de et al. Finance Math Game: An interdisciplinary ludic proposal for Teaching Financial Education with Scratch. In: Proceedings of the Workshop on Computing in School. 2019. p. 1359-1363. 
Oliveira, Manassés Vitorino; Rodrigues, Luciene Cavalcanti; Queiroga, Ana. Ludic didactic material: use of the Scratch tool to aid in the learning of programming logic. In: Anais do Workshop of Informatics at School. 2016. p. 359.

Petersen, Kai; Sairam, Vakkalanka \& Ludwik, Kuzniarz. Guidelines for conducting systematic mapping studies in software engineering: An update. Information and Software Technology 64. 2015. p 1-18.

Santos, Jarles Gomes et al. Gamification as a Methodology for the Development of BNCC General Competencies. In: Proceedings of the Workshop on Computing in School. 2019. p. 812-821.

Segundo, Plácido et al. COMPUTATIONAL THINKING: A strategy for teaching and promoting citizenship in indigenous basic education using free robotics and Scratch programming logic. In: Proceedings of the XXV Workshop on Computing at School. SBC, 2019. p. 1374-1378.

Wing, Jeannette M. Computational thinking. Communications of the ACM, v. 49, n. 3, p. 33-35, 2006. 


\title{
GREEK AND PORTUGUESE MATHEMATICS EDUCATION AND PERFORMANCE, THROUGH THE PRISM OF PISA
}

\author{
Eleni Nolka ${ }^{1}, \&$ Chryssa Sofianopoulou ${ }^{2}$ \\ ${ }^{1}$ Harokopio University of Athens/ PhD Candidate (Greece) \\ ${ }^{2}$ Harokopio University of Athens/ Associate Professor (Greece)
}

\begin{abstract}
Greece and Portugal are two Southern European countries, with nearly the same population as well as a centralized educational system that follows the same vertical structure. Both countries were deeply affected by the economic crisis during the last decade. Despite being severely hit by the economic crisis, Portugal has advanced to the OECD average level in students' mathematical performance in the Programme for International Student Assessment (PISA 2018), while Greece has performed below the OECD average. PISA, as one of the most influential international educational surveys, aims to evaluate educational systems and provides a valuable platform for comparisons. Portuguese students outperformed their Greek counterparts by 7 points in the first PISA 2000 and went on to widen the difference by 41 points in PISA 2018. In addition to having increased the average performance in Mathematics, Portugal has managed to reduce the percentage of low-achieving students and at the same time increase the percentage of high-achieving students. According to PISA 2018 reports, Portugal is the only member of OECD that has experienced significant improvement in mathematics performance of their students through its participation in PISA. In contrast, the performance of Greek 15-year-old students in mathematics has not improved and has remained below the OECD average since it participated in PISA. What national strategies have been set up and implemented in Portugal so as to foster student's mathematical literacy competencies? A clear curriculum, students' regular assessment, teachers' training and the Action Plan for Mathematics. But despite that fact, the Mathematics performance of Greek 15 -year-olds students in PISA in all cycles of PISA remains below the respective OECD average, in contrast with Portugal, that has registered a quantum leap (Crato, 2020).

The main aim of this research is, through a recording of the Greek and Portuguese students' mathematics achievements in PISA and at the same time of the Mathematics Education in both countries, through available policy documents and research reports, to comment on the current outcomes of the two educational systems and their students' performance in Mathematics.
\end{abstract}

Keywords: Mathematics education, mathematics achievement, PISA, Greece, Portugal.

\section{Introduction}

One of the key competences necessary for personal fulfillment, active citizenship, social inclusion and employability in the knowledge society of the 21 st century, is the mathematical competence (European Commission, 2011). Therefore, an understanding of mathematics is recognized by OECD as pivotal to a young person's preparedness for life in modern society and through the Programme for International Student Assessment (PISA), it measures the achievement of 15-years old students on mathematical literacy which is defined as "an individual's capacity to formulate, employ and interpret mathematics in a variety of contexts. It includes reasoning mathematically and using mathematical concepts, procedures, facts and tools to describe, explain and predict phenomena. It assists individuals to recognize the role that mathematics plays in the world and to make the well-founded judgments and decisions needed by constructive engaged and reflective citizens" (OECD, 2014).

The inter temporal importance of PISA can also be located to the point that it has changed the philosophy of world educational policies, by giving feedback to policy-makers to reevaluate their educational system. That's exactly what happened in Portugal, starting from 2001 when the results of first PISA 2000 were published and were disappointing for Portuguese students. It was then that policymakers started to set the stage for the endorsement of a series of ongoing education measures by placing great importance on mathematical education (Marôco, 2021). Furthermore, in Greece, according to Breakspear's (2012) survey, "PISA has provided policy-makers with useful information and tools to 
improve the quality and efficiency of the existing education system in Greece". Nevertheless, the Mathematics performance of Greek 15-year-olds students in PISA in all cycles of PISA remains stable and below the respective OECD average, in contrast with Portugal, that has taken a quantum leap (Crato, 2020).

Below we will develop the major educational policies of both Greece and Portugal, regarding mathematics education, which has taken place in the last 2 decades which are explicitly justified or supported by PISA outcomes in both countries.

\section{PISA and mathematics performance}

Greece's mean performance in Mathematics has been below the OECD average in every year it participated in PISA and can be described as hump-shaped, mainly due to a spike in performance in PISA 2009 while the performance in all other years was stable (OECD, 2019). On the other hand, Portuguese's students mean performance in Mathematics has improved since 2000, 2003 and 2006 while mean performance in 20181 was close to the level observed over the period 2009-2015 and is placed above the OECD average. The average 3-year trend in mathematics mean performance in Greece is only +0.1 points while in Portugal it is +6 points. In the latest PISA 2018, the difference of 41 points between the two countries' mean scores in Mathematics, corresponds to one whole school year, since the OECD has calculated that the 38 points correspond to one school year.

Results from PISA 2018 also showed that the share of Greek low achievers in Mathematics, those who scored below Level 2, remains among the highest in the EU with a shrinkage of 3.1 percentage points since 2003 while the share of students performing at or above proficiency Level 5 has also decreased by 0.3 percentage points since 2003. However, in contrast to Portugal, both low and high achieving students have significantly improved their scores and the corresponding share of students who scored below Level 2 in mathematics has shrank by 6.8 percentage points since 2003 while the share of students performing at or above proficiency Level 5 has increased by 6.2 percentage points. More specific in 2018, more than one-third of Greek 15-year-olds participating in PISA were low achievers in Mathematics (35.8\% compared to an OECD average of $22.2 \%$ ) while in Portugal they were less than one-fourth (23.3\%). The highest Levels 5 and 6 , were reached only by the $3.7 \%$ of Greek students as compared to the OECD average of $11.4 \%$ and to the Portuguese corresponding average of $11.6 \%$. Girls' and boys' performance is also remarkable because in Portugal boys outperformed girls in by 9 score points (OECD average: 5 score points) whereas in Greece there was no difference in Mathematics score-points between genders. This, however, is due to the reduction of boys' performance and not to the improvement of girls (OECD, 2019).

\section{Mathematics curriculum}

In both countries, curriculum is defined centrally. The latest revision and update of the mathematics curriculum for primary and lower secondary education in Greece was in 2003 with the single cross thematic curriculum framework (DEPPS) and the detailed curricula (APS) and in comparison, to Portugal's curriculum that was introduced on 2008, both countries' mathematics curricula are similarly more focused on cross-curricular links and the interaction of mathematics with philosophy, science and technology (European Commission, 2011). A revision of this Portuguese curriculum for Mathematics of the second cycle of primary and lower secondary education took place in 2012/13 with the aim of setting learning standards of basic skills to be reached by all students and to give more flexibility over curriculum management (OECD, 2014). A more flexible curriculum in Portugal has also sprung from a pilot programme in 2017/18 and has been in effect since 2018 (EC/EACEA/Eurydice, 2021b).

The poor alignment of Greek Mathematics curriculum in lower secondary school with the PISA's assessment Mathematics framework and the strong content focus (Breakspear, 2012; OECD, 2018) are highlighted through an IEP's survey which showed that in Greek curriculum, Mathematics applications appear as consequences and not as fields within which Mathematics emerged, like happens in PISA (IEP, 2019). The problem solving in Greek curriculum appears as an application of a specific theory and not as a real-life problem which has an invisible or a subtle connection with the "theory", as encountered in PISA's mathematical literacy problems (IEP, 2019).

\footnotetext{
${ }^{1}$ In PISA 2018 it was required that at least $80 \%$ of the students chosen within participating schools participated themselves and this percentage was not met by Portugal, where only $76 \%$ of students who were sampled actually participated. But, through a non-response analysis based on data from a national mathematics assessment in the country it was shown that the upward bias of Portugal's overall results was likely small enough to preserve comparability over time and with other countries. As a result, the data from Portugal were therefore reported along with data from the countries/economies that met this $80 \%$ student-participation threshold (OECD, 2019).
} 
An important proxy that helps to explain the relative importance of Mathematics as a school subject, compared to others in the curriculum is the recommended taught time which means the curriculum time allocated for teaching mathematics (European Commission, 2011). According to last decades' annual European reports, the weight of mathematics in the curriculum of primary education in Portugal was placed in the highest rank among the European countries and Greece was in the lowest. Moreover, in Greece a student who completes primary school has been taught less than half the number of hours of mathematics in total than his Portuguese counterpart (European Commission/EACEA/Eurydice, 2018). In lower secondary education, Greece is between the European countries with the fewest number of hours but with not so wide gap with Portugal (European Commission/EACEA/Eurydice, 2018; 2011). According to student's responses in PISA 2018, the learning time per week in regular mathematics lessons calculated at 3.4 hours for Greece and 4.5 hours in Portugal (OECD average hours 3.7) (OECD, 2019).

The textbooks, being a central tool for the implementation of the Mathematics curriculum, in Portugal are chosen from the teachers among all available textbooks previously approved by the Ministry of Education, while in Greece schools are limited to one specific authorized mathematics textbook that has been approved by the Institute of Educational Policy (IEP) and is the same for all students attending the same grade (EC/EACEA/Eurydice, 2021). The Greek Mathematics textbooks in lower secondary school, according to an IEP's (2019) survey, contain low percentage of real-life math problems whilst the majority of them could be described as "standard" word problems, which can be solved with any combination of arithmetic operations, rather than "problematic" ones which can be compared to the PISA mathematical literacy problems, according to Verchaffel, Greer and De Corte classification.

\section{Assessment in mathematics}

Student assessment in mathematics is a crucial element of the teaching and learning process and national tests in mathematics are widely implemented and used to inform or guide policymakers to support equity and quality of student learning (European Commission, 2011; OECD, 2018). After Portugal was affected by the poor PISA results, the low-stakes were promoted in 2003 and the corresponding high-stakes exams for Mathematics at the end of Grade 9 were used in 2005 (Marôco, 2021). The application was also expanded (2012) to grades 4 and 6 (OECD, 2014) but was terminated in 2016 (Santiago et al., 2012). Today, student assessment includes both internal and external national assessment in Portugal. The internal student summative assessment is organized by the schools while the external one is carried out by the Educational Evaluation Institute (IAVE) and involves national final exams in the end of basic education cycle, Grade 9, in the subjects of Mathematics and Portuguese, whereas in Grades 2, 5 and 8 standardized tests are administered. There are also national examinations in the end of general secondary education (Liebowitz et al., 2018; OECD, 2020; EC/EACEA/Eurydice, 2021b).

In contrast to Portugal, the Greek educational system has no national assessments in Mathematics to track student performance comparatively across schools, at a regional or national level, either in primary or lower secondary education. The only high-stake national assessment which takes place in Greek educational system is the Panhellenic university admissions examination which is administered only at the end of upper secondary education. In lower and upper secondary school, written progression and school leaving examinations are administered on a number of subjects, as is the case with exams in Mathematics, which are performed by each school and their respective Mathematics' teachers (EC/EACEA/Eurydice, 2021a). It was only as far back as in 2013 that efforts were made to create a more national approach to student assessment in selected school subjects, including Mathematics, in upper secondary school (in Grades 10 and 11) with national tests banks including question items at different levels of difficulty. The use of these test banks was abandoned in 2015/16, given concerns about equity and early school leaving (OECD, 2018).

In Portugal the research work of Marôco and Lourenço, has shown the concurrent and content validity of PISA with the national high-stake exams for mathematics (Marôco, 2020; Crato, 2021). In Greece, due to the absence of national student assessment it is difficult to conduct such surveys. IEP (2019), through some data from the promotion and school-leaving mathematics examinations in 9th grade which were delivered from individual schools and teachers of Mathematics during the last decade, it was estimated that from 232 such tests only on $5(2 \%)$ included at least one item of real-life problem, that could be compared to PISA mathematical literacy problems. So due to the absence of national standardized assessments in Mathematics to provide regular information about students learning outcomes (OECD, 2020) PISA results in Mathematics and data could be provide some evidence to this direction or an international overview of student's performance in relation to other OECD and European countries in order to develop a higher-quality and more equitable Mathematics education (OECD, 2018). 


\section{Improving student's motivation in mathematics}

"Motivation and engagement can be regarded as the driving forces behind learning. Given the importance of mathematics for students' future lives, school systems need to ensure that students have not only the knowledge that is necessary to continue learning mathematics beyond formal schooling, but also the interest and motivation that will make them want to do so" (OECD, 2014). As it is also referred on "PISA in Focus" (OECD, 2014), students who are highly motivated to learn mathematics because they believe it will help them later on score better in mathematics - by the equivalent of half a year of schooling - than students who are not highly motivated or it can be one of the most important determinants of students' achievements in school (European Commission, 2011).

In order to improve student motivation and encourage positive attitudes towards mathematics learning and education, Portugal implemented the "Action Plan for Mathematics", which was launched in 2005. The six components of the plan were: a)implementing a mathematics plan in each school, b)training teachers in basic and secondary schools, c)reinforcing mathematics in initial teacher training, d)readjusting the mathematics curriculum throughout the compulsory education system, e)creating a resource bank or database specifically devoted to mathematics and f)evaluating textbooks on mathematics (OECD, 2013). The Action Plan is referred that "allows students to dedicate more time to the study of mathematics and focus on exploration, investigation and problem-solving" (European Commission, 2011).

In Greece there are no such national strategies or initiatives (European Commission, 2011).

\section{Education and professional development of mathematics teachers}

In Greece both primary teachers and secondary education teachers who teach Mathematics hold at least a first cycle degree (UNESCO, 2015; OECD, 2018) and no additional degrees or pedagogical training certificates are required. In Portugal, with the implementation of the Bologna process (finalized in 2009/2010) the minimum requirement for teaching is a second cycle degree, a master's degree, and the preparation of secondary education mathematics teachers which includes components concerning mathematics, general education, didactics of mathematics and a period of teaching practice (Ponte et al., 2017). In all six grades of primary school in Greece and in the first four grades of basic education in Portugal, Mathematics are being taught from teachers who teach the majority of the subjects but in Grades 5 to 6 in Portugal, Mathematics is being taught by teachers who are qualified in mathematics and may be in other subjects as well. In secondary education, lower and upper, in both countries, Mathematics is being taught by a single teacher with a qualification to this subject only.

The focus on Mathematics teachers training could be regarded also as a measure responsible for the improvement of Portuguese 15-year-old students in Mathematics (European Commission, 2011). Through the "Action Plan of Mathematics", the training of teachers in both primary and secondary education, collaboration between them and co-teaching in the classroom were developed. Also, in measures like "Teams for Success", schools received support teachers, specialists in Mathematics teaching, to help them implement innovative three-year projects focused on the improvement of students' mathematics learning, the promotion of professional development programmes, the creation of database of educational mathematics resources, the reorganization of initial teacher training programmes and access to STEAM teaching (Kearney, 2011). In additional, at the end of the school year, every school carried out self-evaluation within the scope of the Mathematics Plan II which included an evaluation of the strategies implemented, student performance in mathematics, and the development and implementation of the mathematics programme (European Commission, 2011).

\section{Conclusion}

The improvement of the level of students' motivation in Mathematics classrooms, the focus on Mathematic teachers' training that laid emphasis into their collaboration and the implementation of national tests in mathematics in compulsory education, with the scope to inform the policy makers for the curriculum development as well as the improvement in teachers training, could be considered as factors positively related to the performance of Portuguese students in PISA Mathematics. A positive conclusion that can be drawn, as demonstrated by the experience of Portuguese Education system and could prove useful to Greek education as well, is that top performers can be nurtured while simultaneously assisting struggling students, thus strengthening the OECD view that "Countries do not have to choose between nurturing excellence in Education and reducing underperformance" (OECD, 2016). 


\section{References}

Breakspear, S. (2012). The Policy Impact of PISA: An Exploration of the Normative Effects of International Benchmarking in School System Performance. OECD Education Working Papers, No. 71. Paris: OECD. https://doi.org/10.1787/5k9fdfqffr28-en

Crato, N. (2020). Curriculum and educational reforms in Portugal: An analysis on why and how students' knowledge and skills improved. In F. Reimers (Ed.), Audacious Education Purposes (pp. 209-231). Springer, Cham.

EC/EACEA/Eurydice. (2021a). Greece Overview. Retrieved January 10, 2021, from https://eacea.ec.europa.eu/national-policies/eurydice/content/greece_en

EC/EACEA/Eurydice. (2021b). Portugal Overview. Retrieved January 10, 2021, from https://eacea.ec.europa.eu/national-policies/eurydice/content/portugal_en

European Commission/EACEA/Eurydice. (2018). Recommended Annual Instruction Time in Full-time Compulsory Education in Europe - 2017/18. Eurydice - Facts and Figures. Luxembourg: Publications Office of the European Union.

European Commission. (2011). Mathematics Education in Europe: Common challenges and national policies. Brussels: EACEA. Retrieved from https://op.europa.eu/en/publication-detail//publication/3532f22d-eea2-4bb2-941b-959ddec61810

IEP. (2019). Greek Mathematics Education and PISA assessment. Athens: Institute of Educational Policy.

Kearney, C. (2011). Efforts to increase students' interest in pursuing science, technology, engineering and mathematics studies and careers. Brussels: European Schoolnet. http://www.fisme.science.uu.nl/publicaties/literatuur/2011 european schoolnet.pdf

Liebowitz, D., González, P., Hooge, E., \& Lima, G. (2018). OECD reviews of school resources: Portugal 2018. Paris: OECD. https://doi.org/10.1787/9789264308411-en

Marôco, J. (2021). Portugal: The PISA Effects on Education. In N. Crato (Ed.), Improving a Country's Education (pp. 159-174). Springer, Cham. https://doi.org/10.1007/978-3-030-59031-4_8

OECD. (2013). PISA 2012 Results: Ready to Learn (Volume III). Paris: OECD. http://dx.doi.org/10.1787/9789264201170-en

OECD. (2014). Are Grouping and Selecting Students for Different Schools Related to Students' Motivation to Learn? In PISA in Focus, No. 39. https://doi.org/10.1787/5jz5hlpb6nxw-en.

OECD. (2014). Education Policy Outlook Portugal. Retrieved from http://www.oecd.org/education/highlightsportugal.htm

OECD. (2014). PISA 2012 Results: Creative Problem Solving: Students'Skills in Tackling Real-Life Problems (Volume V). Paris: OECD. http://dx.doi.org/10.1787/9789264208070-en

OECD. (2014). PISA 2012 Results: What Students Know and Can Do (Volume I). Paris: OECD. http://dx.doi.org/10.1787/9789264201118-en

OECD. (2016). PISA 2015 Results (Volume I): Excellence and Equity in Education. Paris: OECD. http://dx.doi.org/10.1787/9789264266490-en

OECD. (2018). Curriculum Flexibility and Autonomy in Portugal - an OECD review. Retrieved from https://www.oecd.org/education/2030/Curriculum-Flexibility-and-Autonomy-in-Portugal-anOECD-Review.pdf

OECD. (2018). Education for a Bright Future in Greece. Reviews of National Policies for Education. Paris: OECD. https://doi.org/10.1787/9789264298750-en.

OECD. (2019). PISA 2018 Results (Volume I): What Students Know and Can Do. Paris: OECD. https://doi.org/10.1787/5f07c754-en

OECD. (2019). PISA 2018 Results (Volume II): Where All Students Can Succeed. Paris: OECD. https://doi.org/10.1787/b5fd1b8f-en

OECD. (2020). Education Policy Outlook in Portugal. OECD Education Policy Perspectives, No. 21. Paris: OECD. https://doi.org/10.1787/0e254ee5-en

OECD. (2020). Education Policy Outlook in Greece. OECD Education Policy Perspectives, No. 17. Paris: OECD. https://doi.org/10.1787/f10b95cf-en

OECD. (2020). PISA 2018 Results (Volume V): Effective Policies, Successful Schools. Paris: OECD. https://doi.org/10.1787/ca768d40-en

Ponte, J. P., Santos, L., Oliveira, H., \& Henriques, A. (2017). Research on teaching practice in a Portuguese initial secondary mathematics teacher education program. ZDM Mathematics Education, 49(2), 291-303.

Santiago, P., Donaldson, G., Looney, A., \& Nusche, D. (2012). OECD Reviews of Evaluation and Assessment in Education: Portugal 2012. OECD Reviews of Evaluation and Assessment in Education. Paris: OECD. https://doi.org/10.1787/9789264117020-en

UNESCO. (2015). Education for All 2015 National Review Report: Greece. Retrieved from https://unesdoc.unesco.org/ark:/48223/pf0000229950?posInSet=1\&queryId=ded84546-fe6c-45479480-af101f2cdca1 


\title{
WOMEN FACULTY AND SCIENTIFIC PRODUCTIVITY IN LATIN AMERICAN CONTEXT: EVIDENCE FROM CHILE
}

\author{
Geraldy Sepúlveda-Páez ${ }^{1}$, \& Carmen Araneda-Guirriman ${ }^{2}$ \\ ${ }^{1}$ Universidad de Tarapacá, Arica (Chile) \\ ${ }^{2}$ Facultad de Ingeniería, Depto. de Ingeniería Industrial y de Sistemas, Universidad de Tarapacá, \\ Arica (Chile)
}

\begin{abstract}
Since the 19th century, the position of women in the context of higher education has undergone multiple changes, although their incorporation has not been a simple or homogeneous task. Currently, women face new consequential challenges of a globalized world and the notion of market education that characterizes institutions nowadays. One of the great challenges is related to the under-representation of women in senior research positions (Aiston and Fo, 2020). In this context, new standards have been established to measure the productivity, quality, and effectiveness of teachers, specifically scientific productivity has been internalized as an indicator of professional progress, the type of publication, its impact, and the citation rates today. They have special relevance, where many times achieving high scientific productivity is very complex for academics who do not access the teaching staff early (Webber and Rogers, 2018). Furthermore, it is very difficult for academic women to maintain high levels of productivity constantly both at work and home (Lipton, 2020). In this sense, the principles that encourage academic productivity increase competition among teachers and reinforce gender inequalities together with a valuation of male professional life (Martínez, 2017). Indeed, the participation of women in sending articles is much lower than their male counterparts (Lerback and Hanson, 2017). Therefore, the present study aims to visualize the participation of Chilean academics in current productivity indices, based on the description of secondary data obtained from the DataCiencia and Scival platforms. The sample consists of 427 people, of which $17.3 \%$ were women, with an average of 10 publications for the year 2019. To achieve the objectives, the following strategy was developed: 1) describe and interpret the secondary data obtained during the year 2019 on each of the platforms. 2) Compare the data obtained to national averages and type of institution and gender. Based on the analyzes, the implications of female participation in the number of women observed at the national level and their position in international indicators and new lines of research are discussed.
\end{abstract}

Keywords: Women, faculty, scientific productivity, higher education.

\section{Introduction}

The expansion of higher education since the end of the last century has brought new transformations that lead to rationalization and organization of society and, at the same time, provides the basis for global integration and the modern service economy (Schofer et al., 2020).

In a scenario where academic capitalism has the participation of professors and researchers as entrepreneurs of intellectual capital, because it requires education and research to meet the needs of the labor market and the changing economy, deliver infrastructure and services to companies, and transferring knowledge that contributes to capital accumulation (Jessop, 2017).

Likewise, one of the main objectives of higher education is the creation of new knowledge through research and therefore the publications that are generated from it (Aithal and Kumar, 2017). In this scenario, higher education journals have become the most important repository of research results in higher education, since scientific articles represent the achievement and conclusion of a process to achieve their publication after being reviewed by pairs (Tight, 2018).

This expansion of the university manifests itself through the dialectical development between social achievement and commodification, since, on the one hand, capital needs the knowledge resulting from academic research to drive innovation and, on the other, it requires a highly skilled workforce. qualified (Allmer, 2019). In this context, not only universities but also the academic body have had to adapt to the expectations set by the market and demonstrate their value through productivity in research (Berheide et al., 2020). Indeed, in this scenario, there is an increase in the number of academics around the world, whose number went from 4 million in 1980 to 13.1 million in 2018, with the consequent increase in the 
number of publications between those years from 0.65 million to 3.16 million respectively, among the countries with the highest productivity in the United States (To et al., 2020).

This new academic production results in more flexible, diverse, and complex research careers (Holzinger et al., 2018). However, women have been and continue to be under-represented in science, which can affect their quality and competitiveness in research (Astegiano et al., 2019).

Mayer and Rathmann (2018) point out from the results found that academic women research and publish with different patterns, that is, instead of sending articles to competitive journals, they may feel satisfied with the publication of less prestigious book chapters, a situation that in the long run can be configured as a disadvantage for their professional advancement, since peer-reviewed journals are considered in the academic progression. In general terms, different factors put researchers at a disadvantage, since they have fewer opportunities to become highly productive researchers (Besselaar and Sandström, 2017).

Consequently, men and women dedicated to research have different performances in the scientific publication process, as happens with international collaboration and with scientific productivity that is much lower in women compared to men, which hinders their professional development ( Aksnes et al., 2019). The gender biases experienced by academic women not only have negative consequences for women but also for science. First, this bias affects female scientists who are underrepresented in higher education institutions, especially in the highest hierarchies (Cislak et al., 2018).

The results of a study by Agunis et al. (2018) suggest that researchers with consolidated careers can accumulate levels of productivity similar to their male peers, however, their productivity increases are more limited, therefore, it is observed in this research that women with consolidated research careers need Over-accumulate or do more - that is, gain more knowledge, build more networks, and spend more hours on research - to achieve the same level of results as their male counterparts.

Consequently, gender has an impact on the academic ranking, the role of researchers in research teams and networks, since women researchers tend to be in the lowest academic positions and have fewer leadership positions, which that negatively impact their performance (Besselaar and Sandström, 2017). Likewise, academics tend to allocate more hours of work with students, decreasing their dedication of time to research activities. With this distribution of time, women's academic career is harmed, since the academic system rewards research over publications (Bagilhole, 2019).

\section{Design}

The present study is exploratory and descriptive. Through the analysis of secondary data, we seek to elucidate the participation of Chilean authors in prestigious research concerning their male peers, different categories are considered such as number of publications, number of field citations, h-index.

\section{Objectives}

The purpose of this research is to describe the participation of Chilean academic women in high-quality research and at the same time to make their situation visible with respect to their male peers. To this end, work has been done through the analysis of secondary data on the scientific productivity of Chilean researchers with the highest number of indexed publications.

To fulfill the objective, first, descriptive statistics (means, standard deviations, etc.) are obtained for each of the variables according to the sex of the authors.

\section{Methodology}

Data acquisition and integration

The study data were obtained using two platforms: (1) SciVal (https://www.scival.com/home); and (2) DATACIENCIA (https://dataciencia.anid.cl/). From SciVal, the 500 authors with the highest scientific production in Chile were collected in a period from 2017 to 2019, this platform provides access to the research performance of different institutions and their associated researchers in total SciVal considers 231 countries around the world. Likewise, the DATACIENCIA platform collected 3,303 authors with Chilean affiliation in 2019. This platform provides the dimensions of the national scientific production by gender, institution, region, and publications.

Therefore, for the coding of the authors' gender, the data obtained in DATACIENCIA were manually matched with the top 500 authors with the highest production delivered by SciVal. Also, 2 additional criteria were used for data integration: having at least 3 publications per author and having the $\mathrm{H}$ index (an indicator of scientific production). Based on these requirements, the sample is made up of 427 authors with Chilean affiliations. 


\section{Data analysis}

To characterize the sample, descriptive analyzes were carried out for the study variables (gender, type of institutions, number of publications, citations, weighted citations to the field, and $\mathrm{H}$ index).

The analyzes were carried out through the Statistical Package for the Social Sciences (SPSS) Version 25 program (IBM cor., 2017).

\section{Results}

The results show that the percentage of academic women $(17.3 \%)$ is much lower than their male counterparts $(82.7 \%)$. Descriptive statistics are presented in Table 1.

Regarding the number of publications reported for the year 2019 in the DataCiencia platform, it is observed that men present a higher average (12.9) than their female counterparts (9.6). Likewise, in the Scival platform, the academic production observed between the years 2017-2019 reflects that women present an average (33.12) while male authors present an average (41.24). Regarding the number of citations between the years 2017-2019, it is observed that male authors have a higher average (647) than women (501). However, about appointments in the field of application, the mean of men (1.9) does not present great differences for women (2.0) and finally, concerning the productivity indicator $\mathrm{H}$ index, women presented an average of 23.05 while men an average of 26.90 between the years 2017 and 2019 . These results can also be explained because women in the samples correspond to less than a third of the number of men.

Table 1. Descriptive Statistics.

\begin{tabular}{lcc}
\hline & Women $(N=74)$ & Men $(N=353)$ \\
\hline$N^{\circ}$ of publications of DataCiencia & & \\
\hline Mean & 9.59 & 12.95 \\
Standard Deviation & 11,7 & 17,2 \\
Min-Max & $3-102$ & $3-109$ \\
\hline Academic Production at SciVal (2017- 2019) & & 41.24 \\
\hline Mean & 33.12 & 46,52 \\
Standard Deviation & 25,97 & $20-338$ \\
Min-Max & $21-238$ & \\
\hline Citations & & 647,71 \\
\hline Mean & 501,76 & 1297,8 \\
Standard Deviation & 919,6 & $22-8140$ \\
Min-Max & $43-7077$ & 1.94 \\
\hline Citations in field of application & & 2,4 \\
\hline Mean & 2,09 & $0-29$ \\
Standard Deviation & 2,12 & 26.90 \\
Min-Max & $0-13$ & 17,44 \\
\hline Indice $H$ & & $2-109$ \\
\hline Mean & 23,05 & \\
Standard Deviation & 15,36 & \\
Min-Max & $6-105$ & \\
\hline
\end{tabular}

\section{Discussion}

The present exploratory study made visible that female academics with Chilean affiliation are underrepresented in prestigious research compared to their male peers, which reflects a similar proportion to the national reality where authors with Chilean affiliation represent $(37 \%)$ of the universe compared to men considered active authors, who represent (63\%) (DataCiencia, 2020).

In the results, mean differences are observed between the number of publications, where men present a greater number of published articles than women, although these differences did not undergo any statistical contrast test, it is worth mentioning that the evidence indicates that Men are frequently invited to participate as reviewers of prestigious journals, they have greater ease of access to key networks for production and promotion in the research career, such as a greater possibility of grants (Witteman et al., 2019; Hengel, 2017; Lerback and Hanson, 2017), which undoubtedly can influence the construction of research teams and subsequent scientific publications.

It is necessary to consider that the data worked on in this study contemplate a reality different from the current world scenario where the pandemic already has effects on scientific productivity, which shows 
the difficulty for women where the systematic barriers they face combine and enhance (Oleschuk, 2020), since there is evidence in the international literature that shows gender differences in scientific production, as is the case with the study by Aksnes (2019) whose results show gender differences in international collaboration in research and the consequent concern about gender inequalities in science, due to the low level of productivity of female researchers.

On the other hand, the present study has some limitations to consider when interpreting its conclusions, the exploratory nature, as it is a study that only observes a particular year and did not work with a time series to see the evolution and behavior of the variables over a longer period.

\section{Conclusions}

The purpose of this research was to make visible the participation of women in high-impact research in a Chilean context, as well as to analyze the existence of gender differences in scientific productivity, with a much smaller number of female researchers than their male equivalents.

The results show that the authors with Chilean affiliation are underrepresented in prestigious research, it is observed that both in the data provided by DataCiencia for the year 2019 and in the data provided by Scival between 2017 and 2019 the number of articles published by women is inferior to their peers. The same occurs with the number of citations, men present a greater number and a higher $\mathrm{H}$ index.

\section{Acknowledgments}

The National Research and Development Agency (ANID) supported this work by the research grant Fondecyt Regular $N^{\circ} 1201517$ "Women in higher university hierarchies: perceptions of their career andacademic experience from their voices".

\section{References}

Aguinis, H., Ji, Y. H., \& Joo, H. (2018). Gender productivity gap among star performers in STEM and other scientific fields. Journal of Applied Psychology, 103(12), 1283.

Aiston, S. J., \& Fo, C. K. (2020). The silence/ing of academic women. Gender and Education, 1-18.

Aithal, P. S., \& Kumar, P. M. (2017). Challenges and Opportunities for Research \& Publications in Higher Education. International Journal of Scientific Research and Modern Education (IJSRME), ISSN (Online), 2455-5630.

Aksnes, D. W., Piro, F. N., \& Rørstad, K. (2019). Gender gaps in international research collaboration: a bibliometric approach. Scientometrics, 120(2), 747-774.

Allmer, T. (2019). Academic labour, digital media and capitalism. Critical Sociology, 45(4-5), 599-615.

Astegiano, J., Sebastián-González, E., \& Castanho, C. D. T. (2019). Unravelling the gender productivity gap in science: a meta-analytical review. Royal Society open science, 6(6), 181566.

Bagilhole, B. (2019). Against the odds: Women academics' research opportunities. Gender, teaching and research in higher education. Challenges for the 21st century.

Cislak, A., Formanowicz, M., \& Saguy, T. (2018). Bias against research on gender bias. Scientometrics, 115(1), 189-200.

Hengel, E. (2017). Publishing while Female. Are women held to higher standards? Evidence from peer review. Cambridge Working Paper Economics https://doi.org/10.17863/CAM.17548

Jessop, B. (2018). On academic capitalism. Critical policy studies, 12(1), 104-109.

Lerback, J., \& Hanson, B. (2017). Journals invite too few women to referee. Nature News, 541(7638), 455.

Lipton, B. (2020). Academic women in neoliberal times. Springer Nature.

Martinez, A. (2017). Generational dispositions of women faculty: a critical examination. In Critical approaches to women and gender in higher education (pp. 215-234). Palgrave Macmillan, New York.

Mayer, S. J., \& Rathmann, J. M. (2018). How does research productivity relate to gender? Analyzing gender differences for multiple publication dimensions. Scientometrics, 117(3), 1663-1693.

Oleschuk, M. (2020). Gender equity considerations for tenure and promotion during COVID-19. Canadian Review of Sociology.

Programa de Información Científica (08 January, 2021) DATACIENCIA, Dimensiones de la Producción Científica, Retrieved 20 March, 2021, https://dataciencia.anid.cl/authors

Schofer, E., Ramirez, F. O., \& Meyer, J. W. (2020). The societal consequences of higher education. Sociology of Education, 0038040720942912. 
Tight, M. (2018). Higher education journals: Their characteristics and contribution. Higher Education Research \& Development, 37(3), 607-619.

To, W. M., \& Billy, T. W. (2020). Rise in higher education researchers and academic publications. Emerald Open Research, 2(3), 3.

Van den Besselaar, P., \& Sandström, U. (2017). Vicious circles of gender bias, lower positions, and lower performance: Gender differences in scholarly productivity and impact. PloS one, 12(8), e0183301.

Webber, K.L., Rogers, S.M. Gender Differences in Faculty Member Job Satisfaction: Equity Forestalled?. Res Higher Education 59, 1105-1132 (2018). https://doi.org/10.1007/s11162-018-9494-2

Witteman, H.O., Hendricks M., Straus S. and Tannenbaum C. (2019). "Are Gender Gaps Due to Evaluations of the Applicant or the Science? A Natural Experiment at a National Funding Agency." The Lancet 393(10171):531-40 


\title{
IDENTIFYING THE EFFECTIVE TEACHER: THE CONCEPTIONS OF PRE-SERVICE ASSISTANT NURSES
}

\author{
Katerina Kasimatis ${ }^{1}$, Vasiliki Kontogianni ${ }^{2}$, Andreas Moutsios-Rentzos ${ }^{3}$, \\ \& Varvara Rozou ${ }^{4}$ \\ ${ }^{1}$ Department of Education, School of Pedagogical and Technological Education ASPETE (Greece) \\ ${ }^{2}$ Vasiliki Kontogianni, Psychiatric Hospital of Attica (Greece) \\ ${ }^{3}$ Department of Pedagogy and Primary Education, National and Kapodistrian \\ University of Athens (Greece) \\ ${ }^{4}$ Department of Philosophy, National and Kapodistrian University of Athens (Greece)
}

\begin{abstract}
In this paper, we focus on the conceptions of effective teaching that pre-service assistant nurses hold about effective and ineffective teaching during their training in Public Vocational Training Institutes (DIEK) in Greece. We focused on three aspects of teaching effectiveness: 1) The model of Patrick and Smart (1998), who identified three groups of effective teacher characteristics includes; respect for students, ability to challenge students, organisation and presentation skills; 2) Considering the hands-on teaching experiences of pre-service assistant nurses, we explored their conceptions about teaching effectiveness in problem-based learning educational settings, based on Mayo, Donnelly, Nash and Schwartz (1993), who investigated, amongst others enthusiasm, active interaction and providing feedback. 3) The communicational aspect of teaching effectiveness, drawing upon the work of McCroskey and Richmond (1990) about socio-communicative styles, who identified two dimensions of interpersonal communication; namely assertiveness and responsiveness. All three aspects were explicitly investigated for both effective and ineffective teaching. A three-section (in line with the three-faceted conceptualisation of teaching effectiveness), 56 Likert-type items, questionnaire was completed by 125 students. Our analyses allowed us to identify which aspects of teaching characterise the effective teacher and which are present both in the effective and the ineffective teacher.
\end{abstract}

Keywords: Effective teaching, nurse education, assistant nurses, vocational education.

\section{Introduction}

Effective teaching in diverse educational settings has gathered the interest of numerous research projects, adopting various theoretical and methodological lenses (Creemers, \& Kyriakides, 2008; Muijs, \& Reynolds, 2017). Moreover, the current economic situation has gathered the research focus on vocational education and training (Mouzakitis, 2012) that seems to be amongst the priorities of various countries (see, for example, OECD, 2015), since most of the industrialized countries need to equip their labor force with the new abilities that the labor market demands. In the European context, vocational education emerged in 1990 due to socio-economic factors and transformations. Vocational Education and Training supports individuals to obtain specialized scientific and technical knowledge, improves transition to employment and enhances employability. For example, Biavaschi et al. (2012) revealed an increase of the demand for the connection of youth into labor markets.

In modern societies, nursing education has the pioneering role of producing motivated, competent, qualified and caring professional nurses. Nursing educators hold the key role of the transformation of nursing students to professional practitioners. In Greece, poor staff-patient ratios and the shortage of qualified nurses have been also evident in Greek hospitals over the last few years (Kentikelenis, \& Papanicolas, 2011), underlying the increased need for qualified nurses to meet challenges and increased responsibilities. However, assistant nurses' education and training has not been as extensively researched. In this study, we focus on assistant nurses who are trained in Vocational Training Institutes (IEK) and in particular Public Vocational Education and Training (DIEK). Post-secondary vocational education in Greece aims at the increase of an individual's productivity and results to recognized qualifications or equips people with exploitable knowledge and necessary skills for 
the execution of a set of work (occupational specialization). Vocational Education and Training offers preliminary training alternating between theoretical lessons and classes in workshops (hands on). Over the last decade the Greek government has upgraded vocational training aiming to empower individuals, provide them with the necessary skills for active participation in society and promote employment. Since 1990, IEKs and DIEKs provide several specializations in nursing (Nursing Traumatology, Operating Room nursing, Nursing People with Mental Conditions, Intensive Care Unit nursing etc).

A large body of research has focused on the subject of comparing effective and ineffective teaching behaviors. Most of them reveal that effective nursing teaching practices are crucial to the development and production of competent practitioners. Acknowledging the growing interest in vocational education and, in particular, the importance of providing effective training to the particular population, this study attempts to add to this body of research by investigating the conceptions of pre-service assistant nurses (who study in DIEKs) about teaching effectiveness and ineffectiveness in Greece.

\section{Nurse education and effective teaching}

Nurse education requires appropriate teaching that supports future nurses to obtain a concrete knowledge base that can provide them with the necessary skills and equip them to confidently manage the complex components of clinical practice. Rush, Acton, Tolley, Marks-Maran, and Burke (2010) stress that the health-care system is constantly changing demanding more from nurses and focuses on the need for nurses that can think quickly and effectively, make accurate assessments, solve problems and take decisions. Moreover, over the last decades, a paradigm shift has occurred in nursing education; from a teacher to learner centered approach and from the theory to practice. There is an emerging need for nursing education to be effectively connected to the nursing practice, so that nursing students can be more prepared for their future role and responsibilities in the complex health care environment. Nurse educators need to avoid traditional passive lecture styles and to adopt the use of tools and techniques which facilitate reducing the gap between theory and practice (Wells et al., 2002), including the use of technology as a teaching tool, Project-Based Learning Strategies, simulations, Problem Based Learning (PBL) and role playing (Durham, \& Alden, 2008). Furthermore, today's complex societies demand for nurses to possess strong communication skills. The teachers' communication behavior impacts on student's outcomes and their communicative style.

Considering the two-faceted education of pre-service assistant nurses (theoretical and hands-on), we argue that teacher effectiveness should address both aspects. Regarding hands-on teaching effectiveness, medical schools seem to employ problem-based learning (PBL). Mayo, Donnelly, Nash and Schwartz (1993) focused on the identification of the effective tutors' characteristics in a PBL educational setting. Although PBL first appeared in the 1950s in medical schools in the United States, it is a contemporary pedagogical strategy for posing real world situations, resources and instruction to students, as they develop problem-solving skills (Mayo et al, 1993). The findings of their study indicated that the students viewed the average PBL tutor as competent in all the evaluated skills. The tutors that were most highly rated were the ones that showed enthusiasm, actively interact with the students and exhibited a high degree of comfort outside their areas of expertise. Moreover, the effective tutor helps students to identify issues of importance, errors and deficiencies and provides feedback to students. Feedback is a core feature of an effective tutor and should come not only from tutor but also from the students.

At the same time, an important measure of teacher effectiveness except from teachers' sociocommunicative orientation are teachers' personal traits and qualities. Research has revealed that a high level of teacher competency results to increased student engagement and consequently to better leaning outcomes (Curran, \& Rosen, 2006; Paswan, \& Young, 2002). In the current study we adopted McCroskey and Richmond's (1990) views to examine relations among perceived sociocommunicative styles and teacher effectiveness. McCroskey and Richmond (1990) focused on the empirical relations between personality's unique characteristics and traits and communicative behavior. An integral part of their research is the assumption that the personality of an individual has significant impacts on the communication behavior and that it has a biological base (see also, Beatty, McCroskey, \& Valencic, 2001). More specifically, they suggested that the two basic components/dimensions of interpersonal communication are assertiveness and responsiveness. Responsiveness characterizes an individual who "considers other's feelings, listens to what others have to say, and recognizes the needs of others" (Richmond \& Martin, 1998, p. 136-137), while assertiveness refers to the individuals that "are able to initiate, maintain, and terminate conversations, according to their interpersonal goals" (p. 136). As a result, McCroskey \& Richmond (1990) suggested that teachers who present responsiveness to their students, enhance cognitive and affective learning than the ones not as responsive. 
In the current study, we adopted Patrick and Smart's (1998) teacher characteristics that have been also evident in other research studies on teacher effectiveness. The teacher competencies evaluated in this study, are respect for students, the ability to challenge students, and having presentation and organizational skills. The research study of Patrick and Smart (1998) was conducted in two distinct phases. In phase one, undergraduate students identified specific qualities of effective teachers. In phase two they made use of items from existing tools that measure effective teaching and combined them with items occurred from students' responses in phase one, in order to form a meta-inventory. This meta-inventory was administered to undergraduate students. The analysis revealed that teacher effectiveness has a multi-dimensional nature, consisting of thirty-six effective teacher attributes, qualities or activities, that can be organised in three groups: respect for students, ability to challenge students, organisation and presentation skills.

All three aspects (general and hands-on teaching characteristics, as well as socio-communicative styles) were explicitly investigated for both effective and ineffective teaching, thus allowing for the effective and the ineffective teaching aspects to not a priori diverge.

\section{Methods and procedures}

A three-section, 56 Likert-type items, questionnaire was completed by 125 students $(\mathrm{N}=125$; from 6 DIEKs) in November 2016. Each section included the questionnaires developed by the aforementioned theorists - 24 items, Patrick and Smart (1998), 12 items Mayo et al (1993), 20 items McCroskey and Richmond (1990). It should be stressed, that all items for all scales were transformed to dyads, explicitly requiring the participants to provide answers for both the effective and the ineffective teacher.

We adopted the SocioCommunicative Orientation Scale (SCO) of McCroskey and Richmond (1990). In particular, 20 7-point Likert type items were employed: 10 items to measure responsiveness and 10 to measure assertiveness. According to Mayo et al. (1993) the students evaluate their tutors on 12 characteristics hypothesised to be essential for effective teaching and, respectively, 12 7-scale Likert type items operationalise this perspective. Considering Patrick and Smart (1998), three scales (each consisting of 8 7-point Likert type items) measure the three dimensions of teacher effectiveness (respect, organisation, challenge).

The factorial analyses (Principal Axis Factoring), followed by reliability analyses (Cronbach's alpha), supported the validity and reliability of the employed measures. The convergence between the conceptions of the pre-service DIEK students about the ineffective and the effective teacher was calculated as the difference between the respective answers for each scale. The Wilcoxon Signed Rank Test was used to identify statistically significant difference (chosen at $P<0.05$ ) from the conceptual neutral or from complete agreement. All the analyses were conducted with SPSS 25.

\section{Results}

The results of the conducted analyses are summarised in Table 1. Note that the scales range from ' 1 ' to ' 7 ' (referring to respectively 'completely disagree' and 'completely agree'), with the conceptual median being ' 4 '. In addition, the agreement on effective and non-effective responses was calculated as the difference between the replies given. In this case, the agreement values ranged from ' -6 ' to ' +6 ', with ' 0 ' denoting complete agreement between them.

The effective teacher was found to be statistically significantly more responsive than the ineffective teacher, but not statistically significantly different from the ineffective teacher with respect to assertiveness. Moreover, for responsiveness, the effective teacher was statistically significantly higher than the conceptual neutral, whilst the ineffective was statistically significantly lower than the conceptual neutral. On the contrary, no statistically significantly differences from the conceptually neutral with respect to assertiveness were identified or both the effective and the ineffective teacher

Furthermore, the effective teacher was found to be statistically significantly higher with respect to respect, organisation and challenge than the ineffective teacher. Importantly, in all three scales, the effective teacher was statistically significantly higher than the conceptual neutral, whilst the ineffective was statistically significantly lower than the conceptual neutral.

Considering the 'hands-on' effective and ineffective teacher, the analysis was done at the level of queries in line with the original study. For all twelve items, the effective teacher was statistically significantly higher than the conceptual neutral, whilst the ineffective was statistically significantly lower than the conceptual neutral. At the same time, the effective teacher was found to be statistically significantly more on the positive for all the measured characteristics. 
Table 1. Conceptions of the effective and ineffective teacher of pre-service assistant nurses in DIEKs.

\begin{tabular}{|c|c|c|c|c|c|c|c|}
\hline & & \multicolumn{6}{|c|}{ Convergence } \\
\hline & & $M$ & $S D$ & $P$ & $M$ & $S D$ & $P$ \\
\hline \multirow[t]{2}{*}{ Responsiveness } & Effective & 5.9 & 0.9 & $<0.001$ & 3.3 & 2 & $<0.001$ \\
\hline & Ineffective & 2.6 & 1.5 & $<0.001$ & & & \\
\hline \multirow[t]{2}{*}{ Assertiveness } & Effective & 4.2 & 1.1 & 0.162 & 0.3 & 1.8 & 0.118 \\
\hline & Ineffective & 3.8 & 1.3 & 0.185 & & & \\
\hline \multirow[t]{2}{*}{ Respect } & Effective & 5.9 & 1 & $<0.001$ & 3.6 & 1.9 & $<0.001$ \\
\hline & Ineffective & 2.4 & 1.3 & $<0.001$ & & & \\
\hline \multirow[t]{2}{*}{ Organisation } & Effective & 6.3 & 0.9 & $<0.001$ & 4.1 & 1.8 & $<0.001$ \\
\hline & Ineffective & 2.2 & 1.3 & $<0.001$ & & & \\
\hline \multirow[t]{2}{*}{ Challenge } & Effective & 6 & 1 & $<0.001$ & 3.7 & 1.8 & $<0.001$ \\
\hline & Ineffective & 2.3 & 1.3 & $<0.001$ & & & \\
\hline \multirow[t]{2}{*}{$\begin{array}{l}\text { Asks Thought-Provoking } \\
\text { Questions }\end{array}$} & Effective & 6.2 & 1.3 & $<0.001$ & 4 & 2.3 & $<0.001$ \\
\hline & Ineffective & 2.2 & 1.6 & $<0.001$ & & & \\
\hline \multirow[t]{2}{*}{$\begin{array}{l}\text { Helps Group Be Aware of How } \\
\text { It Is Working }\end{array}$} & Effective & 6.2 & 1.2 & $<0.001$ & 4.1 & 2.2 & $<0.001$ \\
\hline & Ineffective & 2.1 & 1.5 & $<0.001$ & & & \\
\hline \multirow[t]{2}{*}{$\begin{array}{l}\text { Encourages Effective Feedback } \\
\text { Within Group }\end{array}$} & Effective & 6 & 1.2 & $<0.001$ & 3.7 & 2.1 & $<0.001$ \\
\hline & Ineffective & 2.3 & 1.4 & $<0.001$ & & & \\
\hline \multirow[t]{2}{*}{ Shows Enthusiasm for Group } & Effective & 5.6 & 1.4 & $<0.001$ & 3.1 & 2.2 & $<0.001$ \\
\hline & Ineffective & 2.4 & 1.5 & $<0.001$ & & & \\
\hline \multirow[t]{2}{*}{$\begin{array}{l}\text { Actively Contributes, Shares } \\
\text { Info and Experiences }\end{array}$} & Effective & 6.3 & 1.2 & $<0.001$ & 4 & 2.3 & $<0.001$ \\
\hline & Ineffective & 2.3 & 1.6 & $<0.001$ & & & \\
\hline \multirow[t]{2}{*}{$\begin{array}{l}\text { Ensures That Group Stays "On } \\
\text { Track" }\end{array}$} & Effective & 6.2 & 1.2 & $<0.001$ & 4 & 2.2 & $<0.001$ \\
\hline & Ineffective & 2.2 & 1.5 & $<0.001$ & & & \\
\hline \multirow[t]{2}{*}{$\begin{array}{l}\text { Helps Group Identify Errors or } \\
\text { Deficiencies }\end{array}$} & Effective & 6.4 & 1 & $<0.001$ & 4.3 & 1.9 & $<0.001$ \\
\hline & Ineffective & 2.1 & 1.4 & $<0.001$ & & & \\
\hline \multirow[t]{2}{*}{$\begin{array}{l}\text { Helps Group Set Learning } \\
\text { Issues }\end{array}$} & Effective & 6.2 & 1.2 & $<0.001$ & 3.9 & 2.2 & $<0.001$ \\
\hline & Ineffective & 2.2 & 1.4 & $<0.001$ & & & \\
\hline \multirow[t]{2}{*}{$\begin{array}{l}\text { Promotes Use of Outside } \\
\text { Resources }\end{array}$} & Effective & 6.1 & 1.3 & $<0.001$ & 3.7 & 2.4 & $<0.001$ \\
\hline & Ineffective & 2.3 & 1.5 & $<0.001$ & & & \\
\hline \multirow[t]{2}{*}{ Promotes Psychosocial Issues } & Effective & 5.9 & 1.5 & $<0.001$ & 3.6 & 2.3 & $<0.001$ \\
\hline & Ineffective & 2.3 & 1.5 & $<0.001$ & & & \\
\hline \multirow[t]{2}{*}{$\begin{array}{l}\text { Exhibits Comfort Outside Area } \\
\text { of Expertise }\end{array}$} & Effective & 5.5 & 1.6 & $<0.001$ & 3 & 2.6 & $<0.001$ \\
\hline & Ineffective & 2.5 & 1.7 & $<0.001$ & & & \\
\hline \multirow[t]{2}{*}{$\begin{array}{l}\text { Helps Integrate Learning } \\
\text { Issues }\end{array}$} & Effective & 5.9 & 1.4 & $<0.001$ & 3.6 & 2.5 & $<0.001$ \\
\hline & Ineffective & 2.3 & 1.6 & $<0.001$ & & & \\
\hline
\end{tabular}




\section{Discussion, concluding remarks and recommendations.}

The quantitative analyses revealed that though the students' conceptions about the effective teacher were in line with the literature (with the effective teacher statistically significantly including the expected characteristics for all the main measured aspects and dimensions), their conceptions about the ineffective teacher were not always found to statistically significantly differ from the effective (notably about assertiveness). Thus, our analyses allowed us to identify which aspects of teaching characterise the effective teacher (and not the ineffective teacher) and which are present both in the effective and the ineffective teacher. The findings of the study suggest that the pre-service assistant nurses have clear-cut conceptions about teaching effectiveness in most of the measured aspects. The fact that assertiveness did not arise as a differentiating factor between effective and ineffective teacher renders to be further investigated with larger samples, but, importantly, through qualitative techniques to delineate the links of these conceptions with the teaching practices and/or the particular characteristics of the assistant nursing profession.

\section{References}

Biavaschi, C., Eichhorst, W., Giulietti, C., Kendzia, M. J., Murayev, A., Pieters, J., Rodriguez-Planas, N., Schmidl, R. \& Zimmermann, K. F. (2012). Youth unemployment and vocational training. IZA Discussion Paper. DP No. 6890.

Creemers, B. P. M., \& Kyriakides, L. (2008). The dynamics of educational effectiveness: A contribution to policy, practice and theory in contemporary schools. London and New York: Routledge.

Curran, J. M., \& Rosen, D. E. (2006). Student attitudes toward college courses: An examination of influences and intentions. Journal of Marketing Education, 28(2), 135-148.

Durham, C. F., \& Alden, K. R. (2008). Enhancing Patient Safety in Nursing Education Through Patient Simulation. In R. G. Hughes (Ed.), Patient Safety and Quality: An Evidence-Based Handbook for Nurses (Vol. 3, pp. 220-260). Rockville, MD: Agency for Healthcare Research and Quality.

Kentikelenis, A., \& Papanicolas, I. (2011) Economic crisis, austerity and the Greek public health system. European Journal of Public Health, 22(1), 4-5.

Mayo, P., Donnelly, M. B., Nash, P. P., \& Schwartz, R. W. (1993). Student perceptions of tutor effectiveness in a problem-based surgery clerkship. Teaching and Learning in Medicine: An International Journal, 5(4), 227-233.

McCroskey, J. C., \& Richmond, V. P. (1990). Willingness to communicate: Differing cultural perspectives. Southern Journal of Communication, 56(1), 72-77.

Mouzakitis, G. S. (2010). The role of vocational education and training curricula in economic development. Procedia-Social and Behavioral Sciences, 2(2), 3914-3920

Muijs, D., \& Reynolds, D. (2017). Effective teaching: Evidence and practice. London: Sage.

OECD, (2015). OECD Reviews of Vocational Education and Training. Available at http://www.oecd.org/education/skills-beyondschool/OECD_VET_Key_Messages_and_Country_Summaries_2015.pdf

Paswan, K., \& Young, J. A. (2002). Student evaluation of instructor: A nomological investigation using structural equation modeling. Journal of Marketing Education, 24 (3), 193-202.

Patiniotis, N. \& Stavroulakis, D. (1997. The development of vocational education policy in Greece: a critical approach. Journal of European Industrial Training, 21 (6), 192-202.

Patrick, J., \& Smart, R. M. (1998). An empirical evaluation of teacher effectiveness: The emergence of three critical factors. Assessment \& Evaluation in Higher Education, 23(2), 165-178.

Pozo-Munoz, C., Rebolloso-Pacheco, E., \& Fernandez-Ramirez, B. (2000). The 'Ideal Teacher'. Implications for student evaluation of teacher effectiveness. Assessment \& Evaluation in Higher Education, 25(3), 253-263.

Richmond, V. P., \& Martin, M. M. (1998). Sociocommunicative style and sociocommunicative orientation. In J. C. McCroskey, J. A. Daly, M. M. Martin, \& M. J. Beatty (Eds.), Communication and personality: Trait perspectives (pp. 133-148). Cresskill, NJ: Hampton Press.

Rush, S., Acton, L., Tolley, K., Marks-Maran, D., \& Burke, L. (2010). Using simulation in a vocational programme: does the method support the theory?. Journal of vocational education and training, 62(4), 467-479.

Wells, M. J., Wilkie, D. J., Brown, M. A., Corless, I. B., Farber, S. J., Judge, M. K. M., \& Shannon, S. E. (2002). Technology available in nursing programs: Implications for developing virtual end-of-life educational tools. Journal of Cancer Education, 17(2), 92-96. 


\title{
EXPLORING INFORMATION COMMUNICATIONS TECHNOLOGY (ICT) INFUSED MICROTEACHING MODULE AT A UNIVERSITY OF TECHNOLOGY IN SOUTH AFRICA
}

\author{
Paseka Patric Mollo \\ Department of Educational and Professional Studies, Faculty of Humanities, \\ Central University of Technology, Free State, Bloemfontein 9300 (South Africa)
}

\begin{abstract}
The concept of microteaching was first introduced in the 1960s at Stanford University in the USA. From there onwards most universities, universities of technologies and teacher training institutions are using microteaching as a technique to train prospective teachers to function within their teaching and learning environment. At the Central University of Technology (CUT) in South Africa, Microteaching is a compulsory module for all student teachers registered for a Bachelor of Education degree. This module aims to equip student teachers with teaching skills, teaching strategies, teaching styles and confidence needed within the classroom environment. However, with the large numbers of student teacher enrollments at CUT, the delivery of this indispensable teacher training module was faced with a lot of challenges. The challenges, among others are the inadequacies of microteaching laboratories; student teacher peer involvement and evaluation of micro-lessons by lecturers. These challenges called for a review of the present model for microteaching. ICT was infused with microteaching model to solve the above challenges. This article explores the perceptions of CUT student teachers towards the ICT infused microteaching. A questionnaire to obtain student teachers' views about ICT infused microteaching was used to collect data. The findings indicated that student teachers enjoyed the use of this approach and most of the challenges associated with microteaching were solved.
\end{abstract}

Keywords: Information communications technology, microteaching, micro-lessons, student teachers, teacher education.

\section{Introduction}

Microteaching is a teacher training technique currently practiced worldwide by universities and / or teacher training institutions. The history of this teacher training technique goes back to the early and mid-1960s, when Dwight Allen, together with his colleagues, from the Stanford University in the USA first introduced it (Remesh \& Memorial, 2013). Microteaching was developed by these academics as a training programme aimed at improving prospective teachers' verbal and non-verbal skills when presenting lessons in the classroom. Microteaching provides student teachers with an opportunity to perk up their teaching skills by improving the various simple tasks called teaching skills (Moreeng, 2015; Anthonia, 2014).

As a result of the above microteaching has become an indispensable teacher training technique. Most universities use microteaching to equip their student teachers with the necessary teaching skills. However, several universities are experiencing challenges in presenting this crucial teacher training technique. The Central University of technology like most universities is also experiencing challenges in this regard. The challenges emanate from the large enrollments of students taking teaching as a profession. These large numbers of students pose a challenge about the infrastructures, resources and human resources needed to properly implement microteaching. An attempt is proposed by this paper to provide an ICT infused model that can enable universities to properly implement the microteaching processes.

\section{Understanding microteaching}

Microteaching is a skill-based analytical technique used to provide a connection between theory and practice in teaching. It is an activity that encourages engagement, growth, contextualization, and constant refinement of the acquired skills (Anthonia, 2014; Guelcher, Jackson, Necheles, 1970). Microteaching is a scaled-down simulated teaching practice where student teachers teach a small portion of a lesson to a small group of their classmates. Time, number of learners, content coverage and teaching skills are reduced when practicing microteaching. It employs real teaching situation for developing skills 
and helps to get deeper knowledge regarding the art of teaching (Remesh \& Memorial, 2013). It makes it possible to concentrate on specific teaching behaviour and to practice teaching under controlled conditions. In a microteaching session teaching of skills are carried out under a strictly controlled and supervised environment Student teachers present to a small group in 5-20 minutes on a selected and specific aspect of teaching (Anthonia, 2014; Ismail, 2011).

Microteaching has several objectives, among others to mention a few. Microteaching enable student teachers to learn and assimilate new teaching skills under controlled conditions. It enables student teachers to master several teaching skills. Also, it enables student teachers to gain confidence in teaching. Again, microteaching enable student teachers to analyse the complex process of teaching (Anthonia, 2014; Ismail, 2011).

\section{The problem statements}

The above is the ideal scenario on how microteaching should be carried out at universities. However, most universities cannot do that due to the large enrollments of students who wants to pursue teaching as a profession. These large enrollments pose a challenge regarding the infrastructure needed and the resources needed to carry out microteaching. Because of these large classes most universities are having another challenge about provision of feedback to student teachers. These institutions cannot have the supervisory teams as expected by the model above.

Like most universities the Central University of Technology (CUT) has a challenge of properly following microteaching processes and assessing the micro-lessons. According to the Revised Policy on Minimum Requirements for Teacher Education Qualifications of 2015 (Department of Higher Education and Training, 2015), microteaching is a subject offered by the Department of Educational and Professional Studies (DEPS). The specialisations classes are divided into four broad groups; namely languages group, EMS group, Natural Sciences \& Mathematics group and the Technology and Computer Sciences group. DEPS need to service each group regarding the lecturing of this subject (DHET, 2015). Each group comprises of a minimum of 150 students and one lecturer from DEPS is allocated a group. A result of this, it becomes practically impossible to do the microteaching process as discussed above. It therefore requires of the lecturers to come up with a strategy to ensure that the microteaching process is followed.

\section{ICT infused microteaching model}

In order to ensure that microteaching is properly done to respond to the above problems. The researcher implemented an ICT integrated approach to ensure that all the steps of a microteaching model are dealt with. First a workshop to all students teachers registered for the microteaching module at different levels was conducted. During these workshops the lecturers explained and demonstrate the microteaching process and the desired skill(s) for that semester.

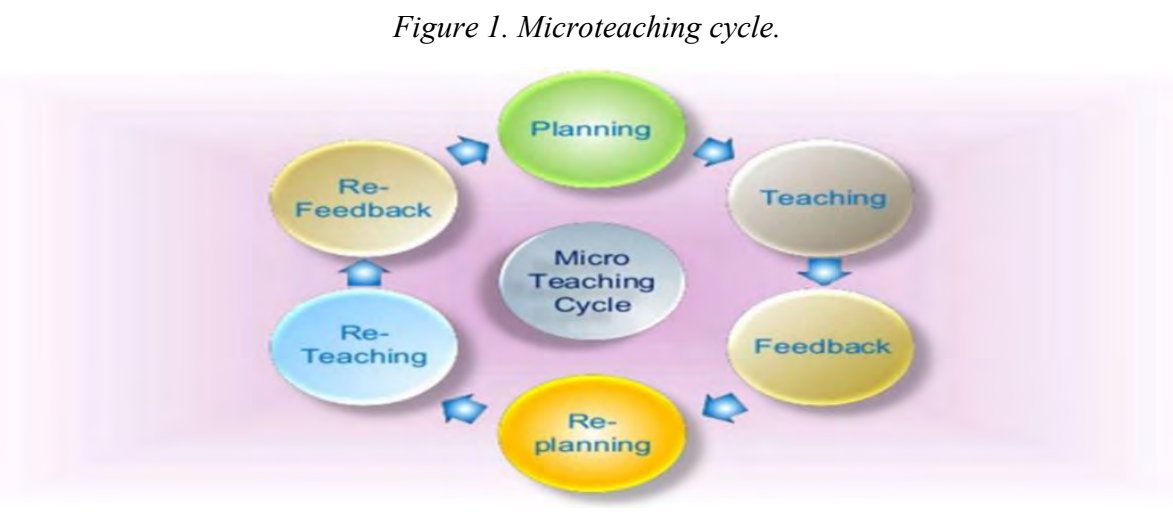

In addition to this, a video of the skill(s) was posted on the institution's Learner Management System (LSM), in the case of CUT, Blackboard/ eThuto to accommodate students that might have missed the workshop and also as a reference to students who would like a revision of the skill(s). During the workshop student teachers are afforded an opportunity to discuss and ask questions based on the demonstrated skill(s). After the workshop student teachers were requested to go through the following phases:

Phase 1: Student teachers were given a task to develop their individual micro-lessons. This process was done in the absence of the lecturer. 
Phase 2: Individual groups had to schedule a time slot for presentations where each member will be presenting (teach) to the other group members.

Phase 3: After this exercise, group members discussed their videos and gave each other feedback on their performances.

Phase 4: Group members had to choose one video that must be submitted to the lecturer for evaluation.

Phase 5: A panel of lectures chooses the best four to five videos which will be shown to the whole class during the lecturer's feedback workshop. The lecturer(s) together with the students will be discussing the skill(s).

All these phases will ensured that student teachers have done all the steps of the microteaching cycle. Again, going through these phases ensured that the lecturers have given opportunities to all student teachers to present a skill(s).

\section{Methodology}

In order to ascertain student teachers' perceptions of the introduced ICT infused microteaching. The methodology was structured as follows.

\subsection{Participants}

The subjects of this paper were 72 student teachers enrolled in the Microteaching level 3 module at CUT. Three groups of six students from the four areas of specialisations namely Maths \& Technology; Economic and Management Sciences; Languages; and Natural Sciences \& Computer Sciences. Each specialisation contributed a total of 18 student teachers i.e. 3 groups of six.

\subsection{Instrument}

A questionnaire was developed and used to collect the required data. The final version of the questionnaire included 24 items organised into six themes in accordance with the purpose of this study. The questionnaire was refereed by three other lecturers that are teaching microteaching at other levels. It used a five -point Likert scale of agreement with the variables ranging from Strongly Agree (5); Agree (4); Neutral (3); Disagree (2) and Strongly disagree (1).

\subsection{Data collection}

Data were collected towards the end of the first semester as Microteaching 3 module is a first semester module. The reason for conducting this research at the end of the semester was that by that time students would have finished all their micro-lessons and they would have received feedback from both peers and lecturers. The participants were invited to a microteaching laboratory to fill the questionnaire. The researcher personally administered the questionnaire and collected it from the participants. All participants were also assured that their responses will be kept confidential and that the data collected will only be used for purposes of this study. The researcher transcribed and analysed the responses.

\section{Findings of the study}

\subsection{Theme 1: ICT infused planning phase}

\begin{tabular}{|c|c|c|c|c|c|c|c|}
\hline & Statement & $\begin{array}{l}\text { Strongly } \\
\text { Agree }\end{array}$ & Agree & Neutral & Disagree & $\begin{array}{l}\text { Strongly } \\
\text { Disagree }\end{array}$ & Total \\
\hline 1 & $\begin{array}{l}\text { ICT equipment were very important } \\
\text { component of my planning phase }\end{array}$ & $38(53 \%)$ & $34(47 \%)$ & $0(0 \%)$ & $0(0 \%)$ & $0(0 \%)$ & $72(100 \%)$ \\
\hline 2 & $\begin{array}{l}\text { ICTs aroused my interest to plan } \\
\text { correctly }\end{array}$ & $39(54,2 \%)$ & $23(31,9 \%)$ & $7(9,7 \%)$ & $2(2,8 \%)$ & $1(1,4 \%)$ & $72(100 \%)$ \\
\hline 3 & $\begin{array}{l}\text { Using ICT enabled me to plan my } \\
\text { lessons thoroughly }\end{array}$ & $39(54,2 \%)$ & $23(31,9 \%)$ & $7(9,7 \%)$ & $3(4,2 \%)$ & $0(0 \%)$ & $72(100 \%)$ \\
\hline 4 & $\begin{array}{l}\text { It was easy use computers to prepare my } \\
\text { lessons, do better worksheets and } \\
\text { assessment sheets }\end{array}$ & $39(54,2 \%)$ & $23(31,9 \%)$ & $7(9,7 \%)$ & $3(4,2 \%)$ & $0(0 \%)$ & $72(100 \%)$ \\
\hline
\end{tabular}

When analyzing Theme 1, which is about ICT infused planning for microteaching, one issue emerges. The majority of student teachers unilaterally agreed that using ICT assisted them greatly to plan their lessons. This majority also indicated that the use of computers enabled them to do better worksheets and assessment sheets. However, there was a constant number of these student teachers who are not sure or are not totally convinced about the applications of ICT in this phase. This can be noticed by the responses provided under neutral or in statements 2,3 , and 4 . In short the majority of student teachers found out that the use of ICT is beneficial to them when planning the micro-lessons. 


\subsection{Theme 2: ICT infused teaching phase}

\begin{tabular}{|c|c|c|c|c|c|c|c|}
\hline & Statement & $\begin{array}{l}\text { Strongly } \\
\text { Agree }\end{array}$ & Agree & Neutral & Disagree & $\begin{array}{l}\text { Strongly } \\
\text { Disagree }\end{array}$ & Total \\
\hline 1 & $\begin{array}{l}\text { During this phase I was able to develop } \\
\text { confidence in my speaking ability }\end{array}$ & $30(41,7 \%)$ & $37(51,4 \%)$ & $5(6,9 \%)$ & $0(0 \%)$ & $0(0 \%)$ & $72(100 \%)$ \\
\hline 2 & $\begin{array}{l}\text { The use ICTs encouraged me to develop } \\
\text { my vocabulary }\end{array}$ & $30(41,7 \%)$ & $37(51,4 \%)$ & $5(6,9 \%)$ & $0(0 \%)$ & $0(0 \%)$ & $72(100 \%)$ \\
\hline 3 & $\begin{array}{l}\text { Using ICTs allowed me to apply ideas I } \\
\text { learned from different courses }\end{array}$ & $30(41,7 \%)$ & $37(51,4 \%)$ & $5(6,9 \%)$ & $0(0 \%)$ & $0(0 \%)$ & $72(100 \%)$ \\
\hline 4 & $\begin{array}{l}\text { ICTs encouraged me to present my } \\
\text { lessons clearly }\end{array}$ & $30(41,7 \%)$ & $37(51,4 \%)$ & $5(6,9 \%)$ & $0(0 \%)$ & $0(0 \%)$ & $72(100 \%)$ \\
\hline
\end{tabular}

In responses to statements on the ICT infused teaching phase the majority of participants indicated that they were in agreement to the fact that ICT greatly assisted them during the teaching phase of the model. A constant number of participants $6,9 \%$ of them were neutral about the use of ICT in the teaching phase of micro-lessons. This means that in general most student teachers were in agreement that the use of ICT is beneficial in the teaching phase of the micro-lessons.

\subsection{Theme 3: ICT infused Feedback phase}

\begin{tabular}{|c|c|c|c|c|c|c|c|}
\hline & Statement & $\begin{array}{l}\text { Strongly } \\
\text { Agree }\end{array}$ & Agree & Neutral & Disagree & $\begin{array}{l}\text { Strongly } \\
\text { Disagree }\end{array}$ & Total \\
\hline 1 & $\begin{array}{l}\text { ICT helped me develop awareness of my } \\
\text { teaching competence }\end{array}$ & $30(41,7 \%)$ & $37(51,4 \%)$ & $5(6,9 \%)$ & $0(0 \%)$ & $0(0 \%)$ & $72(100 \%)$ \\
\hline 2 & $\begin{array}{l}\text { ICTs helped me develop the actual } \\
\text { teaching skills I'll need later }\end{array}$ & $30(41,7 \%)$ & $37(51,4 \%)$ & $5(6,9 \%)$ & $0(0 \%)$ & $0(0 \%)$ & $72(100 \%)$ \\
\hline 3 & $\begin{array}{l}\text { ICTs gave me an opportunity to learn by } \\
\text { observing others }\end{array}$ & $30(41,7 \%)$ & $37(51,4 \%)$ & $5(6,9 \%)$ & $0(0 \%)$ & $0(0 \%)$ & $72(100 \%)$ \\
\hline 4 & $\begin{array}{l}\text { Made me aware of what makes a good } \\
\text { teacher }\end{array}$ & $30(41,7 \%)$ & $37(51,4 \%)$ & $5(6,9 \%)$ & $0(0 \%)$ & $0(0 \%)$ & $72(100 \%)$ \\
\hline
\end{tabular}

In response to the statements in Theme 3 most participants were in agreement that the use of ICT in feedback phase helped them with, among others, teaching competency, teaching skills and be aware of good teaching strategies. Like in the previous theme only $6,9 \%$ of the respondents were neutral about the statements. In short they were either in agreement or in disagreement with the statements. From the table above it is evident that most participants were in agreement that the use of ICT assisted them to provide and be provided with appropriate feedback.

\subsection{Theme 4: ICT infused re-planning phase}

\begin{tabular}{|c|c|c|c|c|c|c|c|}
\hline & Statement & $\begin{array}{l}\text { Strongly } \\
\text { Agree }\end{array}$ & Agree & Neutral & Disagree & $\begin{array}{l}\text { Strongly } \\
\text { Disagree }\end{array}$ & Total \\
\hline 1 & $\begin{array}{l}\text { This phase gave me an opportunity to improve } \\
\text { my lesson planning }\end{array}$ & $32(44,4 \%)$ & $37(51,4 \%)$ & $3(4,2 \%)$ & $0(0 \%)$ & $0(0 \%)$ & $72(100 \%)$ \\
\hline 2 & ICTs aroused my interest to plan correctly & $32(44,4 \%)$ & $37(51,4 \%)$ & $3(4,2 \%)$ & $0(0 \%)$ & $0(0 \%)$ & $72(100 \%)$ \\
\hline 3 & $\begin{array}{l}\text { Using ICT enabled me to plan my lessons } \\
\text { thoroughly }\end{array}$ & $32(44,4 \%)$ & $37(51,4 \%)$ & $3(4,2 \%)$ & $0(0 \%)$ & $0(0 \%)$ & $72(100 \%)$ \\
\hline 4 & $\begin{array}{l}\text { It was easy use computers to prepare my lessons, } \\
\text { do work sheets and assessment sheets }\end{array}$ & $32(44,4 \%)$ & $37(51,4 \%)$ & $3(4,2 \%)$ & $0(0 \%)$ & $0(0 \%)$ & $72(100 \%)$ \\
\hline
\end{tabular}

The responses for the re-planning phase are more positive that the ones of the planning phase. Unlike in the planning phase, no participants gave either a disagree or strongly disagree responses. The majority of the respondents were either in strongly agreement or gave an agreement response. Therefore the majority of the participants were in agreement that the use of ICT greatly assisted them to re-plan their micro-lessons.

\subsection{Theme 5: ICT infused re-teaching phase}

\begin{tabular}{|c|c|c|c|c|c|c|c|}
\hline & Statement & $\begin{array}{l}\text { Strongly } \\
\text { Agree }\end{array}$ & Agree & Neutral & Disagree & $\begin{array}{l}\text { Strongly } \\
\text { Disagree }\end{array}$ & Total \\
\hline 1 & $\begin{array}{l}\text { The re-teaching phase helped me discover and } \\
\text { fix my language problems }\end{array}$ & $32(44,4 \%)$ & $37(51,4 \%)$ & $3(4,2 \%)$ & $0(0 \%)$ & $0(0 \%)$ & $72(100 \%)$ \\
\hline 2 & $\begin{array}{l}\text { ICTs in this phase helped me better understand } \\
\text { different teaching methods }\end{array}$ & $32(44,4 \%)$ & $37(51,4 \%)$ & $3(4,2 \%)$ & $0(0 \%)$ & $0(0 \%)$ & $72(100 \%)$ \\
\hline 3 & $\begin{array}{l}\text { Using ICT helped me discover my teaching } \\
\text { strengths and weaknesses }\end{array}$ & $32(44,4 \%)$ & $37(51,4 \%)$ & $3(4,2 \%)$ & $0(0 \%)$ & $0(0 \%)$ & $72(100 \%)$ \\
\hline 4 & This phase encouraged me to develop autonomy & $32(44,4 \%)$ & $37(51,4 \%)$ & $3(4,2 \%)$ & $0(0 \%)$ & $0(0 \%)$ & $72(100 \%)$ \\
\hline
\end{tabular}


The responses are similar, in percentage, to the responses in Theme 4. The participants are in agreement with the statements. Only a small percentage, i.e. 4,2\%, of participants are neutral about the impact of ICT during the re-teaching phase.

\subsection{Theme 6: ICT infused re-feedback phase}

\begin{tabular}{|c|c|c|c|c|c|c|c|}
\hline & Statement & $\begin{array}{l}\text { Strongly } \\
\text { Agree }\end{array}$ & Agree & Neutral & Disagree & $\begin{array}{l}\text { Strongly } \\
\text { Disagree }\end{array}$ & Total \\
\hline 1 & $\begin{array}{l}\text { Using ICT in this phase enabled me to } \\
\text { critically assess and be assessed by my } \\
\text { peers }\end{array}$ & $32(44,4 \%)$ & $37(51,4 \%)$ & $3(4,2 \%)$ & $0(0 \%)$ & $0(0 \%)$ & $72(100 \%)$ \\
\hline 2 & $\begin{array}{l}\text { This phase improved and enhanced my } \\
\text { effectiveness as a teacher }\end{array}$ & $32(44,4 \%)$ & $37(51,4 \%)$ & $3(4,2 \%)$ & $0(0 \%)$ & $0(0 \%)$ & $72(100 \%)$ \\
\hline 3 & $\begin{array}{l}\text { It helped me to use technology } \\
\text { appropriately to predict classroom } \\
\text { problems }\end{array}$ & $32(44,4 \%)$ & $37(51,4 \%)$ & $3(4,2 \%)$ & $0(0 \%)$ & $0(0 \%)$ & $72(100 \%)$ \\
\hline 4 & $\begin{array}{l}\text { Criticism received from the peers guided } \\
\text { me to improve my standards }\end{array}$ & $32(44,4 \%)$ & $37(51,4 \%)$ & $3(4,2 \%)$ & $0(0 \%)$ & $0(0 \%)$ & $72(100 \%)$ \\
\hline
\end{tabular}

Just like in the feedback phase the participants are still in agreement that the use of ICT greatly assisted them in the re-feedback phase. They agreed that the use of ICT among others enabled them to critically assess and be assessed by their peers, ICT assisted them to predict classroom problems and the use of ICT in micro-lessons guided them to improve on their teaching standards.

\section{Conclusions}

The new ICT infused microteaching model was well received by both lecturers and student teachers at the CUT. Student teachers were requested to submit their videos as part of their assessment task one for the Microteaching Module for the second year of study of their B.Ed degree. Depending on the outcome of the results in terms of the desired outcomes, commitment, enjoyability from both students and lecturers. This model was used at CUT to curb the problems of infrastructure for presenting microteaching and the problem of ensuring that all student teachers in large classes are able to practice the required microteaching skills. The model can thus be recommended for use by other education institutions that are faced with similar microteaching problems as the ones of CUT.

\section{References}

Anthonia, O. I. 2014. Micro-Teaching: A technique for effective teaching. African Research Review, 8(4): 183-197.

Department of Higher Education and Training. 2015. National Qualifications Framework Act (67/2008): Revised policy on the Minimum Requirements for Teacher Education Qualifications. Government Gazette, 596(38487). Pretoria: Government Printer.

Guelcher, W., Jackson, T., Necheles, F. (1970). Microteaching and Teacher Training: A Refined Version.

Ismail, S.A.A., 2011. Student teachers' microteaching experiences in a preservice English teacher education program. Journal of Language Teaching and Research, 2(5), p.1043 -1051.

Merriam, S.B. \& Tisdell, E. J. 2016. Qualitative research: A guide to design and implementation. $4^{\text {th }}$ Edition. California: Jossey-Bass.

Moreeng,B. 2015. Microteaching. In Taole, M.J.2015. Teaching practice, perspectives and frameworks. Van Schaik Publishers: Pretoria

Morrison, B., 2010. Teacher training in China and the role of teaching practice. Retrieved June 16, 2019 from http://sunzil.lib.hku.hk/hkj/view/45/4500089/pdf

Oner, D. 2020. A virtual internship for developing technology pedagogical content knowledge. Australasian Journal of Educational Technology, 36(2), 27-42

Remesh, A.,Memorial, S.2013. Microteaching, and efficient technique for learning effective teaching. Journal of Research in Medical Sciences, 18(2), 158-163

Tunjera, N. \& Chigona, A. 2020. Teacher educators' appropriation of TPACK-SAMR Models for $21^{\text {st }}$ century pre-service teacher preparation. International Journal of Information and Communication Technology Education, 16(3), 126-140. 


\title{
PERCEPTIONS AND PREFERENCES OF ENGLISH STUDENT TEACHERS ON THE ASSESSMENT PRACTICES
}

\author{
Pule Phindane \\ Language and Social Sciences Education, Faculty of Humanities, \\ Central University of Technology, Free State, Bloemfontein 9300 (South Africa)
}

\begin{abstract}
Comprehending the role of assessment and the differential effects on developing students' learning processes is still one of the most explored areas in higher education. The aim of this quantitative study is to investigate English student teachers 'perceptions and preferences on the assessment practices (i.e., formative). The participant were student teachers sampled from the Department of Social Sciences and Language Education, Central University of Technology, Free State, South Africa. The outcomes showed that the assessment practices used by lecturers had an indispensable impact on students' motivation, preparation for future learning tasks, and evaluation of study progress. The data obtained also revealed that while peer assessment is one of the least preferred assessment methods, presentations, self-assessments and research papers were the top preferences. The study outcome relates to previous research while also providing a better understanding into the link between individual differences in the assessment preferences and the learning strategies used by students throughout the years of specialization which might offer lecturers way forward for improving their educational practices.
\end{abstract}

Keywords: Student teachers, perceptions, preferences, assessment practices.

\section{Introduction}

Assessment has been regarded as an integral part in the context of teaching and learning in the higher education. More research (e.g., Carless, 2007; Craddock and Mathias, 2009) has shown that learning is incomplete without assessment because assessment enables the educators to collect pieces of evidence about their students' achievement, scaling and explain their results to decide whether the learning outcomes have been achieved or that some changes and modifications are required. According to Chau and Vien (2020), teachers' instruction is a decisive factor behind students' performance that enables educators to make great attempts to enhance teaching assurance. Al-Dabbus et al (2020) in this regard view assessment as "the process of gathering data" since the instructors will need to prove the achievement of their intended learning outcomes through the data they gather about their teaching and their students' learning.

In normal terms, assessment is categorised as either formative, such as observing students while conducting a learning task, self and peer assessment, question and answer session, application of information, a summary of main points and reflection, or summative particularly when it takes place after the learning is completed and provides information and feedback that sums up the teaching and learning development. This type of assessment is usually conducted in the traditional forms, such as quizzes, midterm and final examinations. However, projects and portfolios could also be used as summative assessments (Al-Dabbus et al, 2020).

In spite of this diversity in the assessment methods, it has been more emphasized that it is the teacher's responsibility to decide which assessment tool should be used to assess his/her students' performance, particularly in the higher education context where academics nowadays are given more responsibility to design and implement diverse methods of assessment in order to fulfil two main demands, which are to increase students' motivation and to achieve quality assurance as represented in achieving the intended learning outcomes (Lynam and Cachia, 2018). Gibbs and Simpson (2004) observed that students' achievement and success in higher education is highly influenced by the assessment system(s) and types that are practiced by their institutions and instructors. Meyer et al. (2010) validate for this finding in the way how assessment can affect the existence of educational institutions or its reputation as a higher education entity within the local or even the international level. 
Investigating the learners' perceptions of their assessment methods can positively impact the emotionality of these learners as well as the workload of their instructors. Craddock and Mathias (2009) emphasise this finding and explains that constant survey of the students' attitudes towards their assessment will lead to more liberal learning in which students are given an opportunity to decide on the choice of assessment method they prefer to have during their learning. Craddock and Mathias (2009) and Gibbs (2006) consider this the transformational target point which should occur to assessment in the higher education context.

\section{Research aim}

This study aims to identify common types of assessment used to assess English student teacher during their study at Central University of Technology (CUT), explore English student teachers' perceptions of those assessment methods, establish the impact of the current assessments on learning from the students' point of view and to suggest alternatives for improving assessment policy for English teacher candidates at CUT.

\section{Research questions}

This study is informed the three main research questions, which are:

1. How do CUT student teacher of English language perceive assessment methods used by their instructors?

2. To what extent such assessment methods influence their learning?

3. What assessment methods are preferred by CUT English student teachers, and why?

\section{Methodology}

The research design used to answer the set of research questions was a quantitative approach. A questionnaire with closed ended question format developed by the researchers was utilised in collecting the data. It consists of twenty-one (21 statements divided into three (3) categories as follows: practices of assessments, impact of assessments on learning and assessment preferences. A five-point Likert type scale ranges from strongly agree to strongly disagree was used. The content validity of the questionnaire was checked by some experts at the university, based on their comments a few modifications were conducted. The questionnaire was chosen as a collection tool in this study as it suits the purpose of the survey and the type of data required.

The total number of participants took part in the study is 50 students, studying in the English Language Education Department, at the CUT during the academic year 2019/2020. They are of different levels: 30 third year students and 20 fourth year students. They were selected randomly and all of them were willing to participate in the study.

\section{Data analysis}

This is a quantitative study that aims to investigate the students' perceptions, preferences of the assessment methods used by their lecturers at the CUT, and the impact of those methods on their learning. The data were collected and analysed as illustrated in the tables below $(1-6)$, which show some descriptive statistics mainly percentages.

\section{Results}

Table 1 demonstrates the responses of the participants regarding their perception towards the practices of assessments given by their instructors. It shows that $30 \%$ of the participants agree that the assessment methods used by their teachers are relevant to their study, whereas $39 \%$ believe that the assessment methods were to some extant relevant. On the other hand, only $1 \%$ was strongly disagree. Concerning to the second statement, the findings indicate that $41 \%$ agree that the assessment methods examine what they know and $43 \%$ of the participants think that the assessment methods to some extent examine what they do in class.

The data also indicate that $31 \%$ of the respondents agree with the statement "the assessment methods examine what my instructor has taught me", whereas slightly higher $32 \%$ to some extent agree with the statement. Regarding the statement that says, "the assessment methods examine my ability to apply what I know in real-life situation", the results show that $15 \%$ strongly agree, $28 \%$ agree and $29 \%$ to some extent agree whereas $16 \%$ disagree. Furthermore, the findings of the study reveal that $31 \%$ agree that "the 
assessment methods have been spread out over the semester". It also shows that $35 \%$ of the total participants strongly agree that their instructors inform them in advance when they would be assessed and in contrast, $0 \%$ strongly disagree. In addition, $40 \%$ agree that they were told in advance what would be assessed. However, the most striking finding revealed by the study is that $42 \%$ to some extent agree that the assessment methods are associated with clear instructions given by the instructor, whereas $28 \%$ agree. The results indicate that $35 \%$ to some extent agree that the assessment methods are attached with clear marking scheme/policy. Similar ratio believe that the assessment types usually vary between formative and summative. $36 \%$ of the respondents reported that the assessments suit my ability whereas $38 \%$ think the assessments are challenging.

Table 1. Practices of assessments.

\begin{tabular}{|l|l|l|l|l|l|}
\hline $\begin{array}{l}\text { Statement } \\
\text { Practices of assessments }\end{array}$ & $\begin{array}{l}\text { Strongly } \\
\text { Agree }\end{array}$ & Agree & $\begin{array}{l}\text { To some } \\
\text { Extent }\end{array}$ & Disagree & $\begin{array}{l}\text { Strongly } \\
\text { Disagree }\end{array}$ \\
\hline $\begin{array}{l}\text { The assessment methods used by my } \\
\text { instructors are relevant to my study }\end{array}$ & $24 \%$ & $30 \%$ & $39 \%$ & $6 \%$ & $1 \%$ \\
\hline $\begin{array}{l}\text { The assessment methods examine what I } \\
\text { know. }\end{array}$ & $11 \%$ & $41 \%$ & $31 \%$ & $14 \%$ & $3 \%$ \\
\hline $\begin{array}{l}\text { The assessment methods examine what I do in } \\
\text { class }\end{array}$ & $9 \%$ & $30 \%$ & $43 \%$ & $14 \%$ & $5 \%$ \\
\hline $\begin{array}{l}\text { The assessment methods examine what my } \\
\text { instructor has taught me }\end{array}$ & $21 \%$ & $31 \%$ & $32 \%$ & $10 \%$ & $5 \%$ \\
\hline $\begin{array}{l}\text { The assessment methods examine my ability } \\
\text { to apply what I know in real-life situation }\end{array}$ & $15 \%$ & $28 \%$ & $29 \%$ & $16 \%$ & $11 \%$ \\
\hline $\begin{array}{l}\text { The assessment methods have been spread out } \\
\text { over the semester }\end{array}$ & $18 \%$ & $31 \%$ & $28 \%$ & $12 \%$ & $12 \%$ \\
\hline I am told in advance when I would be assessed & $35 \%$ & $34 \%$ & $25 \%$ & $6 \%$ & $0 \%$ \\
\hline $\begin{array}{l}\text { I am told in advance on what I would be } \\
\text { assessed }\end{array}$ & $28 \%$ & $40 \%$ & $26 \%$ & $4 \%$ & $3 \%$ \\
\hline $\begin{array}{l}\text { The assessment methods are associated with } \\
\text { clear instructions given by the instructor. }\end{array}$ & $20 \%$ & $28 \%$ & $42 \%$ & $9 \%$ & $1 \%$ \\
\hline $\begin{array}{l}\text { The assessment methods are attached with } \\
\text { clear marking scheme/policy }\end{array}$ & $26 \%$ & $31 \%$ & $35 \%$ & $4 \%$ & $4 \%$ \\
\hline $\begin{array}{l}\text { The assessment types usually vary between } \\
\text { formative and summative }\end{array}$ & $16 \%$ & $34 \%$ & $35 \%$ & $13 \%$ & $1 \%$ \\
\hline The assessments suit my ability & $11 \%$ & $36 \%$ & $33 \%$ & $15 \%$ & $5 \%$ \\
\hline The assessments are challenging & $25 \%$ & $38 \%$ & $34 \%$ & $1 \%$ & $1 \%$ \\
\hline
\end{tabular}

Table 2. Impact of assessments on learning.

\begin{tabular}{|l|l|l|l|l|l|}
\hline $\begin{array}{l}\text { Statement } \\
\text { Impact of assessments on learning }\end{array}$ & $\begin{array}{l}\text { Strongly } \\
\text { Agree }\end{array}$ & Agree & $\begin{array}{l}\text { To some } \\
\text { Extent }\end{array}$ & Disagree & $\begin{array}{l}\text { Strongly } \\
\text { Disagree }\end{array}$ \\
\hline $\begin{array}{l}\text { The assessments assist me in achieving the } \\
\text { course outcome }\end{array}$ & $24 \%$ & $30 \%$ & $39 \%$ & $6 \%$ & $1 \%$ \\
\hline $\begin{array}{l}\text { The assessment methods motivate me to } \\
\text { continue learning }\end{array}$ & $11 \%$ & $41 \%$ & $31 \%$ & $14 \%$ & $3 \%$ \\
\hline $\begin{array}{l}\text { The assessment methods prepare me for the } \\
\text { next learning activities }\end{array}$ & $9 \%$ & $30 \%$ & $43 \%$ & $14 \%$ & $5 \%$ \\
\hline $\begin{array}{l}\text { The assessment methods enable me to evaluate } \\
\text { my progress/improvement/growth in my study }\end{array}$ & $21 \%$ & $31 \%$ & $32 \%$ & $10 \%$ & $5 \%$ \\
\hline
\end{tabular}

Table 2 presents the data concerning the impact of assessments on learning. It shows that $41 \%$ of the participants to some extent agree with the statement "the assessments assist me in achieving the course outcomes" and $37 \%$ agree whereas only $4 \%$ disagree. As indicated in table 2, $25 \%$ of the total samples disagree with the statement "the assessment methods motivate me to continue learning", and $22 \%$ agree with the same statement and very few of them strongly disagree (9\%). Of the total respondents, $35 \%$ agree that the assessment methods prepare them for the next learning activities, in contrast, only $5 \%$ disagree. Highest numbers of the respondents 34\% reported that the assessment methods enable them to evaluate their progress/improvement/growth in their study, while 33\% to some extent agree and only $4 \%$ strongly disagree. 
Table 3. preferences of assessment tools when they are used for formative assessment. $75 \%$ of year 4 participants responded to this statement.

\begin{tabular}{|l|l|l|l|l|l|l|l|}
\hline $\begin{array}{l}\text { Students' } \\
\text { level }\end{array}$ & $\begin{array}{l}\text { Order of } \\
\text { preferences }\end{array}$ & Presentation & $\begin{array}{l}\text { Final } \\
\text { Project }\end{array}$ & Portfolio & $\begin{array}{l}\text { Research } \\
\text { Paper }\end{array}$ & $\begin{array}{l}\text { Self- } \\
\text { assessment }\end{array}$ & $\begin{array}{l}\text { Peer } \\
\text { assessment }\end{array}$ \\
\hline \multirow{4}{*}{$\mathbf{4}^{\text {th }}$ Year } & $\mathbf{1}^{\text {st }}$ & $15 \%$ & $5 \%$ & $0 \%$ & $20 \%$ & $20 \%$ & $10 \%$ \\
\cline { 2 - 8 } & $\mathbf{2}^{\text {nd }}$ & $10 \%$ & $25 \%$ & $15 \%$ & $5 \%$ & $10 \%$ & $15 \%$ \\
\cline { 2 - 8 } & $\mathbf{3}^{\text {td }}$ & $5 \%$ & $0 \%$ & $25 \%$ & $10 \%$ & $25 \%$ & $10 \%$ \\
\cline { 2 - 8 } & $\mathbf{5}^{\text {th }}$ & $10 \%$ & $5 \%$ & $10 \%$ & $10 \%$ & $10 \%$ & $30 \%$ \\
\cline { 2 - 8 } & $6^{\text {th }}$ & $30 \%$ & $35 \%$ & $20 \%$ & $5 \%$ & $10 \%$ & $0 \%$ \\
\hline
\end{tabular}

Table 3 shows the participants of year 4 preferences of the different assessment methods when they are used for formative assessment. It illustrates that $15 \%$ of them chose presentation as their first preference whereas $30 \%$ consider it as their 6 th preference. Only 5\% prefer final project as their first choice and $35 \%$ consider final project as their 5 th preference. None of them chose portfolio as their first preference, whereas $25 \%$ consider it as $3 \mathrm{rd}$ and $20 \%$ as 5 th preference. Research paper was the first preference of $20 \%$ of the participants and $25 \%$ as 6 th preference. Similarly, $20 \%$ chose self - assessment as their first preference and $25 \%$ as $3 \mathrm{rd}$. the data indicate that $30 \%$ of year 4 participants chose peer assessment as their 4 th choice and only $10 \%$ as 1 st.

Table 4. Preferences of assessment tools when they are used for formative assessment. $40 \%$ of year 3 participants responded to this statement.

\begin{tabular}{|l|l|l|l|l|l|l|l|}
\hline $\begin{array}{l}\text { Students' } \\
\text { level }\end{array}$ & $\begin{array}{l}\text { Order of } \\
\text { preferences }\end{array}$ & Presentation & $\begin{array}{l}\text { Final } \\
\text { Project }\end{array}$ & Portfolio & $\begin{array}{l}\text { Research } \\
\text { Paper }\end{array}$ & $\begin{array}{l}\text { Self- } \\
\text { assessment }\end{array}$ & $\begin{array}{l}\text { Peer } \\
\text { assessment }\end{array}$ \\
\hline \multirow{5}{*}{$3^{\text {rd }}$ Year } & $1^{\text {st }}$ & $7 \%$ & $3 \%$ & $0 \%$ & $13 \%$ & $13 \%$ & $3 \%$ \\
\cline { 2 - 7 } & $2^{\text {nd }}$ & $0 \%$ & $10 \%$ & $10 \%$ & $0 \%$ & $7 \%$ & $13 \%$ \\
\cline { 2 - 8 } & $3^{\text {rd }}$ & $10 \%$ & $7 \%$ & $10 \%$ & $3 \%$ & $3 \%$ & $7 \%$ \\
\cline { 2 - 8 } & $4^{\text {th }}$ & $13 \%$ & $3 \%$ & $7 \%$ & $7 \%$ & $3 \%$ & $7 \%$ \\
\cline { 2 - 8 } & $5^{\text {th }}$ & $3 \%$ & $7 \%$ & $3 \%$ & $13 \%$ & $3 \%$ & $10 \%$ \\
\cline { 2 - 8 } & $6^{\text {th }}$ & $7 \%$ & $10 \%$ & $10 \%$ & $3 \%$ & $10 \%$ & $0 \%$ \\
\hline
\end{tabular}

\section{Discussion}

The main aim of the current study was to determine the student teachers' perceptions of the assessment methods used by their lecturers at the CUT, and to what extent such assessments influence their learning. The results of this study reveal several aspects that reflect the perception of the English language student teachers towards the assessment methods used by their lecturers at CUT. Most importantly, the findings align with Lynam \& Cachia (2018); Lizzio \& Wilson (2013), who highlighted the point that, eventually, students' preferences of the assessment methods "have several differential effects on students' learning processes." Despite agreeing that the practices of assessment used by their lecturers were relevant; examined what was taught and learned and suited their abilities, however, most of the student teachers were still uncertain about neither the assessment practices' ability to examine what they do in class and/nor apply what they know in real-life situations.

The second question of this study questioned the impact of assessment practices on student teachers' learning. While third of the responses ranged between 'agree' and 'strongly agree' stating the impact of the assessment practices on the student teachers' motivation; preparation for future learning tasks, and evaluation of study progress and improvement, almost half of the number of the respondents were uncertain that the assessment methods used helped them in achieving the course outcomes. Birenbaum (1997) found 
that "individual differences in assessment preferences overshadow group differences and that differences in assessment preferences correlate to a relatively large extent with learning strategies." Indeed, some questions for further research present themselves here. For example, what is the impact of a particular method (s) of assessment on student teachers' learning approaches? How does this influence their learning in general? How do their learning styles correlate with their preferences of assessment practices, and to what extent?

To maximize student learning experiences, CUT lecturers might consider highlighting the importance of peer assessment at the planning stage; taking into the consideration the findings of Vickerman's (2009) study. The study investigated undergraduate students' perceptions of formative peer assessment. The findings revealed that, even though peer assessment was a positive experience in enhancing students learning and development, "consideration needs to be taken to address individual learning styles, as a limited number of students found the process to be less useful."

\section{Conclusion}

This study investigated the perceptions of student teachers at Central University of Technology, Free State of the assessment methods used by their lecturers. The findings revealed that student teachers need their lecturers to create direct assessment methods, which are, not only aligned with the learning outcomes, but also provided with clear in-advance instructions. The findings showed that the assessment practices used by instructors had an impact on students' motivation, preparation for future learning tasks, and evaluation of study progress. Finally, the findings of this study suggest that further research could be conducted in investigating the influence of different assessment practices on student teachers' learning approaches, and how this influence if any, might correlate with their preferences and learning styles.

\section{References}

Al-Dabbus (2020). Fawzi, H. Al-Wadi, H. (2020). Pre-service English language Teachers' perceptions and preferences of assessment Practices. International Journal of English language and Linguistics Research, Vol.8 (5): 14 - 26.

Birenbaum, M. (1997). Assessment preferences and their relationship to learning strategies and orientations. Higher Education, 33: 71-84.

Carless, D. (2007). Learning-oriented assessment: Conceptual bases and practical implications. Innovations in Education and Teaching International 44: 57-66.

Chau, T \& Vien, T. (2020). Student Evaluation of teaching effectiveness: EFL Teachers' and Students perceptions. International Journal of Education, Learning and Development, Vol 8(6): 1-19.

Craddock, D., and H. Mathias. (2009). Assessment options in Higher Education. Assessment \& Evaluation in Higher Education 34: 127-140.

Gibbs, G. \& Simpson, C. (2004). Does your assessment support your students' learning? Journal of Teaching and Learning in Higher Education, 1(1), 1-30.

Gibbs, G. (2006). How assessment frames student learning. In Innovative Assessment in Higher Education. C.Bryan and K. Clegg (eds), 23-36. Oxford: Routledge.

Lizzio, A. and Wilson, K. (2018). First year students' appraisal of assessment tasks: Implications for efficacy, engagement and performance. Assessment \& Evaluation in Higher Education, 38(4), 389-406.

Lynam, S. \& Cachia, M. (2018) Students' perceptions of the role of assessments at higher education, Assessment \& Evaluation in Higher Education, 43:2, 223-234.

Meyer, L.; Davidson, S.; McKenzie, L.; Rees, M.; Anderson, H.; Fletcher, R.; \& Johnson, P.M. (2010). An investigation of tertiary assessment policy and practice: Assessment and contradictions. Higher Education Quarterly, 64(3), 331-350.

Vickerman, P. (2009) Student perspectives on formative peer assessment: an attempt to deepen learning? Assessment \& Evaluation in Higher Education, 34:2, 221230. 


\title{
TRANSITIONING ARCHITECTURAL PEDAGOGY INTO THE VIRTUAL ERA VIA DIGITAL LEARNING METHODS
}

\author{
Tatiana Estrina, Alvin Huang, Vincent Hui, \& Kristen Sarmiento \\ Department of Architectural Science, Ryerson University (Canada)
}

\begin{abstract}
In an age of physical separation, a new pedagogical paradigm was established via the integration of pre-recorded videos, video conferencing, and online assessments to become hallmarks of the "new normal". In architectural education, the hands-on learning methodologies were suddenly compromised, challenging design pedagogy to reconfigure how students integrate collaborative design, studio culture, and develop analog skills into virtual learning. This prompted the question, how can architecture be effectively taught and experimentally explored through distanced and virtual means? The recent COVID-19 pandemic has disrupted this pedagogical environment and extinguished the opportunity of accessioning collaborative facilities considering recent distancing parameters. Conducting a literature review on experiences of virtual teaching in the realm of architecture, the paper explores scenarios, surveys, and adaptations to an unprecedented full online architecture studio. The paper showcases a series of teaching modifications that prove to be useful in maintaining and improving student engagement and performance in virtual architectural pedagogy.
\end{abstract}

Keywords: Architectural education, pedagogy, remote learning.

\section{Introduction}

After the declaration of the COVID-19 pandemic by World Health Organization (WHO) on March 11, 2020, architectural education pivoted towards a 'new normal' (Adhanom, 2020). With an unprecedented situation for education delivery, institutions enacted strategies for virtual schooling and improve on creating an efficient system for both students and teachers in trying times. The abrupt transition to online education proved difficult, especially as architecture programs are heavily reliant on the social studio setting and resources associated with it. From the initial reaction from students of isolation, disconnect, and disinterest to the difficulties experienced by faculty in communication, retention of engagement, and assessment models. Educators and institutions have begun to seek, develop, and enact strategies for virtual schooling to reduce issues and take advantage of possibilities. Through the research gathered from a keyword search literature review in combination with case studies conducted at the largest architecture school in Canada (Estrina et al., 2021; Hui et al., 2020), this paper provides an in-depth examination of the challenges and opportunities emergent in virtual architectural education.

\section{Methodology}

To review the various distant teaching methodologies implemented by architecture institutions globally, a literature review was conducted to gather peer-reviewed papers recounting the actions professors and instructors have taken to implement effective architectural education through results in students' academic success and positive social interactivity. A literature review on emergent responses to this condition was developed using a range of current publications using keyword search terms including "architecture education during pandemic", "remote design education", "online education during COVID-19 pandemic". Resulting papers stemmed from pedagogical discourse of numerous disciplines including architecture, interior design, traditional art schools, and engineering programs from around the globe. The research was comprised primarily of case studies and surveys evaluating student and faculty response to institutions' strategies to virtual delivery. In addition to the literature review, a parallel case study was conducted at Canada's largest architecture program, assessing the successes of the techniques and opportunities for experimental learning in virtual environments (Estrina et al., 2021; Hui et al., 2020). In relation to architectural pedagogy, a collection of software used for design collaboration, discourse, and research are gathered and examined in their effectiveness within virtual architectural curriculums.

\section{Results}

The rapid adoption of virtual learning in the disciplines architecture and design has been met with varied levels of success. Architecture programs translating virtually becomes a larger challenge, with 
the core component of design studio relying on social interactivity for constructive feedback which traditionally has been stimulated by habiting the physical studio environment (Jandrić et al., 2020). The literature review (Table 1) gathers multiple perspectives from institutions worldwide to observe common challenges, strategies, and resolutions in the transition to virtual learning. Compared to the preferable in-person learning, students easily lost interest in their online studies and were often stressed with the workloads that accompanied virtual learning (Kauser, 2020). This was a common finding amongst the surveys: another questionnaire conducted by Hananto revealed only $25 \%$ of students preferred online to physical classes (Hananto, 2020). Despite the mixed reactions to virtual learning, many online platforms used for student engagement received positive appraisals from students. Digital design platforms became the preferred tools for operations over analog drafting and model making due to the lack of access to resources (Hui et al., 2020). Online visualization and collaboration using software became even more ubiquitous in showcasing design ideas, in which students were required to develop not only their software skills, but their online presentation and organization skills as well (Estrina et al., 2021; Hui et al., 2020).

Table 1. Summary of results from literature studied.

\begin{tabular}{|c|c|c|c|c|}
\hline Authors/Paper & $\begin{array}{l}\text { Success of Virtual } \\
\text { Delivery }\end{array}$ & Challenges Identified & Benefits Identified & Software Used \\
\hline Ahmed K. & $\begin{array}{l}\text { The proposed method is } \\
\text { to allow for remote } \\
\text { learning to be more } \\
\text { efficient }\end{array}$ & Retaining student engagement & $\begin{array}{l}\text { Improved grasp of } \\
\text { spatial environments; } \\
\text { Virtual site visits } \\
\text { safer, inexpensive, } \\
\text { and expansive }\end{array}$ & $\begin{array}{l}\text { Revit, ClassVR, Microsoft } \\
\text { Teams, HoloLens, Magic } \\
\text { Leap One }\end{array}$ \\
\hline $\begin{array}{l}\text { Alhefnawi \& } \\
\text { Afify, } 2021\end{array}$ & $\begin{array}{l}\text { More failures in } \\
\text { web-based learning } \\
\text { compared to traditional } \\
\text { methods }\end{array}$ & $\begin{array}{l}\text { Malpractice during exams, lack } \\
\text { of interaction, increased failure } \\
\text { rates }\end{array}$ & $\begin{array}{l}\text { Higher grades } \\
\text { achieved, older } \\
\text { students more } \\
\text { independent }\end{array}$ & Blackboard, Zoom \\
\hline Brzezicki, M & $\begin{array}{l}70 \% \text { agree groupwork } \\
\text { led to effective } \\
\text { communication, } 76.6 \% \\
\text { enjoyed workshops, short } \\
\text { lectures }\end{array}$ & $\begin{array}{l}\text { Mental stress, internet } \\
\text { challenges, data limits, less } \\
\text { student-lecturer interaction, } \\
\text { sketching limitations with } \\
\text { mouse }\end{array}$ & $\begin{array}{l}\text { Remote learning is } \\
\text { more time efficient, } \\
\text { Increased attendance } \\
\text { ( } 92 \% \text { instead of } 70 \% \\
\text { previously) }\end{array}$ & $\begin{array}{l}\text { Moodle, Kahoot, Socrative, } \\
\text { Google Docs } \\
\text { (presentations), Zoom, } \\
\text { Microsoft Teams }\end{array}$ \\
\hline $\begin{array}{l}\text { Casakin \& } \\
\text { Wodehouse }\end{array}$ & & $\begin{array}{l}\text { Fixation on design, difficulty } \\
\text { emulating traditional studio } \\
\text { environment, creative } \\
\text { discussion difficult }\end{array}$ & $\begin{array}{l}\text { Improved spatial } \\
\text { perception, using } \\
\text { abstract design tasks } \\
\text { freed imagination }\end{array}$ & $\begin{array}{l}\text { Virtual and augmented } \\
\text { reality }\end{array}$ \\
\hline Ceylan et. al & $\begin{array}{l}\text { Results vary amongst the } \\
\text { first, second, third, and } \\
\text { fourth years: first years } \\
\text { are more positive about } \\
\text { the situation }\end{array}$ & $\begin{array}{l}\text { Travel restrictions, adaptation } \\
\text { to new working spaces, } \\
\text { psychological issues }\end{array}$ & $\begin{array}{l}\text { Development of } \\
\text { presentation skills, } \\
\text { access to lecture } \\
\text { recordings }\end{array}$ & $\begin{array}{l}\text { Adobe Connect, Sketchup, } \\
\text { Lumion, AutoCAD, Google } \\
\text { Earth, Google Maps, } \\
\text { Google Hangouts, Skype }\end{array}$ \\
\hline Hananto, B & $\begin{array}{l}75 \% \text { students preferred in } \\
\text { person learning, }>50 \% \\
\text { found online learning } \\
\text { more challenging }\end{array}$ & $\begin{array}{l}\text { Transition to remote education } \\
\text { was challenging for instructor } \\
\text { and students }\end{array}$ & $\begin{array}{l}\text { Less expensive, } \\
\text { Increased flexibility }\end{array}$ & Digital classroom platforms \\
\hline Hui et al., 2020 & & $\begin{array}{l}\text { Reduced social connectivity, } \\
\text { lack of peer support }\end{array}$ & $\begin{array}{l}\text { Worldwide } \\
\text { connectivity, } \\
\text { increased digital } \\
\text { fluency }\end{array}$ & $\begin{array}{l}\text { Miro, Zoom, Enscape, } \\
\text { Rhinoceros } 3 D, \text { Blogspot }\end{array}$ \\
\hline Ibrahim et. al & $\begin{array}{l}75 \% \text { of faculty support } \\
\text { teaching theory online } \\
65 \% \text { agreed that virtual } \\
\text { design education was } \\
\text { ineffective }\end{array}$ & $\begin{array}{l}\text { Faculty reported time } \\
\text { management and privacy } \\
\text { issues, psychological issues } \\
\text { (lack of boundary between } \\
\text { work and home), evaluation } \\
\text { tool and communication issues }\end{array}$ & $\begin{array}{l}\text { According to the } \\
\text { faculty, history and } \\
\text { theory courses were } \\
\text { as effective as } \\
\text { traditional teaching }\end{array}$ & $\begin{array}{l}\text { Zoom, Microsoft Teams, } \\
\text { Facebook Messenger }\end{array}$ \\
\hline $\begin{array}{l}\text { Iranmanesh, } \\
\text { Aminreza } \\
\text { Onur, Zeynep }\end{array}$ & $\begin{array}{l}\text { Overall positive reviews } \\
\text { for virtual design studios }\end{array}$ & Lack of peer learning & $\begin{array}{l}\text { Accessibility to } \\
\text { lecture recordings, } \\
\text { improvement in } \\
\text { software skills }\end{array}$ & $\begin{array}{l}\text { WhatsApp, Facebook, } \\
\text { YouTube, Skype, Google } \\
\text { Meet, AutoCAD, Sketchup }\end{array}$ \\
\hline Kauser, A. & $\begin{array}{l}\text { Faculty agreed that } \\
\text { teaching design studios } \\
\text { online was not effective }\end{array}$ & $\begin{array}{l}\text { Plagiarism, loss of student } \\
\text { interest, increased stress levels, } \\
\text { lack of self-motivation, } \\
\text { psychological and emotional } \\
\text { challenges, reduced design } \\
\text { quality, lack of access to } \\
\text { resources }\end{array}$ & $\begin{array}{l}\text { Students become } \\
\text { more independent, } \\
\text { students from multiple } \\
\text { institutions can } \\
\text { collaborate together }\end{array}$ & $\begin{array}{l}\text { Moodle, Eduwave, Big Blue } \\
\text { Button (BBB), Zoom, } \\
\text { Google Meet, Screencast-O- } \\
\text { Matic, Skype, Facebook, } \\
\text { YouTube, Instagram, } \\
\text { WhatsApp, Turnitin }\end{array}$ \\
\hline $\begin{array}{l}\text { Kristianova K. } \\
\text { \& Joklova V }\end{array}$ & $\begin{array}{l}\text { On-site research and trips } \\
\text { were not possible to } \\
\text { conduct }\end{array}$ & $\begin{array}{l}\text { On-site research abilities were } \\
\text { limited, Lack of ambiance and } \\
\text { atmosphere in virtual site visits }\end{array}$ & $\begin{array}{l}\text { Virtual site visits are } \\
\text { more affordable }\end{array}$ & $\begin{array}{l}\text { Google Suite, Google } \\
\text { Hangouts, Good Maps }\end{array}$ \\
\hline $\begin{array}{l}\text { Peimani, M. \& } \\
\text { Kamalipour, H. }\end{array}$ & & $\begin{array}{l}\text { Impaired student development, } \\
\text { Time zone incompatibility, } \\
\text { Inequality of access digital } \\
\text { resources }\end{array}$ & $\begin{array}{l}\text { Intrapersonal students } \\
\text { were more } \\
\text { comfortable, recorded } \\
\text { lectures more } \\
\text { inclusive }\end{array}$ & $\begin{array}{l}\text { Microsoft Teams, Learning } \\
\text { Central }\end{array}$ \\
\hline $\begin{array}{l}\text { Pregowska, } \\
\text { Et. al }\end{array}$ & $\begin{array}{l}\text { Dissatisfaction with } \\
\text { remote learning } \\
\text { increasing overtime }\end{array}$ & $\begin{array}{l}\text { Pandemic fatigue, lack of } \\
\text { physical contact with peers, } \\
\text { dissatisfaction with group work }\end{array}$ & $\begin{array}{l}\text { Flexibility and access } \\
\text { to remote courses, } \\
\text { virtual reality was } \\
\text { safer and less } \\
\text { expensive }\end{array}$ & $\begin{array}{l}\text { Microsoft Hololens, Magic } \\
\text { Leap One, AjnaLens, } \\
\text { AulaVR }\end{array}$ \\
\hline Spitz et. Al. & & $\begin{array}{l}\text { Lack of engagement, inability } \\
\text { to provide computer resources } \\
\text { to everyone in need, emotional } \\
\text { challenges, lack of privacy }\end{array}$ & $\begin{array}{l}\text { Improved attendance, } \\
\text { Excellent grades and } \\
\text { work }\end{array}$ & $\begin{array}{l}\text { Minecraft, Blender, Hubs, } \\
\text { eLearning platforms }\end{array}$ \\
\hline $\begin{array}{l}\text { Varma A. \& } \\
\text { Jafri M }\end{array}$ & $\begin{array}{l}33 \% \text { were satisfied with } \\
\text { remote learning, but not } \\
\text { satisfied with online } \\
\text { design studio }\end{array}$ & $\begin{array}{l}\text { Digital tools aren't widely used, } \\
\text { professors had difficulty } \\
\text { discussing ideas visually with } \\
\text { lack of hardware }\end{array}$ & $\begin{array}{l}\text { Remote learning } \\
\text { allows more } \\
\text { flexibility - less } \\
\text { distance barriers }\end{array}$ & $\begin{array}{l}\text { Zoom, Microsoft Teams, } \\
\text { WhatsApp, YouTube, } \\
\text { SlideShare }\end{array}$ \\
\hline
\end{tabular}




\section{Discussion}

Although remote learning has largely been integrated into architectural programs worldwide due to closures, lockdowns, and social distancing, there are numerous issues that emerge. These include reduced student interaction, the importance of feedback loops, absence of social engagement, difficulty with assessment, digital fluency, and technical issues. In order rectify and combat some of the emerging issues, the literature examined presents a number of best practices as well as opportunities for capitalizing on the format for enhanced learning.

\subsection{Feedback loops and communication pathways in virtual studio environments}

The virtual format creates somewhat of a disconnect between students and instructors, especially in lecture courses where the education becomes very one-sided. Where in a typical in-person classroom students are able to pose questions and chat with professors individually with relative ease, web-based education makes this challenging as the latency is responses becomes staged and less natural in pacing (Alhefnawi \& Afify, 2021). Conversations become either very public or require students and instructor to connect outside of class hours, which is not always a possibility. Thus, the establishment of efficient feedback exchange and communication amongst students and lecturers should be explored as a priority (Casakin \& Wodehouse, 2021). Whether via the creation of office hours outside of class time, messaging channels for questions, or rapid replies to emails, instructors must invest more time in providing timely and sufficient support for students in web-based instruction (Alhefnawi \& Afify, 2021). Studio courses also pose a multitude of other communication issues affecting collaboration between instructors and students. The virtual communication methods which are typical for studio courses become challenging, especially for professors that are used to hand drawing ("How Virtual Learning Is Impacting Studio Time for Architecture Courses," 2021). Experimentation with both alternative drawing and brainstorming software, such as Miro, in conjunction with additional digital tools including drawing tablets can aid in bridging this disparity (Hui et al., 2018).

\subsection{Evaluation and assessment}

When evaluating student work conducted remotely, many faculty members experienced issues with evaluation tools and methods (Ibrahim et al., 2020). In addition to malpractice during exams, plagiarism and cheating became more prevalent with online education, as the lack of monitoring and social presence eliminated barriers and social pressures against such behaviors (Alhefnawi \& Afify, 2021; Kauser, 2020). In order to avoid such issues, exam-based evaluations may be conducted in open-book formats or replaced with project and paper-based evaluation methods. Conversely, proverbial architectural juries prove to be an opportunity for enhancement when transitioned to the online environment. Despite some limitations, virtual juries gave students more control over the content being viewed as any given moment, causing students to prefer virtual over physical reviews (Iranmanesh \& Onur, 2021). In addition, the digitally-hosted reviews allow for more diverse jury compositions, with the possibility of participation of professionals and academics from around the world (Hui et al., 2020; Iranmanesh \& Onur, 2021). Students also appreciated the ability for reviews to be recorded for re-checking, allowing for deeper learning (Iranmanesh \& Onur, 2021). In fact, student success has proven to be independent of teaching mode, however digital delivery methods are more challenging for high-grade students and those lacking digital design skillsets (Alhefnawi \& Afify, 2021).

\subsection{Attentiveness and student engagement}

Despite the increase in attendance, many educators found it challenging to retain students' attention and create engaging environments when teaching remotely (Brzezicki, 2020). Faculty found lectures to be lonely, with a loss of student interest and attendance despite efforts taken to engage the group, leading to a very dissatisfying experience for both parties (Jandrić et al., 2020; Kauser, 2020; Spitz et al., 2020). Some techniques outlined in order to maintain student interest involve shorter, more compact classes alongside small group discussions (Brzezicki, 2020). This approach allows for a less lengthy and convoluted delivery of the content while also providing increased social connectivity among students, forcing them to engage (Brzezicki, 2020). Furthermore, the incorporation of interactive activities including virtual field trips, proved to increase overall interest and engagement in projects as well as a deeper understanding of context (Hui et al., 2020; Kristianova \& Joklova, 2020). Virtual networks can be used to expose students to a variety of different perspectives, both regionally and internationally, thus the invitation of guest lecturers and reviewers aids in diversifying the experience (Hui et al., 2020; Spitz et al., 2020).

\subsection{Social connectivity}

Prior to the pandemic-driven shift to digital learning, studio was at the center of architectural education, with students using the space to work on their project while also receiving advice and criticism from professors and other students ("How Virtual Learning Is Impacting Studio Time for Architecture 
Courses," 2021). While some students found it easier to communicate solely through virtual means, the lack of direct eye contact, face-to-face communication, and active engagement proved to be detrimental to student's productivity (Peimani \& Kamalipour, 2021). To be around other students allowed them to maintain high energy and spirits, which was found to be lacking in the isolated environment of virtual learning ("How Virtual Learning Is Impacting Studio Time for Architecture Courses," 2021). Peimani and Kamalipour identified the development of professional, communication, and practical skills as critical challenges that emerge in remote learning (Peimani \& Kamalipour, 2021). Despite students' dissatisfaction with graded group work, the inclusion of smaller, ungraded in-class group assignments can stimulate interaction among students, by reducing communication circles and allowing for a more intimate space (Pregowska et al., 2021). Many educators began to conduct studio desk reviews in small groups in order to stimulate peer-to-peer student interaction. As an importance is placed on the sharing and discussion of student projects in architectural education, an emphasis remains on the circulation of in progress and final work, be it via publications, websites, events, blogs, or social media (Hui et al., 2020). These platforms can additionally serve to generate interaction and connections among the students themselves, with the use of blogs proving to be especially effective (Hui et al., 2020).

\subsection{Digital fluency and technical effectiveness}

Upon adoption of the virtual learning model, capitalization on digital learning has been identified as an opportunity for student development. As students are, "native speakers of digital technologies and virtual space", they are equipped for the rapid adoption of new software and toolsets which are becoming more desirable in the industry (Iranmanesh \& Onur, 2021). A mixture of digital learning conditions and difficulties allows for students to develop a variety of skillsets more effectively and collaboratively (Estrina et al., 2021). Additional avenues of expansion of digital fluency involve the inclusion of extended realities mainly virtual reality (VR), augmented reality (AR), and mixed reality (MR), into architectural teaching. The integration of these technologies into digital learning provides students with enhanced virtual opportunities and experiences, both for the learning of lecture-based content and for design work (Ahmad et al., 2020; Aydin \& Aktaş, 2020; Estrina et al., 2021; Hui et al., 2020). To aid student comprehension of spatial relationships, which proved to be a deficiency in virtual education, real-time rendering software visualization using extended realities were able to mitigate this gap (Ceylan et al., 2020; Estrina et al., 2021; Hui et al., 2020). While these environments cannot replace in-person learning, they give agency to students to convey design ideas virtually whilst improving software abilities (Ahmed, 2020). Building information modelling (BIM) software were also widely utilized, bridging disciplines via robust platforms, and providing extensive collaboration features for student (Ahmed, 2020).

However, the inevitable involvement of technologies in virtual education uncovers additional longstanding challenges in contemporary design education. Equal access to resources, software, and hardware proved to be an issue in many developing countries, and providing support is particularly important in ensuring students have equal opportunities for success (Alhefnawi \& Afify, 2021; Varma \& Jafri, 2020). Additionally, provisions for contingency plans in case of technical issues are critical in maintaining successful classes or studios (Alhefnawi \& Afify, 2021). In addition, provision of various training sessions on the assorted software, both for instructors to improve teaching quality and for students to aid in graphic and verbal presentations, is beneficial in reducing technological barriers (Ibrahim et al., 2020). The development of quick and efficient response strategies have emerged as a key to the successful conduction of virtual education and the response to crisis (Al-Taweel et al., 2020).

\section{Conclusion}

While the global pandemic has enacted a myriad of parameters redefining education delivery, the use of online platforms has become paramount to keep students connected and advance methodologies pedagogy. With mixed success, architectural pedagogy was transitioned into the virtual, encountering successes and challenges. Some notable difficulty areas included evaluation, assessment models, and feedback loops; reduced social connectivity; lack of attentiveness and student engagement; and absence of digital fluency and technical effectiveness. A greater effort from faculty in order to establish communication pathways and increase engagement in the virtual lecture hall, in combination with additional instructional software sessions and support, begin to resolve some of these pitfalls. Instead, academics can capitalize on the opportunities emergent in virtual education, namely diverse guest and jury composition, virtual travel, incorporation of extended realities, and the wider reach of education. As countries begin to reopen, conversations have begun around a blend-type of course delivery, where alongside the in-person education additional synchronous virtual meetings are provided (Ibrahim et al., 2020). This approach can harness the benefits of remote online learning while maintaining the social connectivity that this instructional method currently lacks. Despite the passing nature of the COVID-19 pandemic, the effects of the resulting web-based pedagogy are sure to be lasting in architectural education. 


\section{References}

Adhanom, T. (2020). WHO Director-General's opening remarks at the media briefing on COVID-19 - 11 March 2020. World Health Organization. https://www.who.int/directorgeneral/speeches/detail/who-director-general-s-opening-remarks-at-the-media-briefing-on-covid19---11-march-2020

Ahmad, L., Sosa, M., \& Musfy, K. (2020). Interior design teaching methodology during the global COVID-19 pandemic. Interiority, 3(2), 163-184. https://doi.org/10.7454/in.v3i2.100

Ahmed, K. G. (2020). Augmented reality in remote learning: A proposed transformative approach for building construction education. Proceedings of the International Conference on E-Learning, ICEL, 2020-Decem, 115-120.

Al-Taweel, D., Al-Haqan, A., Bajis, D., Al-Bader, J., Al-Taweel, A. R. M., Al-Awadhi, A., \& Al-Awadhi, F. (2020). Multidisciplinary academic perspectives during the COVID-19 pandemic. In International Journal of Health Planning and Management (Vol. 35, Issue 6, pp. 1295-1301).

Alhefnawi, M., \& Afify, H. (2021). Exam Grades in Architecture Classes : A Comparative Assessment of Before and During COVID-19 Pandemic Modes of Teaching and Learning. January.

Aydin, S., \& Aktaş, B. (2020). Developing an Integrated VR Infrastructure in Architectural Design Education. Frontiers in Robotics and AI, 7(October). https://doi.org/10.3389/frobt.2020.495468

Brzezicki, M. (2020). Strengths and weaknesses of architectural education on-line classes conducted during COVID-19. World Transactions on Engineering and Technology Education, 18(4), 381-386.

Casakin, H., \& Wodehouse, A. (2021). A systematic review of design creativity in the architectural design studio. Buildings, 11(1), 1-19. https://doi.org/10.3390/buildings11010031

Ceylan, S., Şahin, P., Seçmen, S., Somer, M. E., \& Süher, K. H. (2020). An evaluation of online architectural design studios during COVID-19 outbreak. Archnet-IJAR, 15(1), 203-218.

Estrina, T., Hui, V., \& Ma, L. (2021). The digital design build. PROJECTIONS, Proceedings of the 26th International Conference of the Association for Computer-Aided Architectural Design Research in Asia (CAADRIA), 2, 41-50.

Hananto, B. A. (2020). Explorations of design by digital \& remote education. Architecture \& Design (IMADe), l(October), p-ISSN. http://eprosiding.std-bali.ac.id/index.php/imade

How virtual learning is impacting studio time for architecture courses. (2021). In The Shorthorn (pp. 1-2).

Hui, V., Estrina, T., \& Huang, A. (2020). Creative Connections: Maintaining Studio Culture In An Age Of Physical Separation. ICERI2020 Proceedings, 5082-5089. https://doi.org/10.21125/iceri.2020.1105

Hui, V., Estrina, T., Zhou, G., Lee, S., \& Kinuthia, V. (2018). Architectural Accessibility And Pedagogy Via Virtual Reality. 1-13.

Ibrahim, A. F., Attia, A. S., Bataineh, A. M., \& Ali, H. H. (2020). Evaluation of the online teaching of architectural design and basic design courses case study: College of Architecture at JUST, Jordan. Ain Shams Engineering Journal, xxxx. https://doi.org/10.1016/j.asej.2020.10.006

Iranmanesh, A., \& Onur, Z. (2021). Mandatory Virtual Design Studio for All: Exploring the Transformations of Architectural Education amidst the Global Pandemic. International Journal of Art and Design Education, 40(1), 251-267. https://doi.org/10.1111/jade.12350

Jandrić, P., Hayes, D., Truelove, I., Levinson, P., Mayo, P., Ryberg, T., \& Monzó, L. D. (2020). Teaching in the Age of Covid-19. Postdigital Science and Education, 2, $1069-1230$.

Kauser, A. N. (2020). Rethinking architecture pedagogy in the era of pandemics. 1-6.

Kristianova, K., \& Joklova, V. (2020). on-Site Research, Excursions, and Field Trips in Architectural Education - Constraints in the Time of Covid-19. ICERI2020 Proceedings, 1(November), 5677-5682.

Peimani, N., \& Kamalipour, H. (2021). Online education and the covid-19 outbreak: A case study of online teaching during lockdown. Education Sciences, 11(2), 1-16. https://doi.org/10.3390/educsci11020072

Pregowska, A., Masztalerz, K., Garlińska, M., \& Osial, M. (2021). A worldwide journey through distance education - from the post office to virtual, augmented and mixed realities, and education during the covid-19 pandemic. Education Sciences, 11(3). https://doi.org/10.3390/educsci11030118

Spitz, R., González, J. R., Ugarte, S., Meythaler, A. Á., Abril, X. B., \& Idiáquez, J. M. (2020). Towards a "Better Normal ": Educational Experiences in Design in Latin America During the COVID-19 Pandemic. Strategic Design Research Journal, 13(03), 564-576.

Varma, A., \& Jafri, M. S. (2020). COVID-19 responsive teaching of undergraduate architecture programs in India: learnings for post-pandemic education. Archnet-IJAR, 15(1), 189-202. 


\title{
LET'S TALK! PROMOTING MEANINGFUL COMMUNICATION THROUGH AUTHENTIC TEACHER CHILD DIALOGUE
}

\author{
Barbara Shapir, Teresa Lewin (Dr.), \& Samar Aldinah \\ Kaye College of Education- Early Educational Department (Israel)
}

\begin{abstract}
The heart of this study is an analysis of teacher-child dialogue in a classroom environment. An authentic dialogue enables children to express their real thoughts and ideas, to present insights, to ask questions, to make comments and to argue about different interpretations.

In an effort to help our future teachers improve the quality of their verbal and nonverbal interactions with children as well as emotional and social support, we created a "community of learners". Mentors and eight students - teachers (Israeli Jews and Arabs) participated in a reciprocal process of learning through experimentation while building new knowledge. Their interactions were examined how the teachers' verbal and nonverbal responsiveness helped them to open or close conversational spaces for children while enabling them to listen to their voices.

The research methodology was a discourse analysis i.e. analyzing the use of language while carrying out an act of communication in a given context. It presents a qualitative analysis of 20 transcripts of students teacher's conversations with Israeli Jewish and Arab children from ages $4-6$ years old. The analysis revealed that as teachers provided open conversational spaces with children, authentic dialogue emerged. Both voices were expressed and the child's world was heard. The significance of this study is to demonstrate the importance that authentic dialogue between teachers and young children has on the learning process as well as teacher's acknowledgment on how children think and feel. This offers an opportunity for them to learn with and from the children.
\end{abstract}

Keywords: Authentic dialogue, verbal \& nonverbal interactions.

\section{Introduction}

This study has grown out of a learning community that has been operating for the past three years in the Early Childhood Educational Department at the Kaye Academic College of Education (Beer Sheva, Israel). The main goal was to study and promote teacher-children quality interactions, focusing on optimal discourse that provides emotional and social support. The learning community consisted of Jewish and Arab lecturers teaching training classes.

\section{The role of dialogue in education}

Dialogue is essential in human relationships in order to reach understandings and consensus among people. Meaningful dialogue in classroom interactions is of pivotal importance because it affects both teachers' and students' sense of security and wellbeing, as well as the quality of students' learning processes and achievements. (Hennessy et al., 2016; Teachman et al., 2018; Vrikki et al., 2019).

Despite the recognition of the importance of reciprocal dialogue, the prevailing form of teacher-student interactions continue to be the traditional structure IRE (Initiation-Reply-Evaluation) (Mehan and Cazden, 2015) or IRF (Initiation-Response-Feedback) (Sinclair \& Coulthard, 1975). This holds true in kindergartens as well. Classrooms and early childhood settings which have followed this pattern have excluded many minority students, as it does not encourage them to actively participate in the classroom talk.

In early childhood education, discourse is especially important and is regarded as the main pedagogical tool of kindergarten teachers. The social learning climate that the teacher provides will determine the quality of their interactions with children and success in school. (McNally \& Slutsky, 2018; Myers \& Sheddield, 2009). In the teacher's role perception of classroom discourse she sees herself in a 
parental role, and by virtue of this role, has the authority and responsibility to be in control, navigate and lead the classroom interaction (Peled-Elhanan \& Blum-Kulka, 2006).

In order to promote personal discourse, the early childhood teacher should foster a supportive environment, sensitively addressing children's interests, characteristics and needs. This requires providing open discourse spaces that will allow children to make their voices heard and express their thoughts and experiences. This discourse has been termed authentic dialogue (Nystrand et al., 2003)

Authentic dialogues can occur only if the different perspectives given by the children are accepted and not judgementally rejected. When a teacher withholds the urge to control the child's thinking or reprimand their behaviour, she can actively listen and be attentive to the children's needs. Respectful and responsive interactions that also honor cultural beliefs and values will strengthen the teacher's relationships with the children and their families (Barrera, Corso \& MacPherson, 2003; Strickland \& Marinak, 2015). Nystrand and his colleagues defined this space as a "positive interaction area" in which many children participate, build on each other's ideas and ask questions enthusiastically and out of interest (Nystrand et al., 2003).

\section{Problem statement}

Previous research has proven the significance of insightful and authentic dialogue in educational settings. However, early childhood teachers often do not fully recognize this and additionally, are not sufficiently trained in conducting authentic, meaningful dialogues with children. Furthermore, educators and researchers often fail to understand the power relationships and values that dialogues convey, as well as the need of addressing cultural norms and multiple perspectives (Guilherme \& Morgan, 2020). We adhere to the view that personal and meaningful dialogues are those which open spaces for diverse perspectives, for the understanding and the construction of new meanings and the development of children's' critical and independent thinking.

\section{Purpose of the study}

To describe, and characterize the dialogue between preservice teachers and children.

\section{Research questions}

What characterizes the dialogue between preservice teacher's and children? Specifically, to what extent did the preservice teacher's implement principles of authentic dialogue they learned?

\section{Research methods}

The research methodology was a discourse analysis i.e., analyzing the use of language while carrying out an act of communication in a given context (Schiffrin, Tannen \& Hamilton, 2001). The work is grounded in the sociolinguistic approach, emphasizing the functionality of language (Vardi-Rath, Teubal, Aillenberg \& Lewin, 2014).

\subsection{Participants}

Participants are 8 Israeli students - teachers (4 Jewish and 4 Arab) in their third and final training year. All of them took part in a community of learners that consisted of pedagogical advisors and lecturers from the early childhood department in the college in a reciprocal process of learning through experimentation while building new knowledge. Sixteen kindergarten children, ages 3-6 years old (8 Jewish and $8 \mathrm{Arab}$ ) participated in the research as well as the dialogue was conducted with them.

\subsection{Research tools and data processing}

Each preservice teacher conducted three personal conversations with the same child. The teachers were instructed to start each conversation with an open-ended question (for example: What would you like to tell me? How do you feel? Tell me about yourself), inviting the child to share experiences through story telling. The work presents a qualitative analysis of 20 transcripts of preservice teacher's conversations with children. The study is based on ethnographic data gathering, i.e., recording teacher - children's discourse. During the conversation with a child, preservice teachers videotaped and took notes. After the session, they produced a transcript combining the information from the oral videotapes and written notes. Video is a tool that is used to document authentic situations and additionally, to help teachers learn to critically reflect on their classroom interactions (Borko, Jacobs, Eiteljorg, \& Pittman, 2008). 
The videos were analysed, using a coding scheme that was developed by the researchers and preservice teachers in the community of learners. It is based on a tool designed by Birenbaum at al. (2004), and adapted to the needs of the study. The coding scheme categorizes qualitative analysis teachers' discourse characteristics and the ways they navigated the conversations with the children based on theoretical literature on the subject.

\section{Findings}

The analysis revealed that as teachers provided open conversational spaces with children, authentic dialogue emerged. Both voices were expressed in a more equalitative fashion and the child's world was heard (Strickland \& Marinak, 2015).

Examples of principles used to analyse functions of talk in order to identify patterns in the interaction are: 1. Opening dialogue; opening statement enables the child to pick a topic of his own free will 2. Reciprocal talk: the teacher commented and expressed respect and appreciation for the children's opinions 3. Supportive reactions: participants feel able to express ideas freely, listen to each other, share ideas and consider alternative viewpoints; 4. Type of questions: the teacher provided open questions that were in line with the children's focus of attention and interest; 5 . Sensitive response: the teachers provide space for children's initiatives and enable them to share their experiences while being sensitive and responsive.

\section{Conclusion}

Referring to the question what characterizes the dialogue between preservice teacher's and children, it can be said that in order to promote personal authentic dialogue, the teacher should foster a supportive environment, sensitively addressing children's interests, characteristics and needs. This requires providing open discourse spaces that will allow children to make their voices heard and express their thoughts and experiences. It is important to create open spaces in all areas of preschool environment and activity corners.

What did the staff learn from this process created through a community of learners? Preservice teachers can experience significant learning through hands on experiences while interacting with children after receiving training on the characteristics of authentic dialogue. In addition, through a reflective process, they become more aware of their role in enabling a more equal dialogue. Therefore, it's essential that the preservice teacher's pedagogical advisors guide them and promote reflective thinking.

This research is still ongoing due to the fact that an extensive amount of data has been collected and not yet analyzed. Our analysis did show some conclusions such as both Jewish and Arab children mainly talk about topics close to their world such as family, friends, personal experiences and these issues are related to the social context in which they live.

The significance of this study is to demonstrate the importance that authentic dialogue between teachers and young children has on the learning process as well as teacher's acknowledgment on how children think and feel. This offers them an opportunity to learn from children, together with children.

\section{References}

Barrera, I., Corso, R. M., \& MacPherson, D. (2003). Skilled dialogue: Strategies for responding to cultural diversity in early childhood. Baltimore: Paul H. Brooks Publishing Co.

Birenbaum, M., Yoad, C., Katz, S., \& Qimron, H. (2004), In Continuous Construction - An Environment for the Professional Development of Teachers on the Subject of the Culture of HL, which cultivates self-direction in learning. Jerusalem: Ministry of Education, Culture and Sports. (In Hebrew).

Borko, H., Jacobs, J., Eiteljorg, E., \& Pittman, M. E. (2008). Video as a tool for fostering productive discussions in mathematics professional development. Teaching and Teacher Education, 24(2), 417- 436.

Borko, Hilda \& Jacobs, Jennifer \& Eiteljorg, Eric \& Pittman, Mary. (2008). Video as a tool for fostering productive discourse in mathematics professional development. Teaching and Teacher Education. 24. 417-436.

Guilherme, A., \& Morgan, W.J. (2020) Filosofia, diálogo e educação: nove filósofos europeus modernos. Brasília: Cátedra Unesco de Juventude, Educação e Sociedade, Universidade Católica de Brasília, ISBN:978-85-62258-44-2. (In English). 
Hennessy, S., Rojas-Drummond, S., Higham, R., Marquez, A. M., Maine, F., Ríos, R. M., et al. (2016). Developing a coding scheme for analyzing classroom dialogue across educational contexts. Learning, Culture and Social Interaction, 9, 16-44.

McNally, S., \& Slutsky, R. (2018). Teacher-child relationships make all the difference: constructing quality interactions in early childhood settings. Early Child Development and Care, 188 (5), 508-523.

Mehan, H., \& Cazden, C. (2015). The study of classroom discourse: Early history and current developments. In L.B. Resnick, C. Asterhan, \& S.N. Clarke (Eds.), Socializing intelligence Chapter 4 (pp. 13-36). Washington, DC: American Educational Research Association.

Myers, S.S., \& Sheffield, M., A. (2009). Examining associations between effortful control and teacher-child relationships in relation to Head Start children's socioemotional adjustment. Early Education and Development, 20(5), 756-774.

Nystrand, M., Wu, L., Gamoran, A. Zeiser, S., \& Long, D. (2003). Questions in time: investigating the structure and dynamics of unfolding classroom discourse. Discourse Processes, 35(2), 135-198.

Peled-Elhanan, N., \& Blum-Kulka, S. (2006). Dialogue in the Israeli classroom: Types of teacher-student talk. Language and Education, 20(2), 110-127.

Schiffrin, D., Tannen, D., \& Hamilton, H. E. (Eds.). (2001). The handbook of discourse analysis. Padstow, Cornwall, UK: Blackwell.

Sinclair, J. M., \& Coulthard, M. (1975). Towards an Analysis of Discourse: The English Used by Teachers and Pupils. Oxford: Oxford University Press.

Strickland, M., \& Marinak, B. (2015). Not Just Talk, But a "Dance"! How Kindergarten Teachers Opened and Closed Spaces for Teacher-Child Authentic Dialogue. Early Childhood Education Journal, 43(6), 1-9.

Teachman, G., McDonough, P., Macarthur, C., \& Gibson, B. E. (2018). A critical dialogical methodology for conducting research with disabled youth who use augmentative and alternative communication. Qualitative Inquiry, 24, 35-44.

Vardi-Rath, E., Teubal, E., Aillenberg, H. \& Lewin, T. (2014). “Let's pretend you're the wolf!": The literate character of pretend-play discourse in the wake of a story. In A. Cekaite, S. Blum-Kulka, V. Grover, \& E. Teubal (Eds.), Children's peer talk: Learning from each other (pp. 63-87). Cambridge: Cambridge University Press.

Vrikki, M., Wheatley, L., Howe, C., Hennessy, S., \& Mercer, N. (2019). Dialogic practices in primary school classrooms. Language education, 33, 85-100. 


\title{
HIGHER EDUCATION INSTITUTIONS' NEED TO INITIATE CHANGE TO THE ACCOUNTING CURRICULUM DURING THE FOURTH INDUSTRIAL REVOLUTION (4IR)
}

\author{
Shaun Peens \\ Department of Languages and Social Sciences, Central University of Technology, \\ Free State (South Africa)
}

\begin{abstract}
In South Africa, the Further Education and Training phase (FET) in Accounting faces a major decline in learner numbers. The current format of FET Accounting serves little purpose in preparing learners for Accounting courses at tertiary level, if FET Accounting is not a precondition to Professional and Chartered Accountant courses. This study followed a qualitative research approach, from five Focus Groups at five Secondary schools in the Motheo Educational district, comprising of 16 FET Accounting Teachers to consider possible reasons for the decline of learners in FET Accounting. As result, uncertainty exists regarding the future of FET Accounting and the Accounting profession, when guidance teachers are presumably advising learners to take less suitable subjects, like Mathematical Literacy, History of Geography to enhance school reports. These findings influence the social responsibility of teachers; and it also results in many Accounting students having to spend two or more additional years at university due to their apparent lack of basic Accounting skills. Additionally, the negative perception towards FET Accounting might impact learners' choices who might not plan a career in Accounting, thereby limiting their ability to secure any career in the financial sector. Collaborative social change is required from the Accounting profession and university alike, especially in the Fourth Industrial Revolution era, where a high degree of ethics and transparency are required.
\end{abstract}

Keywords: Higher education, accounting, further education and training, 4IR.

\section{Introduction}

Did the Fourth Industrial Revolution (4IR) influence (or satisfy) our needs before we realising its existence? How are the Accounting profession and specifically University lecturers going to respond to it? More importantly, when?

In the South African context, Accounting is offered in Grades 10 to 12 (learners aged between 15 and 18); commonly referred to the Further Education and Training (FET) phase. Prior to the FET phase learners in the Senior Phase (SP) are exposed a subject named Economic and Management Sciences (EMS) where Accounting, Business Management and Economics are tangled as one subject, which is compulsory to all SP (Grades 7, 8 and 9) learners (SA Study, 2018).

Investigation at high schools in the Motheo district (Central parts of South Africa), indicated a major decline in learner numbers for FET Accounting linked to selective and/or insufficient assistance from guidance teachers. Additionally, inconsistent pre-requirements from university programmes in Accounting, impacted whether FET Accounting in its current format (curriculum) still serves a contributing resolve to prepare learners for Accounting courses at University and ultimately for the work force.

As an academic the feedback from FET Accounting learners mentioning Accounting as not interesting tend to initiate reflective measures on personal and future choices. It inflates pondering time of value and purpose of Accounting.

Olsen (2011) in Fin24 magazine addresses the discourse in FET Accounting at school level by suggesting possible ways and means to ensure and safeguard the preservation of Accounting as a subject. With 4IR looming around every corner and realising the impact it made during the past 12 months with the COVID pandemic it widened the debate whether the Accounting profession and University lecturers would respond in time to the Fourth Industrial Revolution (4IR) impact on education? 


\section{Purpose of this article}

The main purpose employed in this study was to measure the enthusiasm and opinion Accounting Teachers have with regards to teaching FET Accounting; their willingness to keep on teaching Accounting whilst challenging the importance and validity of the FET Accounting curriculum in its current form compared to challenges posed by the 4IR. The researcher is concerned whether FET Accounting remains relevant to the needs of Accounting Education Departments at universities and the industry itself.

An unprecedented objective emerged where the researcher attempted to determine if FET Accounting and Accounting Education in general are on track compared to the current 4IR influences on the Accounting industry. Klaus Schwab; who coined the 4IR term; stated: "4IR is evolving at an exponential rather than linear pace, disrupting almost every industry in every country". Therefore, the researcher is of the opinion that failing to keep up with current changes in the industry, the education sector, ultimately Accounting Education, will ultimately be left behind. The researcher argues that it is our social responsibility to bring about changes in schools so that our learners will survive and flourish in the 4IR.

\section{Methodology}

Lecturing FET Accounting Methodology and previous exposure to the practice of Accounting, the researcher opted to follow a qualitative approach, specifically employing a phenomenological research method. According to English and English (in Cohen, Manion and Morrison, 2011) phenomenology is a theoretical point of view that advocates for the direct experience taken at face value and an orientation which views behaviour as determined by the phenomena of experience instead of an external, objective and physically described reality. With this method the researcher gathered accurate information and perspectives from FET Accounting Teachers and their Head of Departments (HOD's) in FET Accounting at selected high schools in the Motheo Education District. Schools were purposefully selected to represent different schooling backgrounds; including, Afrikaans, English and Sesotho as language medium; Urban, Suburban and rural as well as wealthy versus poor school. Respondents were as a matter not chosen in the same measure as schools were, but rather a result of being the FET Accounting teacher at the particular schools, with the number of teachers varying per school. These focus group interviews were done after normal working hours with limited influence on their teaching schedule, were voluntary and responses were recorded audibly and transcribed, while the researcher took individual notes to clarify possible uncertainties with follow up conversation and questions.

\section{Focus group interviews}

The researcher agrees with James, Milenkiewicz and Bucknam (2008) and Tomal (2003) that a focus group is a distinctive brand of group interview, generally consists of about five to ten people, who are interviewed in a comfortable, non-threatening setting. De Vos in De Vos, Delport, Fouché and Strydom (2005) in turn explains it as planned discussions aimed at a distinct audience, with the purpose of promoting self-disclosure among participants. An aim of focus groups is to gain a broad range of views on the research topic over a period of 60-90 minutes by creating an environment where participants feel comfortable to express their views as mentioned by Hennink, Hutter and Bailey (2011). As a norm the environment should be non-threatening to all focus group members, preferably a known area.

Data gathering concluded from Focus Group interviews at five selected schools in the Motheo Education District, comprising of a total of 16 FET Accounting Teachers. From the five schools; four indicated Social change is important, all five suggested 4IR will have a huge impact on their method and ability of teaching, and only one school suggested that they will embrace the possible change.

\section{Ethical considerations}

Ethics, defined by Neuman (2006) as what 'is' or 'is not' legitimate to do, or what moral research procedure it involves agrees with the researcher's point of view that ethical issues involve a balance between the pursuit of the rights of those being studied and scientific knowledge. Written consent was therefore obtained from the Department of Basic Education, selected schools and the Central University of Technology. The researcher made a written request to the Principals and the school governing bodies to avail the FET Accounting Teachers to obtain their opinions and working papers, as this data was used to form the background information for the researcher.

\section{Limitations}

This study resorts under the teaching and learning of Accounting Teachers in the Further Education and Training phase (FET) in the Motheo Education District. The researcher followed the outlines as mentioned by Rule and John (2011), as well as Babbie and Mouton (2007) considering both advantages and disadvantages this study could afford. The following limitations were identified: 
1. In all cases, time was of the essence and the conversations seemed rushed. Some participants were too eager to respond to the questions, limiting the responses from other participants, resulting in loss of interest. It seemed difficult for some participants to adhere to the scheduled time frame due to circumstances beyond their control.

2. Focus groups are useful for gaining a sense of the range and diversity of views; whose views are dominant and/or marginal within the group as well how dialogue shifts the understanding of the group members, but unfortunately, the group environment lacks confidentiality, which indicates that focus group discussions could not be ideal for seeking the personal experiences of participants.

3. During the focus groups it was evident that participants felt that being too honest might expose their ability to teach, especially for school with only 2 respondents.

\section{Results}

Results from the study includes a discussion on (1) the value FET Accounting contributes to teaching and learning in Accounting courses at Higher Education Institutions; followed by an elaboration on (2) Focus Group feedback and declining numbers compared to research done by Kohler (2012) and (4) the impact 4IR may have on the Accounting Sector with consequential changes to the FET Accounting curriculum.

\subsection{Value of FET accounting}

Without a doubt the researcher concurs with research outcomes from Rankin, Silvester, Vallely and Wyatt (2003) as well as Barnes, Dzansi, Wilkinson and Viljoen (2009) who asserted that secondary school (FET) Accounting is beneficial to the performance of students in their first year of Accounting studies if there is a close association between the two curricula. The researcher agrees with Rankin et al. (2003) that topics in the school curriculum including The King Code III on corporate governance, Managerial Accounting, Audit-sampling techniques and the use of information technology assists students in their first-year of university Accounting. Although it could be argued these topics were added to the school curriculum only recently, all students who had matriculated since 2008 should have been exposed to these topics when they reach university.

From the Focus Groups, respondents seems to agree that the FET Accounting curriculum has an impact on learners (later students') understanding of basic Accounting concepts and builds a strong foundation for First Year Students to cope with university Accounting curricula and assessment. Without the constructive building of Accounting, basic principles as mentioned by Rankin et al. (2003), students at university level are at the losing end during their tertiary studies; possibly forced to extending their studies or terminating it. The researcher found it out of the ordinary that a learner with the intention to continue his/ her tertiary studies in Accounting would not choose FET Accounting at school as it serves to enhance their basic understanding of the field.

\subsection{Focus group feedback and declining numbers - Study}

Although some teachers suggested they would rather withheld their opinion avoiding exposure as the weak link in the chain, it later became clear they are not part of the subject guiding process. Respondents were asked what might led to the decrease in FET Accounting number at secondary schools. Most noteworthy suggested that FET Accounting might be perceived as a difficult subject. In line with coding explained in the Methodology section, the following comment were significant:

FGA1: "Declining numbers is a concern; it might be that FET Accounting is perceived to be more difficult than it used to be and therefore the learners do not want to take anymore."

Table 1. NSC enrolment in Accounting and Mathematics (Accounting extracted) ${ }^{l}$.

\begin{tabular}{|l|r|r|r|r|r|}
\hline & 2015 & 2016 & 2017 & 2018 & 2019 \\
\hline Accounting & 140474 & 128853 & 103427 & 90278 & 80110 \\
\hline
\end{tabular}

Table 1 indicates how the numbers, combined from DoBE (2019) of learners writing FET Accounting during the National Senior Certificate declined from 2015 to 2019. Reiterating the feedback, the Focus Groups mentioned that one possible reason why numbers are declining might be due to suggestions from Guidance Teachers demotivating learner to choose FET Accounting and promoting Mathematics as a requirement for Chartered Accountant (CTA) courses at major universities. Having mentioned these possibilities the researcher expected the number in Mathematics students to increase as FET Accounting number decrease; but that does not seem to be the case as derived from table 2.

${ }^{1}$ Source: National Senior Certificate Diagnostic Report Part 1 - 2019 (21 April 2021)

https://dbedashboard.co.za/School-Improvement/wp-content/uploads/2020/07/Accounting-2019.pdf 


\subsection{Impact of the fourth industrial revolution}

The Accounting Industry has undergone major reformation since the 1990's as stated by SAICA in the CA2025 drive (BizCommunity, 2018). SAICA mentioned that the Charted Accountant Industry future seems not too dependent on how well Accountants do calculations, but rather on how well they understand the development in the Industry and understanding what certain calculations and disclosures deem to inform the users of financial information. At the inception of this study the researcher felt that FET Accounting should focus primarily on building a strong Accounting foundation by emphasising the basic principles, rather than teaching complicated concepts not directly related to Financial Accounting and bound to change when new technologies will impact on their tertiary studies. A sustainable learning environment is determined by the eagerness of FET Accounting Teachers and learners to accept social change and acceptance that the technological advancements the world is experiencing will only be enhanced and become more complex.

An article in 'See the Future' published in CarringtonCrisp (2014) pointed out that since the 1980 's, research into higher education has explored the digital shift taking place in universities. In South Africa this shift towards technology seems to be more challenging as one of the greatest obstacles in Higher Education Institutions in the 21 st century is not the new technologies themselves, but the ability of educators to embrace the changes brought about by educational technologies. One aspect the researcher observed during visits to schools is the lack of computerized equipment. The reason this serves as a problem is that schools will not be able to match the fast-growing pace of technology Ernst and Young (2013) expects in the private sector. Tynan, Ryan, Hinton, and Lamont Mills (2012) and NMC (2014) point that the challenge existed since the research in 1994, and for this reason, the Accounting profession must push schools and tertiary institutions to adapt and keep up with the fast-paced financial sector fit for its survival.

The Adaptation of technology in Africa, and indeed in South Africa as well has shown a slow adaptation rate since the 1990's, which strengthens the view of Africa as dark, as some countries are struggling to keep the lights on. Although South Africa's private sector is all but behind, it has to be admitted that government schools indeed are feeding off the scraps. An accurate statement by Blair (2019) is "The Fourth Industrial Revolution (4IR) is upending the nature of work as we know it. Policymakers are struggling to grapple with this future in the West, but for African countries; and developing countries generally; the outlook appears even bleaker".

This notion from the Tony Blair Institute for Global Change, which indicates that South Africa, as a low-income country will generally take longer to adapt to new technology. It has to be confirmed that rapid adoption will be 1.2 times quicker than normal adoption for both high- and low-income countries. The reality however is that even a slow adoption in a high-income country seems to quicker and more beneficial than a rapid adoption in low-income country. The researcher realises that changing the country to rapid adoption seems more feasible and possible with accurate support and willingness compared to converting South Africa to a high-income country.

\section{Conclusion}

The researcher has not ventured into the reason why FET Accounting has been excluded as a pre-requirement for Accounting courses at selected universities, and even less understandable whom initiated the change in requirements between traditional universities and professional Accounting bodies. Maybe it is not by accident, and that possible gaps in FET Accounting existed for a while, and it was an easier step to exclude it, than to overhaul it. One argument the researcher can't put aside is that Mathematics drives creative and abstract thinking, and therefore might seem to be a valid alternative as pre-requisite.

A certain conclusion to be made is that industries should have a direct influence on the training learners and students receive, even though FET Accounting Teachers does not seem to be ready for the transition. With the fast pace of technological development and pressures from the corporate world, school and tertiary institutions cannot teach learners and students the basics and expect in service training to prepare them for the 'real job'. Training should be on point and directly related to the industry in which the individual wants to work. Universities, and Accounting lecturers in particular should have a clear vision to guide FET Accounting curriculum and drive the Accounting profession and not vice versa. This might suggest that the Teacher Education should adapt as well to ensure a new generation of FET Accounting Teachers enters the work force with the ability to embrace the much-needed changes.

Sustainable learning environments in schools, keeping the FET Accounting curriculum up to date, ensuring our learners can work around the globe with or without future intended Accounting studies. Guidance teachers should be assisted by universities in their guidance to learners' subject and career choices. The researcher believes that that keeping on drawing lines and casting totals seems outdated and if resources allow, learners should practise Accounting on Accounting Software. The world has entered an automated era where transactions are generated by technology, and the need to interpret them seems more important. If a learner can learn how to utilise Accounting software at secondary school, the industry will probably grab them with open arms. 


\section{Recommendation}

The researcher wants to emphasise that collaborative social change and responsibility rests on the shoulders of Accounting lecturers and the industry to voice the impact 4IR has on the workforce where a high degree of ethics and transparency is required, especially the availability of work in specific spheres. If Accounting as profession wishes to remain relevant, the method and content being taught at school, (and university level) should change to be on par and sustainable with the exponential growth of the 4IR.

\section{References}

Babbie, E. and Mouton, J. 2007. The practice of social research. Cape Town: Oxford University Press.

Barnes, H., Dzansi, D., Wilkinson, A. and Viljoen, M. 2009. Researching the first year accounting problem: Factors influencing success or failure at a South African higher education institution. Journal of New Generation Sciences, 7(2): 36-58.

Blair, T. 2019. Adapting to the 4IR: Africa's development in the age of automation. Available https://institute.global/insight/governance/adapting-4ir-africas-development-age-automation on July 4, 2019 [Accessed 12 September 2019]

Chartered accountants and 4IR https://www.bizcommunity.com/Article/196/511/182058.html on 19 September 2018. [Accessed 13 September 2019].

Cohen, L., Manion, L. and Morrison, K. 2011. Research methods in education. ( $7^{\text {th }}$ Edition). New York: Routledge.

De Vos, A. Delport. C., Fouché, B. and Strydom, H. 2005. Research at grass roots: For the social sciences and human service professions. ( $3^{\text {rd }}$ Edition). Pretoria: Van Schaik Publishers.

Ernst and Young. 2013. University of the Future: A thousand year old industry on the cusp of profound change. Available from http://hdl.voced.edu.au/1 0707/228059. [Accessed 8 March 2017].

Hennink, M., Hutter, M. and Bailey, I.A. 2011. Qualitative research methods. Los Angeles: Sage.

Hesse-Biber, S.N. and Leavy, P. 2011. The practice of qualitative research. (2nd Edition). Thousand Oaks: Sage.

James, E.A., Milenkiewicz, M. and Buckman, A. 2008. Participatory action research for educational leadership: Using data-driven decision making to improve schools. Los Angeles: Sage.

Kohler, S. 2012. SA basic education brief. Creamer Media's Mining Weekly, 1: 4.

Neuman, W.L. 2006. Social research methods: Qualitative and quantitative approaches. (6 ${ }^{\text {th }}$ Edition). Boston: Pearson Education.

NMC. 2014. NMC horizon report: 2014 Higher education edition. The New Media Consortium, Austin: Texas.

Olsen, S. 2011. Maths decline a threat to accounting. Fin24.com, February 1, 2011 Available from https://www.fin24.com/Nuus/Maths-decline-a-threat-to-accounting-20110201 on 2011-02-01. [Accessed 14 March 2018].

Rankin, M., Silvester, M., Vallely, M. and Wyatt, A. 2003. An analysis of the implications of diversity for students' first-level accounting performance. Accounting and Finance, 43:365-393.

Rule, P. and John, V. 2011. Your guide to case study research. Pretoria: Van Schaik.

SA Study. [n.d.]. Going to grade 10 next year? Available from http://sastudy.co.za/article/going-to-grade10-next-year/. [Accessed 14 March 2018].

Schwab, K.M. 2016. The Fourth Industrial Revolution: what it means, how to respond. World Economic Forum Agenda. [Web:] http://www.weforum.org/agenda/2016/01/the-fourth-industrial-revolutionwhat-itmeans-and-how-to-respond. [Access 19 September 2019].

See the future. 2014. Carrington Crisp, ACCA, EFMD. http://www.carringtoncrisp.com/images/ PDFs/See_The_Future_2014.pdf. [Accessed 12 April 2016].

South Africa's Education statistics. South African Market Insights. 2019. https://www.southafricanmi.com/education-statistics.html last updated 29 May 2019. [Accessed 13 September 2019].

Tomal, D.R. 2003. Action research for educators. Lanham, Md.: Scarecrow Press.

Tynan, B., Ryan, Y., Hinton, L. and Lamont Mills, A. 2012. Out of hours: Final report of the project e-teaching leadership: Planning and implementing a benefits-oriented costs model for technology enhanced learning. Sydney: Australian Learning and Teaching Council (ALTC). 


\title{
A REFLECTION ON GENDER ACHIEVEMENT IN SCIENCES' RURAL SCHOOL SETTINGS OF MULTICULTURAL SOUTH AFRICA
}

\author{
Alice Mokoena, \& Gregory Alexander \\ Faculty of Humanities, Central University of Technology (South Africa)
}

\begin{abstract}
The participation of learners in science is important to a country's socio-economic development impediments, therefore, the argument is that the girl learner should be increasingly encouraged to perform well in STEM related subjects (STATS SA). UNESCO indicates 35\% women representative in STEM as students in higher education globally, whilst less than $40 \%$ of South Africa's scientists, engineers and technologists are women. This situation also relates to the South African education system, particularly in rural schools where girl learners are outperformed by boy learners in STEM, especially, in subjects such as Life Sciences and Physical Sciences. The purpose of this reflective paper is to ascertain the factors prohibiting excellent achievement of females in sciences in rural high schools of South Africa. The data has been gathered from numerous documents such as national and provincial analysis of result, examination and assessment directorate analysis and the district statistics in solidifying our investigation as couched by document analysis. Based on our observations and experiences of the conditions prevailing in rural high schools and less participation of female learner access in STEM, suggestions are put forth as to how their performance can be improved. The investment thereof in the body of knowledge will be to fulfil the concern not only of the country but the world at large when the number of female participants increase in STEM.
\end{abstract}

Keywords: Gender achievement, science subjects, rural high schools.

\section{Introduction}

The idea of bridging the gap and increase participation of females in science has been expounded for many years. For instance, Kimotho (2019) registered that for the last three decades, it has been the global mission to invest in STEM by addressing gender equality. An interconnected world economy market liberalization was produced that focused on abilities to master STEM as key for economic growth. In the same vein, United Nations Educational, science and Cultural Organisation (UNESCO) alarmed by $35 \%$ of women and girls participating in STEM, calls for promotion of female empowerment through education by enhancing awareness for the sole reason reiterated that STEM careers are important as jobs for the future, for social being, inclusive growth and sustainable development (UNESCO, 2020).

According to the national development plan of South Africa (NDP) as a guiding document, it is the country`s vision to eliminate poverty and inequality by increasing women and girl participation in science as captured in vision 2030. Its chapter 9 on improving education, innovation and training, envisage about 450000 university entrants in science and maths and 100 STEM PhD graduates in 2030 (National Science and Technology, 2019). Which means Further Education and Training band has a large responsibility to ensure quality throughput in order to meet the vision. Furthermore, the Sustainable Development Goal number 5 of the NDP 2030 focuses on addressing gender equality and equity by suggesting empowering women participation in science (Voluntary National Review (VNR) 2019).

Women make up a large percentage of the poor in rural areas hence it is vital that they are assisted with the aim of contributing towards transformation of the economy (VNR, 2019). Concurring with Shepherd (2017) there are many aspects that may not be ignored such as girls' self-efficacy, motivation, cultural responsibilities coupled with stereotype beliefs and their enthusiasm in closing gender gap towards STEM. Societal stereotypes such as technology and engineering are more relevant for boys than girls, can be so influential that they turn up to be baring negative results for the country. 
The most important field in which people are able to show their knowledge and application of skills globally, is in science. This is the field that seems to benefit most people since it is able to create multiple employment opportunities, economic growth and wealth for various countries, including South Africa.

\section{Aim of paper}

The purpose of this reflective paper is to ascertain the factors prohibiting excellent achievement of females in sciences in rural high schools of South Africa.

\section{Methodology}

To steer the said investigation, a qualitative research method was executed, through document analysis (annual public \& exam results reports, subject policy documents), observations and unstructured interviews, reports such as the national, provincial analysis of grade 12 results; the analysis from the Free State Department of Education's Examination Directorate and statistics were useful in this regard. These sources were analysed and interpreted as data gathering tools and to get an understanding of the realities of girl learner achievement and participation in sciences. Taking into consideration the contribution in the body of knowledge, the objective was provoking girl learners in order to increase female participation and closing the gap in STEM. Schools in the rural, Xhariep educational district of the Free State province were identified as the research sites.

\section{Our reflective overview}

In a previous study we observed that the number of female learners writing science subjects at the end of the year in the Free State province, declined in the previous four to five consecutive years (FSDoE Examination and Assessment Statistics). It is for this reason as to why we became interested in comparing the achievement of females to males. Having reviewed the statistics of the year end grade 12 results, we observed that female learners do not perform well, that's despite their large enrolment as compared to male learners. For instance in 2016, the provincial pass percentage was 86.8 for females and 89.8 for males; in 2017, it was 85.0 for females whilst males performed at $87.5 \%$; in 2018 , females $86.4 \%$ and males $88.7 \%$. (Free State results brief, 2019)-see table 1. The trend we observed is that female's performance in science is improving steadily against males who continuously perform outstandingly. The general performance portrayed is not different from the performance of female learners, specifically in science (Life Sciences and Physical science). In general, learners regard science subjects as the most difficult subjects especially Physical sciences and mathematics. However learners still don't perform exceptional in Life Sciences. Nonetheless, based on the focus for the paper, our belief is that there should be equality in performance comparatively between females and males. Pertaining to gender parity it has been noticed that the number of females enrolling in sciences seem to be higher than male learners- this in turn may give them better chances of achieving at higher levels and as such, pursuing science in institutions of higher learning. Another issue that drew our attention was that the number of females who sit for examination is lesser than the enrolled number, meaning they exit the schooling system during the year. Below is a table displaying statistics of all learners. According to Free State Examination and Assessment Directorate in different years which shows the number of both males and females registered, wrote and the disparity in pass percentage Compared to boys there are more girls sitting for examination at the end of the year but amazingly less pass percentage.

Table 1. Free State examination and assessment statistics per gender 2020.

\begin{tabular}{|l|l|l|l|l|l|l|l|l|}
\hline \multicolumn{7}{|l|}{ FREE STATE OVERALL PERFORMANCE PER GENDER 2016-2019 } \\
\hline Year & $\mathbf{2 0 1 6}$ & $\mathbf{2 0 1 7}$ & $\mathbf{2 0 1 8}$ & $\mathbf{2 0 1 9}$ & \\
\hline Gender & Female & Male & Female & Male & Female & Male & Female & Male \\
\hline Registered & 15919 & 12982 & 15076 & 12647 & 16138 & 13902 & 16566 & 13475 \\
\hline Wrote & 13615 & 11297 & 13640 & 11550 & 13730 & 11932 & 14023 & 11549 \\
\hline Passed & 11821 & 10141 & 11588 & 10107 & 11864 & 10579 & 12254 & 10348 \\
\hline Pass \% & $\mathbf{8 6 . 8 \%}$ & $\mathbf{8 9 . 8 \%}$ & $\mathbf{8 5 . 0} \%$ & $\mathbf{8 7 . 5 \%}$ & $\mathbf{8 6 . 4 \%}$ & $\mathbf{8 8 . 7 \%}$ & $\mathbf{8 7 . 4 \%}$ & $\mathbf{8 9 . 6 \%}$ \\
\hline
\end{tabular}

Data displayed in table 1 above, indicate all learners who wrote in all subjects where boys are performing higher than girls which means the department of education is aware of the fact that there is enormous gender disparity engagement in studies generally. We saw the similar achievement disparity 
especially in Life Sciences (Free State examination and assessment statistics, 2020). Does it mean girls do not take their studies seriously, this is one of the questions that was directed to subject teachers? Xhariep is one rural district in Free State were compared to other streams, learners taking science subjects (Physical Sciences, Life Sciences, Mathematics) form the smallest class in all schools. Furthermore, over and above the gender gap in sciences, female learners in Xhariep become disadvantaged for being in a rural area with other socio-economic challenges affecting them. The situation of Xhariep confirms what 2011 census reported regarding gender disparity that as little as 23.7 of rural females made it through grade 12 at the end of that specific year nationally compared to 33.4 of urban females (Gender series volume II, 2012).

The Xhariep educational district in the Free State province is located in rural areas of the Free State as indicated earlier where lack of basic resources plays a major role; making it more difficult to increase participation in science. For example, resources such as electricity, water, laboratories are scarce and these are imperative resources in Sciences subjects which have experiments to be conducted in order to master specific skills of the subject. These are challenges as observed by the learning facilitator during routine school visits which are part of contributing factors towards poor performance. Only theoretical work is addressed due to non-availability of resources.

Despite the rigorous strategies put forth by teachers, the performance is still not coming to where is expected. We have tracked the performance of Life science (LFSC) and Physical science (PHSC) over the past consecutive years as displayed in the table below after a full implementation of various strategies.

Table 2. Adapted from Xhariep district statistics and subject performance: 2020.

\begin{tabular}{|c|c|c|c|c|c|c|c|c|}
\hline Subject & Grade 12 & Wrote & Pass \% & Average & Subject & Wrote & Pass\% & Average \\
\hline \multirow{4}{*}{ 捳 } & 2020 & 528 & 79 & 43 & \multirow{4}{*}{$\underset{\mathscr{2}}{\mathscr{\Omega}}$} & 234 & 73 & 37 \\
\hline & 2019 & 462 & 76 & 41 & & 199 & 85 & 45 \\
\hline & 2018 & 523 & 73 & 40 & & 187 & 81 & 42 \\
\hline & 2017 & 444 & 80 & 44 & & 206 & 76 & 42 \\
\hline
\end{tabular}

From the data in table 2 above one will notice that the total number of two grade 12 science classes is not large for 25 rural high schools but it is difficult to get to all of them passing not even reaching $90 \%$ which is expected. The total number of schools in this district is 26 and only 20 are offering Physical science. And the actual average percent fluctuates in the $40 \mathrm{~s}$ against the expected $50 \%$. As we were reflecting on learner performance in science, there must be something lacking. Compared to the district we also viewed the provincial performance in LFSC and PHSC as portrayed below.

Our attention is drawn to the fact that the number of learners who are doing Life sciences is always more than those who are taking Physical Science. If then these are the recorded numbers in Life sciences, it means there are even lesser in Physical science therefore less participants in STEM. Characteristics and challenges of rural schools as listed in Jimerson (2005) are found simulating how Xhariep district is. For instance, in 2017 of the 23 schools that offered Life sciences, 12 schools experienced challenges such as lack of teachers, lack of experienced teachers, teachers not completing a full year as they got attracted by urban areas where they become nearer to many facilities that make life to be easy. The district continues to lose experienced teachers for it being rural. Due to small and declining enrolment of learners, some schools did not qualify to get substitute teachers for death and for those who took maternity leave. The larger population of Xhariep district is unemployed which affects furthering studies since parents do not afford to pay for higher institutions. Very few learners manage to continue with their studies which makes it even worse lesser for sciences as it is portrayed by statistics.

\section{Concluding remarks}

Of significance and for better performance, female participation in science should be encouraged from an early age of schooling. Which means it becomes the responsibility of the department of education, teachers and parents to encourage the girl learners to participate in sciences. We take into cognisance that globally there is a gender gap of participation in sciences that even affect the world of work (UNESCO UIS, 2020). 


\section{References}

Department of Education Free State. 2020. Xhariep analysis of results 2019-2020, Bloemfontein. South Africa.

DoE. 2019. Free State examination and assessment directorate analysis of results, Bloemfontein. South Africa.

DoE. 2017. Life sciences examination guidelines. Grade 12 examination guidelines. Department of basic education. Pretoria. South Africa.

Free State examination and assessment directorate. 2019. Examination statistics. Bloemfontein. South Africa.

Free State examination and assessment directorate. 2020. per gender performance of results. Bloemfontein. South Africa.

Free State examination and assessment directorate. 2019. per gender performance of results. Bloemfontein. South Africa

Frees state department of education. 2016-2019. EMIS records. Bloemfontein. South Africa

Free State provincial media brief. 2019. Provincial (SAAC) analysis 2019. Bloemfontein. South Africa.

Gasant, M.W. 2011. Gender and perceptions of science and science education: A case study in Mitchells Plain. University of Western Cape. South Africa.

Human rights commission. 2017. Research brief on gender and equality in South Africa 2013-2017. South Africa

Jimerson, L. 2005. Plasism in no child left behind (NCLB) - How rural children are left behind. University of Massachusetts. Routledge

Juan, A.; Hannan, S. \& Namome, C. 2017. I believe I can do science: self- efficacy and science achievement of grade 9 students in South Africa. S Afr J Sci.2018; 114 (7/8), Art. \#2017-0269, pages. http://dx.doi.org/10.17159 ajs.2018/20170269.

Kimotho, J. 2019. Global partnership for Education: Bridging the gender equality gap in STEM to fully transform Africa. Forum for Africa Women Educationalists Regional Secretariat.

National curriculum statement. 2011. Curriculum and assessment policy statement. Department of basic education. Pretoria. South Africa

National diagnostic report. 2018. Chapter 8: Life sciences report. South Africa

National Science technology forum. 2019. Improving education, innovation and training, Chapter 9 NDP. South Africa.

National science technology forum (NSTF). 2017. Language and STEM education at school - policy and research. Emperor's Palace Convention Centre Kempton Park, Johannesburg.

Shepherd, D.R. Gender, self -concept and mathematics and science performance of South African Grade 9 students. Stellenbosch. South Africa.

Statistics South Africa. 2012. Gender series volume 2. STATS SA report. South Africa

UNESCO. 2020. Girls' and women's education in science, technology, engineering and mathematics (STEM) August /21/2020 from https://en.unesco.org > stemed

UNESCO. 2020. Data for Sustainable development goals. August 21/2020 from https://sdg.uis.unesco.org 


\title{
INTERCULTURAL PARTNERSHIPS THAT FOSTER CULTURAL COMPETENCE
}

\author{
Elizabeth J. Sandell ${ }^{1}$, Katie Archer Olson ${ }^{2}$, \& Maria-Renee Leonhardt Grigsby ${ }^{1}$ \\ ${ }^{I}$ Department of Elementary \& Literacy Education, Minnesota State University, Mankato (USA) \\ ${ }^{2}$ Department of Paraprofessional Education, Alaska Christian College, Soldotna (USA)
}

\begin{abstract}
Institutions of higher education (HE) are emphasizing their capacity to (a) foster equitable access; (b) incorporate global perspectives into teaching, learning, and research; (c) build international and intercultural competence among students, faculty, and staff; and (d) establish relationships and collaborations with people and institutions throughout the world. At Minnesota State University, Mankato, instructors have responded to this emphasis with a specific course for pre-service teachers: Human Relations in a Multicultural Society. Based on this experience, the authors based the course on a foundational theory and engaged in scholarship related to teaching and learning. Adaptations were made in one major assignment, a cultural partnership, so that college students could diversify their perspectives and enhance their intercultural skills, even during a pandemic. For three semesters during the pandemic, instructors facilitated virtual "buddy" matches with students at a university in Armenia (English language classes in Spring 2020) or with students in various US cultures (Alaska Natives in 2020 - 2021). The series of related assignments included establishing a partnership, interviews, shared virtual activities, and reflection. This report briefly reports the analysis of data collected with the IDI in Spring 2020, the latest semester for which data was available for this project.
\end{abstract}

Keywords: Intercultural competence, culture, multiculturalism, diversity, pedagogy.

\section{Introduction}

Institutions of higher education (HE) are emphasizing their capacity to (a) foster equitable access; (b) incorporate global perspectives into teaching, learning, and research; (c) build international and intercultural competence among students, faculty, and staff; and (d) establish relationships and collaborations with people and institutions throughout the world. At Minnesota State University, Mankato, instructors have responded to this emphasis with a specific course for pre-service teachers: Human Relations in a Multicultural Society. Based on this experience, the authors designed the course on a foundational theory (the Intercultural Development Continuum) and engaged in scholarship related to teaching and learning. Adaptations were made in one major assignment, a cultural partnership, so that college students could diversify their perspectives and enhance their intercultural skills, even during a pandemic. For three semesters during the pandemic, instructors facilitated virtual "buddy" matches with students at a university in Armenia (English classes in Spring 2020) or with students in various US cultures (Alaska Natives in 2020 - 2021). The series of related assignments included establishing a partnership, interviews, shared virtual activities, and reflection. This report briefly reports the analysis of data collected with the IDI in Spring 2020, the latest semester for which data was available for this project.

\section{Background}

Bennett first designed the Developmental Model of Intercultural Sensitivity (DMIS; Bennett, 1986). After extensively testing its validity and reliability, Hammer et al (2003) refined the DMIS and suggested the Intercultural Development Continuum (IDC) with five stages of orientation to other cultures. The developmental stages ranged from mono-cultural (Denial or Polarization), through transitional (Minimization), to intercultural (Acceptance or Adaptation). 
Since 2010, for regular evaluation of the course, Human Relations in a Multicultural Society, the instructors have used a measure of intercultural sensitivity based on the IDC: the Intercultural Development Inventory (IDI; Hammer et al., 2003). The IDI version 3 is a 50-item psychometric instrument consistent across gender, ethnicity, and education-level with strong correlations to increased World-mindedness and decreased Intercultural Anxiety scales (Hammer, 2011; Hammer et al., 2003). The IDI has subscales that roughly align with the IDC stages: Denial, Polarization Defense/Reversal, Minimization, Acceptance, and Adaptation (Hammer et al., 2003; Wiley, 2017). Individual and group IDI scores are charted along an ordinal scale from 55 to 145. A proprietary technique is used to tabulate responses to Likert-style questions to produce two distinct scores: the perceptual orientation (PO) and the developmental orientation (DO; Hammer, 2020; 2011). The orientation gap (OG) represents the difference between an individual's PO and DO scores, while smaller OG scores reflect an alignment between relevant perceptions and actions.

Based on previous studies using the IDI in this course (Sandell \& Tupy, 2016; Osborn \& Sandell, 2021), course instructors were 95\% confident that any student would begin this course with a Developmental Orientation (DO) at the beginning of the Minimization orientation. Students in this orientation were likely to overly apply universal values (often as they understand and apply the values to themselves) and principles, such as, for example, "each person should be treated equally" or "we just speak different languages." Furthermore, these students may overlook opportunities to understand their own cultural privileges or to treat others according to the others' cultural norms. As a group, these students were more likely to minimize cultural differences and emphasize human commonalities.

After establishing the baseline of cultural competence with the IDI, instructors realized that students who enrolled in this course had very few relationships with persons from cultures perceived as different than their own. Intergroup contact theory (ICT) suggested that prejudice and bias could be reduced by contact between peers when the contact is interpersonal, cooperative, rewarding, and positively sanctioned by the students' institutions and social networks (Berryman-Fink, 2006). Furthermore, previous studies reported that while domestic students are willing to engage with "others," faculty-led intervention may be needed to actually increase cultural contact (Campbell, 2012; Sakurai et al., 2010; Todd \& Nesdale, 1997; Ward et al., 2009). So, instructors made a major course revision to require experience and reflection with a "buddy" in a cultural partnership. In previous semesters, students were guided to form partnerships with international students from cultures different than their own. This strategy has been used for the in-person, campus-based course since 2012.

In 2020, a pandemic forced the course to be delivered on-line, and in-person cultural partnerships were impossible. For three semesters during the pandemic, instructors facilitated virtual "buddy" matches with students at a university in Armenia (English classes in Spring 2020) or with students in various US cultures (Alaska Natives in 2020 - 2021).

\section{Research questions}

The research during Spring 2020 responded to three basic questions:

1. Did the PO change from the beginning of the semester to the conclusion of the semester?

2. Did the DO change from the beginning of the semester to the conclusion of the semester?

3. Did the OG change from the beginning of the semester to the conclusion of the semester?

\section{Participants and data collection}

Pre-instruction and post-instruction surveys were completed by 33 American students: 26 were female; 7 were male. Thirty students were of European American background. Three students identified, one each as Black or Hmong or Hispanic. All students who completed the survey were born and raised in the US and were US citizens. Due to limitations by the Institutional Review Board for research with human subjects, surveys were not completed by those students in Armenia in Spring 2020 or in Alaska in Fall 2020 or Spring 2021. 


\section{Results}

Table 1 presents the results of the statistical analysis for Spring 2020.

Table 1. Descriptive and Inferential Statistics on IDI Cultural Competence Scores.

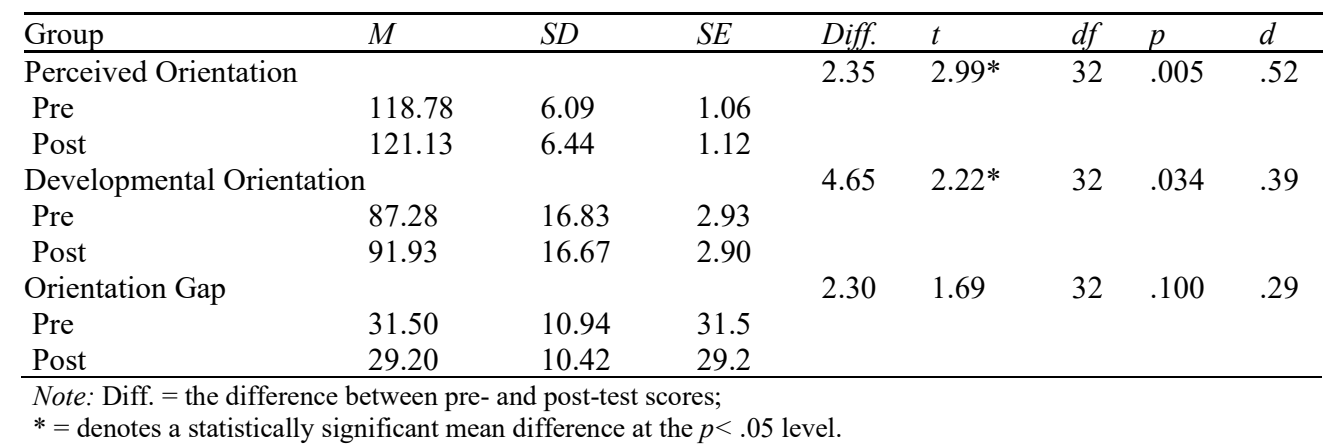

\subsection{Change in perceived orientation toward cultural differences}

A paired-samples t-test was used to determine whether there was a statistically significant mean difference between the scores on the PO pre-test and PO post-test. No outliers were detected that were more than 1.5 box-lengths from the edge of the box in a boxplot. The assumption of normality was not violated, as assessed by Shapiro-Wilk's test $(p=.09)$. Participants scored higher on the PO post-test $(M=121.13, S D=6.44)$ as opposed to the PO pre-test $(M=118.78, S D=6.10)$, a statistically significant difference of $2.35(95 \% \mathrm{CI}, .74$ to 3.95$), t(32)=2.99, p=.005$. The effect size of this difference was moderate $(d=.52)$.

\subsection{Change in developmental orientation toward cultural differences}

A paired-samples t-test was used to determine whether there was a statistically significant mean difference between the scores on the DO pre-test and DO post-test. One outlier was detected that was more than 1.5 box-lengths from the edge of the box in a boxplot. Inspection of its value did not reveal it to be extreme, and it was kept in the analysis. The assumption of normality was not violated, as assessed by Shapiro-Wilk's test $(p=.45)$. Participants scored higher on the DO post-test $(M=91.93, S D=16.67)$ as opposed to the DO pre-test $(M=87.28, S D=16.83)$, a statistically significant difference of $4.65(95 \%$ CI, .38 to 8.91$), t(32)=2.22, p=.034$. The effect size of this difference was slightly moderate $(d=.39)$.

\subsection{Change in Orientation Gap}

A paired-samples t-test was used to determine whether there was a statistically significant mean difference between the scores on the OG pre-test and OG post-test. One outlier was detected that was more than 1.5 box-lengths from the edge of the box in a boxplot. Inspection of its value did not reveal it to be extreme, and it was kept in the analysis. The assumption of normality was not violated, as assessed by Shapiro-Wilk's test $(p=.77)$. Participants scored lower on the OG post-test $(M=29.20, S D=10.42)$ as opposed to the $\mathrm{OG}$ pre-test $(M=31.50, S D=10.94)$. This difference was not statistically significant $2.30(95 \% \mathrm{CI},-.47$ to 5.06$), t(32)=1.69, p=.10$. The effect size of this difference was small $(d=.29)$.

\section{Discussion}

In 2020, the pandemic forced a campus-based course to be delivered on-line, and in-person cultural partnerships were impossible. For three semesters, instructors at a Midwestern American university facilitated virtual "buddy" matches with students at a university in Armenia (English classes in Spring 2020) or with students in various US cultures (Alaska Natives in 2020 - 2021).

The results of the Spring 2020 pre-instruction and post-instruction assessment suggested that a virtual cross-cultural partnership made statistically significant positive changes in the students' cultural competence. Significant positive differences were reported in students' perception of their cultural orientations, as well as their developmental orientation toward cultural differences and similarities.

In their reflection papers, students reported about their experiences. Here are several excerpts:

"This experience has opened my eyes to an entirely different world. Just because someone is different than your normal group of friends does not mean that they are bad or wrong in what they believe." -male second-year student

"I had to understand that my values and their values were not on the same page about how much interaction they should have with their children." -- female fourth-year student 


\section{Conclusion}

The results of the Spring 2020 pre-instruction and post-instruction assessment suggested that a virtual cross-cultural partnership made statistically significant positive changes in the students' cultural competence, especially in terms of their Developmental Orientation to cultural differences and similarities. Additional data analysis (at the conclusion of the Spring 2021 semester) may provide additional insight into the impact of virtual cultural partnerships on students' orientation toward cultural differences and similarities.

\section{References}

Bennett, M. J. (1986). A developmental approach to training for intercultural sensitivity. International Journal of Intercultural Relations, 10, 179-196. DOI 10.1016/0147-1767(86)90005-2

Berryman-Fink, C. (2006). Reducing prejudice on campus: The role of intergroup contact in diversity education. College Student Journal, 40(3), 511-516. SPORTDiscus with Full Text. https://search.ebscohost.com/login.aspx?direct=true\&db=s3h\&AN=22468639.

Campbell, N. (2012). Promoting intercultural contact on campus: A project to connect and engage international and host students. Journal of Studies in International Education, 16(3), 205-227. https://doi.org/10.1177/1028315311403936.

Hammer, M. R. (2011). Additional cross-cultural validity testing of the Intercultural Development Inventory. International Journal of Intercultural Relations, 35(4), 474-487. https://doi.org/10.1016/j.ijintrel.2011.02.014.

Hammer, M. R., Bennett, M. J., \& Wiseman, R. (2003). Measuring intercultural sensitivity: The intercultural development inventory. International Journal of Intercultural Relations, 27(4), 421-443. https://doi.org/10.1016/S0147-1767(03)00032-4.

Osborn, P. \& Sandell, E. J. (2021). University diversity courses and intercultural competence: The role of cultural identification and pedagogical enhancement factors. Manuscript submitted for publication.

Sakurai, T., McCall-Wolf, F., \& Kashima, E. S. (2010). Building intercultural links: The impact of a multicultural intervention programme on social ties of international students in Australia. International Journal of Intercultural Relations, 34(2), 176-185. https://doi.org/10.1016/j.ijintrel.2009.11.002. 


\title{
THE COMPLEXITY OF IDENTITY FORMATION OF BLACK LEARNERS ATTENDING HISTORICALLY WHITE SCHOOLS
}

\author{
Anthony Mpisi ${ }^{1}$, \& Gregory Alexander ${ }^{2}$ \\ ${ }^{1}$ Department of Education, Sol Plaatje University (South Africa) \\ ${ }^{2}$ Department of Post Graduate Studies, Central University of Technology (South Africa)
}

\begin{abstract}
This purpose of this paper is to examine the complexity of identity formation experienced by black learners attending historically white high schools in the Northern Cape. Black South Africans were considered and treated as both intellectually and racially inferior during the apartheid years. This may have created an identity dilemma for a number of generations of South African blacks. The situation was further exacerbated, when black learners were admitted to historically white schools. The staff component (mostly white) of historically white schools appeared to be inadequately prepared for these drastic changes. Consequently, the school that should normally contribute to developing a positive identity formation of learners, seemingly had the opposite effect on black learners. An empirical investigation, by way of the quantitative research method was employed, to ascertain the perceived effect historically white schools have on the identity formation of black learners attending these schools. Some of the findings of this study indicate the manifestation of negative influences, low educator expectations, the disjuncture between the home- and school education, as well as the high failure and drop-out rate, of black learners, as having an effect on the identity formation of black learners. Certain suggestions are made as to how to address the situation.
\end{abstract}

Keywords: Learners, white schools, identity formation.

\section{Introduction}

In South Africa the official and formal segregation of schools along racial and ethnic lines commenced in 1948, when the Nationalist Party came to power. The racial, ethnic and geographical separations within the education system led to the birth of 15 separate education departments, until before 1994. The advent of a democratic made it possible for black learners to enrol at historically white schools. Many of these schools who previously exclusively catered for learners from monocultural background responded by adopting an assimilation approach. Matters were further compounded by the fact that the majority of the educators in the Northern Cape were predominantly white, while black educators only constituted $41 \%$ of the permanently employed teaching staff (Northern Cape Department of Education, EMIS, 2020). However, failure by historically white school to maintain a healthy balance between enculturation, acculturation and de-culturation may prove to be confusing to the black learner. This confusion may in turn hamper the development of a positive identity formation for the black learner, (Ntuli, 1998:9). This study primarily explored influence attending historically white schools has on the identity formation of black learners in Northern Cape high schools.

\section{Aim of paper}

This paper reports on complexity of identity formation of black learners attending historically white schools.

\section{Research methodology}

The study adopted a quantitative research method located in the Social-learning theory research paradigm. Data was collected from 832 black high school learners by way of a self- designed 4-point Likert scale questionnaire to determine the complexity associated with identity formation of these learners attending historically white schools in the Northern Cape. Permission to conduct the empirical study was 
sought from the Northern Cape Education Department, school principals and learners of these specific schools. This aim of this paper is to report on a certain part (10 items) of the questionnaire which has bearing on identity formation in historically white schooling context.

\section{Analysis and discussion of results}

While the study focusses on the South African schooling context, the findings could be relevant to the other parts of the world, as issues of diversity and identity formation remains a challenge, particularly amongst perceived marginalised groupings. The questionnaire completed by these learners contained questions relating to identity formation in a historically white high schooling context. Table 1 presents a summary of how learners responded. Table 1 is a summary of the response of participating learners. We only discuss the most relevant findings relating to identity formation.

Table 1. Summary of learners' responses in relation to questions about identity formation in historically white schooling context.

\begin{tabular}{|c|c|c|c|c|c|c|}
\hline \multirow[b]{2}{*}{ Question } & \multirow{2}{*}{$\begin{array}{c}\chi^{2} \\
\text { Value }\end{array}$} & \multirow[t]{2}{*}{ p-value } & $\begin{array}{c}\text { Strongly } \\
\text { Agree }\end{array}$ & Agree & Disagree & $\begin{array}{l}\text { Strongly } \\
\text { Disagree }\end{array}$ \\
\hline & & & $\%$ & $\%$ & $\%$ & $\%$ \\
\hline $\begin{array}{l}\text { 1. I experienced no difficulty in } \\
\text { adapting to my school. }\end{array}$ & 1 & 0.486 & 41.8 & 40.3 & 13.5 & 4.4 \\
\hline $\begin{array}{l}\text { In our school, all learners, } \\
\text { irrespective of their cultural } \\
\text { background are treated the same. }\end{array}$ & 1 & 0.565 & 27.5 & 38.2 & 25.8 & 8.5 \\
\hline $\begin{array}{l}\text { 3. Enrolling black learners in former } \\
\text { white schools has led to a drop in } \\
\text { standards. }\end{array}$ & 1 & 0.477 & 15.1 & 33.7 & 32.8 & 18.4 \\
\hline $\begin{array}{l}\text { 4. Educators have higher academic } \\
\text { expectations white learners than } \\
\text { learners from black learners. }\end{array}$ & 1 & 0.523 & 25.7 & 28.8 & 26.7 & 18.8 \\
\hline $\begin{array}{l}\text { 5. Black learners tend to be more } \\
\text { withdrawn than white learners } \\
\text { during group work and other class } \\
\text { activities. }\end{array}$ & 1 & 0.524 & 20.0 & 30.5 & 32.9 & 16.6 \\
\hline $\begin{array}{l}\text { 6. The failure and drop-out rate tend } \\
\text { to be higher among black learners } \\
\text { than white learners. }\end{array}$ & 1 & 0.539 & 27.8 & 36.4 & 22.9 & 12.9 \\
\hline $\begin{array}{l}\text { 7. I am more comfortable to be } \\
\text { taught by educators belonging to } \\
\text { my own culture }\end{array}$ & 1 & 0.489 & 18.5 & 42.6 & 20.5 & 18.4 \\
\hline $\begin{array}{l}\text { 8. I sometimes experience conflict } \\
\text { between what I am taught at } \\
\text { school and what I am taught at } \\
\text { home. }\end{array}$ & 1 & 0.475 & 18.6 & 42.5 & 23.3 & 15.6 \\
\hline $\begin{array}{l}\text { 9. My friends who are not attending } \\
\text { historically white schools still } \\
\text { accepts me as a friend and has not } \\
\text { changed their attitude towards me. }\end{array}$ & 1 & 0.623 & 57.8 & 31.6 & 7.2 & 3.4 \\
\hline $\begin{array}{l}\text { 10. If I could choose, I would prefer to } \\
\text { attend a historically black school. }\end{array}$ & 1 & 0.518 & 18.0 & 16.5 & 29.1 & 36.4 \\
\hline
\end{tabular}

The difference is statistically significant if $\mathrm{P}<0.05$ 
Most of the learners (82.1\%) indicated that they have no difficulty in adapting at their school, contrary to views held by (Cross \& Mkwanazi-Twala,1998:28-30) believe that black learners' identity formation is adversely affected, because of the struggle they experience with adapting at these schools. The fact that learners indicated equitable treatment, in spite of their cultural background, may bode well for identity formation enhancement of these learners. The latter further highlight the potential influence, negative perceptions towards certain cultural groups held at schools, may have on the identity formation of learners. The cultural background of all learners is an important consideration in the teaching and learning process (Conklin, 2015:25). Learner participants (50.5\%) seem to concur with the literature that, black learners tend to be more withdrawn than white learners in class. Historically white schools dealt with integration in a manner, that has been characterised by asymmetry, in which white people are the bearers of preferred knowledge and blacks, by contrast, as the embodiment of inferior understanding of the world (McKinney, 2010:192). This state of affairs is hardly conducive for the formation of a positive identity. A total of $54.5 \%$ of learner participants indicated that their educators have higher academic expectations from white learners and that the failure and drop-out rate tend to be higher amongst black learners-this according to $64.2 \%$ of learners. These findings concur with the recent foregrounding of social justice and equity in educational the discourse (Cho, 2017:1). To this effect Świdzińska (2019:96) advises that teachers could assist learners by understanding their culture and supporting them in adapting to their new environment. The majority (61.1\%) of learners indicated that they are more comfortable to be taught by educators belonging to their own culture. The finding that an overwhelming percentage of black learners experienced conflict between what they are taught at school and home, respectively. These findings are echoed by the sentiments of (Erasmus \& Ferreira, 2002:30). They argue that children cannot be treated as learners in the normal sense without considering their immediate background and family history, as well as the impact of these factors on their reaction to the learning environment. Moosa (2018:57) supports this notion by insisting that aim of initial teacher education (ITE) programmes is "to prepare pre-service teachers to teach effectively in diverse classrooms".

In conclusion, although the literature suggests rejection of these learners by township school attending friends, the findings revealed the contrary. Correspondingly, the findings of the study dispute the argument presented by Erasmus and Ferreira (2002:31) that postulate that, when given a choice of schools, black learners would choose a school where all race groups are equally represented. The findings suggest that the majority $(65.5 \%)$ of black learners prefer attending historical white schools.

\section{Conclusion}

This study was meant to investigate the complexity of identity formation of black learners attending historically white high schools in the Northern Cape province of South Africa. Findings from the literature and empirical investigation indicated that some situational experiences encountered by black learners at these schools may well curtail the development a positive identity formation. The display of adverse effects, such as general adaptation challenges, unreceptive and unkind teacher behaviour, as having an effect on the identity formation of black learners. Educators are inherently responsible for assisting learners develop their identity. Hence, it is crucial that the critical pedagogical imperatives such as, low educator expectations (of black learners), the disjuncture between the home- and school education, as well as mitigating the high failure and drop-out rate, be addressed, in teacher education and continuous professional teacher development programmes.

\section{References}

Cho, H. (2017). Navigating the meanings of social justice, teaching for social justice, and multicultural education. International Journal of Multicultural Education, 19(2), 1-19.

Conklin, H. G. (2015). Preparing novice teachers educators in the pedagogy of teacher education. Action in Teacher Education, 37(4), 317-333.

Cross M \& Mkwanazi-Twala Z 1998. The dialectic of unity and diversity in education: Its implications for a nation curriculum in South Africa. In M Cross, Z Mkwanazi-Twala \& G Klein (eds). Dealing with diversity in South African education. Cape Town: Juta.

Erasmus P \& Ferreira G 2002. Black Grade 9 learners in historically white suburban schools and their experience of integration. South African Journal of Education, 22(1):28-35.

McKinney C 2010. Schooling in black and white: Assimilationist discourses and subversive identity performances in a desegregated South African girls' school. Race Ethnicity and Education, 13(2):191- 207. 
Moosa, M. (2018). Promoting quality learning experiences in teacher education: What mentor teachers expect from pre-service teachers during teaching practice. The Independent Journal of Teaching and Learning, 13(1), 57-68.

Northern Cape Department of Education. 2020. EMIS. Statistical Report. February 2020.

Ntuli S 1998. The Life-world of the black child in ex-model "C" schools. MEd. Durban: University of Zululand.

Świdzińska. A. 2019. Kultura i Edukacja. Ukrainian Students in Polish Schools: Selected Aspects of Adaptation on the Example of the City of Lublin. No. 4 (126), pp. 95-108. doi: 10.15804/kie.2019.04.06 www.kultura-i-edukacja.p 


\title{
THE PORTFOLIO OF EVIDENCE IN THE COMPETENCY-BASED EDUCATIONAL MODEL OF THE UNIVERSITY OF GUANAJUATO
}

\author{
María Guadalupe Arredondo-Hidalgo ${ }^{1}, \&$ Diana del Consuelo Caldera González ${ }^{2}$ \\ ${ }^{1}$ Department of Business Management and Administration, University of Guanajuato/Fulltime professor \\ (Mexico) \\ ${ }^{2}$ Department of Organizational Studies, University of Guanajuato/ Fulltime professor (Mexico)
}

\begin{abstract}
In a teaching-learning process, it is essential that the evaluation is summative and formative, from an analytical and holistic basis so that the process is comprehensive and integrates the work that the student has developed throughout the course, for example, a portfolio of evidence. Van der Schaaf and Stokking (2008) state that a portfolio of evidence integrates elements that must be related to each other, in order to be considered valid and reliable to evaluate the teaching-learning process, the elements are: a) the teacher model, b) the task model, c) the scoring model and d) the interpretation model. The objective of this research is to analyze the use of the portfolio of evidence as an evaluation tool within the teaching-learning process, for the Competency-Based Educational Model of the University of Guanajuato. This is a quantitative research with descriptive scope. A 22-item questionnaire was used considering the instrument developed by Romero and Crisol (2011) called "Opinion, satisfaction, usefulness and feelings of students about the use of the portfolio in learning and self-evaluation". The instrument was applied to a sample of 183 students of the Bachelor's Degree in International Commerce of the Economic-Administrative Sciences Division of the University of Guanajuato, distributed in four different Learning Units. The results indicate that students consider important the use of the portfolio of evidence as part of their teaching-learning process. In the part of satisfaction, usefulness and feelings, the students consider that the use of the portfolio is very important as a pertinent and adequate tool, and it is considered useful for learning, since besides serving as reinforcement, it implies a free and creative exercise. As conclusions of the study, the importance of the portfolio of evidence as a method of evaluation in accordance with the Educational Model by Competencies of the University of Guanajuato, which has also been well received at least by the sample of this study, is manifested. As future lines of research, it is expected to expand the sample to other careers and learning units to verify the replicability of the results of the study.
\end{abstract}

Keywords: Competency-based education model, portfolio of evidence, higher education institutions.

\section{Introduction}

It is relevant to associate the competency-based educational model in Higher Education Institutions, so the association of the taught contents of the subjects with the objectives and results of the teaching-learning process becomes valuable. In this regard, Van der Schaaf and Stokking (2008) establish that a portfolio of evidence considers elements that must be related to each other, in order to be considered valid and reliable. These are: a. The teacher model, b. The task model, c. The scoring model and $\mathrm{d}$. The interpretation model. It is essential that the evaluation is summative and formative, from the analytical and holistic basis, considering all the scenarios so that the learning process is comprehensive and considers the work that the student has developed for the content of their evidence portfolio.

Barragán (2005, p. 122) indicates that the term portfolio is understood as: "a technique of compilation, collection and repertoire of evidence and professional competencies that enable a person for satisfactory professional development". As understood in the context that, as faculty members, we are developing university talents that will be incorporated in the short term to a labor market, that increasingly demands that graduates know how to do a job, based on the knowledge they have acquired in the classroom. Pérez (2013) addresses the scenario of the application of the evidence portfolio especially for the competency-based model, as fundamental to understand how it can be applied as a tool for application in university students and quotes De Ketele (2008) who identifies five stages in the evolution of knowledge and knowledge, these are presented in the following Figure 1. 
Figure 1. Stages of learning and knowledge.

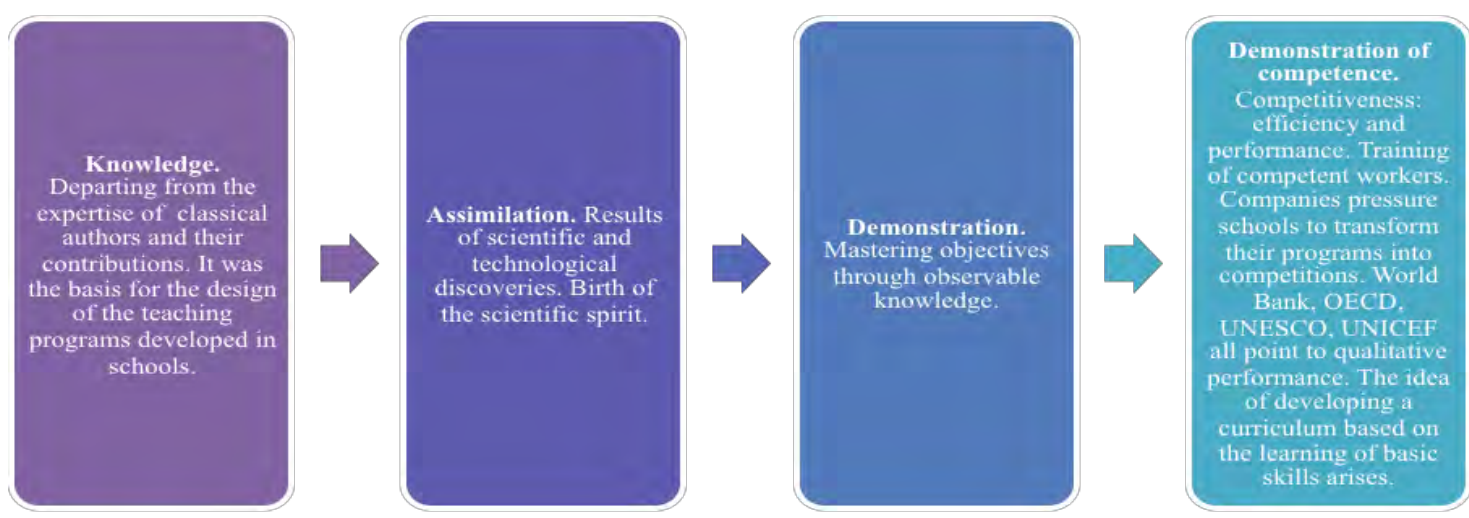

Source: own elaboration based on Pérez-Rendón (2014) and De Ketele (2008).

Subsequent to these stages, De Ketele (2008) proposes a new movement that would be characterized by a more holistic approach, whose mission should be oriented to the development of knowledge "to live in a world in permanent and rapid change". Díaz Barriga (2011) explains that the concept of competences applied in education is certainly recent and involves elements of the social context of the late 20 th and early 21 st centuries. Society is the one who dictates the interests to promote formal education in order to achieve tangible results to develop certain skills in the student, which allows them to join the world to work effectively. This is also the consequence of globalization, both from the system and its people, since the skills in education must be linked to the policies that countries like Mexico apply in their education sector. Given the above, Aguerrondo (2009) establishes that the "challenge of educational reforms is not what the school is for the future, but how the new society solves the need for equitable distribution of knowledge, which characteristics this knowledge must have in order to fit what is 'socially valid' and how the social environment is organized 'to make lifelong learning possible"'(p. 4). UNESCO indicates that the competency-based model must be focused on learning since the student is the center of attention, it must promote comprehensive and high-quality training, as well as provide a solid training from the student having autonomous learning. Taking this into account as a whole, this should promote "flexible, innovative processes that allow the movement of students between educational levels and multiple spaces of relationship with the environment". In this way, the analysis of the interest of measuring the perception of the students around the portfolio of evidence, becomes pertinent in order to identify changes in the way in which the subject is developed in International Trade students. Additionally, it is important to mention that in the document entitled: Guidelines for graduation or obtaining a degree in the educational programs of the Division of Economic-Administrative Sciences of the University of Guanajuato, the presentation of the evidence portfolio is established as a degree option, which is defined as: "a set of evidence such as documents, manuals, diagrams, photographs, models, etc., either in physical or digital form that a student has developed throughout different Learning Units (LU) and are the evidence of the meaningful acquired learning”. Based on the above, the relevance of the research is aligned, both to the educational model and to the degree indicators.

As determined by Romero and Crisol (2011), the portfolio of evidence has the following characteristics:

- It belongs to the student and it is their responsibility. They decide the meaning of it, the way they apply their reflection, so that it becomes a unique experience of self-evaluation of a personal nature.

- The students are the ones who must compile the evidence of their learning, applying a logic that leads them to organize the information in a way that makes sense to them. "The selection will be accompanied by a reflection on the value of each of the chosen documents."

- The student chooses how to design their own portfolio.

- The portfolio is made up of a field diary where the student captures their reflections on what they have learned.

- The portfolio contains all the documents to record the activities that have been carried out under the tutelage of the teacher.

March (2004) quotes Donnay (1996) and indicates that initially, one of the lines of the academic profession is the reflection on practice; it is settled that this is an essential element for teachers to adapt into the challenges of a changing society that demands the realization of daily professional tasks. Secondly, it is about the university professor applying teamwork and collaboration among students: "the culture of collaboration is one of the fundamental strategies for innovation, as well as for professional development, since it is an element that originates satisfaction in the subjects, which will decisively 
influence the quality of the institution" (p. 129). Finally, it is indicated that there must be a link between the pedagogical approaches, the preparation of didactic materials and the procedures to carry out evaluations, all of this starting, also, from the requirement of the ethical dimension in the teaching profession. The specific key questions of the following investigation are: How do students perceive the use of the portfolio? Is it useful for the teaching-learning process? What changes or adjustments should be considered in order to apply the correct assessment to make this process holistic? Martínez-Sánchez (2002) states that the student must possess the evidence of the learning that has been acquired, and the portfolio of evidence must be a valuable tool to achieve teaching-learning.

The portfolio of evidence has been instituted as a form of evaluation for the students in the last semesters of the bachelor's degree in International Trade, for the subjects of International Business, Impact of Logistics on Business Management and Methodology and Preparation of Reports, respectively. It is proposed that this document must be elaborated as follows.

Figure 2. Cover proposal for the Evidence Portfolio.

\begin{tabular}{|c|c|c|}
\hline \multicolumn{3}{|c|}{ EVIDENCE PORTFOLIO OF THE ASSIGNMENT: } \\
\hline STUDENT: & & \\
\hline GROUP-SEMESTER: & & \\
\hline ASSIGNMENT: & & \\
\hline TOPIC-DATE & EVIDENCES: & VALUE: \\
\hline
\end{tabular}

PROFESSOR:

teacher's signature-follow-up

The specific activities are: lecture and video reports, mind maps, reports from official internet pages (World Customs Organization (WCO), World Trade Organization (WTO), Logistics Performance Index as well as repositories of information from sources like EBSCO, Emerald, etc).

\section{Methodology}

In order to know how students perceive their learning experience from the evidence portfolio, a questionnaire was applied. The questionnaire was entitled: "Opinion, satisfaction, usefulness and feelings of students about the use of the portfolio in learning and self-assessment", by the authors Romero and Crisol (2014). It was applied to 183 students of the Bachelor of International Trade. The questionnaire consisted of 22 items in total, the first 17 response items being Likert scale from 1 to 4 ( 1 = Not important at all, 2 = Somewhat important, $3=$ Important and $4=$ Very important), and the last 5 items of multiple selection. Of the 22 items that make up the instrument, the first 14 are intended to assess the achievement of the objectives pursued with the completion of the portfolio, the following 3 items assess the satisfaction, usefulness and tutoring of the tool, and the last 5 items are aimed at acknowledgement of the sensations (emotions) experienced in the students after completing the portfolio. The Cronbach's alpha of the entire instrument was 0.890 for the total items of the questionnaire, which means that it is highly reliable for the objective of the present investigation. The dimensions involved were:

1. The students' opinion. Satisfaction of the portfolio as a tool for learning.

2. Portfolio profit.

3. The students' feelings towards the usefulness of the portfolio.

Sample: 183 students from the bachelor's degree in International Trade were surveyed for the subjects of: Impact of International Logistics on Business Management, Methodology and Reporting, International Trade, World Geography Workshop and International Business.

\section{Results}

The results obtained with the application of the questionnaire are shown below. According to the evaluated dimensions as well as the achievements of the pursued objectives regarding the completion of the portfolio, the following behavior was observed: the students showed a very brief knowledge about the system by competencies and the ideology of the University of Guanajuato, however, most believe that the portfolio helps them to set clear objectives in their learning process. The reliable statistic data: Cronbach's Alpha: 857 of 14 elements. Cronbach's Alpha based in the typified elements: 0.855 . 
Table 1. Dimension: Assess the achievement of the objectives pursued with the completion of the portfolio.

\begin{tabular}{|c|c|c|c|c|c|}
\hline & $\mathrm{N}$ & Minimum & Maximum & Median & Typ. Desv. \\
\hline A01 & 183 & 1 & 4 & 2.89 & .758 \\
\hline A02 & 183 & 1 & 4 & 3.03 & .762 \\
\hline A03 & 183 & 2 & 4 & 3.77 & .485 \\
\hline A04 & 183 & 1 & 4 & 3.52 & .645 \\
\hline A05 & 183 & 2 & 4 & 3.60 & .583 \\
\hline A06 & 183 & 1 & 4 & 3.36 & .742 \\
\hline A07 & 183 & 2 & 4 & 3.30 & .689 \\
\hline A08 & 183 & 1 & 4 & 3.33 & .758 \\
\hline A09 & 183 & 1 & 4 & 3.26 & .701 \\
\hline A10 & 183 & 1 & 4 & 3.34 & .753 \\
\hline A11 & 183 & 1 & 4 & 3.27 & .825 \\
\hline A12 & 183 & 1 & 4 & 3.00 & .791 \\
\hline A13 & 183 & 1 & 4 & 2.91 & .775 \\
\hline A14 & 182 & 1 & 4 & 3.25 & .759 \\
\hline & & & & 3.27 & \\
\hline
\end{tabular}

However, in the rest of aspects, to achieve the pursued objectives with the evidence portfolio, the resulted average of 3.27 indicates that students consider the use of the evidence portfolio as part of their teaching-learning process important.

Table 2. Dimension: satisfaction, usefulness and tutoring of the tool.

\begin{tabular}{|c|c|}
\hline \multicolumn{2}{|c|}{ Reliable statistic data } \\
\hline Cronbach's Alpha & N of elements \\
\hline .629 & 3 \\
\hline
\end{tabular}

\begin{tabular}{|r|c|r|r|r|r|}
\hline \multicolumn{7}{|c|}{ Descriptive statistics } \\
\hline & $\mathrm{N}$ & Minimum & Maximum & Median & Typ. Desv \\
\hline A15 & 183 & 1 & 4 & 3.69 & .580 \\
\hline A16 & 183 & 1 & 4 & 3.60 & .612 \\
\hline A17 & 183 & 1 & 4 & 3.40 & .742 \\
\hline & & & & 3.56 & \\
\hline
\end{tabular}

In the second dimension, satisfaction, usefulness and tutoring of the portfolio, the students consider that the use of the portfolio is very important; an average of 3.56 was obtained, this indicates that this tool is considered to be of good use for learning.

Table 3. Dimension: acknowledgement of the sensations (emotions) experienced in the students after completing the portfolio.

\begin{tabular}{|c|r|}
\hline \multicolumn{2}{|c|}{ Reliable statistic data } \\
\hline Cronbach's Alpha & N of elements \\
\hline .665 & 5 \\
\hline
\end{tabular}

\begin{tabular}{|r|c|r|r|r|r|}
\hline \multicolumn{5}{|c|}{ Descriptive statistics } \\
\hline & $\mathrm{N}$ & Minimum & Maximum & Median & Typ. Desv. \\
\hline A18 & 183 & 1 & 4 & 3.63 & .578 \\
\hline A19 & 183 & 1 & 4 & 3.60 & .646 \\
\hline A20 & 183 & 1 & 4 & 3.51 & .702 \\
\hline A21 & 183 & 1 & 4 & 3.64 & .611 \\
\hline A22 & 183 & 1 & 4 & 3.42 & .674 \\
\hline & & & & 3.56 & \\
\hline
\end{tabular}

For the third dimension, which measures the sensations (emotions) experienced in the students after completing the portfolio, an average of 3.56 is observed. This indicates that they are satisfied with the tool and gives them a good feeling of satisfaction. 


\section{Conclusions}

The conclusions indicate that the portfolio is a fundamental tool for students in order to achieve learning in a competency-based educational model context. When students reflect on their progress, the implementation of the perceived knowledge becomes assimilated since the students build from within the basic knowledge to become better people as well as better professionals. Aguerrondo (2008) insists that meaningful learning must be provided from a skill development education, where it can be applied in multiple areas: capacity expressed through knowledge, skills and attitudes. Likewise, he identifies four characteristics in common: competence takes the context into account; it is the result of an integration process, it is associated with performance or performance criteria, and it implies responsibility. The proper interpretation of the educational model and the academic model consequently leads us to identify the elements for the evaluation of student learning, along with the study plans. Additionally, the educational model must be updated with the graduation profile, it must be linked as well to the relevance and feasibility based on the work of the academic committees with the business sector. The academic model can be understood in how teaching is applied. The aims of the educational model are: the relevance, efficiency, coherence, transparency, competences, integrity and transversality of the University of Guanajuato. At the same time, we must apply innovation in education in order to inspire transcendence in the student's attitudes as well as to know how the material in the educational infrastructure helps us apply innovation. The perspective should be one to motivate us to learn more from these issues that will only help us to become comprehensive and complete teachers that are able to apply the benefits of progress within our practice. Finally, it is a challenge to insist that students become acquainted with the ideology and philosophy of the University of Guanajuato, as well as the competency-based model, since they do not share or do not know the concepts. It would be convenient to inquire why, however, as teachers and tutors it is important to continue guiding their path so that they know that these tools are designed for their benefit.

\section{References}

Aguerrondo, I. (2008). Documento Técnico de la UNESCO. Conocimiento complejo y competencias educativas.

Barragán, R. (2005). El Portafolio, metodología de evaluación y aprendizaje de cara al nuevo Espacio Europeo de Educación Superior. Una experiencia práctica en la Universidad de Sevilla. Revista Latinoamericana de Tecnología Educativa, 4(1), 121-139. Recuperado de: http://www.unex.es/didactica/RELATEC/ sumario_4_1.htm.

De Ketele, J. M. (2008). Enfoque socio-hist rico de las competencias en la ense anza, Profesorado. Revista de curr culo y formaci $n$ del profesorado, 12, (3). Recuperado de: http://www.ugr.es/local/recfpro/rev123ART1.pdf

Díaz-Barriga, Á. (2011). Competencias en educación. Corrientes de pensamiento e implicaciones para el currículo y el trabajo en el aula. Revista Iberoamericana de Educación Superior, II(5) 3-24. Recuperado de http://www.redalyc.org/articulo.oa?id=299123992001

Fernández-March, A. (2004). El portafolio docente como estrategia formativa y de desarrollo profesional. Revista Educar 33, 127-142. Recuperado de http://www.raco.cat/index.php/educar/article/viewFile/20792/20632

Mart nez-S nchez, N. (2002). El portafolio como mecanismo de validaci $\mathrm{n}$ de aprendizaje. Perfiles Educativos, vol. XXIV, n m. 95, 2002, pp. 54-66 Instituto de Investigaciones sobre la Universidad y la Educaci n Distrito Federal, $M$ xico.

Pérez, Rendón, M. (2014). Perspectiva Educacional. Formaci n de Profesores Enero 2014, Vol. 53(1), Pp. 19-35 doi: 10.4151/07189729-Vol.53-Iss.1-Art.213

Romero-López, A. y Crisol, E. (2011). El portafolio, herramienta de autoevaluación del aprendizaje de los estudiantes. Una experiencia práctica en la Universidad de Granada. Revista Docencia e Investigación. $\quad$ No. $\quad 21 . \quad$ Recuperada de http://www.uclm.es/varios/revistas/docenciaeinvestigacion/pdf/numero11/02.pdf

Universidad de Guanajuato. División de Ciencias Económico Administrativas. Campus Guanajuato. (2018). Lineamientos para la Titulación u Obtención de grado en los programas educativos de la División de Ciencias Económico Administrativas.

Van der Schaaf, M. F. y Stokking, K.M. (2008). Developing and validating a design for teacher portfolio assessment. Assessment \& Evaluation in Higher Education, 33 (3), 245-262. 


\title{
SOCIAL SCIENCE STUDENT TEACHERS' AWARENESS OF THE INTERTWINESS OF SOCIAL SCIENCE AND SOCIAL JUSTICE IN MULTICULTURAL SCHOOL SETTINGS
}

\author{
Titus Williams, Gregory Alexander, \& Wendy Setlalentoa \\ Central University of Technology Free State (South Africa)
}

\begin{abstract}
This qualitative study is an exploration of final year Social Science education students awareness of the intertwined nature of Social Science as a subject and the role of social justice in the classroom of a democratic South Africa. This study finds that South African Social Science teachers interpret or experience the teaching of Social Science in various ways. In the South African transitional justice environment, Social Science education had to take into account the legacies of the apartheid-era schooling system and the official history narrative that contributed to conflict in South Africa. Throughout the world, issues of social justice and equity are becoming a significant part of everyday discourse in education and some of these themes are part of the Social Science curriculum. Through a qualitative research methodology, data was gathered from Focus Group Discussion (FGD) sessions with three groups of five teacher education students in two of the groups and the third having ten participants from the same race, in their final year, specializing in Social Science teaching. The data obtained were categorised and analysed in terms of the student teacher's awareness of the intertwined nature of Social Science and social justice education. The results of the study have revealed that participants had a penchant for the subject Social Science because it assisted them to have a better understanding of social justice and the unequal society they live in; an awareness of social ills, and the challenges of people. Participants identified social justice characteristics within Social Science and relate to some extent while they were teaching the subject, certain themes within the Social Science curriculum. Findings suggest that the subject Social Science provides a perspective as to why social injustice and inequality are so prevalent in South Africa and in some parts of the world. Social Science content in its current form and South African context, emanates from events and activities that took place in communities and in the broader society, thus the linkage to social justice education. This study recommends different approaches to infuse social justice considerations Social Science; one being an empathetic approach - introducing activities to assist learners in viewing an issue from someone else's perspective, particularly when issues of prejudice or discrimination against a particular group arise, or if the issue is remote from learners' lives.
\end{abstract}

Keywords: Social science, social justice, awareness, teacher education, teaching.

\section{Introduction}

Since 1994 after the first democratic elections, there has been a significant redesigning process of the education and training landscape in South Africa. The period 1994 introduced a radically new historical era for all South Africans and most importantly, for schooling (Grades 1-12) in South Africa. The political thinking in 1994 was to abolish all the old that had been systemically linked with apartheid and to introduce new policies in all the various spheres in the country (Du Plessis, 2009). As schooling had been in dire straits for many years, government deemed it necessary that policy should be enacted to transform the national system of education and training. The latter needed to recognise that pedagogies, curricula and qualifications were not absolutes, but rather, that they were the result of decisions, as well as priorities, and therefore needed debating (Young \& Kraak, 2001; Wedekind, 2016).It was inevitable that a new curriculum for a new South African dispensation was welcomed and unavoidable, but the sine qua non was that diverse cultures, the background of learners, values in education and so forth, had to be taken into account (Harley \& Wedekind, 2004; Maphosa, Mudzielwana \& Netshifhefhe, 2014 ). The inclusion of social justice in teacher training programmes is viewed by many scholars as a contributor to preparing Social Sciences teachers to be agents of change who can assist the government of South Africa in achieving their educational objectives. 
Social justice generally embraces values, such as the equal worth of all citizens and their equal right to meet their basic needs. Kea, Campbell-Whatley and Richards, (2006) state that in the context of democratic education, teacher competencies such as sociocultural consciousness, adopting responsible teaching strategies, and having an affirming attitude towards learning from culturally diverse backgrounds, should form part of student teachers' professional development. Most advocates of social justice education note that preparing student teachers to teach in such learning environments and challenging oppression is difficult work, facing a multitude of barriers (Pace, 2014). As such, democratic education requires preservice teachers to lead and teach for social justice and in turn, combat oppressive practices, while creating an equal and dignified classroom environment.

The discipline of Social Science is better positioned to examine critical, social issues from multiple perspectives, explore past and present inequities, and propose possibilities for change in an increasingly globalised world (Agarwal-Rangnath, 2013). A significant stated goal of the Social Sciences is understanding the world, and it uses the term 'understanding' consciously because learning in Social Science involves more than simply memorising factual information. Factual knowledge is used as the foundation to support learners in their development of concepts and general understanding. Thinking skills are more imperative in the Social Sciences because learners use them to process facts in order that specific items of information may be related to one another in a variety of ways to become ideas (Ngulube, Mathipa \& Gumbo, 2015). Social Science as a school subject enables learners to deal with multifaceted social reality; reality that is not given but produced and reproduced under the influence of authoritative discourse of power and hegemony. By virtue of being 'social', the best place to teach students to question prevailing social norms, processes and practices, is in the Social Science classroom (Midford, James \& Hutchinson, 2018). The National Curriculum Statement (NCS), in the Curriculum and Assessment Policy Statement (CAPS) (2011) of South Africa state that the Social Sciences curriculum aims to provide opportunities for learners to look upon their own world with fresh and critical mindsets and perhaps more significantly, these policy documents aim to introduce learners to a world beyond their everyday realities. This study therefore aims at enticing teachers to embrace diversity in their classrooms.

\section{Aim of the study}

The aim of this qualitative study was to explore final year Social Science education students' awareness of the intertwined nature of Social Science as a subject and the manifestation of social justice imperatives in democratic classroom settings of South Africa.

\section{Methodology}

A qualitative method was employed for the purpose of this study. Assembling people belonging to similar backgrounds together to ascertain their insights, views, beliefs and attitudes in a coordinated discussion, is regarded as a focus group discussion (McMillan \& Schumacher, 2010). Participants in this type of research were, therefore, selected on the basis that they would have something to say on the topic; are within the age-range; have similar socio-characteristics; and would be comfortable talking to the facilitator and one another (Oladeji, 2012). The discussions were conducted with final year Social Science student teachers of one university. The participants were grouped according to racial groups. The rationale behind this was to garner perceptions based on South Africa's main racial groups. The Focus Group Discussions (FGD) had a white only group of five participants; a coloured group of five participants; and two groups of five each of black African participants. The rationale for having two groups of black Africans is due to a lack of forming an Indian group and because black Africans form the majority race group in South Africa. The aim of the research was to capture the richness and uniqueness of everyone's perception that emanated from the natural settings of the participants' environment. The division according to racial groups allowed participants to open-up and engage freely without fear of prejudice. Although the discussion was guided by a list of questions, the dialogue took the form of free conversation and the participants were encouraged to talk without restraint. The discussions were audio-taped and transcribed with the permission of the participants. This was done to capture the participants' responses. In total, 20 participants partook in the FGD. The participants (from both gender, different race groups and originated from rural and urban residential areas)) were obtained by means of purposive sampling, selected for fitting a particular profile, the FGD's were coded as follow: FGDA1-5; FGDB1-5; FGDC 1-5 and FGDD 1-5. 


\section{Presentation and analysis of results}

The presentation is done according to themes that were drawn from the analysis of discussion data. The same questions were posed to the different groups and as introduction the participants were asked to unpacked their views on Social Science as a subject, both as a learner and a teacher. We now briefly present some of the most pertinent findings in the form of two themes.

Theme 1: Social Science teaching and learning experience (Interesting, fascinating and related to politics)

This section is the presentation of how the teacher education participants view the teaching and learning of Social Science. Social Science is regarded as not similar to other school subjects and is viewed by many scholars as closely related to politics, which makes it a very awkward subject to teach or learn (Ucus, 2018). The participants (FGDA) indicated they found the subject to be interesting and challenging (FGDA A1, FGDA A2). Participant FGDA A3 said it was easy to understand and relate to because it relates to what is happening daily in communities, while participant FGDA A2 indicated it was interesting depending on the type of learners you have in your class. In relation to the views of the latter mentioned, participant FGDA5 highlighted the following aspects: "I found the subject very interesting and challenging, closely related to politics. I found myself at times very uneasy about expressing myself while teaching it during teaching practice." The participants (FGDB B5) responded that they also found the subject to be interesting with elements of politics and in admission to that, they (FGDB B1, FGDB B3 and FGDB B4) were of the opinion that they grew up in the township and were confronted daily by politics, made the Social Science classroom both as learners and teachers fascinating and enjoyable. The participant FGDB B3 further indicated that Social Science connects one to one's environment and community and that the subject can assist in shaping us. In this regard FGDB B2, stated the following: "I enjoy the subject SS because it is fascinating and one always learns something new about one's community, country and the world. I enjoy teaching it because of the interesting facts around Social Science and the impact it can make on the learners."

The participants (FGDC1 C2 and FGDC1 C4) concur with the two other groups that they found Social Science to be very interesting because of its relation to the human being and their environment (FGDC1 C2, FGDBC1 C5, FGDC2 C8 and FGDC2 C10). The participants (FGDC1 C4 and FGDC2 C6) indicated that the element of the subject's interrelatedness to politics, also contributed to their love for the subject. FGDC2 C7 articulated the following sentiment with regard to the nature of Social Science: "I enjoy SS because it makes me understand where I come from as a black person and why my parents and grandparents struggled that much. This subject opened up my horizons to how the earth operates and how people find in it a living space."

The other question that was posed during the focus group discussions was: Have you ever come across the term social justice during your training as a teacher? What is your opinion of social justice and its role in the teaching of a subject, such as Social Science?

Theme 2: Social justice in teacher training and its role in a subject, such as Social Science (Social justice consideration key in Social Science and social justice key in communities)

Education programmes seem to be adding statements about the importance of social justice to their mission, and a growing number of teacher education programmes are fundamentally oriented around a vision of social justice. The term is therefore predominantly used in multicultural settings to address matters of diversity and equality in communities. Hytten and Bettez (2011) argue that despite all the talk about social justice of late, it is often unclear in any practical terms what we mean when we invoke a vision of social justice or how this influences such issues as programme development, curricula, practicum opportunities, educational philosophy, social vision, and activist work.

Teacher education participants FGDA A3, FGDB B1, FGDB B3 and FGDC1 C3 in this study said that they had heard of social justice on other platforms but not as part of their teacher training programme. FGDC1 and $\mathrm{C} 5$ indicated that the term came up several times in debates related to communities and on television. When people refer to disadvantaged communities. Teacher education participant FGDA A2 disagreed with the latter statement and indicated the following: "No, but I think the first time I heard of social justice, might have been on television in a programme that discussed poverty in townships."

We of the view that despite the significant volume of social justice work in education, one of the pieces of the puzzle that seems to be missing is genuine dialogue across various positions that help us to build on each of their strengths, as well as to better acknowledge challenges and reflect on the complexities of education for social justice. 


\section{Discussion of findings}

Findings from the focus group discussion indicated that participants had a penchant for the subject Social Science because it assisted them to have a better understanding of social justice and the unequal society they live in; an awareness of social ills, and the challenges of people living in townships. This is further reinforced by Camicia and Dobson (2010) that learners should leave school with a clear sense of their rights and responsibilities as citizens and be prepared to challenge injustice and promote the common good. The subject Social Science provides a perspective as to why social injustice and inequality are so prevalent in South Africa and in some parts of the world. Gray (2017) reaffirms this notion and indicates that many scholars assert that teaching for social justice should be the core of teacher training, even it means teaching "against the grain". The most important goals of teacher training programmes are social responsibility; social change; and social justice.

It can be concluded that social justice has a particular role to play in education and in particular in Social Science because of the close link to society, communities and the broader population. Social Science content in its current form, from a South African perspective, emanates from events and activities that took place in communities and in the broader society, thus being relevant to the role communities should play. In the South African transitional justice environment, Social Science education also needed to take into account the legacies of the apartheid-era schooling system and the official historical narrative that had contributed to conflict. The segregation of schools and the concurrent underfinancing of black schools conspired to institutionalise deeply unequal education between whites and the majority of South Africans. Social Science education is seen as the hallmark of civilised society, the engine of social justice and economic growth, the foundation of our culture and the best investment that can be made in the future of a country. Studies have documented that regardless of the economic, ethnic, or cultural background, family involvement in a child's education is a major factor in determining success in all areas.

This study has revealed that the primary purpose of Social Science is to develop civic virtues; to assist learners to acquire knowledge, attitudes, values, habits and behaviour that are critical for maintaining a healthy, diverse, and dynamic society. The study additionally indicated that the primary mission of Social Science is to produce competent citizens, and the participants of this study revealed the importance of social impartialities in the Social Science classroom. Consequently, a recommendation would be that social justice considerations be included in the teaching and learning of Social Science, due to its intertwined nature and its value in achieving the governments' educational objectives. Institutions of higher learning should include social justice and multiculturalism in their teacher training programmes.

\section{Conclusion}

The findings of this study revealed that the participants appeared to show an enthusiasm for social justice considerations and the role it could possibly play in social cohesion and nation building. Participants from all racial groups appeared to show willingness to be change-agents society required in post-apartheid South Africa.

\section{References}

Agarwal-Rangnath, R. 2013. Social Studies, Literacy, and Social Justice in the Common Core Classroom: A Guide for Teachers. Kindle Edition.

Camicia, S. P., \& Dobson, D. 2010. Learning how to respond to current events: Partner journals between U.S. preservice teachers and children. Teaching and Teacher Education, 26, 576-582.

Du Plessis, T. 2009. Colonialism, Apartheid and Higher Education in South Africa. Transformation in Higher Education, 1 (1): 87-113.

Gray, R.A. 2017. Social justice educators' road through transformational educational pedagogy: What are the lessons learned? University of Pittsburgh. 205.

Harley, K. and Wedekind, V. 2004. Political change, curriculum change and social formation, 1990 to 2000. In Chisholm, L. (Ed.), Changing class: education and social change in post-apartheid South Africa. Cape Town: HSRC Press, pp.195-221.

Hytten, K., \& Bettez, S.C. 2011. Understanding Education for Social Justice. Educational Foundations, Winter-Spring.

Kea, C, Campbell-Whatley, G \& Richards, H. 2006. Becoming culturally responsive educators: Rethinking

McMillan, J.H. \& Schumacher, S. 2010. Research in Education: Evidence-Based Inquiry (7th ed.) New York: Pearson. 
Midford, S., James, S. \& Hutchinson, G. 2018. Key concepts in humanities and social sciences. La Trobe University Melbourne Australia. 90.

Ngulube, P., Mathipa, E.R. \& Gumbo, M.T. 2015. Theoretical and conceptual framework in the social and management sciences.

Oladeji, J.T. 2012. Investigation in Effectiveness of Questionnaire as a Method of Scientific Research. Education, 2 (1): 16-18

Teacher Education Pedagogy. Retrieved from http://www.niusileaderscape.org/docs/ Accessed 24 July 2017.

Ucus, S. 2018. Exploring Creativity in Social Studies Education for Elementary Grades: Teachers' Opinions and Interpretations. Journal of Education and Learning, 7(2): 111-125.

Young, M. \& Kraak, A.H. 2001. Education in retrospect: policy and implementation since 1990. HSRC, retrieved http://www.hsrcpublishers.ac.za/full_title_info.asp?id=1961 Accessed 1 August 2017 


\title{
COMPARISON OF THE FIRST YEAR LEARNING OUTCOMES OF DUAL AND NONDUAL STUDENTS IN THE LIGHT OF THE INPUT COMPETENCE SURVEY
}

\author{
Róbert Pap-Szigeti ${ }^{1,2}$, \& Erika Török ${ }^{1}$ \\ ${ }^{I}$ GAMF Faculty of Engineering and Computer Science, John von Neumann University, \\ Kecskemét (Hungary) \\ ${ }^{2}$ Bolyai János Secondary Grammar School, Kecskemét (Hungary)
}

\begin{abstract}
The number of students taking part in, and the courses involved in dual education have multiplied since the dual education was introduced. At our university, in the last seven years, some hundreds of students have participated in the training based on the German model, implemented in cooperation with partner companies.

Based on our assumptions at the beginning of the dual training and the experiences accumulated during the training we assume that in general, more motivated students, the ones who are eager to learn and meet the requirements chose this form of education.

The double filter (university and company) makes it possible to choose the best students. The strong selection and the stricter education criteria set by the form of the training (the required progress according to the sample curriculum) results in the students' achievements which are significantly better than the non-dual students' results.

Thanks to the input surveys regarding the dual and non-dual students which have been conducted since 2010 in our institutions, it is possible to measure the competence of dual and non-dual students at the beginning of the training, and we can also get information about the differences between the two groups and compare the achievements of dual students with the non-dual students. This examination gives a chance to examine how successful the training was for the dual students. The sample of our research consisted of the first year BSc full time students $(n=1,341)$. We applied the sample adjustment according to the points of the entrance tests when we analysed the achievements of the different training systems. In our presentation, we demonstrate the main areas of the competence survey, the results reached in those areas, the differences between the achievements in those areas, the impact of the input results on the success of learning (the impact of the differences on the results of the first year) in case of dual and non-dual students. We highlight those areas which significantly influence the study results regardless of training forms.
\end{abstract}

Keywords: Higher education, dual training, competence survey.

\section{Introduction}

There is an increasing demand for highly qualified experts who meet the requirements of economy. The higher education must overcome these challenges efficiently. The renewed strategic programme for higher education adopted by the European Union sets an aim to be reached that $40 \%$ of young people should obtain Bachelor's or Master's degree, and it is predicted that by the year 2025 half of the total number of jobs will require higher education qualification. Higher education must ensure to be inclusive, that is, the institutions of higher education should not be ivory towers, but civilian learning communities which are connected to the local society (COM 2017, 247 final). At the same time it is worth mentioning that a portion of students who gets admitted to higher education does not have the appropriate knowledge in basic skills (reading-writing, arithmetic skills), they lack the experience in independent learning; neither the prospective students nor their parents know what situations, tasks to be solved, expectations to be met they can expect in higher education.

According to the strategy of the Union the higher education institutions must make it possible for the students to obtain skills and experiences through activities in which they must solve real life problems, and also they have to be given the opportunity to the work-based learning. The higher education institutions endeavour to fulfil these requirements in various ways. The dual training is a type of learning system applied 
at several universities. In German speaking countries, this training is known as "Dual" in English speaking countries as "Dual" or "Cooperative" Education. Further synonyms for the dual training are "co-op practice", "experiential learning”, “co-op internship", "work integrated learning", "work based learning" or "university-industry partnership" (Nagy, Török and Angeli 2019). In Hungary the most well-known names used for this practice oriented training are dual, cooperative or partnership training.

At John von Neumann University (formerly Kecskemet College) students have been able to study in this type of training since 2012.

At our university based on the collaboration with employers we attempt to customise our curricula to the demands of the corporate demands and also eminently fulfil the academic requirements and Training and Output Requirements.

In the last 7 years we have gathered a lot of experiences to judge the efficiency of the training. We have indicators regarding the number of courses in which it was possible to choose the dual training (at the beginning there were two basic courses, at the moment we have nine), the number of students who participated in dual training (in the first year, there were 24 students, at the moment, we have 328), the number of collaborating companies (there were 2 collaborating companies at the beginning, and at the moment, we have 82 partners) and also about the activities of the involved companies. We have conducted a student satisfaction survey (Török and Kovács, 2016; Török, Pap-Szigeti, Ailer and Palkovics 2014), and we have come to the conclusion that the students learning outcome numbers is an important indicator of the efficiency of the dual training. In our forgoing investigations we have compared the results of the dual students to the nondual students, who studied at the same study programme, in the same semester, and we found that despite the bigger requirements which the students taking part in the dual training had to meet (placement time at the company, less free time, more responsibility at the workplace) the dual students reached better results. Similar results are reported at the research conducted at Óbuda University (Pogatsnik, 2018). The question emerged when comparing the results of dual and nondual students to what extent we should take into consideration the students' secondary school learning outcomes (entrance examination scores) and the data of the input competence survey. At our university we conduct input competence survey in which all the full time BSc students take part as it is a criterion in the curriculum.

\section{Being admitted and integration - Dual students at university}

There is an important factor which should be mentioned in connection with getting into the dual education system, which might have a great impact on the students' learning outcomes later. The dual students can get into the training through two step screening procedure. The initial screening procedure is - in accordance to the state requirements- that the students are admitted to the university based on their secondary school learning outcome scores. The second screening comes after the students have submitted their application to the "dual" company, in this part; the students take part in a recruitment procedure required by the company to which they applied. It can happen that some companies apply a recruiting procedure consisting of several steps. The ultimate goal of this procedure is that the applicants and the companies get to know each other. The companies take into consideration the students learning outcomes, their aptitude, skills, personality, as well as their foreign language skills are tested orally and in writing. Some companies assess how the applicants can solve tasks individually and in groups. Therefore the students who take part in dual education participate in a stricter filtering procedure than the nondual students. After the students' applications have been accepted, the students sign the contract with the company, and the students' integration into the company starts (getting acquainted with the company, its profile, physical environment, culture, employees, professional tasks etc.) These can be strong motivational forces, which can support the students' professional engagement, commitment and professional identity.

\section{The hypotheses of the research}

In the introduction, we have presented the main features of the dual training and the way students can get into it. Based on the factors which were mentioned especially, the stronger selection, the stricter subject criteria and the social influences we suppose that

(1) There is significant difference between the dual and nondual students' abilities/skills and self-reflexion even at the beginning of their university studies.

(2) As a result of the above mentioned effects and the measurable differences there will be significant differences between the learning outcomes of the dual and the nondual students.

The stronger entrance selection does not mean that all the students who do not take part in the dual education have lower skill levels or self-reflection than the dual students. Therefore in our examination we compare the dual students' learning outcomes with the learning outcomes of a subsample of the students 
studying in the traditional system which has similar distribution based on the skill levels and motivation to skill levels and motivation of the dual students.

(3) The results of the input competences predict the learning success at university - regardless of the form of the form of education.

(4) According to this hypothesis the students who do not take part in the dual education; however, they have high level of cognitive skills and self-reflexion levels have same chances to acquire knowledge successfully as dual students.

\section{Methods}

\subsection{The sample}

The research and collection of data organised by the university gave the possibilities to examine these hypotheses. The sample of this examination consisted of the full time BSc students enrolled between 2016 and $2018\left(n_{1}=1341\right)$. The students were selected who took part in the input competence survey $n=1187$ ) and still study at the university. Table 1 shows distribution of the sample according to year and course.

Table 1. The sample division according to the year of enrolment and course types.

\begin{tabular}{llllll}
\hline \hline education form & 2016 & 2017 & 2018 & total & "dropouts" \\
\hline \hline dual & 80 & 99 & 98 & 277 & 9 \\
\hline nondual & 330 & 254 & 326 & 910 & 100 \\
\hline \hline
\end{tabular}

The entrance exam scores are significantly higher in case of the dual students than the students who do not take part in the dual education (in case of the students enrolled in 2016 the difference in means is 26.4 points; $t=5.01 ; p<0.001$. In case of the students admitted in 2017 the difference between the means is 19.0 points; $t=4.613 ; p<0.001$. In case of the students admitted in 2018 the difference in means is 26.3 points; $t=5.648 ; p<0.001$. The difference in standard deviances is not significant in any years).

For investigating the hypothesis (3) we selected the subsample of nondual students which showed similar distribution based on the entrance scores, the results of the input survey for measuring cognitive skills and the distribution of the students by year $\left(n_{\text {dual }}=270 ; n_{\text {nondual }}=263\right)$.

\subsection{Instruments and procedure}

We used the instrument which had been used at John von Neumann University consisting of a digital test and a questionnaire (Hercz, Koltói, Pap-Szigeti and Török 2014). The reliability of the tests (Cronbach's alpha) was acceptable for every year group (every subtest was above 0.90 and for the whole test it was between 0.92-0.94 in every examined year).

The tasks of the test measured (reading comprehension, writing), thinking skills (solving mathematical problems, conceptual systematization, inductive thinking, understanding interrelations).

The test measured some features of verbal memory and metacommunication. In the questionnaire students reflect their own communication, reading comprehension, and general mental skills. We give a feedback to the students on the results of all tests in percentages (that is $100 \%$ means maximal points).

The survey is conducted every year during the registration week. The students can complete the online test; answer the questions within the given timeframe in the time slot chosen by them. They have 90 minutes to complete the tasks and fill in the questionnaire. The test and the questionnaire are presented on general purpose individually developed software (Pap-Szigeti 2018).

We used different additional data to examine our hypotheses beyond the data provided by the test. We examined other data which were recorded in the learning system, for example, the secondary school learning outcome scores, the students' grade average at the of the first year. In addition, the number of acquired credits in the last semester and the number of active semesters were also analysed.

\section{Results}

The hypothesis (1) was justified because the dual students' cognitive skills are in general more developed than that of the nondual students. The differences between the two groups considering the 3 years are significant but not really big. The average of the dual students is $68.6 \%$ points, nonduals 65.3 points $(t=2.322 ; p=0.021)$. 
In some fields there have been significant differences between the two subsamples. In some fields dual students reached significantly better results nondual students. The fields which show significant differences and the degree of the difference are the following:

- Solving mathematical problems $9.3 \%$ point difference

- inductive thinking $7.2 \%$ difference

- systematisation skills 6,0\%points difference

- concept abstraction $2.7 \%$ points difference

Besides cognitive fields (in relationship with those) the self-reflection regarding the thinking skills is significantly $(4 \%)$ higher in case of dual students. This indicator of self-respect works as learning motivation during learning later.

Taking into consideration the learning outcome average of the first school year, there has not been found a significant difference between the students who study in the traditional and in the dual training in case of students admitted in each individual year. In addition the average of the whole sample does not show a different picture either (the first three years were examined and it was found that the average of the nondual students is 3.57, and the dual students reached average of 3.58).

However, the credit indexes of the last completed semester showed that dual students gained remarkable advantage over nondual students (Table 2). The difference almost reached the significance level in the first two years, as regards the data of the three years together the difference becomes significant, which justifies the hypothesis (2).

Table 2. Comparison of the credit indexes at the end of the last completed semester according to the education form.

\begin{tabular}{llllll}
\hline \hline education form & $\begin{array}{l}\text { enrolled } \\
(\mathrm{N})\end{array}$ & 2016 & $\begin{array}{l}\text { enrolled } \\
(\mathrm{N})\end{array}$ & $\begin{array}{l}2017 \\
\text { enrolled } \\
2018(\mathrm{~N})\end{array}$ & $\begin{array}{l}\text { three } \\
\text { total }(\mathrm{N})\end{array}$ \\
\hline \hline dual & 3.84 & 3.76 & 3.54 & 3.71 \\
\hline nondual & 3.60 & 3.47 & 3.24 & 3.42 \\
\hline & $t=1.132$ & $t=1.751$ & $t=1.942$ & $t=2.830$ \\
& $p=0.259$ & $p=0.081$ & $p=0.053$ & $p=0.005$ \\
\hline \hline
\end{tabular}

Based on the currently available data we can analyse the predictive power of the entrance exam scores and some fields of the competence survey. The correlations of variables were analysed with linear regression where the dependent variable was the scores of first academic year, and the independent variable was the entrance examination scores.

In the whole sample the variance of the entrance scores gives $14.6 \%$ of the regular average/grade point average, the consolidated indicator of the cognitive skills of the input competence survey explains $14.5 \%$ of the regular average/grade point average. The variance of self-reflexion concerning the thinking skills is significant but not outstanding; it explains 3\% of the variance. We employed the regression analysis on the subsamples of dual and nondual students; we did not find significant differences between the subsamples.

In summary, the input competence survey has a similar predictive power to the entrance examination scores. The remaining part of the individual differences in the learning outcomes could not be explained by the instruments.

We chose a subsample of the nondual students which had the same distribution as that of the dual students in order to test the hypothesis (3). The fitting process was based on the number of students who started the semester, the entrance exam scores, the distribution of the consolidated indicator of the cognitive skills of the input competence survey.

In the fitted sample we have not found any significant differences based on regular average/grade point average at the end of the first academic year (average: dual: 3.8; nondual: 3.62; n.s.), neither considering the average of the last completed semester (average: dual: 3.71 ; nondual: 3.73 ; n.s.)

This shows that students with higher skill levels can be successful in the nondual education as well. Therefore, in this respect, they are given equal opportunities.

\section{Summary}

Our examinations confirmed that the students who take part in the dual education have above-average cognitive skills and motivation even at the beginning of their university studies. It is combined with other factors e.g., stricter selection process, higher learning outcome requirements results in significant differences in learning success which appears in the higher credit index. 
The students who do not take part in the dual training, but have the same abilities are similarly successful in learning. It is possible that their success in learning and comparing themselves to their peers compensate them for the lack of factors which support the dual students we mentioned in the introduction.

Based on our investigations we could found little about the individual differences in the in-learning success. We hope that with our further surveys (thus the questionnaire which explores the motivation and its changes, by obtaining data about sociocultural background) we endeavour to get a more precise explanation, and give guidelines to increase the efficiency of the currently ongoing intervention programmes (Török, Brindza, Hercz, Koltói, Pap-Szigeti and Rigó 2016).

\section{Acknowledgments}

This research is supported by EFOP-3.6.1-16-2016-00006 "The development and enhancement of the research potential at John von Neumann University" project. The Project is supported by the Hungarian Government and co-financed by the European Social Fund.

\section{References}

A Bizottság közleménye az Európai Parlamentnek, a Tanácsnak, a Gazdasági és Szociális Bizottságnak és a Régiók Bizottságának Az európai felsőoktatási rendszerek által az intelligens, fenntartható és inkluzív növekedés terén tett hozzájárulás növelése. [Communication from the Commission to the European Parliament, the Council, the European Economic and Social Committee and Committee of the Regions on a renewed EU agenda for higher education aiming to increase the contribution to the sustainable and inclusive development. ] Brüsszel, 2017. 05. 30. COM (2017) 247 final

Hercz, M. - Koltói, L. - Pap-Szigeti, R. - Török, E. (2014): Assessing competencies of freshmen: an on-line measurement in the college. Paper presented at 6th International Scientific and Expert Conference TEAM 2014. Technique, Education, Agriculture \& Management. Kecskemét, November 10th - 11th 2014.

Nagy Dorottya - Török Erika - Angeli Eliza (2019): A duális képzésü hallgatók szakmai fejlődésének követése és értékelése. [Tracking and assessment of dual students] Gradus, 6:(1) 57-62.

Pap-Szigeti Róbert (2018): Szoftver- és mérőeszköz-fejlesztés programozási ismeretek és készségek értékelésére. Gradus, 5:(2) 355-359. [Software and instrument development and assessment of skills]

Pogatsnik, M. (2019): Dual Education: The Win-Win Model of Collaboration between Universities and Industry https://doi.org/10.3991/ijep.v8i3.8111 (2019.10.15.)

Török Erika - Brindza Attila - Hercz Mária - Koltói Lillla - Pap-Szigeti Róbert - Rigó Róbert (2016): TALENTUM: hallgatói sikerességet támogató és tanulást segítő pilot program a Kecskeméti Főiskolán. [TALENTUM Programme helping students‘ learning success at Kecskemét college] In: Fodorné Tóth Krisztina (szerk.): Felsőoktatási kihívások. Alkalmazkodás stratégiai partnerségben. MELLearN Felsőoktatási Hálózat az életen át tartó tanulásért Egyesület, Pécs. 76-85.

Török Erika - Pap-Szigeti Róbert - Ailer Piroska - Palkovics László (2014): A Kecskeméti Főiskola duális képzésének monitoring vizsgálata a hallgatók visszajelzései alapján. [Monitoring dual training based on students‘ feedback ]A jövő jármüve, 2014:(1-2), 32-36. 


\title{
ASCERTAINING THE USE OF EXTRACURRICULAR ACTIVITIES IN PROMOTING LEARNERS' HOLISTIC DEVELOPMENT IN MULTICULTURAL SCHOOL SETTINGS
}

\author{
Gregory Alexander ${ }^{1}$, Sheila Matoti ${ }^{2}$, \& Pieter Van Zyl ${ }^{1}$ \\ ${ }^{1}$ Faculty of Humanities, Central University of Technology (South Africa) \\ ${ }^{2}$ Scholarship of Teaching \& Learning Unit, Central University of Technology (South Africa)
}

\begin{abstract}
Encouraging learners to participate in extracurricular activities should commence in the early phase of their growth where a basis for their personality, learning and development is laid. Extracurricular activities could further assist in improving learners' creativity and artistic talents. Philosophers, such as Rousseau, Spencer and Dewey further reiterate the value of extracurricular activities in developing social relationships and intellectual intelligence. Learners associate with different peer groups which may satisfy their socialisation, self-assessment, self-identification and the fulfilment of their needs in becoming self-actualised. Learners can further be enabled to reach self-actualisation by participating in academic activities, such as maths, science clubs and research projects. Such activities seemingly contribute to learners' academic development which in turn may assist them in mastering certain life tasks; developing leadership roles; increasing their involvement in the community and expressing their civil responsibility. Amidst the latter, it is noted that the lack or in some cases, the non-existence of extracurricular activities hinder learners' growth and learning, especially in multicultural school settings, where the foundation for learners' development has to occur in a conducive environment. Multicultural schools in the Letjweleputswa educational district, Free State province of South Africa seem not to use extracurricular activities as an effective tool in promoting learners' holistic development. The aim of this paper is to ascertain the use of extracurricular activities in promoting learners' holistic development in the Letjweleputswa educational district. Via a qualitative research methodology, three focus group interviews were conducted with 20 learners attached to four multicultural schools. Findings of the study revealed that learner participants are of the view that their involvement in extracurricular activities could give them a greater chance of being employed; of getting a better job; of being accepted into university and of developing certain attributes, such as creativity, innovation, problem solving and endurance. The study further recommends that multicultural schools in the Letjweleputswa educational district need to implement various extracurricular activities as a means of developing various traits and competencies such as learners' physical-, emotional-, cognitive and social skills; moral underpinnings, life-skills, well-being, leadership qualities, analytical thinking processes and communication abilities.
\end{abstract}

Keywords: Extracurricular activities, holistic development, multicultural schools.

\section{Introduction}

Extracurricular activities fulfil a crucial role in school curricula as to allow learners to reveal their hidden potential for development (Krishnamurti, 2003)- it also assists them to improve on their creativity and artistic talents. Learners associate with different peer groups and through this process, they acquire skills with socialisation, self-assessment, self-identification and the fulfilment of their need to become self-actualised. Therefore, we argue that extracurricular activities can contribute to learners' academic development, which later in life may be used to develop leadership roles; increase participation in community initiatives and assist with the empowerment of other citizens (Barge, 2015). Kapur (2015), argues that circumstances in developing countries, such as South Africa, limit human activities in social, economic, cultural and educational development. Lleras (2009) observed that in Illinois high schools in the USA, where learners were exposed to extracurricular activities, they were highly praised by their teachers as having good social skills and work habits. Furthermore, these learners obtained higher levels of education in quicker times, than some of their classmates who participated less in extracurricular activities. Learners' desire to grow can be motivated through the establishment of participation in 
extracurricular activities (Pioner, 2015). In some instances, schools request additional fees and costs from parents as a mechanism of enhancing learners' holistic development- this is fulfilled through various sporting codes, school newspapers, literary activities, drama clubs and cultural clubs. Extracurricular activities need to be managed according to learners' needs and desires and as such ensure an appropriate development structure to ground effective strategies which could possibly be used by teachers. Encouraging learners to participate in extracurricular activities should commence in the early phase of childhood education where the platform for learners' personality, learning and development is laid. Learners come into contact with peers who also engage in extracurricular activities. Therefore, schools should initiate opportunities to advance appropriate strategies as a measure of promoting learners' holistic development, especially in the early phase of their development where learners have to indulged in play (Sampson, 2012). Extracurricular activities assist in improving the creativity and artistic talents of learners. Learners associate with different peer groups, which may satisfy their need for socialisation, self-assessment, self-identification and self-actualisation. Learners can further be enabled to reach self-actualisation by participating in academic activities, such as maths, science clubs and research projects. Such activities contribute to learners' academic growth which in turn may assist them in mastering certain life tasks; developing leadership roles, increasing their involvement in the community and expressing their civil responsibly (Barge, 2015).

According to Thakur (2013), it is an accepted norm that extracurricular activities support learners social and personal development skills. Extracurricular activities generate positive growth in human development. Kapur's (2015) further states that extracurricular activities promote all aspects of human development, regardless of anomalies; even more so in multicultural school environments, where the development of learners as holistic beings, is perceived as cardinal. The holistic view of human development can be observed in different aspects, such as the physical, emotional, mental, spiritual and social. In all, we argue that there is a causal link between participation in extracurricular activities, holistic development and academic performance (Thakur, $2013 \& \&$ Mason, 2017). The vision of the Department of Basic Education in South Arica is pronged in providing conducive learning environments for the enhancement of learners' full potential in all aspects of their holistic growth. Quality care and education as set out by the Department of Education in South Africa during early childhood, is valuable to children's growth and development throughout their lives. The benefits identified by Dlamini (2017), such as physical development (use of sports develop good motor skills);emotional development (learners learn to cope with a wider range of scenarios, such as compassion and empathy); communication skills (learners learn to communicate with a knowledgeable other); cognitive development (give learners opportunity to express creativity); creative development (may develop enthusiastic approach to learning); healthy learning (exercises, activities and games make learners aware of their surroundings); and special awareness (changing learners' developing brains, acquiring skills, such as problem-solving and arithmetic) are cardinal to human development. These are some aspects that could possibly contribute to the holistic development of learners.

\section{Theoretical framework}

The study will be grounded in Urie Bronfenbrenner's bio-ecological model. This model proposes that a person's growth might be influenced by a set of systems in their environment such as family, peers and social institutions, such as school or extracurricular activities (Eggen \& Kauchak, 2014). A learner's growth could be influenced by a set of systems in their environment, such as family, peers and social institutions, schools and exposure/non exposure to extracurricular activities (Eggen \& Kauchak 2014). The surroundings and realities that learners engage with family, peers, teachers and coaches might provide ideal resources and assets for aspects of learners' holistic development (cognitive, emotional, social, spiritual, academic and physical). The visibility of social realities prevalent in Bronfenbrenner's theory, might be absent in the lives of most learners residing in the Letjweleputswa educational district. If teachers have knowledge of the systems and the effect they have on the development of their learners, they may assist learners to develop in relation to their age, ability difference, contextual background and diversity.

\section{Aim of the paper}

The aim of this paper is to ascertain the use of extracurricular activities in promoting learners' holistic development in the Letjweleputswa educational district of the Free State province, South Africa. 


\section{Statement of the problem}

Statistics South Africa (2016), indicate that there is a large percentage of learners in Brandfort schools, Letjweleputswa educational district who experience challenges in completing their schooling. A total of 367 out of 3134 people obtained higher education, while 1065 out of 3134 people completed their grade 12 school leaving certificate. Learners are exposed to various challenges and poor socio-economic conditions. We (authors of paper) also observed that the lack or in some cases, the non-existence of extracurricular activities hinder aspects confined to learners' holistic growth needs, especially in multicultural school settings, where the base for learners' development has to occur in a conducive environment. Multicultural schools in the Letjweleputswa educational district of the Free State province seem not to use extracurricular activities as an effective tool in promoting learners' holistic development. Numerous conditions also seem to contribute to this situation. Teachers lack the knowledge and skills in developing learners optimally and granting them fair opportunities in reaching their full potential, appear also to be a contributing factor in delimiting learners' holistic development. Therefore, the main question guiding this paper is: What do learners think of the use of extracurricular activities in promoting their holistic development?

\section{Research methodology}

A qualitative research approach was pursued in realising, the aim for this study. Learners' views and lived experiences on the use of extracurricular activities in promoting their holistic development was investigated via semi- structured focus group interviews. Qualitative research may refer to research about behaviours, emotions, people's lives, lived experiences and cultural phenomena. According to Eggen and Kauchak's (2014), Bronfenbrenner's bio-ecological systems approach, benefits the use of qualitative approach, purely by the fact that through this approach, data can be gathered to ascertain research participants behaviours, emotions, lived experiences, cultural values and beliefs. From a total of 39 learners from 6 schools who participated in the study, the views and experiences of 20 learners (4 focus groups) attached to four multicultural schools, are only used for reporting in this short paper. The focus group interviews were held with a diverse group of learners who participated in extracurricular and cultural activities. A thematic analysis a was used to interpret data emerging from the focus group interviews.

\section{Analysis and discussion of findings}

For the sake of this short paper, the authors have opted to discuss the findings of the most prominent themes, emerging from the data. For example, the code FGA L1 means Focus Group of School A \& Learner Participant 1.

\subsection{Theme 1: Benefits of various sporting codes}

The authors wanted to get an idea of the extracurricular activities being offered at multicultural schools. Participants (FGA L1, FGA L5, FGA L6, FGB L2, FGB L6, FGD L4, and FGD L5) indicated that their schools offer sport, but were not specific in the sport codes offered. Sport can be defined as an organised, competitive and skilful activity which necessitate dedication and fair play. Participants indicated that their schools offer sports in the form of athletics, netball, cricket, rugby, soccer, swimming, tennis, and horse riding. Some participants expressed their views as follow:

FGB L6: "Sport: athletics, netball, rugby, cricket, swimming, tennis, and horse riding." $\boldsymbol{F G} \boldsymbol{A}$ L3: "My school offers learners the opportunity to participate in horse riding as an extracurricular activity outside the formal school day activities." FGF L6: "My school offers indigenous games as an extracurricular activity. Indigenous games such as Morabaraba and Draft."

It should be noted that the various multicultural schools offer different sport codes- this is also dependent on whether the respective school is well-or under resourced (human, physical and financial resources; adequate infrastructure and facilities). Participating in sport means using time designated for physical, healthy and mental activity that refreshes the human body and as such, yields certain benefits to learners (Steinberg, 2018).

\subsection{Theme 2: Personal acceptance for participation in extracurricular activities}

The authors wanted to get a sense of the specific extracurricular activities (sport, art, choir, drama, indigenous games, library and reading club, cultural events, community service outreach, etc.) learners participate in and the reasons for their choice. Participants (FGA L1 and FGA L4) stated that 
they are involved in extracurricular activities because of the teacher who coaches, encourages, and motivates them as individuals. The role of coaches is often performed by a range of general education and special education teachers with expertise in instructional practices, with school psychologists, often assuming the role of a school coach (Snyder, Hemmeter \& Fox, 2015).

FGA L4: "We are one of the best rural schools when it comes to playing rugby, and the coaches are the ones motivating us." FGB L3: "I participate to get my mind off things and to develop my self-confidence to be able to work in groups." FGA L5: "I participate in the reading club because reading is my favourite activity and I enjoy it." $\boldsymbol{F G B}$ L3: "It increases my abilities and self-esteem to work in a group, interacting with others and also being able to listen to others increases my self-esteem."

Extracurricular activities in multicultural school settings seem to assist learners in strengthening their emotional abilities; develop their social interaction amongst peers; and build their self-confidence. Extracurricular activities promote social and emotional development which is critical in developing learners' ability to develop relationships; be self-confident; trust others; and manage diversity and stress in a healthy way (Wilson, 2009).

\subsection{Theme 3: Value of extra-mural activities with learners' holistic development}

The authors pronged learner participants to indicate how they using extramural activities in assisting with an aspect of their development (academics, physical, social, emotional, spiritual etc.) or with their motivation. Participants (FGB L5, FGB L6, FGB L7, FGD L9, FGC L5, FGC L6, FGD L3) mentioned that the teachers motivate and encourage them to do better in academic activities and also to be more involved during lessons. It is essential for teachers to motivate learners and assist them in identifying their strengths and weaknesses (Shava, 2016). The following sentiments were articulated by some learner participants.

FGB L9 "The teachers are using these activities to assist with academic work and also encouraging me to not think the worst of myself but be positive all the time because positive thoughts create positive achievements." FGC L2: "The teacher has helped me develop physically as well as emotionally; to pressure me in a positive way to be the best player I can be in netball." FGD L5: "Both my teachers motivate me to be more sociable with my peers/friends and that is why I participate in extracurricular activities and am happy when I do so."

From the above said, it appears that teachers motivate learners to be involved in sport and cultural activities which assist with aspects of their holistic development. Sport codes which are played in a team format enhances socialisation amongst peer and friendship groups. It further appears as though teachers motivate learners to participate in extra mural activities, especially to enhance learners' self-esteem, confidence and to motivate them academically, socially and spiritually. Spiritual development is the growth of the non-material aspects of life, concentrating on personal insight, values, meanings and purpose (Roundy, 2018).

\section{Conclusion}

Learner participants stated that their involvement in extracurricular activities in multicultural schools could also give them a greater chance of being employed; of getting a better job one day; of being accepted into university and of developing certain attributes, such as creativity, innovation, and endurance. The study recommends that multicultural schools in the Letjweleputswa educational district need to implement various extracurricular activities as to develop a range of traits and competencies for their learners- this response of schools could possible cultivate an institutional atmosphere for the development of learners' physical, emotional, cognitive, social, moral underpinnings, problem-solving, academic, life-skills, well-being, leadership skills, analytical skills, and communication skills. Furthermore, extracurricular activities in multicultural schools can increase a learner's social support system, develop social skills and good relationships, which in turn could enhance cohesion amongst learners (Freeman, 2017). Learners who participate in extracurricular activities also develop invaluable competencies required for the forging of good relationships, such as having an inclination to isolate themselves from peers/friends who use alcohol and drugs. Moreover, learners learn a sense of accountability, fair play and morality which inspires them to build positive awareness in peer relationships. 


\section{References}

Barge, M.A. (2015). Complete List of Extracurricular Activities: 100s Examples. [Blog post]. Retrieved from http://blog.prepscholar.com/list-of-extracurricular-activities-examples [Accessed on 3 June 2019].

Dlamini, K. (2017) The significant benefits of early childhood development. [Blog post]. Retrieved from Damelin correspondence: https://www.dcc.edu.za/latest-news/the-significant-benefits-of-earlychildhood-development. [Accessed on 31 October 2019].

Eggen, P. \& Kauchak, D. (2014). Personal, Social, and Moral development. In Eggen, P. \& Kauchak, D. (Limited), Educational Psychology Windows on Classrooms (pp. 79-80). Edinburgh Gate, England: Pearson.

Kapur, R. (2015). Approaches and strategies for holistic social development. Arts and Social Sciences Journal, 6(3): 1-5.

Krishnamurti, J. (2003). Links for visitors unfamiliar with holistic education. Holistic Education. [Blog post]. Retrieved from http://holisticeducation.net/visitors.htm. [Accessed on 16 November 2019].

Mason, D. (2017). Prospects. The importance of extra-curricular activities. [BLog post]. Retrieved from https://www.prospects.ac.uk/careers-advice/applying-for-jobs/the-importance-of-extra-curricularactivities. [Accessed on 17 June 2019].

Poiner, J. (2015). The opportunity gap. Extracurriculars and field trips aren't just for fun. [Blog post]. Retrieved from: https://edexcellence.net/articles/the-opportunity-gap-extracurriculars-and-fieldtrips-aren $\%$ E2\%80\%99t-just-for-fun. [Accessed on 3 November 2019]

Roundy, L. (2018). Physical, social and emotional benefits of participating in sports. [Blog post]. Retrieved from https://study.com/academy/lesson/physical-social-and-emotional-benefits-ofparticipating-in-sports.html. [Accessed on 7 November 2019]

Shava, G.N. (2016). Enhancing learner achievement through professional development. South African Journal of Higher Education, 30(6): 56-72.

Snyder, P.A., Hemmeter, M.L., \& Fox, L. 2015. Supporting implementation of evidence-based practices through practice-based coaching. Topics in early childhood special education, 35(3): 133-143.

Steinberg, L. (2018) What defines a "sport"? [Blog post]. Retrieved from https://www.forbes.com/sites/leighsteinberg/2018/07/28/what-definessport4ac723cf2d6 [Accessed on 27 October 2019].

Thakur, A. (2013). Top 10 benefits of extracurricular activities. [Blog post]. Retrieved from http://topyaps.com/top-10-benefits-of-extracurricular-activities. [Accessed on 9 January 2019].

Wilson, N.L. (2009). Impact of extracurricular activities on students. [Unpublished Master's thesis]. University of Wisconsin-Stout. 


\title{
INITIAL AND IN-SERVICE TRAINING FOR SECONDARY SCHOOL TEACHERS TO IMPLEMENT PROJECT-BASED LEARNING (PBL)
}

\author{
Ana María Ortiz-Colón ${ }^{1}$, Rafael Castellano-Almagro², Javier Rodríguez-Moreno ${ }^{1}$, \\ \& Miriam Agreda Montoro ${ }^{1}$ \\ ${ }^{I}$ Department of Pedagogy, University of Jaén (Spain) \\ ${ }^{2}$ Department of Psyhcopedagogy, College Saint Mary of the Chapel (Spain)
}

\begin{abstract}
The continuous evolution of technology, the gradual abandonment of the industrial society and the increasingly standardised inclusion of emerging methodologies in the teaching and learning processes have a significant impact on the quality and way of life of the people involved in them, making it necessary to integrate them in detail into the education system itself through initial and ongoing teacher training.

This paper reflects on the initial university training that new Secondary Education teachers receive on new methodologies, specifically Project Based Learning (PBL), as well as the ongoing training that current teachers at this educational stage receive for their integration and incorporation as valid methodological systems for their daily classroom practice.

Thus, through an in-depth review of the scientific literature on the subject and our experience as active teachers in the "Master's Degree in Teaching Secondary Education, Baccalaureate, Vocational Training and Language Teaching" at the University of Jaen (Spain), we have addressed these issues, determining that the quality of the pedagogical training of new teachers does not correspond to the reality that they will later face in the classroom, In addition, the in-service training that in-service Secondary teachers receive depends on the intrinsic motivations of the teachers or the manifest resources and legal requirements at the time and not so much on the real needs that the students in the context may require.
\end{abstract}

Keywords: Formation, teachers, secondary education, PBL.

\section{Introduction}

The integration in the educational environment of technological resources that reinforce previously planned activities, the new socialising functions required of teachers, the inclusion of key competences and their evaluative environment, active methodologies that precede the teacher's teaching, collaborative or cooperative methodologies that abandon the individualistic idea of the student body in favour of a collective united in the common good, the new role of the teacher as a guide and not as a model pattern of the teaching-learning process and the loss of the reference value that the school, in general, and the teacher, in particular, represents for society, have generated the conception of strategies that facilitate the adaptation of the teaching work and its training to the challenges that the 21 st century society poses to the academic system (Hernández et al. , 2018; Marcelo and Vaillant, 2017; Monge and Gómez, 2018; Serrano and Pontes, 2017), proposing alternatives such as school-family collaboration (Egido and Bertran, 2017; Garreta, 2016; Parody et al., 2019), structural changes in the education system and in the role of the teacher (Calderón and Loja, 2018; European Commission, 2020; Pallarès et al., 2019; Singh, 2018) and, fundamentally, improvements in initial and in-service teacher training (Lombardi and Abrile, 2020; Santaolalla et al., 2020; Shawer, 2017).

For Senge (2017), teachers in the 21 st century have to teach what they do not know, so they must first unlearn and forget traditional pedagogical methods, innovate in new learning techniques and, therefore, train and relearn everything necessary for the new students in front of them.

On the other hand, some aspects of the quality of teaching have been directly related to teachers in terms of their training and qualifications, didactic programming, educational innovation and research, guidance and evaluation of the system itself (Tello and Aguaded, 2009), which is why there are already several authors who have conducted research on the involvement of teacher training and educational innovation from the teachers themselves (Iglesias et al, 2018; Kovacs, 2017; Monge and Gómez, 2018) since, as stated by De Vicente (2007), if we want to reform the education system, we must address the beliefs and initial training of teachers, generating quality training that is adapted to the current educational 
reality and needs, encouraging its protagonists and motivating them towards continuous development, since simply regulating different ways of teaching or changing curricula will not generate change if teachers do not meet the goals or adapt to the strategies of change through continuous training.

Thus, initial teacher training focused on new methodologies is a key part of change, but defining quality training is not always an easy process or always achieves the expected result.

\section{Initial university training that new secondary education teachers}

Secondary Education is a complex educational stage, in its articulation and development, which involves great efforts at all levels, and requires special attention in which teacher training occupies a prominent place (Esteve, 2006; Moreno, 2015). While Secondary Education was being democratised, reorganised, generating a new curriculum and adapting to the new times, the pedagogical and professional culture in line with it did not follow (Escudero, 2009).

Traditionally, the training of Secondary Education teachers has generated controversy and debate as it requires, to the same extent, academic knowledge or knowledge of a speciality and pedagogical and psychological content (León et al., 2011). Currently, in Spain, if we look at the courses and studies that enable pedagogical and didactic qualification with respect to the basic or initial training required to become a Secondary Education teacher, from the academic year 2009-2010, it will be defined by the Master's Degree in Teaching Secondary Education, Baccalaureate, Vocational Training and Language Teaching (Máster de Profesorado de Educación Secundaria, Bachillerato, Formación Profesional y Enseñanzas Idiomas, MFPES) implemented and regulated by Order ECI/3858/2007, following a complex web of laws, provisions and legal articulation that spans the last 35 years and in which not all teacher training is understood in the same way in all areas, by all agents involved, from all sectors and, broadly speaking, by all educational systems.

The contents with which future teachers are prepared, the professional competences they are expected to generate, the learning they manage to acquire and the opportunities and conditioning factors available to them to be able to develop them provide an essential basis within teacher training (Esteve, 2006) which, together with the involvement of the generic training section with specialisation in a subject and the professional section, which refers to specific training aimed at acquiring the basic requirements for the performance of the teaching profession, both theoretical and practical EURYDICE (2013) determine a wide variety of curricula. In our country, a consecutive model is determined, in which professional training is developed after having received the generic one, manifesting endemic basic problems since future teachers have first been trained as scientists and have generated a scientific professional identity and not that of teacher, the latter emerging as added and subordinated to the former, so it seems logical to think, following Lorenzo, et al, (2015), that the simultaneous model, which incorporates the three dimensions of initial training (general, theoretical professional and practical) in a single organisational structure, is more appropriate for obtaining the necessary requirements to produce good professionals because "teachers must be trained from both science and pedagogy and practice, which leads us to think that it would be more convenient to establish a professional degree" (p.753 ), although this is currently not satisfactorily achieved given the accumulation of problems involved in the design and development of teacher training in our country (Muñoz et al., 2019).

Although motivation for the person who wants to become a teacher must be an indispensable and necessary condition for the successful completion of initial teacher training and is linked to the age at which specific teacher training is accessed and the previous academic training from which it is accessed (Muñoz et al., 2019), working on the basis of the motivations, attitudes and expectations of future teachers, including an increase in practical training periods and the updating of this to active and more appropriate methodologies for 21 st century students, should be the basis on which this training is anchored, so that in this way, they acquire in the best possible way the competences they will require for the development of their professional role adapted to the needs of today's classrooms (Castellano-Almagro, 2020).

On the other hand, in today's 21 st century society, individualised, globalised and multicultural, the values and beliefs that are transmitted to future education professionals are a key element that can help to achieve or hinder the integration into this society of personal development, autonomy, community solidarity, peaceful coexistence and social collaboration, freedom, equity, commitment and respect for diversity (Díez-Gutiérrez, 2020), which is why in initial teacher training, a large part of the future and design of society as a whole is at stake, Although teachers are no longer considered a reference in values or a social or ethical model in today's society, their influence is undeniable in the transmission of some or other values that support or question the established sociological model, these values must be incorporated and made explicit in this initial training (Díez Gutiérrez, 2020). Despite all this, the fulfilment of these needs is currently far from reality. 


\section{MFPES and lifelong learning: active methodologies and ABP}

Although the legislative bases regulating initial teacher training in Secondary Education cover most of the points discussed above, different reasons or motivations have created a gap between the legislated intention and reality, with the new MFPES suffering from almost the same shortcomings as its predecessors: overcrowding, low quality, source of income for the university institution, little participation of secondary school teachers, time limitation of the training period to one academic year and the internship period to a single month, parallel realities and timetables that are difficult to reconcile in a real way and with student involvement, easy exit for frustrated professionals in their own professions for which they were trained, little methodological and didactic updating, etc. which has consolidated an incomplete and limited reform of the same (Gil et al., 2018; Muñoz et al., 2019; Tiana, 2013). Despite the above, the graduates and active noble teachers surveyed on their degree of satisfaction with their professional career and degree of training is good, although they recognise that they do not have sufficient competences when they first arrive in the classroom (Sonlleva, et al., 2019; Zurita et al., 2017), which means that teachers' perception of their own preparation to exercise the profession and be able to develop a fundamental role in the education system does not correspond with the initial training they receive or with the existing reality (Lorenzo et al., 2015). Despite this, other studies do point out the defects and weaknesses of this initial training, especially in the methodological aspect (Castellano-Almagro, 2020).

On the other hand, although the training of Secondary Education teachers has been adapted to the European Higher Education Area (EHEA) by requiring a Master's degree, with a minimum duration of 60 credits, this has not been the case in other aspects such as methodology, as the application of active methodologies focused on the student and aimed at the development of key competences and the basis for a society in continuous change, globalised and technified, has not yet been contemplated in its entirety. Although it is necessary to be trained in methodology and to experiment with it in order to be able to subsequently apply it (Pegalajar, 2015), there have been numerous experiences in the application of active methodology in the MFPES (Caldeiro et al., 2018; López, 2015) and others specifically in PBL (Imaz, 2015; Molina, 2019; Navarro et al, 2015; Salido, 2020), all of them positive and with encouraging results, but they are only specific aspects of a globality that shows how far there is still to go and the need for "PBL in initial teacher training to become a long-term experience and to be characterised by the breadth of knowledge, as this is the orientation that this model should acquire in non-university education classrooms" (Salido, 2020).

With regard to lifelong learning, and based on the methodological change implied by the national education law, LOMCE (2013), the Education Administration took a leading role in it, making possible a range of teaching resources of methodological quality available in digital media, promoting the use of ICT, virtual learning environments, etc., all supported by heavy investments that will lead to different results. However, there is still a need for better and more ongoing training from and for teachers that makes it possible to share successful methodological experiences (Castellano-Almagro, 2020), with greater temporality for practice and avoiding the development through a set of fixed and consolidated modalities that have been so poorly valued by the teachers involved (Bazán et al., 2010; Escudero, 2017).

At present, we can find many lifelong learning plans, but there is little innovation, resorting to training systems whose content, learning and practices are rarely implemented in the classroom (Imbernon, 2016). The remedy is to improve the design of the content of this training, seeking to incorporate the demands of daily teaching practice so that it is possible to improve and solve priority professional problems in differentiated contexts (Bazán et al., 2010) by combining training and practice.

\section{Conclusion}

Bearing in mind all of the above, it is essential when facing, debating or designing initial and in-service teacher training to consider and have clear answers to key questions such as: What is the profile of the teacher we are trying to obtain or the challenges they are going to face? What are the social, economic, academic, cultural, etc. objectives they must achieve in the development of their profession? What are the essential values that we must transmit to our teachers so that they can also be educators? What is the hidden curriculum that prevails among students and what impact does it have on them? What are the professional competences that they are expected to develop, strengthen and put into practice? What are the parameters, therefore, that define a teacher as a competent professional? Is the teacher born or made? Being aware of the need for a fluid and extensive dialogue between all the parties involved in the preparation of this training, analysing in a real and reliable way the needs of future teachers in order to give the best professional response to their future students and to society. 
Generating a simultaneous system, differentiated by stages and with a practical load in accordance with and appropriate to the initial training itself, with a real basis based on active methodologies, is essential for the success of initial teacher training in Secondary Education which, together with the intrinsic motivation of teachers, allows the profession to adapt to the needs of today's students, as we need our education systems to have the capacity to attract and captivate the best candidates to become teachers, through the means available or those available at the time (Marcelo, 2009).

We believe that the creation of lifelong learning groups in action research networks would solve part of the training needs of teachers, being the best context for the inclusion of new methodologies or educational innovation, coinciding with the study by Barba et al. (2018) and for PBL, as shown by Botella and Ramos (2019) in their research.

\section{References}

Barba, R., Sonlleva, M. y García, N. (2018). Presencia, participación y progreso: el aprendizaje basado en proyectos en la trayectoria de una maestra en formación. Revista Electrónica Interuniversitaria de Formación del Profesorado, 21(2), 13-25.

Bazán, A., Castellanos, D., Galván, G. y Cruz, L. (2010). Valoración de profesores de Educación Básica de Cursos de Formación Continua. REICE Revista Iberoamericana sobre Calidad, Eficacia y Cambio en Educación, 4 (8).

Botella, A. y Ramos, P. (2019). Investigación-acción y aprendizaje basado en proyectos. Una revisión bibliográfica. Perfiles educativos, 41(163), 127-141.

Caldeiro, M., Sarceda, C. y García, R. (2018). Innovación e investigación en educación superior: desarrollo de competencias digitales y aplicación de metodologías activas en futuros docentes de FP. En R. Roig-Vila (Ed.), El compromiso académico y social a través de la investigación e innovación educativas en la Enseñanza Superior (pp. 1212-1221). Barcelona: Octaedro

Calderón, P. y Loja, H. (2018). Un cambio imprescindible: el rol del docente en el siglo XXI. ILLARI, (6), 35-40.

Castellano-Almagro, R. (2020). Aprendizaje basado en proyectos (ABP). Análisis de las necesidades formativas del profesorado de educación secundaria (Tesis Doctoral). Jaén: Universidad de Jaén.

De Vicente, P. (2007). Variaciones sobre un vínculo inquebrantable: el papel de las nuevas tecnologías en el desarrollo profesional docente. En J. Cabero (Ed.) Nuevas tecnologías en la formación flexible y a distancia (pp. 127-158). Sevilla: Kronos.

Díez-Gutiérrez, J. (2020). Valores transmitidos en la formación inicial del profesorado. Educar, 56(1), 129-144. https://doi.org/10.5565/rev/educar.1079

Egido, I. y Bertran, M. (2017). Prácticas de colaboración familia-escuela en centros de éxito de entornos desfavorecidos. Pedagogía Social. Revista Interuniversitaria, 29, 97-110.

Escudero, J.M. (2009). La formación del profesorado de Educación Secundaria: Contenidos y aprendizajes docentes. Revista de Educación, 350, 79-103.

Esteve, J. (2006). La profesión docente en Europa: perfil, tendencia y problemáticas. La formación inicial. Revista de Educación, 340, 19-40.

European Commission/EACEA/Eurydice, (2020). Equity in school education in Europe: Structures, policies and student performance. Eurydice report. Luxembourg: Publications Office of the E.U.

EURYDICE (2013). Key Data on Teachersad School Leaders in European. Brussel: Publications EU.

Garreta, J. (2016). Fortalezas y debilidades de la participación de las familias en la escuela. Perspectiva Educacional, 55(2), 141-157.

Gil, R., León, A., Calderón, D. e Íñigo, V. (2018). Evaluación de competencias en el Máster en Formación de Profesorado: un estudio exploratorio en una actividad de foro. Revista Educación y Tecnología, 12, 1-16.

Hernández, R., Orrego, R., y Quiñones, S. (2018). Nuevas formas de aprender: La formación docente frente al uso de las TIC. Propósitos y Representaciones, 6 (2), 671-685.

Iglesias, M., Lozano, I. y Roldán, I. (2018). La calidad e innovación educativa en la formación continua docente: un estudio cualitativo en dos centros educativos. Revista Iberoamericana de Educación, 77(1), 13-34. https://doi.org/10.35362/rie7713090

Imaz, J. (2015). Aprendizaje Basado en Proyectos en los grados de Pedagogía y Educación Social: “Cómo ha cambiado tu ciudad?” Revista Complutense de Educación, 26(3), 679-696.

Imbernón, F. (2016). Los retos educativos del presente y del futuro. La sociedad cambia, ¿y el profesorado? Revista Internacional de Formação de profesores, 1, 121-129. 
Kovacs, H. (2017). Learning and Teaching in Innovation: why it is important for education in $21 \mathrm{st}$ century. Neveléstudomány, 5, 45-60. Doi:10.21549/NTNY.18.2017.2.4.

Lombardi, G. y Abrile, M. (2020). La formación docente como sistema: de la formación inicial al desarrollo profesional, en C. Velaz y D. Vaillant (Eds.), Aprendizaje y desarrollo profesional docente (pp. 59-66). Madrid: Santillana y EOI.

López, F. (2016). Metodología participativa en la enseñanza universitaria. Madrid: Narcea

Lorenzo, J., Muñoz, I. y Beas, M. (2015). Modelos de formación inicial del profesorado de Educación Secundaria en España desde una perspectiva europea. Revista Complutense de Educación, 26(3), 741-757.

Marcelo, C. (2009). Los comienzos en la docencia: un profesorado con buenos principios. Profesorado. Revista de currículum y formación de profesorado, 13 (1), 1-25.

Marcelo, C. y Vaillant, (2017). Desarrollo profesional docente ¿Cómo se aprende a enseñar? Narcea.

Molina, M. (2019). El Aprendizaje Basado en Proyectos (ABP) en la formación metodológica del profesorado del Grado de Educación Primaria. Enseñanza \& Teaching, 37(1), 123-137.

Monge, C. y Gómez, P. (2018). Implicaciones de la formación e innovación en la mejora de la calidad educativa. En C. Monge López y P. Gómez Hernández (Coords.), Innovando la docencia desde la formación del profesorado (pp. 23-46). Madrid: Síntesis.

Moreno, A. (2015). Enfoques en la formación docente. Ra Ximhai, 11 (4), 511-518.

Muñoz, G., Rodríguez, P. y Luque, M. (2019). La formación inicial del profesorado de educación secundaria en España: perfil y motivaciones del futuro docente. Educación XXI, 22(1), 71-92.

Navarro, I., González, C. y Botella, P. (2015). Aprendizaje Basado en Proyectos: diferencias percibidas en la adquisición de competencias por el alumnado universitario. Revista de Psicología y Educación, 10 (1), 55-76.

Pallarès, M., Chiva, O., Planella, J. y López, R. (2019). Repensando la educación. Perfiles Educativos, 41(163), 123-137.

Parody, L., Santos, M., Alcalá, M. y Isequilla, E. (2019). El desafío educativo del siglo XXI: relevancia de la cooperación entre familia y escuela. Espiral. Cuadernos del Profesorado, 12(24), 19-29.

Pegalajar, M. (2015). Metodología docente en el máster de formación de profesorado de educación secundaria: valoración del alumnado. RUSC. Universities and Knowledge Society Journal, 12(3). págs. 61-71. doi http://dx.doi.org/10.7238/rusc.v12i3.2246

Salido, P. (2020). Metodologías activas en la formación inicial de docentes: Aprendizaje Basado en Proyectos (ABP) y educación artística. Revista de Currículum y Formación de Profesorado, 24(2), 120-143. DOI: 10.30827/profesorado.v24i2.13565

Santaolalla, E., Urosa, B., Martín, O., Verde, A. and Díaz, T. (2020). Interdisciplinarity in Teacher Education: Evaluation of the Effectiveness of an Educational Innovation Project. Sustainability, 12, 6748, 1-23. doi:10.3390/su12176748

Senge, P. (2017). El profesor del siglo XXI tiene que enseñar lo que no sabe. El País. Retrieved, March 2, 2021 from: https:/elpais.com/economia/2017/01/15/actualidad/1484514194 176496.html

Serrano, R. y Pontes, A. (2017). Diferencias entre expectativas y logros en las competencias del Prácticum del Máster de Formación del Profesorado de Enseñanza Secundaria. Revista Electrónica Interuniversitaria de Formación del Profesorado, 20(1), 1-18.

Shawer, S. (2017). Teacher-driven curriculum development at the classroom level: Implications for curriculum, pedagogy and teacher training. Teaching and Teacher Education, 63, 296-313.

Singh, O. (2018). Role of Teachers in 21th Century: Opportunities and Challenges. International Journal of Scientific Research and Review, 7 (5), 1-7. https://www.researchgate.net/publication/342233089

Tello, J. y Aguaded, J. (2009). Desarrollo profesional docente ante los nuevos retos de las tecnologías de la información y la comunicación en los centros educativos. Pixel-Bit. Revista de Medios y Educación, 34, 31-47. http://www.redalyc.org/articulo.oa?id=36812036003

Tiana, A. (2013). Los cambios recientes en la formación inicial del profesorado en España: una reforma incompleta. Revista Española de Educación Comparada, 22, 39-58

Zurita, F., Viciana, V., Padial, R. y Cepero, M. (2017). Niveles de satisfacción hacia el grado de maestro en alumnos de último curso. Revista de Currículum y Formación del Profesorado, 21 (1), 349-367. 


\title{
THE INTERDISCIPLINARITY OF FORENSIC SCIENCES IN THE EDUCATIONAL SPHERE: AN ANALYSIS OF THIS CONTEXT IN SECONDARY SCHOOL
}

\author{
Shirlene Carmo ${ }^{1}$, Luís Souto ${ }^{2}$, \& Carlos Silva ${ }^{3}$ \\ ${ }^{1}$ Department of Exact and Natural Sciences, Federal Rural University of the Semi-Arid Region (Brazil) \\ ${ }^{2}$ Department of Biology, University of Aveiro (Portugal) \\ ${ }^{3}$ Department of Education and Psychology, University of Aveiro (Portugal)
}

\begin{abstract}
Many students when entering higher education, mainly in courses of exact or natural sciences and engineering, have difficulties in following the initial contents taught, due in part to the lack of knowledge arising from unique traditional methodology applied during their training. Some graduations even promote leveling courses in order to try reducing the deficits brought from previous education. Subjects such as Differential and Integral Calculus that are on the curricular basis of these courses, show high failure rates, strongly linked to gaps in previously acquired knowledge in mathematics. These factors directly contribute to the increase in retention rates and school dropout. So, there is a relentless search for improvement in the teaching-learning of these sciences, in order to motivate students, still in required education to knowledge building. It is commonly observed that young people are very attracted to the scientific disclosures broadcast by the media, as can be seen in the investigative series, which use forensic expertise for solving cases of a judiciary nature. In this sense, this work aimed to summarize studies that have been developed and implemented about the use of forensic sciences in the promotion of teaching-learning in secondary schools. The methodology was based on exploratory qualitative research. The results are based on experiences that occurred in the school context in USA, Brazil and Portugal, where it appears that students are more involved in the development of educational activities when integrated in a forensic like context, benefiting from collaborative work when trying to arrive to a common goal, similar to the assignment of a true forensic scientist. This allows them to recognize the importance of these contents, facilitates the presentation before the classroom, while improving the interaction with the social environment in which they are inserted. Teacher's feedback confirms the beneficial implementation of these activities in the educational context and considers it with potential to attract attention and awaken the interest of these students in the sciences, thus improving the comprehension of theoretical concepts of the contents integrated in the school curriculum. The interdisciplinarity implemented on the production and socialization of knowledge is necessary and decisive to promote effective teaching and learning. The Forensic Sciences contemplate this interdisciplinarity and contribute that students feel more involved and motivated in learning, reducing retention rates and school dropout and increasing the search for science and technological careers.
\end{abstract}

Keywords: Teaching-learning, scientific methodology, criminal investigation, school dropout, CSI effect.

\section{Introduction}

According to D'Ambrosio (1996), education should strategically develop in individuals, promoting stimuli that contribute to individual and collective relationships to be developed in a given culture. Science education is seen as essential since the first years of schooling, because it prepares students for a more adapted social experience and a qualified professional life. Silva, Vieira and Ferreira (2017) address points that directly affect the teaching-learning process, including the school structure, the absence of science laboratories and inadequate teacher training.

In Brazil is high number students that enter Universities, especially in courses of exact and natural sciences, which presenting difficulties due to failure in the learning process throughout their compulsory education, especially when they come from public schools, where there is a strong absence teacher with training in the area and little didactic support structure for development of teaching. 
Until 2018, according to ODCE (2020), the proportion of young adults without a complete secondary school education in Brazil was still large compared to other developed countries. On average, in OECD countries, $47 \%$ of young people (aged 18 to 24 ) have left the educational system, which is closely related with the transition from high school to college. Also according to ODCE (2020), Brazil, Colombia, Israel and New Zealand, more than $65 \%$ of these young adults aren't longer studying. Brazil has two concerns: raising the quality of education, as developed countries also seek, and raising school attendance.

Especially nowadays, the dissemination of scientific knowledge transcends the need and becomes a daily challenge in educators' lives. The educator needs to reinvent himself, reform himself, and mainly, develop works and research based on subjects or problems in his daily life, this will make all this mobilization for teaching-learning become something significant for such.

To understand the disciplines of the exact and natural sciences, whose are integrated in the natural sciences, mathematics and their technologies, according to the areas of knowledge in secondary school as per article 35 LDB (Brazil, 2017a), isn't an easy task for many students, because different contents are difficult to assimilate, especially when taught by traditional method, considered by many students as tedious and preachy. This demotivation has increasingly contributed to academic retention and dropout rates.

Articles arranged by (Brasil, 1996) and (Brasil CNE, 1998) aim to be a learning guide to a greater contextualization, an effective interdisciplinarity and a broader human formation, not only technical, but already advise a greater relationship between theory and practice in their own learning process.

In the incessant search to improve education, Forensic Sciences (FS) emerge as a scientific methodology, where its content naturally lends itself to learning based on constructivist research, because students are asking questions constantly, evaluating evidence and use critical thinking to provide explanations for the issues under analysis.

FS is the science application that answers questions of legal importance, thus it plays a crucial role in the resolution of criminal and civil investigations (Hemanth, Tharmavaram and Pandey, 2020). In addition, its broad, diversified and integrating context allows it to interconnect several areas of knowledge and science, such as Mathematics, Physics and Chemistry, Medicine, Engineering, which makes it an interdisciplinary science.

In recent years, the FS have been gaining space and attention for their great contribution to resolution of judicial cases. Through this high interest on the part of the general population, the so-called "CSI effect" appears, which has given young people, in particular, a great motivation for the area.

Given the above, this theme becomes extremely relevant when it comes to be worked in the classroom, as the methodology is student-centered, allowing that student to develop critical thinking and reasoning, in addition to creativity and independence in the classroom, seeking to integrate various disciplines, thus expanding the range of observations and everyday social life phenomena. The use of this tool promotes scientific literacy, the search for scientific technological careers and is a strategy to decrease dropout and retention rates.

In this sense, this work aimed to synthesize the studies that have been developed and implemented in FS as a pedagogical practice in the promotion of teaching-learning in secondary schools. Due to its interdisciplinary nature, this scientific methodology allows to contextualize, through motivating and challenging facts, various disciplines within the school education.

\section{Methodology}

The present study was based on a qualitative approach located within the exploratory research paradigm by a systematic literature review. Qualitative design was appropriate for this study, because it provides consistent information about the context and provides an understanding of the factors being observed (McLeod, 2017). The study explored pedagogical practices around Forensic Sciences adopted in the educational context of secondary education in the USA, Brazil and Portugal. The analyzes were identified from research with qualitative and quantitative approaches, where it was possible to attest to improvements in interest and performance in the exact and natural sciences subjects, which are largely responsible for the retention rates and school dropout in secondary education.

\section{Findings and discussion}

Secondary school has been a focus on many educational researches around the world and, in relation to Brazilian educational system, it is the level of education that provokes the biggest debates, whether due the persistent problems of retention and school dropout; for the lack of curriculum attractiveness; for the quality of the education offered or even, for discussion about their identity (Souza, 2016). Search for methodological alternatives that promote students' interest and motivation, especially in teaching in the exact and natural sciences, becomes increasingly indispensable. 
At an international level, Saccaro et al. (2019) found that dropout in Higher Education is the result of several reasons, among which is the quality education in compulsory schooling. Differential and Integral Calculus disciplines, for example, inserted in courses of exact and natural sciences, and Engineering, they present high retention rates, resulting many times, from the lack of background knowledge in physics and mathematics acquired during their previous training. (Bigotte de Almeida; Queiruga-Dios; Cáceres, 2021).

Students' Science, Technology, Engineering and Mathematics (STEM) have more likely to drop out of course that students in different areas of knowledge, they instead providing motivation for the technical-scientific area, end up being a barrier one for professional access, contributing for reduction more and more to choose a STEM career (Costa, 2020).

The search for scientific methodologies that provide motivation and interest for exact and natural sciences, make the Forensic Sciences with high didactic potential for students' learning and intellectual development in their knowledge construction, which is essential for social and professional experience. These allow advances in the concepts and processes explained in the classroom. Thus, several studies have been developed in order to validate the insertion of this methodology in the school context as a strategy to improve the teaching-learning process.

Raza (2012) applied a mixed approach of quantitative and qualitative nature to secondary school students, where research-based instruction in the forensic context examined its influence on the use of higher-order thinking skills (HOTS) and development characteristics of scientific literacy. The quantitative data revealed an increasing level of higher-order thinking across the sequence of topics and an improved use of these skills as the forensic science curriculum progressed. The qualitative analysis indicated as main results, benefits of collaborative work in the problem-solving process, HOTS in knowledge formation and connections between classroom learning and real-world applications. The results of this study indicated that forensic science can be used as a pedagogical practice to promote scientific literacy.

The research developed by Rocha, Garrido and Garrido (2014), experiments containing interdisciplinary themes involving forensic sciences were tested in natural science classes. The proposed experiments proved to be easily adapted to the reality of these schools to promote the learning of natural sciences disciplines, especially chemistry and biology. In an analysis based on interviews applied to secondary school students, it is observed that there is an absence of practical teaching in the natural sciences subjects, and about $94 \%$ of these students have great interest in improving learning through practical classes, especially when these classes are contextualized related to criminal expertise themes. $90 \%$ of the interviewed students had already watched investigative films and series, this finding opens an important opportunity to bring scientific knowledge in natural sciences for all students, since they indicated that these contents didn't arouse their interest. They also demonstrated that the use of topics related to Forensic Sciences inserted in the scientific bases teaching would provide more motivation and certainly result in great benefits to the teaching-learning process.

Souto et al. (2015) proposed the use of a Forensic Sciences Educational Kit, designed to be used by secondary school students under the teacher's supervision. From activities that explore forensics cases, it was possible to relate these activities to curricular subjects, such as Biology, Chemistry, Physics and Mathematics. The teachers' feedback confirms the beneficial results through the implementation of these activities in the educational context and considers it with great potential to attract attention and arouse the interest of these students for sciences, thus improving students' learning by developing their understanding of the theoretical concepts in the school curriculum. They also believe that the Educational Forensic Kit can be additional to other educational resources, contributing to minimize the lack of interest and school students dropout at critical ages, as well as contributing to the motivation in educational agents.

Munayera (2018) investigated the use of a suspense paradidactic book about real facts in Forensic Sciences. The technique used in this scientific methodology implementation allowed the use of chemical science topics taught in the secondary school to promote students' productive disciplinary engagement, once they were motivated to solve the cases present in the book, through an investigative analysis. The results allowed us to realize, from a qualitative analysis, the interest, motivation, performance and students' engagement in classes during the performance of this practice. The students were able to understand-experience a new way of scientific concepts and ideas worked in the school context.

Santos and Amaral (2020) applied in their study an activities series related to Forensic Chemistry to promote a meaningful chemistry learning. The action research approach was a qualitative type applied to secondary school students. The activities involved crime-solving. The results showed Forensic Chemistry as a contextualizing theme in the chemistry teaching, improved greater involvement, interest and motivation for students. Analyzing the entire progress of the research, from a previous analysis, during and after the development of the activities, it is possible to perceive the promotion of a potentially meaningful learning by using this method. 
In work developed by Lino, Sá e Silva (2020) they used a learning model including Forensic Sciences interactions aiming to establish new pedagogical motivational practices for 3rd year secondary students. The practice was based on the crime scene simulation made up of several pieces of evidence distributed throughout the scene. This enabled an effective participation of students in the proposed activities around the criminal expert routine. The data indicate that the natural sciences still face a low acceptance among students, however the forensic practices simulations inserted in didactics in the classroom, contributed to scientific stimulation of students by the interconnection between theory and practice, promoting curiosity and helping them to keep them motivated within the teaching-learning process.

The inclusion of forensic scientific topics in school didactics improves students' participation in active learning and contributes to use of critical thinking skills, to scientific literacy and to interpersonal relationships through collaborative work. Interdisciplinarity contextualization of forensic themes contents, in addition to benefiting learning stimulate interest for technological areas in which these sciences are inserted.

\section{Conclusions}

Subjects such as Physics, Mathematics, Chemistry and Biology, aren't always favored by students, many find boring subjects, they think they just won't use those concepts in life. The insertion of Forensic Sciences as a scientific methodology of an interdisciplinary complementary nature to other educational resources, allows the observation of real-life phenomenon present in everyday and contributes to the autonomy of secondary school students, allowing them to feel more involved and motivated in learning, thus providing an improvement in teaching-learning in the exacts and natural sciences, consequently, reducing retention rates and school dropout in curricular components. An interdisciplinary approach presented in Forensic Sciences, provides to teaching these sciences, a methodology centered on the student, allowing him to develop a greater engagement in learning, seeking to integrate various disciplines, thus expanding the range of observations and social phenomenon of everyday life. The reflection of these proposed actions leads to benefits in a horizon that goes beyond the barrier to secondary school, can be observed in a more qualified basic education in the student who reaches higher education and will be decisive for his success during the course.

\section{References}

Bigotte de Almeida, M.E.; Queiruga-Dios, A.; Cáceres, M.J. (2021). Differential and Integral Calculus in First-Year Engineering Students: A Diagnosis to Understand the Failure. Mathematics, 9(1), 61. Retrieved Jan 18, 2021, from: https://doi.org/10.3390/math9010061

Brasil. Lei $\mathrm{n}^{\circ} 13.415$, de 16 de Fev de 2017. Altera as Leis $n^{\circ}$ 9.394, de 20 de dezembro de 1996, que estabelecem as diretrizes e bases da educação nacional. Diário Oficial da União, Brasília, DF, 17 fev. 2017. Retrieved Jan 15, 2021, from http://www.planalto.gov.br/ccivil_03/_Ato20152018/2017/Lei/L13415.htm\#art3

Brasil. Lei n ${ }^{\circ}$ 9.394, de 20 de dezembro de 1996. Estabelece as diretrizes e bases da educação nacional. Diário Oficial da União, Brasília, DF, 23 dez. 1996. Retrieved Jan 10, 2021, from http://www.planalto.gov.br/ccivil_03/leis/19394.htm

Brasil. Ministério da Educação. Conselh̆o Nacional de Educação. Parecer CNE/CP n ${ }^{\circ} 11 / 2009$. Proposta de experiência curricular inovadora do Ensino Médio. Brasília, DF, 2009. Retrieved Jan 10, 2021, from http://portal.mec.gov.br/index.php?option=com_docman\&view=download\&alias=1685pcp011-09-pdf\&category_slug=documentos-pdf\&Itemid $=\overline{3} 0192$

Costa, H. A. (2020). Determinant factors of evasion in brazilian's private higher Education Institutes. Work Project (Master's Degree in Management). Nova School of Business and Economics and Insper, Carcavelos - PT. Retrieved Fev 25, 2021, from: http://hdl.handle.net/10362/108609

D’Ambrosio, U. (1996). Educação Matemática: Da Teoria à Prática. (Coleção Perspectivas em Educação Matemática). Campinas: Papirus.

Dias Filho, C. R.; Antedomenico, E. (2010). A perícia criminal e a interdisciplinaridade. Química Nova na Escola, v. 32, n. 02, p.67-72. Retrieved Fev 22, 2021, from: http://qnesc.sbq.org.br/online/qnesc32_2/02-QS-6309.pdf

Hemanth, K.; Tharmavaram, M.; Pandey, G. (2020). History of Forensic Science. Technology in Forensic Science: Sampling, Analysis, Data and Regulations, p. 1-16, Wiley-VCH. 
Lino, M.; Sá, M.; Silva, C. (2020). Ciência Forense: Uma abordagem da identificação humana no ensino de ciências. International Journal Education and Teaching (PDVL), 3(2), 31 - 49. Retrieved Mar 03, 2021, from: https://doi.org/10.31692/2595-2498.v3i2.133

Munayera, T. K. A. (2018). Utilização de contos de suspense e atividades investigativas no processo de ensino e aprendizagem de química na educação básica: uma proposta de um paradidático sobre ciência forense. Dissertação (Mestrado Profissional em Ensino de Ciências). Universidade Federal de Ouro Preto, Ouro Preto - MG. Retrieved Fev 17, 2021, from: http://www.repositorio.ufop.br/handle/123456789/9914.

OECD (2020), Education at a Glance 2020: OECD Indicators, OECD Publishing, Paris. Retrieved Jan 30, 2021, from https://doi.org/10.1787/69096873-en.

Raza, G. B. (2012). Using Forensic Science as a Context to Enhance Scientific Literacy. Ph.D (Doctor of Philosophy). Columbia University. New York, EUA. Retrieved Fev 15, 2021, from https://academiccommons.columbia.edu/doi/10.7916/D8ZW1T8K/

Rocha, G. X., Garrido, F., \& Garrido, R. G. (2014). Forensic approach to improving science teaching in high school. Procedia-Social and Behavioral Sciences, v. 116, p. 4293-4296. Retrieved Fev 06, 2021, from https://www.sciencedirect.com/science/article/pii/S1877042814009513

Santos, F. R. dos; Amaral, C. L. C. (2020). Forensic chemistry as a contextualizing theme in the teaching of chemistry. Research, Society and Development, vol. 9, n.3, p. e198932772. Retrieved Fev 22, 2021, from http://dx.doi.org/10.33448/rsd-v9i3.2772.

Silva, A. F. da; Ferreira, J. H.; Vieira, C. A. (2017). O ensino de ciências no ensino fundamental e médio: reflexões e perspectivas sobre a educação transformadora. Revista Exitus, v.7, n.2, p. 283-304. Retrieved Fev 27, 2021, from: 10.24065/2237-9460.2017v7n2ID314.

Souto, L., Tavares, F., Moreira, H., Fidalgo, R., Pinho, R., Mendes, A., \& Pombo, L. (2016). Forensic Toolbox: Proposta de kit forense educativo. Indagatio Didactica, 8(1), 1709-1723. Retrieved Fev 14, 2021, from https://proa.ua.pt/index.php/id/article/view/11897/7873.

Souza, T. A. (2016). Ciência forense como lugar interdisciplinar no ensino médio: uma experiência docente. Dissertação (Mestrado profissional em Ensino de Ciências). Universidade Federal de Itajuba, Itajuba - MG, Retrieved Mar 02, 2021, from: https://repositorio.unifei.edu.br/jspui/handle/123456789/469 


\title{
SCHOOL-BASED IN-SERVICE TEACHER TRAINING IN LITERACY
}

\author{
Abha Gupta, \& Guang Lea Lee \\ Department of Teaching and Learning/Old Dominion University (USA)
}

\begin{abstract}
The current study is based on a year-long collaboration between a school and a university regarding professional development training of teachers who taught $4^{\text {th }}$ and $5^{\text {th }}$ grade students in an elementary school in the USA. The three-pronged focus of the study was on teacher knowledge, pedagogy and student achievement. We examined how the teacher capacity building affected the performance of underachieving students in Math and Literacy. Students' disaggregated test data was used to meet differential needs of students. Underachieving students were targeted with specific strategies, projects, problems solving stories, self-reflection, higher level thinking questions, to motivate students. Participating students' performance was measured with respect to literacy achievement. Quantitative and qualitative measures were used for data collection purposes. Students showed progress over previous years in reading scores. The results were positive and showed progress over previous years with respect to student achievement. Overall, 93 percent of students passed the writing test. In addition, the benchmark data revealed improvements during the year in reading, editing and writing scores for both $4^{\text {th }}$ and $5^{\text {th }}$ grade students. For three of the four pre and post-test comparisons, the gain in scores was statistically significant.
\end{abstract}

Keywords: Professional development training, site-based teacher training, literacy training, teacher capacity building in knowledge, pedagogy and student-achievement.

\section{Introduction}

Current standards for students' learning have been developed by the state over the past two decades and are inclusive of both content and practice standards, called Standards of Learning (SOL https://www.doe.virginia.gov/testing/sol/standards_docs/). The idea behind the standards is to ensure that all students receive high quality education. The standards are defined for each subject and each grade. The standards set the goals and annual tests are administered at the end of the year to gauge whether students meet those goals. This puts tremendous pressure on schools to have their students pass the SOLs. This pressure gets trickled down to teachers and, in turn, to the students. All schools are required to publish the results of their SOLs in the form of a "Report card". Funding for the schools is based on the report card, thus high stakes are involved in testing. To support educators in their implementation of these standards, schools provide ongoing training workshops for the teachers. As the expectations for instructional practice have been raised, there is a need for more focused professional development in which teachers develop knowledge and pedagogical skills to support the implementation of these practices in the classroom. Effective professional development is fundamental for teachers to enhance their knowledge, pedagogies, and conducting regular needs assessments to collect data which guides professional learning is crucial (Darling-Hammond, et al., 2017).

Professional development refers to teachers developing and improving their skills to better meet the needs of their students. Characteristics of effective professional development have been identified from the literature (Desimone, 2009; Rotermund, S., DeRoche, J., \& Ottem, R. (2017) and widely endorsed by the field (e.g., Lindmeier et al., 2020; Main \& Pendergast, 2015; Richardson, Miller, $\&$ Reinhardt, 2019). The need for professional development has gained increasing momentum in the current educational practices. Various research studies have highlighted the importance of providing ongoing training of in-service teachers to improve teacher quality (Day, 2002; Niemi, 2015).

Darling-Hammond et al. (2017) conceptualise teacher professional learning "as a product of both externally provided and job-embedded activities that have the potential to increase teachers' knowledge and bring about change in their instructional practice in ways that support student learning". Ajibade \& Bertram (2020) describe the perceptions of selected teachers regarding professional learning and development experiences. In a study to build teachers' capacity to integrate science and math content, Aguirre-Munoz et al. (2021) found that the combination of content knowledge and teacher feedback should be targets of extended professional learning. 


\section{Design}

The mixed method evaluation design used both qualitative and quantitative data to examine participant perceptions and experiences, methods of instruction, and student achievement. To that end, we relied on various data sources to address the research questions outlined above. These sources included teacher questionnaires, teacher grades in the course, classroom observations, and student achievement scores related to reading. The study analyzed data from the teacher participants, classroom observations, and analysis of student achievement data. Descriptive qualitative classroom observations were conducted in all $4^{\text {th }}$ and $5^{\text {th }}$ grade classrooms. The items on the questionnaires and observation instruments were designed to reflect the focus of the study. Student achievement data consisted of scores related to reading achievement from the Standards of Learning (SOL) and Benchmark tests.

\section{Objectives}

The purpose of the study was to enhance teacher knowledge, develop pedagogical skills further and improve student achievement. To achieve this purpose, three research questions guided the current study:

1. How well did teachers master the content \& skills in the professional development activities?

2. To what extent were the content \& skills covered implemented in the $4^{\text {th }}$ and $5^{\text {th }}$ grade classrooms?

3. How did $4^{\text {th }}$ and $5^{\text {th }}$ grade students perform on measures related to reading achievement?

\subsection{Methods}

The school that participated in the study was a Title 1 school with nearly 800 students enrolled in grades preK-five. As many as $98 \%$ of the students were African American and $88 \%$ received free or reduced-price lunch (a determining factor toward Title 1 eligibility), which entitled the school to be a Title 1 school. Title 1 is the largest federally funded educational program in the United States of America. The program provides supplemental funds to school districts to assist schools with the highest student concentrations of poverty to meet school educational goals. Based on the state's Standards of Learning (SOL) test scores, the school had been accredited with warning for the previous two years. Schools with this rating receive extra help to improve their standing by developing a two-year improvement plan with the assistance of local agencies. In order to be fully accredited, an average of $70 \%$ of the students enrolled in the school must pass the SOL tests in each subject area at each grade level. Table 1 shows the SOL scores from 3rd and 5th grade level and subject area since SOLs are tested at these two grade levels. An examination of school's scores show that the criterion was not met for $5^{\text {th }}$ grade students in science. In contrast, ninety percent of $3^{\text {rd }}$ grade students received passing scores in science. The criterion was met in all other subjects for both grade levels. In general, the results demonstrate a steady increase in scores by year. There were 23 teachers who participated in the study.

Table 1. Percentage of Students by Grade Level, Subject Area, and Year who Passed SOL Tests at the local school Compared to State Averages

\begin{tabular}{|l|l|l|l|l|l|l|}
\hline Grade/ Subject & Yr1 @ school & State Avg & Yr2 @school & State Avg & Yr3@school & State Avg \\
\hline Grade 4 & & & & & & \\
\hline English & 61 & 72 & 64 & 85 & 70 & 77 \\
\hline Math & 71 & 83 & 34 & 78 & 85 & $\mathbf{8 8}$ \\
\hline History & 74 & 82 & 78 & 87 & 79 & 89 \\
\hline Science & 75 & 82 & 67 & 84 & 90 & 89 \\
\hline Grade 5 & & & & & & \\
\hline English & 68 & 83 & 64 & 85 & 70 & 85 \\
\hline Math & 47 & 74 & 34 & 78 & 70 & 81 \\
\hline History & 65 & 79 & 78 & 87 & 75 & 85 \\
\hline Science & 43 & 80 & 67 & 84 & 40 & 81 \\
\hline
\end{tabular}

\subsection{Intervention}

Nine teachers from grade $4 \& 5$ participated in the study. Each semester, the university's College of Education faculty members assisted to provide various professional development and other activities for the teachers based on the areas of needs that were identified by the teachers and the school principal. The following section describes the interventions aimed at grades 4 and 5 . The total number of students in grade 4 were 84 and in grade 5, there were 80 students. Most professional development activities remained concentrated in reading and language arts.

Throughout the academic year, professors met regularly with the teachers, conducted classroom visits, and provided materials. Over the course of the research project, the support provided moved from 
formal classes and workshop sessions to more informal one-on-one assistance, advice, and modeling. One of the most important things that we learned was the importance of collaboration. University faculty served as a coach or facilitator rather than as an "expert" providing direct instruction through lectures. Decisions were made collaboratively. The topics or strategies emphasized during professional development were based on an informal survey of the teachers' and administrators' needs and requests and aligned with the research objectives and in the areas of reading, math, and student behavior or discipline.

Criteria used for determining effectiveness were objective, and included student participation and achievement. There was concentrated focus on using higher order questioning strategies to challenge students to think more critically. Teachers concentrated on motivational techniques and ways to promote student accountability. Finally, as a final step in the recursive process, student reflection was guided by more challenging questions such as what they learned and critiques of the authors and readings.

In mathematics, the faculty member worked closely with the schools' lead math teacher in the use of test data to guide instructional decisions. Together, they disaggregated the data to tailor instruction to meet individual needs. The program, "Math Buddies", facilitated this effort because it began simply and progressed to different levels depending on individual student progress. Other strategies designed to actively engage students included the use of manipulatives, calculators, and computer applications.

We used projects, problem solving stories, and library research to actively engage and motivate students. Among students exhibiting discipline or behavioral problems, we contacted other adults in the community to enlist them in providing support and discussed how appropriate behaviors might be reinforced. Faculty members visited the parents in their homes, went to their children's little league games to talk to their coaches, and attended their churches to speak to their pastors or Sunday school teachers.

Teacher Questionnaire: The questionnaire was administered to the nine $4^{\text {th }}$ and $5^{\text {th }}$ grade teachers at the end of the school year. The questionnaire contained both a quantitative rating scale and open-ended items. The rating scale items corresponded to the content covered in the course as well as the topics or strategies covered in the professional development workshops.

\section{Results \& discussion}

Among $4^{\text {th }}$ graders statistically significant improvements were found on both reading and editing scores. There was a significant increase on the average percentage of points obtained when comparing pre- and post-test scores in reading $(\mathrm{t}(1,83)=5.44, \mathrm{p}<.001)$. Students achieved an average of 64.73 percent of the points correct on the pretest and an average of 74.97 percent on the post-test. This represents an impressive increase of over 10 percentage points. Similarly, we found a significant increase in $4^{\text {th }}$ graders editing scores $(\mathrm{t}(1,83)=4.23, \mathrm{p}=.001$. Editing scores improved from a mean of 58.05 to 67.35 , reflecting a substantial increase of nearly 10 points. Fourth graders scored well on these tests, and their scores are improving.

Turning to the performance of $5^{\text {th }}$ graders on the Benchmark tests, we found improvements in both reading and writing scores, but only the change in reading scores was statistically significant $(\mathrm{t}(1,79)=3.21, \mathrm{p}=.02)$. Reading scores improved from a mean percentage of 65.27 to 72.70 . Although the mean difference in writing scores did not reach statistical significance, it did approach this criterion $(p=.10)$, and writing scores did improve from pre to post testing. The average pretest score was 59.48 percent and the average post-test score was 63.39 percent. In both areas these scores reflect improvement and bode well for the actual SOL results presented in the next section.

Table 2. Percentage of $5^{\text {th }}$ Grade SOL English Scores by Category and Proficiency Level.

\begin{tabular}{|l|l|l|}
\hline Category & Proficient & Not Proficient \\
\hline Use word analysis strategies & 66 & 34 \\
\hline $\begin{array}{l}\text { Understand a variety of resource } \\
\text { materials }\end{array}$ & 71 & 29 \\
\hline Understand elements of literature & 74 & 26 \\
\hline
\end{tabular}

In response to first research question, according to the teachers themselves the content and skills were very well mastered. This is evidenced by the consistently high mean scores obtained from the rating scale items pertaining to mastery on the questionnaires. This trend was true across the categories of reading, math, classroom management, and more general strategies. Some exceptions to the pattern of high ratings were the relatively lower ratings found on parental and community involvement, the use of software, and student self-reflection or questioning. However, teachers' confidence in their knowledge of the strategies does not always translate into their frequent use in the classroom.

Teachers own ratings of the frequency with which they used the targeted strategies provided indirect evidence of classroom implementation. High mean ratings were obtained on the use of strategies in the areas of reading, math, and classroom management. In these areas, we found teachers used problem 
solving stories, library research for stories, and parental and community involvement less frequently than the other strategies. Overall, the mean ratings in the general strategies' category tended to a bit lower. Teachers reported less use of technology, literacy across the curriculum, student self-reflection, and a focus on cultural or diversity issues. In the area of reading strategies, we most frequently observed the use of webbing and graphic organizers. Student self-reflection, cooperative learning, and a focus on higher-level thinking were among the most frequently used general strategies. Our own observations, pointing to more frequent use of student reflection, appear to contradict teachers' perceptions on how frequently they employed this strategy.

The third and final question was, "How did $4^{\text {th }}$ and $5^{\text {th }}$ grade students perform on measures related to reading achievement?" The results were positive and showed progress over previous years. This was the first year that $5^{\text {th }}$ grade scores in English reached the state benchmark of a 70 percent passing rate. The $5^{\text {th }}$ grade writing scores were even more impressive. Overall, 93 percent of these students passed the writing test.

\section{Conclusions \& limitations}

While the study provided potentially useful findings regarding content-focused professional development, there are some recommendations that are made and limitations that were observed. First, we did not observe or hear reference to parental involvement activities. Increased parental involvement may promote better student conduct, motivation, and academic engagement among students. Our findings suggest that the level of parental involvement could be increased. Teachers rated the item on parental and community involvement lower than other items under classroom management. Research in the real world of schools often precludes the control of variables to isolate cause-and-effect inferences. In particular, because of the simultaneous implementation of several other programs and interventions within the school, it is impossible to establish a causal link between the activities addressed by the intervention and the academic achievement by the students. Finally, our study relied heavily on self-reporting by the teachers. While the teachers themselves are largely responsible for carrying out any educational reforms, and their feedback is crucial, self-reported data may be biased.

\section{References}

Aguirre-Munoz, Z., Yeter, Ibrahim H., S. Loria Garro, Elias, Koca, Faith. 2021. Building Teachers' Capacity to Integrate Science and Math Content: Implications for Professional Development and Learning. Journal of Science Teacher Education, 32(1) 62-84.

Ajibade, B. A., Bertram, C. 2020. How district teacher development centres support teachers' learning: case studies in Kwazulu-Natal, South Africa. Perspectives in Education 38(2), 103-117.

Cunningham, J. (1982). Generating interactions between schemata and text. In J. A. Niles \& L. A. Harris (Eds.), New inquiries in reading research and instruction (pp. 42-47). Washington, DC: National Reading Conference

Darling-Hammond, L., Hyler, M.E. \& Gardner, M. (2017). Effective teacher professional development. Palo Alto, CA: Learning Policy Institute. Retrieved June 2, 2021, from: https://learningpolicyinstitute.org/sites/default/files/product-files/Effective_Teacher_Professional_ Development_REPORT.pdf

Day, C. (2002). Schools as learning communities: Building capacity through network learning. Education, 30(3), 19-22.

Desimone, L. M. (2009). Improving impact studies of teachers' professional development: Toward better conceptualizations and measures. Educational Researcher, 38(3), 181-199.

Lindmeier, A., Seemann, S., Kuratli-Geeler, S., Wullschleger, A., Dunekacke, S., Leuchter, M., Heinze, A. (2020). Modeling early childhood teachers' mathematics-specific professional competence and its differential growth through professional development - an aspect of structural validity. Research in Mathematics Education, 22(2), 1-20.

Niemi, H. (2015). Teacher professional development in Finland: Towards a more holistic approach. Psychology, Society, \& Education, 7(3), 279-294.

Richardson, K., Miller, S., \& Reinhardt, J. (2019). Professional development as an ongoing partnership: The sum is greater than its parts. School-University Partnerships Furthering the Education Profession: Partnerships in Action, 12 (1), 45-50.

Rotermund, S., DeRoche, J., \& Ottem, R. (2017). Teachers professional development by selected teacher and school characteristics: 2011-2012. [Stats in brief]. NCES 2017-200. National Center for Educational Statistics. Retrieved June 2, 2021, from: https://nces.ed.gov/pubs2017/2017200.pdf 


\title{
DISTANCE TEACHING AND PRESENCE TEACHING TOWARDS A POSSIBLE AND USEFUL INTEGRATION
}

\author{
Andrea Tarantino \\ University of Macerata, Department of Education, of Cultural Heritage and Tourism (Italy)
}

\begin{abstract}
The pandemic emergency seems to have extinguished many residual reservations regarding distance learning, but it has created a consensus that is all in all fragile, because it is non-critical and more charged with assimilative pressures.

The problem is not establishing when, where and whether distance learning or face-to-face training should be promoted. The problem is to understand why and to specify, jointly, with which paradigms it is necessary to operate. It is a question of tackling problems that have remained on the sidelines for too long, in order to understand what digital can offer to ordinary teaching and what from ordinary teaching can also be useful for distance teaching. We will stop on two issues only. On the one hand we will try to enhance the logic of the reticularity and composability of knowledge; on the other hand, we will focus on curricular systems, showing how each of these two aspects can benefit both distance and face-to-face teaching and, above all, how it can benefit their possible integration. And this also in order to be ready for the next emergency. Ready, while hoping it won't come.
\end{abstract}

Keywords: Didactics, new technologies, learning, curriculum.

\section{Introduction}

Never before has there been so much talk of presence and distance in the educational field.

And never before has the world known such a devastating pandemic as the one we are still struggling to face and for which it was necessary to make use of everything possible, including the potential offered by digital.

Thus, while the health emergency forced the isolation and reduction of physical contacts between people, with the help of technology we tried to mitigate the effects of distance in the workplace, leisure, sport, religion and therefore also in the world of education.

Presence and distance, however, are not only logistical options, because they have implications that must not escape those involved in training.

The fact that the world of schools and universities were not ready for this spatial displacement of teaching is understandable and this should make us reflect on the digital skills of teachers and on the use that is made of technology when used in presence.

Teachers who were forced by the pandemic to use technologies for the first time have usually relied on the procedural logic of every day, simply transferring online what they did in the classroom.

Re-proposing the same frontal model made up of lectures and interrogations, leaning on the technologies hastily put in place, certainly could not suggest a new teaching system.

Teaching always involves a sort of orchestration of several elements: organization of time and space, design of the environment (real and / or virtual), preparation of tools and methods ... and each of these elements interferes with everything else. You can't change an element and keep thinking as you did before. It would be an operation that is no longer sustainable.

The fact that today we prefer the mobile phone to the telegram or the e-mail to the letter entrusted to the post office does not only change the means of communication, but also the very meaning of communication.

So much so that today we are questioning - and not without good reasons - about the cognitive strategies of digital natives and their different "mental habitat" (Baricco, 2006).

Perhaps we are in the midst of a cultural phase of epochal transition that at least obliges us to a greater critical vigilance around the person's profile, his deepest needs, his way of dealing with dialogue with the group to which he belongs and so on, to discuss the skills and responsibilities of those involved 
in training or, more generally, of those who wonder about the different way of proposing themselves (and interacting) of the needs of the subjective and the social.

The theme of a possible integration between distance teaching and face-to-face teaching should also be placed in this broad framework, which in these pages we approach through two issues, starting from two apparently opposing perspectives, letting us be guided by a reflection on the possible enhancement of the network and composability of knowledge, on the one hand, and, on the other hand, due attention paid to curricular structures, showing that each of these two aspects can benefit both distance and face-to-face teaching and, above all, it can benefit their possible integration.

\section{Design}

\subsection{Knowledge reticularity} allows

Technology, by giving knowledge an increasingly clearly networked and distributed structure,

a) a greater attendance of potentialities in a certain sense forgotten by the mind set on linear rationality (think of abductive thinking, for example);

b) a different and richer approach to demonstration processes;

c) a new and poietic force to cognitive constructivism and therefore also to the processes of construction and use of knowledge, with very fruitful interferences for teaching / learning;

d) an unsuspected strong support for didactic criteria such as flexibility, individualization, social learning, experiential learning ...;

e) a fertile new recovery of theses, insights and proposals gathered from the history of pedagogy and from the history of teaching whose prophetic value is sometimes not understood.

Think, for example, of J. Dewey's discourse on experience, or even more remote researches such as those of Comenius, Pestalozzi, Decroly.

All this has required, requires and entails epistemological adjustments as well. Think, for example, of the revision of the concept of rule (now in fact replaced by the notion of regularity), of the idea of subsidiarity, of the concept of subordination ... And in any case it broadens the boundaries of educational responsibility, while opening new paths for construction of personal identity, for the consolidation of belonging, for the whole discourse concerning motivation and for the support to be ensured to divergent thinking and creativity.

These are perspectives, potentials, indeed, in many cases of authentic new resources conceptual, even before being instrumental - to be enjoyed with equal profit both in face-to-face teaching / learning paths and along multiple distance learning experiences.

The fundamental premise of learning is always and in any case a non-rigid structuring of knowledge, selected and processed, according to regularities that positively interfere with the subjective organization of knowledge no less than with the epistemic representation of disciplinary knowledge, as well as with motivational apparatuses.

Under these conditions we can also argue that teaching practices, designed for distance learning or even for face-to-face teaching "cannot start other than from the subject, from a careful reading of its reality and the need to be a protagonist in one's own knowledge and growth ". The student "cannot be the recipient of closed and purified designs, but the initiator and participant of desirable, modifiable, socially shared and dynamically lived proposals and projects" (Felisatti, 2007, p. 24).

\subsection{Curricular systems}

Similar difficulties are encountered if resources (conceptual and procedural) that are well present and active in face-to-face teaching are neglected. There are sensitivities, points of attention, hermeneutic constraints that cannot be lost only because we act online.

Sometimes school time appears constricting because it is homologated, little attentive to the diversity of learning styles and rhythms, that is, of individual differences and, consequently, of inclusive needs; but the time axis is always present. It is a question of understanding how it acts and how it can contribute to the good governance of the processes.

In the experiences conducted in the emergency phase, two different errors were made (and there is still the risk of them being made). Or the excess of confidence as if the transition to online can by itself remedy critical issues related to the structural structures of teaching; or - on the contrary - the renunciation of safeguarding structural nodes on which the whole teaching apparatus actually holds. In both cases the accused is the curricular system.

Apart, here, from a useful discussion of merit on the notion of curriculum and its many theoretical declinations (Paparella, 2009, v. II), we must take note of the centrality and unavoidability of a device - which we call the curricular model - which functions "as a hermeneutic structure and as a 
functional mediator to be used to interpret, understand, select, explain, choose, decide, compose, organize the entire range of issues concerning the aims, objectives and tools of didactic action in a coordinated manner and according to participation procedures "(Paparella, 2012, p. 169). Without support of this type, teaching is invaded by improvisation and is doomed to inconclusiveness.

That this organizational and hermeneutic support may then derive from thoughtful theoretical choices or from impromptu practical options is a matter that concerns professional ethics and the level of responsibility of the educational operator. The important thing is that at least the need is felt. And, in this case we must say that the experience of face-to-face teaching is certainly more attentive to this type of need.

What we hypothesize here is that even when a remote intervention is organized, curricular-type devices are put in hand.

In the most experienced experiences, the curriculum remains "implicit", and to some extent hidden in the folds of the operating rules of the so-called platforms.

What, instead, we hypothesize is that educators and trainers maintain a generalized habit with curricular devices, in every teaching situation, so that they can responsibly manage the functional link between objectives and purposes, between knowledge contents and experiential procedures, between learning and developmental needs.

Both in face-to-face teaching and in distance teaching, teaching is in fact called, as F. Frabboni said, to "put-in-communication the dimensions of development of the different generational ages (the cognitive and socio-affective" stages "of childhood, adolescence, youth ...) with the symbolic-cultural systems (the "structures" of the culture spread at school and in the after-school, as well as the ethical-social models of the community to which they belong): all within the multiple places of 'education, such as families, schools, associations, churches, the world of work, etc. " (Frabboni, 1998, p. 753).

\section{Possible integration}

In the moment in which shared dynamisms of functioning are identified, as - by way of example - we have found here in the reticular configuration and in the curricular structures, integration becomes possible.

It is no longer a question of juxtaposing, perhaps with a skillful dosage, assigning one hour to the other form of teaching (attendance and distance) according to this or that factor, but it is instead a question of vivifying one and the other with the same dynamisms. This allows those responsible for teaching to decide and choose without prejudice to common parameters and shared processes.

This is how legitimate interdependencies are established and correct principles of organization are maintained. This is how complexity can be governed, also being able to optimize relations and interpretation paradigms: "norming of behaviors, mapping of selections, construction and control of order" become possible objectives (Galliani, 1993, p.91).

\section{In the pandemic season}

If the pandemic has made the comparison with technology easier and more widespread and has made it somehow experiment the ways and potentialities of reticular knowledge, and if, at the same time, the widespread practice of the school with languages, operational styles and scientific literature flourished around the theme of the curricular system, it will be useful not to waste these resources and to work to bring them a system and to make them flow operationally both in distance teaching and in face-to-face teaching.

The path of integration is certainly richer than what is seen through these two functionalities (reticularity and curricularity); but their centrality with respect to the overall didactic structure makes us think that integration is possible. Above all, they make people believe that integration is extremely beneficial.

It makes you think that a new season is about to open, very promising and full of great promise.

\section{Conclusions}

We can say that the pandemic emergency has offered an opportunity for rethinking and reflection on the spaces and times of formation, spaces and times that are not only near and contingent, but also those not close, which open up to virtual horizons. 
This could be an opportunity for training to rethink old prejudices and try to better understand the potential of the virtual. After all, we are well convinced that it is precisely man to create his own world and then inhabit it, and then go even further towards a territory where subjective and objective meet where real and virtual confront each other and, together, open up the paths of innovation.

\section{References}

Baricco, A (2006) I barbari: Saggio sulla mutazione, Feltrinelli, Milano.

Dewey, J. (1949) Esperienza e educazione, Firenze, La Nuova Italia.

Felisatti E. (2007) La didattica come scienza, in Felisatti E., Rizzo, U. (a cura di), Progettare e condurre interventi didattici, Pensa Multimedia, Lecce.

Frabboni, F. (1998) Nel segno e nel nome della didattica. Problematicità e morfologia dell'ambito didattico, in "Studium Educationis", n. 4.

Galliani L (1993). Didattiche come organizzazione sistemica delle azioni formative, in Calonghi L. (a cura di), Il bosco di Chirone, Tecnodid, Roma 1993.

Paparella, P. (a cura di) (2009), Il progetto educativo. Vol. 2: Comunità educante, opzioni, curriculi e piani, Armando Editore, Roma.

Paparella, N. (2012). L'agire didattico, Guida, Napoli. 


\title{
BURNOUT PREVENTION WITH PSYCHOEDUCATION IN TEACHERS
}

\author{
Mónika Veronika Szigeti \\ “Education and Society” Doctoral School of Education, University of Pécs (Hungary)
}

\begin{abstract}
Our research aims at prevention of burnout, which can be a protective factor in preventing career abandonment and can contribute to creating and maintaining a positive workplace climate. It also promotes the mental well-being and resilience of teachers and students. Therefore, burnout of teachers is especially important in Hungary, as the gradually increasing professional and administrative burden, the lack of social esteem, as well as the changed learning-teaching environment and the methodological shortcomings of general teacher training significantly increase the risk of burnout.

In our research, the staff of the Somogy County Educational Service Center has been involved, mainly special education teachers. The 116-person sample has been conducted with a version of the Maslach Burnout Inventory developed for educators. In our presentation, the test results are presented. According to our findings, out of the three subscales of the subjects' questionnaire, the highest scores were achieved in the Emotional Exhaustion subscale and the lowest in the Depersonalization subscale. However, the emotional exhaustion subscale did not indicate a high burnout value in the study population. The correlations of burnout risk with age and time spent as a teacher has been also analyzed.

Problem-focused and change-oriented psychological counseling models are attracting interest in the international literature today (Egan, 2010). By strengthening resilience and supporting a sense of growth, consultation techniques work to strengthen effective interpersonal communication and help the individual plan constructively for the future (Bonanno, 2004, 2005; Kelley, 2005; Linley \& Joseph, 2005; Litz, 2005; Maddi, 2005). All of this are relevant to our research because we plan to provide burnout prevention psychoeducation counseling programs to educators. The literature also mentions the phenomenon of learned helplessness, which has its roots in childhood and is a breeding ground for both depression and burnout (Seligman,1991). Learned inertia can influence members of the helping professions toward passivity (paralysis, loss of control, hopelessness, unresponsiveness) and is therefore particularly burdensome for the individual, along with the challenges of helping professions. Results of our research shed light on the burnout level of special educators, personality traits important for coping and related burnout prevention (e.g., empathy, psychological immune competence) and the applied coping mechanisms that guide burnout prevention psychoeducation as a comprehensive concept.
\end{abstract}

Keywords: Burnout syndrome, psychoeducation, consultation techniques, burnout prevention of teachers.

\section{Introduction}

"Psychoeducation is a professional information transfer method that aims to increase patients' knowledge about their illness and how to cope with it, and to emotionally process problems associated with the illness" (Bagdi, Harkai, Stoll, Ferenc, 2016, p.20). The focus of psychoeducation is on transfer of information and development of coping strategies. Its long-term goal is not to deal with complaints, but to maintain health and - if necessary - therapeutic cooperation, to develop skills and to change attitudes. To all this, the psychoeducation specialist provides information about symptoms of disease, treatment options, and various self-help techniques (Bagdi et al, 2016). It was Carol M. Anderson who began applying it in its current sense in the 1980s and developed a psychoeducational model for family treatment of schizophrenia (Anderson, 1983). A feature based on a synthesis of clinical experience and interdisciplinary research is that it provides information and guidance to help the family understand the symptoms of the disease, the patient's pathology needs, contribute to reducing family stress, and help the family eliminate isolation, by exploring the development potential of social network (Anderson, 1980). Psychoeducation of burnout syndrome should therefore be part of an institutional mental health strategy. Recognition of symptoms, knowledge of psychological, social characteristics of burnout can play an important role in prevention. Self-recognition allows for early therapeutic interventions, preventing more severe symptoms. 
The development of a method of structured and solution-oriented psychological counseling is attributed to Gerard Egan. The use of this method can be particularly useful for professionals at high risk of burnout. The consulting technique focuses on creating rapport, emotional support, helping identify and explore problems and resources, objective possibilities, and articulating realistic goals. An important element of the process is evaluation of results (Egan, 2011). Bonanno $(2004,2005)$ believes that resilient behavior is not as rare as initially thought and is facilitated by several factors. Toughness at the level of cognitive processes, such as personality traits and self-enhancement, as well as emotionally centered repressive coping, positive emotions and laughter contribute to resilient responses to stress. This also support the healthy functioning of personality for a long time. Linley and Joseph (2005) believe that to understand responses to traumatic life events, psychologist need to be familiar not only with process of resilience but also with psychopathology and adversarial growth. Maddi (2005) complements Bonanno's theory by emphasizing that toughness as a personality trait - as a pattern of action and attitude - provides an opportunity for a person to view stressors as a growth rather than a threatening factor.

Presented literature and performed study draw attention to the fact that phenomenon of burnout should also be addressed in the case of teachers of educational services centers. There is a need for continuous monitoring with repeated examinations and mental health assistance should be provided to teachers through psychoeducation, counseling procedures and supportive therapy to help them cope and become more resilient.

There are 19 counties in Hungary, which are the administrative units of the country. The population of the country on January 1., 2021 was 9.73 million (KSH, 2021). Somogy County is the fifth largest in Hungary. It has 248 settlements. It is one of the least populated counties in the country, with a 50 person/ $\mathrm{km} 2$ population density in 2021 , and the total population was 314.551 people on 1 st of January in 2020 (KSH, 2021). There are eight districts in the county, most of them have villages with hard-to reach settlements.

Figure 1. Map of Hungary, highlighting Somogy County (Retrievered: May 05, 2021, from http://www.szabadi.hu/elhelyezkedes).

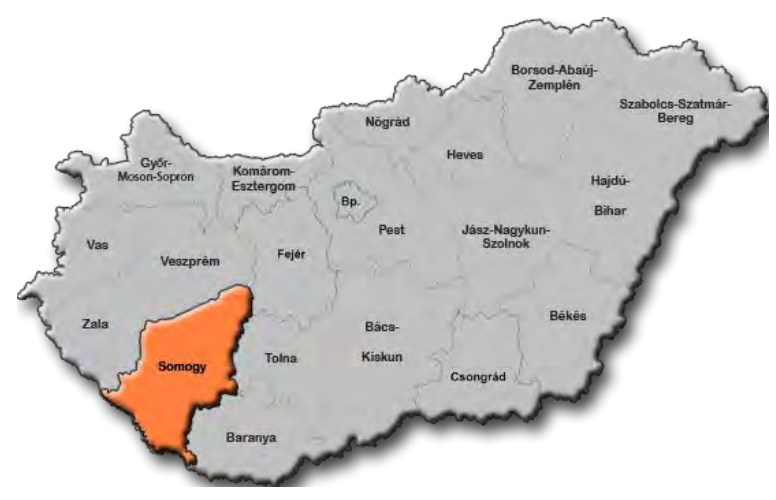

As the Head Director of Somogy County Educational Service Center, I am responsible for professional management of more than 250 colleagues. In addition, I have to monitor the educational and administrative tasks, which comes with a lot of responsibility. In the process, I can experience the high quality of my colleagues' work, which is often performed in less-than-ideal conditions.

The administrative burden is increasing, and we often treat families being in very difficult situation. Due the territorial peculiarities of the county, my colleagues spend a lot of time with traveling. We work with a high level of workload along with long waiting lists, which represents a significant stress potential for both employees and managers. These are also risk factors for burnout. The endangering workplace environmental factors are the following: the work environment does not suit individual needs, therefor the motivation of employees decreases; overburden, which leads to reduction intime, and resources spent on work; strict managerial control, winch prevents the employee from making autonomous decisions about her/his work, within the limits of her/his competence characteristic of the work (long working hours, administrative burdens, role conflicts, crises, poor communication, strict deadlines); lack of social support from colleagues and managers (lack of feedback and autonomy, low participation in decision); characteristics of the profession (continuous work with people, its impact on private life); hierarchy, operating rules (Galletta, Portoghese, Ciuffi, Sancassiani, D’Aloja, \& Campagna, 2016 and Borsi, n.d.).

The description on the definition of burnout syndrome comes from Herbert J. Freudenberger: "Burnout is a state of fatigue to produce the expected reward. It may be defined as the total depletion of physical and mental resources caused by excessive striving to reach an unrealistic work-related goal." (Freudenberger, 1975, p. 73.) 
ICD-11 does not define burnout as a disease. It classifies it as a category of "Factors Affecting Health Status or Contact with Health Services", and it is defined as a syndrome resulting from chronic work-related stress. Improper management of stress contributes to develop the syndrome. The three characteristics of it are the development of a feeling of exhaustion, emotional distance from work, and a decreased sense of professional efficiency. The phenomenon of burnout refers specifically to the occupational dimension, not to other areas of life (ICD-11, 2021).

\section{Goals}

In our research, it is aimed to get to know the burnout level of teachers by examining a group of employees of an institution who perform a special educational task, in the Somogy County Educational Service Center. To this end, the Maslach Burnout Inventory- Educator's Survey questionnaire has been used. Knowing the results of the study, we aimed to develop a mental hygiene program that helps educators' mental well-being, coping with stress, and contributes to resilient behavior. The mental health program includes psychoeducation of burnout syndrome, building on strengthening coping mechanism. In addition, the program provides opportunities for learning relaxation techniques and problem-focused, solution-oriented consultation.

\section{Methods}

\subsection{Presentation of the workplace of the teacher participating in the study: The Somogy County educational service center (Szigeti, 2019)}

The Somogy County Educational Service Center provides the professional service tasks specified in the Hungarian National Public Education Law (CXC. Law of 2011 on National Public Education) in 245 settlements. In addition, the headquarters institution, the organizational structure consists of eight district member institutions. The " $15 / 2013$. EMMI Decree on the Operation of Educational Service Centers" prescribes the tasks of the institution in the following fields: 1. special pedagogical counseling, early development and care, 2. expert examination, 3. educational counseling, 4. speech therapy, 5. continuing education career counseling, 6. conductive pedagogy, 7. physiotherapy, 8. school psychological and nursery school psychological service, 9. care for highly talented children and students. Various forms of care are provided on an outpatient basis and external workplaces, such as nurseries, public educational institutions, care homes for disabled and, if necessary, in families' homes. The qualification of the colleagues who work in the institution are wide. Special education teacher (speech therapist, teacher of mentally handicapped teacher for visually or hearing impaired), psychologist, physiotherapist, conductor, teacher, also a qualified professional. In addition to basic therapies, special development opportunities are also available in member-institutions.

\subsection{Participants in the study}

Employees of the Somogy County Educational Service Center - who works as a teacher participated in the study. At the time of research, in October 2019, there were 172 colleagues working in the institution as active teachers. 116 of them completed the questionnaire: the youngest was 22 years old and the oldest was 59 years old. There were 7 male and 109 female respondents.

\subsection{Presentation of the test procedure}

The examination took place in October 2019 in all member institutions and the headquarters of the Somogy County Educational Service Center. Sampling has been done by random selection. All completed questionnaires could have been included in the investigation. We recorded the data in a Microsoft Excel spreadsheet, and used these spreadsheets for the analysis.

As said the Maslach Burnout Inventory-Educators' Survey has been used for the study. We mastered it during my psychology studies in the University of Debrecen. The questionnaire consists of 22 items and explores the extent of teachers' burnout. The 22 questions can be answered on a seven-point scale, depending on the extent to which statement is specific to the respondent. The value 0 means you never feel the feelings expressed in the statement, and 6 means you feel it every day. By summing the response scores obtained for the items, the total burnout score is obtained. Items of the questionnaire can, in fact, be divided into three subscales:

- Emotional Exhaustion: nine items, feeling exhausted and emotionally overwhelmed in work

- Depersonalization: five items, impersonal reactions to students

- $\quad$ Personal Accomplishment: eight items, success and sense of competence at work (Mészáros, 2013).

\subsection{Research questions}

a. In which subscale teachers of the Somogy County Educational Service Center show the lowest and the highest values? 
b. Does the time spent on profession affect the appearance of burnout? Does the study result in higher values for new entrants (less than 5 years in teaching profession) and for those who have been working as a teacher for a longer time (minimum 35 years) than other people of the study population?

\section{Discussion}

The descriptive statistics of the collected data are representative for the employees of Somogy County Educational Service Center. The 116 random selected individual present $67,4 \%$ of the study population. In evaluating the questionnaire, individuals are classified into three categories: low (75 items), medium (37), and high (4) risk of burnout. To answer the first researcher's question, we have examined all three subscales of Maslach Burnout Inventory- Educators' Survey in the three categories above. Since the number of questions for each subscale are different in the questionnaire, we normalized the obtained scores, accordingly, thus obtaining a percentage with respect to the maximal possible score in each particular subscale. In case the individual has been classified as of low-level-burnout, we observed the lowest values on the Depersonalization subscale (with a maximum of $20 \%$ in that class) and the highest values on the Emotional Exhaustion subscale (maximum 60\%). For medium-level-burnout, we also obtained the lowest values on the Depersonalization subscale (maximum 50\%) and the highest ones on the Emotional Exhaustion subscale (between 50\% and 100\%). The values dominated in both subscales the respective values in the low-level-burnout category. Only four teachers in the sample have been classified as of high-level-burnout, no further conclusion on the subscales can be drawn for this group due to its small cardinality. The analysis of the impact of Personal Accomplishment in all categories yielded results ranging from $0-50 \%$. When analyzing the sample as a whole (that is, without differentiating between the low, medium, and high clusters), the respondents achieved the highest value as expected - on the Emotional Exhaustion subscale (40\%), the lowest value on the Depersonalization subscale (11\%). For the Personal Accomplishment the average was $27 \%$.

For the second researcher's question, the results indicate that the time spent on profession does not significantly affect the burnout-level, as can be seen in Figure 2.

Figure 2. Total score as a function of time spent on profession.

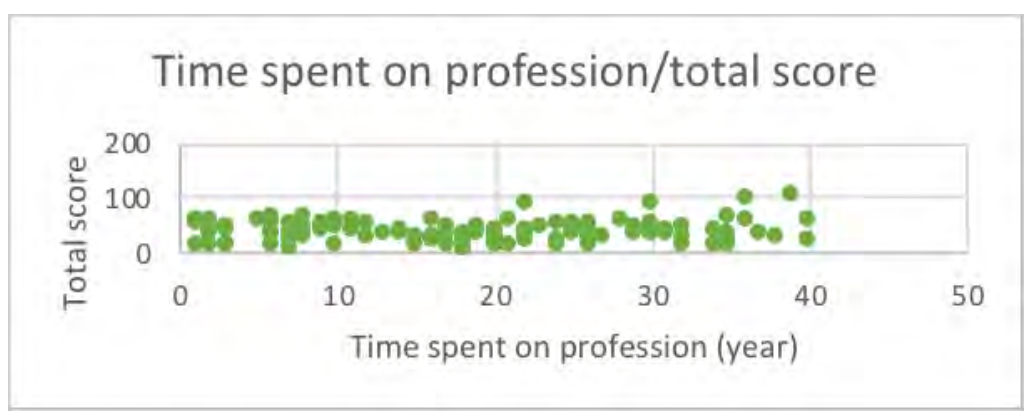

\section{Conclusions}

According to results of the study, teachers of Somogy County Educational Service Center cannot be characterized by a high level of burnout. The questionnaire indicated a high level of burnout in case of four teachers only, and a medium level in the case of 37 colleagues, so it is definitely worth addressing the issue. It is noteworthy, as expected, that we obtained the highest score on the Emotional Exhaustion subscale and the lowest on the Depersonalization subscale. The time spent as a teacher has not significantly affected the level of burnout. Given the results, as a secondary prevention of burnout, it is worth considering the use of institutional psychoeducation and solution-oriented psychological counseling as intervention techniques in the future.

\section{Acknowledgements}

Sponsored by the Cooperative Doctoral Program Doctoral Student Scholarship - KDP-2020. Application number 1010959. 


\section{References}

15/2013. EMMI Decree on the Operation of Educational Service Centers. in Hungarian: 15/2013. EMMI rendelet a pedagógiai szakszolgálati intézmények müködéséről. Retrieved May 23, 2021, from: https://net.jogtar.hu/j ogszabaly?docid=a1300015.emm (law)

Anderson, C. M. (1983). A Psychoeducational Model of Family Treatment in Schizophrenia. In Stierlin, H., Wynne, L.C., Wirsching, M. (Eds.): Psychosocial Intervention in Schizophrenia- An International View (227-235), Springer-Verlah Berlin Heidelberg GMBH. Retrieved May 07, 2021, from: https://link.springer.com/chapter/10.1007/978-3-642-68966-6 22

Anderson, C.M., Hogarty, G.E., Reiss, D. J. (1980). Family Treatment of Adult Schizophrenic Patient: A Psycho-educational Approach. Schizophrenia Bulletin, 6(3), 490-505. Retrieved May 07, 2021, from: https://doi.org/10.1093/schbul/6.3.490

Bagdi P., Harkai V., Stoll D.P., Ferenc M. (2016). Psychoeducation in spinal medicine. in Hungarian: Pszichoedukáció a gerincgyógyászatban. Retrieved May 07, 2021, from: https://www.researchgate.net/publication/319058846_PSZICHOEDUKACIO_A_GERINCGYOG YASZATBAN. 2021.05.07

Bonanno, G.A. (2004). Loss, Trauma, and Human Resilience: Have We Underestimated the Human Capacity to Thrive After Extremely Aversive Events? American Psychologist, 59(1), 8-20. Retrieved May 15, 2021, from: DOI:10.1037/0003-066X.59.1.20

Bonanno, G.A. (2005). Clarifying and Extending the Construct of Adult Resilience. American Psychologist, 60(3), 265-267. Retrieved May 07, 2021, from: DOI:10.1037/0003-066X.60.3.265b

Borsi A. (n.d.). The Phenomenon of Burnout in Teachers and Methodes of Supportive Intervention, in Hungarian: A kiégés jelensége pedagógusoknál és a segitö beavatkozás módszerei, Retrieved October 30, 2019, from: http://korhazlelkesz.hu/doc/Kieges.pdf

Central Statitics Office (2021). Hungary in Numbers, 2020. in Hungarian: Központi Statisztikai Hivatal (2021): Magyarország számokban, 2020. Retrieved May 20, 2021, from: https://www.ksh.hu/docs/hun/xftp/idoszaki/mosz/mosz20.pdf

CXC. Law of 2011 on National Public Education. in Hungarian: 2011. évi CXC. törvény a nemzeti köznevelésről. Retrieved: May 23, 2021, from: https://net.jogtar.hu/jogszabaly ?docid=a1100190.tv (law)

Egan, G. (2011). The Skilled Helper, in Hungarian: A képzett segitő. ELTE Eötvös Kiadó, Budapest.

Freudenberger, H. J. (1975). The staff burn-out syndrome in alternative institutions. Psychotherapy: Theory, Research \& Practice, 12(1), 73-82.

Galletta, M., Portoghese, I., Ciuffi, M., Sancassiani, F., D 'Aloja, E., Campagna, M. (2016). Working and Environmental Factors of Job Burnout: A Cross-sectional Study Among Nurses, Bentham Open, 12, 132-141. Retrieved May 06, 2021, from: https://benthamopen.com/FULLTEXT/CPEMH-12132

Kelley, T.M. (2004). Positive Psychology and Adolescent Mental Health: False Promise or True Breakthrow? Adolescence. 39(154), 257-278. Retrieved May 20, 2021, from: https://innateevolution.com/wp-content/uploads/2019/07/Positive-Psychology-and-AdolescentMental-Health-False-Promise-or-True-Breakthrough.pdf

Linley, P. A., \& Joseph, S. (2005). The Human Capacity for Growth Through Adversity. American Psychologist, 60(3), 262-264. Retrieved May 15, 2021, from: https://doi.org/10.1037/0003066X.60.3.262b

Litz, B. T. (2005). Has Resilience to Severe Trauma Been Underestimated? American Psychologist, 60(3), 262. Retrieved May 15, 2021, from: https://doi.org/10.1037/0003-066X.60.3.262a

Maddi, S. R. (2005). On Hardiness and Other Pathways to Resilience. American Psychologist, 60(3), 261-262. Retrieved May 15, 2021, from: https://doi.org/10.1037/0003-066X.60.3.261

Maslach, C., Jackson, S. E. (1981). Maslach Burnout Inventory Manual. Palo Alto, CA: Consulting Psychologists Press.

Mészáros V. (2013). Burnout in Healthcare - Correlates of Burnout and ways to prevention. In Hungarian: Kiégés az egészségügyben - A kiégés korrelátumai, valamint megelözésének lehetőségei, PhD Dissertation, Eötvös Lóránd University Faculty of Education and Psychology Budapest, Retrieved May 22, 2021, from: http://pszichologia.phd.elte.hu/vedesek/doktorjelolt_Meszaros-Veronika_disszertacio.pdf

Seligman, M.E. (1991). Learned Optimizmus: How to Change Mind and Your Life. New York. N.Y.: Pocket Books

Szigeti, M. (2019). Work Plan of Somogy County Educational Service Center, 2019/2020. School Year. In Hungarian: A Somogy Megyei Pedagógiai Szakszolgálat éves munkaterve, 2019/20. tanév, Kaposvár 


\title{
INVESTIGATING THE USE ACTION LEARNING APPROACHES IN CIVIL ENGINEERING AND CONSTRUCTION STUDIES: A CASE OF SKILLS CENTRE
}

\author{
Khojane Geoffrey Mokhothu, Charles S Masoabi, \& Alfred H Makura \\ Central University of Technology Free State (South Africa)
}

\begin{abstract}
Civil Engineering and Construction studies are the study fields that embraces practical and theory. While action learning approaches is encompassed with a myriad of teaching and learning methods to closed the deficits. The research aims to investigate the use of action learning approaches in Civil engineering and Construction studies. while the objective of the research is to assess the extent to which action learning approaches is employed in teaching practical and content knowledge in Civil Engineering and Construction studies. The research used a mixed-method approach comprising quantitative and qualitative methodology to collect data. Questionnaire and face to face semi-structured interview were used as the tools to gather data. Participants were all 10 lecturers and assistance lecturers, males and females from different culture, age and race. Findings of the research revealed that lecturers are using action learning approaches unaware. The research, suggests that all lecturer at the skills centres should be afforded opportunities to attend facilitations and assessor courses or Universities of Technology should develop a short education methodology for them of which it will equip their teaching and learning skills.
\end{abstract}

Keywords: Action learning, civil engineering and construction, skills centre.

\section{Introduction}

Action learning approaches are classified as suitable and effective method to promote skills development and theory awareness. Hence, Civil Engineering and Construction studies at skill centres are confided to address high volume of practical work and less volume of theory. In support of the above mentioned statement, the DHET (2019:11) in their mission statement states that (To improve access to occupations in high demand and priority skills aligned to supporting economic growth, employment creation and social development whilst also seeking to address systemic considerations). Therefore, the paper seeks to investigate the use of Action Learning approaches in Civil Engineering and Construction studies to achieve the mission.

\section{The conceptualisation of the study}

\subsection{Action learning}

"There is no learning without action and no (sober and deliberate) action without learning" (Peddle, 1991). The Action Learning Approach is described in this study as an approach to working with and developing people on a real project or problem as a way to learn." Participants collaborate in small sets to solve their dilemma and learn how to apply what they have learned (Marsick and O'Neil, 1999:6; Mughal 2016).

\subsection{Skill centre}

Skill Centre are designed to provides the content and high skills to be taught across the period of learning (Western Cape Government, nd:1). The skills centre objective is to learn the skills needed by students and students can learn the skills of students based on the school area of the Urban Area, Central Region, and Rural Areas.

\subsection{Civil engineering and construction studies}

In this study Civil Engineering and Construction refers to Building environment in general which include skills such as: bricklaying, tilling, woodworking, plumbing and many others (Mokhothu, 2018:323). The Department of Higher Education (DHET) and Training asserts that Civil Engineering and Building Construction course covers construction, masonry building and woodworking; design, drainage and sanitation in a practical, theoretical, management and design environment. This course integrates academic knowledge and theory with practical skills and values (DHET, 2015:8; Maeko, 2020:38). 


\section{The aim of the study}

The aim of the study is to investigate the use of Action learning approaches in Civil Engineering and Construction studies at skills centre level.

\section{The objective}

The main objective of the research is to assess the extent to which action learning approaches is employed in teaching practical and content knowledge in Civil Engineering and Construction studies.

\section{Proposition}

Action Learning Approaches play a pivotal role in promoting effective teaching and learning of practical work and theory in Civil Engineering and Construction studies.

\section{Methodology}

\subsection{The context of the study}

The researcher visited theory classes and workshops where teaching and learning for Civil Engineering and Construction studies occurs all the time. Classes and workshops are allocated for the following subjects: Bricklaying and plastering, Plumbing, woodworking (carpentry and cabinet making). At the end of the tour the instructors were presented with the questionnaires.

\subsection{Participants}

All study participants were instructors responsible for Civil Engineering and Construction studies: Bricklaying and plastering, Plumbing, woodworking (carpentry and cabinet making) at the skills centre. The total number of participants was 10 which comprises of $2(20 \%)$ females and $8(80 \%)$ males from diverse ethnic group. Each subjects were allocated 1 instructor responsible for theory and practical and 1 responsible for practical only assistant instructor.

\subsection{Procedures}

All participants were asked to complete the questionnaire for two days as the research process was scheduled for seven days. Then on the third day, the research began with the face to face interview to gather data using voice recorder to produce qualitative data through transcribing. The interview was scheduled for one hour for two days. All questionnaires were received and all were completed then quantitative was produced. Both quantitative and qualitative data were produced, analysed and presented.

\section{Results presentation, interpretation and discussion}

\subsection{Quantitative data}

Table 1 below present the results obtained from the questionnaire.

Table 1. Action Learning Approached.

\begin{tabular}{|c|c|c|c|c|c|}
\hline \multirow[t]{2}{*}{ B } & \multicolumn{5}{|c|}{$\begin{array}{l}\text { The extent lecturers use action learning approaches in Civil Engineering and Construction studies at } \\
\text { TVET colleges }\end{array}$} \\
\hline & & SA (1) & A (2) & D (3) & SD (4) \\
\hline & & \multicolumn{4}{|c|}{ No. response (\%) } \\
\hline 1 & $\begin{array}{l}\text { I understand the difference and relationship between } \\
\text { approaches and methods of Action Learning. }\end{array}$ & $4(40 \%)$ & $\mathbf{0}$ & $\mathbf{0}$ & $6(60 \%)$ \\
\hline 2 & $\begin{array}{l}\text { I use case studies as a teaching and learning technique } \\
\text { frequently in my class. }\end{array}$ & $\begin{array}{c}10 \\
(100 \%)\end{array}$ & $\mathbf{0}$ & $\mathbf{0}$ & $\mathbf{0}$ \\
\hline 3 & $\begin{array}{l}\text { I use simulations frequently as a teaching and learning } \\
\text { technique in my class. }\end{array}$ & $\mathbf{0}$ & $\begin{array}{c}2 \\
(20 \%)\end{array}$ & $\mathbf{0}$ & $\begin{array}{c}80 \\
(80 \%)\end{array}$ \\
\hline 4 & $\begin{array}{l}\text { I use projects frequently as a technique to teach other aspect of } \\
\text { the content. }\end{array}$ & $\begin{array}{c}10 \\
(100 \%)\end{array}$ & $\mathbf{0}$ & $\mathbf{0}$ & $\mathbf{0}$ \\
\hline 5 & $\begin{array}{l}\text { I use research as a teaching and learning technique frequently } \\
\text { to promote critical thinking in my class. }\end{array}$ & $\mathbf{0}$ & $\mathbf{0}$ & $\mathbf{0}$ & $\begin{array}{c}10 \\
(100 \%) \\
\end{array}$ \\
\hline 6 & $\begin{array}{l}\text { I use demonstration method as the main teaching method in my } \\
\text { class. }\end{array}$ & $\begin{array}{c}10 \\
(100 \%) \\
\end{array}$ & $\mathbf{0}$ & $\mathbf{0}$ & $\mathbf{0}$ \\
\hline 7 & $\begin{array}{l}\text { I use problem solving method to teach integration of content } \\
\text { knowledge and practical work in my class. }\end{array}$ & $\mathbf{0}$ & $\mathbf{0}$ & $\mathbf{0}$ & $\begin{array}{c}10 \\
(100 \%) \\
\end{array}$ \\
\hline 8 & $\begin{array}{l}\text { I use technological process method to teach integration of } \\
\text { content knowledge and practical work in my class. }\end{array}$ & $5(50 \%)$ & $\begin{array}{c}1 \\
(10 \%)\end{array}$ & $\begin{array}{c}1 \\
(10 \%)\end{array}$ & $3(30 \%)$ \\
\hline
\end{tabular}

Strongly agree (SA), Agree (A), Disagree (D), Strongly Disagree (SD) 
Table 1 above presents the results from the questionnaire, which indicates that at question 1 high number of instructors $n=6(60 \%)$ strongly disagree, while $n=40 \%$ indicates that strongly agree. Question 2 show that all instructors $n=10(100 \%)$ strongly agree. Majority of instructors $80(80 \%)$ at question 3 are strongly disagree with the statement. At question 4 and 6 all instructors $n=10(100 \%)$ strongly agree. instructors in majority $n=10(100 \%)$ are strongly disagree with the statement. All aforesaid results indicate that majority of the instructor did not receive formal training of teaching and learning methodology. Therefore, the results prove the statement pronounced by Makole (2015: iv) that skills programme requires instructors or facilitators who are competent in totality (theoretical and practical) content. The study revealed that skills programme instructors perform excellent work in nourishing practical skills the only deficit is they are not qualified and lack pedagogical skill.

\subsection{Interview Questions (Qualitative)}

Table 2 Semi- structured.

\begin{tabular}{|c|}
\hline 1. What is your view regarding the use of ALA in CEC studies at Skills centre? \\
\hline $\begin{array}{l}\text { Instructor A: I'm really not sure what is action learning exactly but I teach theory } \\
\text { and more practical using teaching methods } \\
\text { Instructor B: It is important because you learn while you are on action } \\
\text { Instructor C: Should be use because of practical, practical needs action } \\
\text { Instructor D: I think we have to use it if action learning is all about action and learn } \\
\text { Instructor E: I use it because my learners are always hands-on }\end{array}$ \\
\hline 2. What are your favourite techniques when implementing ALA in CEC studies? \\
\hline $\begin{array}{l}\text { Instructor A: I'm not sure what are the techniques but I like demonstration method } \\
\text { Instructor B: Demonstration } \\
\text { Instructor C: I'm not sure really, I just teach and show them if they don't } \\
\quad \text { understand } \\
\text { Instructor D: Demonstration } \\
\text { Instructor E: Demonstration, hand-on and simulation }\end{array}$ \\
\hline 3. What makes them your favourite techniques of action learning in CEC studies? \\
\hline $\begin{array}{l}\text { Instructor A: Because, I always get a chance to work with my learners } \\
\text { Instructor B: To make sure that your learners see what you want them to do } \\
\text { Instructor C: Because I can show them skills } \\
\text { Instructor D: That's an only method we use in skill centre } \\
\text { Instructor E: Yes as an assessor those are the most significant } \\
\quad \text { methods/techniques to use during skills development }\end{array}$ \\
\hline 4. Can you explain how do you use these favourite techniques of ALA in your CEC studies class? \\
\hline $\begin{array}{l}\text { Instructor A: I show my learners how to set-out foundation then they do the same } \\
\text { Instructor B: Demonstrate the lesson then they follow me } \\
\text { Instructor C: They learn what I do and I give them a chance to do again and again } \\
\text { Instructor D: I demonstrate first then they follow } \\
\text { Instructor E: I explain; I show them then I allow them to practice until they master } \\
\quad \text { the skill }\end{array}$ \\
\hline $\begin{array}{l}\text { 5. Which teaching and learning methods or techniques you use during application } \\
\text { of ALA in CEC studies class? }\end{array}$ \\
\hline $\begin{array}{l}\text { Instructor A: I like demonstration, presentation and gaming } \\
\text { Instructor B: Demonstration and Video's } \\
\text { Instructor C: Demonstration and others maybe I mix, I don't know! } \\
\text { Instructor D: Demonstration and presentation of videos } \\
\text { Instructor E: Demonstration, Visual and Question and answer(discussion) method }\end{array}$ \\
\hline
\end{tabular}

Table 2 above presents the results from semi-structured interview. The interview in general results demonstrated that instructors are aware but not aware that, they are using action learning approaches for effective teaching and learning in everyday teaching and learning activities. The above statement compensates Pedler (1991) in Mokhothu (2020:166) when state that "There is no learning without action and no sober and deliberate action without learning". 


\section{Conclusion}

In conclusion the study has shown that skills centre are the main hub of skills production and recycling or rehabilitation of communities' technical skills in the country South Africa. As the study has exposed, the effective and sustainable knowledge and skills transferred by the instructors to the learners without formal teaching qualifications but they have only training acquired form the skills centre. Therefore, the study recommend that different government department involved in skills centre should initial programmes that allows skills centre instructors to acquire formal teaching qualification and assessor certificate.

\section{References}

Maeko, MSA 2020. Teaching and Learning Through Hands-on Activities in Civil Technology Teacher Training Programmes at South African Universities. Journal of Human Ecology, 71(1-3): 38-48

Makole, KZ. 2015. The Implementation of the National Certificate Vocational Programme at Tshwane North FET College. MM Dissertation. Johannesburg: University of Witwatersrand.

Mokhothu, KG 2018. The Effectiveness of Demonstrational Method in Promoting Student Centred Method: Case Study, C. Mafalda (Ed). Proceedings of $6^{\text {th }}$ International Conference on New Developments (END), 27-29 June, 2018. Budapest Hungary. 322-325. ISBN: 978-989-99864-8-0.

Mokhothu, KG 2020. Investigating the Impact of Learn by doing in Civil Technology Class: Students Action, C. Mafalda (Ed). Proceedings of $8^{\text {th }}$ International Conference on New Developments (END), 27-29 June, 2020. Porto Portugal. 164-167. ISBN: 978-54815-2-1.

Pedler, M 1991. Action Learning in Practice, $2^{\text {nd }}$ edn. Brookfield, VT: Gower. 


\title{
PEDAGOGICAL INTERACTIONS IN PRIMARY SCHOOL REINTEGRATION PROCESSES: A CASE STUDY IN CHILE
}

\author{
José Manuel Medina, Tatiana Herreros, Pamela De Barca, \& Carolina Crovetto \\ Facultad de Educación, Universidad de Las Américas (Chile)
}

\begin{abstract}
In Chile, despite the great coverage achieved, there are still children and adolescents who leave school without being able to complete 12 years of compulsory education (Casen, 2015); moreover, among the countries that make up the OECD, Chile is in the first places of deschooling (TALIS, 2013). This marginalization from the school system is affecting a significant number of children and hindering areas of integration and social development, which accentuates processes of social exclusion and violation of rights in Chile (Casen, 2015; Mide-UC, 2016; Mineduc, 2017). This is reinforced by pedagogical practices that strengthen these probabilities of failure (Román, 2013).

The phenomenon of school reintegration has little evidence in relation to the human and technical component in school reintegration processes, either locally (Mide-UC, 2016; UNESCO-UNICEF-Chilean Association of Municipalities, 2012), or internationally (CEPAL, 2010; Contreras et al, 2014; Sucre, 2016), which implies observing and analyzing pedagogical intervention practices in these contexts, in terms of how these dialogical-reflective relational dynamics between teachers and children and adolescents are developed, from the perspective of pedagogical interactions, an area of growing interest in educational sciences, which looks at more than the action itself, at how and what happens in the interaction. (Colomina et al, 2001)

This research from a qualitative, transactional approach, oriented from the perspective of descriptive studies (Hernández,et al, 2010) and enriched with the symbolic interactionism of Blumer (1969), whose contributions indicate that the nature of the teaching-learning processes can only be unraveled through direct examination, seeks to understand pedagogical intervention practices from the perspective of pedagogical interactions which are developed between teachers and their students, within the framework of the specialized protection programs in school reintegration implemented in Chile by the National Service for Minors of the Ministry of Justice and Human Rights, in vulnerable sectors of the communes of Talca, Region of Maule and La Pintana, Metropolitan Region.

The analysis through the theoretical and empirical contributions provided by the scientific evidence on pedagogical interactions, in terms of how they are configured, deployed and how these pedagogical intervention practices are perceived by the actors involved, added to the findings obtained, provides an opportunity to innovate by allowing the observation of school reintegration as a scenario of human relations and to deepen around this professional action as a critical element, constituting the improvement of teaching and effectiveness in school reintegration processes.
\end{abstract}

Keywords: School reintegration, educational interaction, learning, teacher, students.

\section{Formulation of the study}

This project is part of the field of education and school reintegration, with a focus on the educational interactions that take place in the pedagogical interventions between teachers and children and adolescents assigned to the Specialized Protection Programs in Educational Reinsertion in different communes of Chili.

There is proven national and international evidence regarding children and adolescents who are outside the school system or show indicators of educational fragility, which represents a clear situation of violation of rights. In this regard, in the international context, the evidence shows that in Latin America approximately 3 million of the child population are outside the school system, which is equivalent to $6.1 \%$ (UNICEF, 2012b) and in secondary education, in its phase early childhood (between 11 and 15 years old), $7.6 \%$ of adolescents, that is, 3 million, are out of school (UNESCO, 2014). In Chile, the CASEN survey (2015) indicates that, despite the high coverage achieved, there are still boys, girls and 
adolescents who drop out of school without being able to complete 12 years of compulsory education. Moreover, among the countries that make up the OECD, Chile is in the first places in out-of-schooling in secondary education (TALIS, 2013).

In response to this need to guarantee a successful school career for Chilean children and adolescents, in 2010 the Specialized Protection Program in Educational Reintegration (hereinafter PDE) was born, basing its main argument on a rights approach where access to both basic and secondary education constitute a right formally guaranteed by the State of Chile.

Today, reintegration projects face complex processes that pursue, through resignification, a transformation of the learning experience (SENAME, 2017), since the abandonment of the school system is due, among other causes, to inadequate experiences from what pedagogical (Román, 2013). The responsibility of resignifying the learning experience requires that these projects tend towards an ecological intervention model where the progressive mutual accommodation between a human being in the process of development and the changing properties of the immediate environments (Bronfenbrenner, 1987), are conditioned by means of Intervention practices that ensure a correct acquisition or strengthening of knowledge and the development of psychosocial skills so that children and adolescents can be conceived as a subject with learning capacity (MIDE UC, 2016).

Studies on the effectiveness of school reintegration plans in Latin America and Chile, carried out through the analysis of intervention programs (ECLAC, 2010; Contreras et al, 2014; Sucre, 2016), or reinsertion trajectories (MIDE UC, 2016), show evidence that supports the need to observe and analyze pedagogical intervention practices in contexts of school reintegration (UNESCO-UNICEF-Chilean Association of Municipalities, 2012).

In this regard, research on interaction, a field of growing research interest in science (Colomina et al, 2001) makes sense in processes of school reintegration, as it emerges as a contribution to the understanding of human relationships in specific contexts. This represents a dialogical and didactic challenge for the education professional who tries to maintain constant communication with the student, linked to multiple relationship channels (Schütz, 1993) and which also empowers him to recognize progress states supported by performance evidence and student performance in pedagogical intervention processes.

Analyzing the intervention practices in execution in the framework of these school reintegration programs from the voice of the education professionals involved, provides an opportunity to observe the intervention practice from its configuration as a scene of human relations and deepen around this Professional action as a critical element, constitutive of effectiveness in school reintegration. Therefore, the research question is: What meaning do the education professionals linked to these school reintegration programs attribute to the educational interactions between teachers and students during the pedagogical intervention processes?

\section{Methodology}

The design is theoretical-methodological, being a non-experimental investigation with a qualitative, transactional approach, oriented from the perspective of descriptive studies (Hernández and others, 2010) and enriched with the symbolic interactionism of Blumer (1969).

Grounded Theory will be used through the method of constant comparisons (Glaser and Strauss, 1967). This is a generative and constructive method in which the inductive coding of categories is combined with the constant comparison between them. It seeks the dynamic construction of meanings, focusing on temporal patterns of meaning, enabling intra and intersubjective analysis of perceptions and meanings. It starts from the sociolinguistic premise that the construction of meanings strongly depends on the various forms that the combination of contents and meanings takes during the flow of discourse.

Regarding the selection of informants, this study assumes an intentional non-probabilistic sampling for the selection of informants (Taylor and Bogdan, 1987; Hernández and others, 2010). It is planned to have the participation of 16 teachers belonging to the Specialized Protection Programs in Educational Reintegration from different communes of the country.

Regarding the instruments for collecting information, it is intended to respond to the specific objectives through the use of in-depth interviews to recall the memory (Erickson and Simon, 1993).

\section{Discussion and preliminary conclusions of an ongoing investigation}

Favoring the conditions and strengthening the educational trajectory of children and adolescents who are out of school or present educational fragility is established as an effective response, through school reintegration programs, to this country responsibility, where education should be within everyone's reach. However, the marginalization of the school system seen from school dropout is an undeniable fact 
(CASEN, 2015; MIDE UC, 2016) affecting a large number of minors, preventing the exercise of the right to education and hindering areas of integration and development social, either in terms of peer relationships, family relationships and work projections, accentuating processes of social exclusion and violation of rights (SENAME, 2017).

In relation, this study has confirmed the relevance of understanding pedagogical intervention practices from the perspective of educational interactions between teachers and children and adolescents assigned to the Specialized Protection Programs in Educational Reintegration in two communes of the country, by observing of intervention practices from its configuration as a scene of human relations and to deepen around this professional action as a critical element, constitutive of the effectiveness in school reintegration. The above constitutes an epistemic and understanding contribution to the phenomenon of school reintegration from interaction, in addition to contributing to the field of studies from the knowledge and meanings of the actors involved in relation to their practices in educational settings, establishing itself as a point of analysis and discussion about its impact on school reintegration and student learning.

\section{References}

ECLAC. (2010). chap. 2. Education in the face of the reproduction of inequality and exclusion: Situation and challenges in Latin America. In Social Panorama in Latin America. United Nations.

Colomina, R., Mayordomo, R., Onrubia, J. (2001). The analysis of discursive activity in educational interaction. Some theoretical and methodological options. Childhood and learning.

Erickson, K.; and Simon, H. (1993) Protocol analysis: Verbal reports as data. Cambridge, MA: MIT. Press.

Glaser, B. and Strauss, A. (1967). The discovery of Grounded Theory. Chicago: Aldine.

Gumperz, J. (1982). Discourse strategies. Cambridge: England.

Hernández, R., Fernández, C. \& Baptista, P. (2010). Investigation methodology. Mexico: McGraw-Hill. (5th ed.). Retrieved from http://soptecc.perujar.com/metodo/inicio.html

Jeong, A. (2005). A Guide to Analyzing Message - Response Sequences and Group Interaction Patterns in Computer mediated Communication. Distance Education. 26 (3), 367-383.

Law 19.876. (2003). Constitutional reform that establishes the compulsory and gratuitous nature of secondary education. Ministry of Education. Library of the National Congress of Chile. Recovered from: https://www.leychile.cl/Navegar?idNorma=210495

MEASURES UC. (2016). Characterization Study of the Educational Reintegration Programs of Sename and Mineduc. Recommendations for public policy and good territorial practices.

Mercer, N., Wegerif, R. and Dawes L. (1999). Children's talk and the development of reasoning in the classroom. British Educational Research Journal, Vol 25, No. 1, 95-111.

Ministry of Education, Division of General Education (2013). Educational Mainstreaming Unit. Chili.

Nasta, L. (s.f.) Effective communication and interaction with educational scope. (s.p.) Psychotherapy Research: Journal of the Society for Psychotherapy Research, 20 (5), 546-563. doi: 10.1080 / 10503301003641886.

Rizo García, M. (2007). Interaction and communication in educational environments: Theoretical, conceptual and methodological reflections. Revista da Associação Nacional two Programs of Post-Graduação em Comunicação.

Román, M. (2013). Factors associated with school dropout and dropout in Latin America: An overview. Iberoamerican Magazine on Quality, Efficacy and Change in Education.

Sucre, F. (2016) School reintegration for vulnerable youth in Latin America. Inter-American Dialogue, December 2016.

Talis. (2013). TALIS 2013 Results: An International Perspective on Teaching and Learning. Paris: OECD.

SENAME. (2017). specialized protection program for children and adolescents with problematic use of alcohol and / or other drugs (pdc). 24 hour program. Ministry of Justice and Human Rights. Chili.

UNESCO. (2015) A growing number of children and adolescents are out of school. Policy Document 22, informative 31.

UNESCO, UNICEF, Chilean Association of Municipalities. (2012b) Educational Exclusion an Urgent Challenge for Chile. Chili.

Weston, C., \& McAlpine, L. (2002). Parallel transcripts: an innovative approach for capturing the impact reflective teaching on student learning experience. In Annual Meeting of the American Education Research Association. New Orleans, LA. 


\title{
REFLECTIVE OBSERVATIONS ON THE DESIGN AND STUDIO ART PROGRAMME AT A UNIVERSITY OF TECHNOLOGY
}

\author{
Lebogang Nthejane \\ Department of Design and Studio Art, Central University of Technology Free State (South Africa)
}

\begin{abstract}
The Central University of Technology (CUT) in South Africa compels that all programmes without a Mathematics module to offer Numeracy to first-year students. Initially, the Department of Mathematical and Physical Sciences at CUT was requested to facilitate this module from 2014 within the first semester. However, Numeracy was offered in a general manner without considering the applicability to the Design and Studio Art programme. The aim of this study was to revise the current curriculum and modify it to be applicable to the Design and Studio Art programme. Thus, the objectives of this study were firstly, to identify the gap in the current curriculum, which related to mathematical concepts within the Numeracy module which seemed to be not applicable to this programme. Secondly, to identify the mathematical concepts within the Numeracy module that could possibly be applicable to this Programme and modify them, accordingly. These concepts were identified as geometry, ratios and proportions, scale drawings, grid system, units and conversions. The final objective of this study related to the teaching of these concepts into the programme. The purpose of this paper report on the reflective observations on the revision and modification of the curriculum, more specifically on the application of these concepts in the Drawing module of the Design and Studio Art programme. A qualitative research approach was employed through reflective observations by the lecturer in the drawing lesson of 38 students who were enrolled on this programme. An analysis was further done on students' abilities to apply mathematical concepts in their drawing project and what they have learnt in the Numeracy module. Findings revealed students' abilities to apply mathematical concepts with ease- this after the lecturer explained the relations amongst these concepts to drawing. It appeared as though this intervention benefited mostly the students who were struggling with drawing. A key recommendation is that the application of the stated mathematical concepts be practiced in other modules within the Design and Studio Art programme at CUT.
\end{abstract}

Keywords: Mathematics, drawing, geometry, ratio and proportion.

\section{Introduction}

A question has been raised often if there is a relationship between art and Mathematics. It is evident through literature that a relationship does exist between Art and Mathematics. From ancient history of the Egyptian murals, the use of plane geometry is evident, as well as on the American folk quilts. During the European Renaissance, projective geometry is evident on the works of Durer and da Vinci (Bickley-Green, 1995). According to (Hickman \& Huckstep 2003), the link between art and mathematics has been evident centuries ago on the Euclidean geometry and is recently evident in cross-curricular in schools. However, a lot of art students and art educators do not recognise the relationship between art and Mathematics. In her study (Bickley-Green, 1995) stated that students and preservice teachers could not identify any mathematical concepts in the art curriculum. Teachers only saw themselves as artists and not mathematicians, hence they did not do well in mathematics, and students claimed that they have never been asked to calculate anything in art.

According to (Lusardi, 2012), to succeed in today's economic environment, Numeracy and financial literacy are recently deemed to be crucial lifetime skills. Since 2014 the Central University introduced the Numeracy module to the 1st year curriculum of all the programmes that do not offer mathematics, as being numerate is one of the university's graduate attributes. However, the Numeracy module was offered as an individual discipline, and therefore seemed irrelevant to the Design and Studio Art students. Therefore, based on the evident relationship between mathematics and art, there was a need to revise the Numeracy module curriculum to be applicable to Design and Studio Art. The objectives for Numeracy were for students to be able to apply these skills in real-life situations, hence it was necessary 
for Design and Studio Art students to be able to apply numeracy skills in their daily life of art making. These objectives led to a curriculum integration approach of Numeracy module and Drawing module which is one of the Design and Studio Art modules. Society is changing, the art world changes too as well as our communication modes changes, due to these changes there is a renewed interest in an integrated curriculum approach in art education. (Parsons 2004) is of the opinion that curriculum integration could enhance the teaching of art.

Drawing is a fundamental aspect of art, and it involves the ability to see and interpret what you see into a two-dimensional plane (Bulduk, 2010). When looking at an object to be drawn, one must ask themselves what is it that they see and not just merely see a human being, but rather see line, shape, form and so on (Barber 2003). This way of seeing is what brings mathematics and drawing together, both disciplines involve geometry. The "Vitruvian Man" one of Leonardo da Vinci's famous drawings demonstrates the old ways of using geometry to achieve correct human figure proportions. The Vitruvian man concept suggested that a circle and a square which were known to be perfect geometric figures, would frame a perfectly proportional man with his extended arms and legs (Mello 2010). The Drawing process is mathematical itself.

\section{Aim of the study}

The aim of this qualitative study is to revise and modify the Numeracy curriculum to make it applicable to Design and studio Art and observe the ability of students to apply the mathematical concepts in the Drawing module of the Design and Studio Art programme.

\section{Methodology}

A qualitative method was employed for the purpose of this study. Data was collected through a reflective observation by the lecturer during two drawing lessons in the department of Design and Studio Art at the Central University of Technology, Free State. According to (Dewey 1997), reflection is about searching for new evidence to support one's suggestions. This study aims at developing a strategy to assist students to develop their ability to apply mathematical concepts in drawing through an integration of both the Numeracy module and Drawing curriculum. The Participants were 38 first year students enrolled for the Drawing Module and Numeracy Module. Participants were informed that their classroom activities will be observed and that the observations will be used for research purposes in order to enhance teaching and learning. Only a few participants had some background in art and majority of the participants did not have any prior knowledge in art as it was not a requirement to enrol for the Design and Studio Art programme. Students were taught the revised and modified Numeracy module and thereafter given two tasks in the drawing Module to test their ability to apply mathematical concepts in their drawings. For the purpose of this study, only four mathematical concepts were observed, namely geometry, proportions, scale drawing and grid system. Firstly, students were instructed to apply geometry and proportions in one project and use scale drawings and the grid system in the other project, without the mention of Numeracy. Subsequently, an observation was done through a written report. Secondly, a demonstration of the relationship of these concepts between Numeracy and Drawing was given to the students and thereafter expected to draw accordingly. More focus on the demonstration was given to the students who were struggling with drawing. Another observation was done while students were drawing after the demonstration. Thereafter a reflection was done on these written observations to determine the ability of students to apply proportions and the grid system in their drawing projects.

\section{Presentation and analysis of results}

The presentation is done according to the mathematical concepts that were drawn from the analysis of the reflective observation data. Four of the mathematical concepts identified in the Numeracy module were taught to students and therefore students were instructed to apply these concepts in their drawing projects. Findings of the reflective observations will be presented briefly in two sections.

\subsection{Application of geometry, ratios, and proportions in drawing}

This section is the presentation of how the students performed in the drawing class in an attempt to apply geometry, ratios and proportions in their drawing projects. In drawing, proportions are very challenging and need an understanding of measurement. When drawing for accuracy, it is important to keep the same proportion in the drawing as on the actual object. In Numeracy the students learn that proportion means rations are equal whether scaled up or down. In drawing proportions is how objects relate to each 
other in size. These approaches are similar although they appear to be different. The difference is numbers for Numeracy and size for drawing, of which size can be seen as a number too.

Students were given a life human figure drawing project to exercise the use of geometry and proportions. In their first attempt they could not break down the figure into geometric forms. Regarding first attempt of proportions, students were able to measure the life human figure with their pencils, however the majority were not able to translate the measurements onto paper. Some students did not understand that where they hold the pencil to measure the head is actually a measuring unit, they did not hold the pencil at the same place, making the measuring unit to be unstable and therefore miscalculating the proportions of the figure. On the other hand, some students were able to keep the measuring unit stable, however were unable to scale up the proportions on a big paper. They would draw a tiny figure on less than a quarter of the paper. A second attempt was given to the students after showing them geometric forms they learnt from Numeracy and how they could be used to simplify a complex organic figure. On the second attempt, students showed an improvement in their measuring skills and were able to recognise geometric forms on the structure of the human being. Those students who could only draw a stick man were able to use geometric forms to give their stick man some form.

\subsection{Application of scale drawing and grid system in drawing}

The performance of students on the application of scale drawing and grid system in their drawing projects will be presented in this section. In Numeracy scale drawing entails enlarging or reducing a real object size to a bigger or smaller scale on paper. The grid system is also used in scale drawing. These concepts are also evident in drawing; however, students struggle with scale calculations as they dislike mathematics. There has to be a mind shift to get students to measure.

Students were instructed to draw their self-portraits from a small photo to a bigger paper using the grid system. Although they were given instructions on how to draw a grid in order to achieve the correct proportions on a bigger scale, many students did not draw the grids properly. The grids were either not equal or they were skew. Some students struggled to scale up the grids from the photo to the drawing. Due to these challenges encountered by the students, examples were given to them from what they learnt in the Numeracy module and thereafter they were advised to use the same calculation method used in the Numeracy module. Students faced another challenge of following the grids to draw on the bigger paper and this led to distortion or proportional disorders of the portrait. Students were thereafter encouraged to number the grids on the $\mathrm{x}$-axis and the $\mathrm{y}$-axis and place the facial features according to the grid reference method they used in the Numeracy module. After this intervention, students were able to conquer some of the challenges they faced as well as improve their portrait drawing skill.

\section{Discussion}

Findings from the reflective observation on the students' ability to apply mathematical concepts, indicate that knowledge alone is not significant, alternatively the ability to apply knowledge contributes significantly in learning. According to (Dicker 1972) Dewey states that "...knowing is not the act of an outside spectator but of a participator...". He further explains that knowledge is a result of action taken. Results show that students were able to understand the link between maths and art within the Numeracy module, however, they had challenges to apply the knowledge in a real life situation of a drawing project. Subsequently, the students were able to apply the mathematical concepts through the integration of both the Numeracy and Drawing module curriculums. This indicates that the integration of the two disciplines contributed to the development of the students' ability to apply mathematical concepts in their drawing projects. Findings also indicate that the traditional way of teaching drawing with the use of structural lines was a bit challenging to the students who had no background in art. However, the application of geometry, proportions, scale drawings and grid system as a way of learning to draw, seemed to be assisting the students in the development of their drawing skills. This was more evident on the students who were struggling to draw. This suggestion is supported by (Christenson 2017) that using mathematics to teach art is crucial and that it provides supportive ways for students to be able to solve creative problems in art.

It can be concluded that modifying the Numeracy module to be applicable to Design and Studio Art assisted the students to recognize the connection between mathematics and art. The relationship between these two separate disciples has been evident The integration of the curriculum of Numeracy and Drawing module curriculum brought an interesting way of learning that enabled students to develop their ability to apply mathematical concepts in their drawing projects as well as improve their drawing skills. These results show that mathematics should not be separated from art as they are intertwined in their processes. 


\section{Conclusion}

The findings of this study revealed that mathematics is relevant to art and that applying mathematical concepts from the Numeracy module into the drawing module assisted the students to understand the relationship better and therefore improving their drawing skills. Students who already had adequate drawing skills perfected their skills while those who did not have any drawing background were able to develop the drawing skill adequately.

\section{References}

Barber, B. (2003). Advanced Drawing Skills: A Course in Artistic Excellence. Barnes \& Noble.

Bickley-Green, (1995). Math and Art Curriculum Integration: A Post-Modem Foundation Cynthia. A Journal of Issues and Research National Art Education Association, 37 (1), 6-18.

Bulduk, B. (2010). The relationship of the traditional drawing education with technology and graphic design. Procedia - Social and Behavioral Sciences, 2(2), 2019-2023

Christonsen, M. (2017). 3 Ways Using Math Can Improve Students' Drawings. May 24, 2021, https://theartofeducation.edu/2017/04/12/april-key-ways-draw-using-math/

Dewey, J. (1997). How we think (Dover. Ed.). Boston: D, C, Heath \& Co

Dicker, G. (1972). John Dewey on the Object of Knowledge. Transactions of the Charles S. Peirce Society, 8(3), 152-166

Hickman, R. Huckstep, P. (2003). Art and Mathematics in Education. The Journal of Aesthetic Education 37(1): $1-12$

Lusardi, A. (2012). Numeracy, Financial Literacy, and Financial Decision Making. Numeracy: Advancing Education in Quantitative Literacy 5(1), Art2

Mello, HA. 2010. Geometry in Art. February 2, 2018, http://www.hamello.com/PDF/livro_en.pdf

Parsons, M. (2004). Art and Integrated Curriculum. Eisner, EW. Day, MD. Handbook of Research and Policy in Art Education (20). New York: Routledge 


\title{
THE IMPORTANCE OF REFLECTION-BASED STRATEGIES IN TRAINING PROFESSIONALS WORKING WITH MDVI CHILDREN
}

\author{
Andrea Hathazi, \& Ioana-Letitia Serban \\ Department of Special Education, Babes-Bolyai University (Romania)
}

\begin{abstract}
This paper focuses on the professional development regarding communication abilities of the teachers and therapists working with children with multiple disabilities and a visual impairment (MDVI). Since the development of communication abilities is a complex process, it must be approached from a continuous, systemic and structured perspective. MDVI children acquire and develop communication skills based on various factors which depend on their specific features and usually they need a large amount of time to learn how to employ different systems of communication so they can express a need or a desire and have an impact on other people or on the environment.

In this context, a team of 3 universities, 4 special schools for the blind and visual impaired, one NGO and one IT company have come together in an Erasmus+ European project called PrECIVIM (Promoting Effective Communication for Individuals with a Vision Impairment and Multiple Disabilities) to address the need of a professional training in communication abilities of the specialists working with MDVI children. As a result, a complex training program has been created, based on common experiences, reflective strategies, and different training components.

Method: We have focused on a group of 21 professionals working with MDVI children. They were the beneficiaries of a four-part training programme conducted by three experienced trainers on a time frame of 6 months. The programme was delivered in multiple ways, each of them with great reflective value: training manual (individual study), onsite group training, online group supervision and written individual reflective logs.

Results: The individual feedback of each participant has been processed and discussed revealing significant improvement in their intervention approach toward MDVI children, in their selection of communication methods or in their professional relationship with the MDVI child. The results of the training programme are presented in terms of the efficiency of the reflection-based strategies for the professional development of each participant.

Conclusion: The training programme applied to this group of professionals has emphasized the need of mentors and partners who offer constructive feedback and who implement reflective strategies in the intervention process regarding communication with MDVI children. In this sense, the reflective logs should be considered a great resource in the intervention and therapeutic process of MDVI children.
\end{abstract}

Keywords: Teacher training, MDVI, reflection-based strategies.

\section{Theoretical background}

Reflective writing is meant to support a professional in developing a deep learning style, by understanding the process rather than memorising facts (Powell et al., 2017) and it is used to improve professional decision making. It addresses the idea of looking back to own activity and writing down the steps of the actions. In this view the specialist will easily and immediately gain a perspective of strategies and a personal feedback. So, while a participant is writing back his/her activity our goal was to guide $\mathrm{him} /$ her to constantly observe and analyse the process (alternatives which may come to mind, different angles of interpretation of a behaviour or of an intention on communication from the MDVI child). Reflective thinking addresses relating, experimenting, exploring, and connecting theory and practice (McCarthy, 2011; Helyer, 2015). Effective professional development is an on-going process which includes training, practice and feedback, provides sufficient time for the trainee to deepen their knowledge, but also allows follow-up support (Darling-Hammond et al., 2017). When engaging in a professional development programme, the specialists working with MDVI children should develop different sets of skills to support the evaluation and the intervention regarding the communication process. Among the professional responsibilities highlighted by a training programme the participants should find: making a reflection about 
teaching, creating their own documents and resources adapted to the needs of the MDVI child, communication strategies with the child's family, engaging in the professional community and general professional development (Rudiyati et al., 2019). Even though reflective practices are always encouraged, sometimes the trainer must select a range of different techniques and strategies that teach the reflection process itself, for there are professionals who are not prepared to reflect or have never done it (Kreber \& Castleden 2009, Coulson et al., 2013).

\section{Method}

The present research included a group of 21 professionals working with MDVI children. They were the beneficiaries of a four-part training programme conducted by three experienced trainers from a Romanian university on a time frame of 6 months. The programme was delivered in multiple ways, each of them with great reflective value: a training manual for individual study, an onsite group training, online group supervision sessions and written individual reflective logs delivered by e-mail. The participants' profile was as follows: 17 women and 4 men; 13 professionals with an experience between $0-5$ years and 8 professionals with 6 to 10 years of experience; 7 participants were special education teachers, 4 occupational therapists, 3 caregivers, 3 psychologists, 2 educators and 2 speech and language therapists.

\section{Procedure}

The first component of the programme that has been delivered to the participants was the training manual - meant for individual study and reflection. The second component was the onsite group training. This has been delivered by one of the university experts in a modular way on a 3-days session. The next component was the presentation of the reflective logs. They were delivered individually via e-mail to all the participants of the onsite training. The reflective logs consisted in the presentation of a case study.

Each case study had to be described in the reflective log in terms of: the communication profile of the beneficiary, the preparation steps for the intervention plan (assessment tools, materials, long and short-term objectives, strategies and techniques), the description of the intervention (strategies, resources, challenges), reflection on the observation techniques that they have used during the intervention and finally a self-reflection section (challenges, progress, feelings about the relationship with the beneficiary, improved aspects in their strategies, etc.). The reflective logs were completed by the participants and sent to two university trainers who then provided individual feedback on each case. During a 6-month period, the participants have each completed between 3 and 4 reflective logs. The fourth training component consisted of the online group supervision sessions. They were introduced after the participants started to get familiar with the reflection logs and aimed two objectives: (a) to follow the way the information from the manual and the onsite training was used in the reflective logs tasks and (b) to give an opportunity to the participants to share their experiences, challenges, outcomes, successes with the other participants in the group while also receiving group-feedback and feedback from the expert. The trainer of the online group sessions was the same one who conducted the onsite training session.

\section{Results}

We are going to discuss the results of the reflection-based strategies in our training programme by the analysis of the reflective logs. We considered these reflective logs as the most insightful instrument of professional growth because it contributed to the development of the participants' reflective skills and it gained value as it was supported by a strong feedback on the intensity of reflection that they have achieved. According to some studies (Bain et al., 2002, Coulson et al., 2013) the feedback given by the mentor to their trainee should also be combined with issue-related questions which challenge critical thinking.

The reflective logs were the final component of the training programme and in this section, we are going to present what a reflective perspective focuses on in this type of individual assessment and supervision tool. As previously stated, the reflective logs were an individual written task comprised of an analysis of a current working case that the specialist decided to share with his/her mentor and supervisor via e-mail. These reflective logs were used in the Erasmus+ PrECIVIM project as an individual evaluation and supervision tool. At the end of the 6-month period, many of the participants have already made new intervention plans or had a new or better vision on how to improve their intervention, their relationship with the MDVI child, and so on, as illustrated in Table 1. The reflective logs gave participants the possibility to reflect on their own intervention by acknowledging the objectives they have achieved, stating how they managed challenging behaviours, recognising, and naming their feelings about the intervention and finally revealing what has changed in their professional development (relationship with the child, a better 
understanding of the child, higher acceptance/ tolerance of the child's opinions, and so on). The reflective logs had a very important component: the feedback section completed by the mentor. The feedback allowed the specialists to reflect further by comparing it to their own thoughts as well as to the opinions of the other team members. All the interventions have been improved during the 6 months of the unfolding of the reflective logs and the contribution of these reflective logs to the personal growth of each professional was undeniable and the final comments of each one of them is proof to that statement. Reflective logs require describing experiences and critically reassessing the activities, thus achieving a higher level of understanding (Powell et al., 2017; Walker et al., 2013; Urdang, 2010). This kind of individual process has ensured for the participants the specific significance of the communication development in the context of MDVI children where the diversity of the needs and abilities is so great.

Table 1. Participants reflections about self-development as registered in the reflection logs (RL).

\begin{tabular}{|l|c|c|c|c|}
\hline \multicolumn{1}{|c|}{ Type of reflection } & $\begin{array}{c}\text { Participants } \\
\text { responding in } \\
\text { RL 1* } \\
\text { Total N=21 }\end{array}$ & $\begin{array}{c}\text { Participants } \\
\text { responding in } \\
\text { RL 2** } \\
\text { Total N=21 }\end{array}$ & $\begin{array}{c}\text { Participants } \\
\text { responding } \\
\text { in RL 3*** } \\
\text { Total N=21 }\end{array}$ & $\begin{array}{c}\text { Gain } \\
\text { indicator**** } \\
\text { at the end of } \\
\text { the } \\
\text { programme }\end{array}$ \\
\hline $\begin{array}{l}\text { I will use the reflecting log } \\
\text { as a tool for recording data } \\
\text { and building teamwork }\end{array}$ & 3 & 9 & 12 & 3 \\
\hline $\begin{array}{l}\text { I feel much more } \\
\text { confident and secure about } \\
\text { my intervention }\end{array}$ & 10 & 11 & 13 & 0,3 \\
\hline $\begin{array}{l}\text { I feel that my intervention } \\
\text { is now more appropriate } \\
\text { and focused }\end{array}$ & 16 & 16 & & 0 \\
\hline $\begin{array}{l}\text { I feel much more tolerance } \\
\text { and/ or acceptance toward } \\
\text { the MDVI child I am } \\
\text { working with }\end{array}$ & 5 & 8 & 9 & 0,8 \\
\hline $\begin{array}{l}\text { I feel that the relationship } \\
\text { between me and the } \\
\text { MDVI child has been } \\
\text { improved }\end{array}$ & 3 & 10 & 11 & \\
\hline
\end{tabular}

*RL 1 (reflective log no. 1) has been completed after 2 months of the training programme.

**RL 2 has been completed after 4 months of the training programme.

$* * *$ RL 3 has been completed after 6 months of the training programme.

$*_{* * *}$ The gain indicator measures the profit of self-development regarding a certain type of reflection from the first reflective log to the last one. The formula for the gain indicator is:

(P3/P1) - 1; where P3 represents the number of participants acknowledging that type of reflection in the RL3 and P1 represents the number of participants acknowledging that type of reflection in the RL1.

\section{Discussion}

As presented in Table 1, there were some immediate benefits after the first two components of the training programme (the manual and the onsite training) in terms of adjusting the intervention to the needs of the MDVI child. 16 out of 21 specialists have stated that studying the training manual, acknowledging the specific communication strategies, planning the intervention and observing their relationship with the MDVI child as he/she is making steps toward the short-term objectives have given the professionals the feeling that their intervention is now more appropriate and focused. This type of reflection was written in the logs in multiple ways as this self-reflection question was asked in an open manner: How do you feel about what you have learnt? How do you intend to use the data which occurred from the action and observation phase in order to improve or move on to your next interventions? Some examples of the responses which were registered under the tag: I feel that my intervention is now more appropriate and focused are presented in Table 2. 
Table 2. Participants responses on self-reflection analysis of their intervention.

The intervention helped me to proceed with my objectives for the student. The communication diaries were used in a more systematic way.

This procedure reminded me that we should have small and clear objectives each time.

I'll use the data to improve the intervention in order for him to communicate better with his environment.

I feel that I need to be prepared to re-think an activity and practice it tirelessly with the student. I think this procedure is really helpful in that manner.

The data we gather will be used to determine whether our intervention is successful and what has to be corrected, so that the results will be the best possible.

This data will help to improve the design of the next interventions since it will be easier to assess the level of communication of the student. So, the choice of the intervention methodology will also be more appropriate and focused.

I feel it helps me become more structured and organized.

This type of reflection was constant in all three important steps of the reflection logs which means that our training programme has reached its objective in terms of identifying and observing the use of the communication strategies needed for each specific MDVI case.

A second type of reflection which also had a constant presence in all the 3 steps of the reflective logs was: I feel much more confident and secure about my intervention. This was a very positive and encouraging feedback for our training programme. Some of the answers in the reflective logs that were registered in this category are presented below in Table 3 :

Table 3. Participants responses regarding confidence with their interventions.

\begin{tabular}{|l|}
\hline The information, the suggestion and the methodology proposed make me feel safer about my decisions. \\
\hline I feel more prepared to interact with the student \\
\hline I feel more prepared and flexible to change \\
\hline I feel confident and think I can continue with my next objective \\
\hline I am very satisfied \\
\hline I feel more confident and thankful for this training trip \\
\hline $\begin{array}{l}\text { I feel prepared and safe to interact with the student but I am always alert that her reactions may be unsafe } \\
\text { for other trainees or that these reactions may trigger other trainees too. }\end{array}$ \\
\hline The feedback given by an external trainer make me feel more confident. \\
\hline
\end{tabular}

The other 3 types of reflections presented in Table 1 illustrate that the programme had an impact on the way the participants began to use their knowledge as they became more aware of their new skills through the continuous feedback from the mentors - either in the online group supervision sessions or in the reflective logs. There was an increasing number of specialists from the first to the last reflective logs who began to use this type of instrument to record their data and build a strong team of specialists with real-time feedback from different interventions.

\section{Conclusions}

The Erasmus+ PrECIVIM project has emphasized most of all the need to have mentors and partners with a constructive opinion and feedback. The professional development conducted in all 4 participating countries as a multicultural approach has highlighted the importance of reflecting from the MDVI child's perspective. Based on that, reflective logs should be considered part of the intervention process because they provide precious information about the communication development of an MDVI child which can only be built through a functional curriculum. The evaluation and intervention practices need to be permanently perfected and reflected upon and specialists working with MDVI children should always converts their reflections into actions.

\section{Acknowledgements}

This material was created with the financial support of the EU within the Erasmus + programme, PrEciVIM project, No: 2017-1-EL01-KA201-036289. The article reflects exclusively the authors' opinions and views, and the European Commission is not responsible for any use of the provided information. 


\section{References}

Bain, J. D., Mills, C., Ballantyne, R., Packer, J. 2002. Developing Reflection on Practice Through Journal Writing: Impacts of Variations in the Focus and Level of Feedback. Teachers and Teaching 8(2): 171-196.

Coulson, D., Harvey, M. (2013). Scaffolding student reflection for experience-based learning: A framework. Teaching in Higher Education, 18(4): 401-413. doi:10.1080/13562517.2012.752726

Darling-Hammond, L., Hyler, M. E., Gardner, M. (2017). Effective Teacher Professional Development (research brief). Palo Alto, CA: Learning Policy Institute.

Helyer, R. (2015). Learning through reflection: the critical role of reflection in work-based learning (WBL), Journal of Work-Applied Management, 7(1): 15-27. https://doi.org/10.1108/JWAM-10-2015-003

Kreber, C., Castleden, H. 2009. "Reflection on Teaching and Epistemological Structure: Reflective and Critically Reflective Process in 'pure/soft' and 'pure/hard' Fields." Higher Education 57(4), 509-531.

McCarthy, J. (2011). Reflective Writing, Higher Education and Professional Practice, Journal for Education in the Built Environment, 6:1, 29-43, DOI: 10.11120/jebe.2011.06010029

Powell, R., Vlachopoulos, P., Shaw, R. (2017). Development and Evaluation of a Reflective Log Assignment Designed to Enhance Postgraduate Psychology Students' Learning Experience. Journal of Perspectives in Applied Academic Practice. 5 (3). doi: 10.14297/jpaap.v5i3.232. available at: https://jpaap.napier.ac.uk/index.php/JPAAP/article/view/232/html

Rudiyati, S., Sukinah, S, Rahmawati, R. (2019). Requirements Need to be Fulfilled in Learning Children with Multiple Disabilities Visually Impairment. Advances in Social Science, Education and Humanities Research, vol. 296: 432-437.

Urdang, E. (2010). Awareness of self - a critical tool, Social Work Education, 29 (5): 523-538.

Walker, R., Cooke, M., Henderson, M. and Creedy, D.K., (2013). Using a critical reflection process to create an effective learning community in the workplace, Nurse Education Today, 33(5): 504-511. 


\title{
GAME-BASED TRAINING: AN EFFECTIVE METHOD FOR REDUCING BEHAVIORAL-FINANCE BIASES
}

\author{
Francesco Tommasi, Andrea Ceschi, Marija Gostimir, Marco Perini, \& Riccardo Sartori \\ Department of Human Sciences, University of Verona (Italy)
}

\begin{abstract}
Nowadays, being able to understand and infer reasonable conclusions based on great amounts of numerical information represents a key competence to succeed both in education and work. Numeracy is defined as the ability to understand, think, and reason using numbers and math concepts. Such a competence is key in the field of behavioral-finance where individuals manage numerical information to face important choices. Indeed, numeracy is fundamental to analyze data and to make predictions on the likelihood of future events. Moreover, research shows that individuals who score high on numeracy report higher ability in creating alternative options when it turns to make decisions. Building on the computer-supported collaborative learning and on the technology acceptance model, this study aimed to evaluate the efficacy of different interventions to reduce psychological biases related to numerical information processes in a group of university students $(\mathrm{N}=800)$. Specifically, we devised two training interventions based on the two educational approaches, i.e., the computer-supported collaborative learning and on the technology acceptance model. Participants were randomly assigned to one of the two conditions, and -post measures were collected after the interventions to assess their numerical information processing ability. Moreover, post-training results were compared with the results of a control group. Results of a one-way ANOVA showed that in the control group reported the highest incidence of numeracy biases. Our preliminary findings support the main literature on the use of technological instruments and distant training as keys to develop cognitive and operational competences. Such results are limited since we were unable to collect -pre-measures of participants' numeracy biases. Overall, the present contribution provides initial insights into how different kind of technology-based trainings can be effective to reduce biases referred to numerical information processing.
\end{abstract}

Keywords: E-learning, distant training, cognitive biases, numeracy, decision-making.

\section{Introduction}

By the recent labor economic transformation, being able to understand and infer reasonable conclusions based on great amounts of numerical information represents a key competence to succeed both in education (Lusardi \& Mitchell, 2014) and work (Tommasi, Franceschinis, Perini and Sartori, 2020). Nowadays, the increase in numerical data charges led to consider how individuals process information and make informed decisions (Waeneryd, 2001; Lusardi, 2015; Lusardi and Mitchell 2014). Evidence attesting the inadequacy of rational models to explain individual decision-making made the basis for insights into the area of Behavioral-Finance Biases (DeLong and Magin, 2009; Thaler, 1985). For example, literature shows the incidence of numeracy as a core aspect to be considered when making decisions in this domain. Such mental errors occur when individuals do not consider numerical information or are not able to understand numerical data, preferring different evaluation objects (Rieger, 2012; Fox and Tversky, 1995). Personal interests and preferences, mental representations, or anchoring on specific information are cases of cognitive biases which compromise the effect of individuals' decision-making process. Indeed, individuals show inadequate models in making reasonable decisions during economical financial deals (Rieger, 2012; Shefrin and Thaler, 1992; Thaler, 1985, Waeneryd, 2001). For instance, a low level of low level of numeracy is seen in the application of wrong mental calculations which violate economical and mathematical calculations. Alternatively, else, individuals avoid risks when information is ambiguous or prefer mental and personal representations of the information rather than the numerical and economical values. Cognitive errors are caused by fewer levels of numeracy, which cover both the knowledge and the abilities needed to understand, think, and reason using numbers and math concepts (Lusardi and Mitchell, 2014; MacGregor, Slovic, Dreman and Berry, 
2000; Olsen and Cox, 2001; Shapira, 1995). The growing financialization and the rise of financial complexity, training interventions for helping individuals to reduce the cognitive biases' incidence are largely recommended. Hence, in the area of possible interventions for improving and developing individuals' skills, remedial training methods for reducing behavioral-finance biases are offered by the technological progress. Over the years, authors proposed technological methods suggesting that didactic instruments for distance training and real-life simulations are effective tools for helping individuals learning (Dal Santo and Martelli, 2015; Król and Król, 2019; Willis, 2011) which are rooted into different educational approaches, i.e., the computer supported collaborative learning and the technology acceptance model (Król and Król, 2019). While e-learning platforms are used to refer to the Computer Supported Collaborative Learning (CSCL), simulations refer to the Technology Acceptance Model (TAM). The CSCL is a pedagogical approach where learning happens through social interaction using computer systems and users develop knowledge through communications and access to online resources. As a method for numeracy, by enhancing the numerical and logical abilities, e-learning platforms have been proven as useful systems (Amagir, Groot, Maassen van den Brink and Wilschut, 2018). On the other hand, TAM is an information system model based on the users' abilities to embrace and utilize tech-systems. Here, the learning process is facilitated via learning by doing in real-life simulated contexts (Ceschi, Dorofeeva, and Sartori, 2014). Evidence from research shows that the use of simulations is effective to improve financial decision-making (Harter and Harter, 2010; Jones and Chang, 2014).

According to the need for numerical literacy, we devised two training procedures based on the CSCL and TAM paradigms, i.e. using an e-learning platform and a simulation to evaluate their effectiveness. We focused on the incidence of behavioral-finance biases as the core evaluation for assessing numeracy among participants after the trainings. The present paper reports the preliminary results of our experimental exploration of the effectiveness of such methods. After briefly presenting the theoretical background of the technological methods, the method used, and the results of the examinations are present. In the last section, we discuss the results and the limitations of the study by providing indications for further examinations.

\section{The present contribution}

Considering the call for numerical abilities, we wanted to explore the effectiveness of technological methods for reducing behavioral-finance bias incidence based on the two main theoretical frameworks aforementioned. Referring to the CSCL paradigm, we proposed an e-learning system, Moodle (Moodle.org, 2018), in which participants were instructed to math and numerical principles as core abilities for financial decision-making (Wolla, 2017). Additionally, we devised a simulation training - TAM-based, the game-based training, Börse (Planspiel-Boerse, 2018). Through the learning-by-doing paradigm, participants were expected to show an increase their numerical abilities (Dal Santo and Martelli, 2015; Harter and Harter, 2010). After a brief presentation on financial decision-making, participants in the game-based training condition had to invest a virtual capital to be increased in the following ten weeks. To assess their performance, we selected five cognitive errors measures for evaluating the incidence of behavioral-finance biases (DeLong, \& Magin, 2009). We examined the effectiveness of both training methods comparing the two intervention groups and a control group. Our objective was to explore the effectiveness of the two technological tools for reducing behavioral-finance biases.

\subsection{Method}

Participants were recruited at the Department of Human Sciences, Verona University and they were randomly assigned to one of the three groups, two experimental groups and one control group. Each of them took part in the survey where we measured their level of behavioral-financial biases incidence. Eight hundred students were involved, with 22 years of median age $(S D=7.96$; range 19-59; 69\% female). $19.9 \%(N=159)$ of the participants attended the game-based training, $21.3 \%(N=170)$ the Moodle course while the rest of them $58.8 \%(N=471)$ composed the control group. Participation was anonymous. Self-report measures of financial-biases were used in a randomized system. During the e-learning intervention, participants were left to access to materials for studying, and search, and retrieve information from online databases. We presented them course materials in different forms and we mainly focused on mathematical and numerical concepts for enhancing numerical deals comprehension. The other group was involved in the simulation training, a Stock Market Game, i.e., a competition where participants had to invest a virtual capital trying to increase their amount of money or at least reduce the decrease. A brief presentation about stock market deals was given to leave students to only refer to their learning by gaming. To assess the decision-making process, five cognitive biases were selected as behavioral-Finance Biases for their occurrence during financial deals (DeLong and Magin, 2009; Thaler, 
1985). After all the trainings, participants completed the same questionnaire. Data have been analyzed with IBM SPSS statistics, version 21.1. After analyzing the reliability of the measures and the normal distributions within the samples, we used the one-way analysis of variance (one-way ANOVA) to explore whether there were significance differences between participants assigned to different groups in the level of the five cognitive biases selected.

\subsection{Results}

One-way ANOVA was conducted to compare the effect of technological methods on behavioral-finance biases incidence (E-learning platform vs Game-Based Training vs Control group). We found significant differences between groups. Participants in the Game-Based training group showed the lowest incidence of behavioral-financial biases, suggesting that such approach was more effective than the e-learning platform. In particular, the significant difference for cognitive task named money illusion, $\left(F(2,552)=2.61, p=.001, \eta^{2}=0.01\right)$ reveled a lower level for participants of the simulation $(M=47.73$, $S D=33.40)$ than other groups, as for the Zero Risk Bias, $F(2,670)=28.79, p=.001, \eta^{2}=0.08$, with a small average of incidence $(M=47.00, S D=30.85)$. On the other hand, the E-learning group reported a significantly lower incidence $(M=36.77, S D=16.67)$ of the Representation Bias $F(2,670)=4.88, p=.001$, $\eta^{2}=0.14$. There were no statistically significant differences between groups concerning other measures, rather than for Anchoring $\operatorname{Bias}(F(2,615)=19.36, p=.001)$ with a lower level for the game based group $(M=15.80, S D=10.46)$ than the other two groups. Regarding the last measures, mental account error, such behavioral finance bias resulted to be significantly higher in the control group and lower in the game-based group $\left(F(2,744)=19.61, p=.05, \eta^{2}=0.01\right)$. Although only four statistical differences are reported by the ANOVA, by the descriptive statistics, Game-Based training group revealed a lower incidence of behavioral-financial biases among the three groups. Participants of the real-life simulation showed better ability in solving economical and financial deals in comparison with the other two groups. On the other hand, the two groups didn't show significant differences reporting similar results in the incidence of cognitive errors.

\section{Discussion and limitations}

This study was motivated by the call for financial literacy and linked methods for improving individuals' performance in the increase of charges of numerical information (Lusardi, 2015). Accordingly, thanks to the current development of technological offers for training methods, coupled with the two major educational approaches (Dal Santo and Martelli, 2015; Król and Król, 2019; Willis, 2011), we devised two tech-interventions for reducing behavioral-finance biases. The assessment of financial literacy has been made by the evaluation of cognitive errors incidence. In fact, behavioral-finance biases occur when individuals have low level of numerical and financial literacy. Such complex measures have been considered and analyzed to verify the effectiveness of the tech-methods stressing the role of tech-training and formation as important for human beings. Our findings support that the existing evidence for game-based simulations training for financial biases. Although we did not find large significance among the tasks used, by the descriptive statistics, we can stress the effectiveness of the training. In fact, participants reported lower incidences among all the behavioral-finance biases except for the Anchoring Bias. On the other hand, the E-learning training did not reveal significant improvement. We believe that this training was not sufficiently rooted for helping participants to apply numerical and mathematical knowledge in financial tasks. Future studies may improve this training adding practical contents at the end of sessions.

Due to the fact that training, innovation, and new competences are highly recommended for facing with societal and organizational changes (Sartori, Costantini, Ceschi and Tommasi, 2018), as well as the recent the labor transformation with the massive presence of numerical information in digital shapes as a result of the so-called industry 4.0 (Tommasi, Franceschinis, Perini and Sartori, 2020), the present paper was additionally motivated to propose possible applied applications for training and education. Technological interventions can be used to enhance students' knowledge in school and academic context. Moreover, in organizational context, technological interventions can be used for life-long training to address not mastering individuals. Having noted the important implications of numerical literacy in today life, and the relevance of decision-making as key-competence to succeed in education and at work, this study hopes to add possible insights on how different kind of technology-based trainings can be effective to reduce cognitive biases. In particular, the present study aims to offer a possible exploration of such method in order to advance further examinations. 


\section{Conclusions}

The present study is not without limits. The sample composition and distribution limit our results to specific kind of populations giving few extended evidences. Forward empirical explorations and examinations may distribute participants equal groups. Additionally, although these findings support the notion that game-based learning is key to develop cognitive and operational competences, it should be noted, however, that we were unable to collect -pre-measures of participants' cognitive biases. Then, future studies may address our gaps devising more complex experimental design. Moreover, further examinations might address such examinations by involving examinations of individual math skills (Weller, Dieckmann, Tusler, Mertz, Burns \& Peters, 2013; Dal Santo and Martelli, 2015), as well as soft skills that might help in the development of specific knowledge (Tommasi, Franceschinis, Perini \& Tacconi, 2020). Technological methods for training are important offers of the increasing world of technologies. Coupled with learning theories (CSCL and TAM), we are able to make important insights into the learning process, and to build even more effective procedures for training. Our findings support the use of simulation for training intervention fostering numerical abilities for financial tasks. On the other hand, the results show our limits in E-learning training intervention devised. We suggest for future studies to add practical contents to improve, simultaneously, knowledge and financial abilities Overall, we hope these data and theoretical contributions will provide ideas for developing future evidence-based methods addressing the challenge of distant training and development.

\section{References}

Amagir, A., Groot, W., Maassen van den Brink, H., \& Wilschut, A. (2018). A review of financial-literacy education programs for children and adolescents. Citizenship, Social and Economics Education, $17(1), 56-80$.

Ceschi, A., Dorofeeva, K., \& Sartori, R. (2014). Studying teamwork and team climate by using a business simulation: How communication and innovation can improve group learning and decision-making performance. European Journal of Training and Development, 38(3), 211-230.

Dal Santo, A., \& Martelli, D. (2015). Increasing Financial Literacy through Simulations: The Case of the CFA Society Italy Fund Management Challenge. Journal of Financial Management, Markets and Institutions, 3(1), 69-100.

DeLong, J. B., \& Magin, K. (2009). The US equity return premium: past, present, and future. Journal of Economic Perspectives, 23(1), 193-208.

Fox, C. R., \& Tversky, A. (1995). Ambiguity aversion and comparative ignorance. The quarterly journal of economics, 110(3), 585-603.

Harter, C., \& Harter, J. F. (2010). Is financial literacy improved by participating in a stock market game. Journal for economic educators, 10(1), 21-32.

Jones, D. A., \& Chang, M. (2014). Pecunia-A Life Simulation Game for Finance Education. Research \& Practice in Technology Enhanced Learning, 9(1), 7-39.

Król, M., \& Król, M. (2019). Learning From Peers' Eye Movements in the Absence of Expert Guidance: A Proof of Concept Using Laboratory Stock Trading, Eye Tracking, and Machine Learning. Cognitive science, 43(2), 12-16.

Lusardi, A. (2015). Financial literacy: Do people know the ABCs of finance?. Public understanding of science, 24(3), 260-271.

Lusardi, A., and Mitchell, O.S. (2014) The economic importance of financial literacy: Theory and evidence. Journal of Economic Literature 52: 5-44.

MacGregor, D. G., Slovic, P., Dreman, D., \& Berry, M. (2000). Imagery, affect, and financial judgment. The Journal of Psychology and Financial Markets, 1(2), 104-110.

Moodle. International Society for Technology in Education. Retrieved March 27, 2019, from URL: https://moodle.org/

Olsen, R. A., \& Cox, C. M. (2001). The influence of gender on the perception and response to investment risk: The case of professional investors. The journal of psychology and financial markets, 2(1), 29-36.

Planspiel-Boerse, Retrieved March 27, 2019, from URL: http://www.sparkassen-schulservice.de and URL: http://www.planspiel- boerse.de

Rieger, M. O. (2012). Why do investors buy bad financial products? Probability misestimation and preferences in financial investment decision. Journal of Behavioral Finance, 13(2), 108-118. 
Sartori, R., Costantini, A., Ceschi, A., \& Tommasi, F. (2018). How Do You Manage Change in Organizations? Training, Development, Innovation, and Their Relationships. Frontiers in Psychology, 9, 313-324.

Shapira Z. (1995). Risk taking: A managerial perspective. New York: Russell Sage.

Shefrin, Hersh M. and Richard H. Thaler (1992), "Mental Accounting, Saving, and Self-Control," in Choice Over Time, George F. Loewenstein and John Elster, eds. New York: Russell Sage Foundation, 287-330.

Thaler, R. (1985). Mental accounting and consumer choice. Marketing science, 4(3), 199-214.

Tommasi, F., Franceschinis, I., Perini, M., \& Sartori, R. (2020). A systematic scoping review on skills variety for VET in the industry 4.0. In Proceedings of the International Conference on Education and New Developments (END) (pp. 474-476).

Tommasi, Francesco, Ioris Franceschinis, Marco Perini, and Giuseppe Tacconi. "Skilling for Tomorrow at School: A Training Project for IVET And Technical Students' soft Skills." In Education and New Developments (END) (pp. 100-104).

Waeneryd K.E. (2001). Stock market psychology: How people value and trade stocks. Northampton: Edward Elgar Publishing.

Weller, J. A., Dieckmann, N. F., Tusler, M., Mertz, C. K., Burns, W. J., \& Peters, E. (2013). Development and testing of an abbreviated numeracy scale: A Rasch analysis approach. Journal of Behavioral Decision Making, 26(2), 198-212.

Willis, L. E. (2011). The financial education fallacy. American Economic Review, 101(3), 429-34.

Wolla, S. (2017). Evaluating the effectiveness of an online module for increasing financial literacy. Social Studies Research and Practice, 12(2), 154-167. 


\title{
DIGITALLY CHANGING TEACHING PRACTICE ENVIRONMENTS: AN EXPLORATION OF CONCEPTS AND IMPLICATIONS
}

\author{
Marloes de Munnik ${ }^{1}$, \& Osama Al-Mahdi ${ }^{2}$ \\ ${ }^{1}$ Centre for Researching Education and Labor, University of the Witwatersrand $/ P h D$ fellow \\ (South Africa) \\ ${ }^{2}$ Educational Studies Department, Bahrain Teachers College, University of Bahrain \\ (Kingdom of Bahrain)
}

\begin{abstract}
This paper proposes using different concepts for guiding institutional practices in times of digitally changing professional teaching work environments. This paper draws upon our previous research and offers a first step of a framework, to understand and explore the new digital changes for professional teaching and learning practice, while engaging in online and virtual work and learning environments. Thereby focusing on the notion of a professional and the social implications of digital work technologies that are used for teaching and learning. The theoretical paper is structured around concepts we identified in our previous work and its potential of adopting them in the context of digital communities of professional practices. Addressing these objectives can hopefully help us to understand, what the effects of digital professional teaching work environments on teaching practice and for teacher's professional responsibility are, their social effects in everyday teacher work and their practice related knowledge? What capabilities, features or skills are enabling teachers to do so and what guidelines can help them to cope with the current changes? And ultimately, how workplaces, schools and universities can benefit from these ideas? We focus on both human social factors and digital material factors as being inherent to professional teaching and learning practice. We hereby build upon concepts derived from socio-cultural and socio-material theories which are currently not commonly used in the same context, such as: communities of practice which is popular in socio-cultural learning theories whereby the understanding of human development relies on the social world; and extending the community of practice with materiality whereby human development also involves the material world. We contribute with this paper by suggesting that our framework, drawing on concepts of two different but related learning theories is useful for further research, such as on the institutional and individual response to digital change in teaching and learning practice. We believe that our theoretical informed conceptual approach enables to inform an increased professionality of teaching professionals in times of digital work change, activates thinking about different concepts, a change of mindset or at least provide the guidelines for an improved understanding among those involved in teaching practice.
\end{abstract}

Keywords: Education, communities of digital practice, professional practice, digital technologies, participatory learning practices.

\section{Introduction}

The Covid-19 pandemic has forced humanity to adapt to digital change as never before. The pandemic has forced individuals to look beyond traditional approved approaches for working and changed the generalized appetite for digital advanced ways of working. The digital change implications of the fourth industrial revolution are believed impacting work and have implications on individual workers at various levels (International Labour Organization, 2015; Schwab, 2016). An example of accelerated change that has happened during the current Pandemic, is that more individual professionals were forced into a work ecosystem with digital technologies. People were namely, forced into a situation of remote work and had to work with digital technologies to support them in this way of working. For instance, the digital technologies played a role in executing work practices directly and in communicating with people. Some of the changes are directly automating or innovating traditional work techniques and processes. For example, teachers were forced into online teaching and academic institutions which were previously reluctant to change, were forced to adjust their standpoint and adapt to the required change by exploring less-traditional ways of working. The rapid changes and new trends in our environments resulted in digital technologies being further invited in our work and learning environments. This resulted in them being strongly embedded in both. Fenwick \& Edwards (2016) suggest that a lack of detailed research 
about digital technologies and effects on professional responsibility exist and we believe that adding a conceptual framework to understand institutional teaching practices in times of digital change would contribute to this gap. This paper draws upon our previous research (de Munnik, 2020), (Al-Mahdi \& Alwadi, 2015) and offers a first step of a framework to understand and explore the new digital changes for professional teaching practice and changing professional teaching work environments, drawing on and merging ideas from sociomaterial and sociocultural theories. The paper is structured around concepts that may help to answer questions such as, what are the implications of digital technology in teaching practice for teacher's professional responsibility, their social effects in everyday teacher work and their practice related knowledge? What capabilities, features or skills are required from teachers and what frameworks or theories can help them to cope with the current changes? And ultimately, how workplaces, schools and universities can benefit from these ideas? Given the variance in the topics of investigation and the multidisciplinary nature, the modest contribution we make is therefore, not intended to be a comprehensive research, a literature review, or purely academically centered suggestion. In fact, our suggestion rather relies on acting as an exploratory conceptual starting point, drawing selectively on literature in sociocultural and sociomaterial theories and taking an ontological approach of the existence of multiple realities instead on one ultimate scientific truth. Ultimately, we hope hereby to contribute to a discussion and stimulate to look beyond stabilized and commonly accepted approaches which could enable diverse ways of dealing with learning and teaching in times of digital change. Our position is that digital technologies must be seen as professional enhancing aspects (de Munnik, 2020) rather than threats, are contributing value to professional teaching practices and are resulting in emerging possibilities for creating innovative learning and teaching contexts. We hereby acknowledge that digital technologies may pose challenges for both individuals as well as organizational practice, but we see these as small obstacles to overcome considering their strong positive value proposition. This thought-provoking theoretical paper discusses how sociocultural and sociomaterial approaches can be used to understand the importance of adapting to change for teaching professionals in a changing digital work context - and the possible social implications of digital change for teaching professionals.

\section{Theories and concepts}

Various learning theories and traditions in the field of education exist and change over time. One of which is a conceptualization of how people think and act, developed by the sociocultural school of thought. The primary set of principles of this theory were developed by Vygotsky (1978) and his colleagues and a multitude of scholars around the world (e.g., Lave \& Wenger, 1991; Moll et al., 1992; Rogoff, 1990; Tharp \& Gallimore, 1988). This theory suggests that human development requires an understanding of the extended social world. It is impossible to understand cognitive development by just studying the individual; the extended social world of the learner must be taken into consideration because focusing only on the individual may divide human functioning into smaller units that no longer work as does the larger living unit (Rogoff et al., 2003; Rowe \& Wertsch, 2002; Siegler \& Alibali, 2005). Furthermore, the sociocultural theory suggests that human cognitive development is influenced not only by social interactions, but also by cultural tools. These tools divide into several categories including: material tools (e.g., calculators, computers, or smart phones) and symbolic systems (e.g., spoken and written language, signs, symbols, number systems, rituals, models of behaviors, scientific concepts, and techniques that assist memory in thinking). These tools influence the way people organize, process, and remember information. In the sociocultural view, learning is regarded as a process that occurs in a larger context where knowledge has a functional importance for the learner and this process of linking the individual understanding with the wider context can aid the learner in achieving his or her personal goal that is socially valued within the community. Thus, learning is not seen as just a separate activity undertaken for its own sake in the sociocultural perspective (Wells, 1999). The sociocultural theory was utilized as a perceptive and practical framework for examining various educational, social and psychological phenomena in a plethora of research in different parts of the world. Lave and Wenger (1991) proposed the concept of 'situated learning' and learning through participation in the 'community of practice'. Communities of practice was a trend in learning for work theories which is different from traditional understandings of learning found in cognitive-behavioristic theories, according to Lave and Wenger (1991); it relied on human collaboration as a rudimentary wheel for learning and learning is conceptualized as a social event. To conclude this section about sociocultural theories, we can establish that the experience of 'learning' itself is a complex process and, thus, can be approached through different perspectives. More recent views define learning as a social process that involves participation in learning communities through social interactions with humans and materiality, and this perspective shall be given more focus in the following sections.

In later years, the concept of social communities of practice was expanded upon and new learning theories, both including participating humans and materiality emerged. Materiality is hereby understood as the involvement of other participants beyond humans, whereby materiality such as objects, tools, technologies, and processes are participating in the work practice and have an active role in the 
process of this work practice. The theoretical approach in which this materiality received further acknowledgement, beyond being non-participating constituents of a work practice, were those of sociomaterial theories (Fenwick et al., 2012). Sociomateriality here is referring to different theories of work such as Actor Network Theory [ANT] (Latour, 2005), post-humanism, and the practice-theory (Nicolini, 2012). Critiques of the sociomaterial theory and related approaches often tend to refer to the false allocation of agency to materiality. However, following one of the main historical figures in ANT, Latour, no upfront agency is allocated to any member or actor of the practice (Latour, 2004) but all are considered relevant in the practice network. In sociomateriality, humans are found to perform together with all actors in a practice, both human and nonhuman. Performing is hereby understood as a work-related activity that changes and relies on the specific context. We are thereby drawing on Barad (2003) and asking questions about professional accountability and responsibility. Each practice participant then contributes in its own way, both considered and accidentally to the development of that specific work practice. The degree of this individual professional contribution relies on the concept of the 'enactment of boundaries' following Barad (2003) and in advanced ways through application or change (Orlikowski, 2000). Enactment used here, thus means that those professionals who are engaging in a digital technology impacted work context, may act in varies ways. And as such, the impact on their work, as well as how they use, and negotiate professional agreements with digital technology varies. In any case of working with other participants in a work practice, the professionals must 'translate' their actions and 'mobilize' (Callon, 1984) and negotiate to reach a common agreement or achieve a "dynamic stability" (Scoles, 2017, p. 83). To conclude, sociomaterial approaches are relevant to the current context since professionals must work in a digital work environment, thus theories acknowledging their participating role are required. Since the Covid-19 pandemic forced professionals to work in unusual ways together, communities of work practice thereby move beyond human constitutions only and are including digital technologies. The digital technologies, which are thus a form of materiality, are having an impact on professionals and their professional responsibilities (Elliott, 2017; Fenwick \& Edwards, 2016) based on the notion of their considered participation in a work practice. Nevertheless, we suggest that while including digital technologies as considered participating members in the practice while leaving space for human collaboration and their professional practice argues for maintaining the social aspects as found in sociocultural theories which combination is what we suggest for a conceptual framework.

\section{Sociomateriality considered in digital communities of professional teaching practice}

To illustrate the idea of technology and materiality we are focusing on engineers as exemplars of professionals working in a digital technology impacted work environment and conceptualize the application to teachers later on. Whereby we are assuming, that while their professional responsibilities and ability to enact upon digital technologies may vary, as well as their 'negotiated' agreements, the principles of applying a sociomaterial informed conceptual framework are similar. This is based on them both being semi-regulated professions, relying on an agreed and regulated body of knowledge (Abbott, 1988) and therefore subject to perform successful negotiations for reaching a common agreement. Abbott suggest that professions are relying on the control of knowledge and skill and the regulation of techniques (practices) and are therefore "more likely resistant to change" (de Munnik, 2020, p. 9) their agreed body of professional knowledge. This agreed body of professional knowledge relies on accepted standards agreed over time among professional bodies and groups and may feed into the delay between changes in work and professional practice and required skills, skills here are understood to be both residing in humans and work (McGuinness et al., 2017).

In the professional context of engineering, recent research (de Munnik, 2020) applied the concepts of performing and enactment to two specific engineering work practices, namely, preparing project reports and developing construction plans. The professional responsibilities of the engineering professionals in the research were shared or were changing in the digital technology context. The engineering work practice was then termed an unique sociomaterial networked relative "stability" (Scoles, 2017, p. 196), since the engineering work practice was not static and similar in each context. This resulted in the understanding that learning opportunities for the engineering professionals were developed, based on the performing of each sociomaterial member of that engineering practice (de Munnik, 2020) or the successful 'enactment' upon each other. Hereby, the former applies to our earlier suggestion that of a professional practice being sociomaterial, whereas the latter refers to the notion of a social cultural community of practice.

The sociomaterial members of the work practice are performing themselves into meaningful action. Thus, also digital participants may change the work practice directly and indirectly. This change can be caused by the task/skill complementary or replacing capabilities of digital technologies. Digital capabilities may be exceeding the level of human capabilities. Such as those identified by Elliott (2017), suggesting that some technological systems are able to perform the reasoning of information, found to be closely to the identified existing human reasoning abilities. This subsequently result in digital technology's enhancing power for professional decision-making work of humans by using reasoning in 
the process. We therefore suggest that both social and material have a significant participating role in a work practice and may define and guide its associated learning. Next, we explore the digital impacted network of professional practice.

In the same research (de Munnik, 2020), simulation as a digital technology was found as a part of this particular network of the engineering professional work practice of preparing project reports, namely, for $35 \%$ of the 41 engineering professionals. A detailed sociomaterial tracing of the practice network of one particular engineering professional, which relied on the perception that practitioners were being trustworthy expert informants (Mulcahy, 2013), showed the important role of simulation in the sociomaterial network of this particular professional. The network showed that simulation was part of the engineering work practice and the connections to both other actors, actions and learning illustrated that the professional experienced both social and material implications from this shared participation. The engineering professional was in fact sharing his/her professional responsibilities with digital technology. The implications for the respective engineering professional were that boundaries were being pushed and more was possible in fewer time and with an increased quality (de Munnik, 2020).

Simulation is also used in teacher practices, such as by imitating a realistic learning environment and simulating a specific professional action of the learner in its situated environment or also differently used in teaching scientific concepts through Virtual Reality. In essence, a teacher is then both a provider in this digital community, and at the same time a professional participant which requires us as teachers to reconsider our social role into a sociomaterial role.

Imagining working in an Artificial Intelligence [AI] impacted environment. AI is hereby understood as the performing of "human-like cognitive functions" (Organisation for Economic Co-operation and Development, 2017, p. 25) by systems and devices. AI has the potential for further sharing of professional responsibilities and may further accelerate change in our professional work practices. This in turn requires us to perform differently, relying on our successful abilities to enact upon the digital participants such as AI. This means that our current digital capability status may require improvement, as well as our broader skills, and at the least, we should inform ourselves about digital capability developments to allow for a successful further sharing of professional work responsibilities for both ourselves and for our students. The implications for learning for a digital work practice approached with the conceptual framework of a community of a social material practice can help professionals to understand that lifelong learning is key. Learning for professional practice can thus not end, is continuous, unique and context dependent. For professional upskilling and reskilling discussions, this means that professional development is required when changes of the work context, environment or in participating sociomaterial members happen. Participating in a work practice is performing ones own existence and translate own knowledge and skills in the sociomaterial digital-human community, as well as the ability to come to mutual agreements with other actors in the practice. To illustrate, being a teacher thus requires not only considering the social aspects of one's own professional practice and learning and teaching, but also requires considering the materiality of learning (Mulcahy, 2012; Sørensen, 2009).

\section{Conclusion - How work and learning stakeholders may benefit from the ideas of sociomaterial communities of practice}

The strength of sociomaterial theories is that the approaches drawing on them, allowing to see the social effects of a digital impacted practice. For example, such as online learning and teaching. A practice which is taking place in a virtual community with both human and non-human participants (e.g. digital technology). Adopting a sociomaterial approach, the focus shifts away from seeing online learning as an own and practice changing event, to an activity in which both human and digital actors are taking part and creating learning opportunities. This may help to see our professional learning for work professional teaching- practice as something we need to sociomaterial collaboratively participate in, and which keeps changing and evolving. Recommendations for education and learning for work may move beyond traditional understandings of school-based only. Models such as work-based learning with the "importance of exposure and participating in practice and experience" (de Munnik, 2020, p. 225) may become increasingly valuable in times of digital changes. In Work based learning, adapting to change is through developing in practice all the time and thereby, acknowledging learning for professional practice as an 'unique relative stability' (de Munnik, 2020; Scoles, 2017). Learning is not an individual event but something that requires consideration of an active participation of a work practice in the 'real' context and with all, both direct and mediating participating members who have to negotiate to come to common agreements in the work practice. Further questions we can ask and answer with using the new proposed sociomaterial conceptual frameworks in the digital context, are therefor: Whether or not, the accelerated digital changes resulting from the Covid-19 pandemic have resulted in professionals' knowledge and skills set suitable to deal with these changes or allowing the professionals to enact upon the technologies? - Have professionals in semi-regulated professions been able to adapt to the change required of them, and in what way have they been limited by the possible regulations or agreed body of knowledge in their professions? 


\section{References}

Abbott, A. (1988). The system of professions: An essay on the division of expert labor. University of Chicago Press.

Al-Mahdi, O., \& Alwadi, H. (2015). Towards a sociocultural approach on teachers' professional development in Bahrain. Journal of Teaching and Teacher Education, 3(1), 89:100.

Barad, K. (2003). Posthumanist Performativity: Toward an Understanding of How Matter Comes to Matter. Signs: Journal of women in culture and society, 28(3), 801-831.

Callon, M. (1984). Some Elements of a Sociology of Translation: Domestication of the Scallops and the Fishermen of St Brieuc Bay. The Sociological Review, 32(1_suppl), 196-233.

de Munnik, M. (2020). Exploring learning for work in the context of digital work technologies: The sociomaterial case of engineering professionals in the construction industry (Unpublished doctoral dissertation). University of the Witwatersrand, Johannesburg South Africa.

Elliott, S. W. (2017). Projecting the impact of information technology on work and skills in the 2030s. In C. Warhurst, K. Mayhem, D. Finegold, \& J. Buchanan (Eds.), The Oxford handbook of skills and Training (pp. 557-575). Oxford University Press.

Fenwick, T., \& Edwards, R. (2016). Exploring the impact of digital technologies on professional responsibilities and education. European Educational Research Journal, 15(1), 117-131.

Fenwick, T., Nerland, M., \& Jensen, K. (2012). Sociomaterial approaches to conceptualising professional learning and practice. Journal of Education and Work, 25(1), 1-13.

International Labour Organization. (2015). World Employment and Social Outlook 2015 - The changing nature of jobs (13.01.3; p. 155). ILO.

Latour, B. (2004). Why has critique run out of steam? From matters of fact to matters of concern. Critical Inquiry, 30(2), 225-248.

Latour, B. (2005). Reassembling the Social: An Introduction to Actor-Network-Theory (1st ed.). Oxford University Press.

Lave, J., \& Wenger, E. (1991). Situated learning: Legitimate peripheral participation. Situated Learning: Legitimate Peripheral Participation, 138-138.

McGuinness, S., Pouliakas, K., \& Redmond, P. (2017). How useful is the concept of skills mismatch? International Labour Office.

Moll, L., Amanti, C., Neff, D., \& Gonzalez. (1992). Funds of knowledge for teaching: Using qualitative approach to connect home and classroom. Theory into Practice, XXXI (2), 132-141.

Mulcahy, D. (2012). Thinking teacher professional learning performatively: A socio-material account. Journal of Education and Work, 25(1), 121-139

Mulcahy, D. (2013). Turning Around the Question of 'Transfer' in Education: Tracing the sociomaterial. Educational Philosophy and Theory, 45(12), 1276-1289.

Nicolini, D. (2012). Practice theory, work \& organization. Oxford University Press.

Organisation for Economic Co-operation and Development. (2017). OECD Digital Economy Outlook 2017. OECD Publishing.

Orlikowski, W. J. (2000). Using Technology and Constituting Structures; A Practice Lens for Studying Technology in Organizations. Organization Science, 11(4), 404-428.

Rogoff, B. (1990). Apprenticeship in thinking: Cognitive development in social context. Oxford University Press.

Rogoff, B., Paradise, R., Arauz, R., Corra-Chavez, M., \& Angellio, C. (2003). Firsthand Learning through intent participation. Annual Review of Psychology, 54, 175-203.

Rowe, S., \& Wertsch, J. (2002). Vygotsky's model of cognitive development. In U. Goswami (Ed.), Blackwell handbook of childhood cognitive development (pp. 538-554). Blackwell Publishing.

Schwab, K. (2016). The fourth industrial revolution. Penguin.

Scoles, J. (2017). Exploring professional engineers' knowings-in-practice in an emerging industry: An Actor-Network Theory approach (Doctoral dissertation University of Stirling), retrieved from https://dspace.stir.ac.uk/handle/1893/26857\#.YCTAyugzY2w

Siegler, R., \& Alibali, M. (2005). Children's thinking (4th ed.). Parson Education International.

Sørensen, E. (2009). The Materiality of Learning: Technology and Knowledge in Educational Practice. Cambridge University Press; Cambridge Core.

Tharp, R., \& Gallimore, R. (1988). Rousing minds of life: Teaching, learning and schooling in social context. Cambridge University Press.

Vygotsky, L. (1978). Mind in society: The development of higher psychological processes. Harvard University Press.

Wells, G. (1999). Dialogic inquiry: Toward a sociocultural practice and theory in education. Cambridge University Press. 


\title{
DISTANCE EDUCATION AND LEARNING PROCESSES. A SURVEY AT UNIVERSITY OF CATANIA DURING THE COVID-19 PANDEMIC
}

\author{
Valeria Di Martino, \& Raffaella C. Strongoli* \\ Department of Education, University of Catania (Italy)
}

\begin{abstract}
The emergency situation caused by the COVID-19 pandemic required all Italian universities to implement alternative teaching strategies to traditional face-to-face lessons. At the University of Catania, this situation prompted the start of distance learning paths in a synchronous mode at the very beginning of the emergency. At the same time, the lecturers were encouraged to video-record the lessons in order to make them available to students also in asynchronous mode. On the basis of this emergency situation, an investigation was immediately launched to identify the consequences of the new teaching methods on student learning processes; the research began in the first phase of the lockdown in Italy (March 2020) and ended in January 2021.

The aim of this contribution is to present the results of the research conducted on a sample of 300 students following bachelor degree courses of the Department of Education at the University of Catania. The research aims to detect the students' points of view on the strengths and weaknesses of the synchronous and asynchronous ways of presenting lessons and their respective impact on learning processes. The results of the research could provide useful insights to rethink university teaching even when the emergency situation comes to an end.
\end{abstract}

Keywords: Learning processes, distance learning, synchronous and asynchronous teaching, higher education, COVID-19.

\section{Introduction. The SARS-CoV2 pandemic and emergency remote teaching}

As of March 2020 throughout Italy, and April 6, 2020 in 188 countries, a temporary shutdown of all services considered non-essential was imposed to curb the spread of the highly contagious COVID-19 pathogen (Sohrabi et al., 2020). This completely unprecedented situation required universities around the world to respond extremely quickly to the education and training needs of their students, often without being sufficiently prepared to plan, monitor and evaluate these new educational practices (Houlden, Veletsianos, 2020). There has been much discussion regarding Emergency Remote Teaching (ERT) in order to identify the special features of this new scenario. Emergency Remote Teaching is defined as a sudden temporary shift from the regular in-person educational process to an online mode of teaching and learning as a result of an immense catastrophe; in this sense, ERT is very different from regular online courses that are conceived and designed to be delivered virtually. What we know from academic research on the subject is that effective online learning is the result of careful and systematic educational design. Indeed, the design process and the careful planning of different phases and the components of the activities have a significant impact on the quality of the learning experience (Means, Bakia, Murphy, 2014). Clearly, this careful planning process - that the academic literature identifies as the main way to ensure the success of online teaching activities - is not possible in cases of Emergency Remote Teaching.

When ERT is initiated, what happens is that a course that was intended and designed didactically to be face-to-face or hybrid instruction is transformed into a distance education course; in some cases, the course is simply moved to a digital platform while maintaining the same instructional characteristics. ERT has particular features that distinguish it from what is normally referred to as online learning (Hodges, Moore, Lockee, Trust, Bond, 2020). These are the distinctive characteristics of ERT: it must be temporary; it is activated in response to a crisis or something beyond human control; it may involve working with few or poor resources; and the students involved may have no choice and may not be able to make the most of the content offered. The primary goal in these circumstances is not to recreate a sound educational ecosystem similar to face-to-face educational activities, but rather to provide temporary

*This paper is the result of the joint work of the two authors. Specifically Valeria Di Martino is author of the paragraphs 4 and 5 , Raffaella C. Strongoli is author of the paragraphs 1,2 and 6. 
access to instruction and teaching aids in such a way that the course is quick to set up and reliably available during an emergency or crisis.

Many universities responded to the emergency situation in similar ways; with regard to the organizational aspects, basically, three forms of teaching activities have been put in place: synchronous, asynchronous and blended. The strengths of synchrony lie in the fact that the teaching activities can be kept almost unchanged from face-to-face activities with the possibility of the teacher interacting with students and therefore providing them with constant feedback. However, regarding the management of class time, due consideration should be given to the fatigue load caused by the continued use of electronic devices and screens. The flexibility of time is the main advantage of the asynchronous mode, since it allows students to access the lesson when it suits them best; in this way, problems concerning space and electronic devices that may arise from synchronous ERT are partially resolved. Obviously, this mode also has many critical elements since it does not allow for immediate feedback and collaborative activities that are carried out with the presence and assistance of the teacher. From what has been briefly described so far, it is clear that a mid-way solution in the form of the blended mode may be the best choice, since it provides synchronous lessons with the related interactions and feedback and, through the recording of lessons or the provision of supplementary materials and analytical, asynchronous exercises, it can meet the already mentioned needs for flexibility of distance activities (Hodges, Moore, Lockee, Trust, Bond, 2020).

Numerous difficulties were encountered during the transition to virtual education following the ERT model. These difficulties could be attributed to several factors: organizational, pedagogical and personal aspects. Regarding the organizational aspects, we can certainly mention the problems that academic institutions, teachers and students encountered in adapting to the characteristics of the new teaching and learning environment. The pedagogical aspects include the difficulty for teachers to redesign the modules to adapt them to the online platform, especially if this had to be done in a short period of time. As far as students are concerned, the problems involved the possibility of not being able to access the network and the fact that they found it difficult to concentrate during the online lesson due to the absence of eye contact, gestures and the typical atmosphere of a classroom lesson. Among the personal aspects, the need to carry out all these activities in a home setting certainly played a role: the family atmosphere is very often not conducive to the teaching and learning process. There can be many distractions for both teachers and students. The elements of the home environment that may have a dysfunctional impact on the process of online learning and teaching are the following: space management, sharing of devices, childcare responsibilities, and the differentiation between work-time and leisure time (Ferri, Grifoni, Guzzo, 2020).

However, in spite of these critical aspects, ERT seems to have just as many strengths for both teachers and students, such as: the student can view recorded sessions multiple times, and the frequent access to resources can provide extra opportunities for students to consolidate their knowledge; the new online learning environment can allow students to learn independently or customize learning pathways; after the initial emergency redesign of the curriculum, it can be reused for any sudden future changes; academic institutions have gained new skills and experience that may be useful in the future to adapt to similar situations; and the transition from conventional teaching to online teaching has, in part, bridged the digital divide in the conscious and functional use of advanced digital technologies for both teachers and students (Abdalellah, Basim, Abdul, Vigil, 2020).

\section{Design and objectives}

Following the spread of the SARS-CoV2 pandemic, the University of Catania promptly started Emergency Remote Teaching courses in synchronous mode on the Microsoft Teams platform. Although the University decided to adopt a single mode and a single platform, it nevertheless encouraged teachers to video-record the lessons in order to make them available to students also in asynchronous mode, thus creating a blended form. In the wake of this emergency situation, a survey was immediately launched to detect the consequences of the new teaching methods on the students' learning processes and to investigate the students' points of view on synchronous and asynchronous teaching activities.

The research started in the first phase of the lockdown in Italy (March 2020) and ended in January 2021; it involved students of the first year of the bachelor degree course in Educational Sciences at the Department of Education of the University of Catania.

The objective of the research was to detect the students' points of view regarding the strengths and weaknesses of the synchronous and asynchronous modes of the lessons and their respective impact on learning processes. The more general purpose of the survey was to give us useful insights to rethink university teaching at the end of the emergency situation by incorporating any strengths that emerged into traditional teaching and, if the emergency situation were to remain for a long time, to put in place actions to redefine the educational design of ERT to reduce the critical points detected. 


\section{Methods}

\subsection{Participants}

The research set out to involve 300 students in the first year of the bachelor degree course in Scienze dell'Educazione e della Formazione (Pedagogy) at the University of Catania. A total of 194 students actually participated in the research, with an average age of 21 years $(\mathrm{SD}=4.9)$, predominantly female $(94.3 \%)$.

\subsection{Tools}

By means of the online application Google Forms, students were given a questionnaire consisting of a) contextual questions, b) questions aimed at investigating the ways in which the students approached the lectures during the emergency period, as well as the positive aspects and difficulties encountered and, finally, c) the Questionnaire on Learning Processes (QPA-D) by Klement Polàčeck (2005). The latter consists of 90 questions on a 5-point likert scale, grouped into five scales:

- intrinsic motivation (MI): i.e., the belief that one can achieve success with a continued commitment to study;

- metacognition and self-regulated learning (MA): that is, the ability to adapt one's method of study to the discipline to be learned and to the activity proposed, to find ways to remember the content more easily and, at the same time, to be aware of the method used;

- learning strategies (SA): concerns the ability to understand if the strategies - the ways of setting up and conducting learning - are productive;

- consolidation of learning (CA): investigates how well students feel they can do the following: relate the content to be learned to what they already know; apply what they learn by studying to their everyday experience; integrate concepts and theories into a coherent structure; and consult various sources to better understand a topic; and

- superficial learning (AS): detects whether students are used to learning in a complete, schematic way, with great personal involvement and not by mere memorization aimed at social recognition, such as passing an exam; and whether they are able to grasp the differences between apparently similar ideas and find no difficulty in memorizing definitions.

\section{Analysis of results}

The minimum and maximum scores obtained by the students are shown for each scale. The mean scores obtained by the group are also shown (Table 1).

Table 1. Descriptive statistics for the QPA scales.

\begin{tabular}{lcrrrr}
\hline & $\mathrm{N}$ & Minimum & Maximum & Mean & Std. deviation \\
\hline MI & 194 & 31,00 & 90,00 & 69,07 & 11,47 \\
MA & 194 & 27,00 & 90,00 & 69,39 & 11,24 \\
SA & 194 & 30,00 & 90,00 & 68,22 & 12,65 \\
CA & 194 & 36,00 & 90,00 & 66,97 & 12,38 \\
AS & 194 & 19,00 & 78,00 & 47,18 & 11,65 \\
\hline
\end{tabular}

As shown in Table 1, the students' mean scores were: metacognition and self-regulated learning (MA - 69.39), intrinsic motivation (MI - 69.07), learning strategies (SA - 68.22) and modes of consolidation of learning (CA - 66.97). However, albeit significantly lower, there is still a substantial percentage of students who show superficial learning (AS - 47.18).

Of the 194 students who responded to the questionnaire, 175 followed the lectures primarily in the synchronous mode, while the remaining 19 did so in the asynchronous mode. From the data shown in Table 2, higher scores on all scales of the QPA are evident among students who followed the lectures in the synchronous mode.

Table 2. Descriptive statistics related to the QPA scales for students who followed the lecturers synchronously and asynchronously.

\begin{tabular}{ccccccc}
\hline & & N & Minimum & Maximum & Mean & Std. deviation \\
\hline \multirow{2}{*}{ MI } & asynchronous & 19 & 46 & 84 & 64,84 & 11,16 \\
& synchronous & 175 & 31 & 90 & 69,53 & 11,44 \\
\hline \multirow{2}{*}{ MA } & asynchronous & 19 & 45 & 84 & 67,47 & 11,62 \\
& synchronous & 175 & 27 & 90 & 69,59 & 11,22 \\
\hline \multirow{2}{*}{ SA } & asynchronous & 19 & 47 & 85 & 65,95 & 12,72 \\
& synchronous & 175 & 30 & 90 & 68,46 & 12,66 \\
\hline CA & asynchronous & 19 & 41 & 88 & 66,37 & 12,95 \\
& synchronous & 175 & 36 & 90 & 67,04 & 12,36 \\
\hline AS & asynchronous & 19 & 23 & 64 & 46,16 & 11,23 \\
& synchronous & 175 & 19 & 78 & 47,29 & 11,72 \\
\hline
\end{tabular}


However, the non-parametric Mann-Whitney test did not show statistically significant differences between the scores of the two groups. Specifically, for the scale relating to intrinsic motivation (MI), the scores were $\mathrm{U}=1242.50, \mathrm{z}=-1.808, \mathrm{p}=0.071$; for the scale relating to metacognition and self-regulated learning (MA), the scores were $\mathrm{U}=14872.50, \mathrm{z}=-.753, \mathrm{p}=0.451$; for the scale relating to learning strategies (SA), the scores were $U=1453.50, z=-.900, p=0.368$; for the scale relating to consolidation of learning, the scores were (CA), $\mathrm{U}=1578.50, \mathrm{z}=-.362, \mathrm{p}=0.718$, and for the scale relating to superficial learning (AS), the scores were $\mathrm{U}=1602.50, \mathrm{z}=-.258, \mathrm{p}=0.796$.

The lack of significant differences between the two groups in the QPA scores could perhaps be attributed to the fact that only 28 of the 175 students who followed the lectures in synchronous mode $(16 \%)$ took advantage of this possibility to actively interact with the teacher during the lecture, asking for more clarification or expressing their own ideas. The students who did not take advantage of this possibility attribute this choice to the clarity of the content presented, the lack of time or need and, in some cases, also the awareness of having the video recordings available to return to certain topics.

Since the University of Catania encouraged all the teachers to video-record their lectures, our interest also concerned the use that the students made of these lessons. The data show that the students who attended the lectures in synchronous mode made a great deal of use of this possibility $(70.3 \%$ 123/175). Among the main reasons given by those who attended the lectures in synchronous mode and chose to review video recordings are the following: to return to specific aspects of the lecture; to enrich notes; to compensate for any distractions during the lectures or internet connection problems; or even to facilitate the learning process by listening more than once to the same topic.

The questionnaire also aimed to investigate the main difficulties encountered by students during distance learning. From the analysis of the answers provided by the students, the followed difficulties were reported: problems of a technical nature linked to the platform used (Microsoft Teams) and the connection to the internet network; difficulties in concentration, sometimes associated with situations in which other family members were also involved in smart-working or distance teaching; interaction with colleagues and teachers; and, in some cases, a decrease in psycho-physical well-being linked to spending most of the time in front of the PC. It should, however, be pointed out that about $31.4 \%$ of students did not experience any difficulties.

The students were also asked to identify any positive aspects related to the restriction of face-to-face activities due to the Covid 19 pandemic. Despite the fact that $15.4 \%$ of the students did not identify any positive aspects linked to the situation they unexpectedly found themselves in, many students recognized the importance of issues related to safety and the consequent reduction in the risk of contagion, especially for those who, before the emergency, used means of transport on a daily basis. The data also show how the reduction in travel time facilitated the possibility of devoting more time to study and, more generally, to a greater capacity for time management. Many also highlighted the convenience of being able to follow lectures from home and, if necessary, review video-recordings, the reduction in costs and, in some cases, the rediscovery of the value of small things, particularly in-person, human interaction which - obviously-is missing in the online learning experience.

Finally, the last question aimed to find out which elements of the distance learning experience the students wanted to maintain even after returning to the classroom. The data clearly show a desire to maintain the possibility of video-recording the lectures (46.9\%), to offer a blended form of teaching, in which the students can choose whether to go to the class in person or continue to follow the lectures at a distance, on the basis of their needs. It also appears that the students appreciate the active teaching strategies implemented by some teachers and want to use the supplementary materials provided —often of a multimedia nature - also in face-to-face lectures.

\section{Conclusions and measures that could be implemented}

What our investigation has revealed may enable us to make many changes to the planning of educational activities for face-to-face teaching and distance learning in the future. Although the differences between students who have followed the lessons in synchronous and asynchronous mode are not statistically significant in intrinsic motivation, self-regulated learning and the other variables detected by the QPA scale, we may nevertheless hypothesize that the slightly higher scores for synchronous teaching activities are due to the interaction with the teachers. In addition, the fact that the student population requests that the possibility of using the recordings of the lectures remain at the end of the emergency situation - and the relative reasons given for this-leads us to believe that the video recording has become a real study tool for them and an important aspect of the communication channel between the teacher and the students.

To this regard, interesting issues have been identified that are open to further development. With the emergence of ERT, people were drawn to the use of platforms, tools, and modes of communication that are used by everyone. This has inevitably enhanced basic technical and computer skills related to educational aspects. Teachers and students have found themselves reinventing their classic modes of interaction by drawing on the strengths of distance learning platforms. 
The success of the ERT experiences - from the point of view of both the students and the lecturers - has shown that university institutions should put in place some measures in the event that ERT situations continue in the near future, or in the case of another emergency situation, such as:

- training activities for lecturers on the functions and uses of the platforms to enable them to make the most of the potential of the platforms, also in terms of possible interactions, both synchronous and asynchronous;

- training activities on the pedagogical design of online courses so that ERT will not consist of the mere transposition of courses designed to be delivered in person to the online platform;

- training activities of a technical nature for students to help them avoid all the practical difficulties encountered during online lessons; and finally

- actions to strengthen the internet connection networks and increase the possibility of access to the platforms also from secure public locations.

In other words, the possible need for ERT means that it must become part of the skill set of all members of the academic institution. We have listed just a few of the measures needed in order to develop an infrastructure that can support the online learning-teaching process. Indeed, the success of face-to-face education is the result of the interplay of numerous factors that determine a true teaching and educational infrastructure: learning spaces, pathway sharing, teacher-student and peer exchanges, library resources, housing, career services and health services. The reason why face-to-face education is successful is not just because the lectures are done well. The lectures are an instructional aspect of a global ecosystem designed specifically to support students with formal, informal and social resources.

In the event of a return to face-to-face classes, still far off according to the latest estimates of contagion in Europe (Agosto, Campmas, Giudici, Renda, 2020), academic institutions will have to build on these experiences and implement the use of technological tools to encourage forms of interaction and feedback in addition to putting in place study resources capable of exploiting the visual learning channels that students say that they appreciate and use a great deal.

Therefore, the planning of an online education program that is effective even in an emergency situation requires the creation of an ecosystem of support for students and teachers alike, which requires time and further investigation of the topic. This gives rise to numerous challenges for educational research in the field, which will not only need to be able to implement the strengths that have emerged from ERT experiences in face-to-face teaching, but must also develop forms of instructional design that can quickly respond to additional emergency situations that may occur in the future.

\section{References}

Abdalellah O. M., Basim A. K., Abdul N., Vigil J.V. (2020). Emergency remote teaching during Coronavirus pandemic: the current trend and future directive at Middle East College Oman. Innov Infrastruct Solut. 5(3): 72.

Agosto, A., Campmas, A., Giudici, P. and Renda, A. (2020), Monitoring COVID-19 contagion growth in Europe, CEPS Working Paper. Available at: https://www.ceps.eu/ceps-publications/monitoringcovid-19-contagion-growth-in-europe/Monitoring Covid-19 contagion growth in Europe

Ferri F., Grifoni P., Guzzo T. (2020). Online Learning and Emergency Remote Teaching: Opportunities and Challenges in Emergency Situations. Societies. 10, 86.

Hodges C., Moore S., Lockee B., Trust T., Bond A. (2020). The Difference Between Emergency Remote Teaching and Online Learning. EDUCAUSE Rev. Retrivied February, 4, 2021, from: https://er.educause.edu/articles/2020/3/the-difference-between-emergency-remote-teaching-andonline-learning

Houlden S, Veletsianos G. (2020). Coronavirus pushes universities to switch to online classes — but are they ready?. The Conversation. Available at: https://theconversation.com/coronaviruspushesuniversities-to-switch-to-online-classes-but-arethey-ready-132728

Means B., Bakia M., Murphy R. (2014). Learning Online: What Research Tell Us about Se, When and How. New York: Routledge.

Polácek, K. (2005). QPA - Questionario sui Processi di Apprendimento. Superiori e università. Firenze: Giunti O.S. Organizzazioni Speciali.

Sohrabi C, et al. (2020). World Health Organization declares global emergency: A review of the 2019 novel coronavirus (COVID-19). International Journal of Surgery. 2020; 76 (5): 71-76. 


\title{
THE PLIGHT OF FIRST-YEAR TEACHERS IN PUBLIC PRIMARY SCHOOLS
}

\author{
Xiaotian Han \\ School of Primary Education, Shanghai Normal University Tianhua College (China)
}

\begin{abstract}
First-year teachers are teachers who are new to teaching. The number of public school teachers is increasing in many countries and areas. Meanwhile, data also showed that some newly qualified teachers anticipated leaving or already left after the first year teaching. The purpose of the study aims to present a review and synthesize literature regarding the challenges of first-year teachers in public primary schools. Peer-reviewed articles $(\mathrm{N}=30)$ are collected from Google Scholar via systematically searching key words "first-year teachers" with one or more of the following terms: challenge, difficulty, attrition, leaving, and public primary schools. The results show first-year teachers meet general challenges listed as below: (a) building a professional teacher identity, (b) applying teaching theories in real class practice, and (c) handling the same heavy teaching loads and responsibilities as experienced teachers. In addition, first-year teachers in Shanghai public primary schools also meet the following challenges: (d) not having enough pre-service teaching programs, (e) facing high competition and a workload, and (f) building positive and stable relationships with parents/administrators. Considering by new qualified teachers' internal motivation and the external challenge they meet, first-year teachers are overwhelmed in dealing with these imbalances.
\end{abstract}

Keywords: First-year teachers, challenges, public primary schools.

\section{Introduction}

First-year teachers are teachers who are new to teaching. The number of public school teachers is increasing in many countries and areas. In California, the number of public K-12 teachers has been increasing every year since 1985 (National Center for Education Statistics, 2015). In Shanghai, the number of public primary teachers has been increasing sharply since 2015. Compared to the number of teachers in 2010 (44,278 teachers), there were 51,481 and 52,321 teachers serving in Shanghai public primary schools in 2015 and 2016 (Shanghai Statistics Yearbook, 2017). The data indicate that more teachers are joining the profession.

Meanwhile, data also showed that some newly qualified teachers anticipate leaving or already left after the first year teaching. In the United States, researchers widely accepted a study result that forty to fifty percent of novice teachers (teaching experience from one to three years) quit within the first five years of teaching by analyzing federal data in 2003, which is a much higher rate than in any other occupation and it becomes a primary factor for the shortage of teachers (DeAngelis \& Presley, 2010; Ingersoll, 2004; Ingersoll, 2012). However, this first-year teacher retention rate approximation is critiqued by the U.S. Department of Education's National Center for Educational Statistics because "the data included private school teachers and excluded the $3 \%$ of teachers who left and returned to teach within the five-year period" (Fensterwald, 2015). In the new U.S study, researchers used 2007-2008 federal data from only public school teachers and calculated that ten percent of U.S. first-year teachers in the public schools left the profession and did not return (Darling-Hammond, 2000). Although the data is changed, the first-year teacher attrition rate is concerned. In the United Kingdom, $12 \%$ of newly qualified teachers are planning to leave their positions after their first year teaching and $43 \%$ of teachers thought that teaching was not their life-long job (Bai, 2018). In China, a nation-wide survey discovered that first-year teachers account for a major proportion of the $65 \%$ anticipated teacher attrition rate. In Shanghai, how to retain new-qualified teachers and support their professional development is in the Shanghai Government Plan (the period of 2016-2020).

Research indicated that high teacher attrition will lead to negative consequences. Two of the negative consequences are financial crisis and low student achievement. The U.S. government spent $\$ 1$ billion on recruiting new teachers and $\$ 2.2$ billion on replacing teachers in 2014 (Alliance for Excellent Education, 2005; Duncan, 2009). To renew teaching credentials and support new teachers in their first two 
years, California's budget provided $\$ 66$ million to support over 12,000 beginning teachers in 1998 and \$128 million to support 30,118 first-year teachers in 2007-2008 (Report on New Teacher Induction, 2015). Similarly, the Shanghai government has funded more teacher support in the current decade. According to the data from the Shanghai Teacher Training Center, the funds for teacher professional development is constantly increasing from 2,742.36 million yuan in 2015 to 3,851 million yuan in 2017, and to 7,772 million yuan in 2018 (Shanghai Teacher Training Center, 2015; 2016; 2017). If the attrition rate of first-year teachers is going to rise, the amount of funding will be wasted.

Generally, first-year teachers have high motivation for teaching and learning. As Brookhart and Freeman (1992) stated, "altruistic, service-oriented goals and other intrinsic motivations are the source of the primary reasons entering teacher candidates report why they chose teaching as a career" (p. 46). Also, researchers reported that beginning teachers have "a desire to work with children and adolescents," which stimulates their learning/teaching attitudes, expectations, and engagement in the first year (Löfström \& Poom-Valickis; Watt \& Richardson, 2008). However, first-year teachers do face various extrinsic challenges.

The purpose of the study aims to present a review and synthesize literature regarding the challenges of first-year teachers in public primary schools. Peer-reviewed articles $(\mathrm{N}=30)$ are collected from Google Scholar via systematically searching key words "first-year teachers" with one or more of the following terms: challenge, difficulty, attrition, leaving, and public primary schools.

\section{The challenges of first-year teachers in public schools}

First, they are expected to build a professional teacher identity in a very short time. In other words, they need to transform from a student teacher to a teacher of students quickly. However, building and exploring teacher identity should be an ongoing process, developed over years of teaching experience and reflection, instead of a stable identity (Erikson, 1986). The procedure of this transformation includes a series of observations, imitations, explorations, reflections, and practices. In the process, teachers need to consistently explore and reflect on questions such as, "Who am I at this moment", "Who do I want to become", and "How and from where do teacher educators develop their understandings of what is means to do their work?" (Conway, 2001). To answer these questions and develop a professional teacher identity in their first-year teaching is challenging and overwhelming (Beijaard, 1995; Zhang, Ding, \& Xu, 2016).

The second challenge is that first-year teachers are expected to skillfully apply teaching theories in real class practice; however, they are overwhelmed, most of time by the tasks of delivering instructions and managing class (Banville, 2015; McAnulty \& Cuenca, 2014; Tsui, 2004). Moreover, Flores (2006) studied a group of beginning teachers in Europe and realized that they were struggling to achieve the expected performance -- "learning while doing", at school, so many beginning teachers switched from a student-centered classroom to traditional lecture (p. 2021).

The third challenge is that first-year teachers are expected to handle the same heavy teaching loads and responsibilities as experienced teachers (Banville, 2015). Renard (2003) argued that "schools often overwhelm new teachers by expecting them to juggle all the responsibilities and duties that veteran teachers do. Instead, we need to give new teachers to grow" (p. 62). Researchers suggested school and district administrators improve new teacher retention by adjusting their workloads in teacher induction programs such as avoiding to assign them to the most challenging grade level or students, avoiding to assign extra duties (i.e.: intervention, committee members, student council advisor), and assigning first-year teachers the same planning period with their mentors (Farrell, 2003; Clark, 2012)). However, the reality is not ideal. According to Alliance for Excellent Education (2005), a Washington, DC-based national policy and advocacy organization, reported that, $60 \%$ of teachers transferred schools or left teaching because of too heavy a workload. In both England and Finland, new teachers experienced extensive national-level curriculum and assessment, which challenges them and becomes a main reason of turnover (Webb et al., 2004). Expecting new teachers to perform all responsibilities as experienced teachers is unrealistic (Allen, 2000). When first-year teachers meet these workloads as seasoned professionals, new teachers often fall into a feeling of "demoralized and dispirited, anxious about their efficacy and their capability to cope" (Scott, 1995, p. 96). These experience and perceptions persuade them to leave the teaching profession (DeAngelis \& Presley, 2010; Ingersoll, 2004; Ingersoll, 2012).

\section{The challenges of first-year teachers in Shanghai public schools}

In addition to the above general first-year teachers' challenges, first-year teachers in Shanghai public primary schools have additional challenges. First, new-qualified teachers may not have enough training because teacher preparation programs are not mandatory in Shanghai public primary schools. Being a primary school teacher is only required to have a bachelor degree (four-year college/university 
degree) or a higher degree and a Shanghai teaching credential. Teachers in Shanghai public primary schools are all specialists rather than all-subject teachers in other countries. Based on their college majors, teachers can be categorized into three groups: general educations, core course majors (i.e., Chinese, Math, and English), and subsidiary course majors (i.e., science, arts, and physical education). For teachers who major in education, they experienced approximate 20 weeks a teacher preparation program/intern program in the four-year college setting so they are automatically issued the credential (Ding, 2011; Xia, 2018). However, for teachers whose majors were other than education (core course majors and subsidiary majors) and were willing to train into teaching, they did not experience any teaching practice but concentrated on all subject-based courses in their universities, they must take a teaching credential test (Chen \& An, 2016; Xia, 2018). The credential test is a law and subject knowledge based written and oral test. It does not require class practice hours. Therefore, the latter group of first-year teachers may lack practice in classroom teaching when they are hired.

Second, first-year teachers are expected to build positive and stable relationships with colleagues, administrators, parents, and students (Ren, 2014). However, they always feel powerless and isolated in the first years (Zhao, 2003). Cao and Zhou (2007) pointed out that dealing with student-teacher relationships is the greatest challenge first-year teachers meet. Knowing students well and having positive relationships with students are relative to course design, planning and organization, motivating students' interests, and delivering differentiated instructions. However, first-year teachers are not confident in building teacher-student relationships.

Third, Shanghai public school teachers are facing high competition and a workload. They are expected to show high student academic achievements via standardized exams and a series of government interventions than teachers in some other countries (Gao, 2008; Ministry of Education, 2010). To improve students' academic scores, they must bear heavy workloads -- their average working time is 9.16 hours per day without extra-time payment $(\mathrm{Wu}, 2018)$. Considering by new qualified teachers' internal motivation and the external challenges they meet, first-year teachers are overwhelmed in dealing with these imbalances.

\section{Summary}

Literature review shows that first-year teachers meet general challenges listed as below: (a) building a professional teacher identity, (b) applying teaching theories in real class practice, and (c) handling the same heavy teaching loads and responsibilities as experienced teachers. In addition, first-year teachers in Shanghai public primary schools also meet the following challenges: (d) not having enough pre-service teaching programs, (e) facing high competition and a workload, and (f) building positive and stable relationships with parents/administrators. Considering by new qualified teachers' internal motivation and the external challenge they meet, first-year teachers are overwhelmed in dealing with these imbalances.

\section{References}

Allen, M. (2000). Teacher preparation and induction. Retrieved from https:/files.eric.ed.gov/ fulltext/ED473451.pdf

Alliance for Excellent Education. (2008). What keeps good teachers in the classroom? Understanding and reducing teacher turnover. Washington, DC: Alliance for Excellent Education.

Bai, M. (2018). Ying guo jiao shi gong hui diao cha xian shi gong zuo liang da dao zhi jiao shi li zhi. Retrieved from http://www.jyb.cn/zgjyb/201801/t20180126_945084.html

Beijaard, D. (1995). Teachers' prior experiences and actual perceptions of professional identity. Teachers and Teaching: Theory and Practice, 1(2), 281-294.

Cao. L., \& Zhou. Y. (2007). Xiao xue jiao shi ru zhi chu qi chang yu wen ti ji jie jue dui ce. He Tian Shi Fan Zhuan Ke Xue Xiao Xue Bao, 27(3), 68-69.

Chen, X. \& An, G. (2016). On the new induction education system for primary and secondary teachers in Shanghai. Teacher Education Research, 28(2), 45-50.

Clark, S. K. (2012). The plight of the novice teacher. The Clearing House: A Journal of Educational Strategies, Issues and Ideas, 85(5), 197-200. doi:10.1080/00098655.2012.689783

Conway, P. (2001). Anticipatory reflection while learning to teach: From a temporally truncated to a temporally distributed model of reflection in teacher education. Teaching and Teacher Education, 17, 89-106.

Darling-Hammond, L. (2000). Teacher quality and student achievement: A review of state policy evidence. Education Policy Analysis Archives, 8(1), 1-44. 
Deangelis, K. J., \& Presley, J. B. (2010). Toward a more nuanced understanding of new teacher attrition. Education and Urban Society, 43(5), 598-626.

Ding, G. (2011). Report of Chinese teacher professional development survey and policy analysis. Shanghai: East China Normal University Press.

Duncan, A. (2011). The Obama administration's plan for teacher education. Retrieved from https://www.ed.gov/sites/default/files/our-future-our- teachers.pdf

Erikson, E. H. (1986). Identity, youth and crisis. New York: W.W. Norton \& Company.

Farrell, T. (2003). Learning to teach English language during the first year: personal influences and challenges. Teaching and Teacher Education, 19(1), 95-111.

Fensterwald, J. (2015). Half of new teachers quit profession in 5 years? No true, new study says. Retrieved from https://edsource.org/2015/half-of-new-teachers-quit-profession-in-5-years-not-truenew-study-says/83054

Gao, X. (2008). Teachers' professional vulnerability and cultural tradition: A Chinese paradox. Teaching and Teacher Education, 24, 154-165.

Ingersoll, R. M. (2004). Do teacher induction and mentoring matter? NASSP Bulletin, 88(638), 28-40.

McAnulty, J., \& Cuenca, A. (2014). Embracing institutional authority: The emerging identity of a novice teacher educator. Studying Teacher Education, 10(1), 36-52.

New Teacher Center. (2016). New teacher development for every inning. Retrieved from https://newteachercenter.org/wp-content/uploads/NewTeacherDevelopmentEveryInning.pdf

Odell, S. J., \& Ferraro, D. P. (1992). Teacher mentoring and teacher retention. Journal of Teacher Education, 43(3), 200-204. doi:10.1177/0022487192043003006

Ren, S. (2014). The implementation research of Shanghai "standardized training programs for new teachers" in base school (Master thesis). Retrieved from http://kns.cnki.net/KCMS/detail/detail.aspx?dbcode=CMFD\&dbname=CMFD201701\&filename= 1016126006.nh\&v=MTgwMzZyV00xRnJDVVJMT2ZadWRzRnl2aFdydktWRjI2R0xLNkdOSE1 xWkViUEISOGVYMUx1eFITN0RoMVQzcVQ

Shanghai Educational Municipal Commission: Shanghai Teacher Professional Development Program Leading Group. (Eds.). (2017). Effective strategies for new teacher standardized training. Shanghai: East China Normal University Press.

Shanghai Municipal Education Commission (2013). Education statistics 2013. Shanghai: Shanghai Education.

Shanghai Municipal Government (2016). The 13th five-year plan for Shanghai education reform and development.

Tsui, A. B. (2004). Understanding expertise in teaching. Understanding Expertise in Teaching, 245-282. doi:10.1017/cbo9781139524698.011

Wu, G. (2018). Shanghai primary and secondary school teachers occupational status and policy suggestions. Retrieved from http://news.sina.com.cn/c/2014-03-10/080529668179.shtml

Xia, Z. (2018). Review on the normalized induction manual for Shanghai primary and secondary school trainee teacher. Journal of Schooling Studies, 15(2), 55-65.

Zhang, M., Ding, X., \& Xu, J. (2016). Developing Shanghai's teachers. National Center on Education and Economy, Report.

Zhang, P. (2017). Gaokao: How one exam can set the course of a student's life in China. Retrieved from https://www.scmp.com/news/china/society/article/2097512/gaokao-how-one-exam-can-set-coursestudents-life-china

Zhao, C. (2003). The study on teachers' growth (Doctoral dissertation). Retrieved from CNKI. (Accession: G451) 


\title{
INSTRUCTIONAL DESIGN OF KNOWLEDGE NUGGETS
}

\author{
Christian Ploder, Lisa Ehrhardt, Laura Gamper, \& Christoph Hazy \\ Management Communication \& IT, MCI, Innsbruck (Austria)
}

\begin{abstract}
Throughout their careers, all students experience the same set of learning routines within the same time frame and following the same pedagogical approach based on identical materials. In contrast, Knowledge Nuggets provide students with different opportunities to achieve specific learning outcomes through self-directed learning activities. An individual student's skill inventory could improve the full individualization of the Knowledge Nugget delivery at the start of each class. Knowledge Nuggets are considered learning materials organized within small, defined topics. This granularity makes the content easier to consume at an individual pace. Depending on their scope and size, these Knowledge Nuggets can vary. The level does not indicate the amount of content or the shared knowledge's difficulty but how the learning is prepared and conveyed.

The simplest way (level 1) to share knowledge is only to provide text within a document. The next higher level 2 includes a slideshow explained in more detail by playing an audio podcast - so the combination of visual with audio should attend two senses in parallel. The slides contain images or diagrams in addition to keywords. Video tutorials are the most advanced ways to share knowledge. This type of tutoring allows instructors to visually illustrate content to minimize complexity by combining text, speech, images, and animation. With level 3 (video tutorials), it is possible to address more senses simultaneously.

However, all three levels offer the same characteristics: practicality, reproducibility, and manageable time. These characteristics are of great relevance to be accepted as training methods in any educational program. The progressive redistribution of dimensions occurs in elaboration, the use of technology, and the cognitive load. The paper aims to determine why the different levels are essential for the overall picture and how the measurement of learning success can be measured.
\end{abstract}

Keywords: Knowledge nuggets, knowledge sharing, cognitive load.

\section{Introduction}

Digitalization is proceeding in the economy and society, and the educational sector is experiencing far-reaching changes. Higher educational institutions are increasingly opening up towards the potential of digitization. With it comes the expectation that research and administration, and instruction will improve quality and become more professional. Although the overall concept and degree of implementation can vary from institution to institution, digitization also requires structural preconditions and technological implementations and comes with its challenges. (Gilch et al., 2019)

With the Corona pandemic causing massive restrictions on public life since spring 2020 and in-person lectures being banned, digital instruction is coming to the fore. To continue sustaining education, the short-term development and use of digital teaching formats are essential.

One approach to share knowledge is by providing Knowledge Nuggets (Ploder et al., 2020), created for self-directed learning. Knowledge Nuggets are digitally prepared learning materials that are organized within small thematic categories. (Knowledge Nuggets are deeply related to E-Learning.) The learning content can be provided in different ways. For example, as a video, a slideshow, a web page, or a podcast. (Bailey et al., 2006; Shaw et al., 2014)

These Knowledge Nuggets differ based on an individual's cognitive ability to elaborate/ process them and, therefore, be classified into different levels. The term cognitive ability also includes the concept of cognitive load. A higher stress level indicates a more complicated and unpleasant perception of information intake (Sweller, 1994). This paper focuses on elaborating the factors to define these levels, separate them from each other and thus have to be considered for planning differentiated Knowledge Nuggets. The initial idea was to start with three different levels respectively Knowledge Nuggets based on their relevance and frequency of use in higher education. In section 3 , the explanation and all the factors are described.

After the first section with a brief introduction, section 2 outlines the authors' literature review and framing and the primary resources. The research focused in general on the thematic area of designing digital learning content. The literature sources were used to identify the relevant factors for developing knowledge nuggets and differentiating the different levels by design. The determining factors were then 
specified in more detail in the Instructional Design and integrated into an overall framework in section 3. Section 4 continues by describing opportunities for testing the three design levels to determine which level offers the highest potential. In the end, a review of limitations is given in section 5.

\section{Theoretical background}

This section represents a precise analysis of the current state of research and selects suitable approaches to identify studies and other sources comparing instructional design principles for Knowledge Nuggets. The authors elaborated a systematic literature review. As a guideline, the NHS Centre for Reviews and Dissemination (2009) approach was adapted to this work's requirements. The selected phases are outlined in table 1.

Table 1. Search terms used in the systematic literature review.

\begin{tabular}{|c|l|l|}
\hline Phase No. & Phase & Steps \\
\hline 1 & Planning the review & $\begin{array}{l}\text { Purpose of the literature review } \\
\text { Developing the review protocol }\end{array}$ \\
\hline 2 & Conducting the review & $\begin{array}{l}\text { Searching the literature and assessing studies for relevance } \\
\text { Assessing and grading studies for validity (quality) } \\
\text { Extracting data from the selected studies } \\
\text { Synthesizing data from the selected studies }\end{array}$ \\
& & Documentation and interpretation of the results \\
\hline 3 & Reporting &
\end{tabular}

Phase 1 starts with the definition of the framework for the analysis and is followed by the formalization of the review protocol, which determines the methods used to perform the review. To formulate a search strategy and create this framework, gaining familiarity with a deep understanding of the study field through relevant contributions and discussions is needed. Through topic-related preliminary research, carried out through the Google Scholar database and a general internet search, it was possible to determine the first state of knowledge for the topic to be worked on. Fundamental studies found at this stage were directly incorporated into the collection. Ongoing the systematic literature review process, the Google Scholar database was used as a basis for identifying qualified sources. The further specialization by including relevant search terms refined after the initial search helped to focus the analysis's scope. The summarized list of all used search terms is represented in table 2.

Table 2. Search terms for the systematic literature review.

\begin{tabular}{|l|l|}
\hline Keywords \\
\hline Design of video; cognitive load; learning performance; multimedia learning & Signaling; multimedia learning \\
\hline Learning from text and video; instructional design; multimedia learning & Emotional design; multimedia learning \\
\hline
\end{tabular}

Besides these mentioned criteria, a further characteristic was established regarding the publication period and the full-text availability. To focus on the most recent research on this topic, only full-text accessible articles from 2014 are included. The items were sorted in the relevance ranking of Google Scholar. A limit of the first 50 references was set to be reviewed if the search results in an excessively high number of hits.

Based on this entire collection of different criteria and the research protocol development, proceed to phase 2, illustrated in figure 1. Generally, in phase 2, searching the literature is executed. More precisely, it identifies potential studies and assesses the quality of these ongoing in the procedure. If the database search matches the outlined requirements and the search terms, validation is initially required by removing all presented duplicates. All references that had the identical title and author and published within the same year were excluded-moving on to the stage "First level screening", by reading just the title and abstract of the candidate studies and then deciding whether to include or exclude the study. In this way, studies that are not related to the topic can be removed. Whether to include an article, the full document was retrieved (Second level screening). The result represented as a pool of 16 studies is ready for the data extraction and quality assessment and can be synthesized to finalized.

Figure 1. Study selection.

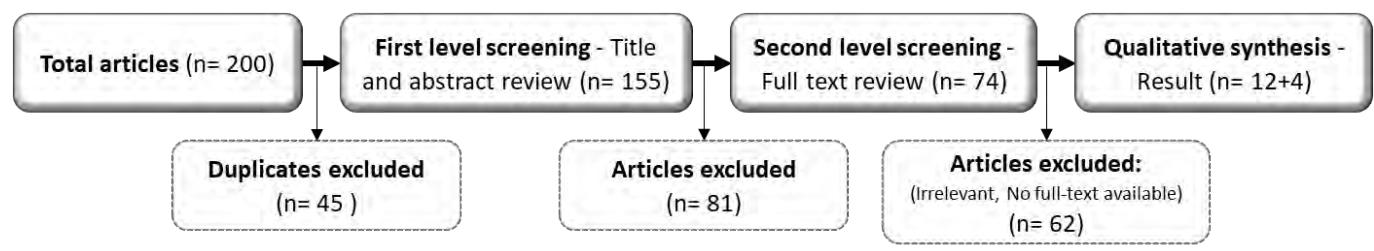


In the final stage in phase 3, the last documentation and the interpretation of the findings is carried out. Table 3 shows illustrate all selected relevant literature with title, Authors, and names.

Table 3. Overview Literature.

\begin{tabular}{|c|c|c|c|}
\hline No & Title & DOI & Year \\
\hline 1 & $\begin{array}{l}\text { A meta-analysis of how signaling affects learning with } \\
\text { media }\end{array}$ & https://doi.org/10.1016/j.edurev.2017.11.001 & 2018 \\
\hline 2 & $\begin{array}{l}\text { Assessing the effects of different multimedia materials on } \\
\text { emotions and learning performance for visual and verbal } \\
\text { style learners }\end{array}$ & https://doi.org/10.1016/j.compedu.2012.05.006 & 2012 \\
\hline 3 & Benefits of emotional design in multimedia instruction & https://doi.org/10.1016/j.learninstruc.2014.02.004 & 2014 \\
\hline 4 & $\begin{array}{l}\text { Cognitive load in multimedia learning environments: A } \\
\text { systematic review }\end{array}$ & https://doi.org/10.1016/j.compedu.2019.103618 & 2019 \\
\hline 5 & $\begin{array}{l}\text { Cognitive load theory and multimedia learning, task } \\
\text { characteristics and learning engagement: The Current State } \\
\text { of the Art }\end{array}$ & https://doi.org/10.1016/j.chb.2010.05.003 & 2011 \\
\hline 6 & $\begin{array}{l}\text { Effective Educational Videos: Principles and Guidelines } \\
\text { for Maximizing Student Learning from Video Content }\end{array}$ & https://doi.org/10.1187/cbe.16-03-0125 & 2016 \\
\hline 7 & $\begin{array}{l}\text { Effects of different video lecture types on sustained } \\
\text { attention, emotion, cognitive load, and learning } \\
\text { performance }\end{array}$ & https://doi.org/10.1016/j.compedu.2014.08.015 & 2015 \\
\hline 8 & $\begin{array}{l}\text { Emotional design in multimedia learning: Differentiation } \\
\text { on relevant design features and their effects on emotions } \\
\text { and learning }\end{array}$ & https://doi.org/10.1016/j.chb.2014.11.009 & 2015 \\
\hline 9 & $\begin{array}{l}\text { Emotional design in multimedia learning: Effects of shape } \\
\text { and color on affect and learning }\end{array}$ & https://doi.org/10.1016/j.learninstruc.2013.02.006 & 2014 \\
\hline 10 & How multimedia can improve learning and instruction & https://doi.org/10.1017/9781108235631.019 & 2019 \\
\hline 11 & $\begin{array}{l}\text { Instructional animation versus static pictures: A meta- } \\
\text { analysis }\end{array}$ & https://doi.org/10.1016/j.learninstruc.2007.09.013 & 2007 \\
\hline 12 & $\begin{array}{l}\text { Learning from Examples: Instructional Principles from the } \\
\text { Worked Examples Research }\end{array}$ & https://doi.org/10.3102/00346543070002181 & 2000 \\
\hline 13 & $\begin{array}{l}\text { Learning from the text, video, or subtitles: A comparative } \\
\text { analysis }\end{array}$ & https://doi.org/10.1016/j.compedu.2020.104034 & 2021 \\
\hline 14 & $\begin{array}{l}\text { Signaling text-picture relations in multimedia learning: A } \\
\text { comprehensive meta-analysis }\end{array}$ & https://doi.org/10.1016/j.edurev.2015.12.003 & 2016 \\
\hline 15 & Thirty years of research on online learning & https://doi.org/10.1002/acp.3482 & 2018 \\
\hline 16 & $\begin{array}{l}\text { Trends and issues in multimedia learning research in } \\
\text { 1996-2016: A bibliometric analysis }\end{array}$ & https://doi.org/10.1016/j.edurev.2019.100282 & 2019 \\
\hline
\end{tabular}

\section{Instructional design}

In this section, the collected findings from the systematic literature review provide a framework for planning differentiated Knowledge Nuggets by design. The three levels which correspond with the given literature can be named: (i) text within a document, (ii) slideshow with an added audio podcast, and (iii) video tutorials, the various principles and techniques were applied, and factors identified. The designed model depicted in table 4 provides an overview of the relevant characteristics to obtain the desired Knowledge Nugget at a certain level. All the factors and their expressions in explained in the following subsections. It is worth mentioning that all levels are assumed to provide the same quality and the same amount of knowledge.

Table 4. Relevant factors for the Instructional Design.

\begin{tabular}{|l|l|l|l|}
\hline Factors & Level 1 & Level 2 & Level 3 \\
\hline Visual Elements & & Static images & Dynamic images/animations \\
\hline Recipient engagement & Self-regulated & Self-regulated & Controlled \\
\hline Language Style & Formal Style & Conversational style & Conversational style \\
\hline Sensory Modalities & Visual sense & Auditory + visual senses & Auditory + visual senses \\
\hline
\end{tabular}

Visual Elements - One of the factors that differentiate the Knowledge Nuggets and, therefore, the levels from one another are visual elements. In general, visual features are considered to be, e.g., graphics, images, diagrams, and animations (Li et al., 2019) on top of text. Since visual elements do not support a pure continuous text, it strongly differs among the other levels. For instance, slideshows, compared to level 1, often contain a variety of static visual elements, such as diagrams and images. However, according to Lewalter (1997), static images can sometimes cause misinterpretations and result in an inaccurate understanding or prospect. Moreover, misinterpretations may increase a participant's cognitive load.

Besides static graphics, dynamic images like animations are familiar. According to Rieber and Kini (1991), an animation is formed by a series of fast-changing computer screen visuals that create the impression of motion to a viewer. These are primarily used for video productions, representing level 3. However, it should be noted that animations do not represent permanent information but a current capture 
(Hegarty, 2004). The risk of misinterpreting images can be decreased by (using) animations, as they facilitate procedural explanations that can lower an individual's cognitive load. To visualize the same complex process differently, multiple static graphics would be required. (Höffler \& Leutner, 2007)

Recipient engagement - A further factor that distinguishes each level is the active regulation of Knowledge Nuggets by the recipient. Examples include repeating or skipping information and regulating the speed of information intake. Regarding videos, the transmission of information is preferably controlled by the sender since the receiver does not influence the rate of animations or the speaker's performance speed. Repeating or skipping information in a controlled way is more difficult in this case since videos usually do not have well-defined section headings/ delineated sections. A slideshow including an integrated podcast, on the other hand, is more comfortable to regulate as the individual slides structure the presentation. The recipient proceeds with the presentation autonomously by browsing through the slides and can initiate the voice-over of each slide independently. In comparison to videos and slideshows, processing texts can be controlled by the recipients to a much greater extent. The reader has the opportunity to reread sentences or paragraphs, skip parts, and adjust his reading pace to his needs. Thus, the learning process is even more personalized. (Merkt et al., 2011; Tarchi et al., 2021)

Language Style - Moving on to the next factor, the authors examine the influence of language style. Principally, language is another crucial component of the transmitter-retriever model and represents the primary medium through which we can share knowledge. Changing narration from a formal textbook-like style to a more personalized conversational style in multimedia instruction has shown a significant effect on learning in the past; people may know more deeply (Mayer, 2002). Mayer describes this phenomenon as the personalization principle (Mayer, 2008). Mayer believes that using conversational language instead of formal language in multimedia teaching will encourage retrievers to establish social relationships with the narrator. That leads to greater participation and effort. For instance, while explaining, make instead use of "your" alternatively to "the" when involving the retriever or the use of "I" to point the narrator's viewpoint. While the text in level 1 is only a composite of words and therefore has to be presented more formally, level 2 and level 3 can use the personalization principle. Regardless of the version, the same factual information is always transmitted. (Mayer, 2018)

Sensory Modalities - Another factor of level differentiation is the form/ expression of visual and auditory stimuli/ allures. Based on how Knowledge Nuggets are set up, the cognitive load resp. The stimuli of the participants are strained differently. According to Mayer (2001), individuals possess separate channels to process auditory/verbal and visual/pictural information. The continuous text provided in the first level is processed in the vocal track. When consuming a slideshow, the load is divided into two channels. The spoken words and keywords on the slides are captured in the auditory/verbal channel. The static images are displayed in the visual/pictorial channel.

Regarding videos, the visual/pictorial channel is additionally claimed by animations. Referring to Mayer (2001), individuals only have limited capacity to process input material in these channels. Therefore, the channels should not be overloaded. While the cognitive load generated by texts arises from the verbal channel only, it is divided between both channels when viewing slideshows and videos. Consequently, the cognitive load is strained in different ways. That also influences the design of the considered Knowledge Nuggets. Thus, the only formatted continuous text is used in level 1. Since slideshows additionally use images and audio files for presentation, the text is limited to keywords on the slides. The unique characteristics of videos are the animations. These, in return, replace some verbal/auditory stimuli of slideshows. In conclusion, the Cognitive Load mustn't be overloaded in any of these levels. (Mayer, 2018).

To sum it up finally, this section provides an understanding of how the levels differ and indicates that this may significantly change the learning experience.

\section{Future research}

During the elaboration of the theoretical framework, further interesting considerations could lead to additional research soon. Creating differentiated Knowledge Nuggets should not only be based on the factors mentioned above but also on general design factors. Therefore, for an expanded approach, design aspects should be addressed and included. Moreover, the level factors identified in this paper only provide a theoretical policy regarding how levels differ from one another and how they influence the cognitive load of Knowledge Nugget recipients. To verify these factors and their effect in practical application, they can be tested by running an empirical study. Conducting such a study requires that differentiated Knowledge Nuggets are created based on the previously mentioned theoretical framework and can be provided digitally on suitable platforms, such as LMSs. Subjects may begin the learning process subsequently by retrieving the instructional materials under predetermined conditions. After performing the learning process, the stress level based on the Cognitive Load Theory can be measured using standardized scales. Questionnaires or tests are suitable for evaluating comprehension and reproducibility. The results given by these measurements may then indicate which types of levels, and thus which factors, should be utilized for learners such as students of higher education institutions to impart knowledge. 


\section{Limitations}

When interpreting the findings of this study, some limitations need to be taken into account. First, it has to be mentioned that the literature review was restricted to some specific journals within a certain period. Another factor is that the Knowledge Nuggets instructional design is not yet validated in a practical setting. Experts can be used in the validation process to minimize this impact in the future.

Furthermore, by designing the Knowledge Nuggets, the authors decided to prepare exactly three levels of Knowledge Nuggets. That is a limiting factor because it would be possible to split the nuggets into more detailed levels. The last limiting factor is that our Knowledge Nuggets are designed for digital learning. That means that the purpose of the nuggets is to work correctly on digital screens compared to the idea of differentiation of analog and digital systems based on (Singer \& Alexander, 2017).

\section{References}

Bailey, C., Zalfan, M. T., Davis, H. C., Fill, K., \& Conole, G. (2006). Panning for Gold: Designing Pedagogically-Inspired Learning Nuggets. Educational Technology \& Society, 9(1), 113-122. https://eric.ed.gov/?id=EJ836698

Gilch, H., Beise, A. S., Krempkow, R., M. Müller, Stratmann, F., \& Wannemacher, K. (2019). Digitalisierung der Hochschulen: Ergebnisse einer Schwerpunktstudie für die Expertenkommission Forschung und Innovation. Studien Zum Deutschen Innovationssystem Expertenkommission Forschung Und Innovation (EFI).

Hegarty, M. (2004). Dynamic visualizations and learning: getting to the difficult questions. Learning and Instruction, 14(3), 343-351. https://doi.org/10.1016/j.learninstruc.2004.06.007

Höffler, T. N., \& Leutner, D. (2007). Instructional animation versus static pictures: A meta-analysis. Learning and Instruction, 17(6), 722-738. https://doi.org/10.1016/j.learninstruc.2007.09.013

Lewalter, D. (1997). Lernen mit Bildern und Animationen: Studie zum Einfluss von Lernermerkmalen auf die Effektivität von Illustrationen. Pädagogische Psychologie und Entwicklungspsychologie. Waxmann.

Li, J., Antonenko, P. D., \& Wang, J. (2019). Trends and issues in multimedia learning research in 1996-2016: A bibliometric analysis. Educational Research Review, 28, 100282. https://doi.org/10.1016/j.edurev.2019.100282

Mayer, R. E. (2001). Multimedia learning. Cambridge University Press. https://doi.org/10.1017/CBO9781139164603

Mayer, R. E. (2002). Multimedia learning. Psychology of Learning and Motivation, 41, 85-139. https://doi.org/10.1016/S0079-7421(02)80005-6

Mayer, R. E. (2008). Applying the science of learning: Evidence-based principles for the design of multimedia instruction. The American Psychologist, 63(8), 760-769. https://doi.org/10.1037/0003066X.63.8.760

Mayer, R. E. (2018). Thirty years of research on online learning. Applied Cognitive Psychology, 33(2), 152-159. https://doi.org/10.1002/acp.3482

Merkt, M., Weigand, S., Heier, A., \& Schwan, S. (2011). Learning with videos vs. learning with print: The role of interactive features. Learning and Instruction, 21(6), 687-704. https://doi.org/10.1016/j.learninstruc.2011.03.004

NHS Centre for Reviews and Dissemination. (2009). CRD's Guidance for Carrying Out or Commissioning Reviews (2. ed.). Systematic reviews. York Publ. Services.

Ploder, C., Dilger, T., Bernsteiner, R. (2020) Knowledge-Nuggets based Self Learning - COVID-19 based Qualitative Research Lecture, ICERI2020 Proceedings, pp. 2389-2393. ISBN: 978-84-0924232-0

Rieber, L. P., \& Kini, A. (1991). Theoretical foundations of instructional applications of computer-generated animated visuals. Journal of Computer-Based Instruction, 18(3), 83-88.

Shaw, C., Larson, R., \& Sibdari, S. (2014). An Asynchronous, Personalized Learning Platform-Guided Learning Pathways (GLP). Creative Education, 05(13), 1189-1204. https://doi.org/10.4236/ce.2014.513135

Singer, L. M., \& Alexander, P. A. (2017). Reading on Paper and Digitally: What the Past Decades of Empirical Research Reveal. Review of Educational Research, 87(6), 1007-1041. https://doi.org/10.3102/0034654317722961

Sweller, J. (1994). Cognitive load theory, learning difficulty, and instructional design. Learning and instruction, 4(4), 295-312.

Tarchi, C., Zaccoletti, S., \& Mason, L. (2021). Learning from text, video, or subtitles: A comparative analysis. Computers \& Education, 160, 104034. https://doi.org/10.1016/j.compedu.2020.104034 


\title{
CHANGE MANAGEMENT: EXPERIENCES OF PRIVATE TVET COLLEGE EDUCATORS REGARDING VIRTUAL LEARNING DURING COVID-19
}

\author{
Adebunmi Yetunde Aina ${ }^{1}, \&$ Ayodele Ogegbo ${ }^{2}$ \\ ${ }^{I}$ Department of Educational Management and Policy Studies, University of Pretoria (South Africa) \\ ${ }^{2}$ Department of Science and Technology Education, University of Johannesburg (South Africa)
}

\begin{abstract}
This study explored the experiences of private TVET college educators regarding virtual learning during the Covid-19 school lockdown. The Kanter theory of change is adopted as the theoretical base in this study. Data collection was done through face-to-face semi structured interviews and non-participant observation. Collected data was analyzed using content analysis. Findings reveal that though participants have positive attitude toward the process of change required in transitioning from traditional environment to virtual environment, majority of them did not receive substantive training on how to use technology to support virtual teaching. However, educators indicated that the change process comes with several challenges such as technical problems, ineffective communication from management, workload, inadequate training, lack of access to ICT tools and lack of other structural support within the college which impacts their effective implementation of virtual teaching. Thus, teachers should be adequately prepared, supported and empowered to cope with the changes and transition processes involved to continue teaching in a virtual environment. More so, TVET college managers and policy makers should priorities change management programmes designed to prepare teachers for the inevitability of technological change in education.
\end{abstract}

Keywords: Change management, educator, traditional classroom, virtual classroom, TVET college.

\section{Introduction}

In virtual learning context Parlakkic (2017 p. 640) described change management as the "combination of processes, activities, and approaches that manage the people of the organization through the transition from the old way of teaching to new e-learning". Parlakkic (2017) further indicates that it is very difficult to change the behaviours, culture and routine of the educational institutions' users such as the students, educators, school leaders. In agreement with Partlakkic, change will be tougher when the change process is sudden and forceful such as what most of the schooling system have to do in order to ensure continuity of teaching and learning during the school lockdown cause by the novel Coronavirus (Covid-19).

The outbreak of the Covid-19 has caused a shift in almost every system or model in the world's civilization and the education model has been no exception to this change. On the 15th of March 2020, the President of South Africa declared a national state of disaster and announces the institution of a nation-wide lockdown, including the closing of schools from the 18th of March 2020 (Haffajee 2020). The Basic education minister further announced that various platforms will be used to ensure that learning continues from home, i.e., online, radio and television platforms (Brodie, McFarlane and Ally, 2020). The introduction of the fourth industrial revolution has since been moving the education system in the virtual learning direction. It is unfortunate that the Covid-19 pandemic has forced change upon the education system moving from traditional learning to virtual learning; however, it is important to understand how educators experience the changing process. Hence this study aims at exploring and describing the experiences of private TVET college educators in Pretoria regarding virtual learning during the school lockdown. The research questions to achieve this aim are "What are the experiences of TVET college educators when transitioning from traditional learning to virtual learning during Covid-19 school lockdown?" and "what are the factors that inhibit and support TVET college educators transitioning from traditional learning to virtual learning?" 


\section{Literature}

Technologically, the world is changing so fast. Hence, educators should be in a position to adapt to these changes and still able to deliver quality teaching. The fourth Industrial revolution brought about changes in our teaching and learning environment globally including South African schools. Ramorola (2013) points out that the new focus on use of Information Communication Technology (ICT) in South African schools indicates that educators are expected to use computers and other technologies as tools to adopt the new and evolving teaching methods. For educators to effectively adapt to use of technologies (virtual classroom) in the place of the usual face-to-face traditional classroom, many factors must be put into consideration such as the educators understanding of virtual learning, educators' readiness or attitudes towards technology, availability of the relevant tools and training.

Educators, students, and administrators are used to traditional pedagogy, research constantly report that virtual learning projects are failing to achieve their objectives due to many reasons, more pronounce in the reasons is the user resistance to change (Parlakkilic, 2017 p. 638). Parlakkilic (2017 p. 642) further state that there are different views about the nature and aims of ICTs in education consequently, diverse behaviours and attitudes are found in the development, use and change management of virtual learning. In line with Parlakkilic finding regarding use of virtual learning, this present study seeks to explore and describe TVET college educators' regarding virtual classroom during the school lockdown.

Technical and vocational education and training play an essential role in increasing a knowledgeable and skilled community that will be able to effectively improve the social and economic growth of a country (DHET, 2013 p.3). Similarly, Boateng (2012 p. 108) described vocational technical education as the educational courses that involve the study of technologies and the gaining of practical skills and knowledge in order to discover and improve labor in various part of economic for the purpose of economy growth. For the TVET colleges to achieve skills development for economy growth, effective management from the relevant stakeholder is vital especially the educators' ability to manage change process that would enhance their performance during teaching and learning engagement with the students.

\section{Theoretical framework}

The Kanter theory of change is adopted as the theoretical base in this study, given its correlation with the researchers' intentions to explore and describe the experiences of TVET college educators when transitioning from traditional classroom to virtual classroom particularly during the Covid-19 school lockdown. The Kanter theory buttressed this study by highlighting how TVET educators managed the change processes involved, on account of their attitudes and behaviours during transitioning to virtual classroom. While different models and approaches have been developed to better understand the process change in organisations and educational settings as viewed by Kanter's theory, the particular areas of change that need to be articulated when addressing lecturers' experiences in this study utilizes the ADKAR model to provide a valuable interpretation of TVET college educators transformative efforts during the transition to virtual classroom.

\section{Methodology}

To achieve the objectives of the study, a qualitative research approach was used to obtain first-hand information in the research setting (Neuman, 2011); and to interpret and understand the participants experiences regarding their transitioning from traditional classroom to virtual classroom (Babbie \& Mouton, 2015). This study engaged a multiple case study research design as it was deemed most appropriate to obtain multiple information from various perspectives (Baxter \& Jack, 2008). The study focused on four private TVET colleges in Pretoria central to provide answers to the research questions. Case studies permits spending time in the setting of the research subject (Hamilton \& Corbett-Whitter, 2013). Table 1 depicts the educators' profile. 
Table 1. Educators profile.

\begin{tabular}{|l|l|l|l|l|l|}
\hline College & $\begin{array}{c}\text { Educators' } \\
\text { pseudonyms }\end{array}$ & \multicolumn{1}{|c|}{ Age } & Gender & Highest Qualification & \multicolumn{1}{c|}{$\begin{array}{c}\text { Years of teaching } \\
\text { experience in TVET } \\
\text { college }\end{array}$} \\
\hline \multirow{2}{*}{1} & Mr. A & 31 & Male & National Diploma & 6years \\
\cline { 2 - 6 } & Ms. B & 28 & Female & Bachelor of science Degree & 3years \\
\hline \multirow{2}{*}{2} & Ms. C & 27 & Female & Bachelor of science Degree & 3years \\
\cline { 2 - 6 } & Ms. D & 35 & Female & National Diploma & 6years \\
\hline \multirow{2}{*}{3} & Ms. E & 40 & Female & Bachelor of science Degree & 2years \\
\cline { 2 - 6 } & Ms. F & 40 & Female & Master's degree & 10years \\
\hline
\end{tabular}

Data was generated through face-to-face semi-structure interviews and non-participant observation of the ICT tools in the learning environment. The covid-19 restrictions were observed, during the interview sessions. Minimum of 45 minutes was spent with the participant at the college in order to understand them from their view. Data analysis was done thematically through analytically coding and categorizing the generated data into themes that emerged from the data. The research questions and conceptual framework also guided the researcher in the systematic analysis of data in terms of sorting it according to themes.

\section{Findings and discussion}

The findings are presented and discussed in the three sub-headings below.

\subsection{Attitude of TVET college educators toward virtual learning}

In the aim of attempting to answer the research questions while analyzing the participants shared experience regarding virtual learning during the covid-19 school lockdown, it was discovered that most of the participants had a mixed feeling towards the changing process from the traditional learning to virtual learning. Majority of the participants have positive attitude about virtual learning however, the circumstances that surrounded their movement negatively affected the change process from traditional learning to virtual learning. Mr. A and Ms. C, E and F described their feelings towards virtual learning as follow respectively -

"It is not that bad, but it is a bit challenging because of the rushing to change due to the national lockdown",

"I think online learning in itself is not a bad idea, but I don't think it can be the main mode of learning",

"I think virtual classroom is essential, I don't want us to go back to the traditional way of teaching"

"it's not boring asides the network issues which are the basic technical issues that we see regarding online classes. Online learning for me is actually more convenient".

The positive attitude displayed by majority of the participants towards the moving from traditional learning to virtual implies that there should be successful integration of virtual classrooms in our TVET colleges. However, the good attitudes displayed by the participants come with some hindrance which would affect the adoption of virtual learning in their colleges. The findings of this present study agree with Nokwali, Mammen and Maphosa (2017) in their study where they found that teachers have a positive view towards the idea of using ICTs in lessons. According to Torres \& Giddie (2020) teachers' attitudes towards technology, as well as their readiness to accept ICT into their teaching are key factors for the successful integration and use of technology in education. Similarly, Davis, Bagozzi \& Warshaw, (1989) in their Technology Acceptance Model (TAM) firmly indicate that attitude that users formed toward a system will actually determine if users will accept or reject it. Invariably educators' attitude towards virtual learning is important but more important are the situations surrounding the use of virtual learning. The following themes below are used to discuss factors that affect virtual learning in the participated TVET colleges.

\subsection{Supporting factor towards successful virtual learning}

Data collected through the interviews and observation revealed that the educators with background IT skills are in better position to successfully adapt to virtual learning despite the circumstance regarding the change process. For example, Mr A and Ms E said respectively that "For me I have IT background, I had certificate course in IT engineering, I have adequate knowledge on IT, so the changing from traditional classroom to virtual classroom was easy for me" and "Luckily for I was from 
the IT industry, so I was able to apply my background knowledge by giving them online activities with traditional face-to-face teaching". Data collection also reveals that the piece of trainings provided to the educators helped them during the moving from traditional classroom to virtual classroom. Although, the training seems not to be sufficient due to the short period that the educators have to change to virtual learning. This was narrated by Ms. E and B respectively "the institution tries to do some short training where online learning platform was explained", and "Immediately the President announced the national lockdown, decision was made to replace traditional classroom to virtual classroom by the college management and little or no form of training could be provided within that period". This finding indicates that training is essential to ensure smooth transitioning to virtual learning. In line with this finding is the recommendation made by Cheok, Wong, Ayub, and Mahmud (2017: 30) that "room to experiment, to make mistakes, to try again and finally learn must be made part of the school culture if change is expected". This implies that practical and continuous training regarding virtual learning should be provided for the educators.

\subsection{Mitigating factor towards successful virtual learning}

It was discovered from the analysis of the interviews and the observation of the learning environment of the participated TVET colleges that there is lack of ICT tools such as personal laptops for the educators, and access to Wi-Fi connection to facilitate virtual learning. According to the participants response, Mr. A said that "...there was not enough time for the school to provide the adequate and necessary materials such as laptops, android phones". He further stated that "the students also need the online garget like the phone, laptop, data, so that they can be able to stay online whenever they are having online classes. If students don't have any of these tools, it means that they will not be able to connect to the online classes" Similarly, Ms. C shared her experience regarding ICT tools "that is the biggest problem because the ICT gadget is lacking if I can say". Ms. D also added "in my college, lecturers were given data to work online but it is not frequent and sufficient. No provision regarding laptop or router for the lecturers. The students were also not supported with any resources needed for online learning. The students are on their own because this is a private college". The findings of this present study correlate with Nokwali, Mammen and Maphosa (2017) studies where they found that challenges such as a lack of ICT resources, space, and time compromises the teachers' ability to implement the use of ICT in lessons in an effective manner. This implies that lack of ICT tools would negatively affect the changing process from traditional classroom to virtual classroom. The lack of appropriate ICT tools experienced by the participants of this study made them to conclude that virtual learning has not come to stay but is just used to ensure continuity of learning during school lockdown. Ms. D stated that "I can say I have good attitude concerning online learning but the essential tools for online learning are not provided. So we have to move back to traditional learning because the students are expected to write national vocational examination in July". Ms. F added by saying "....not too much that was invested in the virtual learning, no infrastructure. So now that we are back to traditional learning, I can say that the virtual learning died a natural death".

\section{Conclusions}

Existing literature recognized the benefits of virtual learning and adapting ICT tools in learning environment to improve the output of education sector and transform the economy at the long run (Torres \& Giddie, 2020; Dlamini, Marais, Mwapwele \& Van Biljon, 2019: Rubagiza, Were \& Sutherland, 2011). However, the adaptation of virtual learning comes with several challenges (Nokwali, Mammen \& Maphosa, 2017). This study was an attempt to provide insights about the state of virtual learning in some selected TVET colleges in Pretoria by exploring the experiences of the educators regarding virtual learning during the school lockdown due to the Covid-19 pandemic. This study reveals that the participated TVET college educators have good attitude towards virtual learning. However, challenges such as ICT skills, training and lack of ICT resources made participants to conclude that virtual learning has not come to stay in their colleges. Hence, to ensure successful integration of virtual learning/ ICT in our TVET colleges it is recommended that the educators which be provided with practical and continuous training regarding virtual teaching and learning. It is also recommended that the Government should support the private TVET colleges which this study focused on regarding ICT resources to facilitate proper and progressive integration of virtual learning. 


\section{References}

Babbie, E. \& Mouton, J. (2015). The Practice of Social Research. London: Oxford University Press.

Baxter, P., \& Jack, S. (2008). Qualitative case study methodology: Study design and implementation for novice researchers. The qualitative report, 13(4), 544-559.

Boateng, C. 2012. Restructuring Vocational and Technical Education in Ghana: The Role of Leadership Development. International Journal of Humanities and Social Science, 2(4) 108-114.

Brodie, M., McFarlane, R., \& Ally N. (2020). Learning in the time of Covid-19: Equitable support during school closures desperately needed. Daily Maverick. [Online] Available from: https://www.dailymaverick.co.za/article/2020-04-21-learning-in-the-time-of-covid-19-equitablesupport-during-school-closures-desperately-needed/ [Accessed 5 September 2020].

Cheok, Mei Lick, Su Luan Wong, Ahmad Fauzi Ayub, and Rosnaini Mahmud. (2017). "Teachers' Perceptions of E-Learning in Malaysian Secondary Schools." Malaysian Online Journal of Educational Technology, 5(2), 20-33.

Davis, F. D., Bagozzi, R. P., \& Warshaw, P. R. (1989). User acceptance of computer technology: A comparison of two theoretical models. Management Science, 35(8), 982-1003.

Department of Higher Education and Training. 2013. White Paper for Post-School Education and Training: Building and expanded, effective and integrated post-school system. Pretoria: Government Printer.

Dlamini, S., Marais, M., Mwapwele, S. D., \& Van Biljon, J. (2019). Teachers' ICT adoption in South African rural schools: a study of technology readiness and implications for the South Africa connect broadband policy. The African Journal of Information and Communication, 24(1), 1-21. https://doi.org/10.23962/10539/28658

Haffajee, J. (2020). Ramaphosa shows mettle as he declares Covid-19 a national disaster and the world's gravest emergency. Daily Maverick. [Online] Retrieved from https://www.dailymaverick.co.za/article/2020-03-15-ramaphosa-shows-mettle-as-hedeclarescovid-19-a-national-disaster-and-the-worlds-gravest-emergency/ [Accessed 5 September 2020].

Hamilton, L., \& Corbett-Whittier, C. (2013). Defining case study in education research. Using case study in education research, 3-22.

Kanter, R. M., \& Stein, B. A. Jick. T.D. (1992). The challenge of organizational change: How companies experience it and leaders guide it. New York, United States: The Free Press.

Neuman, W. L. (2011). Social Research Methods. Qualitative and Quantitative Approaches. (7 $7^{\text {th }}$ Ed.). New York: Allyn and Bacon.

Nokwali, M., Mammen, K., \& Maphosa, C. (2017). How is technology education implemented in South African schools? View from technology education learners. International Journal of Education Sciences, 8(3), 563-571. Retrieved from doi:10.1080/09751122.2015.11890278

Parlakkiliç, A. (2017). Change management in transition to e-learning system. Qualitative and Quantitative Methods in Libraries, 3(3), 637-651.

Ramorola, M. Z. (2013). Challenge of effective technology integration into teaching and learning. Africa Education Review, 10(4), 654-670. Retrieved from https://doi.org/10.1080/18146627.2013.853559

Rubagiza, J., Were, E., \& Sutherland, R. (2011). Introducing ICT into schools in Rwanda: Educational challenges and opportunities. International Journal of Educational Development, 31(1), 37-43. Retrieved from https://doi.org/10.1016/j.ijedudev.2010.06.004

Torres, K. M., \& Giddie, L. (2020). Educator Perceptions and Use of Technology in South African Schools. Peabody Journal of Education, 95(2), 117-126. Retrieved from https://doi.org/10.1080/0161956X.2020.1745611 


\title{
IMPACT OF IDENTITY-ORIENTED LITERATURE EDUCATION ON ADOLESCENTS' INSIGHT INTO THE SELF AND THE OTHER
}

\author{
Peter Grandits \\ Faculty of Education, University of Ljubljana (Slovenia)
}

\begin{abstract}
A mixed-methods quasi-experimental study evaluated the effects of a pedagogical intervention in literature education on Austrian upper secondary high school students' insight into the self and the other. The intervention is based on the newly developed NDR-model, the letters in the abbreviation representing the basic practices of narration, dialogue and response underlying the model. Two cycles of NDR interventions on the identity issues of "happiness" and "relations" were implemented.

An IPA study was conducted to explore how the implementation of the NDR-model of literature education affected participants' learning outcomes (self-understanding and understanding of the other). Qualitative analysis of interview and artefact data suggested that NDR students experienced insight into the self and the other because they were stimulated to engage with literary texts in the context of their personal identities.
\end{abstract}

Keywords: Literature education, scientific study of literature, narrative engagement, insight.

\section{Introduction}

Fialho, Zyngier and Miall (2011) discovered that methods in language arts classes "ha[ve] not been subjected to much empirical research investigation and classroom interventions are generally taken for granted" although "the way classes are conducted can play a role relevant to students' responses to literature" (ibid., 237). The prevalent methods primarily aim at teaching students interpretation and formal analysis, thus distancing students from genuine literary experience (ibid.). Students do not perceive literature as a source of pleasure (Mahling, 2016) and reading as a personally significant process (Sumara, 2002). In addition, emotions and values constitutive of a meaningful reading process (Koopman \& Hakemulder, 2015) are neglected in dominant approaches to literary education.

As literary education fails to encourage students to make literature significant by establishing personally relevant connections, the learning potential of fictional narratives to intersect with and build upon the learners' lives is not fully realized.

The implementation of the NDR-model primarily aims to improve students' narrative engagement and self-insight, trigger meaningful literary response and foster accommodative and transformative learning (Illeris, 2017). The present qualitative study addresses the following research question:

RQ: How does the pedagogic intervention on the basis of the NDR-model of literary education affect participants' learning outcomes (self-understanding and understanding of the other)?

\section{Methods}

A quasi-experimental mixed methods design was implemented (Creswell \& Plano Clark, 2018). First, a Wilcoxon Signed Rank Test revealed statistically significant changes in reading orientations, attentional focus, narrative engagement and self-insight following participation in the educational intervention. In addition, the results of the Mann-Whitney U Test indicated that there was a statistically significant difference in reading orientations, attentional focus, narrative engagement and self-insight between the experimental group and the control group after completion of the intervention. (Grandits, 2021).

Second, quantitative results were used for purposive sampling in the qualitative study and the design of the interview protocol. Third, interviews were conducted, discussions were observed, and artefacts were collected which were analyzed according to the principles of Interpretative Phenomenological Analysis (Smith, Flowers \& Larkin, 2009).

In order to be able to generate a detailed description of the phenomenon in question and to prevent data overload, sample size for this study is small $(\mathrm{N}=70$; seventh-form grammar school 
students). For the qualitative study, stratified purposive sampling (Teddlie \& Tashkkori, 2009) on the basis of the results from the quantitative study was used. The participants were selected on the basis on their scores on reading orientations, reading experiences and self-insight in the pretest. A limited number of participants within the experimental group was selected $(n=6)$.

The qualitative study was conducted within the framework of Interpretive Phenomenological Analysis (IPA; Smith, Flowers \& Larkin, 2009) because this methodology allows us to gain a detailed personal insight into participants' experiences and their interpretations of these experiences. In line with the theoretical underpinnings of IPA, the qualitative study pursues two purposes: (a) to phenomenologically explore participants' descriptions of their experiences of literature education, (b) to hermeneutically understand how the intervention affects the participants' learning outcomes.

Individual face-to-face semi-structured interviews were conducted in a receptive style (Wengraf, 2001). A semi-structured interview protocol containing open-ended questions to encourage detailed responses was used. The questions focused on (a) the general description of the experience, (b) the personal relevance of the experience, (c) agency during the experience, and (d) the detailed description of the learning experience. The interviews were audiotaped and transcribed verbatim. In addition, participants produced experiential reports and artefacts. Discussions were videotaped and transcribed verbatim. All the data were anonymized and treated confidentially. Informed consent was obtained in written form from each participant prior to the implementation of the intervention.

In accordance with the principles of IPA, the following strategies of data analysis were applied to the qualitative data in an iterative cycle until thematic saturation was reached: a. reading and rereading, b. initial noting, c. developing emergent themes, d. searching for connections across emergent themes, e. moving to the next case, f. looking for patterns across cases. Finally, the data are presented in a coherent narrative format, citations from the data are supposed to illustrate each theme.

\section{Results and discussion}

Five main themes were identified from interviews, artefacts and observations. Participants described their experiences of how the intervention affected: (a) engagement; (b) learning practices; (c) self-insight; (d) insight into the other; and (e) text understanding. Themes three and four, which proved to be central to the given qualitative research, are presented below.

\section{Theme 3: Insight into the Self}

Participants distinguished between five effects of the intervention on identity learning. Students' interpretations of the effects on their (a) traits and behavior, (b) attitudes to life, (c) psychological well-being, (d) storied lives, (e) perception of time, and (f) identities as readers and learners will be outlined below.

Bob stated that you could "learn something for yourself, in most cases". In the following, we will present what students said they had learned for themselves during the intervention. First, participants reported that the intervention prompted self-assessment. Students pondered about their action patterns and their character traits as a result of the transaction with the literary text. As a consequence, they discerned a change in behavior and character traits: "[...] I try to partly improve my behavior and my qualities or I simply do not push my negative qualities aside, but I rather really reflect on them, and I consider various perspectives." (Sarah) Reflection raised the awareness for the need of change and self-care: "This clearly showed me that I need to change a bit and that I need to take more care of myself." (Sarah) Bob gave an example of the change, he stopped being very stubborn in everyday encounters. And Mary recounted that she had realized that harmony was essential because her parents had told her that family life made them most happy. Therefore, she tried "not to have my way in stress situations, but I simply stopped and avoided an argument."

Self-assessment also impacted on how students valued their lives. By comparing the tragic life stories of characters with their own stories, they understood the true value of their lives: "It [the intervention] evoked good things, yes, that I'm simply happy with my life as it is." (Sarah)

Second, participants pictured the intervention as transformative as far as their attitudes to life are concerned. These were modified and therefore students gained self-insight:

What did I learn? This is hard to tell, but, I have already mentioned it, concerning happiness, find out what really makes you happy, don't be superficial. Now, personally it was a big advantage for me. (Mary)

Students achieved self-insight by feeling into themselves. This was prompted by the authentic questions posed during the intervention, e.g. 'What makes you truly happy?'. This kind of self-insight had effects on participants' actions: "[...] and maybe I'll do some things or won't do them in the future so that I'm happier, yes, this really made me thinking very much, and, I think, this also influence me, yes." (Mary). Bob had a similar experience:

Yes, in this text about happiness, there were two characters who had a lot of problems, but the ending still was like, ehm, 'Yes, we are fine!' And then I thought for myself, yes, whatever harm happens to me, in the end everything will be alright, and that's what I learned. (Bob) 
Bob's attitude to life changed, he grew more optimistic because of the transaction with the literary text: "Yes, I'm a somewhat pessimistic person as far as my future is concerned, but what I've maybe learnt from the tasks is that I should be hopeful for the future whatever happens."

Third, the intervention also affected the psychological well-being of the participants. Narration enabled the participants to cope with sad events, thus changing their lives. Judith found the writing of the autobiographical story transformative:

No, not depressing because I don't have a problem to tell people about negative events, but I found the task hard when I did it at home, I found it really difficult to write about it or it took me quite long because I needed breaks all the time. But I have benefitted, I feel better when I think about it now. [...] Telling the personal story, the self-experience, it really helped me, I can cope with it now, it was like a therapy. (Judith)

Other students confirmed this purging effect: "For me, it was very important to write the story in the beginning, that sad experience that I had, in order to come to terms with it." (Mae) Mary highlighted the consequences of the disclosure of repressed life episodes: "[...] that you are thankful in the first place, that it doesn't come to that anymore, and, that you'll maybe change your behavior because of it."

Fourth, participants experienced an effect on their personal life stories. Past events were recalled and reflected when students told their personal stories: "[...] It [the past] was called to mind and I could think about it once more." (Bea) Not only recent memories were remembered, but also distant events: "I also thought of things that had happened long ago, which I perhaps repressed because they were bad, and then I took them up again [...], and I was thankful in the first place that, yes, things are not like that anymore, yes, and maybe I'll change my behavior" (Mary) Disturbing memories were revived in the present, they aroused feelings and had future implications on students' behavior. For example, Sarah realized through the identity task that she had been too submissive in the past, she disapproved of her behavior and decided to change it. She stated that it was the intervention that "made me realize my past, and where I went wrong and what I could have done better". Recall of the relevant episodes of the life story also gave participants the opportunity to account for how they acted in the past.

In addition, the evocation of memories raised participants' awareness of the fact that past experiences shaped their present being. This awareness was regarded beneficial for the future as life was perceived less superficially.

Fifth, students also reported an influence on their time perception, they became aware of the temporality of their being. They realized that time perception was closely linked to their storied lives. When telling their personal stories, the past was reflected in the present, and this present reflection provided students with additional future opportunities. Past memories were evoked during the present transactional engagement: "Yes, I realized what I had experienced in my short life, [...] and, yes, I found it nice that I could account for the past yet again, from childhood till now, so that you can recall the past." (Judith) Participants experienced the effect that the temporal distance between past and present was bridged during the process of remembering, discontinuities were overcome. In addition to personal memories, cultural experiences of the past were recalled in the intertextual reading of the literary texts.

The present experience that the students linked up with their past had implications for the future. Participants explained that a changed attitude to life, which had become apparent in new life concepts, shaped their perception of the future. Bea discovered that she had a different perspective on problems although having read the book did not help her solve the problem. Mary realized that the intervention had offered her future possibilities for action. She was taught that she was agentive and that she could change her behavior. Awareness of the past made Sarah recognize the need for change.

Sixth, the intervention also changed the participants' identities as readers. Bea stated that she had not been interested in reading before the intervention, but as a result of the intensive engagement with the literary text she enjoyed reading. Therefore, she identified the future objective of adopting a new reading attitude. In addition, modified orientations to reading were reported: "I think I would read the book with a different attitude now." (Mary) In the same vein, we can sense a change of reading orientation in Judith's testimony.

Yes, I should not see reading ..., for example, because I didn't enjoy it for some time, because in the past I really enjoyed reading, I should not see it in a negative light, but, that I should try it again and maybe engage more with the books. (Judith)

Judith adopted a new approach to reading which was grounded in perseverance. She had realized that high engagement was essential for the learning outcome. We can conclude that intensive engagement could facilitate a change in reading orientations. Mae also noticed a better overall performance at school because of the change in reading attitude.

Participants also remarked on the insight into the Self on the meta level. Emotional resistance was regarded a precondition for change. Learning was experienced as transformative: traits, actions, attitudes, psychological condition, life stories and habits were changed due to the intervention. Although they answered the question in the negative whether the intervention fundamentally changed them as a person, participants reported changes in self-understanding, in their psychological condition, in their storied lives, in their perception of time, and their identities as readers and learners. They actively 
increased their capacity to rethink life. In the discussions, participants additionally mentioned changes in their relational identities.

Participants agreed that the reported changes could be traced back to the intervention. No other factors were detected. Moreover, students repeatedly stated in their experiential reports that were written three months after the intervention that the lessons had a lingering effect. The ideas triggered by the intervention had stayed with them by then. Students also highlighted a better retention of the learning outcome. Sarah concluded in her report that students gained a lot of new insights about themselves, they got to know literature better, they got to know their classmates better, and they escaped the daily school routine. Despite their spontaneous negative answers to the question whether fundamental changes had taken place, we can infer from the interviews, artefacts and observations that transformative learning occurred as an effect of the intervention.

\section{Theme 4: Insight into the Other}

Mae's description of how participants experienced the insight into the relationships with others is representative: "I don't know, I just think I will treat people differently than before." Bob, for instance, decided to respond to significant Others in a more friendly way because he had learned to empathize with characters during the intervention. Mary expounded on the insight into the Other:

It was very interesting, I think, to get to know close people better once again, and I think that the question what people think about happiness is very interesting though very personal. If people tell a story ... what really makes them happy, and, as I said, that really influenced me. First, how I see these people, and second, how I treat them, and, what I maybe want to do to make others happy. (Mary)

Insight of the other was yielded by listening to significant Others telling their personal stories. Identity work in phases one and two influenced the participants' perception of others, their response to others as well as the actions towards others. Changes in students' perception of their relations could be partly traced back to a change of life concepts. Affective behavior toward others was also altered. Mae, for instance, acted more emotionally expressive towards others after the intervention.

A further effect on the insight into the Other was that people were evaluated differently: "In any case, I'll be able to judge people differently from what I thought before" (Judith). Higher tolerance for others was shown, participants had become more unwilling to change others and interfere with others' beliefs: "Yes, well, I'll try to let people be the way they are, and I'll try not to think ill of them somehow. [...] Everybody can decide for themselves, and, it doesn't concern me. And, I think, I've learned this only recently." (Judith). In conclusion, general insight into human nature was reported. Others were perceived and judged differently, and as a consequence, actions towards the others changed.

Adopting different views was considered a means to insight into the Other: "It was interesting that, I've said this before, that there were different opinions, and that you allow these different opinions, and that you change your own opinion a bit or that you can rethink things, yes." (Mary) Acceptance of alternative views was facilitated by putting yourself in the other's position: "It made me clear that I had to see things from different perspectives because I think, well, I tried this before, but through it [the intervention] you got a much better picture of it, you see things differently." (Sarah). To sum up, participants reported a better understanding of the other through the change of perspective.

The intervention also had ethical implications. First, students reconsidered ethical norms:

"Well, I wouldn't draw a clear line between good and evil anymore because there are people who somehow seem, well, not bad, but nasty, but there is a reason why they are that way, and therefore I wouldn't divide people simply in two groups, in good and evil, but you have to question these categories." (Judith)

Ethical reflection of that kind was caused by a thorough analysis of characters' traits and reasons for their actions. Students held that both the text's structure and the intensive engagement with the text provoked ethical thinking.

In addition, participants discovered the harmful nature of prejudices. They also felt a moral obligation to voice their own opinions and to defend their opinions, but also to scrutinize others' opinions and to accept them.

In conclusion, participants reported a change in perceptions and evaluations of significant Others and in actions towards these significant Others. Identity work and the transactions in personal response to the literary text were seen as causing these changes. In addition, different views in external dialogues facilitated insight into the Other. Finally, the intervention did not only affect personal relationships. Ethical knowledge about norms, obligations and imperatives was generated as well.

\section{Conclusions}

It can be concluded from the qualitative results that the intervention based on the NDR-model affected participants' learning outcome (self-insight, insight into the other).

There is empirical evidence for the insight into the Self. In the literature, the following effects of reading literary texts on identity are postulated. First, identity can be aesthetically experienced during 
reading (Kuiken, Miall \& Sikora, 2004). During the transactional process, personal connections were established. Students responded both cognitively and affectively to the text in aesthetic experience. They imagined the world of the text and were transported to this imagined world. During the transactions, attention was mostly balanced between the world of the text and the world of the reader. It could be proven that aesthetic experience is a precondition for insight into the self. Second, knowledge about identity is discussed and performatively produced (Krammer, 2013). Participants reflected and co-reflected on their traits, their behavior, their attitudes to life, their habits, and their storied lives in response to reading literary texts, and by reflecting identity, they generated new knowledge about identity. Third, reading literature has the potential of transforming the reader's identity (Ricoeur, 1991). Behavior, attitudes, psychological condition, personal stories, time perception, and identity as readers and learners were changed due to the intervention. Fourth, literature affects personal identity in its temporal dimension (Ricoeur, 1992). The students experienced themselves in their temporality. They realized how past, present and future are interrelated. New possibilities of agency were opened up by learning how to apply the learning outcome to personal life. In addition, participants realized that the personal story could provide continuity. Narrative change and consolidation were experienced as indicators of development. Fifth, literature affects social identity negotiations in situated contexts (Beach, Johnston \& Thein, 2015). Dialogue allowed insight into how identity was conditioned by relationships to significant Others. Thus, both understanding of the Self and the Other was enhanced. Sixth, literature emphasizes the ontological status of identity as cultural fiction (Krammer, 2013). Participants' recalled and reflected their storied lives, thus they became aware of the fictional nature of the story and the selective mechanism that generates the story.

The qualitative study also proved that the intervention yielded insight into the other. Changes in the perception and evaluation of others and in the actions towards others were evident. In addition, ethical norms that regulate social living together were reconsidered.

The findings of the qualitative study corroborate the quantitative results that both insight into the Self and insight into the Other were promoted by the intervention. In conclusion, the intervention based on the NDR-model is purposeful as it met the principal learning objective set out at the beginning of the design process. The intervention fostered students' learning about themselves and others.

\section{References}

Beach, R., Johnton, A. \& Thein, A.H. (2015). Identity-focused ELA teaching: A curriculum framework for diverse learners and contexts. New York. Routledge.

Creswell, J.W, \& Plano Clark, V.L. (2018). Designing and conducting mixed methods research. $3^{\text {rd }}$ ed. Thousand Oaks, CA: Sage.

Fialho O., Zyngier S., \& Miall, D. (2011). Interpretation and experience: Two pedagogical interventions observed. English in Education, 45(3), 236-253.

Grandits, P. (2021, March). Impact of identity-oriented literature education on adolescents' attentional focus, modes of engagement and self-insight. Paper presented at the INTED 2021.

Illeris, K. (2017). How we learn: Learning and non-learning in school and beyond. 2nd ed. Oxon: Routledge.

Koopman, E.M., \& Hakemulder, F. (2015). Effects of literature on empathy and self-reflection: A theoretical-empirical framework. Journal of Literary Theory 9(1), 79-111.

Krammer, St. (2013). Identität und Performanz: Aspekte der Literaturlehr- und -lernforschung. (Unpublished habil. dissertation). University of Vienna.

Kuiken, D., Miall, D., \& Sikora, S. (2004). Forms of self-implication in literary reading. Poetics Today, 25(2), 171-203.

Mahling, M. (2016) Lesepraxis von Kindern und Jugendlichen: Die Bedeutung von Familie, Schule und Peers für die Beschaffung und Nutzung von Lesestoffen. Berlin: de Gruyter.

Ricoeur, P. (1991). Narrative Identity, Philosophy Today, 35(1). 73-81.

Ricoeur, P. (1992). Oneself as another. Chicago: University of Chicago Press.

Smith, J., Flowers, P., \& Larkin, M. (2009). Interpretative Phenomenological Analysis: Theory, Method and Research. London: Sage.

Sumara, D.J. (2002). Why reading literature in school still matters: Imagination, interpretation, insight. New York: Routledge.

Teddlie, C., \& Tashkkori, A. (2009). Foundations of mixed methods research. Thousand Oaks, CA: Sage.

Wengraf, T. (2001). Qualitative research interviewing: Biographic Narratives and Semi-structured Methods. London: Sage. 


\title{
"MIND THE GAP": THE TRANSFORMATIVE LEARNING PROCESS OF SECOND LANGUAGE PRACTITIONERS WHEN BECOMING SCHOLARS
}

\author{
Dana Kaplan ${ }^{1}, \&$ Maya Wizel ${ }^{2}$ \\ ${ }^{1}$ Department of Sociology, Political Science and Communication, The Open University (Israel) \\ ${ }^{2}$ Middlebury Language Schools, Middlebury College (VT, USA)
}

\begin{abstract}
This paper is about transformations from knowing to not-knowing and from doing to becoming. The paper's focus is an ongoing research project on a new Doctorate program in Modern Languages studies (DML) and the process that the students in this program undergo when transitioning from being practitioners to becoming novice scholars. This program is part of a conscious effort to create an academic field whereby scholarly and professional types of knowledge are organically co-produced and this interlaced knowledge is expected to fertilize practitioners' professional practices. The program's graduate students are mostly in their mid-career and are motivated to pursue their DML studies for multiple reasons. The necessity of developing a study plan that can foster their transition from practitioners to scholars and help them develop a researcher identity became evident early on. Students were expected to quickly re-adjust their self-image as future theorizers who could carry out independent research and produce original scholarship. While the challenges mentioned above are not unique to this specific doctorate program and are well documented in the extensive scholarship on doctorate students' education, fewer studies have addressed the particular challenges faculty and students face as part of the latter's transition from practitioners to graduate students and novice researchers. Therefore, we ask, what accounts for a successful process of supporting language teachers in becoming novice researchers? Our aim is twofold: first, to detail our pedagogical rationale, dilemmas we faced, and the solutions we carved out; and secondly, to contribute to a nascent discussion on doctorate students' training and academic socialization in applied disciplines. Using Mezirow's adult learning theory of Transformative Learning, we describe the challenge of designing a process of academic socialization that can support adult learners' development and shift in perceptions, skills, and actions. During the first four cohorts of the program, in an introductory course, "Research Foundations," we faced dilemmas regarding reading materials and teaching activities, and collected students' reflections and communications with us, the course professors. Accordingly, the paper explicitly emphasizes our efforts to actively foster a culture of independent learning and a productive learning community by introducing new knowledge and skills. The paper can benefit instructors who design and lead graduate programs for practitioners in any field of practice.
\end{abstract}

Keywords: Higher education, transformative learning, teaching, doctorate supervision, academic socialization.

\section{Introduction}

This paper addresses some of the complex dilemmas and ad-hoc solutions the two authors devised when instructing the first four cohorts of a new doctorate (Doctor of Modern Languages - DML) program specializing in second language teaching and learning. These doctoral students who also work as second language teachers state - in many versions, "This is not in the slightest my everyday experience when teaching! What is written in this article is not true at all!" They are quick to address personal experiences as well-established truths. This anecdote reflects the wide gap in perceptions and academic identity of graduate students who are also practitioners. Boud and Lee (2009) suggest that, recently, a "new interest in the educative work of doctoral programs has surfaced at a time of major social and policy-led change in the field of doctoral research and practice" (p.1). In light of the expansion of graduate education (Altbach, 2015 ) in many national higher education contexts, Boud and Lee further recommend that scholars pay more attention to the "whys" and "hows" of doctoral studies. They argue that the task ahead is to recalibrate both the rationale and actual practices of the Ph.D. training process. Doctoral training is already a transformative process that involves learning new skills, modes of thinking, and ways of being in the world. Yet, it is less clear what might be the best practices to help students socialize into the new "researcher" habitus. The gap 
between the entry and exit points in the doctoral training process has been described as a journey and has been extensively studied (Hughes \& Tight, 2013). However, less attention has been paid to this academic development journey in disciplines that are markedly practice-based (such as, education of applied linguistics). Equally understudied is the training process of students who are already established professionals in their respective fields of practice and who, furthermore, do not conceive of their doctoral studies solely as a segue for an academic career.

Our aim in this paper is twofold. First, we shall survey the specific training challenges in the context of a practitioner doctorate. Secondly, based on our experience as co-instructors of the Research Foundations course of an emerging DML program, we shall provide insights and solutions we devised to help students acquire a researcher's habitus even if they do not plan on becoming full-blown researchers themselves.

\section{Opening the "black box" of the practitioner doctoral training process}

In recent decades, the academic employment market has been extensively restructured, with the rise of the worldwide casualization of academic labor (Whitchurch, 2019). These developments have led to the expansion of applied and practitioner doctorate programs, such as EdD in the field of Education (Wildy, Peden \& Chan, 2015; Hawkes \& Yerrabati, 2018). According to Boud and Lee (2009), a new ideal type of doctoral student is on the rise, as part of a transformation in the way universities "think" and is in tandem with broader societal changes that reshape the role of knowledge and knowledge production in the new global economy (Shin, Kehm \& Jones, 2018). These top-down macro forces have also affected the doctoral training process and led to the diversification of doctoral degrees (Burrington \& Throne, 2021, Shin et al., 2018). Thus, while universities and faculty are still highly committed to the classic "pure" academic research orientation (Teichler, Arimoto \& Cummings, 2013), current higher education trends increasingly approach graduate studies through the prism of non-academic human capital and emphasize the practical applicability of research outcomes (Altbach, 2015; Shin et al., 2018; Wildy et al., 2014). Evidently, the traditional desired end result of the doctoral training process - the academic job - is conceived as neither sustainable nor desirable by many doctoral students themselves. These students may enroll in doctoral programs in order to enhance their employability outside of the traditional academic market by deepening their professional knowledge or for the sake of personal development.

These structural changes challenge many hard-wired truths and training practices in the doctoral education process (Shin et al., 2018). Despite the evident rise in practitioner doctoral programs, there still remains a gap between the social imagining of the university as a site for universal knowledge production and the current demand for applied doctoral training programs (Barcan, 2013). This ambivalence in the role of the University directly translates into the training process of some practitioner doctoral programs. As a new kind of graduate scholar emerges who, besides the required traditional field-specific knowledge, needs to also become research-capable, reflexive and flexible (Shin et al. 2018), the question is, how to we train this "multi-talented" practitioner doctoral scholar?

The tension between practice and scholarship is also experienced by the doctoral students themselves, as the academic environment sends them mixed messages. Practitioner doctoral students are expected to quickly socialize into the new "researcher" role, even if this is not the reason they embarked on this "mountain-climb" in the first place (Burrnigton \& Throne 2021). The first steps of the training process, we contend, are particularly difficult and challenging for both students and instructors and they require a bit of unlearning, too. In the following, we therefore ask, how can practitioner doctoral training simultaneously accommodate the actual needs of students while not betraying the ethos of scholarly habitus?

We are specifically interested in the ways both students and instructors "mind" two kinds of gaps while taking and teaching the course: the gap between research and practice; and the gap between novice and accomplished researchers. Burrington and Throne (2021) suggest that practitioner doctorate leadership should be more reflexive "in the pedagogical redesign of the practitioner doctorate to strengthen the development and preparation of these scholar-practitioners" )p. 64). Following this advice, we ask, how does a "profession-based doctorate" work? What are the challenges both DML candidates and their instructions face in that first, crucial stage of initiation into the researcher's role in the context of a practice-based training program? How are the demands for a doctoral-level education being met for those who do not necessarily wish to proceed to an academic career? What are the affective investments and knowledge bases required in the transition from being a stakeholder in a purely professional field to becoming a novice scholar in the academic world? This paper dissects the "whys" and "hows" of that introductory course, focusing on the experience we, the course instructors, have accumulated over four years of experience in teaching it in the emerging doctorate program for second language teaching at an American university during the years 2016-2021. 


\section{The transformational process}

The challenges mentioned above can be described as a need for a transformational process:

There are [...] fundamental transformational processes comprising threshold concepts and troublesome knowledge that higher degree students have to work through before they are enabled to progress with their studies. Unless these thresholds of learning are crossed and the troublesome knowledge 'managed', students are not transformed nor empowered to move from a space of 'becoming' magisterial students to actually undergoing a shift in identity that moves them into a space of 'being' postgraduate students (Vahed et al., 2018: 317).

One of the best illustrations of the difficulty to cross these troubled waters can be found in our students' tendency to stay in the comfort zone of thinking like a practitioner. This has often served as a hindrance for the required change of values, assumptions, and skills. We wish to describe our pedagogical choices and solutions in light of Mezirow's (1994) adult learning Theory of Transformational Learning. According to Mezirow, learning is "the social process of constructing and appropriating a new or revised interpretation" (p. 222) or meaning-making. Based on their background and previous experiences, individuals have frames of reference, divided into sociolinguistics frames, psychological frames, and epistemological frames. According to Mezirow, adults tend to resist learning, especially parts that are irreconcilable with existing frames. The idea of transformation is dominant in other adult learning theories and we find the definition offered by Stevens-Long et al. (2012) as descriptive and relevant to our case study. They claim that "transformation as an outcome refers to a deep and lasting change, equivalent to what some people term a developmental shift or a change in worldview" (p. 184). Distinguishing between informative learning that creates changes in what we know and transformative learning that promotes changes in how we know, Kegan's (2010) formulation summarizes well the transformative nature of doctoral studies. Based on the above compatible conceptualization, our goal was to instill habits that would enable a shift in existing frames and foster learning and development.

Over the last four years, we have constantly revised the course, tailoring it to address the gap between the students' practitioner frames and the scholarly frames we wanted them to develop. Changes over the years have included formal course goals, reading materials, class design, assignments, types of feedback, and our role as instructors. Together, all these practices were meant to improve the transformational learning process and help students start narrowing the gap. Using some of Mezirow's (1994) recommendations regarding reflection, discourse, and communication, we will now exemplify our teaching practices.

In the first two years of teaching the course, the goals detailed in the syllabus focused on expanding students' knowledge of social sciences epistemology. To this focus on "how scholars know," we later added another transformative layer, indicating that becoming a scholar is a clearly defined goal. This change was not merely semantic. Rather, we devoted much time to explaining the nature of this change and made sure to acknowledge the uncertainty and confusion students felt once they realized that even though they have substantial prior knowledge in being practitioners, they nevertheless still have a lot to learn in the new academic setting. By way of doing what we preach, we anchored their transformative experience in serious scholarship, assigning readings that resonated with their own transformative process (for example: Kiley, 2017).

Mezirow stressed the importance of employing a discourse that advances learners' critical thinking. Following this lead, we gradually adopted a discussion-based, active learning mode. This meant devoting most of the class time to discussions led by the students themselves. Students' active roles as discussion moderators helped them develop scholarly critical skills since they needed to locate gaps in the literature, take a critical approach with the readings, and lead thoughtful, full class discussions. In addition, we utilized our roles as co-instructors and openly debated various epistemological issues, also stressing (rather than down-playing) our disciplinary differences (sociology and education). This demonstrated that polemic is invaluable for the production of academic knowledge. These various communicative practices were geared to "cultivating the learners' ability to negotiate meanings and purposes instead of passively accepting the social realities presented by others" (Mezirow, 1994: 226).

One of our main goals was to foster students to become self-learners. One activity that helped students understand that each student has her own path took place at the beginning of the course. In the second meeting, we asked each participant to create a concept map of topics and questions they find interesting to potentially further inquire. The impact was huge and long-lasting; it showed that each student had her own experiences, passions, and intellectual interests. This activity also helped students realize that much independent work is required and that our role as instructors is to facilitate and support that individual process. The effort to help students develop a self-learners' state of mind led to some frustrating moments. We often resisted giving concrete answers to questions by raising more questions, a process that some 
students appreciated while others felt that they were neglected or abandoned. This was another gap of perceptions and actions that, over time, narrowed.

Research can be a very lonely process; this loneliness can carry with it confusion, frustration, and the risk of losing one's voice (Hughes \& Tight, 2013). In order to tackle these anticipated difficulties, we have dedicated a great deal of effort to building a supportive cohort through much group work, with the reasoning that this could either facilitate or impede students' development during the whole doctorate process (Cusick, 2015). For some participants, this expectation was perceived with reservations. The students were not accustomed to focusing on someone else's ideas, lacked the habits of giving meaningful and productive feedback, and felt that this requirement shifted them from concentrating on their own work. For example, there was a lack of cooperation with tasks that included peer review. It seems that the traditional structure of the professors as the source of knowledge dominated. In the few cases that peer review took place, the students tended to ask for additional feedback from us while expressing the need for more "reliable" feedback. We insisted on the importance of peer feedback and supported creating non-formal communication of the cohort members outside of class time and without our presence.

We shared a number of our teaching decisions and activities for planning and teaching graduate students and helping them close the gap successfully to become scholars. Stevens-Long, Schapiro and McClintock (2012) found multiple key factors for a successful transformative learning process, such as self-reflection, self-direction, and various kinds of interpersonal and community support. We recommend naming this transformation challenge, talking about it, and assigning reading materials that discuss transforming from being a practitioner to being a scholar in an explicit way. Another consideration is to create opportunities for students' reflection. Some students are able to reflect spontaneously but this needs to be encouraged in assignments and during class time to support individuals in this process. One tension that needs addressing while designing such a course is the balance between encouraging self-directed learners while, at the same time, being part of a cohort of learners. It is like having it both ways: encouraging learners to work independently, inquire and become accustomed to the individual aspects of researching while, at the same time, understanding the benefits and the habits that an effective cohort can contribute at any step of the way. Lastly, as discussed earlier, instructors' role in doctorate programs' preliminary courses are important precursors (Cusick, 2015). Part of the goal should be to "walk the talk" and share areas of uncertainty, provide guidance and confidence in the process and, at the same time, allow for independent work and decrease the dependency of students.

The course syllabus is flexible enough to adapt from one cohort to another and from one student to another. We nevertheless see it as a continuous effort to create and sustain a learning environment that supports transformation. Our work has proved successful as one student concluded a two-hour class saying happily that "everything I thought before class is now overturned! I leave class today with more question marks than exclamation points."

\section{References}

Altbach, P. G. (2015). Building an academic career. A twenty-first century challenge. In M. Yudkevich, P., G. Altbach, \& L. Rumbley (Eds.), Young Faculty in the Twenty-first Century: International Perspectives (pp. 5-19). Albany: State University of New York Press.

Barcan, R. (2013). Academic Life and Labour in the New University, Hope and Other Choices. England: Ashgate Publishing Limited.

Boud, D. \& Lee, A. (2009). Changing practices of doctoral education. British Journal of Educational Studies, 57(3), 339-341

Burrington, D. D., \& Throne, R. (2021). Navigating the doctoral labyrinth: Reflexivity as transformative catalyst for practitioner doctorate persistence and completion. In Throne, R. (Ed.), Practice-Based and Practice-Led Research for Dissertation Development (pp. 64-86). USA: IGI Global.

Cusick, A. (2015). Research training as occupational socialization: Doing research and becoming researchers. Asian Social Science, 11(2), 252-261.

Hawkes, D. \& Yerrabati, S. (2018). A systematic review of research on professional doctorates. London Review of Education. 16(1), 10-27.

Hughes, C. \& Tight, M. (2013) The metaphors we study by: the doctorate as a journey and/or as work. Higher Education Research \& Development, 3(5), 765-775.

Kegan, R. (2000). What "form" transforms?: A constructive-developmental approach to transformative learning. In J. Mezirow (Ed.) \& Associates, Learning as Transformation (pp. 3-34). San Francisco: Jossey-Bass.

Kiley, M. (2017). Career professionals entering doctoral study: Advantages and challenges. Innovations in Education and Teaching International, 54(6), 550-559. 
Mezirow, J. (1991). Transformative Dimensions of Adult Learning. San Francisco: Jossey-Bass.

Mezirow, J. (1994). Understanding transformation theory. Adult Education Quarterly, 44(4), 222-232.

Patterson, C.A., Chang, C.-N., Lavadia, C.N., Pardo, M.L., Fowler, D.A. and Butler-Purry, K. (2019), Transforming doctoral education: preparing multidimensional and adaptive scholars. Studies in Graduate and Postdoctoral Education, 11(1), 17-34.

Shin, J. C., Kehm, B. M., \& Jones, G. A. (2018). Doctoral Education for the Knowledge Society. Cham: Springer.

Stevens-Long. J, Schapiro, S. A, McClintock, C. (2012). Passionate Scholars: Transformative Learning in Doctoral Education. Adult Education Quarterly: A Journal of Research and Theory, 62(2), 180-198.

Teichler, U., Arimoto, A., \& Cummings, W. K. (2013). The Changing Academic Profession. Dordrecht: Springer.

Vahed, A., Ross, A. Francis, S., Millar, B., Mtapuri, O. \& Searle, R (2018). Research as transformation and transformation as research. In Bitzer, E., Frick, L., Fourie-Malherbe, M. \& Pyhältö, K. (Eds.). Spaces, Journeys and New Horizons for Postgraduate Supervision. (pp.315 - 334). Stellenbosch: Sun Press.

Whitchurch, C. (2019). From a diversifying workforce to the rise of the itinerant academic. Higher Education, 77(4), 679-694.

Wildy, H., Peden, S. \& Chan, K. (2015). The rise of professional doctorates: case studies of the Doctorate in Education in China, Iceland and Australia. Studies in Higher Education, 40(5), 761-774. 


\title{
UNIVERSITY STUDENTS' STRUGGLES WITH ONLINE LEARNING DURING THE COVID-19 PANDEMIC LOCKDOWN
}

\author{
Esther Chiner ${ }^{1}$, Marcos Gómez-Puerta ${ }^{2}$, Victoria E. García-Vera ${ }^{3}$, \\ \& M. Cristina Cardona-Moltó ${ }^{1}$ \\ ${ }^{I}$ Department of Health Psychology, University of Alicante (Spain) \\ ${ }^{2}$ Department of Developmental Psychology and Teaching, University of Alicante (Spain) \\ ${ }^{3}$ Department of Architecture and Building Technology, Technical University of Cartagena (Spain)
}

\begin{abstract}
As a result of the COVID-19 pandemic that affected most countries during the year 2020, the society had to adapt rapidly to new forms of working in which the Internet has been an essential tool. And so did the higher institutions around the world, which had to move from a face-to-face classroom environment to an online one. The change from traditional learning to online learning was so unexpected that neither the instructors nor the students may have been prepared for it and could have important consequences on students' learning and academic achievement. The purpose of this study was to explore how university students had to struggle with online learning during the COVID-19 pandemic lockdown attending to three aspects: (a) availability and use of electronic devices, (b) personal factors, and (c) teaching factors. A non-experimental study based on a survey design was conducted, in which a convenience sample of 496 undergraduate and graduate students from two different universities located in south eastern Spain participated. The majority of the participants $(66.3 \%)$ had very little or no experience in online learning and $55 \%$ considered that their academic performance was being worse than in face-to-face classes. Findings showed that most of the students had the electronic devices required for online learning (e.g. laptops, earphones, webcams, smartphones), although they mainly used laptops and earphones. They did not have other devices at home such as desktop computers, printers and scanners. The personal factors that most affected their academic performance were family problems and/or responsibilities $(46.6 \%)$, psychological or emotional problems (41.6\%), an inappropriate study environment (41.2\%), and a bad Internet connection $(31.4 \%)$. With regard to teaching factors, students complained of excessive assignments $(82.6 \%)$, lack of lesson explanations $(78.6 \%)$, loss of concentration during synchronous classes (64.3\%), having to learn through the computer screen (58.9\%), and feeling of being abandoned (57.4\%), among others. In sum, university students' struggles with online learning were more related to teaching factors than to personal and material factors. Therefore, higher education institutions and faculty should be prepared to respond to student's needs in different teaching scenarios, and more specifically in online environments, by adapting not only their teaching styles and resources but also the way they interact with students.
\end{abstract}

Keywords: Online learning, higher education, academic performance, COVID-19.

\section{Introduction}

The outbreak of the Coronavirus disease (COVID-19) in China in December 2019 was classified as a global pandemic by the World Health Organization (WHO) in March 2020 (WHO, 2020). From that moment, most countries regulated to follow strict protocols to slow down and prevent the spread of the virus by ordering complete lockdowns and social distancing (Bozkurt \& Sharma, 2020). As a result, businesses and schools closed and were urged to work from home. The world had to adapt to new ways of working, interacting, and learning in which technology became the best ally.

According to the United Nations Educational, Scientific and Cultural Organization (UNESCO), by April 2020, school closures had affected 172 countries, and $84 \%$ of students of all educational stages (from preschool to higher education) moved from traditional face-to-face classes to different modalities of distance or remote learning (UNESCO, 2020). Higher education institutions had to accommodate their technology and teaching practices in record time when, in many cases, neither the institutions were technologically prepared for that change nor did the instructors have the digital competence to meet the 
new demands (Amhag, Hellström, \& Stigmar, 2019; Portillo, Garay, Tejada, \& Bilbao, 2020). Although many universities provided teachers with guidelines, tools, and training on online teaching, the urgency of the situation left in educators' hands how they accommodated their classes to distance learning. Subsequently, university students had to face not only a new modality of learning but also different methodologies and instructional strategies depending on teachers' preferences and digital skills.

Traditionally, the new generation of students have been considered "digital natives" since they have grown up in the digital age and in close contact with technology and the Internet (Cabero-Almenara \& Llorente-Cejudo, 2020). However, research has shown that students are not that competent when they have to deal with educational technology (Álvarez-Flores \& Núñez-Gómez, 2019; Bossolasco, Chiecher, \& Dos Santos, 2020). Institutions and faculty may have failed to understand this fact, expecting university students to be "naturally" prepared for the shift to online learning and avoiding their needs, difficulties and competences to respond to their learning demands adequately.

In this context of uncertainty, it is key to understand students' learning experiences during the lockdown to provide high-quality education in emergency times in the future.

\section{Objectives}

The purpose of this study was to explore how university students had to struggle with online learning during the COVID-19 pandemic lockdown in 2020 in terms of: (a) availability and use of electronic devices, (b) personal factors, and (c) teaching factors. It also aimed to determine which factors (personal vs teaching factors) affected students the most.

\section{Methods}

\subsection{Design}

A cross-sectional survey design was conducted to explore students' experiences with online learning during the COVID-19 pandemic lockdown. This research design has the advantage to provide information about individuals' opinions, attitudes or practices at one point in time (Creswell, 2015).

\subsection{Participants}

A convenience sample of 496 undergraduate and graduate students from two different universities in south eastern Spain participated in the study. Students' age ranged between 18 and 49 years old $(M=23.77, S D=5.69)$ and the majority were female students $(85.1 \%)$. Most of the participants had little or no experience in online learning (66.4\%). With regard to their academic performance, $54 \%$ of the students expected lower outcomes compared with traditional learning.

\subsection{Instruments}

An electronic questionnaire was designed to collect data about students' perceptions of online learning during the lockdown derived from the COVID-19 pandemic. The instrument comprised six sections: (a) sociodemographic information, (b) usage of electronic devices, (c) use and utility of teaching materials and resources, (d) use and utility of teaching strategies, (e) use and utility of online evaluation resources, and (f) difficulties encountered during online learning. Participants had to respond to a 5-point Likert scale that ranged from $1=$ Never to $5=$ Always. This paper presents the main results related to the use of electronic devices ( 9 items) and the inconveniences of learning online in terms of personal factors (11 items) and teaching factors (15 items). The instrument showed good internal consistency for the overall scale $(\alpha=.94)$ and for both sections presented in this work [use of electronic devices $(\alpha=.66)$; difficulties encountered $(\alpha=.90)]$.

\subsection{Procedure}

The electronic questionnaire was disseminated via email and the noticeboard of the university online platform among students enrolled in Education programmes and Architecture of two different universities. Informed consent was requested before the participation in the study. The survey started with general information about the purpose of the survey, and students had to respond to the questions attending to their overall experience in online learning during the lockdown and not to a specific subject. Time to complete the survey was 10-15 minutes and the survey remained open during the last two months of the second semester (from mid-May to mid-July). 


\subsection{Data analyses}

Descriptive analyses were carried out to meet the purpose of the study (i.e. percentages, means, standard deviations). To explore differences between personal and teaching factors a paired-samples t-test was performed.

\section{Results}

\subsection{Availability and use of electronic devices}

Overall, students had the necessary electronic devices to follow online learning adequately (Table 1). The primary tools used for the classes were laptops $(94.3 \%)$ and headphones or speakers (70.7\%). Half of the participants barely used the webcam (52.1\%) and only one third used the microphone frequently $(34.6 \%)$. Other devices such as smartphones $(48.5 \%)$ and printers $(46.3 \%)$ were used to a certain extent.

Table 1. Frequency of use of electronic devices for online learning during the COVID-19 pandemic.

\begin{tabular}{|l|l|l|l|l|l|l|}
\hline & & & Never / rarely & Sometimes & Often / Always & Do not have \\
\hline & $M$ & $S D$ & $\%$ & $\%$ & $\%$ & $\%$ \\
\hline Webcam & 2.52 & 1.23 & 52.1 & 27.0 & 20.9 & 5.2 \\
\hline Microphone & 3.07 & 1.18 & 32.9 & 32.5 & 34.6 & 2.6 \\
\hline Headphones / speakers & 3.92 & 1.29 & 15.7 & 13.6 & 70.7 & 2.2 \\
\hline Desktop computer & 2.35 & 1.61 & 61.9 & 8.9 & 29.2 & 59.3 \\
\hline Laptop & 4.75 & 0.74 & 3.5 & 2.2 & 94.3 & 1.0 \\
\hline Tablet & 2.39 & 1.47 & 56.1 & 17.4 & 26.5 & 53.6 \\
\hline Smartphone & 3.27 & 1.45 & 32.6 & 18.9 & 48.5 & 2.8 \\
\hline Printer & 3.21 & 1.44 & 31.1 & 22.7 & 46.3 & 35.1 \\
\hline Scanner & 2.30 & 1.36 & 58.2 & 20.0 & 21.8 & 42.1 \\
\hline
\end{tabular}

\subsection{Struggles with online learning due to personal factors}

With regard to the personal factors affecting online learning during the COVID-19 pandemic lockdown, students reported family responsibilities and concerns $(46.6 \%)$, the difficulty to adapt to online learning (46\%) and psychological or emotional problems (41.5\%). To a lesser extent, they complained about excessive workload not related to online learning $(32.3 \%)$ and bad Internet connection $(31.5 \%)$. Details are displayed in Table 2.

Table 2. Personal factors affecting online learning during the COVID-19 pandemic.

\begin{tabular}{|l|l|l|l|l|l|}
\hline & & & Never / rarely & Sometimes & Often / Always \\
\hline & $M$ & $S D$ & $\%$ & $\%$ & $\%$ \\
\hline Family concerns or responsibilities & 3.31 & 1.32 & 26.4 & 27.0 & 46.6 \\
\hline Health problems & 2.11 & 1.27 & 67.5 & 15.3 & 17.1 \\
\hline Psychological problems & 3.02 & 1.47 & 36.5 & 22.0 & 41.5 \\
\hline Excessive workload (not related to online learning) & 2.76 & 1.42 & 44.6 & 23.2 & 32.3 \\
\hline Inappropriate study environment & 2.96 & 1.49 & 41.5 & 17.3 & 41.1 \\
\hline Lack of specific devices & 2.11 & 1.32 & 66.7 & 15.5 & 17.7 \\
\hline Sharing electronic devices & 2.16 & 1.43 & 65.5 & 12.1 & 22.4 \\
\hline Lack of specific software & 2.20 & 1.38 & 63.9 & 15.1 & 21.0 \\
\hline Bad Internet connection & 2.62 & 1.48 & 50.2 & 18.3 & 31.5 \\
\hline Difficulties to adapt to online learning & 3.29 & 1.31 & 26.8 & 27.2 & 46.0 \\
\hline $\begin{array}{l}\text { Wasting time by using the computer for other } \\
\text { purposes than learning }\end{array}$ & 2.67 & 1.38 & 50.4 & 19.8 & 29.8 \\
\hline
\end{tabular}

\subsection{Struggles with online learning due to teaching factors}

Concerning teaching factors affecting students' online learning (Table 3), they mainly struggled with the excessive autonomous learning $(82.75 \%)$, the lack of lesson explanations $(78.6 \%)$ and the loss of concentration during live streaming classes (64.3\%). They also complained about the teachers' response during online learning such as feeling abandoned by them $(57.5 \%)$ as well as shorter lesson explanations and no feedback of the activities carried out (50.8\%). 
Table 3. Teaching factors affecting online learning during the COVID-19 pandemic.

\begin{tabular}{|l|l|l|l|l|l|}
\hline & & & Never / rarely & Sometimes & Often / Always \\
\hline Feeling abandoned by teachers & $M$ & $S D$ & $\%$ & $\%$ & $\%$ \\
\hline Insufficient information on week assignments & 3.60 & 1.19 & 17.7 & 24.8 & 57.5 \\
\hline Excessive autonomous learning & 3.04 & 1.28 & 34.3 & 28.0 & 37.7 \\
\hline Lack of lesson explanations & 4.20 & 0.98 & 7.5 & 9.9 & 82.7 \\
\hline Lack of teaching materials & 3.41 & 1.30 & 6.7 & 14.7 & 78.6 \\
\hline Difficulty to contact teachers & 2.62 & 1.27 & 50.0 & 25.0 & 49.6 \\
\hline Learning through a computer screen & 3.60 & 1.40 & 23.4 & 25.8 & 24.2 \\
\hline Loss of concentration during streaming classes & 3.76 & 1.36 & 22.0 & 17.7 & 58.9 \\
\hline Low quality of live streaming classes & 3.47 & 1.35 & 24.6 & 23.8 & 51.6 \\
\hline $\begin{array}{l}\text { Shorter lesson explanations and no feedback } \\
\text { about the results/solutions of activities }\end{array}$ & 3.36 & 1.42 & 28.8 & 20.4 & 50.8 \\
\hline $\begin{array}{l}\text { Not keeping the class schedule and some classes } \\
\text { overlapping }\end{array}$ & 2.25 & 1.46 & 63.9 & 13.7 & 22.4 \\
\hline $\begin{array}{l}\text { Teaching materials are protected and do not let } \\
\text { printing or editing }\end{array}$ & 2.25 & 1.29 & 60.9 & 21.0 & 18.1 \\
\hline $\begin{array}{l}\text { Difficulty to fulfil assignments due to online } \\
\text { learning conditions (e.g. large images or pictures } \\
\text { on screen) }\end{array}$ & 3.09 & 1.47 & 37.9 & 19.8 & 42.3 \\
\hline $\begin{array}{l}\text { Having to buy specific material for academic } \\
\text { assignments (e.g. printer, scanner) }\end{array}$ & 2.33 & 1.46 & 61.5 & 14.7 & 23.8 \\
\hline Diversity of online learning platforms by teachers & 3.03 & 1.42 & 39.3 & 19.0 & 41.7 \\
\hline
\end{tabular}

\subsection{Comparing personal and teaching factors affecting students' online learning}

A paired-samples t-test was conducted to compare students' perceptions with regard to the factors that most affected their online learning. There was a statistically significant difference between personal and teaching factors $(t(495)=-14.420, p<.001)$. According to the participants, they had to struggle more with teaching factors $(M=3.18, S D=0.80)$ than with personal factors $(M=2.69$, $S D=0.85)$ during their online learning. The Cohen's $d$ statistic $(0.63)$ indicated a medium effect size.

\section{Discussion and conclusions}

The purpose of this research study was to explore university students' experiences of online learning during the COVID-19 pandemic. This work presents the preliminary findings with regard to the availability and use of electronic devices and the personal and teaching factors that could have affected their learning and academic outcomes.

Access to technology did not seem to be a problem for participants since the great majority reported that they had the necessary electronic devices to follow online learning such as laptops, webcams and headphones. According to the National Institute of Statistics (INE, 2020), more than 90\% of Spanish households have access to the Internet and almost the same percentage have computers and this fact was reflected in university students' responses.

However, participants had to struggle with personal factors that could have affected their learning. For instance, combining online learning with family responsibilities was reported by almost half of the students. In addition, the uncertainty of the pandemic crisis and the unexpected and sudden changes in daily lives had consequences on the adaptability of $40 \%$ of the participants. In this sense, the study conducted by Besser, Fleet and Zeigler-Hill (2020) confirmed that students had more pervasive negative reactions to online learning than to a more typical face-to-face learning condition (e.g. higher levels of stress and isolation, negative mood, less motivation and performance). Likewise, the lack of experience in online learning of the majority of the students could have led to some of them to express difficulties to adapt to online learning.

But the greatest complaints were concerning teaching factors. Similarly to other studies, students had to struggle with too much autonomous learning and the lack of lesson explanations, the difficulty to concentrate during live streaming classes, a feeling of being abandoned by their educators and the lack of interaction and feedback (Adnan \& Anwar, 2020; Castellano Gil, Carrera Flores, \& Crespo Crespo, 2020).

Findings from this study highlight the need of putting into practice the best teaching strategies during an emergency remote teaching situation (Bozkurt \& Sharma, 2020; Hodges, Moore, Lockee, Trust, $\&$ Bond, 2020), especially with regard to student-teacher interaction. Instructors need to set the conditions for a meaningful relationship and communication with their students in order to create the best online environment in which to learn. The lessons learnt from this crisis will help to take better instructional decisions in the future. 


\section{References}

Adnan, M., \& Anwar, K. (2020). Online learning amid the COVID-19 pandemic: students' perspectives. Journal of Pedagogical Sociology and Psychology, 2(1), 45-51. http://www.doi.org/10.33902/JPSP.202020261309

Álvarez-Flores, E. P., \& Núñez-Gómez, P. (2019). Efectividad del uso de herramientas digitales en el desarrollo académico de estudiantes universitarios [Effectiveness of the use of digital tools in the academic development of university students]. In S. Amavizca Montaño (Ed.), Alfabetización informacional para la gestión del conocimiento en la universidad (pp. 49-74). Sonora: Universidad Estatal de Sonora.

Amhag, L., Hellström, L., \& Stigmar, M. (2019). Teacher educators' use of digital tools and needs for digital competence in Higher Education. Journal of Digital Learning in Teacher Education, 35(4), 203-220. https://doi.org/10.1080/21532974.2019.1646169

Besser, A., Flett, G. L., \& Zeigler-Hill, V. (2020). Adaptability to a sudden transition to online learning during the covid-10 pandemic: understanding the challenges for students. Scholarship of Teaching and Learning in Psychology. Advance online publication. http://dx.doi.org/10.1037/st10000198

Bossolasco, M., Chiecher, A., \& Dos Santos, D. (2020). Perfiles de acceso y apropiación de TIC en ingresantes universitarios. Estudio comparativo en dos universidades públicas argentinas [Profiles of access and appropriation of ICT in freshmen students. Comparative study in two Argentine public universities]. Píxel-Bit. Revista de Medios y Educación, 57, 151-172. http://dx.doi.org/10.12795/pixelbit.2020.i57.06

Bozkurt, A., \& Sharma, R. C. (2020). Emergency remote teaching in a time of global crisis due to CoronaVirus pandemic. Asian Journal of Distance Education, 15(1), i-vi. https://doi.org/10.5281/zenodo.3778083

Cabero-Almenara, J., \& Llorente-Cejudo, C. (2020). Covid-19-transformación radical de la digitalizacion en las instituciones universitarias [Covid-19: radical transformation of digitization in university institutions]. Campus Virtuales, 9(2), 25-34.

Castellano Gil, J. M., Carrera Flores, R., \& Crespo Crespo, W. (2020). Educación on line en tiempo de Covid-19: percepción en estudiantes de la Universidad Católica de Cuenca (Ecuador) [Online education in COVID-19 times: perception in students from the Catholic University of Cuenca (Ecuador)]. Revista de Historia, Patrimonio, Arqueología y Antropología Americana, 3, 149-175. https://doi.org/10.5281/zenodo.4066073

Creswell, J. W. (2015). Educational research: planning, conducting, and evaluating quantitative and qualitative research (5th ed.). Upper Saddle River (NJ): Pearson.

Hodges, C., Moore, S., Lockee, B., Trust, T., \& Bond, A. (2020, March 27). The difference between emergency remote teaching and online learning. EDUCAUSE Review. Retrieved from https://er.educause.edu/articles/2020/3/the-difference-between-emergency-remote-teaching-andonline-learning\#fn8

Instituto Nacional de Estadística. (2020). Equipamiento y uso de TIC en los hogares. Año 2020 [Equipment and use of ICT in households. Year 2020]. Retrieved from https://www.ine.es/dyngs/INEbase/es/operacion.htm?c=Estadistica_C\&cid=1254736176741\&men $\mathrm{u}=\mathrm{ultiDatos} \& \mathrm{idp}=1254735976608$

Portillo, J., Garay, U., Tejada, E., \& Bilbao, N. (2020). Self-Perception of the Digital Competence of Educators during the COVID-19 Pandemic: A Cross-Analysis of Different Educational Stages. Sustainability, 12(23), 10128. https://doi.org/10.3390/su122310128

United Nations Educational, Scientific and Cultural Organization. (2020). COVID-19 impact on education. Retrieved from https://en.unesco.org/covid19/educationresponse

World Health Organization. (2020). Coronavirus Disease (covid-19) pandemic. Retrieved from https://www.who.int/emergencies/diseases/novel-coronavirus-2019 


\title{
ESCAPE ROOM AS A MOTIVATING TOOL IN THE ENGLISH LITERATURE CLASSROOM AT TERTIARY EDUCATION
}

\author{
Madalina Armie, José Francisco Fernández Sánchez, \& Verónica Membrive Pérez \\ Department of English Studies, University of Almería (Spain)
}

\begin{abstract}
The escape room, also known as escape game, is a gamification tool that aims to promote increased motivation and improved teamwork (Wood \& Reiners, 2012). Recently, escape rooms have achieved prominence in the classroom as pedagogical instruments valid for any type of discipline. In the educational field in particular, the escape room can be defined as an action game in real time where the players, in teams, solve a series of puzzles or problems and carry out tasks related to the curricular contents worked on throughout the course, in one or more rooms with a specific objective and at a specific time (Nicholson, 2015). To do this, learners must put into practice the knowledge acquired about a particular subject, as well as their creative and intellectual abilities, and deductive reasoning. Despite being a pedagogical tool that has emerged as an innovative element in the last five years or so, the use of escape rooms for teaching-learning the English language at different educational levels has been studied qualitatively and quantitatively (Dorado Escribano, 2019; López Secanell \& Ortega Torres, 2020). However, there is no study on the applicability of the escape room in the English literature classroom at the tertiary educational level. This paper aims to demonstrate how the inclusion of this innovative pedagogical tool can serve not only for teaching the language, but also for working on theoretical-practical contents of subjects focused on literary studies of the Degree in English Studies. In order to achieve the proposed objectives, the study will focus on the identification of types of exercises to implement as part of the educational escape room aimed at a sample of students; the preparation of tests/ exercises based on the established objectives; the design of a pre- and a post- questionnaire based on the established objectives; the implementation of the escape room in the literature class and the evaluation of the impact of this educational tool to foster students' motivation.
\end{abstract}

Keywords: Escape room, new technologies, intrinsic motivation, English literature, higher education.

\section{Introduction}

The reason for presenting this paper has to do with the need felt by a group of lecturers of literature in English, an area of knowledge normally labelled under the general term of 'English Literature', to engage their students with the subjects of their respective courses at university level. The teaching of literature has traditionally been at the mercy of to two kinds of pressures, those that push the discipline towards the implementation of scientific methods, and those which celebrate the multifarious concerns that are normally associated with the idea of reading for pleasure. It is the second aspect, the natural tendency of literature towards interdisciplinarity, that has traditionally been uppermost in the daily practice of this activity: "One of the reasons for this is that literature is about everything - love, sex, friendship, family relationships, aging, death, social and historical change, religious faith, intellectual ideas, and so on. In short, it is about life in all its diversity, and this is hard to accommodate within the narrow parameters of a discipline" (Moran 2002: 21). The present proposal, however, starts from the assumption that it is possible to celebrate literature's extraordinary transversality of interests and, at the same time, to carefully design and implement activities for the teaching of the subject which take into account academically-tested methods and scientifically-oriented perspectives.

The framework of gamification has been chosen because it is "an emerging approach and tool for teaching [which] provides the opportunity to create new, challenging, meaningful and interactive learning experiences for today's students" (Santamaría and Alcalde 2019: 84). The main concern as educators is to keep abreast professionally and, therefore, to apply in our courses recent theories related to motivation, not because of a superficial need to stay in tune with the times, but because students in the 21 st century demand new perspectives on education that participate in the technological world in which they live. 
Motivation in the literature class, on the other hand, just as it happens in the foreign language class, is far from being an easily packed and digested concept. Lecturers of literature are aware of the multiple factors (cognitive, socio-cultural, psychological, etc.) that have to be considered when designing a course: "Motivation has long been a hot topic in educational research because of its complexity. The construct of motivation is not a single entity but a multi-factorial one" (Wong 2014: 38). The aim of this paper is to explore one of the most successful developments of gamification, namely, the use of escape rooms in class as a motivational tool, and to apply it to the teaching of English literature. A succession of challenges and a diverse assortment of activities may raise the interest of students and increase their engagement with the dynamics of the course.

\section{Escaping boredom in the classroom: Advantages and disadvantages}

The origins of escape rooms are somehow diffuse, although research (Gómez Sesé 2020) considers 2007 as a point of inflexion in the historical development of this form of entertainment and edutainment. In 2007, the Japanese movie and anime director Takao Kato hosts in Kyoto the Real Escape Game (REG), and shortly afterwards, a big game named HEP Hall in Osaka. These events that are soon followed by the creation of a digital magazine by Kato under the name Real Escape Games, where the concepts and ideas behind this gamified experience are laid bare. Considering these first successes, numerous rooms are opened in Singapore in 2011, and only one year later, the escape room concept becomes famous in San Francisco with the "Puzzle Break" project. At the same time and in Europe, the first escape room is opened in Budapest by Attila Gyurkovics the founder of the franchise Parapark (Gómez Sesé 2020: 33). By 2019, there were over 7,200 escape rooms in 1,445 cities in 105 countries (Kroski, 2019, p. 3), and their numbers keep rising every day, offering fun and enjoyment to people of all ages with missions as diverse as saving the world, travelling to Mars, escaping zombies, getting out of a medieval castle or a haunted mansion, breaking out of a prison, time travels etc.

Definitely, the field of escape rooms is one in expansion due to the infinite number of possibilities which it offers, especially when included in the educational curriculum. Learning is inherent to games, as intrinsic motivation is triggered, and deep knowledge is consolidated through playing which is always a desirable experience. Students' motivation is one of the major quandaries for education and research nowadays, no matter the educational level under consideration, with many studies emphasizing the obsolescence of the teacher-centered approach and that of the ineffectiveness of the overreliance on traditional forms of delivering content in class (Lee \& Hammer, 2011). These studies draw a concluding connection between intrinsic motivation and problems of levels cheating, disengagement from school, and with this, higher attrition rates, while proposing gamification as a possible panacea (Cronk, 2012; Deterding, 2012; Stott and Neustaedter, 2013). Frequently along sessions, educators can observe their distracted students checking the time, looking at their watches or their mobile phones hopelessly and impatiently. This might be a clear sign of boredom, distraction, and an open manifesto of our pupils' enormous desire to escape the class as soon as possible. Nonetheless, terms can be shifted, and students can check the time for a totally different reason: they do not want the class to be over; they want to remain there trapped until they have successfully concluded their class activity. Time limits and space confinements are only two of the key elements in escape room games, and by extension educational escape rooms which foment motivation and widen the universe of learning.

Escape rooms have evolved despite their short historical existence and have adapted themselves perfectly to the vicissitudes of the current pandemic situation, to the extent that it has become totally feasible to create and play an escape room totally online. What is more, the use of the ICT dimension in the elaboration of a hybrid version of this form of gamification - which might combine physical and virtual resources - help to diversify and enrich the players' experience. As a matter of fact, curiously and contrary to what is expected, it was the virtual version - where "an avatar in a specific setting, interacting with various objects to uncover clues and using information from those clues to solve puzzles" (Brainy Rantz 2017) - the precursor for the live and physical experiences offered by escape rooms nowadays worldwide.

Escape rooms can be designed around any subject or around many transversal contents of diverse disciplines such as mathematics, chemistry, history, etc, providing dynamism to the lessons and to content which might not be very appealing to students. Educational escape rooms, therefore, are conceptualized as bridges between reality and adventure (Kato, n.d.), knitted systems, where all the elements form a complex whole. The gamified experience, then, is not a single element but an entire context, where knowledge is placed at the very centre. Nonetheless, the success of a game in the classroom depends not only on external factors to the students, such as the difficulty of the game, its regularizing system of rewards and punishments, its didactic objectives, its duration, the props used to recreate the thematic atmosphere of the game etc., but also on internal factors related to the players 
themselves, as their motivations, perspectives, and tastes. Considering their nature, escape room games are closed systems that engage players in a well-planned structure, but which might present unequal and uncertain outcomes. The maintenance of high levels of motivation and engagement along the experience is drawn from equilibrated doses of difficulty and challenge offered by the game. The design of an escape room is not exactly and easy process, but one that requires knowledge in the different fields ranging from the arts, psychology to computer science, and which follows basic steps marked by literature and experimentation that stress the importance of a careful selection of the thematic, the conceptualization of the idea to be carried out into practice, the design of the mechanics of the game, the cycle for the development of the game and the establishment of the elements to be included, among others. In relation to all these ideas, one of the most important pieces for the assembling of an escape room experience carried out in the classroom is the drawing of a connection between the game and the non-ludic or didactic objective; that is, the game must present a balance between what is known as edutainment and game, without forgetting the major aim of this educational tool: the didactic side of the experience.

This dynamic method based on escape room experiences might be used either as a reinforcement activity or as an evaluation tool, and it can last for only one session, for days, or even an entire school year, a process along which the student plays an active role in the leaning process. With the implementation of escape rooms, the boredom provoked by conventional exercises is fought with novelty, and although pressure exists, this is a totally different experience to the one infused by traditional exams. Here the existence and perception of pressure is constructive, as the urgency to solve the challenges helps students to focus on a scenario where every second counts; however, students do not feel alone facing the mission or the trouble. While promoting the development of personal qualities such as persistence and resilience through extended play (McGonigal, 2011), the student is part of a mechanism, of a team that works together, which puts knowledge together, unfolding students' deductive thinking, and attempting to overcome challenges by calibrating and discussing decisions. Individual creativity, resourcefulness, and good communication skills mark the difference when managing to solve each task collectively, therefore the application of this form of gamification in class foments negotiation and collaboration. The improvement of self-awareness, strategizing, and the triggering of critical capacities to make decisions or to adopt a position of leadership are also learnt. These interpersonal or social abilities stimulate the strengthening of relationships among players, facts that on long term can be beneficial for the development of lessons and other group activities, as they create a positive atmosphere among peers and improve class management and dynamics. In relation to gamification in the literature class at university level, apart from all these mentioned aspects, escape room and by extension gamification promote the assimilation of new vocabulary and grammar (Abrams \& Walsh, 2014), and improve oral communication, as oral skills are used along the entire experience for communication and negotiation of decisions. Written comprehension and production much present in the challenges (Mazur, Rzepka \& Araki, 2011; Grouling, Hedge \& Schweigert, 2014) are strengthened.

As regards the disadvantages of this innovative instrument and gamification tool, these are common to the pitfalls of the methodology of gamification in general. It is worth here mentioning the great amount of time which must be invested for the creation of an escape room that might mirror the class's necessities, objectives, and contents. However, despite being time consuming and tedious, this educative instrument can be easily later adapted to different educative levels. Also the implementation of escape room experiences might not be totally satisfactorily, especially following the online format due to possible technological problems. The escape room might also become an unmanageable activity when considering the numerous groups and the high number of students in each university class. In this case, the lecturer might need help from other colleagues in order to carry out the experience. The present article, nonetheless, considers that the disadvantages of escape rooms fall short in comparison to the benefits offered by this valuable form of edutainment with so many positive side effects as the following pages are going to reveal.

\section{Results}

After assessing the applicability of Escape Rooms to education and the advantages and disadvantages of their use in the classroom as an educational tool, especially in the English classroom, the experimental session was carried out. This experience was aimed at adding extra value to regular sessions on English literature, with the purpose of evaluating an improvement of students' active participation, teamwork and engagement regarding the course contents both theoretical and practical. What is more, the function of Escape Rooms in an English literature classroom is an innovative approach to the pedagogical dynamics of Escape Rooms since, as it has been explained, there is no scientific evidence to this point that this kind of resource has been used before as an educational instrument. Since this experiment was carried out in 2020 and tertiary education sessions were taught online due to the emergency derived from 
Covid-19, the Escape Room experience was designed to be developed online by educators/facilitators and, by extension, students too. This implied a great adaptability to educators' training requirements and usefulness as well as students' interest which allowed us to explore the effectiveness of a combination of gamification and IT tools in the English literature (virtual) classroom.

The study aims at analyzing, qualitatively and quantitatively, the degree of motivation before and after the implementation of the Escape Room when compared to conventional teaching methods. The sample group for this intervention was composed of 29 undergraduate students (19 to 27 years old, 85,2 $\%$ female and $14,8 \%$ male) who have taken any courses on English Literature (second or third year) as part of their regular academic load in a Spanish university. The experiential cluster was selected because of its accessibility for the researchers and because of a considerable number of newly arrived students who were not motivated. The experiment took place once at the end of the semester with a length of approximately 3 hours each to solve the virtual Escape Room with the intention of reviewing the main contents taught for 16 weeks. Spoken and written production and comprehension were part of the daily schedule and proposed activities. The first half an hour of the intervention was devoted to eliciting the Escape Room regulations and functionality and to solve questions.

The designed Escape Room consisted of six challenges, each of them only accessible progressively after a suitable completion. All challenges were set in the historical context of the authors included in the syllabus of the corresponding course on English Literature and related to texts and genres dealt with throughout the semester. The challenges included a variety of activities such as puzzles, padlocks, audiovisual resources, or the use of (simulated) social networks and participants were aimed not only at searching for answers on the course materials (which allowed participants to properly review course contents) but also to extend their knowledge by looking for information from other sources (websites, audiovisual contents, books, and articles).

Before the experiment, all participants filled out a survey composed by 24 close-ended questions on a 1-5 scale to investigate students' motivational approach and enthusiasm towards English Literature lessons at a tertiary level and traditional and current teaching methodologies. Besides, they were also asked to identify their observations regarding cooperation and competition in learning, teamwork and working on online assignments. Finally, students had to expose their degree of interest in gamification as a tool to learn English Literature. Similarly, a post-intervention survey composed by 15 close-ended questions on a 1-5 scale was designed to assess the impact of the tool on the students' acquisition and learning process, insisting upon the degree of stimulation and significance of the content of the activities, the usability of the tool after the experiment and whether or not students would recommend this teaching practice to acquire contents related to English Literature.

Results from the survey before the intervention expose that a 70,4\% participants consider that learning English Literature is useful and a $63 \%$ believe that its acquisition is difficult. General participation in activities done in the classroom is average (a 55,5\% participants chose 4 or 5 out of 5) and a 70,3\% claim to work hard to acquire the required knowledge to pass the course. However, even if a $37 \%$ enjoy attending English literature classes and that a 48,1\% feel the need to learn more because they like the contents, one of the key questions related to engagement reveals that only a $18,5 \%$ participants feel motivated in English Literature lessons and only a 14,8\% are willing to participate actively. Besides, $85,2 \%$ of students admit that their motivation depends on the professor teaching the course. Regarding questions related to gamification as a pedagogical tool, all participants (100\%) believe that learning through games is useful to strengthen their knowledge related to course contents and that they prefer games than traditional learning styles (63\%).

The post-experiment survey focuses on questions related to the Escape Room experience carried out virtually and its impact on students' motivation when learning English Literature. Most participants considered that learning English Literature through escape rooms was useful $(89,7 \%)$ and easier $(89,6 \%)$. Besides, the experience done in the virtual classroom was very successful since a $96,6 \%$ declared to have enjoyed their active participation. The experiment seemed to have impacted respondents' attitude towards English Literature classes as an $89,7 \%$ claimed to show a more positive approach towards contents and activities if Escape Rooms are part of the teaching methods used in the classroom and considered that the professor would motivate them $(93,1 \%)$ when Escape Rooms are included an assessment method. Finally, learning through games such as this one would be beneficial for students' acquisition (89,7\%) and it was preferred by a $96,5 \%$ participants to traditional learning styles. According to the results delivered by respondents' answers, the Escape Room as a pedagogical tool seems to confirm to be a particularly beneficial and motivating resource to teach English literature and to have a strong impact on students' approach to contents. 


\section{Conclusion}

The results of our activity are overwhelmingly positive in the sense of achieving a great level of motivation among the students in the English literature class. The use of escape room experiences is revealed as an appropriate method to incorporate students to the learning process and to create in them the need to know more about the topics dealt in the classroom. These positive results, however, should not distract educators and students from the fact that there are several constraints that may prevent the activity from being totally successful. First of all, online activities are prone to suffer interruptions due to powercuts or faulty internet connections. The improper use of computer devices such as cameras or microphones may also play their part in the lack of fluidity of the teaching process. Additional problems are presented by the density of academic programmes and sheer lack of time during a regular working week. Creating and implementing an engaging and attention-grabbing escape room for the students also implies a considerable investment of time on the part of educators and this time is usually taken in detriment of their personal lives. All in all, the benefits conveyed by the use of escape rooms in the English literature class may compensate for all the difficulties that are met along the way.

\section{References}

Abrams Schamroth, S. \& Walsh, S. (2014). Gamified Vocabulary. Journal of Adolescent \& Adult Literacy $581,49-58$.

Cronk, M. (2012). Using Gamification to Increase Student Engagement and Participation in Class Discussion. EdMedia+: Innovate Learning Association for the Advancement of Computing in Education (AACE), 311-315.

Deterding, S. (2012). Gamification: Designing for Motivation. Interactions, 19 4, 14-17.

Dorado Escribano, G. (2019). New approaches to learning and assessing through escape rooms in English and Science areas. Advances in Building Education, 3 1, 9-19.

Gómez Sesé, P. (2020). Escape Room. Todo lo que deberías saber sobre el mundo de los Escape Room. La guía definitiva. Wroclaw, Poland: Amazon Fulfillment.

Grouling, J., Hedge, S., Schweigert, A., \& Snider, E. G. (2014). Questing through Class: Gamification in the Professional Writing Classroom. Computer Games and Technical Communication: Critical Methods and Applications at the Intersection, 265-82.

Kato, T. (n.d.). Thoughts on Real Escape Game. Retrieved April 20, 2021, from https://realescapegame.com/thoughts-reg/

Kroski, E. (2019). Escape Rooms and Other Immersive Experiences in the Library. Chicago, US: Ala Editions.

Lázaro, A. (2019). Próximo Destino: Un Escape Room. April 20, 2021, from https://viajes.nationalgeographic.com.es/lifestyle/turismo-escape-room-espana_14701

Lee, J. J., \& Hammer, J. (2011). Gamification in education: What, How, Why Bother? Definitions and Uses. Exchange Organizational Behavior Teaching Journal, 15 2, 1-5.

López Secanell, I. \& Ortega Torres E. (2020). Escape room educativa: Concepción de los futuros maestros de Educación Secundaria en especialidad de Educación Física y Tecnología sobre la experiencia de diseñar y participar en una escape room educativa. Didacticae 8, 176-192.

Mazur, M., Rzepka, R. \& Araki, K. (2011). Proposal for a Conversational English Tutoring System that Encourages User Engagement. Proceedings of the 19th International Conference on Computers in Education, 10-12.

McGonigal, J. (2011). Reality is Broken: Why Games Make Us Better and How They Can Change the World. London: Penguin.

Moran, J. (2002). Interdisciplinarity. London: Routledge.

Nicholson, S. (2015). Peeking behind the locked door: A survey of escape room facilities. Scott Nicolson. April 22, 2021, from http://scottnicholson.com/pubs/erfacwhite.pdf

Santamaría, A., \& Alcalde, E. (2019). Escaping from the English Classroom. Who Will Get out First?. Aloma, 37(2), 83-92.

Stott, Andrew, and Carman Neustaedter. (2013). Analysis of Gamification in Education. Canada 8, 1-8.

Why Educational Escape Rooms Will Benefit Students in the Long Run (2017). April 20, 2021, from https://brainyactzsocal.com/educational-escape-rooms-will-benefit-students-longrun/\#: :text=Escape\%20rooms\%20are\%20innovative\%20learning,Learning\%20is\%20an\%20activ $\mathrm{e} \% 20$ sport.

Wong, R. (2014). Motivation to Learn English and School Grade Level. Porta Linguarum, 21, 37-50.

Wood, L. C., \& Reiners, T. (2012). Gamification in logistics and supply chain education: Extending active learning. In IADIS 2012 International Conference on Internet Technologies and Society, 101-108. 


\title{
TEACHING IN DIGITAL SURROUNDINGS - STUDENTS OPINION ON DIGITAL TOOLS AND DIGITAL LECTURES
}

\author{
Marcin Fojcik ${ }^{1}$, Martyna K. Fojcik ${ }^{2}$, Lars Kyte ${ }^{3}$, Bjarte Pollen ${ }^{1}$, \\ \& Jan Ove Rogde Mjånes ${ }^{4}$ \\ ${ }^{1}$ Department of Electrical Engineering, Western Norwegian University of Applied Sciences (Norway) \\ ${ }^{2}$ Faculty of Humanities and Education, Volda University College (Norway) \\ ${ }^{3}$ Department of health and caring sciences, Western Norwegian University of Applied Sciences (Norway) \\ ${ }^{4}$ Department of Mechanical Engineering, Western Norwegian University of Applied Sciences (Norway)
}

\begin{abstract}
In today's world, education in higher education institutions needs to use digital technologies to reach students without them being in the same room as the teacher. The "classical lecture", with a teacher talking and writing on a blackboard interacting with students, has been in many ways exchanged with different digital or hybrid solutions. On one hand, it allows teachers to challenge their practices and try new ways of engaging students to learn, but on the other hand, it can be challenging to master different digital solutions in a way that ensures a clear message for the students.

When the whole world went into lockdown, the education at all levels needed to emergency transform learning in classrooms to learning through digital platforms. New structures had to be made, new routines, and new approaches. For some subjects it was not enough to move from sitting in a lecture room to sitting in front of a computer, it was necessary to develop solutions for presenting different programs or motivating students to be active, even if they were without a camera or microphone. Some teachers needed a blackboard to write and draw on while they talk, others needed to change between different programs to show different representations or purposes. In some cases, the digital lectures were synchronous, with teachers and students meeting at the same time to discuss a topic both in small and big groups, other times the digital lectures were asynchronous to give the students more time to prepare themselves and to activate their learning by giving them a responsibility to study individually (self-study).

After few months of trying different solutions, the teachers from Western Norway University of Applied Sciences (HVL) and Volda University College (HVO) have investigated the student's views on the different solutions they have experienced. The students were asked to answer an anonymous questionnaire of their opinion, views, and experiences with different digital solutions. The results were categorized and analyzed to select some tools or approaches that most of the students found either better or worse for their learning.
\end{abstract}

Keywords: Digital learning, integrated learning, students views on digital tools.

\section{Introduction}

In today's pandemic era, delivering online lectures, via video or streaming, is often the only option in higher education (Hussein et al., 2020, Lin \& Gao, 2020, Nieuwoudt, 2020). This is due to the need to temporarily close campuses, or limit student attendance. Sometimes the restriction for a meeting on campus are national, sometimes they are local, sometimes the institution themselves that decides to proceed only with online courses, and sometimes there are the students that demand access to the lessons without the need to come on campus. The frequencies of online lectures have been like never before. Both asynchronous (not real-time) and synchronous (real-time) classes are conducted at higher education institutions in Norway, by teachers from different professions. Some teachers have been teaching online for many years, with many experiences, assignments, resources, and methods to prepare and to conduct online lectures, and some are just starting, with little experience and resources.

This study asked the students about their opinions, experiences, and attitudes towards the online lectures they have had these past semesters. The research questions are: How do online lectures work one year after the pandemic has started and what are students' opinions and experiences about the lectures they have had? 
To answer these questions, the authors surveyed 1st-year students from two study lines at Western Norwegian University of Applied Sciences (HVL), campus Førde and two study lines at Volda University College (HVO). All of the participants have had a unique schedule since they started their studies, with some lectures and seminars on campus (groups of max 25 people), and some lectures and seminars online. The survey was designed to asked students with some experience in both synchronous, asynchronous, and physical/on-campus lectures, to get students to compare their experience and opinions of the different methods. In total 57 students participated in the survey. Participation in the survey was voluntary, all 1 st-year students were asked, but only about $60-80 \%$ responded depending on the study line. Not every question was answered by all the participants. Both higher education institutions have specific profession-education and the size of the groups is quite small. The lines from HVL were Automation line with 6 students participating and IT line with 9 students participating. From HVO was Teacher Education 1-7 (primary school, grades 1-7) with 22 students participating and Teacher Education 5-10 (primary and lower secondary, grades 5-10) with 20 students participating in the questionnaire.

The survey was anonymous and voluntary and had been previously examined by the Norwegian Centre for Data Surveys (NSD) and was assessed as not requiring reporting and not sensitive. No personal information was gathered about the participants. Some of the results obtained were compared with the results of a previous survey conducted before the pandemic (Fojcik \& Fojcik, 2020).

\section{Survey structure and some results}

The survey covered several aspects of learning through online lectures. Students were asked, among other things, about the self-assessment of their digital skills, the learning software used, their favorite or expected forms of lectures, exercises, and teaching methods. Other questions asked about student input. For example, if and why they use a camera in synchronous online lectures, if and why they use a microphone or chat, how they acquire study materials, what equipment and internet connection they use. Due to space constraints, only selected elements will be described in this article.

\subsection{Place/role of the teacher}

A total of 57 students responded fully or partly to the survey. They evaluated both the preferred teaching methods. The vast majority of students expect a variety of digital teaching methods - only $17 \%$ expect only classical methods.

One of the main purposes of the study was to gather students' opinions on the learning method that they preferred. Some questions in the survey asked students their perspective on the teacher's role in the learning method they liked best. The results show that most of the students expect to learn with a physically present teacher, all or some of the time. The reasons for this were mainly to explain difficult topics, to answer questions and to motivate the students, and lead the discussion by showing different examples and perspectives. These results (Fig 2) were compared with a similar study (Fojcik \& Fojcik, 2020) from before the pandemic (Fig 1), where 17 Automation students and 9 IT students participated. The largest change in student's opinion is that more students want this interaction with the teacher present, and fewer want just online lectures.

Figure 1. HVL: Lecture form according to student's needs (before coronavirus).

\begin{tabular}{|l|l|}
\hline HVL - Automation & HVL - IT line \\
\hline & \\
\hline
\end{tabular}

Figure 2. HVL: Lecture form according to student's needs (after 1 year of coronavirus).

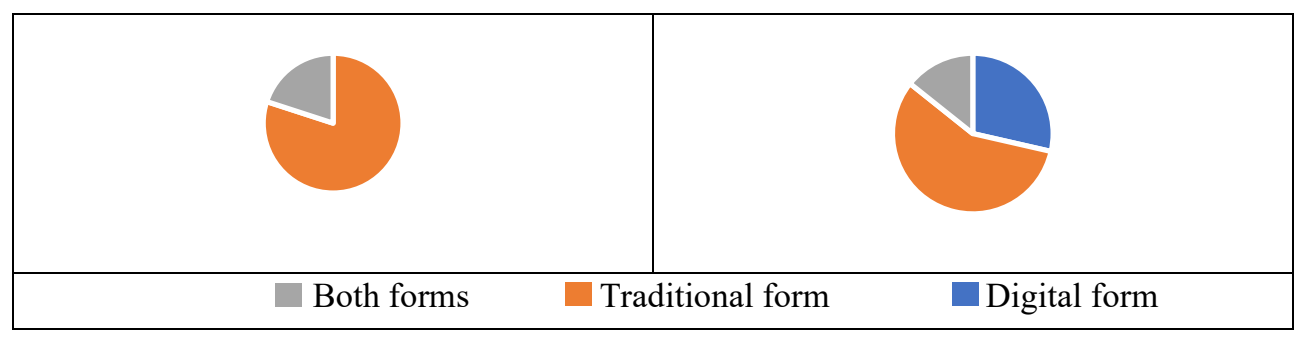


Gathering all students' opinions on what kind of lectures they perform, there is a dominance of students that want to have just physical/on-campus lectures (Figure 3).

Figure 3. Lecture form according to student's needs (after the first year of coronavirus).

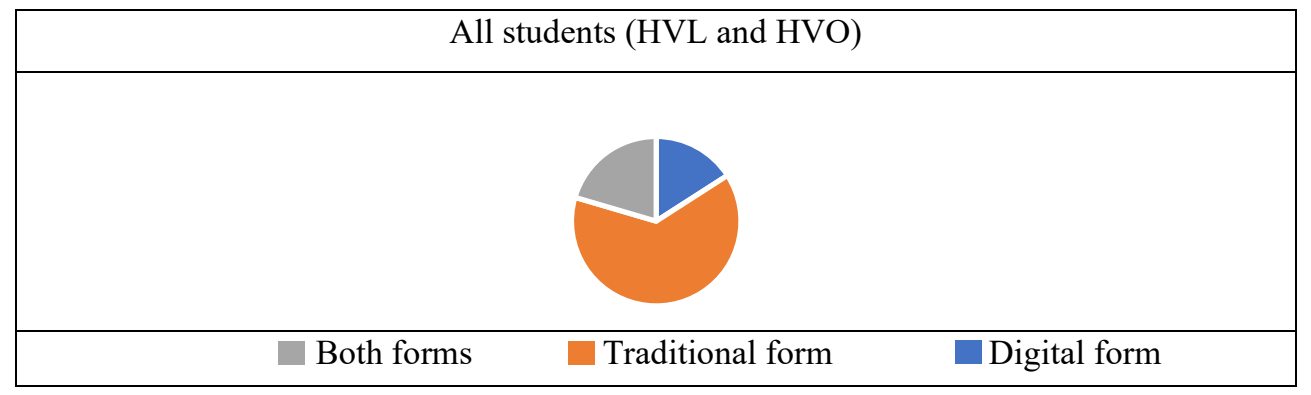

\subsection{Students motivation for learning in lectures}

Some other questions in the survey were about the motivation to learn using digital methods or comparing the motivation in different types of lectures. The survey asked the students about:

Whether they think that online lectures have less variety than on-campus lectures, and if so, why?

Whether the motivation is different: in on-campus and online lectures. What about the synchronous or asynchronous lecture?

The results show that most of the students $(66 \%)$ express that they are not motivated at all by the online lectures and some of them (13\%) express that they are partially or temporarily motivated to learn via the Internet (very divided answers, some are motivated just by asynchronous lectures while some just for synchronous when they can work in groups/breakout rooms). Only $21 \%$ of the students thought they were motivated for online lectures.

In the answers on the survey the students complained about a variety of issues that make it difficult to concentrate on learning through online lectures, and many times the disadvantages for some students were advantages for others. This is a common result when comparing these forms of online lectures (Lin \& Gao, 2020, Nieuwoudt, 2020). Students commented both the way of teaching: monotonous monologue of the teacher, looking at the screen for many hours in a raw, lack of discussion, dialogue, social elements and the technical: problem with the configuration of the equipment, inability to use it correctly both on the part of the student or the teacher or both, problems with the Internet and so on. Surprisingly, while some students in a group explained why they were motivated by asynchronous lectures, comparing them to podcasts, praise the ability to stop the video or repeat a part, or just doing the lecture when they felt well awake and well-rested. Other students from the same group complained that the asynchronous lectures were difficult to do on their own, hard to self-control, there was no interaction or discussion, the video did not answer their question or understandably explained the topic. This shows that there are many different opinions about online lectures and if or how they manage to motivate students learning.

\subsection{Preferred methods of lectures}

Students participating in this research want a teacher who will be using a variety of possible devices and different learning methods to both present the content and make it interesting and exciting for the students to participate in the lecture. Most students explained that concerning the online lectures, they do not have strong opinions about their preferences (Brockfeld et al., 2018) and that they like to have both forms; asynchronous and synchronous lectures combined. The reasons for this are interesting and sometimes in opposition to others' wishes (Nieuwoudt, 2020). Students want to have a synchronous form to have the possibility to contact a teacher, ask questions, ask about explanation or repetition. But very few of them are asking questions at all. $70 \%$ of the students from this study do not ask questions at all and 29\% do so only sometimes, in smaller groups. One possible explanation for this is that students want the possibility rather than the result. In this case, when a student knows that he or she can ask questions and get an answer from the teacher they may be contempt enough to concentrate on other things, but when the student knows that it is up to him or her to make sure everything is clear and the support is not as visible or easy to access, the maybe more distracted during the lecture. This allegation should be further research in future studies.

The survey showed that today's students expect lectures with good quality recordings, a variety of activities, and interactive forms even for online lectures - Padlet, Kahoot, or quiz. Such a recording should have both relevant subject content, a pedagogical approach and be technically good. That is another surprising result. Before and at the beginning of the pandemic the students did not pay much attention to the technical quality of the video and were satisfied as long as the content was clear (Fojcik et al., 2020), now, after a year, they much more expect a better quality of the video or at least a proficiency in using the 
equipment from the teachers. This can mean that the students are more occupied by the quality of the online lectures when they are exposed to them for longer periods, than when the videos were used as a variation in the learning process.

When students were asked to describe their ideal lectures (without thinking of practical applications), many of them answered that the absolute best would be on campus/synchronous online lectures with a variety of activities, exercises, and discussion, as well as an asynchronous video explaining the topic to watch when they are writing assignments or preparing for the exam. Some preferred to have separate videos, while others said it would be enough with a recording of synchronous or on-campus lectures/exercises. Students want to have this form to learn at their speed, with a possibility to pause and rewind forward or back or repeat some more challenging parts. One of the courses in this study records all of the lectures (both digital and on-campus), but unfortunately, the statistics from software managing video files show that most of the students will re-watch the recording only some days before the exam if they will re-watch it at all. This can again be a form for students' feeling of security, to want something just to know that it is available on-demand, but not necessary to make it a central part of learning.

\subsection{Students activity during lectures and self-regulated learning}

By analyzing the results, the authors found some tendencies in students' answers about their views on what is student's role in a lecture. One of them is that many students seemed to expect to be comfortable while learning and the feeling of comfort and security seem stronger than the feeling of learning, for some students. While describing synchronous online lectures many students express that they are not accustomed (especially when using digital media) to being involved, to showing off, to being active. They focused on things like not being seen, not disturbing the teacher, not being taken a picture of, not showing the camera, not being active, not asking questions, and generally not having any attention from the class whatsoever. The results show that when students are participating in a lecture while staying at home, many of them feel uncomfortable both by showing a part of their private home and by the way they look/have the attention during synchronous online lectures. $53 \%$ of the students in this study do not use the camera at all, $35 \%$ of the students only use the camera occasionally, (in smaller groups/when others do the same/when they are in a good mood), and only $11 \%$ of the students answered that they use the camera constantly during the online lectures.

The arguments students describe are reasonable in larger groups or publicly open lectures, but they at in some part questionable when the student meets the same group of people again and again, both in online lectures and on class lectures and the groups are less than 25 students. Another questionable factor is the lack of technical skills such as remove the background (available in many programs) or switching the microphone (mute on / mute off), or the lack of conditions or interest to find creative solutions such as preparing the learning station before the lecture, clear the presence of other people, noise and other distractions which in itself makes learning difficult. There may be many reasons why the students rather choose not to participate in online lectures than take some time to prepare their surroundings, physically or digitally.

The tendencies in survey answers show that many students largely expect a momentary solution to their challenges. Lecture - yes, but participation - no, recording - yes, but later. This may indicate an inability to cope with today's challenges or an inability to adjust to previously accepted norms of behavior. A few years ago, sitting in lectures was a necessity. Today, many people would like to avoid it. The widespread availability of video games and movies with special effects means that a "normal" lecture recording can be uninteresting. This can be a result of a reluctance to show up, to get involved, social exclusion, problems with self-regulated learning, or something else. Students may not be aware that it is significant for learning to either come ready with solutions that are suited for the conditions or take an easy way out and not participate in an online lecture. They might not know the difference, or they might think that it does not matter for them, or the feeling of comfort is more important than trying different alternative setups, or any other reason.

\subsection{Equipment and self-assessment of digital skills}

Students' answers in the questionnaire show that they have good equipment for digital learning. They all have a laptop (but many write they don't use a camera because they don't have a built-in one) and a mobile smartphone, most of them also have a desktop computer with multiple monitors at home. Besides that, about $1 / 3$ of them have a notepad/MacBook/tablet. This comes at a cost, which can be a problem, especially for a student. The students were satisfied with their equipment, but most of them explained that they used only one or two devices in lectures, both on-campus and online lectures.

Besides questions about the equipment used, the students were asked to grade their own digital skills on a 1-5 scale, where 1 was very poor, while 5 was very good. Table 1 shows the mean from each class. 
Table 1.

\begin{tabular}{|l|c|}
\hline \multicolumn{1}{|c|}{ Class } & Mean of students self-assessment \\
\hline HVL Automation & 2,6 \\
\hline HVL IT & 4,3 \\
\hline HVO Teacher education 1-7 & 4,1 \\
\hline HVO Teacher education 5-10 & 3,6 \\
\hline
\end{tabular}

Unfortunately, comparing students' self-assessment of digital skills with other answers on the questionnaire, there were many uncertainties about their actual skills. This manifests itself in the way they describe the programs they use, the technical problems they have, the quality of the Internet connection, etc...). Another surprising result is that when asked about their Internet connection, most of the students said to have broadband connections of quite high speed, but students who evaluate their digital skills as very good, answer: "good quality", those students who consider themselves less competent answer: „50/50Mb/s” or ,300Mb/s". These descriptions show the ability to name and define certain elements and do not coincide with self-assessment or the self-assessment can be interpreted in different ways (Fojcik et al., 2017). It is often, but of course not always, more an opinion of oneself than an assessment of one's abilities.

\section{Discussion and conclusion}

Most of the students in the selected subjects taught at HVL and HVO participated in the survey, but both schools are rather small, so the survey is not fully quantitatively representative. The results can only show a trend in both places.

This study tried to answer the research questions: How do online lectures work one year after the pandemic has started and what are students' opinions and experiences about the lectures they have had?

The results show that the students seem to have specific expectations about the different methods of lectures, they know what they like and what they dislike, but their answers are often contradicting both within a class, and with students themselves. Some students like asking questions, use the camera, and participate actively in the lectures, while others preferred to learn at their own speed, with videos and less interaction, or just without any camera or microphone so that no one can notice them. Most students in this study seem to have struggled with motivation for online lectures, and the social connection with other students. Another result is that some of the students comment on the insufficient technical knowledge of teachers; errors in recording, problems with sound, image, graininess, illegibility of text, image freezing, constant switching, etc.

The authors have noticed multiple times that the process of learning is much more effective when the teacher is a part of the learning process and can guide and support the students in their learning. While students comment on things like "they would not want to disturb" or "they want to do this themselves", which often may be a good idea, but the students should know that teachers' role is to guide and support so that they are not completely on their own.

\section{References}

Brockfeld, T., Müller, B., \& de Laffolie, J. (2018). Video versus live lecture courses: a comparative evaluation of lecture types and results. Medical Education Online, 23(1), 1555434.

Fojcik, M., Fojcik, M. K. (2020). Digitalisation of higher education - teachers and students experience. Proceedings of International Conference on Education and new Developments 2020 (END2020), 26-27 June. InScience Press

Fojcik, M., Fojcik, M. K., Hegland, P. A., Kyte, L., Midtbø, T. G., Pollen, B., Sande J, Sande, O. (2020). Praktisk digitalisering av høgskuleundervising. I Digital samhandling (pp. 321-335).

Fojcik, M., Galek, J. og Fojcik, M. K. (2017). IKT kompetanse blant studenter. Er vi klare for fremtiden? Proceedings of MNT-conferance 2017, 30-31 March, Oslo.

Hussein, E., Daoud, S., Alrabaiah, H., \& Badawi, R. (2020). Exploring undergraduate students' attitudes towards emergency online learning during COVID-19: A 9+case from the UAE. Children and Youth Services Review, 119, 105699.

Lin, X., \& Gao, L. (2020). Students' sense of community and perspectives of taking synchronous and asynchronous online courses. Asian Journal of Distance Education, 15(1), 169-179.

Nieuwoudt, J. E. (2020). Investigating synchronous and asynchronous class attendance as predictors of academic success in online education. Australasian Journal of Educational Technology, 36(3), $15-25$. 


\title{
STUDENTS EXPERIENCES ON THE USE OF GOOGLE CLASSROOM: CASE STUDY OF A UNIVERSITY IN RWANDA
}

\author{
Ayodele Ogegbo ${ }^{1}, \&$ Oyebimpe Adegoke ${ }^{2}$ \\ ${ }^{1}$ Department of Science and Technology Education, University of Johannesburg (South Africa) \\ ${ }^{2}$ School of Education, Mount Kenya University (Rwanda)
}

\begin{abstract}
Google is a popular Web 2.0 tools with many interesting facilities and applications. Like many other Web 2.0 tools, Google classroom has potential for teaching and learning due to its unique built-in functions that offer pedagogical, social and technological affordances. With this in mind, Google classroom as an open-source learning platform created in 2015 to simplify and enhance user collaboration, was considered a prominent technology tool used to enhance teaching and learning at a particular University in Rwanda. This study adopts a quantitative descriptive design to investigate university students' Google classroom experiences in Rwanda after participating in an online STEM education course. Data were collected using questionnaires sent to students via a Google form link. The collected data were analyzed using frequency and descriptive analysis. The study has generally confirmed that students have a positive cognitive, affective, and behavioural attitude towards Google classroom use. The study also revealed immediate feedback, accessibility, user-friendliness, collaboration, effective and efficient communication as positive experiences recognized by students using Google classroom in their online STEM education course. Nevertheless, students faced problems such as poor internet connection, lack of technology to access the classroom, insufficient time to submit tasks, lecturers inadequate and untimely response to students' questions, isolated learning, poor knowledge about the user interface, inadequate skills on how to use the classroom. To further encourage the use of google classroom particularly as a learning management system in Rwandan universities and other universities across Africa, findings from this study recommends that education institutions provide students and lecturers with adequate training and platform on how to use the google classroom interface, improve ICT infrastructures, lecturers' use of video chat or asynchronous mode to provide adequate and timely feedback to students within stipulated virtual office hours, ensure quality course content.
\end{abstract}

Keywords: Google classroom, online learning, Rwandan university, STEM course, students experiences.

\section{Introduction}

The introduction of Information Communication Technologies (ICTs) in education continues to change the way schools and universities across the globe embrace technological systems to redefine teaching and learning in the $21^{\text {st }}$ century. However, the Rwandan educational sector policy emphasises the synergistic adoption of ICTs in education as a strategic lever for achieving social and economic transformation after the 1994 genocide that devastated the country's economy and education system (Republic of Rwanda Ministry of Education, 2016; Twagilimana \& Mannikko-Barbutiu, 2018). As part of the transition mechanisms aimed to transform the delivery and quality of education in Rwanda, some institutions of higher learning have adopted various technological equipment, tools and learning management systems including Sakai, Blackboard, Moodle, and Microsoft Teams to promote online social learning environment through distance education, open online courses and/or blended learning (Darius, 2020; Harerimana \& Mtshali, 2018). However, the use of such learning management systems seems to pose several challenges for many university students in the country. In the setting of this inquiry, one of the challenges faced by students was learner isolation. This was due to the fact that the learning management system adopted by the university served a vast population of students from other campuses of the same university. For instance, students located in Kenya, Burundi, and Uganda all accessed the same platform for learning. Additionally, lecturers who handled courses for the face-to-face sessions were different from lecturers who handle the online sessions on the university's Learning Management System platform. Hence, students felt alienated, and found it difficult to participate actively or interact with lecturers as expected. This predicament calls for lecturers and researchers to explore the potential of other web-based technologies to fit the best classroom practice, promote active learning and improve skills development of university 
students. Hence, the university campus in Rwanda took steps to explore Google Classroom as an alternative learning platform. Google is a popular Web 2.0 tools with many interesting facilities and applications developed for academic institutions whose purpose is to facilitate, create, distribute and grade assignments in a paperless way (Sukmawati \& Nensia, 2019). Like many other Web 2.0 tools, Google classroom has potential for teaching and learning due to its unique built-in functions that offer pedagogical, social and technological affordances. Google classroom has shown to be more beneficial compared to other leaning management systems because it is accessible as a free mobile app, easy to use, reliable and provides a platform for network community with a slight resemblance to Facebook user interface (Jordan \& Duckett, 2018). However, Pappas (2015) asserts that not all learning courses are suitable using Google Classroom because it has difficult account management, limited integration options, no automated updates, difficult learner sharing, editing problems, no automated quizzes and test. Given the need to harness the affordances of free and user friendly technological applications to promote a knowledge based society within the broader Rwandan educational context, this study explored the experiences of students on the use of google classroom as a learning tool in a science education course offered at a university in Rwanda. In this study, understanding students' attitudes towards the use of google classroom also provided meaningful insights into their experiences. Thus, this study is guided by the following research questions:

- What are the opinions of students' regarding their experiences on the use of Google classroom as a learning tool in a university in Rwanda?

- What are the attitudes of students regarding the use of Google classroom?

\section{Research design and methodology}

A quantitative research design located within the descriptive research paradigm was adopted in this study. The quantitative design was appropriate for this study as it provides the fundamental connection between empirical observation and mathematical expression of quantitative relationships that allows the use of statistical procedures and the principles of objectivity (Queirós, Faria, \& Almeida, 2017). Data was collected through survey questionnaires created electronically using Google forms and the link was sent to undergraduate students that participated in the blended learning course education technology at a university in Kigali, Faculty of Education. However, a total of seventy-one (71) students consisting 25 females $(35.2 \%)$ and 46 males $(64.8 \%)$ responded to the questionnaire. The questionnaire consisted of three open-ended questions and 26 items to which students could rate their agreement or disagreement via Likert scale: Strongly Disagree $=\mathrm{SD}$, Disagree $=\mathrm{DA}$, Neutral $=\mathrm{N}$, Agree $=$ A, and Strongly Agree $=$ SA. Analysis of data was guided by the use of percentage and frequency distribution.

\section{Findings}

Results from participants responses showed that the questionnaire has a high internal consistency with a Cronbach alpha value of 0.953 . From the responses of students, their experiences were expressed based on their opinion and attitude towards using google classroom.

Figure 1. Usage of Google classroom.

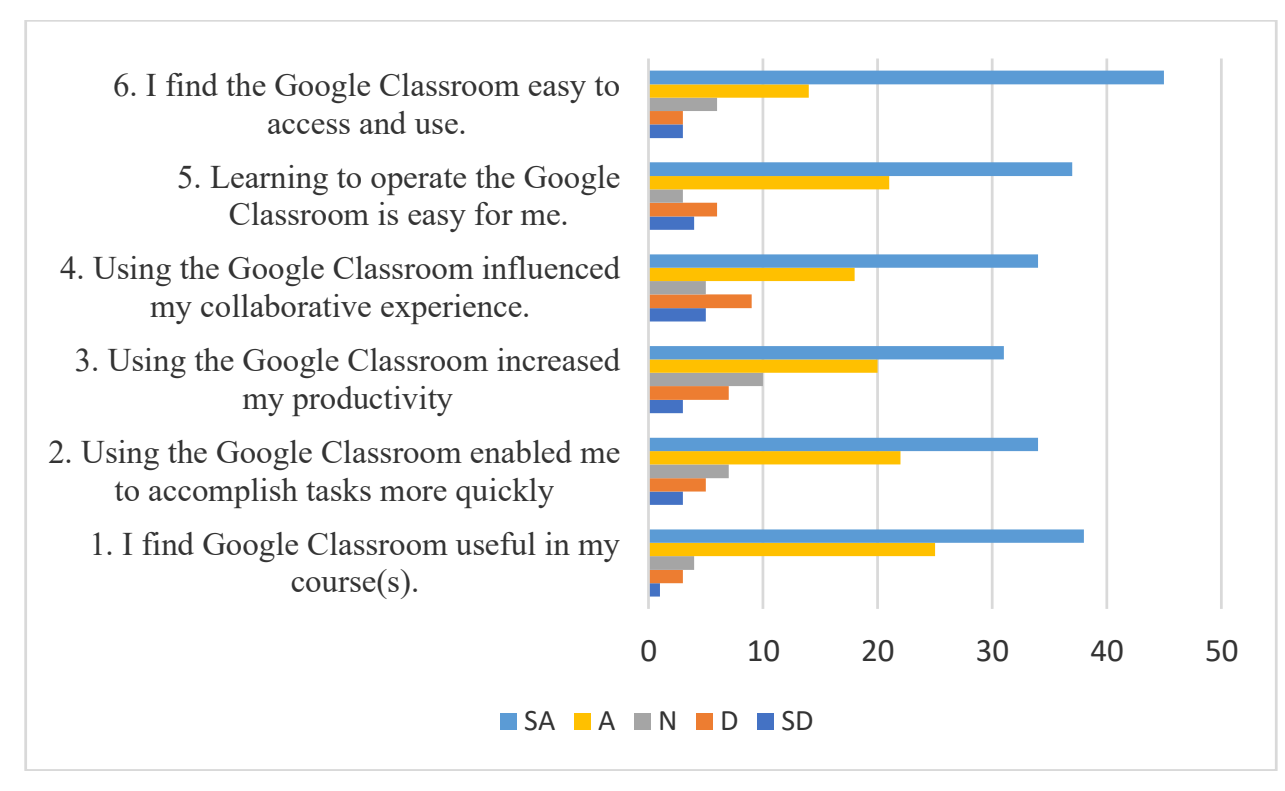


Figure 1 shows that $63.4 \%$ of the students strongly agreed that google classroom was easy for them to access and $52.1 \%$ indicated that google classroom was easy for them to navigate. Students ease of access was further explained in the open-ended questions using statements such as "easy to submit assignment, log in, receive course materials, navigate the icons in the google classroom application”. Similarly, 47.9\% of them strongly agreed that using google classroom influenced their collaborative experience with colleagues and enabled them to accomplish tasks more quickly. More so, during the analysis of the open-ended question that required students to share their experiences, $30 \%$ of the students indicated time management as one the benefits of using google classroom using statements such as "it saves time, it helps me to submit assignment on time, I am able to get information about the course and material on time". Findings from the survey also reveal that students experiences regarding the use of Google classroom was viewed based on challenges they encounter while using the technology application as shown in figure 2.

Figure 2. Challenges encountered while using Google classroom.

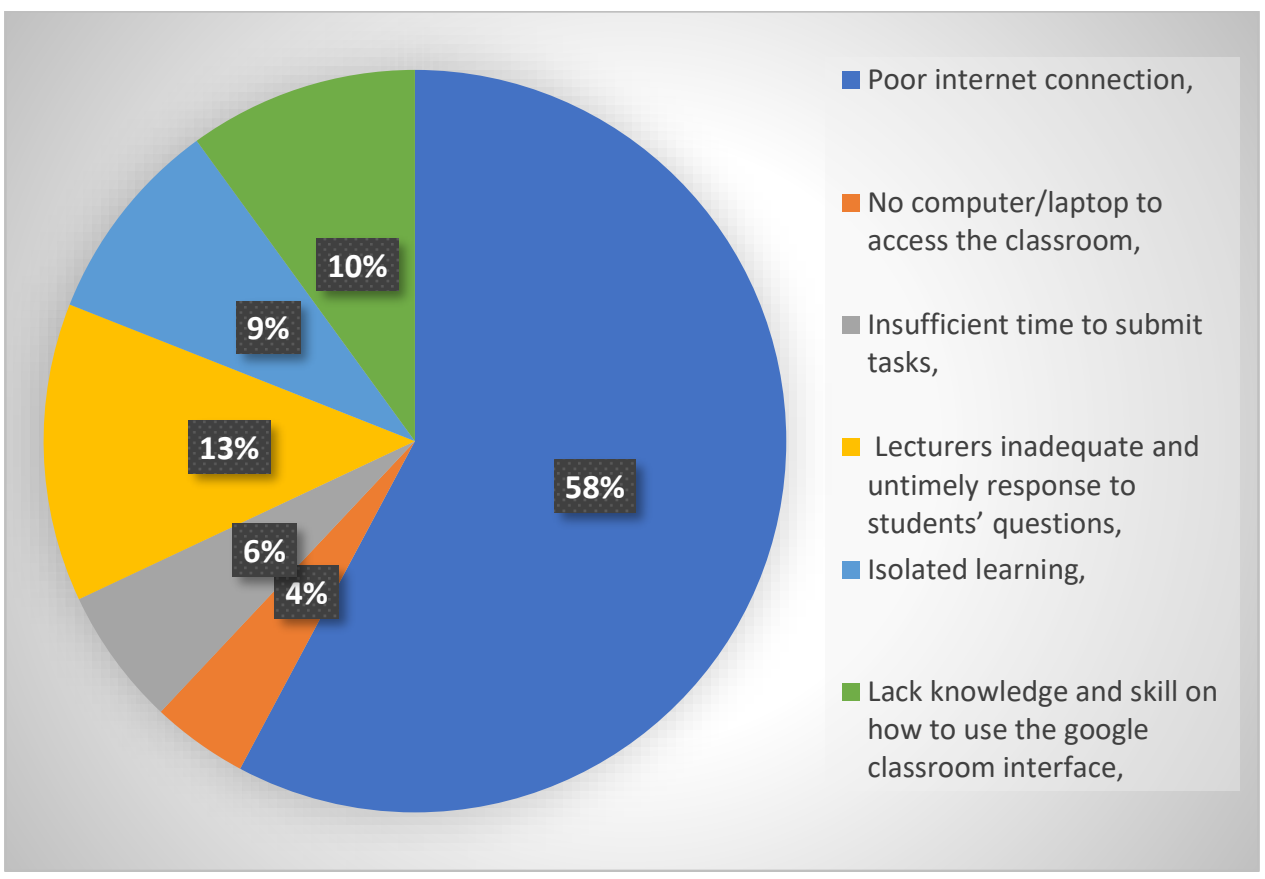

As reflected in Figure 2 above, a vast majority of the students mentioned poor internet connection as the major challenge encountered when using google classroom. $13 \%$ of the students claimed that when they submit assignments using google classroom lecturers sometimes do not grade the assignment neither do the give clear and adequate feedback to students, lecturers also do not explain content in details. More so, $10 \%$ of the students indicated that they do not have the knowledge or skills to use the google classroom application. Another challenge encountered as indicated by students include a feeling of isolated learning where students stated that they get bored using google classroom because they lack physical contact with colleagues. In addition, students' experiences were also reported based on their attitude towards the use of google classroom as shown in Table 1.

Table 1. Students experiences relating to attitudes.

\begin{tabular}{|l|l|l|l|l|l|}
\hline Statements on student experiences related to & \multicolumn{5}{|c|}{ Distribution of students' responses } \\
\cline { 2 - 5 } their attitude & SD & D & N & A & SA \\
\hline $\begin{array}{l}\text { I have the knowledge necessary to participate in } \\
\text { Google Classroom. }\end{array}$ & $4.2 \%$ & $8.5 \%$ & $12.7 \%$ & $25.4 \%$ & $49.3 \%$ \\
\hline $\begin{array}{l}\text { Participating in Google Classroom makes me } \\
\text { engage more in learning }\end{array}$ & $15.5 \%$ & $18.3 \%$ & $16.9 \%$ & $29.6 \%$ & $19.7 \%$ \\
\hline $\begin{array}{l}\text { I can get help from others when I have difficulties } \\
\text { participating in Google Classroom. }\end{array}$ & $4.2 \%$ & $9.9 \%$ & $4.2 \%$ & $29.6 \%$ & $52.1 \%$ \\
\hline $\begin{array}{l}\text { I feel excited about using Google classroom } \\
\text { I like using Google Classroom compared to face to } \\
\text { face (offline) classes or other LMS. }\end{array}$ & $7.0 \%$ & $9.9 \%$ & $15.5 \%$ & $28.2 \%$ & $39.4 \%$ \\
\hline
\end{tabular}


Table 1 above showed the percentage distribution of students responses to the attitude developed as a result of their experience using google classroom. Results indicates that majority of the students strongly agreed or agreed with each of the statements concerning their attitude towards the use of google classroom. Thus implying that most of the students appear to have a favourable cognitive, behavioural and affective attitude towards the use of Google classroom. However, further analysis of participants responses to the questionnaire revealed that $45.1 \%$ of the students rarely use google classroom but would like to learn more, $21.1 \%$ of the students occasionally use google classroom and would like to learn more, $9.9 \%$ of the students use google classroom almost every time but do not like to use it within the classroom while $23.9 \%$ of the students use google classroom every time and extremely well.

\section{Discussion and conclusion}

The present study was designed to investigate students' experiences regarding the use of Google Classroom for online learning in a University in Rwanda. In the process, the study also uncovered the attitude of students towards the use of google classroom. The study provided evidence that majority of the students recognise the benefits of using google classroom such as easy to access and navigation of the google classroom platform compared to other learning management system, easy access to course materials, enhancing their ability to collaborate and share information with colleagues, enhances their knowledge as well as improves their ability to be well acquainted with the use of technology and e-learning platforms, creating effective and efficient communication with colleagues and lecturer during the online STEM education course. It was also found that students demonstrated a positive cognitive, behavioural, and affective attitude towards using Google classroom. These results echoed previous research (e.g. Islam, 2019; Khalil, 2018).

Findings also show that a number of challenges were mentioned by the students which is better to be addressed by the various educational stakeholders, Government and Higher institutions authorities as well as lecturers. For instance, despite students' positive experience while using google classroom in Rwanda, many of them struggle to log into the class because they are in areas where internet connection is bad, and some have to share laptops /computers with others. This implies that the most common challenge faced by the students is their lack of access to technological resources. More so, some of the students mentioned that they do not have the adequate knowledge on how to use Google classroom thereby indicating their lack of technological knowledge. Whereas some of the students mentioned that they do not receive optimal feedback from the lecturer and communicating privately with lecturer and/or colleagues appears impossible, thus supporting the findings of Islam (2019). More so, a lower percentage of the students indicated that using google classroom did not provide them the critical human interaction and engagement required to make learning fun and as a result learning becomes too serious and boring.

It is suggested that institutions of higher learning in Rwanda and other African countries encourage the adoption of Google classroom as a learning management platform that can help facilitate online learning experiences for students, foster pedagogical and positive attitude towards the use of technology outside the classroom. In addition, there is a crucial need for Government and higher education institutions to facilitate the promotion and provision of better ICT infrastructures such as computer, laptops, and internet connectivity in order to make access to google classroom and other innovative instructional platform easier for students. Adequate training on how to leverage Google classroom for successful teaching and learning experience should also be provided to lecturers and students. This will allow lecturers to ensure quality content for their course and using video chat or asynchronous mode to provide students with adequate and timely feedback within specified virtual office hours.

\section{References}

Darius, (2020). University of Rwanda online learning at a glance: what you need to know about the platform. Retrieved from https://ur.ac.rw/?UR-online-learning-at-a-glance-what-you-need-to-knowabout-the-platform

Harerimana, A., \& Mtshali, N. G. (2018). Implementing e-learning in resource-constrained nursing education institutions in Rwanda. Research and Reviews: Journal of Nursing and Health Sciences, 4, 1-14.

Islam, M. S. (2019). Bangladeshi University Students' perception about using Google Classroom for Teaching English. International Journal of Psycho- Educational Sciences, 8(2), 57 - 65.

Jordan, M. M., \& Duckett, N. D. (2018). Universities confront 'tech disruption': Perceptions of student engagement online using two learning management systems universities confront 'tech disruption': Perceptions of student. The Journal of Public and Professional Sociology, 10(1) 
Khalil, Z. M. (2018). EFL Students' Perceptions towards Using Google Docs and Google Classroom as Online Collaborative Tools in Learning Grammar. Applied Linguistics Research Journal, 2(2), 33-48.

Pappas, C, (2015). Google Classroom Review: Pros and Cons of Using Google Classroom In eLearning. Retrieved from https://elearningindustry.com/google-classroom-review-pros-and-cons-of-usinggoogle-classroom-in-elearning

Queirós, A., Faria, D., \& Almeida, F. (2017). Strengths and limitations of qualitative and quantitative research methods. European Journal of Education Studies, 3 (9), 369-387. doi: $10.5281 /$ zenodo. 887089

Republic of Rwanda Ministry of Education (2016). ICT in education ploicy. Retrieved from http://planipolis.iiep.unesco.org/sites/planipolis/files/ressources/rwanda_ict_in_education_policy_a pproved.pdf

Sukmawati, S., \& Nensia, N. (2019). The Role of Google Classroom in ELT. International Journal for Educational and Vocational Studies, 1(2), 142-145.

Twagilimana, I., \& Mannikko-Barbutiu, S. (2018, June). ICT in education policy in Rwanda: current situation, challenges and prospects. In ACRID 2017: EAI International Conference for Research, Innovation and Development for Africa (p. 360). European Alliance for Innovation. 


\title{
TEACHERS' ATTITUDES IN APPLICATION OF TECHNOLOGY AND EFFECTIVE TEACHING PLANNING IN PRIMARY SCHOOL
}

\author{
Arjana Zhubi \\ Doctoral Student of Prishtina/Faculty of Education (Kosovo)
}

\begin{abstract}
The planning of teaching with technological tools in Kosovo schools has brought new and challenging experiences for teachers at all levels of education. The purpose of the research is to analyze the attitudes of teachers about the application of technology in effective planning of teaching and raising learning outcomes in primary school. Furthermore, the research determines the impact of age and level of teacher's education on the application of technology according to curriculum areas.

The TPACK model was used as the theoretical framework during the research, which helped us to clarify the notions: technological knowledge, pedagogical knowledge, and teaching contents in the effective planning of teaching by applying technology.

The data were collected from a questionnaire with 25 teachers in an elementary school where technology finds higher applicability in teaching. To analyze the learning outcomes during the application of technology and applicability in other subjects, the Post Hock test, and the Correlation was used to measure the relationship between the two variables, respectively the correlation between the age and the level of education of teachers.

The results of this research show that learning planning through technology affects the increase of focus and gain a higher understanding in each subject, acquiring knowledge of new concepts, raises the desire to learn independently, makes the learning process more innovative and more attractive to students.

The research recommends for the local and central level to give priority to equipping primary schools with technological tools to improve teaching by having the opportunity to plan different practices.
\end{abstract}

Keywords: Technology, teachers, lesson planning, curriculum, elementary school.

\section{Introduction}

The application of technology in teaching cannot be effective if a prior lesson plan is not prepared (Krauskopf, 2012) if the teacher's technological attitudes and knowledge are not verified (Baturay, 2017). Acknowledging this fact, during the research we will be based on the TPACK (The Technological, Pedagogical, and Content Knowledge framework) model. This model reflects the attitudes of teachers about the application of technology in the classroom (Koehler \& Mishra, 2005) and identifies three types of technology knowledge: technological knowledge, pedagogical knowledge, and knowledge of teaching content. Technological knowledge (TK), which corresponds to the attitudes of teachers regarding the application of technology, available technological resources, and the necessary skills to use them in teaching. Pedagogical knowledge (KP) refers to the way teaching and learning are developed, including the strategies, methods, and activities used by the teacher in the curricular areas and cross-curricular integration. Content knowledge (CK) refers to subject knowledge, curriculum planning, and unit development. These three interrelated areas will determine whether preparation, planning, and teaching are effectively developed using technology (Voogt, 2013), which will be used as background to understand research data.

The application of technology in teaching has been part of numerous studies around the world. Researchers investigated the effects of technology on teaching and found that in classrooms where technology is used, teaching is significantly improved compared to classrooms where teaching takes place without technology (Hixon, E., \& So, H. J., 2009; Voogt, J., \& McKenney, S., 2017). Researcher Sylvestre (2018) conducted a study with 144 teachers of 8 primary schools, where the level of technology application was very low and the teaching process resulted in poor success by students. The recommendation from this study was that the government should equip all schools with technological tools to achieve efficiency in the teaching process. The study done with these teachers was descriptive and it was concluded that the more technology is applied, the more the teaching process will develop and the learning outcomes will be significantly higher in each subject. Another study conducted in Brighton, UK, by the authors Cox and Preston (1999), examined the evidence from teachers regarding the application of technology in teaching, 
their experiences in technology, attitudes, and knowledge in the use of technological tools. The authors based on the research findings concluded that teaching takes place in attractive forms for students, traditional classrooms were transformed into digital classrooms, and that teachers were ready to start a new way of research teaching.

Recently, many researchers (Blau \& Nusan, 2014; Hermans et al., 2008; Alqurashi \& Carbonara, 2017) identified other factors that influence teachers' attitudes about the use of technology. The level of education, and the age of the teachers were particularly influential. These two aspects are closely related because without professional development the teacher will not be able to plan and organize teaching with technology, there will be no working knowledge of equipment, resources, and technological applications as supporting or integrating material in the classroom. Researchers (Alqurashi, E., Gokbel, E. N., \& Carbonara, D, 2017) explain that older teachers do not support this methodology because their level of education does not correspond to technology programs and does not even express interest in integrating technology into the classroom because of the skills, knowledge, and negative attitudes they possess (Soetan, A. K., \& Cokerb, A. D. , 2018). Being part of the training, many of them do not prefer the application of technology (Voogt, 2013). However, some older teachers put their technology skills into practice very effectively, which contradicts the ideas of many researchers that age hinders the use of technology (Sánchez-Mena et al, 2017). For this reason, the TPAC model allows to identify the specifics of teachers, their actions during the planning and use of technology in the classroom, the challenges, and the level of implementation of the technology.

Figure 1. Explanation of TPACK fields.

\begin{tabular}{|l|c|l|}
\hline \multicolumn{1}{|c|}{ Knowledge } & Abbreviations & \multicolumn{1}{c|}{ Explanation } \\
\hline Content knowledge & CK & $\begin{array}{l}\text { Knowledge of current issues of the subject being taught or should } \\
\text { be taught. Understanding the contents of curricular areas. Selects } \\
\text { relevant content for students taking into account the link between } \\
\text { subjects and curriculum areas. }\end{array}$ \\
\hline Pedagogical knowledge & PK & $\begin{array}{l}\text { Knowledge of teaching processes and methods, teaching } \\
\text { techniques and strategies. Knowledge about lesson planning. }\end{array}$ \\
\hline $\begin{array}{l}\text { Technological } \\
\text { knowledge }\end{array}$ & TK & $\begin{array}{l}\text { Knowledge of the application of technological tools/resources in } \\
\text { achieving goals. }\end{array}$ \\
\hline $\begin{array}{l}\text { Knowledge of } \\
\text { pedagogical content }\end{array}$ & PCK & $\begin{array}{l}\text { Knowledge to understand the subject matter and to find different } \\
\text { ways/methods/techniques, adaptation and integration of materials. }\end{array}$ \\
\hline $\begin{array}{l}\text { Knowledge of } \\
\text { technological content }\end{array}$ & TCK & $\begin{array}{l}\text { Knowledge to understand technology and content harmonization } \\
\text { because they can affect and limit each other. }\end{array}$ \\
\hline $\begin{array}{l}\text { Technological } \\
\text { pedagogical knowledge }\end{array}$ & TPK & $\begin{array}{l}\text { Knowledge of how to use technology in specific ways to change } \\
\text { learning and teaching. Recognition of the pedagogical benefits and } \\
\text { limitations of technologies. }\end{array}$ \\
\hline $\begin{array}{l}\text { Knowledge of } \\
\text { technological } \\
\text { pedagogical content }\end{array}$ & TPACK & $\begin{array}{l}\text { Knowledge of content integration, pedagogy, and technology. } \\
\text { Being able to learn specific content with specific techniques and } \\
\text { methods and appropriate technology. }\end{array}$ \\
\hline
\end{tabular}

\section{Research questions}

The questions that the research corresponds to are:

What are the attitudes of teachers to the application of technology in effective lesson planning? How much does technology affect students' learning outcomes, independent work and attractive learning? What are the data on the applicability of teaching technology in other subjects? What correlation exists between raising learning outcomes and making learning more attractive? What is the correlation between the age and the level of teacher's education?

\section{Method}

In this research, we used the method of quantitative research. The participants were 25 teachers of the primary school "Kelmend Rizvanolli" from Gjakova, Kosovo, working with students from grades 1-5. Sampling was intentional because this school has a personal laptop for teachers in each class.

\subsection{Instruments for data collection}

For data collection, we used the program for social sciences (SPSS). To analyze teachers' attitudes towards the application of technology in effective lesson planning we used the survey with teachers. To verify the learning outcomes during the application of technology and suitability/applicability in other subjects we used the Post Hock test and the Correlation to measure the relationship between the two variables, respectively the correlation between age and level of teacher's education. 


\section{Results}

The table below presents information on technology planning and implementation by teachers and their attitudes in implementing new technology strategies. This study reported only 1 participant (4\%) who spends more than two hours on the computer to plan any learning unit, 4 participants $(16 \%)$ stated that they spend 1 to 2 hours, while 20 participants $(80 \%)$ reported that less than 1 -hour passes on the computer planning for any subject, which means that planning with technology is organized more easily than of the traditional form. Asked about the use of technology in school, 21 participants $(88 \%)$ reported that they use it a lot, 2 reported moderately (8\%) and 1 reported using little technology in school $(4 \%)$. In the third question, 21 participants (84\%) stated that planning with technology has a very high impact and 4 participants stated slightly lower values, which means that the implementation of new strategies through technology is easier and more understandable to students.

Table 1. Teachers' attitudes towards the application of technology in effective lesson planning.

\begin{tabular}{|c|c|c|c|c|c|c|}
\hline \multirow[t]{2}{*}{$\mathrm{N}=\mathbf{2 5}$} & \multicolumn{2}{|c|}{$\begin{array}{l}\text { How much time do } \\
\text { you spend on the } \\
\text { computer planning } \\
\text { for any subject? } \\
\end{array}$} & \multicolumn{2}{|c|}{ I used technology at school: } & \multicolumn{2}{|c|}{$\begin{array}{l}\text { How much has technology } \\
\text { planning influenced the } \\
\text { implementation of new } \\
\text { strategies? }\end{array}$} \\
\hline & $\mathrm{N}$ & $\%$ & $\mathrm{~N}$ & $\%$ & $\mathrm{~N}$ & $\%$ \\
\hline Less than 1 hour & 20 & 80 & & & & \\
\hline 1 to 2 hours & 4 & 16 & & & & \\
\hline More than 2 hours & 1 & 4 & & & & \\
\hline Many & & & 21 & 88 & & \\
\hline Average & & & 2 & 8 & & \\
\hline Less & & & 1 & 4 & & \\
\hline 4 & & & & & & \\
\hline 5 & & & & & 0 & 0 \\
\hline 6 & & & & & 1 & 4 \\
\hline 7 & & & & & 1 & 4 \\
\hline 8 & & & & & 1 & 4 \\
\hline 9 & & & & & 1 & 4 \\
\hline 10 & & & & & 21 & 84 \\
\hline
\end{tabular}

This study has included 25 teachers, $12(48 \%)$ were male and $13(52 \%)$ female. In question, planning through technology affects the increase of learning outcomes in students, 23 participants (92\%) reported totally agree, $1(4 \%)$ agree and $1(4 \%)$ participant was the neutral. When they asked about a technique that influences students to learn independently and more requirements, 24 participants $(96 \%)$ stated totally agree, only 1 participant (4\%) was agreed, while no participant has been declared neutral and disagree. This situation informs us that all other schools must be supplied with technological tools.

Table 2. Technology affects the increase of learning outcomes in students, making learning attractive and independent.

\begin{tabular}{|c|c|c|c|c|c|c|}
\hline \multirow[t]{2}{*}{$\mathbf{N}=\mathbf{2 5}$} & \multicolumn{2}{|c|}{ Gender } & \multicolumn{2}{|c|}{$\begin{array}{l}\text { Planning through technology affects } \\
\text { the increase of learning outcomes in } \\
\text { students }\end{array}$} & \multicolumn{2}{|c|}{$\begin{array}{l}\text { Technology has influenced students } \\
\text { to learn independently and make } \\
\text { learning more engaging }\end{array}$} \\
\hline & $\mathrm{N}$ & $\%$ & $\mathrm{~N}$ & $\%$ & $\mathrm{~N}$ & $\%$ \\
\hline Man & 12 & 48 & & & & \\
\hline Female & 13 & 52 & & & & \\
\hline Totally agree & & & 23 & 92 & 24 & 96 \\
\hline Agree & & & 1 & 4 & 1 & 4 \\
\hline Neutral & & & 1 & 4 & & \\
\hline Disagree & & & & & & \\
\hline
\end{tabular}




\subsection{Averages}

The table below presents the data to used technology in other subjects. Participants believe that technology applied very successfully in the Natural Science subject $(M=1.36)$, English $(M=1.87)$, and Albanian language $(\mathrm{M}=1.54)$. According to the participants, the subjects in which not necessary to apply the technology were Art $(\mathrm{M}=3.52)$, Civic Education $(\mathrm{M}=3.69)$ and Physical Education $(\mathrm{M}=3.08)$.

Table 3. Average data on the applicability of teaching technology in other subjects.

\begin{tabular}{lccc}
\hline Subjects & N & M & SD \\
\hline Art & 23 & 3.52 & .98 \\
Physical education & 24 & 3.08 & .87 \\
Mathematics & 24 & 2.37 & .92 \\
Albanian language & 24 & 1.54 & .65 \\
Musical education & 25 & 2.24 & .77 \\
English language & 24 & 1.87 & .89 \\
Natural Sciences & 25 & 1.36 & .56 \\
Civic education & 23 & 3.69 & .79 \\
History & 23 & 3.00 & .90 \\
\hline
\end{tabular}

\subsection{Correlates}

The table below presents the correlation between raising learning outcomes and making learning more demanding. There is a positive signaling correlation from teacher's attitudes who express that the use of technology for new acquaintances is easier.

Also, data present that there is a positive signaling correlation between increasing success in all subjects, and the reason that teaching is made more attractive because of using the application of technology.

Table 4. Data on the correlation between raising learning outcomes and making learning more engaging.

\begin{tabular}{lcccccc}
\hline & 1 & 2 & 3 & 4 & 5 & 6 \\
\hline 1. Easier acquisition of new knowledge & - & & & & & \\
2. Interest and desire to learn more & .382 & - & & & & \\
3. Researching new information & .161 & .046 & - & & & \\
4. Increasing success in all subjects & .326 & -.035 & $.522^{* *}$ & - & & \\
5. The lesson is more appealing & .372 & .107 & .324 & $.532^{* *}$ & - & - \\
6. Expanding knowledge about the subject & $.600^{* *}$ & .371 & .023 & .220 & .241 & - \\
\hline
\end{tabular}

From the analysis of the correlation made between the age of teachers and the level of implementation of teacher education, we have confirmed that there is a low positive correlation $\mathrm{r}=.119$. This means that with the age of teachers there is a possibility that teachers will not apply technological tools. The value of the correlation makes it clear that we are moving away from the zero points or from not correlating the variables with each other. In this case, although with a weak positive correlation, the correlation between the two variables still exists in the selected sample.

\section{Conclusions and recommendations}

This study investigated the impact of technology implementation in Kosovo primary schools and the need for planning and organizing the learning process through technology. It was proved that the results of the research are in line with the international ones where technology is applied, but, equipping schools with technological tools cannot be realized due to financial means. The findings reflect that the essential attitudes of teachers towards the planning and implementation of teaching through technology are pedagogical, technological, and content knowledge, specified as the three main elements to understand the complexity of teaching with technology. Planning through technology influenced the increase of learning outcomes in students, knowledge of new concepts, deepened knowledge of the different subjects, inspired students to learn independently, and the development of more attractive learning by offering multiple selections and alternatives around the learning units. The results from the study confirmed that technology planning influenced the implementation of new strategies in the classroom by teachers as a new approach to teaching practices. Also, their age and level of education emerged as determinants in technology planning and implementation, although they had a low positive correlation. From this, it can be concluded that teachers need to start planning differently by now because technology creates and offers many opportunities 
in our schools. To push the Ministry of Education to find opportunities or donors for technological equipment in all schools in Kosovo as a permanent part of the teaching process. Education Directorates obligated to cooperate with schools to influence the creation of conditions that enable the integration of technology in all educational institutions.

\section{References}

Alqurashi, E., Gokbel, E. N., \& Carbonara, D. (2017). Teachers' knowledge in content, pedagogy and technology integration: A comparative analysis between teachers in Saudi Arabia and United States. British Journal of Educational Technology, 48(6), 1414-1426. doi:10.1111/bjet.12514

Baturay, M. H. (2017). Associations among Teachers' Attitudes towards Computer-Assisted Education and TPACK Competencies. Informatics in Education, 16(1), 1-23.

Blau, I., Peled, Y., \& Nusan, A. (2014). Technological pedagogical and content knowledge (TPACK) in one-to-one classroom: Teachers developing "Digital Wisdom". Interactive Learning Environments, 24(6), 1215-1230. doi:10.1080/10494820.2014.978792

Cox, M., Preston, C. \& Cox, K. (1999). What Factors Support or Prevent Teachers from Using ICT in their Classrooms? Paper presented at the British Educational Research Association Annual Conference. University of Sussex, Brighton.

Hermans, R., Tondeur, J., Van Braak, J., \& Valcke, M. (2008). The impact of primary school teachers' educational beliefs on the classroom use of computers. Computers \& Education, 51(4), 1499-1509. doi:10.1016/j.compedu.2008.02.001

Hixon, E., \& So, H. J. (2009). Technology's role in field experiences for preservice teacher training. Educational Technology \& Society, 12(4), 294-304. Retrieved from learntechlib.org/p/74980/

Koehler \& Mishra. (2005). What happens when teachers design educational technology? The development of technological pedagogical content knowledge. Journal of Educational Computing Research, 32(2), 131-152. doi:10.2190/0EW7-01WB-BKHL-QDYV

Krauskopf, K. Z. (2012). Leveraging the affordances of Youtube: The role of pedagogical knowledge and mental models of technology functions for lesson planning with technology. Computers \& Education, 50(4), 1194-1206. doi:10.1016/j.compedu.2011.12.010

Sánchez-Mena, A., Martí-Parreño, J., \& Aldás-Manzano, J. (2017). The Effect of Age on Teachers' Intention to Use Educational Video Games: A TAM Approach. Electronic Journal of e-Learning, 15(4), 355-366.

Soetan, A. K., \& Cokerb, A. D. . (2018). University lecturers' readiness and motivation in utilizing online technologies for instructional delivery in Kwara state, Nigeria. World Journal on Educational Technology, 10(4), 165-181. doi:10.18844/wjet.v10i4.408

Sylvestre, M. H. (2018). Information communication technology policy and public primary schools` efficiency in Rwanda. South African Journal of Education, 38(1). doi:10.15700/saje.v38n1a1445

Voogt, J. F. (2013). Technological pedagogical content knowledge-a review of the literature. Journal of Computer Assisted Learning, 29(2), 109-121. doi:10.1111/j.1365-2729.2012.00487

Voogt, J., \& McKenney, S. (2017). TPACK in teacher education: Are we preparing teachers to use technology for early literacy. Technology, pedagogy and education, 26(1), 69-83. doi:10.1080/1475939X.2016.1174730 


\title{
IDENTIFICATION OF FACTORS AFFECTING ELEMENTARY TEACHERS' ATTITUDES TOWARDS INCLUSION IN KOSOVO: THE ROLE OF DEMOGRAPHIC VARIABLES
}

\author{
Donika Koliqi ${ }^{1}$, \& Naser Zabeli ${ }^{2}$ \\ ${ }^{1}$ Doctoral Student, University of Prishtina/Faculty of Education (Kosovo) \\ ${ }^{2}$ Professor at the University of Prishtina/Faculty of Education (Kosovo)
}

\begin{abstract}
Inclusion is at the center of interest of international institutions and associations and is considered as one of the main challenges facing education systems worldwide. According to different studies for the implementation of inclusive practices, positive attitudes of teachers are essential in the successful implementation of this change in education. The aim of this paper was to research the elementary teachers' attitudes towards inclusive education and to identify factors that influence their attitudes, such as: gender, age, training for inclusive education, level of education, educational experience, and experience with children with special needs. The methodology of the study is quantitative method. The population of this study include teachers of elementary level of education in the Kosovo and the sample include 300 respondents, who were surveyed with the Teachers' Attitudes towards Inclusion Scale (TAIS). The research findings have shown that the attitudes of primary school teachers towards inclusive education are below the neutral middle point. The findings have confirmed that the demographic variables have a moderate impact on teachers' attitudes, too. A slightly higher impact is noticed while they have been part of trainings and their experience on working with students, who are considered with special needs has also helped in raising awareness.
\end{abstract}

Keywords: Students with special needs, inclusive education, teacher attitudes, demographic variables.

\section{Introduction}

The inclusion of children with special educational needs in regular school institutions has been a global movement for at least three decades (Amor, et al., 2019). A special contribution to the conception of inclusive education was made by The Salamanca Declaration (UNESCO, 1994) according to which, the inclusive education is a form of education that provides access, support and effective education to students with special educational needs in regular schools while being included in activities with their peers.

Currently, inclusive education remains a major challenge of education systems (Sharma, Loreman, \& Forlin, 2011) and it is considered a central point in the educational agendas of different countries (Muntaner, Rosselló, \& de la Iglesia, 2016). This practice has influenced the reform of educational policies, however they have failed to guarantee the inclusion of all children with special needs (Peters, Johnstone, \& Ferguson, 2005). The full implementation of inclusive education depends on several preconditions. According to Ainscow and Sandill (2010) one of the most important dimensions in developing inclusive schools is the attitudes of factors towards diversity. Furthermore, key factors in the implementation of policies and the implementation of inclusive practices have been assessed by teachers, especially their attitudes towards inclusive education (UNESCO, 2009).

Numerous scientific researches have shown that teachers' attitudes determine the successful implementation of inclusive education (Saloviita \& Schaffus, 2016; Saloviita, 2018; Avramidis \& Norwich, 2002). Therefore, the teacher's pedagogical preparation is not considered to be enough, as it is also expected the positive attitude towards inclusive education. This has been proved by the conducted research in which 8200 children with special needs have been part of it in Germany, who have succedded more with teachers who have had more positive attitudes, in contrast to other students who have not succeeded as a result of teachers' negative attitudes towards their inclusion (Van der Veen, Smeets, \& Derriks, 2010).

Attitudes are defined as "an individual's disposition to react to a certain degree in favor or disadvantage to an object, behavior, person, institution or event, or to any other discriminatory aspect of his or her individual world" (Ajzen, 1993, p. 41). According to Eagly and Chaiken (1993) attitudes consist of cognitive, affective and conative elements. Taking into account the teachers' attitudes towards 
inclusive education, the cognitive component includes positive or negative statements towards inclusive education, the affective component represents the emotional connection with inclusive values, and the conative component represents teachers' approach based on their beliefs and knowledge about inclusiveness (Saloviita, 2018).

According to Czyż (2018) the intensity and orientation of the attitude depends on several factors. Researches have identified several variables that impact teaching attitudes such as: gender, age, country, experience on working with children with special needs, work experience, vocational training, training regarding inclusive education. Studies, in which, gender has been researched, female teachers have dominated with more positive attitudes towards inclusive education compared to male teachers (Alquraini, 2012).

Regarding age, researches have shown that younger teachers have more positive attitudes than the older ones (Ahmmed, Sharma, \& Deppeler, 2014). According to Stoiber, Gettinger and Goetz (1998) the higher the professional preparation of teachers, specifically when talking about, the educational level, it is noted a positive tone regarding their attitudes towards inclusive education. One of the most influential factors in the positive attitudes of teachers according to research is attending trainings about inclusive education (Avramidis \& Norwich, 2002; Ahsan, Sharma, \& Deppeler, 2012). According to Beh-Pajooh (1992) among other details, teachers who have attended training for children with special needs are emotionally attached to them, unlike their counterparts who have not attended such training. Also, teachers with less than 14 years of experience have more positive attitudes towards the integration of students with special needs than those with more than 14 years of work experience (Leyser, Kapperman, \& Keller, 1994). As another important factor in attitudes towards inclusiveness is the contact and work with children with special needs (Saloviita, 2018), so teachers with more contact and work experience with children with special needs have more positive attitudes.

Based on the importance of recognizing the impact of factors, this research aims to identify teachers' attitudes towards inclusive education. In the meantime, it aims to identify the demographic factors that influence the attitudes of primary level teachers.

\section{Methodology}

In this study, there was used the quantitative method. This approach has enabled the reflection of teachers' current attitudes towards inclusive education and the identification of factors that have implicated their attitudes.

\subsection{Procedure}

Initially, permission to contact and teachers' e-mail addresses were obtained from Municipal Education Directorates in seven towns and then school principals were informed, too. The e-mail which was sent to the teachers contained information about the study as the research tool was placed in Google Forms format. A total of 500 emails were sent to teachers, while the forms were completed by 300 teachers to an account on Google Forms.

\subsection{Instruments for data collection}

The data collection tool was The Teacher Attitude towards Inclusive Education Scale" (TAIS) which is a degree that has achieved reliability up to $a=.90$ (Saloviita, 2015). "The scale included items on expected outcomes, rights of the child, teacher workload and inclusion as a value" (Timo \& Simone, 2019, p. 9). This instrument consists of 10 statements with five Likert scale answers: I completely disagree, I disagree, I am neutral, I agree and I completely agree. Part of the instrument were also 15 demographic questions.

\subsection{Participants}

Participants in this study were 300 primary school teachers from grades 1-5, part of public schools in Kosovo. Out of the total number of teachers $(\mathrm{N}=300), 90.33 \%(\mathrm{~N}=271)$ were females and $9.67 \%(\mathrm{~N}=29)$ males. Whereas, the average age of theirs was 45 , and the teaching experience average was 17 years. It is important to mention that the sample was unintentional.

\section{Results}

Descriptive and correlative statistical analyzes were used to identify teachers' attitudes and the influence of demographic factors on teachers' attitudes towards inclusive education. Based on the data, the attitudes of primary level teachers with the TIAS scale resulted (average $=26.6$ ) below the grade point average (average $=30.0)($ Table 1$)$. 
Table 1. Attitudes of teachers towards inclusive education as measured by "The Teacher Attitude towards Inclusive Education Scale" (TAIS).

\begin{tabular}{lrrrrrr}
\hline Elementary teacher & $\mathrm{N}$ & Mean & $\mathrm{SD}$ & $\mathrm{df}$ & $\mathrm{F}$ & $\mathrm{p}$ \\
\hline Sum total & 300 & 26.69 & 7.12 & 2,1644 & 60.12 & .000
\end{tabular}

Based on the data in TAIS, female teachers $(\mathrm{N}=271)$ had more positive attitudes in comparison to male teachers $(\mathrm{N}=29), \mathrm{t}(1,635)=3,59, \mathrm{p}=.000$ and with a slight differentiation $\mathrm{d}=.20$. In terms of age, teachers under the age of $30(\mathrm{~N}=97)$ were more positive than those over the age of $50(\mathrm{~N}=121)$, respectively with a statistically significant difference with $\mathrm{t}(181,233)=2,11$ and $\mathrm{p}=0.001$. Therefore, younger teachers were slightly more positive as opposed to older ones $(\mathrm{d}=.28)$. The results have shown that teachers with work experience under 15 years $(\mathrm{N}=179)$ were slightly more positive than teachers with more than 25 years of work experience $(\mathrm{N}=98)$, with $\mathrm{t}(1,523)=2,26, \mathrm{p}=0.031$. Thus, the most experienced teachers in education had slightly more positive attitudes compared to the less experienced teachers $(\mathrm{d}=.21)$. Based on the results, the educational level turns out to be statistically significant $\mathrm{t}(2,151)=3,22$ and $\mathrm{p}=.001$, respectively the teachers with the completed master level $(\mathrm{N}=211)$ were slightly more positive in contrast to the teachers who have completed only the bachelor level $(\mathrm{N}=89)$, with $(\mathrm{d}=.23)$. Teachers who attended more than three trainings for inclusive education $(\mathrm{N}=163)$ were more positive than their counterparts who have attended only one training $(\mathrm{N}=97)$, with $\mathrm{t}(2,675)=4,21$, $p=0.021$ and with an effect $d=1.38$. 10 years of experience of teachers working with children with special educational needs $(\mathrm{N}=120)$ have shown more positive attitudes than teachers with experience less than 5 years $(\mathrm{N}=86)$, with $\mathrm{t}(3,866)=5,18$ and with $\mathrm{p}=0.053$. More experienced teachers felt more positive than less experienced teachers with children with special needs with $d=1.42$.

\section{Discussion and conclusions}

This study has surveyed the Kosovar primary school teachers' attitudes towards inclusive education. The influence of some demographic variables on their attitudes was also investigated. The research results have showed that the attitudes of primary school teachers towards inclusive education are below the neutral middle point, similar to the results of other research where teachers were neutral or even indifferent (Ross-Hill, 2009; Czyż, 2018). Whereas, in terms of the demographic variables impact, female teachers were more positive than male teachers (e.g. Ahsan, Sharma \& Deppeler, 2012), younger teachers resulted in slightly more positive attitudes than older teachers (eg Saloviita, 2020), teachers with less teaching experience were slightly more positive than those with more teaching experience (e.g. Marshall, Ralph, \& Palmer, 2002), teachers with higher education level were more positive compared to those with lower education level (e.g. Stoiber, Gettinger, \& Goetz, 1998). As the variable with slightly greater impact turned out to be the largest number of trainings for inclusive education and years of experience with children with special needs (e.g. Majoko, 2017).

According to these findings, it can be concluded that it is important for teachers to attend trainings on inclusive education and having experience with children with special needs. They constantly need evolving in a professional perspective to change attitudes towards inclusive education. On the other hand, it is also important for every teacher to have contact and then face working with children with special educational needs, given that experience changes their negative or neutral attitudes. This professional development of teachers and this challenging experience is possibly going to affect the quality of teaching, considering the fact that each student should be supported no matter how different from the other, both in terms of skills and educational needs.

\section{References}

Ahmmed, M., Sharma, U., \& Deppeler, J. (2014). Variables affecting teachers' intentions to include students with disabilities in regular primary schools in Bangladesh. Disability \& Society, 29(2), 317-331. doi:10.1080/09687599.2013.796878

Ahsan, M. T., Sharma, U, \& Deppeler, J. M. (2012). Exploring pre-service teachers' perceived teaching-efficacy, attitudes and concerns about inclusive education in Bangladesh. International Journal of Whole Schooling, 8, 1-20. Retrieved from http://www.wholeschooling.net/ Journal_of_Whole_Schooling/articles/8-2\%20Ahsan\%20et\%20al.pdf

Ainscow, M., \& Sandill, A. (2010). Developing Inclusive Education Systems: The Role of Organisational Cultures and Leadship. International Journal of Inclusive Education 14(4), 401-416. doi:10.1080/13603110802504903 
Ajzen, I. (1993). Attitude Theory and the Attitude-Behavior. In D. Krebs, \& P. Schmidt, New Directions Measurement (pp. 41-57). Berlin-New York: Walter de Gruyter.

Alquraini, T. A. (2012). Factors related to teachers' attitudes towards the inclusive education of students with severe intellectual disabilities in Riyadh, Saudi. Journal of Research in Special Educational Needs, 12(3), 170-182. doi:10.1111/j.1471-3802.2012.01248.x

Avramidis, E., \& Norwich, B. (2002). Teachers' attitudes towards integration/inclusion: A review of the literature. European Journal of Special Needs Education, 17(2), 129-147. doi:10.1080/08856250210129056

Beh-Pajooh, A. (1992). The effect of social contact on college teachers' attitudes towards students with severe mental handicaps and their educational integration. European Journal of Special Needs Education, 7, 231-236. doi:10.1080/0885625920070201

Czyż, A. (2018). An Analysis of Polish Teachers Attitudes towards Inclusive Education. Future Human Image, 10, 4-19. doi: 10.29202/fhi/10/1

Eagly, A. H \& Chaiken, S. (1993). The psychology of attitudes. Fort Worth, TX: Harcourt, Brace Jovanovich.

Leyser, Y., Kapperman , G., \& Keller, R. (1994). Teacher attitudes toward mainstreaming: a cross-cultural study in six nations. European Journal of Special Needs Education, 9, 1-15. doi:10.1080/0885625940090101

Majoko, T. (2017). Inclusion in Early Childhood Education: a Zimbabwean perspective. International Journal of Inclusive Education, 21(12), 1210-1227. doi: 10.1080/13603116.2017.1335354

Marshall, J., Ralph, S., \& Palmer, S. (2002). 'I wasn't trained to work with them': Mainstream Teachers' Attitudes to Children with Speech and Language Difficulties. International Journal of Inclusive Education 6(3), 199-215. doi: 10.1080/13603110110067208

Muntaner, J. J., Rosselló, R. M., \& de la Iglesia, B. (2016). Buenasprácticas en educación inclusiva. [Good practices in inclusive education]. Educatio Siglo XXI 34(1), 31-50. doi:10.17811/rifie.46.2017.49-56

Peters, S., Johnstone, C., \& Ferguson, P. (2005). A disability rights in education model for evaluating inclusive education. International Journal of Inclusive Education, 9, 139-160. doi:10.1080/1360311042000320464

Ross-Hill, R. (2009). Teacher Attitude Towards Inclusion Practices and Special Needs Students. Journal of Research in Special Educational Needs 9, 188-198. doi: 10.1111/j.1471-3802.2009.01135.x

Saloviita, T. (2015). Measuring pre-service teachers' attitudes towards inclusive education: Psychometric properties of the TAIS scale. Teaching and Teacher Education, 52, 66-72. doi:10.1016/j.tate.2015.09.003

Saloviita, T. (2018). Attitudes of Teachers Towards Inclusive Education in Finland. Scandinavian Journal of Educational Research. doi:10.1080/00313831.2018.1541819

Saloviita, T. (2020). Teachers' Changing Attitudes and Preferences around Inclusive Education. International Journal of Disability, Development and Education. doi: 10.1080/ 1034912X.2020.1828569

Saloviita, T., \& Consegnati, S. (2019). Teacher attitudes in Italy after forty years of inclusion. British Journal of Special Education, 46(4), 465-479. doi: 10.1111/1467-8578.12286

Saloviita, T., \& Schaffus, T. (2016). Teacher attitudes towards inclusive education in Finland and Brandenburg, Germany and the issue of extra work. European Journal of Special Needs Education, 31(4), 458-471. doi:10.1080/08856257.2016.1194569

Sharma, U., Loreman, T., \& Forlin, C. (2011). Measuring teacher efficacy to implement inclusive practices. Journal of Research in Special Educational Needs, 12(1), 12-21. doi:10.1111/j.14713802.2011.01200.x

Stoiber, K. C., Gettinger, M., \& Goetz, D. (1998). Exploring Factors Influencing Parents' and Early Childhood Practitioners Beliefs about Inclusion. Early Childhood Research Quarterly 13(1). 107-131. doi: 10.1016/S0885-2006(99)80028-3

United Nations Educational, Scientific and Cultural Organisation (UNESCO). (1994, June 7-10). The Salamanca statement and framework for action on special needs education. Salamanca: World Conference on Special Needs Education: Access and Quality

United Nations Educational, Scientific and Cultural Organisation (UNESCO). (2009). Policy guidelines on inclusion in education. Paris: Author.

van der Veen, I., Smeets, E., \& Derriks, M. (2010). Children with Special Educational Needs in the Netherlands: Number, Characteristics and School Career. Educational Research 52(1), 15-43. doi:10.1080/00131881003588147 


\title{
VERIFICATION OF AFFORDANCE EFFECT OF HMI IN THE VR ENVIRONMENT
}

\author{
Maki Arame ${ }^{1,2}$, Junko Handa ${ }^{1,2}$, Yoshiko Goda ${ }^{2}$, Masashi Toda ${ }^{2}$, Ryuichi Matsuba ${ }^{2}$, \\ \& Tatsuru Daimon ${ }^{3}$ \\ ${ }^{1}$ Polytechnic University of Japan, Tokyo (Japan) \\ ${ }^{2}$ Kumamoto University, Kumamoto-city (Japan) \\ ${ }^{3}$ Keio University, Tokyo (Japan)
}

\begin{abstract}
There are always big issues to use new technology. The users need to know how to use it, and what will happen if they don't use it properly because of lack of knowledge. Level 3 and 4 automated vehicles will be on the road shortly in Japan. Drivers and pedestrians need to deal with new types of cars to keep themselves safe. It is thought that there are individual differences in the perception of affordances when encountering self-driving cars. In this research, the environment of encounter with an automated vehicle were developed in VR that verified the difference in affordance perceptions depending on individual attributes. As a result, it was suggested that a metaphorical HMI of automated vehicle may promote proactive behavior.
\end{abstract}

Keywords: Automated vehicle, affordance, VR environment, person centered approach.

\section{Introduction}

Self-driving cars will soon be widespread on public roads. It is important not only the technological development of hardware and software that support automated driving but also the communication between automated vehicles and humans from the perspective of safety (Zhou, Itoh, \& Kitazaki, 2018; Zhou, Itoh, \& Kitazaki, 2019). This study investigated pedestrians' behaviors at a crosswalk when they encountered an automated vehicle. Considering their risks, an environment of the intersection in which pedestrians encountered an automated driving vehicle was created using Virtual Reality (VR).

This study investigated the factors that contributed to pedestrians' judgments that they could safely cross the crosswalk and their relation to personal attributes and external Human-Machine Interfaces(eHMI).

\section{Purpose of study}

A traffic safety education course for the general public has only about 5 minutes of teaching time. In order to prevent accidents caused by human error, Keskine (1996) states hierarchical approach theory of driving behavior consists of five levels. The first level includes basic driving skills and knowledge of laws and regulations, the second level includes a response to traffic others and hazard prediction. The third level includes skills related to the purpose of driving and the formulation of operation plans (setting travel times and routes). The fourth level is self-control skills such as awareness and responsibility to drive safely and avoid accidents. The fifth level encompasses social environment. Current traffic safety education mainly targets up to the second level, but in order to achieve safety education in the whole society, it is important for people to have a higher level of safety awareness (Keskinen, 2014).

In previous studies, it was confirmed that the learning effect may differ depending on individual attributes when the same content is taught in different teaching materials: pamphlet format, quiz format, and video format. The purpose of this study is to construct a walking environment with automated vehicles in a VR environment, and to examine the factors that increase safety awareness through the experience of participants encountering automated vehicles as pedestrians. 
Figure 1. Position of a pedestrian in a VR environment.

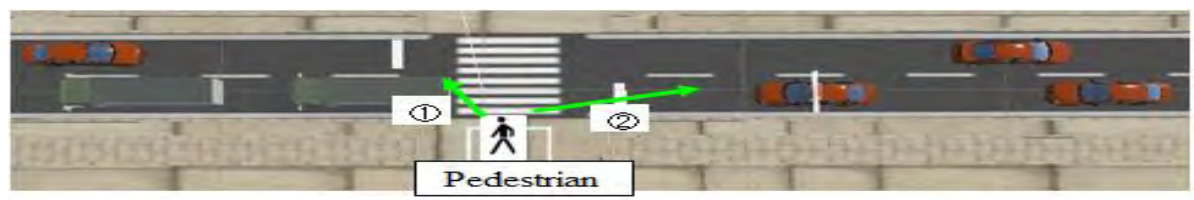

\section{Literature Review}

\subsection{Situation awareness model}

Endsley (2013) proposed a model of situational awareness, in which he states that people are required to accurately recognize situations as they dynamically change, to predict future situations, and to do what people can in the present to achieve a good situation in the future. In this process, the following three steps of situational awareness are key.

Level 1: Perceive the current situation surrounding you. Level 2: Understand the implications of the situation you notice. Level 3: Predict how the situation will unfold in the future. Then, decide what steps to take in the present to deal with the predicted future situation, and solemnly execute the decision. In the case of an encounter with an automated car, it notices the approach of an oncoming car (Level 1), understands what it means for its own path (Level 2), and predicts the future situation (Level 3). The situational awareness model points out the need to check the effectiveness of the support at each level.

To put it in the context of this study, it is whether the subject was able to recognize whether there was an automatic vehicle in the surroundings when walking (Level 1), whether the subject was able to understand the contents of the automatic vehicle's eHMI when recognizing the vehicle (Level 2), and whether the predictive development of the future situation change was presented (Level 3). If the situational awareness is appropriate, the time required to take coping actions is expected to be shorter.

\subsection{Experiential Learning Cycle}

Kolb proposes the Kolb's Experiential Learning Cycle. Kolb described four stages for learning abstract concepts that can be applied in the real world. The four stages are concrete experience, reflective observation, abstract conceptualization, and active experimentation (Kolb, 1984).

Concrete experience is when the learner has a new experience or encounters a new situation. Reflective observation is when the learner observes others or makes observations about his/her own experiences. Abstract conceptualization is the process of understanding what has happened and interpreting events and the relationships between them. Active experience is the learner's application of his or her ideas and concepts to the real world.

The experiential learning model recommends appropriate feedback during learning. The framework of feedback is divided into information notification and rebuilding. In the informational notification type of feedback, missing knowledge and information are compensated. For inexperienced people, it is to inform them of the situation and the results. In the rebuilding type of feedback, it is to support their self-reflection and to help them create action plans for improvement.

Feedback appears to be something that is pinpointed, but pedagogically, it is closely related to overall instructional design and goals. If appropriate feedback is provided during experiential learning with VR, it is thought that safety awareness when walking may be improved.

\section{Research Question}

The research questions were the following three points.

1. Do the messages make a difference in the pedestrian's behavior? If so, which message was appropriate for the pedestrian to initiate the crossing?

2. What messages cause pedestrians to observe their surroundings more carefully?

3. What kind of message will raise awareness of safety considerations for the driver and others?

\section{Method}

\subsection{Participants and procedure}

The survey data used in this study were a secondary analysis of the results of $101 \mathrm{VR}$ experiment data in 2020. In the survey, in addition to age and gender, driver's license existence was surveyed as basic attributes of respondents. A VR experiment was conducted in about 5 minutes, and when an automated 
vehicle equipped with eHMI approached a no-signal pedestrian crossing, one of three types of language messages ((1) after you, (2) I will stop, and (3) no message) was displayed.

In this study, the time from when the automatic vehicle stops until the subject starts crossing was measured. Furthermore, a questionnaire and an interview were conducted after the experiment to investigate the relationship between behavior and recognition by the displayed message. The experiment was conducted 11 times for one subject, and the data of the 11th time were analyzed in this study.

\subsection{Measurement}

In this study, the following three types of questionnaires are conducted after the VR crossing experiment. Answer each question in 5 stages (1: I do not agree at all-5: I strongly agree).

Q1. The first car approaching from the right side gave way to you.

Q2. I was able to cross with confidence before the first car approaching from the right side passed.

Q3. I tried to cross quickly, paying attention to the car that stopped.

After the experiment was completed, subjects were interviewed about "How did you think the driver would judge and act when the driver of the oncoming vehicle saw the situation of the self-driving car (including the contents if there was an outward HMI)?"

\section{Results}

\subsection{Results of pre-posttests by learning material type}

Table 1 summarizes the age and the presence or absence of a driver's license as individual attributes of the subjects for each message displayed in the experiment. The ages were classified into 12 to 15 years old (hereinafter, junior high school), 16 to 65 years old (hereinafter, non-elderly), and 65 years old and over (hereinafter, elderly). It is considered that there is a difference in judgment depending on whether the person has a driver's license or not.

Table 1. Subject attributes.

\begin{tabular}{l|c|c|r|r}
\hline eHMI & $\begin{array}{c}\text { elderly } \\
\text { (license holders) }\end{array}$ & $\begin{array}{l}16 \text { to 64 years } \\
\text { (license holders) }\end{array}$ & $\begin{array}{c}12 \text { to } 15 \text { years } \\
\text { (license holders) }\end{array}$ & $\begin{array}{l}\text { Total } \\
\text { (license holders) }\end{array}$ \\
\hline After you & $4(4)$ & $20(10)$ & $10(0)$ & $34(14)$ \\
\hline I will stop & $3(3)$ & $18(10)$ & $8(0)$ & $29(13)$ \\
\hline No message & $9(9)$ & $19(10)$ & $10(0)$ & $38(19)$ \\
\hline
\end{tabular}

\subsection{Results of coping time by pattern}

Figure 2 compared the average time from when the automated vehicle stopped to when it started crossing for each displayed message. A positive value of the coping time means the start of walking after the automated vehicle stops. And a negative value means the start of walking before the automated vehicle stops. It can be seen it takes less time to deal with "(1) after you" and "(2)I will stop" compared to the case "no message." In addition, since there was a significant difference in the time required for coping with each type of eHMI, it can be considered that the message influenced their judgement. By age groups, it can be seen the older the person, the longer the coping time, regardless of the type of message.

Figure 2. Comparison of coping time by age group by message.

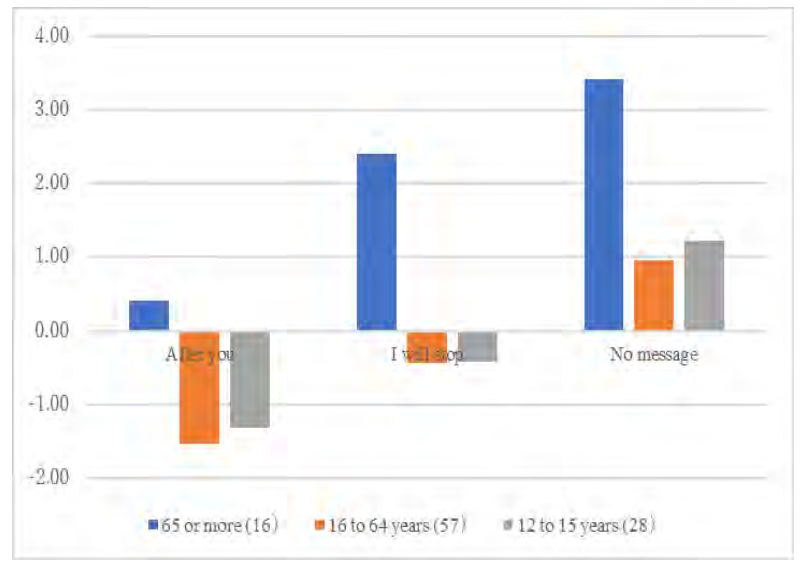




\subsection{Questionnaire analysis results}

Table 2 compared the average answers to each question for each message. The average answer for Q1 "The first car approaching from the right side gave way to you" was the highest "no message". And the average answer for Q2 "Did you cross with confidence?" had become "(1) after you" the lowest, then "(3) no message”, and "(2) I will stop." Q3 "I tried to cross quickly with care" had the highest average response "no message."

Although the presence of eHMI did not necessarily foster a sense of security, it has been confirmed that it may have the effect of predicting the next behavior.

Table 2. Average score for questions by message.

\begin{tabular}{l|c|r|r|r}
\hline eHMI & & Q1 & Q2 & Q3 \\
\hline \multirow{2}{*}{$\begin{array}{l}\text { After you } \\
\mathrm{N}=34\end{array}$} & Mean & 4.50 & 3.65 & 3.21 \\
\cline { 2 - 5 } I will stop & SD & 0.66 & 1.37 & 1.25 \\
$\mathrm{~N}=29$ & Mean & 4.52 & 4.10 & 3.00 \\
\hline \multirow{2}{*}{$\begin{array}{l}\text { No message } \\
\mathrm{N}=38\end{array}$} & SD & 0.74 & 0.98 & 1.41 \\
\cline { 2 - 5 } & Mean & 4.55 & 3.89 & 3.24 \\
\hline
\end{tabular}

Table 3 compared the average answers to each question for each message for car license holders. It was considered that the driver's license holders made a judgment based on their driving experiences so far. As result of the analysis, it can be seen the average score of Q1 and Q2 is the highest and the average score of Q3 is the lowest for "I will stop". This result shows that "I will stop" was the most appropriate eHMI for license holders.

Table 3. Average answers by question for car license holders.

\begin{tabular}{|c|c|c|c|c|}
\hline eHMI & & Q1 & Q2 & Q3 \\
\hline \multirow{2}{*}{$\begin{array}{l}\text { After you } \\
\mathrm{N}=14\end{array}$} & Mean & 4.36 & 3.43 & 3.00 \\
\hline & SD & 0.74 & 1.34 & 1.24 \\
\hline \multirow{2}{*}{$\begin{array}{l}\text { I will stop } \\
\mathrm{N}=13\end{array}$} & Mean & 4.46 & 4.00 & 2.92 \\
\hline & SD & 0.78 & 1.22 & 1.19 \\
\hline \multirow{2}{*}{$\begin{array}{l}\text { No message } \\
\mathrm{N}=19\end{array}$} & Mean & 4.42 & 3.79 & 3.11 \\
\hline & SD & 0.90 & 1.23 & 0.99 \\
\hline
\end{tabular}

Figure 3 shows a comparison of the average scores of Q1, Q2, and Q3 between license holders and non-license holders. It can be seen that the average of license holders was low in Q1 and Q2 regardless of the message, and the average of license holders was high in Q3. "After You" showed that the difference between licensed and unlicensed was greater than other eHMI.

Figure 3. Score comparison by questionnaire by message with or without driver's license.

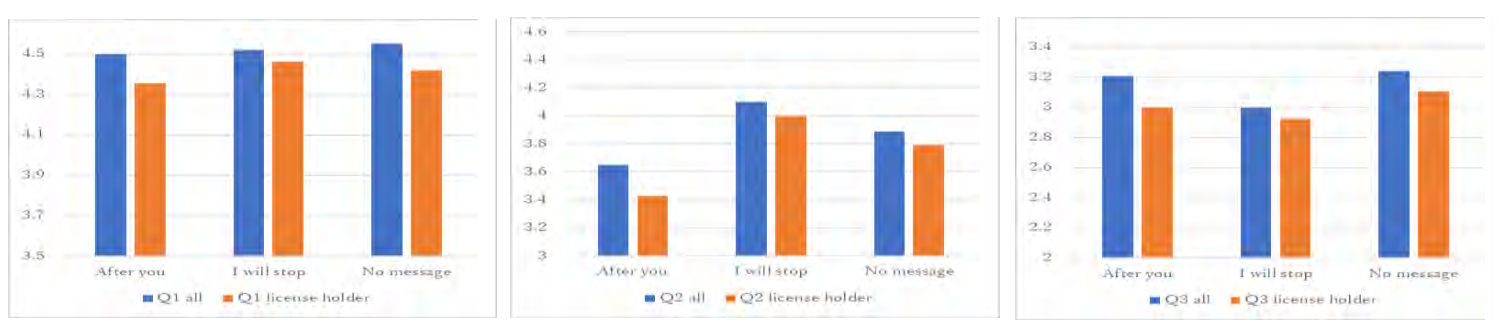

\subsection{Free description analysis results}

Table 4 was an analysis of the interview, "How did you think the driver would judge and act when the driver of the oncoming vehicle looked at the situation of the self-driving car (including the contents if there was an outward HMI)?" The results of morphological analysis using text analysis software (KH Coder ver3) were as follows. In the chi-square test of independence, there were significant differences in three items. It can be seen the subjects of "after you" highly evaluate HMI as a judgment material, while "I will stop" had a high evaluation other than HMI. There was no significant difference in the morphological analysis results whether the person was the license holder or not. From this, learning of automated vehicle by VR may have had a greater impact than previous driving experience. 
Table 4. Results of morphological analysis.

\begin{tabular}{l|r|r|r|r|r} 
& \multicolumn{1}{|l|}{ Not stop } & \multicolumn{1}{l|}{ Slow down } & \multicolumn{1}{l|}{ Stop } & unknown & look at the HMI \\
\hline after you & $2(5.88 \%)$ & $19(55.88 \%)$ & $26(76.47 \%)$ & $2(5.88 \%)$ & $11(32.35 \%)$ \\
\hline I will stop & $0(0.00 \%)$ & $12(41.38 \%)$ & $18(62.07 \%)$ & $1(3.45 \%)$ & $4(13.79 \%)$ \\
\hline No message & $7(20.00 \%)$ & $7(20.00 \%)$ & $24(68.57 \%)$ & $3(8.57 \%)$ & $0(0.00 \%)$ \\
\hline Chi-square value & $8.29 *$ & $9.47 * *$ & 1.55 & $\begin{array}{r}0.73 \\
* \mathrm{p}<0.5 * * \mathrm{p}<0.01\end{array}$
\end{tabular}

\section{Conclusions}

In this study, we examined the effect of eHMI on learning with the aim of introducing a VR environment into traffic safety education for pedestrians. Based on the situational awareness model, we investigated the coping time and recognition for each eHMI, and confirmed that the response time and consideration contents differed depending on the eHMI. Especially a message of "After you" made a pedestrian hurry. Thus, it is less time to start to walk. Yet, they may not have observed surroundings that may be a risk for them. Instead, "I will stop" made a pedestrian feel safe although it takes a time to start crossing. "No message" took a long time for a pedestrian to start crossing, but they check their surroundings. Pedestrians who have driver's licenses seemed to be more careful to initiate crossing. In conclusion, there were differences in the pedestrian's behavior depending on the messages. A message seemed to influence pedestrians' judgment. It may be based on their personal experience. In this study, which message raised awareness of safety were not able to discover, they need to have experience for automated driving vehicles.

\section{Limitations and recommendations}

In this VR experiment, detailed education on automated vehicles was not given before the experiment. In the future, after experiencing VR learning materials, we will make a plan to consider the implications of implementing explicit guidance and feedback methods. The eHMI of this study was compared only with three types, "after you", "I will stop", and no message. In the future, it will be necessary to verify whether similar trends can be seen in more diverse HMIs.

\section{Acknowledgments}

This work was supported by Council for Science, Technology and Innovation (CSTI), Cross-ministerial Strategic Innovation Promotion Program (SIP), entitled "Human Factors and HMI Research for Automated Driving" (funding agency: NEDO).

\section{References}

Endsley, M. R. (2013). Situation awareness. In J. D. Lee \& A. Kirlik (Eds.), Oxford library of psychology. The Oxford handbook of cognitive engineering (p. 88-108). Oxford University Press.

Keskinen, E. (1996). Why do young drivers have more accidents? Junge Fahrer und Fahrerinnen. Referate der Esten Interdiziplinären Fachkonferenz 12-14. Dezember 1994 in Köln. Berichte der Bundesanstalt für Strassenwesen. Mensch und Sicherheit, Heft M 52.

Keskinen, E. (2014). Education for older drivers in the future. IATSS Research, Vol38, Issue1, pp. 14-21.

Kolb, D. A. (1984). Experiential Learning: Experience as the Source of Learning and Development. Englewood Cliffs, NJ: Prentice Hall.

Zhou, H., Itoh, M., Kitazaki S. (2018). How Does Knowledge about System Limitations Contribute to Interventions into Partial Automation Among Elderly Drivers? Proceedings of the 2018 IEEE international Conference on Systems, Man, and Cybernetics (SMC2018), pp. 851-820.Miyazaki, Japan,

Zhou, H., Itoh, M., Kitazaki, S. (2019). Long-term Effect of Experiencing System Malfunction on Driver Take-over Control in Conditional Driving Automation. Proceedings of the 2019 IEEE international Conference on Systems, Man, and Cybernetics (SMC2019), pp. 1950-1955. Bari, Italy (2019). 


\title{
A LIFE-HISTORY CASE STUDY ON SELF-RELIANCE EXPERIENCE OF DIVORCED MIGRANT WOMEN
}

\author{
SooAn Choi ${ }^{1}$, \& YoungSoon Kim ${ }^{2}$ \\ ${ }^{I}$ Doctoral student, Dept. of Multicultural Education, Inha University (South Korea) \\ ${ }^{2}$ Professor, Dept. of Multicultural Education, Inha University (South Korea)
}

\begin{abstract}
This study aims to examine the life history of migrant women who have experienced divorce in a socio-cultural context. Five people participated in the study, and they have been living in self-reliance support facilities since their divorce. They were selected from interviews on the life history of 80 married migrant women, which were funded by the Korea Research Foundation from 2017 to 2019. The method of research is a life-historical case study. The results of the study are as follow; first, their marriage was to escape gender hierarchy and poverty in their home country. Therefore, it was confirmed that marriage migration took place within the transnational trend of feminization of migration. Second, self-reliance support facilities provide strong social support for divorced migrant women. As a result, it works as an important space that allows them to escape from voluntary self-exclusion and explore new subjectivity. Suggestions of the implications are as follow; the social support from self-reliance support facilities after divorce is a driving factor that is the subjective and active effort of single-parent migrant women. Discussions should continue that those who are free from the spouses of the people can live as practical and public citizens of Korean society.
\end{abstract}

Keywords: Divorced migrant women, self-reliance experience, self-reliance support facility, life-history case study.

\section{Introduction}

In Korea, marriage migrant women emerged as part of a project to solve the marriage problem of rural bachelors in the 1980s. Since the 1990s, the number of married migrant women has increased gradually. In 2009, there were about 33,000 international marriages, accounting for $10 \%$ of the total for the first time (Statistics Korea, 2020). The spread of capitalism at the global level has amplified the feminization of women from underdeveloped countries in Southeast Asia. In this new order, Korea aims to maintain patriarchal gender division through a new marriage system called international marriage. It also aims to solve social reproduction and care labor problems (Kim, 2016). In other words, the migration of migrant marriage women to Korea goes beyond personal life and choice. Their migration can be seen as having a great impact on the socio-cultural context.

Meanwhile, more migrant women are experiencing divorce as much as the increase in marriage. It accounted for 12.6 percent of all divorces in 2011, with an average annual rate of 9 percent (Statistics Korea, 2020). After divorce, most migrant women experience a sense of loss and the burden of self-reliance on a new life. Furthermore, they face limitations on social relations within Korean society. (Lee, 2013). The Seoul Metropolitan Government opened a self-reliance support facility for migrant women in 2010 to help them stand on their own feet. However, it is difficult to find research on women using that area. Therefore, this study aims to examine the experience and meaning of self-reliance support facilities in the context of their life history.

\section{Research method}

\subsection{A life-history case study}

To study life history is to place personal experiences in historical and social contexts. This is a useful way to interpret the meaning of a particular experience and event (Kim, 2012), i.e., personal perspectives that emerge throughout life history reveal a person's special situation. At the same time, it reveals the universal culture to which the individual belongs (Choi, 1999). The migrant women chose to 
go to Korea for patriarchal hierarchies and economic difficulties in their home countries. Behind it is the great trend of womenization of migration. However, marriage immigration also has its own self-determination. Kim (2014) says this uncertainty in married migrant women types them as "internal strangers," not outsiders or insiders. Kim (2014) also points out that Korean society portrays women as immoral subjects who easily choose divorce. Sociocultural influence resides in the lives of migrant women who have experienced marriage and divorce. This cannot be overcome entirely by individual power.

This study aims to capture the voices of migrant women who live in self-reliance support facilities after divorce and prepare for independence. Self-reliance support facilities are the only places in Korea that provide a solid sense of intimacy. Therefore, we would like to examine how the experience here relates to the self-reliance process. Through life-history case study, we will be able to bring their experiences to life more vividly.

\subsection{Research participants}

Five people were selected as research participants in interviews with 80 married migrant women from 2017 to 2019. The criteria for selection were for those who lived in self-reliance support facilities for migrant women after divorce or separation. Only one facility in Seoul is operated to support the independence of migrant women. This place allows single-parent migrant women who have experienced domestic violence and their accompanying children to enter the facility and receive support necessary for self-reliance and self-support. The maximum residence period of the facility is two years. It operates Korean language education, employment education, parent education, and programs for children. The basic information of the participants is shown in Table 1.

Table 1. Participant Information

\begin{tabular}{|c|c|c|c|c|c|c|c|}
\hline No. & Age & $\begin{array}{c}\text { Period of } \\
\text { Residence }\end{array}$ & Status & Origin Country & $\begin{array}{c}\text { Type of } \\
\text { marriage }\end{array}$ & $\begin{array}{c}\text { Form of } \\
\text { marriage }\end{array}$ & $\begin{array}{c}\text { Child } \\
\text { (age) }\end{array}$ \\
\hline 1 & $25 \mathrm{y}$ & $6 y s$ & F-6 & Vietnam & Agency & First/First & $2(3,6 y)$ \\
\hline 2 & $27 y$ & $5 y s$ & F-6 & Vietnam & Introduction & First/Re & $1(4 y)$ \\
\hline 3 & $28 y$ & $7 y s$ & F-6 & Cambodia & Introduction & First/Re & $1(7 y)$ \\
\hline 4 & $37 y$ & $7 y s$ & F-6 & Vietnam & Agency & Re/Re & $1(4 y)$ \\
\hline 5 & $28 y$ & $4 y s$ & F-6 & Vietnam & Agency & First $/ \operatorname{Re}$ & $2(5,3 y)$ \\
\hline
\end{tabular}

The basic information of participants is as follow; their ages range is from 20 s to 30 s and average residence period is 5.8 years. All of them are eligible to stay in F-6 (marriage visas) and have not obtained permanent residency or nationality. The reason for being a marriage visa is that it can be maintained if a Korean spouse divorced due to an attributable reason. Their marriage type is all introductory marriage. Also, if you look at the marriage type, all husbands are remarried except for participant 1. All participants are staying at the facility with their children, and in the case of Participant 1, the first child lives with her ex-husband. Participant 4's ex-marriage children live in Vietnam and want to bring their children with them when she achieves independence.

\section{Research Results}

\subsection{Before divorce}

There are a number of factors affecting gender composition in international migration flows. It is immigration legislation in the country of acceptance, selective foreign labor demand according to gender, and changes in gender relations in the country of origin (Carling, 2005). The conditions of labor migration are tricky in Korea. Therefore, women from Southeast Asia chose to move to marry to make a living for their families. They want to escape gender inequality that exists in their country of origin and dream of a better life through international marriage with hope for Korean life. However, their purpose is not achieved. Because it is a little different from the reason why Korean husband chose international marriage. What Korean husbands wanted was a person who took good care of their ex-married children and worked in accordance with patriarchal culture.

"Work only at home. Do you know why I brought you here? You have to take good care of my parents!" That's what my ex-husband says. Disappointed." -Participant 3

Other participants, except for Participant 4, were divorced due to tangible and intangible violence by their husbands and families. They endured violence and hesitated to divorce their children in order to give them a full home. But eventually, it leads to divorce. Participant 4 still does not know the 
reason for the divorce. However, she seems to think her ex-husband thought that if Participant 4 made her money, she might go back to Vietnam. She only speculates that this was the cause of her divorce.

"I think the Chinese people who lived in the same neighborhood said, "If she makes money, she will go to Vietnam or not live in Korea." That's why my husband believes that, and I think he got divorced right away." -Participant 4

From the perspective of Sassen (2002)'s "feminization of survival," participant 4 has more inevitable economic support relations to Vietnamese family than other participants. Therefore, her can be seen as one of the survival strategies. Korean families want to incorporate her into Korea's paternalistic family relationship. However, due to the hybrid nature of participant 4 , the ex-husband decided that he would not be able to achieve this goal.

\subsection{Transition}

In Korea, there is a tendency to find the basis of migrant women's policy support in terms of Korean wife and Korean mother (Hwang, 2012). From the pre-divorce period, they realize that their rights can be decided by their husbands. In other words, they face the reality that they are not recognized as whole subjects and are treated as others.

"If you get divorced, say, "Go to Vietnam." Said her husband all the time. It wasn't good, but I couldn't do anything. She was afraid to leave the baby. Everyone in my Vietnamese families thought so." - Participant 5

Participant 1 has not shown any experience in this transition period. Unlike other participants, she divorced her husband on her own will, and this seems to have had an impact. Li (2021) categorized migrant women's divorce types into dominant, institution-driven, and non-dominant. The dominant type refers to the case of choosing a divorce by one's will. People of this type have already experienced psychological confusion before the divorce, and that is why after the divorce, a willingness to quickly adapt to the changed life appears. In addition, Participant 1 expressed her own negative emotions in conflict situations during her marriage, and took these expressions for granted. In other words, it can be said that she has a strong self-esteem. This personal disposition also seems to have an effect on the transitional experience.

"I was angry and threw it away. I mean, when I'm angry, I hate him so much. I don't want to see it, and I think it's a natural feeling." - Participant 1

\subsection{Self-reliance period}

Divorce causes migrant women to lose their spouse status of the people. But this is not necessarily hopeless. Rather, it is a driving force for self-reliance as a subject with a new purpose in a new environment. Li (2021) mentioned three things that affect the changes and growth since becoming a single parent. They are 'religious beliefs,' 'social support,' and 'personal efforts.' This study identified the interaction between 'social support' and 'personal effort'. Social support is more important than anything else to move toward self-reliance. 'Support facilities' become a place to provide strong social support to them (Im, 2016). Social support can be formed by all forms of interaction with others (Cobb, 1976), and this interaction is the driving force behind 'personal effort'.

"The child and I tried not to understand each other. Whenever I had a hard time, I yelled at my child. My relationship with my child continued to deteriorate, and my child was stressed out. So he stood up and peed. He peed and looked at me, and it made me so angry. I didn't know what to do, and I didn't know how to raise my child. I was educated here, and now I can understand each other with my child." Participant 2

Through programs provided at support facilities, it helps to restore relationships with children and to build psychological stability to raise children on their own. In addition, the private relationship network formed here plays a role in taking care of and healing each other's pain.

"I was also stressed at first. But because I studied hard, I passed. Now I can talk to other people too. "If you work a little hard, you can do everything." It's all stressed out at first. tiring." -Participant 5

Behind the marriage process of immigrant women, there is a provisional agreement that they must comply with the new hierarchical order of patriarchy in Korea from patriarchy in their home country 
and take responsibility for the livelihood of their home country. This is called Modus Vivendi (Kim, 2016). However, the divorce made Modus Vivendi no longer effective. The provisional agreement is abolished, and several aspects emerge in the process of entering into a new agreement. Participant 1's divorce provides an opportunity to better understand the position of the husband and each other, and Participant 2 hides the fact of the divorce from his parents. Participant 3, 4, and 5 are also supported by their origin family about divorce. In addition, they get away from the difficult situation they had to come to Korea, receive vocational education in an independent facility, and recall their forgotten dreams.

"My mom says she's sorry now. At that time, she was so upset that she could not support her daughter's heart. She now says 'my daughter is doing well' and she comforts me a lot." -Participant 3

"(Beauty) I've liked it since I was young. My parents didn't let me because we didn't have enough money. (omitted). I didn't know I was this good." - Participant 1

Korean society is a patriarchal society that values paternal lineage. In this atmosphere, marriage immigrant women are forced to act as mothers, daughters-in-law, and wives (Kim, 2016). The Multicultural Family Support Act in Korea only recognizes families composed of Korean spouses and marriage immigrants as multicultural families. In addition, multicultural policies are dealt with only in terms of family maintenance and child rearing of marriage immigrants. Therefore, after divorce, women feel fear that they cannot be reborn as subjects with "my name". This is because the legal authority of the husband has been recognized by the country. Nevertheless, they fully recover their name through support facilities and prepares to move forward as a subject in a new position.

"I like calling my name the most. I'm getting bigger and more thoughtful here. If I live with my husband, I can't learn Korean and I have to stay at home. But I can go to the government office and make documents. I'm proud to be able to do anything on my own." - Participant 2

\section{Conclusions and discussions}

This study intended to address the self-reliance experience of divorced migrant women in a socio-cultural context. Migrant women regarded migration to Korea as an escape from poverty and patriarchal hierarchy in their home countries. However, they face divorce due to unexpected Korean life and tangible and intangible violence by their husbands and families. Divorce places them in a different socio-cultural position than marriage. In the process, self-reliance support facilities supported to stand on their own feet within the changed social position. It takes care of psychological difficulties and helps raise children. It comforts each other through self-help gatherings and helps find myself that I haven't found in my home country.

Participants' marriage migration process did not deviate from the ideology of "feminization of migration." However, after the divorce, they want to gain strong social support through self-reliance support facilities and become independent members. In the post-divorce process of poverty, 'heteronomous exclusion' and 'voluntary self-exclusion' appear in social relationships (Kim, 2012). It was confirmed that self-reliance support facilities are the driving force for migrant women to escape from voluntary self-exclusion. Practical discussions should be carried out so that migrant women, not the spouses of the people, can overcome the heteronomous exclusion in Korean society. In addition, it suggests in-depth follow-up research on the self-reliance experience of migrant women by examining the post-retirement process of self-reliance support facilities.

\section{References}

Carling, J. (2005). Gender dimension of International Migration. Global Commission on International Migration (GCIM). Global Migration Perspectives. 35.

Choi, Y. S. (1999). Collecting Qualitative Data. Anthropology of education, 2(2), 1-22.

Cobb, S. (1976). Social support as a moderator of life stress, Psychosomatic medicine, 38(5), 61-82.

Hwang, J.-M. (2012). Positioning Migrant Mothers in a Multicultural Society: Realities, Discourse, and New Perspectives in Korea. The Journal of Asian Women, 51(2),03-142.

Im, G. B. (2016). The Effect of Social Support of Battered Immigrant Women on Willingness to Become Self-Reliant: Focusing on Mediating Effect of Social Adjustment and Moderating Effect of Social Exclusion (Doctoral dissertation, Kyonggi University, South Korea). Retrieved from http://www.riss.kr/link?id=T14201828 
Kim, E. J. (2016). Married Immigrant Women's Life and Global Care Work Context (Doctoral dissertation, Chung-Ang University, South Korea). Retrieved from http://www.riss.kr/link?id=T14170685

Kim, J. H. (2012). Impoverishment of Unprivileged Divorcees: Their Social Exclusion Experience in family and Labor market. Korean Journal of Family Social Work, 38, 69-102.

Kim, S. E. (2012). Life History of the Dismissed Journalists: Focused on Dong-A Committee for Free Press. Korean Journal of Journalism \& Communication Studies, 56(3), 292-319.

Kim, S. N. (2014). Precarious Life and Life Mapping Strategies in Migrant Women's Experiences of Marriage and Divorce in Korea. Journal of Korean Women's Studies, 30(4), 189-231.

Lee, H. J. (2013). A Study on Child Care Work and Lives of Immigrant Single Moms. Journals of Women's Studies. 23(1). 171-214.

Li, C. (2021). A Life-historical Narrative Study on the Growth Experiences of Single-parent Migrant Women (Doctoral dissertation, Inha University, South Korea). Retrieved from http://www.riss.kr/link?id=T15773818

Sassen, S. (2002). Global Cities and Survival Circuits. In B. Erenreich and A.R. Hochschild (eds.). Global Woman: Nannies, Maid, and Sex Workers in the New Economy. New York: Metropolitan Books.

Statistics Korea (2020). Multicultural demographics. Retrieved January 10, 2021, from http://kostat.go.kr/assist/synap/preview/skin/doc.html?fn=synapview385962_1\&rs=/assist/synap/pr eview 


\title{
DIGITAL STORYTELLING AND LIFELONG LEARNING EDUCATION IN INFORMAL CONTEXTS: THE MEMEX PROJECT
}

\author{
Elisabetta Falchetti, Pascuala Migone, Cristina Da Milano, \& Maria Francesca Guida \\ $\operatorname{ECCOM}$ (Italy)
}

\begin{abstract}
This contribution intends to present the design, methodology and first results of MEMEX, a 3-year project (2019-2022) funded by the European programme Horizon2020, aimed at promoting social cohesion through collaborative, heritage-related tools that provide inclusive access to tangible and intangible cultural heritage $(\mathrm{CH})$ and, at the same time, facilitates encounters, discussions and interactions between communities at risk of social exclusion. Cultural participation is conceived as a way to engage communities in lifelong learning processes taking place in informal contexts, aiming at promoting social inclusion and cohesion. To achieve these goals, MEMEX uses innovative ICT tools that provide a new paradigm for interaction with heritage through Digital Storytelling (DS), weaving heritage-related memories and experiences of the participating communities with the physical places/objects that surround them. The project encompasses the ICT tools and the use of DS in the framework of Audience Development (AD), defined as a strategic and dynamic process enabling cultural organisations to place audiences at the centre of their action. The use of DS applied to $\mathrm{CH}$ is highly related to lifelong learning processes, since it provides knowledge, understanding, awareness, engagement and interest, enjoyment and creativity. The evaluation of a number of DS produced by migrant women participating in a MEMEX pilot project in Barcelona confirms the validity and soundness of the methodology and the power of DS to engage in cultural experiences.
\end{abstract}

Keywords: Socio-cultural inclusion, participation, digital storytelling, cultural heritage, pilot project.

\section{Introduction}

Culture is recognized as a natural feature of human beings (and not only). The Article 27 of the Universal Declaration of Human Rights (1948) states that "everyone has the right freely to participate in the cultural life of the community, to enjoy the arts and to share in scientific advancement and its benefits". In the Article 5 of the 2001 UNESCO Declaration on Cultural Diversity, this concept of "right" is emphasized and defined as the right of access to, participation in and enjoyment of culture for individuals and communities to know, understand, visit, make use of, maintain, exchange and develop cultural heritage $(\mathrm{CH})$ and cultural expressions, as well as to benefit from the cultural heritage and cultural expressions of others. In the Articles 4 and 5 of the same Declaration on Cultural Diversity, it is recognized that the defence of cultural rights is inseparable from the achievement of human rights and fundamental freedoms, in particular the rights of women, minorities and indigenous peoples. The right to culture is complemented by the freedom of expression and cultural diversity, information and education; and is conditioned by opportunities and chances of access and participation. The cultural access and enjoyment are a matter of human dignity, equality, individual and collective identity, participation in democratic and civil societies. Thus, education, cultural access and participation are among the key/vital challenges of the postmodern societies and particularly among the values and policies of the EU.

In the last decades, both material and immaterial $\mathrm{CH}$ has been understood as a strategic tool, an opportunity to promote and ensure the right to knowledge, to quality education; to encourage the expression of individual and collective potentialities, skills and characteristics; to foster civil-social participation and inclusion; and to build identities and develop a sense of belonging to a community. The European strategy and vision is clear in its cultural goals and guidelines: the Faro Convention (Council of Europe, 2005) recognizes that everyone, individually or collectively, has the right to benefit from $\mathrm{CH}$ and to contribute towards its enrichment rights; the relationship between the conservation and sustainable use of $\mathrm{CH}$ and human development and quality of life ; the role of $\mathrm{CH}$ in the construction of a peaceful and democratic society, in processes of sustainable development and the promotion of cultural diversity and The Member 
States be committed to improve the access to $\mathrm{CH}$, namely for young and disadvantaged people, in order to the expand their awareness about its value, the need of its conservation and its individual and social benefits. In the recent document signed by the Organization for Economic Co-operation And Development (OECD) and the International Council of Museums (ICOM) "Culture and local development. Maximizing the impact" (2019), social inclusion through $\mathrm{CH}$ is a strategic theme, as a means to change people's perception about their needs and problems and foster them to be active in improving the quality of their lives; increase their individual wellbeing, with special attention towards marginalized or excluded people; raise their self-esteem, empowering skills and competencies for professional pathways; and strengthening social cohesion. Other EU Declarations and Documents reaffirm the link between the use of $\mathrm{CH}$, access, participation and inclusion of marginalized people. These statements are reinforced by the first of the five pillars identified by the "European Framework for Action on Cultural Heritage" (2018), which is "Cultural Heritage for an inclusive Europe, participation and access for all": it recommends to break up whatsoever barrier (physical, educational, economic, social, sensorial, digital, etc.) to cultural access. Strategies to overcome barriers and obstacles are fundamental themes for Audience Development (AD) projects aiming at promoting cultural access, engagement and participation of different people, as stated by the "Study on Audience Development" published by the European Commission in 2015.

In this scenario, the MEMEX project (Memories and Experiences for inclusive digital storytelling; https://memexproject.eu/) was born - thanks to a funding by the Horizon2020 programme -, from the collaboration of 8 partners, with socio-cultural and technological profiles and expertise ${ }^{1}$. The communities chosen to participate in the MEMEX pilot projects are: migrant women in Barcelona; inhabitants of the 19th district of Paris; and first, second and third generation Portuguese migrants living in Lisbon, all communities at risk of cultural exclusion. During the pilot projects, Digital Storytelling (DS) was employed to work with the participants, starting from local expressions of $\mathrm{CH}$ in each place. This paper aims at opening a debate about the theoretical frameworks of MEMEX and its methodologies, focusing on the first results of the pilot activities carried out in Barcelona.

\section{Objectives and theoretical framework}

MEMEX's primary objectives consist in experimenting the synergic power/impact of digital technologies (ICT), $\mathrm{CH}$ and storytelling for the cultural and social inclusion of potentially marginalized people, through a) three pilot projects actively and creatively engaging the above mentioned targets in the implementation of personal storytelling inspired by local $\mathrm{CH}$, and $\mathrm{b}$ ) testing the impact of a smartphone App offering an AR experience co-designed and based on DS. Currently, two of the pilot projects are still ongoing and the Barcelona one completed the first phase of implementation.

MEMEX objectives and methodologies are based on some assumptions and theoretical frameworks hereafter presented:

1) Cultural participation impacts positively on social cohesion and inclusion; 2) Digital Technologies (ICT Tools) can improve cultural and social inclusion of potentially marginalized people, excluded from cultural benefits (cultural accessibility and participation); or citizens less used to take part in $\mathrm{CH}$ activities and enjoyment; 3) ICT Tools can contribute to audience development and engagement in cultural experiences; 4) Storytelling is considered a powerful and universal form of communication, a tool for personal and social empowerment and intercultural dialogue; 5) $\mathrm{CH}$ is a special field/horizon for social comprehension, inclusion, intercultural dialogue and individual and social empowerment.

These assumptions have been strategically based and developed on the following frameworks and guidelines.

All these theoretical assumptions and frameworks are strictly related to the understanding and acknowledgement of Audience Development (AD) defined as a strategic and dynamic process enabling cultural organizations to place audiences (understood not only as visitors, but also as individuals and communities) - at the centre of their action. This approach is aligned with the already mentioned Faro Convention (2005) on the Value of Cultural Heritage for Society, by emphasizing the active role of communities in re-interpreting existing heritage as well as in co-creating plural meanings of it. There are many strategies and tools to pursue different audience goals, and they can be classified in many different ways. For the purposes of MEMEX, four key action areas that represent the main assets for AD strategies have been identified:

Place refers to those projects and cultural organisations strategies strongly relying on the "place factor", creating links and building relationships based on a physical site (e.g. interventions on space design, brand identity, etc.) and aimed to foster ownership towards a cultural and physical space. In the MEMEX

${ }^{1}$ Istituto Italiano di Tecnologia (IIT) (project leader, Italy), Interactive Technologies Institute (ITI, Portugal), NOHO Limited (Ireland), Ernst \& Young Italia (Italy), Michale Culture-Dédale (France), Interarts (Spain), ECCOM (Italy), Mapas das Ideias (Portugal). 
framework, place is fundamental in the participants' lives and experiences, but also for their sense of belonging and inclusion, in the cities they migrate to some material or immaterial elements of the place can be especially significant and associated to $\mathrm{CH}$.

Digital refers to those projects and cultural organisations strategies strongly relying on the "digital factor", as a key to reach audiences and foster engagement. In the MEMEX framework, the working group chose DS as the adequate strategy to foster the participants' engagement, creativity and empowerment.

Capacity building refers to those projects and cultural organisations strategies strongly relying on the "people factor". The empowerment of the staff and the development of their skills, competences and leadership are a key factor of different experiences, recognizing the need for change inside the organisation to pursue alterations in the audience behaviour. In the context of MEMEX, ECCOM led a professional training workshop for social partners and their local stakeholders, aimed at improving their skills and attitudes towards narrative strategies and their technical expertise in DS to implement the methodology and to engage the participants in the process of producing their DS. As part of this training experience, the partners realized their own DS.

Co-creation refers to those projects and cultural organization strategies strongly relying on the "participatory factor". These are also particularly interesting in terms of impacts on the organisations. In MEMEX, participation/co-creation mainly refers to the working group and consequently to the other participants; the storytelling option both for the mediators and the other participants is connected to its power of engaging, of encouraging participation, enhancing motivation, fostering personal believes and emotions, stimulating imagination and creativity.

Storytelling - and namely digital storytelling (DS) - lies at the heart of the MEMEX project. Storytelling is a widespread communication practice, whose origins, motivations and uses are rooted in the mental-cultural complexity of human beings. It is therefore of great interest for a variety of disciplines, both at a theoretical and at a practical level, aiming to understand how and why it became so pervasive, what are its mechanisms and its educational, social and even therapeutic role. All human languages and cultural-communication codes include storytelling. It is typical of both oral/informal and formal cultures, artistic expressions included. It therefore unfolds as a common expressive feature of all human beings, whose mind gather and interpret sensory information, events and emotions, and organizes them in the shape of a story. All human beings, everywhere and in every time, have used storytelling. Informally, we tell stories virtually every moment of our daily lives: our minds are organised to perform this function. Stories (imagined, told) have a great individual and social value, they play a fundamental role in language learning, in constructing and exchanging knowledge, in shaping educational processes, in sharing moral and ethical rules, values and traditions. They make a contribution to shaping or reinforcing personal identity and self-esteem; all individuals, in fact, define and recognise themselves in a process of "narrative creation of the self" (Bruner, 2003), through both personal stories and stories about their families, communities and cultures of origin. The shaping of an individual identity also makes it possible to understand others and helps creating or consolidating social identities and shared cultures. In turn, these shared, community cultures enrich narrative thinking with their stories, traditions, languages and educational practices, thus building the symbolic, cognitive and expressive features of the different peoples in different times and place (for a wider treatment of Storytelling and DS see Da Milano and Falchetti, 2014). A fundamental role in the human communication, education, knowledge construction and learning, creativity and imagination and intercultural dialogue, social cohesion and the definition of individual and collective identities is recognized to narration and storytelling (Bruner, 2003; Demetrio, 1996, 2012; Graesser \& Ottati, 1995; Falchetti, 2014). This communication shape is accessible also to people not formally educated. Moreover, storytelling engages both storytellers and audiences/listeners in a cognitive and emotional-empathetic relationship. As a consequence, the postmodern shapes of formal and informal communication and education prefer storytelling.

DS is a short digital story/tale with texts, images, videos and sound effects which combines the traditional narrative power with the creative resources of the digital tools. DS requires, harmonizes and promotes multiple skills: disciplinary, artistic, musical, logic, technological competencies. It is cognitively and emotionally engaging and fosters multiple intelligences. DS is considered a valid tool of social, democratic and transformative processes; it is effective and manageable also by not formally educated people or by subjects at risk of marginalization or exclusion (Lambert, 2013). For these reasons, DS is mostly recommended among the digital resources for all the socio-cultural-educational (but also therapeutic) interventions. Its role in upholding human rights is today acknowledged. The partners experimented the inclusive power of DS with many potentially marginalized audiences/people (see the Diamond project in Da MiIano and Falchetti, 2014; Falchetti and Guida, 2019).

DS constitutes an invaluable strategy for communication, mediation and valorisation of $\mathrm{CH}$ (see the programs "We are Mont'e Prama", aimed at enhancing Sardinian pre-historical sculptures; and Live Museum Live Change for the Roman "Mercati di Traiano"; https://monteprama.it/we-are-monte-prama/; 
http://www.pav-it.eu/live-museum-live-change). Many museums in the world are exploiting this tool for operators' training, for visitors' inclusion and participation, and the interpretation of the collections. In MEMEX, the DS implementation has been conceived as a tool and an opportunity to give voice to the participants, to promote personal expression and creativity, cultural and social empowerment, promotion of skills and competencies. $\mathrm{CH}$ is the field within which their creativity, memories, emotions, beliefs, metaphors, social representations emerge and develop.

\section{Methodology}

ECCOM elaborated a 32-question preliminary questionnaire, aimed at providing an initial overview of the perceptions of the target of interest -migrant women at risk of socio-cultural exclusion in Barcelona - about $\mathrm{CH}$ and cultural participation, before the implementation of the pilot project. The questionnaire was translated into Spanish and applied in person by MEMEX Spanish partner, Interarts Foundation. 22 questionnaires were completed in two sessions between July and August 2020, coded and handed to ECCOM for analysis. All respondents were migrant women living in Barcelona. They are in the 30-59 age range, and arrived in Spain between 2016 and 2019. The vast majority of them come from different Latin American countries, while 2 from Nigeria and 1 from Italy. Consequently, most of them speak Spanish as a first language, and 6 of them speak also a second one (mainly English). Half of them completed high secondary education and most of them were, at the time of the survey, unemployed and actively looking for a job. $82 \%$ of the respondents had a smartphone, device used for the MEMEX app, and $91 \%$ had access to internet on their smartphones and/or at home. $64 \%$ of them declared a medium to a high level of skills with technology and electronics. The great majority of the respondents understands $\mathrm{CH}$ as both tangible and intangible, referring to it as History and Memory, Tradition, Identity, Architecture and Community. When asked about what they considered to be the main expressions of their own $\mathrm{CH} /$ origin, they mainly mentioned heritage buildings, archaeological sites, examples of their gastronomies, music and dance. Only $23 \%$ of the respondents feel they can freely express their own $\mathrm{CH}$ in Barcelona. Between $77 \%$ and $82 \%$ of them agree with the idea that diverse cultural groups should be able to maintain their customs and traditions within host societies; that cultural exchanges between different cultures and groups are important to learn from each other and to develop more understanding societies. 10 of the women which completed the preliminary questionnaire actively took part in the pilot project for the implementation of the DS. The pilot activities were led by Interarts Foundation with the collaboration of 2 local stakeholders: LaBonne and Sindillar-Sindihogar. 3 meetings between the facilitators and migrant women were organized online and at LaBonne cultural center to present the MEMEX objectives, explain the goals and technical approach of DS and start a dialogue about CH. 4 walks were organized to inspire narrations, foster emotion and feelings, gather impressions, traces and images. During 4 sessions, each participant created and edited their own DS. To date, 8 DS have been finalised and evaluated by ECCOM, as described I the following section.

\section{Evaluation and discussion}

The 8 DS realized by the migrant women were analysed following as indicators the 7 points identified by Lambert (2002) as fundamental points of DS: Points of view, Dramatic questions, Emotional contents, The gift of your voice, The power of soundtrack, Economy, Pacing of narration; as well as the purpose of the story and contents and some technical approaches, systematized in four main dimensions: style, content, personal/emotional elements and technical quality. All the stories are coherent from the point of view of contents and purposes; they narrate about the women' lives, memories, relationships with past and present times, original culture and traditions and about feelings, perceptions and disposition towards their new lives in Barcelona. The personal emotional aspects prevail in all the stories; the city places, the events, the life habits, everything recalls the women' experience of migration, the sense of belonging to their home countries, the deep bond with their traditions, and for some of them, a sense of disorientation about themselves and their "double" personality. Some of them also express a sort of gratitude for the new opportunity provided and describe some special moments of mental, emotional and spiritual engagement in certain places of the city they migrated to. The sense of $\mathrm{CH}$ is linked to a work opportunity or to the places and events that trigger those special moments.

Some DS reveal dramatic questions of migration history or past injustice, that remain in the mind, emotions and memories of these women.

All the storytellers narrate their stories with an engaging, strong and evocative, charming tone of voice, that determines also the involving pace of narration; no uncertainty or hesitation emerges from their voices. They appear pleased to have this opportunity to express themselves without limits and constraints; probably, this opportunity promotes their self-esteem, their imagination and creativity and reinforce social bonds by the sharing of experiences and feelings and the awareness of the interest shown by the project partners. Sounds and music are coherent with the pace, the contents and questions of narrations. The video 
technic has been preferred by all the women; many technical aspects are lacking and weak, but this problem do not decrease the value and effect of the narrative performance. Altogether, these special storytellers reveal a well-developed narrative inclination and skills, but the project strategy of privileging storytelling is confirmed as valid and engaging with special audiences, namely migrants or other potentially excluded people. DS is verified as a tool that is fit to engage, to promote participation and give opportunity to people belonging to different cultures, backgrounds and imaginary horizons to express, for its focus/point of strength on the personal storytelling/narration (by texts, images, voices, music, etc.) and its easiness of digital format/realization. The MEMEX strategy based on DS and CH therefore can have a great/promising value in terms not only of $\mathrm{AD}$, but also of cohesion, understanding, intercultural, intergenerational and inter-human trust. Yet by these preliminary results this strategy appears to be an appropriate relational form to generate a climate of real dialogue, democracy, promotion of different personalities, experiences and potential skills. Beyond the quantifiable and evident results the contribution of the "MEMEX Stories" can be considered an enrichment of the diverse $\mathrm{CH}$ narrations, of intercultural dialogue and community cohesion. MEMEX Stories can contribute to the construction of cultural and social capital.

A brief SWAT analysis applied to this pilot highlights as points of Strength: the potentialities of narration (cognitive and emotional involvement, empathic relationships, universality of the framework, inclusive inter-cultural and social value), increased by digital resources and by the $\mathrm{CH}$ environment/context; as point of Weakness: the possible lack of training/practice in the digital field; as Opportunities: the enhancement of accessibility and inclusion for vulnerable and marginalized people, mediation in the intercultural dialogue, production of new $\mathrm{CH}$ storytelling, positive impact on basic, transversal and soft skills; as Threats: the hard and demanding task for the participants - both cultural operators and the "disadvantaged" storytellers - in the DS implementation.

\section{References}

Allen, T.F.H. \& Giampietro, M. (2006). Narratives and transdisciplines for a post-industrial world. System Research and Behavioral Science, 23: pp. 595-615.

Bollo, A., Da Milano, C., Gariboldi, A. \& Torch, C. (2017). Study on Audience Development - How to place audiences at the centre of cultural organisations [online]. Brussels, Belgium: European Commission. Retrieved May 21, 2021 from: http://engageaudiences.eu/files/2017/04/Final-reportNC-01-16-644-EN-N.pdf.

Bruner, J. (2003). Making Stories. Law, Literature, Life. Harvard: Harvard University Press.

Commission staff working document (2018). Retrieved May 21, 2021 from: https:/ec.europa.eu/culture/sites/culture/files/library/documents/staff-working-documenteuropean-agenda-culture-2018.pdf

Council of Europe (2005). Convention on the Value of Cultural Heritage for Society (Faro Convention, 2005). Retrieved May 21, 2021 from: https://www.coe.int/en/web/conventions/full-list//conventions/treaty/199

Da Milano, C. \& Falchetti, E. (2014). Stories for Museums, Museums for Stories. Nepi: Vetrani Editore.

Da Milano, C. (2013). Museums and New technologies: the case of digital storytelling. Transfert, Journal semestriel de la formation pédagogique des enseignants-stagiares du secondaire, Universitè du Luxembourg, Automne 2013, p. 17

Demetrio, D. (1996). Raccontarsi. L'autobiografia come cura di sé. Raffaello Cortina Ed., Milano, p. 230.

Demetrio, D. (2012). Educare è narrare. Mimesis Ed., Milano, pp. 320.

Falchetti, E. \& Guida, M.F. (2019). MUA - Musei Accoglienti. Un modello di Governance per l'intercultura. In: Dal Lago A., Falchetti E. (eds), 2019. I musei scientifici nell'anno europeo del patrimonio. Museologia Scientifica Memorie, vol. 20: pp. 104-107

Falchetti, E. (2014). Dal pensiero narrativo allo storytelling digitale. In Da Milano C. e Falchetti E., Stories for Museums, Museums for Stories. Vetrani Ed., pp. 35-48.

Graesser, A. C. \& Ottati, V. (1995). Why Stories? Some evidence, questions, and challenges. Knowledge and Memory: The Real Story. In: Wyer R.S. (ed). Lawrence Erlbaum Associates, Hillsdale, NJ, pp. 121-132.

Lambert, J. (2002). Digital Storytelling: Capturing Lives Creating Community. Routledge.

Lambert, J. (2013). Digital Storytelling. Capturing Lives. Creating Community. Story Center, 5TH Edition, p. 224.

OECD, ICOM (2019). Culture and local development. Maximising the impact. Retrieved May 21, 2021 from: https://icom.museum/wp-content/uploads/2019/08/ICOM-OECD-GUIDE_EN_FINAL.pdf 


\title{
AN EXPLORATORY STUDY ON THE RESEARCH TENDENCY OF SCHOOL COUNSELORS IN SOUTH KOREA
}

\author{
Sumin Kim, \& YoungSoon Kim \\ Department of Multicultural Education, University (South Korea)
}

\begin{abstract}
This study aimed to examine a research tendency through Master's and Doctoral dissertation in South Korea related to school counselors. In this study, school counselors were used in terms that included full-time and contractual counselors. School counselors are teachers who specialize in understanding students' daily psychological counseling, problem behavior and maladaptive counseling and establishing a prevention support system of fundamental reason of problem behavior for students. This is because their tasks required in school are similar. They were deployed to unit schools after Wee Project implemented in 2007 to ensure that students and all students experiencing poor learning and school maladaptation for having a happy school life. This study aimed to lay the foundation for improving and developing policies for improving the welfare and professionalism of school counselors, focusing on the subject of the degree thesis related to school counselors. This study conducted an exploratory study based on the year of publication and topics of the dissertation based on key words extracted from the data. The dissertations were published from 2010 to 2021 and were collected through Riss, a domestic database website in South Korea. This study focused on the frequency of emergence and Word Cloud which shows research tendency based on the year of publication analyzed by the frequency of emergency, title of the dissertation, and key words in abstract of the dissertation extracted from a file in MS Excel from the domestic database homepage. The analysis results of this study are as follows. First, the role and awareness of professional counseling teachers and Wee classes are required. Second, research was conducted to develop the capabilities of school counselors teachers working in the Wee class.it will serve as a foundation for improving professionalism, leading to the protection of ethics as a counselor working in the Wee class and ensuring the rights and welfare of counselors. In order to improve counseling capabilities, supervision and a certain amount of counseling practice are required in the process of training school counselors.
\end{abstract}

Keywords: Dissertation, exploratory study, school counselor, teacher.

\section{Introduction}

School counselors experience problems in qualification and training courses, unclear regulations on roles, problems with awareness and treatment, and problems with support systems due to lack of legal grounds (Kim, 2013). Research on professional counselors has been carried out steadily since the introduction of the system, and it has been actively conducted since 2007, when professional counselors began to be appointed and deployed (Nam, Park ,2017). Nam and Park (2017) analyzed research trends focusing on academic papers and degree papers published in 2005-2017 for professional counselors. In addition to the research topic, trends were analyzed using research methods and statistical analysis methods as the framework for analysis. However, Nam and Park (2017) did not look at research trends since 2017 because a total of 15 dissertations were conducted between 2018-2021. The researcher expects to analyze the results based on the 2010-2020 academic thesis and include the results of the study differentiated from Nam and Park (2017).

This work forms an analytical framework based on the research of Ahn (2018) and Kim (2018) who analyzed the network based on Word Cloud techniques. Word Cloud is applied to clusters, summaries, and information extraction of documents and is used as a method of content analysis (Park, Kim, 2021). This provides an intuitive understanding of the flow as it provides an economical and effective summary of the words in the content (Seo, 2015). Analysis using Word Cloud improves understanding of the phenomenon because key words that exhibit high frequency are visible (Kim, 2018). This study formed Ahn (2018) using Word Cloud as an analytical framework for reference. We wanted to look at changes in Ahn (2018) by showing the frequency of research trends by numerically or visually, focusing on key words 
that have emerged frequently by borrowing from Word Cloud analysis methods. Finally, this research was intended to identify research trends through the analysis based on Word Cloud among network analysis methods as an analysis frame.

The following research questions were selected: First, what is the current status and trend of school counselors' research? Second, how about Word Cloud analysis between key words in school counselor research published from 2010 to 2021? In this study, through Word Cloud analysis, we analyze the research trends related to school counselors by year to identify changes in the overall trend flow. Based on Word Cloud analysis results, this study aims to explore the current status of school counseling in Korea compared to the school counseling system in the United States and Japan.

\section{Theoretical background}

\subsection{School counselors and School counseling system}

Wee project is an integrated support service network that supports students to have a healthy and enjoyable school life in conjunction with schools, education offices, and communities. In the Wee Project, students in crisis are the main targets, but they are also applying to ordinary students (Kim, 2012). The Wee class was named after emphasizing emotional and educational aspects to escape the negative image of the school counseling center and consisted of a space tailored to the student's emotions and culture. Through the Wee project, a school counseling office called Wee Class was implemented, which was led by the state to strengthen teachers' ability to guide students' lives and improve school counseling rooms. After the Wee project was implemented, most school counselors in Korea have been working in Wee classes. In this study, school counselors were defined as terms that included professional counselors and professional counselors. There are differences in their employment methods, but the work at the school site is similar.

Korea's school counseling system was established under local education offices and the Ministry of Education, supplemented by the advantages of the U.S. school counseling system and Japan's school counseling system. The duties and conditions of school counselors in the United States and Japanese school counselors are different. According to the Korean school counseling system, the conditions for appointment for professional counselors are met by obtaining first- and second-degree certificates for professional counselors through completion of teaching courses. Korean school counselors were appointed as teachers of comparison department. According to the U.S. school counseling system, most states selected qualified teachers as school counselors in the 1970 s, but most states do not regulate teachers' qualifications and careers (ASAC, 2007; Lee, Oh, Seo, 2007 recited). In most cases, a master's degree is required to become a professional school counselor. In the case of professional school counselors in the United States, not only counseling and education, but also supervisory and management roles in each school shall be performed. According to Japan's requirements for school counselors, those who have completed graduate or Master's degree, have experience in psychological clinical or counseling for children, and those who graduate from the university require more experience (Kim, 2009). In fact, more than 90 percent of school counselors owned clinical psychologists (Park, 2005). Japan's school counseling system is similar to the U.S. school counseling system, in which private institutions unite to grant certain qualified people clinical psychologists to meet the requirements for school counselors.

\section{Research methods}

The analytical paper in this study is limited to the key words in the paper green, which reflect the core topics of the paper most intensively, and the words in the paper's topic. It focused on the thesis on school counselors published from 2010 to 2021. In order to extract analysis data, researchers searched RISS, a database operated by the Korea Educational Research and Information Institute, under the theme of "school counselor", "school professional counselor" and "professional counselor" in early March 2021. The researcher selected the master's degree papers as analysis papers because he believed that they included trends in the research topics that were spotlighted in the field of research related to school counselors. The researcher excluded academic papers from analysis papers because he believed that academic papers would sometimes be studied on the same subject as academic papers. A total of 510 "school counselors" were searched, 1,306 "school professional counselors" were searched, and 392 "professional counselors" were searched. Among the discovered dissertations, those that lack relevance to the subject were removed from the analytical thesis. Among the dissertations adopted as analytical papers, 27 are Master's dissertations and 23 are Doctoral dissertations are considered. In order to explore the research topic of the dissertation, key words recorded in the title and abstract of the thesis were extracted and analyzed. 
Key words describing the research methodology were removed because they did not conform to the purpose of this research analysis. Key words such as 'school counselor', 'task', 'research', 'paper', 'exploration' and 'analysis' were excluded. The researcher judged that these words could have an effect on eliciting key analysis contents in the process of analyzing key words close to this research topic.

\section{Results}

Figure 1. Word Cloud of degree papers published in 2010, 2012.

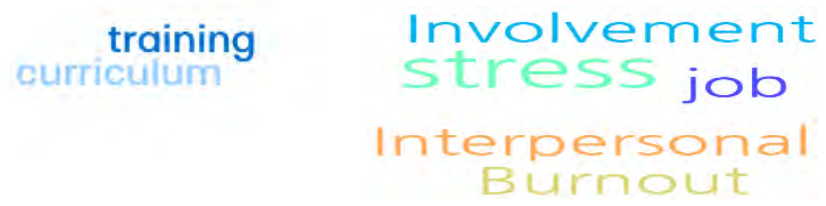

In 2010, research was conducted to develop a curriculum organization system to foster professional counselors. It was intended to develop a compilation system through the establishment of educational goals, selection of educational contents, and the stage of the organization of educational contents. In 2012, research was conducted to ultimately improve job involvement by analyzing the relationship between interpersonal stress and burnout and job involvement experienced by school counselors. It emphasized the need for human environment and related policies, support, and training to improve the interpersonal relationship of counselors.

Figure 2. Word Cloud of degree papers published in 2013, 2014.
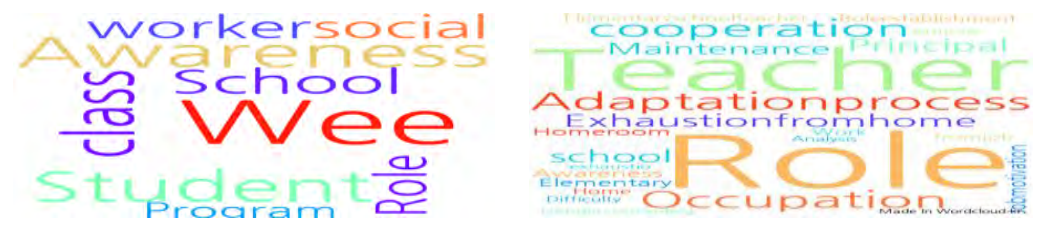

In 2013, students and professional counselors conducted research on the Wee Class program. Proposals are made to ultimately improve the awareness of counseling rooms and counseling programs through analysis. Research was conducted to organize the roles of school counselors and school social workers. Chaos existed because the role between school counselors and school social workers was not clearly established in the school. This research wanted to compare students and professional counselors' perceptions of Wee class programs to examine the contribution and continuity of Wee class programs in schools and come up with measures to promote them.

Figure 3. Word Cloud of degree papers published in 2015, 2016.
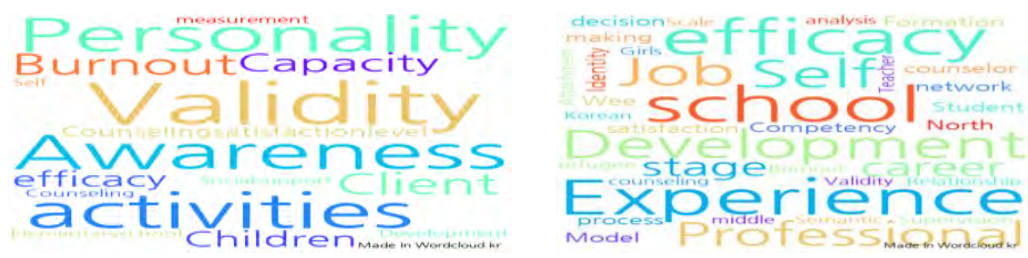

In 2015, research was conducted to develop and rationalize measures to explore the capabilities of professional counselors. It was intended to improve the understanding of capabilities by developing questions about the job performance of professional counselors. Among the personal characteristics of school counselors, the relationship between personal characteristic of counselors and the satisfaction level of counseling by counselors and clients was examined. Ultimately, the government wanted to develop measures for the efficacy of professional counselors. It was hoped that the process of forming professional identity of professional counselors and its main factors would be the foundation of programs for the development of current or prospective professional counselors. Research was conducted to develop supervision models according to the development stage of professional counselors. An analysis was conducted on the effect of school counselors' satisfaction with their duties on self-efficacy and exhaustion. 
Figure 4. Word Cloud of degree papers published in 2017,2018.
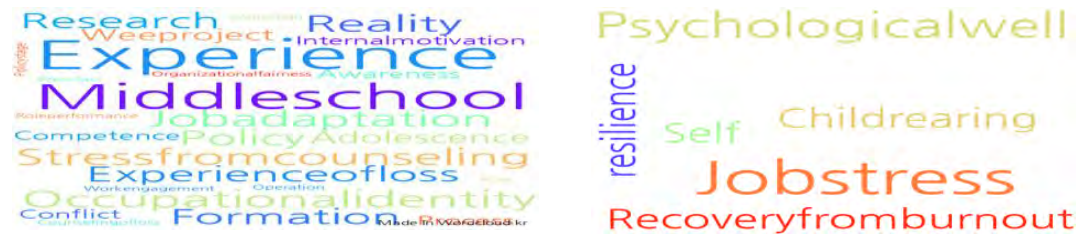

In 2017 , the government tried to build a theory on the process of forming identity through the process of forming a professional identity of professional counselors working in middle school. It was found that school counselors had difficulties experiencing from counseling experiences of loss and experiences of losing adolescence to consider in counseling. The Wee project policy was approached and evaluated step by step to prepare measures for the promotion of school counseling and the development of the policy. We studied the meaning of the experience of playing the role of a professional counselor working at Wee Class. We looked at the counseling stress experience experienced by school counselors. We looked at the impact of organizational fairness on the job involvement of school counselors. We looked at the impact of role conflicts experienced by school counselors on awareness of capacity. The meaning of the experience of recovery from exhaustion of professional counselors was studied. We looked at the effect of self-resilience of school counselors on job stress and psychological well-being.

Figure 5. Word Cloud of degree papers published in 2019, 2020, 2021.
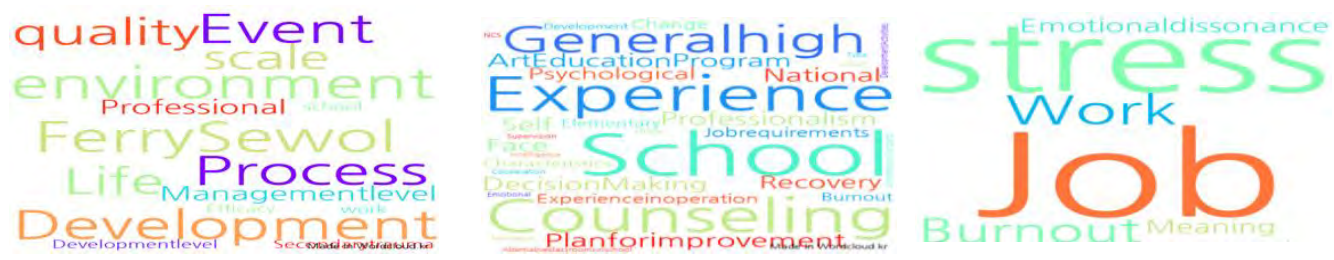

It was intended to explore the development process of professional counselors and prepare methods for their development. By describing the experience of working as a counselor at a school that experienced the Ferry Sewol incident, which was socially issued event in Korean society, the direction of the counselor's intervention, knowledge, and attitude in the disaster site was presented. The impact of management on the quality of life on the job environment, efficacy, and secondary trauma of school counselors was studied. It laid the foundation for enhancing the level of indirect trauma management experienced by counseling. We studied the supervision experience of professional counselors. It was intended to provide information for the education and training of professional counselors. It was intended to present policy implications by studying professional counseling teachers to form their expertise in school counseling. The types and characteristics of communication were studied in the ethical conflict experienced by professional counselors during school counseling. We looked at changes in self-development activities after recovery and recovery from exhaustion experienced by professional counselors. We studied the experiences faced by professional counselors and looked at the impact on the counselors' growth process. The effectiveness of emotional intelligence-based art education programs developed in collaboration with professional counselors was studied. In order to improve the National Standards for Psychological Counseling (NCS), professional counselors' job requirement was studied. We looked at the effects of job stress and emotional harmony of school counselors on burnout.

\section{Conclusion}

The results of the analysis through Word Cloud and its implications are as follows.

First, it is required to improve the role of school counselors and awareness of Wee classes. According to Word Cloud analysis results of the degree papers published in 2013 and 2014, the number of human resources involved in school counseling varies from school professional counselors, professional counselors, social workers, school counselors, career counselors, and community education experts. The involvement of such diverse groups of experts can obscure the identity of school counseling (Kim, Cho, 2011). This can negatively affect the role and job selection of school counselors and the strengthening of professionalism (Korea Teachers' University Industry-Academic Cooperation Group, 2014). Proposals are made to ultimately improve the awareness of the counseling room and the counseling program (Kim, 2013; Shin, 2013). Efforts were required to improve and develop the Wee project policy in its activation. School 
counselors in Korea are burdened with classes because they are responsible for teaching in schools. They experience skepticism in my position as a school counselor, as they have to fulfill various tasks such as administrative work and counseling in school. The boundary between stress and work experienced a teacher at school is collapsing. As a result, they are experiencing confusion and stress about their duties.

Second, research was conducted to develop the capabilities of professional counselors working in Wee class. Studies that analyzed affecting professionalism, such as job stress, have been carried out steadily. Research was also conducted to prevent burnout of professional counselors that could negatively affect capacity development. This study expects these studies to be the basis for improving professionalism and to protect ethics as counselors working in Wee classes and help ensure the rights and welfare of clients.

Third, according to the school counseling system in the United States and Japan, professionalism was emphasized as a requirement for counselors. In the United States and Japan's school counseling system, those who met the qualifications of clinical psychologists were selected. In comparison, teachers were selected through the teacher appointment system in Korea and based on education in addition to counseling, which is a major subject. In addition to counseling, the Korean system required academic knowledge of overall education. Those who possess national qualifications, such as certificates for counselors for youths and clinical psychologists or others issued by private institutions such as the Korea Association of Counselors meet the conditions, but candidates for school counselors' counseling practice was not sufficient (Kim, 2013). They emphasized that they have to take more professional counseling skills. In order to take them, more supervision and counseling practice are required in the school counseling training course to improve counseling skills.

\section{References}

Ahn, Myung-Suk. (2018). Multicultural key words and network analysis using Big Data. The society of convergence knowledge transactions, 6(2), 67-76.

American School Counselor Association. (2007). State certification requirements. Retrieved on May 25, 2007, from http://www. schoolcounselor.org/content.asp?contentid=242

Industry-Academic cooperation group in Korea National University of Education. (2014). A Study on Curriculum Development for Professional School Counselor Education and Competence Enhancement. Policy R\&D Project, Ministry of Education in South Korea.

Kim, Eun-Ju. (2013). Study on the Establishment of the Role of school Counselor and School Social Workers. Master's dissertation. Gyeonggi, South Korea: Gachon University, South Korea.

Kim, Hye-Young. (2009). Comparative Analysis on School Counseling System in Korea, America and Japan. Master's dissertation. Daegu, South Korea: Kyungpook National University.

Kim, In-Gyu, \& Jo Nam, Jung. (2011). A Study on the Development of Training and Ongoing Education Curriculum of Professional School Counselor using DACUM method. The Journal of Korean Teacher Education, 28(4), 41-60.

Kim, Yune Jung. (2018). A Study on the Patterns of Self-introduction and Educational Methods for Employment in University Students: Focusing on Keyword Using Word Cloud. Culture and convergence, 40(8), 403-443.

Lee, Sang Min, \& Oh, In Soo, \& Suh, Su Hyun. (2007). Comparison Study of Korean and American School Counseling for Developing a Korean School Counseling Model. The Korean Journal of Counseling and Psychotherapy, 19(3), 539-567.

Nam, Soon-Im, \& Park, Ju-Young. (2017). Research Trends for Professional School Counselors. Korea journal of counseling, 18(6), 451-471.

Park, Byung-sik. (2005). System of Japan's school counselor. The journal of humanities and social science research, 12, 149-166.

Park, Esther, \& Kim, Joungmin. (2021). Research Trends in Liberal Art Education Applying Word Cloud and KJ Method. Journal of learner-centered curriculum and instruction, 21(4), 1209-1231.

Seo, Jun Il. (2015). A Study on the Activating Smart Education using Semantic Network Analysis. Doctor's dissertation. Gyeonggi, South Korea: Kyonggi University. 


\title{
THE IMPACT OF ONLINE ACTIVITIES ON STUDENTS' HEALTH AND THE IMPORTANCE OF TIME MANAGEMENT
}

\author{
Carolina Bodea Hațegan ${ }^{1}$, Dorina Talaș ${ }^{2}$, \& Raluca Trifu ${ }^{3}$ \\ ${ }^{1}$ PhD Associate Professor, Department of Special Education, Faculty of Psychology and Education \\ Sciences, Babeș-Bolyai University, Cluj-Napoca, (Romania) \\ ${ }^{2}$ PhD Associated Lecturer, Department of Special Education, Faculty of Psychology and Education \\ Sciences, Babeș-Bolyai University, Cluj-Napoca, (Romania) \\ ${ }^{3}$ PhD Assistant Professor, Department of Medical Education, University of Medicine and Pharmacy, Iuliu \\ Hațieganu, Cluj-Napoca, (Romania)
}

\begin{abstract}
The aim of this study is to highlight the importance of time management during online activities for students. At the beginning of the pandemic period, on March the 2020, after the first online activity, a pilot study was conducted to identify the students' perception about online activities, the time they should spend online during the day, the time students spend on different devices (computer, tablet or mobile phone) and the difficulties they have during the first online activities. A number of 106 students (44 boys and 62 girls) in 5th grade, from a middle school located in an urban area, in Romania, participated in this study. The results demonstrate that most of the students (33) representing 31.1\% spend $1-2$ hours/day online but there are 6 students $(5.6 \%)$ who spend more than 6 hours/day online. Most of the students (56.6\%) consider they should have 3 online activities/day and the duration of these activities should be 40 - 50 minutes. Strategies to promote students' wellbeing during online activities are also presented focusing on identifying the best way to use the time spend online in order to reach the necessary curricular objectives and to avoid health problems. The conclusions highlight the importance of finding the best time management strategies for online activities to avoid future health problems for students, especially in the situation in which at the global level the pandemic period is not even closed to the end point. As screen time is a controversial factor, with high implication for health and education, data are important for sustainability of educational system and future decisions.
\end{abstract}

Keywords: Time management, online activities, students' wellbeing, IT devices, screen time.

\section{Introduction}

Screen time is a very studied concept especially in this time when children and adults tend to be preoccupied, and in the same time, tend to rely their learning and working experiences on all the instruments that are covered under this concept umbrella: television, smartphones, tablets, computers, laptops, video game consoles, iPads, handheld electronic or gaming devices. Oswald, Rumbold, Kedzior, \& Moore (2020) underline that when defying screen time, the use of the internet, social media, or communicating via text message are all means and activities that are considered as part of this concept while just auditory activities, such as talking on a phone and listening to music, are not included. This concept is related with digital media use and the concept of mental health due to the important implications that spending time on these screen -based devices can have (Stiglic, Viner, 2019).

The green time is the opposite term of screen time and it refers to the time a person spends in a natural environment, walking, working or doing physical exercise and relaxing. The opposition screen vs green time must be reinterpreted, nowadays, in pandemic situations, when the outdoor walking, travelling and other common activities such as visits and holidays are restricted and even forbidden.

A study published in 2012 (Sigman, 2012) indicates that at a rate of 2 hours/day, a child born nowadays, by the age of seven years, will have spent one full year of $24 \mathrm{~h}$ days watching screen media. The same study (Sigman, 2012) calculates that by the age of 18 years, the average European child will have spent 3 years of $24 \mathrm{~h}$ days watching screen media and at this rate, by the age of 80 years, they will have spent 17.6 years on media screens.

${ }^{1}$ Corresponding author: anamaria.bodea@ubbcluj.ro, hateganbodeacarolina@gmail.com 
In a study The Centers for Disease Control and Prevention (CDC,2021) reports that children ages eight to 10 spend an average of six hours per day in front of a screen, kids age 11 to 14 spend an average of nine hours per day in front of a screen, and youth ages 15 to 18 spend an average of seven-and-a-half hours per day in front of a screen. Doctors, especially the pediatricians, underline the needs for one rule no screens for children who are under the age of two, and 1 hour/day for children under 5 ( WHO, 2019; APA, 2016; (Guram \& Heinz, 2018)) Common Sense Media support group (2018) indicates specific information about children age 5-7 use the screen time for different reasons - $42 \%$ own their own tablets, $63 \%$ play games online for nearly 7.5 hours, $82 \%$ are online almost 9 hour a week and $70 \%$ use YouTube, watch cartoon and funny video.

The psychological implications related to screen time are in detail described by analyzing specialized literature in the field on three age intervals: young children $(<5$ years $)$, schoolchildren (5-11 years), early adolescents (12-14 years), and older adolescents (15-18 years). The psychological following aspects are related with mental health, cognitive functioning and academic achievement, in the figure below these three dimensions are operationalized. In order to illustrate these aspects, researchers investigated 186 studies that the authors identified in four relevant databases (PubMed, PsycInfo, Scopus, Embase).

Table 1. Psychological implications to be studied related to screen time (according to Oswald, Rumbold, Kedzior, \& Moore, 2020).

\begin{tabular}{|c|c|c|}
\hline Constructs & \multicolumn{2}{|l|}{ Variables } \\
\hline \multirow[t]{2}{*}{ Indieators of Poor Mental Health } & \multicolumn{2}{|c|}{ Common internalising or externalising disorders 2 or their symptoms, buch as: } \\
\hline & $\begin{array}{l}\text { - Depression } \\
\text { - Anxicty } \\
\text { - Stress } \\
\text { - Psychological distress } \\
\text { - Poor self-regulation }\end{array}$ & $\begin{array}{l}\text { - Emotional problems } \\
\text { - Psychological difficultics } \\
\text { - Psychosomatic symptoms } \\
\text { - Negative affect or mood }\end{array}$ \\
\hline Indicators of Positive Mental Health & \multicolumn{2}{|c|}{ Refers to elements of positive psychology or overall well-being, such as: } \\
\hline \multirow[t]{2}{*}{ Cognitive Functioning } & \multicolumn{2}{|c|}{ Refers to mental processes, such as: } \\
\hline & $\begin{array}{l}\text { - Attention } \\
\text { - Working memory } \\
\text { - Executive function }\end{array}$ & - Visual, spatial, verbal, language, and cognitive development \\
\hline
\end{tabular}

hiths:/doi.org/10.1371/joumal.pone.0237725.t001

This article is a very comprehensive and in depth analysis of the specialized literature in the screen time filed, the large number of investigated studies underlying both the fact that research preoccupation in this field is significantly increasing, in direct relation with the increase in the time spent in front of screens during a day, not only in small children but mostly in adolescents and even in adults, and, in the same time, that both negative and positive aspects related with these increase have to be considered as they can lead to significant impact on global development.

Results of the research (Oswald, Rumbold, Kedzior \& Moore, 2020) underlined that the cognitive and behavior disorders in children aged under 5 are correlated with an increased number of hours, more than 2 hours using screens. Among these cognitive am behavior disorders the following are listed: communication disorders, language disorders, effort engagement control, self-regulation and self-control. These results are strengthened by data provided by Stiglic and Viner (2019) Canadian Paediatric Society, 2017 and American Pediatric Society, 2016 that established several regulations in order to help parents limit the children screen time due to the cognitive and health negative implications (obesity and other physical problems). Madigan, Browne, Racine, Mori, Tough, 2019 underline that at this age, screen exposure can influence the children 's global development, obtaining lower results in developmental screening tests.

In school age children, beyond the cognitive and physical problems, researchers underline that the learning outcomes are very much negatively influenced, thus: attention and memory deficits as well as visuo-spatial processing and executive functioning are correlated with learning disorders and increase screen time (Barlett, Gentile, Barlett, Eisenmann, Walsh, 2012; Rosenqvist, Lahti-Nuuttila, Holdnack, Kemp, Laasonen, 2016;Swing, Gentile, Anderson, Walsh, 2010; Stiglic, Viner, 2019; Tremblay, LeBlanc, Kho et al. 2011; Oswald, Rumbold, Kedzior \& Moore, 2020).

In adolescents and older children, beyond the above mentioned cognitive and health problems researchers underline the correlation between screen time and psychological disorders such as: higher 
anxiety symptoms, depression/depressive symptoms, externalizing problems (Cao, Qian, Weng, Yuan, Sun, Wang, et al. 2011; Oswald, Rumbold, Kedzior \& Moore, 2020, Stiglic, Viner, 2019; Babic, Smith, Morgan, Eather, Plotnikoff, Lubans, 2017; Benson, Williams, Novick, 2013).

It is obvious that screen time exposure influences greatly both small children and adolescents, screen time exposure constantly increase, and the type of screen exposure too, if older studies brought into light the negative effects of television on general health and psychological development, the nowadays studies enlarge the screen exposure type a lot and tablets, smartphone and other technological devices are increasingly used. In pandemic time, this increase exposure as well as wider the screen type possibilities were a necessity, their impacts or the way the mandatory facet and the health ensuring are important to be considered both at micro level (by parents and educators), and at macro level (by national and international authorities).

\section{Design}

The research methodology for this study was to identify students' perception about the first online activity, their screen time and the difficulties they identified. This quantitative study involved 106 students (44 boys and 62 girls) in 5th grade (four classes), from a middle school located in an urban area, in Romania at the beginning of SARS-CoV2 pandemic.

\section{Objectives}

The objectives of this research are:

- To identify the students' perception about online activities;

- To determine the student's perception on the time they should spend online during a school day;

- To determine the difficulties students in $5^{\text {th }}$ grade have during the first online activities.

\section{Methods}

A Google Form questionnaire was used to collect data starting from March 19, 2020 to April 02, 2020. The questionnaire was sent to the students using Google Classroom. The first part of the questionnaire contains demographic information about the students, the second part contains information about the devices students use for online activities and about the difficulties they encountered (technical problems or poor internet connection). The third part of the questionnaire contains information about the advantages of online classes, the difficulties they encountered and the feelings they experienced during the first online activity from their life. The last part of the questionnaire was about the time students spend online/day and their perception on the time they should spend online per a day during a class and during a school day.

\section{Results}

Most of the students use a computer or a tablet (69,8\%), 24,5\% students use the phone and only $5,7 \%$ of the students use a tablet. The students encountered the following problems: technical problems $(28,3 \%)$, poor Internet connection $(10,4 \%)$ and $61,3 \%$ declared they did not have any problems.

The advantages and disadvantages identified by the students during the first online activity are presented in table 2, they being similar with those presented by specialized literature (Guram, Heinz, 2018; Bodea Hațegan, Talaș, 2020).

Table 2. Advantages and disadvantages identified by the students during the first online activity.

\begin{tabular}{|l|l|}
\hline \multicolumn{1}{|c|}{ Advantages students identified during online activities } & Disadvantages students identified during online activities \\
\hline -activities are interesting; & -we cannot concentrate because we cannot see our \\
-we can continue our lessons; & teachers face to face; \\
-we pay attention; & -we spend more time in front of the computer; \\
-we can interact with our colleagues and teachers; & -the sound quality is poor sometimes; \\
-we can stay at home and save the time we spend to go to & -poor internet connection; \\
school; & -we do not socialize, lack of interaction between the \\
-it is possible to participate in a class from all over the & students; \\
world; & -excessive screen time; \\
-we are safe; & -communication barriers; \\
-it is simple and comfortable; & -lack of socialization; \\
-we do not have to change classes anymore; & -connection difficulties; \\
-we can sleep longer; & -maybe some children do not have devices; \\
-these online activities change our lifestyle & \\
\hline
\end{tabular}


Some of the students' answers to the question "How did you feel when you first went online with colleagues and the teacher?" are: "I felt good and it was very interesting.", "I felt good and I'm glad to see my colleagues and the teacher again.", "I felt very good when I first went online with colleagues and the teacher because I haven't seen them in a long time and I was happy.", "Interesting and unusual.", "Interesting, captivating.", "I felt a little excited." "I was a little stressed, because it was the first time I used that site", "I was a little excited because I never had online classes again. But in time, I felt great!", "I was a little excited because I never had online classes again. But in time, I felt great!", "I felt good and I was a little surprised.", "A little excited, but happy because I see my colleagues again.", "I felt good and I really prefer online courses.", "Normal.", "Worse", "A little weird, bad.", "Strange”, "Curious, delighted."

The results recorded to the question "How many hours/minutes do you spend on the computer/laptop/tablet per a day?" are: $31.1 \%$ of the students declared they spend 1-2 hours/day in front of the computer/laptop/tablet/phone per a day, 26,41\% spend 30-60 minutes/day, 14,20\% spend 2-3 hours/day, 13,26\% spend 3-4 hours/day, 3,83\% spend 4-5 hours/day, 0,94\% spend 5-6 hours/day, 4,71\% spend 0-30 minutes/day and 5.6\% spend more than 6 hours/day in front of a device.

For the question "How long do you thing an online activity should be?", 42,5\% of the students consider that an online activity should have 40 minutes and the same percent $(42,5 \%)$ of students consider that an online activity should have 50 minutes. Only $12,3 \%$ consider that an online activity should have 30 minutes and 2,8\% chose 60 minutes. The answers for the question "How many online classes/day do you think a student in $5^{\text {th }}$ grade should have?" are: $56.6 \%$ chose 3 classes, 18,9\% chose 2 classes, 11,3\% chose 4 classes, $8,49 \%$ chose 5 classes and 4,7\% chose 1 class. Results are according with data promoted by Canadian Paediatric Society.

\section{Discussion}

Using a computer or a laptop is very important during online activities because during these activities, students must solve different tasks and the number of students using these devices is high $(69,8 \%)$. The majority of the students $(61,3 \%)$ did not have any problem working online, but $28,3 \%$ had some technical problems and $10,4 \%$ had poor Internet connection. The technical problems were probably due to the students lack of IT knowledge because students start the first IT lessons in schools only in $5^{\text {th }}$ grade.

Students are aware of the importance to reduce screen time and they identified the extended screen time as a disadvantage for online activities. They also identified a lot of advantages for online learning. Most of the students spend 1-2 hours/day in front of the computer/laptop/tablet/phone per a day $(31,1 \%)$ but $5.6 \%$ spend more than 6 hours/day in front of a device. The same number of students $(42,5 \%)$ chose 40 minutes and 50 minutes for an online class probably because face to face school classes used to have 50 minutes. Even if the school schedule includes 5 classes/day the majority of students prefer to have less online classes per a day. These results are very encouraging, students are aware of the implications screen time can have on their development and are really interested in being accordingly trained having into consideration the screen time moderation (Sigman, 2012; Stiglic, Viner, 2019).

Results also prove that online school for $5^{\text {th }}$ graders is not so difficult and it can be a valuable option especially in difficult situations as those represented by pandemic context.

\section{Conclusions}

This study reflects the students' opinion related to the first online activity at the beginning of SARS CoV-2 pandemic, when the online activities structure was not defined in Romanian legislation. Changes must come in the educational system; IT classes should start in primary grades and programs for preventing screen dependency must be implemented. Parents and teachers must encourage a healthy and balanced life for children in the context of online education. New studies are recommended in this field.

\section{References}

Babic, M.J., Smith, J.J., Morgan, P.J., Eather, N., Plotnikoff, R.C., Lubans, D.R. (2017). Longitudinal associations between changes in screen-time and mental health outcomes in adolescents. Mental Health and Physical Activity. 2017; 12:124-31.

Barlett, N.D., Gentile, D.A., Barlett, C.P., Eisenmann, J.C., Walsh, D.A. (2012). Sleep as a Mediator of Screen Time Effects on US Children's Health Outcomes. Journal of Children and Media. 2012;6(1):37-50. 
Benson, L.P., Williams, R.J., Novick, M.B. (2013). Pediatric obesity and depression: a cross-sectional analysis of absolute BMI as it relates to children's depression index scores in obese 7- to 17-year-old children. Clin Pediatr (Phila). 2013;52(1):24-9

Bodea Hațegan, C. Talaș, D. (2020). Ghid Practic de Organizare a Activităților Online (Practical Guide for organizing Online Activities), Colecția Terapia Tulburărilor de Limbaj și de comunicare, Cluj-Napoca: Presa Universitară Clujeană.

Browne, D. T., May, S., Hurst-Della Pietra, P., Christakis, D., Asamoah, T., Hale, L., Delrahim-Howlett, K., Emond, J. A., Fiks, A. G., Madigan, S., Prime, H., Perlman, G., Rumpf, H. J., Thompson, D., Uzzo, S., Stapleton, J., Neville, R., \& Media Impact Screening Toolkit Workgroup of Children and Screens: Institute of Digital Media and Child Development (2019). From 'screen time' to the digital level of analysis: protocol for a scoping review of digital media use in children and adolescents. BMJ open, 9(11), e032184. https://doi.org/10.1136/bmjopen-2019-032184

Canadian Paediatric Society DHTFOO. Screen time and young children: Promoting health and development in a digital world. Paediatrics and Child Health 2017; 22:461 77.

Cao, H., Qian, Q., Weng, T., Yuan, C., Sun, Y., Wang, H., et al. (2011). Screen time, physical activity and mental health among urban adolescents in China. Prev Med. 2011;53(4-5):316-20. pmid:21933680

CDC. (2021). Infographics - Screen Time vs. Lean Time | DNPAO | CDC. https://www.cdc.gov/nccdphp/dnpao/multimedia/infographics/getmoving.html

Common Sense Media: Age-Based Media Reviews for Families. (n.d.). Retrieved March 20, 2021, from https://www.commonsensemedia.org/

Guram, S., \& Heinz, P. (2018). Media use in children: American Academy of Pediatrics recommendations 2016. Archives of Disease in Childhood: Education and Practice Edition, 103(2), 99-101. https://doi.org/10.1136/archdischild-2017-312969

Madigan, S., Browne, D., Racine, N., Mori, C., \& Tough, S. (2019). Association Between Screen Time and Children's Performance on a Developmental Screening Test. JAMA pediatrics, 173(3), 244-250. https://doi.org/10.1001/jamapediatrics.2018.5056

Oswald, T. K., Rumbold, A. R., Kedzior, S., \& Moore, V. M. (2020). Psychological impacts of "screen time" and "green time" for children and adolescents: A systematic scoping review. PloS one, 15(9), e0237725. https://doi.org/10.1371/journal.pone.0237725

Rosenqvist, J., Lahti-Nuuttila, P., Holdnack, J., Kemp, S.L., Laasonen, M. (2016). Relationship of TV watching, computer use, and reading to children's neurocognitive functions. Journal of Applied Developmental Psychology. 2016;46:11-21

Sigman, A. (2012). Time for a view on screen time. Archives of Disease in Childhood, 97(11), 935-942. https://doi.org/10.1136/archdischild-2012-302196

Stiglic, N.; Viner, R. M. (2019). Effects of screen time on the health and well-being of children and adolescents: a systematic review of reviews. BMJ Open. 9 (1): e023191. doi:10.1136/bmjopen2018-023191. PMC 6326346. PMID 30606703.

Swing, E.L., Gentile, D.A., Anderson, C.A., Walsh, D.A. (2010). Television and video game exposure and the development of attention problems. Pediatrics. 2010;126(2):214-21. pmid:20603258.

Tremblay, M.S., LeBlanc, A.G., Kho, M.E., et al. (2011). Systematic review of sedentary behaviour and health indicators in school-aged children and youth. Int J Behav Nutr Phys Act 2011; 8:98 $10.1186 / 1479-5868-8-98$

World Health Organization. (2019). Guidelines on physical activity, sedentary behaviour and sleep for children under 5 years of age. World Health Organization. https://apps.who.int/iris/handle/10665/311664. License: CC BY-NC-SA 3.0 IGO 


\title{
USE OF SOCIAL NETWORKS FOR THE TRAINING OF FUTURE TEACHERS IN EARLY CHILDHOOD EDUCATION
}

\author{
Mercedes Llorent-Vaquero, África M. Cámara-Estrella, Elena M. Díaz-Pareja, \\ \& Juana M. Ortega-Tudela \\ Department of Pedagogy, University of Jaen (Spain)
}

\begin{abstract}
Currently, social networks have a great potential in the educational field, being useful to promote motivation, the active role of students, communication or flexibility in time and space, among others. In this line, this paper shows an experience of educational innovation in higher education mediated by the use of social networks. Specifically, the social network Instagram was used with students in the second year of the Early Childhood Education Degree at the University of Jaen. The objective of this study was to analyze the impact of the use of social networks on aspects related to the quality of the educational process, such as motivation, creativity, communication or monitoring. In order to respond to the proposed objective, a quantitative methodology was used, with a descriptive method and a survey design. The data collection instrument was a student questionnaire through which the impact of the use of the social network Instagram in the teaching-learning process was evaluated. The results point to a positive effect of the use of social networks on the variables under study. It should be noted how the use of this social network has influenced the motivation towards their learning and the communication processes that were developed with all those involved.
\end{abstract}

Keywords: Social networks, Instagram, teachers training, early childhood education, higher education.

\section{Introduction}

Social networks have become a tool that encompasses many aspects of daily life, and education is one of them. As a social process, education can be enriched by the use of these networks to share, collaborate, exchange experiences, knowledge, resources, etc. (Mora, Signes, De Miguel \& Gilar, 2015).

The use of social networks in the classroom enables the transmission of knowledge and the inter-group collaboration. In this sense, they motivate the students to personal reflection and group work, fostering autonomous work (Buxarrais, 2016). They also facilitate the exchange of knowledge, while promoting the dissemination of learning in a faster and wider way (Mora, Signes, De Miguel \& Gilar, 2015).

The research on university teaching and social networks that we present has been developed around the idea that the use of the social network Instagram is a motivating and encouraging element of the active role of the student in the training process. In order to know the knowledge management capacity that the use of the social network Instagram brings to university students, we have adapted the educational practices of the students to the use of this social network. In this way, the objective is to know the benefits of the use of Instagram in the teaching-learning process.

As an educational tool and support for the dissemination of acquired professional skills (Pérez, 2015; Piscitelli, 2010), it is an open field of work for university teaching. Currently, the world of young people cannot be understood without knowing these socialization tools, and we cannot turn our backs on this reality. Moreover, as teachers, we need to approach social networks and turn them into methodological resources close to the students.

\section{Design}

This study describes the results of an innovative learning experience. This experience was carried out in the University of Jaen, specifically in the second year of the degree in Early Childhood Education. The subject in which the experience was developed was Educational Technology. In this sense, this 
academic year $(2020 / 21)$ the professors team of the subject decided to change the methodology in the development of the practices of the subject.

The purpose of these practices is to create multimedia materials for early childhood education students. For several years we used the Service Learning methodology in this process. We contact educational centers asking for their needs for multimedia materials. According to the teachers' needs we elaborate the multimedia materials and we deliver it to them, so it can be useful. The changes introduced this academic year was the use of Design Thinking in the design process of the multimedia materials and the use of the social network Instagram as a learning tool. Through Design Thinking we expected the development of the creativity of the student by using different techniques. Instagram was introduced as a learning tool thinking about the motivation that could be for the students and the possibilities that it has for communication and monitoring.

In the development of the project of creating multimedia materials, the students formed work groups. Each group has an Instagram account and they used this social network as a blog, creating an Instablog. They publish their project phases, step by step, sharing with their colleagues and trying to get some dissemination and interaction in this social network. It is worth mentioning the creativity they showed in the exhibition of their contents.

The professor has another account in which she was publishing information about the process, techniques, deadlines, etc. Also the professor used the account to encourage the students and give them support and inspiration.

\section{Objectives and methods}

This paper analyzes the assessment of the innovative learning experience described above, specifically in relation to the use of the social network Instagram. Thus, the objective of this study is to analyze the impact of the use of social networks on aspects related to the quality of the educational process, such as motivation, creativity, communication or monitoring. In order to respond to the proposed objective, a quantitative methodology was used, with a descriptive method and a survey design.

The data collection instrument was an ad-hoc student questionnaire, validated by experts, through which the impact of the use of the social network Instagram in the teaching-learning process was evaluated. This questionnaire was created online using Google Forms. It was composed of 38 items that analysed different dimensions. From all the dimensions, this study focuses on fourth of them because of their interest in relation with the assessment of the learning experience. These dimensions are: Motivation, Creativity, Communication and Monitoring.

A total of 61 students answered the questionnaire. Most of them were females $(88,5 \%)$ compared to a small percentage of men $(11,5 \%)$. Their ages ranged from 18 to 35 years old, with a mean value of 20,93 . Only a few percent were repeat students $(8,2 \%)$. And a high percentage $(63,9 \%)$ had never used social networks in the teaching-learning process before.

The results of this paper show the descriptive study carried out. The data analysis was accomplished using the SPSS statistical software in its 26 version.

\section{Results}

The results are presented according to the four dimensions of the study. First, the percentages achieved in each of the items that compose the dimensions are shown. Secondly, the averages of the dimensions are presented for comparison purposes.

Figure 1. Results of the motivation dimension.

Encouraged you to seek out and learn how to handle new applications and resources

Increased your motivation for the project

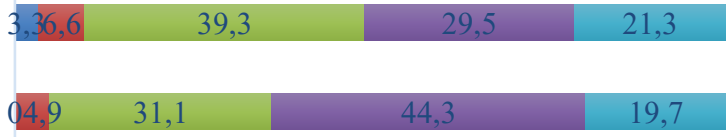

$\begin{array}{lllllllllll}0 & 10 & 20 & 30 & 40 & 50 & 60 & 70 & 80 & 90 & 100\end{array}$

- Mostly disagree $\quad$ Slightly disagree $\quad$ Slightly agree $\quad$ Mostly agree $\quad$ Completely agree 
Almost all the students agree (slightly, mostly or completely) with the statements related to the motivation. The use of Instagram as a learning tool has encouraged them to seek out and learn how to handle new applications and resources and also it has increased their motivation for the project.

Figure 2. Results of the creativity dimension.

\begin{tabular}{|c|c|c|c|c|c|c|}
\hline \multirow{6}{*}{$\begin{array}{r}100 \\
80 \\
60 \\
40 \\
20 \\
0\end{array}$} & 9.8 & & & & & \\
\hline & 27,9 & 36,1 & & & 26,2 & 45,9 \\
\hline & & 31,1 & & & 31,1 & \\
\hline & 52,5 & 23,0 & & & 36,1 & 27,9 \\
\hline & $\begin{array}{l}\text { It has favored your } \\
\text { reflection and critical } \\
\text { thinking }\end{array}$ & Improved your & creativity & $\begin{array}{r}\text { It has e } \\
\text { look } 1 \\
\text { diff }\end{array}$ & $\begin{array}{l}\text { ncouraged you to } \\
\text { or inspiration in } \\
\text { erent contexts }\end{array}$ & $\begin{array}{l}\text { It has made you want to } \\
\text { do something different } \\
\text { from the rest, being } \\
\text { original. }\end{array}$ \\
\hline & Mostly disagree & lightly disagree & Slightl & $y$ agree & Mostly agree & Completely agree \\
\hline
\end{tabular}

With respect to creativity, a few students slightly disagree with the idea that using Instagram has boosted their creativity. However, most of them consider that they have improved their creativity, their reflection and critical thinking, and the search for inspiration in different contexts. In addition, among all of them, they consider that this learning experience makes them want to do something different, being more original than usual.

Figure 3. Results of the communication dimension.

\begin{tabular}{|c|c|c|c|c|c|}
\hline \multirow[t]{3}{*}{$\begin{array}{r}40,0 \\
35,0 \\
30,0 \\
25,0 \\
20,0 \\
15,0 \\
10,0 \\
5,0 \\
0,0\end{array}$} & $\begin{array}{r}36, \mathrm{~B} 6,1 \\
23,0\end{array}$ & $26,2^{39,5}$ & $31,1^{34,4} 29,5$ & $\begin{array}{r}31,1,27,96,2 \\
14,8\end{array}$ & $\begin{array}{r}34,46,1 \\
24,6\end{array}$ \\
\hline & $\begin{array}{l}\text { It has favored the } \\
\text { closeness with your } \\
\text { teacher }\end{array}$ & $\begin{array}{l}\text { It has favored the } \\
\text { closeness with your } \\
\text { class-group }\end{array}$ & $\begin{array}{l}\text { It has imporved your } \\
\text { communication with } \\
\text { the teacher }\end{array}$ & $\begin{array}{l}\text { r It has facilitated the } \\
\text { exchange of } \\
\text { experiences with } \\
\text { other colleagues }\end{array}$ & $\begin{array}{l}\text { It has made it easier } \\
\text { for you to better } \\
\text { understand the steps } \\
\text { to be taken to } \\
\text { develop your project }\end{array}$ \\
\hline & Mostly disagree & - Slightly disagree & - Slightly agree & Mostly agree & Completely agree \\
\hline
\end{tabular}

Regarding the communication dimension, the results point out that most of the students think that the use of Instagram has improved the communication. Specially, they are convinced that it has favored closeness and communication with the professor, more than with the class-group or the colleagues. Nevertheless, most of them agree (slightly, mostly or completely) with all the items of this dimension.

Figure 4. Results of the monitoring dimension.

It has favored the teacher's monitoring of your progress in the project

It has improved the feedback from the teacher

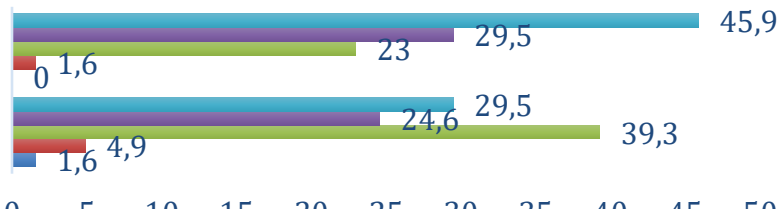

घompletely agree $\quad$ Mostly agree $\quad$ Slightly agree $\quad$ Slightly disagree $\quad$ Mostly disagree 
The fourth and last dimension analyze the monitoring of the learning experience. In this sense, most of the students completely or mostly agree with the statement that the use of Instagram improved de professor's monitoring of the projects. Also, they think it has favored the professor's feedback.

Likewise, when we analyze the mean values of each dimension, we realize that there are some differences between them. Motivation dimension is the lowest rated, although we can consider its value $(3,69)$ as a good assessment by the student, since the scale ranges from 1 to 5 . The dimensions Creativity $(3,8)$ and Communication $(3,81)$ are valued more than Motivation but less than Monitoring, that is the highest rated $(3,98)$.

\section{Discussion}

After analyzing the questionnaire answered by the students, the results affirm that, as concluded in other studies (Buxarrais, 2016), the attitude of students towards the educational use of social networks has been a success. This success is based on the promotion of cooperative learning, the creation of more flexible environments in terms of space and time, the increase of the students' protagonism in their own learning, the improvement of information exchange, the promotion of creativity and the generation of new contexts to work and interact.

However, we found that these facts contradict the research of Espuny, González and Leixà i Gisbert (2016), in which they manifested students' resistances towards the educational use of social networks.

Taking into account the existing concern about how the time dedicated to the use of social networks by young people takes time away from other activities (Sanmartín, Ballesteros, Calderón, \& Kuric, 2020), it is worth noting that these university students use them as tools for study, creation and knowledge management (Buxarrais, 2016). In this sense, they improve their creativity, looking for new sources of inspiration in contexts different from the merely educational ones, and they encourage motivation in the rest of their classmates to deepen their work and share it.

We understand that promoting the use of social networks in the university educational environment as a teaching resource is a necessity in the process of knowledge management and transformation of teaching-learning methodologies. Thus, through its use, the teaching-learning process becomes more active, motivating and shared.

\section{Conclusions}

The results point to a positive effect of the use of social networks on the variables under study. In general, the four dimensions analyzed obtain good valuations by the students. In this sense, we can state that the use of the social network Instagram as a learning tool has fostered motivation and creativity in students as well as improved communication and monitoring.

Among all dimensions, the monitoring was the most valued dimension, especially the monitoring of the progress in the projects made by the students. Also, it should be noted how the use of this social network has influenced the motivation towards their learning and the communication processes that were developed with all those involved.

The use of Instagram has led to improvements in the teaching-learning process during the development of this innovation experience.

\section{References}

Buxarrais, M.R. (2016). Redes sociales y educación. En La educación en la sociedad del conocimiento, 17 (2), 15-20. [Fecha de Consulta 9 de Marzo de 2021]. Disponible en Disponible en: http://www.redalyc.org/articulo.oa?id=535554762002

Espuny, C., González, J., Lleixà, Mar, \& Gisbert, M. (2011). Actitudes y expectativas del uso educativo de las redes sociales en los alumnos universitarios. En: «El impacto de las redes sociales en la enseñanza y el aprendizaje» [monográfico en línea]. Revista de Universidad y Sociedad del Conocimiento (RUSC). Vol. 8, n. ${ }^{\circ} 1$, págs. 171-185. UOC.

http://rusc.uoc.edu/ojs/index.php/rusc/article/view/v8n1-espuny-gonzalez-lleixa-gisbert/v8n1-espunygonzalez-lleixa-gisbert 
Mora Mora, H., Signes Pont, M. T., De Miguel Casado, G., \& Gilart Iglesias, V. (2015). Management of social networks in the educational process. En Computers in Human Behavior, 51, Part B, 890-895. doi:http://dx.doi.org/10.1016/j.chb.2014.11.010

Pérez, N. (2015). Facebook como plataforma de aprendizaje. Etic@net, 15(2), 395-402. DOI: https://doi.org/10.30827/eticanet.v15i2.11959

Piscitelli, A. (Coord.) (2010). El proyecto Facebook y la posuniversidad. Sistemas operativos sociales y entornos abiertos de aprendizaje. Barcelona/Madrid: Ariel/Fundación Telefónica. Disponible en http://www.codajic.org/sites/www.codajic.org/files/El\%20Proyecto\%20Facebook.pdf

Sanmartín, A., Ballesteros, J.C., Calderón, D. \& Kuric, S. (2020) De puertas adentro y de pantallas afuera. Jóvenes en confinamiento. Madrid. Centro Reina Sofía sobre Adolescencia y Juventud, Fad. DOI: $10.5281 /$ zenodo.4054836 


\title{
PARTICIPATION TO EMPOWER CHILDREN AND STRENGTHEN THE COMMUNITY
}

\author{
Sabina Langer \\ Free University of Bolzano/Bozen (Italy)
}

\begin{abstract}
In a pandemic, children's participation is even more important than before. This paper presents the first stage of an exploratory study for my PhD research in Pedagogy beginning in January 2021 in Milan.

The participants are 19 pupils of class 4B (primary school), their parents and the teachers who joined energies to reproject a square, in order to transform it into a welcoming space for the entire community. In Italy, public speeches did not mention children who could not finally use public spaces for months as they were identified as the "plague spreaders".

The project revisits this perspective by considering children as potential actors of the transformation. Only if adults set the conditions for a change, children, their needs and their imagination could become agents for that change and centre of the community. The project name is Piazziamoci (Let's place ourselves here) to signify the conscious act of taking a place together.

After a theoretical framework of the study within Student Voice, I describe the generative circumstances, the context and the first steps of the project. The children explored the square, interviewed the inhabitants, shared information and dreams with their classmates coming up with proposals to present to City Council. This first phase aimed to set the basis of my investigation on the participants self-awareness as people and members of the community; it also focuses on the perception of the square as a common good. To this purpose, this work introduces concepts as the capacity to aspire (Appadurai, 2004), imagination and creativity (Vygotsky, 1930/2004), interdependence (Butler, 2020), and, therefore, a political and educational interpretation of the project.

Imagine a city where there is no desire. A city without desire is a city of no imagination. Here people think only what they already know. Anne Carson, Eros the bittersweet (Normal, IL, Dalkey Archive Press, 1988, p.168).
\end{abstract}

Keywords: Participation, imagination, community, empowerment, common good.

\section{Introduction}

This paper presents the first stage of an exploratory study for my $\mathrm{PhD}$ research in Pedagogy. After outlining the theoretical framework within Student Voice, it describes the context and the first steps of the project Piazziamoci (Let's place ourselves here) begun in January 2021 in Milan. The participants are 19 pupils of class $4 \mathrm{~B}$ (primary school), their parents and their teachers who joined energies to reproject a square, in order to transform it into a welcoming space for the entire community. This first stage aimed to set the basis for investigating if the participants are about to become aware of themselves as people and members of the community and if they are about to perceive the square as a common good.

\subsection{The right to participate: The context of the exploratory study}

The exploratory study can be framed within Student Voice, that emerged in the 1990s in the English-speaking world: "Authorising student perspectives means ensuring that there are legitimate and valued spaces within which students can speak, re-tuning our ears so that we can hear what they say, and redirecting our actions in response to what we hear" (Cook-Sather, 2002, p. 4). The Student Voice approach starts listening and involving students to change all those issues that affect them. Over time, two main currents took shape, both followed by a large number of researchers: the first starts with Jane Rudduck (2004) and focuses on teaching/learning processes; the second, outlined by Fielding (1999, 2001, 2012), deals with more political topics (democracy, power, participation) and is based on the empowerment of students as people. 
Levin (2000) identified reasons for including students in the processes of rethinking places and institutions, which are still very relevant in Italy:

"1. Effective implementation of change requires participation by and from all those involved, students no less than teachers; 2 . Students have unique knowledge and perspectives that can make reform efforts more successful and improve their implementation; 3. Students' views can help mobilise staff and parent opinion in favour of meaningful reform; 4. Constructivist learning, which is increasingly important to high standards reforms, requires a more active student role in schooling; 5. Students are the producers of school outcomes, so their involvement is fundamental to all improvement." (Levin, 2000, pp. 156-157).

In Italy, some meaningful research on Student Voice was carried out and collected in a volume by Grion \& Cook-Sather's (2013). This publication also contains an important article arguing on the concordance of this approach with the Italian National Guidelines for the school (Grion, 2013). The Student Voice studies and experiences highlight a better relational and learning environment in schools where active participation is encouraged. The project Piazziamoci develops both aspects, the political and the learning/teaching one; nevertheless, this paper does not deal with the interdisciplinary part of the project. Besides the transformative aim, the project has an educational and political purpose to empower children as active participants in the community: pupils learn to connect different "spaces" (the classroom, the square) and people (classmates, teachers, parents, inhabitants of the square). Although political participation skills do not belong to the standard school curriculum, they are among the most important acquisitions everyone should achieve (Levin, 2000).

This first stage aimed to set the basis for my research. During the first lockdown due to the Covid19, in spring 2020 in Italy, children were not mentioned in public discourses and could not leave their homes, identified as "plague spreaders". This unusual situation, in which children were forgotten (Novara, 2020), fits in the Italian educational context. Despite article 12 of the UN Convention on the Rights of the Child (1989), assuring children the right to express themselves freely in all matters affecting them, the participation of children and young people is still neither frequent nor encouraged.

Concerning the ongoing studied project started in Milan (Italy) in January 2021, the first phase described in this paper, had to stop at the beginning of March with the second lockdown and the closure of schools.

Against the Italian trend, in the project, children have space for action and operational autonomy (Lansdown, 2001) to become radical agents of change (Fielding, 2001). While adults are supporters, preparing the preconditions for action: children, their needs and imagination are put at the centre of the community. The name of the project is Piazziamoci (Let's place ourselves here) to signify the conscious act of taking a place together.

The project Piazziamoci is embedded in peculiar generative circumstances. Ms G., the main teacher, and more than half of the parents were trained in nonviolent practices and strategies for three years by ED.UMA.NA (www.edumana.it), a network promoting nonviolent education and practices to empower the school community. Ms G. has also been working for years to increase children participation. For these reasons, she decided to partake in a call of the City Council, which invited schools to develop projects involving pupils to take care of their surroundings. She was aware that such a project could have brought empowerment and well-being to the pupils and the class. Hence, in December 2020, Ms G. made arrangements with the City Council and an ED.UMA.NA tutor started helping her to involve the parents in the project. Parents were happy to participate actively. Another important occurrence is the habit of this class to have an "agora" every morning: the pupils sit in a circle and discuss some relevant issues among them and with their teacher. In times of pandemic, it is harder to have the agora as it is not allowed to sit close to each other. However, class 4B did not suspend this practice. It is considered important for learning to speak, express feelings and emotions, and listen to others. Therefore, they still have the agora sitting at their desk respecting the safety rules.

\section{The first steps of Piazziamoci}

Piazziamoci is an exploratory study for my ongoing PhD. The goal is to verify if, through participation: (1) children and adults will become aware of themselves as people (empowerment) and as members of the community and (2) participants will perceive the square as a common good and develop empathy with the territory. I will conduct a relevant number of interviews, groups of discussion and questionnaires with the involved participants.

Through data triangulation, I will get to the results of the investigation and see if a transformative and generative process took place. The main idea grounding the investigation relies on Appadurai's assumption that culture cannot be understood just as origins, past, or identity. Rather, the concept must include possible futures, desires, reasons and share these aspirations. Girls and boys who 
dream and reproject a square, a public space, thus represent the "capacity to aspire", a fundamental human ability, a cultural capacity and a measure of democratic evaluation (Appadurai, 2004).

In this paper, I describe the first stage of the project according to the data collected during my participation in public actions and the frequent planning-meetings with the teachers, the coding of the materials produced by pupils, a first exploratory questionnaire made for children and for/ parents and an in-depth interview with each teacher.

January and February 2021 were essential months for the foundations of Piazziamoci, turning the dream into a concrete project for the square, although the main teacher, Ms G. got injured in January and left the class to Ms M., a teacher-in-training.

During an agora the project started: at the beginning, each child imagined the square as they would like it to be. By probing their desires and sharing them with peers, they began the creative process. These first inputs were collected in a single "dream-square" containing: swings, ramps for skates, flowery lawns and big trees, tables for playing chess, designs on the floor to make it colourful, goal doors and baskets for playing football and basketball, a maze, an outdoor library, a fountain, a stage for performances, a treehouse... As the square is a common good and should be perceived like that, it was decided to gather the opinion of the other people who use it. Together with Ms M., the pupils structured an interview. Together with the parents, children went in small groups to the square and collected information from its inhabitants. The following days, they worked to design the square, considering their wishes and what emerged from the interviews. Children worked in cooperative learning, a method they use since first grade, to plan how they would like the square to be. They also built three-dimensional models with cardboard, paint, scissors and glue. Metacognitive work in this first phase included two moments in mid-February. Documentation is also a citizenship practice that supports the educational and learning process. In order to belong to a wider community than the classroom, it is crucial to give visibility to what is done at school, shown, and be seen. In collective writing, inspired by the practices of Mario Lodi (1970/2014), children wrote an article for the neighbourhood newspaper describing their project. The second "public" moment was the presentation of the project to the City Council. With the support of the teacher, the pupils prepared slides for the presentation of Piazziamoci, combining texts and photographs. The representatives of the Girls and Boys Council introduced the collective work at the online City Council meeting. On that occasion, the President of the City Council recalled the importance of considering the market, which is held twice a week on the square; therefore, the square cannot have stable games and equipment everywhere. To adjust the ideas for the square and make them feasible, the ED.UMA.NA tutor called children and parents to an agora in the square. Maieutic questions stimulated their imagination. A new plan started to be developed: boys and girls decided to set in the smaller area allowed colourful benches, tables for homework, playing chess, relaxing corners. In the rest of the square, they would like to have an enormous drawing to use as a track for bicycles, skates, skateboards and scooters. The design should be a city within a city (houses, school, supermarket, park) then becoming countryside, sea, mountains, savannah, jungle, sky. At the beginning of March, a new lockdown and the following school closures interrupted the project, which started again in the middle of April, while I am writing this paper. For the children of class $4 \mathrm{~B}$ something already changed: now they are the ones who use the huge grey square to play and spend time together. Slowly the square will be filled with children and colours.

\section{Imagining together to become citizens and community}

A square, as well as an agora, are common spaces. The pupils of class 4B are used to have an agora every morning. When the Ancient Greeks founded a new city, they left an empty space in the middle of it: the agora, the square. From this unique space, the Greeks started democracy. Like the agora in the classroom, the town square is a collective area, a place for relationships where people can play, discuss, share ideas, opinions and meet. Both are places of social aggregation, knowledge and exchange. The square can become a place of conviviality (Illich, 1973/1974), where everyone brings and finds something of themselves and shares it with others. For this reason, working on the project Piazziamoci has a strong symbolical meaning that makes it possible to consider imagination and creativity as political and citizenship skills. As already affirmed by many pedagogies since Dewey (1916/1995), the community has a fundamental role in education. The social and cultural environment determines the capacity of each person to take place and voice as well as the capacity to imagine a different future, the capacity to aspire (Appadurai, 2004). One issue of investigation in this first phase is the role of imagination, as the following data show. 
Boy: "I really enjoyed making the model of the square because there was much space for imagination."

Mother: "They learn to put ideas together to create spaces they have imagined themselves."

Teacher: "Imagination was the engine that lit the fire and then the glue for everything. [...] I think it is important, especially for children, to imagine something beautiful for themselves and others, and I mean for everyone."

The collected data suggest the importance of imagination at this early stage of the project. Quoting Vygotsky, "it is precisely the human creative activity that makes the human being a creature oriented toward the future, creating the future and thus altering his own present." (Vygotsky, 1930/2004, p. 3). To Vygotsky, creativity is not simply the recollection of lived impressions but a creative re-elaboration, a process through which the child combines experiences and constructs a new reality, responding to its needs and curiosities. The creative activity of imagination depends on the social environment, the richness and variety of the individual previous experience. This experience provides the material from which the constructions of the imagination are made. "Every inventor, even a genius, is also a product of his time and his environment." (Vygotsky, 1930/2004, p. 24).

Another issue of my investigation was about active citizenship, especially concerning the openness towards the territory. According to the collected data, the interviews with the inhabitants of the square seemed to be an important opportunity for interaction and growth. Preparing such an interview is a big step of citizenship. It means opening up to the world, leaving the safe community of the classroom and seeing ourselves as citizens and members of a larger community. It activates curiosity for the unfamiliar, widening our thinking to include the needs of others. In fact, some children were initially scared about the idea of talking to strangers ("What if I'm not able to ask questions? What if someone does not answer me?"). After talking wildly in class, they were reassured and understood the importance of overcoming fear for considering the voice of others.

Ms M. said in the interview: "Children are aware that this will not be just their square but everyone's square and the fact that they thought about it, about who attend high school, the shopkeepers, about grandparents with grandchildren and dogs, is a fundamental skill of citizenship. They did not think of a square tailored for the class $4 \mathrm{~B}$, but of a square that is for everyone, beautiful for everyone."

The first collected data seem also to show that the pandemic has changed the meaning of the square for teachers and parents. It has become a space in which it is possible to be together in safety, a place to use more and more, somewhere to change in order to make it more "of us". Concerning the question on the meaning of the project Piazziamoci, parents answered: "It is a good exercise in planning and active citizenship"; "It is an opportunity to give the community a voice to decide on the spaces that belong to us"; "A way to bring children closer to institutions and the common good"; "An opportunity to experience a sense of civic community, democracy and an exchange of ideas"; "Meaningful, doing something positive with my son and feeling part of the community".

It is possible to use Judith Butler's (2020) concept of 'interdependence' in which she proposes an anti-individualistic and nonviolent approach and states that everyone is always involved in the lives of others. No person stands alone at any time in life; on the contrary, everybody is always related to society and the environment. Violence against others means, therefore, violence against oneself because violence attacks the interdependence of the living (Butler, 2020). From this perspective, Piazziamoci may counteract the situation of isolation created by the pandemic, which has deprived everyone, especially children and young people, of community life and life outside their home. Participants seem to be aware of it. Furthermore, they feel the opportunity to rediscover an intentional public space and enjoy common planning. In this perspective, the square could become a convivial tool (Illich, 1973/1974), i.e., a space that can be mastered and used together with the community, in contrast to what normally happens, where the tool dominates and shapes human action.

\section{Conclusion}

In this first stage, I tried to lay the foundations of this study to observe if Piazziamoci impacted the participants in terms of self-awareness as members of the community and their perception of the square as a common good. Therefore, the interpretation I propose of this participatory action is educational and political because it concerns the building of meaningful experiences in that space between people. The space that is possible in relationships, the space that allows the creation of something new: the act of imagining together becomes a political act. Today, in times of pandemic, we need a new collective imaginary starting from interdependence to help children finding their place in the world. 


\section{References}

Appadurai, A. (2004). The Capacity to Aspire: Culture and the Terms of Recognition. In V. Rao \& M. Walton (Eds.), Culture and Public Action (59-84). Stanford: Stanford University Press.

Butler, J. (2020). La forza della nonviolenza: Un vincolo etico politico. Milano: nottetempo. (Original work published 2020)

Dewey J. (1995). Democrazia e educazione. Firenze: Nuova Italia. (Original work published 1916)

Fielding, M. (1999). Radical collegiality: Affirming teaching as an inclusive professional practice. Australian Educational Researcher, 26, 1-34.

Fielding, M. (2001). Students as radical agents of change. Journal of Educational Change, 2, 123-141.

Fielding, M. (2012). Beyond Student Voice: Patterns of partnership and the demands of deep democracy. Revista de Educación, 359, 45-65.

Grion V. \& Cook-Sather A. (Eds.). (2013). Student Voice. Prospettive internazionali e pratiche emergenti in Italia. Milano: Guerini Scientifica.

Grion, V. (2013). Partecipazione e responsabilità nelle indicazioni nazionali per il curricolo del primo ciclo di istruzione. In V. Grion \& A. Cook-Sather (Eds.), Student Voice. Prospettive internazionali e pratiche emergenti in Italia (pp. 136-152). Milano: Guerini Scientifica.

Illich, I. (1974). Convivialità. Milano: Mondadori. (Original work published 1973)

Lansdown G. (2001). Promoting Children's Participation in democratic decision making. Firenze: Unicef Innocenti Research Centre.

Levin B. (2000). Putting Students at the Centre in Education Reform. Journal of Educational Change, 1, $155-172$.

Lodi M. (2014). Il paese sbagliato. Diario di un'esperienza didattica. Torino: Einaudi. (Original work published 1970)

Novara, D. (2020). I bambini sono sempre gli ultimi. Come le istituzioni si stanno dimenticando del nostro futuro. Milano: BUR Rizzoli.

Rudduck, J. (2004). Pupil voice is here to stay! University of Cambridge: QCA Futures.

Vygotsky L. (2004). Imagination and Creativity in Childhood. Journal of Russian and East European Psychology, 42 (1), 7-97. (Original work published 1930) 


\title{
DESIGN THINKING IN FUTURE TEACHERS TRAINING
}

\author{
Juana M. Ortega-Tudela, Elena M. Diaz-Pareja, África M. Cámara-Estrella, \\ \& Mercedes LLorent-Vaquero \\ Department of Pedagogy, University of Jaén (Spain)
}

\begin{abstract}
Innovation in education entails not only the incorporation of technological tools and applications, but also the implementation of methodologies that could break the inertia and incorporate processes of Divergent Thinking. Future teachers must be creative professionals capable of developing professional activities to improve and not only to replicate the social experience in order to create new learning experiences.

In this way, the main aim of our work was to explore how the use of Design Thinking Methodology improves learning processes in a group of 75 college students of the Primary Education Degree. This group of students, divided into 21 smaller working groups, created different educational videos and multimedia design projects through Design Thinking methodology. They were also encouraged to use Social Networks (specifically Instagram) to present and publicize the progress they were making on their work, in order to obtain feedback from their classmates. All the projects developed were related to three thematic areas: Art for everyone; Attention to diversity and Making great neighborhoods. At the end of the creation process, we analysed the students' perception of how the design thinking methodology helps them through their learning process. Based on an ad hoc questionnaire, the impact of the use of Design Thinking in the learning process and its influence on variables such as motivation, communication, creativity, among others, was studied. The results show that the use of this methodology had a positive impact on practically all the variables, facilitating and optimizing the learning process of future teachers.
\end{abstract}

Keywords: Design thinking, innovation, teachers training, creativity.

\section{Introduction}

Design Thinking is an innovative and creative process centered into students that uses collaborative teams in order to generate the most original solutions. In the past years, wide interest towards Design Thinking has been applied in education because of its ability of advancing creativity and innovation. In addition, Brown (2008) explains that Design Thinking (DT) is a discipline that uses the designer's methods to satisfy the needs of the end-users.

In education, design thinking promotes innovation, problem solving, creativity and collaboration (Anderson, 2012). Rauth, Koppen, Jobst \& Meinel (2010) noted that design thinking allows the participants to work successfully in multidisciplinary teams as they creatively solve difficult real-life problems. Brown (2008) explained that design thinking is seen as a powerful and effective approach to impact innovation that can be integrated in education and other fields. However, what sets design thinking apart from other innovative approaches is that it focuses on the process instead of the product.

Design thinking as a process follows an iterative dynamic process broken down into five specific phases:

Empathize, Define, Ideate, Prototype and Test (Dam \& Siang, 2018).

Empathize is the first stage of the Design thinking process, it is to gain an empathic understanding of the problem we are trying to solve. This first step is crucial to a user-centered design process and allows students to set aside their own assumptions about the problem in order to gain insight into users and their needs.

The second stage is Define. In this step students put together all the information they have gathered during the Empathise stage in order to define the core problems they have identified up to this point.

During the third stage (Ideate) students are ready to start generating ideas, identifying new solutions to the problem defined at the second stage. At the beginning of this phase, it is important to get as many new ideas as possible in order to find the best solution. 
The Prototype stage is an experimental phase and during it, students have to identify the best possible solution for each of the problems. The students implement solutions within prototypes, and all the prototypes must be tried, one by one. At the end of this stage, the students will have a clearer view of how real users would solve the problem using the student's product.

The last phase is Test. During this phase students test the complete product using the best solutions identified during the prototyping phase.

In order to improve future teachers training we have chosen Design Thinking because it could be adapted to any discipline and profession, developing fundamental skills and competencies in today's society. This methodology has been shown to improve teaching-learning experiences and it is beneficial for both teachers and students (Scheer; Noweski \& Meinel, 2012).

\section{Method}

The new educational framework demands the shaping of responsible professionals, committed to their work and willing to transform and improve the reality that surrounds them. In order to institute the changes and innovations that are necessary at the educational and social level, it is imperative for the training of such professionals to be in line with these approaches. Future teachers must be creative professionals capable of developing professional activities to improve and not only to replicate the social experience in order to create new learning experiences. In this way, the main aim of our work was to explore how the use of Design Thinking Methodology improves learning processes in a group of college students of the Primary Education Degree.

\subsection{Sample}

The study was carried out with a sample composed of a total of 65 participants aged between 19-28 years $(\mathrm{M}=20.16, \mathrm{SD}=1.51)$, all of whom were students at the University of Jaén (Spain). The participants belonged to the second year of the Degree in Elementary Education. This group of students, divided into 21 smaller working groups, created different educational videos and multimedia design projects through Design Thinking methodology. The students were participating in the subject New Technologies applied to Education. The practical curricular placements for the subject were carried out in accordance with the DT methodology, such that students designed and carried out, in collaboration with the teachers involved, small design-thinking projects that responded to the needs observed in their social environment. These practical placements were undertaken in small groups (4-6 students) and followed the fundamental scheme and the defining principles of this methodology. They were also encouraged to use Social Networks (specifically Instagram) to present and publicize the progress they were making on their work, in order to obtain feedback from their classmates. All the projects developed were related to three thematic areas: Art for everyone; Attention to diversity and Making great neighborhoods.

At the end of the creation process, we analyzed the students' perception of how the design thinking methodology helps them through their learning process.

\subsection{Instrument}

An ad hoc questionnaire was designed in order to analyze the impact that the use of the Design Thinking methodology and the use of Instagram in the learning process and its influence on different variables was studied. The questionnaire was composed by 38 items divided into nine dimensions:

a) Identification items; Items related to the personal data as gender, age, ...

b) Motivation; items focused on analyzing the student's motivation during the process.

c) Involvement to connect to class; to participate in, to achieve learning...

d)Creativity; searching for sources of inspiration; searching for different answers; ...

e)Communication; Between class groups; between group members; between groups and teachers; quantity; quality; fluency....

f) Supervise; accompaniment; feedback; teacher guidance; supervision; support.

g)Publish; Publicizing results; publicizing their work;...

h)Success; motivation towards success; Perception of usefulness of work...

i) Social Implication: To awaken interest in the service; to encourage participation in other social actions.

The questionnaire was validated through expert judgement. Lawshe content validity index was used to measure strength of agreement $(\mathrm{CVI}=.966)$ (Ayre \& Scally, 2014). A Likert scale with five-point agreement was used to measure students' agreement (being $0=$ completely disagree to $5=$ completely agree). 


\section{Results}

The students score all the variables above 3.5 (see figure 1). For the dimension of Motivation all the items scored above 3,6.

Figure 1. Mean Averages for variable.

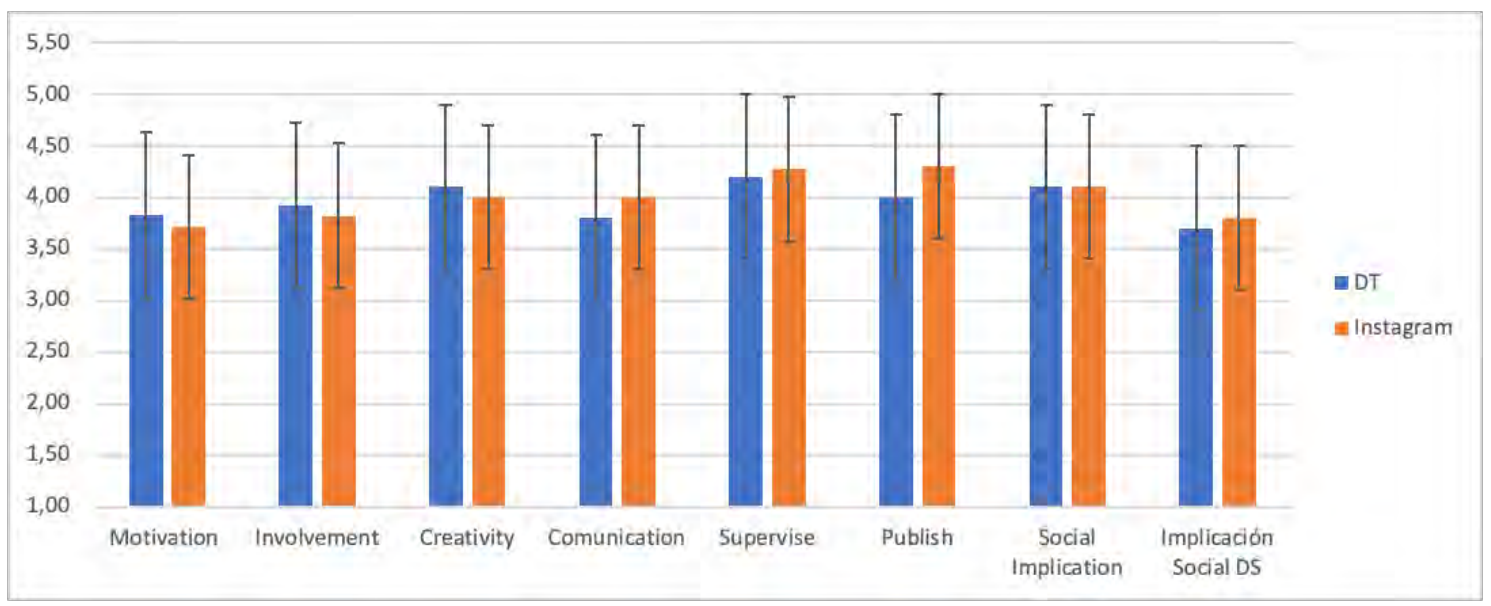

Some of the most significant results could be observed when analyzing the percentages achieved in some of the items that compose the dimensions. Almost all students agree with the statement that Instagram and DT are increasing their motivation for the project.

Figure 2. Percentages for the item "increased your motivation for the project".

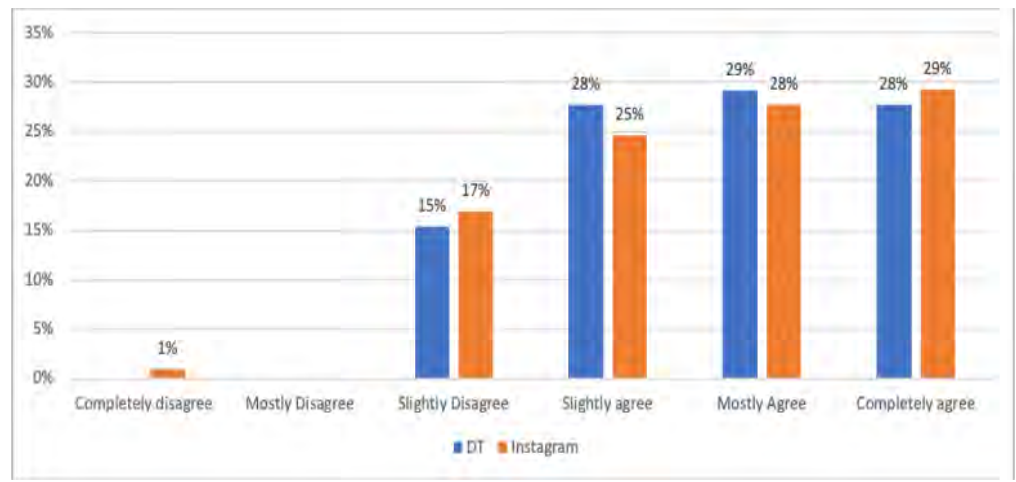

Asked about effort, most of the students strongly or completely agree that both methodologies increased their level of effort towards the project (see Figure 3). The same level of agreement could be observed with the statement about the level of creativity (see Figure 4)

Figure 3. Percentages for the item "increased your effort".

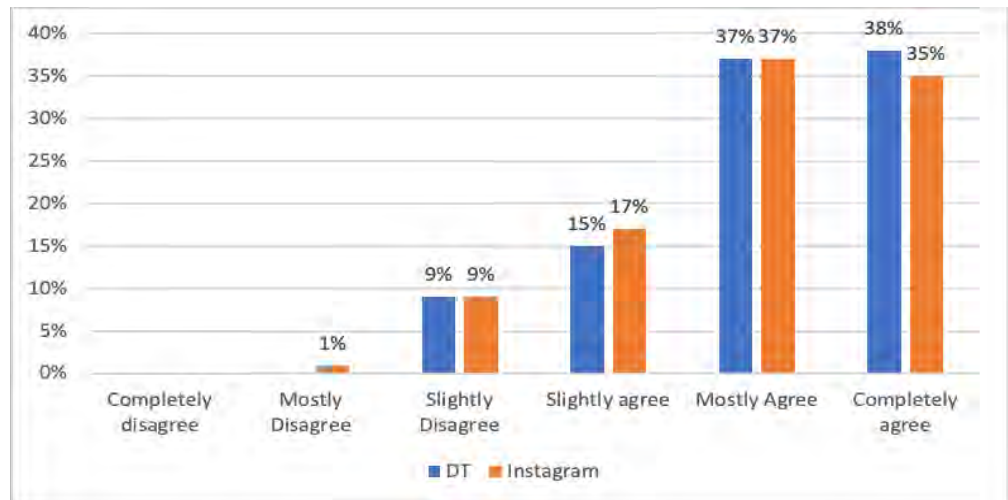


Figure 4. Percentages for the item "increased your creativity".

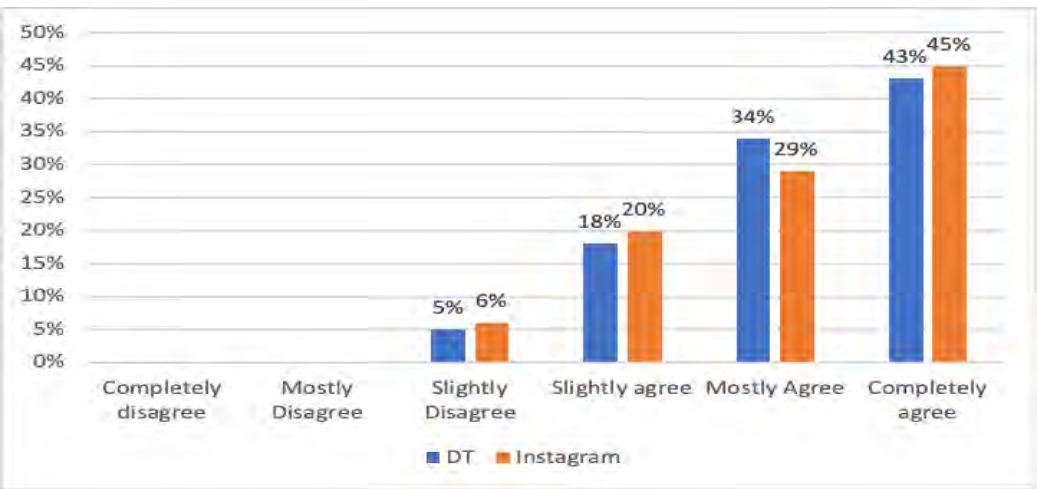

Regarding the variable communication most of the students consider that they have improved their communication with the teacher (see Figure 5). In addition, among all of them, consider that the use of those methodologies has favoured the teacher's monitoring of their progress in the project (see Figure 6).

Figure 5. Percentages for the item "Improved your communication with the teacher".

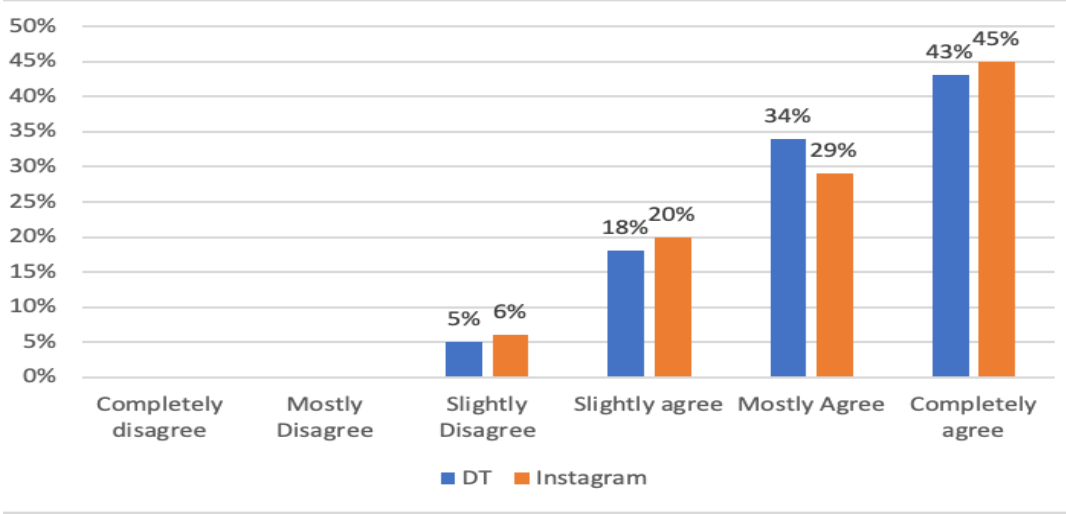

Figure 6. Percentages for the item "Favored the teacher's monitoring".

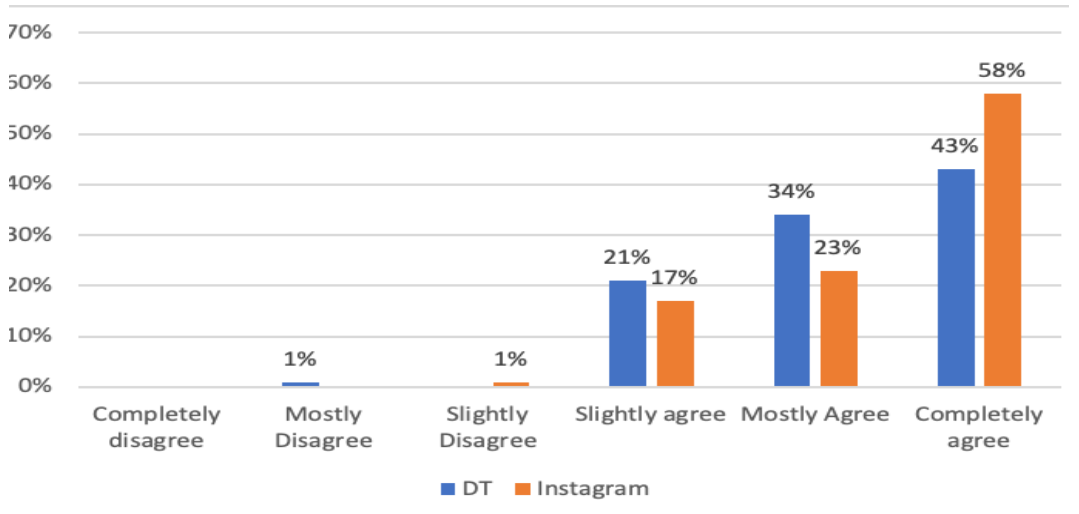

\section{Conclusions}

In recent years, DT has been configured as a novel and creative strategy to address problem solving that can be applied to a multitude of fields and disciplines (Dorst, 2011). Design thinking is a teamwork method that encourages student participation, creative thinking and improves their learning experiences 
(Bongiovanni \& Balgabekova, 2021). In addition, Design thinking helps students to contextualize needs, generate useful solutions and develop empathy, since it is part of human-centered design.

In our study, the results show that the use of this methodology had a positive impact on practically all the variables, facilitating and optimizing the learning process of future teachers. Students have improved not only in creativity and metacognition, but communication with teachers has increased, being one of the variables that we highlight as very positive. In addition, we agree with Scheer, Noweski \& Meinel (2012) that it is necessary for teachers to be trained in this technique and gain confidence in its use, so we think it would be necessary to include it in the training of future teachers.

\section{References}

Anderson, N. (2012). Design Thinking: Employing an Effective Multidisciplinary Pedagogical Framework to Foster Creativity and Innovation in Rural and Remote Education. Australian \& International Journal of Rural Education, 22(2), 43-52. Retrieved from http://search.ebscohost.com/login.aspx?direct=true\&db=ehh\&AN=80037529\&site=ehostlive

Ayre, C., \& Scally, A. J. (2014). Critical values for Lawshe's content validity ratio: revisiting the original methods of calculation. Measurement and Evaluation in Counseling and Development, 47(1), 79-86. https://doi.org/10.1177/0748175613513808

Bongiovanni, I., \& Balgabekova, D. (2021). Ask me if I am Engaged: A Design-led Approach to Collect Student Feedback on their University Experience. Design and Technology Education: An International Journal, 26(1), 89-117. Retrieved from: https://ojs.lboro.ac.uk/ DATE/article/view/2864

Brown, T. (2008). Design Thinking. Harvard Business Review, 1-10.

Dam, R. \& Siang, T. (2018). 5 stages in the design thinking process. Retrieved from https://www.interaction-design.org/literature/article/5-stages-in-the-design-thinking-process

Dorst, K. (2011). The core of 'design thinking' and its application. Design Studies, 32, pp. 521-532. doi:10.1016/j.destud.2011.07.006

Rauth, I., Köppen, E., Jobst, B., \& Meinel, C. (2010). Design Thinking: An Educational Model towards Creative Confidence. In First International Conference on Design Creativity (pp. 1-8). Kobe, Japan.

Scheer, A.; Noweski, C. \& Meinel, C. (2012). Transforming Constructivist Learning into Action: Design Thinking in education. Design and Technology Education: An International Journal, 17 (3), pp. 8-19. Retrieved from: https://ojs.lboro.ac.uk/DATE/article/view/1758 


\title{
THE IMPACT OF COVID-19 ON THE SCHOOL WORLD
}

\author{
Rosanna Tammaro', Anna D’Alessio' ${ }^{2}$, Annamaria Petolicchio ${ }^{2}$, \& Anna Iannuzzo ${ }^{3}$ \\ ${ }^{1}$ Department of Human, Philosophic and Education Sciences (DISUFF), University of Salerno (Italy) \\ ${ }^{2}$ Salerno (Italy) \\ ${ }^{3}$ Avellino (Italy)
}

\begin{abstract}
The COVID-19 pandemic is firstly a health crisis, but also a huge shock for the educational world (from primary school to university). The impact of COVID-19 on the school world has been very strong. Education has been hit hard with schools closing down internationally and students forced to stay home. The global lockdown of schools has caused a severe and probably unparalleled disruption in student learning. In this scenario, teaching has moved online, the school world has suddenly been forced to move towards the dimension of distance learning, in Italian DAD. A new acronym, DAD, which is used to identify a type of training and teaching that is implemented, precisely, remotely or where there is no sharing of a space and a physical interaction between teacher and students, but everything is mediated by the use of technological means and the internet.

The article aims to describe to a teacher audience, the most important steps in online/distance learning, DAD, adopted during pandemic in Italian school system, with its implications for teachers and students. After a brief overview of the main theoretical frameworks, we will try to describe the current state, in our country, of this methodology, its characteristics, its objectives and the roles of the actors involved. This article is an exploratory case study that involved the use of an observational research technique. It sought, through "living the situation in first person", to critically consider the advantages and disadvantages of this new didactic approach, of this different way of studying/teaching and the future prospects in restarting lessons in a Covid world.
\end{abstract}

Keywords: Distance learning, face-to-face learning, pandemic, digital technologies, COVID-19.

\section{Introduction}

The COVID-19 pandemic has changed education permanently. It has drastically forced the distinctive rise to e-learning, so that teaching is undertaken remotely and on digital platforms. A new acronym, DAD, distance learning, is often used in a generic way to identify a type of training and teaching that is implemented, precisely, remotely or where there is no sharing of a space and a physical interaction between teacher and students, but everything is mediated by the use of technological means and the internet.

The term online/e-learning is commonly used. Or perhaps it would be more accurate to say that it has become a "hot" word, used, sometimes abused, in educational areas. The difference at present is that every segment of the education sector must launch this method of teaching, which is therefore highlighting, on a large scale, its advantages and disadvantages. Online and traditional education, in presence, involve two different types of learning, each with its own teaching method, its own channels and guidelines. This asynchronous system allows students to attend classes, work, communicate, take exams, and access content wherever they are. Another aspect of distance learning is that it stimulates students' independence and curiosity, collaborative work, critical thinking, and self-directed learning. This system also diversifies sources of knowledge. With classroom learning, students go to a physical class where teaching takes place and much of the learning takes place. With this method, students take on a more passive role and adapt to the teacher's pace and teaching method. The teacher is the primary source of information.

Turning to the theories underlying distance education, we will start with the opening sentence in the 2003 Handbook of Distance Education states, "America's approach to distance education has been pragmatic and theoretical" (Saba, 2003, p. 3). In addition, Charles Wedemeyer, a theorist who has made notable contributions in the area of distance education theory, claims that distance education has yet "to develop a theory related to the mainstream of educational thought and practice" (Keegan, 1996, p. 56). As noted by Saba (2003), distance education's roots in the United States date back to the 1800's; however, the first scholarly journal, The American Journal of Distance Education, was not started until 1987, by 
Michael G. Moore. This journal History, Theory, and Quality of DE 15 and the symposia of the American Center for the Study of Distance Education, organized by Moore, emphasize the importance of distance education theory and recognize the contributions of research and practice in the discipline of distance education (Saba, 2003). Distance education theories, developed from leading scholars in the discipline, such as Holmberg, Wedemeyer, Moore and Peters, can be categorized into three broad groups (Keegan, 1996; Saba, 2003).

1. Theories of autonomy and independence. Borje Holmberg, Charles Wedemeyer, Rudolf Delling, and Michael G. Moore developed theories of distance education that placed the learner in the middle of the educational process (Keegan, 1996; Saba, 2003). According to Saba (2003), "the centrality of the learner is one of the distinguishing features of distance education, and understanding this fact is essential for discerning why it is essentially different from other forms of education" (p. 4).

2. Theory of industrialization. Otto Peters, Desmond Keegan, Randy Garrison, and John Anderson are theorists in distance education that have developed theories that are mainly interested in how the field functions and how it is organized. Structural concerns and issues (e.g. industrialization) are the main foci of this group of theories, along with how those issues influence the teaching and learning process (Keegan, 1996; Saba, 2003).

3. Theories of interaction and communication. Contemporary ideas and views of Holmberg, John A. Baath, Kevin C. Smith, David Stewart, and John S. Daniel History, Theory, and Quality of DE 16 highlight the constructs of interaction and communication as important factors in distance education (Keegan, 1996).

\section{Method}

\subsection{Face to face vs distance learning}

Traditional learning, Face-to-face, is essentially linear, it tries to follow a predetermined sequence of programmed and pre-ordered passages typical of lectures and textbook contents; it is centered on the knowledge achieved by each student and basically follows a single direction, which goes from the teacher to the learner. Traditional teaching sees the teacher "only" in front of the class and the transmission of the didactic content is linked to his knowledge and his ability to be understood and to arouse interest. It is characterized by the verticality of the communication, by the passivity of the addressees; the success of the lesson is directly based on the communication and teaching skills of the teacher; on the teaching model based on the idea of teaching as a "transfer of knowledge" from the teacher to the students; on the difficulty in differentiating the teaching contribution; on the tendency to favor verbal communication over other communication codes; excessive weight of the "class group" compared to other possible aggregations.

According to Ray Williams, a writer who contributes to Psychology Today, human interaction is fundamental to one's life and is one of the characteristics that distinguishes the human being (Harry, Keith, John Magnus, Keegan, Desmond, 1993).

Distance learning can adversely affect the quality of training provided, and virtual training creates a blanket of anonymity which allows students to participate in a misleading way. The school covers conditions of space, time and relationship, which can only be activated in presence. Space is of considerable importance for the learning process of students. They must be able to face each other and with teachers during the preparation of an activity; have the opportunity to work as a couple and in a small group; be able to move, work and relate in a shared space; have opportunities to meet and exchange with other mates of the school. The digital environment is a virtual place and it is therefore a different kind of learning environment from the classroom, which has its own physicality (Anna D'Alessio, 2019). Physical space, which was the specific and shared element of schooling, has been restricted to housing. Children and young people are located in very different environments and almost never suitable for learning. The public-school space enters the private space house, creating a hybrid element that involves disorientation.

The remote learning relationships have changed considerably: without bodies the relationship is only virtual. At school the educational model is based on the autonomy of the students, on self-study: it is a personal work in a collective path, shared with the classmates and checked before, during and after by the teacher, who notices the difficulties and intervenes, dealing directly with the student, supporting him, reassuring him. With distance learning all this is impossible: the student is alone (Moore, G. Michael, Kearsley, Greg, 1996).

2.1.1. Teachers and students' role within distance learning. In distance learning, the horizontal relationship among students, that is, among peers who activate questions, answers, initiatives, forms of mutual help and links that strengthen or prevent learning and make them significant on human level, is greatly reduced, but for this reason it must be treated with the utmost care. Within a virtual class students can share thoughts and images, jobs and opinions, but they cannot share the experience that a group of 
students make a class: smiles, eyes, quick interactions without the teachers' knowledge, the sandwich had together on break, the volleyball match are all possibilities of mutual knowledge and informal learning that in distance learning environment fail. However, efforts can be made to remedy this by planning activities that require exchange and collaboration between students, such as collective writing, debates, exchanges of messages to develop shared responses to problems that require a common effort. In any case, you should not give up having a class perspective.

The vertical educational relationship, since it provides a relationship between teachers and students, that is among adults, who possess expert knowledge, and learners, it is activate primarily by teachers and, as in presence - but with reduced possibilities for correction in itinere - must be calibrated according to the students, the contexts from which they come from, the difficulty of the content and the tools available. Proposing distance activities, therefore, we must consider the pedagogical profiles of students, their learning styles, their motivational drive, their knowledge, the tools they possess and their autonomy. In this sense, precisely because there is a lack of direct comparison in situation, distance learning requires greater attention in the planning phase and a strong sharing of basic choices (Andersen, S C, and H S Nielsen, 2019).

The context of distance learning is more rigid than that of teaching in presence. In addition, as mentioned above, the educational motivation of the group is changed, but the teacher can still act as a mediator. First of all, the teacher can present the contents in multidimensional form, in order to speak to the cognitive styles of all students, also he can calibrate the contents and fix time so that no one is left behind, finally he can continue to stimulate the relationship between peers and to make his human closeness felt with direct personal contacts. The aim of teaching should promote greater autonomy, and distance learning must be kept firm and declined according to the possibilities offered by the tools available (Anna D’Alessio,2014).

2.1.2. To convert a face to face class to online/remote learning. Our original and innovative learning experience. The 2020 will surely be remembered in the history manuals as a year of great social, relational, educational changes. Imagining a new secular dating, it could be considered as the year zero, the year of "non-return", which has seen a sudden transformation in economic, health, geopolitical, organizational terms. The school was overwhelmed by this tsunami and was catapulted into a dimension that, although long desired, was struggling to take off: distance learning. As Bonazza (2014) points out, the means that will be used cannot be conceived according to an exclusively instrumental function but must be considered "as constitutive elements of the end itself: it will therefore be necessary to proceed by identifying the values enclosed in the means, contemporary to their function" (p.229). The first obstacles we faced were of a practical nature: protection of privacy, primarily of learners; choice of the platform that could be closer to our educational needs. With regard to the first issue, the bounce of circulars and ministerial statements, often contradictory, initially led to autonomous choices within the class councils and then to arrive at a shared solution, with the consent of the parents, which provided for the use of the camera only during the written tests and interviews. It was difficult to choose, within the wide range of offers, the educational platform that would meet everyone's needs. In our daily pre-Covid practice, we used more than one platform, according to the disciplines and their purposes of use. Each had strengths and weaknesses, but it was necessary, both to facilitate our students and for the traceability of the routes, to adopt only one that could guarantee access through institutional accounts.

Once the practical problems were resolved, there have been basically three guidelines along which we have moved: ensuring fair conditions; redesigning educational interventions; remodulating of the assessment tests and the evaluation headings.

Even before proceeding with distance learning, it was necessary to control the instrumental equipment of the individual students, the possibilities of connection and the quality of the network. The school has tried to provide learners without the necessary equipment, but in some areas, especially inland, the lack of broadband network has partially frustrated the effort.

Speech aside deserves the re-design of educational and training interventions. It was immediately apparent that the objectives had to be recalibrated, certain new evidence of acceptability had to be recalibrated and teaching experiences rescheduled, in view of the different educational context. The contingent circumstance has made us more aware that the challenge is to make the transition from a highly centralized design on teaching, which anticipates and breaks down the process in an analytical way, corroborating the transfer of disciplinary content, to a design aimed at learning, which does not anticipate actions but adapts to processes and reflects the project, bending it on the training needs of the students. Distance learning involves a different methodological-didactic approach than the lesson in presence. In order to make educational intervention effective and efficient, it is necessary to promote the sharing and active participation of the learner. In view of the fact that the attention does not remain unchanged throughout the lesson, presenting an alternation between moments of increase and moments of decrease in the level of attention, video lessons with a maximum duration of 15/20 minutes were chosen. It was also necessary to make further choices regarding the content and based on the suggestions made by 
Wiggins and McTighe (2005). In their design proposal, Backward Design, the two U.S. authors identify four principles that can guide teachers in choosing content: transferability: centrality: involvement.

Great importance has been given to monitoring, both formally, through regular documents on the progress of activities, and informal, based on the exchange of views and information between teachers and learners.

"Referring to the monitoring of training in multimedia environments, Moretti (2005), taking up the distinction presented by Calvani \& Rotta (2000), distinguishes three types of monitoring: internal to the training system and transparent to some of the system's staff; reactive: the documentation and data provided by the surveys are used to modify, integrate or correct the paths or "to guide the movements adopted by some of the protagonists of the training path" (Moretti, 2005, p.235); dynamic: its main feature is to change together with the learning paths" (Petolicchio, 2019, p.143).

With regard to evaluation, we focused, as Galliani suggests (2015), on the three conditions that ensure alignment and consistency between the training process and the evaluation process: identify the aims of the training process; develop interactions between trainees and learning objects, manage the enactive dynamics that link content to cognitive and motivational strategies.

Great importance has been given to the training function of the evaluation, which, thanks to the continuous feedback received and sent to the students, has allowed not only to orient and remodulate the activities but, above all, to tend to individualized curricula, which allow each student to achieve the same cultural, and personalized skills, which offer the opportunity to discover the originality of the individual.

\section{Result}

What has the covid-19 crisis taught us about online teaching?

As the coronavirus spread, education institutions were obliged to face a major challenge: how could they continue to offer instruction if face to face classes and lectures were closed? An increasing number moved classes online as a short-term solution.

When the lesson is supported by technology, the expectations of the students change. A simple diffusion of modern technological equipment should not be considered but rather a support for innovation of the learning environment. In this context, the risk of " isolation" can be very high when considering that students are greatly attracted by the world of the media. Thus, the teacher must consider the emotional-affective factors of the educational relationship and should pay attention to the training as well as organization of the class, ie the way of working out the goals and the tasks, and of communicating student deliveries, predisposing the spaces, times, preparing and distributing materials, tests and evaluating processes and products.

Our personal teaching experience has shown that a new learning environment starting from the renewed classroom is powerful. Proper teaching methodology should be moved by the student. This will make learning meaningful to students, because it starts from their interests, their training needs, socio-cultural reality in which they live, thus maintaining high motivation level and the interest and reward the application. Students have changed and so have their development needs. The demand for education is very different from the past. It starts from understanding the students and responding to their needs.

Preparing for tomorrow. We must remember that, as the Chinese proverb says, spring always ends winter. It is important to establish a reference framework that helps decision-making processes in the higher education sector (Anna D'Alessio,2006), without forgetting that the first priority must be the protection of health; ensuring the right to education of all persons within a framework of equal opportunities and non-discrimination is the first priority; as well as promoting and supporting inclusive, relevant, adequate and quality programs and initiatives; leaving no student behind, the crisis has a different impact on different student profiles, but it is undeniable that it deepens existing inequalities and generates new ones. Prepare in time for the resumption of face-to-face classes, avoiding having to rush and offering, from the beginning, clarity in communication to the entire academic community and administrative and academic security, so that teachers, administrative and service personnel, and students can place themselves in the new context knowing in advance the provisions, processes and mechanisms designed to resume teaching activities.

\section{Discussion}

In the recent months the school has been at the centre of a debate that, never before, has everyone involved.

Suddenly the way of "schooling" has changed, the community dimension has been lost with its rituality. There is no doubt that one of the key elements of the learning process is the dynamic relationship shared among students, and between students and teachers. Face-to-face learning fosters these relationships; this dynamism can be minimized, or lost, when training is undertaken remotely or in 
virtual format. The wealth of information and experiences are deduced from body behaviour and language, gestures, tone and volume of voice. Face-to-face communication allows the whole experience not only to be heard, but also seen and felt. That shared "physical" space, considered by Gennari (1997) "pedagogical object", therefore usable in teaching, and "pedagogical subject", as an activator of autonomous training courses, has been missing. It is sad to see that it has taken a pandemic to put into practice what has long been planned on paper!

Vertecchi's thought (1999) is fully topical and fully acceptable, pointing out that there is still "great confusion about the role of the school in contemporary society. It is no longer clear what its task is, since the responsibility of the school in relation to cultural acquisitions appears to have diminished, while an increasing emphasis is placed on educational dimensions which, in most cases, are only an attempt to remove aspects of the discomfort of civil society. The contradictions of the latter are passed on to the school, with the sole effect of making the specificity of its role in the social context less and less recognizable" (p.145).

\section{Acknowledgements}

The views, thoughts, and opinions expressed in this article are solely those of the authors and not necessarily associated with the view of a specific research in education. They are only linked to an original and innovative learning experience. The authors' professional experience has been mainly focused on the teaching trying to turn lessons into an online version in a few weeks using a $100 \%$ online synchronous approach. This was an exploratory case study since the main purpose was to "live in first person the situation" to see if a well-structured online class is a powerful tool to facilitate the teaching /learning process in Times of Crisis.

\section{References}

Andersen, S C, \& H S Nielsen (2019). Learning from Performance Information, Journal of Public Administration Research and Theory.

Bonazza V. (2014). La dimensione assiologica: equità, rendicontazione, miglioramento. In L. Galliani, A.M. Notti (Ed). Valutazione educativa, 227-254. Lecce-Brescia: Pensa MultiMedia

Calvani A., Rotta M. (2000). Fare formazione in Internet. Manuale di didattica online. Trento: Erikson.

D’Alessio A. (2006), La progettazione didattica. In A.M.Notti, Il controllo dei processi didattici e gestionali. La scuola che si valuta. Pensa, Lecce.

D’Alessio A. (2014), La relazione educativa come esperienza reale del vasto e complesso mondo dei rapporti interpersonali, Quaderni dell'Istituto Superiore di Scienze Religiose Giovanni Duns Scoto.

D’Alessio A. (2019), Immersive didactic approach teaching with virtual reality as integrated learning environments, 11th International Conference on Education and New Learning Technologies.

Galliani L. (2015). Epistemologia della valutazione educativa. In L. Galliani (Ed). Agire valutativo: manuale per docenti e formatori, 25-39. Brescia: La Scuola.

Gennari M. (1997). Pedagogia degli ambienti educativi. Roma: Armando Editore.

Harry, Keith, John Magnus, Keegan, Desmond (1993) Distance Education: New Perspectives Routledge in London and New York.

Keegan, D (Ed.) (1996). Foundations of distance education (3rd ed.). London: Routledge.

Keegan, D. (1986). The foundations of distance education. London: Croom Helm.

Moore, G. Michael, Kearsley, Greg (1996) Distance Education System View. Wadsworth Publishing Company in United States of America.

Moretti G. (2005). Prove semistrutturate e valutazione negli ambienti multimediali per la formazione. In G. Domenici (Ed). Le prove semistrutturate di verifica degli apprendimenti, 228-246. Torino: UTET.

Petolicchio A. (2019). Progettare per competenze. La progettazione nella logica del Lifelong learning. Roma: Anicia.

Saba, F. (2003). Distance education theory, methodology, and epistemology: A pragmatic paradigm. In M.G. Moore \& W.G. Anderson (Eds.), Handbook of distance education, 3-20. Mahwah, NJ: Lawrence Erlbaum Associates

Vertecchi B. (1999). Cinque idee per la riforma. In A. Sasso, S. Toselli (Eds). La scuola nella società della conoscenza. Formazione, tecnologie, informazione, modelli di vita. Milano: Bruno Mondadori.

Wiggins G., McTighe J. (2005). Understanding by Design. Alexandria-Virginia (USA): ASCD, expanded 2nd edition. 


\title{
MASSIVE OPEN ONLINE COURSES CAMPS: BEFORE AND DURING THE PANDEMIC
}

\author{
Janaina Cardoso \\ Anglo-Germanic Department, Institute of Languages and Literatures, UERJ-Universidade do Estado do \\ Rio de Janeiro (Brazil) \\ CNPq - National Council for Scientific and Technological Development, CNPq Researcher (Brazil)
}

\begin{abstract}
MOOC Camps have been used as a successful blended alternative to more traditional MOOCs (totally online). A "camp" here means "an informal gathering of learners working together to discuss new ideas and concepts" (Sowell, 2019). MOOC Camps combine the positive aspects of MOOCs, such as high-quality of professional development and low cost for participants with the advantages of using the "camps", such as adaptation to the local context and a simpler way of promoting interaction among participants, who consequently feel highly motivated to complete the online course (Cardoso, 2020).

The aim of this presentation is to consider the effects of the physical distance imposed by the COVID-19 pandemic in the MOOC Camps been offered by an extension and research project developed at a public university in Rio de Janeiro, Brazil (CEALD/UERJ) in partnership with the American Government (RELO-Brazil) since 2019. The main objectives of these MOOC camps are: (a) to promote language and methodology development; and (b) to build stronger communities of teachers and teachers-to-be, by giving them the opportunity of sharing their experiences. However, in 2020, due to the pandemic, the camp had to be adapted to a remote mode, using a web-conference platform. Therefore, this action-research study compares and contrasts the MOOC Camp participants' feedback given before the pandemic with their responses to the activities developed during the pandemic. In this way, the idea is to understand how the adaptations we were forced to make have influenced the development of the camps and possibly affected participants' interest.

The discussion considers some of the advantages and drawbacks of adopting the remote mode for the camps, and a better understanding of some theoretical concepts, such as: blended learning (Gruba et al., 2016); blended MOOCs (Albó et al., 2015; Orsini-Jones, 2018, 2019), online interaction (Silva, 2014), and education in the pandemic context (Liberali, 2020).
\end{abstract}

Keywords: $M O O C$ camps, pandemic context, online interaction, blended learning, remote teaching.

\section{Introduction}

Since 2019, we have used Massive Open Online Courses Camps (MOOC Camps) for language teacher development as an alternative to the regular MOOCs. The term "camp" in this context is defined as "an informal gathering of learners working together to discuss new ideas and concepts" (Sowell, 2019). These face-to-face facilitated sessions were offered by a research the extension project developed at a public university in Rio de Janeiro, Brazil (CEALD/UERJ). In fact, UERJ was the first university to organize MOOC Camps in partnership with the American Embassy in Brazil (RELO-Brazil). The American Government sponsored the MOOCs and the university was responsible for the camps.

MOOC Camps differ from other MOOCs because it allows more interaction between participants (Silva, 2014). Participants (including the facilitators) work together, exchanging work experience, discussing topics introduced in the online course, preparing lesson plans and developing teaching activities. However, it also differs from many other kinds of blended MOOCs (bMOOCs) (Albó, 2015; Orsini-Jones, 2018, 2019) because it is not a way of integrating MOOCs to the traditional curriculum, but to offer support to the online course. MOOC Camps have been used as continuous education and, consequently, participants have no formal obligation to take them.

MOOC Camps have combined the positive aspects of MOOCs such as high-quality of professional development and low cost for participants with the advantages of using the "camps", such as adaptation to the local context and a simpler way of promoting interaction among participants, who 
consequently feel highly motivated to complete the online course (Cardoso, 2020). The main objectives of CEALD MOOC camps are: (a) to promote language and methodology development; and (b) to build stronger communities of teachers and teachers-to-be, by giving them the opportunity of sharing their experiences.

The results of this previous studies (Cardoso, 2020) showed that CEALD MOOC Camps were successful. According to the participants' feedback, they have developed their methodology awareness and improved their knowledge of the English language. Not only did they consider the face-to-face facilitated sessions useful, but they believed that these sessions helped keeping them more interested in the online course. However, in 2020, with the Covid-19 pandemic, we had to adopt a remote mode. The in-person gathering were substituted by synchronous meeting using a web-conference platform (RNP - a Brazilian open platform).

Therefore, this study presents the findings of this second cycle of a participatory action research project. The main objective is to discuss the effects of the physical distance imposed by the COVID-19 pandemic in these MOOC Camps. In this phase, the research compares and contrasts the MOOC Camps participants' feedback given before the pandemic with their responses to the activities developed during the pandemic, in order to understand how the adaptations we were forced to make have influenced the development of the camps and possibly affected participants' interest.

We believe that this discussion may help in the development of new versions of the MOOC Camps in the future.

\section{Research background}

As mentioned before, the present study is part of a bigger research and extension project called CEALD, which in Portuguese stands for "Collaboration, Learning Strategies and Digital Literacies". The aim of the project is to provide opportunities for language and methodological development for teachers adopting a reflective and critical approach (Cardoso, 2018). The project is based on three main concepts: equity, resistance and collaboration. The first objective was "to help learners who have lower level of English than their classmates succeed in their ELT graduate course" (Mateus, Miller \& Cardoso, 2019), but as time went by, we noticed that there were teachers who also needed language improvement and/or methodology update but could not afford paid courses or did not have time for formal post-graduate education. MOOC Camps which focused on teaching methodology awareness seemed a good option as teachers and university students (teacher-to-be) from different backgrounds and at different levels of English could work together, collaboratively discussing new teaching and learning approaches, designing activities and exchanging experiences, fostering Silva (2014)'s concept of "interactive classroom". Another positive point is that the online courses help participants develop their digital literacies (Pegrum \& Cardoso, 2019), and to adopt a more positive view towards using technology in the classroom in a creative and critical way. For all these reasons, the MOOC Camps have been used as one of the intervention activities of the research project. There are other intervention activities, such as events, lectures, research groups, individual assistant, but in the present study we will focus on the camps.

In 2019, we offered three MOOC Camps: Teaching Grammar Communicatively, Integrating Critical Thinking Skills into the Exploration of Culture in the EFL Setting and Teaching English to Young Learners. For each camp, we had from 20 to 30 participants (divided in two groups), about 83 participants altogether in that year. Our plans were to offer at least two camps in 2020, but due to the Covid-19, we were able to offer only one, by the end of the year when the classes restarted (September 23 - October 28), with a one-hour synchronous session a week. As Liberali (2020) mentions, with the pandemic we had to rethink our priorities as educators. The most important aim was to survive, and the pandemic showed that many of us was substantially vulnerable not just in relation to health conditions, but to basic survival needs. Liberali mentions that "necro-politics" (which deals with the decision of who will survive and who will die) led also to "necro-education" (which deals with the decision of who will be able to study who will not), but we could not surrender. Emergency remote education has seemed to be the only option, but for some of the learners and teachers this was not an option at all, for lack of equipment or internet connection, unhealthy conditions (including lack of concentration), and/or unemployment (which in many cases led to hunger). Most teachers were not prepared to adopt this new kind of teaching, but we had to learn fast. The most heard term was "adaptation". But how to be flexible and creative in such conditions? Collaboration became one of the most important alternatives. We had to share ideas to find solutions to our common problems. Autonomy was transformed into interdependence.

In our case, with adaptation in the modality and collaboration of colleagues and university students who worked as a team of facilitators we were able to offer the MOOC Camp TESOL Methodology. 


\section{Research methodology}

As already mentioned, this study is a second cycle of a participatory action research project. The first phase we considered the usefulness of the face-to-face facilitated sessions. We found out that participants who finished the camp had a very positive perspective in relation to the online course and the in-person facilitated sessions. Besides, they felt highly motivated in taking other MOOC Camps (Cardoso, 2020). Following Kemmis \& Wilkson (2011) and Thiollent (2011) and steps of the action research cycle of our project were defined as can be seen in Figure 1:

Figure 1. CEALD Project Action Research Cycle (Cardoso, 2018, 2020).

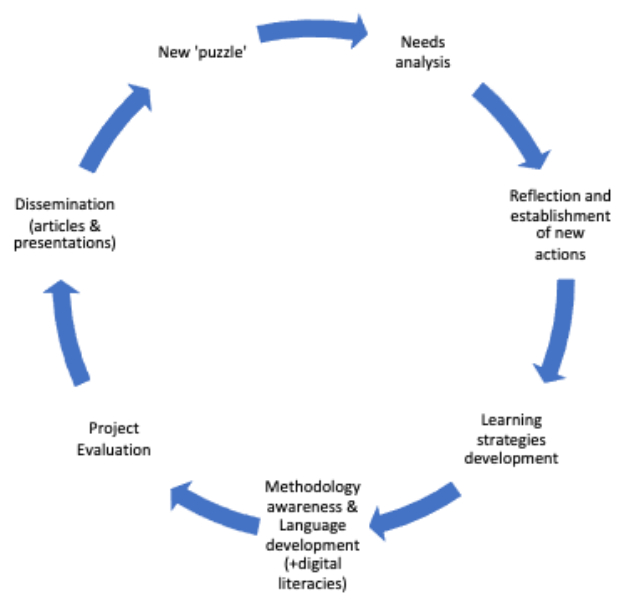

In the first cycle, we had already evaluated the project, disseminated ideas (in conferences and articles), but suddenly we had a new 'puzzle' (Allwright 2002, 2003 apud Cardoso 2020), which was the adaptations we had to do because of the pandemic. After considering the problems and much discussion, we (group of facilitators) decided to use virtual meetings, during the sessions again we discussed teaching and learning strategies and tried to improve their language use and digital literacy through methodology awareness. Now we are using their feedback to evaluate the process and disseminate the findings. This discussion will help decide about the project next steps.

\subsection{Research participants}

In the previous versions of CEALD MOOC Camps, about two-third of the participants were English language teachers and one-third were university students (future teachers). In each group, there were at least four facilitators and 10 participants. We accepted 15 participants for each group (30 altogether), but only 22 answered the feedback questionnaire. Therefore, they will be considered our main research participants. The participants were between 20 and 50 years old. In each group, there were always four or five facilitators. In group one, the facilitators were 2 monitors (undergraduate) and 3 professors, while in group two, there were 1 monitor (undergraduate), 1 teacher (Master degree student and part-time university teacher) and 2 professors. The university teachers were between 40 and 59 years old. As for the monitors, they were in their 20s. All participants (including the facilitators) are Brazilian, being Portuguese our first language, but we only spoke in English during the synchronous virtual meeting. In the WhatsApp group, we normally interacted in Portuguese, but exchanged texts and videos in English.

\subsection{Research questions}

The main aim of the research is to understand how the adaptations we were forced to make because of the Covid-19 pandemic have influenced the development of the camps and possibly affected participants' interest. Therefore, our main research questions are the following:

RQ1: How has the pandemic forced a change in the MOOC Camps?

RQ2: What were the participants' responses? In which ways do they differ from previous ones?

RQ3: How may this experience affect our future plans (taking into consideration not just 2021, but afterwards)? What can be done in the future?

To answer these questions, besides comparing and contrasting the participants' feedback before and during the pandemic, we will also use facilitators' opinions. 


\subsection{Instruments}

In CEALD research project, we generally use three kinds of instruments: questionnaires, answered by the intervention activities participants; diaries used by facilitators and interviews with invited participants and facilitators. For this specific cycle of the participatory action research, we intend to use a questionnaire suggested by the RELO Office (Sowell, 2019) and adapted by us to be answered using Google Forms. It consists of nine questions, in the format of statements to be confirmed or denied. The topics being considered are the following: methodology awareness; English language improvement; facilitated sessions usefulness; completion of the course online; interest in taking another MOOC Camp; preferred mode (facilitated and/or online course). The last item of the questionnaire is an open question asking for other comments about the MOOC Camp. Participants do not have the obligation of answering the questionnaires and none of them are signed. The answers are compiled after each course, and the offering of other courses are based on these responses and the availability of the courses they are interested in taking.

Informal interviews with facilitators will also be used in an attempt to answer the first and the last questions.

\section{First findings and discussion}

30 (future) teachers enrolled to the camp, but only 22 received the certificates (attended more than $75 \%$ synchronous meetings). The same number answered the feedback questionnaire. The dropout rate was $27 \%$ (if we consider only the (future)teachers) and consequently the rate of retention (73\%) was very similar to the average results of the face-to-face camps (74\%) (Cardoso, 2020).

If we consider the answers to the questionnaire, they were very similar to the ones collected in the first cycle. For example, in relation to methodology awareness, most of the participants (86\%) of the participants strongly agreed that "because of the course they now know more about the TESOL methodology", in other courses $84 \%$ strongly agreed with this first statement. The same happened in relation to facilitated session, in the virtual interaction group, $90.9 \%$ strongly agreed that they were useful and $9.1 \%$ agreed. In the previous face-to-face (F2F) groups, again most participants (84\%) strongly agreed, $13 \%$ somewhat agreed and $2 \%$ agreed. The majority of the participants want to take a MOOC Camp in the future (virtual 100\% and F2F 94\%). Another very positive aspect which was confirmed in both cases is that most participants followed both the online course and facilitated sessions (virtual $96 \%$ and $\mathrm{F} 2 \mathrm{~F}$ 95\%).

The main difference may be found in the answers to two questions: (2) "Because of the course, my English improved" and (6) "I completed all the online coursework." See the table below:

Table 1. Feedback questionnaires - Contrasting F2F and Virtual learners'answers - Questions 2 and 5.

\begin{tabular}{|l|c|c|c|c|c|}
\hline \multicolumn{7}{|c|}{ (2) Because of the course, my English improved. } \\
\hline F2F & $\begin{array}{c}\text { Strongly } \\
\text { agree }\end{array}$ & $\begin{array}{c}\text { Somewhat } \\
\text { agree }\end{array}$ & Agree & $\begin{array}{c}\text { Somewhat } \\
\text { disagree }\end{array}$ & Disagree \\
\hline Virtual & $24.0 \%$ & $40.0 \%$ & $31.0 \%$ & $2.0 \%$ & $3.0 \%$ \\
\hline \multicolumn{7}{|c|}{$40.9 \%$} & $31.8 \%$ & $27.3 \%$ & $0,0 \%$ & $0.0 \%$ \\
\hline F2F & Yes I completed all the online coursework. & Not yet \\
\hline Virtual & $66 \%$ & No & No answers & $8 \%$ & $68 \%$ \\
\hline
\end{tabular}

Although learners from both groups agreed that because of the course their English improved, the learners from the virtual group were much more positive than the other groups, as $40.9 \%$ of them strongly agree and only $24 \%$ from the F2F strongly agreed (Table 1).

The biggest difference has to do with the completion of the online course (Table 1). When the camp was F2F most learners finished the course before the last facilitated session. As for the virtual camp, only $32 \%$ completed the online course before the last facilitated session and most of them answered they had not finished yet. However, we have to consider that in the previous questionnaires there was not the option "Not yet", so most learners who had not finish the course answered "No" and only a few included a third option ("Not yet"), showing that they were interested in finishing it. Anyway, the results show that we must be more careful in relation to the completion of the online course the next time. 


\section{Conclusions and future work}

The research questions are partially answered. As the participants from previous MOOC Camps, the one who took the virtual version believed the facilitated sessions were useful for methodology awareness and language development. However, the number of participants who finished the online course was much lower than when they attended face-to-face sessions. In a way, it may be related to the previous phase of the participatory action research, in which we advocated the importance of the face-to- face interaction to foster more interest in the online course. In fact, that was the reason for creating the camps.

The next step is to informally interview the facilitators to help answer the other research questions. Another instrument that may help our discussion is the blended language program evaluation (Gruba et al, 2016). For this evaluation, they take into consideration different criteria, such as: purpose, appropriateness, multimodality and sustainability (Gruba et al., 2016, p. 29-32).

Besides, for 2021, three MOOC Camps are being planned: Assessment of English Language Learners (May/June); TESOL Methodology (July/August), Integrating Critical Thinking Skills into the Exploration of Culture in EFL Setting (September/October).

\section{References}

Albó, L., Hernandez-Leo, D. \& Oliver, M. (2015). Blended MOOCs: university teachers' perspective. Trends in Digital Education. Selected papers from EC-TEL 2015 Workshops CHANGE, WAPLA, and HybridEd. Retrieved October 10, 2020 from http://ceur-ws.org/Vol1599/2HybridEd_2015.pdf

Cardoso, J. (2018). The challenge of fostering equity in a TESOL graduate course: a participatory action research project. In M. Carmo (Ed.), Education and New Developments 2018 (317-321). Lisbon: inScience Press.

Cardoso, J. (2020). Massive Open Online Course Camps: Promoting effective blended courses for language teachers' development. The International Journal of Humanities Education. Common Ground. (in press)

Gruba, P., Cárdena-Claros, M., Suvorov, R. \& Rick, K. (2016). Blended language program evaluation. London: Palgrave Macmillan.

Kemmis, S. \& Wilkinson, M. (2011). A pesquisa-ação participativa e o estudo da prática. In J. E. Diniz-Pereira \& K. M. Zeichner (Eds.), A pesquisa ação na formação e no trabalho docente (39-60). Belo Horizonte: Autêntica.

Liberali, F. Construir o inédito viável em meio a crise do coronavírus - lições que aprendemos, vivemos e propomos. In F. Liberali, V. Fuga, U. Diegues \& M. Carvalho (Eds). Educação em tempos de pandemia: brincando com um mundo possível. Campinas: Pontes.

Mateus, E. Miller, I. Cardoso, J. (2019). Teaching to learn: ways of experiencing the practicum, teacher education and development. D.E.L.T.A. v. 35 N. 3. Retrieved October 10, 2020, from https://doi.org/10.1590/1678-460x2019350303

Orsini-Jones, M. \& Carrascosa, A. C. (2019). BMELTET - Blending MOOCs into English language teacher education with telecollaboration. In A. Plutino, K. Borthwick \& E. Corradini (Eds.) New educational landscapes: innovative perspectives in language learning and technology (pp. 1-17). Research-publishing.net. Retrieved October 15 from https://www.researchgate.net/publication/334374205_BMELTET_-

Blending_MOOCs_into_English_language teacher_education_with telecollaboration

Orsini-Jones, M. Conde, B., Borthwick, K., Zou, B., Ma, W. (2018). B-MELTT: Blending MOOCs for English Language Teacher Training. ELT Research Papers 18.02. London: British Council. Retrieved October 10, 2020 from https:/www.teachingenglish.org.uk/article/b-meltt-blendingmoocs-english-language-teacher-training

Pegrum, M. \& Cardoso, J. (2019). Digital literacies in language education: Janaina Cardoso interviews Mark Pegrum. Matraga, v. 26, n. 47. p.462-469.

Silva, M. (2014). Sala de aula interativa. São Paulo: Loyola.

Sowell, J. (2019). MOOC Camp Facilitation Guide. Washington, DC: Bureau of Educational and Cultural Affairs, United States Department of State.

Thiollent, M. (2011). Metodologia da pesquisa-ação. São Paulo: Cortez. 


\title{
STORYTELLING AND DIGITAL ART AS A MEANS TO IMPROVE MULTILINGUAL SKILLS
}

\author{
Véronique Delplancq ${ }^{1}$, Ana Maria Costa ${ }^{1}$, Cristina Amaro Costa ${ }^{2}$, Emília Coutinho $^{3}$, \\ Isabel Oliveira ${ }^{4}$, José Pereira ${ }^{1}$, Patricia Lopez Garcia ${ }^{5}$, Romain Gillain ${ }^{6}$, Susana Amante ${ }^{1}$, \\ Susana Fidalgo ${ }^{1}, \&$ Susana Relvas ${ }^{4}$ \\ ${ }^{1}$ Instituto Politécnico de Viseu, CI\&DEI (Portugal) \\ ${ }^{2}$ Instituto Politécnico de Viseu, CERNAS (Portugal) \\ ${ }^{3}$ Instituto Politécnico de Viseu, UICISA-E (Portugal) \\ ${ }^{4}$ Instituto Politécnico de Viseu (Portugal) \\ ${ }^{5}$ Universidad Autonóma de Barcelona, Eurola (Spain) \\ ${ }^{6}$ Instituto Politécnico de Leiria, CI\&DEI (Portugal)
}

\begin{abstract}
The use of storytelling and digital art as tools to understand a migrant family's life path will be in the center of an innovative methodology that will ensure the acquisition of multilingual skills and the development of plurilingual awareness, reinforcing the various dimensions of language (aesthetic and emotional, in addition to cognitive), in a creative, collaborative and interdisciplinary work environment. This is especially important among students who are not likely to receive further language training.

It is not yet clear how teachers can explore multilingual experiences of learners, both in terms of language learning dimensions but also related with the multiple cognitive connections and representations, as well as to the awareness of language diversity.

The JASM (Janela aberta sobre o mundo: línguas estrangeiras, criatividade multimodal e inovação pedagógica no ensino superior) project involves a group of students of the 1st cycle in Media Studies, from the School of Education of Viseu, who will work using photography, digital art and cultural communication, collecting information pertaining to diversified cultural and linguistic contexts of the city of Viseu (Beira Alta, Portugal), both in French and English, centered on a tradition or ritual of a migrant family.

Based on an interview, students write the story (in French and English) of the life of migrants and use photography to highlight the most relevant aspect of the migrant's family life. Using as a starting point an object associated with religion, tradition or a ritual, students create an animated film, in both languages. This approach will allow the exploration of culture and digital scenography, integrating in an innovative interdisciplinary pathway, digital art, multilingual skills and multicultural awareness. Students' learning progress and teacher roles are assessed during this process, using tests from the beginning to the end of the project.
\end{abstract}

Keywords: Pedagogical innovation, higher education, project-based learning, foreign languages and cultural diversity, multilingual and multimodal artistic creativity.

\section{Introduction}

The JASM project was conceived as a teaching-learning experience in foreign languages (FL) in Higher Education (HE), with students from the Media Studies degree at the Polytechnic Institute of Viseu, Portugal. It falls within the scope of pedagogical innovation in HE, for a holistic approach, combining several methodologies of active, incorporated and constructivist learning, such as project-based learning and research-based learning, which place the student at the centre of the teaching-learning process, in a multilingual, multicultural and interdisciplinary environment.

In recent decades, Higher Education (HE) has witnessed new challenges that arise from globalization, migrations and transits (Piccardo, 2013) and the exponential development of technologies, which demand high levels of competitiveness in the labour market. In this sense, the teaching-learning process requires innovation in its practices with the aim of increasing student motivation and developing successful strategies, adapting learning experiences to their goals and needs, in line with the complexity of the real world. 
In this new context, the role of the teacher has undergone radical changes, from a mere someone who conveys content $\mathrm{s} /$ he has become knowledge facilitator, promoting exchanges inside and outside the classroom. Following a socio-constructivist approach allows for autonomy in the teaching-learning process, with the student assuming the role of actor in his/her own learning process. In this sense, cooperation is encouraged by carrying out integrated tasks adapted to the real environment. In turn, project pedagogy facilitates access to research and promotes lasting knowledge. This new approach implies a progression in the learning activity and improves the student's accountability and motivation.

With a view to acquiring multilingual and multicultural skills, in the process of learning foreign languages, the JASM project aims at deepening knowledge and developing skills, understanding and accepting attitudes and values, promoting self-confidence and respect for others, stimulating and developing the understanding and acceptance of different socio-cultural universes.

\section{Enhancing multilingual skills through storytelling and digital art}

According to the Council Recommendation of 22nd May 2018, the European Union identifies eight key skills for lifelong learning, trying to manage the cultural diversity of today's societies and to promote interculturality in an increasingly plural and globalized world. This European reference framework secondly highlights the importance of multilingual skills, which "(...) define the ability to use different languages appropriately and effectively for communication." (p. C189 / 8), especially in intense global mobility contexts.

In fact, languages not only define individual identity, but are also part of a common heritage. They link peoples and cultures, promoting mutual understanding and the development of a common feeling of European identity. Therefore, according to Morgado (2019), it is important to realise that

(...) a language is a culture and [...] one of the key aspects of identity or cultural identification of any individual is the language. To want someone to give up their language, thinking through it or learning through it is equivalent to asking them to give up their culture and a core dimension of their identity. (2019: 20)

Thus, underlying the relevance of the acquisition of multilingual skills is the appreciation of cultural diversity, the interest and curiosity about different languages and the promotion of intercultural communication, positive attitudes, essentially resulting from the creation of the single market and the increasing mobility in the European Union, the advent of the knowledge society, emigration and globalization. In this context, multilingualism has acquired special prominence, in order to allow individuals and companies to take full advantage of the opportunities at hand. Thus, the first decade of this century saw the emergence of an inclusive language learning policy, respecting individual linguistic profiles, with the aim of valuing all languages, including the regional, minority or migrant ones, in parallel with the official languages of the different countries.

Also, the fact that the Barcelona European Council in 2002 established for each citizen the ambitious goal of learning two other languages in addition to their mother tongue, contributed to the development of an active policy concerning multilingualism, mostly aiming at encouraging language learning and enhancing linguistic diversity within society, fostering a sound multilingual economy and promoting social integration through better linguistic knowledge and the acceptance of other languages.

So, acknowledging that one currently inhabits a globalized world implies knowing how to facilitate a multilingual dialogue and to value it, being aware of the advantages and disadvantages of a lingua franca such as English, which facilitates communication, but limits plurilingual learning and relies on use of verbal and non-verbal intercomprehension strategies that allow people to understand one another. Therefore, it is important to have a critical knowledge of the role of languages and communication also in the educational contexts, trying to develop, within the scope of school practices, not only an intercultural sensitivity, but at the same time an ability for intercultural dialogue and communicative efficacy, enabling empathy with those who speak other languages and have different worldviews.

A Curriculum based on multilingualism-inspired pedagogy privileges collaborative work and minimises barriers between languages (Piccardi, 2013: 604). In this case, "knowledge, skills, and the ability to learn are transversal and transferable across languages. Synergies would be created between languages with the purpose of reaching a common higher goal" (Piccardo, 2013: 604). In this sense, the development of multilingual skills through digital storytelling represents an asset in language teaching, allowing the construction of different realities, cultures and meanings. According to Reinders (2011:1) "The power of stories is such that many anthropologists, psychologists, and other scientists see it as being at the core of what makes us human". On the other hand, Valença and Tostes (2019) stress that telling stories has always been a form of transmission of concepts, values, ideas and images of the world, focussing mainly on human 
experiences and behaviours. If the mastery of different languages contributes to a global communication, storytelling as an educational tool allows for sharing experiences that can bring together different cultures.

Digital storytelling is, according to Robin (2006), the combination of storytelling with the use of digital multimedia, such as images, audio, and video. Soundtrack allows the recording of dialogues and the inclusion of musical moments that give expressiveness to the story told. In order to build a narrative combined with a soundtrack, students need to consider different issues, starting from the characters' point of view, social context and the emotions portrayed (Robin, 2006). Furthermore, students have the opportunity to express their thoughts, taking advantage of this experience to express their impressions on the story, and the impact it has on them. Storytelling favours, in this sense, the development of linguistic, discursive, strategic, sociolinguistic and intercultural skills. Expressing individual life worlds through narrative forms, multilingual digital storytelling (MDST) elicits collaborative work and the development of transversal linguistic competences (Anderson, Chung, Macleroy, 2018: 197). Thus, given the cultural authenticity and thematic diversity conveyed by storytelling, it provides learning contexts of an informative / cognitive nature (linguistic and cultural), as well as of a formative / educational nature (emotional, social, moral and aesthetic) essential to the holistic well-being of the student.

As a motivating strategy, storytelling contributes to the development of an emotional relationship with the foreign language, helping to overcome difficulties in a constructive way. Storytelling will allow the students to consider concepts and values and to express them in a more comprehensive way (Reinders, 2011). An additional benefit that digital storytelling offers, is the possibility of sharing the results both with other students and teachers, obtaining feedback, either to show that the point of view is well expressed and the message conveyed has been correctly interpreted by the student (Robin, 2006).

\section{The JASM project,}

The JASM project involved 20 students from the Media Studies degree course at the School of Education of the Polytechnic Institute of Viseu (Portugal). The study plan of the said course includes curricular units within the fields of FL, photography, digital art and intercultural communication. Professional opportunities range from media, media production, organization and information management, institutional and organizational communication, followed by a detailed study of the most illustrative aspects related to the culture and language of each country. This task allowed for research-based learning, crossing direct observation methods and data resulting from interviews.

In addition to the project, seminars were delivered by an expert in the fields of photography and digital art, to support the students' tasks. The first was carried out at the beginning of the experiment, in order to raise student awareness about the documentary value of photography. The second, put into practice later, focused on the potential of the Korsakow platform, fostering key components such as interdisciplinarity, the hybrid language of digital art and the use of communication technologies.

With regard to the field work, the first task consisted in identifying and locating immigrants representing previously selected nationalities, residing in the city. To this end, social networks helped to exchange information and, in addition, the Local Support Centre for Migrants Integration facilitated some contacts. The purpose of the first contact was to present the project and conduct an interview, thus allowing for the students to rely on their training profile to develop and master professional skills.

In addition, the students created a photographic record with the purpose of documenting important aspects of the interviewees' path, highlighting facets of their personalities. Subsequently, the students recorded the immigrants' life stories in writing. These task results were also discussed in the FL classes and were subject to evaluation.

The last step consisted in choosing a particular object or tradition with significant meaning for the immigrant, problematizing an aspect of the immigrants' culture. This project stage was recorded using the language of animation films. Digital scenography consisted in the development of a storyboard of fictional stories created by the students. Photographs previously taken were used and further research was carried out to ensure a more reliable illustration of the fictionalized narratives. As closure to the project, all the material produced, in different media and languages, was organized in the Korsakow system, resulting in a dynamic and interactive documentary, under the direction of a specialist in digital art.

The final results of this research work and the consequent investigative inquiries were fully addressed by the students and presented to the class and the teachers involved, both in French and English. All details of this project are available on the JASM website and displayed on social networks and have been the subject of exhibitions, presentations at events and publication in an e-book. 


\subsection{Assessment}

The constraints resulting from the pandemic which affected the period of implementation of the project required a revision of the outlined methodology. Assessment was based on a mixed evaluation method. Quantitative data were collected at the beginning of the process, using comprehension, oral and written tests. A language level test was applied, in each FL, to the group of students involved (20) and to the rest of the classmates (12). The tests, inspired by the DELF, DALF and TOEFL formats, were developed according to the levels of the Common European Framework of Reference for Languages, for comprehension, written and oral production. Response time was checked for each skill block.

\section{Conclusion}

The project allowed for pedagogical innovation in HE in the teaching of FL in study cycles whose predominant training was not aimed at learning a specific foreign language. FLL (foreign language learning) took place on the basis of social, cultural and artistic stimuli and was promoted through content production in the context of linguistic and cultural diversity. It was also intended to encourage good interdisciplinary practices, consolidate knowledge and stimulate know-how in a collaborative and cooperative way; with the intention of strengthening multilingual and multicultural awareness among students, using, for this purpose, varied, creative and multimodal approaches. As a strategy inserted in the scope of communicative paradigms, digital storytelling allows for a reflection on the most appropriate processes for cognition and values the socio-cultural dimension, focusing on individual and collective identity, through the JASM project.

\section{References}

Anderson, Jim; Chung, Yu-Chiao; Macleroy, Vicky (2018). Creative and critical approaches to language learning and digital technology: findings from a multilingual digital storytelling project. Language and Education, vol.32, $\mathrm{n}^{\circ} .3,195-211$ https://doi.org/10.1080/09500782.2018.1430151 Retrieved 15.04.2021 from https://www.tandfonline.com/doi/pdf/10.1080/09500782.2018.1430151 ?needAccess $=$ true

Conselho da Europa (2007). Grupo de alto nível sobre o multilinguismo - Relatório Final (Resumo), 1-9.

Conselho da Europa (2018). Recomendação do conselho sobre as competências essenciais para a aprendizagem ao longo da vida. Jornal Oficial da União Europeia, (Edição em língua portuguesa), C189/1-C189/8.

Gaballo, Viviana. "Digital Language Teaching and Learning: A Case Study". Innovation in Language Learning. International conference. https://www.researchgate.net/publication/337415640_ Digital_Language_Learning_and_Teaching

JASM Project: Open Window onto the world: Foreign Languages, Multimodal Creativity and Pedagogical innovation in Higher Education. https://www.esev.ipv.pt/jasm/

Morgado, M. (2019). Competências para gerir a diversidade e a interculturalidade. Exedra, Revista Científica ESEC, número temático EIPE2019, 11-27.

Piccardo, E. (2013). "Plurilingualism and Curriculum Design: Toward a Synergic Vision". TESOL Quarterly, 47(3), Sept.:600-614.

Reinders, Hayo. "Digital Storytelling in the Foreign Language Classroom". ELTWorld online.com, april 11, vol. 3.1-9. Retrieved 15.04.2021 from https://www.researchgate.net/publication/ 323186783_Digital_Storytelling_in_the_Foreign_Language_Classroom

Robin, Bernard R. "The Educational Uses of Digital Storytelling". Society for Information Technology \& Teacher Education International Conference, Mar 19, 2006 in Orlando, Florida, USA Association for the Advancement of Computing in Education (AACE), Waynesville, NC USA. ISBN 978-1-880094-58-7 https://www.learntechlib.org/primary/p/22129/

Valença, Marcelo M.; Tostes, Ana Paula Balthazar (2019). "O storytelling como ferramenta de aprendizado ativo". Revista Carta Internacional. Belo Horizonte, vol. 14, $\mathrm{n}$ 2, 221-243. Retrieved 30.03.2021 from https://www.researchgate.net/publication/335469301_O_Storytelling_como_ferramenta_de_apren dizado_ativo 


\title{
$4^{\mathrm{TH}}$ IR - IMPLICATIONS FOR HIGHER EDUCATION BY LOOKING AT THE USE OF MOBILE TEACHING DEVICES
}

\author{
Johannes Andreas Gerhardus Beukes \\ School of Mathematics Science and Technology Education, Faculty of Humanities, \\ Central University of Technology, Free State (South Africa)
}

\begin{abstract}
Students and lecturers use mobile devices more and more and within a few years they will become indispensable tools in the classroom. Recent research clearly indicates that mobile devices such as smartphones, laptops and tablets are the tools of choice for students, scholars, teachers and lecturers. It will play a major role in teaching and learning, especially in higher education as the $4^{\text {th }} \mathrm{IR}$, the development of artificial intelligence and new ways of communication need to take their place in the classroom. The integration of these new technologies into the teaching and learning experience in the classroom will be dependent on effective pedagogical implementation and planning to be successful. Taking this into account, this paper explores the effect that mobile devices have in the classroom on the teaching and learning experience of the student. The advantages of the implementation of mobile devices must be weighed against the negative influence they may have. All of the participants in the study reported that they have access to and use mobile devices to access the internet to source information.
\end{abstract}

Keywords: Mobile technology, $4^{\text {th }} I T, 4^{\text {th }}$ industrial revolution, higher education.

\section{Introduction}

During the $4^{\text {th }}$ industrial revolution (4th IR) the world will see the emergence of a new form of higher learning institutions. These institutions will have no classrooms, no library and no onsite lecturers. The institutions will be inter-disciplinary, will have virtual classrooms and laboratories, the library will be online and the lecturers will either be virtual or located anywhere in the world. Higher Education in the $4^{\text {th }}$ IR is creating an exciting but complex opportunity which has the potential to transform society for the better. Artificial intelligence is driving the $4^{\text {th }}$ IR and the needs of the workplace will be transformed from task-based orientation to human-centred characteristics. Due to the merging of "man" and machine, the distance between social sciences and humanities as well as between technology and science will be reduced. This will necessarily require more interdisciplinary teaching, research and innovation. All the components of the "new" higher education system will be inter-dependable of each other, but will also remain independent of each other.

\section{Aim}

The main purpose of higher education will always remain the same and that is to ensure quality of learning via teaching; to enable the students to be exposed to technology and the latest knowledge through research, and innovation to sustain the development of societies by means of service. One of the foremost tasks of every university is to educate and prepare the youth. Therefore, it is necessary to use the most appropriate, current and innovative teaching strategies and to organise the teaching experience in a way that promotes learning. This has implications on learning programmes, better learning experience, and the cultivation of lifelong learning attitudes. The impact of the $4^{\text {th }}$ IR and the utilisation of mobile teaching devices on higher education need to be researched and t understood. The question is what the impact of the $4^{\text {th }}$ IR will be on higher education. 


\section{Literature review}

Our society has been transformed by technology which has changed our lives irreversibly over the last 25 years. In the education and training environment technology and especially mobile technology has become an essential tool for the modern student. The digital age caused an upsurge in access to information, as well as increased and immediate interaction between people. Bilbao-Osorio, Dutta, and Lanvin (2013) stated, in their study on the state of global information technology, that the number of mobile subscribers will reach 6.9 billion worldwide in the year 2020. They indicated that the use of mobile technology in the form of tablets, phones and laptops is on the increase at all universities and even schools.

\subsection{Role of technology in learning}

Researchers have indicated that student engagement is the aspect of learning that focuses on the activities in which students are involved during their studies and which promote learning and result in their academic achievement (Sidelinger, Frisby \& Heisler, 2016). While researching student engagement researchers suggested that the main objective of education is for students to construct their own knowledge (Covington, 2017; Sidelinger et al., 2016). Therefore, a research study which examines the influence of mobile devices on learning, engagement, and performance shall be relevant and valuable.

\subsection{The effect of mobile technology on academic performance}

Radesky, Schumacher \& Zuckerman (2015) argue that mobile devices do have a noteworthy influence on academic performance by causing distractions. However, several studies found that mobile technology does not have any effect on the student's academic performance (Heflin, Shewmaker \& Nguyen, 2017; Rabiu, Muhammed, Umaru, \& Ahmed, 2016). Student performance was linked with cell phone use during class time in a study by Duncan, Hoekstra, \& Wilcox (2012). They found an average negative grade difference of $0.36 \pm 0.08$ (on a four-point scale) for students who reported regular cell phone use in class. Information from the same study revealed that students accessed their phones at a rate of seven times per class period.

\subsection{Educational benefits of mobile devices}

It is time that we start thinking of cell phones as computers. The description of cell phones seems unclear. Several terms are used by researchers such as cell phones, mobile phones, portable media players, tablet computers or smartphones (Al-Emran, Elsherif \& Shaalan, 2016). In an academic setting there are many effective uses for cell phones, such as supplementing the class experience and getting tutoring assistance from instructors (Tao \& Yeh, 2013). They found in their study that using cell phones to augment teaching helped increase the quality and quantity of student feedback. Students use their mobile devices to access other media such as the Internet, Facebook, Twitter, YouTube, and other information communication technology. Bannon, Martin, \& Nunes-Bufford (2012) suggested that the use of social media by college students ages 18 to 34 was increasing. Gikas and Grant (2013) explored the process of integrating mobile technologies into teaching and learning. The faculty members at the institutions where they conducted their research incorporated mobile technologies into their courses. They concluded that the use of mobile technologies in these institutions of learning resulted in positive outcomes that would make learning a meaningful and fruitful experience for the students.

\section{Methodology}

An integrated methodology, the FraIM (Frameworks for an Integrated Methodology) was followed with the research. FraIM integrates qualitative and quantitative methods in a way that is argued will enable a researcher to employ a mixed methods approach with any research project (Plowright, 2011). It is appropriate for carrying out small-scale empirical investigations that are aimed at evaluating, developing, and improving an understanding of practice. It can be applied to research undertaken for a programme of study in a university setting. It can also be deployed to solve problems in a variety of professional, vocational and workplace contexts and locations. (Fourie-Malherbe et al., 2016).

\subsection{Limitations}

The sample group was small- and the-time frame was limited. Another limitation was access to all the new technologies that are available to demonstrate and for students to have hands- on interaction (Rossing et al., 2011). The target group consisted of 85 students (52 females and 33 males) enrolled in their $3^{\text {rd }}$ year of the B Ed (SP \& FET) Technology qualification. 


\subsection{Findings}

This research focused on how the $4^{\text {th }}$ IR impacted on students' engagement and learning in the classroom using mobile devices.

- $65 \%$ of the participants reported that other students' use of mobile devices distracted them from paying attention in class, while $33 \%$ disagreed with this notion and $2 \%$ of the participants were uncertain. This finding indicates that the use of mobile technology by other students in class distracted other classmates from paying attention in class.

- $25 \%$ of the participants reported that they played games on their mobile devices in class, while $65 \%$ disagreed with this and $10 \%$ of the participants were uncertain. This finding indicates that a quarter of the participants were not constantly focusing on learning in class.

- $70 \%$ of the participants reported that they enjoy the use of mobile devices for classroom activities, while $8 \%$ disagreed with this notion and $22 \%$ of the participants were uncertain. The participants reported that they enjoy the availability of more information than what is given by the lecturer.

- $68 \%$ of the participants reported that the use of mobile devices in the classroom facilitated their ability to collaborate with other students, while $20 \%$ disagreed with this notion and $12 \%$ of the participants were uncertain. This finding indicates that many of the participants were able to collaborate with others, using mobile devices in class.

- $65 \%$ of the participants reported that they concentrated better on their studies when using mobile devices, while $15 \%$ disagreed and $20 \%$ were uncertain. The participants who reported that mobile devices helped them to concentrate more on their studies validated this by stating that they could confirm the validity of the information received while learning, they could easily connect with their peer groups, take notes in the class and get informed videos for better understanding on their studies. Thus, this finding indicates that many of the participants concentrated better on their studies when using mobile devices in class.

- $48 \%$ of the participants reported that they access social media in the classroom during the lecture, while $30 \%$ disagreed and $22 \%$ were uncertain. This finding indicates that many of the participants do not pay attention in class when using mobile devices.

- More than $70 \%$ of the participants reported that they do use their mobile devices in class to access learning material online in the classroom during the lecture, but the worrying factor is that up to $75 \%$ of the participants use their mobile devices in class for non-academic purposes.

- $82.3 \%$ of the participants reported that they use their smartphone in class to access the information needed, but the small screen of the smartphone is seen as a problem and it makes it difficult to read the notes. Only $2.4 \%$ use their laptops in class and the main reason for this is the lack of power outlets to charge laptops.

- $98 \%$ of the participants reported that they use the free university Wi-Fi for their data connection even if it is slow. The $2 \%$ of participants that use their own data packages are still not registered due to circumstances out of their control such as bursaries.

\section{Summary of findings}

Based on the data the beneficial use of mobile technology in the classroom, together with the students' need to use the technology, and the potential for future academic preparation had a substantial influence on students' learning and engagement. It shows clearly that mobile technology has its place in the classroom and that the advantages far outweighs the disadvantages.

\section{Discussion}

The findings of this study are in line with several other studies on the impact of mobile devices in the classroom. The $4^{\text {th }}$ IR will only increase the availability of mobile devices; even some that do not even exist today. Over the last few year students have increasingly benefited from electronic technologies, podcast lectures, online courses, educational apps on mobile devices, and cooperative activities through social networking platforms (El-Hussein \& Cronje, 2010; Traxler, 2007). Students enjoy the freedom technology provides them in becoming more actively engaged in the learning process. Most of the mobile learning technology devices, like tablets provide students direct access to information, course material, and real- world application of knowledge (Alsaadat, 2009; Martin et al., 2013). This is evident in the fact that $73 \%$ of the participants in this study indicated that they are comfortable with the use of technology in the classroom. Moreover, they all regard this access as indispensable to their learning experience. New technology often evokes feelings of both excitement and anxiety from students and faculty, and the usage of mobile teaching devices proved no different. Students indicated that the freshness of the usage of mobile teaching devices contributed positively to the learning experience. Students also recounted that the 
instantaneous access to information enhanced in-class discussion because they could easily search for information to share with the class. Cobcroft, Towers, \& Smith (2006) suggest that students benefit from "flexibility and ubiquity, that is, 'anywhere, anytime, and any device' learner engagement". As discussed, instructional design and the use of technology predominantly affects student perceptions of learning (Armstrong, 2011). But as students gain access to immense amounts of information, educators must provide direction. Educators must support students using mobile information in order to make better assessments and judgments when accessing information on their own. Educators must sensibly adapt the technology to specific learning goals and outcomes. Institutions of higher learning need to get policies and regulations in place to govern the use of mobile devices in the classroom. Clear "rules" on the use of mobile devices in the classroom need to be communicated to the students to minimize the distraction of other students by those that are using their mobile devices to access non-academic information such as social media during class time.

\section{Conclusion}

The $4^{\text {th }}$ industrial revolution ensures that new technologies are developed rapidly, and the pace is picking up each year. Guri-Rosenblit (2005) perceives that the human capacity to respond to and adapt to the pace of new technologies is meaningfully slower and limited. Therefore, educators using mobile devices in the classroom must be committed to learning how to use devices effectively in classroom. In summary, mobile information and communication technologies such as tablets, laptop computers and mobile phones will feature importantly in the future of learning and classroom environments. Mobile devices offer benefits such as apparently boundless access to information and advantages for collective learning. However, these devices if not controlled properly, can distract learners and create frustration in the classroom. When integrated into the classroom experience sensibly and under control, educators will maximize their potential to enhance learning and minimize their interference with learning.

\section{References}

Al-Emran, M., Elsherif, H. M., \& Shaalan, K. (2016). Investigating attitudes towards the use of mobile learning in higher education. Computers in Human Behavior, 56, 93-102.

Alsaadat, K, (2009). Mobile Learning and University Teaching. In international Conference on Education and New Learning Technologies Barcelona, Spain.

Armstrong, DA (2011). Students' perceptions of online learning and instructional tools: A qualitative study of undergraduate students use of online tools. Turkish Online Journal of Educational Technology TOJET, 10(3), 222-226

Bilbao-Osorio, B., Dutta, S., \& Lanvin, B. (2013). The global information technology report 2013. In World Economic Forum, 1-383

Cobcroft, RS, Towers, S \& Smith, J (2006). Mobile learning in review: Opportunities and challenges for learners, teachers, and institutions. Proceedings of the Online Learning and Teaching Conference 2006, 21-30

Covington, M. (2017). If not us then who? Exploring the Role of HBCUs in Increasing Black Student Engagement in Study Abroad. College Student Affairs Leadership, 4(1), 5.

Duncan, D., Hoekstra, A., \& Wilcox, B. (2012). Digital devices, distraction, and student performance: Does in-class cell phone use reduce learning. Astronomy Education Review, 11(1), 1-4.

El-Hussein, MOM, \& Cronje, JC, (2010). Defining mobile learning in the higher education landscape. Journal of Educational Technology \& Society, 13(3), 12-21.

Fourie-Malherbe M, Aitchison C, Blitzer E, Albertyn R (eds) (2016). Postgraduate Supervision-Future Foci for the knowledge society. Stellenbocsh: SUN PRESS

Gikas, J., \& Grant, M. M. (2013). Mobile computing devices in higher education: Student perspectives on learning with cell phones, smartphones \& social media. The Internet and Higher Education,19(1), $18-26$.

Guri-Rosenblit, S, (2005). Eight paradoxes in the implementation process of e-learning in higher education. Higher Education Policy, 18(1), 55-29

Heflin, H., Shewmaker, J., \& Nguyen, J. (2017). Impact of mobile technology on student attitudes, engagement, and learning. Computers \& Education, 107, 91-99.

Martin, R., McGill, T., \& Sudweeks, F. (2013). Learning Anywhere, Anytime: Student Motivators for M-learning. Journal of Information Technology Education: Research, 12(1), 51-67

Plowright, D, (2011). Using mixed methods, SAGE Publications Ltd, London 
Rossing JP, Miller WM, Cecil AK, \& Stamper SE, (2011). iLearning: The Future of Higher Education? Student Perceptions on Learning with Mobile Tablets. Journal of the Scholarship of Teaching and Learning, 12(2): 1-26.

Sidelinger, R. J., Frisby, B. N., \& Heisler, J. (2016). Students' out of the classroom communication with instructors and campus services: Exploring social integration and academic involvement. Learning and Individual Differences, 47, 167-171.

Tao, Y., \& Yeh, C. R. (2013). Transforming the personal response system to a cloud voting service. In S. Uesugi (Ed.), IT enabled services. Verlag, Austria: Springer, 139-156

Tindell, D. R., \& Bohlander, R. W. (2012). The use and abuse of cell phones and text messaging in the classroom: A survey of college students. College Teaching, 60(1), 1-9.

Traxler, J, (2007). Defining, discussing, and evaluating mobile learning: The moving finger writes and having writ. The International Review of Research in Open and Distance Learning, 8(2), 1-12. 


\title{
REFLECTIONS ON OFFERS AND USE OF DIGITAL MEDIA FOR TRANSFERRING KNOWLEDGE IN TEACHER EDUCATION
}

\author{
Susanne Schumacher ${ }^{1}$, \& Ulrike Stadler-Altmann ${ }^{2}$ \\ Faculty of Education, Free University of Bozen-Bolzano (Italy)
}

\begin{abstract}
Digital processing, augmented reality and virtualisation have been developed and tested in the gaming world and working environment for some time. In educational settings, media should become learning objects that arouse the interest of learners, establish a connection to their previous knowledge, and enable interactive action and self-control (cf. Göhlich \& Zirfas, 2007; Sesink, 2008). In parallel with technological developments, the question of imparting knowledge methods as well as increasing learners' knowledge is consistently subject of debates on competence in higher education didactics (see Erhardt, 2010). In terms of knowledge theory, the question arises to which extent knowledge changes as a result of media processing and, not least, how students' knowledge assets build up, transfers and influence each other (see Stadler-Altmann \& Keiner, 2010).

In the first decade of the millennium, numerous activities introduced in higher education had been carried out related to media-based knowledge transfer and information acquisition in the context of curricular offerings, pilot events or third party financed projects with non-university cooperation partners (Iske \& Meder, 2010; Gördel at al., 2018; Hofhues, Jochuma \& Kohrs, 2013; Reinmann, Ebner \& Schön, 2013).

In this paper, concepts of media-supported teaching and learning environments in the context of the training of pedagogical professionals in South Tyrol are depicted. Didactic designs for lectures and seminars are presented and critically reflected. These two teaching formats are mainly intended for the one-level master's degree in Primary Education at the Free University of Bozen-Bolzano. The design research approach chosen for this purpose does not diminish input-output comparisons, but rather raises the question of which media-pedagogical innovations and didactic interventions can improve the existing teaching-learning situation (Fishman et al., 2013). First, the pedagogical fields of action are analysed by considering both the specific context of the given structure at university and the existing teaching-learning settings. Consequently, impulses for a didactic re-framing in the context of the methodological dimensions of control and teaching style will be discussed in the light of the current state of research.
\end{abstract}

Keywords: Digital added value, transfer of knowledge, active learning, university didactic, design research approach.

\section{Introduction}

The master's degree in Primary Education at the Free University of Bozen-Bolzano has been reformed within the Italian legislation La Buona Scuola (State Law 107/2015). The in 2017/18 relaunched degree program leads to a professional qualification in five years. Graduates will be qualified for pedagogical workers in kindergarten and primary schools and furthermore, acquire the qualification for teaching English lessons at primary school.

According to the study manifesto, in the first two years of study the focus of teaching is on the areas of Historical and Comparative Pedagogy, General Didactics, Intercultural and Inclusive Pedagogy as well as Pedagogical Psychology and Developmental Psychology, plus Linguistics (L1, L2). The third and the fourth academic year is intended for in-depth study of the respective subject didactic content. Linguistics (L3) and media pedagogy as well as didactics of early-reading instruction complete the course offerings. In the fifth year of study, elective subjects and socio-political content are discussed; furthermore, the specific institutional framework and working conditions are explained. Moreover, the master thesis is to be written in the final year of study (Study Manifesto, 2019). 


\section{Objectives and methods}

Based on the course descriptions of General Didactics information about formal details is given such as workload, attendance regulations, the lecturer's office hours as well as the objectives and topics of courses. In addition, the main teaching and learning formats are described. Lectures are tagged as weekly, with media support, partner work and short in-depth group work. In addition, preparation based on literature is expected. The labels for seminars are fortnightly, joint reading and discussion, group work, collection of material, portfolio work. Preparation and work separate the seminar are expected (Course Offerings 2019).

In a first step, the lecture is presented from a historical-systematic point of view. This is followed by a specification of the media-didactic conception of the factual class. The aspects mentioned above are assigned to conceivable resulting types of knowledge. Following the same approach, the seminar is being introduced as a learning environment with both the corresponding media-didactic interventions and the kind of knowledge that might emerge from this. Finally, the additional value of digital media for the learning environments is elaborated.

\section{Analysing lectures as pedagogical field of action}

Since the rising of universities in the 12th century, lectures have been the predominant practise of imparting knowledge (Schiewe, 2007, p. 36). The origins of this way to transfer knowledge are located at the Greek antiquity in correspondence to the current educational ideal of the time, the eu legein. By this is meant the skill of talking well about the good -as a sum of intangible entities- including not only rhetorical eloquence, but also philosophical and scientific argumentation (cf. Apel \& Koch, 1997). In Roman antiquity, public speech was developed to a discipline that could be taught and learned as well. Erler and Tornau $(2019$, p. 3$)$ point out that in teaching the art of oratory, a distinction between pragmatic routine and exact science was made; an adaptation to addressees was also taken into account. Regarding teacher training it is required both contributing actively to scientific discourse and pupil-oriented speech to lead theory-based facts into practice. Mandl \& Reinmann-Rothmeier (2006, p. 615) classifies the lecture as a system-oriented learning environment in which learning processes can be externally planned and controlled. From the perspective of educational psychology, the advantages of teacher-centred instruction are seen in the fact that both average and individual learning outcomes are higher (see Brophy \& Good, 1986). Attending lectures students are recommended to listen actively and write down crucial facts. This scheme is effective only if the essentials are understood first and then recorded. Attempting to file what literally is said tends to result in failing the core issue. From the students' point of view, echoing the transcripts is equated with responding demands and in turn, mistaken with knowledge (cf. Neubert, Reich \& Voss, 2001, p. 253). However, the idea of learning as acquisition of content is associated with an enhanced rationality.

\subsection{Concepts of media-supported interventions in the context of lectures}

University as a service provider in the education system aims to facilitate academic experiences of students, including both material resources e.g. rooms, hardware equipment or software tools and personal support for learning processes or workflows. Regarding the digital lecture hall, this means, to provide a technological infrastructure with security standards for privacy, steady and fast interoperable lines as well as compatibility to the end-users with heterogeneous operating systems of devices (see Kollmann, 2018, p. 77f). In March 2020, MS TEAMS has been set up to live stream or record lectures and seminars as well. The software solution is a platform combining various applications for classroom-management, such as chat in private or in general, tasks, forms, meetings, notes and various attachments. However, given the proper volume of technical features, neither runs teaching and learning by itself nor improves it than in presence. Looking reverse, consuming the services does not release from efforts of the learning process to build up one's own knowledge.

In preparation for the lecture, students can download a script that point out main facts of the required reading chapter (see table 1). From the didactic point of view, a summary always dissolves information units from a whole text intended for rereading, thus, reducing its complexity. Within lectures hours, it is assumed that the complexity of facts as well as dependencies on circumstances can be verbally restored. Nonetheless, problems of comprehension and understanding can only be solved at best for those present. Kade \& Seitter (2003, p. 609) argue that the mechanisms of media communication linked to presence can only refer immediately to and influence addressees. In turn, the additional value of media offered by visually prepared summaries is not applicable to those who are absent. 
Table 1. Assignment of meta-cognitive competences, deliberate media support and implementation in the teaching-learning process for lectures.

\begin{tabular}{|l|l|l|}
\hline $\begin{array}{l}\text { Meta-cognitive components to } \\
\text { accomplish the transfer of knowledge } \\
\text { from the teaching point of view }\end{array}$ & media-based support & $\begin{array}{l}\text { potentially emerging types of } \\
\text { knowledge within the learning-process }\end{array}$ \\
\hline Providing learning material. & $\begin{array}{l}\text { License-based online } \\
\text { resources such as e-books, E- } \\
\text { Journals or databases. } \\
\text { Lecture manuscripts. }\end{array}$ & $\begin{array}{l}\text { Gaining declarative knowledge by } \\
\text { exploration of the provided material. }\end{array}$ \\
\hline $\begin{array}{l}\text { Representation of facts and explanation } \\
\text { of connections. }\end{array}$ & $\begin{array}{l}\text { Animated power point slides } \\
\text { supplemented by personal } \\
\text { speech. }\end{array}$ & $\begin{array}{l}\text { Grow declarative knowledge by } \\
\text { monitoring and comprehending the } \\
\text { speech and asking questions. }\end{array}$ \\
\hline $\begin{array}{l}\text { Guiding of short time group work, } \\
\text { controlling, support and feedback. }\end{array}$ & Poster presentation. & $\begin{array}{l}\text { Increase declarative and metacognitive } \\
\text { knowledge by working deliberately on } \\
\text { tasks and discussing results. }\end{array}$ \\
\hline Highlight the systematic of knowledge. & $\begin{array}{l}\text { Animated power point slides } \\
\text { supplemented by personal } \\
\text { speech. }\end{array}$ & $\begin{array}{l}\text { Raise strategic knowledge by } \\
\text { monitoring and comprehending the } \\
\text { speech and asking questions. }\end{array}$ \\
\hline
\end{tabular}

\section{Analysis seminars as pedagogical field of action}

In the second year of study, the General Didactics puts an emphasis to approaches and results of empirical research in teaching and learning. To offer an apparent approach to transfer theory into practice, it is highly recommended to join the EduSpace Learning Workshop; at least every seminar once in the study cycle. The Learning Workshop is an open space at the first floor of the library containing material such as picture books directed to foster language learning in kindergarten as well as sensory material for the promotion of mathematical experience in elementary school (Stadler-Altmann \& Winkler, 2019). The conceptual considerations for the methodological design of all seminars point at the central question of how the materials -available in the EduSpace Learning Workshop- can be used and modified as well to bring a specific learning object easily into the learners' horizon (Schlicht, 2013). Based on the didactic concept and taking the design-oriented research approach into account, the real space of the EduSpace Learning Workshop at the one hand accomplishes a learning environment for imparting scientific generated facts, on the other hand practical knowledge for lesson planning, material development and for practicing procedural application knowledge as well (Schumacher, Emili \& Stadler-Altmann, 2019).

\subsection{Concepts of media-supported interventions in the context of seminars}

As mentioned above, learning by project planning is a guiding didactic principle of the EduSpace Learning Workshop. Learning and working in a project are closely interwoven and related to didactic-methodological features of cognitivist and even more constructivist learning theories. In the following, major paradigms of contemporary learning theories are considered in the context of their hypothesised effects on knowledge acquisition (see table 2).

Since the mid-1960s, cognitive research has increasingly focused on the processes of perception, attention, memory, and internal information processing in humans. In particular, the areas of the mental representation of knowledge have been studied as well as the processing within the construction of knowledge representations (e.g., Collins, 1987; Dennett, 1969; Stich, 1983). The results of the research from cognitive psychology serve the development of didactic theories for teaching and learning processes. According to the situated cognition perspective, learning is seen as a process of enculturation, or participation in socially organized practices, through which specialized skills are developed by the learner as they engage in an apprenticeship in thinking (Rogoff, 1990), or in legitimate peripheral participation. The 'Cognitive Flexibility Theory' by Spiro, Coulson, Feltovich \& Anderson (1988) focuses on the complexity of the learning situation and learning in multiple contexts. To grasp the complexity of a problem, it is essential to be confronted with realistic issues and furthermore, to work on the context several times from different perspectives and with different objectives. Spiro et al. consider hypermedia to be a suitable digital tool for mapping complex contexts as well as organising context under the new aspects differently. As stated by Collins et al. (1989), the key components of the apprenticeship process include modelling, coaching, scaffolding, fading, and encouraging learners to reflect on their own problem-solving strategies. This apprenticeship leads to the learner becoming involved in the authentic practices of a 'community of practice' (Lave \& Wenger, 1991). 
Table 2. Assignment of teaching strategies, media-based support and potentially emerging types of knowledge within seminars.

\begin{tabular}{|c|c|c|c|}
\hline & $\begin{array}{l}\text { Teaching strategies to enhance } \\
\text { transfer for knowledge with examples }\end{array}$ & media-based support & $\begin{array}{l}\text { potentially emerging } \\
\text { types of knowledge }\end{array}$ \\
\hline 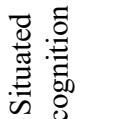 & $\begin{array}{l}\text { Analysing problems embedded in } \\
\text { theory. } \\
\text { Prepare a teaching situation. }\end{array}$ & $\begin{array}{l}\text { Tool for set up a group. } \\
\text { Chatroom: for text-based synchronous } \\
\text { discussion. }\end{array}$ & $\begin{array}{l}\text { Procedural } \\
\text { knowledge. }\end{array}$ \\
\hline 离 & $\begin{array}{l}\text { Learner conducted construction of } \\
\text { different application scenarios. } \\
\text { Collaborative creation of technical } \\
\text { features for communication (such as } \\
\text { auditory or non-electronic aids to } \\
\text { supplement text comprehension) }\end{array}$ & $\begin{array}{l}\text { stop-motion }(\mathrm{mp} 4) \text {, } \\
\text { AnyBook Reader } \\
\text { URL-links to tutorials or freeware }\end{array}$ & $\begin{array}{l}\text { Procedural and } \\
\text { conceptual } \\
\text { knowledge. }\end{array}$ \\
\hline 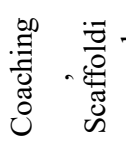 & $\begin{array}{l}\text { Developing an expert culture through } \\
\text { authentic interactions. }\end{array}$ & $\begin{array}{l}\text { Screencasts, } \\
\text { Poster presentations, } \\
\text { long-term asynchronous discussion in a } \\
\text { forum }\end{array}$ & $\begin{array}{l}\text { Metacognitive } \\
\text { processing of subject } \\
\text { content. }\end{array}$ \\
\hline
\end{tabular}

\section{Conclusion}

Media-based teaching strategies and its expected knowledge types were portrayed for lectures and for seminars. To conclude, if media-based lectures and seminars continue the model of centrally controlled instruction aligned to traditional structures and practices, like content focused outcomes or rather declarative knowledge. The central mode in which learning happens there is memorisation. However, reproductive learning contains a certain productive moment, which is a preliminary stage of discursive learning in terms of knowledge methodology. Preferably, learning takes place oscillating between the overarching teaching-learning discourse of the lecture and the discourse in the seminars (cf. Ehlich, 2014). Great coherence within the scientific domain is of advantage because it's getting visible more than ever.

Digital tools, such as screencasts provide a closer insight into the learning process or rather the knowledge construction. This result from the fact that single steps of the task responses are transparently linked, therefore learning moments can be tracked back to the pedagogical intervention even better. Learning in these contexts shifts the boundary from known to unknown knowledge. While inquiry learning is still oriented towards teaching knowledge, productive learning represents a qualitative advance in that learning research knowledge is now integrated. In this way, the threshold towards emancipation from institutional teaching-learning discourses can be approached.

In general, pedagogical teaching-learning environments are characterised by a material offer of opportunities for connection, acquisition and communication. If these facilities are mono-functional, existing structures are maintained. The situation is different with multi-functional spaces. Thinking about hybrid spaces means to consider differentiated and individual learning in advance.

\section{References}

Apel, H.-J. \& Koch, L. (1997). Überzeugende Rede und pädagogische Wirkung. Zur Bedeutung traditioneller Rhetorik für pädagogische Theorie und Praxis. Weinheim: Juventa.

Brophy, J. E., \& Good, T. L. (1986). Teacher behavior and student achievement. In M. C. Wittrock (Ed.), Handbook of Research on Teaching, (pp. 376-391). New York, NY: Macmillan.

Collins, A., (1987). The Nature of Mental Things, Notre Dame: Notre Dame University Press.

Collins, A., Braun, J.S. \& Newman, S.E. (1989). Cognitive Apprenticeship: Teaching the Crafts of Reading, Writing and Mathematics. In L. B. Resnick (ed.), Knowing, Learning and Instruction. Essays in Honour of Robert Glaser. (pp. 453-494). Hillsdale, NJ.

Course Offerings (2019). Retrieved Jan. 30, 2021 from https://www.unibz.it/de/faculties/ education/master-primary-education/course-offering/

Dennett, D. (1969). Content and Consciousness, London: Routledge \& Kegan Paul.

Ehlich, K. (2014). Argumentieren als sprachliche Ressource des diskursiven Lernens. In A. Hornung, G. Carobbio \& D. Sorrentino (eds.): Diskursive und textuelle Strukturen in der Hochschuldidaktik. Deutsch und Italienisch im Vergleich, (pp. 41-54). Münster: Waxmann.

Erhardt, U. (ed.). (2010). Neue Impulse in der Hochschuldidaktik. Sprach- und Literaturwissenschaften. Wiesbaden: Springer. 
Fishman, B. J.; Penuel, W. R.; Allen, A. R. \& Cheng, B. H. (eds.) (2013). Design-Based Implementation Research: Theories, Methods, and Exemplars. National Society for the Study of Education. The 112th Yearbook. Issue 2. New York: Columbia University.

Göhlich, H.D. M. \& Zirfas, J. (2007). Lernen. Ein pädagogischer Grundbegriff. Stuttgart: Kohlhammer

Gördel, B.-M.; Schumacher, S. \& Stadler-Altmann, U. (2018). Durch digitale Medien gestützte Seminarformen. Zwischen dem Anspruch technologisch zeitgemäßer Wissensvermittlung und pädagogisch angemessener Lernumgebung. In J. Othmer, A. Weich \& K. Zwickwolf (eds.), Medien, Bildung und Wissen in der Hochschule, (pp. 99-113). Wiesbaden: Springer.

Hasselhorn, M. \& Gold, A. (2009). Pädagogische Psychologie: Erfolgreiches Lernen und Lehren. Stuttgart: Kohlhammer.

Hofhues, S., Jochums, A.-S. \& Kohrs, L. M. (2013). Vielfalt der Medien, Komplexität medialer Bildungsräume? Gestaltung und Erforschung crossmedial-vernetzter Medienprojekte an Hochschulen. medien + erziehung (merz) Wissenschaft 6/2013, pp. 108-119.

Iske, S. \& Meder, N. (2010). Lernprozesse als Performanz von Bildung in den Neuen Medien. In K.U. Hugger \& M. Walber (eds.), Digitale Lernwelten. VS Verlag für Sozialwissenschaften

Kade, J. \& Seitter, W. (2003). Von der Wissensvermittlung zur pädagogischen Kommunikation, Theoretische Perspektiven und empirische Befunde. Zeitschrift für Erziehungswissenschaft, 4/2003, pp. 602-617.

Kollmann, F. (2018). Technologische Unterstützung der Wissensvermittlung in Vorlesungen: informatische Entwicklung und empirische Erforschung der Wirkung und Wirksamkeit digitaler Lernobjekte. Retrieved Feb. 20, 2021 from http://dokumentix.ub.unisiegen.de/opus/volltexte/2018/1313/

Lave, J. \& Wenger, E. (1991). Situared learning. Legitimate peripheral participation. Cambridge: University Press

Neubert, S., Reich, K. \& Voß, R. (2001). Lernen als konstruktiver Prozess. In T. Hug (Ed.), Die Wissenschaft und ihr Wissen, Bd. 1. Baltmannsweiler: Schneider Verlag Hohengehren

Reinmann, G., Ebner, M. \& Schön, S. (eds.) (2013). Hochschuldidaktik im Zeichen von Heterogenität und Vielfalt. Doppelfestschrift für Peter Baumgartner und Rolf Schulmeister. Retrieved April. 20, 2021 from http://bimsev.de/n/userfiles/downloads/festschrift.pdf

Rogoff, B. (1990). Apprenticeship in Thinking. Cognitive Development in Social Context. Oxford University Press, New York,

Schiewe, J. (2007). Zum Wandel des Wissenschaftsdiskurses in Deutschland. In P. Auer \& H. Baßler (Eds.), Reden und Schreiben in der Wissenschaft. Frankfurt a.M./New York: Campus, 2007, pp. 31-49

Schumacher, S.; Emili E. A. \& Stadler-Altmann, U. (2019). Effective Learning Experiences with UDL in teacher training at University. Richerche di Pedagogia e didattica. Journal of Theories and research in education. Bologna: OpenJournal. Retrieved April 4, 2021 from https://rpd.unibo.it/article/view/8483

Sesink W. (2008). Bildungstheorie und Medienpädagogik. Versuch eines Brückenschlags. In J. Fromme \& Sesink W. (eds.), Pädagogische Medientheorie. VS Verlag für Sozialwissenschaften.

Spiro, R. J., Coulson, R. L., Feltovich, P. J., \& Anderson, D. K. (1988). Cognitive flexibility theory advanced knowledge acquisition in ill-structured domains, Technical Report No. 441. University of Illinois at Urbana-Champaign, pp. 1-20.

Stadler-Altmann, U. \& Keiner, E. (2010). The persuasive power of figures and the aesthetics of the dirty backyards of statistics in educational research. In P. Smeyers \& M. Depaepe (eds.), Educational Research, 1, Vol. 5, Educational Research - the Ethics Aesthetics of Statistics (pp. 129-144). Wiesbaden: Springer.

Stadler-Altmann, U. \& Winkler, G. (2019). Aus zwei Orten wird ein Lernraum. Transformationsprozesse inhaltsbezogener Raumgestaltung - die Kooperation zwischen Universitätsbibliothek und EduSpace Lernwerkstatt, In S. Tänzer, G. Mannhaupt, M. Berger \& M. Godau (eds.), Lernwerkstätten im Spannungsverhältnis zwischen Individuum, Gemeinschaft, Ding und Raum, Bad Heilbrunn: Klinkhardt.

State Law 107 (2015). Retrieved April 20, 2021 from http://www.paschinimarchi.it/legge-107-del-13luglio-2015-riforma-della-scuola-con-note.pdf

Stich, S. (1983). From Folk Psychology to Cognitive Science, Cambridge, Mass.: The MIT Press.

Study Manifesto (2019). Retrieved January 28, 2021 from https://www.unibz.it/assets/Documents/StudyManifestos/2019/Manifesto-2019-02-27-Master-Primary-Education-LM85bis-de.pdf

Tornau, Chr. \& Erler, M. (2019). Sachregister. In Chr. Tornau \& M. Erler (eds.), Handbuch Antike Rhetorik (pp. 801-810). Berlin: De Gruyter. 


\title{
DISTRIBUTED INTERCULTURAL PROJECT-BASED LEARNING - A NOVEL APPROACH - EXPERIENCES FROM A QUADRILATERAL INTERDISCIPLINARY COLLABORATION
}

\author{
Manfred Meyer ${ }^{1}$, Agung Nugroho ${ }^{2}$, José Ochoa-Luna ${ }^{3}$, Colin Stanley ${ }^{4}$, \\ \& Heike Winschiers-Theophilus ${ }^{4}$ \\ ${ }^{1}$ Department of Mechanical Engineering, Westfälische Hochschule, Bocholt (Germany) \\ ${ }^{2}$ Department of Business Administration, Atma Jaya Catholic University of Indonesia (Indonesia) \\ ${ }^{3}$ Department of Computer Science, Universidad Católica San Pablo, Arequipa (Peru) \\ ${ }^{4}$ Faculty of Computing and Informatics, Namibia University of Science and Technology, Windhoek \\ (Namibia)
}

\begin{abstract}
This paper describes a new concept and experiences of a distributed interdisciplinary learning programme for students across continents. The aim is to provide students with a truly Global Intercultural Project Experience (GIPE) by working together with peers from around the world, and solving real-life client's problems. We have received seed-funding for four annual projects to engage students from Germany (Europe), Namibia (Africa), Indonesia (Asia), and Peru (Latin-America). In 2020, 30 students from four continents engaged in a one-semester distributed software development project for a Namibian client. Despite Covid-19 they successfully completed the project expressing deep appreciation for the learning opportunities overcoming challenges of working across wide-spread time zones, cultures, changing requirements, and various technical challenges. Considering the vast learning benefits, we suggest to incorporate such projects in all tertiary education curricula across the globe.
\end{abstract}

Keywords: Project-based learning, COIL, distributed software development, intercultural collaboration.

\section{Introduction}

Globalization requires Higher Education Institutions (HEIs) to provide relevant 21st century skills and knowledge, while embracing digital transformation. The ongoing pandemic has fast-tracked a long-awaited educational transformation promoting distributed interdisciplinary on-line learning.

While Project-Based Learning (PBL) has been established since long and not only in HEIs as a student-centered approach where students acquire a deeper knowledge through active exploration of real-world challenges and problems (Bender, 2012), Collaborative Online International Learning (COIL) is nowadays receiving a growing interest as an innovative, cost-effective instructional method that promotes intercultural learning through online collaboration between faculty and students residing in different countries or locations within the context of a course (DePaul University, 2017). Although the idea of distributed student projects with online collaboration among different HEIs dates back to the late 1990s where it has already been successfully applied at least in the field of Software Engineering (Brereton, Gumbley \& Lees, 1998), the international and intercultural aspect came into focus only during the last decade (Appiah-Kubi \& Annan, 2020).

Although the concept of COIL is often being referred to as 'virtual mobility' only (SUNY COIL Center, n.d.), De Wit (2013) regards COIL "an important addition to the many forms of physical mobility" and Helm \& O'Dowd (2020) claim that it "should not be seen as being in competition with physical mobility, rather ... as a complement to physical mobility in blended mobility initiatives and as an inclusive, international learning opportunity for students and staff who may not be able to or want to have a physical or blended mobility." It is exactly this understanding that has led to our approach of enhancing the COIL setup by phases for short-term physical mobility to focus on a much denser intercultural exposure of students and staff in preparation for a successful online collaboration across continents and cultures.

\section{Background}

A quadrilateral partnership was conceptualized, building on long-term individual staff and institutional bilateral collaborations of the Westfälische Hochschule Bocholt with the Namibia University 
of Science and Technology, Windhoek, Atma Jaya Catholic University of Indonesia, Jakarta, and Universidad Católica San Pablo, Arequipa. The proposed programme was modelled on prior successfully completed bilateral student software development projects between German and Namibian students. Concerned with providing equal learning and traveling opportunities for all students and operating within funding options the programme incorporates traveling for all students; turn-taking client selections from the partner countries with an emphasis on interdisciplinary projects. The programme offers selected students the opportunity to gain a truly Global Intercultural Project Experience (GIPE) by working in a multicultural team on an international project. The main objective of the GIPE programme is to provide students with state-of-the art technical knowledge while working in a distributed multicultural team across continents. GIPE also aims at strengthening the collaboration among its partner universities and promoting intercultural exposure in general through 'internationalization@home' activities.

\section{The GIPE framework}

In an effort to strengthen internationalization efforts at German Universities of Applied Sciences, the German Academic Exchange Service (DAAD) has awarded a four year (2019-2023) funding for the GIPE framework programme. At the beginning representatives of all four Universities congregated in Germany to plan the implementation of the framework. A German representative then visited all partner Universities promoting GIPE at management level to ensure institutional commitment and support.

At the core of the GIPE framework are the annual student projects taking place from February to June/July (subject to different academic calendars and lecturing periods) proceeded by a client and project selection, evaluation of students' applications and awarding scholarships as well as requirements gathering and detailed project planning together with the selected client (see Figure 1).

Figure 1. The Masterplan for the GIPE Framework 2019-2023.

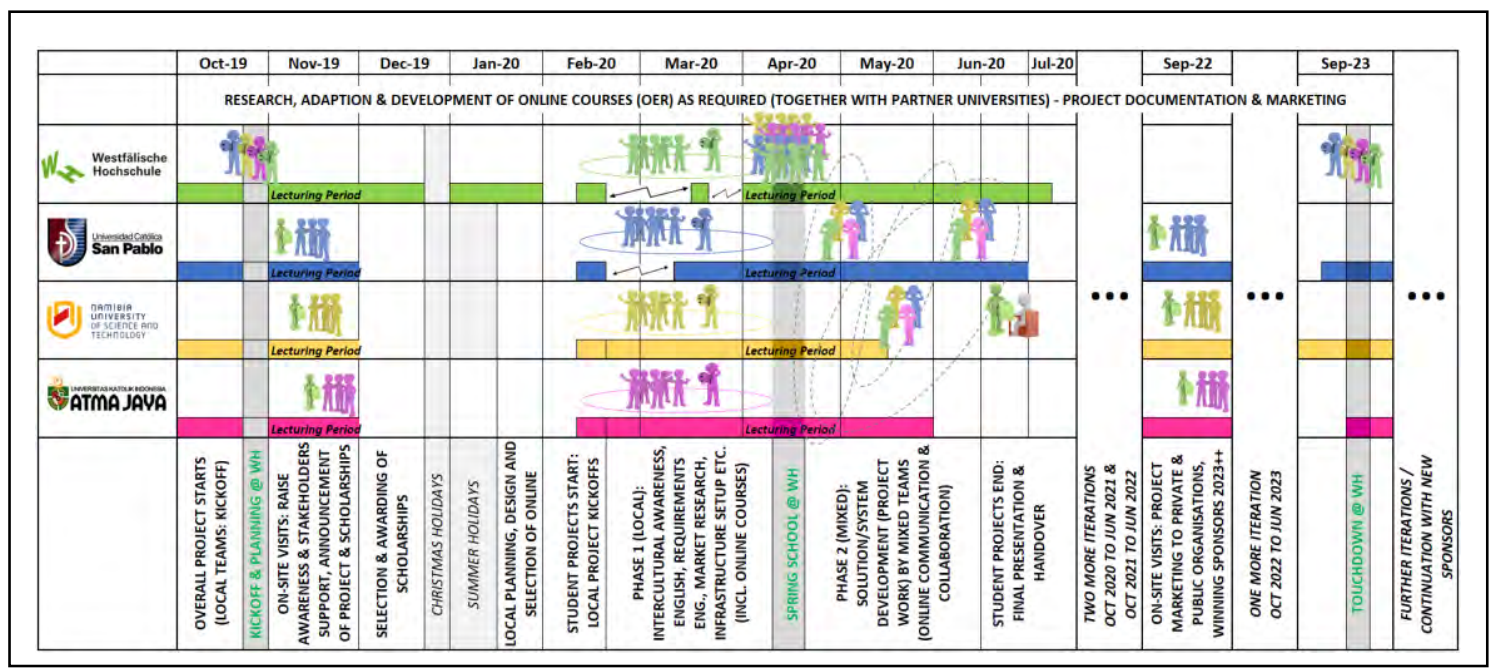

The annual GIPE projects consist of four phases:

1. On-line collaboration preparation: A virtual global kick-off event brings all stakeholders together. Students then get prepared for the various project tasks through targeted trainings. Students join the project in intervals depending on the home universities lecturing schedules.

2. Two-week face-to-face phase: All participating students and one representative lecturer from each university meet in Germany for team-building, intercultural exposure and mixed-team-setup ('Spring School').

3. On-line collaboration: the students continue working on their project tasks in mixed teams using various on-line collaboration tools.

4. One-week project-touchdown and hand-over: The German students travel to the client situated in Namibia, Peru or Indonesia (alternating) offering true international exposure.

To be noted is that the 2020 project was held entirely on-line due to the Covid-19 pandemic and the consequent travel restrictions.

\section{The GIPE 2020 project}

A diverse set of students was selected from each partner University prior to the start of the project. In Peru, four male and one female student joined, with one Business Administration and four Computer Science students (one master and three undergraduate students). In Indonesia, four male and one female student were chosen from the engineering discipline, i.e. electrical, mechanical and industrial 
engineering. In Germany, one female and four male students from IT-related and International Management programs (all Bachelor) and Mechanical Engineering (Master) were selected. In Namibia, the entire postgraduate Advanced Software Development class consisting of 13 students ( 2 female, 11 male) joined the project. Five travel grants were allocated based on the student's portfolio, however due to Covid-19 no student traveled. Each University had a dedicated lecturer overseeing their students, called guide. One part-time project coordinator situated in Germany was responsible for project communication and providing technology support.

A Namibian parastatal was identified as a suitable client, with whom high-level requirements were agreed upon prior to students joining the project. The task was to develop a national web portal to manage research projects, publications and researcher profiles. After signing off the requirement specification document and deciding on the most appropriate state-of-the-art technologies (mostly Software) to be used, the project was internally divided in six sub-projects, each assigned to one team of students: (1) Object Model, (2) Documentation, (3) Quality Control and Assurance, (4) Frontend, and (5) Business Logic. The allocation of students to teams was based on their country (mixed teams), their prior competencies as well as their interest. Thus, students filled in a skill competency survey, which was created by the project coordinator on the basis of needed competencies for the successful completion of this project. The students were then assigned ensuring skills matched, e.g. students who rated themselves very competent on user interface development such as HTML and JavaScript were assigned to the Frontend team. The skills competency survey also allowed the project coordinator to identify skills that were overall rated low yet needed. Thus, interventions were planned. For example, some students needed training on a concurrent version system (CVS) such as GitLab, which allows them to submit their work to a central repository and handle conflicts of files overwriting. Those students who were experienced using CVS systems conducted online tutorials showcasing the other students how to use GitLab.

The project progress was monitored on a weekly basis with meetings and presentations providing feedback. A variety of tools for collaboration and communication were used. For the core facilitation of the GIPE course content, Moodle was used. Slack was used for instant messaging, Slite was used for the overall project administration and Zoom for web meetings. The Object Team duties were adjusted towards the end of the project to focus on preparing deployment (handing over the developed application to the client) since their main task was a prerequisite for most of the other teams and was completed. The developed application (see interface in Figure 2), including the documentation, was handed over to the client, with a minimal delay. The client requested assistance with deployment as well as an extension of some functionalities. Thus, two Namibian students continued working on the project on the client-side, on a part-time basis.

Figure 2. The new STI web portal developed for NCRST.

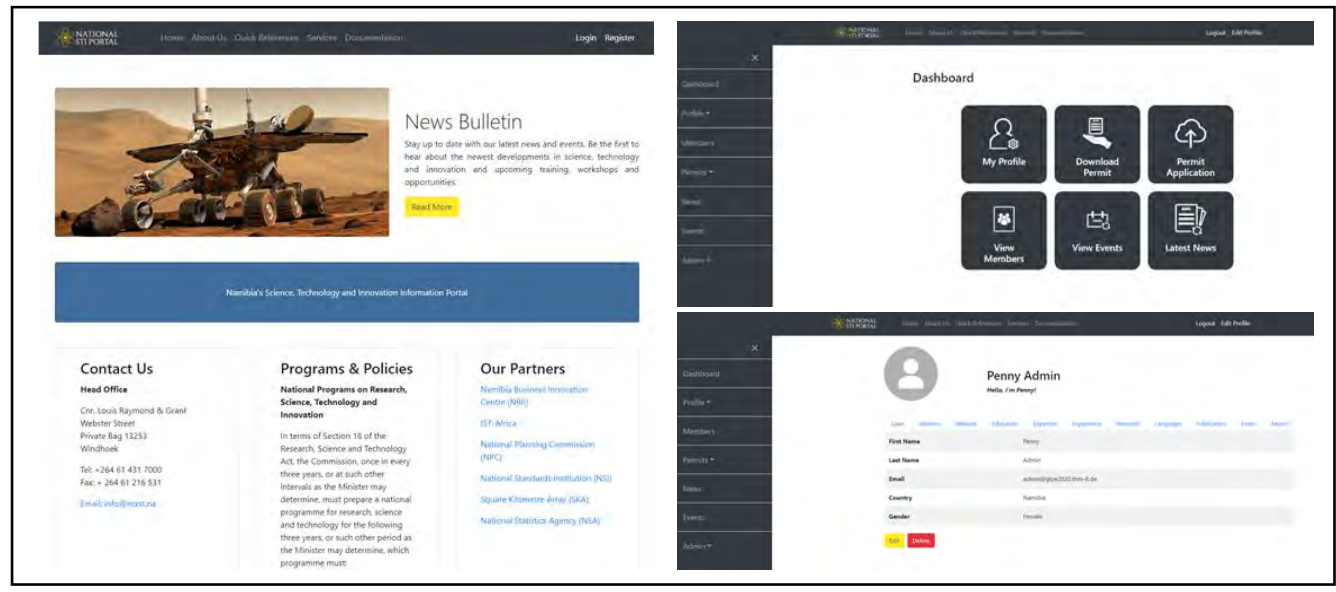

Each guide provided a performance feedback on each student's contribution to the success of the project. Each partner University further applied their own grading system to their students separately with credit points for passing/failing the course they registered for from their specific University. For example, in Namibia, each student was assessed on an individual project process report, a sub-project team deliverable (depending on the team a model, document, code, interface), a team presentation, and individual contribution.

\section{Student feedback}

Student feedback was provided on a voluntary basis by the students in form of videos or text at the end of the project, as well as formal challenges and reflections in the individual student process 
reports form by the Namibian students. It was observed that the Indonesian students provided much more details in their own language than in the English testimonials they also provided. At this point no systematic feedback analysis was undertaken but rather a search of personal statements confirming identified topics in the word frequency analysis. Figure 3 shows a word frequency word cloud, based on the video transcripts and written text feedback by the students, illustrating the most prominent topics such as project, experience, time, team, work, challenge.

Figure 3. Word Cloud generated from all testimonials from GIPE 2020 students.

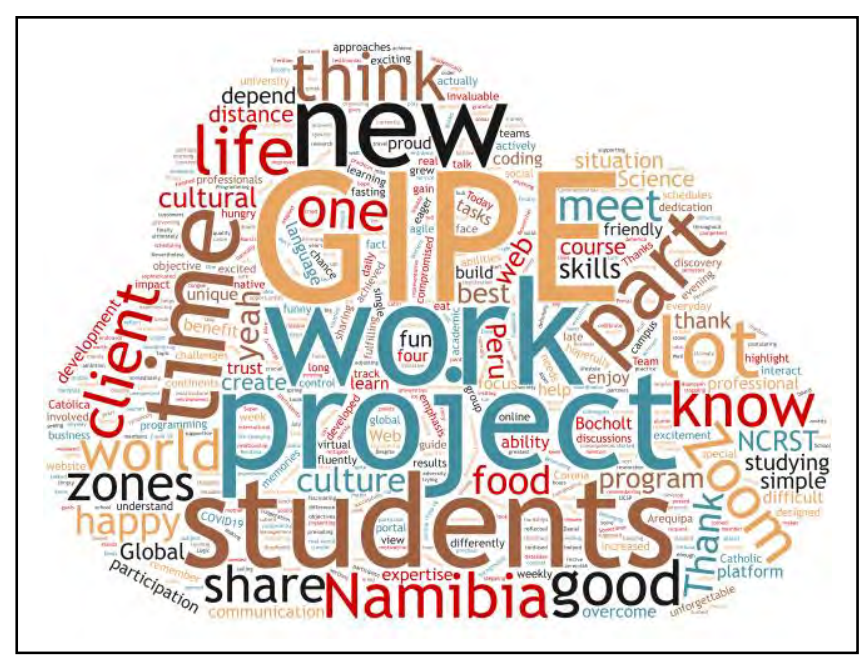

Related to the project work itself, the students appreciated the professional support provided by the project coordinator and the guides. An Indonesian student voiced that: " I appreciate this project and when I go through the trouble, all the guides will help me through many problems." A Namibian student added that "there was always support, it was as much social as it was technical. (LN)." A German student testifies that "Due to the expertise of professionals, a great project manager who kept us on track every week, and the dedication of each team, we were able to do the final product that I am personally proud off".

Regarding their overall experiences, students expressed strong emotions. A male student from Indonesia stated that "this is truly a life-changing experience, although it wasn't smooth sailing all the way." while a German student, exclaimed that " that's something you would normally never think of." Students fully acknowledged the learning opportunity the project provided, be it communication, technical or intercultural. For most of them, it was a chance to improve their professional English skills, as mentioned by a German student: "Within the project, I could improve my English skills and learned how to work with an international team through different time zones."

The students appreciated working in a multicultural team and expanding their personal relations over continents. As expressed by an Indonesian student: "We were getting to know each other and even talking about our countries, such as our culture, food and daily life." The Peruvian female student said "I think the most amazing thing about it is the fact that I've worked with a lot of people from all over the world and we have achieved a very wonderful product for our client."

Besides the disruptions caused by the pandemic the students mentioned a number of challenges with working across time zones as the most prevalent. A Peruvian student stated that: "One of the major challenges of the project was coordinating the team because of time zones. For some of us, that day was just beginning, others were about to have lunch and some others were finishing their day". While another Peruvian student said that "From the beginning, we knew that it would be difficult to reconcile the schedules, since there is a difference of 12 hours with Indonesia, so our weekly coordination meetings and meetings with the students were adapted to that time." This sentiment was further confirmed by one of the German students "I think the most required ability, though, was being agile, adjusting to different time zones, participating sometimes late in the evening, all the morning during the weekends with different time zones and different means of communication." Yet another Peruvian student expressed the challenge of having to deal with multiple issues "I have to manage to overcome the difficulties associated with the pandemic, schedules, language, and, perhaps, specific knowledge of tools, to be able to develop together with students from Germany, Namibia, and Indonesia". One of the female students was concerned with having been the only female in a team and her challenges of being heard and respected. 


\section{Reflections and conclusion}

In conclusion, the GIPE project experience was enriching in many ways: culturally, academically, and professionally. Reviewing the sentiments expressed by the students confirms observations made by the guides, that though the students experienced many new challenges they equally appreciated the learning and the multicultural context. Working in an interdisciplinary team on a software development project required a steep learning curve in a short time. The students received structured technical training and were exposed to new web programming frameworks, and learned good project management practices using professional tools. An invaluable reward was the creation of new personal and professional relations during a time of "social distancing". The Covid-19 pandemic drastically changed the implementation of the planned GIPE framework, depriving the students from travelling to Germany and experience a two-week team-building workshop, as well as depriving the German students from handing over the project to a client on another continent. Yet the distributed interdisciplinary project was completed successfully with a multicultural team of students from four continents, serving as a proof of concept.

We postulate that integrating such international projects in existing curricula across the globe promotes the acquisition of 21 st-century skills for students from all disciplines. Although GIPE received funding for a period of four years only, it is intended to be continued and sustain once the processes have been established and the value for all participating institutions has been recognized. The coordination of such international educational collaborations, however, requires consideration of (1) formal university structures such as lecturing periods, curriculum integration, university calendars, and crediting systems; (2) human resource intensive project preparations, planning and management; (3) communication dynamics and challenges, and the facilitation of peer-instruction and team guidance; (4) technical and methodological aspects of distributed solution development, such as agile development, client interactions, and state of the art development tools and technology implementations. Based on our experiences, we conclude that a refined concept of this interdisciplinary, international project-based learning is a promising approach to support global educational development, even during pandemic times.

\section{Acknowledgements}

The GIPE Project is funded by the German Federal Ministry for Education and Research (BMBF) through the German Academic Exchange Service (DAAD) under grant no. 57510482.

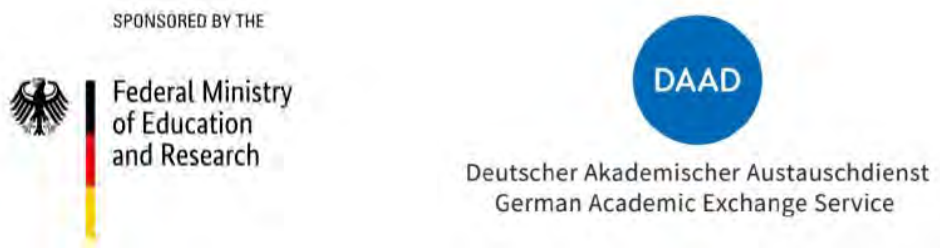

\section{References}

Appiah-Kubi, P. \& Annan, E. (2020). A Review of a Collaborative Online International Learning. International Journal of Engineering Pedagogy (iJEP), 10 (1), 109-124

Bender, W. (2012). Project-Based Learning: Differentiating Instruction for the $21^{\text {st }}$ Century. Thousand Oaks, CA, USA: Corwin Press.

Brereton, P. \& Gumbley, M. \& Lees, S. (1998). Distributed Student Projects in Software Engineering. In Conference on Software Engineering Education and Training (4-22), Los Alamitos, CA, USA: IEEE Computer Society.

De Wit, H. (2013). COIL - Virtual mobility without commercialization. University World News. Retrieved from https://www.universityworldnews.com/post.php?story=20130528175741647

DePaul University (2017). Global Learning Conference: Transcending Boundaries Through Collaborative Online International Learning (COIL). Retrieved from http://www.globallearningconference.org/

Helm, F. \& O'Dowd, R. (2020). Virtual Exchange and its role in Blended Mobility Initiatives. UNICollaboration Position Paper. Retrieved from https://www.unicollaboration.org/wpcontent/uploads/2020/09/Position-paper-on-Blended-Mobility.pdf

SUNY COIL Center (n.d.), Faculty Guide for Collaborative Online International Learning Course Development (vol. 1.4), Center for Collaborative Online International Learning, State University of New York Global Center, Retrieved from http://www.ufic.ufl.edu/uap/forms/coil_guide.pdf 


\title{
THE EFFECT OF A ONE-ON-ONE DIALOGUE-BASED MATHEMATICAL INTELLIGENT TUTORING SYSTEM FOR LEARNING EQUIVALENT FRACTION
}

\author{
Shu Chuan Shih, Hao Yu Tsai, \& Mei Ling Chen \\ Graduate Institute of Educational Information and Measurement, National Taichung University of \\ Education (Taiwan)
}

\begin{abstract}
The purposes of this study are to develop a one-on-one dialogue-based mathematical intelligent tutoring system (ITS) for learning equivalent fraction in the 4th grade math, and evaluate its learning effect. The system used the course content and dialogue script designed by the math teaching experts in advance, and a computer agent teacher asked questions based on the course script. After the student answered, the system was able to identify the error pattern and misconception according to the student's response, then provided each student with adaptive teaching guidance or feedback. Students could construct correct equivalent fraction concepts through a series of interactive dialogues between students and the computer agent teacher step by step. In order to evaluate the effectiveness of this ITS, a quasi-experiment design was conducted. The pretest and post-test were parallel tests involving equivalent fraction. The participants of the study were 76 students in the fourth grade of two elementary schools chosen from midland of Taiwan. They were divided into the experimental group of 39 and the control group of 37 . The experimental group used the "one-on-one dialogue-based mathematical intelligent tutoring system" for teaching. The control group used traditional classroom instruction by a human teacher. The learning content and time were controlled to be the same. Finally, the learning effectiveness and learning interest were assessed by comparing the pre-test and post-test performance of students. The results of the study showed that both teaching methods can significantly improve the students' learning achievements of equivalent fraction, and the learning effectiveness of "one-on-one dialogue-based mathematical intelligent tutoring system" was significantly better than that of traditional classroom instruction. In the "one-on-one dialogue-based mathematical intelligent tutoring system" group, the learning improvement of students with different genders and different ability levels were also reaching a significant level. It indicated that this system benefited the learning achievements of students with different genders and different abilities. Furthermore, from the response data of the learning interest questionnaire, both teaching methods could significantly improve the learning interest of students. But there was no significant difference between the two teaching methods. By interviewing students, the probable causes included that low learning interest students of the experimental group also lack interest to familiar system operation, and some students think this ITS is not interesting enough because of lacking learning games.
\end{abstract}

Keywords: One-on-one, dialogue-based mathematical intelligent tutoring system, basic concepts of fraction, learning effect.

\section{Introduction}

An intelligent tutoring system (ITS) is a computer-assisted tutoring program powered by artificial intelligence (AI). A meta-analysis (Kulik \& Fletcher, 2016) showed that ITSs can be very effective instructional tools for improving students' learning. In particular, one type of ITS is dialogue-based ITS, in which the computer agent has synthesized speech, facial expression in addition to displaying text, graphics, and animation in normal ITSs. The interaction between the speaking agent and learners makes the learning in an ITS more similar to that in the real classroom (Latham et al., 2012). After decades of development, ITSs have been applied in a large spectrum of application, but there are few ITSs for mathematics learning in literature. It can be seen that the development of a math ITS faces more challenges. 


\section{The purpose of this study}

The purposes of this study are to develop a one-on-one dialogue-based mathematical intelligent tutoring system (ITS) for learning equivalent fraction in the 4th grade math, and evaluate its learning effect by a quasi-experiment on 4 th graders in Taiwan.

\section{Method}

In order to evaluate the effectiveness of this ITS, a quasi-experiment design was conducted.

\subsection{The dialogue-based math ITS developed in this study}

The one-on-one dialogue-based mathematical intelligent tutoring system (ITS) for learning equivalent fraction used a talking head at the user interface (UI) to interact with the user. Figure. 1 shows the UI of the math ITS. The tutoring program starts with a main question, which is displayed in the upper left corner. Concurrently, the agent in the upper right corner gives the learner a message about the main question. In the lower left corner is the response area, in which the learner enters input using the keyboard and mouse. After the learner's response has been analyzed, the agent provides encouraging feedback or guidance depending on whether the response is correct or not. The interaction continues until the learner has successfully solved the main question or until he/she fails to solve it, in which case a completed instructional video is presented.

Figure 1. UI of the math ITS.

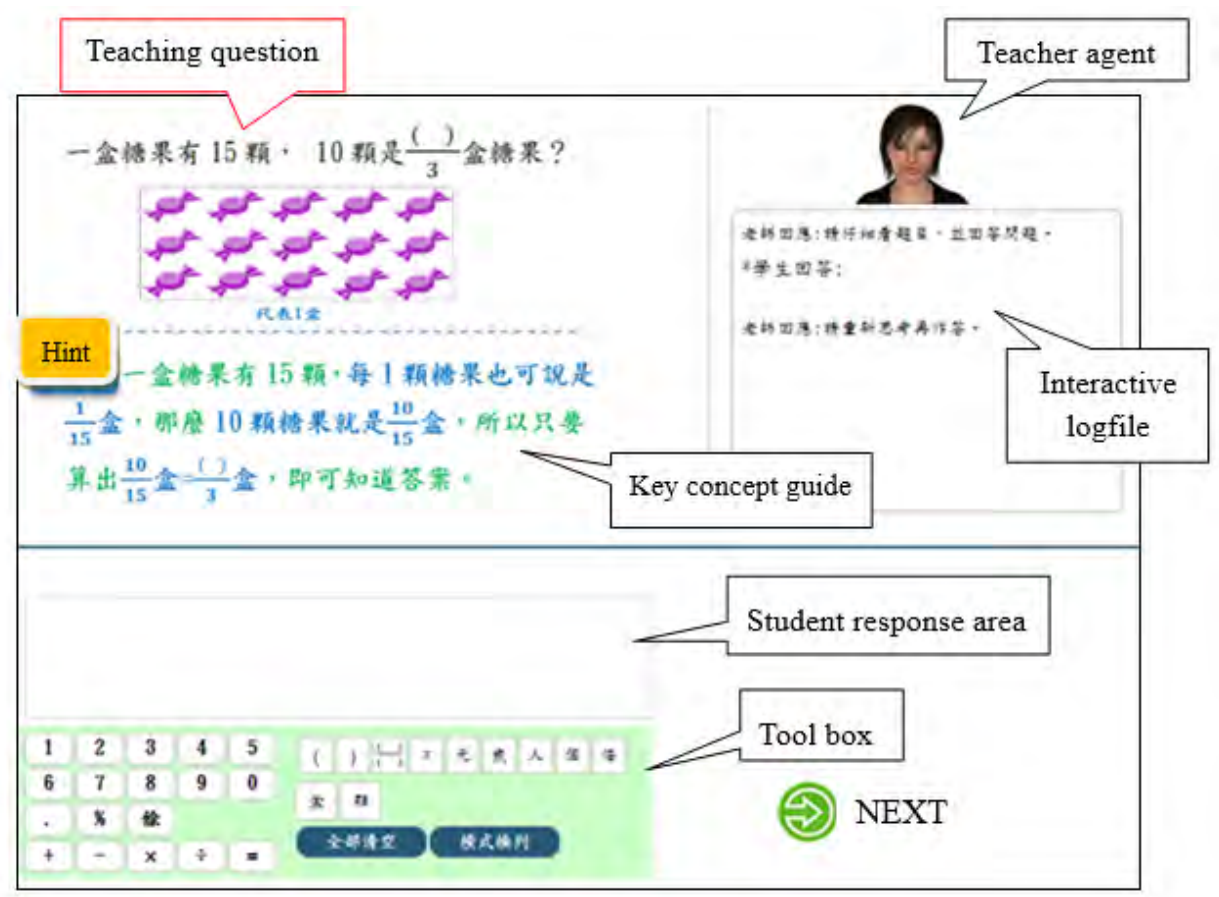

\subsection{Experimental design and participants}

This study used a quasi-experimental design (Figure. 2), the pretest and post-test were parallel tests involving equivalent fraction. Further, the learning interest questionnaire was also conducted before and after the teaching intervention. The participants of the study were 76 students in the fourth grade of two elementary schools chosen from midland of Taiwan. They were divided into the experimental group of 39 and the control group of 37. The experimental group used the "one-on-one dialogue-based mathematical intelligent tutoring system" for teaching. The control group used traditional classroom instruction by a human teacher. The learning content and time were controlled to be the same, and learning time is two hours. Finally, the learning effectiveness and learning interest were assessed by comparing the pre-test and post-test performance of students. 
Figure 2. Experimental design.

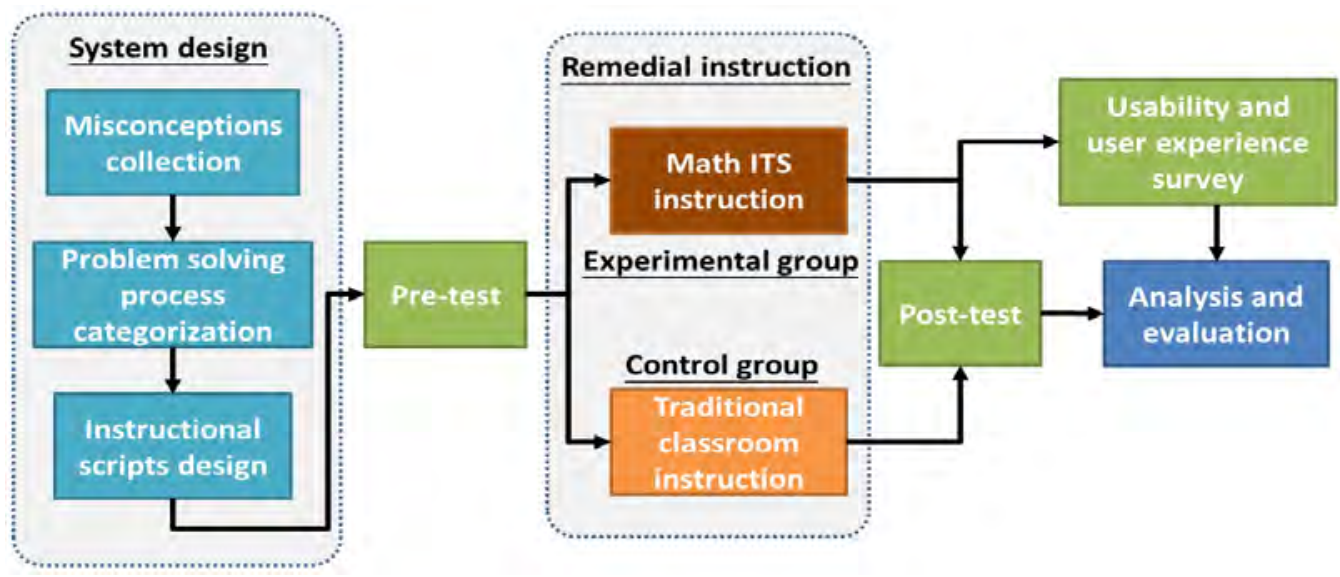

\section{Result}

The results of the study showed that both teaching methods can significantly improve the students' learning achievements of equivalent fraction, and the learning effectiveness of "one-on-one dialogue-based mathematical intelligent tutoring system" was significantly better than that of traditional classroom instruction. In the "one-on-one dialogue-based mathematical intelligent tutoring system" group, the learning improvement of students with different genders and different ability levels were also reaching a significant level. It indicated that this system benefited the learning achievements of students with different genders and different abilities. Furthermore, from the response data of the learning interest questionnaire, both teaching methods could significantly improve the learning interest of students. But there was no significant difference between the two teaching methods. By interviewing students, the probable causes included that low learning interest students of the experimental group also lack interest to familiar system operation, and some students think this ITS is not interesting enough because of lacking learning games.

\section{References}

Efuwape, B. M., \& Aremu, A. (2013). Gender differences in acceptability and usability of computer based learning package in electrical and electronics technology in Nigeria. American Journal of Educational Research, 1(10), 419-424.

Kulik, J. A. \& Fletcher, J. D. (2016). Effectiveness of intelligent tutoring systems: a meta-analytic review. Review of Educational Research, 86(1), 42-78.

Latham, A., Crockett, K., McLean, D., \& Edmonds, B. (2012). Adaptive tutoring in an intelligent conversational agent system. In Transactions on Computational Collective Intelligence VIII (pp. 148-167). Springer, Berlin, Heidelberg. 


\title{
THE GOOD, THE BAD AND THE FUTURE - THE CHALLENGES, POSITIVES AND FUTURE STRATEGIES FOR HIGHER EDUCATION BLENDED TEACHING
}

\author{
Monica Ward \\ Dublin City University (Ireland)
}

\begin{abstract}
There have been many changes that have taken place in all levels of education since the Covid-19 pandemic, including at Higher Education (HE). While the swift pivot to blended teaching has been challenging and not welcomed by all, there are some positives have come about because of it and it would be good to be able to hold on to these. The challenges include moving learning materials (written, video and audio) online, engaging with students in a constructive manner and how to do assessments that are academically rigorous and have academic integrity. It is difficult for those who are used to teaching in a face-to-face environment to suddenly switch over to developing online resources and know who do this effectively and efficiently. Interacting with students online requires a different skill set than in a face-to-face environment and educators should not be expected to acquire these skills automatically. Closed-book, invigilated exams are the norm in HE institutions and ensure a level of academic integrity that has worked well for many years. It is difficult to switch from this scenario to an open-book, non-invigilated exam. It means that questions have to be re-thought to explore the students' understanding in an academic rigorous manner. Ideally, it would be good to be able to address these challenges as they mean a less positive experience for both educators and students.

The positive aspects include a more flexible approach to teaching and learning, facilitation of different modes of learning and in some cases, more interesting and authentic assessments. A more flexible approach enables students to learn at a time and place that suits them and is in keeping with the needs of the more diverse population that makes up student body in HE today. While there is a debate around learning styles, providing learning materials in a variety of formats is beneficial for all students. While it is definitely more difficult to develop open-book assessments, it is also an opportunity to do more real-world, authentic assessments that assess students' higher order skills. This moves assessment further along the Bloom's taxonomy.

This paper looks at the challenges and positives outcomes of the move to blended teaching and learning and how the challenges can be addressed, the positive aspects maintained and how a sustainable approach can be adopted to ensure that future changes to teaching are less challenging and more positive.
\end{abstract}

Keywords: Blended learning, online learning, teaching and learning, authentic assessment, future sustainability.

\section{Introduction}

Change is a constant in almost all aspects of life and Higher Education (HE) is no different. Sometimes the pace of change is slow as it can take a while for teaching, learning and assessment innovations, including blended approaches, to spread out through an institution. Lewin's change model (1947) of unfreeze, change and freeze is common in many institutions. There will always be the super-innovators (Sinclair \& Aho, 2018), innovators and early adopters (Rogers, 1962) who will use innovations more quickly than others, but there is a time lag for the early majority and late majority to deploy these innovations. The final cohort, the laggards are the last to accept and use innovations and sometimes they manage to avoid using them altogether, unless actively encouraged or made to do so. Rienties, Giesbers, Lygo-Baker, Ma, and Rees (2018) discuss teachers' use of a Virtual Learning Environment (VLE) from a technology acceptance perspective. This pattern has been in place for many years in academia. However, the Covid-19 pandemic was a sudden shock to the HE system and forced HE institutions to react rapidly and adopt new modes of teaching, learning and assessment in a very short space of time. The swift pivot to emergency online teaching brought many challenges for academics, 
students and administrators. It also brought about opportunities that could change the way things are done in HE institutions. Only time will tell which elements are retained and which ones are dropped as soon as the pandemic passes and there is the option of returning to campus and delivering face-to-face teaching. This paper looks at the challenges that arose due to the sudden shift to online teaching. It reviews the positive aspects of this shift and what future strategies might come into play in the future.

\section{Background}

While each traditional HE institution's approach to teaching, learning and assessment is different, there are some general commonalities in these approaches. Many HE institutions have an academic that teaches students in a physical location, usually a lecture hall or classroom. They have students who learn via on-campus classes, tutorial and perhaps, practical and lab sessions. Their assessment mechanism is usually a combination of continuous assessment and end of term or semester exams. The continuous assessments may be projects, assignments or other pieces of work produced by the students throughout the academic period. Some of these teaching, learning and assessment activities are paper-based, but in recent years, many HE institutions have adopted the use of VLEs for teaching and learning. At a most basic level, these may be just a repository of static documents for students to access lecture notes. At a more advanced level, it can involve the use of sophisticated quizzes, self-tests for students, discussion fora, peer review and the integration of a variety of resource types to enhance student learning. Innovators and early adopters will use the more advanced features, while the late majority will use it at a very basic level. In some cases, the laggards may manage to avoid using it altogether.

The profile of students has changed with the widening participation at higher level. In the past, the typical student would have been a full-time student, probably a young student straight out of post-primary school and from a certain socio-economic background. It was relatively easy for HE institutions to cater for this type of student with a chalk-and-talk, fully synchronous face-to-face approach. However, while this type of student still predominates, there are other types of students who do not fit this profile. There are more part-time students than before. Students have part-time jobs or other responsibilities that preclude them from attending college full time. HE institutions have more mature students and students from diverse backgrounds than ever before and the 'standard' pedagogical approaches may not work as well for these students. For example, a more andragogical approach may work better with mature students. Barrington (2004) discusses how Gardner's (1992) multiple intelligence theory can help to teach a diverse group of students.

Before the Covid-19 pandemic there was a need for change, but a lack of time (Gregory \& Lodge, 2005) and general inertia meant that there was limited impetus for real change. It is important to note that change applies to not only teaching and learning but also to assessment. Most of the commentary in the context of Covid-19 has focused on teaching and learning, but the assessment piece is challenging and must not be ignored. There are many terms used in the context of the changed teaching approaches during the Covid-19 pandemic - emergency online teaching, synchronous and asynchronous teaching, blended or hybrid teaching. In the context of this paper, emergency online teaching refers to the sudden and immediate pivot to teaching online via a video communications tool, without the usual planning, design and pedagogical supports that exist in a tradition, fully online learning environment e.g. like that of a Massively Open Online Course (MOOC). Blended or hybrid teaching refers to a mix of online synchronous and asynchronous sessions, possibly combined with some element of face-to-face teaching (Garrison \& Vaughan, 2008). Flipped classroom (Tucker, 2012) refers to a teaching approach where the instructional materials are provided to the student in advance and the synchronous classroom time can be used for more active learning approaches.

Mackey, Gilmore, Dabner, Breeze and Buckley (2012) look at the role of blended learning in a time of crisis (in their case, post earthquakes) and their findings are relevant for the current Covid-19 pandemic situation. It is somewhat ironic that they are based on New Zealand as that is the country that has dealt best with the current pandemic. They note four phases that exist in this context and although there are differences, there are many parallels Phase 1 is react, recover and redesign which aligns with the emergency pivot to online teaching. Phase 2 is the restart which was a few weeks after Phase 1 in their case but happened in parallel in the current Covid situation, Phase 3 is reconsolidation (with changes to exams) and Phase 4 was review and reflection. While there has been an element of review and reflection in the current situation, as the Covid-19 pandemic is still around, there has not been sufficient time to reflect properly on the move to blended teaching in HE institutions. 


\section{Higher education blended teaching}

There are often good reasons why people adapt slowly to change or try to avoid it altogether. In an academic context, the status quo has worked reasonably well for a long time and there is a lot of effort involved in implementing change. Academics have many claims on their time apart from teaching as they also have research and administrative duties to perform. They do not have time to explore innovations in teaching, learning and assessment and integrate them into their teaching.

\subsection{Challenges}

There were three main challenges in the move to emergency online teaching - moving learning materials (written, video and audio) online, engaging with students in a constructive manner and how to do assessments that are academically rigorous and have academic integrity. It is difficult for those who are used to teaching in a face-to-face classroom environment to develop resource for an online, asynchronous context. In the in-classroom context, a lecture might use slides with bullet points of the topics being taught but this is insufficient for asynchronous learning resources. The lecturer either has to provide more information or record a voice-over to explain the concepts to students. A further complication in the Covid-19 pandemic situation is that there was no advance planning for the switch staff had no training, no experience and no lead-in time to develop resource. The students needed the resources immediately in order to continue with their learning and know who do this effectively and efficiently.

Teaching and learning has traditionally been a social experience (Kim, 2001). The educator interacts with the students and they can ask questions if something is not clear. In a planned online learning environment, there are facilities put in place to ensure that there is a forum for student-educator interaction. In an asynchronous online learning environment, there are discussion fora that learners can use to discuss topics amongst themselves as well as ask questions. In the emergency pivot to online learning, lecturers had to learn how to use webinar apps to deliver materials synchronously. While some academics may have had experience in this area, many did not, and it was challenging enough for them to focus on teaching, without having the extra cognitive overhead of facilitating and fostering real-time interaction with students. Teaching synchronously online, while monitoring comments and questions in the chat and encouraging students to ask questions in the first place is not an easy set of skills to master in a short space of time. This is particularly true when there is no time to practice in a safe space. Lecturers are accustomed to being competent when teaching their material and removing the familiar aspects of the real classroom and replacing them with an online substitute was challenging for many academics.

Pre-Covid 19, many HE institutions would have used closed-book, invigilated exams as one of their main assessment mechanisms. There are several reasons for this - it is easy to ensure basic academic integrity, it has worked relatively well in the past and there are templates to follow rather than designing assessments from scratch. Moving from the tried and tested approach to an open-book, non-invigilated exam means that exam papers had to be completely redesigned. Lecturers had to consider how to assess students' understanding of a concept rather than asking easier questions that required students to write down memorized definitions and pieces of text. This was challenging to do in the short period available to lecturers from the start of the Covid-19 lockdown and the actual exam period.

\subsection{Positives}

There are three main positive aspects of the move to a blended approach to teaching including a more flexible approach to teaching and learning, facilitation of different modes of learning and in some cases, more interesting and authentic assessments. Flexibility is important in any learning environment. It can foster learner autonomy (Holec, 1979; Little, 1991) where learners can take charge of their own learning. Increased flexibility means that students can learn at a time and place that suits them and is in keeping with the needs of the more diverse population that makes up student body in HE today. This element of flexibility was particularly important in the early stages of the Covid-19 pandemic when students (and staff alike) had to contend with caring responsibilities, health issues and internet connectivity issues.

The concept of learning styles has been around for some time. While there are many different learning styles models (Hawk \& Shah, 2008) they generally assume that people differ in how they learn. There is a debate around learning styles and to whether or not they actually exist (Pashler, McDaniel, Rohrer \& Bjork, 2009). However, one positive outcome of the Covid-19 blended approach is that students have access to materials and topics in a variety of formats. With the flipped classroom model, students can use whichever resources work best for them, before coming into the online or face-to-face classroom. The provision of learning resources in different formats is beneficial for all students, regardless of their learning preferences. 
Not too many people like assessments. In general, lecturers do not like setting or marking exams. Most students do not like taking exams. Assessments should be learner centered and educative (Wiggins, 1998) but, in many HE institutions across the world, a terminal exam is the most common way to do summative assessment (Knight, 2002). Designing and developing open-book, non-invigilated assessments is definitely more difficult than for closed-book, invigilated exams. For example, instead of asking "What is the definition of $x$ ?", academics have to ask a more probing question exploring a student's knowledge of $\mathrm{x}$, as the student could easily just copy or paraphrase a definition form an available source. While this is more demanding, it is also an opportunity to do more real-world, authentic assessments that assess students' higher order skills. This moves assessment further along the Bloom's taxonomy (Bloom, 1956) and gives better insight into a student's knowledge, skills and mastery of particular concepts.

\subsection{Future strategies}

There are several different observations from a strategic point of view that must be considered for the future direction of travel for HE institutions in the blended area. It was a testimony to the competence and adaptability of staff that they were able to pivot so quickly to online teaching. While it may not have been the rounded, polished experience of a well-planned and designed learning environment, they did manage to teach, the students managed to learn and assessments were carried out successfully. Even those who were technophobic before the Covid-19 pandemic managed to get to grips with a blended learning approach. This indicates that changes aimed at incorporating educational technologies into teaching, learning and assessment can be made if there is the will or the need to implement them. Sometimes it takes a major incident or impetus to give energy and purpose to the change mechanisms within an institution and once people are on the blended path, it is easier to keep them there.

The need for planning for future possible problems has been clearly heighted by the Covid-19 pandemic in all societal domains, including HE. There were very few institutions who were ready or had plans for such an event, although some institutions had started planning a few weeks in advance as they anticipated that a lockdown might occur. Hopefully, there will not be an event like Covid-19 again in the future, but it is not impossible. There are twin planning needs of having the right technological infrastructure but also the right pedagogical infrastructure in HE institutions. This pedagogical infrastructure includes having a knowledge learning enhancement unit (or equivalent), regular, focused Continuous Professional Development (CPD) opportunities for staff and that they are encouraged to attend. They should have the opportunity to learn about the research behind blended teaching and learning approaches and have the opportunity to experiment with them in a safe environment before actually using them in their own teaching. As with their students, the information should be designed with the target learner in mind with enough theory to demonstrate the research, but also a practical element so that academics can see how they can actually use the approaches. A co-creation approach should be adopted to ensure that CPD opportunities are leveraged correctly. Peer learning is very powerful in this context, as when academics can see that their peers and colleagues have used something successfully, they will feel more comfortable and confident using it themselves.

\section{Discussion and conclusion}

While experiences of academics in different countries have varied during the Covid-19 pandemic, there are some common elements. One is the lack of preparedness for such an event (Goedegebuure and Meek, 2021). HE institutions should have risk management plans and it is clear that most of them were under-prepared for a crisis of the magnitude of Covid-19. However, there are also lower level risks that are often overlooked by senior management. In some HE institutions, if an academic is unable to deliver a module, there is often a scramble to find someone to cover for that person. There is very little backup coverage. Goedegebuure and Meek (2021) also note that frustration, isolation and reflection were key aspects of staff's professional experience of the Covid-19 pandemic.

As blended learning becomes more mainstream in HE institutions, it is important to ensure that educators and students are comfortable and competent in this area. There should be basic onboarding resources for academics and learners that does not assume any prior knowledge. There are specific skills that are required to be a successful online and blended lecturer and to be a successful online a blended learner and it is important. There should be some mechanism for continual learning in this space, as knowledge in the blended learning space increases, academics who have to teach in that space should be aware of that knowledge to improve their own blended teaching skills. There is still a piece of work to be done on assessment in the blended space, as academics aim to ensure academic integrity in an open-book non-invigilated context. There will be a variety of approaches ranging from proctoring, to interactive oral examinations (Sotiriadou, Logan, Daly, \& Guest, 2020) and re-designed contextualized exams. Academics and students alike will need upskilling if these approaches are adopted. 
Post-Covid 19, HE institutions will not go back to being like they were before the pandemic. Certainly, many of them will return to the traditional face-to-face mode of teaching and this will be welcomed by many. However, now that academics and students have experienced be benefits that come with a blended approach, they will look to hold on to them in the future. Who would not want the benefit of having (extra) online resources to help with their learning? The flipped classroom has been around for some time and facilitates a more active learning paradigm for students. Although the level of preparation is initially higher for this approach, it yields benefits in the long run. It also requires a shift in an academic's perception of their role - less 'sage on the stage' and more 'guide on the side' and this might take some time to bed down. The flexibility available with a blended approach is something that students will not want to relinquish.

In summary, there are and there will continue to be many challenges in the rollout of blended learning in HE institutions. These challenges will change over time as general awareness and knowledge increases in the wider academic community of staff students and administrators. Just as those who are vaccine hesitant must be treated with respect and encouraged to get vaccinated, so too must those who are blended hesitant be treated with respect and their concerns addressed. Those who are familiar with the blended learning approach will already know the benefits but pre-Covid may have had difficulties persuading others to adopt (at least some elements of) the approach. The changes that have occurred in one year due to Covid-19 could possibly have taken 10 years under normal circumstances. Not everyone will stick with blended, but there is now a much wider community that will continue to drive forward the approach and continue to improve things in the blended arena.

\section{References}

Barrington, E. (2004). Teaching to student diversity in higher education: How multiple intelligence theory can help. Teaching in Higher Education, 9(4), 421-434.

Bloom, B. S. (1956). Taxonomy of educational objectives: The classification of educational goals. Cognitive domain.

Gardner, H. (1992). Multiple intelligences (Vol. 5, p. 56). Minnesota Center for Arts Education.

Garrison, D. R., \& Vaughan, N. D. (2008). Blended learning in higher education: Framework, principles, and guidelines. John Wiley \& Sons.

Gregory, M. S. J., \& Lodge, J. M. (2015). Academic workload: the silent barrier to the implementation of technology-enhanced learning strategies in higher education. Distance education, 36(2), 210-230.

Hawk, T. F., \& Shah, A. J. (2007). Using learning style instruments to enhance student learning. Decision Sciences Journal of Innovative Education, 5(1), 1-19.

Holec, H. (1979). Autonomy and foreign language learning.

Kim, B. (2001). Social constructivism. Emerging perspectives on learning, teaching, and technology, $1(1), 16$.

Knight, P. T. (2002). Summative assessment in higher education: practices in disarray. Studies in higher Education, 27(3), 275-286.

Lewin, K. (1947). Change management model.

Little, D. (1991). Learner autonomy. Dublin, 86, 11.

Mackey, J., Gilmore, F., Dabner, N., Breeze, D., \& Buckley, P. (2012). Blended learning for academic resilience in times of disaster or crisis.

Pashler, H., McDaniel, M., Rohrer, D., \& Bjork, R. (2008). Learning styles: Concepts and evidence. Psychological science in the public interest, 9(3), 105-119.

Rienties, B., Giesbers, B., Lygo-Baker, S., Ma, H. W. S., \& Rees, R. (2016). Why some teachers easily learn to use a new virtual learning environment: a technology acceptance perspective. Interactive Learning Environments, 24(3), 539-552.

Sinclair, J., \& Aho, A. M. (2018). Experts on super innovators: understanding staff adoption of learning management systems. Higher Education Research \& Development, 37(1), 158-172.

Sotiriadou, P., Logan, D., Daly, A., \& Guest, R. (2020). The role of authentic assessment to preserve academic integrity and promote skill development and employability. Studies in Higher Education, 45(11), 2132-2148.

Tucker, B. (2012). The flipped classroom. Education next, 12(1), 82-83.

Wiggins, G. (1998). Educative Assessment. Designing Assessments to Inform and Improve Student Performance. Jossey-Bass Publishers, 350 Sansome Street, San Francisco, CA 94104. 


\title{
ASSESSING THE ACADEMIC WRITING SKILLS OF FINAL YEAR ENGLISH SECOND LANGUAGE (ESL) EDUCATIONS STUDENTS TO DETERMINE THEIR PREPAREDNESS AS LANGUAGE TEACHERS: A PRACTICAL APPROACH AT A UNIVERSITY OF TECHNOLOGY
}

\author{
Atrimecia Hass ${ }^{1}$, \& Brigitte Lenong ${ }^{2}$ \\ ${ }^{1}$ Department of Languages, Central University of Technology (South Africa)) \\ ${ }^{2}$ Department of Education and Professional Studies, Central University of Technology (South Africa)
}

\begin{abstract}
The schooling system plays a significant role in teaching basic literacy skills such as reading and writing, yet students from al schooling backgrounds find it challenging to uphold an acceptable standard of academic writing in higher education in comparison with their advantaged peers. The fact that universities have adopted English as the medium for teaching and learning purposes makes it difficult for students to demonstrate the ability to write in their own words, as they are second or third language speakers. Student success at institutions of higher learning depends largely on the adequate mastery of reading and writing skills required by the discipline. The article assesses the academic writing skills of final year education students completing their studies at a University of Technology in South Africa. This study was necessitated by the realisation that students at both undergraduate and post-graduate level are struggling to express themselves through writing in the academic language which is critical for them to succeed at university. The article draws on a writing process skills questionnaire administered to fourth year students and English lecturers in the Department of Education and Communication Sciences. General academic writing conventions such as organisation, development, building an argument, grammar, and spelling were examined through an academic essay. The results highlight the poor writing skills and lack of mastering of academic writing skills of students.
\end{abstract}

Keywords: Academic writing, academic literacy, writing skills, final-year, education.

\section{Introduction}

Historically, university was meant for a few elites in South Africa who came from a good schooling system and were better prepared for university as they have naturally acquired academic literacies at home. This supports the findings by Gee (1990) who believes that such homes and communities should be acknowledged for socialising students to acquire academic literacies by exposing them to particular social spaces. The South African higher education system is confronted with different challenges which stem from a history of racial and class inequalities during the apartheid era (CHE, 2016). As a result of the culturally and linguistically diverse student body, many students are not prepared for the specialised type of writing expected at university and therefore should be introduced into disciplinary writing as it is imperative that they master the writing expectations of the discipline (Pineteh, 2014). Academic writing plays a fundamental role in socialising students into the discourse of subjects and disciplines in universities (Pineteh, 2014; Tuck, 2012; Lillis \& Scott, 2007; Jones, Turner \& Street 1999). The study gives insights into the poor academic writing skills and lack of mastering of academic conventions such as organisation, voices, explicitness, development, argument, grammar, and spelling. To understand this problem, the article investigates how well students are prepared in class for assessment tasks and if they are given extended opportunities to improve their academic writing skills. In addition, this article examines the preparedness of education students as future language educators and makes recommendations to address this problem. The article is written against the background of diverse accounts around the rationale for the poor academic writing skills of students at university of technology and the growing burden on South African universities to transform and "to standardise and systematise the teaching and learning context by introducing quality assurance measures" (Bailey 2008:2). Furthermore, it is also set against the criticism of increasing "marginalization of writing from mainstream curricula" with reference to universities of technology such as the case of the Central University of Technology, Free State (CUT) (Archer 2010:496).

Hence this paper will attempt to answer the following research questions:

1. What major challenges are encountered with fostering academic writing skills?

2. To what extend are students prepared for writing tasks?

3. What strategies can be used improve academic writing skills of Education language students? 
The above questions directed the data collection process and the responses to the questions and provided a structure for the discussions in the ensuing sections of this paper.

\section{Literature review}

The academic writing skills of students in higher education have received significant interests amongst researchers (Tuck, 2012; Lillis \& Scott, 2007). For the purpose of this article, academic writing refers to a literacy practice instead a skill because writing in higher education is not just "a set of neutral techniques that are somehow separate from the social context..." (Archer 2010: 499). The Academic Development Centre at Rhodes University (ADC, 2013:03) defines "academic literacy" as the process to learn how knowledge is structured and produced in diverse disciplines and locations. Examples include the rules for what "counts as an acceptable argument" or substantial evidence and in addition issues such as "structure, voice, referencing, explicitness, links between theory and practice, vocabulary". Writing is the main form of assessment at the (CUT) as students are expected to demonstrate competence in writing of assignments, research proposals, essays and report writing. To respond to this problem many universities have put different students support programmes in place to address the inadequate academic writing skills which the poor schooling system could not solve. This led to an increase demand for academic development programmes as a practical approach to improve the academic writing skills and other soft skills essential for students (Fernsten \& Reda, 2011; Jacobs, 2007). Consequently, CUT writing centre was established against this backdrop to assist undergraduate students with writing skills by supporting the academic language needs of non-English speakers. Archer (2010, p.496) believes that the "language of academia is a very specialized discourse which presents a problem for all students whether they are first or second language speakers" of English.

The biggest challenge with regards to academic literacies at CUT is that lecturers and students use the concepts "academic literacy" and "English" interchangeable. As a result of this misunderstanding the dominant culture in the institution is that lectures cannot teach language skills during their classes because they are not qualified English teachers to teach English skills. Lecturers regard themselves as discipline specialists but show unwillingness to teach other skills such as academic writing conventions. Given this linguistic gap, such approaches focus on teaching English as a set of apparent 'neutral reading and writing skills' in the belief that this was what students needed to become successful university (Boughey and Mckenna, 2016). The approaches towards academic literacies at CUT have a deficit approach as such practices are not taught by discipline experts. Students struggle to master academic literacies practices despite all efforts is place because such practices are taught through mandatory courses at CUT such as Academic Literacy Courses (ALC), Communication skills and Writing centre practices. This argument was supported by McHarg and Thompson (2014) who believe that the remediating strategies adopted by institutions to introduce English Second Language (ESL) students to academic literacy has created feelings of inadequacy, incompetency, and discrimination among such students.

Research by Stein, Dixon, and Isaacson (1994, p392) suggest that "many writing disabilities may derive from too little time allocated to writing instruction or from writing instruction inadequately designed around the learning needs of many students. The useful methods proposed in their study are the notion of big ideas, approaches, scaffolding, and review. Another important component in accomplishing excellence in writing is the reflective process - the skill to critique your own writing as well as the writing of your peers. The fact that today's university students communicate primary through texting and sending emails also contributes to the problem. The main challenge with these is that students might depend on the use of abbreviations and informal language. The inability of writing adequately is the result of many reasons (Bartlett, 2003; Odell and Swersey, 2003). Much attention was given to the preparedness of lectures to teach academic writing skills and how well students are prepared for academic writing tasks. Another huge challenge is the overcrowded classes and small venues makes it difficult for lecturers, especially the Education programme to teach and assess academic writing skills (Matoti \& Lenong, 2018). The findings of Boughey and McKenna (2016) suggested that it has become obvious that the way in which academic literacies expected of students in academic contexts is viewed by some students as colonial and writing 'skills' out the belief that it was needed by students to succeed in the academy (Pineteh, 2014.).

\section{Research methodology}

The population of the study comprised of final year students who were studying towards Bachelor of Education degree, specializing in Languages and lectures teaching English and Academic Literacy. One hundred and one (101) final year students were selected for the study; 77 females and 24 males. The Language course final-year students were selected because English is their compulsory subject until third year level of their studies, which would qualify them as English teachers. A mixed method design comprising both quantitative and qualitative research methods was used for this study, which can be characterised as a QUANqual design (Ivankova \& Creswell 2009:138;). The quantitative approach was based on questionnaire surveys, while the qualitative component was based on semi-structured interviews 
to add depth and scope to the study. The self-constructed questionnaire contained 28 statements and the pilot track showed that the statements on the questionnaire were well understood by the respondents. The mixed method design further enhanced validity and reliability. The second phase semi-structured interviews were used by the researchers to collect qualitative data from the lecturers teaching English and Academic Literacy. In both phases of the study, the sample method used in this research is purposive sampling. The researchers observed the following ethical guidelines, namely, informed consent, privacy, and confidentiality. Participants were not obliged to answer any questions they did not want to and were free to withdraw from the research process at any time if they felt uncomfortable. In the first phase, descriptive as well as inferential statistics were generated from the data and in the second phase, the semi-structured interviews were recorded and transcribed, thereafter text analysis was used to analyse and interpret the data.

\section{Findings and discussion}

The findings discussed in this paper are drawn from both the questionnaire and the semi- structured interviews. Whist English is the sole medium of instruction at CUT, most of the respondents (99\%) speak African home languages, with only one percent (1\%) of the respondents being English speaking. It is for this reason that Bradbury (1993) argues that the challenges black students encounter as they participate in learning in higher education is since they are being taught in a language that is not their home language.

\subsection{Before writing}

Table 1. Before Writing $(n=101)$.

\begin{tabular}{|c|c|c|c|c|c|c|c|c|c|c|c|c|c|}
\hline \multirow[t]{2}{*}{ Questions } & \multirow[t]{2}{*}{ Scale } & \multicolumn{2}{|c|}{ Q1 } & \multicolumn{2}{|c|}{ Q2 } & \multicolumn{2}{|c|}{ Q3 } & \multicolumn{2}{|c|}{ Q4 } & \multicolumn{2}{|c|}{ Q5 } & \multicolumn{2}{|c|}{ Q6 } \\
\hline & & $\mathbf{F}$ & $\%$ & $F$ & $\%$ & $\mathrm{~F}$ & $\%$ & $\mathrm{~F}$ & $\%$ & $F$ & $\%$ & $F$ & $\%$ \\
\hline $\begin{array}{l}\text { 1. I consider the assignment } \\
\text { or topic carefully before } \\
\text { writing. }\end{array}$ & 1 & 1 & 0,99 & 4 & 3,96 & 1 & 0,99 & 1 & 1 & 2 & 2 & 4 & 3,96 \\
\hline $\begin{array}{l}\text { 2. I ask questions about the } \\
\text { topic. }\end{array}$ & 2 & 4 & 3,96 & 9 & 8,91 & 7 & 6,93 & 10 & 10 & 7 & 7 & 8 & 7,92 \\
\hline $\begin{array}{l}\text { 3. I think about what I } \\
\text { already know about the } \\
\text { topic. }\end{array}$ & 3 & 16 & 15,84 & 29 & 28,71 & 16 & 15,84 & 25 & 25 & 27 & 27 & 29 & 28,71 \\
\hline $\begin{array}{l}\text { 4. I brainstorm and write } \\
\text { down facts. }\end{array}$ & 4 & 46 & 45,54 & 34 & 33,66 & 45 & 44,55 & 40 & 40 & 34 & 34 & 44 & 43,56 \\
\hline
\end{tabular}

From the above table $80 \%$ of respondents were confident that they consider the assignment or topic before writing but only $59 \%$ of the students can ask questions about the topic. On average above $60 \%$ of the students can engage on finding ideas, organise ideas or generate their thoughts and gather information before writing.

\subsection{During writing}

Majority of the students (65\%) have confirmed that they can write a good introduction, a clear topic sentence and can give sufficient support to topic sentence, whilst $56 \%$ of responded indicated their ability to edit content, use dictionary, write good conclusions, write difficult words without errors, use their own independent thinking. However, only $29 \%$ paraphrased effectively. It is evident that most students still struggle to reference properly and as a result they commit plagiarism. Teaching students referencing techniques would be one way to introduce students to disciplinary ways of writing, thinking, and arguing their points coherently. This supports the findings by authors such as by Stefan and Carroll (2001) who believe that teaching students how to avoid plagiarism should be part of the core curriculum where lecturers should teach students what is regarded as right and wrong academic writing.

\subsection{After writing}

Table 2. After Writing $(n=101)$.

\begin{tabular}{|l|l|l|l|l|l|l|l|l|l|l|l|l|l|l|l|l|l|}
\hline Questions & Scale & \multicolumn{2}{|c|}{ Q22 } & \multicolumn{2}{|c|}{ Q23 } & \multicolumn{2}{|c|}{ Q24 } & \multicolumn{2}{|c|}{ Q25 } & \multicolumn{2}{|c|}{ Q26 } & \multicolumn{2}{|c|}{ Q27 } & \multicolumn{2}{|c|}{ Q28 } \\
\cline { 2 - 16 } & $\mathbf{F}$ & $\mathbf{\%}$ & F & $\%$ & F & $\%$ & F & $\%$ & F & $\%$ & F & $\%$ & F & $\%$ \\
\hline $\begin{array}{l}\text { 5. I go back to my } \\
\text { writing to revise } \\
\text { the content. }\end{array}$ & $\mathbf{1}$ & 4 & 3,96 & 6 & 5,94 & 2 & 2 & 1 & 0,99 & 1 & 0,99 & 0 & 0 & 1 & 0,99 \\
\hline $\begin{array}{c}\text { 6. I go back to my } \\
\text { writing to check } \\
\text { if it is coherent. }\end{array}$ & $\mathbf{2}$ & 11 & 10,89 & 9 & 8,91 & 8 & 8 & 6 & 5,94 & 6 & 5,94 & 8 & 7,92 & 9 & 8,91 \\
\hline
\end{tabular}

Majority of the respondents $(70 \%)$ can proofread their documents to find errors, revise the content to make appropriate corrections. 


\subsection{Qualitative data from interviews with lecturers}

The study included five lecturers from the Education and Communication Sciences Department and all of them had a postgraduate qualification either in Language Practice or Education, which are relevant qualifications for teaching this course. The semi-structured interview questions were sent to all lecturers well in advance and they had to respond to seven questions. The questions were developed around the type of academic writing tasks given to students, support offered to foster writing skills, collaboration with other departments, and challenges encountered by students to acquire writing skills and strategies to improve academic writing.

\subsection{Challenges regarding academic writing}

According to the Communication Science lecturers, students do not understand what academic writing is or what it entails and often refers to it as English lessons. All lecturers agreed that not enough is being done in the institution to teach academic writing skills. The identified challenges included the following:

"Never mind academic writing, students struggle to write in basic English."

"Lecturers do not receive any training by the university on how to teach academic writing skills to students."

"Students who enter university are not well prepared on how to write properly by the schooling system."

Compounding the problem is that there is no liaison and collaboration in fostering academic writing across academic programmes and Faculties. As proof in this regard is a comment made by one discipline lecture, who said; "I teach large classes and do not have the time to teach academic writing skills, someone else should do it". Another challenge is that students are from diverse backgrounds, therefore are expected to learn and write academic tasks in English and not their home language (Bradbury,1993). Lecturers indicated that they are unable to give constructive feedback due to large numbers of students in the lecture room, thus missing an opportunity to correct deficiencies in academic writing. (Gibbs \& Simpson, 2001). The respondents also corroborated the view by other discipline lecturers that it is not their responsibility to teach writing skills. Mitchell and Evison (2006) argue that teaching writing should be part of the responsibility of disciplinary academics and should occur within the disciplines' curriculum.

\subsection{Preparedness of students in academic writing}

Whilst the majority of responses $(65 \%)$ from student respondents in this study were that they are well versed in academic writing in English and can reference properly, Lecturer's analysis of written tasks by students found a contradiction between student's perception of their academic writing abilities and the tasks they submit. Most written tasks had no clear thesis statement and topic sentences were not clearly written with a lack of effective organization of ideas. About $70 \%$ of students committed general grammatical errors in their writing and are unable to transition ideas between paragraphs coherently. Most students $(72 \%)$ failed to acknowledge sources nor a reference list at the end of their written tasks. Stefani \& Carroll (2001) mentioned that lecturers who request students to write essays as assessment tasks should model the process and the referencing of sources.

\section{Strategies to improve writing skills}

The education lecturers advocated for a credit bearing course that should be offered in the first year or be incorporated into the English course (LCS 5012) with the emphasis on sustained academic writing, and not only short programmes in the writing centre. The participants suggested that there is a need for more collaboration with discipline lecturers, as well as model correct writing skills needed in academic writing.

\section{Conclusion}

The paper assessed the academic writing skills of final year education students at CUT. The results highlight the poor writing skills and lack of mastering of academic writing skills by students. This article concludes that there are many reasons for the poor academic writing abilities of undergraduate students at CUT. A lack of teaching academic writing skills by discipline lecturers could be a major contributing factor. Firstly, academic writing is often outsourced to external practitioners such as writing centres and communication lecturers who often have very little to no knowledge of the discipline. Teaching academic literacy skills should be infused in everything you do as a teacher and learning cannot take place outside the classroom. The study identified a lack of cooperation between the different departments at the institution to foster academic writing skills. The researchers would therefore recommend that academic writing skills should be a joint effort between language and discipline specialist. Secondly, very little time is allocated in time for academic writing and most lecturers regard the teaching of such skills as an ad-on activity and do not include it as part of the curriculum. Teaching writing skills should be an integrated and on-going part 
of socialising students into disciplinary ways of learning. Academic writing plays a critical role in socialising students into disciplinary ways of thinking, writing, arguing, and speaking. Writing skills are only taught at first- year level of study with the belief that students will sustain such skills throughout their academic journey. Academic writing skills should be taught at all levels of academic study, not only in first year as students from all levels of study struggle to write as new literacies are introduced during each year of study. The findings conclude that despite the reasons for the poor academic writing skills of students, most students still struggle to cope with the demand of academic writing expected at university. Limited sample population sourced from one faculty is acknowledged as a potential limitation of this study.

\section{References}

Academic Development Centre (2013). Rhodes University: Grahamstown.

Archer, A. \& Richards, R. eds., (2011). Changing spaces: Writing centres and access to higher education. AFRICAN SUN MeDIA.

Archer, A. (2010). Challenges and potentials for writing centres in South African tertiary institutions. South African Journal of Higher Education. 24 (4): 495-150.

Bailey, R. (2008). Academic staff perceptions of the role and utility of written feedback on students' written work. Zeitschrift Schreiben. 2-6.

Bartlett, T. (2003). Why Johnny can't write, even though he went to Princeton. Chronicle of Higher Education, 49 (17), A39-A40.

Beard, C. Clegg, S. \& Smith, K. (2007). Acknowledging the affective in higher education. British Educational Research Journal. 33 (2): 235-252. http://dx.doi.org/10.1080/01411920701208415

Boughey, C. \& McKenna, S., (2016). Academic literacy and the decontextualised learner. Critical Studies in Teaching and Learning, 4(2), pp.1-9.

Bradbury, J. (1993). The meta-language of cognition. Paper presented at the Kenton, Olwandle Conference, October 1993.

CHE. (2016). South African Higher Education Reviewed: Two Decades of Democracy. Pretoria: Council on Higher Education.

CUT Institutional Planning (2018). Central University of Technology, Free State: Bloemfontein.

Fernsten, L.A. \& Reda, M., (2011). Helping students meet the challenges of academic writing. Teaching in Higher Education, 16(2), pp.171-182.

Gee, J.P. (1990). Social linguistics and literacies: Ideology in Discourses. Basingstoke, Falmer.

Gibbs, G. \& Simpson, C., (2005). Conditions under which assessment supports students' learning. Learning and teaching in higher education, (1), pp.3-31.

Jacobs, C. (2007). Towards a critical understanding of the teaching of discipline-specific academic literacies: making the tacit explicit. Journal of Education, 41: 59-81.

Lillis, T. and Scott, M., (2007). Defining academic literacies research: Issues of epistemology, ideology and strategy. Journal of applied linguistics, 4(1), pp.5-32.

Matoti, S.N. \& Lenong, B., (2018), July. Teaching large classes at an institution of higher learning in South Africa. In Proceedings of International Academic Conferences (No. 6509064). International Institute of Social and Economic Sciences.

McHarg M.P., \& Thompsom, G. (2014). Reconceptualizing the writing centre in the wake of local admissions: Redefining writing centres in Qatar. Arab World English Journal, 3, 77-85.

Mgqwashu, E. (2009). On becoming literate in English: A during- and post-apartheid personal story. Language Learning Journal, 37(3): 293-303.

Mitchell, S. \& Evison, A. (2006). Exploiting the potential of writing of educational change at Queen Mary, University of London. In L. Ganobcsik-Williams (Ed) Teaching Academic Writing in UK Higher Education: Theories, Practices and Models, New York: Palgrave, Macmillan.

Odell, L., \& Swersey, B. (2003). Reinventing invention: Writing across the curriculum with WAC. Language and Learning Across the Disciplines, 6 (3), 38-43.

Pineteh, E.A. (2012). Using virtual interactions to enhance the teaching of communication skills to information technology students. British Journal of Educational Technology. 43 (1): 85-96. http://dx.doi.org/10.1111/j.1467-8535.2011.01193.x.

Stefani, L. \& Carroll, J., (2001). A briefing on plagiarism. LTSN.

Stein, M., Isaacson, S. \& Dixon, R.C., (1994). Effective writing instruction for diverse learners. School Psychology Review, 23(3), pp.392-405.

Tuck, J. (2012). Feedback-giving as social practice: teachers, perspectives on feedback as institutional requirement, work, and dialogue. Teaching in Higher Education. 17 (2), 209-221. http://dx.doi.org 


\title{
EXPERIMENT D' - SERIOUS GAME FOR THE DEVELOPMENT OF INTERCULTURAL COMPETENCES. CONCEPT, CONTENT, AND EXPERIENCES
}

\author{
Gala Rebane ${ }^{1}$, \& Maik Arnold ${ }^{2}$ \\ ${ }^{I}$ Chemnitz University of Technology, Faculty of Philosophy (Germany) \\ ${ }^{2}$ Fachhochschule Dresden - University of Applied Science, Faculty of Applied Social Sciences (Germany)
}

\begin{abstract}
The paper presents an intercultural serious game 'Experiment D', which was developed in a cooperation between the junior professor of Intercultural Competence (Chemnitz University of Technology) and the chair of Social Work Management (FHD Dresden - University of Applied Sciences). The game was successfully tested and assessed in the summer term 2017 and 2018. The main plot consists of a communicative negotiation and strategic handling of a complex situation at university that involves various stakeholders, both within and without it. The game fosters cultural awareness and self-reflection, appreciation of and a creative approach towards diversity, as well as general communicative, social, and team competences. Since it does not require any specialised prior knowledge, 'Experiment D' potentially addresses students of all disciplines. The participants of the two test sessions were students of the study fields MERGE Technologies for Resource Efficiency (study component "Soft Skills", Faculty of Mechanical Engineering) and Intercultural Communication and Competence (compulsory study component Intercultural Learning, Faculty of Humanities) at the Chemnitz University of Technology. Ethnicity, nationality, first language(s), degree of proficiency in English and German, and academic background were all factors that engendered a highly diverse game setting. Aside from the concept of the game, as well as its methodology and didactics, the paper also discusses the results of its assessment.
\end{abstract}

Keywords: Diversity, interculturality, intercultural competence, intercultural learning, serious games.

\section{Serious games in cross-cultural learning}

Nowadays, serious games are an acknowledged didactic instrument in higher education mostly used in business and technical study courses as a means of furthering soft skills (cf. Hoeborn 2016; Strohschneider 2010). Their specific potential for intercultural learning is also increasingly exploited. Intercultural competence is regarded as a "key competence of the $21^{\text {st }}$ century" and has therefore become a normative precept in educational politics (cf. Straub 2007). Most definitions of intercultural competence include social, communicative, and performative competences that could be acquired and trained in serious games (see Bolten 2006 for a conceptual differentiation between general and intercultural performative competence). Complexity, dynamism, non-transparency, uncertainty in the processes of decision-making, and a relative freedom of action on the part of their participants are the common properties of all serious games. Other chief elements of simulation include time pressure, role conflicts and conflicts of interest. In contrast to those serious games where an increase in intercultural competence is conceived as a mere side effect of a promotion of general communicative and social competences as well as leadership and decision-making skills, the main learning objective of intercultural simulation games is an enhancement of cultural and intercultural expertise. Digital communication technologies are ushering in new possibilities of creating immersive learning environments in which intercultural encounters and interactions can be simulated in a realistic manner, while students also practice their 'digital skills' (cf. e.g. Lane / Hays 2008; Strohschneider 2010).

On the whole, intercultural simulations and serious games ground on either a culture-general or a culture-specific approach (Landis / Bhagat 1996) that underlie their conception. There are three principal strategies of integrating intercultural aspects into the game context. First, it can be achieved through direct interculturality when various (real or fictitious) 'cultures' are embedded in the game concept as its integral element, and the respective 'cultural scripts' are set by the game rules. Examples of such games include, for instance, Modis \& Trados (Flechsig 2007), InterAct (Bolten 2002) and Globelia (research 
group "Social Competences" of Chemnitz University of Technology, no date). Second, interculturality may also emerge from the participants' linguistic and cultural diversity and therefore be of indirect nature; such is the case of the serious game Atlanticon (Stumpf et al. 2003). Finally, there is also the option of implicit interculturality, whereby misunderstandings and conflicts do not solely or necessarily arise from cultural-as-ethnic differences of players but are, rather, a result of both conflictual role interests and an unequal distribution of power and resources which are predetermined by the game design (cf. Strohschneider 2010:250). It is this form of interculturality the serious game Experiment $D$ draws on. However, indirect interculturality played a likewise vital role in its practical implementation in heterogeneous student groups and afforded an additional layer of complexity. In what follows, we shall present and discuss the conceptual framework, methods, and didactics of Experiment $D$ as well as some central results of its assessment.

\section{The serious game Experiment D}

\subsection{Outset and objectives}

The serious game Experiment $D$ was developed in cooperation between Assistant Professor for Intercultural Competence (Chemnitz University of Technology) and Chair for Social Management (Dresden University of Applied Sciences) within the framework of the seminar "Cross-Cultural Learning" at Chemnitz University. Since it requires no specialised knowledge, the game targets students of all disciplines. In particular, students of Intercultural Communication / Competence (compulsory module Cross-Cultural Learning, Faculty of Humanities, Chemnitz University of Technology) as well as students of the research cluster MERGE Technologies for Resource Efficiency" (optional module Soft Skills, Faculty of Mechanical Engineering, Chemnitz University of Technology) were actively involved in its conception, development, practical implementation and assessment. The strongly pronounced heterogeneity of the group was also used as a vital intercultural game resource. Due to the varying expectations, disciplinary cultures, levels of language proficiency, ethnic/national backgrounds, and other differences between the participants, the learning settings were marked by a high degree of ingrained diversity. The main objectives of the game were sensitisation for interculturality, initiation of cultural (self-)reflection, promotion of constructive and creative strategies in dealing with (cultural) differences as well as acquisition and development of cross-disciplinary key competences (soft or, else, transferrable skills).

The intercultural serious game Experiment $D$ has several unique features. Firstly, its design does not involve any direct intercultural aspects. By this token, it critically distances itself from a static concept of culture (concept of culture as a 'system' or a 'set of rules'), which underlies many other intercultural serious and role games. Instead, the game prioritises the performative aspects of culture (the concept of 'doing culture'). With our long-term professional experiences as intercultural trainers in mind, we wanted to make the task of 'learning' their respective roles easier for the participants, for even in very simple role exercises, it is hardly possible to expect students to get into the spirit of a randomly assigned and unfamiliar role at short notice, let alone act on it effortlessly. Therefore, differences were generated, secondly, by harnessing role conflicts and conflicts of interest on one hand, individual differences concerning language, socialisation, academic disciplines, and expectations on the other. This secured an alienating potential of specific gaming situations, which was imperative for the striven-for cultural (self-) reflection. Thirdly, acquisition of intercultural competence fundamentally requires intercultural learning receptivity as a voluntary and creative involvement with the unfamiliar. In order to prompt all students to meet this challenge regardless of their cultural background and assigned role, the Other is introduced into the game both as the trigger of the onset conflict and the central object of discussions. What is more, it is an unfathomable, untransparent, and estranging Other, in dealing with which students cannot draw on any real-world interpretative frameworks and solution strategies, nor are they restrained by any pre-existing behavioural patterns: the 'Object D' is a dragon accidentally cloned in the course of a biogenetic experiment at Sonnenstadt University. This circumstance requests students to leave their comfort zone and deploy their creative potential. Relation to reality was, however, maintained by means of situating the game scenario at university as a context relatively well-known to all participants. The introduction of a blatantly fictitious object of controversy ensured that no participants have qualms about involuntarily slighting an actually existing group of people, which, in turn, resulted in a wider variety of options for individual and collective action. At the same time, it also allowed focusing on ethical concerns that are often left out of consideration in intercultural trainings. Ethical issues were raised and critically discussed in the debriefing phases. 


\subsection{Contents, actors, and course of the game}

Main content of the game consists in a negotiation of, and coping with, a complex emergency situation at a university/college that involves communication with various stakeholders both with and without the organisation itself. At the onset, the participants were presented with the following story:

At a university in a medium-sized town, a dragon ('Object D') was cloned as a side product of a bioengineering experiment. The available third-party funds, which may otherwise have been used for its study, are nearly exhausted and the subsequent funding application has been turned down due to an interference of the Ethics Council. The university innovation budget would likewise not suffice to conduct further research on this unprecedented phenomenon. Both the scientists and the university administration are, however, interested in the resumption of the experiment and are currently looking for alternative funding options. Representatives of industry try to seize the opportunity and approach them with various offers. Furthermore, two influential local initiatives, the action group FEDORA (For Environment, Democratic Opportunities and Realistic Approaches) as well as the animal protection society Cloud Nine, are vehemently protesting against the experiment, although on different grounds. The mayor is running for re-election and is therefore trying to mediate between the parties: it is the university that provides most workplaces for the local community that has hard time dealing with high rates of unemployment, detrimental state of many buildings and vacant premises in the town centre. In the course of the game, all actors should attempt to work out a satisfactory solution for the crisis in accordance with their respective functional roles.

Roles in the game include members of the university administration (President, Chancellor, PR Manager), researchers (Head of the Department, Head of the Laboratory, further scientific staff), local authorities (Mayor, Mayor's Aide), representatives of FEDORA and Cloud Nine as well as deputies of the industrial corporations Ignis Bio and Lux.

In summer terms 2017 and 2018, the game was tested out in the course of five 90-minute-long sessions. Each of those included the phases of briefing, intervention, and debriefing. The first session started with an introduction to the game concept and narrative by the facilitators, after which individual roles were assigned and the preliminary strategic brainstorming within separate action groups took place. The second session encompassed three parallel discussion rounds between different stakeholders. The third session consisted of two parallel discussion rounds in larger stakeholder groups. In the fourth session, all participants met at a round table for the final negotiation. Each session began with a briefing and closed with a debriefing. In the fifth and final game session, the participants discussed the game experience and outcomes and were instructed in written self-reflection.

The game process was facilitated by the use of the Learning Management System OPAL, which enabled individual actors and stakeholder groups to maintain active asynchronous contact between separate sessions. The game could not, however, be fully converted to a digital format. Aside from OPAL, students both engaged in face-to-face interactions and exchanged information and relevant materials (e.g., open letters and press releases) via private communication channels such as WhatsApp, SMS, and e-mail. Between the first and the second session, the facilitators also published a controversial newspaper article on OPAL in order to additionally stimulate the game dynamic.

During the whole game, the following rules of communication applied: (1) each role had to be performed with its functional description in mind; (2) everyone was free to communicate with other people und groups; (3) language(s) of communication could be chosen freely; (4) participants were free to use any analogue or digital channels of communication for exchange of information, campaigning and public relations activities; (5) the participants had to abide by the game agenda and the time plan; (6) all agents and stakeholder groups were expected to develop and pursue their own strategy; their respective goals had to be attained up to $80 \%$ at least.

\section{Assessment of the serious game Experiment D: Discussion and reflection}

The game has so far been tested in four groups (Group A: 2017; Groups B and C: 2018; Group D: $2017^{1}$ ), which ranged significantly in terms of their size and acceptance of the game. Groups A and B (ca. 15 participants each) showed high levels of acceptance and participated actively. They also stood out with regard to their creativity in task accomplishment. In contrast, Group C (ca. 30 participants) displayed much lower levels of acceptance, and Group D (8 participants) scored the lowest. Language diversity of the participants was particularly strong in Groups B and C. In those, main challenge was, admittedly, of

\footnotetext{
${ }^{1}$ In contrast to groups A, B, and C, which encompassed students of intercultural communication and competence as well as students of mechanical engineering (MERGE), group D consisted of non-academic staff of Dresden Technical University, at which we run the game in 2017 as a one-time offer in SprInt programme.
} 
communicative (although not exclusively language-related) nature. Group C, and even more so Group D had major difficulties with getting into the spirit of the assigned roles and/or enacting them strategically. The gaming experience was assessed with the help of (1) oral questions for consideration both during the debriefing phases and in the framework of the final plenary discussion; (2) individual written reports submitted at the end of the term. The latter were subsequently subjected to qualitative content analysis (Glaser / Strauss 1967) by the facilitators. The main findings are presented below.

(i) Culture concept: With regard to communication, the participants stressed the fact that integrated references to university culture - even though they may not have possessed full knowledge of its particulars - enabled them to better identify with the game on the whole. Due to the individual differences in national and disciplinary background, the groups viewed themselves as heterogeneous. Acquisition of intercultural experiences was supported by the variation in tasks and group constellations. The participants put emphasis on their practically relevant understanding of culture that could neither be reduced to the concept of 'national cultures' nor to an idea of static system of differences. Instead, they perceived culture as both a dynamic process of negotiation and an expression of collective and individual agency that also entails controversy and power struggles. It was thus possible to critically challenge a utopian vision of interculturality as a peaceful coexistence and focus instead on its practical challenges.

(ii) Communication patterns and language issues: In the course of the game, students learned to know and embrace different styles and patterns or communication (e.g. communicative conventions of expressing one's opinion, reaction to criticism in plenum debates). Use of English as language of conversation (lingua franca) was generally perceived as an ambivalent challenge. Aside from requiring good improvisation skills, could in some cases hinder an in-depth exchange, lead to communicative difficulties and misunderstandings, and restrain display of personal rhetorical abilities.

(iii) Cognitive patterns and solving strategies: The game sessions made visible different approaches to problem solving such as, for instance, pre-planned vs. spontaneous and episodic vs. continuous strategies. The participants described their awareness, appropriation, and modification of different patterns of problem solving as a positive learning effect. The continual debriefings helped them to apprehend their respective experiences so that the gained insights could be fruitfully translated into future action.

(iv) Stress management and adjustment skills: With regard to the degree of personal involvement, the participants' perception of the game also varied. Some of them voiced their insecurity and stress caused by its complexity and dynamic character. However, phases of indecision gave way to phases of goal-driven further development in teams. The participants emphasised the necessity of active stress reduction in unclear situations that would make possible further collaboration with other people even if those might not share one's own values and convictions. This specific experience was also likened to the experiences previously made in the course of a term/traineeship abroad.

(v) Stereotypes and prejudice: Both consciously and unconsciously as well as deliberately and unintentionally, various stereotypes and prejudiced attitudes - such as sexist, racist, or otherwise disparaging comments directed at the members of outgroups - were reproduced in the course of the game. Their negative impact on the group dynamic in teams was nonetheless swiftly recognised and critically discussed.

(vi) Leadership skills: Students reported to have watched internet videos in the timespan of the game in order to optimise their respective role performance. They also appreciated the opportunity to try out their 'hidden leadership qualities' during the game on a trial-and-error principle. Furthermore, they also expressed the view that in future, those skills and abilities should be targeted in the curricula in a more comprehensive manner. They also reported that by assuming leadership in the game they had discovered new facets of their personality that needed further honing (e.g. active listening skills, empathy).

\section{Didactic considerations and conclusions}

With regard to the game implementation, both the participants and the facilitators made the following observations that are of relevance for future development of intercultural serious games:

(i) Impact of setting and context: In the course of the game, it became apparent that external circumstances have a significant impact on its structure, process and outcome. In some cases, introduction to the game, separate gaming sessions and debriefing required more time than planned. In larger groups that generally allowed for more communication, communicative processes tended to grow less straightforward. Physical settings predetermined by the respective infrastructure (too little space in the classroom, high noise levels, use of technical appliances) were also among the factors that influenced the game. 
(ii) Immanent deficits of the game and possible solutions: In nearly all groups, the debriefing phases showed the necessity of even greater detail in role descriptions and individual briefings. It also became apparent that in different stages of the game, it would be necessary to encourage consensus building and compromising on the part of the decision makers (e.g. by providing more detailed information about the respective budgets of industry partners, the upcoming mayor election, and the attractive offers of internationally renowned research institutions) while taking into consideration possible limitations which different functional roles put on the individual freedom of action. Furthermore, an introduction of a score system for separate goal achievements would also boost up the overall play motivation.

(iii) Intercultural learning didactics: The serious game warranted a topical examination of interculturality and enhanced the students' sensibility towards plural and dynamic concepts of culture. Due to the different backgrounds of the participants, it helped to bring home diversity in the sense of implicit and indirect interculturality without having to directly stipulate cultural differences in role descriptions. The game promoted transdisciplinary intercultural, communicative, and social skills, prompted the use of German or, else, English as foreign language and furthered active strategies of stress management in dealing with communicative misunderstandings. Moreover, it enabled the participants to practise, and deliberate on, such central interpersonal competences as frustration tolerance, empathy, and the ability to change perspective. As a format predicated on experimental and problem-oriented learning, the game allowed gathering practical experience in a sheltered environment, experimenting with new patterns of behaviour and enhancing personal performative potential with the help of new self-knowledge. It is our conviction that in future, intercultural serious games should be given primary consideration both in the framework of internationalisation of study programmes and in didactics of higher education.

\section{References}

AG Soziale Kompetenzen, Technische Universität Chemnitz (n.d.). Globelia (Interkulturelles Planspiel).

Bolten, J. (2002). InterAct (Medienkombination): interkulturelles Verhandlungstraining/Intercultural negotiation training. Wissenschaft und Praxis. Sternenfels.

Bolten, J. (2006). Interkulturelles Lernen mit Multimedia gestalten. In: Hohenstein, Andreas und Wilbers, Karl (Hrsg.) Handbuch e-Learning. Expertenwissen aus Wissenschaft und Praxis - Strategien, Instrumente, Fallstudien. 16. Jg. Fachverlag Wirtschaftsdienst. Köln, o.S.

Flechsig, K.-H. (2007). Modis und Trados (Interkulturelles Planspiel).

Glaser, B.G. und Strauss, A.L. (1967). The Discovery of Grounded Theory. Strategies for Qualitative Research. New York: Aldine.

Hoeborn, G. (2016). Serious games in engineering higher education. In: Proceedings of the $19^{\text {th }}$ Verona Toulon International Conference Excellence in Services. URL: http://sites.les.univr.it/eisic/wpcontent/uploads/2018/07/Hoeborn-serious-games.pdf [Zugriff am 11.10.2020].

Landis, D. \& Bhagat, R.S. (Hrsg.). Handbook of Intercultural Training. $2^{\text {nd }}$ ed. London, New Delhi: Sage.

Lane, H.C. \& Hays, M.J. (2008). Getting Down to Business: Teaching Cross-Cultural Social Interaction Skills in a Serious Game. In: Blanchard, Emmanuel und Allard, Danièle (Hrsg.) CATS 2008: Workshop on Culturally-Aware Tutoring Systems. Proceedings. Montreal. URL: https://www.iro.umontreal.ca/ blanchae/CATS2008/CATS2008.pdf [Zugriff am 11.10.2020].

Straub, J. (2007). Kompetenz. In: Straub, Jürgen; Weidemann, Arne und Weidemann, Doris (Hrsg.) Handbuch interkulturelle Kommunikation und Kompetenz. Verlag J.B. Metzler. Stuttgart, Weimar, S. 35-46.

Strohschneider, S. (2010). Planspiele und Computersimulationen. In: Weidemann, A.; Straub, J., Nothnagel, S. (Hrsg.), Wie lehrt man interkulturelle Kompetenz? Theorien, Methoden und Praxis in der Hochschulausbildung. Transcript. Bielefeld, S. 241-264.

Stumpf, S., Michel, T., Sokolowski, M. \& Wenzl, A. (2003). Training interkultureller Kompetenz mit dem Verhaltensplanspiel Atlanticon. In: Wirtschaftspsychologie aktuell 2, 47-53. 


\title{
ATTITUDES OF GRADE ONE EDUCATORS TOWARDS THE IMPLEMENTATION OF INCLUSIVE EDUCATION IN CLASSROOMS AT BOTSHABELO SCHOOLS
}

\author{
Nomvuyo Joyce Mantshiyane ${ }^{1}$, Wendy Setlalentoa ${ }^{2}$, \& Pule Phindane ${ }^{3}$ \\ ${ }^{1}$ Department of Postgraduate Studies, Central University of Technology (South Africa) \\ ${ }^{2}$ Faculty of Humanities, Central University of Technology (South Africa) \\ ${ }^{3}$ Department of Languages and Social Sciences, Faculty of Humanities, Central University of Technology \\ (South Africa)
}

\begin{abstract}
The provision for learners with disabilities has been part of a process and the development of an inclusive education system can be traced back to the nation's founding document, the Constitution of the Republic of South Africa 108 of 1996. Creating an inclusive education environment is about celebrating diversity among learners and creating a welcoming culture where all learners are valued and made to feel that they belong. Inclusivity is about recognising that no two children are alike, and all children can learn. Most children with barriers to learning are accommodated in ordinary schools. Frequent causes of barriers to learning include discriminatory attitudes, labelling and discouragement. The study investigated Grade one educators' attitude towards the implementation of inclusive education at selected Botshabelo Primary Schools in the Free State Province. The study adopted an interactive qualitative approach. The population comprised educators and principals from selected primary schools in Botshabelo. A non-probability selection of participants was used to randomly select educators and principals from five schools. Data were analyzed by means of thematic analysis. The results of the study revealed that there are different factors contributing to the attitudes of Grade one educators towards the implementation of inclusive education in classrooms, amongst others, untrained educators for inclusive education; unsuitable environment for the disabled learners with learning barriers; lack of resources for inclusive education and curriculum at the level of learners with learning barriers; lack of parental involvement; and classroom overcrowding. The results revealed solutions to the negative attitudes of Grade one educators towards the implementation of inclusive education in classrooms which include training educators for inclusive education; parental involvement in learner's education; a suitable environment for disabled learners and those with learning barriers, consideration of learner-teacher ratio; availability of suitable resources for inclusive education; and availability of inclusive curriculum.

The study recommends that educators should be developed professionally by being trained about inclusive education; parents should be involved to support educators and their children; the school environment and buildings should be free from hazards; and overcrowding in classrooms should be avoided.
\end{abstract}

Keywords: Learning barriers, inclusive education, disability, educator, mainstreaming, attitude, inclusive, inclusion, curriculum.

\section{Introduction}

In 1994 democracy was established in South Africa, when there was a radical overhaul of government policy from an apartheid framework to providing services to all South Africans on an equitable basis. Learners with disabilities/ special needs and the development of an inclusive education system were included as part of the process. Learners with special needs are predominantly still in separate 'special' schools for learners with disabilities (Jordaan, 2015). South African inclusion initiatives that seek comparable learning models supported critical adaptation in the curriculum. Education systems had increased responsibility on the part of the teachers in learning styles to teach learners effectively by means of inclusive education models. Learners need to learn in ways that are accessible to them (Wildeman $\&$ Nomdo, 2007). Creating an inclusive education environment aims to celebrate diversity among learners and create a welcoming culture where all learners are valued and made to feel that they are acceptable. Inclusivity should recognise that no two children are the same and all children can learn. Children with learning disabilities should be accommodated at ordinary schools. The causes of learning barriers in learning include discriminatory attitudes, labelling and discouragement (Kratochvilova \& Havel, 2014). 


\section{Theoretical framework}

For this study to be coherent and focused, two social theories, namely Vygotsky's constructionist theories and Bandura's cognitive theories were used to support the data.

\subsection{Vygotsky 's theory on Social constructionist view of disability}

Vygotsky considered disability as a social aberration which springs from children 's changing social, environmental relations causing disturbances in social behaviour. According to Vygotsky (1993), cited by Rodina (2007), children with disabilities tend to have a special need for "detours" i.e. in other special educational environments (adapted educational milieu) and this milieu provides the necessary conditions for the cultural introduction of children with disabilities and realisation for mankind's inherent socio-cultural experience. Vygotsky stressed the importance of the distinction between primary and secondary developmental complications and succeeding symptoms in the study of upbringing, teaching, and education of children with different disabilities. Vygotsky (1993) indicated primary developmental complications as being primary deficient, which resulted from the very nucleus of directly interconnected deficiency and less subjected to remediation, while secondary developmental complications were social and psychological consequences of primary disabilities and less resistant to and more subjected to elimination.

Secondary disability can be prevented and eliminated by medical and educational means. Vygotsky (1993) stressed the importance of the dynamic, socio-cultural nature of disability for the methodology of inclusive education and importance of social learning in the upbringing and education of children with disabilities. According to Vygotsky, psychological-physical insufficiency was determined by a certain social setting, arrangement, or "aberration", hindering children's normal socialisation (cited by Rodina, 2007). Moore (2012) regards Vygotsky' s idea of learning and teaching as essentially social activities that take place between social actors in socially constructed situations. Both views suggest that Vygotsky's theory focused on interactions within classrooms where the teaching and learning process takes place (Botty \& Shahrill, 2014).

\subsection{Bandura's social cognitive theory}

The construct of self-efficacy had grown from the social cognitive theory of Bandura. Bandura defined self-efficacy expectation as the conviction of successfully executing the behaviour required to produce the outcomes (Bandura, 1977 cited by Scheer, Astrid, Scholz \& Donie 2015). Bandura (1997) cited by Sewel and St George (2000) regarded self-efficacy as judgement of one's ability to organise and execute given types of performance. Bandura (1982) cited, by Sewel and St George (2000) emphasised that the most effective way to create a strong sense of efficacy was through mastery experiences. Successful performance accomplishments provided the most authentic evidence of whether one had brought about success.

\subsection{Inclusive education}

Inclusive education is considered as a reform aimed to eliminate all barriers to the integration of children into the general education system, regardless of their differences and social background (Özokwu, 2018). Inclusive education requires a stimulating and responsive school environment that enables pupils to develop their inner potential, promoting their social corporation and guides them to corresponding future employment (Kratochvílová \& Havel, 2014).

\subsection{Inclusive schools}

The South African Education White Paper 6 (2001) defines an inclusive or full-service school as colleges, further and higher education institutions that are first and foremost mainstream education institutions that provide quality education to all learners by supplying the full range of learning needs in an equitable manner. Furthermore, with the introduction of the policy on Inclusive Education as published in Education White Paper 6 of 2001, the Department of Education made a commitment to ensure that all children are welcomed in all schools and that they would be supported to develop their full potential irrespective of their background, culture, abilities or disabilities, their gender or race. The concept inclusive or full-service school was introduced to show how ordinary schools could transform themselves becoming fully serviced schools.

Bhatnagar \& Das (2014) state that the regular classroom teacher is the single most important variable in the success of inclusion programmes. What they do and what they believe shape the quality of instruction that all learners, particularly those with disabilities, receive in the classroom. No matter how excellent the educational infrastructure might be, how well -articulated educational policy might be, how well- resourced a programme might be; effective inclusion does not take place until regular classroom 
teachers deliver relevant and meaningful instruction to learners with disabilities. Chakraborti-Ghosh (2017) poses that inclusive classrooms might contain several learners with special needs who have been mainstreamed full-time into the general classroom, or one or two learners who spend time each day in both a special educational classroom and a general classroom.

\section{Aim of the study}

The aim of the study was to investigate educators' attitude towards implementation of inclusive education at Botshabelo primary schools in the Free State Province.

\section{Research questions}

The study sought to answer the following questions:

$>$ Do grade one educators understand their duties towards the implementation of Inclusive Education and what views do they have on it?

Do Grade one educators get professional development on Inclusive Education?

\section{Research methodology}

In this study interactive qualitative research was carried out. It was the research method used in the interviews (Kumar, 2014). According to McMillan and Schumacher (2014), qualitative techniques or interactive qualitative research collect data primarily in the form of words rather than numbers. Qualitative techniques provide verbal descriptions, portraying richness and complexity of events that occur in natural settings from participants' perspectives. The qualitative data were collected by means of interviews with Grade one educators of inclusive education and School Management Teams (SMT) at selected Botshabelo primary schools.

\subsection{Population and sampling}

The research population consisted of three educators from each of the randomly selected schools offering inclusive education in Botshabelo.

The method that was applied involved non-probability sampling. As sample of two schools was drawn and selected randomly. Two schools from Section F and Section K were selected were selected, respectively. The researcher distributed questionnaires and interviewed the Grade one educators who were information-rich participants in inclusive education, as well as the Site-Based Support Team (SBST).

\subsection{Data analysis}

The study was essentially qualitative; therefore, the analysis of data gathered was equally qualitative. The educators' responses to the questions, the behaviour, utterances, as well as perceptions of all informants and observations conducted were recorded and noted down, and collectively assessed against the generally accepted behaviour, attitude, and requirements of inclusive education in the classroom.

\section{Results}

When asked about inclusive education the teachers seemed to know exactly what it entails as well as the role they are expected to play. The results also revealed that the socio-economic background of learners; under- resourced, overcrowded classrooms, parents, school, and the community contributed to the attitudes of Grade one educators on Inclusive classrooms at selected schools in Botshabelo. Educators expressed concerns on having stress and anxiety when including learners with barriers.

Quoted verbatim Educator Z "All learners are capable of learning even if they are challenged".

Educator X: "Our classes accommodate all learners in the mainstream, quite often, the physical resources are a problem"

The negative attitudes of educators regarding the Implementation of Inclusive Education in classrooms contribute to the problems encountered by inclusive education. The success of inclusive education relies on the success of teachers in learning skills and perspectives assumed by new visions of inclusion and unlearning practices and beliefs with regards to learners and instruction that dominated their professional lives up to this moment. According to Chander (2016) attitudes of educators to the successful 
implementation of inclusive education vary from one person to another and they played an important role in determining how people react to a situation and help to predict human behaviour.

Most educators have problems in implementing inclusive education in classrooms.

Educator W indicated that: "Our school is not developed to accommodate disabled learners. Also, we do not get support from some parents. How can I perform?"

Educator Z: "Some parents at times interfere and want to tell us how we should treat and teach learners in our classes"

Educator U: "Our classrooms are crowded. This makes it practically impossible to accommodate learners with special needs in teaching and learning".

Effectively the inclusion of children with special educational needs in the classroom was a crucial goal as it provided important factors that helped them to adapt, i.e., being taught together with other children, feeling part of the class, and being recognized by it, with the resources it furnishes and the issues it entails (Ainscow, Booth \& Dyson, 2006 by cited Santos, Sardinha \& Reis 2016). Without sufficient resources, the work of the educator becomes difficult. Research that involved principals in schools in Gauteng, the richest and best resourced province of South Africa, also determined that disabled learners received specialised support services either "seldom" or "never" (Nel, Muller \& Rheeders, 2011). The study indicated that successful Implementation of Inclusive Education mainly depends on the positive attitude of educators.

Nine of the ten teachers interviewed indicated that they attended workshops on inclusive education, however, Educator Y further stated that:

"Yes, even though workshops have been organised for us, but I think they were not enough, I still am not confident enough to teach learners with challenges regarding learning".

The study indicated that lack of training of educators constitute a key problem and the most crucial obstacle that hampers policy makers' endeavour to establish Inclusive Education successfully. It is important to take into cognisance that more support needs to be given to educators even after workshops. The attitude of Grade one educators on Inclusive Education Implementation in classrooms at Botshabelo can be attributed to lack of training of educators. Educators have a vital role to play in the successful Implementation of Inclusive Education.

\section{Conclusion}

The need of support for educators is often overlooked, this contributes to anxiety on their part and the barriers to successful inclusive education. Lack of differentiation in instruction and pressure put by parents of learners without special needs also contributes to the attitudes of Grade one educators on Inclusive Education Implementation. Educators who are already overworked and overstrained experience additional pressure from parents who do give support to their own children. Parents should also ensure that learners with special needs are supported and treated with respect by their peer group and teachers.

\section{References}

Bhartnagar, N. 2014. Regular schoolteachers' concerns and perceived barriers to implement inclusive education in New Delhi, India. International Journal of Instruction, 7(2): 89-102.

Booty, H. M.R.H. \& Shahrill, M. 2014. The impact of Gagné, Vygotsky and Skinner theories in pedagogical practices of Mathematics teachers in Brunei Darussalam. Review of European Studies, 6(4): 100-109.

Chander, R. 2016. Attitudes of teachers and students towards mainstreaming, Indian Journal of Health and Wellbeing, 7(1):101-1-5.

Chankraborti-Ghosh, S. 2017. Inclusive education in India: a developmental milestone from segregation to inclusion. Journal of Educational Systems. 1(1): 53-62.

Department of Education. 2001. White Paper 6: Special Needs Education-Building an inclusive education and training system. Pretoria: Department of Education. Available http://www.education.gov.za/LinkClick.aspx?fileticket=gVFccZLi/tl=\&tabit=191\&mid=484. (Accessed 06/11/2017).

Grant, C. \& Osanloo, A. 2014. Understanding, selecting, and integrating a theoretical framework in dissertation research: creating the blueprint for your "house". Administrative Issues Journal, 4(2): 12-16.

Jordaan, A. 2015. Inclusive education in South Africa: the good, bad and ugly. Accessed from: http://news.nwu.ac.za/inclusive-education-south-africa-good-bad-and-ugly 
Kumar, R. 2014. Research methodology: a step-by-step guide for beginners. $4^{\text {th }}$ ed. California: Sage Publications.

McMillan, J.H. \& Schumacher, S. 2014. Research in education: evidence-based inquiry. $7^{\text {th }}$ ed. New York: Pearson Education Limited.

Moore, A. 2012. Teaching and learning. $2^{\text {nd }}$ ed. London: Routledge.

Nel, N., Muller, H. \& Rheeders, E. 2011. Support services within inclusive education in Gauteng: The necessary and efficiency of support. International Journal of Education, 1(1):38-53.

Özokwu, O. 2018. The relationship between teacher attitude and self-efficacy for inclusive practices in Turkey. Journal of Education and Training Studies, 6(3): 6-12.

Rodina, K.A. 2006. Vygotsky's social constructionist view on disability: a methodology for inclusive

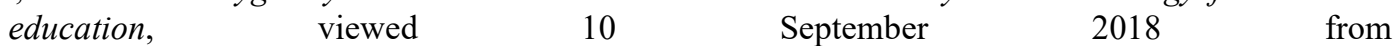
http://lchc.ucsd.edu/mca/Paper/VygotskyDisabilityEJSNE2007.pdf

Santos, G.D., Sardinha, S. \& Reis, S. 2016. Relationships in inclusive classrooms. Journal of Research in Special Educational Needs, 16(1): 950-954.

Scheer, D., Scholz, M., Rank, A., \& Donie, C. (2015). Inclusive beliefs and self-efficacy concerning inclusive education among German pre-service teachers. Journal for Cognitive Education and Psychology, 14 (3): 270-293.

Sewell, A. \& St George A. 2000. Developing efficacy beliefs in the classroom. Journal of educational enquiry, 1 (2): 58-71.

Wildeman, R.A. \& Nomdo, C. 2007. Implementation of inclusive education: how far are we? Occasional Paper, IDASA: Pretoria. 


\title{
CHALLENGES WITH THE IMPLEMENTATION OF THE ADMISSION POLICY FOR GRADES R AND 1 IN THE MOTHEO DISTRICT IN THE FREE STATE PROVINCE OF SOUTH AFRICA
}

\author{
Jaysveree M Louw \\ Department of Educational and Professional Studies, Central University of Technology (CUT), \\ Bloemfontein (South Africa)
}

\begin{abstract}
At the beginning of every year thousands of learners report for Grade $\mathrm{R}$ and Grade 1 across schools in South Africa. Unfortunately, many learners are refused admission to these grades when parents apply. The national policy that guides and governs admission of learners to public schools is the South African Schools Act (SASA) 84 of 1996. This policy stipulates that the admission age of a learner to a public or independent school for Grade $\mathrm{R}$ is age four, turning five by 30 June in the year of admission. For a learner to be admitted to Grade 1, the learner has to be five, turning six by 30 June in the year of admission (SASA 1996 Section 5a-6; Ramadiro and Vally 2005:1). But SASA (1996: Section 3(1) also states that attendance is compulsory in the year in which a learner turns seven. According to the National Education Policy Act (NEPA) 27 of 1996 and SASA (1996: Section 5) the Admission Policy of a public school is determined by the School Governing Body (SGB). However, according to the findings of the research there is no uniformity and consistency in schools as far as admission to Grades R and 1 is concerned. In addition, the study reveals that many parents are unaware of the age requirements for Grades $\mathrm{R}$ and 1 . Although SASA does stipulate the admission age to Grade R and Grade 1, it also states that schools, in the form of the SGB, can determine their own Admission Policy. Hence some schools admit learners according to SASA, while others ignore the requirements stipulated in SASA and determine their own Admission Policies. The study aims to determine what the challenges are with the implementation of the policy. A qualitative research method in the form of interviews was conducted to collect data from teachers, parents, SGBs, school principals and departmental officials. Based on the findings recommendations were made, one of which is that there should be uniformity amongst schools as far as policy implementation is concerned. The theoretical framework that guides this study is document phenomenology.
\end{abstract}

Keywords: Admission, policies, grade $R$, grade 1, admission age.

\section{Introduction}

There are very few aspects of society that are not impacted by law, including education (Meier and Marais 2018:61). Some of the laws that govern education in South Africa include the South African Constitution 108 of 1996, NEPA 27 of 1996, the Education White Paper 5 on Early Childhood Education (ECE), SASA 84 of 1996 and the Curriculum and Assessment Policy Statement (CAPS) of 2011. The two policies that regulate admission to Grades $\mathrm{R}$ and 1 , and that will mainly inform this research, are SASA 84 of 1996 and NEPA 27 of 1996. The Constitution is the supreme law of South Africa. It stipulates that 'everyone has the right to a basic education, which the state, through reasonable measures, must make progressively available and accessible' (South African Constitution of 1996, Section 29). Early Childhood Education (from birth to about nine years, or from birth to the end of Grade 3) is particularly crucial because it lays the foundation for the child's further and future education (Department of Education 2001a: 3). Primary school education starts with the application process for admission to a school. In many cases, especially in urban areas, parents can exercise their choice of schools (Miller 2018: vi and 30). After parents apply, they are typically given a waiting period, after which they will be informed of the outcome of the application. Usually there are three outcomes: the learner is accepted at the school, the application is rejected, or sometimes learners are placed on a waiting list. 
The primary research question this paper seeks to address is: Why are there challenges with regards to the implementation of the Admission Policy to Grades R and 1? I will address this question by attempting to answer the following sub question:

- What is the age of admission to Grades $\mathrm{R}$ and 1 , according to SASA?

\section{Aim of the study}

The aim of this qualitative study was to determine the challenges that schools experience with the implementation of the Admission Policy to Grades R and 1, and why they experience these challenges.

\section{Problem statement}

SASA stipulates that learners should be admitted to Grade R when they are four years old, turning five by 30 June in the year of admission. Grade R (also called the Reception Year) is the year of schooling before Grade 1 (Janse van Rensburg 2015:1). For admission to Grade 1, learners must be five years old, turning six by 30 June in the year of admission (SASA 1996 B-6 and B-19). But SASA also has a clause that states that 'subject to this Act, and any applicable provincial law, every parent must cause every learner for whom he or she is responsible to attend a school from the first day of the year in which such learner reaches the age of seven years until the last school day of the year in which such learner reaches the age of 15 years or the ninth grade, whichever occurs first'. The assumption is that when a child is seven years old, he or she is compelled to attend school, presumably Grade 1. But a child can and should be admitted to Grade $\mathrm{R}$ at the age of four, and to Grade 1 at the age of five. However, analysis of the results indicates that $70 \%$ of parents claim that some schools did not want to admit their children, even though they met the age requirements (cf. Janse van Rensburg 2015:1). Some schools informed parents that for admission to Grade $\mathrm{R}$, the child has to be five, turning six anytime during the year of admission, not necessarily by 30 June. For admission to Grade 1, parents were informed their child has to be six, turning seven in the year of admission, not necessarily by 30 June in the year of admission, as stipulated by SASA. Some schools indicated that, in their experience, four-year old learners are too young to be in Grade R, and that five-year olds are too young to be in Grade 1. The result is that some children that are supposed to be in Grade $\mathrm{R}$ are placed in pre-Grade $\mathrm{R}$, and some children that should rightfully be in Grade 1 are placed in Grade R. Subsequently these learners are 'one year behind' with their schooling. What further complicates the problem of learner admission, is the fact that schools can determine their own admission requirements for Grades R and 1. SASA (1996: Section 5) allows SGBs to determine the Admission Policy of schools, but this determination must be subject to the Act. Do schools then correctly implement the admission policy if they place Grade R and Grade 1 learners a year behind? Most of the schools that participated in the research opt to admit learners to Grade R only in the year they turn six, and to Grade 1 only in the year they turn seven. The most common reason for this choice is that teachers feel learners turning five in Grade R are too young and not school ready, and learners turning six in Grade 1 are too young for Grade 1 (Bruwer, Hartell and Steyn 2014:1; Janse van Rensburg 2015:1). SASA also stipulates that the SGB of a public school, or any other person, may not administer any tests related to the admission of a learner to a public school (SASA 1996: Section 5). This implies that school readiness tests should not be used to determine whether or not children are ready for school, regardless of the child's age. The policy does, however state that under exceptional cases, parents can apply for admission for learners who are at a lower age than the admission age (for Grades R and 1), if such an admission is in the child's best interest (SASA 1996: Section 5c).

\section{The importance of early childhood education}

Early childhood education refers to a comprehensive approach to policies and programmes for children from birth to nine years of age with the active participation of their parents and caregivers (Department of Education 2001; Denham, Bassett and Zinsser 2012). In South Africa, Grade R forms part of the Foundation Phase and can be provided by public or independent schools, community-based EDC sites and independent EDC sites attached to primary schools (Naude and Meier 2019: 58; SASA 1996: Section 5; Department of Basic Education 2001). It provides a key foundational year where the gap between home and formal schooling is bridged (Meier and Ndou 2021:82). Grade R is however, more informal than Grade 1, and the focus is on learning through play (or play-based learning), exploration, incidental and spontaneous learning (Department of Education 2001: 3.2-3.2.9; 5; Naude and Meier 2019:58). In countries such as South Korea and the USA children start formal primary school (referred to as elementary school) at around age five (www.asmilan.org:2021; Nuffic 2015:6). This is also the trend in 
European countries such as Austria, Bulgaria and the Netherlands (Depp: 2020). In Zimbabwe primary education starts from age six (www.scholaro.com: 2021). In South Africa, policy recommendations were made in 1997 to make Grade R compulsory for admission to Grade 1, and its provision was to be phased over a five-year period (Department of Education 2001). The plan was to make it compulsory from 2019. But the question is: is Grade R currently compulsory? The Constitution of South Africa (Act 108 0f 1996: Section 29) states that every child has a right to basic and further education. It also stipulates that the state must, through reasonable measures, make education available and accessible to children. According to SASA, a public school must admit learners and serve their educational requirements without unfair discrimination in any way (SASA 1996: Section 5). Some schools unfairly discriminate against learners in terms of the requirement age for admission to Grades $\mathrm{R}$ and 1.

\section{Research methods}

The theoretical framework that underpins the study is document analysis, also referred to as document phenomenology. It is an analytical framework in which the researcher can review or evaluate documents. It is often used in combination with other qualitative research methods as a means of triangulation - the combination of methodologies in the study of the same phenomenon (Bowen 2009:27). After reviewing and analysing the Admission Policy, I conducted interviews with the participants. Qualitative, exploratory research was conducted to collect data. Data collection methods in the form of structured, face-to-face interviews were employed. Okeke and Van Wyk (2017:209) state that qualitative research is concerned with understanding how a particular individual, or groups of individuals think and the meaning they attach to their thinking. The rationale for conducting interviews to collect data is because interviews allowed me to understand how and what the participants think about the topic, and subsequently the questions they were asked that stemmed from the topic. Purposeful sampling was used to identify and select the population (participants), which consisted of parents, teachers, principals, SGB members and departmental officials. Unstructured, focus group interviews were conducted with 15 teachers from five primary schools (three teachers from each school), and with 30 parents who had children who were either going to start Grade R or Grade 1. Individual, in-depth, face-to-face interviews were conducted with two officials from the Department of Basic Education, and with five principals. The questions posed to the parents were generally to determine whether they are aware of the Admission Policy and what it stipulates regarding Grade $\mathrm{R}$ and Grade 1 admission. The rest of the participants were asked questions related to how the Admission Policy is implemented.

\section{Analysis and findings}

The study found that $70 \%$ of parents are unaware of the requirement age for admission, as stipulated by law. $82 \%$ of parents are not aware of the South African Schools Act. Some are aware that there is such an act but are unaware of the content. Therefore, if the schools informed parents their children were too young for admission, either for Grade R or Grade 1, some parents accepted the outcome without question. Also, many parents are unaware that, should their children be refused admission to a public school, they can appeal against the decision to the Member of the Executive Council (MEC) of education (SASA 1996: Section 5 (9)). From the findings it is evident that some schools do not implement the admission policy as they should because the policy is confusing. Thus, some schools adhere to the requirements as stipulated in SASA, some do not. The schools that do not, are not acting in accordance with SASA. Subsequently, some children are placed in Grade R when they are supposed to be in Grade 1. Some children are referred by schools to pre-Grade R, when they are actually supposed to start Grade R. There is no question that chronological age alone does not determine whether a child is ready for Grade $\mathrm{R}$ or Grade 1. It is quite possible that some children are in the correct age group to be admitted to Grade R for instance, but schools may feel that the child is not school ready or that the child is not mature enough. Some teachers stated that "many five year olds are not emotionally mature to be placed in Grade 1, and that these children should rather be placed in Grade R". One teacher made the example of a five year old Grade 1 learner who cried to be with her older brother, who was at the same. There thus seems to be certain instances where schools can motivate why some children have to be 'held back', but this should be the exception rather than the rule. In cases where teachers feel that children are too young to be admitted to Grades $\mathrm{R}$ and 1 (even though the children are, by law, in the correct age group), teachers can at best only advise the parents to put their children in a lower grade. Ultimately the final decision must be made by the parents, not by the schools. The Department officials admitted that they are aware of the non-implementation of this policy. According to both, learners should be admitted to Grade $\mathrm{R}$ when they are four and should be in Grade 1 when they are five. When asked what the Department does to rectify the problem, the officials explained that they undertake school visits yearly to 
inform schools about the correct implementation of the policy. One official claimed that "schools just do what they want and many schools ignore, or do not correctly implement policies." The official explained that the admission ages to Grades $\mathrm{R}$ and 1 is also sometimes published in local newspapers, together with dates of when parents can apply.

\section{Recommendations}

According to Bowen (2009) documents can be a rich source of data, but researchers should look at documents with a critical eye and be cautious in using documents in their studies. The researcher should consider the original purpose of the document - the reason it was produced. The Admission Policy for Grades R and 1 was formulated to guide schools with the admission of these grades. But the research reveals that some schools do not implement the policy the way they should - there is thus a gap between policy on paper and policy in practice. There seems to be gaps and inconsistencies between the policy and how it is applied in practice. Based on this non-implementation it is recommended that all schools should admit and enrol learners according to the age requirement stipulated in the Admission Policy (unless there are valid reasons for non-implementation). This was clearly stated by the Department officials during interviews. The South African Schools Act is a national policy, and there should thus be uniformity as far as its implementation is concerned. The problem is that many schools do not implement the policy because they feel that four year old learners are not ready for Grade R, and five year olds are still too young for Grade 1. Schools reject these 'young' learners because they feel it is in the learners' best interest. What also makes implementation difficult is the fact that the policy states that the governing body of a public school must determine the admission policy of that school. This then means that schools can determine their own admission policy, although the age requirements are stipulated in SASA. The schools and the Department of Basic Education need to operate in sync, and the Department of Basic Education has to ensure that schools implement policies, whether it be the Admission Policy or any other policies that address education issues.

\section{Summary and conclusion}

The paper aimed to highlight the challenges experienced with the implementation of the Admission Policy for Grades R and 1 in schools in South Africa. Document analysis was employed, which was followed by interviews. Data collected reveal that many schools do not implement the Admission Policy as they should. What complicates the matter is the fact that, although the policy gives the admission ages for Grades R and 1, the same policy stipulates that the governing bodies of schools can determine their own admission policies. The researcher critically reviewed the policy and found that there is gap or discrepancy in the policy - this is a possible reason why the policy is not correctly implemented. The Admission Policy was designed to provide for a uniform policy for admission to Grades $\mathrm{R}$ and 1 , but there seems to be no uniformity.

\section{References}

Bowen, A. 2009. Document analysis as a Qualitative Research Method. Qualitative Research Journal. Volume 9. No 2: 27-40.

Bruwer, M., Hartell, C. \& Steyn. Inclusive education and insufficient school readiness in Grade 1: Policy versus Practice. South African Journal of Childhood Education. Volume 4. No. 2: 1-12.

Denham, A., Bassett, H.D. \& Zinsser, K. 2012. Early Childhood Teachers as Socializers of Young Children's Emotional Competence. Early Childhood Education Journal. Published Online.

Department of Education. 1996. National Education Policy Act 27 of 1996. Pretoria.

Department of Education. 1996. South African Schools Act No. 84 of 1996. Pretoria.

Department of Education. 2001. Education White Paper on Early Childhood Education. Pretoria.

DEPP. 2020. Education in Europe: key figures. $3^{\text {rd }}$ Edition.

Janse van Rensburg, O. The school readiness performance of a group of Grade R learners in Primary Schools in the Gauteng Province of South Africa. South African Journal of Childhood Education. Volume 5. No. 1: 1-11.

Meier C., \& Ndou, N. (Eds.). 2021. Teaching in the Foundation Phase: Contemporary strategies, curriculum development and assessment. Pretoria. Van Schaik Publishers. 
Meier, C. \& Marais, P. 2018. (Eds.). Management in Early Childhood Education: A South African perspective. Pretoria. Van Schaik Publishers.

Miller, D.E. 2018. Factors affecting parental choice of schools for Grade 1 learners. M. Ed Thesis. Pretoria. University of Pretoria.

Naude, M. \& Meier, C. (Eds.). 2019. Teaching Foundation Phase Mathematics: A guide for South African students and teachers. Pretoria. Van Schaik Publishers.

Nuffic. 2015. Education system South Korea described and compared with the Dutch system. $1^{\text {st }}$ Edition.

Okeke, C. \& Van Wyk, M. (Eds.). Educational Research: An African approach. Cape Town. Oxford University Press.

Ramadiro, B. \& Vally, S. 2005. (Eds.). Admission Policy: Your Rights. Johannesburg. Wits Education Unit.

South Africa. 1996. The Constitution of the Republic of South Africa. Act 108 of 1996. Pretoria.

www.asmilan.org. Retrieved on 28 April 2021.

www.scholaro.com. Retrieved on 28 April 2021. 


\title{
THE ROLE OF COMMUNICATION AS THE DRIVE FOR IMMIGRATION: A CASE STUDY IN FINLAND
}

\author{
Zahra Hosseini, \& Sirkku Kotilainen \\ Information Technology and Communication, Tampere University (Finland)
}

\begin{abstract}
Recently many studies have remarked migration issues. Thus, in countries such as Finland, having a governmental strategy for increasing the number of migrants, especially educated immigrants or encouraging international students to stay, is highly important. While Finland is recognized as the happiest country, it would be arguable why it is not included in the list of top destination countries for immigration. The literature shows communication is one of the most issues for immigrants and international students, particularly those from Asian countries. Therefore, this study aims to understand how technology-based communication such as the use of social media influences international students' decision to immigrate. Respectively, 23 Iranian tertiary-level students were interviewed as the case of the study. Uses and Gratification theory was employed to investigate the role of media usage among the participants. The findings showed that although there is high desire among the participants to immigrate to Finland, the difficulty and unpopularity of the Finnish language and culture of distance in Finland reduces the motivation to emigrate and made the participants feel being the outsider in the university and society. The use of communication media has facilitated university admissions and communication with family, friends, compatriots and other international students, but has not been able to connect them to Finnish society. While educated immigrants in every country are human resources, the results of this study draw our attention to explore different aspects of communication, identifying motivating factors and reducing frustration among international students for immigration. These results emphasize on the development of strategies and tools for harnessing the potential of media and technology to connect international students as future educated immigrants in the host community.
\end{abstract}

Keywords: Communication, international students, Finnish culture, media, immigration.

\section{Introduction}

Globalization has modified the way that people become aware of different opportunities particularly for working and studying around the world. With the growth of the number of international students abroad, the number is expected to hit 8 million by 2025 (ICEF, 2017). Typically, International students in Europe usually experience the new lifestyle that may decrease their intentions to return their home countries. These aspects may relate to religion, violence, inequality, corruption, poverty (Stanojoska \& Blagoce, 2012). QS World University Ranking (2018) published four top destination countries including the United State, the United Kingdom, France, Australia attracts foreign students to their universities. While the World Happiness Report (2021) has introduced Finland as the happiest country in the world, it would be arguable why it is not included in the list of top destination countries for immigration.

On the other hand, assistance of communication technology has provided the opportunity for online admission and registration in institutes and universities from the home countries and caused an increase in the number of international students (Stevenson 2009; Thulin \& Vilhelmson, 2013). People may become familiar with laws and rules of other countries via internet before any decision for emigration and after migration; they receive information from the different digital portals and media, which effects on their decisions for immigration. Several studies acknowledged the role of social media aiding international students to communicate with each other (Saw et al., 2013; Hamid et al., 2016) and even when it was not shown beneficial for academic achievement, it still helped the participant with their host culture acculturation (Yu et al., 2019).

In this regard, this study utilizes Uses and Gratifications Theory (UGT) to recognize how technology-driven communication such as social media usage affects international students' decision for immigration in Finland. UGT has a root in communication perspective that deals with the effect of 
audience's motivation and their media-consuming activities. Some studies utilized UGT for studying the dual role of the internet and social media for cultural adaptation and resulted differently. For instance, Wang and Sun (2009) believe having the poor cultural adaptation and feeling loneliness of immigrants in the host country enhance their social media usage, while, Yang (2018) argues that Chinese international students used social media for being better acculturated into the host society. In this study, UGT opens ways to understand role of media regarding communication challenge in the case study.

\section{Methods}

By considering the Iranian nationality of the main researcher, Iranian students in Finland were selected as the case for this study $(\mathrm{N}=23$, data collected in 2017). The study employed the snowball sampling method to participate 23 Iranian tertiary-level students. A semi-structured interview protocol uncovered the interviewees' values, feelings, beliefs, and experiences of the phenomenon. The participants were interviewed face-to-face or online based on their location. The data were collected through audio recordings and transcribed verbatim for analysis of the meanings, especially those between the sets of categories. Thematic analysis was employed to identify, analyze, and reporting following Braun and Clarke's (2014) guide. In this respect, the transcribed data was coded and categorized at the next step, themes were defined based on UGT and accordingly patterns were determined. The researchers considered and followed the ethical principles of research with human participants and ethical reviewing the human sciences in Finland (TENK, 2019).

\section{Finding}

\subsection{Communication issues}

The finding demonstrated although most participants (18 of 23) had positive intentions to immigrate to Finland, however, they had discomforted experiences in communication which affected their decision for immigration. In their opinion, Finnish culture and language reduce the opportunities to find a suitable career and increase level of unpleasant feeling about cold and darkness.

Finnish culture seems unwelcoming for immigrants because; a) communication avoidance: the participants described Finnish culture as a culture with limited verbal and nonverbal communication with foreigners. Most participants experienced the Finnish lifestyle as individualist and many of them believed that there is a huge distinction between Finnish people and them. A young student yielded his disappointment: "What I am missing here is the people whom I can talk with." Some participants stated that Finnish students hesitated participating in student's assignment groups. A few participants believed that Finnish students avoid participating in study activities more with students from non-EU countries. b) silence, distance, and privacy in Finnish culture although were respected by the participants, only two of 23 participants felt comfortable with them, and others were struggling with communication issue and feeling outsiders in Finnish society.

Based on the findings, most of the participants had chosen Finland for studying because of available English education for tertiary-level many participants believed Finland. They believed living in Finland is easier for English speakers among non-English countries in Europe. Most participants had attended at least one course to learn Finnish but were not motivated to continue. Three participants stated that they did not want to learn Finnish. Some participants regretted choosing to immigrate to Finland when they felt they had to learn Finnish to find a job. The main reasons for discouragement were: 1) Learning Finnish is difficult and time consuming. 2) Finnish is not popular and "it is a language spoken by only 5 million people" (participant 18) and, 3) life and particularly professional activities can progress in Finland even with the limited Finnish skills. "Many people here speak the English language. They know English, it helps us to reduce misunderstandings" (participant 23 said).

\subsection{Media, as a drive}

Based on UGT the role of media, particularly social media as a drive for migration and immigration is demonstrated in the following aspects:

3.2.1. Source of information for migration. Most of the participants used some forums and social media to gain information about Finland before migration. For all participants the process of admission was online and online services and social media helped their settlement in Finland. It seems communication technology has a positive role in the first steps of migration by providing information and facilitating official communication with distance. 
3.2.2. Communication support, Participants utilized the different applications of social media to connect to their friends and family in Iran more than in Finnish society. They contacted their families at least once a week. Most participants were always available to their families in virtual groups or individually.

3.2.3. Source of news. The participants were members of groups or channels in social media to receive news. a) News about Iran via online TV, Facebook, or Telegram channels, b) University news, via newsletter email, Facebook pages, and Student Union website, c) Events in Finland mostly via Facebook pages.

3.2.4. University tasks. Formal communication with other international or Finnish students was usually done through Facebook, the student union, and the newsletter pages in the emails. "In the case of student events, we receive them from our Facebook groups. To attend the event with friends, we are informed in our private group, the content of the lessons is also in the Moodle" (Participant 13 said).

3.2.5. Sharing. All participants were Facebook members, and they asked questions from students or other compatriots, but they were reluctant to share content. "Facebook wastes my time. I read but do not post much although I am a member of many pages" (participant 17 said). Participant 7 used Facebook and YouTube to get the news, but had a negative attitude towards most social media, believing that these platforms are managed by powerful people or organizations that manipulate people's minds and give them biased information. He used the media, but believed that he had to analyze everything before believing the content. Two students were the passive members in Finnish forums and groups.

\section{Discussion}

The results of the study demonstrated the efforts of international students in communication with Finnish society and insufficient role of media in reducing this struggle. While Finland itself is in the list of brain drain countries (Mahroum, 2005), the strategy of Finland for accepting educated immigrants is planned, Finland is not the first destination for international students due to its geographical location.

Whereas, the quality of its education system is known all over the world, which creates international interest (Balbutskaya, 2015) adopting a new strategy to reduce the challenge for immigration seems essential. Despite the help of technology to facilitate communication, Finnish language learning difficulty appears to be a serious barrier for cultural integration, especially for job seekers in Finland (Bontenbal \& Lillie, 2019). This study highlighted the communication challenge as a pushing factor for foreigners living in Finland. Also, showed the communication challenge as stressors for foreigners in Finland. Croucher et al (2013) explain that Finland is not a country for immigrants and Finnish history influences the way Finnish people treat foreigners. The researchers assert that Finns moved to Sweden to work before the 1970s, and most immigrants to Finland during the 1980s were those who had left the country in the past decades. The immigrants who had been living abroad in Finland since the 1990s. They were usually from Russia and Estonia (Korkiasaari \& Soderling, 2003).

Indeed, many participants in the study felt that Finns would not accept non-EU friendships. Likewise, Jaakkola (2005) argues that Finn feel more comfortable communicating with foreigners who are more culturally and economically like the Nordic countries than with foreigners who came from a lower standard of living countries. The survey in 1993-2003 indicated that Finns have a more positive attitude towards immigrants living in Finland than in the past, especially in the case of educated immigrants who have higher-level jobs as doctors, teachers and assistants, social employment agency and police officials. However, they prefer migrants to be hired as cleaners and taxi drivers (Jaakkola 2005). This negative attitude is more relevant to refugees and Muslims than educated students (Jaakkola 2005; Säävälä 2008).

Ryabina (2008) states Finnish culture has its specific characteristic aspects of communication as other culture. It is individualistic and low-context communication. These characteristics distinguish Finnish culture from other cultures even in Europe. That claim is in line with the finding of this study that many participants described silence as the characters in Finnish culture which is a barrier to communication. Differences in communication behavioral styles seem to have been an obstacle to the cultural integration of international students.

As an important aspect of communication, language can always act as a barrier to the communication of immigrants in the host country (Adsera \& Pytlikova 2015; Yao 2016). The Finnish Language has reported the issue in education (Sinkkonen \& Kyttälä, 2014) and business (Grinblatt \& Keloharju 2000). Learning Finnish academic language takes four to eight years (Hakuta, Butler \& Witt 2000). Although most of the interviewed students had passed a few Finnish language courses, most of 
them were not confident to speak or even understand Finnish. However, the participants did not need to learn the Finnish language because they felt Finns are not interested to communicate with them even if they were competent to communicate in English language. Lack of local language proficiency and communication acted as a dual failure to keep the international students as outsiders.

Although Communication technology is developed in Finland and all students have access to the internet facilities in the university, home, and other places, it did not show a remarkable positive role in connecting international students to locals. This result is in line with the findings of Wang and Sun (2009) and Yang (2018) adopting the Use and Gratification Theory to explain the role of social media among immigrants to deal with their acculturation in the host society. The result of this study demonstrated that communication technology was used for personal communication more than creating a network in institutional settings (Sleeman et al, 2020; Hosseini et al, 2020).

Graduated people are always the human resource for every country; however, Europe seems to accept low-skilled immigrants easier (Berger, 2019). In recent years, official governments-organized integration training programs have been investing to help immigrants to learn the language, find a job and integrate into Finnish society. In addition, Civil Society Organizations in Finland (CSO), which is established by native Finn, is offering support to immigrants (Bontenbal \& Lillie 2019). These services seem more beneficial for helping unskilled immigrants than educated ones, and there have been fewer efforts to motivate graduated international students for immigration in Finland.

\section{Conclusion}

Regarding the Uses and Gratification Theory, the finding of the study indicated that despite the increasing use of social media in everyday life to obtain information or connect with international students, it does not help them communicate much with the Finnish people. Perhaps because social media and current portals such as Facebook and reduction of their trustworthiness among educated people do not specialize in filling the cultural gap between locals and immigrants. In this regard, the findings recommend the strengthening of communication portals, which provide reliable and unbiased information about immigrants' relations with the host country.

On the other hand, while many language courses, programs, and sites try to develop the language skills of immigrants, it still seems challenging because international students need to be more motivated to learn and use language to communicate with Finns in informal setting. Currently, the international student's study and deal with their basic needs in Finland in English. They communicate only with their competitors and students of other nationalities through the media. Media is a bridge to connect them to their own country relative to the host country. Respecting UGT, social media has failed to facilitate communication between the foreigners and locals in Finland.

The results of this study draw attention to the use of maximum technology potential in Finnish society. There is a need to adopt strategies for the participation of international students and graduated in Finnish society to increase their cultural integration. Regarding the importance of the context in communication, more studies are recommended in design and practice media to utilize the potential of communication technology and media to help migrants and enhance their cultural adaptation in different contexts. Moreover, the current Covid 19 crisis around the world makes communication technology and media more important than ever for succeeding in any country.

\section{References}

Adsera, A., \& Pytlikova, M. (2015). The role of language in shaping international migration. The Economic Journal, 125(586), F49-F81. https://doi.org/10.1111/ecoj.12231

Balbutskaya, E. (2015), Demand for Finnish Education Export in Russia. Case: Saimaa University of Applied Sciences master thesis. http://urn.fi/URN:NBN:fi:amk-201505117205

Berger, A. (2019). EU justice and home affairs: towards an inclusive research agenda? Journal of European Integration, 41(4), 563-568. https://doi.org/10.1080/07036337.2019.1647003

Bontenbal, I., \& Lillie, N. (2019). The Role of the Third Sector in the Labour Market Integration of Migrants, Refugees and Asylum Seekers in Finland. URL: https://www.jyu.fi/hytk/fi/laitokset/yfi/en/staff/bontenbal-ilona/finland-report-final-4-102019.pdf

Braun, V., \& Clarke, V. (2006). Using thematic analysis in psychology. Qualitative research in psychology. Qualitative Research in Psychology, 3(2), 77-101.DOI: 10.1191/1478088706qp063oa

Croucher, S.M. (2008). Looking beyond the hijab. Cresskill, NJ: Hampton Press. 
Grinblatt, M., \& Keloharju, M. (2000). Distance, language, and culture bias: The role of investor sophistication. Helsinki School of Economics and Business Administration Department of Accounting and Finance. http://dx.doi.org/10.2139/ssrn.222169

Hakuta, K., G. Y. Butler, and D. Witt. (2000). How Long does it take English Learners to Attain Proficiency? Policy Report 2000-1. Irvine, CA: University of California, Linguistic Minority Research Institute. URL: https://eric.ed.gov/?ID=ED443275

Hamid, S., Bukhari, S., Ravana, S. D., Norman, A. A., \& Ijab, M. T. (2016). Role of social media in information-seeking behaviour of international students. Aslib Journal of Information Management. https://doi.org/10.1108/AJIM-03-2016-0031

Hosseini, Z., Kotilainen, S., \& Okkonen, J. (2020, February). The Potential of Social Media to Enhance Cultural Adaptation: A Study on Iranian Students in the Finnish Context. In International Conference on Information Technology \& Systems (pp. 535-549). Springer, Cham. http://urn.fi/URN:NBN:fi:tuni-202003242843

ICEF (2017). OECD charts a slowing of international mobility growth. Revised on 17 July 2020: https://monitor.icef.com/2017/09/oecd-charts-slowing-international-mobility-growth/

Jaakkola, M. (2005) The Attitudes of Finns towards Immigrants in 1987-2003. Labour Policy Studies 286. Ministry of Labour, Helsinki.

Korkiasaari, J., \& Söderling, I. (2003). Finnish emigration and immigration after World War II. Turku: Siirtolaisuusinstituutti.

Mahroum, S (2005). The international policies of brain gain: a review. Technology Analysis \& Strategic Management, 17 (2), pp 219-230. https://doi.org/10.1080/09537320500088906

Neyer, A. K. \& Harzing, A. W (2008). The Impact of Culture on Interactions: Five Lessons Learned from the European Commission. European Management Journal, 26(5), 325-334. https://doi.org/10.1016/j.emj.2008.05.005

QS World University Ranking (2018) revised on 12 July 2020. URL: https:/www.qs.com/4-countriesattract-international-students/

Ryabina, E. (2008). Comparison of Udmurt, Estonian, and Finnish dialogues: Characteristics of communicative behaviour. Trames, 12(1), 40-50. DOI: 10.3176/tr.2008.1.03

Säävälä, M. (2008). How do locals in Finland identify resident foreigners. Finnish Yearbook of Population Research, 115-130. DOI: https://doi.org/10.23979/fypr.45037

Saw, G., Abbott, W., Donaghey, J., \& McDonald, C. (2013). Social media for international students-it's not all about Facebook. Library Management https://doi.org/10.1108/01435121311310860

Sinkkonen, H. M., \& Kyttälä, M. (2014). Experiences of Finnish teachers working with immigrant students. European Journal of Special Needs Education, 29(2), 167-183. https://doi.org/10.1080/08856257.2014.891719

Sleeman, J., Lang, C., \& Dakich, E. (2020). Social media, learning and connections for international students: The disconnect between what students use and the tools learning management systems offer. Australasian Journal of Educational Technology, 36(4), 44-56. https://doi.org/10.14742/ajet.4384

Stanojoska, A, \& Blagoce, P. (2012), Theory of push and pull factors: A new way of explaining the old. In Book of the International Scientific Conference (pp. 179-194). Belgrade, Serbia. URL: https://nsar.org.rs/sites/default/files/docs/Rajs2012-Tom1.pdf

Stevenson B., (2009). The Internet and Job Search. In Autor DH. (ed.) Studies of Labour Market Intermediation, 67 - 86. National Bureau of Economic Research, Cambridge, MA. URL: https://www.nber.org/papers/w13886

TENK (2019). Retrieved on 2021/01/25. URLÖ https://tenk.fi/sites/default/files/202101/Ethical_review_in_human_sciences_2020.pdf

Thulin E and Vilhelmson B., (2013). Virtual practices and migration plans: a qualitative study of urban young adults. Population, Space and Place. https://doi.org/10.1002/psp.1766

Wang, Y., \& Sun, S. (2009). Examining Chinese students' Internet use and cross-cultural adaptation: Does loneliness speak much? Asian Journal of Communication, 19(1), 80-96. https://doi.org/10.1080/01292980802618494

World Happiness Report (2020). Revised on 12 April 2021: URL https://worldhappiness.report/

Yang, C. (2018). US-based social media use and American life: A study of Chinese students' acculturation and adaptation in America. Global Media and China, 3(2), 75-91. https://doi.org/10.1177/2059436418783765

Yao, C. W. (2016). Unfulfilled expectations: Influence of Chinese international students' roommate relationships on sense of belonging. Journal of International Students, 6(3), 762-778.

Yu, Q., Foroudi, P., \& Gupta, S. (2019). Far apart yet close by: Social media and acculturation among international students in the UK. Technological Forecasting and Social Change, 145, 493- 502. https://doi.org/10.1016/j.techfore.2018.09.026 


\title{
EDUCATION AND TECHNOLOGY DURING COVID-19 TIMES
}

\author{
Daniel Nicolas Dominguez-Perez ${ }^{1}, \&$ Nicolas Dominguez-Vergara ${ }^{2}$ \\ ${ }^{1}$ Universidad Nacional Autónoma de México (Mexico) \\ ${ }^{2}$ Universidad Autónoma Metropolitana (Mexico)
}

\begin{abstract}
It is difficult to separate technology from education because technology is embedded in teaching. The best technology for teaching is the one that does not interfere with the communication between the teacher and the students. In other words, it should be barely "noticeable" in how it is used, and easy enough to use that it does not require special training, such as window in a room to see the flowers outside, without interfering in any way. The technology used during an in-person classes is so basic, transparent, and simple, since it consists of a classroom, chairs, blackboard and pieces of chalk. However, a piece of chalk could break. In this case, the flow of information is interrupted; which is why the plastic whiteboards and markers are preferable and cleaner. An electronic board may seem to be better with its many improvements with computers; however, its higher technology could get in the way if it is not used properly. During the pandemic, different technologies, like computers and cell phones, connected to internet were massively used. Yet, computers and cell phones with the appropriate software and apps had an additional cost; with no guarantee of antivirus applications against viruses or worms, leaving aside protection for documents, software and hardware. On top of that, a Zoom, Google or any similar online platform was necessary. Using these platforms, other technologies had to be relied on, including Ethernet or a USB adapter. On the other hand, in developing countries before the pandemic, low-tech was used by most students to store and pass information to their peers and teachers. They would use mainly pens and notebooks to write notes, or CD-Rs or USB to pass information. However, during the pandemic, with the advances in internet speed, many students have now moved on to using e-mail and cloud drives where they can transport their files. All the electronics listed to make online education or tech-based education needed electricity to work. In other words: no electricity, no class; no electric supply or stored electricity in batteries, no class. In this paper we analyze the role of technology in education, and how this technology could enhance or obstruct the communication between the teacher and the students.
\end{abstract}

Keywords: Education, technology, COVID-19.

\section{Introduction}

Before the COVID-19 pandemic most of the students all around the world used paper notebooks and pens or pencils to take notes in class; mainly in public universities and developing countries. The students in class had a direct contact with the teachers and all of them, once inside a classroom, were isolated from the outside world. The communication was transparent as a crystal window to see the flowers outside. There was no interference of any electronic technology between the students and the teacher; if the teacher asked a question the students responded on the spot. The teacher never had to ask, "are you there?", “do you hear me?", “do you see what I am writing?" The classroom was a safe haven for teachers and students; there were less distractions and less exposure to outside dangers, with no family members asking questions or children interrupting. In case of the need of internet, the signal was usually present, provided by the school. After class, the students would close their notebooks, where they would store their information from class. If the notebooks got wet, the information, the physical information, was lost forever; as well as if the notebooks were stolen or lost. And then, suddenly, the COVID-19 pandemic came dismantling the educational systems of many countries of the world. Countries rushed to teach online; that is, using computers for the communication between teachers and the students. These computers could be anything from smartphones to tablets, laptops, or desktops. In some parts of underdeveloped countries, computers were not affordable by all students and teachers. When the internet signal was too expensive to reach, of bad quality, or perhaps non-exist, the elementary and secondary education was held through digital television or even through radio. Online education is based solely 
upon technology. If the technology fails or the electricity fails, there is no communication and consequently, no class. The link to communicate both the teachers' and students' computers, is the internet. Along with the computers and the link between them, there are other technologies used to facilitate the interaction between the teachers and the students: Zoom, Google Meet, along with other online platforms such as WhatsApp, electronic mail, and others. In this paper, the role of technology in education is discussed and some thoughts are given to the future of education.

\section{Technology and education}

Technology is a tool which helps carry out an activity. It could be hard and soft. Hard technologies are those which are physical tools that aid in completing tasks. Examples of these can range from simple cups to drink water, to stoves to cook and prepare food, to vaccines, to computers, to weapons, and even to space probes. Soft technologies differ in being tools that are either intangible or imaginary that would require a medium for it to be used. Examples of soft technologies are procedures (recipes) to fabricate cakes or series of instructions to be interpreted by machines such as software. Viewed in this way, it is the computer software used to write a text in a virtual document in a computer. Many of the technologies we know are the result of inventions and innovations since the first human appeared on earth. The technology can be low, medium or high. High technology is invented or innovated using advanced knowledge of physics, chemistry, mathematics or other sciences. Examples of high technology are vaccines against COVID-19, laptops, wireless interfaces, and computer software. On the contrary, low technology does not require the most advanced knowledge to be created, for example: notebooks, pens, pencils or blackboards. Developed countries dominate the inventions and innovations of high technology. Differently, underdeveloped countries acquire some high technology through purchase in the world market, because it is sold in order to recover the investment for its development, with exception to technologies that may jeopardize safety or security such as advanced weaponry or newly invented encryption algorithms. Underdeveloped countries do not spend money in developing high technology. This is why they are at the expense of what developed countries create, which will not be necessarily appropriate for their needs.

Education is the collection of training and exercises used to prepare a person enough to independently perform tasks in their professional and daily life. All people receive some form of education whether it be institutional or by the community around them. Most people who do not receive a formal education will learn something from their own families and communities. A formal education through schooling is important to be able to be part of the larger world community that exists beyond the family or local community. Currently, it is often believed that the necessity of an education is for people to be able to become qualified for working or for starting a business. While receiving an education will allow a person to reach better opportunities it is not the only reason an education is important. A proper education is necessary for people to know and understand the world and society around them while also having a proper understanding on the events that may be happening in the world.

Education could be also defined as the systematic process to transmit knowledge and methodologies to acquire abilities from a teaching agent to a student through the communication between them. The teaching agent before the pandemic in the developing countries was mostly the teacher, in flesh and blood, who met the students in a convened physical place to communicate. This communication was mainly through voice, eyes, physical language, and handwriting on the blackboard or whiteboard with chalk or markers, respectively. In this sense, the technology used for education prior to the pandemic was very basic: a classroom in a building, chairs, blackboard, whiteboard, chalk, markers, notebooks, and subject books. The teaching of some knowledge and abilities requires special equipment like computers, chemical equipment, medical specialized devices, and even well-equipped laboratories and workshops (to feel, to test, and to practice). Occasionally, the location for in-person education could temporarily move to other places, such as hospitals in the case of medical careers, or to factories in the case of industrial engineers. During the pandemic the teaching agent was not physical, also, there was not a physical place to meet, and the communication was through computers and internet. Technology for education consists of all of the tools that are involved in allowing the teacher to communicate with their students and helping them understand the subjects of the courses. This includes markers and dry-erase boards for the professor to communicate with their students, besides the writing tools that students use to capture the information and to create notes, such as notebooks, paper, pencils, pens, or in some cases, computers and tablets with their respective software used for note taking.

Now, the teaching-learning process takes place at home; the computers are not in the physical school, nor is the teacher-student communication. Actually, the school is distributed in all of the students' computers and the teacher's computers. As online education is technology-based and this technology has its cost, a lot of teachers and students must pay for the new tools of the learning-teaching process. 
Financing in many cases the schools they work for or study in; similar to Uber and Rappi workers, who use their own vehicles to work for their companies. Therefore, the families all around the world had extra expenses in buying the technologies to teach or to learn. In Mexico, the percentages of dwellings with telephone for members in the range of 3 to 29 years old spent additional money to attend online classes due to COVID-19. Analyzed by type of expenses: smartphone, 28.6\%; fixed internet service, $26.4 \%$; chair, table, or other furniture to condition space to study, 20.9\%; laptop or desktop, $14.3 \%$; other electronic devices, $6.8 \%$; prepaid phone plan, $6.2 \%$; digital television, 5.2\%, and tablets, 5.1\% (INEGI, 2021). The advantages of online education according to the population of 3 to 29 years old are (INEGI, 2021): limited health risks for students (56.4\%); allows family life (22.3\%); savings in transportation and school materials, $(19.4 \%)$; no time loss in transportation $(15.0 \%)$, and fosters self-learning and self-study abilities $(8.5 \%)$. Interestingly, there were those who did not notice any advantages $(12.4 \%)$. The disadvantages according to the same survey are: there is no learning or little learning (58.3\%); there is no follow-up on the learning of the students $(27.1 \%)$; lack of pedagogical technical capacity or ability of parents/tutors to transmit knowledge to students (23.9\%); excessive homework and scholar activities $(18.8 \%)$; no appropriate space at home $(18.2 \%)$ and lack of coexistence with friends and classmates $(16.1 \%)$.

\section{Physical classrooms versus virtual tools}

The teacher needs to communicate with various students at once in a classroom or a group. To do this, it is necessary to have a medium that allows every student to view the information presented by the teacher. For many years, a blackboard has allowed this by providing a large space to write and draw, with enough clarity for students to read properly. The blackboard has been used for many years to provide this. The technology used here is transparent enough to allow this communication to be almost seamless, until a piece of chalk breaks or when it is time to erase the board. The whiteboard has become the replacement for chalkboards, which has allowed a much more clean and seamless transition between subjects, and facilitating the continuity of the class due to the use of dry-erase markers, which are much easier and faster to erase. Primarily, there is very little need to learn on how to switch from a chalkboard to a whiteboard. It is however, necessary to know that a specific type of marker must be used on these boards to prevent permanent or semi-permanent marks, or to prevent smudges on the board that will need to be cleaned later. Various companies in computation and digital interfaces have attempted to create a new replacement for the whiteboard by integrating computer technology, but it is still far from completely replacing the traditional whiteboard. In the adaption of computer technologies, many professors have adopted the use of projectors which has allowed a better visual communication with the students in the class. However, in many cases these classes are mostly given in a digital presentation that are either not well prepared enough or they only use the minimal number of tools that the presentation software has to offer. When a classroom includes the use of a computer, such as a desktop or a laptop and a projector, the teacher is able to prepare the class more easily and quickly, as the previously prepared material can be shown instantly before the students. However, there are moments in which this communication is either delayed or interrupted when there are problems such as software errors, hardware errors, power outages, or a limited ability in the use of the tools. All of these cause the computer and projector to lose their transparency as teaching technologies in the classroom. There may also be cases in which the software itself has features that are more of a distraction than helpful tools, such as attempts of software companies that add unnecessary features in virtual whiteboard software or other programs that may be used for teaching. Virtual education has become a necessity during the pandemic as a way to avoid physical contact and possible infection between students by moving all classes at home. Due to this, professors and students needed to adapt to classes that were in a similar style to the classes given either through presentations or through a webcam, with the professor explaining in the closest manner they could to using a whiteboard. During the pandemic, platforms were used where students could consult the course plan, classes, assignments, projects they have to carry out, and to also "turn in" their homework, exams and assignments; the google classroom is one of them.

\section{Notebooks, USB, and storing in the cloud}

When students take notes and work on assignments, they also need a way to write and store them. In most cases this is done through handwritten mediums using notebooks, binders, or loose paper. Prior to the pandemic, most teachers would hand out photocopies of worksheets or questionnaires for the students to complete and turn in to the class. It is very common for students to write reports and essays on a computer as it is more readable and cleaner than handwritten tasks. It should be noted that these reports would commonly need to be printed and turned in physically to the teacher. Due to this, schools were 
obliged to provide computers and printers in their campuses for students to complete their work for those who did not have easy access to a computer away from school. It was however necessary to have a method of portable storage for the students to carry with themselves, and use for editing and printing documents when needed. There have been also cases in which students no longer had to print and instead, turn in their assignments digitally. It was very common in earlier years for assignments, such as multimedia projects or programming assignments, to be turned in on floppy disks and writable CD's. When USB flash drives appeared they became more popular due to having a higher storage capacity and were easier to manage files. These have been used more for holding multiple files for the student to carry with themselves to be able to either work on different computers in the computer labs of the school, or to take the file to a printer. As teachers became more familiar with internet technologies, such as email, they would begin to simply ask their students to send their completed assignments to them directly, at any time, before a deadline. In other cases, students have been able to use email and cloud storage to replace the use of their USB drives where it is even possible to access the document they are working on and edit it from their cell phones.

\section{The future of education and technology. The end of physical teachers?}

The teaching agent in the future may not be physical for a considerable number of careers, in which software and apps could store all the information of courses, including information with sound and video that may help transmit the information necessary to the students. More advanced software might be constructed, such as one that could answer any student's questions (by uploading to the computer's site a great deal of possible questions beforehand, choosing the closest to the question asked by the student, and answering with the recorded answer). All this can be possible in the future and, in the long term, improved with artificial intelligence, internet of things, augmented reality, and other technologies. This could be the end or the replacement of physical teachers by virtual teachers in the future; although not completely. In that manner, teachers in Modern schools could be in jeopardy at least at certain degree; but not in the underdeveloped countries, for instance Mexico, where only $40 \%$ of the households can afford to buy a computer. In the developing countries for many economic activities, the labor force is still cheaper compared to the investment of acquiring and using robots (Dominguez-Perez et al., 2017) that is partly why automation has not greatly advanced. What is taught in education is knowledge that is complex to understand or abilities that are not easy to acquire (Bobbitt, 1915). Therefore, there is the need of a teaching agent to help understand the concepts or to help to acquire the mental or physical abilities required. The knowledge and abilities needed in the world will change in the future. Accordingly, the careers will change, the specializations may flourish, and, therefore, the virtual teachers would be prepared with the information to form special professionals. If this scenario materializes, the developing world will be at the mercy of developed countries because the latter will have the technology to produce the virtual teachers and the courses. If this is the case, the underdeveloped countries will have to define strategies for their academic independence from the advanced countries, since the developed technology will be appropriate for the culture, race, economy, habits, religion, songs, and society's needs of the same countries that have developed the technology. For example, some technologies are biased to work effectively to only a limited amount of people because the developers only took into consideration the characteristics of the people they know locally.

Being the communication crucial for education, it is clear that previsions have to be taken in the future for other types of communications. For example, sign language could be convenient to be used in certain situations, such as removing the language barrier that currently exists between deaf and hearing people, maintaining communication with a person who has lost their ability to hear or even to be used in situations where spoken communication is not viable such as noisy environments or situations where silence is necessary. It is unknown what tools, including those of communication, will be more crucial during future climate change disasters. It is still unknown what could specifically happen due to climate change yet, but it is important to make as many predictions as possible. If the world continues developing the information and communication technologies, their use will become even more massive in the future and, therefore, it is time to start developing strategies to assure their future production in distributed places, and not just the production that is convenient for certain places. For example, during the progression of the COVID-19 crisis there is a shortage of microchips, and therefore the massive production of electronic devices which are needed in several economic sectors is compromised. Consequently, the dependence of microchips should be addressed for future crises. Likewise, the dependence on electricity in order to assure alternate and direct distributed electricity all around the world. Also, affordable technology to store electricity should be developed, because laptops, cell phones, and other technologies depend on batteries. Electricity should be obtained from clean renewable sources, 
and hydrogen technologies should develop in order to use them to safely produce affordable and clean electricity.

In the future, in developed and rich countries, there will be in-person, online and hybrid education. However, in poor countries in which education is secular, free and obligatory, like in Mexico, most schools will only offer in-person education because online education requires a lot of technology, which will not be affordable for all students, as it is being documented during the COVID-19 pandemic. The surviving private schools will make cost-benefit studies to decide what mix of in-person, online, and hybrid education will offer, along with which careers to teach. Online education will require less infrastructure and less physical teachers, but there are families with barely enough economic resources to have their children educated in in-person schools, no matter how expensive they might be; and in those schools, physical teachers will do the teaching.

In the past, there were short technical careers taught by sending the course material by mail. It is possible that in the future, the whole course material, including all homework and tests, could be in internet sites that students can download just one time to work with at home. These will require no internet, because students would have stored all the information in their computers. In this type of education, the students could upload the answers of their homework and tests to the school's internet sites once finished. In this type of education, there might not be a school calendar and the students could start at any time a course or a career. There may be several educational systems that could be created in the future; it would not be solely in-person, online, and hybrid education. Technology is important for countries to advance forward, and gain advantages in areas such as economy and defense. As such, it is noted that developed countries will have high competition in these areas. Countries with more advanced technologies of weaponry have conquered, or are still conquering by force other countries' land. Although not only powerful technology is sufficient to defeat adversaries or enemies, but also the strategies used. There are plenty of examples of this in the many wars around the world in the history of humanity. So, it is possible that from now on, the technology for education can be used to quickly prepare technicians or professionals in certain strategic fields of science and technology to create a valuable edge to overcome competitors. For example, the competition to conquer the world market between the United States and China is already happening: China is the largest producer of electric cars while the United States has fallen behind. The United States has lost expertise and know-how in the manufacturing of several critical technologies and requires new educational policies to have young educated people who can become the top-notch leaders in the world of science and technology. This would not be easy, given the fact that higher education in the United States is very expensive. Online education has increased the socioeconomic inequality in the world; the disparity in the future involving online education among the countries in the world will be an indicator of the further inequality and poverty, which will be generated. Online education is not exclusively to learn skills and knowledge but to understand, manage and dominate other ways to communicate, and socialize. It involves mastering new technologies, which can make the students acquire advantages for getting better jobs.

\section{Conclusions}

The COVID-19 pandemic uncovered the challenge of educating the world through computers and internet, technologies which are not as transparent as whiteboards and markers. The crisis has opened the possibilities of new systems of education, which could trigger further socioeconomic inequality in the world and even inside a country, region or city. The world should anticipate the technology and resources needed for future crises based on the experience of the one that is, apparently, ending.

\section{References}

Bobbitt, J.F. (1915). The Project Gutenberg eBook, What the Schools Teach and Might Teach. Retrieved 23 May, 2021, from: https://www.gutenberg.org/ebooks./13482

Dominguez-Perez, D.N., Dominguez-Vergara, N., Dominguez-Perez, R.M., \& Pantoja-Gallegos, J.L. (2017). A future of isolation: control and automation in the developing countries. ICERI 2017 Proceedings. pp. 7964-7973.

INEGI. Encuesta para la Medición del Impacto COVID-19 en la Educación (ECOVID-ED) 2020. (2021). Retrieved 23 May, 2021, from: https://www.inegi.org.mx/contenidos/investigacion/ ecovided/2020/doc/ecovid_ed_2020_nota_tecnica.pdf 


\title{
FLIPPING A 700 STUDENT CLASSROOM
}

\author{
Peter Purgathofer, \& Kay Kender \\ HCI Research Department, Faculty of Informatics, TU Wien (Austria)
}

\begin{abstract}
Because of the pandemic, we had to switch our first-semester informatics course with 700 students from lecture hall teaching to online teaching. We used the opportunity to rethink our approach and come up with forms of teaching that fit the circumstances. In the evaluation, we found that students generally appreciated our efforts, and although we raised the requirements for a positive grade, the share of students who passed the course was higher than usual.
\end{abstract}

Keywords: Flipped classroom, university, large course, experiences, feedback.

\section{Context and motivation}

While the origins of the flipped classroom concept are hard to pin down, we can attribute widespread academic attention to this concept to around 2012, when a number of scientific conferences were dedicated to this idea, e.g. the first ICM Conference in Munich. The flipped classroom is, in short, defined as »events that have traditionally taken place inside the classroom now take place outside the classroom and vice versa« (Lage, Platt \& Treglia, 2000). In a setting like the one we experience at TU Wien, where roughly 700 students are admitted into the bachelor programs of the faculty of informatics, little of what happens outside the classroom, or rather, the largest lecture hall of TU Wien, is under our control. Consequently, flipping the classroom was never something we considered, focusing instead on making the lectures as good as possible under the circumstances.

COVID-19 made us reconsider when we were forced to leave the lecture hall behind. Moving our lectures to an online format without losing essential aspects of a physical lecture hall was impossible: hundreds of students in the same room at the same time, interacting before, during, and after the lecture, the possibility to »feel the crowd«, the joy of physical presence, the commitment to a shared experience, and other facets of classroom lectures had to be left behind as we were all confined behind private screens in small rooms.

We had to explore new forms of teaching as we redesigned our course to create an adequate learning environment in a mode of operation where physical presence was impossible. This paper describes our approach in this redesign, presents its result, offers a glimpse into the evaluation of our reorganization, and discusses our conclusions and further plans.

\section{Relevant related research}

The concept of the flipped or inverted classroom has seen a lot of academic attention lately. While in August 2019, a search of Google Scholar yielded »approximately 70,000 and 60,000 hits for the

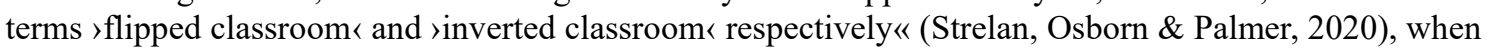
this article was written in May 2021, these numbers had risen to 120,000 and 90,000. This heightened attention can at least partially be attributed to the necessities of teaching during a pandemic, with many scholars forced to rethink their approaches to teaching.

Strelan et al. (2020) give an excellent overview over the existing research regarding the effectiveness of flipping the classroom in the form of a meta-analysis of nearly 200 studies. They conclude that »Overall, flipping a classroom has a positive, moderate effect on student performance «. In our view, their core finding is that »what distinguishes a flipped classroom from traditional teaching is not so much that information is pre-recorded [...] but, rather, that students have an opportunity to engage in active learning and problem-solving with hands-on guidance provided by an expert.«.

Active, self-determined and responsible learning has long been a goal in our efforts to redesign our exercises. The pandemic gave us the incentive to rethink our lectures completely. 


\section{Our approach}

Before the changes made necessary by the pandemic, our course »Ways of thinking in informatics « (Frauenberger \& Purgathofer, 2019) was a rather traditional, if very large, university course. We held lectures twice a week for 135 minutes in the largest lecture hall of TU Wien, offering a detailed treatment of the course content. This was complemented with exercises for some of the chapters, where students had to do their own research, read literature, and produce a research paper of sorts describing their work and results. Of the nine chapters of our lectures, six were essential enough to warrant such exercises. These exercises are organised in a way that requires students to review the work of their peers (Luckner \& Purgathofer, 2015), using a platform we have been developing for over ten years now (Luckner, Purgathofer \& Fitzpatrick, 2019). Towards the end, the course required the students to discuss a problem in small groups and hand in a paper documenting their individual positions as well as the results of the discussion.

The pandemic removed the lecture hall from the equation. Since our course is held in the winter term, we had the chance to hear from students who had witnessed direct online transformation models in other large lectures during the previous semester, when lockdowns first began. While students generally praised the flexibility and availability of recorded lectures, online lectures of equal length as classroom lectures were perceived as exhausting and stressful. This experience was shared by many lecturers, who describe the experience as »talking into the void« and »losing all contact to students«. Drawing from these anecdotes, we decided that the one thing we did not want to do were 135 minute zoom lectures.

Another aspect we considered was that the »Ways of thinking in informatics « course is designated for the first semester. The 2020 winter term was thought to be the first time first-semester students would come to our university without meeting each other. Usually, they meet at lecture halls, seminar rooms and other workspaces, as well as cafeterias and canteens. But this year, they would only meet online, and most of these online meetings barely deserve the term »meeting« at all.

\subsection{Goals}

Based on these thoughts and observations, we came up with a catalogue of goals. We wanted students to experience our course as different from the other courses in a positive way. We wanted to give them an opportunity to talk to each other in a social setting, guided by our course content. We wanted to encourage them to ask questions about the course content, the organization of the lecture, and about how what they learn in the course relates to the rest of informatics, and the world around them. We wanted students to have experiences in the online course that feel less distanced than the rather anonymous lecture hall version, even if they are at home or in their dorm room. We wanted to use the possibilities technology offers us to do things we had never done before. And finally, we wanted to offer students a variety of ways to access the course content.

The exercises and the way they are organized and graded were to remain largely unchanged. We raised the requirements a little, adding a task to each chapter in which students had to produce a summary of the chapter's topic as presented. The goal of this assignment was to establish better connections between lectures and exercises. We decided to leave this part mostly untouched, because the exercise part that was already working well in an online format (Luckner \& Purgathofer, 2015), and since we were planning to change so many things, we had no resources to completely rethink it. In other words, the exercise component formed the basis for our reorganization.

\subsection{Building blocks}

The following formats were devised to implement our goals as efficiently as possible in the given timeframe, with the available means:

$\rightarrow$ We set up a little production/streaming studio that enabled us to create a video format where the lecturer was part of the presentation. We did this to have control over the position of the lecturer in the streamed or recorded content, so that facial expression and gestures could be captured regardless of the students' setup. With this setup, we were able to create several different presentation layouts and make them available to lecturers.

$\rightarrow$ We developed a community-moderated Q\&A routine, based on the format of the Office Hour by Alex Lindsay, described by Daulton (2020), using the Q\&A-tool of Zoom webinars. In a Zoom webinar, only explicitly invited participants (panelists) share their video, while the rest (audience) can watch video and audio streams. All participants can propose questions using Zoom's built-in Q\&A-tool, see the questions proposed by others, and »upvote« the questions they deem interesting. That way, a list of questions ordered by audience interest is available to the panel. A »question moderator « on the panel reads the top-rated question from this list out for the panelists to discuss or answer. This is repeated until either time runs out or all questions are answered. As all questions are available as plain text, they can be 
downloaded after the session. By tracking the time code of when each question asked, we were able to create an indexed list of questions that enabled students to navigate to a specific answer in the videos.

$\rightarrow$ The bi-weekly 135 minute lecture format was replaced by short 30 to 45 minute online introductory lectures that provided an overview over each chapter. The Zoom sessions for these were planned to take an hour so the remaining time could be dedicated to answering comprehension questions asked by the students. For this, we used the community-moderated Q\&A-format described above, with the lecturer and the question moderator as the only panelists. These introductory sessions were recorded.

$\rightarrow$ All the additional content for each week was prepared in a format we called SlideBooks, which was developed by a graduate student (Kuroll, 2020). SlideBooks are created from the presentation slides using automation, based on a simple syntax of commands that are embedded in the speaker notes. In their final form, they combine images and text from the slides with additional text, as well as links to sources and external resources from the speaker notes. SlideBooks can be commented on by students on a slide-by-slide basis. Most SlideBooks were made from the slides of the respective introductory lectures, but expanded with text and links from the speaker notes to contain approximately double the information from the lecture.

Figure 1. Section from a SlideBook, showing three slides with different layouts, additional links and comments.
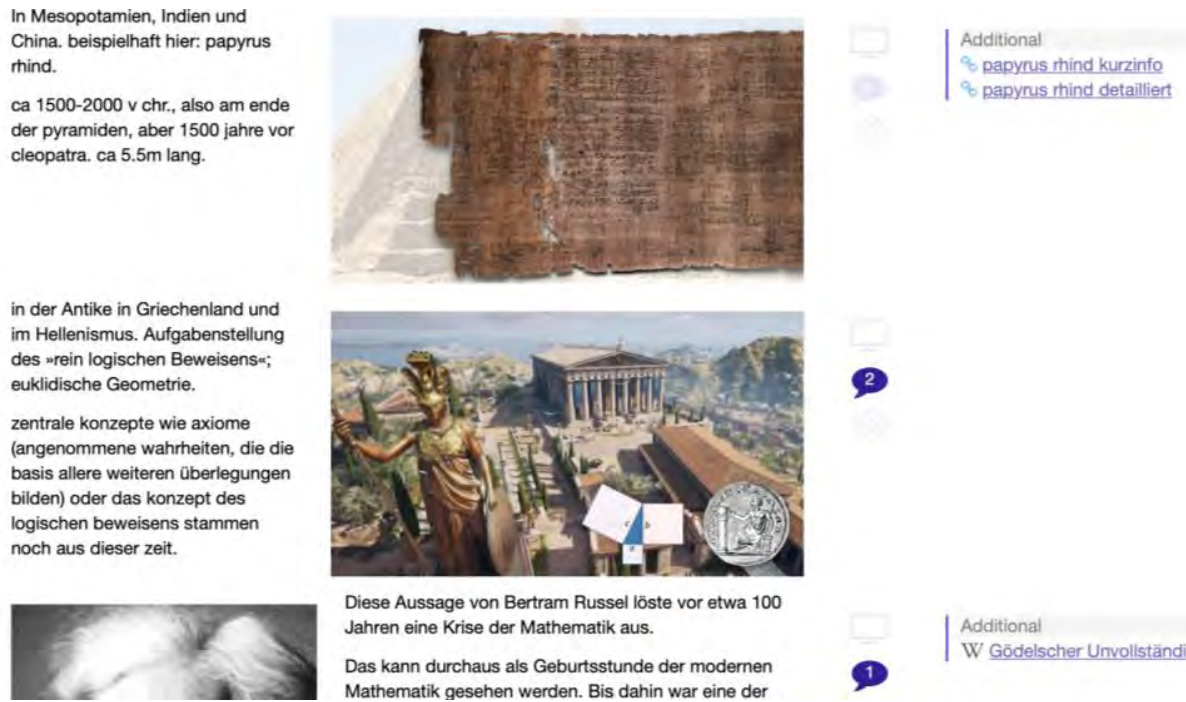

| Adiditional

Diese Aussage von Bertram Russel löste vor etwa 100 Jahren eine Krise der Mathematik aus.

Das kann durchaus als Geburtsstunde der modernen

$\rightarrow$ Additionally, we produced short video clips for content that detailed or expanded on the content of the introductory lectures. These videos were produced using the same setup as the lecture itself, a talking head on top of the slides. Eighteen videos of this type were produced over the semester, with an average length of 15 minutes.

$\rightarrow$ To enable social interaction centered in the content of our course, we required students to partake in an online interactive session every other week, held via Zoom. We asked students to work on specific assignments in groups of ten to fifteen people in breakout rooms. The assignments were derived from the content of the course, and were specifically designed not to be too difficult, so that the conversations would be stress-free and casual. We used platforms like miro.com to facilitate interaction. As an example of such a session, in a chapter focused on responsibility and ethics, students discussed the Chinese social credit system from various perspectives. To protect the students' privacy, these sessions were not recorded.

$\rightarrow$ Our community-moderated Q\&A format was the basis of the discussion sessions. Here, we invited external experts for the topics at hand to discuss questions provided by the students. We usually had between two and three experts on the panel, and additionally invited students who volunteered to the panel. With a thematic moderator and the question moderator, those sessions had between five and ten panelists, answering and discussing whatever came from the students via the Q\&A-tool. Those sessions were recorded and could be watched later, where the indexed list of questions made it possible to easily navigate to selected parts of the discussion.

\subsection{Structure and progress}

Starting October 2020, the course was held using the building blocks described above. Each of the nine chapters began with an introductory lecture (usually Monday), followed by an interactive session a couple of days later (usually Wednesday). Longer chapters featured a second introductory 
lecture. Each chapter would end with a discussion session (usually on Thursday). Additional materials like SlideBooks and video clips were made available starting with the introduction of each chapter, with all materials available by the time of the discussion. Six of the chapters had exercises associated with them that were published on the day after the discussion session, with a two-week deadline. Other than the interactive sessions and the hand-in of assignments, no format was mandatory to attend or watch.

\section{Methodology, evaluation \& discussion}

At the very end of every semester, we ask all students for feedback about their experiences attending the course. Last winter term, students answered six questions, writing an average of roughly 3.000 ( $\min 700$, max 9.000) characters. 497 completed and handed in feedback, of which 170 were chosen randomly as a basis for this evaluation.

One of the questions specifically asked for feedback and suggestions regarding the new elements: introductory lectures, interactive sessions, discussion sessions, SlideBook, and additional videos. We conducted a mixed qualitative/quantitative evaluation of these answers, using a variant of sentiment analysis (Feldman, 2013) to extract an understanding of the overall satisfaction with our format. In this analysis, we assigned each statement an integer value between 1 (very positive) and 5 (very negative) in relation to the aspect evaluated against.

Figure 3. Distribution of sentiment towards the different formats. All graphs use the same scale of absolute numbers.
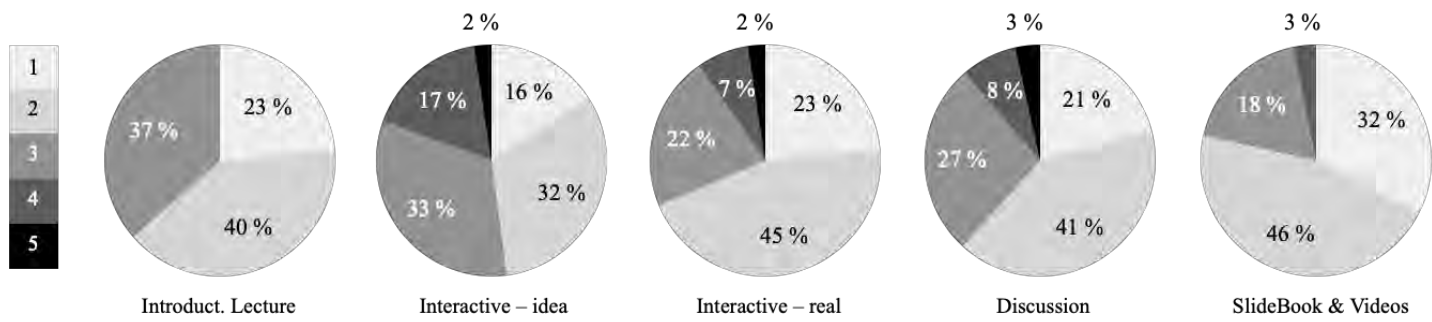

\subsection{Introductory lectures}

$\rightarrow$ Introductory lectures were watched by more than $85 \%$ of our students. $23 \%$ of these students positively mentioned the possibility to ask questions after the lecture part. The average sentiment towards the introductory lectures by the students who used them was 2.1., with no student having negative sentiment (4 or 5) towards this element.

Among the aspects attributed to this positive rating were that the duration was appropriate, especially compared to other courses, and that questions could be asked at the end. Criticism was offered regarding the low resolution of the recording (this was solved during the semester), and students wanted to play back the recordings faster than real-time (also solved during the semester). One student found our presentation »too informal«, and asked us to cut the occasional chit-chat at the beginning of lecture units, while others favourably mentioned that the informal tone made us appear more approachable.

$\rightarrow$ We experienced some technical difficulties in the organization of interactive sessions. Contrary to the documentation, Zoom did not allow us to open enough breakout rooms, so that the group sizes were larger than expected. Creating the breakout rooms turned out to be an iterative process, where we had to start with a too-high number of rooms and slowly reduce it until it worked. These problems were noted by many students as distracting and annoying. A frequent conclusion was that they liked the concept, but didn't like the implementation.

Because of the technical difficulties, our evaluation differentiated between the idea and the implementation of the interactive session. The average sentiment of the students toward the idea was quite positive with 2.2, while the actual implementation was criticized more, with a resulting value of 2.6. Figure 3 shows the distribution of sentiments here.

One of the goals of the interactive sessions was to create an environment for students to meet colleagues and socialize in the context of a course. As these sessions were mandatory and not recorded, all students had to participate in person. $18 \%$ of the students stated that they used the format as an opportunity to get in touch and interact with their new colleagues. On the other hand, $25.9 \%$ of students reported incidents where colleagues disrupted their work with immature »trolling «, or went »dark « during the group work phases. Both problems indicate that some students did not take this format seriously enough, as we only required their attendance, not contributions. Still, one student wrote (translated from German): »Especially during the pandemic it was my only chance to talk to and collaborate with other students, and thus I have met my first university friend «. 
$\rightarrow$ The discussion sessions were voluntary, we found a significantly lower interest in them. Only $68 \%$ of students attended or watched discussions. On average, their rating was positive, with a sentiment average of 2.3, but opinions were strong: while some students rated the discussions as completely useless, others described them as their favourite part of the course, especially when the guests were interesting. Some students wrote that the written Q\&A is too cumbersome, especially when you want to listen to the discussion and at the same time write a question. Others mentioned that the written question format was especially suitable for a discussion with so many participants.

Our own observation is that the format offered a couple of unique advantages over lecture hall discussions. One obvious advantage is that for the guests, it is time-saving and generally much easier to participate in an online discussion than come to a lecture hall. We were able to invite German-speaking guests from all over Europe. The written questions were also an advantage. This effectively made it impossible to ask long and rambling questions, and it meant that questions were generally more focused and precise. Also, there were less inhibitions to write and submit a question compared to standing up and asking a question in front of a full lecture hall. As a result, a broader variety of questions were asked, and we presume that some students asked questions who never would have spoken out in a lecture hall. Finally, the community ranking makes it possible for students to ask questions tentatively, leaving the community to decide whether a question is worth asking, rather than self-censoring. Consequently, some of the most interesting, weird and challenging questions we have ever heard were discussed.

$\rightarrow$ SlideBook has seen the best reception among our new formats. With an average sentiment of 1.9 - see Figure 3 for more details - no other format was praised so much for its value. Students emphasized the structure and organization, which makes access to individual topics much quicker than searching in videos. They also highlighted that a text-based format leaves the choice of pace to the learner.

$\rightarrow$ Strangely enough the additional videos were not seen as such, but as an alternative to the SlideBook content by most students. This can partly be attributed to a problem in presentation, but probably also goes back to a conflict in media semantics. In the case of introductory lectures, SlideBooks were offered as a different representation of the same content, although SlideBooks contained videos that extended this content in other places.

\section{Conclusions}

Our evaluation supports the understanding that the concepts and formats we deployed were welcomed by students. The extensive textual feedback from the students gives us plenty of starting points to improve on, but we end our discussion here with the result, as we have run out of space. In the end, the share of students that passed the course was slightly higher than average, compared to recent years. This is especially interesting since, in many other courses at our university, the number was much lower than usual this year. We take that as an affirmation of our approach.

\section{References}

Daulton, Doug. (2020) Office Hours with Alex Lindsay. Retrieved May 24, 2020, from https://focusonmobile.com/2020/05/01/office-hours-with-alex-lindsay-and-friends

Feldman, R. (2013). Techniques and applications for sentiment analysis. Communications of the ACM, 56(4), 82-89.

Frauenberger, C., \& Purgathofer, P. (2019). Ways of thinking in informatics. Communications of the ACM, 62(7), 58-64

Lage, M., Platt, G., Treglia, M. (2000). Inverting the Classroom: A Gateway to Creating an Inclusive Learning Environment- The Journal of Economic Education 31, Nr. 1: 32.

Luckner, N., \& Purgathofer, P. (2015). Exploring the use of peer review in large university courses. IxD\&A, 25, 21-38.

Luckner, N., Purgathofer, P., \& Fitzpatrick, G. (2019). Involving Students in the Co-Creation of a Complex. Evolving Learning Environment. IxD\&A, 42, 70 - 92.

Strelan, P., Osborn, A., \& Palmer, E. (2020). The flipped classroom: A meta-analysis of effects on student performance across disciplines and education levels. Educational Research Review, 30, 100314. 


\title{
INTEGRATION OF PEDAGOGY INTO TECHNOLOGY: A PRACTICAL PARADIGM
}

\author{
Zahra Hosseini $^{1}$, \& Jani Kinnunen ${ }^{2}$ \\ ${ }^{1}$ Information Technology and Communication, Tampere University (Finland) \\ ${ }^{2}$ Information Systems, Abo Akademi (Finland)
}

\begin{abstract}
Technology, with its rapid growth and vast impacts on all areas of human life, has increased well-being and facilitated daily tasks in our private life as well as in business and marketing, medical and healthcare services, and education. The global Covid-19 pandemic has shown the importance of Internet and technology to keep businesses running and reduce the problems emerging from social distancing and even saving lives through healthcare systems; likewise, educational systems speeded their technological facilities to run and develop normal educational activities. Although many studies had already acknowledged the necessity of using technology in education, the lack of facilities and knowledge of using technology in educational systems was reported in the beginning of the pandemic. The pandemic pushed educational systems to integrate technology into pedagogy by facilitating information transfer and communication. However, the challenge of enhancing the quality of information is still prevalent. This paper focuses on a bilateral necessity of integration of pedagogy and technology: while the potential of technology in educational systems is widely acknowledged, the practical usage of learning theories and pedagogical principles in designing digital services is far from a completed mission. Many user-experience (UX) studies determine technological, behavioral, social, and motivational factors to promote user-centric design to enhance the quality of content, while limited attention is given to pedagogical factors. We introduce integration of pedagogy into technology as a new paradigm in user-centric design, not only in the educational system but also in a general context. Mishra and Koehler (2006) introduced integration of technology into pedagogy (TP) through the Technological Pedagogical Content (TPACK) framework as required knowledge for teachers. This paper employs the TP concept in a broader context of Technological Pedagogical Content Design (TPCD), which utilizes the pedagogical element in the user-experience based practice to develop a user-centric design approach.
\end{abstract}

Keywords: Technology integration, TPACK, TPCD, user experience, user-centric design.

\section{Introduction}

Rapidly developing technology, adoption to ever broader areas, and increasing usage has had impressive effects on our lives and increased the quality of our lifestyle as well as on the areas of business and marketing (Grewal, 2020), medical and health care industry (Hussien et al., 2021; Nomani \& Hussain, 2020) and education (Cloete, 2017; Budhwar, 2017). The global Covid-19 pandemic has demonstrated the importance of Internet and technology to save lives and reduce the problems that were emerging from social distancing. (Ting et al., 2020; Singh et al., 2020). Similarly, educational systems speeded their technological facilities to return to normal activities. Technology-supported education with different aspects and affordances have concerned online education, e-learning, blended learning, web-based education, virtual education, or IT-supported teaching. Further, Internet and different tools and software are facilitating teaching and learning in pandemic conditions (Ionescu et al., 2020; Hoq, 2020, Kinnunen \& Georgescu, 2020). Using different apps and online meetings improve digital literacy, enhance the use of soft copy of materials, encourage students to be self-learners, improve collaboration, and give attention toward using electronic facilities for education (Jena, 2020). In addition, Learning Management System (LMS) that was already available received more attention during the lockdown period; however, at starting a pandemic, the lack of facilities and knowledge of using technology in educational systems was reported in many countries. Onyema et al. (2020), after collecting data from 200 respondents including policymakers, parents, teachers, and students in different countries, found how the pandemic had pushed educators and students to rely on technology to continue education, while problems arose from poor infrastructures of network, power, inaccessibility issues, or poor digital skills ed. The pandemic pushes educational systems to facilitate information transfer and communication, however, the still prevailing challenge of enhancing the quality of information cannot be over-emphasized. 


\section{The current phase of the bidirectional integration}

\subsection{Integrating technology into pedagogy}

Integrating technology into pedagogy is a suggested approach to enhance the quality of using technology for teaching and learning. Technology integration is promising in increasing the meaningfulness of the use of a device or a tool (Hyndman, 2018) for students' engagement as the best teaching practice (Hechter et al., 2012). The concept of technology integration has drawn educators' attention by Morton's (1996)'s claim that using technology does not mean just using a computer as an add-on or a tool for teaching and learning. Accordingly, many researchers followed by developing the concept of technology integration defined as integrating technology affordances into teaching (in the classroom or educational environments) for educational purposes and extended it through theories, frameworks, and models. In the last two decades, many scholars have presented different approaches for integrating technology into teaching. Some of recent technology integration models include Substitution, Augmentation, Modification and Redefinition (SAMR), Level of Teaching Innovation (LOTI), Technology Integration Matrix (TIM), Triple E framework (Extend, Enhance and Engage), and Technological Pedagogical Content Knowledge (TPACK) (Arora \& Chander, 2020). Each model has shown its potential in under specific conditions. With a critical and analytical view, Shirley (2018) listed the issues and barriers of integrating technology into teaching, concluding that technology cannot replace a teacher; however, pandemic restrictions have increased the necessity of technology integration more than ever, and the knowledge about technology integration has become critical in education.

\subsection{Integrating pedagogy into technology}

When the concept of technology integration is under discussion, mostly only the integration of technology into teaching is considered, e.g. within the framework of Technological Pedagogical Content Knowledge (TPACK), one of the most popular models for integrating technology into teaching. Technological Pedagogical Content (TPC) is an intersection of technology, pedagogy and content that provides special knowledge of technology to make difficult concepts easier to learn. This knowledge requires a deep understanding of the representation of concepts using technological and pedagogical techniques (Mishra \& Koehler, 2006). TPACK is widely known by scholars and administrators and it is discussed in numerous studies (Hosseini 2015a, 2015b, 2016; Sintawati \& Abdurrahman, 2020; Wijaya, 2020). Nevertheless, utilizing the TPACK framework for integrating pedagogy into technology, in order to design digital services, is a new paradigm. Human-computer Interaction (HCI) with respect to behavioral science and User Experience (UX) methods has already attempted to enhance the quality of digital services and products (Hassenzahl, 2013; Mtebe, 2019; Semerádová \& Weinlich, 2020). While HCI researchers utilize technological, behavioral, social, and motivational factors to promote user-centric design to enhance the quality of content, less attention is paid to pedagogical factors in designing. It seems evident that pedagogical principles get a place only when the purpose relates to designing an educational environment. Hence, this study attempts to introduce the potential of integrating pedagogy into technology also in a broader context of non-educational areas such as online digital design of, e.g. websites of corporations or government organizations.

\section{Method}

Our aim is to draw attention to a bilateral necessity of integration of pedagogy and technology and propose the practical model and provide instructions on how to use pedagogical principles not only in the educational environment but also in a broader context of the modern digital society. Therefore, to elaborate the new paradigm, we undertake a design research study in line with the definition: "Design research involves an investigation of strategies, procedures, methods, routes, tactics, schemes, and modes through which people work creatively. Design involves the testing of ideas, materials, and technologies. It involves innovative conceptual development, product evolution, and market modification. It also involves research into cultural, social, economic, aesthetic and ethical issues" (Roggema, 2017. p. 2).

We introduce integration of pedagogy into technology as a new paradigm of a user-centric design in a general context. Accordingly, we construct and introduce the Technological Pedagogical Content Design (TPCD) model as a practical design extension of Technological Pedagogical Content Knowledge (TPCK) with more focus on integrating pedagogy into technology than integrating technology into teaching and learning. The purpose is to take up the challenge presented by Don Norman as quoted by Hassenzahl (2013): "Design has moved from its origins of making things look attractive (styling) to making things that fulfill true needs in an effective understandable way (design_studies and interactive design) to the enabling of experiences (experience design). Each step is more difficult than the one before each requires and builds upon what was learned before". 


\section{Integrating pedagogy into technology as a design model (TPCD)}

Mishra and Koehler (2006) were the first to introduce integration of technology to pedagogy (TP) through the Technological Pedagogical Content (TPACK) framework as the required knowledge for teachers. This paper employs the TP concept in a broader context to create the new model of Technological Pedagogical Content Design (TPCD). It utilizes the pedagogical element in the user-experience practice to develop a user-centric design approach. TPCD is a model to integrate pedagogy to the technology in designing digital services (e.g. websites). Based on TPCD, users are self-learners, who are after some information transferred and learned through digital services. TPCD is a potential model not only to define the criteria for evaluating a design but also to offer systematic instructions to design. TPC is the core of design and defined as the integration of the three fundamental facts: (a) technology that includes different available technology to create and design; (b) pedagogy, which is mostly related to learning theories and knowledge about learners (users); and (c) content that defines the construct of each subject that can be linear on nonlinear. There are three sub-integrations of TPC including Pedagogical Content (PC), Technological Content (TC), and Technological Pedagogy (TP) as described in Figure 1.

Figure 1. Technological Pedagogical Content Design (TPCD).

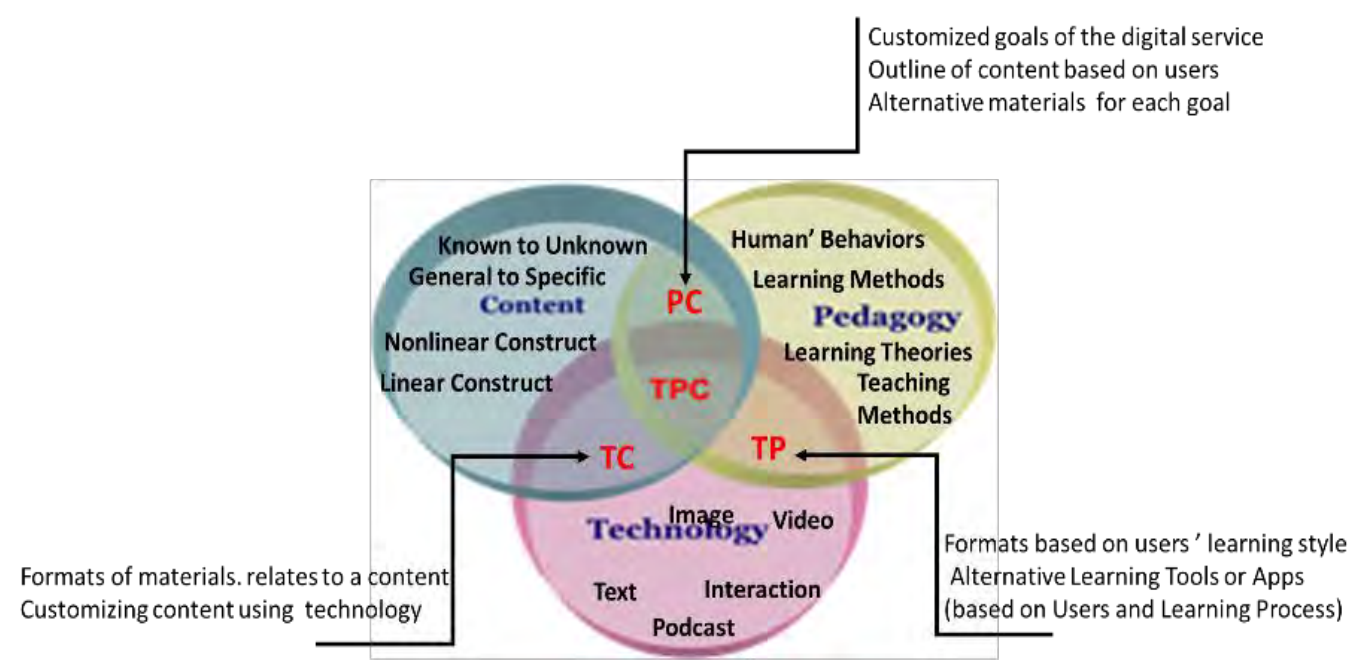

The TPCD utilizes a user-experience method for collecting data from users. The literature has shown the potential of user-experience methods as behavioral science to design technology (Hassenzahl, 2013; Mtebe, 2019; Semerádová \& Weinlich, 2020). However, considering the pedagogical aspect of users (e.g. their learning style) is suggested to lead to a new practical paradigm. Designing the content based on increasing attractiveness is assumed an important criterion for a successful design and regarding some method (e.g. teaching method) for organizing the outline of the content may increase the easiness of use and findability of content for users (PC).

Using technology tools and environments for delivering content (TC) is usually a familiar skill for designers but looking at the users as learners to integrate pedagogy into technological content (TPC or PTC) is a new challenging task to increase the user satisfaction. Another application example of a non-educational environment is organizing peer-learning or collaborative-learning options as a part of designing a game to increase the satisfaction of gamers. Further, considering the diversity of learning styles for selecting materials or predicting the paths of a user to read or learn information from a website may increase the findability and usability of information on the pages of a website.

This paper describes the integration of pedagogy into technology design without a direct educational purpose. At the level of design, components of TPC are clarified. Each level includes syllables of concepts, which helps the designer ensure the integration. To fulfil each task, selected key questions are suggested in Table 1. These questions can be obtained through exaction methods. It is notable that concepts and questions may vary based on the design case of a digital service (e.g. website). 
Table 1. The systematic instruction to design based on TPCD.

\begin{tabular}{|c|c|c|c|}
\hline Level & Concepts & Key questions / issues & Execution methods \\
\hline \multirow[t]{2}{*}{$\begin{array}{l}\text { Pedagogical } \\
\text { Analysis }\end{array}$} & $\begin{array}{l}\text { Aim of the digital } \\
\text { service }\end{array}$ & $\begin{array}{l}\text { Why is this service required? } \\
\text { What the digital service aims to offer? }\end{array}$ & $\begin{array}{l}\text { Interviews with digital } \\
\text { service creators }\end{array}$ \\
\hline & $\begin{array}{l}\text { Overlapping the aim of } \\
\text { digital service and } \\
\text { users }\end{array}$ & How the aim is customized and compromised? & Discussion \\
\hline $\begin{array}{l}\text { Pedagogical } \\
\text { Content }\end{array}$ & $\begin{array}{l}\text { Content sequence } \\
\text { Learning styles } \\
\text { Learning theories } \\
\text { Teaching and learning } \\
\text { methods }\end{array}$ & $\begin{array}{l}\text { What is the consequence of content (linear or } \\
\text { non-linear)? } \\
\text { How a user gets content easier or faster? } \\
\text { What is the conceptual map of the content? } \\
\text { What are activities to transfer the content } \\
\text { (constructivism or direct education)? }\end{array}$ & $\begin{array}{l}\text { Preparing content outlines' } \\
\text { sequences } \\
\text { Alternative methods and } \\
\text { materials to gain a particular } \\
\text { goal }\end{array}$ \\
\hline $\begin{array}{l}\text { Pedagogical } \\
\text { Technology }\end{array}$ & $\begin{array}{l}\text { Peer learning or } \\
\text { collaborative tools } \\
\text { Learning tools } \\
\text { Learning theories in } \\
\text { visualization or } \\
\text { textualization }\end{array}$ & $\begin{array}{l}\text { What activity users do to reach the goal } \\
\text { (reading, listening, game, etc.)? } \\
\text { In which ways technology helps users } \\
\text { understand and reach their purposed } \\
\text { destination easier, faster and more effectively? }\end{array}$ & $\begin{array}{l}\text { Using principles } \\
\text { (e.g. Gestalt in designing) } \\
\text { Formats based on users' } \\
\text { learning style } \\
\text { Aural, visual, verbal, logical } \\
\text { and ...learning }\end{array}$ \\
\hline $\begin{array}{l}\text { Technological } \\
\text { Pedagogical } \\
\text { Content }\end{array}$ & Scaffolding the design & $\begin{array}{l}\text { How easily users move on, get to destination, } \\
\text { and receive satisfaction? }\end{array}$ & $\begin{array}{l}\text { alignment of elements and its } \\
\text { consistency }\end{array}$ \\
\hline
\end{tabular}

\section{Conclusions}

Technology has revolutionized life in modern digital societies as part of all aspects of human life. The constant development of technologies makes their optimal usage a challenging task. This challenge is taken by design science. Its role has been evolving from user-friendly design towards user-centric design. Conclusively, this paper suggested using pedagogy to design technology in non-educational domains (such as games and websites, for instance) to enhance the quality of digital services in a society. Interdisciplinary knowledge is required to understand the diversity of users and designing team members in different application areas. The rapid development and increasing use of technology have forced the design process to become more dynamic and complex. However, this should not discourage the researchers, companies, and designers to define the instructions to guide building digital services. This paper introduced the general model for integrating pedagogy into technology as a new paradigm and suggested practical instructions for designing technology based on pedagogical integration (Table 1). TPCD is still taking its first steps to become an established model; the authors have implemented it to redesign a soon-published English-language part of a business association website (Suomen Yrittäjät) in Finland (Hosseini et al., unpublished).

\section{References}

Arora, C., \& Chander, S. (2020). Integrating Technology into Classroom Learning. Indian Journal of Educational Technology, 2(1), 84-105.

Budhwar, K. (2017). The role of technology in education. International Journal of Engineering Applied Sciences and Technology, 2(8), 55-57.

Cloete, A. L. (2017). Technology and education: Challenges and opportunities. HTS Theological Studies, 73(4), 1-7.

Grewal, D., Hulland, J., Kopalle, P. K., \& Karahanna, E. (2020). The future of technology and marketing: a multidisciplinary perspective. Journal of the Academy of Marketing Science volume, 48, 1-8.

Hassenzahl, M. (2013). User experience and experience design. The Encyclopedia of Human-Computer Interaction. Retrieved April 27, 2021, from: https://www.interactiondesign.org/literature/book/the-encyclopedia-of-human-computer-interaction-2nd-ed/userexperience-and-experience-design 
Hechter, R. P., Phyfe, L. D., \& Vermette, L. A. (2012). Integrating technology in education: Moving the TPCK framework towards practical applications. Education Research and Perspectives, 39, $136-152$.

Hoq, M. Z. (2020). E-Learning during the period of pandemic (COVID-19) in the kingdom of Saudi Arabia: an empirical study. American Journal of Educational Research, 8(7), 457-464.

Hosseini, Z. (2015a). Development of technological pedagogical content knowledge through constructionist activities. Procedia-Social and Behavioral Sciences, 182, 98-103. doi:10.1016/j.sbspro.2015.04.743

Hosseini, Z. (2015b). The Usage of Constructivism to Enhance Technology Integration Knowledge. Technology of Education Journal (TEJ), 10(1), 65-74. doi:10.22061/TEJ.2015.439

Hosseini, Z. (2016). The Comparison between the Effect of Constructivism and Directed Instruction on Student Teachers' Technology Integration. New Educational Approach. Journal of University of Isfahan, 10(2), 21-40. Retrieved April 27, 2021, from: https://www.sid.ir/en/journal/ViewPaper.aspx?id=574895

Hosseini, Z. Hytönen, K., \& Kinnunen, J. (unpublished). Technological Pedagogical Content Design (TPCD) for User-Centered Website: A User Experience Case Study in Finland (in publishing).

Hussien, H. M., Yasin, S. M., Udzir, N. I., Ninggal, M. I. H., \& Salman, S. (2021). Blockchain technology in the healthcare industry: Trends and opportunities. Journal of Industrial Information Integration, 22, 100217.

Hyndman, B. (2018). Ten reasons why teachers can struggle to use technology in the classroom. Science Education News, 67(4), 41-42.

Ionescu, C. A., Paschia, L., Gudanescu Nicolau, N. L., Stanescu, S. G., Neacsu Stancescu, V. M., Coman, M. D., \& Uzlau, M. C. (2020). Sustainability Analysis of the E-Learning Education System during Pandemic Period-COVID-19 in Romania. Sustainability, 12(21), 9030, 22 pp. Retrieved April 27, 2021, from: https://www.mdpi.com/2071-1050/12/21/9030

Jena, P. K. (2020). Impact of pandemic COVID-19 on education in India. International Journal of Current Research (IJCR), 12(7), 12582-12586.

Kinnunen, J., Georgescu, I, (2020). Disruptive Pandemic as a Driver towards Digital Coaching in OECD Countries. Revista Romaneasca pentru Educatie Multidimensionala 12(2 Sup 1), 55-61. doi:10.18662/rrem/12.2Sup $1 / 289$

Mishra, P., \& Koehler, M. J. (2006). Technological pedagogical content knowledge: A framework for teacher knowledge. Teachers College Record, 108(6), 1017-1054.

Mtebe, J. S. (2019). Examining user experience of eLearning systems implemented in two universities in Tanzania. Interactive Technology and Smart Education, 17(1), 39-55. doi:10.1108/ITSE-05-20190025

Nomani, M. Z. M., \& Hussain, Z. (2020). Innovation technology in health care management in the context of Indian environmental planning and sustainable development. International journal on emerging technologies, 11(2), 560-564.

Onyema, E. M., Eucheria, N. C., Obafemi, F. A., Sen, S., Atonye, F. G., Sharma, A., \& Alsayed, A. O. (2020). Impact of Coronavirus pandemic on education. Journal of Education and Practice, 11(13), $108-121$

Roggema, R. (2017). Research by design: Proposition for a methodological approach. Urban science, 1(1), 2, 19 pp.

Semerádová, T., \& Weinlich, P. (2020). Factors Influencing User Experience. In Semerádová, T., \& Weinlich, P, Website Quality and Shopping Behavior (pp. 29-62). Cham: Springer.

Shirley, M. A. J. (2018) Issues and Barriers of Integrating Technology in Education. Special Issue Published in International Journal of Trend in Research and Development (IJTRD), pp 32-35. Retrieved April 27, 2021, from: http://www.ijtrd.com/papers/IJTRD15933.pdf

Singh, R. P., Javaid, M., Haleem, A., \& Suman, R. (2020). Internet of things (IoT) applications to fight against COVID-19 pandemic. Diabetes \& Metabolic Syndrome: Clinical Research \& Reviews, 14(4), 521-524.

Sintawati, M., \& Abdurrahman, G. (2020). The effectiveness of blended learning to improve pre-service teacher TPaCK in developing multimedia learning mathematics at elementary school. Journal of Physics: Conference Series, 1521, 032014, 6 pp.

Ting, D. S. W., Carin, L., Dzau, V., \& Wong, T. Y. (2020). Digital technology and COVID-19. Nature medicine, 26(4), 459-461.

Wijaya, T. T., Tang, J., \& Purnama, A. (2020). Developing an interactive mathematical learning media based on the tpack framework using the hawgent dynamic mathematics software. In Miraz M.H., Excell P.S., Ware A., Soomro S., \& Ali M. (Eds.) International Conference for Emerging Technologies in Computing (pp. 318-328). Cham: Springer, Cham. doi:10.1007/978-3-030-600365_24 


\title{
DEVELOPMENT OF HEALTH-PROMOTING BEHAVIOUR OF A CHILD AS AN EDUCATIONAL GOAL IN FAMILIES OF HANDICAPPED MOTHERS WITH MENTAL HEALTH DISORDERS
}

\author{
Petra Hájková, \& Lea Květoňová \\ Charles Univ, Fac Edu, PedF UK (Czech Republic)
}

\begin{abstract}
The mental health of adult women is an important attribute of their motherhood. Weakening of mental health poses a threat to activities in the field of self-care and healthy development of their children. Even under these conditions of health disadvantage, women-mothers remain as the main mediators of health-promoting habits for their children, thus they become theirs first educators. The health literacy of these women also plays a role in this regard. For this reason, it is crucial to provide these women with sufficient special education that takes their individual needs into account.

This research project is focused on finding connections between the mental health disorder of mothers, their health literacy with manifestations in the field of health-promoting behaviour, and with the need for support in the relevant area of childcare by professionals and close family members.

The author will present an overview of research focused on this issue as well as her own proposal for a research solution, which received the support of the Charles University Grant Agency for the years 2021-2022.
\end{abstract}

Keywords: Mental health disorders, women with mental illness, health literacy, shared childcare, research.

\section{Introduction}

Within the European area, one in four persons gets affected by a mental health disorder (WHO, 2018). The statistics show that in the Czech Republic there are 53,212 women with a registered mental disorder spanning across the whole spectrum of diagnoses F00 - F99 which already qualifies as a disability. Out of this number, 25\% are women in their fertile years aged 20-39 (ÚZIS, 2018) who have custody of a child or more children. WHO study (2018) also indicates that the prevalence of women is similar worldwide. Cumulated roles in the society contribute to increasing the psychological pressure women are exposed to, and they affect their mental health. Women with SMI are, similarly to healthy women, expected to take over the primary responsibility for the developmental needs of their children even though they are themselves disadvantaged (Doucet et al., 2010, p. 298). However, serious mental illness (SMI) has the potential to affect the woman's functioning on a physical, social, professional as well as parental level (Saddock \& Saddock, 2007, p. 467). It can also influence the quality and quantity of her parental activities with regard to looking after the child's health (teaching him hygiene habits, healthy eating habits, sleep hygiene, mental hygiene, maintaining an exercise routine, injury prevention). In this context, the health literacy of women with SMI plays its role too, which means that there is an area involved that can be influenced by education also in adulthood or under the circumstances of SMI.

Our research team decided to investigate the links among the SMI of mothers, their motherly behaviour which encourages healthy habits in their children, and their need to share this care for children with a partner or other close family members. The goal of our research was to create an empirically grounded special educational intervention for women with mental health disorders provided within the integrated community care for people with SMI, which is - in the Czech Republic - just being developed.

Our research approach led us to a systematic review of domestic and foreign publications that provide empirical data for special educators focused on educational work towards women with mental health disorders during their motherhood. 


\section{Systematic review}

The systematic review, carried out by the research team in autumn 2020, was targeted on finding out a typical conceptualization of the problems listed in professional literature concerning women with SMI. We followed published results of research works carried out in years 2010-2020, which were indexed in three important bibliographic databases.

At first, relevant literature sources registered in the largest Czech bibliographic database Bibliographia medica Czechoslovaca (BMC) were chosen. This database includes 855 thousand specialised medical and health care documents of Czech as well as foreign origin (magazines, newspapers, monographs, collections). In addition to the medical field, the database expands to related social sciences.

Subsequently, sources from the international database CINAHL (Cumulative Index to Nursing \& Allied Health) which indexes 1,500 nursing and medical magazines as well as 5,500 journals from the whole world were chosen. CINAHL provides on its portal a full-text access to more than 500 magazines which also focus on health. The database indexes publications not only for researchers in the medical field but also for researchers from related social sciences. Therefore, it served as an important source for our systematic review too.

Further search was carried out in the MEDLINE database (Medical Literature Analysis and Retrieval System Online) at the US National Library of Medicine, which indexes international medical publications from research, clinical practise, administration, social politics and services aimed at public health and its protection. All above mentioned databases contain entries and full texts in multiple language versions. Only German and English, or as the case may be Czech and Slovak, versions were chosen for our purposes.

The selection included published results which met the following criteria:

1) They provided research data and outcomes concerning motherhood (parenthood) of women with mental health disorders (case studies, experimental research results, observations, qualitative studies including interviews, focus group, etc.);

2) They offered content concerning SMI in the context of family functioning and needs of women-mothers (functioning within the family and as a mother, or a combination of these key topics);

3) As to the conception of women's mental health, they went beyond a purely medical context.

The results were examined with regard to two interrelated research questions:

1. Are there any special needs of women with SMI during motherhood and child care?

2. Does SMI create any obstacles hindering care provision aimed at healthy development of the child?

\section{Research results}

Among the results published 2010 - 2020 we found in BMC 7 monographs and 16 specialised articles in Czech professional magazines, among others also 1 article published in Speciální pedagogika (Czech professional periodical for special educators). 3 found monographs didn't meet the 1st, the 2nd or the 3rd inclusive criterion. 7 specialised articles were eliminated due to duplicity and/or because of a purely medical focus (3rd inclusive criterion). 13 relevant publications of Czech provenience were examined as to represented topics and concepts of SMI.

Altogether, we identified 8 conceptual models of SMI depicted in professional literature published in the Czech Republic. Here you find them listed according to the frequency of their presence:

1. psychological model (12 occurrences) dealing with the developmental context of disorders and mental condition, self-concept, sense of self and self-perception of women with SMI in their role as a mother; 2. medical model ( 7 occurrences) focused on diagnosis and symptomatology of mental health disorders, their impact on the usage of health care services, medical costs linked to SMI, and results of psychiatric intervention as well as pharmacological treatment aimed at the well-being of women with SMI and their families; 3. sociological model (4 occurrences) highlighting the social consequences of chronical conditions in women, community service and supporting tools provided by the society; 4 . and 5 . Pedagogical/educational and training models (3 occurrences) following the educational impact a mother with SMI has on her child/children; 6. social work model (2 occurrences) focused on social services and intervention done by social workers in families of mothers with SMI; marginally also pathophysiological and socio-demographic model in which the authors concentrated on specific topics linked to mothers with SMI in families with children.

In the analysed publications, no attention was paid to the needs of mothers with SMI as to teaching the child heath promoting behaviours. The same applies to the chances of mothers with SMI to be involved in parenting activities in this respect. Being informed, health literacy and related responsibility of mothers with SMI or their need to share the care for a healthy development of their child 
in the family weren't mentioned in the followed sources at all. An exception represented two publications dedicated to motherhood of women with mental impairment written by a team of authors from Charles University (Strnadová, Bernoldová, Adamčíková, Klusáček, 2015; Strnadová, Mužáková, 2010).

Analysis of publications in English or German indexed in the databases CINAHL (Cumulative Index to Nursing \& Allied Health) and MEDLINE (Medical Literature Analysis and Retrieval System Online) brought a higher number of occurrences with clear relevance fulfilling our inclusive criteria.

Among the publications indexed in MEDLINE and CINAHL (Plus) in 2010-2020 could be found 50 magazine articles, out of which 33 met the inclusive criteria whereas 17 got eliminated because of not fulfilling the 2nd and 3rd criterion. Overall, 10 conceptual models could be identified in foreign sources, out of which were predominant:

1. psychological (14 occurrences); 2. social work models (9 occurrences); 3. medical (8 occurrences); 4. sociodemographic (7 occurrences), 5. educational and training models (7 occurrences); 6. socio-legal (6 occurrences); 7. pedagogical (6 occurrences), 8. epidemiological (4 occurrences); 9. socio-economic ( 2 occurrences) and 10. ethnological (1 occurrence), which was introducing the context of subcultures.

Foreign publications more often connect psychological topics to therapeutic, medical, educational themes as well as to informational support offered to women with SMI. They more frequently point out possible risks in regard to providing health promoting care for children in families where the mother has SMI. The thematization of these risks also happens with respect to accessible community services and family therapy. In German publications, publications from Great Britain, Finland, Australia, and the USA significant attention is paid to modern interventions and psycho-educational programs as well as rehabilitation programs for parenting couples or mothers with SMI and their children.

14 out of the found results directly focus on the needs of women-mothers in the fields of psychology, psycho-social help, practical help, help with developing a strategy in the family as well as concerning shared care for the child, or in the field of education and awareness. 27 found results contain support (online, educational, psycho-rehabilitation, etc.) programs verified by action or evaluation research. Significant tendencies to solve issues of women-mothers with SMI in an interdisciplinary manner could be found here. Besides, the conceptual models were intermingling much more. It can be stated that within the conceptual framework of foreign literature, the inclusive paradigm is predominant compared to the bio-medical paradigm. This is the case in all foreign sources which go beyond the medical context.

The review study has shown that it's necessary to widen the view researchers in the Czech Republic take on the motherhood of women with SMI. Besides, the instrumental content of support intervention offered in families of women-mothers with mental health disorders has to be broaden as well. It is needed to supply research argumentation in order to cover their individual and specific needs during motherhood and child care focused on the healthy development of the offspring. The persisting bio-medical paradigm in the conceptualisation of professional support given to these women is to be overcome. In addition to that, supporting educational and psycho-rehabilitation programs aimed at retaining functional parenting as well as family life of these women have to be developed. Apart from that, such programs have to give them opportunities of self-realization in their common social roles. Integrated services for mothers with SMI thematized in professional literature should cover not only their treatment and psychological or therapeutic service aimed at overcoming the consequences of SMI. They should also bring impulses in order to develop their parenting skills and practical family functioning in harmony with the inclusive paradigm in social sciences.

These findings inspired our team to conceive a research proposal named "The Needs of Women-Mothers with Chronical Mental Illness in the Area of Shared Childcare and Health Literacy" which received 100\% support of Charles University Grant Agency for 2021-2022.

\section{Research intent}

Our research intents to identify the needs of women with chronical mental illness with regard to the area of shared child care and to find out strategies these women intentionally use for ensuring the healthy development of their children.

The research will be conducted through semi-structured interviews with 22 women with chronical mental illness who have been having this condition since more than a year during their motherhood and care for a child (children) under 7 years of age. The control group will be constituted by 22 women-mothers without any diagnosed disorder in the area of mental health. These mothers will have children of the same age. The interviews with both groups of women will focus not only on needs during motherhood and child care but also on specific significance they (or their family members) attribute to mental health and health literacy. 
The study will be based on purposive sampling of women with chronic disease in the diagnosed spectrum F00-99 according to ICD-10 and on the control group of women without any diagnosed mental illness. The selection will be made on the basis of comparable demographic features of the two groups (age, family status, number of children up to 7 years of age, education).

We will make use of the following four technical elements which support the interviewing process in its function and fill the gaps in the data collection:

1. indicative questionnaire (for the collection of demographic data)

2. audio recording of the interview (dictating machine)

3. interview transcripts (MS Word, Excel)

4. postscripts

The indicative questionnaire can concentrate on biographical information about the participants: age, status, education, work position or disability level, diagnosis (F00-F99, with the exclusion of disorders due to alcohol addiction or addiction on any other substances), frequency of relapses, number of children in custody, etc. Audio recording the interview will ensure that all the statements are registered in an exact way. Subsequently, the recordings will be completely transferred to a text version according to transcription rules. All names and places will get changed in order to respect anonymity of research. The so-called postscripts will be added to the audio recording, that means field comments such as comments on the course of the interview, information about non-verbal and situational behaviour of participants or any other important circumstances of the interview. The interviews will undergo an analysis using software XLSTAT Basic+ for coding and data modelling. After that, the comparative method will be used to distinguish needs of women with SMI and without (in the area of health literacy and shared care for a child or children in their families).

The outputs will be confirmed by using members check and peer debriefing where partial conclusions will be given to several research participants for comments and assessment. Continuous assessment and commenting on the outcomes during "peer debriefing" (procedure review, methodology also with regard to outcomes in order to ensure validity) will be primarily carried out within the research team.

\section{Expected outcomes}

Identifying the needs of mothers with SMI in the area of care for the healthy development of their children in the context of shared care in the family will bring concrete impulses for specialised educational intervention based on proofs addressed at families in which mothers have SMI. Educational service for women with SMI can improve the relationships and wellbeing in the families, liberate them from fear and anxiety caused by insufficient family and parental functioning. In addition to this, it can contribute to their destigmatisation.

This paper was written thanks to GA UK (Charles University Grant Agency) which fully supported the project Needs of Women-Mothers with Chronic Mental Illness in the Area of Shared Child Care and Health Literacy (no. 251891, 2021-2022). The researcher is a doctoral student at the Faculty of Education, Charles University in Prague.

\section{References}

Doucet, S., A. et All. (2010). Contemporary paradigms for research related to women's mental health. Health Care for Women International, 31 (4), p.296-312, Retrieved March 31, 2021, from: http://dx.doi.org/10.1080/07399330903518509.

Institute of Health Information and Statistics of the Czech Republic. (2018). Psychiatrická péče 2017. Prague: IHIS CR. ISBN 978-80-7472-178-6.

Sadock, B., J., Sadock, V., A. (2007). Kaplan \& Sadock's synopsis of psychiatry: Behavioural science/clinical psychiatry (10th ed.). Philadelphia: Lippincott Williams \& Wilkins.

Strnadová, I., Bernoldová, J., Adamčíková, Z., Klusáček, J. (2015). Good Enough Support? Exploring the Attitudes, Knowledge and Experiences of Practitioners in Social Services and Child Welfare Working with Mothers with Intellectual Disability. JARID, 30 (3), p.563-572. ISSN: 1360-2322.

Strnadová, I., Mužáková, M. (2010). Mateřství žen s mentálním postižením. Speciální pedagogika, 20 (3), p.205-216. ISSN: $1211-2720$

World Health Organization. (2018). Culture and reform of mental health care in central and eastern Europe. Klecany: The WHO Regional Office for Europe, Czechia. ISBN 978-92-8905-307-5. 


\title{
ONLINE SPEECH AND LANGUAGE THERAPY. FOCUS-GROUP BASED STUDY
}

\author{
Carolina Bodea Hațegan ${ }^{1}$, Dorina Talaș ${ }^{2}$ \& Raluca Trifu ${ }^{3}$ \\ ${ }^{1}$ PhD Associate Professor, Department of Special Education, Faculty of Psychology and Education \\ Sciences, Babeș-Bolyai University, Cluj-Napoca, (Romania) \\ ${ }^{2} \mathrm{PhD}$ Associated Lecturer, Department of Special Education, Faculty of Psychology and Education \\ Sciences, Babeș-Bolyai University, Cluj-Napoca, (Romania) \\ ${ }^{3}$ PhD Assistant Professor, Department of Medical Education, University of Medicine and Pharmacy, Iuliu \\ Hațieganu, Cluj-Napoca, (Romania)
}

\begin{abstract}
In March 2020, due to the pandemic situation from our country, the National lockdown was imposed for almost two months. Speech and language therapy field was very affected in this period of time and harsh decisions were to be taken. Children who strongly needed therapy were in the situation to either go on with the rehabilitation process in an online setting or to wait and postpone therapy sessions. The aim of this research is to present the situation in a SLT (speech and language therapy) private specialized center and to underline the advantages and the disadvantages of SLT online therapy after one year (from March 2020, till March 2021). In the beginning of March 2020, 37 children attended SLT sessions in this private center, 2 of them were recently assessed and they were supposed to begin therapy exactly on the first lockdown day. From all of them, 20 children $(54 \%)$ switch to online therapy sessions progressively. Starting with April 2020, after a three weeks break, 9 children diagnosed with mild to moderate speech and language disorders, switch from face to face to on-line. In May, 6 more children and in June another 5 children were brought back to therapy, even if we remained in an online setting. The other children, 17 $(46 \%)$, either stopped all therapy sessions or began therapy in other centers that organized onsite therapeutic sessions after the lockdown period of time. At this present moment, in March 2021, at one year distance, the SLT center offers SLT services exclusively online, both assessment and therapy and the number of cases asking directly for online therapy is increasing daily (in March 2021, N=31). Results of this study, organized as focus-groups with 3 parents, 3 children and 3 therapists underlined that online SLT is very efficient as long as parents' involvement is high. The main advantages listed by all persons in the research, even by children are: easier to be more consistent; the attendance in the SLT sessions is definitely higher, parents can participate directly in these activities, resources are easily to be found. Among disadvantages, the fact that parents have to be very involved in this therapeutic process seems to be the most frequently listed. In discussions and conclusions of this study a profile of the online SLT users is about to be depicted, a profile related to the one found in specialized literature from the field.
\end{abstract}

Keywords: Online therapy, speech and language therapy (SLT), speech and language disorders, focus-group.

\section{Introduction}

Telepractice in speech and language therapy has been with the services for a long time, initially presented as ways to address people's needs in distance areas or specific groups or peoples.

\subsection{Online speech and language therapy definition}

Online speech therapy services have developed in the last decade, but last year most SLT's around the world, forced by circumstances, moved face-to-face services to online services due to COVID- 19 pandemic.

Telepractice is seen as use of apps and tech technology to SLT/SLP (Harrison, 2011). The American Speech-Language-Hearing Association (ASHA) defines the term telepractice as "the application of telecommunications technology to the delivery of speech-language pathology and audiology professional services at a distance by linking clinician to client or clinician to clinician for assessment, intervention, and/or consultation". (ASHA, 2018). Parallel, the World Health Organization 
(2016), defined telehealth as the delivery of health care services using information and communications technology (ICT).

In Romania the term telepractice is not wildly implemented, but "online speech therapy" is preferred and used for any speech and language therapy session delivered by a speech and language therapist using a computer or any other device (laptop, tablet, phone) connected on the Internet.

\subsection{Advantages of online speech and language therapy}

The switch from face-to-face to on line session in speech and language therapy, consequently impose a debate between the advantages and the disadvantages of the new delivery setting.

The most relevant advantages when using telepractice are related to saving time, diminish cost associated with traveling and reduced waiting time. (Eslami, 2018). Others researchers such Tucker J. K. (2012) considers the following advantages of telepractice services: access to SLT services, individualized programming, delivery options for students, access to specialists, and increased learning for students. For students with ASD, telepractice helps them to stay on task and typing on the computer is easier than handwriting. If the children wear headphones during SLT sessions, it could help them reduce other distractions.

Kraljević et al. (2020) identified the following advantages of using telepractice: equity of services, mitigation of distance and travel issues as well as transfer to natural settings.

The focus in telepractice is also on the type of activity used which can influence the results of therapy sessions. O'Brian et al. (2014) in their study concluded that the use of synchronous methods is more effective than using asynchronous methods (e-mail) in stuttering context.

In telepractice, SLT services are more accessible and these types of services proved to influence positively the patients' cooperation during therapy. (Marcin, 2016)

Due to Covid-19 pandemic, online speech and language therapy reduce the risk of illness for children, their families and for therapists. Because children do not have digital skills to access the platform and to connect with the therapist, the parents must offer support them and they are more involved in the therapeutic process.

\subsection{Disadvantages of online speech and language therapy}

At the beginning of telepractice, one of the main concerns raised was related to protecting the patient's privacy during online sessions (Kully, 2000). The new end to end encrypted apps and programs tried to address this disadvantage, but the security problems are not completely resolve.

The quality of sound and image influence the quality of telepractice services. There are different factors that can influence the quality of sound and image: the devices used during online therapy (microphone, camera) and the speed of the Internet. Low bandwidth and network congestion have a negative impact on sound and visual signal during online therapy. (Constantinescu et al., 2011).

Tucker J. K. (2012) identified the following barriers during telepractice: technology failures, lack of training, lack of procedures, nature of the environment, lack of physical contact, establishing therapeutic relationships, ethical concerns, student candidacy, dissatisfaction, lack of research. Talas (2015), Bodea Hațegan, Talaș, (2020) consider that the lack of physical contact, static position, and the lack of family training using the computer are the main disadvantages of online speech and language therapy. Telepractice Working group study (Trifu, R et al 2018) underline the benefits of speech language therapy in case of distance and poor access to speech therapy, in contrast with the challenges which imposed special training, diminish resources and budget restrictions.

\section{Design and methodology}

This is a two-stage research. First a quantitative analysis was made in terms of frequencies in order to determine the number of online SLT therapy beneficiaries at the level of the Private SLT Center. Then a focus- group with 9 participants (3 parents, 3 children and 3 therapists) was organized to gain insight on the topic.

In March 2021 we decided to organize a small focus-group at the level of the SLT center, with parents, therapists and children in order to learn more about this situation and to find out how all three parts involved in this online therapeutic process appreciate the situation.

The focus-group with parents and children was organized just with beneficiaries of online SLT therapy and it was based on the following questions/directions:

1. Do you appreciate as useful the online speech and language therapy?

2. Do you prefer online SLT over onsite SLT?

3. Do you want to continue (as necessary) the online SLT?

4. List at list three advantages of online SLT.

5. List at list three disadvantages of online SLT.

6. Please provide us other info you consider relevant. 
The therapists gathered involved in the focus-group delivered both online and onsite SLT in the private center.

\section{Objectives}

The aim of this study was (1) To identify the advantages and disadvantages of speech and language online therapy, (2) To draw a profile of the SLT therapy beneficiaries during the pandemic period of time, (3) To identify the new ways in which the advantages of the online SLT can be furthered exploited.

\section{Participants in this research}

Parents and children were randomly selected from the three main waves of participants in the online therapy: 1 parent and one child who started online sessions in April (diagnosis of the child reading and writing disorder); one parent and one child who started online sessions in May (diagnosis of the child articulation disorder) and one parent and one child who started online therapy in June (diagnosis of the child speech and language disorder secondary to the autism spectrum disorder).

\section{Results. Frequencies study}

This study was organized based on the experience we had in a Speech and Language Therapy Private Center from Romania. In the beginning of March, the total number of children who used to benefit from the speech and language therapy services in this specialized center was 35, the other two children were recently assessed and they were supposed to begin their therapies next week, 37 in total. The center has two working points, a main working point and a secondary working point organized in a private kindergarten.

At the lockdown moment in the working point from the kindergarten 7 children benefit from the therapeutic services. On 13th of March 2020 in Romania, the possibility of national lockdown was announced by our president and it became low starting with the 16th of March, In Romanian being announced the State of Emergency, for a period of one month. Unfortunately, the State of Emergency was prolonged for another month, in April, and then Romania entered in the Alert State.

During the State of Emergency most of the private services ensuring speech and language therapy closed their face-to-face activities. The Private Centered analyzed started online therapy in 21.03.2020 with a speech and language assessment, in April they also started therapeutic activities and continue delivering, most of the time, online speech and language therapy even now, based on the results obtained and on the fact that beneficiaries ask for online speech and language therapy.

From the total 37 beneficiaries of the SLT Center, 20 entered the online speech and language therapy, while the other 17 left the center and ask for face-to face SLT therapy in other private or public services.

Figure 1. Graphical representation of SLT therapy at the beginning of the pandemic situation.

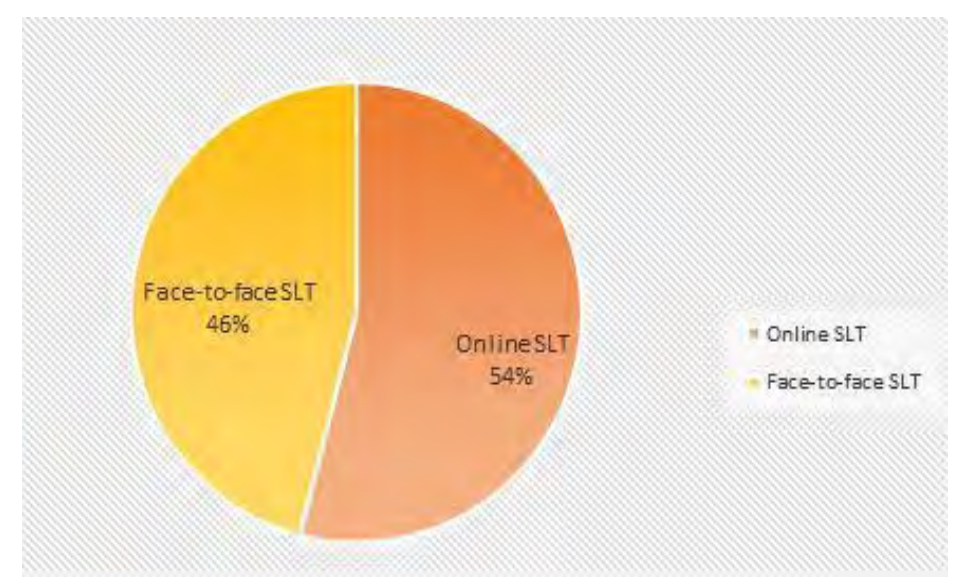

The 20 (54\% from the Center's beneficiaries) beneficiaries of the online therapy came into online therapy as follows: 9 children, started in April 2020 (immediately after the centered offered this possibility), after a three weeks break, all of them diagnosed with mild to moderate speech and language disorders, 6 children in May, after parents understood that pandemic situation prologues for and an indefinite period of time and in June other 5 children, at the end of the school year, when parents understood that during the almost 3 months of absence from SLT therapy children really need to restart it. 
The composition of the diagnosis of the 20 beneficiaries of online SLT is as follows: 5 children with phonologic and articulation disorder, 6 children with reading and writing disorders, 2 children with stuttering, 4 children with speech and language delay and 3 children with speech and language disorders secondary to the autism spectrum disorder.

The other children 17 (46\%), either stopped all therapy sessions or began therapy in other centers that organized onsite/face-to-face therapeutic sessions after the lockdown period of time.

The group of the 17 children who did not accept online therapy is composed from the following diagnosis: 10 children with speech and language disorders secondary to the autism spectrum disorder, 5 children with speech and language delay and 2 children with reading and writing disorders.

At this present moment, in March 2021, at one year distance the SLT center offers SLT services exclusively online, both assessment and therapy and the number of cases asking directly for online therapy is increasing daily (in March 2021, N=31).

\subsection{Focus-Group study results}

Based on the question presented on the methodology section, discussions were actively between the therapist, the parents and the children.

The most relevant data of the focus-group are included in the following table.

Table 1. Results of the focus-group.

\begin{tabular}{|c|c|c|c|}
\hline & Parents & Children & Therapists \\
\hline $\begin{array}{l}\text { 1. Do you appreciate as } \\
\text { useful the online speech } \\
\text { and language therapy? }\end{array}$ & $\begin{array}{l}\text { All } 3 \text { parents consider it useful and } \\
\text { are happy with the decision to } \\
\text { have accepted online therapy }\end{array}$ & $\begin{array}{l}\text { All } 3 \text { children are very } \\
\text { happy with this type of } \\
\text { therapy and they } \\
\text { consider it helpful. }\end{array}$ & $\begin{array}{l}\text { Yes, in special situations only (all } 3 \\
\text { therapists underlined this). }\end{array}$ \\
\hline $\begin{array}{l}\text { 2. Do you prefer online } \\
\text { SLT over onsite SLT? }\end{array}$ & $\begin{array}{l}2 \text { parents definitely prefer onsite } \\
\text { therapy over the online one. } \\
1 \text { parent consider online therapy } \\
\text { very useful due to the fact that it } \\
\text { reduces a lot his travelling costs }\end{array}$ & $\begin{array}{l}\text { All children prefer online } \\
\text { therapy and underline } \\
\text { this aspect. }\end{array}$ & $\begin{array}{l}1 \text { therapist declared that yes she } \\
\text { prefers this type of therapy, } \\
\text { especially in this pandemic situation } \\
2 \text { therapists declared they do not } \\
\text { prefer it at all }\end{array}$ \\
\hline $\begin{array}{l}\text { 3. Do you want to } \\
\text { continue (as necessary) } \\
\text { the online SLT? }\end{array}$ & $\begin{array}{l}\text { All parents are willing to continue } \\
\text { online therapy as necessary. }\end{array}$ & $\begin{array}{l}\text { Children even prefer this } \\
\text { type of therapy over the } \\
\text { onsite one. }\end{array}$ & $\begin{array}{l}1 \text { therapist underline that she wants } \\
\text { this type of therapy just in pandemic } \\
\text { situation } \\
2 \text { therapists are ready to offer it } \\
\text { based on the demand }\end{array}$ \\
\hline $\begin{array}{l}\text { 5. Please provide us } \\
\text { other info you consider } \\
\text { relevant. }\end{array}$ & $\begin{array}{l}\text { "The online SLT therapy was the } \\
\text { only stable educational aspect my } \\
\text { child benefit from in this period" } \\
\text { (underlined one parent). }\end{array}$ & $\begin{array}{l}\text {-"I really like it" } \\
\text { (confessed one child); } \\
\text {-"I hope we will continue } \\
\text { online therapy" (said } \\
\text { another child). }\end{array}$ & $\begin{array}{l}\text { "I learned a lot in this period" (said a } \\
\text { therapist). } \\
\text { I hope we will combine online } \\
\text { therapy with the onsite one, in } \\
\text { future, after the pandemic period } \\
\text { stops (said another therapist). }\end{array}$ \\
\hline
\end{tabular}




\section{Discussions and conclusions}

Based on these dates we can build the following profile of the online SLT beneficiary: children with parents familiar with technologies, who understand that the pandemic situation is not at all time limited and who are ready to help their children no matter the situation and the efforts they have to engage.

This profile of the online SLT beneficiary places this type of therapy in the family based approaches and underlines once again the importance of family support during the SLT intervention.

Online speech and language therapy must be considered and must be developed in the future. Before online speech therapy starts, the following factors should be considered: age, type of speech-language disorders, severity of disorders and cognitive ability including attention (Jung et al. 2020). New platforms for speech and language therapists need to be created and new training for specialists and for parents need to be delivered in the future.

\section{References}

American Medical Association. (2018). Issue brief: Interstate medical licensure compact. Retrieved from https://www.ama-assn.org/

Bodea Hațegan, C., Talaș, D. (2020). Ghid Practic de Organizare a Activităților Online (Practical Guide to Organise Online Activities), Colecția Terapia Tulburărilor de Limbaj şi de comunicare, Presa Universitară Clujeană, p. 115, ISBN: 978-606-37-0978-4, www.editura.ubbcluj.ro/bd/ebooks/pdf/2829.pdf.

Constantinescu G, Theodoros D, Russell T, Ward E, Wilson S, Wootton R. (2011). Treating disordered speech and voice in Parkinson's disease online: a randomized controlled non-inferiority trial. Int J Lang Commun Disord 201; 46:1-16.

Eslami Jahromi M, Ahmadian L. (2018). Evaluating satisfaction of patients with stutter regarding the tele-speech therapy method and infrastructure. Int J Med Inform 2018;115: 128-33.

Harrison, D. (2011) - Speech Language Clinicians Connect with Telepractice. Retrieved from https://thejournal.com/articles/2011/02/02/speech-language-clinicians-connect-withtelepractice.aspx

Jung S.-I.; Lim S.; Jo E.; Sim H.S.; Sung J.E.; Kim Y.T. (2020). The Efficacy of Telepractice Intervention for Children \& Adolescents with Speech, Language \& Hearing Impairments: A Meta-Analysis. Communication Sciences and Disorders vol. 25, no. 4, pp. 976 - 986.

Kraljević, J. K., Matić, A., \& Dokoza, K. P. (2020). Telepractice as a Reaction to the COVID-19 Crisis: Insights from Croatian SLP Settings. International journal of telerehabilitation, 12(2), 93-104. https://doi.org/10.5195/ijt.2020.6325

Kully D. (2000). Telehealth in speech pathology: applications to the treatment of stuttering. J Telemed Telecare 2000;6 Suppl 2:S39-41.

Marcin JP, Shaikh U, Steinhorn R H. (2016). Addressing health disparities in rural communities using telehealth. Pediatr Res 2016; 79:169-76.

O'Brian S, Smith K, Onslow M. (2014). Webcam delivery of the Lidcombe program for early stuttering: a phase I clinical trial. J Speech Lang Hear Res 2014; 57:825-30.

Talaş, D., (2015). On-line Speech and Language Therapy, Revista Română de Terapia Tulburărilor de Limbaj și Comunicare-RRTTLC, Nr. 1, ASTTLR, Cluj-Napoca, p.34-40, ISSN: 2457-9262.

Trifu, R. N., Münch, H., Kleer, F., \& Mészáros, É. (2018). Telepractice in SLT. Results from an European survey. Book of Abstract. 10th CPLOL European Congress of Speech and Language $\quad$ Therapy, $226 . \quad$ ISBN $978-2-9552505-1-8$. http://www.cplolcongress2018.eu/en/content/abstracts/abstract.-book/abstract-book.html

Tucker J. K. (2012). Perspectives of speech-language pathologists on the use of telepractice in schools: the qualitative view. International journal of telerehabilitation, 4(2), 47-60. https://doi.org/10.5195/ijt.2012.6102

World Health Organization (2016). Global Health Observatory (GHO) data - Telehealth: Analysis of third global survey on e-health based on the reported data by countries. https://www.who.int/gho/goe/telehealth/en/ 


\title{
UPGRADING MOOC STUDENTS' ENGAGEMENT AND PARTICIPATION IN HUMANITIES-ORIENTED ONLINE COURSES: THE EXAMPLE OF THE MOOC BASED ON THE PROJECT “DETECT"
}

\author{
Jan Baetens, Roberta Pireddu, \& Frederik Truyen \\ Literary Theory and Cultural Studies, KU Leuven (Belgium)
}

\begin{abstract}
Massive Online Open Courses (MOOCs) have become a grounded reality and a stable concept in the distance education panorama with worldwide universities continuously creating and offering every year broad selections of online courses. Nevertheless, despite the many developments in terms of individual and distance learning approaches, it is indetermined if MOOCs can deliver effective pedagogical methods and tools suitable for the implementation of online courses in the categories of art and humanities as well as in creating environments that give equal space to the two complementary layers of distance learning and distant teaching. Consequently, also the development of a valid, and captivating e-learning experience able to effectively reach out to students of different backgrounds, creating an impactful learning community represents a challenge. This issue acquires certain relevance particularly in relation to the much-debated question around the most effective pedagogical methodology to deliver humanities-oriented knowledge in a distant learning context. This paper provides an overview of the educational and pedagogical formulas adopted for the creation of a MOOC on European Crime Fiction, currently being developed in the framework of DETECt - Detecting Transcultural Identity in European Popular Crime Narratives (https://www.detect-project.eu/) a project funded by European's Union Horizon 2020. The MOOC concept presented in the framework of this research concentrates on the development of mixed e-learning and e-teaching strategies, that leverages the application of pedagogical elements like social network and independent learning and combines them with users' engagement methods. On the one hand, this research aims to challenge the debate related to the effectiveness of teaching and learning a humanities-oriented subject in a distance learning environment. On the other hand, intends to recreate a vibrant learning community capable of broadening the academic research carried out by the project enabling the collaboration between the MOOC public and the researchers and teachers.
\end{abstract}

Keywords: E-learning, MOOC, learning community, online learning, e-teaching.

\section{Introduction}

This paper explores the instructional and pedagogical strategies utilized to create and deliver a MOOC on European Crime Fiction developed within the framework of DETECt - "Detecting Transcultural Identity in European Popular Crime Narratives" (https:/www.detect-project.eu/), a large collaborative project funded by European Union's Horizon 2020.

Over the last decade, MOOCs development and diffusion lead to a considerable improvement in the instructional methodologies and approaches used to enhance the distance learning experience, partially encouraging the overcome of the issue of the suitability of humanities subjects for online learning environments (Reichard, 2013). A consequence of this change of tendency can be recognized in the slight increase in the percentage of humanities MOOCs offered by Higher Educational Institutions (Shah, 2020). However, despite these recent educational and technological upgrowths the creation of humanities-oriented MOOCs still represents a challenge that involves not only the learning but also the teaching context (Limarev et al, 2020). The essential role played by e-teaching both in the instructional development of the distance learning ecosystem and in the creation of a learning network appears in fact still underrated and in need of gaining more attention by the leading MOOCs platforms. While elements such as scalability, user capacity, and distance learning methods were further developed, teachers and educators' functions received marginal attention and were left behind. (Blackmon, 2018). Besides, in this context also the question around the right educational methodology to deliver humanities online courses, that support students' interaction in a massive environment, is a debated issue (Kaplan \& Bornet, 2014). 
This research aims to design a learning environment based on a humanities subject where equal attention is given not only to distance learning and to the enhancement of the student's engagement but also to the distance teaching context and methods. This investigation also intends to fit into the still intense discussion revolving around the most impactful methodologies for delivering and teaching humanities-oriented MOOCs.

\section{The DETECt Project}

Funded by the European Union Horizon 2020 Research \& Innovation Program, DETECt
DETECt - Detecting Transcultural Identity in European Popular Crime Narratives (https://www.detect-project.eu/) is a combined initiative involving researchers and professionals from eighteen different European institutions. DETECt aims to investigate the contribution of European crime narratives in influencing the creation and representation of a European cultural identity. Through a broad series of cultural and educational initiatives, the project's intention is to bring the public's attention to the DETECt research outcomes fostering the dialogue between crime fiction enthusiasts and academia.

One of the vehicles that intend to lead to the dissemination of the research results and to the expansion of the DETECt learning community is represented by the creation of a MOOC on "Euro Noir: Transcultural Identities in European Popular Crime Narratives" (https://www.edx.org/course/euro-noirtranscultural-identities-in-european-popular-crime-narratives), designed and developed by six of the partner's institutions that collaborate to the project and that comprehend KU Leuven -which as member of the edX consortium manages the development process of the MOOC-, University of Bologna, University of Limoges, University of Debrecen, University of Bucharest, Aalborg University. The MOOC is based on two different educational purposes. On the one hand, it intends to create an environment where not only student interaction but also teachers' communication, especially during the development of the distance teaching approach, are emphasized. On the other hand, it aims to leverage the DETECt knowledge network in order to create a vibrant learning community: a purpose in line with the DETECt intention of promoting cultural diversity and intercultural dialogue around the topic of European Crime Fiction.

\section{Design and educational challenges of a MOOC on European crime fiction}

Although the educational and technological improvement in the online learning field allowed the acquisition of more sophisticated pedagogical methodology for the MOOCs' development, some elements that distinguish the MOOCs concept are still being considered the primary obstacles in the creation of valid humanities-oriented MOOCs (Kaplan \& Bornet, 2014 and Blackmon 2018). One of the basic characteristics of MOOCs, the "massive" component, is recurrently indicated as one of the most debatable due to the fact that the presence of a very broad and diverse audience represents a challenge for developing a MOOC in a sector such as the humanities that usually bases its classes on a low number of students (Blackmon, 2018). In this context, in fact, the "scale" element could affect the co-construction of knowledge hindering the students' interaction not only with the other students but also with the teachers (Blackmon, 2018). Also, it represents a challenge in relation to the student's assessment, which in learning environments based on a humanities subject cannot uniquely rely on an automatic grading system as normally can be observed in science MOOCs (Kaplan \& Bornet, 2014).

These challenges are further emphasized by the internal structure and pedagogical approach of some of the MOOCs leading platforms and emerged during the implementation of the MOOC based on the DETECt research project, hosted on the edX platform. EdX usually orients their courses on the xMOOCs model -based on the behaviorist theory of learning-. These are generally built using a static textbook structure that encourages independent learning but that also tends to hinder student interaction. In fact, the only interaction medium, which is represented by discussion forums, does not completely allow a fluid synergy among the participants since this component is presented more as a tool for asking questions than as a medium to boost users' discussion (Waller et al, 2019). Besides, as many other platforms, also edX does not offer equal space to the two equally essential layers of distance learning and distant teaching and does not guarantee support to the educators during the process of the content design. These elements represented the main challenges to the development of a MOOC whose main objectives were not only to encourage the creation of a learning community within the online course itself but also to build an environment that could support teachers in the creation of a coherent educational framework, essential for the knowledge delivery.

In order to overcome these issues, we adapted the design of the MOOC to our main educational purposes, operating on the two levels of distance learning and distance teaching. On the one hand, through a thorough design of the learning activities, we aimed to point to the need of different types of 
students by combining independent learning approaches with forms of social networks. This is intended to encourage students to go beyond the platform textbook structure and expand and apply their knowledge by navigating outside the platform. On the other hand, we integrated on the same edX platform elements belonging both to the $\mathrm{xMOOC}$ and the cMOOC models. This enabled the creation of a more flexible educational methodology that could also involve elements of participatory teaching.

\subsection{Distance teaching strategy}

In this context, one of the major elements of concern during the development of distance education environments is represented by the design phase of the learning structure, which implies teachers' and educators' commitments and collaboration in the creation of an impactful virtual environment (Markova et al 2017). In this context, students' satisfaction is in fact directly influenced by the educational structure of the distance learning environment as well as by educators' ability to manage knowledge delivery and interaction among the participants (Markova et al 2017). For this reason, teachers play a crucial role in the delivery of an engaging and coherent educational structure (El Emrani et al 2017). Consequently, it is necessary not only that they develop further expertise on adapting teaching methods to distance education environments but also that their role becomes fully recognized as essential in the delivery of a MOOC (Markova et al 2017). Distance learning and distance teaching should not only coexist and be equal elements of the same structure but their mutual communication should be allowed and maintained.

Teacher's training and teacher's communication represented the main challenge for the development of the online course based on the DETECt project since the edX platform used for the development of this MOOC does not offer valid support for the development of the aforementioned elements. In order to address this issue and enable both a smooth collaboration among the teachers and instructional design skills acquisition we have combined two different components:

1) A Moodle instance linked to the main DETECt web portal (https://www.detectproject.eu/portal/learning/) and utilized during the MOOC instructional design process as a content repository for the unique use of the teachers involved in the MOOC development. The platform was in fact used to gather the learning material and test it before it was included in the online course. The use of Moodle helped develop consistency in the content creation allowing teachers' remote communication and collaboration.

2) The e-teaching training was supported from the beginning of the designing process through the adoption of KU Leuven pedagogical and technical support. This resulted crucial in providing the teachers with further skills related to the creation and shaped of the environment in line with the learning goals of the project.

\subsection{Distance learning strategy}

Since the diffusion of the MOOCs concept, students' interaction and involvement within the distance learning environment constitutes the central element of many research studies (Markova et al, 2016). Some traditional characteristics of the e-learning contexts - such as the educational effectiveness of independent learning, the MOOCs' scalability, and learners' background diversity - have often been objects of critics and labeled as elements that would hinder knowledge acquisition. Although at the same time the benefits of distance learning cannot be denied -especially in extreme contexts such as during the COVID19 pandemic -, the debate around teaching and learning humanities subjects in a distance learning environment is still debated (Limarev et al, 2020).

Exploiting the many potentialities of a distance learning environment in order to create not only a coherent and effective learning experience but also a solid learning community was at the base of the development process that leads to the creation of the MOOC on "European Crime Fiction". From a distance learning point of view, the main goal was to challenge the main structure of the edX course based on the independent learning approach and to apply strategies of user engagement and social networking in order to enhance students' interaction and participation.

The MOOC based on the DETECt research project was designed as an environment where autonomous learning and interactive and participatory learning were equally balanced. In this regard the following elements were at the base of the DETECt MOOC's structure and approach:

- The use of a series of external ecosystems developed within the DETECt project, which comprehends: The DETECt Portal, a platform enriched with additional learning material, and the DETECt Atlas, a platform that allows students to explore European crime fiction using and playing with interactive maps.

- The use of interactive collaborative environments (e.g., Wakelet, MindMap) to allow social interaction and collaboration among the students.

On the one hand, the acquisition of these components and the parallel use of the edX platform's structure would enable students who prefer undertaking a learning path centered on individual studying to 
still acquire the right knowledge and skills for understanding and discussing European crime fiction. On the other hand, the presence of collaborative tasks, which include not only group discussion within the platform but also the interaction with further learning material outside the platform, would encourage students to go beyond the traditional independent learning trajectory.

\section{Conclusion}

The pedagogical and instructional approaches described in this paper and utilized for the development of a humanities-oriented MOOC on "European Crime Fiction" aimed to challenge the traditional MOOC structure highlighting not only the complementary role of distance learning and distance teaching within the same environment but also the possible interrelation between efficient e-teaching and students' satisfaction. The methodologies and strategies applied for the creation of this online environment represent the first step of this research study. This will be followed by a thorough investigation both of student's engagement and behavior during their learning process as well as the efficacy and consistency of the two parallel ecosystems dedicated on the one hand to distance learning and on the other hand to distance teaching with regards to the knowledge delivery and management.

\section{Acknowledgments}

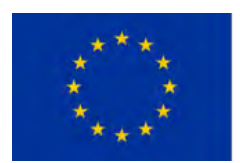

This project has received funding from the European Union's Horizon 2020 research and innovation programme under grant agreement No. 770151

The views and opinions expressed in this publication are the sole responsibility of the author(s) and do not necessarily reflect the views of the European Commission.

\section{References}

Blackmon, S., (2018). MOOC Makers: Professors' Experiences with Developing and Delivering MOOCs. International Review of Research in Open and Distributed Learning, Volume 19(4), 75-88.

DETECt, Detecting Transcultural Identity in European Crime Narratives. (2018-2021) Retrieved May $14^{\text {th }}, 2021$ from https://www.detect-project.eu/

El Emrani, S., El Merzouqi, A., Khaldi, M. (2017). The MOOC: Challenges and Opportunities from a Pedagogical View. International Journal of Computer Applications, Volume 162(9), 25-29.

Kaplan, F., Bornet, C. (2014). A PREPARATORY ANALYSIS OF PEER-GRADING FOR A DIGITAL HUMANITIES MOOC. Digital Humanities 2014: Book of Abstract. Retrieved May 14 ${ }^{\text {th }}, 2021$, from: https://infoscience.epfl.ch/record/200911? ln=en.

Limarev, P. V., Limareva, Y. A., Zinovyeva, E. G., Vikulina, V. V., Votchel, L. M., Grygoryants, I. A. (2020). Distance learning online technologies as a promising form of the educational process for the humanities. Journal of Physics: Conference Series, Volume 1691. Retrieved on 12th May, 2020, from: https://iopscience.iop.org/article/10.1088/1742-6596/1691/1/012188.

Markova, T., Glazkova, I., Zabarova, E. (2017). Quality Issues of Online Distance Learning. Procedia Social and Behavioral Sciences, Volume 237, 695-691.

Reichard, C., (June 4th, 2013). MOOCs face challenges in teaching humanities. Retrieved May 5th, 2021 from https:/www.stanforddaily.com/2013/06/04/moocs-face-challenges-in-teaching-humanities/.

Shah, D., (November 30th, 2020). By The Numbers: MOOCs in 2020. Retrieved May 11th, 2021, from https://www.classcentral.com/report/mooc-stats-2020/.

Waller, D. R., Douglas, K. A., Nanda, G. (2029). A Case Study of Discussion Forums in Two Programming MOOCs on Different Platforms. American Society for Engineering Education. Retrieved on 12th May, 2020, from: https://peer.asee.org/a-case-study-of-discussion-forums-intwo-programming-moocs-on-different-platforms.pdf. 


\title{
DIGITAL ENGINEERING: COMPETENCE ACQUISITION AND PROGRAM DEVELOPMENT AS AN OPEN CO-CREATION PROCESS
}

\author{
Vanessa Mai, Susanne Wolf, Paul Varney, Martin Bonnet, \& Anja Richert \\ Faculty of Process Engineering, Energy and Mechanical Systems, TH Köln (Germany)
}

\begin{abstract}
Dealing with the increasingly complex interrelationships in companies, technologies and markets requires engineers to have a holistic, systemic understanding of digital change. Future engineers need future skills and must be able to react to ever faster changing technical requirements by independently expanding their knowledge, developing (technology-based) solution strategies as well as designing, evaluating and communicating these with regard to social, ecological and cultural aspects and requirements. In order to integrate these future skills into existing curricula, study programs must be designed in such a way that they are permeable to continuous and agile adaptation in relation to new knowledge and new technologies. This process can only succeed if universities see themselves as open learning systems that promote co-creation processes among all university stakeholders.

The Faculty of Process Engineering, Energy and Mechanical Systems at TH Köln/University of Applied Sciences has recently recognized the resulting need for a transformation process in program development and has further developed the consecutive master's program "Mechanical Engineering/Smart Systems", in which agile learning environments and innovation spaces are created. However, the redesign and further development of modules is not enough. A holistic, systemic understanding in dealing with transformative technologies requires a cultural change in which lecturers and students shape the digital transformation on an equal footing. In a joint learning and research process, they iteratively and agilely test which competencies best prepare students for an increasingly digitalized workplace and which analog and virtual learning spaces this requires.

As part of the project "Digital Engineering - Competence Acquisition for Mechanical Engineers in the Digital Age", the faculty is currently implementing the Technology Area, a measure whose aim is to accompany these digital transformation processes at the faculty and to provide lecturers and students with the necessary freedom to experiment with new technologies in teaching. Here, subject-specific teaching and research concepts for the use of new technologies are to be developed and tested together in a co-creation process. The first concepts developed in the Technology Area as well as other Best Practices from the faculty will be presented in the paper. These include the Mixed-Reality-Game FutureING, the Serious Game Worlds of Materials and the development of a StudiCoachBot. In order to promote co-creation processes within and outside the university, a Digitalization Conference was held in May as part of the project to present innovative and forward-looking innovations in engineering education. The reflection of all of the presented initiatives is structurally anchored and professionalized by the House of Excellence in Engineering Education.
\end{abstract}

Keywords: Engineering education, digital transformation, digital engineering, co-creation processes, program development.

\section{Requirements for an engineering education fit for the future}

Dealing with increasingly complex contexts (companies, technologies, markets) requires engineers to have a holistic understanding of the challenges of digital transformation. They must combine technical and methodological competencies (STEM fundamentals) with specialized technical competencies (e.g., from mechanical engineering, computer science, etc.) and interdisciplinary competencies (VDMA 2019, VDI 2019). These competencies are often still addressed separately in engineering education, so that students specifically experience the acquisition of future skills (Stifterverband 2019a, Stifterverband 2019b) as an add-on rather than an integral part of their studies. Integrative teaching requires innovative formats of physical, virtual, and hybrid teaching and learning, as well as curricular structures that are sufficiently flexible to respond dynamically to changing job profiles. 
The Faculty of Process Engineering, Energy and Mechanical Systems at TH Köln - University of Applied Sciences is responding to these requirements with its project "Digital Engineering Competence Acquisition for Mechanical Engineers in the Digital Age" (TH Köln 2020), the aim of which is to initiate a culture of joint research and creation processes. As part of the project, the master's program "Smart Systems - Sociotechnical Systems" was developed, in which agile learning environments and innovation spaces enable future mechanical engineers to acquire competencies in the digital age (see section 2). In addition to that, a Technology Area is currently being implemented in which subject-specific teaching and research concepts for the use of new technologies are being developed and tested. The following section describes successfully tested and innovative teaching and learning concepts for the acquisition of employability skills that have been developed in the faculty and/or in the Technology Area. Both measures are elements of a transformation process at the faculty, which enables innovative and hybrid teaching and learning settings on a curricular and didactic level to foster the acquisition of employability skills in a co-creation processes between students and lecturers. This transformation process is also professionalized and structurally anchored in the House of Excellence in Engineering Education (HEEE) (see section 4).

\section{Master's program "mechanical engineering/smart systems": Program development as a co-creation process}

The master's program "Mechanical Engineering/Smart Systems" developed at the faculty and accredited in 2020 is characterized by a consistent competence and research orientation. For this purpose, competencies are bundled in competence clusters, which are trained in an integrated manner in experience-based and research-based learning settings. These competencies are thought of integrally and interconnectedly from the very beginning. The program is also closely interlinked with the BA program in mechanical engineering and also ensures the continuous acquisition and development of competencies across the degree programs (TH Köln 2020a).

The study program makes a valuable contribution to the digitalization of teaching and consistently implements so-called seamless learning - understood as learning across different contexts - in a model-building way by integrating analog and digital forms of teaching/learning in the modules by combining presence and AR/VR applications, offering time- and location-independent research and teaching, alternating formal with informal teaching formats, and networking different modules in the BA and MA study programs. Thus, the program makes a transformative contribution to the consistent networking of BA and MA study programs in curriculum development.

A special feature of the program development process presented here are also the initiated exchange and reflection formats in the curriculum workshop of the MA study program. In this bi-weekly format, peer-to-peer coaching and reflection on the modules of the participating professors and lecturers takes place on a regular basis. Within this framework, all courses, their didactic elements as well as their content and curricular integration with those of other colleagues are reflected upon. For the MA study program, it was also possible to recruit lecturers from other research-oriented faculties, thus advancing the interdisciplinary networking of relevant university actors at the curricular level. These initiatives in program development have a model-building effect for the programs of the entire university and especially for the other engineering faculties.

\section{FacING digitalization in the technology area: Contemporary competence acquisition in engineering education}

The Technology Area established at the faculty is a permanent, hybrid space where lecturers and students test new technologies. They can "check in" here with an idea for implementing technologies in teaching and develop subject didactics for using technologies in teaching. In this way, researching and teaching professors and staff, together with students, can bring their (research) expertise into teaching, both in terms of subject-specific methodology (real labs, empirical studies, etc.) and in terms of teaching-learning research (subject-specific didactic research questions). They are given freedom to conduct research, test new teaching/learning fields and the latest technologies. The results serve as teaching impulses in the project- and research-oriented modules. In the premises, demonstrators are made available by the faculty and in cooperation with other engineering faculties of TH Köln - University of Applied Sciences for use in teaching as a kind of "parcours". Currently, the Technology Area exists as a virtual space due to the Covid-19 pandemic. The construction of a container on campus is planned for the end of 2021 in order to also provide a physical space. The Technology Area currently includes a telepresence robot (Double III), a virtualizer, AR/VR glasses (HTC Vive, HoloLens) as well as a 360 Degree Camera and a Merge Cube. 
Innovative teaching concepts are being developed, shared and made visible in cross-faculty exchanges. The first best practices developed at the faculty and/or in the Technology Area are presented below. In addition, as part of the Curriculum 4.0 project, the first three-day "FacING Digitalization" conference was hosted at TH Köln - University of Applied Sciences in May 2021 (TH Köln 2021). Here, innovative and future-oriented technologies in engineering education were presented. In addition to university stakeholders and students, external experts and practitioners were also involved.

\subsection{Mixed-Reality-Game FutureING: AR/VR/MR technologies in engineering education}

Hybrid and digital learning worlds are playing an increasingly important role in education and offer opportunities for open communication, the mapping and support of individual learning processes, as well as networked learning independent of time and place. In the BA study programs Mechanical Engineering, Renewable Energies, Energy and Building Services Engineering, Mobile Work Machines and Rescue Engineering, the first-year compulsory course "Work Techniques and Project Organization" is offered at the faculty for approximately 800 students per year. This course was transformed from a classical lecture with seminar-based elements to a more future-oriented concept by integrating the mixed reality game FutureING in the winter term of 2020/21 (Richert et al. 2019). Using Augmented Reality (AR) and Virtual Reality (VR) technologies and incorporating reflection and feedback-oriented formats, digital learning worlds were created in which students can build subject-specific and interdisciplinary competencies and experiences together and individually as well as test themselves in different roles. FutureING integrates the existing components of the course with an analogous business game into a digital, game-based overall concept. In this way, the mixed reality game succeeds in making reflection-promoting and diversity-oriented formats scalable even for large numbers of participants.

As early as in the first semester of their engineering studies, students thus have the opportunity to experience the digital transformation in a production company. FutureING consists of interconnected game modules. When playing, students form virtual engineering offices, that are given the task of designing and optimizing the production processes of a robotics manufacturer in the AR part of the game. In the VR part, the groups of students enter their planned factories and solve occurring problems during a production cycle. In this process, students are trained to act in a technically sound manner when working on and solving complex problems, as well as communication and teamwork skills and project organization techniques, which are regularly reflected upon. By creating this experiential, immersive and hybrid learning environment, a learning atmosphere is created in which open exchange takes place, thought processes are stimulated and reflection on learning processes takes place.

With the mixed reality game FutureING, the faculty is trying to set new national and international standards in media and university didactics. The accompanying research taking place within this framework focuses on the effects of structural changes on learning success and thus provides a valuable contribution to university didactics. It puts the possibilities of improving teaching through the use of digital media on a solid data basis. For the mixed reality game, on the one hand, in-game data is collected to identify patterns in player behavior, and performance parameters on the required competencies are developed and operationalized. In addition, students' self-assessment of skill acquisition will be investigated concurrently (Varney et al. in press). Serious changes are expected both in the way students learn and work and in the levels of competence they achieve. Linked to this is the further development of examination formats that no longer test classical knowledge but make competencies visible in the sense of performance analyses.

\subsection{StudiCoachBot: Accompanying digital learning processes}

Competency-based teaching/learning settings thrive on systematic and process-oriented feedback so that students can ascertain their learning status and lecturers can steer learning processes. Since reflection and feedback processes are time- and staff-intensive, scaling them for large groups is challenging. Digital media and AI-based technologies can help make feedback more individualized, systematic, and process-oriented. They enable low-threshold, automated feedback and encourage self-coaching processes in preparation for face-to-face reflection sessions.

In this context, AI-based dialogical communication systems are being used increasingly in the context of higher education to provide professional support for students. Building on existing, curricularly anchored coaching formats at the faculty, reflection conversations will be made scalable in the future via the implementation of a Coachbot. Currently, a decision- and text-based StudiCoachBot is conceptualized and developed to deepen students' self-reflection processes on learning and working strategies in a coaching process (Mai \& Richert 2021). In such a process, concerns and goals are defined (e.g., dealing with exam anxiety, developing learning goals and/or strategies, clarifying team roles) in order to implement interventions based on these. These consist of, on the one hand, a structured coaching conversation that uses open-ended questions to deepen students' self-reflections and, on the other hand, 
materials in the form of summaries, videos, reflection tools such as self-assessment tests, and scaling and visualizations to develop goals.

Interaction with a coachbot cannot replace real-life reflection and feedback conversations between students and instructors, but it offers advantages: In AI-based interactions, the willingness to reveal something about oneself may be higher - especially for sensitive topics - because the systems are perceived by users as unbiased. This can lead to students identifying counseling concerns earlier on their own. In addition, AI-based offerings are a good preparation for having in-depth conversations with instructors, for which students can then formulate concrete concerns.

The coaching processes between StudiCoachBot and students are being researched concurrently as part of a PhD project (Mai \& Richert 2020). The StudiCoachBot is being developed within the framework of projects at the Cologne Cobots Lab and Cologne TraingING Center, is closely docked to the Technology Area, and is to be made available university-wide in the future. A suitable system architecture is currently being selected. A curricular anchoring in modules of the BA program in mechanical engineering - e.g. in preparation for reflection discussions with lecturers - is planned.

\subsection{Serious game worlds of materials: Game-based learning in engineering education}

Serious games combine learning situations from the field of education with games from the entertainment industry. These are games or game-like situations that do not primarily serve the purpose of entertainment, but instead focus on learning new skills and competencies. Learning content and learning tasks are integrated into the game world so that new skills can be taught and trained in a playful way. This type of digital exercise form contributes to students' competence enhancement through motivational drivers such as play instinct, fun, need for recognition, competitive spirit and ambition (Young et. al. 2012).

Worlds of Materials is a point-and-click adventure game for students in various engineering programs and those interested in materials science. The game takes student Nicole Nickel through ten parallel dimensions where she encounters different versions of her materials science professor. A mysterious man in black has been manipulating the professors in each of these worlds, keeping them from their assignments. To solve this, the player must use the knowledge gained from the ten chapters of the Fundamentals lecture series. The game design closely adheres to the curriculum, but repeatedly picks up the content of the previous chapters. The goal is to reach levels three (Apply) and four (Analyze) of Bloom's Taxonomy. In the spirit of Open Education, the game, like the lectures, is made freely available. For students of the various engineering sciences at the TH Köln - University of Applied Sciences, who take the elective subject materials science, there is the possibility to get bonus points for the exam by completing the game. However, this option is irrelevant for the game experience: It was explicitly designed to be played by students from other universities as well as by material science enthusiasts.

The game was developed between 2019 and 2021 by a small team of students and staff of the Cologne Game Lab (CGL). The team received technical support from staff members of the Institute for Materials Application (IWA). Since its release in 2021, the effectiveness of the didactic measure has been investigated in a joint research of the IWA and the CGL. The gamification approach can serve as best practice for similar developments in other subjects with regard to technology and didactics. In addition, the game won the German Computer Game Award for best serious game in April 2021.

\section{Structural anchoring of co-creation processes in the house of excellence in engineering education}

The digital transformation of work and everyday life has an impact on qualification goals, the design of teaching and learning formats, and the support of students inside and outside the TH Köln University of Applied Sciences. With their contributions to teaching, research and program development, the measures presented here explore what it means when universities see themselves as open learning systems in which co-creation processes of all university actors are promoted in order to create a framework for individualized study design, personalized learning on the basis of intelligent systems, and a stronger link between research and teaching.

With the measures and processes presented here for the creation of agile learning environments and innovation spaces for prospective mechanical engineers, the faculty at the TH Köln - University of Applied Sciences has taken on a pioneering role and is actively involved in university development processes based on co-creation. In particular, it benefits from the measures implemented in teaching for cross-context and interdisciplinary learning, in which interdisciplinary structures are built up and hierarchical constellations, for example between lecturers and students, are dismantled for structural reasons. Systemic formats such as peer teaming of lecturers, agreement on common basic curricular 
elements and the development of a common language can significantly promote the networked development of hybrid curricula and the further development of curriculum workshops.

The House of Excellence in Engineering Education (HEEE) (TH Köln 2019) professionalizes and structurally anchors the regular reflection on the implementation of these principles within the framework of study program development processes. It bundles the diverse activities in the area of teaching across all study programs at the faculty, promotes the university-wide networking of actors in teaching and research and enables the transfer of innovative teaching concepts to the university. The foundation of the HEEE is the combined integration of professional, methodical and social competences in the study programs. In coaching and training sessions, students and lecturers can continuously reflect on their team and work processes, formulate lessons learned from project work and develop quality patterns for future tasks. Across the common teaching and learning areas of the faculty lie common research topics, which are worked on within the framework of the Scholarship of Teaching and Learning.

In the next step, more consultation activities will be initiated within the framework of the HEEE and the Technology Area in order to develop further teaching/learning innovations together with lecturers and students. Other planned exchange formats to initiate co-creation processes include a Masters Conference in September 2021, at which master's students from the Mechanical Engineering/Smart Systems program will present current research work, and the Faculty Research Day planned for October 2021.

\section{References}

Mai, V. \& Richert, A. (2020). AI Coaching: Effectiveness factors of the working alliance in the coaching process between coachbot and human coachee - an explorative study. In I. Gómez Chova \& A. López Martínez (Eds.), EDULEARN20 Proceedings (pp. 1239-1248). doi: https://library.iated.org/publications/EDULEARN20 : IATED Academy.

Mai, V. \& Richert, A. (2021). StudiCoachBot an der TH Köln - Reflexionsprozesse KI-basiert begleiten. fnma Magazin - Forum neue Medien in der Lehre Austria (01/2021), pp. 21-23. March 26, 2021, from: https://www.fnma.at/publikationen/magazin.

Richert, A., Mai, V., Mengen, H., Wolf, S. (2019). Mixed-Reality-Games in Engineering Education. In A. Cardoso, M.T. Restivo (Eds.), Proceedings of the 2019 5th Experiment@, International Conference (exp.at'19). Online Experimentation (pp. 365-370). Funchal: Institute of Electrical and Electronics Engineers (IEEE).

Stifterverband für die Deutsche Wissenschaft e.V. (2019a). FutureSkills: Welche Kompetenzen in Deutschland fehlen. Diskussionspapier 1. March 29, 2021, from: https://www.stifterverband.org/medien/future-skills-welche-kompetenzen-in-deutschland-fehlen.

Stifterverband für die Deutsche Wissenschaft e.V. (2019b). FutureSkills: Strategische Potentiale für Hochschulen. Diskussionspapier 3. March 29, 2021, from: https://www.stifterverband.org/ medien/future-skills-strategische-potenziale-fuer-hochschulen.

TH Köln (2019). Organisationsstruktur. House of Excellence. March 29, 2021, from: https://www.thkoeln.de/anlagen-energie-und-maschinensysteme/organisationsstruktur_71325.php.

TH Köln (2020). Curriculum 4.0: Kompetenzerwerb für MaschinenbauingenieurInnen im digitalen Zeitalter. March 29, 2021, from: https:/www.th-koeln.de/anlagen-energie-und maschinensysteme /curriculum-40-an-der-fakultaet-fuer-anlagen-energie--und-maschinensysteme_80248.php.

TH Köln (2020a). Mechanical Engineering (Master's program). March 29, 2021, from: https://www.thkoeln.de/en/academics/mechanical-engineering-masters-program_7778.php.

TH Köln (2021). FacING Digitalization: Innovative and Contemporary Education in Engineering Sciences. March 29, 2021, from: https://www.th-koeln.de/anlagen-energie-und-maschinensysteme/ faceing-digitalization_82140.php.

Varney, P., Mai, V., Richert A. (in press): Mixed-Reality-Game FutureING: Research on effectiveness. In: European Journal of Engineering Education. Special Issue: Online Laboratories in Higher Engineering Education: Solutions, Challenges, and Future Directions from a Pedagogical Perspective.

VDMA (2019). Ingenieurinnen und Ingenieure für Industrie 4.0. Impuls-Studie. München.

Verein Deutscher Ingenieure e.V. (VDI) (2019). Ingenieurausbildung für die digitale Transformation. Zukunft durch Veränderung. VDI-Studie April 2019. March 29, 2021, from: https://www.ftinformatik.de/pdf/FTIV-1901-A-02m-VDI-Studie-Ingenieurausbildung-DigitaleTransformation.pdf.

Young, M. F., Slota, S., Cutter, A. B., Jalette, G., Mullin, G., Lai, B. et al. (2012). Our Princess is in Another Castle. A Review of Trends in Serious Gaming for Education. In: Review of Educational Research 82 (1), pp. 61-89. 


\title{
ANALYZING INDIGENEITY IN ACADEMIC AND ARCHITECTURAL FRAMEWORKS
}

\author{
Tatiana Estrina, Shengnan Gao, Vivian Kinuthia, Sophie Twarog, Liane Werdina, \\ \& Gloria Zhou \\ Department of Architectural Science, Ryerson University (Canada)
}

\begin{abstract}
While the Truth and Reconciliation Commission of Canada fosters agency for Indigenous Canadians, this mandate like others, attempts to Indigenize an existing colonial system. The acknowledgement of the Indigenous experience within academic institutions must begin with a deconstruction of educational frameworks that are enforced by pre-existing neo-colonial policies and agendas. The colonial worldview on institutional frameworks is rooted in systemic understandings of property, ownership and hierarchy that are supported by patriarchal policies. These pedagogies do not reflect Indigenous beliefs or teachings, resulting in an assimilation or dissociation of Indigenous members into Western-centric educational systems. Addressing this disconnect through Indigenizing existing institutional frameworks within state control favours a system that re-affirms settler-societies. The tokenization and lack of Indigenous participation in the decision-making process reinforces misinformed action towards reconciliation. decentralized. The case studies explored emphasize the rediscovery of an authentic culture-specific vernacular, facilitation of customs through programme, and the fundamental differences between Indigenous and colonial worldviews. The critical analysis of these emerging academic typologies may continue to inform future architectural projects while fostering greater responsibility for architects and positions of authority to return sovereignty to Indigenous communities and incorporate design approaches that embody Indigenous values. This paper will propose the decolonization of academic frameworks to reconstruct postcolonial methodologies of educational architecture that serve Indigenous knowledge and agency.
\end{abstract}

Keywords: Indigenous, decolonization, architectural design, indigenizing education.

\section{Introduction}

Canada's colonial history must be contextualized before making the case for decolonizing its academic institutions. Described as settler colonialism, Canada's formation and occupation is "a unique form of imperialism that re-settled large populations of European settlers onto Indigenous territories to help facilitate the dispossession of Indigenous lands and waterways [for] the financial wealth of natural resource extraction" (Manuel \& Derrickson, 2016). As a result of Western land occupation, Indigenous people were stripped of their cultures, ideologies, and livelihoods through reservation land parcelization and the assimilative policy of the Indian Act (1876). Its lasting effects contribute to the intergenerational and cultural genocide inflicted on these communities. Settlers understand land as property to be acquired, whereas the Indigenous vision finds common roots in a relationship to the land as sacred living ancestors or as places of origin that cannot be owned by an individual. Indigenous ways of knowing extends to both the natural and built environment as settings of generational lived experiences which is central to understand what they learn and how they approach education (Chakasim, 2010). Therefore, decolonizing academic institutions, frameworks, and environments must include a decentralized approach rooted in action-based, and post-colonial methodologies to better serve the education of Indigenous communities. For this transition to occur, there must be given an opportunity for self-determination either through leveraging Indigenous knowledge and/or by centering local community participation and agency in the conception of the architecture in their communities. 


\section{Decolonizing academic institutions}

For Indigenous peoples, culture is an element retained "despite interaction with the West" and therefore, is a form of resistance and self-identity (Castagno \& McKinley, 2008). Assimilation into western-centric educational systems proves to be detrimental due to the intrinsic desire to retain the ontologies that separate Indigenous peoples from the rest of the population (Castagno \& McKinley, 2008). Furthermore, academic institutions have assimilated generational Indigenous teachings with deep ancestral roots and ideologies that subsequently remove Indigenous education from historical teachings and therefore reinforce paternalistic authority and creates boundaries in education (George, 2019). With lack of resources, participation, funding, and academic preparation, many generations of Indigenous academics have been failed by a system that in its origin is constructed in neo-colonialist beliefs (Frawley, Larkin, \& Smith, 2017). However, academic institutions within state control lend themselves to favor indigenization of this existing framework, rather than demolishing the neo-colonial, settler-society reaffirming system rather than rebuilding a system that values Indigenous people's land and rights (George, 2019). It is also crucial for community members to be given prominent roles of involvement within academia, and to be viewed as equals in the development of the curricula. By utilizing chief and parental input, educational institutions can tailor and refine systems to become more relevant and appropriate for the cultural groups.

These systemic changes would involve addressing the increase of diversity in educational avenues and increase participation of elders and community members in school activities. Furthermore, responsive schooling facilities must cater towards the physical and cultural environment in which they are situated (Castagno \& McKinley, 2008). The Indigenization of academia plays into systemic roots of traumatic and oppressive policies. This is identified as a form of "tokenization" within many Canadian institutions in which professors or students of Indigenous heritage are recruited to meet quota and indigenize the academic population. This contributes to a sense paternalism of neo-colonialism with a multi-cultural agenda that benefits the institution (George, 2019). Although these educational policies attempt to integrate Indigenous awareness, they do not validate the need for Indigenous teaching and the protection of Indigenous academics, teachings, and land. A notable hesitation for Indigenous academics is this dependence on state. As most Collegiate institutions are heavily state controlled, they maintain a generational affirmation of oppression and control towards Indigenous people (George, 2019). To bring about an intergenerational healing of these injustices within a Canadian framework, policy driven academic institutions must revert to decolonization before indigenizing through qualitative and action based postcolonial policies separate from political agenda (George, 2019). The design of academic spaces that reconstruct educational frameworks utilizing community collaboration addresses the reinstatement of Indigenous autonomy.

\section{Leveraging indigenous knowledge}

Indigenous society believes knowledge is intrinsic to the being who is born complete; as a descendant and ancestor within their own lineage, each individual holds knowledge of "the past, present, and future" (Cardinal, 2012). Inversely, Douglas Cardinal (2012) observes that the hierarchical worldview positions knowledge as separate from the being who seeks it and is validated by those revered as more knowledgeable within institutional frameworks. These contradicting worldviews and their conceptualizations of one's relationship to knowledge result in differences in architecture's engagement with education and how the built environment facilitates learning. Reverence for knowledge, from an Indigenous worldview, guided Cardinal's approach for the Oujé-Bougoumou Village in Northern Quebec's James Bay region (Cardinal, 2012), ensuring the embodiment of Indigenous knowledge into the governing principles of the village's buildings (Figure 3).

Douglas Cardinal (2012) emphasized that his technical expertise and Indigenous knowledge from his Blackfoot Métis heritage did not qualify him to dictate the needs of the Oujé-Bougoumou community at the onset of this project. To prevent the colonial impact caused by determination through an outsider's perspective, Cardinal involved the community's ideas, way of life, and vision into the ideation of the project through a comprehensive consultation process (Williams, 2013). This gave rise to two main objectives, upholding prominent facets of the "life, world-view, values and rituals of the Cree" and following the long-established precedent of a Cree village layout with building expressions of traditional Oujé-Bougoumou homes (2013). For first objective, the heating method emphasized fundamental values of a cyclical economy by incorporating a large waste-product-fueled furnace that would burn by-products from nearby sawmills and distribute warmth through a network of below-grade pipes (Stevens \& Reid Acland, 1999, p. 8). This innovative approach demonstrates sensitivity towards the environment through waste reduction and ensured longevity by attempting to preserve the wellness of the environment for 
future generations. Each building in the community was thus a product of clear articulation of the community's desires, ensuring self-determination not only through formal built expression, function, and use. By thoroughly consulting all residents, regardless of their age and role in the community, the belief of each individual's capability and intrinsic knowledge applicable to the formation of their lived environment was observed.

The masterplan significantly valued the relationships buildings would have to one another and to their physical site. Such is the case with the Waapihitiiwewan school, which intentionally inhabits the spiritual interstitial space amid "home and the world" to gesture towards the future of its students who may pursue higher education and professional careers (Williams, 2013). Within the school, shoe storage by the entrance promotes the wearing of traditional moccasins while indoors because of the sandy site, which went a long way towards ensuring the continuation of the cultural practice of removing outdoor shoes before entering buildings (Stevens \& Reid Acland, 1999). Additionally, the proposed design provided a view of Lake Opemiska to every building on the site which, through its continual visualisation, established its central relationship to the village (Williams, 2013). These considerations, at different scales of design and planning, demonstrate a commitment to the embodiment of Indigenous knowledge in how this village would serve the community as well as the natural environment, strengthening the presence of site in the community's daily experience. The aligning of cultural practices and views with the ways in which the built form facilitates daily life significantly facilitated autonomy in determining how community needs would be addressed while preserving and reflecting their world views.

\section{Incorporating indigenous community participation and agency}

The Seabird Island School was designed by John and Patricia Patkau in 1988, located on the North end of the Fraser Valley in Agassiz, British Columbia (Figure 2). Its significance derives from the school's remote context and culture, environmental forces, and building technology (Frampton, 1997). The leading principle behind the design was to provide an educational space for the community where cross-cultural and intergenerational relationships can be fostered to resist the loss of tradition and language. Moreover, Patkau valued Indigenous knowledge to inform and project how the building may accommodate for multiple generations to follow (The Canadian Architect, 1993). Its architecture prioritized the ownership and agency of the Coast Salish Community which compelled the rediscovery of an authentic culture-specific vernacular to bring Indigenous identity to the forefront of the project (Chakasim, 2010). Formally, it looked to architectural elements such as the roof, columns, and walls for implied cultural meaning rather than representation through mimetic expressions and/or pastiche (Gruft, 1992).

The interactive consultative process fostering a co-designing relationship between Patkau Architects and the client became integral to the success of the school. The facility was funded by the federal government, however members of the Seabird Island School Band echoed concerns regarding the characteristics of educational facilities. Students in the area described how the organization and material language of schools resonated with their negative experiences associated with the residential school system (Patkau, 2018). In an effort to break away from the typical form of educational facilities, the laminated timber frame and cedar shingles drew from a deep respect for the manual construction, and totemic elements associated with the Pacific Northwest vernacular (Chakasim, 2010).Notably, the school is the largest edifice on the reserve thus its spatial planning was designed to accommodate community events while the educational spaces integrated farming gardens to pass on agricultural skills to the next generation. Formally, the design responds to the site by using large sculptural volumes on the North side to mediate environmental factors such as harsh winds by diverting it away from the front of the building (The Architectural Review, 1992).

The construction of the school was significant as it provided a skills-learning opportunity for members of the Band; it placed the trust and responsibility on the community to build the school on their own. Its tectonics expressed the capabilities of modern technology coupled with Indigenous traditions of construction as a cooperative approach. The construction was informed by traditional Salish ways of building in heavy logs although it was hybridized to suit its complex formal gestures (The Canadian Architect, 1993). Patkau was committed to developing a framing model and repetitive structural system that aligned with the technical capacity of the community. Due to the project's complex geometry and the limitations of 2D drawings, the community frequently referred to a physical framing model to understand, scale and cut the structural members on site (Patkau, 2018). Although this is unconventionally practiced in Western construction, the project "reveals an Aboriginal world view through a type of hand-crafted construction exercise prompting a cultural response," (Chakasim, 2010). The Seabird Island School is also referenced as a catalyst for new construction of schools in the region being built by and for Indigenous communities (Canty, 1992). 


\section{Retaining indigeneity and authenticity}

Although the previous projects aim to engage and design Indigenous spaces, the final case study is challenged by decentralized techniques within the framework of urban contexts, technical circumstances, and city-enforced building laws. The Centre for Native Child and Family Services intends to "create a place that would reconnect urban aboriginals with nature in the heart of the city and project a bold visual presence for the First Nations community" (Archdaily, 2011) (Figure 3). However, the building's location in Toronto's downtown core limits design possibilities and encourages more regular typologies based off zoning and code requirements. This questions whether Indigenous architectural design should integrate within the existing structure or if city planning systems should be decentralized. These discussions do not only criticize the Centre for Native Child and Family Services from a designer's perspective, but they also question the flexibility of Toronto's urban context. Programmatically, there are very few features that point to the Indigenous practices that the building intends to represent. Rather, the spatial organizations are more reminiscent of typical state-influenced building standards. Neglecting to create a design dialog with the natural and urban contexts, the building reverts to tokenizing various stereotypically Indigenous elements. This is exemplified in interior, where a rounded 'longhouse' room marks the only deviation from a typical floor plan and glazing features animal etchings. The roof, which serves as the primary natural space, it incorporates an igloo-like dome and fire pit, both of which alludes to mimetic forms of Indigeneity.

Failing to address the colonized aspects of design can enforce existing traumas and hesitations for Indigenous communities that will further enforce social barriers in urban contexts (Frawley, Larkin, \& Smith, 2017). Hirini Matunga suggests Indigenous architecture should be one unique architectural typology, rather than an adoption of Westernized building ideologies (Matunga, 2018). He emphasizes an awareness towards the evolution of Indigenous architecture and its correlation to modern design due to the impacts of colonization (2018). The design of the Seabird Island School presents a more successful design which in its sensitivity to Indigenous ideologies and most significantly, inclusion of community while the Oujé-Bougoumou Village emphasizes the linkage of residents to their living environment through visual and functional means (The Canadian Architect, 1993; Stevens \& Reid Acland, 1999). Despite these three precedents sharing the opportunity to create space for Indigenous communities, which is of value and necessity, not all have a profound understanding of Indigenous architectural typology and community demand. Most importantly, there is a reverence for the cultural and sacred history of their colonized land.

\section{Conclusion}

Along with more socially and circular-driven issues that Indigenous communities face in education, the lack of Indigenous culture and reverence present in architectural practice and the conception of space acts as a barrier to reconciliation and decolonization of land. To support facilities and overall education more adequately for Indigenous students, state-enforced-institutions within architectural practice must commit to decolonizing existing frameworks that reinforce existing trauma and obstruct pathways for rectification (George, 2019). Ultimately, existing academic facilities and architectural spaces exist on land that holds Indigenous value and meaning (George, 2019). The active analysis of these emerging typologies may continue to inform future projects and instigate a deeper understanding of the architect's responsibility towards returning sovereignty to these communities.

\section{Acknowledgments}

Although providing opinions on this subject, none of the authors of this paper belong to the cultural and racial groups discussed. Rather, our paper proposes an open discourse on the issues and themes educational architecture faces with respect to addressing indigeneity through evidence and precedent. We will discuss how designers (both Indigenous and non-Indigenous) have addressed the needs of these populations through their work, and the implications of such precedents. We would like to thank Kenneth J. (Jake) Chakasim for his thoughtful insights into the Indigenous perspectives on institutional architectures 


\section{References}

Aborginal Education Council. (2014). Land Acknowledgement. Retrieved from Aboriginal Education Council: Aborginal Education Council Retrieved from May $16 \quad 2021$ https://www.ryerson.ca/aec/land-acknowledgment/

Archdaily. (2011, March 17). Native Child and Family Services of Toronto / Levitt Goodman Architects. Retrieved May 162021 from Archdaily: https:/www.archdaily.com/120391/native-child-andfamily-services-of-toronto-levitt-goodman-architects

Canty, D. (1992). Aerodynamics School. Progressive Architecture 73(5), 142-147.

Cardinal, D. (2012, March 9). Different Worldviews: Aboriginal Centres in Canadian Universities. (Carleton University) Retrieved May 162021 from YouTube: https://www.youtube.com/ watch? $=$ D2wXToJumug\&ab_channel=CarletonUniversity

Castagno, A., \& McKinley, B. B. (2008). Culturally Responsive Schooling for Indigenous Youth: A Review of the Literature. Review of Educational Research, 78(4), 941-993.

Chakasim, K. J. (2010). Re-contextualiing the architectural learning experience: the alternative perspective (PART V). Toronto: Ryerson University.

Frampton, K. (1997). Patricia and John Patkau. Tecto-Totemic Form: A Note on Patkau Associates. Perspecta 28, 180-189.

Frawley, J., Larkin, S., \& Smith, J. A. (2017). Indigenous Pathways, Transitions and Participation in Higher Education. Singapore: Springer Open.

George, C. T. (2019). Decolonize, then Indigenize: Critical Insights on Decolonizing Education and Indigenous Resurgence in Canada. Antistasis, 9.

Gruft, A. (1992). Seabird Island Community School, Agassiz, B.C. Patkau Architects. In The Canadian Architect 37(1) (pp. 14-23).

Manuel, A., \& Derrickson, R. (2016). Unsettling Canada: A national wake-up call. Toronto, ON: Between the Lines.

Matunga, H. (2018). A discourse on the nature of Indigenous architecture. Lincoln: Lincoln University.

Ottmann, J. (2017). Canada's Indigenous Peoples' Access to Post- secondary Education: The Spirit of the 'New Buffalo'. In Indigenous Pathways, Transitions and Participation in Higher Education (pp. 95-117).

Patkau, J. (2018, October 26). Wood at Work 2018 Keynote. (U. o. Toronto, Interviewer) Retrieved May 162021

Stevens, C., \& Reid Acland, J. (1999). Building sovereignty: the architectural sources of Ouje-Bougoumou. Canadian Issues, 21, 124-142. Retrieved May 162021 from http://ezproxy.lib.ryerson.ca/login?url=https://www-proquest-

com.ezproxy.lib.ryerson.ca/scholarly-journals/building-sovereignty-architectural-sourcesouje/docview/208699154/se-2?accountid=13631

The Architectural Review. (1992). Ancestral Forms. The Architectural Review, 43-45.

The Canadian Architect. (1993). A Conversation with John Patkau. In The Canadian Architect 38(5) (pp. 22-28).

Truth and Reconciliation Commission. (2015). Honouring the Truth, Reconciling for the Future Summary of the Final Report of the Truth and Reconciliation Commission of Canada.

Williams, M. (2013, October 15). Douglas Cardinal and the Oujé Bougoumou Community. Vault Review. Retrieved May 162021 from https://vaultreview.wordpress.com/2013/10/15/douglas-cardinal-andthe-ouje-bougoumou-community-written-by-marianne-williams-carleton-university/\#_ftnref 


\title{
SOCIAL SKILLS TEACHING PROCEDURES IN ASD-HF
}

\author{
Maria Carla Ricci, Francesca Di Carmine, Antonia Bosco, Agnese Lombardi, \\ \& Alessandro Frolli \\ DRC - Disability Research Centre, University of International Studies of Rome, 00147 Rome (Italy)
}

\begin{abstract}
Introduction. Autism Spectrum Disorders (ASD) refer to a heterogeneous group of clinical disorders that share a qualitative alteration of Social/Communication and an atypia of the Repertoire of Activities and Interests with poor cognitive flexibility and a tendency to perseverance (APA, 2013). The Core Deficit is represented by a fall in Social Reference with a consequent alteration of Mentalization Processes and Social Skills.

Materials and Method. In this study, three Social skills teaching procedures are compared: Role Play and Instructional Feedback (RPIF), Self-Videomodeling (SVM) and Virtual Reality Training (VRT). The sample is composed of 45 Subjects with Autism Spectrum Disorder - High Functioning (ASD-HF) who were divided into three groups: the ASD-HF Gr1 trained through RPIF, the GR2 performed training through SVM and the Gr3 which performed a VRT. For the three groups, it was required to learn two social skills: (a) starting and maintaining a conversation for 10 minutes with a peer; (b) starting and maintaining a pleasant activity with a peer.

Results. The evaluation parameter used for both social skills was the time of acquisition. The Gr3 showed faster learning compared to the other two groups; the Gr2 showed, for both tasks, a faster acquisition compared to the Gr1, but slower than the Gr3.

Conclusions. In this study we tried to reduce any differences in stimuli exposures between the three groups. Therefore, VRT has indeed proved to be the best teaching procedure for rapid acquisition. The immersive nature of VRT could actually explain much of the benefits of teaching in Virtual Reality. In fact, this procedure allows an active participation in the learning context so that, even subjects with ASD-HF, can improve their acquisition speed.
\end{abstract}

Keywords: Virtual reality, self-videomodeling, role play, instructional feedback, autism spectrum disorders.

\section{Introduction}

Asperger's Syndrome (AS) and / or High Functioning Autism (HFA) in DSM-IV-TR (American Psychiatric Association, APA, 2000) and ICD-10 (World Health Organization, WHO, 1993) is included in the more global chapter of Pervasive Developmental Disorders and can only be diagnosed in the absence of an intellectual disability. For these children, deficits in social skills can affect interactions with family, peers, and other adults. In turn, limited social skills can affect their ability to achieve normal developmental milestones and establish satisfying peer relationships (Krasny et al., 2003). Children with this disorder lack in social skills and do not have an adequate behavioral repertoire to be able to interact with others according to social conventions. Unlike children with other subtypes of Pervasive Developmental Disorder, children with HFA also have speech in a normal range of functioning (APA, 2000). In DSM 5 (APA, 2013), the term Asperger's Syndrome disappears to give way to Level 1 Autism Spectrum Disorder. However, the social skills deficits identified in children with Level 1 ASD remain the same as in HFAs and include: lack of orientation towards social stimulation and inadequate use of eye contact, problems in initiating social interactions, difficulty in interpreting both verbal and non-verbal social cues, inappropriate emotional responses and lack of empathy (Weiss \& Harris, 2001). Young people with HFA also have difficulty sharing emotional experiences or understanding the point of view of others, two skills that are vital for social reciprocity and the development of friendships (Gutstein \& Whitney, 2002). Therefore, subjects presenting a deficit of discrimination and social reference often fail to discriminate socially significant behaviors from self-referential ones. Since the social component is affected, even the learning style turns out to be highly self-referential: the autistic child learns in a self-referential way and therefore learns only what attracts him 
and which, moreover, does not always have a socially significant value. This determines, even in the presence of a normal IQ, a disharmonious profile with islands of hyper-competence and areas of deficit. From a cognitive point of view, several authors have tried to study the functioning of people with autism and have hypothesized a deficit in the acquisition of the Theory of Mind (ToM) (Rutherford et al., 2002; Pellicano, 2007; Goldstein \& Winner, 2012). This deficit is manifested by an inability to recognize one's own and others' mental states, the absence of shared attention, intentional communication and the ability to imitate. A variety of intervention models have been proposed and used for the development of social skills in ASD / HF in order to favor their inclusion (Shin-Yi Wang et al., 2011; 2013): behavior modification techniques, Peer Tutoring strategies, the use of Social Stories, Self-Management / PRT (Pivotal Response Training) strategies, and the use of Videomodeling (Bass \& Mulick, 2007; Matson, Matson and Rivet, 2007; Scattone, 2007). Videomodeling is also a tool used by Applied Behavior Analysis (ABA) to teach complex social tasks: acquisition of conversational skills (Charlop \& Milstein, 1989; Sherer et al., 2001) and pragmatic skills (Gena et al. , 2005), as well as the acquisition and strengthening of the ability to initiate and sustain social relationships (Wert \&Neisworth, 2003; Nikopoulos\& Keenan, 2004; Buggey, 2005) by exploiting, in particular, the motivation of subjects with ASD towards new technologies: tablets, smartphones, and PCs (Frolli et al., 2020). Further studies also examined the effectiveness of Virtual Reality (VR) as a treatment option for individuals with ASD / HF (Parsons, Leonard \& Mitchell, 2006; Mitchell et al., 2007; Wainer \& Ingersoll, 2011). Recent research has highlighted the advantages of using VR interventions such as simulations of reality with the use of information technology in which such subjects can practice difficult or individually challenging social interactions (Wainer and Ingersoll, 2011; Kandalaft et al., 2013; Maskey et al., 2014; Didehbani et al., 2016). VR provides a controlled environment to meet the needs of the subject with the real-time feedback option that can enhance the learning experience. Furthermore, computer technology is often highly motivating and rewarding for people with ASD (Parsons \& Cobb, 2011). In this study, three Social skills teaching procedures are compared: Role Play and Instructional Feedback (RPIF), Self-Videomodeling (SVM) and Virtual Reality Training (VRT) since there are not many studies in the literature that document the effectiveness of one intervention rather than another for the enhancement of social skills. For the three groups, two social skills were required to be learnt: (a) starting and maintaining a conversation for 10 minutes with a peer; (b) starting and maintaining a pleasant activity with a peer. In particular, the hypothesis tested in the work is that the VRT can allow a faster acquisition compared to the other two procedures.

\section{Materials and methods}

\subsection{Participants}

In this study we considered 45 subjects between the ages of 13 and 14 who had received a diagnosis of ASD Level 1 (HFA) (APA, 2013). Participants were divided into three groups based on the type of training Performed: Gr1 trained through RPIF, GR2 trained through SVM and Gr3 performed VRT. All subjects were administered the Wechsler Intelligence Scale for Children (WISC IV) (Orsini, Pezzuti and Picone, 2012) to exclude any participant with impaired intellectual abilities and therefore a comorbidity with intellectual disability. Therefore, the inclusion criteria were as follows: a) aged between 13 and 14 years, b) diagnosis of Level 1 Autism Spectrum Disorder in the absence of nosographically defined comorbidities, c) IQ $\geq 105$ assessed through WISC-IV, d) absence of other neuropsychiatric pathologies. After confirming the diagnosis and the possibility of inclusion in the sample, we divided the subjects into three experimental groups consisting of 15 subjects each. The subdivision was randomized. The three groups were assigned to three different types of treatment, as will be discussed in the next paragraph. The first experimental group was composed of 15 subjects with an average mean age of $13.5(\mathrm{SD}=0.70)$ and an average mean for IQ of 112.22 ( $\mathrm{SD}=1.20)$, of which 11 males and 4 females. The second experimental group is composed of 15 subjects with a means age of $13.7(\mathrm{SD}=0.50)$ and a means IQ of $112.83(\mathrm{SD}=1.10)$ of which 12 males and 3 females. The third experimental group is composed of 15 subjects with a means age of $13.6(\mathrm{SD}=0.30)$ and a means IQ of $112.45(\mathrm{SD}=1.05)$ of which 11 males and 4 females. Finally, there were no significant differences in age or QIT in the three groups. The data were collected at the FINDS Neuropsychiatry Outpatient Clinic by licensed psychologists in collaboration with the University of International Studies of Rome (UNINT).

\section{Results}

Data analyzes were performed using SPSS 26.0 statistical survey software (2019). Significance was accepted at the $5 \%$ level $(\alpha<0.05)$. We compared the acquisition times of the two social skills tasks between the three training groups, using the Analysis of Variance (ANOVA) test, a parametric test that allows to compare two or more groups of data comparing the variability within these groups with the 
variability between groups. The relationship between these variances follows the Fisher F distribution, which allows us to examine the hypotheses on the significance of the difference between the variability due to the treatment and the residual one. In this study we performed a one-way ANOVA to compare the scores between group 1 (RPIF), group 2 (SVM) and group 3 (VRT) and to evaluate the acquisition times of the two tasks. We called Acquisition 1 (ACQ 1) the task of starting and maintaining a conversation for 10 minutes with a peer and Acquisition 2 (ACQ 2) the task of starting and maintaining a pleasant activity with a peer. Specifically, in the comparison between the three groups, a significant effect emerged for both ACQ $1[\mathrm{~F}(2,44)=249.053, \mathrm{p}<0.05]$ and ACQ $2[\mathrm{~F}(2,44)=212.815, \mathrm{p}<0.05]$ (table 1$)$. To understand the differences between the groups and verify our hypothesis, we performed the Post Hoc tests (Bonferroni). From these analyzes it emerged that the scores of group 2 differ significantly from those of group 1 both for ACQ $1[\mathrm{~F}(2,44)=-2.133, \mathrm{p}<0.05]$ and for ACQ $2[\mathrm{~F}(2,44)=-2,200 \mathrm{p}<0.05]$ (table 2). The comparison between group 3 and group 1 revealed significant differences both for ACQ 1 $[\mathrm{F}(2,44)=-4,000, \mathrm{p}<0.05]$ and for ACQ $2[\mathrm{~F}(2,44)=-4.067, \mathrm{p}<0.05]$ (table 3 ). The comparison between group 3 and group 2 showed significant differences both for ACQ 1 [F $(2,44)=-1.867, p<0.05]$ and for ACQ $2[F(2,44)=-1.867, p<0.05]$ (table 4).

\subsection{Tables and figures}

Table 1. Comparison of the three groups to the two social skills activities.

\begin{tabular}{ccccccccc}
\hline & Group1 & & Group2 & \multicolumn{2}{c}{ Group3 } & & & \\
\hline & Means & SD & Means & SD & Means & SD & F & p \\
ACQ 1 & 7.40 & 0.507 & 5.27 & 0.458 & 3.40 & 0.507 & 249.053 & $<0.05^{*}$ \\
ACQ 2 & 9.47 & 0.516 & 7.27 & 0.458 & 5.40 & 0.632 & 212.815 & $<0.05^{*}$ \\
\hline
\end{tabular}

Table 2. Comparison between group 2 and group 1 to the two social skills activities.

\begin{tabular}{|c|c|c|c|c|c|c|}
\hline & \multicolumn{2}{|c|}{ Group 2} & \multicolumn{2}{|c|}{ Group 1} & \multirow[b]{2}{*}{$\begin{array}{l}\text { Difference in } \\
\text { Means }\end{array}$} & \multirow[b]{2}{*}{$\mathrm{p}$} \\
\hline & Means & SD & Means & SD & & \\
\hline ACQ 1 & 5.27 & 0.458 & 7.40 & 0.507 & -2.133 & $<0.05^{*}$ \\
\hline ACQ 2 & 7.27 & 0.458 & 9.47 & 0.516 & -2.200 & $<0.05^{*}$ \\
\hline
\end{tabular}

Table 3. Comparison between group 3 and group 1 to the two social skills activities.

\begin{tabular}{|c|c|c|c|c|c|c|}
\hline & \multicolumn{2}{|c|}{ Group 3} & \multicolumn{2}{|c|}{ Group 1} & \multirow[b]{2}{*}{$\begin{array}{c}\text { Difference in } \\
\text { Means }\end{array}$} & \multirow[b]{2}{*}{$\mathrm{p}$} \\
\hline & Means & SD & Means & $\mathrm{SD}$ & & \\
\hline ACQ 1 & 3.40 & 0.507 & 7.40 & 0.507 & -4.000 & $<0.05^{*}$ \\
\hline ACQ 2 & 5.40 & 0.632 & 9.47 & 0.516 & -4.067 & $<0.05^{*}$ \\
\hline
\end{tabular}

Table 4. Comparison between group 3 and group 2 to the two social skills activities.

\begin{tabular}{|c|c|c|c|c|c|c|}
\hline & \multicolumn{2}{|c|}{ Group 3} & \multicolumn{2}{|c|}{ Group 2} & \multirow[b]{2}{*}{$\begin{array}{c}\text { Difference in } \\
\text { Means }\end{array}$} & \multirow[b]{2}{*}{$\mathrm{p}$} \\
\hline & Means & SD & Means & SD & & \\
\hline ACQ 1 & 3.40 & 0.507 & 5.27 & 0.458 & -1.867 & $<0.05^{*}$ \\
\hline ACQ 2 & 5.40 & 0.632 & 7.27 & 0.458 & -1.867 & $<0.05^{*}$ \\
\hline
\end{tabular}




\section{Discussions}

This study was created with the aim of comparing three types of training for the acquisition of social skills in subjects with ASD-HF. In particular, we have chosen to compare the procedures of RPIF, SVM and VRT as, to the best of our knowledge, literature presents only few studies regarding their use. Mainly, each of these procedures is documented to have good results in improving social skills, but it has not yet been documented which of these procedures is the most effective in terms of speed of acquisition, in particular referring to subjects with ASD-HF. Our analyzes have shown, in line with previous literature studies (Bellini \& Akullian, 2007; Delano, 2007; Dillon, \& Bates, 2010) that both the RPIF, the SVM, and the VRT guarantee rapid acquisition of social skills; more specifically, our work highlights how the SVM guarantees faster acquisition than the RPIF. This could be explained by the fact that, subjects with ASD may need to reviewing the task performed with the consequence of speeding up the acquisition of the task compared to the classic role play. However, what was most evident is that the use of VRT has proved to be even more effective than SVM. This could be explained by the fact that VR environments can offer individuals with ASD the freedom to make social mistakes without the anxiety or fear of rejection, which is commonly associated with social interactions. Furthermore, this practice can be carried out in different VR contexts, facilitating the generalization of social skills learned to contexts of everyday life (Bellani et al., 2011; Parsons and Cobb, 2011; Tzanavari et al., 2015). In addition, the use of environments in VR allows the involvement of different cognitive, affective and bodily systems, also favoring the Embodied Cognition, by involving the motor system and favoring the sense of Embodiment (the possibility of acting within the virtual environment and promoting the active involvement of children in the first person.

\section{Limits and conclusions}

This study represents a preliminary work that demonstrates the effectiveness of using VRT among subjects with HFA. VRT provides an interactive and visually stimulating approach capable of simulating multiple social scenarios which allow participants to practice meaningful social exchanges in a safe and socially non-threatening platform. We hope that future research may replicate the present study by implementing a larger sample and a follow up design, with the wider purpose to extend the protocol to clinical practice and implement the technology that better helps each individual.

\section{References}

American Psychiatric Association (APA). (2000). Diagnostic and statistical manual of mental disorders (4th ed., Text Revision). Washington, DC: APA.

American Psychiatric Association (APA). (2013). Diagnostic and statistical manual of mental disorders (5th ed., Text Revision). Arlington, VA: APA.

Bass, J. D., \& Mulick, J. A. (2007). Social play skill enhancement of children with autism using peers and siblings as therapists. Psychology in the School, 44, 727-734.

Buggey, T. (2005). Video self-modeling applications with students with autism spectrum disorder in a small private school setting. Focus on autism and other developmental disabilities, 20(1), 52-63.

Charlop, M. H., \& Milstein, J. P. (1989). Teaching autistic children conversational speech using video modeling. Journal of applied behavior analysis, 22(3), 275-285.

Corp, IBM (2019). Statistiche IBM SPSS per Windows, versione 26.0. Armonk, NY: IBM Corp.

Delano, M. E. (2007). Video modeling interventions for individuals with autism. Remedial and Special Education, 28(1), 33-42.

Didehbani, N., Allen, T., Kandalaft, M., Krawczyk, D., \& Chapman, S. (2016). Virtual reality social cognition training for children with high functioning autism. Computers in human behavior, 62, 703-711.

Frolli, A., Ricci, M. C., Bosco, A., Lombardi, A., Cavallaro, A., Operto, F. F., \& Rega, A. (2020). Video Modeling and Social Skills Learning in ASD-HF. Children, 7(12), 279.

Gena, A., Couloura, S., \& Kymissis, E. (2005). Modifying the affective behavior of preschoolers with autism using in-vivo or video modeling and reinforcement contingencies. Journal of autism and developmental disorders, 35(5), 545-556.

Goldstein, T. R., \& Winner, E. (2012). Enhancing empathy and theory of mind. Journal of Cognition and Development, 13(1), 19-37.

Gutstein, S. E., \& Whitney, T. (2002). Asperger syndrome and the development of social competence. Focus on autism and other developmental disabilities, 17(3), 161-171. 
Kandalaft, M. R., Didehbani, N., Krawczyk, D. C., Allen, T. T., \& Chapman, S. B. (2013). Virtual reality social cognition training for young adults with high-functioning autism. Journal of autism and developmental disorders, 43(1), 34-44.

Krasny, L., Williams, B. J., Provencal, S., \& Ozonoff, S. (2003). Social skills interventions for the autism spectrum: Essential ingredients and a model curriculum. Child and adolescent psychiatric clinics, 12(1), 107-122.

Maskey, M., Lowry, J., Rodgers, J., McConachie, H., \& Parr, J. R. (2014). Reducing specific phobia/fear in young people with autism spectrum disorders (ASDs) through a virtual reality environment intervention. PloS one, 9(7), e100374.

Matson, J. L., Matson, M. L., \& Rivet, T. T. (2007). Social-skills treatments for children with autism spectrum disorders an overview. Behavior Modification, 31,682-707.

Mitchell, P., Parsons, S., \& Leonard, A. (2007). Using virtual environments for teaching social understanding to 6 adolescents with autistic spectrum disorders. Journal of autism and developmental disorders, 37(3), 589-600.

Nikopoulos, C. K., \& Keenan, M. (2004). Effects of video modeling on social initiations by children with autism. Journal of applied behavior analysis, 37(1), 93-96.

Orsini, A., Pezzuti, L., \& Picone, L. (2012). WISC-IV: Contributo alla taratura Italiana (WISC-IV Italian ed.). Florence, Italy: Giunti O. S.

Parsons, S., \& Cobb, S. (2011). State-of-the-art of virtual reality technologies for children on the autism spectrum. European Journal of Special Needs Education, 26(3), 355-366.

Parsons, S., Leonard, A., \& Mitchell, P. (2006). Virtual environments for social skills training: comments from two adolescents with autistic spectrum disorder. Computers \& Education, 47(2), 186-206.

Pellicano, E. (2007). Links between theory of mind and executive function in young children with autism: clues to developmental primacy. Developmental psychology, 43(4), 974.

Rutherford, M. D., Baron-Cohen, S., \& Wheelwright, S. (2002). Reading the mind in the voice: A study with normal adults and adults with Asperger syndrome and high functioning autism. Journal of autism and developmental disorders, 32(3), 189-194.

Scattone, D. (2007). Social skills interventions for children with autism. Psychology in the Schools, 44, $717-726$.

Sherer, M., Pierce, K. L., Paredes, S., Kisacky, K. L., Ingersoll, B., \& Schreibman, L. (2001). Enhancing conversation skills in children with autism via video technology: Which is better, "self" or "other" as a model?. Behavior modification, 25(1), 140-158.

Tzanavari, A., Charalambous-Darden, N., Herakleous, K., \& Poullis, C. (2015, July). Effectiveness of an Immersive Virtual Environment (CAVE) for teaching pedestrian crossing to children with PDD-NOS. In 2015 IEEE 15th International Conference on Advanced Learning Technologies (pp. 423-427). IEEE.

Wainer, A. L., \& Ingersoll, B. R. (2011). The use of innovative computer technology for teaching social communication to individuals with autism spectrum disorders. Research in Autism Spectrum Disorders, 5(1), 96-107.

Wang, S. Y., Cui, Y., \&Parrila, R. (2011). Examining the effectiveness of peer-mediated and video-modeling social skills interventions for children with autism spectrum disorders: A meta-analysis in single-case research using HLM. Research in Autism Spectrum Disorders, 5(1), 562-569.

Wang, S. Y., Parrila, R., \& Cui, Y. (2013). Meta-analysis of social skills interventions of single-case research for individuals with autism spectrum disorders: Results from three-level HLM. Journal of autism and developmental disorders, 43(7), 1701-1716.

Weiss, M. J., \& Harris, S. L. (2001). Teaching social skills to people with autism. Behavior modification, 25(5), 785-802.

Wert, B. Y., \&Neisworth, J. T. (2003). Effects of video self-modeling on spontaneous requesting in children with autism. Journal of Positive Behavior Interventions, 5(1), 30-34.

World Health Organization. (1993). International classification of diseases (10th ed.). World Health Organization. 


\title{
ENSURING SUCCESS IN THE FLIPPED CLASSROOM WHEN TEACHING ON- LINE
}

\author{
Marie J. Myers \\ Faculty of Education, Queen's University (Canada)
}

\begin{abstract}
As teaching moved on-line we had to rethink and readjust what approaches to use in order to reach the outcomes. Adjustments had to be made to the designed activities especially when groups had to meet in breakout rooms.

We will present the various aspects that came under scrutiny, as for example, peripheral participation, the development of mini-communities of practice, cooperation, collaboration and mediation.

We analyzed instructor's journal notes and students' products. There were 53 students in the classes concerned.

The main research question is what was effective in making participants improve learning and how did the implementation increase their understanding of working together virtually.

The method used is qualitative (Creswell, \& Poth, 2018). The instructor took observational notes of processes and actions during planned activities. These notes were analyzed to uncover insights. In addition, student 'products' of group work were analyzed for the triangulation of results.

Results show that the effort put into creating more engagement in the module brought about a number of interesting results that increased student understanding. Overall, findings show that participants reiterate expectations and summarize them, the repetition allowed a better grasp and this could also be due to the fact that during the reconversion, participants had to make sure they really understood the contents, i.e. ensuring that the meanings were clear which, in turn led to a better intake of specific features. As regards working together, several issues were identified, yet overall, all students were highly successful, due mostly to a supportive approach as regards feedback or a 'feed-through' approach.

The theoretical underpinnings came from research on learning and pointed to the requirement of additional insights on the part of instructors especially when teaching has to take into account equity, diversity, inclusion and indigenization (EDII). Instruction had to be more connected to students' lives. Bransford et al (2000) assert that "to develop competence in an area of inquiry, students must: a) have a deep foundation of factual knowledge, b) understand facts and ideas in the context of a conceptual framework, and c) organize knowledge in ways that facilitate retrieval and application" (p. 16).
\end{abstract}

Keywords: Learning in the flipped classroom, examining success, issues and insights.

\section{General considerations}

Due to unprecedented circumstances we experienced the transposition from face to face to on-line teaching in the middle of a course. Thanks to new technological means, although learning situations might be very familiar, new parameters come into play. It is important to uncover their impact and what deviations might be caused (Myers, 2011; Sperber, \& Wilson, 1986). Many problems have surfaced over time in on-line teaching, and according to previous studies (Kebritchi, Lipschuetz, \& Santiague, 2017) these include overall, for teachers, issues around their changing roles, transitioning to on-line, time management and teaching style. As regards learners, problems stem from their expectations, their readiness, their identity and their participation. In terms of content, questions are related to course development, multimedia use, instructional strategies and the development of content. With the flipped classroom approach adopted, group work during in-class meetings was crucial to allow everyone's participation. When moving to on-line teaching while maintaining the same approach, a number of adjustments were necessary. We used zoom and placed student groups in breakout rooms. 
With breakout rooms students have to talk and show their competences in negotiating activities for completion by their group. This entails capacities around ways of being, in other words, behavior in social contexts. Processes however are not as clear cut as they may appear: it requires students to carry them out, to know what to do and to be willing to do it.

\section{The problem}

On-line dialogue is often reported as shallow or sparse. Indeed, meaningful dialogue can be elusive and discussion facilitation could produce more superficial dialogue.

The theoretical underpinnings came from research on learning and pointed to the requirement of additional insights on the part of instructors especially when teaching has to take into account equity, diversity, inclusion and indigenization (EDII) as in this case as mandated by the university. Instruction had to be more connected to students' lives.

As on-line teaching was mandated unexpectedly due to COVID the instructor had to find ways to cater to students and cover remaining course content in the middle of a semester. The course had been set-up using the flipped classroom approach which involved students mainly working in groups. Within this group work, while on-line, the instructor could only connect with breakout room participants, one breakout room at a time. Therefore, when the instructor is not present, the discussion taking place may not be very formal, nor would there be expectations as to what should be said next or saying what people want to hear which would happen when students know they are being observed (Myers, 2009). This could be positive as it allows students the freedom to 'intermingle virtually', of course as long as it is around the topic under scrutiny.

The instructor's presence while entering breakout rooms, places more pressure on group activity. By providing the group work, students are given an opportunity to use their new factual knowledge while having access to immediate feedback from peers and the instructor, and in that sense, the flipped classroom helps students learn to correct misconceptions and organize their new knowledge such that it is more accessible for future use. Furthermore, the immediate feedback that occurs in the flipped classroom also helps students recognize and think about their own growing understanding, thereby supporting Bransford and colleagues' major conclusion that "a 'metacognitive' approach to instruction can help students learn to take control of their own learning by defining learning goals and monitoring their progress in achieving them" (p. 18). As on-line teaching added new components to the instructor's teaching approach, everything done had to come under close scrutiny.

\section{Method}

\subsection{Approach}

Because of the nature of the study, a qualitative approach was best suited for researching details about categories and themes in the notes taken by the researcher during on-going class activity (Creswell $\&$ Poth, 2018). While reflecting upon what to improve for the following year, as on-line teaching was still mandated, the instructor analyzed journal notes she had taken all along to uncover what worked and what didn't in order to modify delivery for the following year. This study is based on observations in an academic context with 53 participants across different classes.

The context is a professional training program at a university for future teachers of French. Instructor's notes were analyzed to identify patterns and results were triangulated to uncover similarities and differences and students' assignments were also taken into consideration. Analyzing teaching notes and comments on assignments only involved notes on paper or looking at written assignments and there was no involvement of human subjects. For ethical considerations anonymity was maintained throughout. The decision to carry-out this analysis stemmed from a comparison of the instructor's notes from the first cohort of students, who had met face to face during the first half of the semester which was then followed up with on-line only contacts. This note taking is the regular practice of an instructor trying to improve course delivery.

The common basis for each group will be presented and overarching principles delineated showing how specific groups were affected. The evolvement of the learning contents was monitored and what had unfolded, contextualized. Possible underlying premises, perhaps untold, were uncovered during the analysis of the notes and are discussed.

As regards class procedures, the objective of the course was ensuring success, the best way to report on that was through the outcomes of work the students carried out. This work basically took two forms, one which consisted of on-going reinforcement discussions on content that had to be prepared ahead of class time and the second one, on actual assignments handed in. 
The theoretical framework for analyzing and interpreting the data came for both class participation and assignments from Bransford et al's (2000) assertion that "to develop competence in an area of inquiry, students must: a) have a deep foundation of factual knowledge, b) understand facts and ideas in the context of a conceptual framework, and c) organize knowledge in ways that facilitate retrieval and application" (p. 16).

\subsection{On-going interactions on topics to be assimilated}

Because of the nature of the study, a qualitative approach was best suited for researching details about categories and themes in the notes taken by the researcher during on-going class activity (Creswell \& Poth, 2018). While reflecting upon what to improve for the following year, as on-line teaching was still mandated, the instructor analyzed journal notes she had taken all along to uncover what worked and what didn't in order to modify delivery for the following year. This study is based on observations in an academic context with 53 participants across different classes.

The context is a professional training program at a university for future teachers of French. Instructor's notes were analyzed to identify patterns and results were triangulated to uncover similarities and differences and students' assignments were also taken into consideration. Analyzing teaching notes and comments on assignments only involved notes on paper or looking at written assignments and there was no involvement of human subjects. For ethical considerations anonymity was maintained throughout. The decision to carry-out this analysis stemmed from a comparison of the instructor's notes from the first cohort of students, who had met face to face during the first half of the semester which was then followed up with on-line only contacts. This note taking is the regular practice of an instructor trying to improve course delivery.

The common basis for each group will be presented and overarching principles delineated showing how specific groups were affected. The evolvement of the learning contents was monitored and what had unfolded, contextualized. Possible underlying premises, perhaps untold, were uncovered during the analysis of the notes and are discussed.

As regards class procedures, the objective of the course was ensuring success, the best way to report on that was through the outcomes of work the students carried out. This work basically took two forms, one which consisted of on-going reinforcement discussions on content that had to be prepared ahead of class time and the second one, on actual assignments handed in.

\subsection{Outcomes of assignments}

With the intent to promote success as the Ontario Ministry of Education' logo is success for all, and with an EDII policy we thrive at supporting every student. Therefore, we provide detailed guidance and continuous support to ensure successful completion, which is evidence of the learning that took place.

\section{Discussion}

Many studies of on-line teaching point to technical difficulties, lack of appropriate access to WIFI, poor connectivity, outdated equipment, we experienced none of these challenges. So we can start by stating that easy access to and quality of the technological means are necessary to ensure success. In this study we are looking more closely at the actual work students were expected to engage in.

In the instructor's journal notes she closely observed if a deep understanding of factual knowledge had taken place around each theme or topic, she took steps to check that students understood the conceptual frameworks underlying their professional practice and ensured activities and assignments were directly connected to the knowledge to be acquired. Success was measured by students' outcomes from both on-going class interactions on the weekly topics under scrutiny as well as the completion of their assignments during the semester.

On all fronts students did extremely well, although throughout there were some concerns that were addressed in order for students to improve upon their final work, evidence of the learning that took place. Themes uncovered were related to peripheral participation, the development of mini-communities of practice, cooperation, collaboration and mediation, both during interactions on topics covered and in-class discussions on assignments.

\subsection{Results from on-going interactions}

In class, questions were fielded and answered by peers as much as possible with follow-up by the instructor leading to further discussion and probing deeper into topics. Various degrees of interest in the new ideas were usually expressed. Through group interactions students were verifying factual foundations, thereby verifying their conceptual understanding. 
During the first semester of on-line teaching, compared to carrying out these processes in face-to-face teaching, it appeared that the whole class discussion during on-line teaching sparked more interest with more discovery. Indeed prior to on-line teaching, all peers in class could overhear what different groups discussed as well as interactions with the instructor. During on-line teaching after breakout rooms were left to gather the whole class together, there was some discovery of others' ideas that had not been heard before, altering some thinking, bringing about adjustments, more exchanges among groups with as well added challenges and variety in the interactions. More engagement from everyone was observed although some students early on only participated at the periphery which is legitimate too (Wenger, 1998; Lave \& Wenger, 1991). It appeared that some students were somewhat hesitant about using French, their second language and the language used in class. The further discrepancy was due to the fact that students have two teaching specialties and for some in these groups French was not their first choice. Nevertheless, over time they eased into using the language and were more active. These students sometimes used English to contribute to the discussion although when the instructor entered breakout rooms, French was usually being used, on occasion a sentence that had started out in English was continued in French. In view of this aspect, it could also be assumed that students who only spoke sporadically when the instructor had entered the room, might in fact have been actively engaged earlier on, although using the English language. Hence perhaps the problem was not at the level of lack of foundations in factual knowledge. Perhaps to have all students engage more fully, instead of groups of four or five in breakout rooms, some activities should be devised to have students work in pairs. This way upon the instructor's entry, it is possible to really observe both people interacting.

Given the requirement that materials be prepared ahead of class time, we would have anticipated that there would be an understanding of facts and ideas in the context of the presented conceptual frameworks, according to Bransford et al's thinking. Sometimes the instructor noticed a lack of depth in the students' preparation. This was further corroborated by the fact that some colleagues felt that they needed to administer a quiz at the beginning of each class. Although students seemed to demonstrate their understanding in their assignments, as is noted in the next section, sometimes a superficial discussion of important items led the instructor to doubting actual deep learning of some content. This being said we also have to note that often words cannot account for the big picture, so perhaps the thinking took place but the concepts had not materialized in their minds yet for retrieval verbally. There was also the suggestion by researchers to make the discussion questions harder in order to have students produce 'modified output' (Swain, 2000).

As regards the organization of knowledge to facilitate retrieval and application we uncovered the following. In the larger groups synergy among participants developed as they became mini communities of practice. During these in-class discussions of pre-studied materials, the atmosphere was usually relaxed among group members and because of the nature of the work to be completed as there were no wrong answers possible, they were commenting on their prior readings only bringing to light items of interest and proposing creative ideas to further enquiry into the field without set directions. Overall, findings show that at the start of each group meeting participants reiterated expectations and summarized them, setting up a workable format for themselves and clarifying understanding. Although they were not directed to do so, they clearly displayed excellent work habits and were interested in anchoring the knowledge gained. The repetition involved allowed a better grasp and this could also be due to the fact that during the reconversion, participants had to make sure they really understood the contents, i.e. ensuring that the meanings were clear which, in turn led to a better intake of specific features. During these discussions all aspects of the EDII policy could easily be accommodated.

Before on-line teaching the instructor could oversee the whole class and it was obvious that on-line the dynamics were different. It was especially concerning when dealing with more theoretical concepts. The instructor's presence, moving around the classroom kept everyone on their toes, actively engaged, even when discussions veered off, often students went on a tangent but still connected to the matters at hand, bringing in more personalized experiences to the table related to the topic. During on-line breakout room visits, as soon as the instructor joined, instructor's presence was acknowledged, either by greeting or through a pause, or redirecting a question at her. So although it was possible to glean a few seconds of the groups' activity, noticing whether they were on task or not, discussions were often quickly adjusted. Nevertheless, it was obvious that groups worked well together, in an efficient way and even when their talk was more of a socializing type it usually was related to the topics to be mastered, often through relating to some personal experiences and in this way also providing better ways for the crystallization of thought. Initially at least, it appeared that the students tried to figure out the instructor's positioning relative to the work assigned and also as a person which could somewhat explain this difference between the two semesters. 


\subsection{Results for assignments}

Models were given for all assignments so that students knew how to proceed although the idea never was to copy exactly the model given as models were only intended as guidelines with the idea to allow a wide margin of personal expression, as an EDII policy would be expecting to happen. Also to better support students, first assignments were group assignments in a cooperative way and then later in collaboration each student was to produce an original personal rendition with slightly different directions although working along similar lines as the group had been all together. So there was a progressive easing into the work to be submitted.

The assignments were given in order to develop students' competence in their area of specialty. Students were tasked with applications keeping in mind theoretical tenets that had been examined.

Findings point to overall supportive efforts although some restrain was sometimes observed even among people who were close. Students were advised that for these assignments they could meet outside class through their preferred application therefore minimizing the difficulty in using the technology. All students completed all their assignments at top level although some of them had to be given additional time, which was in line with university policy. For cooperative assignments, the groups came together well and produced superior work. For the following collaborative assignment students worked together, however each person had to hand in their own assignment after group collaboration.

\section{Conclusion}

During the instructor's breakout room entries, various degrees of reactions to inquisitiveness were noted, which could normally have been overlooked in face-to-face meetings (Rorty, 1991) as students would have known when the instructor was approaching their group. The use of silence and topic changes could be questioned at times, and some protectiveness of absentees was interesting. Some type of erosion or undermining was also identified, although of a different type, perhaps due to the different people involved (Scollon, \& Scollon, 1981). Whether the motives behind these interactions was just to redirect where an assignment was going, whether it was due to culturally different ways of being, it was noted that negotiations took place and after some mediating students got past the hurdles. Despite some perceived difficulties, it appears that there were negotiations of meaning and of content, the give and take in sharing ideas, and advice shared as how to better fulfill expectations listed in the assignment templates. So we can say that success, as per Bransford et al's (2000) quotes, has been identified at least in most of the areas concerned.

\section{References}

Bransford, J.D., Brown, A.L., \& Cocking, R.R. (2000). How people learn: Brain, mind, experience, and school. Washington, D.C.: National Academy Press.

Creswell, J., \& Poth, C. (2018). Qualitative inquiry and research design $\left(4^{\text {th }}\right.$ ed). ThousandOaks, Cal.: SAGE

Kebritchi, M., Lipschuetz, A.,\& Santiague, L. (2017). Issues and Challenges for Teaching Successful Online Courses in Higher Education: A literature review. Retrieved My 11, 2021 from https://doi.org/10.1177/0047239516661713

Lave, J., \& Wenger, E. (1991). Situated learning: legitimate peripheral participation. Cambridge, UK: Cambridge University Press.

Myers, M.J. (2011). Effectiveness in dialogic language use despite deviations. Procedia-Social and Behavioral Sciences 12, 248-254.

Osherson, D. (1995). The study of cognition. In L. Gleitman, \& M. Liberman (Eds.) Language. An invitation to cognitive science, vol. 1 . xi-xviii, Cambridge, Mass.: The MIT Press.

Rorty, R. (1991). Texts and lumps. In Objectivity and realism, Cambridge: Cambridge University Press 78-92.

Scollon, R., \& Scollon, S. (1981). Narrative, literacy and face in interethnic communication, Advances in Discourse Processes, vol 7. Norwood, N. J.: Ablex.

Sperber, D., \& Wilson, D. (1986). Relevance, communication and cognition. Oxford: Blackwell.

Swain, M. (2000). The Output Hypothesis and beyond: mediating acquisition through collaborative dialogue. In J.P. Lantolf (Ed.), Sociocultural theory and second language learning, 97-114. Oxford: Oxford University press.

Wenger, E. (1998). Communities of practice: learning, meaning, identity. Cambridge, UK: Cambridge University Press. 


\title{
VIRTUAL LEARNING APPLYING EDUCATIONAL STRATEGIES IN TIMES OF COVID-19; CASE OF TECHNOLOGY IN MILITARY SCIENCES
}

\author{
Flor Emperatriz Garcés Mancero, Magaly Margarita Narváez Ríos, \\ Luis Germánico Gutiérrez Albán, \& Víctor Danilo Lazo Alvarado \\ Departamento de Seguridad y Defensa; Universidad de las Fuerzas Armadas ESPE (Ecuador)
}

\begin{abstract}
The educational system in times of pandemic has had to transform itself urgently and unexpectedly to a virtual modality. This paper presents an exploratory study on the main difficulties encountered in the Soldiers Training School "Vencedores del Cenepa", where the objective of this work was to expose some strategies mediated by ICTs, for the virtualization of the teaching-learning process; When the didactic and functional methodology was applied in virtual education, I necessarily involve externalizing the demands of the teachings where they are enrolled; in this online educational process-COVID 19; the students of the institution consider their class grade as a basic educational tool, where the student himself,

Virtual learning behaves as an extension of the face-to-face classroom, mainly supported by technologies that allow, even remotely, activities that challenge students to produce a collective text, electronic portfolio, infographic or video that address a topic, can be worked collaboratively. in particular related to the topic of the class, they are generally more accepted by students than exercises or questionnaires whose objective is to record the content of a discipline; Therefore, we must see the opportunity that shortens the distances and enriches the teachers' process, maintaining their structure and development of methods according to reality; where the development of study programs is allowed, strengthens relationships and instills collaboration among all actors.
\end{abstract}

Keywords: Educational system, pandemic, virtual modality, Virtual learning, electronic portfolio.

\section{Introduction}

Education dignifies culture and beliefs, and everything that represents the human being; for this reason it is important in all its senses, since it transforms life and generates changes. However, in the 21st century and in the midst of a pandemic, most governments around the world have temporarily closed educational institutions in an attempt to contain the spread of the disease.COVID-19 pandemic.

The conditions of social distancing and forced confinement lead to the paralysis of educational, economic, industrial activities, both public and private in almost all nations, and we observe the impact on our daily lives in all actions and activities of the entire society.(Tárrega Astigarraga \& Palau Pellicer, 2017)

With this consideration, the different social actors that make up the IES such as students, academic manual and administrative workers and authorities, as well as other sectors of society that are related to educational units, colleges, universities and higher institutes and research centers, They have been facing with creativity and haste the challenge of the reality that we are going through, rethinking the activities planned to comply with and to give continuity to the exercise of their substantive functions and teaching activities, to continue addressing the challenges and problems they faced since before the COVID-19 crisis will break out.

When the COVID-19 pandemic arrived in Ecuador, at the Soldiers Training School "Vencedores del Cenepa", nothing was planned, they were only mere assumptions of the situations that were coming, in addition to the expectation of the applicants of uncertainty, if they stay in the institution or if they return home; But no one clarified the panorama, of course, of course, in the same way the teachers who provide services in the school, as occasional teachers and guest teachers.

On March 18, 2020, the students of the Military Sciences Technology Career belonging to the University of the Armed Forces - ESPE, are sent to their homes, for better connectivity in the classes and to comply with the periods established for the training of Technologists; In other words, the educational system must continue to guarantee this online teaching-learning process and the right to study in this new 
scenario; However, not all have the necessary materials in their homes to start this migration to virtual education.

Possibly there will be concern in some cases of vulnerable students, who do not have connectivity and technological devices in their homes, by virtue of the fact that in ESFORSE there are applicants with low economic possibilities, which makes it a great challenge for educational equity. In this sense, the following unknowns arose: Is the training school prepared to generate a teaching-learning process in a virtual way? Do parents have the economic possibilities and technological tools necessary for their children to achieve the acquisition of new knowledge, for the present academic challenge?; From these questions in mention arises the need to answer the main question that is knowledge;

The following specific objectives emerge from these forecasts: (a) investigate the perception of education today; (b) identify the challenges of the Soldiers Training School; "Vencedores del Cenepa", in this new setting. These objectives gave rise to the central purpose of the research which was to identify the challenges of the institution in the context of the COVID-19 pandemic, mainly from information and communication technologies and interrelated with the methodology of the educational process.

\section{Virtual learning: The applicant and the teacher}

The suspension of face-to-face teaching activities gave way to virtualization, where teachers and students had to adapt to a new educational context. In addition, the turn to this online teaching has been sudden, ignoring the long training processes, redesign of subjects and infrastructures that support the demand for tele-teaching (González-Calvo et al., 2020).In fact, in several Latin American countries, COVID-19 had a negative influence on the teaching-learning process, due to the fact that for many years there was no investment in the adaptation of virtual campuses, institutional websites, digital scientific journals and in the training of teachers and students in the use of ICTs, having to improvise technological solutions (Ríos Campos, 2020).

\section{Adaptation of the methodology: Means and Procedures}

At the institutional level, the ESPE published a resolution on July 9, 2020, where it approved the Study Guide Methodology to Develop the academic activities of the subject through learning, in which it established Academic criteria for the adaptation of the classroom teaching format to the not face-to-face, guaranteeing the achievement of the competencies programmed for the course in the context of the state of alarm generated by Covid-19.

The activities that were planned to be carried out in person have become e-activities without having had enough time to adapt them properly; When the didactic and functional methodology is applied in virtual education, it necessarily involves externalizing the demands of the teachings where they are enrolled; in this online educational process-COVID 19; where the students of the institution consider their classroom grade as a basic educational tool, perhaps it is sought that the applicant himself now, awakens his creativity, constitutes a didactic complement to the study and a support to the teaching-learning process through the different tools and materials available supplementary materials, research resources, others.

The virtualization of direct educational materials involves the application of the main quality criteria that guarantee an efficient accessibility to the materials, the cognitive economy and the acquisition of knowledge; where automation in the creation and publication of online educational resources, which obviously guarantee a high production with minimal human and technical resources, must never forget the peculiarities of the discipline and the needs of the members involved in this process: authorities, teachers and aspirants; the main objective being the transmission of knowledge and reaching a meaningful learning.

\section{Conclusions}

Virtual learning from home during the COVID-19 pandemic has had a significant impact on the education systems of all countries in the world. In response to this crisis, countries have applied different rules and methods to deal with changes in the apprenticeship system. In a few months, the national educational systems resorted to solutions such as online methods, conscious of creating an active system that favors interest, personal motivation, reflection, responsibility, creativity and sharpening the understanding of the contents taught. in virtual form; where the student became an actor of his own education, favoring his intelligence to increase, through problematic situations inherent to his military professional profile. 
The situation caused by Covid-19 has opened the door to the generation of teaching and methodological innovation by all teachers. The chosen methodologies have raised in some cases the need to rethink the reduction of the contents of the subjects compensated by the activities to be carried out by the students that allow to complement or specify the theoretical aspects explained.

Although it is true, it is the opportunity to use strategies in pedagogy, didactics and evaluations; through distance learning, with the use of technological formats and platforms, generating an adequate environment for the health, psychological and economic well-being of students; projecting new opportunities for learning and educational innovation, after having overcome the crisis generated by the pandemic.

The student-applicants belonging to the Career of Technology in Military Sciences complied with the planning established in the Curriculum Mesh through the technological methodologies used by teachers, thus fulfilling their role in the teaching-learning process within their professional training to the student.

\section{References}

https://plus.google.com/+UNESCO. (2020, March 4). Education: From disruption to recovery. UNESCO.https://en.unesco.org/covid19/educationresponse

https://plus.google.com/+UNESCO. (2017, September 21). Education in crisis situations. UNESCO.https://es.unesco.org/themes/educacion-situación-crisis

González-Calvo, G., Bores-García, D., Barba-Martín, RA, \& Gallego-Lema, V. (2020). Learning to be a teacher without being in the classroom: COVID-19 as a threat to the professional development of future teachers. International and Multidisciplinary Journal of Social Sciences, 9 (2), 152-177. https://doi.org/10.17583/rimcis.2020.5783

Millán, T., Heresi, C., Díaz, F., Weisstaub, G., \& Vargas, NA (2020). The covid-19 pandemic as a reflection opportunity in health sciencies education. Revista Chilena de Pediatria, 91 (4), 489-491. https://doi.org/10.32641/rchped.vi91i4.2784

Olmedo Plata, JM (2020). Learning styles and school academic performance from the cognitive, procedural and attitudinal dimensions. Learning Styles Magazine, 13 (26), 143-159.

Pallisé, JS, González, CB, i Verges, CB, \& i Daniel, MB (2016). Blendedness in Higher Education: Case Studies in the Degrees of the University of Barcelona. EDUTEC. Electronic Journal of Educational Technology, 58, 15-33. https://upo.es/revistas/index.php/IJERI/article/view/5015

Ríos Campos, C. (2020). COVID-19 and Public University Higher Education of Peru. Clake Education Magazine, 1, 1-1.

Ruiz, ABM (2010). ICT teacher training Are teachers prepared for ICT (R) evolution? International Journal of Developmental and Educational Psychology, 4 (1), 35-44.

Tárrega Astigarraga, O., \& Palau Pellicer, P. (2017). Plastic and visual education in contemporary art spaces. Research Forum, 19, 239-258. https://doi.org/10.6035/forumrecerca.2014.19.17

Tejedor, S., Cervi, L., Tusa, F., \& Parola, A. (2020). Education in times of pandemic: reflections of students and teachers on virtual university education in Spain, Italy and Ecuador. Revista Latina, 78, 1-21. https://doi.org/10.4185/rlcs-2020-1466

Vite Cevallos, H., Carvajal Romero, H., Samaniego Ocampo, R., \& Prado Ortega, M. (2020). Virtual competencies of teachers in the face of the Covid-19 challenge in higher education institutions in Ecuador. Revista Conrado, 16 (S 1), 178-183. 


\title{
SERVICE LEARNING INTEGRATED WITH FOREIGN LANGUAGES LEARNING: PROMOTING TRANSVERSAL COMPETENCIES
}

\author{
Dana Hanesová \\ Department of Pedagogy, Faculty of Education, Matej Bel University (Slovakia)
}

\begin{abstract}
In this article, the author will present an innovative way how to develop students' foreign language communicative and intercultural competence alongside with a whole set of transversal competencies via an innovated version of foreign language courses. They may be attended by both university students or secondary school students. The basic idea of such a course, in our case called "Global Encounters in Local Settings", is giving students space to create a service-learning project for a community. Students have to work in linguistically and ethnically mixed groups. Each group decides to about the focus of their project and the procedures of its implementation. Via these cooperative projects accomplished while using various foreign languages - suitable also for online learning space, the students can develop various transversal competencies, such as critical and reflective thinking, plurilingual and intercultural competence, problem-solving, team-work skills, interpersonal and other social competencies, willingness to take risks and seek challenges, leadership development skills, time management and planning skills, inclusive approach, and active citizenship. The first version of such course was tested on several groups of university students in Slovakia (in 2020). The post-tests and reflections after accomplishing this course showed evident growth in the above-mentioned competencies.
\end{abstract}

Keywords: Innovation, service learning, transversal competencies, foreign language learning.

\section{Introduction}

The purpose of our paper is to point out one of the possible innovative ways of developing not only foreign language communicative skills, but also several transversal competencies of university students. It is also applicable to high school students.

It is necessary to realize that as the changes in a globally connected society accelerate, so do the requirements for university education outcomes and, in particular, the qualifications of university graduates. Universities in the Slovak Republic prepare students in accordance with the current European and National Qualifications Frameworks. However, the World Economic Forum reports (2016 and 2018) on the future of jobs show that there is a rapid change in the supply of potential professions, so graduates from all schools will soon have to take up new professions that are still being formed. According to the authors of these international reports, most education systems today provide "dead", too specific education. In the future, it will be necessary for graduates to be interdisciplinary prepared and equipped with broader, transversal competencies, which will enable them to solve a certain area of problems, taking into account all related and emerging contexts, both theoretical and practical. Of course, the need to be able to use more foreign languages remains a challenge, as foreign language and intercultural competencies actually open up access to the labor market for graduates of various levels of education.

\section{Key terms and theoretical outcomes}

Before presenting the implementation of our specific educational innovation focused on the development of competencies in foreign languages as well as transversal competencies, we consider it necessary to clarify these concepts, as well as the essential strategy of learning services. We dealt with the definition of these terms in our monograph (Kosová, Hanesová, Šukolová et al, 2019).

Transversal skills and competencies - The word connection transversal skills and competencies is often used as a synonym with the terms generic, key, transferable, global or even 21 st century skills or competencies. They all have the same essence but differ slightly in emphasis and purpose, and there are no precise definitions of their use. 'Generic skills' are skills that are important for work, education and 
life in general, applicable in various occupations (e.g., general communication, organizational, interpersonal or analytical skills and abilities). They are sometimes referred to as 'key competencies' and operate mainly in the relationship area between education and employment. The term 'transferable skills and competencies' emphasizes that these are competencies acquired in one context, e.g., in research, but they can be effectively used and further developed in another context e.g. in employment, or in business. Similarly to transferable competencies, the transversal ones are not related to one specific profession, but "they can be used in different situations and working conditions" (UNESCO - IBE Glossary, 2013). The terms transversal and transferable competencies can therefore be considered almost synonymous, differing only slightly in their emphasis. Transversal skills and competencies emphasize cross-sectionality in terms of the content; transferable skills focus more on transferability in terms of the process of individuals' careers. Since 2013, the term transversal skills started to be used also with the emphasis on humanity and holistic development of the personality of learners, at least within one UNESCO report. In this sense, transversal skills include e.g., "collaboration, self-discipline, resourcefulness, and respect for the environment" (UNESCO, 2015). To some extent, they are considered overlapping with the concept of global competencies, which, however, e.g. according to PISA 2018, relate in particular to the ability "to examine local, global and intercultural issues, understand and appreciate and worldviews, interact successfully and respectfully with others, and take responsible action toward sustainability and collective well-being."

For the purposes of this paper, focused on education, we will use the term transversal competencies, as a synonym for the term transferable competences. Both - as in the case of the other mention synonyms - consist of knowledge, skills, values, attitudes and will. The OECD Classification (2012) mentions an inspiring classification of categories of these skills, which we have used also in our innovation. According to this OECD document, it is possible to talk about the need to develop interpersonal skills, organizational skills, research competencies, cognitive skills, communicative and entrepreneurial skills (2012).

Global competencies necessary for the next generation of professionals include intercultural competence, which can be defined both as knowledge of culture but also the ability to show intercultural empathy, respect, tolerance, sensitivity, flexibility, the ability to negotiate and argue, try to understand, discuss and achieve consensus with others as well as the ability to communicate in several languages. Foreign language communicative competence - from the point of view of contemporary linguistic didactics - is focused primarily on the ability to communicate in a foreign language. The concept of communicative competence was coined by D. Hymes in his theoretical study (1972). By foreign language communicative competence, we mean the ability of students to use the acquired vocabulary, pronunciation and grammar in the way required by the socio-cultural context and linguistic system, through all four communication skills (listening, speaking, reading, writing) (Bérešová, 2009). Communicative foreign language competence "contains a static part, ie. complex multilayer knowledge, and a dynamic part, ie. the ability to use this knowledge in various communication contexts" (Nováková, 2020, p. 12). According to the White Paper on Education and Training by EU Commission (in 1995), we should have adequate communication skills in at least two foreign languages.

An innovation of foreign language teaching can be achieved in the case of a combination, or better to say, synergy of the goal - which is foreign language communicative and other transversal competencies - with the pedagogical strategy of service-learning. Service learning is based on the integration of learning processes with meaningful voluntary service to a community, ie it is literally about learning through service. It is a form of experiential learning, where learning occurs in a cycle of activities and critical reflection. It enables students to acquire meaningful learning experiences at the same time as implementing common community solutions to real problems of a particular community. Mitchell and Donahue consider the ideal service-learning experience related to the involvement of students in the community, solving its specific problems, contributing to the real development of communities in particular. According to these authors, "students may see the community as a place of learning equivalent to the classroom or even more valuable than the classroom because knowledge and skills are gained in the context of hands-on use" (Mitchell \& Donahue, 2017, p. 464).

It should be emphasized that service-learning includes not only projects for the community, but also their creation in reciprocal relations with the community. The current concept of service-learning includes a critically-reflective practice of better understanding human dignity, oneself, culture, but also socio-economic, political and environmental issues, power relations and social responsibility, in a way emphasizing "the impact of global structures in local contexts. The key dimension of global service-learning is community building, and especially "the development of relational trust and mutual respect" ... It prioritizes the goals of "economic equity, equal partnership, mutual learning, cooperative and positive social change, transparency, and sustainability". It creates a space for building a "world that recognizes human dignity across nations" (Hartman \& Kiely, 2017, 322-324). 


\section{Empirical research of pedagogical innovation}

In this part we will move on to the practical application of the idea of a functional synthesis of a service-learning strategy with the development of transversal competencies. We will first describe this innovation in more detail and then present methods for examining its pilot implementation.

\subsection{Description of the pedagogical innovation}

In 2019, a group of language teachers across the faculties of Matej Bel University (MBU) in Banská Bystrica created a new foreign language course, Global Encounters in Local Settings (GELS), based on service learning strategy. The course was created within the broader project 'Plurilingual and intercultural edulab supporting university strategy of internationalization 'in Slovakia (project KEGA 004UMB-4/2019) which began in 2019 and ends in 2021. It has been offered as a selective subject for students of any Bachelor, Master and doctoral study programs at this university since January 2020. Information about this course, including its aims to develop plurilingual, intercultural and other, the above-mentioned transversal competencies of students, as well as an overview of the assignments and expected student's workload, was published on the MBU website. It was made public also on the foreign language website version, so that foreign students interested in mobility at UMB can also access it.

As we found out at the first GELS meeting with students, those who were interested in improving their foreign language and intercultural competence, learning about other cultures, as well as in acquiring transversal competencies applied for the course. So far, both domestic and foreign students (studying entire programs at UMB or mobility students) have applied for GELS in each semester.

The task of the students, working in linguistically and culturally mixed groups, was to analyze their socio-cultural background and to select a need of a certain community, and to prepare and implement a project fulfilling this need.

After the initial introductive and instructional meeting with the supervising teachers, the groups of students worked independently, using instructional worksheets. Teachers continuously monitored the work in groups. Together they met again for the final presentation of the students' group projects. Reflective diaries and group reports were written by the students throughout the creation and implementation of the project. During the final meeting in the whole class, the students presented their projects and their self-reflections in front of the teachers and the whole class, on the basis of which they were finally evaluated. The output of the course were projects created for the community of the city, for the community of foreign students as well as foreigners in the city of Banská Bystrica, and finally during the pandemic in general for foreign university students.

\subsection{Methods of data acquisition and data processing}

The GELS course was implemented during two semesters in 2020. The research sample consisted of 60 students in total (30 in the experimental group and 30 in the control group). The effectiveness of the implementation of the GELS course was verified by the so-called mixed research methodology of data acquisition and data processing:

a) By pre-tests and post-tests of plurilingual and intercultural competence in both experimental and control groups. These questionnaires were constructed by the KEGA team researchers, they consisted of open and closed questions. Closed questions were evaluated through descriptive statistics and open questions through qualitative content analysis. Subsequently, the differences between pre-tests and post-tests were found by comparison.

b) By content analysis of individual students' diaries and the categorization of the analyzed data, using OECD framework of specific categories of transversal competencies;

c) By content analysis of projects - course outcomes and of group reports, again focusing on assessing transversal competencies;

d) By analysis of self-reflections, feedbacks, mutual reflections, evaluations of external evaluators.

\subsection{Results from empirical research of the implementation of the GELS course}

The data processed so far through qualitative analysis and comparison confirm the increase of the following competencies:

As it turned out from the analysis of works and presentations of students in a foreign language, as well as from the comparison of pre-tests and post-tests, except for students with an entry level of C2 (according to CEFR, 2018), it is possible to confirm a clear increase in foreign language communicative competence of at least one level, i.e., if the student was initially at the B1+level, the final level was B2- , and so on in other cases, if B2- at the beginning - then at least B2 at the end of the course Most importantly, students themselves noticed an increased fluency in their speaking in a foreign language and 
reduced fear of speaking in it, improved listening skills, and more self-confidence to write about professional matters in a foreign language.

From financial reasons, we did not have access to any standardized framework for assessing intercultural and other transversal competences, but we used the OECD classification (2012) for the qualitative evaluation of their potential increase. Content analysis and comparison of data obtained from all available sources showed an increase in skills and competencies in the following areas (in order of frequency and intensity - starting with the most developed ones):

a) Development of inter-personnel competence;

b) Intercultural competence - increasing the level of knowledge and attitude of tolerance towards other cultures;

c) Critical thinking, problem solving;

d) Willingness to take risks and look for challenges;

e) Ability to work in a team, leadership skills;

f) Project and time management;

g) Project writing, planning, implementation and evaluation;

h) Communication skills - communication with team members, with teachers, with the target community;

i) Written and oral presentation skills;

j) Creativity and ability to think abstractly in project design;

k) Active citizenship.

\subsection{Discussion}

The overview of the results shows that the expectations from the project intention of GELS - to develop, in addition to foreign language competence, also the above-mentioned transferable competencies, have been fulfilled. Although there is no room here to detail them, the analysis so far and especially the student outcomes have shown an increase in all the above-mentioned areas. Service learning strategy. Service learning strategy has proven to be a natural, attractive, effective method of mutual students' learning, enabling their transversal competencies to flourish.

Similarly, Burbach et al. (2004) describe the positive impact of service-learning subjects, namely, e.g., to develop critical thinking. The team around Eyler (2001) compiled a whole list of studies that prove the positive impact of service-learning on personal, social and educational outcomes, as well as on career development and relationships with domestic institutions, namely the impact on:

- personal development (awareness of self-efficacy, personal identity, moral development) and development of interpersonal skills to cooperate, lead, communicate despite differences, belief in the importance of diversity,

- development of the social dimension - social skills, elimination of stereotypes, facilitation of cultural understanding, development of social responsibility and civic skills, willingness to decide to help the community, involvement in the community,

- cognitive but also affective growth - ability to apply the acquired knowledge in practice, critical thinking, ability to solve problems, and others (positive impact on preparation for the profession after graduation).

\section{Conclusion}

In summary, the main idea of this contribution was to present an innovation consisting of the integration of foreign language teaching with the development of transversal competencies, through a new university course using a service-learning strategy. Within it, internationally mixed groups of university students performed analyzes of the specific needs of a specific community, and subsequently prepared projects to meet them.

The whole innovation has been research-proven. The results showed that such a pedagogical strategy, where students had to cooperate, create and be responsible for the results of group work, contributed to the development of their transversal competencies more than in other, traditionally taught language subjects. Although these were small groups of students, and more massive research would certainly be needed, the results of our validation show that it is extremely successful and, in addition, very popular with students and teachers, as it is a natural, independent and cooperative way of learning. 


\section{Acknowledgements}

This study is an integral part of the project 'Plurilingual and intercultural edulab supporting university strategy of internationalization' (KEGA 004UMB-4/2019) supported by the Cultural and Educational Grant Agency of the Ministry of Education, science, research and sport of the Slovak Republic.

\section{References}

Bérešová, J. (2009). Didaktika anglického jazyka. [Methodology of Teaching English Language.] Bratislava, Slovakia: Metodicko-pedagogické centrum.

Burbach, M. E., Matkin, G., Gina, S., \& Fritz, S. M. (2004). Teaching Critical Thinking in an Introductory Leadership Course. College Student Journal, 38(3), 482-493.

Council of Europe. (2018). Common European Framework of Reference for Languages: Learning, Teaching, Assessment. Companion Volume with New Descriptors. Strasbourg: Council of Europe.

EU Commission. (1995). White Paper on Education and Training - Teaching and Learning - Towards the Learning Society. COM (95) 590 final, 29 November 1995. Retrieved May, 4, 2021 from https://europa.eu/documents/comm/white_papers/pdf/com95_590_en.pdf

European Qualifications Framework (EQF). https://ufm.dk/en/education/recognition-andtransparency/transparency-tools/qualifications-frameworks/european-qualifications-framework

Eyler, J., Giles, D. E., Stenson, Ch. M., \& Gray, Ch. J. (2001). At A Glance: What We Know about The Effects of Service-Learning on College Students, Faculty, Institutions and Communities, 1993- 2000. Higher Education. 139. https://digitalcommons.unomaha.edu/slcehighered/139

Hartman, E., \& Kiely, R. (2017). Global Service Learning: Definition, Theoretical Lineages, and Application Efforts. In C. Dolgon, T. Mitchell, \& T. Eatman (Eds.), The Cambridge Handbook of Service Learning and Community Engagement (Cambridge Handbooks in Psychology, pp. 321-334). Cambridge: Cambridge University Press.

Hymes, D. H. (1972). On Communicative Competence. In: J. B. Pride \& J. Holmes. Sociolinguistics. Selected Readings (pp. 269-293). Harmondsworth: Penguin. Retrieved April, 14, 2021 from https://fdocuments.in/document/on-communicative-competence-01-by-dell-hymes.html

Kosová, B., Hanesová, D., Šukolová, D. et al. (2019). Doktorandská škola - cesta k transformácii a inovácii doktorandského vzdelávania vo svete a na Slovensku [Doctoral School - A Way to Transformation and Innovation of Doctoral Education in the World and in Slovakia]. Banská Bystrica: Univerzita Mateja Bela v Banskej Bystrici - Belianum.

Mitchell, T., \& Donahue, D. (2017). Ideal and Real in Service Learning: Transforming the Ideal Based on the Real. In: Dolgon, C., Mitchell, T. \& Eeatman, T. (eds.). The Cambridge Handbook of Service Learning and Community Engagement (pp. 458-469). Cambridge: Cambridge University Press.

Nováková, Zuzana. (2020). Using digital tools to facilitate self-assessment and feedback for the development of students' speaking skills. Prešov: Prešovská univerzita.

OECD. (2012). Transferable Skills Training for Researchers: Supporting Career Development and Research. OECD Publishing, 2012. Retrieved May, 17, 2021 from https://www.oecd.org/science/transferableskills.htm

OECD. (2019). PISA 2018 Assessment and Analytical Framework, Paris: OECD Publishing. Retrieved May, 5, 2021 from https://doi.org/10.1787/b25efab8-en, p. 166

UNESCO. (2013). IBE Glossary of Curriculum Terminology. Geneva: UNESCO International Bureau of Education. Retrieved May, 1, 2021 from http://www.ibe.unesco.org/fileadmin/ user_upload/Publications/IBE_GlossaryCurriculumTerminology2013_eng.pdf; TVETipedia Glossary. UNESCO UNEVOC.

UNESCO. (2015). Asia-Pacific Education Research - Institute Network Regional study on Transversal Competences in Education Policy and Practice. Paris; Bangkok: UNESCO. Retrieved April, 14, 2021 from https://unesdoc.unesco.org/ark:/48223/pf0000231907, S. 2

WEF World Economic Forum. (2016). The Future of the Jobs Employment, Skills and Workforce. Retrieved May, 14, 2021 from http://www3.weforum.org/docs/WEF_Future_of_Jobs.pdf

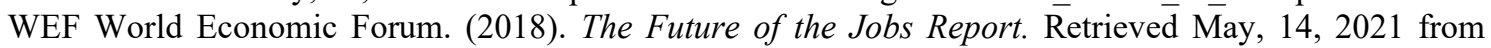
http://www3.weforum.org/docs/WEF_Future_of_Jobs_2018.pdf 


\title{
VIEW OF SECONDARY TECHNICAL SCHOOL STUDENTS ON THE PATHS AND BARRIERS TO THEIR PROFESSIONAL DEVELOPMENT
}

\author{
Dana Vicherková, \& Josef Malach \\ University of Ostrava; Faculty of Education, Department of Pedagogy and Andragogy \\ (Czech Republic)
}

\begin{abstract}
Students in the Czech Republic are increasingly interested in secondary school studies with a universal technical focus providing job security and a swift path to retraining according to existing labour market requirements.

The aim of the paper is to find out how Czech students of secondary technical schools evaluate their professional development in the course of their secondary school studies. Qualitatively oriented research is focused on the quality of development of the secondary school studies as regarded by the secondary technical school students in the Moravian-Silesian Region of the Czech Republic. The research outputs provide suggestions for students to improve their professional development throughout the secondary school studies, as well as suggestions for procedures that may help remove the occurrence of barriers in their educational paths to a technically oriented profession. A partial output of the research questionnaire survey is to describe, characterise and evaluate the idea of secondary technical schools' students about their future profession and the level of their motivation to study at Czech technical secondary schools.

Students consider the low number of teaching hours per week for teaching new modern technologies and computer-controlled machines to be a critical external barrier in their professional development. They admit low motivation to learn a large amount of theoretical information, without linking theory with practice. Practical work in workshops belongs among popular subjects.
\end{abstract}

Keywords: Professional development, students of secondary technical schools, barriers in educational paths, motivation to study, idea student's about profession.

\section{Introduction}

Critical views on the evaluation of factors influencing, both positively and negatively, the learning of the secondary technical school students in the Moravian-Silesian Region of the Czech Republic are the expressions of students' subjective opinions on the quality of teaching in terms of content and form, teaching conditions, processes related to teaching and professional practice, personal relationships in educational practice, motivational factors supporting students' interest in technology and other selected educational problems.

The problem of supports and barriers in the secondary education can also be reflected by the insight into the adult education as the secondary technical schools' students are the border group between the period of ending pubescence, when an individual creates their identity with an inevitable transition from the status of a child to an adult (adolescent) accompanied by a desire to become independent, to adjust their values, attitudes, goals. Secondary school students' self-concept is influenced by the desire to take specific patterns (e.g. from the family, extracurricular context) and the manifestation of anti-identifications, postponement of decisions, deeper socialisation, fluctuations in work or school performance, etc.

The study aims to point out the degree of readiness of the secondary school students for the further lifelong learning and entry into professional, technically oriented practice, and to find out how technical secondary school students evaluate professional development or its barriers during secondary school studies. 


\section{Support for education and lifelong learning}

Current trends of the education policy in the Czech Republic point to individuals' benefits from lifelong learning in various, e.g. economic, civic, social or technological, areas. Due to the formation and development of so-called human capital, we can talk about shifts in the economic development of current economies based on knowledge and competencies, e.g. according to the concept of Rizzo and Gallo (2012), Wawrocs and Heissler (2013). The need to educate social groups excluded from the labour market (unemployed, low-skilled) and regions affected by the decline of heavy industry, such as coal mining (which also includes the Moravian-Silesian Region in the Czech Republic), according to Eurydice (2015, pp. 8, 73). The European Union and the Ministry of Education, Youth and Sports of the Czech Republic emphasise the need to increase participation in the adult population's lifelong learning by $15 \%$. The removal of barriers to participation in education at secondary schools and universities and the promotion of interest in technology across age can help to achieve this ambitious goal.

\section{Paths to remove barriers in education}

Offering a diverse range of educational opportunities, regardless of age, is a way to eliminate indifference to education. Studies (Rabušicová, Rabušic \& Šed'ová, 2008) have pointed out the main trends in the occurrence of barriers in adult education. A case study (Kalenda \& Kočvarová, 2017, p. 71), based on research (Cross, 1981), pointed to the model of critical sociodemographic factors influencing the occurrence of barriers in contemporary Czech educational reality. Both studies emphasise three types of barriers to learning: situational, institutional, dispositional. Del Preto research (2013) focused on people without any interest in lifelong learning and identified the reasons for their demotivation for further education. An interesting outcome of the research is that "gender" is not one of the barriers to further education. Research by Rubenson (2010, p. 217) has pointed to an educational barrier related to the lack of time to learn. The adult population also shows a high workload in relation to a lack of interest in further study.

According to OECD (2011) and Kalenda and Kočvarová (2017), individual countries differ in the degree of perception of educational barriers. The Czech Republic is in the mid-range of the table according to the barrier rate (Desjardins \& Rubenson, 2013 and Kalenda \& Kočvarová, 2017, p. 74). Nordic European countries with a stronger motivation to learn are managing situational and dispositional barriers to lifelong learning most efficiently. A lack of influence of institutions with the characteristics of the "welfare state", as pointed out by structuring theory (Rubenson \& Desjardins, 2009) is persistent in the Czech Republic. A somewhat hybrid Czech model was identified by Vanhuysee (2006) and Kalenda and Kočvárová (2017, p. 74). The structure of barriers to lifelong learning in adults is relatively complex, containing situational, institutional and dispositional barriers. The results of the research (Rabušicová, Rabušic, \& Šed'ová, 2008, p. 105) explain the motivation of adults for education according to their relationship to it and the value respondents attach to it by identifying internal personality barriers (e.g. fear of failure, lack of purpose of further education) and external situational barriers (e.g. workload, health problems, many other interests) to motivation in formal and non-formal adult education. An interesting insight into the problem of students' self-evaluation as a particular effect of learning self-regulation and students' self-effectiveness was provided by research (Pandero, Jonsson \& Botella, 2017).

\section{Research methodology}

Data collection for the questionnaire research was carried out by members of the TAČR project, students of teaching and academics of the University of Ostrava in March 2020 - September 2020 who visited five selected secondary technical schools. The Technology Agency (TAČR) project is implemented by the Faculty of Education of the University of Ostrava and the Czech Machinery Cluster, the application guarantor. The TAČR project focuses on the support and innovation of education in engineering fields for the current labour market's needs. The research aimed to identify students' interest in the selected secondary technical school studies, stimuli, needs, and proposals to increase it further. The partial goal of the research conducted on 907 respondents (students of five secondary technical schools in Moravian-Silesian Region of the Czech Republic) was to identify barriers that may weaken students' initial interest in technology, engineering and new technologies and supporting factors of professional development through secondary technical school studies. For this paper, two open-ended questions were selected from the whole set of 41 items: (No. 29) What do you think could improve your professional development? (No. 30) What hinders you the most (which obstacles) in technical studies? We created 16 key categories (factors influencing the professional development of secondary technical school students) 
and 17 key categories (as obstacles in the professional development of secondary technical school students) by analysing the collected qualitative data at the level of open coding (axial and selective). They are presented in a graphic representation.

\subsection{Results}

What factors could improve the professional development of Czech students of secondary technical schools in the Moravian-Silesian Region? In the Czech context, we obtained the following results (see Graph 1). What barriers (obstacles) in professional development do the selected secondary technical schools' students in the Moravian-Silesian Region list? (see the graphical representation of results (see Graph 2) Regarding the factors influencing the professional development of students, the most frequently mentioned reason was "Increase in the number of hours of practice teaching $(20 \%$ of respondents) - the most strongly represented factor in the study support. Students (men) selected it across all years of study of secondary schools aged 15 to 19 . The second reason for supporting students' professional development was "more intense self-learning" (19\% of respondents) which related more frequently to students (men) aged 16 to 19 . The third reason for supporting development was "increasing the quality of teaching across subjects - theory and practice" (15\%). Respondents' answers include: "improve practice and vocational training", "have more intensive interaction with machines and equipment belonging to engineering", "more representation in theory and practice", "improve the diversity of the work in practice", "more experience and practice in the field". The fourth reason for supporting development was "better didactic, and professional skills/competencies of teachers" (8\% res.), chosen more frequently by students aged 17-19. Respondents' answers include: "better preparation of teachers", "more knowledge of teachers, discussions, better approach", "improve the innovative approach to teaching", "use of new terminology by teachers". The fifth reason for supporting development was the "change in the content of vocational education" (6\% res.) which applied to students across 15-19. From the list of respondents' answers: "see all parts of machines and be able to think about their function", "use of knowledge of the latest technologies", "to see more professional equipment with your own eyes, be able to touch it, connect theory with practice". The sixth reason for supporting development was "more excursions" (5\%) and "better organisation of teaching and better timetable $(5 \%)$. Both reasons were most frequently selected by students aged 17-18. Other student priorities of selected key supports for the professional development include "higher quality of curriculum interpretation" (4\%), "interest in technology, mechanical engineering" (3\%), "more intensive contact with the company" (3\%), "part-time job in the field of studies" (2\%), "higher quality of school aids" (2\%), "different choice of school" (2\%), "elimination of the pupil's own laziness" (2\%), "finances" (2\%), "higher motivation of teachers" (1\%). Among the barriers to professional development, students aged 15-19 most frequently chose "laziness" (19\%). Answers of students include: "I am lazy to learn", "laziness and comfort", "laziness and procrastination". The second obstacle in professional development was "lack of time" (19\% of respondents), which was most frequently mentioned by students (men) aged 16 - 17 years. Answers include, for example, "little time", "lack of time", "little time to study", "I do not have time to devote to school". The third obstacle to development was "other (unnecessary, non-technical) subjects" (10\%) selected by students aged 15 - 19. The rank of answers includes "unnecessary subjects", "many unnecessary subjects", "subjects that are not connected with the field of study". The fourth barrier to development was "school" (8\%), from the selected answers of the respondents we present "my school", "school and self-study", "studying at this school". The fifth obstacle to students' professional development is "poor teachers - low quality of teaching" (7\%), respondents' statements include "bad teachers", "poor didactic approach of some teachers", "annoying and lazy master in the workshop". The sixth - eighth barrier to development is "ways of teaching" (6\%). Some of the answers were "everything is very theoretical and I do not have the opportunity to try how it works", "speed of dictation by the teacher ", illogical system of explaining", "a lot of information at once", "insufficient explanation". Other barriers to development include "other interests" (6\%) and "little practice" (6\%). An alarming finding is that students consider "lack of interest in the field" (5\%) as an obstacle to development. Students stated: "during school I lost interest in the field", "lack of interest in studying the field", "lack of interest in the technical field ". A total of 5\% of students said that they were an obstacle to their development, a problem called "myself". Answers include "my clumsiness", "my brain", "my intelligence", "myself". A total of 19 pupils (3\%) consider the "quality of the curriculum" to be an obstacle to growth, such as "uninteresting topics", "information about cars that everyone knows", "lack of information". The twelfth obstacle to development is "I don't know how to do something", "I don't understand something" (3\%.), e.g. "because of the amount of theory I don't understand it", "sometimes I don't understand something", "I can't draw". Only $11(2 \%)$ students admitted the obstacle of "learning little". The following barriers to growth are: "inattention" (1\%), "classmates" (1\%), homework (1\%), health (1\%). Barriers: "transport", "money", "memory", "disruptive digital technologies" were identified in smaller numbers. 
Graph 1. Supports in the professional development as seen through the lens of students.

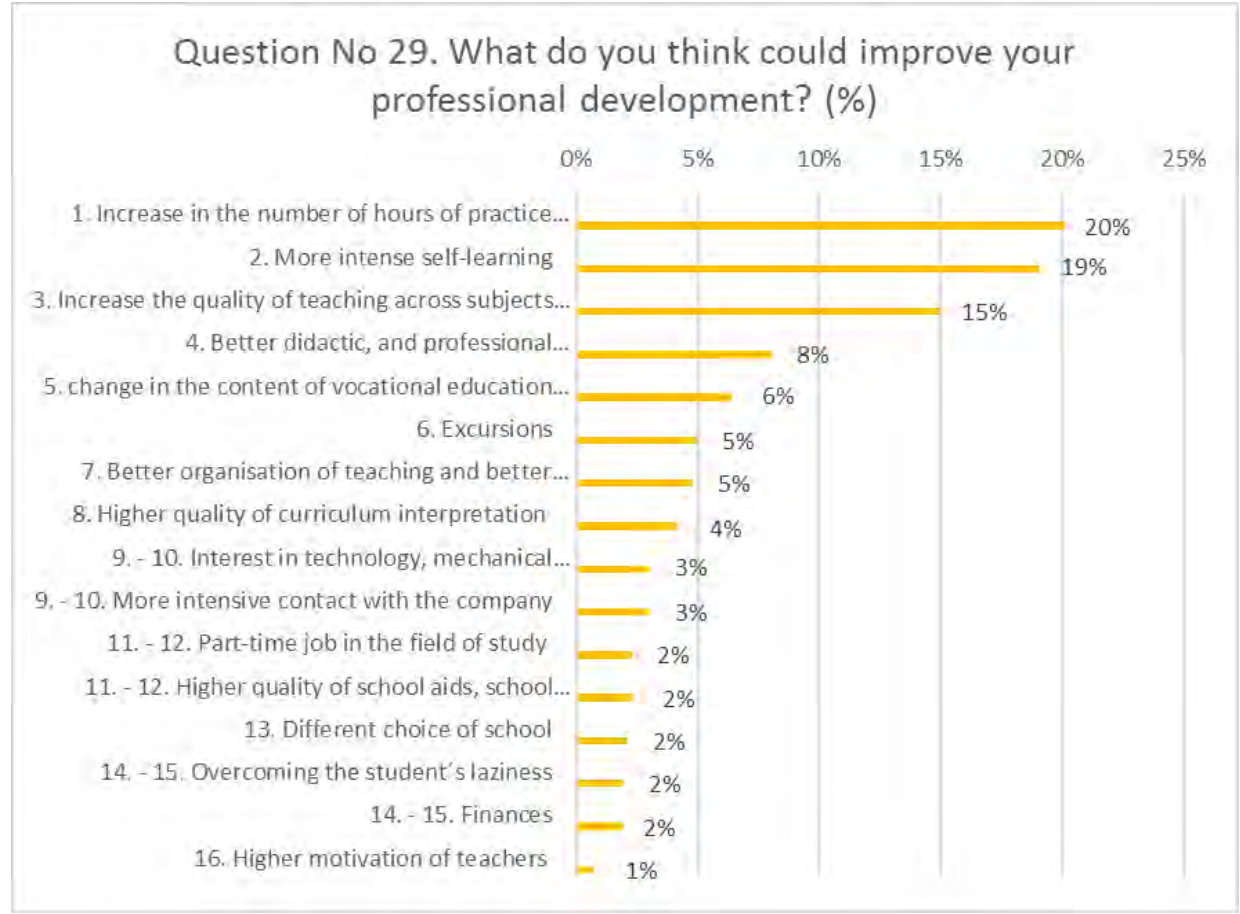

Graph 2. Barriers to the professional development as seen through the lens of students.

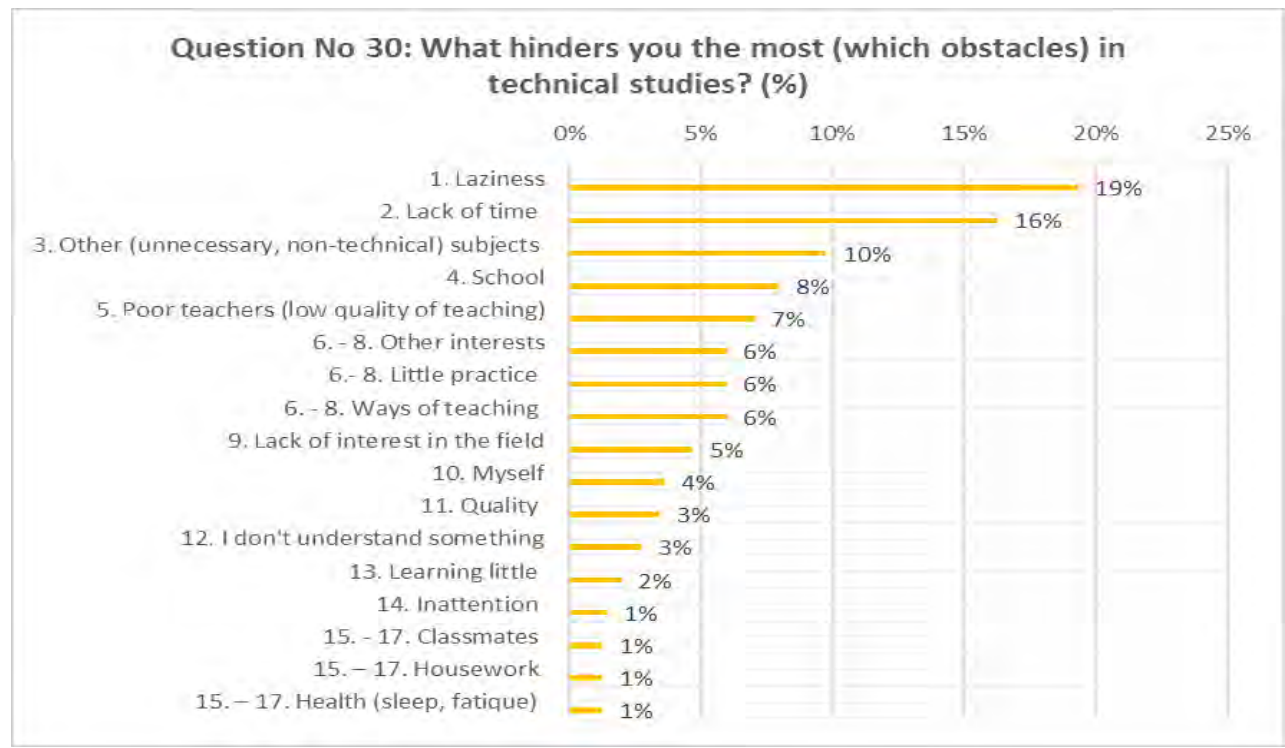

\section{Conclusion}

Students assessed difficulties (barriers) and supporting factors in professional development. Some respondents' answers were general, many students could not find a logical answer to the selected problem, and a third of respondents did not answer functionally correctly. The majority of respondents (561) were critical of the quality of their professional knowledge, skills, approaches to study the popularity of study, the field of study, the context of theory and practice in the teaching of technical secondary schools, problems related to classroom society and themselves, quality of content and forms of teaching, extracurricular interests, interest in technology and technical field, specific conditions of secondary school studies, the influence of family and home environment on studies, and other problem areas. Self-critically, the respondents commented on their laziness and lack of motivation to learn, inattention, lack of technical talent. Students consider the lack of quality professional practice and lower quality of professional subjects taught by outdated methods to be a key barrier in professional 
development. We understand pupils' self-reflection as one of the highest categories of assessment with an educational aspect. Through self-reflection, students can realise the stimulus for developing their personality, influencing their knowledge growth or obstacles in their professional procedural development. Important educational support for students' professional development is the school's effective pedagogical communication with the pupils' parents and the pupils themselves about barriers to learning and with an offer to develop plans for solving selected educational barriers (INEE, 2010, p. 88). Following the Dvořáková research (2016), we defined three types of barriers (situational, institutional, dispositional) in the access of adults (students of technical high schools) to education, in addition to personnel and curricular barriers.

\section{Acknowledgements}

This study was created as part of the research task of the Technology Agency of the Czech Republic entitled "Education in engineering and its optimisation for the needs of the labour market", ID TJ02000083.

\section{References}

Cross, P. K. (1981). Adults as learners. Increasing participation and facilitating learning. San Francisco:Jossey-Bass.

DelPreto, D. (2013). Students' voices: The live dexperience of faculty in civility as a barrierto professional formation in associate degree nursing education. Nurse Education Today,33(3), 286-290.

Desjardins, R., \& Rubenson, K. (2013). Participation patterns in adult education: The roleof institutions and public policy frame works in resolving coordination problems.European Journal of Education, $48(2), 262-280$.

Dvořáková, M. (2016). Andragogika v praxi. Odborný čtvrtetník pro vzdělávání a rozvoj dospělých 10/2016. Praha: AIVD ČR. [Dvorakova, M. (2016). Andragogy in practice. Professional quarterly for adult education and development 10/2016. Prague: AIVD CR.]

Eurydice (2015). Adult education and training in Europe. Widening access to learning opportunities.

Eurydice Report. Luxembourg: Publication Office of the European Union. Retrieved from http://eacea.ec.europa.eu/education/eurydice/documents/thematic_reports/179EN.pdf

INEE (2010). Minimum Standards for Education: Preparedness, Response, Recovery, s. 88. Retrieved from https://inee.org/standards.

Kalenda, J., \& Kočvarová, I. (2017). Proměny bariér ke vzdělávání dospělých v České republice. Studia paedagogica, vol. 22(3). [Kalenda, J., \& Kočvarová, I. (2017). Changes in barriers to adult education in the Czech Republic. Educational Studies, vol. 22(3).]

OECD (2011). Educationat a glance. Paris: OECD Publishing.

Panadero, E., Jonsson, A., \& Botella, J. (2017). Effects of self-assessment on self-regulated learning and self-efficacy: four meta-analyses. Educ. Res. Rev. 22, 74-98. doi:10.1016/j.edurev.2017.08.004.

Rabušicová, M., Rabušic, L., \& Šed’ová, K. (2008). Motivace a bariéry ve vzdělávání dospělých.In M. Rabušicová \& L. Rabušic (Eds.), Učíme se po celý život? O vzdělávání dospělých v Českérepublice (s. 97-112). Brno: Masarykova univerzita. [Rabušicová, M., Rabušic, L., \& Šed’ová, K. (2008). Motivation and barriers in adult education. In M. Rabušicová \& L. Rabušic (Eds.), Do We Learn Through Life? On adult education in the Czech Republic (pp. 97-112). Brno: Masaryk University.]

Rizzo, M., \& Gallo, A. (2012). Human capital and resources: Developments, management and strategies. New York: Nova Publishers.

Rubenson, K. (2010). Barriers to participation in adult education. In P. Peterson, E. Baker \& B. McGaw (Eds.), International encyclopedia of education (s. 234-239). London: Elsevier.

Švaříček, R., Šed’ová, K., Janík, T., Kaščák, O., Miková, M., ... Zounek, J. (2007). Kvalitativní výzkum v pedagogických vědách. Praha: Portál. [Švaříček, R., Šed’ová, K., Janík, T., Kaščák, O., Miková, M., ... Zounek, J. (2007). Qualitative research in pedagogice sciences. Prague: Portal.]

Vanhuysee, P. (2006). Czech Exceptionalism? A Comparative Political Economy Interpretationof Post-Communist Policy Pathways, 1989-2004. Czech Sociological Review, 42(6), 1115-1136.

Wawrocs, P., \& Heissler, H. (2013). Vybrané bariéry investic do lidského kapitálu. Naše společnost,11(1), 36-45. [Wawrocs, P., \& Heissler, H. (2013). Selected barriers to investment in human capital. Our society, 11(1), 36-45.] 


\title{
EXPLORING THE RELATIONSHIPS BETWEEN CONSTRUCTIVIST LEARNING ENVIRONMENT AND CRITICAL THINKING ABILITY OF SECONDARY SCHOOL STUDENTS
}

\author{
Yee Wan Kwan \\ University of St Joseph (Macau SAR)
}

\begin{abstract}
Constructivist learning environments are a core instructional factor affecting students' critical thinking (Mathews \& Lowe, 2011). However, few classroom environment research have specifically investigated relationships between students' perceptions of their learning environment and their critical thinking ability (e.g., Fraser, 2012), especially in the context of Chinese learners. Therefore this study would fill this research gap by investigating the relationships between constructivist learning environments and critical thinking ability among Hong Kong secondary school students.

The study used a cross-sectional survey design to collect data from a convenience sample of 967 students studying Liberal Studies or Integrated Humanities in Secondary Three (Grade 9) in Hong Kong. The respondents completed a self-administered questionnaire which included the Constructivist Learning Environment Survey (CLES), Cornell Critical Thinking Test Level X, and demographic information on age and gender.

The findings showed that students perceived their learning environment to be moderately constructivist in nature, and scored a moderate level of critical thinking ability. Both age and school banding differences were identified in which younger and students in schools with higher banding tended to perceive a higher degree of constructivist characteristics in their learning environment and they obtained higher critical thinking ability scores. Multiple regression analyses indicated that five of the seven independent variables were predictors of critical thinking ability. Shared Control was the strongest predictor and negatively associated with critical thinking ability. Personal Relevance, Critical Voice, and Uncertainty were positively while age was negatively related to critical thinking ability. The hypothesized model of seven demographic and CLES variables accounted for $10 \%$ of variance of critical thinking ability, suggesting a medium effect size. Findings of the study are discussed with reference to developing students' critical thinking ability in classrooms.
\end{abstract}

Keywords: Constructivist learning environment, critical thinking ability, secondary school students.

\section{Introduction}

A constructivist learning environment is an environment facilitating learning so as to develop learners' own, active cognitive abilities (Yilmaz, 2008). In other words, it helps to develop reasoning, critical thinking, understanding and use of knowledge, self-regulation and mindful reflection. However, there are few classroom environment research specifically investigating the link between students' perception of their learning environment and their critical thinking ability (e.g., Fraser, 2012), especially in Hong Kong. This study would fill this research gap by investigating the associations between constructivist learning environment and critical thinking ability of Hong Kong secondary school students.

\section{Study objectives \& significance}

The purpose of this study was to investigate the relationships between constructivist learning environment and critical thinking ability among Hong Kong secondary school students. The study was guided by the following research questions:

1. What are the differences in students' perceptions of constructivist learning environment and critical thinking ability in terms of gender, age, and school banding?

2. Which of the seven variables (i.e. gender, age, and five scales of constructivist learning environment) is the most important in predicting critical thinking ability? 
The current study would fill the research gap by providing empirical data on the relationship between constructivist learning environment and critical thinking, as well as determining the important predictors of developing students' critical thinking. Results of this study would be useful for teachers when they design lessons grounded on constructivist teaching approaches to foster students' critical thinking ability.

\section{Literature review}

\subsection{Learning environment in constructivist nature}

Constructivism could be interpreted from perspectives ranged from philosophy, science education, educational psychology to instructional technology (Driscoll, 2020). From the educational perspective, it associates with instructional theories, such as collaborative learning, student-centered learning, and authentic assessment (McNichols, 1999), assuming students that are active learners and can construct knowledge for themselves.

Educators (e.g., Dryden \& Fraser, 1998; Jonassen, 1994) proposed core characteristics that reflect a constructivist learning environment. Dryden and Fraser (1998) defined constructivist learning environment as an environment in which "students should find personal relevance in their studies (Personal Relevance), share control over their learning (Shared Control), feel free to express concerns about their learning (Critical Voice), view subject knowledge as ever changing (Uncertainty), and interact with each other to improve (Student Negotiation) (p.1)". Taylor, Fraser, and White (1994) developed an instrument entitled, Constructivist Learning Environment Survey (CLES) aligned with these theoretical characteristics suggested by Dryden and Fraser (1998). There are few instruments like CLES that is explicitly and theoretically grounded on constructivism. This study would adopt it in assessing the constructivist learning environment.

\subsection{Relationships between constructivist learning environment and critical thinking}

Existing studies that investigated the influence of learning environment on critical thinking usually adopted a pre-/post-test quasi-experimental design or qualitative methods to measure the effects of the constructivist-oriented learning environment on students' critical thinking. Most of their findings showed that there was a positive relationship between constructivist-oriented learning environment and critical thinking.

However, these studies used different forms of constructivist instructional approaches. For example, Ernst and Monroe (2006) adopted a pre- and post- test design, examining the impact of environment-based education, featured with constructivist approaches, on the critical thinking of 9th and 12th grade students in the US. They found that such constructivist-oriented program improved the post-test critical thinking of both 9 th $[t(159)=3.186, p<.01]$ and 12 th grade students $[t(221)=3.657$, $p<.001]$. As observed, these studies on constructivist learning environments which might be in the forms of learner-centered learning (Ernst \& Monroe, 2006), web-based learning (Rumpagaporn, 2007), and discussion and cooperative learning (Yang, Newby, \& Bill, 2005), their conclusions of the impacts of constructivist learning environments might not refer to same characteristics of a learning environment.

Therefore, this study aimed to further understand the associations between constructivist learning environment as measured by a standardized instrument, CLES, and critical thinking ability.

\section{Study method}

\subsection{Participants}

Data were obtained from a convenience sample of 967 students who enrolled in Secondary Three (i.e., Grades 9) in seven government aided secondary schools in Hong Kong. The sample included 425 boys $(44 \%)$ and 539 girls $(56 \%)$. They aged from 14 to 18 years and the mean was 14.8 years. They were either studied Liberal Studies or Integrated Humanities.

\subsection{Instruments and data analysis}

A questionnaire was created by combining various dimensions from the Constructivist Learning Environment Survey (CLES) (Aldridge, Fraser, Taylor, \& Chen, 2000), Cornell Critical Thinking Test, Level X (CCTT-X) (Ennis, Millman, \& Tomko, 1985) to measure perceptions on constructivist learning environment and critical thinking ability respectively. A section comprising items to measure demographic information from the participants, such as age and gender, was also included in the questionnaire. The version of five-factor structure with 25 items of CLES used in this study was modified and validated by Kwan (2020). The reliability coefficients of this Chinese version of 25-item CLES 
ranged from .67 to .93 in this study, while that of the 36 -item Chinese CCTT-X in the present study was .81 , demonstrating good internal consistency.

T-tests, analyses of variance (ANOVA) and multiple regression analysis were used to determine the differences of perceptions on constructivist learning environment and critical thinking ability scores by gender, age group, and school bandings, as well as to examine the important predictors of critical thinking ability.

\section{Study results}

\subsection{Differences in constructivist learning environment and critical thinking ability by gender, age, and school banding}

The overall mean score for CLES was $3.23(\mathrm{SD}=.49)$. With the highest possible score being 5 , a mean of 3.23 was slightly above the mid-point and indicated that the students perceived their learning environment to be moderately constructivist in nature. The total mean score of students' critical thinking ability was 22.48 ( $\mathrm{SD}=6.12$ ). With the highest possible score being 36 , a mean of 22.48 was above the mid-point, demonstrating that the students also had a moderate level of critical thinking ability.

Gender differences. Results obtained from the independent-samples t-tests indicated that there was no significant gender differences in students' perceptions of their constructivist learning environment and critical thinking ability scores $(p>.05)$.

Age differences. The range for participants' age was from 14 to 18, the age group was recoded into three sub-groups: $14(\mathrm{n}=367), 15(\mathrm{n}=440)$, and 16-18 $(\mathrm{n}=138)$. Using the ANOVA, differences were found between these three age groups on the total CLES and all its scales (i.e., Personal Relevance, Uncertainty, Critical Voice, and Student Negotiation) except for the Shared Control scale. Age difference was also found on their critical thinking ability. These results suggested that younger students perceived a higher level of constructivist nature in their learning environments across a number of scales of CLES and obtained higher critical thinking scores generally $(p<.05)$.

School banding differences. Students' perceptions of the constructivist learning environment were analyzed by their school banding: Bands $1(n=241), 2(n=588)$, and $3(n=127)$. The majority of students in Band 1 schools are assumed those with the best academic results. Differences were found on the total CLES and for all of its scales with the exception of the Shared Control scale. There was school banding difference on their critical thinking ability. Students in band 1 schools tended to perceive a higher level of constructivist learning environment across a number of scales of CLES and obtained higher critical thinking scores generally than those in other school bandings $(p<.05)$.

\subsection{Predictors of critical thinking ability}

In order of determine the predictors of critical thinking ability, correlations and regression analysis were performed (Table 1). All variables were significantly correlated with critical thinking ability except gender.

Table 1. Correlation and multiple regression analyses for associations between gender, age, and constructivist learning environment and critical thinking ability.

\begin{tabular}{lccc}
\hline \multicolumn{1}{c}{ Variable } & \multicolumn{3}{c}{ Associations with critical thinking ability } \\
& $r$ & $(\mathrm{~N}=947)$ & $(\mathrm{SE})$ \\
\hline Gender (Dummy Female=0) & .05 & $\beta$ & $(.38)$ \\
Age & $-.16^{* * *}$ & $-.12^{* * *}$ & $(.24)$ \\
Personal Relevance & $.19^{* * *}$ & $.16^{* * *}$ & $(.36)$ \\
Uncertainty & $.15^{* * *}$ & $.07 *$ & $(.31)$ \\
Critical Voice & $.11^{* * *}$ & $.08^{*}$ & $(.29)$ \\
Shared Control & $-.14^{* * *}$ & $-.21^{* * *}$ & $(.25)$ \\
Student Negotiation & $.08^{* *}$ & .03 & $(.29)$ \\
$\quad \mathrm{F}$ & & $15.37 * * *$ & \\
df & & $(7,935)$ & \\
Adjusted $R^{2}$ & \multicolumn{3}{c}{}
\end{tabular}

The $\mathrm{F}$ ratio demonstrated that gender, age and the CLES scales were significantly related to students' score of critical thinking ability. Concerning the standard regression coefficients for these seven independent variables, five variables were significant predictors of critical thinking ability. The strongest 
predictor was Shared Control $(\beta=-.21, p<.001)$ but in a negative direction. Personal Relevance $(\beta=.16$, $p<.001)$, Age $(\beta=-.12, p<.001)$, Critical Voice $(\beta=.08, p<.05)$, and Uncertainty $(\beta=.07, p<.05)$ were also the predictors of critical thinking ability. Gender and Student Negotiation had no effect on critical thinking ability. According to Kline (2011), a value of $R^{2}$ about .10 represents a medium effect size. The hypothesized model of seven variables accounted for $10 \%$ of variance of critical thinking ability, indicating a medium effect size.

\section{Discussion, implications and conclusion}

Results of this study showed that (1) the students perceived their learning environment to be moderately constructivist in nature and scored a moderate level of critical thinking ability; (2) younger students and students in band 1 schools tended to perceive their learning environment to be more constructivist in nature, and obtained higher critical thinking ability scores; (3) Shared Control, Personal Relevance, Critical Voice and Uncertainty of CLES and age were significant predictors of critical thinking ability; and (4) the seven demographic and CLES variables explained $10 \%$ of variances in critical thinking ability, indicating a medium effect size.

\subsection{Discussion}

First, younger and students in band 1 schools scored higher in constructivist learning environment and critical thinking ability in this study. Constructivist approaches are believed favorable to advanced students because they are likely equipped with knowledge and strategies for them to self-construct learning in these lessons (Driscoll, 2020; Yilmaz, 2008). Since students in band 1 schools in Hong Kong are generally those with better academic achievement, so they might be ready to learn in constructivist learning approaches and eventually result in higher critical thinking ability as expected. Similarly, Alansari and Rubie-Davies (2020)'s recent review on decades of learning environment research in pre-tertiary level also pointed out that environments with positive perceptions were significantly associated with higher levels of academic performance. However, the findings of previous studies on gender difference were mixed. Like the results of the present study, Kesal and Aksu (2005)'s study with Turkish students also found that perceptions of constructivist learning environment did not differ significantly by gender. Further studies are recommended to test whether there is gender difference in perceptions of classroom environment and in what ways.

As for the relationships between CLES scales and critical thinking ability, the results showed that four (i.e., Personal Relevance, Uncertainty, Critical Voice, and Shared Control) out of the five scales were found to be the predictors of students' critical thinking ability. These findings confirmed that characteristics of the constructivist learning environment that were favorable to students' critical thinking ability. For example, higher relevance of learning content to students' daily life, allowing to express their views on current teaching plans and methods, and less sharing of control by teachers with their students in designing and managing learning activities. Interestingly, constructivist learning environment is believed to be student-centered in nature which emphasizes students' active involvement in learning and assessment activities. However, students with minimum guidance from teachers felt lost, frustrated, and confused (Brown \& Campione, 1994). Therefore, the finding of a negative relationship between Shared Control and critical thinking ability in this study might reflect such dilemma in practicing the core ideas of constructivist learning approaches. Teachers have to maintain a balance between well-planned and guided lessons by them on one hand, on the other hand they should endure flexibility to change timely so as to address students' needs and feedback.

\subsection{Significance, limitations and conclusion}

Theoretically constructivist learning environments aim at promoting critical thinking. This study filled the research gap by examining the relationship between constructivist learning environment and critical thinking ability explicitly, measuring the operationalized characteristics of the constructivist learning environment.

There are several limitations of this study. The study employed a convenience sample which might cause selection bias affecting the generalisability of the findings to a larger population. As this study focused on Secondary Three (Grade 9) students, the findings may not be generalisable to students of other grade levels. Similar studies are suggested to conduct at different education levels, in particular the tertiary education level (Alansari \& Rubie-Davies, 2020). In addition, this study explored the relationship between demographics and constructivist learning environment and critical thinking ability, other possible factors and how these factors interacted with each other on critical thinking ability were not covered. Further researches on this topic are recommended to explore different theoretical and research methodologies. 
In conclusion, there is rare study that measured the constructivist learning environment and critical thinking ability by adopting the CLES and CCTT-X, particularly in the context of Chinese learners. Hence, the findings of this research provided empirical information about their associations. This study confirmed that most of dimensions of constructivist learning environment are important and helpful to critical thinking ability. One of the findings interestingly demonstrated that Shared Control was negatively while Critical Voice was positively associated with critical thinking ability. This finding could inform teachers who use constructivist learning approaches in making the balance between teacher-dominated guidance and student-centered knowledge construction in their classrooms.

\section{References}

Alansari, M., \& Rubie-Davies, C. (2020). What about the tertiary climate? Reflecting on five decades of class climate research. Learning Environments Research, 23, 1-25.

Aldridge, J. M., Fraser, B. J., Taylor, P. C., \& Chen, C. C. (2000). Constructivist learning environments in a crossnational study in Taiwan and Australia. International Journal of Science Education, 22(1), 37- 55 .

Brown, A., \& Campione, J. (1994). Guided discovery in a community of learners. In K. McGilly (Ed.), Classroom lessons: Integrating cognitive theory and classroom practice (pp. 229-270). Cambridge, MA: MIT Press.

Driscoll, M. P. (2020). Psychology of learning for instruction (4th ed.). Boston: Pearson.

Dryden, M. \& Fraser, B. J. (1998, April). The impact of systemic reform efforts in promoting constructivist approaches in high school science. Paper presented at the annual meeting of the American Educational Research Association, San Diego, CA.

Ennis, R. H., \& Millman, J., \& Tomko, T. N. (1985). Cornell Critical Thinking Tests (3rd ed.). Pacific Grove, CA: Midwest Publications.

Ernst, J., \& Monroe, M. (2006). The effects of environment-based education on students' critical thinking skills and disposition toward critical thinking. Environmental Education Research, 12(3/4), 429-443.

Fraser, B. J. (2012). Classroom learning environments: Retrospect, context and prospect. In B. J. Fraser, K. Tobin, \& C, McRobbie (Eds.), Second international handbook of science education (Vol. 2, pp. 1191-1239). Dordrecht: Springer.

Jonassen, D. (1994). Thinking technology: Toward a constructivist design model. Educational Technology, 34(3), 34-37.

Kesal, F. \& Aksu, M. (2005). Constructivist learning environment in English language teaching methodology II courses. Hacettepe University Journal of Education, 28(1), 118-126.

Kline, R. B. (2011). Principles and practice of structural equation modeling (3rd ed.). New York: Guilford Press.

Kwan, Y.W. (2020). Psychometric properties of a Chinese version of the Constructivist Learning Environment Survey among secondary-school students in Hong Kong. Learning Environments Research, 23, 167-184.

Mathews, S. R., \& Lowe, K. (2011). Classroom environments that foster a disposition for critical thinking. Learning Environment Research, 14(1), 59-73.

McNichols, T. J. (1999). Deconstructing constructivism: The Kantian connection. Journal of Philosophy and History of Education, 49, 141-146.

Rumpagaporn, M. W. (2007). Students' critical thinking skills, attitudes to ICT and perceptions of ICT classroom learning environments under the ICT schools pilot project in Thailand (Doctoral dissertation). http://adt.caul.edu.au/. Accessed 6 March 2012.

Taylor, P. C., Fraser, B. J., \& White, L. R. (1994, April). CLES: An instrument for monitoring the development of constructivist learning environments. Paper presented at the annual meeting of the American Educational Research Association, New Orleans, LA.

Yang, Y., Newby, T., \& Bill, R. (2005). Using Socratic questioning to promote critical thinking skills through asynchronous discussion forums in distance learning environments. American Journal of Distance Education, 19(3), 163-181.

Yilmaz, K. (2008). Constructivism: Its theoretical underpinnings, variations, and implications for classroom instruction. Educational Horizons, 86(3), 161-172. 


\title{
ONLINE LEARNING QUESTIONNAIRES BASED ON RENEWABLE ENERGY RESEARCH EQUIPMENT
}

\author{
F. Javier Maseda Rego ${ }^{1}$, Itziar Martija López ${ }^{1}$, Patxi Alkorta Egiguren ${ }^{2}$, Izaskun Garrido \\ Hernández ${ }^{1}$, \& Aitor J. Garrido Hernández ${ }^{1}$ \\ ${ }^{I}$ Automatic Control Group (ACG), Institute of Research and Development of Processes, Faculty of \\ Engineering in Bilbao, University of the Basque Country (UPV/EHU) (Spain) \\ ${ }^{2}$ Engineering School of Gipuzkoa, University of the Basque Country (UPV/EHU) (Spain)
}

\begin{abstract}
This paper resumes the main ideas to develop different sets of questionnaires based on renewable energy research equipment to improve online learning in engineering education. These educational activities, on the one hand, promote the connection between technological and education environments and, on the other hand, improve the motivation for studying theoretical and practical issues. The implementation of the proposed teaching and learning tasks will contribute to integrate students with different motivation and attitudes since the use of the close physical equipment for questionnaires development has an evident educational benefit when using it as a study model.

The evolution of technological environments to educational units involves a functional Disassembly/Analyze/Assembly conversion to different modules adapted to specific subjects, the link with the theoretical knowledge, and finally, the questionnaire construction.

The combination proposed offers the following positive results in master or grade studies: the effectiveness of competences training is improved, the students experimental work progresses significantly and the students' motivation for better theory comprehension is more intensively developed. The use of these kind of questionnaires as educational tools is not new and their advantages are well known: the quick feedback results and the systematic data collection to support the educational proposal effectiveness, among others. Nevertheless, this tool has become a necessity with the massive use of online education.

In summary, promoting the evolution of engineering education to online techniques and the use of renewable energy research equipment to promote the students' vision on social necessities are two examples of educational goals stated in this paper.
\end{abstract}

Keywords: Engineering education, renewable energy, learning methodologies.

\section{Introduction}

The new generation of students has grown up with a great knowledge of digital technology and a no less concern for environmental issues. This reality has been taken into account in academic studies offered by the universities (Alameri, Masadeh, Hamadallah, Ismail \& Fakhouri, 2020). The inclusion of grade and master programs related to Renewable Energy Generation and Information and Communication Technologies topics has a great acceptance among the students. In addition, the Covid19 pandemic has given an impulse to the online education in the last year, in many traditional face-to-face university studies (Kövecses, Lampert, Pongráez \& Lörinez, 2020).

The growth and importance of renewable energy generation, fundamentally solar (Ott, Broman, Blum, 2018), wind and marine (Lekube, Garrido, Garrido, Otaola \& Maseda, 2018), are motivated by the need to overcome the negative impact on the environment associated with fossil fuels. This fact has led to an increased interest in these technological areas and to the importance of the required engineering education in these fields (Gutiérrez, Ghotge, Siemens, Blake-Rath \& Pätz, 2018).

Renewable energy research equipment in is not always used in educational areas, being labelled as complex machines. The methodology of dissection of industrial artifacts based on reverse engineering techniques has been applied with the objective of improving the comprehension of their functionality (Dalrymple, Sears \& Evangelou, 2011). Functional Disassemble/Analyze/Assemble (fDAA) is a 
well-adapted educational methodology applied to renewable energy generation equipment. The "functional" term in this context means that DAA activities will be performed based on the relationship between input and output signals for each block of the energy system (Martija, Maseda \& Martija, 2013). In addition, the fDAA activities are developed to be integrated in different teaching and learning methodologies, such as, Project Based Learning (PjBL) (Maseda, Martija \& Martija, 2014), Challenge Based Learning (CBL) and Research Based Learning (RBL) (Fojcik, Fojcik, \& Pollen, 2020). This combination, active educational methodology and fDAA activities, creates a general framework for obtaining a better and deeper comprehension of theoretical and practical concepts based on the division of complex equipment into basic functional components. The limit of this division depends on the academic interest for a specific subject.

In this framework, the online learning questionnaires have become one of the most important issues, because the modularity and analysis of each block or component of the equipment are used for developing different questionnaires (Esnaola-Arribillaga and Bezanill, 2020). These questionnaires are a powerful tool because they are easy to use anywhere and anytime, give a quick feedback for students, and allow teaching staff to have a complete assessment picture about the acquired knowledge and competences, among others. However, as main disadvantages, there are the considerable amount of time for generating a complete set of online questionnaires for a specific subject and the potential fraud in their resolution (Pehlivanova, 2019).

The following sections present the research equipment used as case of study, the online questionnaires, the discussion about schedule, feedback, assessment and potential fraud, and finally, the conclusions.

\section{Educational environment}

The educational activity proposed can become a great advantage for understanding renewable energy generators and their energy converters in a common framework.

At the Faculty of Engineering in Bilbao, in the University of the Basque Country, one of the renewable energy research equipment used for educational proposals is a solar plant implemented by $2 \mathrm{~kW}$ solar panels and different power electronic converters. This research equipment is integrated in the educational environment for teaching and learning activities. Figure 1 shows the integration where the solar scenario is combined with the PjBL methodology, fDAA activities and the assessment tools.

Figure 1. Educational environment.

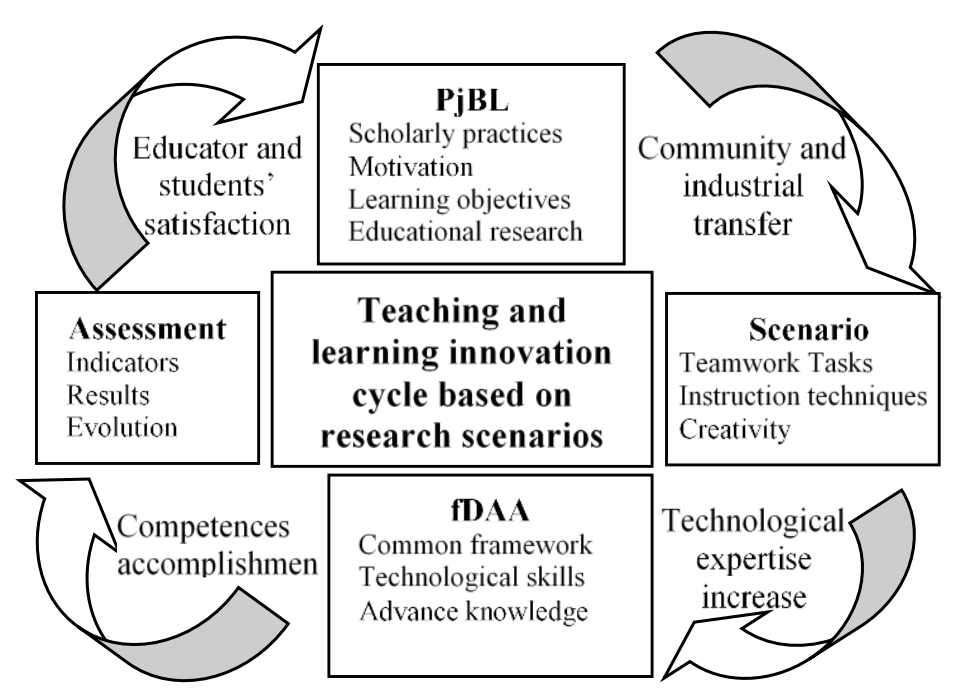

The online questionnaires are included in this environment in the assessment module, but their real practical use is in the entire educational environment. They are part of the PjBL methodology because the continuous evaluation is based on difficulty-adapted online questionnaires which are programmed along the semester. The educational scenario activities are the main pole of attraction for students. On these scenarios, numerical and theoretical questions applied to real cases are developed for PjBL implementation. The fDAA activities help to modulate questionnaires into different technological topics. 


\section{Renewable energy research equipment and online questionnaires}

The systematic collection of evidences to corroborate the educational proposal effectiveness in the different aspects of the teaching-learning process should be implemented (Weronika, 2020). Among these evidences, the online questionnaires constitute a relevant help. Moodle platform is one of the most commonly applied tools to develop different sorts of questionnaires and their subsequent analysis (Luminita Gogan, Sirbu \& Draghici, 2015).

The online questionnaires have different aspects, which must be carefully studied before using them: Are they easy to develop? Do they improve information transfer? Are they a good assessment tool? Do they favor the communication and the interaction? Do they support the preparation of the matter of study? Do they develop skills related to Bloom's taxonomy, such as, knowledge, comprehension, application, analysis, among others? The answer to these questions depend on the educational environment where the questionnaires are used.

The analysis of the questionnaires results gives an extensive vision about different educational aspects: students' assessment distribution bias, standard deviation or variance of this distribution, difficulty index of different matter topics or their discriminative performance, among others.

Moodle questionnaires present a wide sort of questions. Figure 2 shows a graphic synopsis of the most commonly used questions and their relationship with the renewable energy research equipment.

Figure 2. Questionnaires and the relationship between renewable energy research equipment and questions.
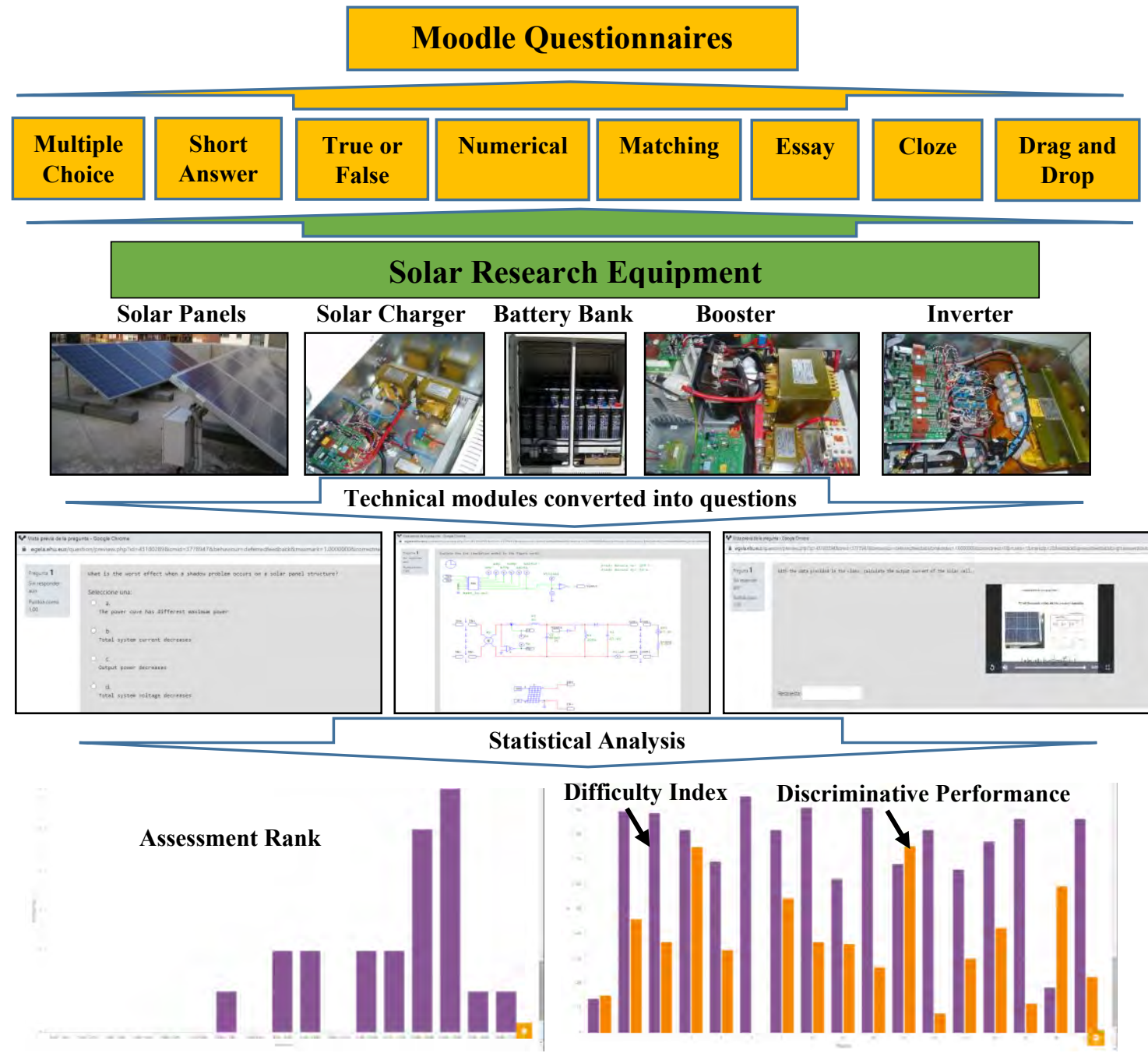

The possibility of integrating images, videos, simulation models, in any sort of question, such as, Multiple Choice, Short Answer, True or False, or Matching, improves the aesthetic appearance of questionnaires and provides them with a more attractive dynamic for students. The ability to develop engineering problems in a set of Numerical and Cloze questions makes them easier to understand and, 
at the same time, more feasible to resolve. The different Drag and Drop questions allow to configure block diagrams and simulation models, extending the possibilities of the questionnaires within the experimental activities. In summary, the quantity and variety of the sort of questions that are available in Moodle allow integrating the majority of the traditional engineering exams in questionnaires. Finally, the statistical analysis of questionnaire results are easy to obtain. In Figure 2 it is possible to observe a students' mark rank graphic and the relationship between difficulty index and discriminative performances of the different questions.

\section{Discussion: Schedule, feedback, assessment and potential fraud}

Most of the universities base their teaching and learning methodologies on face-to-face interaction. However, the online activities are growing up and platforms like Moodle have become ubiquitous tools (Esnaola-Arribillaga and Bezanill, 2020). This increase in the online activities use results in different issues that must be discussed. Schedule, feedback, assessment and potential fraud in the questionnaires are some important issues for a successfully implementation.

The schedule must be carefully studied because the questionnaires should put a constant pressure on students for obtaining a continuous effective attention. The excessive number of questionnaires with an established date can produce an excess of psychological pressure, which can develop a certain disappointment and a loss of interest in the subject studied, in case of repetitive low results.

The level of feedback is other aspect that should be analyzed because the answers could disable the question for other questionnaires, and this means having to reconstruct the questionnaires every year. On the other hand, the feedback is necessary for students to analyze their own faults and to motivate themselves for theory thoughtful study.

Marks are a fundamental issue for students and the online assessment including questionnaires have an increasing weight in the final students' marks. It is unlikely to obtain $100 \%$ right answers on online questionnaire because it is difficult that students understand all the questions without doubts, what could lead them to take a wrong solution. In this way, the lecturers should have solutions for this situation and in particular, if the questionnaires have negative punctuation in wrong answers.

Finally, a considerable disadvantage associated with online questionnaires is the potential fraud in its different modalities (Pehlivanova, 2019). The pandemic Covid19 became an inflection point last year when these educational tools had to be applied in a massive way and so, the possibility of fraud was increased. However, this situation should not prevent the use of these educational platforms. Different methodologic, organizational and technologic solutions could be applied (Pehlivanova, 2019), (Matos, Carvalho, Torräo \& Vieira, 2012).

As a real example of application -Power Electronics, second semester subject, Grade of Industrial Electronics and Automation, in the Faculty of Engineering in Bilbao-, the schedule used is shown in Table 1. This schedule was applied from January 2020 to May 2020 during Covid19 pandemic. Timetable only shows the programmed questionnaires and how they are considered in the final student mark.

Table 1. Schedule proposed for online questionnaires and students global assessment.

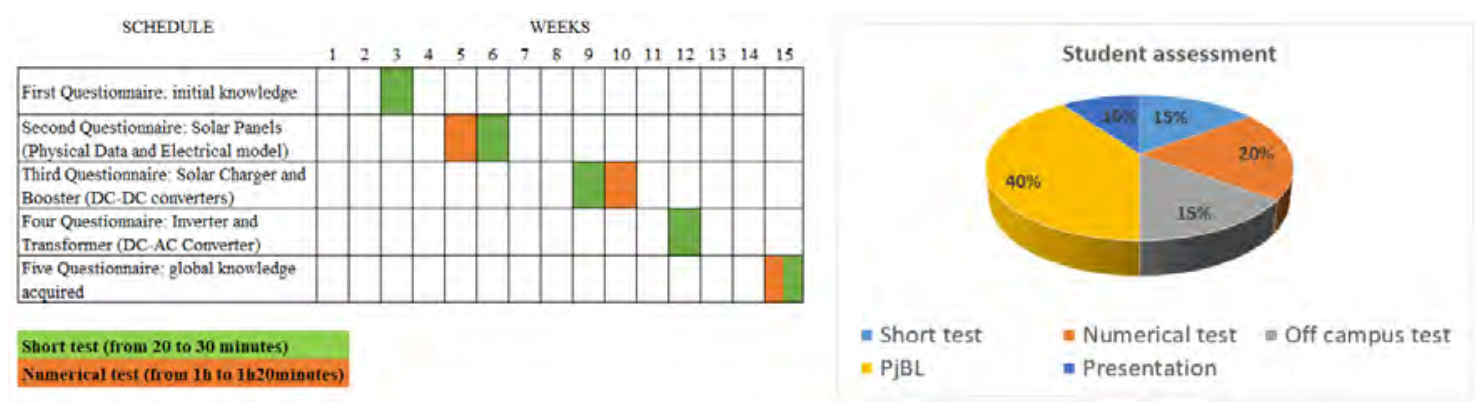

An important aspect in the ECTS (European Credit Transfer System) is the off-campus study time that the student weekly spends in different academic tasks. In these tasks the online asynchronous questionnaires can play an important role for working specific subject aspects, if they result interesting for students. The renewable energy research equipment is very attractive for them and the questionnaires have become something similar to an online game for playing. In addition, these off-campus activities, related to the online questionnaire, help in a more effective $\mathrm{PjBL}$ implementation to complement the face-to-face activities. 


\section{Conclusions}

The progressive use of online platforms and in particular of online questionnaires has improved the academic efficiency in both teaching and learning processes. This improvement has been reflected in the student marks. Additionally, students' vision about the assessment methods has also positively evolved.

The renewable energy research equipment links the theoretical knowledge to a real solar energy plant and, in this way, facilitate the required competencies for professional development of future engineers in this technological area. In the next few years, the new engineering advances in renewable energy generation will be a crucial necessity. The engineering education will have to give the methodological tools for this development, and the online platforms will help in this task.

The environment created allows collecting the experiences of students and teachers, promoting its adaptation and evolution. Based on this same principle, the indicators and tools for evaluating the proposal will also evolve during the next years.

Finally, the Covid19 pandemic has supposed a great challenge for many universities based on face-to-face education in which the questionnaires have become a useful tool for evolving towards an online education. In addition, this change has come to stay.

\section{Acknowledgements}

This work was supported in part by the Basque Government, through project IT1207-19 and by the MCIU/MINECO through RTI2018-094902-B-C21/RTI2018-094902-B-C22 (MCIU/AEI/FEDER, UE).

\section{References}

Alameri, J., Masadeh R., Hamadallah, E., Ismail, H. B., \& Fakhouri H. N. (2020). Students` Perceptions of E-learning platforms (Moodle, Microsoft Teams and Zoom platforms) in The University of Jordan Education and its Relation to self-study and Academic Achievement during COVID-19 pandemic. Advanced Research \& Studies Journal, 11 (5), 21-33.

Dalrymple, O., Sears D. A., \& Evangelou, D. (2011). The Motivational and Transfer Potential of Disassemble/Analyze/Assemble (DAA) Activities. Journal of Engineering Education, 100 (4), 741-759.

Esnaola-Arribillaga, I., \& Bezanill, M. J. (2020). Levels of Moodle Use to Support University Face-to-Face Teaching. IEEE Revista Iberoamericana de Tecnologias del Aprendizaje, 15 (3), 129-137.

Fojcik, M., Fojcik, M. K., \& Pollen, B. (2020). Students in Research-Experience with Research-Based Teaching. Education and New Development (END), 122-126.

Gutiérrez, M., Ghotge R., Siemens, A., Blake-Rath, R., \& Pätz, I. (2018). Influence of diversity in lectures on the students` learning process and on their perspectives about renewables energies in an international context - The students` view. Solar Energy, 173, 268-271.

Kövecses, V. G., Lampert, B., Pongráez, A., \& Lörinez, C. (2020). University Lectures' Distance Learning Experiences Gained during the COVID-19 Pandemic Period. IEEE International Conference on Cognitive Infocomunications, 173, 268-271.

Lekube, J., Garrido, A. J., Garrido, I., Otaola, E., \& Maseda, J. (2018). Flow Control in Wells Turbines for Harnessing Maximum Wave Power. Sensors, 18 (2), 535.

Luminita Gogan, M., Sirbu, R., \& Draghici, A. (2015). Aspects concerning the use of Moodle platform Case study. Procedia Technology, (19), 1142-1148.

Martija, I., Maseda, F. J., \& Martija, I. (2013). Functional Dissection of Power Electronic Systems as Learning Technique. IEEE Global Engineering Education Conference (EDUCON), 11-15.

Maseda, F. J., Martija, I., \& Martija, I. (2014). An Active Learning Methodology in Power Electronic Education. IEEE Frontiers in Education (FIE), 1-5.

Matos, R., Carvalho, F., Torräo, S., \& Vieira, T. (2012). Moodlewather: One Year Experience of Detecting and Preventing Fraud When Using Moodle Quizzes. International Conference on Education and New Learning Technologies (EDULEARN).

Ott, A., Broman, L., \& Blum, K. (2018). A pedagogical approach to solar energy education. Solar Energy, 173, 740-743.

Pehlivanova, T. (2019). Prevention of Cheating when Using Quizzes in Moodle. International Conference on Virtual Learning (ICVL).

Weronika, F. (2020). Moodle quizzes and their usability for formative assessment of academic writing. Assessing Writing. (46). 


\title{
EDUCATIONAL INITIATIVES TO DEVELOP TRANSVERSAL SKILLS IN THE MANAGEMENT SUBJECT OF MASTER'S DEGREE IN INDUSTRIAL ENGINEERING AT UNIVERSITAT POLITÉCNICA DE VALÉNCIA
}

\author{
Mónica Martínez-Gómez ${ }^{1}$, José Jabaloyes, \& Andrea Conchado Peiró \\ Centre for Quality and Change Management, Universitat Politècnica de València, València, València,
} (Spain)

\begin{abstract}
This work presents an improvement of the structure and methodology of a subject entitled Management, belonging to the Master's Degree in Industrial Engineering (ETSII) at the Universitat Politècnica de València (UPV). The presented subject deals with the basic and fundamental aspects that the student will need in order to correctly perform the functions of business management in changing and competitive markets and environments and contributes to the formation of professionals capable of carrying out management, direction and evaluation tasks in productive organizations. From the subject, the students' management skills are strengthened to elaborate and build strategic alternatives of decision, both in relation to the understanding of the problems, as well as in the decision making and in the evaluation of the consequences that the own actions can have for the company and for the people. It is centered on the improvement of professional skills. In this context, UPV transversal competences (TC), aim to synthesize a competence profile acquired by all UPV graduates. This study comes from an Institutional Educational Innovation and Improvement Projects to develop a methodological coordination through webs of support in ETSII CT (PIME/19-20/151). The main goal of this project was to make easier our students to acquire the more complex CTs-UPV with an effective model that does not place an additional burden on instructors, providing students with e-learning resources such as support for their training.

This study is focused in CT04.-Innovation, Creativity and Entrepreneurship. Innovation is shown as a key competence for companies to remain competitive in the market. Innovation is based on creativity, knowledge and organization, understood as a way of working to achieve objectives. A new trend in higher education is the current shift towards improving innovation, creativity and entrepreneurship of students.

To work on these skills, students of Management have to do different exercises in groups where there are 4 to 6 randomly selected students with different roles. Each working group will start by creating a company, on which the different tools and methodologies will be developed through practical cases to achieve innovative and creative solutions that add value to the main stakeholders.

The achievement of the proposed techniques for developing Innovation, Creativity and Entrepreneurship competency has been revealed as a significant aspect for the students, and the web CTs-UPV designed on the project (https://ctetsii.blogs.upv.es) has been considered as a strong support for their achievement.
\end{abstract}

Keywords: Transversal skills, web ETSII transversal competencies, innovation competency, group dynamics.

\section{Introduction}

In the context of the European Higher Education Area (EHEA) it is necessary to guarantee that at the end of the degree the different competences have been achieved, the specific skills of the subjects studied of each degree and the acquisition of another skills, so-called transversal competences. The institutional project of Transversal Competence of the Universitat Politècnica de València (TC-UPV) carries out a classification in 13 competences (TC) were defined and introduced within all the curricula: Understanding and integration (TC1), Application practical thinking (TC-2), Analysis and problem solving (TC-3), Innovation, creativity and entrepreneurship (TC-4), Project design (TC-5), Teamwork and leadership (TC-6), Professional and ethical responsibility (TC-7), Effective communication (TC-8), Critical thinking (TC-9), Knowledge of contemporary issues (TC-10), Continuous learning (TC-11), Planning and time management (TC-12), and Instrumental specific (TC-13).

${ }^{1}$ Corresponding author: momargo@eio.upv.es; Tel.: +34-963-877-000; ORCID: orcid.org/0000-0003-2401-9403 
The UPV, at this time in which the adaptation to learning environments different from the usual ones due to the COVID19 pandemic, has gained special relevance, and always in its commitment to seek synergies of all institutional actions that are being carried out in relation to the improvement of the teaching-learning process initiated the 2018-19 academic year a joint plan of educational innovation, under the name of "Learning and Teaching" (A+D).

The School of Industrial Engineering (ETSII) through the Teaching Innovation project PIME/19-20/151 has designed an e-learning platform, with the aim to make easier the acquisition of these skills by students. The goal of this platform is to bring students closer to these competences as you can see in Figure 1.

Figure 1.

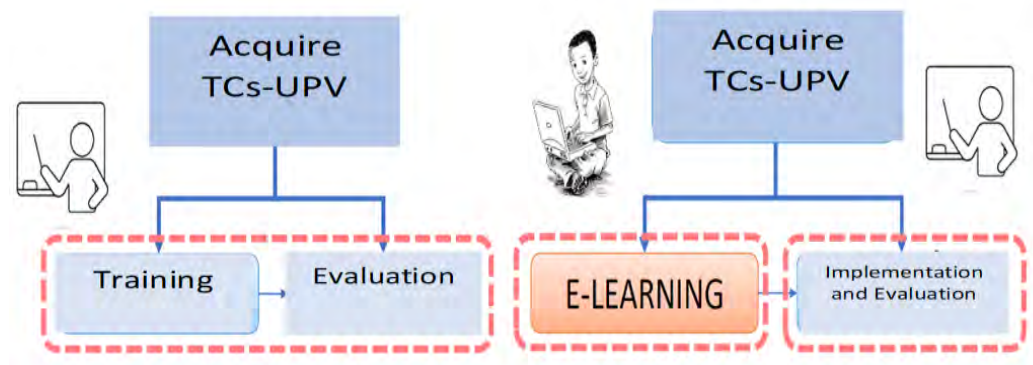

Source: Presentation of Institutional PYMES ETSII. Transversal Competences

The main objective of this work is to analyze if the level of CT-04, Innovation, creativity and entrepreneurship has increased after the students have used the platform.

This paper is structured as follows. Section two describes a review of the innovation competency. The third section presents the methodological framework for the design and implementation of this competence in the platform. Finally, the main results and conclusion are presented.

\section{Innovation competence}

Currently, one of the prerequisites required by companies is that professionals improve their qualifications in soft skills. The innovation competency appears as a source of competitive advantage in the business world. Innovation has become a relevant factor for the achievement of a competitive suitable advantage of companies in the market. The innovation competency can be considered as a cluster of different capacities and skills. However, it is not easy to define innovation, since it implies the acquisition of different capabilities and capacities among which the following are noteworthy: creativity, creative problem-solving, problem identification, independent thinking, be open to new ideas, focus on research, team work, forward-looking approach, among others and which have been discussed in different papers (Kairisto-Mertanen \& Mertanen, 2012; Marin-Garcia et al., 2011; Marin-Garcia et al., 2012, Martinez-Gomez, 2017 and Penttilä \& Kairisto-Mertanen, 2012 ). Innovation is a complex process that comprises several competencies, such as, perception of opportunities, ideas generation and evaluation, action plans, cooperation and risk. It is one of the most competitive advantage in determining the success or failure of a company in the global market, and nowadays is considered a as the magical recipe for all of today's problems in companies. In this context, we can define innovation as a presentation of the novelty (an idea, procedure, device, invention or process) or improvement of something that exists and adds value, and is useful for organizations. In order to improve organizational or group performance, innovation begins with generating ideas and finishes with implementing and using them (Marin-Garcia, Perez-Peñalver, \& Watts, 2013; Perello-Marin, Marin-Garcia, \& Marcos- Cuevas, 2013; Ramirez Bayarri, Marin-Garcia, \& Atares-Huerta, 2016).

A new trend in higher education is the current shift towards improving innovation, creativity and entrepreneurship of students. To build innovation competency, companies must include innovation in their competency models. Innovation represents the strategic process for competitiveness. In this context it has become an essential condition to know the expectations and needs of the customers. Many companies have opted to place the customer at the center of their business strategy as a formula to offer him what he demands and thus obtain better results.

A program of change towards innovation begins by defining what is of value to the customer, which will allow many innovative strategies to be generated, as can be seen in the Excellence Model for Innovation Management (EMOI) shown in Figure 2, which is based on the continuous improvement cycle or Deming cycle (PDCA). The first of the four stages covered by the EMOI model is fundamental for the success of its implementation and is the one that basically very few organizations develop. It basically consists of knowing the expectations and needs of customers and, therefore, understanding the purpose of 
the organization and its environment. The need to know the customer arises from the phrase "the world needs empathy" and that is what we will try to teach the students: how to empathize with their customers which contribute to increase their innovation competence.

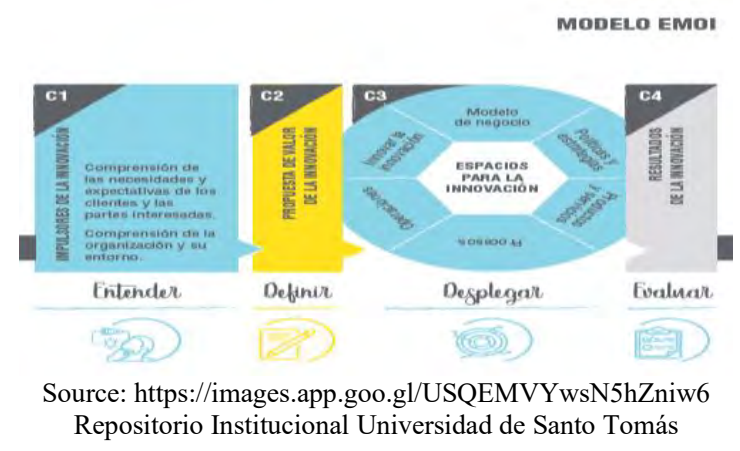

\section{Methodology}

To design the e-learning platform, the 6 transversal competencies that students recognized that they had more difficulties in acquiring were chosen: CT-4, CT6, CT-7, CT-10, CT-11 and CT12. The teachers who participated in the project focused on one of the competencies they had to evaluate in their subject and their contribution was to create an educational video explaining the methodology or activity they were going to work on to enhance it. With all the material, the ETSII TCs web page was created and can be accessed at https://www.etsii.upv.es/competencias/index-es.php.

At the beginning of the subject, the professors encourage the students to enter the page and consult the contents. In order, to check the usefulness of this tool, a survey was created by the Institute of Education Sciences. The survey was given to the students at the beginning and at the end of the course, to evaluate the level of knowledge of the students in the competence before and after visualizing its contents. The complete questionnaire is available upon request from the authors.

In our case we evaluated the competence CT-04 and the sample consisted of 72 students of the subject Business Management (BM), belonging to the Official Master's Degree in Industrial Engineering. As it was an online survey, only 30 students answered.

The Innovation Competences questions in the survey are showed in table 1.

Table 1. Items of Survey Innovation Competence.

Items of Survey Innovation Competence

1. I critically analyze the concepts and theories presented in the subjects.

2. In certain subjects, once I have studied them in depth, I am able to contribute personal ideas and justify them.

3. When a theory, interpretation or conclusion is presented in class or in books, I try to see if there are good arguments to support it.

4. I look for alternatives and original solutions to problems that are different from those usually used.

5. I am able to question the given things and when faced with a problem or challenge I try to identify aspects that can be improved or opportunities that can be taken advantage of.

6. I am able to use some creativity strategy and/or technique to generate ideas/solutions and represent them in a way that is understood.

7. I try to integrate knowledge I have acquired in different subjects to generate new ideas or proposals.

8. Before implementing an idea or solution, I analyze in depth the expected results to evaluate the value of the solution and draw conclusions.

9. To carry out an improvement or innovation, I plan in detail an action plan with its tasks and phases and I execute and control them.

10. Faced with a problem, to carry out an improvement or innovation, I plan in detail an action plan and execute its phases.

Once the data has been obtained, we proceeded with the statistical analysis. 


\section{Results}

The main descriptive statistics are shown in the Table 2, and for better understanding means are represented in Figure 3.

Table 2. Descriptive statistics of items of survey innovation competence.

\begin{tabular}{|c|c|c|c|c|c|c|c|c|}
\hline \multirow[t]{2}{*}{ Survey } & \multicolumn{4}{|c|}{ Pre } & \multicolumn{4}{|c|}{ Post } \\
\hline & Mean & $\begin{array}{l}\text { Standard } \\
\text { Deviation }\end{array}$ & Min & Max & Mean & $\begin{array}{l}\text { Standard } \\
\text { Deviation }\end{array}$ & Min & Max \\
\hline I critically analyze & 5,00 & 0,00 & 5,00 & 5,00 & 5,00 & 0,00 & 5,00 & 5,00 \\
\hline In certain subjects, & 4,17 & 0,83 & 3,00 & 5,00 & 4,37 & 0,49 & 4,00 & 5,00 \\
\hline When a theory, & 3,93 & 0,94 & 3,00 & 5,00 & 4,03 & 0,81 & 3,00 & 5,00 \\
\hline I look for alternatives & 3,00 & 1,34 & 1,00 & 5,00 & 4,00 & 0,00 & 4,00 & 4,00 \\
\hline I am able to question & 3,07 & 1,01 & 2,00 & 5,00 & 4,43 & 0,90 & 3,00 & 5,00 \\
\hline $\begin{array}{l}\text { I am able to use } \\
\text { some creativity }\end{array}$ & 3,93 & 0,58 & 3,00 & 5,00 & 4,33 & 0,48 & 4,00 & 5,00 \\
\hline I try to integrate & 3,80 & 0,66 & 3,00 & 5,00 & 4,07 & 0,83 & 3,00 & 5,00 \\
\hline Before implementing & 4,00 & 0,74 & 3,00 & 5,00 & 4,67 & 0,48 & 4,00 & 5,00 \\
\hline $\begin{array}{l}\text { To carry out an } \\
\text { improvement or i }\end{array}$ & 3,80 & 0,85 & 3,00 & 5,00 & 3,73 & 0,52 & 3,00 & 5,00 \\
\hline $\begin{array}{l}\text { Faced with a } \\
\text { problem }\end{array}$ & 3,37 & 0,85 & 2,00 & 5,00 & 3,90 & 0,48 & 3,00 & 5,00 \\
\hline
\end{tabular}

Figure 3. Means of items.

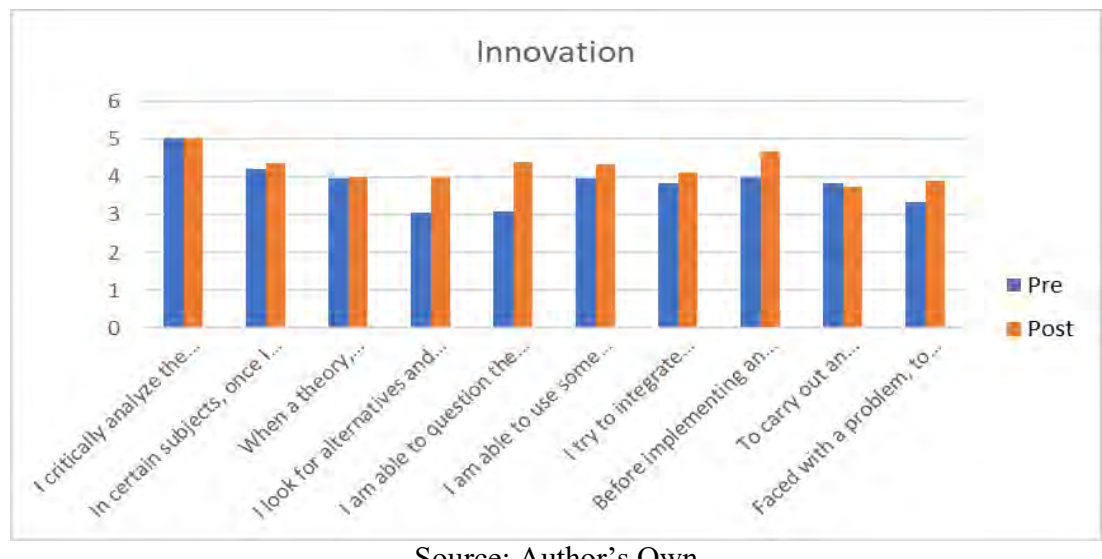

Source: Author's Own

As we can appreciate in Figure 3, except in the first and ninth items (I critically analyze the concepts and theories presented in the subjects and To carry out an improvement or innovation, I plan in detail an action plan with its tasks and phases and I execute and control them), students claimed to have improved their performance after working with the e-learning platform. To regard if there were indeed significant differences, an ANOVA was performed. Results are showed in Table 3 and we can notice that in many of the items the difference are significance.

Table 3.

\begin{tabular}{lrrrrr}
\hline & Sum of Squares & df & Mean of Scare & $\mathrm{F}$ & P-value \\
\hline In certain subjects, once I have &, 600 & 1 &, 600 & 1,283 &, 262 \\
When a theory, interpretation &, 150 & 1 &, 150 &, 194 &, 661 \\
I look for alternatives and orig & 15,000 & 1 & 15,000 & 16,731 &, $000^{* *}$ \\
I am able to question the given & 28,017 & 1 & 28,017 & 30,525 &, $000^{* *}$ \\
I am able to use some creativity & 2,400 & 1 & 2,400 & 8,419 &, $005^{* *}$ \\
I try to integrate knowledge I h & 1,067 & 1 & 1,067 & 1,894 &, 174 \\
Before implementing an idea o & 6,667 & 1 & 6,667 & 17,059 &, $000^{* *}$ \\
To carry out an improvement &, 067 & 1 &, 067 &, 135 &, 715 \\
Faced with a problem, to carry & 4,267 & 1 & 4,267 & 8,945 &, 004 \\
\hline
\end{tabular}

Note: F-tests are post-hoc, based on assigning cases to groups to minimize within-group and maximize between group distances. ** Significant lever al $5 \%$ 


\section{Conclusions}

This work has allowed to contextualize the process of development and acquisition of transversal competencies through an e-learning platform and places its development beyond the scope of a subject. All this has been applied to the transversal competence related to Innovation, a framework that can be extended to the rest of the transversal competences.

\section{Acknowledgements}

This work has been developed within the research project called "Methodological coordination through support websites in ETSII Degrees for CT04.-Innovation, Creativity and Entrepreneurship and CT07.-Ethical, environmental and professional responsibility." (Ref. PIME/19-20/151) funded by the Vice-Rectorate for Studies, Quality and Accreditation at Universitat Politècnica de València

\section{References}

Acuña, P. V. (2016). La innovación como proceso y su gestión en la organización: una aplicación para el sector gráfico colombiano. Suma de Negocios, 7(16), 125-140. doi: https://doi.org/10.1016/j.sumneg.2016.02.007

Guzman, LM (2019) aplicación del modelo emoi y la herramienta mpdca para la innovación en las empresas colombianas. Ensayo de grado presentado. Universidad Militar Nueva Granada. retrieved from https://repository.unimilitar.edu.co/bitstream/handle/10654/35804/GuzmanGuzmanLuis Miguel2019.pdf? sequence $=1$

Marin-Garcia, J. A., Aznar-Mas, L. E. \& González-Ladrón de Gevara, F. (2011). Innovation types and talent management for innovation. Working Papers on Operations Management, vol 2, no 2, pp. 25-31.

Marin-Garcia, J., Andreu Andres, M., Atares-Huerta, L., Aznar-Mas, L., Garcia-Carbonell, A., González-Ladrón- de-Gevara, F., Montero Fleta, B., Perez-Peñalver, M., \& Watts, F. (2016). Proposal of a Framework for Innovation Competencies Development and Assessment (FINCODA). WPOM-Working Papers on Operations Management, 7(2), 119-12 6.

Marin-Garcia J.A., Pérez-Peñalver, M.J., Vidal-Carreras, PI. \& Maheut, J. (2012). How to assess the innovation competency of higher education students. Proceedings of the 7 th International Conference on Industrial Engineering and Industrial Management, p.p. 920-928. 2012.

Marin-Garcia, J. A., Perez-Peñalver, M. J., \& Watts, F. (2013). How to assess innovation competence in services: The case of university students. Direccion y Organizacion (50), 48-62.

Martínez-Gómez, M; Marí-Benlloch, M \& Marin-Garcia, J.A. (2017). Validation of Incode Framework for Assessment of Innovation Competency of Higher Education Students: A Multidimensional Technique for Affinity Diagram to Detect the most Relevant Behaviors and Skills". Modeling Human Behavior: Individuals and Organizations. Nova Science Publishers, Inc. pp. 25-36. 2017.

Penttilä, T. \& Kairisto-Mertanene, L. (2012) Innovation competence barometer ICB: a tool for assessing students' innovation competences as learning outcomes in higher education, Proceedings of INTED2012 Conference. pp. 6347-6351.

Perello-Marin, M. R.; Marin-Garcia, J. A. \& Marcos-Cuevas, J. (2013). Towards a Path Dependence Approach to Study Management Innovation. Management Decision 51(5), 1037-1046.

Ramírez Bayarri, L.; Marín García, JA.; Atarés Huerta, LM. (2016). ¿Cómo se ha evaluado la competencia de innovación en las empresas y las universidades?. Working Papers on Operations Management. 7(2):140-167. https://doi.org/10.4995/wpom.v7i2.6886

Universidad Politécnica de Valencia (UPV). (2020) Herramientas de metaplanificación. https://poliformat.upv.es/access/content/group/CFP_69392_27242/Material\%20Docente\%20Asign aturas/Asignatura $\% 202 . \% 20$ Herramientas $\% 20 \mathrm{de} \% \overline{2} 0$ metaplanificacion.pdf

Universidad Politécnica de Valencia (UPV). (2020) Herramientas de metaplanificación. https://poliformat.upv.es/access/content/group/CFP_69392_27242/Material\%20Docente\%20Asign aturas/Asignatura $\% 202 . \% 20$ Herramientas $\% 20 \mathrm{de} \% \overline{2} 0$ metaplanificacion.pdf 


\title{
ANALYSING LESSON-BASED INTERVIEWS USING THE LESSON ACTIVITIES MAP (LAMAP) AS A VISUAL TOOL
}

\author{
Annamaria Savona \\ Department of Arts Education, Schwyz University for Teacher Education \& University of Zurich \\ (Switzerland)
}

\begin{abstract}
During training as generalists, some teachers find it complex and challenging to teach songs and lead class singing. The Song Leading research project longitudinally examines case studies of 16 trainees to explore how they acquire and develop the knowledge and skills to conduct a class singing lesson. The data corpus consists of video-recorded lessons, audio-recorded lesson-based interviews and personalised open-ended questionnaires. In this paper some phases of the interview analysis are presented. As each interview is conducted while watching the video-recorded lesson, its analysis should not be separated from the lesson content. The central question guiding this analysis is: How can the analysis of a lesson-based interview be combined with the video analysis of the lesson itself? We present a visual system to combine the analysis of interviews and videos. This system involves the use of the Lesson Activities Map (LAMap) - the transcript of the class singing lesson - based on the methodology developed in the Song Leading project. During the thematic analysis of the interviews, the LAMap is a visual tool that allows the researchers to systematically describe the lesson moments that were the starting points of the teachers' reflections. In addition, LAMap is a visual tool for collecting initial codes and identifying relationships between potential interview themes. The implications of the use of a visualisation system for lesson-based interview analysis are an added value for the coherence of case study interpretation. The paper contributes to research in education by providing concrete examples of how to make a qualitative analysis process explicit.
\end{abstract}

Keywords: Lesson activities map, reflexive thematic analysis, professional development, song teaching, song leading.

\section{Introduction}

This paper presents some stages of the case study analysis of the Song Leading research project. The project focuses on the cultural practice of group singing in the school context. In many pre-schools and primary schools, the teaching of songs and the conducting of class singing are delivered by generalist teachers (de Vries, 2015). They are expected to achieve and/or consolidate subject-specific skills during their training (Russell-Bowie, 2009). The study aims to explore how pre-service generalist teachers carry out the task of song teaching and reflect on their song leading experiences at three different points during their professional training - initial, intermediate and final. We want to analyse how teachers experience their development, both from a personal perspective and from that of familiarisation and deepening of subject-specific knowledge and skills. The data corpus of the project consists of videos, interviews, and personalised open-ended questionnaires. In this paper some phases of the interview analysis are presented. The examples and discussion concern how the Lesson Activities Map (LAMap) (Savona et al., 2021) - i.e., the transcript of a song leading lesson created with the methodology developed in the Song Leading project - can be a tool for researchers to analyse the lesson-based interviews. The LAMap methodology contributes to qualitative research in education by providing a visual analytical tool. It enhances the characteristics of the subject matter, facilitates the systematic organisation of data, and supports the coherence of the interpretation of verbal data relating to a specific educational event and context.

\section{Design}

The Song Leading research project examines case studies of 16 pre-service teachers attending their three-year training course as generalists. The data set for each case study consists of three video-recorded lessons, three interviews - lesson-based and audio-recorded - and a personalised 
open-ended questionnaire. This data was collected once a year during the pre-service teachers' internships. Five $\mathrm{PhD}$ students and two supervisors work on the ongoing project (2018-2022). Each PhD student has a background as a professional musician and singing or instrument teacher, and/or as a music educator at primary, secondary or tertiary level. The two supervisors are professors with research backgrounds in developmental and cultural psychology, arts education, and research methodology. This information is necessary for positioning the team members in the data analysis process.

\section{Objectives}

This paper aims to show how we use LAMap while analysing interviews. For the analysis of the interviews, we follow the reflexive thematic analysis as defined by Braun and Clarke (2006). They outline six phases for this process. For phases 2, 3 and 4 - generating initial codes (2), searching for themes (3) and reviewing themes (4) - Braun and Clarke (2006) suggest the creation of tables and mind-maps. This suggestion coincides with the LAMap as our visualisation system of a song leading lesson. Through examples, this paper demonstrates how LAMap is a useful visual tool for analysing lesson-based interviews.

\section{Method}

Videos, interviews and personalised questionnaires are analysed with different qualitative methods and methodologies. The interviews, on which we focus in this paper, are analysed through reflexive thematic analysis (Braun \& Clarke, 2006) to identify and describe patterns in the way teachers relate their teaching experience with comments. The analysis is framed within the epistemological approach characterised as the teacher-object-learner paradigm called "didactics" (Reusser, 2008; Schneuwly, 2021). The identification of themes is guided by a semantic and explicit interpretation level based on the relationship between experience, meaning, and language (Wooffitt \& Holt, 2011). Through reflexive thematic analysis we aim to report a detailed and subject-related description of each interview. In the project, each $\mathrm{PhD}$ student is responsible for transcribing video and interview data and guiding the analysis of several case studies. AS, the author of this paper, leads the analysis of Ruth's case, which serves here as an example to show the application of reflexive thematic analysis to lesson-based interviews. Each team member is familiar with the interviews from all the case studies. The analysis of each case is regularly discussed by the team at all stages. As each interview is conducted by watching the video-recorded lesson, the pre-service teacher's comments and reflections are often "triggered" by the context of the lesson in question. In the following paragraphs we provide examples of how the LAMap is used to produce the map of initial codes and potential themes generated by the interview interpretation. Indeed, 'the most basic segment, or element, of the raw data or information that can be assessed in a meaningful way regarding the phenomenon' (Boyatzis, 1998: 63) is often the lesson activity which can be visualised with the LAMap.

\subsection{The LAMap as a visual domain summary}

The LAMap was devised in the initial stage of the Song Leading project in an iterative manner in order to gain a systematic overview of the relevant and recurring activities of each lesson. The result is a methodology for transcribing class singing lessons. It consists of symbols and icons that are used to represent the course of recurrent activities that constitute lessons in this specific subject, such as making semantic gestures to learn the lyrics of the song. Although the analysis of the videos is guided by the same epistemological decisions as the analysis of the interviews, i.e., teacher-object-learner interaction (Schneuwly, 2021), the result of the video analysis is a domain summary (Braun \& Clarke, 2019) and not themes generated by a reflexive thematic analysis. However, the combination of the two analyses contributes to an overview of how the content of the interviews refer to the actions during the lessons. Thus, the pre-service teachers' comments can be directly linked to the course of actions during the lesson as visualised by the LAMap.

Figure 1 shows on the left side the LAMap of Ruth's first leading a class singing lesson. The LAMap is divided into two parts by the speaking line, along which the spoken communication between teacher and children is marked. Ruth's actions are written above the speaking line and the children's below. On the right, the Song Leading Activities Key provides definitions for the symbols and icons that represent the song leading activities in LAMap.

\subsection{The LAMap as a tool for reflexive thematic analysis in education}

The following figures were created for analysing Ruth's first leading of a class singing lesson. Note that they do not show the final results of the analysis, but rather represent the phases 2, 3 and 4 as outlined by Braun and Clarke (2006). Thereby, the LAMap serves as a graphical tool for: 
1) Systematically locating the initial codes of the interview sections during the course of the lesson (phase 2, figure $2 \mathrm{~A}$ ).

2) Contextualising interview extracts concerning the same code to check their coherence before 'nominating' them for potential themes (phase 3, figure $2 \mathrm{~B}$ ).

3) Creating a mind-map of the initial themes generated by the analysis (phase 4, figure 3 ).

Figure 2 (A) shows the LAMap of Ruth's lesson. The vertical lines on the LAMap indicate the moments when Ruth paused the recording to comment. The interview started with an opening dialogue (OD), the video-viewing sections are numbered consecutively (in the figure: 1, 2 and 3), and a concluding dialogue $(\mathrm{CD})$ took place at the end of the video-viewing. The lower part shows the summary table of the initial codes. The code 'known song vs. new song' is highlighted in grey and is selected for the next analysis phase. Figure 2 (B) shows the extracts related to the 'known song vs. new song' code. It provides information about the team member responsible for transcription and translation, the interview section (OD, 1, 2, 3, CD) and the location of the extracts in the transcript (text chunks). Screening the extracts for a single theme is a necessary step to check the coherence of the coding and to nominate initial codes for potential themes.

Figure 3 shows the initial thematic map of the lesson-based interview combined with the LAMap. The symbols and icons highlighted in grey indicate the lesson moments on which Ruth commented while watching the video. From these extracts initial themes and sub-themes were generated, the interpretation of which requires completion through the description of those lesson moments. Other initial themes have been generated from reflections of a general nature and not strictly related to the lesson activities.

\section{Discussion}

The development of visual tools like the ones presented in this article is desirable when analysing interviews based on a context "bound" to a specific event. In the case of the Song Leading project this is the lesson-based interview. Consequently, part of the interview content is derived from the input the interviewer receives while watching the video-recorded lesson. During the analysis of the interviews, the LAMap is a tool for the researchers to systematically locate and describe the lesson moments that gave rise to the teacher's comments. By taking into account the teaching content enacted during the lesson and graphically transcribed in the LAMap, we achieve a convincing coherence between the observed actions and generated themes. However, this essential aspect of analysis remains still a challenge. The transition from description to abstraction of themes with shared meanings requires both familiarity and a distancing from the lesson content (not the interviews!). Researchers have to go beyond description and produce themes with generalised meanings in order to reconstruct and understand how teachers develop skills and how they conceive of their own professional development.

\section{Conclusion}

The aim of this paper was to show how the transcription of a lesson can support lesson-based interview analysis. One example is the use of the LAMap - the transcription of a class singing lesson with the methodology developed in the Song Leading project. The visualisation of the transcribed lesson combined with the interview analysis can offer new possibilities for qualitative research into subject-specific teaching. Comprehensive analytical narratives can be created through both the systematic description of teachers' subject-related actions and the coherent interpretation of their personal perspectives of their own professional development. 
Figure 1. LAMap of the first song leading lesson of the pre-service teacher Ruth.
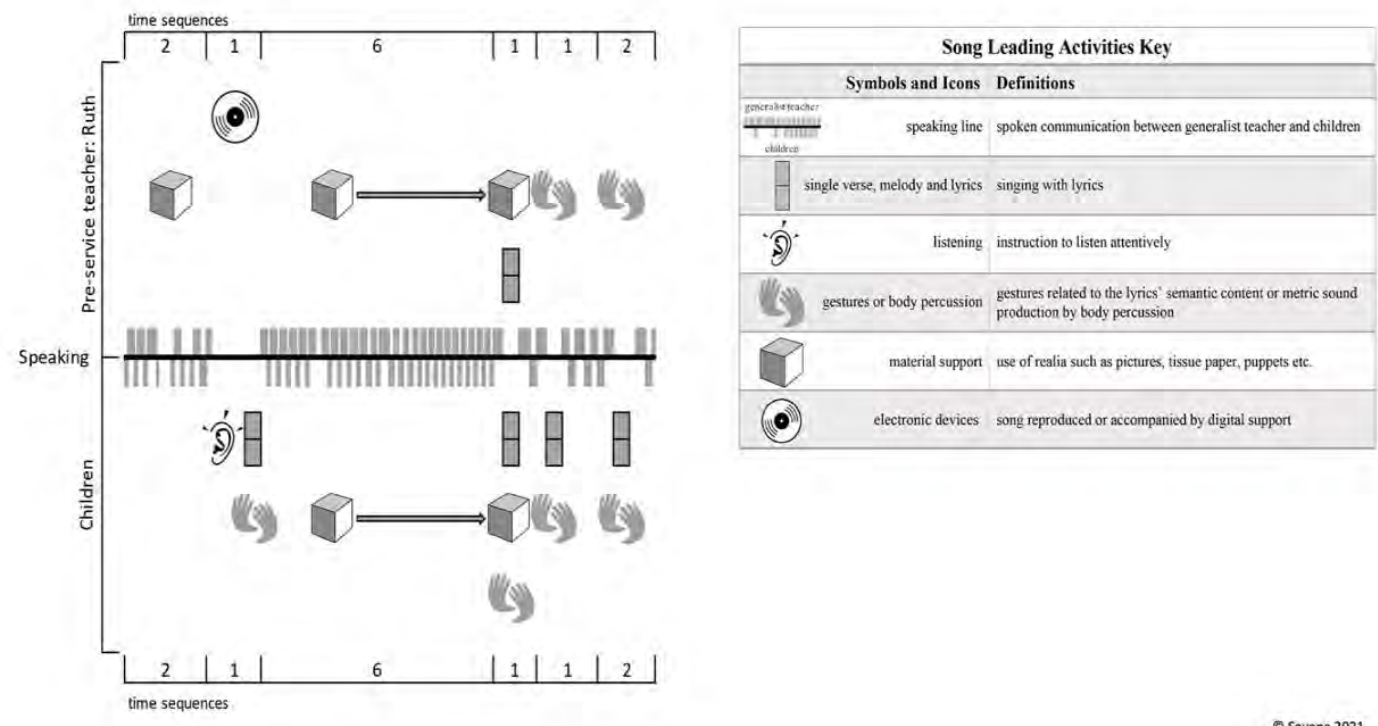

OSavona 2021

Figure 2. LAMap and map of initial interview codes (A). AMap and data extracts coded for 'known song vs. new song' $^{\prime}(B)$.

A
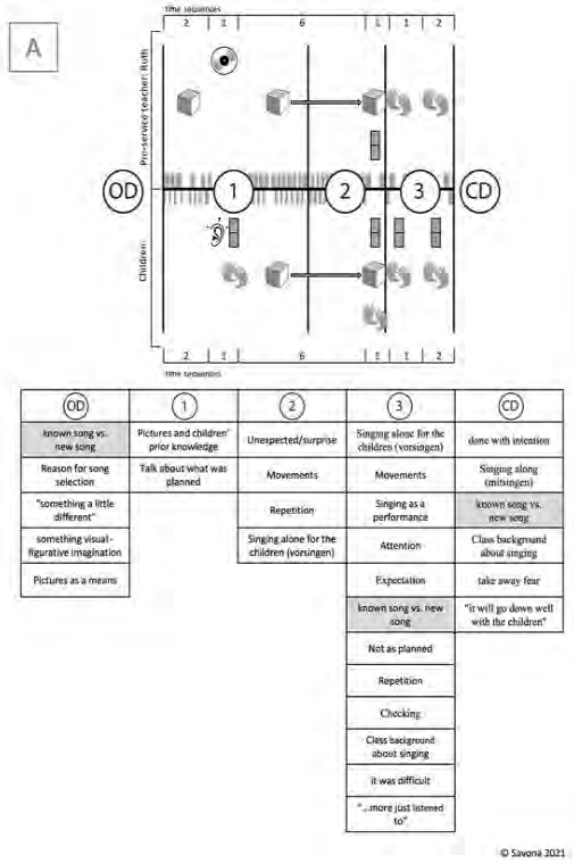

B

(0D)
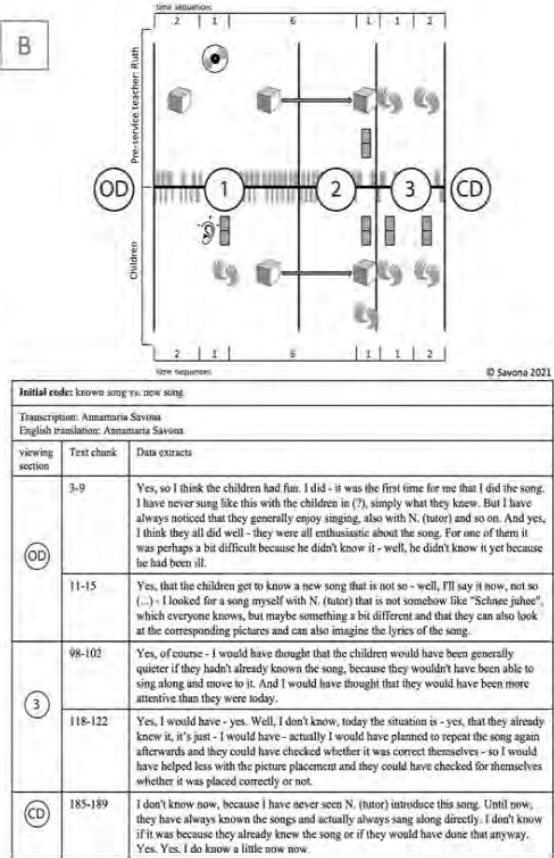
Figure 3. Initial thematic map of Ruth's first lesson using LAMap.

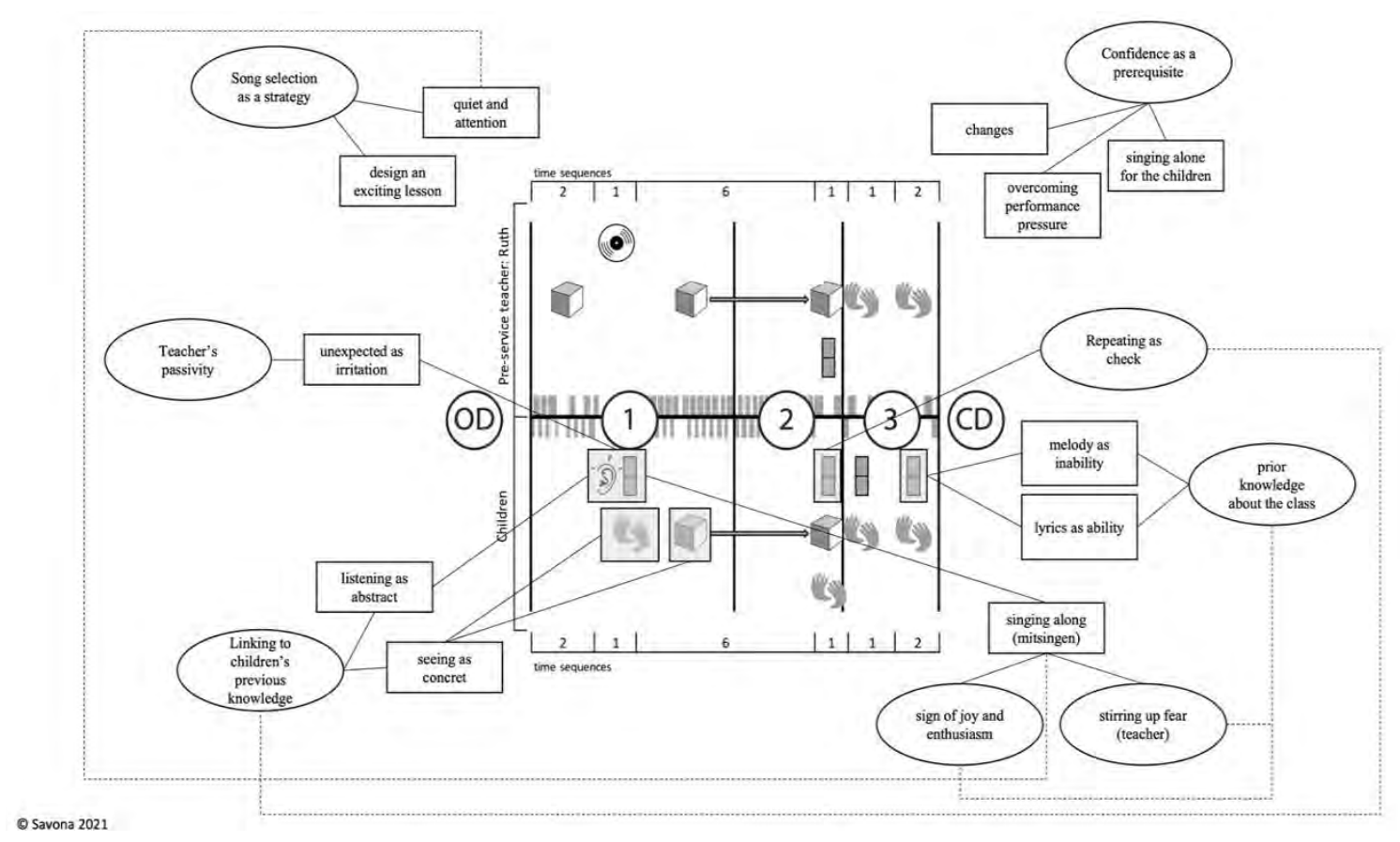

\section{References}

Boyatzis, R.E. (1998). Transforming Qualitative Information. Thematic Anaylsis and Code Development. London: Sage.

Braun, V., \& Clarke, V. (2006). Using thematic analysis in psychology. Qualitative Research in Psychology, 3, 77-101.

Braun, V., \& Clarke, V. (2019). Reflecting on reflexive thematic analysis. Qualitative Research in Sport, Exercise and Health, 1(4), 589-597.

De Vries, P. A. (2015). Music without a music specialist: A primary school story. International Journal of Music Education, 33(2), 210-211.

Reusser, K. (2008). Empirisch fundierte Didaktik - didaktisch fundierte Unterrichtsforschung. Eine Perspektive zur Neuorientierung der Allgemeinen Didaktik. In M.A. Meyer, M. Prenzel \& S. Hellekamps (Eds.), Perspektiven der Didaktik. Zeitschrift für Erziehungswissenschaft. Sonderheft 9 (219-237). Wiesbaden: VS Verlag für Sozialwissenschaften.

Russel-Bowie, D. (2009). What me? Teach music to my primary class? Challenges to teaching music in primary schools in five countries. Music Education Research, 11(1), 23-26.

Savona, A., Stadler Elmer, S., Hürlimann, A.E., Joliat, F., \& Cavasino, G. (2021). The Lesson Activities Map: A domain-specific lesson transcription methodology. European Journal of Educational Research, 10(2), 705-717.

Schneuwly, B. (2021). 'Didactiques' is not (entirely) 'Didaktik'. The origin and atmosphere of a recent academic field. In E. Krogh, A. Qvortrup \& S. T. Graf(Eds.), Didaktik and Curriculum in Ongoing Dialogue (164-184). London: Routledge.

Wooffitt, R., \& Holt, N. (2011). Looking In and Speaking Out: Introspection, Consciousness, Communication. United Kingdom: Imprint Academic. 


\title{
PRE-SERVICE TEACHERS' CRITICAL REFLECTION ON THE KNOWLEDGE AND SKILLS LEARNED IN LIFE SCIENCES METHODOLOGY MODULE
}

\author{
Lydia Mavuru \\ Department of Science and Technology Education, University of Johannesburg (South Africa)
}

\begin{abstract}
The complex roles teacher educators and teachers face require their ability to critically reflect on their practices. The question is on whether teachers are trained to make critical reflections of learning experiences for them to be able to critically reflect on their teaching practices. Based on constructivist approach, teacher educators continuously reflect on their practices in order to modify and improve their modules. It is however imperative that pre-service teachers who are the recipients, be given an opportunity to critically reflect on the services they receive and at the same time develop critical reflection skills. By creating reflective teaching and learning environments in the Life Sciences Methodology and Practicum module at the beginning of the academic year, 77 Bachelor of Education students specialising in Life Sciences and in their last year of study at a South African University, were purposefully selected to participate in a qualitative study. The study sought to answer the research questions: 1. What are pre-service teachers' reflections on the knowledge and skills learned in their last year of study? and 2. What pedagogical and content knowledge aspects can be drawn from pre-service teachers' critical reflection for the improvement of the module Life Sciences Methodology and Practicum? In collecting data, each pre-service teacher was tasked to compile a critical reflection report which they submitted towards the end of the year, and was analysed through content analysis. The findings showed important knowledge and skills learned which included the contextualization of teaching to ensure learners comprehend abstract concepts such as immunity. Amongst the teaching approaches and strategies covered in the module, argumentation as a social constructivist strategy stood out particularly when teaching controversial topics embedded with socioscientific issues e.g. genetics and evolution. The pre-service teachers indicated that the way practical work was taught, equipped them with knowledge and skills on how inquiry-based approaches can be implemented in the classrooms. Suggestions to improve the module included the provision of pre-service teachers with opportunities to conduct virtual micro lessons in light of COVID-19 pandemic; that the testing of Life Sciences concepts should include the assessment of pre-service teachers' capabilities to teach the same concepts in the classrooms. The pre-service teachers' argument is that since they are in their final year, the focus of the module should be on the development and assessment of their pedagogical content knowledge (PCK) and TPACK. The findings of the study have implications for teacher professional development.
\end{abstract}

Keywords: Critical reflection, life sciences, knowledge and skills, pre-service teachers.

\section{Introduction}

As with most professional development programmes, critical reflection in teacher education plays an important role in improving the quality of teaching and learning (Šarić \& Šteh, 2017). The global trend in science education focuses on meaningful and authentic science teaching and learning, which can only be achieved if teachers are reflective practitioners. Despite the consensus role of reflection in teacher development, the actual reflection thereof remains minimal. Previous researchers (e.g. Moon, 2004; Van Eekelen, Vermunt, \& Boshuizen, 2006) have debated on teachers' readiness and capabilities to engage in reflection. Šarić and Šteh (2017) questioned whether teachers are developed with skills to critically reflect on teaching and learning practices during in-service teacher professional development. Emanating from the problem statement, the current study demonstrates how pre-service teachers were engaged in a practice of reflecting on their educators' practices and in the process inculcate in them a culture of critical reflection on own practice. The assumption is that as pre-service teachers were engaged in a critical reflection of what and how they were taught, this fostered intuitive knowledge and skills in reflecting on how they in turn could teach their own learners. Consequently, the study sought to answer the research questions: 1. What are pre-service teachers' reflections on the knowledge and skills learned in their last year of study? and 2. What pedagogical and content knowledge aspects can be drawn from pre-service teachers' critical reflection for the improvement of the module Life Sciences Methodology and Practicum? 


\section{Literature review}

Teacher educators are challenged to foster critical reflection in their modules and at the same time in modelling reflective practice for their pre-service teachers (Šarić \& Šteh, 2017). Critical reflection transforms teachers into flexible practitioners who are responsive to the diverse sociocultural and political contexts affecting the teaching and learning process (Zeichner, 2006). This is pertinent particularly in education systems that cater for learners who come from culturally, ethnically, and racially diverse contexts for example South Africa. There is a lack of clarity on the definition of critical reflection from literature but the current study takes the conceptualisation by Liu (2015) that critical reflection involves one to always analyse, question, and critique one's assumptions about teaching and learning and how the society and politics have implications on the implementation process. Liu (2015) proposed that teacher educators should go beyond the mere development of reflective teaching, but teach and foster critical reflection in pre-service teachers. In concurrence, Krumm and Kimmie (2013) pointed out that to improve learners' performance in science the teaching should be transformative where learners are empowered to take responsibility of their own learning process by interrogating and critically reflecting on their thought processes.

The current study is underpinned by the social constructivist theory since reflection is conceptualised as a communal process of teachers supporting each other to gain professional growth (Zeichner \& Liston, 1996). For effective reflection to occur, one has to be involved in interactive and collaborative learning (Maor, 2003), which is characteristic of social constructivist learning environments.

\section{Methodology}

This study adopted the qualitative interpretive paradigm and employed a qualitative case study design. The interpretive qualitative approach allowed the researcher to discern and understand the participants' reflections on the content they had learned in the module Methodology and Practicum for Life Sciences, a course that prepared them for classroom practices and experiences. Through a qualitative case study (Creswell, 2014), the participants' perceptions of the relevance of the knowledge and skills they learned could be deduced. At the beginning of the academic year, 77 Bachelor of Education students (referred in as pre-service teachers) specialising in Life Sciences and in their last year of study at a South African University, were purposefully selected as participants. In collecting data, each pre-service teacher was tasked to compile a report in which they reflected on the knowledge and skills learned in the Life Sciences Methodology module. The specifications of the reflection were that it should show evidence of the knowledge and skills acquired and their relevance, the adequacy or inadequacy of the development attained, and reflections on what went well and what could have been done differently in the implementation of the module. The reports were submitted towards the end of the year. Through content analysis the researcher carefully reviewed the reflections to identify pertinent information from nonpertinent information and to make sure the information was organised into categories related to the research questions (Bowen, 2009).

\section{Research findings}

The findings from the pre-service teachers' reflections raised important aspects on knowledge and skills acquired, and their relevance in preparing them for meaningful classroom practices when they qualify. The pre-service teachers raised important issues on the adequacy or inadequacy of the development attained. Of note are suggestions made on the aspects to be improved on the methodology course and its implementation in order to fully develop upcoming groups of pre-service Life Sciences teachers.

\subsection{Relevant knowledge learned in the methodology course}

The pre-service teachers were quite explicit on the knowledge and skills they learned in the module during the course of the year. It was evident that their reflections were measured against the content they had been exposed to in the previous three years and as well as the experiences they had when they taught in actual Life Sciences classrooms during school experience. They indicated that an analysis and interpretation of the Life Sciences curriculum at the beginning of the year was profound as it provided them with the baseline for their understanding of the content learned throughout the year. The participants appreciated the experiences as they reminisced that being a teacher is more than knowing and understanding the content, but it is also about knowing how to present the content you are teaching. Just to put the reader in context, these pre-service teachers had been taught Life Sciences in the Faculty of Science, and Life Sciences methodology course in the Faculty of Education. In this case, they were now connecting the relationship between the content they learned with the manner in which it should be taught to high school learners. It is unfortunate that for the previous three years, they were learning Life Sciences content and the pedagogical knowledge learned in the methodologies as discrete knowledge and skills. According to the participants, it was now in this module that the content and methodology were being 
merged to close the gap. To show their realisation and appreciation, one of the participants wrote, "The module provided me with pronounced knowledge to prepare me for the schools in my community".

The pre-service teachers pointed out that during the course of the module controversial topics e.g. evolution, genetics and reproduction, proved to be complex in nature and required sensitivity when teaching them and that the module developed them on how to approach these particular topics. In their reflections they acknowledged the importance of treating each topic in Life Sciences as unique and consider the different unique approaches of teaching them. Such knowledge was learned through contextualisation of the teaching and learning process, which they viewed as one of the themes which they valued in preparing them for real classroom diverse contexts. In this case, they indicated that knowledge and skills in the development of teaching strategies that take into consideration contextual factors helped them a lot. The following are some of the excerpts from the pre-service teachers' reflections. One of the participants wrote, "I learned some of the limitations, efficiencies and appropriateness of the teaching approaches and strategies for particular Life Sciences topics. The other had this to say:

Life Sciences is unique and has different unique ways of teaching it. I had done a task based on cloning and that assignment had given me a better understanding of being a teacher who knows how to handle different controversial topics and handling them with an understanding that learners may come from different racial/cultural and religious backgrounds and may seem to dislike/disregard certain concepts. As a teacher you must find ways to explain and teach the lesson in an unbiased manner and by maintaining a stable classroom environment.

From these reflections, it shows that the module equipped the pre-service teachers with relevant knowledge and skills to teach Life Sciences in different classroom contexts.

The pre-service teachers' engagement with the constructivist teaching philosophies and teaching strategies as applied in Life Sciences teaching helped them to appreciate the adaptation of teaching strategies for different contexts. They indicated that it helped them realise the need to understand the learners in a Life Sciences classroom in terms of their sociocultural backgrounds, their learning styles and preferences. In this way learners' prior knowledge should be elicited and teachers need to use examples familiar to learners and make references to their lived experiences in their different communities. As such one of the pre-service teachers wrote the following as extracted in the reflection report:

Engaging with constructivist philosophies and strategies provided me with the knowledge and skills of always using strategies that break down large chunks of Life Sciences content into digestible information for learners. It made me aware that not all learners grasp information in the same way and at the same pace. As such I now focus on diversifying my teaching strategies, examples and activities.

The pre-service teachers indicated that they realised that knowing the learners helps the teacher to prepare for meaningful teaching and learning.

The pre-service teachers commented on how they were fascinated by both the content and the manner in which the module was implemented which taught them to work under pressure and in unfamiliar situations particularly that at the beginning of the year they had face to face lectures and from March they transitioned rapidly to online lectures and assessments due to the COVID-19 pandemic. In this regard, they learned to embrace, adapt and accept changes encountered in the profession. To show the confidence the pre-service teachers acquired from the course, one of them said, "From everything that I have learned in this module I can confidently say that I am fulfilled, and I feel very much prepared for the world of work".

4.1.1. Important pedagogical practices and skills learned in the methodology. The pre-service teachers appreciated the opportunities they got in practising teaching different Life Sciences topics using the different approaches learned throughout the module. These activities included micro lessons where they developed interpersonal and presentation skills. They indicated that these soft skills developed as a result of the feedback from lecturers and colleagues who observed them teaching. Through encouragement and constructive criticism, they developed confidence as teachers and inculcated in them the skills of building confidence in their learners in their future Life Sciences classrooms. The following is an excerpt from one of the pre-service teachers.

As we had presentations earlier during the year I was able to observe how other student teachers teach and reflect on some of their teaching skills. This assisted me to identify things that should and should not be done.

Discussions during face to face and online lectures helped them on how they can initiate, manage and sustain discussions in their own classrooms. According to the pre-service teachers, if the lecturers could use discussions so effectively in the Life Sciences Methodology module, which had close to a hundred students, surely they could do the same in their overcrowded Life Sciences classrooms with around 50 learners. In South African classrooms, classroom management skills are pertinent considering that learner discipline is a big issue.

The pre-service teachers also reflected on the teaching approaches and strategies they learned and how important it was for them to observe each other employing such approaches when teaching 
micro lessons. The participants mentioned particularly the use of real-life case scenarios, inquiry-based approaches and argumentation as pertinent strategies that captivate learner interest to engage meaningfully in learning. They reflected on how the module also taught them the importance of practical and investigative work as effective science teaching approaches despite the 'lack of resources', which most teachers normally mourn about. The following is an excerpt from one of the reflection report.

The module broadened my understanding on what is practical work is examples of practical work, why do it, how to manage investigations, safety in the labs and also assessing for learning through practical work.

In their reflection reports, the participants indicated how much they have learned that as teachers it is important to get out of one's comfort zone and be innovative when teaching. They pointed out how much they were now wary about the various teaching strategies and their dynamics especially when they were contrasting the traditional methods which their high school teachers employed with the active learner-centred approaches they were taught in the Methodology and Practicum module. In summary the pre-service teachers reflected how much they have become critical thinkers. One of the participants wrote,

I can now dissect complex information through the controversial and philosophical discourses which come out as topics in Life Sciences such as evolution, genetics, human impact on the environment etc. are taught.

As such, the participants reflected on how their ICT knowledge and skills developed $\mathrm{i}$ as it was mandatory that they use technology when teaching. The pre-service teachers indicated that they were also equipped to develop 21 st century skills in their learners. They could now design and formulate online assessments through Google forms, Kahoot, using FlipGrid to engage learners and formulate quizzes through Mentimeter. They indicated that they learned about many other online resources that they could use in their own teaching. They also indicated that they acquired skills on how to design a fair and valid test which meets all levels of Bloom's taxonomy.

The pre-service teachers reflected on motivational and conflict resolution skills which were taught through the manner in which the lecturers behaved during lectures. In turn the pre-service teachers were equipped on how to also remain calm and professional even during the tough moments in the classrooms. These skills are very important particularly in today's overcrowded classrooms where classroom management skills are needed more than before. The pre-service teachers reflected on how the skills they learned such as empathising and building trust with learners, were important in contemporary classrooms where learners come from diverse backgrounds in terms of broken homes, poor socio-economic backgrounds and abused backgrounds. They realised that as teachers they needed to act in 'loco parentis'.

4.1.2. Aspects which could be done differently in future methodology classes. Whilst the pre-service teachers raved about the knowledge and skills they learned in the module, they also critically reflected on the negative things that they thought could have been done differently to improve their experiences. They felt strongly that the lecturers took for granted the issue of English language (medium of teaching and learning), which is a second and third language to most of the pre-service teachers from township backgrounds. They gave an example of how they wished they were given elaborate instructions on how to complete assessments. They bemoaned that the assumption that everyone was an English first language speaker, disregarded those not so proficient in the language of teaching and learning. The pre-service teachers pointed out that they would not want their own learners to experience that hence would use code switching where necessary when teaching. Still on the assessment tasks the pre-service teachers indicated that the nature of the feedback they received from this module was not satisfactory for some of the assessments. They indicated that the comments were too blunt and did not give meaningful recommendations for one to improve on their performance. In fact, they bemoaned the negativity they perceived was characteristic of the comments they received in their assessments, a situation which they indicated as demotivating.

Because the pre-service teachers came from different socioeconomic backgrounds with others coming from disadvantaged homes, they reflected on how they struggled to access online teaching and learning materials and online lectures held synchronously. They indicated that the online lectures used up a lot of data via the Blackboard management learning system particularly the blackboard collaborate tool. Whilst they appreciated the lecture slides and lecture recordings made available after every session on the learning management system, they wished the university or government could have subsidised substantially on data for internet connection. They also felt more could be done in the module to enhance training on how to use technological tools in the future.

\section{Discussion}

In the current study the educators of the Life Sciences Methodology module allowed the recipients of their teaching (pre-service teachers) to critically reflect on how they were taught. In this way, the teacher educators had an opportunity to think about their own teaching which Schön (1987) 
referred to as reflection on action. This was meant to inculcate in pre-service teachers the culture of critically reflecting on ones' teaching. This was evident in the findings where pre-service teachers made a realisation of the importance of contextualisation of learning, the role of prior knowledge, consideration of learners' sociocultural backgrounds, their learning styles and preferences, which they (pre-service) resolved to use in their own classrooms. The pre-service teachers appreciated the knowledge and skills they learned about the contextualisation of learning and the use of constructivist teaching strategies. These are competencies which Liu (2015) pointed out as important in analysing and adapting the teaching and learning environment for learners. The pre-service teachers critically reflected on the manner in which they were taught and like what Watson and Kenny (2014) indicated, it is hoped that this improved their pedagogical knowledge and skills for their future classrooms.

When examining the findings from pre-service teachers' critical reflections, the teacher educators of the Module Methodology and Practicum for Life Sciences, may draw a lot of pedagogical and content knowledge aspects for the improvement of the module. The findings show the need to emphasise on the integration of context in their teaching.

\section{Conclusion and recommendations}

Whilst pre-service teachers indicated the relevant knowledge and important pedagogical practices and skills learned in the module, they also brought out aspects which could be done differently in future methodology classes. Within their reflections the integration of subject matter knowledge (Life Sciences content) they learned in the Faculty of Science and the knowledge and skills of how to teach that content to their high school learners stood out. They pointed out the need to identify and select teaching and learning approaches suitable for each Life Sciences topic; the need to contextualise their teaching whilst taking into cognisance the diverse groups of learners found in the classrooms; and the utilisation of ICT affordances considering that online/remote teaching and learning has taken centre stage due to COVID-19 pandemic.

Aspects on the improvement of the module included the need to give clear instructions on assessments; providing meaningful and constructive feedback on assessments; and the need for concerted effort in developing students' ICT skills when teaching Life Sciences. The study informs many preservice teacher development programmes on the need for continuous critical reflection on both the providers and the recipients. In this way, both sides take responsibility for their practices and strive to do better.

\section{References}

Bowen, G. (2009). Document analysis as a qualitative research method. Qualitative Research Journal, 9(2), 27-40.

Creswell, J.W. (2014). Research design. Qualitative, quantitative, \& mixed methods approach (4th edition). Los Angeles: Sage Publications.

Kayapinar, U. (2018). Reflection in teacher development. In V. Mahlangu (Ed.) Reimagining new approaches in teacher professional development pp.776. https://doi.org/10.5772/intechopen.78257

Krumm, P. \& Kimmie, R. (2013). South African Journal of Science, 109(7-8),

Liu, K. (2015). Critical reflection as a framework for transformative learning in teacher education. Educational Review, 67(2), 135-157. http://dx.doi.org/10.1080/00131911.2013.839546

Maor, D. (2003). The Teacher's Role in Developing Interaction and Reflection in an Online Learning Community. Education Media International, 40 (1/2), 127-135. http://doi.org/10.1080/ 0952398032000092170

Moon, J. A. (2004). A handbook of reflective and experiential learning: Theory and practice. London: Routledge Falmer.

Šarić, M. \& Šteh, B. (2017). Critical reflection in the professional development of teachers: Challenges and possibilities much attention. Center for Educational Policy Studies Journal, 7(3), 67-85.

Schön, D. A. (1987). Educating the reflective practitioner. San Francisco, CA: Jossey Bass.

Van Eekelen, I. M., Vermunt, J. D. \& Boshuizen, H. P. A. (2006). Exploring teachers' will to learn. Teachers and Teaching Education, 22(4), 408-423.

Watson, G.P.L. \& Kenny, N. (2014). Teaching critical reflection to graduate students. Collected essays on learning and teaching, 1, 56-61.

Zeichner, K. (2006). Reflections of a university-based teacher educator on the future of college- and university-based teacher education. Journal of Teacher Education 57 (3), 326-340.

Zeichner, K. M. \& Liston, D. (1996). Reflective teaching: An introduction. Englewood Cliffs, NJ: Lawrence Erlbaum Associates Publishers. 


\title{
SLEEP QUALITY AND SLEEP HABITS IN STUDENTS
}

\author{
Beatriz Almeida ${ }^{1}$; Carlos Albuquerque ${ }^{2}$, Madalena Cunha ${ }^{2}, \&$ Anabela Antunes ${ }^{3}$ \\ ${ }^{I}$ Student, Project "Verão com Ciência", IPV-Higher School of Health, Viseu (Portugal) \\ ${ }^{2}$ Doctors Professors, IPV-Higher School of Health, Viseu, UICISA:E, CIEC - UMinho (Portugal) \\ ${ }^{3}$ Nurse, Centro Hospitalar Tondela-Viseu, Viseu (Portugal)
}

\begin{abstract}
Introduction: The student stage is marked by many changes that will affect different aspects of young youth life, including changes in sleep patterns. Sleep is known to play an active role in the overall development of students, mainly because of its restorative functions and an insufficient number of hours of sleep can be associated with consequences on physical and mental health.

Objectives: To analyze the factors that interfere with higher education students' sleep quality.

Methods: A systematic review of the literature was carried out drawing on a selection of articles published between 2012 and 2020, following the method proposed by the Joanna Briggs Institute and according to the Preferred reporting items for systematic reviews and meta-analyzes (PRISMA). This selection was carried out using PubMed, B-On and SCIELO search engines. The review was based on 5 articles whose methodological quality was found to be undeniable.

Results: Results show that, on the whole, students suffer from a poor quality of sleep. This situation is commonly associated with factors such as being a higher education student worker, shift work, or caffeine, alcohol, and tobacco use, among others.

Conclusions: In view of the outcomes, it became clear that higher education students need to be made more aware of the importance of sleep habits and daytime sleepiness, and to improve their health literacy. They need to be informed and trained in these areas so they may reduce or at least prevent certain risk behaviours that increasingly threaten their sleep quality and overall health.
\end{abstract}

Keywords: Students, sleep, sleep disorder, health, higher education.

\section{Introduction}

Sleep plays a complex role in a person's life and is essential to the life of every human being. The definition of normal sleep is subjective and complex. It is an important indicator of overall health and well-being and a basic biological need that has a strong impact on the quality and longevity of people's lives (Marques, 2017).

Students have to face several challenges when they enter higher education. They have to learn how to deal with different issues, including leaving home, increased independence, changes in peer groups, new social situations and maintenance of academic responsibilities, among others (Taylor, Bramoweth, Grieser, Tatum \& Roane, 2013). According to Schlarb, Bihlmaier, Hautzinger, Gulewitsch and Schwerdtle (2015), many students in higher education face special challenges and circumstances that are significantly associated with sleep disorders. About $60 \%$ of those students suffer from poor quality of sleep and $7.7 \%$ meet all the criteria for insomnia disorder. The study conducted by Schlarb, Friedrich and Claßen (2017) revealed that all university students are at risk of at least one sleep disorder.

Furthermore, they report that a minimum $7.7 \%$ of students suffer from insomnia and $24.3 \%$ from nightmares. These same authors state that sleep disorders and sleep problems severely impair higher education students' academic success. Sleep problems correlate with impeded learning, especially poorer declarative and procedural learning, neurocognitive performance, and academic success. Sleep problems have a major impact on the students' daily life due to irregular daytime routines, chronotype changes, side jobs and exam periods. In view of the above, this systematic review of the literature aims to analyze the factors that interfere with higher education students' quality of sleep.

${ }^{1}$ Corresponding Author; Carlos Albuquerque (cmalbuquerque@gmail.com) 
Following the issue under study, the research question was formulated according to the PI[C]OD methodology: Which factors will interfere with the sleep quality of higher education students?

\section{Method}

\subsection{Type of Study}

A systematic review of the literature was carried out in order to systematize current knowledge of the factors that may interfere with higher education students' sleep habits, in accordance with Preferred reporting items for systematic reviews and meta-analyzes (PRISMA) (Moher et al. 2009).

\subsection{Studies eligibility criteria}

Specific selection criteria were defined and applied to limit the number of articles to be included in the study, considering the existing inclusion and exclusion criteria (see Table 1).

Table 1. Studies inclusion and exclusion criteria.

\begin{tabular}{|l|l|l|}
\hline Selection criteria & Inclusion criteria & Exclusion criteria \\
\hline Participants & Higher education students & Age $\geq 18$ years old \\
\hline Interventions & Factors that influence sleep habits & $\begin{array}{l}\text { Studies that do not assess the } \\
\text { inclusion variable }\end{array}$ \\
\hline Comparisons & Unenforceable \\
\hline "Outcomes" & $\begin{array}{l}\text { Factors that interfere with higher } \\
\text { education students' sleep habits }\end{array}$ & $\begin{array}{l}\text { Studies that do not assess the } \\
\text { factors that interfere with higher } \\
\text { education students' sleep habits }\end{array}$ \\
\hline Type of study & $\begin{array}{l}\text { Experimental studies, quasi } \\
\text { experimental studies, analytical cross- } \\
\text { sectional studies, controlled clinical } \\
\text { trials, randomized studies, controlled } \\
\text { randomized trials, exploratory studies. }\end{array}$ & $\begin{array}{l}\text { Other designs that do not meet } \\
\text { the inclusion criteria }\end{array}$ \\
\hline
\end{tabular}

The following were also considered as inclusion criteria: date of publication between 2012 and 2020; articles written in Portuguese and English; article available full text.

\subsection{Resources used in the current study}

The studies were identified in accordance with the inclusion criteria defined and PubMed, B-On and SCIELO were the electronic database platforms of choice.

\subsection{Search strategy}

The following descriptors were used in conjunction with the Boolean operators: "Sleep" OR "Sleep Habits" [Entry Term(s)] AND "Sleep Disorders, Circadian Rhythm" [MeSH Major Topic] AND "Students" [MeSH Major Topic] AND "Education" [MeSH Major Topic] AND "Universities" [MeSH Major Topic] AND "college students" [Entry Term(s)]. Although the terms "Higher education", "Sleep Quality", "university students", "sleep characteristics", "sleep problems" and "sleep disturbances" are not MeSH descriptors, they were considered in the research as they are terms used in the specific literature. These descriptors, in Portuguese and English, were used through the different search engines to obtain full text articles.

\subsection{Studies selection}

56 articles were identified through the database search conducted. First, duplicate records were identified and removed $(n=14)$. In a second phase, the articles were analyzed $(n=42)$ through their titles and abstracts. 19 of them were excluded because they did not meet some of the inclusion criteria (date of publication, were not available full text and because of the language used), and 23 full text articles were assessed for eligibility. Of these, 18 were removed since they did not meet the remaining inclusion criteria. 5 studies made it to the final stage (see Figure 1). 
Figure 1. Diagram showing the selection procedure followed (PRISMA).

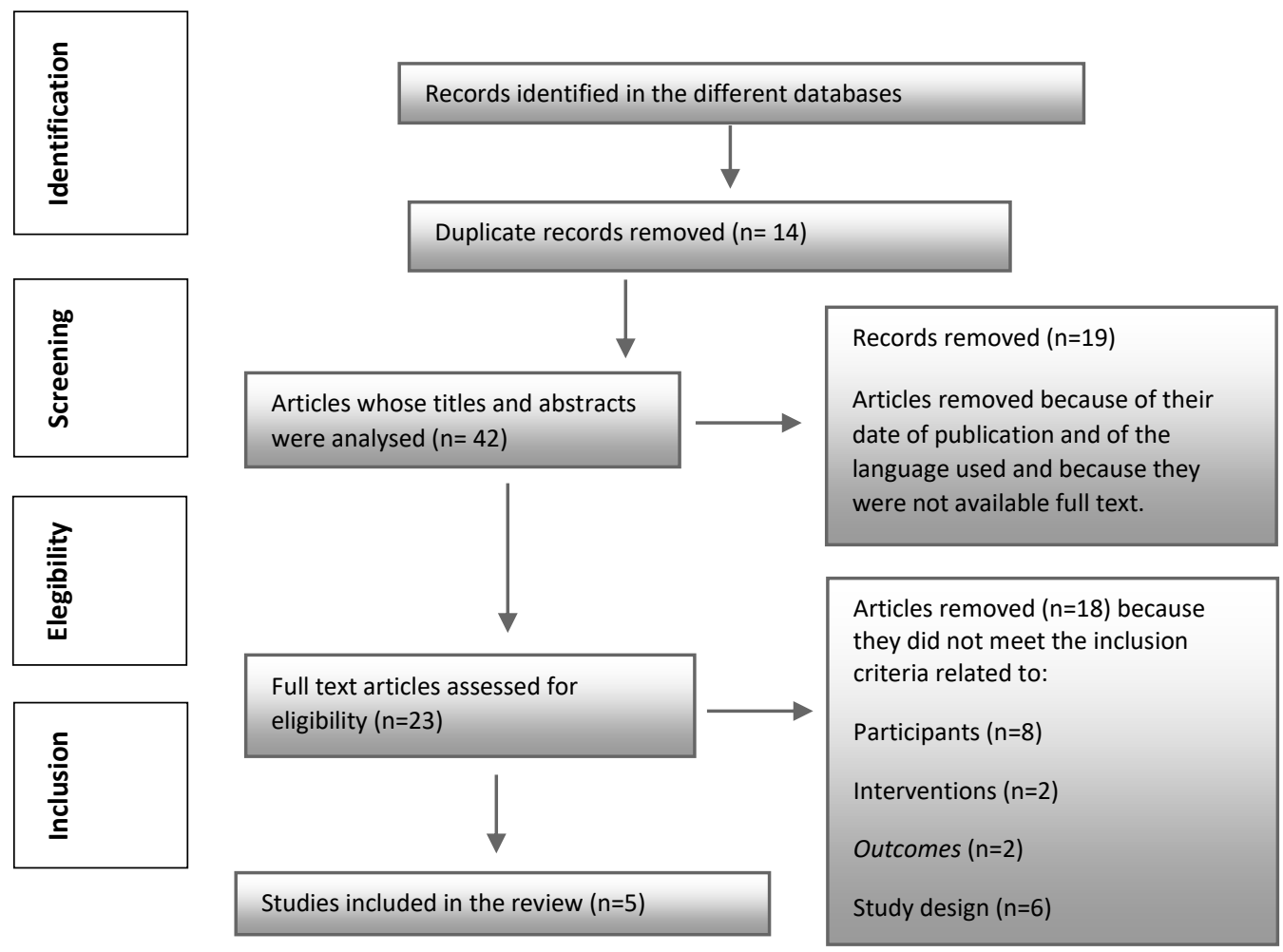

\section{Results}

The following table presents the characteristics of the articles that were included in the corpus of the review (table 2).

Table 2. Characteristics of the studies that became part of the corpus of the review.

\begin{tabular}{|c|c|c|c|}
\hline Studies & Participants & Type of study/interventions & Objectives \\
\hline $\begin{array}{l}\text { Martini, } \\
\text { Brandalize, } \\
\text { Louzada, } \\
\text { Pereira \& } \\
\text { Brandalize } \\
(2012) . \\
\end{array}$ & $\begin{array}{l}199 \text { students attending the } \\
\text { Physiotherapy course of a private } \\
\text { teaching institution in } \\
\text { Guarapuava - Brazil }\end{array}$ & $\begin{array}{l}\text { Quantitative, descriptive, and } \\
\text { cross-sectional study; the } \\
\text { Pittsburgh Sleep Quality Index } \\
\text { (IQSP) was used; environmental } \\
\text { /social and sociodemographic } \\
\text { variables. }\end{array}$ & $\begin{array}{l}\text { To analyze the sleep pattern of } \\
\text { university students attending the } \\
\text { physiotherapy course and the } \\
\text { factors associated with sleep } \\
\text { quality. }\end{array}$ \\
\hline $\begin{array}{l}\text { Mendes, Sousa, } \\
\text { Leite, Belchior } \\
\& \text { Medeiros } \\
(2019) \text {. }\end{array}$ & $\begin{array}{l}257 \text { higher education students } \\
\text { from seven higher education } \\
\text { institutions [Azores (Ponta } \\
\text { Delgada and Angra do Heroísmo) } \\
\text { and mainland Portugal (Oporto, } \\
\text { Lisbon, Coimbra, Leiria, Évora } \\
\text { and Minho) }\end{array}$ & $\begin{array}{l}\text { Quantitative, descriptive, and } \\
\text { cross-sectional study. The } \\
\text { Portuguese versions of the Sleep } \\
\text { Quality Index (PSQIPT) and the } \\
\text { Daytime Sleepiness Scale (ESS) } \\
\text { and a sociodemographic } \\
\text { questionnaire were applied }\end{array}$ & $\begin{array}{l}\text { To characterize the components } \\
\text { of subjective sleep quality and } \\
\text { excessive daytime sleepiness in } \\
\text { higher education students }\end{array}$ \\
\hline $\begin{array}{l}\text { Toscano- } \\
\text { Hermoso, } \\
\text { Arbinaga, } \\
\text { Fernández- } \\
\text { Ozcorta, } \\
\text { Gómez-Salgado } \\
\text { \& Ruiz-Frutos } \\
(2020) \text {. }\end{array}$ & 855 university students & $\begin{array}{l}\text { Ex post facto study. } \\
\text { The following instruments were } \\
\text { applied: the Pittsburgh Sleep } \\
\text { Quality Index (IQSP), Nightmare } \\
\text { Proneness Scale; Composite } \\
\text { Scale of Morningness }\end{array}$ & $\begin{array}{l}\text { To analyze, according to the } \\
\text { gender of the students, } \\
\text { possible sleep-related differential } \\
\text { patterns }\end{array}$ \\
\hline $\begin{array}{l}\text { Araújo, Lima, } \\
\text { Thiago, Veras, } \\
\text { Zanetti \& } \\
\text { Damasceno } \\
(2014)\end{array}$ & $\begin{array}{l}701 \text { students from Fortaleza, } \\
\text { Brasil. }\end{array}$ & $\begin{array}{l}\text { Cross-sectional study. } \\
\text { A Sociodemographic Form and } \\
\text { the Pittsburgh Sleep Quality } \\
\text { Index (IQSP) were applied }\end{array}$ & $\begin{array}{l}\text { To analyze the relationship } \\
\text { between socio-demographic } \\
\text { variables and the poor sleep } \\
\text { quality of Brazilian university } \\
\text { students }\end{array}$ \\
\hline $\begin{array}{l}\text { Okano, } \\
\text { Kaczmarzyk, } \\
\text { Dave et al. } \\
(2019)\end{array}$ & 493 Dutch university students & $\begin{array}{l}\text { Cross-sectional study. } \\
\text { The Pittsburgh Sleep Quality } \\
\text { Index (IQSP) was used }\end{array}$ & $\begin{array}{l}\text { To study the individual and social } \\
\text { factors associated with } \\
\text { unsatisfactory sleep and its } \\
\text { consequences on higher } \\
\text { education students }\end{array}$ \\
\hline
\end{tabular}




\section{Discussion and conclusion}

The results reveal that, on the whole, higher education students show poor sleep quality and that this fact is related to factors like being a student worker, working shifts, or to the consumption of caffeine, alcohol and tobacco. Sleep disorders seem to be associated, according to Mendes et al. (2019, p. 45), "with physical and psychological consequences and, in the long term, can become a public health problem". On the other hand, studies show that the right quantity and quality of sleep seems to be associated with more positive academic results in higher education students

Higher Education Institutions are capital places for the promotion of healthy habits, therefore the results obtained justify the implementation of sleep education programmes aimed at students, following the premise that if students are provided with the right knowledge, they will be able to make healthier choices by changing their behaviour. We believe that this type of sleep education programmes will make students aware of the importance of sleep-wake cycles, demonstrating that the knowledge to be acquired can be useful not only to improve their sleep quality, but also to provide them with the right tools to encourage and stimulate healthy sleep habits. Investing in good sleep habits is investing in the future. It is therefore important to provide students with a set of healthy sleep rules and practices that will enable them to develop empowerment and help them promote their health.

\section{Acknowledgements}

This work is financed by National Funds through FCT -- Fundação para a Ciência e a Tecnologia, and DGES under the initiative Summer School with Science "Dynamics and implementation of inclusion for health promotion and literacy in higher education" and the project:"iPV with Health Plus", reference: PROJ/IPV/ID\&I/005. The authors would like to extend particular thanks to the Polytechnic Institute of Viseu for its support.

\section{References}

Araújo, M.F.F.M. de, Lima, A.C.S.A., Thiago, M de, Veras, V.S., Zanetti, M.L., \& Damasceno, M.M.C. (2014). Association of sociodemografic factors and sleep quality in brazilian university students. Texto \& Contexto - Enfermagem, 23(1),176-184. https://doi.org/10.1590/S010407072014000100021

Marques, J.A.C.P. (2017). Qualidade de Sono de Adolescentes em Contexto Escolar (Dissertação de Mestrado). Escola Superior deEnfermagem de Coimbra.

Martini, M., Brandalize, M., Louzada, F.M., Pereira, É.F. \& Brandalize, D. (2012). Fatores associados à qualidade do sono em estudantes de Fisioterapia. Fisioterapia e Pesquisa, 19(3), 261-267. https://doi.org/10.1590/S1809-29502012000300012

Mendes, J., Sousa, M., Leite, V.M., Belchior, N., \& Medeiros, T. (2019). Qualidade do sono e sonolência em estudantes do ensino superior. Revista Portuguesa de Investigação Comportamental e Social; Vol. 5 (2), 38-48. In: http://repositorio.ismt.pt/bitstream/123456789/1128/1/150-Texto\%20Artigo1247-1-10-20191130.pdf

Moher, D. , Liberati, A., Tetzlaff, J. Altman, D. (2009). Preferred reporting items for systematic reviews and meta-analyses: the PRISMA statement. BMJ 2009; 339 doi: https://doi.org/10.1136/bmj.b2535

Okano, K., Kaczmarzyk, J.R., Dave, N. et al. (2019). Sleep quality, duration, and consistency are associated with better academic performance in college students. npj Sci. Learn.; 4, 16. https://doi.org/10.1038/s41539-019-0055-z

Schlarb, A.A., Bihlmaier, I., Hautzinger, M., Gulewitsch, M.D., \& Schwerdtle, B. (2015). Nightmares and associations with sleep quality and self-efficacy among university students. J Sleep Disord Manag.; 1(2), 1-5. In: https://clinmedjournals.org/articles/jsdm/journal-of-sleep-disorders-and-managementjsdm-1-006.pdf

Schlarb, A.A., Friedrich, A., \& Claßen, M. (2017). Sleep problems in university students - an intervention. Neuropsychiatric Disease and Treatment; 13, 1989-2001. Acedido em https://www.ncbi.nlm.nih.gov/pmc/articles/PMC5536318/pdf/ndt-13-1989.pdf

Taylor, D.J., Bramoweth, A.D., Grieser, E.A., Tatum, J.I., \& Roane, B.M. (2013). Epidemiology of insomnia in college students: relationship with mental health, quality of life, and substance use difficulties. Behav Ther.; 44(3), 339-348. doi:10.1016/j.beth.2012.12.001. Epub 2012 Dec 19. PMID: 23768662.

Toscano-Hermoso, M.D., Arbinaga, F., Fernández-Ozcorta, E.J., Gómez-Salgado, J., \& Ruiz-Frutos, C. (2020). Influence of Sleeping Patterns in Health and Academic Performance Among University Students. Int. J. Environ. Res. Public Health; 17, 2760. doi:10.3390/ijerph17082760 


\title{
A QUESTIONNAIRE FOR EVALUATING PUPILS' COGNITIVE PATH ABOUT SYMMETRY AT PRIMARY SCHOOL
}

\author{
Simone Brasili, \& Riccardo Piergallini \\ School of Science and Technology, University of Camerino (Italy)
}

\begin{abstract}
The fundamental role of symmetry has to be more closely enhanced in the interplay between mathematics and physics to foster the teaching of the Nature of Science. In our presentation, we explore the positive effect of introducing the modern concept of symmetry viewed as "sameness within change". A teaching-learning sequence (TLS) was conducted to test the challenges of an interdisciplinary approach based on symmetry and invariance in the educational context, namely at the primary school level. In the design of this sequence, solving the game of closing special cardboard boxes provides a fundamental role. The study evaluates how the specific teaching action makes the modern concept of symmetry in principle appropriate for primary school students through manipulative games. We investigate the students' cognitive paths about symmetry during the sequence by analysing pre- and post-sequence questionnaires. The questionnaire comprises four questions with dichotomous choice, items text, narrative text, and open justification. It is structured mainly in three domains devoted to cognitive, affective, and psychomotor dimensions. The analysis is composed of a mixed method approach. The investigations incorporate qualitative data with Text Analytics and Natural Language Processing (NLP) statistics to identify and extract information from pupils' written reflections. Our study also explores whether the emotion experienced by students plays a role in the TLS. Results show that educational activities induce the increasing knowledge and skills of students. In particular, most students interpreted the lessons as experiences rich in stimuli and insights on symmetry and mathematics in general. The findings also bring important suggestions and contents of reflection that teachers can consider for exploiting the potential learning path on symmetry and invariance.
\end{abstract}

Keywords: Nature of science, symmetry, questionnaire, cognitive path, primary school.

\section{Introduction}

This study is based on an ongoing research project that investigates the concept of symmetry across mathematics and physics to foster the teaching of the Nature of Science. The unitary nature of symmetry across mathematics and science is definite throughout historical and scientific development. However, symmetry has a more far-reaching role in the educational context, even if its role in the teaching/learning process is a story seldom told (Dreyfuss \& Eisenberg, 1990). Indeed, symmetry intervenes in different disciplines, and too often, it is presented as a collection of disconnected concepts. According to Darvas (2015, p. 328), symmetry has an important role in mathematics education as a vehicle of a general scientific method applicable throughout the sciences as a set of principles. We introduced an interdisciplinary approach based on the connection between symmetry and invariance, besides consolidating pedagogical-educational practices. Our educational project designed and implemented a teaching-learning sequence (TLS) based on introducing the modern concept of symmetry viewed as "sameness within change" (Leikin et al., 1998) at primary school. Previous work (Brasili \& Piergallini, 2020) indicates that the changed view of symmetry linked to the search for invariance is theoretically appropriate for primary school students through manipulative games. This mixed-methods study aims at investigating the pupils' cognitive path about symmetry during the sequence. We focus on the pupils' answers to the open question in the post-test. Open questions prompting students to reflect on the insight they gained and sensed during the teaching-learning unit can shed more light on their thought processes. Exploring the pupils' reflections and observations allows examining the extent to which the students have elaborated and mastered the contents and how conscious they were of the whole activity. 


\subsection{Theoretical framework}

In addition to the visualization and construction process, the reasoning is one of three kinds of cognitive processes in geometry affecting practical functions (Duval, 1998). The activity of thinking about symmetry is not simply about recognizing symmetrical shapes but refers to the deep knowledge and regulation of the cognitive process of symmetry. Authentic learning occurs when there is a change in cognitive schemes (Piaget, 1964). Learning should be considered a dynamic process of modification and restructuring of representative schemes inherent in a given phase and its potential future development.

Moerk (1974) demonstrated close parallels between aspects of cognitive development theory and independent language development. According to Sfard (2008), learning occurs when a definite change in vocabulary, visual mediators, routines and narratives operates in a cognitive perspective. The theoretical framework displays the foundation for investigating the pupils' narratives in terms of keywords and signs showing interaction with the learning path's visual mediators as artifacts, actions and dynamics in the classroom social setting.

\section{Materials and methods}

Our teaching-learning sequence (TLS) is structured into five activities, three lessons of two hours, and a timeframe of three weeks. The sequence is proposed to a sample of 96 pupils (aged 10) of the primary school in Italy. The researcher proposes various activities, and the teachers participate in the lessons as observers. The main activity is centered on the task game consisting of closing cardboard boxes. The pupils, divided into small homogeneous groups of 4/5 pupils chosen by the teacher, carry out manipulative work following the instructions and filling out the task game questionnaire. The manipulative work consists of folding and taping these cardboard models to obtain boxes with their covers. The covers are designed in such a way that they can only be rotated. The task game is to find in how many ways it is possible to put the cover on each box. This game refers to the rotation symmetries of the differently shaped lids. We take, for example, the triangle-shaped cover. The symmetries of the equilateral triangle can be thought of as the transformations (i.e., rotative actions) that allow covering of its respective box. This way, pupils can play and, in the meantime, deal intuitively with triangle invariants under rotations. The activities are designed to promote discussion and construct the mathematical concept behind the game, comparing the symmetries and invariants for all shapes in Figure 1.

Figure 1. Models of cardboard boxes and covers of 7 shapes.

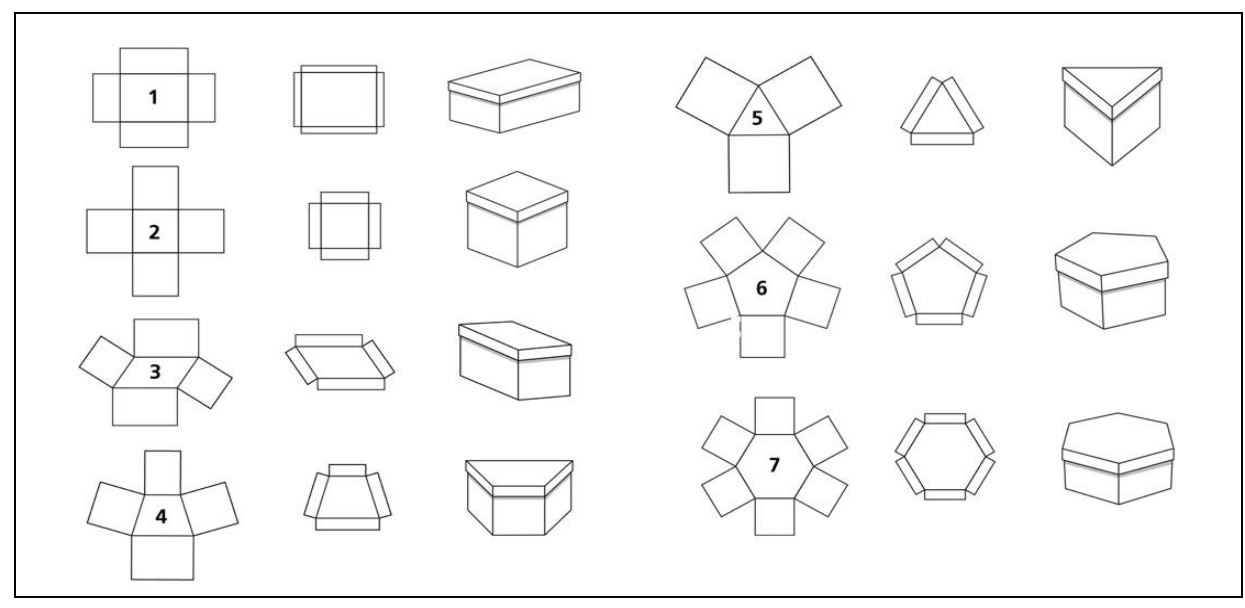

We evaluate the effectiveness of the TLS by examining the learning changes in the level of pupils' knowledge of symmetry resulting from the teaching-learning session by pre-/post-tests. The questionnaire comprises four questions: dichotomous choice, items text, narrative text, and a task with open justification each addressing a specific aim and learning object. It is structured mainly in three domains devoted to cognitive, affective, and psychomotor dimensions. Our present work focalizes the study on the third open question ${ }^{1}$. It aims at letting students to reflect and shape on their personal experiences during the TLS. The resulting inner dialogue should help the student in the authentic personal construction of concepts and the relative regulation in the cognitive process.

${ }^{1}$ Question 3: Tell the "Little Prince" the activities carried out in the classroom, what you liked, what you learned about symmetries and if you had any difficulties. 
The analysis is composed of a mixed method approach. The investigations incorporate qualitative data with Text Analytics and Natural Language Processing (NLP) statistics to identify and extract information from pupils' written reflections. The use of text analysis technologies from NLP reconciles the qualitative character of semantic meaning with the quantitative aspect of their pertinence (Wiedemann, 2016).

The qualitative and quantitative approach for empirical investigation aims at broadening the dimension level of study understanding and reducing errors of interpretation. We addressed the analysis in three main dimensions: (D1) the emotional and affective dimension; (D2) the cognitive dimension of learning gain; (D3) the possible presence of a cognitive conflict in processing information on the difficulties encountered.

The first step is to identify the principal lexicographic information in the pupils' narratives, which form our corpus, using the text analysis tool Textalyser (Gregori-Signes \& Clavel-Arroitia, 2015). The results obtained are illustrated in Table 1. The set of distinct words (i.e., lexemes or word tokens) determines the lexical size of vocabulary $(\mathrm{V})$. We indicate the number of i-times recurring lexemes with the $\mathrm{i}$-th vocabulary $\mathrm{V}_{\mathrm{i}}$. Indeed, the vocabulary $\mathrm{V}$ is the sum of each single vocabulary $\mathrm{V}_{\mathrm{i}}$ starting from the words that occur only once in the text $V_{1}$ (i.e., hapax) up to the vocabulary with the maximum number of occurrences $\mathrm{V}_{\text {fmax }}$ where fmax indicates the maximum frequency.

Table 1. Complete lexicometry measurements report of corpus (elab. Textalyser).

\begin{tabular}{|l|l|l|l|}
\hline Total word count (Tokens, N) & 4.452 & Total number of characters & 26.523 \\
\hline Distinct words (Types, V) & 660 & Character length without spaces & 19.967 \\
\hline Complexity Factor Lexical Density (LD, V/N) $[<20 \%]$ & $15 \%$ & Average syllables per word & 2,08 \\
\hline Lexical Richness ( $\left.\mathrm{V}_{1} / \mathrm{V}\right)[<50 \%]$ & $48 \%$ & Sentences count $(\mathrm{S})$ & 175 \\
\hline Readability (Gunning-Fog Ind.) [6-easy - 20 hard] & 13,5 & Average words per sentence (WPS) & 27,1 \\
\hline General average frequency (FMG, N/V) & 6,7 & Max sentence length (words) (MW) & 87 \\
\hline Guiraud's Index (V//N) & 10 & Min sentence length (words) (LW) & 4 \\
\hline
\end{tabular}

The corpus contains a total number $(\mathrm{N})$ of 4452 words (types), 175 sentences with 660 unique forms (token) (V). The lexical density (LD) is the ratio between the vocabulary width and the corpus size $(\mathrm{V} / \mathrm{N})$. It expresses the lexical extension of the text or, better to say, the variety of the vocabulary. The LD index is one of the fundamental parameters for evaluating the corpus suitability since a language that presents a corpus with a wide lexical extension (i.e., rich vocabulary) should have an equally large number of occurrences. Empirically to extrapolate useful information in the textual analysis, the LD acceptability threshold should be less than or equal to $20 \%$. In our case, this is a good value because the basic vocabulary represents $15 \%$ of the entire corpus with an average of words per sentence (AWPS) of 27.1. Another important parameter for evaluating the text statistical tractability is the percentage of hapax with the vocabulary size $\left(\mathrm{V}_{1} / \mathrm{V}\right)$. This index represents a lexical richness measure since it specifies how many graphic forms appear once compared to distinct words. In general, the number of hapaxes should not exceed more than half the extent of the vocabulary; the corpus again respects the indication being $\mathrm{V}_{1}$ equal to 320 with a percentage ratio of hapax equal to $48 \%$. Therefore, our corpus is sufficiently large for quantitative analysis. Consequently, the lexical size of the text is deemed representative of the language for primary school students. On the contrary, a too rich vocabulary compared to the size of the corpus would not make the text a characteristic sample of the language (Corral et al., 2015).

The vocabulary distribution is not homogeneous because there are many words with a low frequency corresponding to the highest rank positions and few terms persistent with a lower rank. The most frequent different terms constitute the core of the keywords of the corpus. Indeed, identifying the keywords is essential for getting the meaning of the answer content. They can highlight the latent structure underlying the text by reducing the representation space of the linguistic variables. To obtain a list of thematic keywords of the corpus, we grouped the terms into three frequency classes: high frequencies (HF), medium frequencies (MF), and low frequencies (LF). The first six graphic forms in the high-frequency class have a cumulative frequency equal to $42.7 \%$. By adding the classes of medium and low frequencies, we obtain $57.3 \%$ of the occurrences. It corresponds to $99 \%$ of the vocabulary. Consequently, we considered the union of the two groups MF and LF as a sub-corpus to extract the set of keywords.

Such selection of the most recurring terms should provide a synthetic representation of the peculiar semantic references even though they represent less than $10 \%$ of the vocabulary. These terms make up a descriptive structure not as a summary of the content but as key descriptive indices of the analysis" three dimensions. The term "simmetria" [symmetry] is the theme word par excellence (122 occ.) followed by "molto" [a lot] (76 occ.), "imparare" [to learn] (74 occ.), "piacere" [pleasure] (73 occ.), "cosa" [thing] (60 occ.), "difficoltà" [difficulty] (54 occ.), "scatole" [boxes] (51 occ.). 
To investigate any specificities related to the central theme of symmetry, we highlight the presence of other critical keywords such as "film" (33 occ.), "palindromo" [palindrome] (32 occ.), "parola" [word] (27 occ.), "figura" [figure] (25 occ.), "mela" [apple] (17 occ.), "stella" [star] (14 occ.), "numero" [number] (13 occ.). These graphic forms constitute essential traces of the activities carried out in the classroom, connected especially to the main task of cardboard boxes. They define the broad spectrum of the "semantic trait" that revolves around the symmetry argument, even better framed through the most common verbs "vedere" [to see] (49 occ.), "fare" [to do] (47 occ.), "potere" [can] (29 occ.), "chiudere" [to close] (25 occ.), "capire" [to understand] (24 occ.), "scoprire" [to discover] (23 occ.), "costruire" [to build] (21 occ.), "leggere" [to read] (15 occ.), "divertire" [to enjoy] (16 occ.), "tagliare" [to cut] (13 occ.).

The techniques of lexical analysis can extend the effectiveness of analysis by finding other textual regularities such as repeated groups of words with a precise semantic meaning. Repeated text segments of three graphic forms (3-grams or trigrams) are very connotative for the content extraction. They are particularly suitable for highlighting syntagmatic connections between the graphic forms because they have more explicit significance than the same words would have individually. We extracted a list of 15 segments from the corpus using the Textalyser application. We identified the most predominant trigrams that offer precise indications on the analysis dimensions (D1, D2, D3).

Table 2. Summary of predominant trigrams for dimensions D1, D2, D3.

\begin{tabular}{|l|l|l|l|l|l|}
\hline (D1) Emotional dim. & ISr & (D2) Cognitive dim. & ISr & (D3) Conflict dim. & IS r \\
\hline $\begin{array}{l}\text { mi è piaciuto } \\
\text { [I liked it }]\end{array}$ & 0,92 & $\begin{array}{l}\text { ho imparato che } \\
{[\text { I learned that }]}\end{array}$ & 0,62 & $\begin{array}{l}\text { non ho avuto } \\
{[\text { I didn't have }]}\end{array}$ & 0,70 \\
\hline $\begin{array}{l}\text { è piaciuto molto } \\
\text { [I loved it }]\end{array}$ & 0,36 & $\begin{array}{l}\text { in quanti modi } \\
\text { [in how many ways }]\end{array}$ & 0,48 & $\begin{array}{l}\text { ho avuto difficoltà } \\
{[\text { I had difficulty }]}\end{array}$ & 0,83 \\
\hline $\begin{array}{l}\text { mi sono divertito } \\
\text { [I had fun] }\end{array}$ & 0,68 & $\begin{array}{l}\text { imparato molte cose } \\
\text { [learned things }]\end{array}$ & 0,48 & $\begin{array}{l}\text { po' di difficoltà } \\
{[\text { little bit of difficulty }]}\end{array}$ & 0,31 \\
\hline $\begin{array}{l}\text { mi sono piaciute } \\
\text { [I liked them }]\end{array}$ & 0,59 & $\begin{array}{l}\text { abbiamo scoperto che } \\
\text { [we found that }]\end{array}$ & 0,50 & $\begin{array}{l}\text { avuto nessuna difficoltà } \\
\text { [had no difficulty }]\end{array}$ & 0,30 \\
\hline $\begin{array}{l}\text { piaciuta di più } \\
\text { [I liked most }]\end{array}$ & 0,36 & $\begin{array}{l}\text { ho capito che } \\
\text { [I understood that }]\end{array}$ & 0,47 & $\begin{array}{l}\text { ho avuto nessuna } \\
\text { [had not any }]\end{array}$ & 0,26 \\
\hline
\end{tabular}

To further evaluate the students' emotional and affective dimensions, the narratives were afterward analysed using natural language processing techniques called Natural Language Processing "NLP". The textual statistical analysis used is the Sentiment Analysis "SA" to extract information from texts about associated attitudes (i.e., sentiment). The attitude can be of various types: judgment or evaluation of the topics and the pupils' emotional reaction. The fundamental task of the "SA" is the classification of the overall polarity of the answer (i.e., positive, negative, or neutral value about the topic in question) with API (Application Programming Interface) library functions provided by free software Meaning Cloud. Although the algorithmic analysis does not ensure objectiveness, adopting such procedures allows to orient the semi-structured question towards objectivity, reducing interpretation errors. The performance metrics used to evaluate the classification results are accuracy, precision, recall, and F-measure. The metrics are calculated on the values of agreement positive (TP), disagreement positive (FP), agreement negative (TN), and disagreement negative (FN) (Altrabsheh et al., 2014). The levels of processing metrics achieved on the data set are relatively good, showing that the model allows a fairly correct sentiment characterization to the corpus of pupils' answers.

Table 3. Sentiment Analysis report of corpus and polarity classification performance metrics (elab. Meaning Cloud).

\begin{tabular}{|c|c|c|c|c|c|c|}
\hline Sentiment & Count & Percentage & Agreement & Disagreement & \multicolumn{2}{c|}{ Performance Metrics } \\
\hline Positive & 112 & $60 \%$ & $103(\mathrm{TP})$ & $9(\mathrm{FP})$ & Accuracy & $89 \%$ \\
\hline Neutral & 15 & $8 \%$ & 4 & 11 & Precision & $92 \%$ \\
\hline Negative & 17 & $9 \%$ & $14(\mathrm{TN})$ & $3(\mathrm{FN})$ & Recall & $97 \%$ \\
\hline No Sentiment & 42 & $23 \%$ & 42 & 0 & F-measure & $94 \%$ \\
\hline Total & 186 & $100 \%$ & 163 & 23 & Accuracy & $89 \%$ \\
\hline
\end{tabular}

\section{Results}

As shown in Figure 2, the emotional component D1 is $77 \%$ (S.D. 16\%). These indices show that the classes had a very positive but not regular emotional and affective attitude. The most positively involved class is the VG $(100 \%)$, while the least involved are the VA and VF classes $(63 \%)$. The cognitive dimension of D2 learning is right and relatively constant in the various classes, with an average 
percentage index of 71\% (S.D 6\%). In the corpus, the dimension of cognitive conflict is 55\% (S.D. 14\%). The detail of cognitive conflict distribution shows that $10 \%$ of pupils had difficulties, $22 \%$ some difficulties and $23 \%$ no difficulties, while $45 \%$ mention no perceived difficulties.

Figure 2. Bar graphs of the diffusion of dimensions (left) and the detail of cognitive conflict distribution (right).

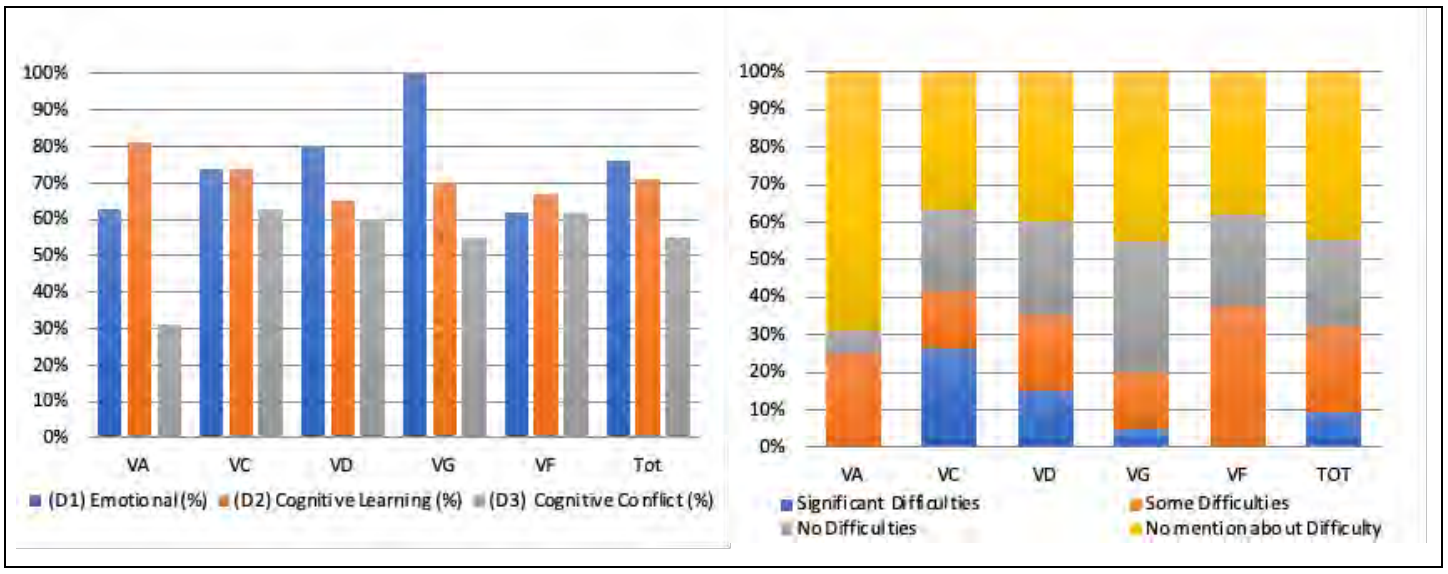

A coherence of judgment is identified between the two estimates obtained with different methods. Indeed, it emerged that the polarity of attitude is positive for $60 \%$ (S.D. 5\%) (Table 3), comparable with the D1 index shown in Figure 2.

\section{Conclusions}

The findings suggest that open questions are effective when exploring pupils' answers in the questionnaire. This study reports some results about the validity and potentiality of using Text Analytics and Natural Language Processing (NLP) in the mixed-methods analysis. Additional qualitative information expanding structured analysis responses can provide signs and key insight about students' cognitive path. Their positive feedback to the TLS indicates that the activities linked to the manipulative games motivate and advance the learning process on symmetry and mathematics in general. The findings also bring important suggestions and contents of reflection that teachers can consider for exploiting the potential learning path on symmetry and invariance.

\section{References}

Altrabsheh, N., Cocea, M., \& Fallahkhair, S. (2014). Sentiment Analysis: Towards a Tool for Analysing Real-Time Students Feedback. 2014 IEEE 26th International Conference on Tools with Artificial Intelligence, 419-423. doi.org/10.1109/ICTAI.2014.70.

Brasili, S., Piergallini, R., (2020) Nature of Science Interdisciplinary Teaching based on Symmetry and the Search of Invariants, International Conference on Education and New Developments, 394-398.

Corral, Á., Boleda, G., \& Ferrer-i-Cancho, R. (2015). Zipf's Law for Word Frequencies: Word Forms versus Lemmas in Long Texts. PLoS ONE, 10(7). doi.org/10.1371/journal.pone.0129031.

Dreyfus, T., \& Eisenberg, T. (1990). Symmetry in mathematics learning. International Reviews on Mathematical Education, 2, 53-59.

Duval, R. (1998). Geometry from a cognitive point of view. In C. Mammana \& V. Villani (Eds.), Perspectives on the Teaching of Geometry for the 21st century, 37-52. Dordrecht: Kluwer Academic Publishers.

Gregori-Signes, C., \& Clavel-Arroitia, B. (2015). Analysing lexical density and lexical diversity in university students' written discourse. Procedia - Social and Behavioral Sciences, 198, 546-556.

Leikin, R., Berman, A. \& Zaslavsky, O. (1998). Definition of Symmetry. Symmetry: Culture and Science: Order and Disorder, 9 (2-4), 375-382.

Moerk, E. (1974). Changes in verbal child-mother interactions with increasing language skills of the child. Journal of Psycholinguistic Research, 3, 101-116.

Piaget, J. (1964). Part I: Cognitive development in children: Piaget development and learning. Journal of Research in Science Teaching, 2, 176-186.

Sfard, A. (2008). Thinking as Communicating: Human Development, the Growth of Discourses, and Mathematizing. New York: Cambridge University Press.

Wiedemann, G. (2016). Text Mining for Qualitative Data Analysis in the Social Sciences. Wiesbaden: Springer VS. 


\title{
TEACHERS EXPERIENCE WITH INTRODUCING PROGRAMMING IN DIFFERENT COURSES FOR NON-COMPUTER SCIENCE STUDENTS
}

\author{
Martyna K. Fojcik ${ }^{\mathbf{1}}$, \& Marcin Fojcik ${ }^{\mathbf{2}}$ \\ ${ }^{1}$ Faculty of Humanities and Education, Volda University College (Norway) \\ ${ }^{2}$ Department of Electrical Engineering, Western Norwegian University of Applied Sciences (Norway)
}

\begin{abstract}
Digital literacy has become more and more important in the last decade, and many people predict that in the future, the need for digital skills will be even more crucial than it is today. The dynamic development and use of technology are becoming increasingly common in all areas of life, changing demands of modern life and the labor market, which makes it necessary to educate students from many different study-programs on how to use different digital tools and how to program.

Depending on different professions, there are different requirements on what it means to have digital literacy. For some it is most important to know how technologies are created or to use the product effectively, for others it is the security of data transfer that is essential. The different professions have different needs for digital literacy and different use for programming skills.

Teaching computer programming can be particularly difficult in the case of introducing programming for non-computer scientists. While computer science itself (programming) is relatively well described in the subject's literature, the use of programming in other professions is not well defined. There are different suggestions, recommendations according to the level of education (primary, secondary, higher) or the study-programs the students take. There is no definition of what digital literacy is in different professions, what it means to know computer programming in different professions, and to what extend the students from non-computer science courses should master digital literacy and programming. That can cause challenges for the teachers and students in non-computer science professions that are required to know computer programming for their future jobs. There is no doubt that academic computer science skills for non-programmers can mean/contain different knowledge depending on course curriculum, teachers' experience, chosen literature, but the level of obtaining digital skills should be comparable, adequate, and relevant for the modern citizen.

This article presents requirements, some descriptions/cases of introduction to programming for non-computer scientists from a teacher's perspective. An adaptation of the general programming knowledge into the specific need of different subjects. The data is collected from higher education teachers that have different backgrounds and are teaching at different study-programs to get various views and experiences. The analysis of the findings uses SOLO-taxonomy to compare to what extend the different courses introduce programming to students.
\end{abstract}

Keywords: Digital literacy, programming for non-computer scientists, introduction to programming.

\section{Introduction}

According to research, almost two-thirds of all new jobs created since 2010 in America require either high or medium ICT skills (World Economic Forum, 2020). This trend is similar in other countries around the world and forced by the rapidly changing technology market. The dynamic development of information technologies and services and the changing demands of modern life are leading to changes in the labor market and, consequently, in all levels of education. To fill this gap and supply the needed digital competencies for society programming has been introduced in many non-computer science professions.

Today, university students have many subjects related to information technology, programming, or the use and distribution of digital machines, but many subjects focus on theoretical knowledge rather than skills development, or develop skills in computer science programming rather than focus on what kind of programming skills are needed in different professions. On the one hand, there is computer science and programming as a part of computer science, and on the other hand - teaching programming people from other fields, not as a part of computer science. This means that many students learn programming skills from the creators' point of view, even though they are studying the use of programming in their professions 
rather than creating a computer program. A key challenge for today's universities is to identify which programming skills are being taught and how to teach them according to the students' study program. What are the requirements for programming in each profession? How can this be done to convey an important element and at the same time not overload the curriculum with elements that are unnecessary for this course? (Does a math teacher in primary school need to learn how to sort binary trees?)

This article will present some challenges with teaching digital literacy, and some definitions on digital literacy/digital competencies presented in EU and national documents. Then it will present two courses, one automation engineering course from Western Norway University of Applied Sciences (HVL), and one teacher education course from Volda University College (HVO). These two courses are introducing programming for non-computer scientists to, amongst other things, support students' development of digital literacy through programming. These courses represent only a part of students' skill development in their study programs, but they were chosen for this comparison since they are mainly focusing on the central part of digital literacy in these study programs. The chosen courses were analyzed according to the SOLO-taxonomy and then compared to the EU and national requirements on digital competencies.

\section{Challenge in teaching digital literacy}

Regardless of the field of knowledge, new competencies related to digital literacy and their practical application are needed both in professional development and private lives. These competencies depend on the skills of the workers, which in turn are based on knowledge, experience, and additional (non-professional) skills. Digital literacy is a broad gathering of different theoretical and practical skills and competencies on how to use technology and different functions that comes within, how to be aware and safe using technology, how are digital media and digital systems constructed, and how to use it in an efficient, secure and functional way (Buckingham, 2010). These skills can be divided into soft and hard competencies. Hard competencies are developed through academic education, work experience, and technical knowledge, while soft skills can be understood as a set of personal, interpersonal, and managerial competencies, like time-management, professionalism, reliability, ability to work under pressure, communication skills, creativity, and self-confidence. Andrews and Higson (2008) noticed a difference between graduates' skills and employers' expectations, where the set of skills the students develop during education weren't enough for the employers. The future employer needs the student to have not only soft and hard skills fitted for the work but also experience and practical knowledge about how to use technology. The Gallup-Purdue indicator provides statistics on the employment of graduates (Gallup, 2014), and according to their statistics students who have worked on projects lasting at least one semester or who have had a job or practice in the same area as their studies double their chances of getting involved in work later in life because they had more experience in developing practical skills needed in their professions.

The challenge in higher education is to adapt to the form of knowledge transfer to help students develop these practical skills during the course. To support skill development needed in each profession and prepare students for future employment. Today's students expect new forms of teaching that will help them to acquire practical skills, especially such as teamwork, cooperation, and responsibility, but the structure of teaching in higher education is not prepared for such forms. A higher education teacher might explain theoretical perspective and show technological tools and functions for the student, but that is not enough to let the student develop his own skills. The challenge for today's teachers is to find out what existing and new approaches are needed in teaching and how best to meet students' needs to facilitate students' development of digital literacy.

\section{EU and national requirements}

The Council of the European Union, first in 2006 and then in a new Recommendation of 2018, has placed digital competence as one of the eight key competencies for lifelong learning. The Recommendation defines digital competence as self-confidence, critical thinking, and responsibility for using digital technologies and describes it in terms of knowledge, skills, and attitudes (Council Recommendation, 2018). International documents provide guidance for improving and understanding digital competence, highlighting the need to plan innovative educational activities and assess student competence levels.

The need for developing digital competencies have been researched in project DigComp 2.0 (Vuorikari et al, 2016), which identifies the key components of digital competence in 5 areas which can be summarised as follows: 
- Information and data literacy: To articulate information needs, to locate and retrieve digital data, information and content. To judge the relevance of the source and its content. To store, manage, and organize digital data, information and content.

- Communication and collaboration: To interact, communicate and collaborate through digital technologies while being aware of cultural and generational diversity. To participate in society through public and private digital services and participatory citizenship. To manage one's digital identity and reputation.

- Digital content creation: To create and edit digital content. To improve and integrate information and content into an existing body of knowledge while understanding how copyright and licenses are to be applied. To know how to give understandable instructions for a computer system.

- Safety: To protect devices, content, personal data, and privacy in digital environments. To protect physical and psychological health, and to be aware of digital technologies for social wellbeing and social inclusion. To be aware of the environmental impact of digital technologies and their use.

- Problem-solving: To identify needs and problems, and to resolve conceptual problems and problem situations in digital environments. To use digital tools to innovate processes and products. To keep up-to-date with the digital evolution.

\section{Requirements for non-computer science professions; engineers and teachers}

Norwegian National Curriculum Regulations for Engineering Education (UHR-MNT, 2020) describes what students should accomplish through developing digital competencies during a course:

- The candidate has knowledge of software useful at work and broad engineering skills, including basic programming skills.

- The candidate may work inappropriate physical and digital laboratories and master methods and tools as a basis for targeted and innovative work.

- Candidates will be able to identify the security, vulnerability, privacy, and data security aspects of ICT products and systems. Based on these descriptions of learning outcomes are learning outcomes in ICT programming and security

National curricula also describe the requirements for programming skills - and not only for programmers. Digital literacy plays an important role in the development of future society and industrial solutions. This means that programming, software, and computer technology are taken into account as technologies for the development and implementation of many system solutions. Because of this development, the engineering education framework requires basic programming skills in all fields of engineering.

In a similar document presenting teacher education should develop (NRLU, 2016), it is written that basic skills: reading, counting, writing, speaking, and using digital technology are both a prerequisite for developing academic knowledge and part of academic competence in all subjects. Teacher education supports the development of students' basic skills at the subject level. Teaching practice includes the teaching and use of digital resources. A teacher should have knowledge of the use of various teaching aids, both digital and other, and of the possibilities and limitations of these aids.

\section{SOLO-taxonomy of introduction to programming at universities}

In a previous study, the authors analyzed two introductions to programming courses (Fojcik et al. 2020) and compared the content of the courses based on SOLO-taxonomy (Structure of the Observed Learning Outcome) by Briggs and Collis (1982). This taxonomy is used to evaluate the observed students learning outcomes in a lecture or a course. Based on the analysis of Fojcik et al. (2020), some criteria for developing programming skills were described into an extended model of 5 phases of SOLO-taxonomy. The overall results and description of skills developed in each programming course are presented in Table 1. 
Table 1. Compared of HVL and HVO courses based on Fojcik et al. 2020.

\begin{tabular}{|c|c|c|c|c|}
\hline Level & Name & $\begin{array}{l}\text { Programming competence } \\
\text { (computer science) }\end{array}$ & $\begin{array}{c}\text { Programming for teachers } \\
\text { (HVO) }\end{array}$ & $\begin{array}{l}\text { Programming for auto. } \\
\text { engineer (HVL) }\end{array}$ \\
\hline 5 & $\begin{array}{l}\text { Extended } \\
\text { Abstract }\end{array}$ & $\begin{array}{l}\text { Develop the skill of creating, } \\
\text { testing, and operating } \\
\text { programs, making and } \\
\text { distributing classes, libraries } \\
\text { for multiple uses, cooperation, } \\
\text { and collaboration with other } \\
\text { programs and users. }\end{array}$ & $\begin{array}{l}\text { Show pedagogical, } \\
\text { didactical, and content } \\
\text { knowledge of programming, } \\
\text { the skill to use simple } \\
\text { programs, understanding and } \\
\text { explaining computational } \\
\text { structures, supporting } \\
\text { computational thinking in } \\
\text { students/pupils in all levels } \\
\text { of education, etc. }\end{array}$ & $\begin{array}{l}\text { Model of software as a } \\
\text { model of real } \\
\text { action/automation, } \\
\text { libraries, interfaces, } \\
\text { analogies between real- } \\
\text { world and software }\end{array}$ \\
\hline 4 & Relational & $\begin{array}{l}\text { Create a working program, } \\
\text { divided into different elements } \\
\text { (class, structure, etc.), full } \\
\text { debugging, collaboration and } \\
\text { cooperation with the user, } \\
\text { saving state, file handling, } \\
\text { network, database, etc. }\end{array}$ & $\begin{array}{l}\text { Explain why the program } \\
\text { works, reading and } \\
\text { understanding other's code to } \\
\text { debug programs, etc. }\end{array}$ & $\begin{array}{l}\text { Dividing action into } \\
\text { smaller, repeatable } \\
\text { elements, reusability, } \\
\text { safety, friendliness of the } \\
\text { software }\end{array}$ \\
\hline 3 & $\begin{array}{l}\text { Multi- } \\
\text { structural }\end{array}$ & $\begin{array}{l}\text { Show sophisticated elements } \\
\text { in coding, combining several } \\
\text { different actions, compiling } \\
\text { user interface, etc. }\end{array}$ & $\begin{array}{l}\text { Independent writing of the } \\
\text { algorithms and create simple } \\
\text { working programs, } \\
\text { explaining efficiency and } \\
\text { accuracy of their own work, } \\
\text { etc. }\end{array}$ & $\begin{array}{l}\text { Repetitions of actions, } \\
\text { more complicated } \\
\text { elements, user interface, } \\
\text { error-handling }\end{array}$ \\
\hline 2 & $\begin{array}{c}\text { Uni- } \\
\text { structural }\end{array}$ & $\begin{array}{l}\text { Show simple skills, using } \\
\text { variables, comparing elements, } \\
\text { simple loops. Everything in } \\
\text { one file, with no dividing in } \\
\text { sections, classes or structures, } \\
\text { etc. }\end{array}$ & $\begin{array}{l}\text { Independent writing of } \\
\text { simple commands/sequences, } \\
\text { using simple loops and/or if- } \\
\text { sentences, etc. }\end{array}$ & $\begin{array}{l}\text { Understanding the idea of } \\
\text { planning and operations } \\
\text { order, the definition of } \\
\text { variables (connected with } \\
\text { real measurements), and } \\
\text { simple operations on } \\
\text { them }\end{array}$ \\
\hline 1 & $\begin{array}{c}\text { Pre- } \\
\text { structural }\end{array}$ & $\begin{array}{l}\text { Barely anything or just a very } \\
\text { general or divided knowledge } \\
\text { - wrong assumptions and } \\
\text { unconnected information, etc. }\end{array}$ & $\begin{array}{l}\text { Barely anything or just a } \\
\text { very general or divided } \\
\text { knowledge - wrong } \\
\text { assumptions and } \\
\text { unconnected information, } \\
\text { etc. }\end{array}$ & $\begin{array}{l}\text { Barely anything or just a } \\
\text { very general or divided } \\
\text { knowledge - wrong } \\
\text { assumptions and } \\
\text { unconnected information, } \\
\text { etc. }\end{array}$ \\
\hline
\end{tabular}

\section{Comparison and discussion}

Depending on different needs, there is no coherent plan for teaching digital competencies. Requirements from the employers and the European Union indicate basic digital literacy as the creation, modification, use of digital components understandably and responsibly. Many of these elements are reduced in university programs. The role of universities is to train professionals, but digital skills are often described as a basic level, and usually more or less combined with programming skills, even though they might not intersect in EU and national requirements for digital competencies.

There is a gap between requirements at different courses and overall requirements at higher education levels when teaching digital literacy. This is most evident in teaching programming. Programming can be presented as the most important digital skill for the students, but not all of the students should be programmers. That is not their goal when they choose to study engineering, teacher education, biology, or any other professions, but all students must learn to use digital tools responsibly and safely both in their professional and private life.

Another challenge is how to teach non-computer scientists to program. The results of SOLO-taxonomy comparison of HVL and HVO courses show that the development of programming skills should be customized to the pedagogical and didactical requirements of the profession they are thought in, and not necessarily as computer scientists. 
The analysis based on SOLO-levels of the course content shows differences in what students learn about programming and what they do on assignments to what they perform on exams and evaluations (Fojcik et al, 2020). This result shows that students understand the theory of programming and using technologies at a higher level than they can perform on practical exercises in using programming or technology. The challenge in higher education is to support students to develop understanding and practical skills to match their theoretical knowledge on the same topics.

\section{References}

Andrews, J., \& Higson, H. (2008). Graduate employability, 'soft skills' versus 'hard' business knowledge: A European study. Higher education in Europe, 33(4), 411-422.

Buckingham, D. (2010). Defining digital literacy. In Medienbildung in neuen Kulturräumen (pp. 59-71). VS Verlag für Sozialwissenschaften.

Council Recommendation (2018). On key competences for lifelong learning. In Official Journal of th European Union 189, 4.6.2018, p. 1-13. Retrived form https://eur-lex.europa.eu/legalcontent/EN/TXT/?uri=uriserv\%3AOJ.C_.2018.189.01.0001.01.ENG

Fojcik, M. K., Fojcik, M., Sande, O., Refvik, K. A., Frantsen, T., \& Bye, H. (2020). A content analysis of SOLO-levels in different computer programming courses in higher education. In Norsk IKT-konferanse for forskning og utdanning (No. 4).

Gallup (2014), Great Jobs Great Lives. The 2014 Gallup-Purdue Index Report. Retrieved from https://www.gallup.com/services/176768/2014-gallup-purdue-index-report.aspx

NRLU (National Council for Teacher Education) (2016). National Guidelines for the Primary and Lower Secondary Teacher Education Programme for Years 5-10. Retrieved from: https://www.uhr.no/_f/p1/iecd98eeb-d012-44ce-b364-

c8787ca51a95/national_guidelines_for_the_primary_and_lower_secondary_teacher_education_pro gramme_for_years_5_10.pdf

Recommendation of the European Parliament and of the Council (2006). On key competences for lifelong learning. In Official Journal of the European Union 394, 30.12.2006, p. 10-18. Retrieved from https:/eur-lex.europa.eu/eli/reco/2006/962/oj

UHR-MNT (2020). National Curriculum Regulations For Engineering Education. Retrieved from https://www.uhr.no/_f/p1/i0cb3d399-4d21-4317-8978-e4f44c2306c1/nasjonale-retningslinjer-foringeniorutdanning-vedtatt-av-uhr-mnt-november-2020.pdf

Vuorikari, R., Punie, Y., Carretero, S. \& Van den Brande, L. (2016). DigComp 2.0: The Digital Competence Framework for Citizens. Update Phase 1: the Conceptual Reference Model. Retrieved from https://ec.europa.eu/jrc/en/publication/eur-scientific-and-technical-research-reports/digcomp-20digital-competence-framework-citizens-update-phase-1-conceptual-reference-model

World Economic Forum (2020). The Future of Jobs Report 2020. Retrieved from http://www3.weforum.org/docs/WEF_Future_of_Jobs_2020.pdf 


\title{
QUALITY CONTROL TOOLS IN THE ANALYSIS OF COVID-19 CAUSED PROBLEMS
}

\author{
Nicolas Dominguez-Vergara ${ }^{1}, \&$ Daniel Nicolas Dominguez-Perez ${ }^{2}$ \\ ${ }^{1}$ Universidad Autónoma Metropolitana (Mexico) \\ ${ }^{2}$ Universidad Nacional Autónoma de México (Mexico)
}

\begin{abstract}
Quality control tools are taught in engineering careers to analyze and try to solve problems in the production of goods and in the performance of service businesses. Those tools can be used to analyze and understand many problems. The coronavirus pandemic has caused many problems around the world, like many people infected in people's agglomerations in public transportation, in celebrations like parties, in political rallies and in public markets because of the people not wearing masks. A Pareto diagram clearly shows the most dangerous comorbidities in case of covid-19 infection. A lot of doctors and nurses have been contagious around the world in many cases because of lack of protection materials for them, hopefully health and safety procedures (check lists) and Poka Yoke devices are being created and implemented to reduced contagion. In this paper we identified and analyzed some covid-19 caused problems using basic quality control tools and for some cases we proposed solutions to them. Examples of a Pareto Diagram in analyzing the death rate in age ranges is used to explain the decrement in deaths in the United States of America if certain age groups are first vaccinated, an Ishikawa Diagram is used to analyze the ineffective distant learning in Mexico, a Check List is elaborated to avoid contagion in shopping and a Dispersion Diagram is used to find a relation between the number of contagious and the number of deaths in many countries of the world. Some other tools are briefly explained and some problems which could be analyzed with those are identified. The examples could enhance the interest of the students in learning the usefulness of those tools in a variety of fields.
\end{abstract}

Keywords: Teaching-learning process, covid-19.

\section{Introduction}

There are plenty of examples of the usefulness of quality control tools to analyze industry problems or even to find solutions for them. For example, in the April 26, 1986 nuclear accident in Chernobyl a simple analysis shows that a Check List mirroring its nuclear safety procedure could have been very useful to avoid the accident together with a Poka Yoke device (a double container system). The nuclear accident in Fukushima on March 11, 2011 could possibly have been prevented using taller walls against high tides and water tanks on towers nearby the nuclear reactors (both Poka Yoke devices). Also, a simple Check List on the right metric system of measurement to use during the whole trip to Mars could have avoided the disaster of the Mars Climate probe on September 23, 1999. The covid-19 pandemic has caused alarm in many countries because of the number of contagious and deaths of their people. The countries have followed very different strategies trying to reduce contagion, hospitalizations and the number of deaths. In this paper quality control tools (Gutierrez \& de la Vara, 2013) are used to understand some of the problems that the pandemic has caused (Dominguez-Perez \& Dominguez-Vergara, 2020) (Dominguez-Vergara \& Dominguez-Perez, 2020) and to analyze some of the data available. The aim is that the students learn that these tools can be used to analyze problems beyond engineering. Examples in which a Pareto Diagram, an Ishikawa Diagram, a Check List and a Dispersion Diagram are used, are reported in this paper.

\section{Pareto diagram}

The Pareto Diagram is very useful to identify which are the most important problems that are needed to be addressed in a situation (Gutierrez \& de la Vara, 2013). This diagram is also called the 80-20 Diagram because in the classic example $80 \%$ of the accumulated frequency of the problems is caused only by $20 \%$ of them. That is, there are many trivial problems but only a few vital, the $20 \%$ of the problems, and it is recommended that these are resolved. In a lot of cases, the classic Pareto Diagram it is not the outcome, 
that is, not exactly the $20 \%$ of the problems are vital. In those cases, decision makers must decide which problems to solve depending on the available human and material resources. Also, sometimes it is necessary to consider other issues as in the example given bellow. The students learn that some research has to be carried out in order to better understand the problem being analyzed.

In the first example, a Pareto Diagram is used regarding the decision of which part of the population must be vaccinated first in the United States. The determination has been reached in many countries that medical personnel must be first in line, then older people because they have died more. The first column of Table 1 contains the age group, the second column the covid-19 mortality rates in deaths by 100000 inhabitants in the United States of America (US) (US Center for Disease Control and Prevention, 2020) and the third column is the percentage of accumulated mortality rate.

Table 1. Covid-19 mortality rates by age range in the US and their accumulated frequency.

\begin{tabular}{|l|l|l|}
\hline Age range & Mortality rate & $\begin{array}{l}\text { Percentage of accumulated } \\
\text { mortality rate }\end{array}$ \\
\hline $85+$ & 1118.3 & $65.67 \%$ \\
\hline $75-84$ & 366.2 & $87.18 \%$ \\
\hline $65-74$ & 143.2 & $95.59 \%$ \\
\hline $50-64$ & 50.6 & $98.56 \%$ \\
\hline $40-49$ & 15.7 & $99.48 \%$ \\
\hline $30-39$ & 6.3 & $99.85 \%$ \\
\hline $0-29$ & 2.5 & $100.00 \%$ \\
\hline
\end{tabular}

The corresponding Pareto Diagram of the data in Table 1 is shown in Figure 1.

Figure 1. Pareto Diagram of the covid-19 mortality rates in the US.

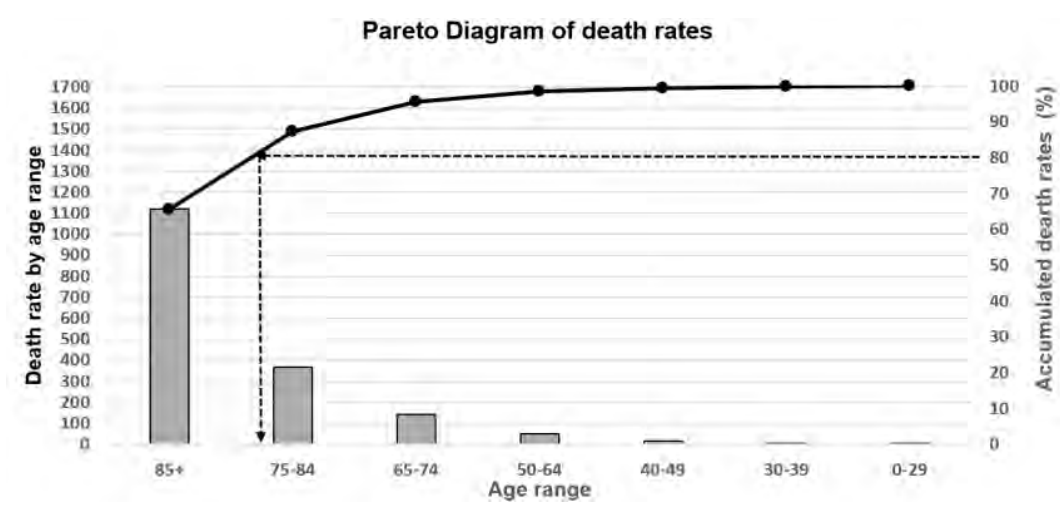

From Figure 1, it is noticeable that $65.67 \%$ of the deaths could be avoided if the population of 85 years old and older are vaccinated first. If the goal is to reduce $87.18 \%$ of the deaths, the adults 75 and older should be vaccinated. This is not so formidable because the people in the US having 75 years or more are only $6.8 \%$ of the whole population (De Wulf, 2019). In this way the hospitalizations would be greatly reduced leaving space for the less vulnerable population. The Pareto Diagram would change dramatically if life expectancy is considered in the United States. An argument could be made that older people would not live more than just a few more years while young people in the age range of 20-40 years old would still have more than twice their age to live (Schwab \& Malleret, 2020). If the "lost years" were taken into consideration, the column of the number of deaths could be multiplied by the potential lost years and the Pareto Diagram would look very different and therefore the prioritization for vaccination could change. Students learn that there are many aspects to be considered when analyzing problems, mainly during the covid-19 pandemic in which economics is weighted against the health of the population.

Once that a Pareto Diagram has been constructed the vital problems can be analyzed using other tools, or a Pareto Diagram could be elaborated for each of the most important problems. For example, Pareto Diagrams for the covid-19 mortality rates for the 85+ and the 75-84 age groups for states of the Union, comorbidities, races, socio-economical conditions, regional degree of urbanization, regional hospital infrastructure or medical resources or for other variables, could be elaborated. These Pareto Diagrams could be very useful because noticeable difference could be detected and if there is lack of resources an extra analysis could help to curb deaths more effectively. 


\section{Ishikawa diagram}

Sometimes, once that a Pareto analysis is carried out an Ishikawa Diagram is worked out for each of the vital problems. In an Ishikawa Diagram the problem is considered the effect and the causes are looked for, also for each cause there are sub causes which must also be found. Once that the Ishikawa Diagram has been constructed, another diagram can be easily drawn with the solutions to solve the problem. In the next example, an Ishikawa Diagram is used to analyze the problem of why distance learning has not been very successful in Mexico (Dominguez-Perez \& Dominguez-Vergara, 2020) (Dominguez-Vergara \& Dominguez-Perez, 2020). In this example the issues of courses which cannot be taught easily at distance, like laboratories, are not considered. Likewise, there are other problems which are not included, for example, power outages, because although important, they are considered sporadic.

Figure 2. Ishikawa Diagram for distance learning problems in Mexico.

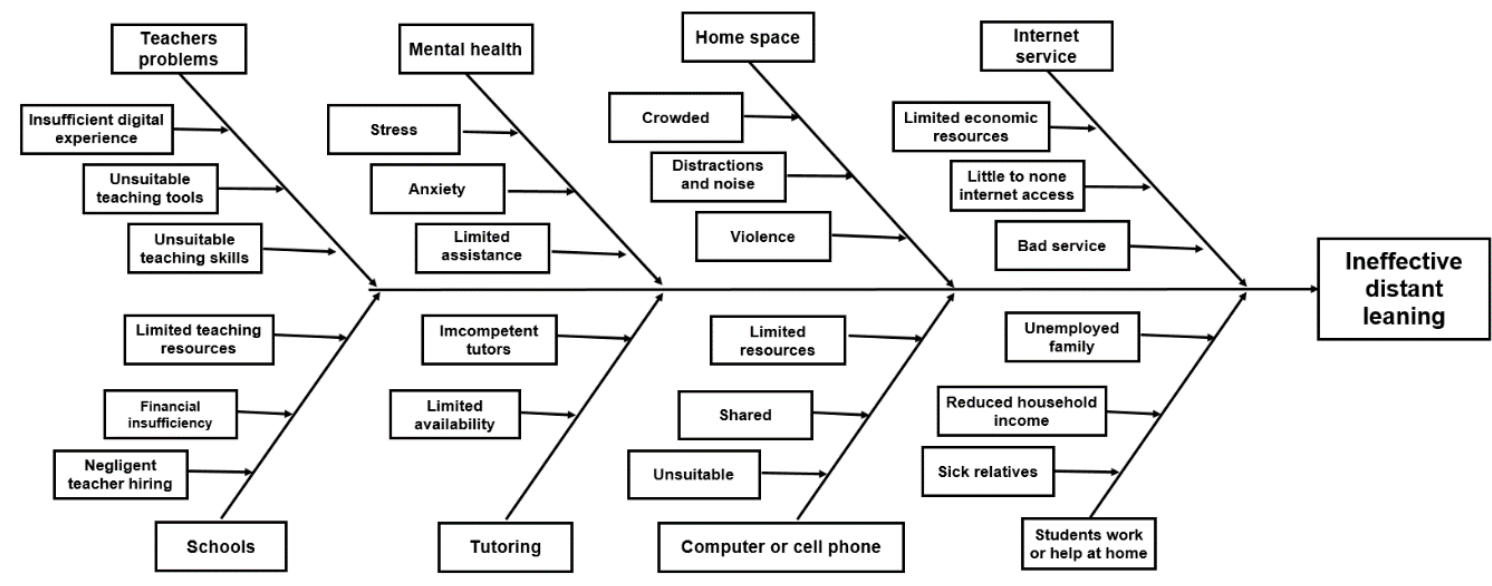

A very useful Ishikawa Diagram can be easily constructed if a very competent team acquainted with the problem participates. For example, in the US the vaccination priorities (effect) was reached after considering Science, Ethics and Implementation (causes) (US Center for Disease Control and Prevention, 2020 ) by a multidisciplinary group. Ishikawa diagrams have been explained in class by one of the coauthors of how to reduce contagion at home, and why in Mexico the number of deaths has been disproportionately high (because of lack of testing, confused government messages to the population and other causes.)

\section{Check list}

The Check List is a very useful tool which can prevent huge mistakes despite its simplicity. Students are given assignments to elaborate check lists to avoid contagion in shopping during the pandemic. The checks lists include precautions which must be taken leaving home, in the way to the supermarket, in the markets or supermarkets and in returning home, as it is explained in Table 2. A Check List Diagram can be very helpful instead of a simple list; however, sometimes just a list could be easier to review and handle. Although the Check List should be very detailed, in this example, a generic list was elaborated to stress the most important steps.

\section{Dispersion diagram}

Several examples of dispersion diagrams of two variables are explained to the students and homework is assigned in order that they practice their use. One of the variables could be an effect and the other the cause. Or both variables could be effects or causes which could be related. Also, the students must learn that sometimes it is necessary no to consider one of the variables or both of the variables directly but after being mathematical transformed. In the next example the relation between the number of contagious and the number of deaths for many countries is explored (Worldometer, 2021). The data corresponds to the 14 of February of 2021 and to the first 192 countries of the list in reference (Worldometer, 2021). Instead of using the variables directly the base 10 logarithms of the two variables are used. The results are shown in the Dispersion Diagram in Figure 3. 
Table 2. Check list of preparing, traveling to, visiting and returning from a supermarket.

\begin{tabular}{|c|c|c|}
\hline Activities & YES & NO \\
\hline \multicolumn{3}{|l|}{ 1. Before leaving home } \\
\hline Is your shopping list complete? & & \\
\hline Is the place and mode of transportation well defined? & & \\
\hline Will you pay with a debit or credit card? & & \\
\hline Are you already wearing a mask and carrying gel? & & \\
\hline If you are traveling by car, did you disinfect it? & & \\
\hline If you are traveling by public transport, do you have change? & & \\
\hline \multicolumn{3}{|l|}{ 2. During the journey } \\
\hline \multicolumn{3}{|l|}{$\begin{array}{l}\text { If you travel by public transport, do you follow the hygiene measures of that transport (face masks, } \\
\text { distance between passengers, open windows, etc.)? }\end{array}$} \\
\hline \multicolumn{3}{|l|}{$\begin{array}{l}\text { If you travel by public transport paying in cash, did you disinfect the change before and after } \\
\text { entering the vehicle? }\end{array}$} \\
\hline \multicolumn{3}{|l|}{ 3. At the supermarket } \\
\hline \multicolumn{3}{|l|}{$\begin{array}{l}\text { Did you follow the hygiene measures of the place when entering (cart handle cleaned with gel, } \\
\text { mask, distance from other visitors)? }\end{array}$} \\
\hline Did you follow the hygiene measures while inside the place (mask, distance from other visitors)? & & \\
\hline \multicolumn{3}{|l|}{ Did you check before paying that you carry all the products? } \\
\hline \multicolumn{3}{|l|}{ Did you follow the hygiene measures when paying (mask, safe distancing)? } \\
\hline \multicolumn{3}{|l|}{ Did you disinfect the change or your payment cards? } \\
\hline \multicolumn{3}{|l|}{ 4. On the way back } \\
\hline \multicolumn{3}{|l|}{$\begin{array}{l}\text { If you travel by public transport, do you follow the hygiene measures of that transport (face masks, } \\
\text { distance between passengers, open windows, etc.)? }\end{array}$} \\
\hline \multicolumn{3}{|l|}{$\begin{array}{l}\text { If you travel by public transport with cash payment, did you disinfect the change before and after } \\
\text { entering the vehicle? }\end{array}$} \\
\hline \multicolumn{3}{|l|}{ 5. At home } \\
\hline \multicolumn{3}{|l|}{ Did you disinfect the keys upon entering? } \\
\hline \multicolumn{3}{|l|}{ Did you disinfect or change your shoes when you entered? } \\
\hline Did you disinfect everything you brought (merchandise, clothing, shoes, etc.)? & & \\
\hline Did you bathe and change clothes? & & \\
\hline
\end{tabular}

The result in Figure 3 shows that there is a linear relation between the two variables considered. Students must learn to explore mathematical transformations of the variables and also to adequately treat the data. For example, in Mexico the authorities since April of 2020 declared based on insufficient information that the pandemic was under control and in August 2020 some extrapolation was made to establish that the pandemic was receding, when the worst weeks were coming in January 2021. Wrong conclusion was given because of insufficient data and insufficient analysis of the data.

\section{Stratification, histogram, decision tree, Shewhart charts and Poka Yoke}

There are many other tools learned and used by engineering students (Gutierrez \& de la Vara, 2013) which are not explained at length in this paper but only briefly in what follows. Students are recommended to use stratification of the data in studying many problems. For example, in studying deaths a stratification by sex is very important and it is easily seen that women die much less that men. For example by studying the population pyramids is found that in the US from the ages 0 to 39 years there are more men than women but after 55 there are more women than men (De Wulf, 2019). In Mexico there are more men than women in the ages 0 to 24 but in the ages 34 and more there are more women than men (De Wulf, 2019). Therefore, apparently women are more resilient than men in old ages and the coronavirus impact on deaths is not different because men are dying more that women. In the first example in this paper, a stratification by the age of the population was first carried out. There are many examples of stratifications carried out to explain that deaths by coronavirus have been disproportional in minorities in the US or to remark that minorities are being left behind in virtual education. Combination of Stratification and a Histogram should show that minorities working in essential activities have been more contagious by classifying the population by job activity, age range and race. A decision tree is very useful to analyze consequences of the federal authorities' decisions. For example, in Mexico flights from other countries were never prohibited, very few tests to detect coronavirus contagion have been carried out, also the use of masks was never enforced, even the Mexican President publicly refused to use them; the effect of this government's measures could be analyzed using a Decision Tree. Shewhart control charts (Gutierrez 
\& de la Vara, 2013) are also very useful to detect non-random events during the observations of variables in some periods of time (like the proportion of deaths in a country), examples using that tool will be reported elsewhere. Also, some Poka-Yoke tools (Gutierrez \& de la Vara, 2013) should be created to contain or avoid contagion, so far the best Poka-Yoke are social distancing, washing hands, use of masks and definitely the best and most important of them: the vaccine.

Figure 3. 10 base logarithms of the number of contagious people (horizontal axis) and the number of deaths due to covid-19 (vertical axis).

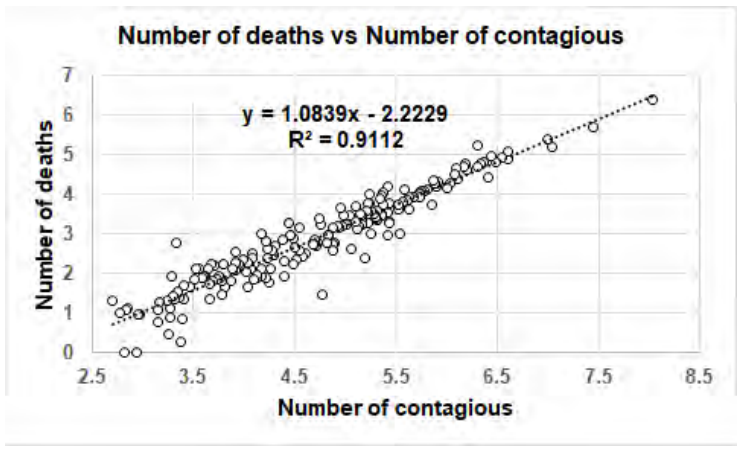

\section{Conclusion}

Quality control tools are very useful to analyze many formidable problems and make useful recommendations beyond engineering.

\section{References}

De Wulf, M., (December 2019). Pirámides de población del mundo desde 1950 hasta 2100, Estados Unidos. Retrieved 14 February, 2021, from: https:/www.populationpyramid.net/es/estados-unidos/2020/

De Wulf, M., (December 2019). Pirámides de población del mundo desde 1950 hasta 2100, Mexico. (December 2019). Retrieved February 14, 2021, from: https://www.populationpyramid.net/es/m\%C3\%A9xico/2020/

Dominguez-Perez, D.N., \& Dominguez-Vergara, N. (2020). From the lessons of coronavirus, a whole new world in education? EDULEARN 2020 Proceedings. pp. 6412-6421.

Dominguez-Vergara, N., \& Dominguez-Perez, D.N. (2020). Some impacts of covid-19 to higher education in Mexico. ICERI 2020 Proceedings. pp. 3691-3700.

Gutierrez, R., \& de la Vara, R. (2013). Control estadistico de la calidad y seis sigma. Cd. de Mexico/Mexico: McGraw-Hill/Interamericana.

Schwab, K., \& Malleret, T. (2020). Covid-19: el gran reinicio. Coppell, TX/USA: Forum Publishing.

US Center for Disease Control and Prevention. (December 2020). Phased allocation of covid-19 vaccines. Retrieved February 14, 2021, from: https://www.cdc.gov/vaccines/acip/meetings/downloads/slides2020-12/slides-12-20/02-COVID-Dooling.pdf

Worldometer. (2021). Covid-19 coronavirus pandemic. Retrieved February 14, 2021, from:https://www.worldometers.info/coronavirus/ 


\title{
THE FACTORS INFLUENCING THE PEDAGOGICAL ORIENTATIONS OF THE FINAL YEAR PHYSICAL SCIENCES PRE-SERVICE TEACHERS
}

\author{
Aviwe Sondlo, \& Umesh Ramnarain \\ University of Johannesburg (South Africa)
}

\begin{abstract}
Almost all pre-service teachers enter the profession of education with a strong belief that their efforts will make a positive contribution to society and the lives of individual learners. The statement above can be achieved or not achieved depending on different factors influencing pre-service teachers' pedagogies. The purpose of this study was to establish and explain factors influencing Physical Sciences pre-service teachers' pedagogical orientations. 'Orientation' refers to teachers' knowledge and beliefs about teaching sciences. There are various classifications of pedagogical orientations and they can be classified into Direct Didactic, Direct Active, Guided Inquiry and Open Inquiry. A qualitative approach was adopted to establish factors influencing the Physical Sciences pre-service teachers' pedagogical orientations. The data was collected through an existing instrument called the Pedagogy of Science Teaching Test (POSTT) and interviews. A POSTT was administered to final year undergraduate secondary school Physical Sciences pre-service teachers and is comprised of five items portraying an actual teaching scenario for a particular Physical Sciences topic. When responding to the POSTT, pre-service teachers were requested to select the most appropriate and the most inappropriate pedagogical orientation from the four options given and justify their selected option. Eight Physical Sciences pre-service teachers were purposefully selected for interviews. The interviews were part of the study to give pre-service teachers a chance to elaborate on their POSTT responses. The findings of this study revealed that the Physical Sciences preservice teachers' pedagogical orientations were influenced by the following factors: time constraints, availability of resources, and curriculum goals to mention a few.
\end{abstract}

Keywords: Pedagogical content knowledge, pedagogical orientations, inquiry-base learning.

\section{Introduction}

After 1994 when South Africa received democracy, the educational system experienced several changes that were part of redressing the wrongdoings of the previous government and promoting quality education to all citizens. The school curriculum was changed to make it relevant, significant, address skill shortages, promote knowledge and mirror education that reflects the needs of all South Africans (Mouton, Louw, \& Strydom, 2012). For the past 27 years, several school curriculums were introduced and changed until recently (2011) were a Curriculum and Assessment Policy Statement (CAPS) was introduced at school. CAPS is significantly different from the previous curriculums, where subject boundaries are no longer vague compare to others and it has week-by-week teaching plans. However, there is less room for teacher creativity and possibly even more constricted space for the integration with other teaching methods because the CAPS give detailed guidance to teachers on what they should teach and how to assess learners (Umalusi, 2014). Even though the CAPS emphasis is on inquiry-based learning (IBL) as a teaching approach for science subjects, it still doesn't give teachers room to employ IBL. The emphasis on IBL is reflected in specific aim two (Department of Basic Education, 2011) and the CAPS aims are in line with the trends in science education worldwide which promote inquiry-based instructions (Mokiwa, 2014). However, the pre-service teachers experienced different factors/challenges that forbids them to implement IBL activities in the science classroom. This paper defines inquiry-based learning as a teaching strategy where learners are given a chance to grapple with data, using evidence and logic to make sense of some event or phenomena in a social, collaborative environment (National Research Council, 1996; 2000; NRC, 2012). The NRC (1996) refers to an inquiry as activities where students develop knowledge and understanding of scientific ideas and understanding of how scientists study the natural world in their everyday lives. The inquiry stems from how people learn, where learning stems from natural curiosity which will make learners develop curiosity and have an interest in science at a young age (Mupira \& Ramnarain, 2018). This study aimed to explore factors influencing the Physical 
Sciences pre-service teachers' pedagogical orientations towards their classroom teaching. To achieve the aim, the following research question was conceptualised:

i. What factors influence the pedagogical orientations of Physical Science pre-service teachers?

To understand the factors influencing Physical Sciences pre-service teachers' pedagogical orientations, we administered a questionnaire (POSTT) to Physical Sciences final year undergraduate preservice teachers (Cobern et al., 2014).

\section{Factors influencing teachers at school}

The research shows that pre-service teachers in their early years of teaching, their level of understanding science is like that of their learners (Mavhunga, 2014). However, as they gain experience their awareness of science changes significantly, moving from reasoning as learners or how they were taught science at school, to become conscious of how the subject is transformed for learner understating (Angell, Ryder, \& Scott, 2005). Students' secondary school education background, a limited number of science teachers, large numbers of under-qualified or non-qualified Physical Science teachers and over-crowded classes were some of the factors (Makgatho \& Mji, 2006). Mokiwa (2014) asserts that teachers think that learners find it challenging to learn through inquiry because they get distracted. Other factors that prevent teachers to adopt a learner-centred approach; Most of the teachers were not exposed to this method early as either learner at school or as pre-service teachers at university. Lack of resources, large classes and lack of exposure to inquiry-based learning are other factors that hinder the implementation of IBL in some of the schools (Nyirenda, 2019; Ramnarain et al., 2014). These are some of the factors that pose a significant challenge to teachers at school as they try to shift from traditional instruction to inquiry-based approaches (Ladachartm, 2019).

\section{Theoretical framework}

Pedagogical Content Knowledge (PCK) underpins the study as a theoretical framework. PCK is a blend of pedagogical and content knowledge that formulates the transformation of the two mentioned knowledge into the most powerful, teachable forms to express the subject and make it comprehensible for learners understanding (Shulman, 1987). Within PCK, Grossman (1990); Magnusson, Krajcik, and Borko (1999) extended the PCK model by adding a key construct in teaching and referred to this as teaching orientations. Cobern et al. (2014) were interested in the teaching of science content and they developed an assessment device that borrowed from the concepts of PCK, teaching orientations and Ausubel's theory of meaningful learning (Ausubel, Novak, \& Hanesian, 1986) to conceptualised the idea of pedagogical orientation. The construct 'orientation' refers to teachers' knowledge and beliefs about the purposes and goals of teaching science at a particular grade level (Magnusson et al., 1999). Anderson and Smith (1987) referred to teaching orientations as various approaches to teaching science and general patterns of teacher's behaviours and thoughts to promote learner's chances of comprehending science concepts. Magnusson et al. (1999) assert that teaching orientations are an essential factor shaping teacher's PCK. Orientations shape teacher's knowledge of science curricula and knowledge of learner understanding which includes learner's prior knowledge (Gess-Newsome, 2015). Therefore, this study used the four pedagogical orientations proposed by Cobern et al. (2014) and they are:

- Direct Didactic- a teacher, presents and explains the science concept directly to the students and illustrates it with examples. Students apply this knowledge to questions and problems. There are no or few student practical activities in this method.

- Direct Active- similarly entails direct teacher exposition, but this is followed by a student activity based on the presented science content, for example, hands-on practical verification of a law.

- Guided Inquiry- a teacher plans an activity where students explore a phenomenon, from this, the teacher guides them to develop the desired science concept.

- Open Inquiry orientation- students explore a phenomenon on their own, devising ways of doing so, minimally guided, after which they report what they did and found.

The first two orientations are direct approaches, these are referred to as teacher-centred and the last two orientations are inquiry approaches and are more learner-centred. These four orientations were used to explore pre-service teacher's pedagogical orientations. 


\section{The context of the study}

The starting point of this study was to establish the pedagogical orientations of pre-service teachers, this was done by administering a questionnaire called POSTT and each POSTT had five teaching scenarios where pre-service teachers were required to envisage their teaching approaches i.e. how they were going to teach each lesson. The goal of each item was to elicit teacher's orientations towards teaching science and encourage the pre-service teacher to visualise himself or herself teaching that particular concept, playing the role of a decision-maker and respond as if he/she was going to teach that lesson. They were required to select the most appropriate pedagogical orientation from the four options given and justify their choices. The POSTT quantitative results were in descending order, were: Guided Inquiry (34\%), Open Inquiry (24\%), Direct Active (24\%) and Direct Didactic (18\%) (Sondlo \& Ramnarain, 2019). Therefore, Guided Inquiry was the most preferred pedagogical orientation among this cohort of pre-service teachers (Sondlo \& Ramnarain, 2019). Following the quantitative results, the researchers were then interested to find out what were factors influencing these Physical Sciences pre-service teachers to select a particular choice instead of the other three choices. The pre-service teachers' reasons/justifications will be presented in this paper as factors that influenced the Physical Sciences pre-service teachers' pedagogical orientations. The quantitative results assisted the authors to understand the factors that influenced the pre-service teachers to select a particular orientation.

\section{Research design}

A qualitative approach was used where a questionnaire item was administered to all Physical Sciences final year students at a South African university and interviews followed. The pre-service teachers were required to select the most appropriate pedagogical orientation from the four options given and justify their choices. Then eight Physical Science pre-service teachers were selected for interviews. The selection was based on their responses/pedagogical orientation and based on the context of the school they were teaching at during their teaching practicum. Therefore, the provided reasons helped the researchers to understand the factors influencing their orientations. The qualitative data from the POSTT and semi-structured interviews were analysed using standard methods where the data was first transcribed, coded and analysed. The deductive and inductive reasoning approaches were used to establish factors influencing the Physical Science pre-service teachers' pedagogical orientations where themes were generated following Saldana (2009) methods. When generating thematises, in-vivo coding, as well as descriptive coding were used. In-vivo coding is when the coder takes the exact words spoken by a participant, while descriptive coding is used when summarising what is said in a passage by one word or a short phrase (Saldana, 2009).

\section{Results}

In the previous paper by Sondlo et al. (2019), it emerged that the Physical Sciences pre-service teachers exhibited a preference for learner-centred orientation, which was a guided inquiry pedagogical orientation. However, when analysing the pre-service teachers' qualitative responses it emerges that most of them selected an inquiry orientation but their reasons support a traditional method orientation which can be Direct Didactic or Direct Active orientation. Therefore, this paper is curious to understand factors that influenced them to select a guided inquiry orientation which is equivalent to an inquiry based learning approach on the POSTT but prefer a teacher-centred orientation approach. The factors influencing the Physical Sciences pre-service teachers are presented below.

\subsection{Theme one: Environmental factors such as class size, resources and time constraints at school influenced the preferred Physical Sciences pre-service teachers}

Lack of resources, large class size and insufficient teaching time were factors that influenced Physical Sciences pre-service teachers in their preference for a teacher-centred orientation.

6.1.1. Lack of resources and a large number of learners per class. The availability of resources and large classes emerged as factors influencing the pre-service teachers' pedagogical orientations since these factors impact the autonomy of the pre-service teachers to adopt a learner-centred teaching approach. One of the participants, Mr Motsapi mentioned that at his school there was a laboratory but there were few resources to use.

Taking the resources of the school, the school has a laboratory but it does not have the most resources, so I ended up doing a demonstration. This strategy may seem teacher-centred at first but there is learner involvement and discovery learning. 
Mr Motsapi agrees that at a school where he was placed during teaching practicum there were few resources and he was aware that demonstrations tend to be teacher-centred instead of being learnercentred. The second pre-service teacher (Ms Faltein):

In my school, they were no lab and there were many students in one class, so, I had to use home materials when teaching other concepts.

She further elaborates that even though there was no laboratory at her former school, she was willing to go beyond, however, her lessons were teacher-centred since she was the person doing all the work while learners were observing.

Therefore, on paper, the preservice teachers were willing to adopt inquiry, however, factors such as resources, and large numbers of learners in one class had an impact on them to revert into traditional methods.

6.1.2. Insufficient teaching time. Lack of time was another factor that led pre-service teachers to opt for a teacher-centred approach towards their teaching.

At the secondary school level, timetabling is the responsibility of the School Management Team (SMT). However, they get guidance from the CAPS document where Physical Sciences as a subject is allocated four hours per week and the school had the prerogative to distribute time the way they want. In most schools, Physical Sciences lessons are less than 1-hour. Some schools prefer to have at least one double period per week and the remaining time is divided into single periods according to the school time table. The four hours per week was for both theory and laboratory experiments. Therefore, time was a factor to some Physical Sciences pre-service teachers. one of the pre-service teachers Ms Sibeko explained that insufficient time to teach was always a factor.

Most of the inquiry lessons are time-consuming as other learners may not find the correct equipment's or resources to experiment on their own and it might seem impossible to find another way of measuring the volume of objects without measuring the objects themselves.

Ms Sibeko further pointed out that CAPS was limiting her creativity and this was the reason she pointed out the impact of time in her teaching. Mr Jacobs also shared similar sentiments as Ms Sibeko where he argued that time to teach Physical Sciences was not enough.

The time given for Physical Sciences classes is not enough to follow the learner-centred approach in class unless if it was made a practical where they will have to spend the time in the laboratory doing this experiment.

Ms Sibeko and Mr Jacobs claim that insufficient time for Physical Sciences lessons was a factor since the four hours per week were for both content/theory and practical work.

\subsection{Theme two: Curriculum goals specified in the CAPS document influenced the Physical Sciences pre-service teachers to select Inquiry pedagogical orientations}

The goals of the curriculum influenced some of the pre-service teachers' preference for learner-centred pedagogical orientations. One of the CAPS goals is to promote inquiry-based learning (IBL) as a teaching approach for science subjects and this is reflected in specific aim two. CAPS encouraged an active and critical approach to learning and discourage rote learning. Quite a number of the Physical Sciences pre-service preferred orientation that were aligned to the goals of the curriculum which led them to select learner-centred pedagogical orientations. Mr Motsapi in one of the items selected an Open Inquiry orientation since it was based on inquiry approaches.

I selected option B because in grade 9 Natural Sciences, the learners studied acids and bases and also common examples of acids and bases. Therefore, I will let them do practical to improves the learners' manipulative and investigative skills (and the Physical Sciences Specific Aim 2 'doing Science'.

Ms Sibeko was using CAPS to determine skills that were important to develop the learners by the end of the lesson or topic.

This approach makes learners develop creative and critical thinking skills which are required by the curriculum.

Even Mr Matoto was in favour of inquiry orientation since they were in line with the skills that were listed in the CAPS document.

This option also addresses the specific aim 1 of doing science whereby the learners are allowed to be hands-on and do the work themselves.

Therefore, the curriculum goals stipulated in the CAPS document assisted some of the Physical Sciences pre-service teachers to favour a learner-centred teaching orientation that promotes IBL and even though curriculum specifications listed above limit them to adopt IBL or learner-centred teaching approaches. 


\section{Discussions and conclusion}

To respond to the research question 'what are the factors influencing the pedagogical orientations of the Physical Sciences pre-service teachers?'. The findings from this paper brought to light that the Physical Science pre-service teacher's pedagogical orientations were influenced by factors such as the number of learners, time constraints, availability of resources and curriculum goals. The results of this study were similar to Nyirenda (2019); Ramnarain, Schuster (2014); Makgatho et al. (2006) which shows that lack of resources, large classes and lack of exposure to inquiry-based learning hinders the implementation of IBL. Nyirenda (2019) study also show that curriculum and time were dominant factors influencing the Zambian science pre-service teachers. The findings from this paper are similar to Ramnarain et al. (2014: 2016) that context influence teacher's orientations and teaching orientations are like a map guiding teacher's decisions making process when preparing a lesson (Magnusson et al., 1999).

\section{References}

Askew, M., Venkat, H., Rollnick, M., \& Loughran, J. (Eds.), (2014). Exploring Content Knowledge for Teaching Science and Mathematics: Windows into teacher thinking. Abington, UK: Routledge.

Ausubel, D. P., Novak, J. D., \& Hanesian, H. (1986). Educational Psychology: A Cognitive View (2 ${ }^{\text {nd }}$ ed.). New York: Werbel \& Peck.

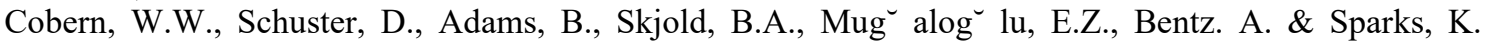
(2014). Science Teaching Tests: Formative assessments of science teaching orientations. International Journal of Science Education, 36(13), 2265-2288.

Department of Basic Education, Republic of South Africa. (2011). Curriculum and Assessment Policy Statement (CAPS): Physical Sciences. Final draft. Pretoria: Government Printer.

Gess-Newsome J. \& N. G. Lederman (Eds.), (1999). Examining pedagogical content knowledge (pp. 95-132). Dordrecht, the Netherlands: Kluwer.

Koehler, J. (Ed.), (1987). The educator's handbook: A research perspective (pp. 84-111). New York: Longman.

Ladachart, L. (2019). Thai First-Year Preservice Science Teachers' Orientations Toward Teaching Science. Asia-Pacific Edu Res.

Makgatho, M. \& Mji, A. (2006). Factors Associated with High School Learners' Poor performance: A spotlight on mathematics and physical science. South African Journal of Education. 26(2), 253-266.

Mokiwa, H., O. (2014). Exploring the Teaching of Physical Science through Inquiry. International Journal of Edu Sci, 7(1): 21-27.

Mouton, N., Louw, G. P., \& Strydom, G. L. (2012). A Historical Analysis of the Post-Apartheid Dispensation Education in South Africa (1994-2011). International Business \& Economics Research Journal, 11 (11), 1211-1222.

Mupira P. \& Ramnarain U. (2018). The effect of inquiry-based learning on the achievement goal-orientation of grade 10 physical sciences learners at township schools in South Africa. Journal of Research in Science Teaching, 55(6), 810-825.

National Research Council [NRC]. (1996). National science education standards. Washington, DC: National Academy Press.

Nyirenda, E. (2019). Zambian Secondary School Pre-Service Science Teachers Pedagogical Orientations and Beliefs about Science Teaching. Unpublished Doctoral thesis, Southern Illinois University Carbondale.

Ramnarain, U., \& Schuster, D. (2014). The Pedagogical Orientations of South African Physical Sciences Teachers towards Inquiry or Direct Instructional Approaches. Research in Science Education, 44(4), 627-650.

Saldana. (2009). An Introduction to Codes and Coding. Retrieved on 23 Feb 2019. From: http://www.sagepub.com/sites/default/files/upm-binaries/24614_01_Saldana_Ch_01.pdf

Shulman, L. (1986). Those who understand: Knowledge growth in teaching. Educational Researcher, 15(2), 4-14.

Sondlo, A., \& Ramnarain, U. (2019, June). Exploring the South African Physical Sciences Pre-Service Teachers Pedagogical Orientations. International Conference on Education and New Developments (END 2019). Porto, Portugal, 22 - 24 June 2019. 


\title{
ACTION RESEARCH - APPROACH FOCUSED ON THE DEVELOPMENT OF EDUCATIONAL PRACTICE
}

\author{
Maja Domazet ${ }^{1}, \&$ Siniša Opić ${ }^{2}$ \\ ${ }^{1}$ Kindergarten Maslačak, Zaprešić (Croatia) \\ ${ }^{2}$ Faculty of Teacher Education - University of Zagreb (Croatia)
}

\begin{abstract}
The aim of the paper is to introduce a different approaching perspective of the children with internalizing behaviors using the implemented action research. In fact, this action research is a tool for approaching to the study of the internalizing behavioral problems. Practitioners and other participants of the research can awake their own practice and thus start some changes and improvements while using it. Considering the fact that in the literature are not many described models of prevention, support and action targeted to these behaviors, especially in the facilities of early and preschool education, the approach using action research has been imposed as the most appropriate. It is the most suitable for working with children who do not manage to create social opportunities by themselves nor develop their social and emotional skills and resistance. The largest part of this research is referred to direct interaction of children identified as reclusive, shy and fearful. Specific workshops and targeted activities contributed to a significant change in children's social skills. This research will result in strong awareness of educators, expert teams, principle and parents for the necessity of the children. A different organization of educators' working hours will influence the quality of support which has proven to be an irreplaceable reliance of safety, so it is important that it is available to children even after structured working hours. Hence, the principle introduces a special professional training and different structure of working hours in order to keep the quality of support reached through this research.
\end{abstract}

Keywords: Internalizing behaviors, action research, action research outcomes.

\section{Introduction}

Action research is the basic strategy of professional growth which is an individual or a group examination of proper professional practice with the purpose of self-advancement. This self-advancement will influence the methods of the better quality aimed towards children. In action research practitioners upgrade their own practice in direct surroundings. The researcher begins the study by questioning his own practice and attempting to recognize the areas he can change and improve using his inner reflection (Markowitz, 2011). Thus, a reflexive practice becomes a starting point for changes. The author Fullan uses the term educational changes whose aim is to influence a pupil positively (child). However, during this process of changes, the emphasis is given to professional development (Fullan, 1993, 1999: according to Slunjski 2016). Bognar (2006) quotes that teachers/educators cannot only be the users of research implemented by someone from the outside. By accepting the active role in the schools' research, teachers become the reflexive practitioners (Schoen, 1984; according to Bognar 2006), teachers' researchers or action researchers (McNiff 2002; according to Bognar (2006). Accordingly, educators from the facilities of early and preschool education have been observed. Slunjski (2016) quotes that action research is very effective form of sustained professional development of preschool teachers aimed towards consolidation of collaborative modalities of their educational reflection and impact. The author Miljak (2015) assumes that the educational practice is still much unexplored and it will never be fully explored because it is the area of continuous worry for further, deeper and better researches and improvements. When we go one step further in the research of practice, our horizons start changing. Exactly here the educators become the main bearers of the research and changes. Thus, action research is valuable tool, not just as for making changes, but also as the tool of studying and constant questioning and exploring. "Action research is form of collective self-reflected studying implemented by participants in the social situations in order to improve rationality and justice of own social or educational practices, as well as understanding of these practices and situations in which they are conducted. This approach is action research only when it is cooperative, although it is important to understand that action research of the group is implemented 
throughout the critically questioned impact of particular members of the group "(Kemmis \& McTaggart 1988; according to Cohen, Manion, Morrison 2007; 227). Action research enable that participants can get a feedback in the specific condition of their professional development and accordingly, correct their actions in order to achieve desired changes (Bognar, 2001). In that way action research is valuable for all participants, both for groups and individual because action that is the subject of research brings to improvement or changes of the group and individual and their impacts. It is important to emphasize that action research imply active participation of all interested participants, so they are not implemented on people but with people (Reason, 1994; according to Bognar 2001).

Some of the authors revolve the objectivity that can appear as a problem in the implementation of action research (Grounlund, 1981; Stinger, 1996; Sekulić-Majurec, 2007; Zuber-Skerritt,1996; Winter, 1982), but Kemmis, McTaggert and Nixon (2014) think that people inside the research have the particular advantages such as the fact that only the participants can precisely see and understand their actions and thus awake the change as well as the consequence of their behaviors and actions. Also, through the report of the implemented action research it is attempted to represent the effort of researchers and practitioners in the change of their own practice and educational actions, dilemmas and reflections they had. The directed action as a result of reflexive practice is represented. Even though the particular changes have not been managed, it is important that a process of learning has been noticed during this process, which is the aim of action research.

\section{The start of research}

Above mentioned action research has been implemented in the kindergarten during one pedagogical year. The kindergarten consisted of 25 groups with two preschool teachers (educators) in each group. The initiator of the action research is the preschool teacher who has three children with internalizing behaviors in the group. It has been noticed that a small amount of time has been dedicated to those children, not only within the group, but also in the kindergarten generally which is clearly seen later from the curriculum of the facility as well as from the educator's surveys. It is probably because children with these behaviors are invisible and non-demanding and do not attract any attention, so the educators turn to more difficult and demanding situations. The analysis of the curriculum of the facility in the last five years, has given a clear insight into no existing planned support for these children, although the educators mentioned internalizing behaviors as very concerning through a few reports on the curriculum. Also, the surveys completed by educators, were used as the tool for analysis of the initial situation. The analysis of the survey implemented among the educators of nineteen groups on the sample of 369 children aged 3-7, shows a particular frequency of characteristic behaviors. For instance, from the total number of surveyed children, the educators estimate that $11,11 \%$ of them often play alone or $13,27 \%$ of them never initiate a play, $6,23 \%$ separate from other children, $6,77 \%$ observe the play but do not participate or $4,06 \%$ of them do not ask for help when needed. This is one part of the characteristic behaviors observed by educators, but their numbers are alarming. The educators mention some other behaviors they notice: biting nails, quiet moaning, hidden delight, passive observing, avoiding eye contact, looking for their educator, choosing uncrowded places, avoiding noise, noisy or dynamic games, verbal aggression, obtrusion, like when being encouraged by the child they trust to. The imposing problem for educators is: "yes, the problem exists; the children with internalizing behaviors exist in every group, but what to do with them? How to help them? How far to be involved? Will our intervention help them? How to react? How to be sure in intervention? Those questions have led to approach to this problem throughout action research that includes observation the children and action in the practice.

It has been demanded from the researchers to estimate their own methods aimed towards these children and to inspect whether they have been useful or not. For instance, anxiety, occurring in the pre-school period, is not disturbing for the surrounding, but if the adults do not pay attention and just leave it to develop, it can be a trigger for emotional problems. It is similar with the restraint which is most often a reflection of not being confident into yourself and others and can lead to social incompetence which results in uncomfortable emotional conditions (Đuranović \& Opić, 2013). Moreover, a necessity of dedicating to this problem has been noticed because the number of children mentioned by the educators in this context is not individual, but there really exist a great number of children who need the attention of adults. Therefore, some research questions have been asked: How to response to silent needs and requests of children with internalizing behaviors? How to give a support to a child and follow his needs, possibilities and interests? 


\subsection{Internalizing behaviors}

The starting point of the further research was the examination of literature and theory that embrace those behaviors in order to understand the characteristics and needs of children. The classification on internalizing and externalizing disorders quotes Brajša Žganec (2003). The author claims that internalizing disorders refer to overreacted controlled behaviors, depressive behaviors, somatic changes and reclusiveness. According to Bouillet and Uzelac (2007), disorders are divided into externalizing or mostly active behavioral disorders, and they refer to not enough controlled behaviors (obtrusion, lying, aggression, destruction, opposing, defiance), while internalizing or mostly passive disorders refer to overreacted behavioral control aimed towards yourself (fear, carelessness, reclusiveness). This division does not classify or determine an exact division, but it is only an orientation classification. In internalizing behaviors, the child creates a problem only for himself while in the externalizing, he creates a problem for the surrounding. This kind of behavior does not attract a huge attention, so those difficulties are usually discovered later. According to Lebendina Manzoni (2007), the children of this behavior show fear, tense, shyness, anxiety and sadness. Hence into the group of those behaviors also belong fears in childhood, social reclusiveness and depression. The same author explains that social reclusiveness is mainly based on concern what others think about us. So, the work targeted on children should be based on reinforcement of "self" as well as the attempt of changing the negative way of thinking and experience acquisition which will change the negative schemes the child possesses. Katz and McClallen (1999) quote reclusiveness and shyness as the risky factors and behaviors that should not be ignored. Shyness is according to them, a certain dose of child's reticence, which is a sign that he is aware of unknown situation and its participants, but this shyness cannot be overcome during the childhood. This dose of shyness, according to the same authors, it a result of the fact that children do not possess enough of knowledge, skills or understanding necessary to enter the pleasant relationships. A reclusive child is mostly quiet, calm, alone, daydreaming, timid, unsecure, speaks little, quietly or whispers, stutters, has difficulties with interaction, doesn't have permanent friends, chooses a company of much older or younger, avoids new and unknown situations, is shy, complains about physical difficulties, is slow in most of social contacts, does not like speaking aloud and in front of the others, sits absently and thoughtfully, needs a little for himself, emotional reactions are mild and sometimes barely noticeable. A deficit in social relationships and subjective reaction on that deficit result in emotional experience named loneliness (Klarin, 2002). Lebedina Manzoni (2007) claims that the best treatment for reclusiveness is learning the positive model of behavior, acquiring the positive experiences in social contacts and learning social skills in interaction with others. The child like that requires attention and feeling of love, encouragement to start communicating, activity he likes in order to gain faith in his abilities. In other words, it is necessary to release him of this isolation to participate in a free and spontaneous communication (Čuturić,1995). From the assessment of initial condition and from these scientific conclusions a need for working with those children has been imposed and action research enables the critical thinking and improvement of educational practice.

\section{Implemented action research}

After procedures including gathering of participants, initial problem identifying, researching and finding the answers from the literature, some particular postulates, aims and initial tasks have been determined and will eventually be modified after recruitment. A team consisting of 9 educators (preschool teachers) has been defined. The first focus group has been arranged and some theoretical basis for discussing this issue as well as the educators' motivation has been considered. From discussion of educators, it can be concluded that educators have awaken the problem but are insecure in actions they can do. They do not doubt to support children. Also, working within small groups has been suggested. A table for monitoring behavior of children has been formed and participants can write direct perceptions from the practice to share them with the group at the next meeting. The questions that have been considered and discussed about on the focus group are a kind of guidance for monitoring children in everyday environment. From educators' perceptions, behaviors mentioned in the literature can be confirmed. Those children are insecure, calm, quiet, lonely, have difficulties with interaction, need to be encouraged by educators and like quiet games. From all these examples it can be noticed that children need educators' help, so a discussion on suggested workshops organized by educators included into the research has been initiated. The workshops would be integrated into scheduled curriculum and the emphasis is put on the work in small groups and calm atmosphere. The children with internalizing behaviors estimated by educators would be included into the workshops, but only with the consent of a child and parents. The children have a right to choose whether to participate or not. Other children from the group also can participate, but the workshop manager must beware a calm atmosphere and that the groups are less than those in which children usually stay. From the previous mentioned survey for 
educators, a special interest of those children is clearly seen which could be used as stimulus on activities at workshops. Educators of nineteen groups estimated that children have the biggest interests for art and calm activities. This fact also matches with literature. Expressive techniques, such as drawings, molding, help reclusive children to say something about themselves with no force. With the help of expressive techniques, a child will relax and encourage himself (Čuturić, 1995). Throughout the survey some methods of educators are visible and it shows how they encourage activating children they consider having internalizing behaviors. The answers show that educators' intervention is inevitable. Some specific behaviors of children have been analyzed as well as the proposals of action. Considering the estimation that those children like to work in smaller groups or individual approach, the suggestion is to implement workshops with them in order to express themselves through planned and creative activities, especially on social plan. Twelve children aged 5-7 years have been included into the workshop and 19 workshops have been organized in total. Before children's inclusion, parents who supported the idea were consulted. Discussions with parents show that they are very aware of the behavior of their child and are mostly concerned. The conclusion of the second focus group is starting the workshops. Also, the principle has supported workshops and continuance of research. In the next focus group, the workshops that encourage interaction within small groups through the art and other creative activities will be analyzed. Every workshop is planned to have a topic, aim, chosen task and finally should be documented and estimated. In the analysis of workshops, a special emphasis is given to children and their reactions. Thus, the estimations of the workshops are very important because they transfer important information about child and the according to their results the next workshop is planned. Every new workshop has introduced activities that include more cooperation and communication among children. Information and conclusions of each workshop have been discussed at participants' meetings. What is more, each activity of the child has been documented and those recordings have been of a great importance for reflection and further planning. The behaviors and reactions of both children and educators have been analyzed. Self-reflections of educators who critically explained their actions and their influence on children are very important. After analyzing and implementation of the workshops, reconsideration of research questions is analyzed. In fact, particular assumptions have been concluded, for instance, by reflections and different approaches it can be answered to children's demands although those kinds of approaches are not usual (workshop organization, for example). Furthermore, by gradual and mindful procedures, educator does not change a child, but helps him to develop new skills in appropriate way. New research questions have been imposed through reflections: How to raise a support quality? How to transfer the behaviors developed at workshops to the group? Answers on these questions have happened at the fourth focus group which was the analysis of the influence of the research on children's behaviors. A detail effect of workshops on every child, the methods children used to change their behaviors and the procedures of educators have been commented. A comparison of behaviors before and after workshops has been done. This moment is very important because it discovers the level of usefulness of the procedures and actions made by the research. It also discovers how this type of support helps a particular child.

\section{Results of action research}

Comparison and analysis of children's behaviors before and after workshops' implementations have given excellent results. Educators and parents estimated that children are more open-minded, less shy, verbalize their needs more easily, are more confident towards other children, communicate with other children within regular group, firstly with the friends from workshops and then with other children, do not need the constant presence of educator, leave their parent more easily. There is a drastic change visible in one boy's behavior. He started speaking aloud at the workshops and he did not do it before. There are no changes in the behaviors of two children, but they express their will to participate at the workshops. The greatest contribution is awareness of teachers and co-experts about importance of dealing with this issue. A planned support of those children has been put in the next curriculum of the facility. According to the clear evidence that this program of support helps children, the principle has adjusted and reacted on their needs. It means that she has flexibly approached to the organization of working hours of educators in order to continue with the support program. So, she adjusted the children's and educators' timetables in order to accept children's needs. Also, she enabled professional development of interest, not the linear one. The educators who develop support to children with internalizing behaviors are given a great chance to direct their education exactly where necessary including the flexible organization of working hours. 


\section{References}

Bognar, B. (2001). A critical-emancipatory approach to action research. Life and school: a journal for the theory and practice of education, 47 (2001), 6. 45-60. Retrieved from https://www.bib.irb.hr/679320

Bognar, B. (2006). Action research in school. Educational sciences, 8 (1 (11)), 209-228. Retrieved July 16,.2020, from: https://hrcak.srce.hr/26189

Bouillet, D., \& Uzelac S. (2007). Fundamentals of social pedagogy. Zagreb: Školska knjiga.

Brajša-Žganec, A. (2003). Child and family: emotional and social development. Jastrebarsko: Naklada Slap.

Cohen, L., Manion, L. \& Morrison, K. (2007). Research Methods in Education. Jastrebarsko: Naklada Slap.

Čuturić, N. (1995). My child worries me. Zagreb: Školska knjiga.

Đuranović, M., \& Opić, V. (2013). Possibilities of preventing of risky behaviors of preschool children. Magistra Iadertina, 8. (1.), 101-111. Retrieved June 9, 2020, from: https://hrcak.srce.hr/122644

Katz, L. G., \& McClellan, D. E. (1999). Fostering children is social competence: The teacher's role. Zagreb: Educa.

Kemmis, S., McTaggart, R. \& Nixon, R. (2014). The Action Research Planner Doing Critical Participatory Action Research. eBook. Singapore: Springer Science+Business Media.

Klarin, M. (2002). The feeling of loneliness and social behaviour of school children in the context of social interaction. Annual of Social work, 9 (2), 249-258. Retrieved July 20.7, 2020, from: https://hrcak.srce.hr/3523

Lebedina-Manzoni, M. (2007). Psychological basics of behavior disorders. Jastrebarsko: Naklada Slap.

Markowitz, A. (2011). Teachers action research in teaching: different view. In D. Kovačević, R. Ozorlić-Dominić (Eds.), Action Research for the Professional Development of Teachers. (11-26). Zagreb: Education and Teacher Training Agency.

Miljak, A. (2015). Early Childhood Development Curriculum: Model Source II: A Handbook for Educators and the Professional Team in Kindergartens. Zagreb: Mali professor.

Slunjski, E. (2016). Outside of the frame 2: Change. From a competent individual and institution to a competent learning community. Zagreb: Element. 


\title{
STUDENTS' ATTITUDES TOWARDS SCIENCE: WHERE DO WE GO FROM HERE
}

\author{
Elena Elliniadou, \& Chryssa Sofianopoulou \\ Department of Informatics and Telematics, Harokopio University of Athens (Greece)
}

\begin{abstract}
Students' attitudes towards science have long occupied the interest of the scientific community. The confirmed decline of students' interest in pursuing the study of science, alongside the increasing recognition of scientific knowledge's importance and economic utility, makes the issue even more imperative for any society attempting to raise its standards of scientific literacy. Attitudes towards science have been found to depend on variables like instructional teaching and curriculum. The latest research indicates that childhood experiences serve as a major influence on academic interest. The broad recommendation is to concentrate on improving 10 to 14 -year-olds' experience of science. Despite the recent flurry of media interest and the latest research in the scientific community, the school curriculum in most countries is still teaching obsolete science with scarce reference to current, cutting-edge scientific research. There is an urgent need to introduce the concepts of 20th-century Physics within the curriculum and exciting science programs that will enhance the interactive learning experience among students, as is shown by evaluating reports of OECD and PISA results. While this has led to several changes in the curriculum of secondary schooling in some countries, it is still an imperative case for others and definitely for Greece. There are some individual or institutional projects around the globe that introduce modern science and technology to upper primary students, yet of no nationwide effect. This paper aims to review the latest research on students' attitudes towards science and to present the possible next research steps in amplifying students' interest and engagement in science.
\end{abstract}

Keywords: Attitudes, scientific literacy, education research, STEM.

\section{Introduction}

Science has contributed to our modern understanding of the world through technologies and discoveries, establishing new grounds for modern Physics. Despite the importance of these theories, rarely do these become part of lower high or/and primary schools physics curricula worldwide, mostly due to advanced mathematics required for being taught.

However, there has been a growing interest to bring these theories to younger students and the general public as well as a piece of growing evidence that appropriate teaching can result in measurable learning (Blair, Henriksen, \& Hendry, 2016; Dua, Blair, Kaur, \& Choudhary, 2020; Foppoli et al., 2019; Kaur, Blair, Moschilla, Stannard, \& Zadnik, 2017a; Sheldrake, Mujtaba, \& Reiss, 2017).

Nevertheless, there is a decline in student interest in Science, Technology, Engineering and Mathematics (STEM) subjects which causes alarm in societies dependent on technical skills and scientific literacy (Foppoli et al., 2019). The research on the subject is extensive, and the findings are well known: science is perceived as difficult and not relevant to the lives of most people, interest in science declines over the years of secondary schooling, science is more attractive to boys than girls, and problems are most acute in the physical sciences (Barmby, Kind, \& Jones, 2008; Bennett \& Hogarth, 2009). The falling numbers of students choosing to pursue the study of science, have caught the attention of the science education research and has led to focus on the factors that influence attitudes towards science (Barmby et al., 2008).

\section{Attitudes towards Science}

"Attitudes towards science", are defined as a set of affective behaviors in science education including the manifestation of favorable attitudes towards science and scientists, the acceptance of scientific inquiry as a way of thought, the adoption of 'scientific attitudes', the enjoyment of science 
learning experiences, the development of interests in science and science-related activities, and the development of an interest in pursuing a career in science (Archer et al., 2013; Gardner, 1975). It includes the feelings, the beliefs, the values, the disposition held about science, school science, the impact of science on society and the idea of scientists, that have been found to depend on a great number of variables and is addressed as a complex and multi-faceted construct (Osborne, Simon, \& Collins, 2003).

Students' attitudes towards science are, in other words, the preference, the acceptance, the appreciation and the commitment to science (Hacieminoglu, 2016). And, although the research of these attitudes is long enough with numerous studies throughout the decades, it should be noted that, results cannot transfer from one society to another, neither from one time period to another, as it must be regarded as a characteristic of the context in which it has been conducted. Attitude research is an ongoing issue and students' attitudes towards science should be explored according to the current social, financial, religious and educational situation (Barmby et al., 2008).

And the current situation is somehow ready to accept modern Physics, that is, Quantum Physics and Einsteinian Physics, from an early age, in upper primary school or lower secondary as recent studies seem to claim.

\section{Objectives}

It's been in the discussion for many years that new inventions and discoveries should be taught early in primary schools to make science purposeful, attractive and relevant to students' everyday life (Shabajee \& Postlethwaite, 2000) and that the age of 10-14 is a critical time to establish positive attitudes towards science that could lead to scientific careers (Archer et al., 2013; Blair et al., 2016; Eshach \& Fried, 2005). Research has focused upon late elementary and middle school students, in particular, because student attitudes toward science and interest in science-related careers are created before students enter secondary school (Newell, Zientek, Tharp, Vogt, \& Moreno, 2015; Tai, Liu, Maltese, \& Fan, 2006).

The purpose of this paper is to investigate, through a literature review, whether a newly updated curriculum with modern Physics and STEM subjects, combined with gender and culturally inclusive science teaching strategies and hands-on workshops/activity-based learning, affect students' attitudes towards science in late elementary/primary and middle/secondary school students, age 10-12. The questions that led the review were:

-What is the impact of introducing concepts of 21 st-century Physics and STEM activities to younger students in informal scientific environments?

-How attitudes towards science are affected?

-Could an updated science curriculum earlier at school be the answer to negative attitudes towards science and therefore become one solution to the decline of science-related educational pathways?

Results are presented concerning the country conducted.

\section{Australia}

With the thought that "we're underestimating what primary school students can understand in science" Blair (Blair, 2012) and other educators in Western Australia have been bringing Einsteinian physics concepts to primary schools. Exploring the ideas of space, time, and gravity with 11-12-year-olds resulted in interesting conclusions that the subject was very interesting for the students and that they weren't too young to learn these concepts (Blair et al., 2016).

Some years later, an enrichment program on aspects of Einsteinian Physics on Year 6 students, studied science knowledge and attitudes towards science (Pitts et al., 2014). Students felt interested and engaged in the activities but also, at a good age to learn concepts related to Einstein's physics. These efforts and the gravitational waves research (2017) led to Australia's "Einstein-First" project, which aims to teach the basic concepts of modern physics from an early age, with models and analogies appropriate to young students and change the paradigm of school science teaching (Kaur, Blair, Moschilla, Stannard, \& Zadnik, 2017a; 2017c). Interactive and engaging activities were found to enhance students' enjoyment and understanding of the core concepts, and influence attitudes towards science to improvement.

In the context of the "Einstein-First" project, Foppoli ignited a pilot study introducing Einsteinian concepts from an early age, involving teachers, parents and the public in an attempt to gauge support (Foppoli et al., 2019). Results on students' attitudes and learning at ages 11-16 have shown that the fundamental knowledge has been easily grasped and attitudes have been positively correlated. Choudhary, on the other hand, engaging younger ages in a one-day intervention, argues that not only long 20-lesson programs, as the Einstein-First, has influence on students' knowledge and attitudes but also short ones can be significant in influencing their career choices. Results, added to previous findings, indicate that modern physics is readily accepted by students and showed significant evidence that girls respond more positively compared to boys (Choudhary et al., 2018). 


\section{USA}

Attitudinal changes and related content knowledge were explored in a high-quality, one-semester, science after-school program in the USA (Newell et al., 2015). The study investigated whether an activity-based, discovery-oriented intervention -which was also the case in the above studies- affects students' in-school science achievement and interest in pursuing a STEM-related career path. In addition, it examined if the students' attitudes to science could serve as predictors of gains on content knowledge. The findings revealed a positive relationship between students' attitude and academic achievement, serving as predictors recommending further research especially because informal scientific environments may benefit disadvantaged students.

\section{United Kingdom}

The detection of gravitational waves triggered Boyle, in Scotland, to design a teaching module based around this exciting new branch of astronomy and to use it as an opportunity to bring cutting-edge science into the classroom, whilst allowing students to explore future potential exciting careers in physics, astronomy and engineering by inviting "real" scientists (Boyle, 2019a, 2019c; Choudhary et al., 2018). Intending to inspire students to become scientists, improve scientific literacy and aid the development of STEM skills, a gravitational waves-based STEM club took place $1 \mathrm{~h}$ per week for a year. Presented as the perfect scenario to assess the benefits of introducing Einsteinian physics into the lower secondary stages in UK schools and to monitor its effect on the self-belief within the students, particularly that of the girls (Boyle, 2019c), appeared to increase interest in STEM careers throughout the project and to influence girls' view of Physics addressing stereotypes and the current loss of potential. The project had a transformative effect upon achievement, self-efficacy and attitude towards science, confirming previous findings regarding age and gender (Kaur et al., 2020).

"The Blue Marble", a project conducted by Muller and her team, introduced interdisciplinary, hands-on workshops for primary schools on space technology and the role of the research scientist for students aged 6-11. Scientists and postgraduate students delivered workshops on science, scientists and space exploration, dismantling a scientist's stereotypic image. The project's results demonstrated a significant influence on students' enjoyment of science and on the perception of scientists. The key to its success was integrating real-world science into aspects of the curriculum and the interactive, engaging activities delivered by scientists themselves (Muller et al., 2013).

In terms of introducing modern Physics in younger ages, CERN (Conseil Européen pour la Recherche Nucléaire; European Organization for Nuclear Research) conducted a professional development teacher training course, "Playing with Protons" (Alexopoulos et al., 2019; Nantsou, Kapotis, Tombras, 2021). The course initiated in 2016 with Greek primary school teachers and UK teachers have followed since 2018. The teacher program took place at CERN as a one-week summer school training, introduced Particle Physics with innovative, hands-on, engaging activities with teachers committed to teaching their students Particle Physics, in the creative, interactive way they attended. The evaluation of the project did not directly assess students' attitudes towards science, but secondarily, by exploring the impact on teachers' interest, confidence, creativity and knowledge and subsequently of their students'.

\section{Greece}

"Playing with Protons" first got underway in 2016 as a primary school teacher training course at CERN with 10 Greek teachers. Since then, every summer, (except 2020 due to Covid-19) teachers attend the program with the obligation of implementing aspects of modern Physics in their classes (Alexopoulos et al., 2019; "Playing with Protons: Engaging Teachers to Engage K-6 Students with Science, Technology and Innovation," 2016). Research on a four-year implementation of the class program has indicated that the proposed activities and workshops improve significantly the STEM skill of students to a great extent. Additionally, it confirmed that interactive, hand-based activities at school promote students' interest, affecting positively their attitudes towards science and aspirations for the future (Nantsou, Kapotis, Tombras, 2021).

In 2019 a series of educational courses aimed at elementary and secondary education teachers from the Attica region in Greece, launched on a pilot phase. The "Universe for All" with the participation of internationally renowned organizations, research centers and universities, as Perimeter Inst. Canada, European Gravitational Observatory (EGO), National Observatory of Athens (NOA), ("The Universe for All - Eugenides Foundation," 2019), approached modern Physics current issues, latest scientific discoveries, aiming at inspiring and motivating teachers to implement innovative and participative activities with their classes and with students with limited or zero access to modern science. Students benefit from well-trained teachers and literature has pointed out the importance of the teacher figure and style of teaching in attitudes towards science (Barmby et al., 2008; Gardner, 1975; Osborne et al., 2003). 


\section{Discussion}

In this paper we have explored the impact of implementing modern Physics in younger ages by reference to countries conducting teaching modules, workshops, projects and their effect on attitudes towards science. Including Quantum Physics and Einsteinian Theory in the secondary curriculum is something being viewed happening in many countries already, like the Netherlands, Norway, Germany, Argentina, Australia, South Korea (Alstein, Krijtenburg-lewerissa, \& Joolingen, 2020), underpinning the increasing recognition of the need to modernize school physics (Choudhary et al., 2018). But, the implementation of modern Physics at the early stages of education is something new and innovative. The review of the literature has investigated ways of integrating real-world science into primary school curriculum mostly in an informal extracurricular scientific environment. Results show that early childhood experiences serve as a major influence on academic interest, leading to an increase of interest in science, in attitudes and probably in a positive commitment afterward (Osborne et al., 2003).

Still, the decline of interest in science remains a serious matter of concern, especially when looking at the ranking of some countries in OECD reports and PISA results. Greece in particular, in PISA- 2018, ranked 24th, a low score on the scale of the countries involved (Sofianopoulou, Emvalotis, Karakolidis, \& Pitsia, 2019). Particularly Physics report presents that one in four secondary students intend to pursue a science-related educational career (Sofianopoulou, Emvalotis, Pitsia, \& Karakolidis, 2017).

Referring to the third question of this review, if there is a possibility to reverse the decline in students' STEM involvement and subsequently increase students' awareness and performance in science, what should be done is the introduction of exciting science programs, maximizing the interactive learning experience in the formal curriculum and not as outsiders only. Students are willing to experience hands-on activities, acquire new knowledge and approach life with their sense of creativity, curiosity and persistence (Nantsou, T., Kapotis, E.,Tombras, G., 2021). However, teaching expertise (Nantsou, Frache, Kapotis, Nistazakis, \& Tombras, 2020) and constant professional development in universities and academic institutions are not to be overlooked as they are significant variables influencing students' attitudes towards science. The drastic decline of scientific capital at school and university could in part be due to our failure to challenge young people with modern ideas.

\section{Conclusion}

Where do we go from here? Literature insists on trying on new science curriculum at schools, in younger ages with modern and contemporary content, with interactive teaching strategies and advanced teachers' knowledge. Further research must follow, with emphasis on the relationship between attitudes towards science, curriculum and appropriate activities for each matter. We owe it to our students to teach our best understanding of reality and to give them fun ways and scientific ideas to address today's complicated world.

\section{References}

Alexopoulos, A., Pavlidou, M., \& Cherouvis, S. (2019). "Playing with Protons": A training course for primary school teachers at CERN. Physics Education, 54(1). https://doi.org/10.1088/13616552/aae7a4

Alstein, P., Krijtenburg-lewerissa, K., \& Joolingen, W. R. Van. (2020). Teaching and learning special relativity theory in secondary and lower undergraduate education: A literature review. 1-16.

Archer, L., Osborne, J., DeWitt, J., Dillon, J., Wong, B., \& Willis, B. (2013). Young people's science and career aspirations, age $10-14$. King's College London Department of Education \& Professional Studies, 40.

Barmby, P., Kind, P. M., \& Jones, K. (2008). Examining changing attitudes in secondary school science. International Journal of Science Education, 30(8), 1075-1093. https://doi.org/10.1080/09500690701344966

Bennett, J., \& Hogarth, S. (2009). Would you want to talk to a scientist at a party? high school students' attitudes to school science and to science. International Journal of Science Education, 31(14), 1975-1998. https://doi.org/10.1080/09500690802425581

Blair, D., Henriksen, E. K., \& Hendry, M. (2016). Why don't we teach Einstein's theories in school?

Boyle, J. (2019a). Teaching gravitational waves in the lower secondary school. Part I. A teaching module. Physics Education, 54(2). https://doi.org/10.1088/1361-6552/aaf779

Boyle, J. (2019c). Teaching gravitational waves in the lower secondary school. Part III. Monitoring the effect of a STEM intervention on students' attitude, self-efficacy and achievement. Physics Education, 54(2). https://doi.org/10.1088/1361-6552/aaf771 
Choudhary, R. K., Foppoli, A., Kaur, T., Blair, D. G., Zadnik, M., \& Meagher, R. (2018). Can a short intervention focused on gravitational waves and quantum physics improve students' understanding and attitude? Physics Education, 53(6). https://doi.org/10.1088/1361-6552/aae26a

Dua, Y. S., Blair, D. G., Kaur, T., \& Choudhary, R. K. (2020). Can einstein's theory of general relativity be taught to indonesian high school students? Jurnal Pendidikan IPA Indonesia, 9(1), 50-58. https://doi.org/10.15294/jpii.v9i1.22468

Eshach, H., \& Fried, M. N. (2005). Should science be taught in early childhood? Journal of Science Education and Technology, 14(3), 315-336. https://doi.org/10.1007/s10956-005-7198-9

Foppoli, A., Choudhary, R., Blair, D., Kaur, T., Moschilla, J., \& Zadnik, M. (2019). Public and teacher response to Einsteinian physics in schools. Physics Education, 54(1). https://doi.org/10.1088/13616552/aae4a4

Gardner, P. L. (1975). Attitudes to science: A review. Studies in Science Education, 2(1), 1-41. https://doi.org/10.1080/03057267508559818

Hacieminoglu, E. (2016). Elementary school students' attitude toward science and related variables. International Journal of Environmental and Science Education, 11(2), 35-52. https://doi.org/10.12973/ijese.2016.288a

Kaur, T., Blair, D., Choudhary, R. K., Dua, Y. S., Foppoli, A., Treagust, D., \& Zadnik, M. (2020). Gender response to Einsteinian physics interventions in school. Physics Education, 55(3). https://doi.org/10.1088/1361-6552/ab764d

Kaur, T., Blair, D., Moschilla, J., Stannard, W., \& Zadnik, M. (2017). Teaching Einsteinian physics at schools: Part 1, models and analogies for relativity. Physics Education. https://doi.org/10.1088/1361-6552/aa83e4

Kaur, T., Blair, D., Moschilla, J., Stannard, W., \& Zadnik, M. (2017). Teaching Einsteinian physics at schools: Part 3, review of research outcomes. Physics Education. https://doi.org/10.1088/13616552/aa83dd

Muller, C. L., Roberts, S., Wilson, R. C., Remedios, J. J., Illingworth, S., Graves, R., ... Desai, A. (2013). The Blue Marble: A model for primary school STEM outreach. Physics Education, 48(2), 176-183. https://doi.org/10.1088/0031-9120/48/2/176

Nantsou, T., Kapotis, E., Tombras. G. (2021). A Lab of Hands-on STEM Experiments for Primary Teachers at CERN. IEEE Global Engineering Education Conference, EDUCON, 2021-April, paper accepted

Nantsou, T., Frache, G., Kapotis, E. C., Nistazakis, H. E., \& Tombras, G. S. (2020). Learning-by-doing as an educational method of conducting experiments in electronic physics. IEEE Global Engineering Education Conference, EDUCON, 2020-April, 236-241. https://doi.org/10.1109/ EDUCON45650.2020.9125324

Newell, A. D., Zientek, L. R., Tharp, B. Z., Vogt, G. L., \& Moreno, N. P. (2015). Students’ Attitudes Toward Science as Predictors of Gains on Student Content Knowledge: Benefits of an After-School Program. School Science and Mathematics, 115(5), 216-225. https://doi.org/ $10.1111 / \mathrm{ssm} .12125$

Osborne, J., Simon, S., \& Collins, S. (2003). Attitudes towards science: A review of the literature and its implications. International Journal of Science Education, 25(9), 1049-1079. https://doi.org/10.1080/0950069032000032199

Pitts, M., Venville, G., Blair, D., \& Zadnik, M. (2014). An Exploratory Study to Investigate the Impact of an Enrichment Program on Aspects of Einsteinian Physics on Year 6 Students. Research in Science Education, 44(3), 363-388. https://doi.org/10.1007/s11165-013-9386-6

Playing with Protons: Engaging Teachers to Engage K-6 Students with Science, Technology and Innovation. (2016, August 31). Retrieved March 20, 2021, from The Cylindrical Onion website: https://cylindricalonion.web.cern.ch/blogs/playing-protons-engaging-teachers-engage-k-6students-science-technology-and-innovation

Sheldrake, R., Mujtaba, T., \& Reiss, M. J. (2017). Science teaching and students' attitudes and aspirations: The importance of conveying the applications and relevance of science. International Journal of Educational Research, 85(February), 167-183. https://doi.org/ 10.1016/j.ijer.2017.08.002

Sofianopoulou, C., Emvalotis, A., Karakolidis, A., \& Pitsia, V. (2019). An Analysis of the effects of PISA 2015: Performance of Greek students and the influencing factors. Dianeosis, 1-13.

Sofianopoulou, C., Emvalotis, A., Pitsia, V., \& Karakolidis, A. (2017). PISA 2015: PISA (Programme for International Student Assessment). In IEP. https://doi.org/http://dx.doi.org/ 10.1787/9789264266490-en

Tai, R. H., Liu, C. Q., Maltese, A. V., \& Fan, X. (2006). Planning early for careers in science. Science, 312(5777), 1143-1144. https://doi.org/10.1126/science.1128690

The Universe for All - Eugenides Foundation. (2019). Retrieved March 19, 2021, from https://www.eef.edu.gr/en/news/the-universe-for-all/ 


\title{
EDUCATIONAL UTILIZATION OF NARRATIVE MEDICINE IN KOREAN MEDICAL SCHOOLS
}

\author{
Youngsub Oh \\ Department of Multicultural Education, Inha University (South Korea)
}

\begin{abstract}
The purpose of this study is to explore current status and future task of educational utilization of medical humanities, focusing on narrative medicine in Korea. For this end, firstly, this study reviewed Korean research literatures on medical humanities. Second, this study reviewed the educational utilization of narrative medicine in medical education and humanities education in Korea. Lastly, this study provided the implication and future task for education and research. This study is expected to be a useful reference for developing teaching and learning model to nurture medical professionals, counselors and therapists, and researchers.
\end{abstract}

Keywords: Medical humanities, narrative medicine, narrative, current status, teaching model.

\section{Introduction}

Narrative, as a basic element of humanities, has been expanding and transforming beyond humanities toward various fields such as culture, economy, education, information industry, and tourism (Kim, 2011). This trend is a global phenomenon that is called a "narrative turn". Narrative has emerged as a very noteworthy force in counseling and psychotherapy, and even in the medical field. Academic fields such as narrative therapy and narrative medicine have already begun to be established in North America and Europe. Narrative-based materials has been utilized in educational fields, and medical research on clients from various backgrounds has been in progress (Oh et al., 2018).

Although South-Korea is relatively a late comer in the field of narrative-based therapeutic industry, there has been recently a rapid movement of convergence between narrative and therapy in the areas of medicine, humanities, and social sciences.

Interestingly, those medical schools and the humanities and social sciences schools respectively have different focus on utilizing narrative (Kim \& Oh, 2020). Medical schools pay attention to cultivating the narrative competence of medical personnel. In contrast, focusing on narrative's therapeutic nature, humanities and social sciences schools pay attention to the clinical utilization of narratives. In this regard, that difference implies how to compensate for the shortcomings of each educational institution. In other words, those medical schools lack interest in the therapeutic nature of narrative itself, and the humanities and social sciences schools lack interest in the cultivation for counselors and therapists with narrative competence. Therefore, both educational institutions need to learn each other's strengths in utilizing narratives in education and research to compensate for their own weaknesses.

\section{Research methods}

This study adopted literature research method. Research procedure is as follow:

First, Data Collection. Two keywords such as narrative medicine and medical humanities were used to search all papers and theses in Research Information Sharing Service (RISS, 2020). As a result, 27 papers, including 15 journal articles, 4 dissertations, and 8 research papers, were finally collected with the search word of narrative medicine. And 50 papers, including 39 journal articles, 1 dissertation, and 10 research papers, were finally collected with the search word of medical humanities. Those papers have been published between 2009 and 2020. Thus, 2009 was the first year of publication of medical humanities research in Korea.

Second, Selection. Among 27 papers with the theme of narrative medicine and 50 papers with the theme of medical humanities, this study finally selected those papers with focus on educational utilization. The number of those final papers were totally 22. Those selected papers were divided with two groups like medical education and humanities and social science education.

Third, Analysis. This study analyzed 13 papers to explore medical education's trend and characteristics of educational utilization. As well, implications and future research agendas were suggested, based on the analysis of trend from medical education. 


\section{Educational utilization of narrative medicine in Korean medical schools}

The number of medical humanities class has been increasing recently in Korean universities. However, there are still more medical schools that do not have any medical humanities coursework, and even if that coursework is opened, adjunct professors take on the role and medical professors without the relation of medical humanities are in charge of medical humanities education in most of Korean medical schools (Kim, 2019).

According to the current status in Korean medical schools in 2019 (Kim, 2019), there are 41 medical schools and medical graduate schools. Among these schools, only 24 schools $(59 \%)$ have medical humanities coursework or related coursework, but only 14 schools $(34 \%)$ have employed professors majoring in humanities. Moreover, 11 schools (27\%) have employed professors majoring in medical humanities. The lack of human resources in dental schools in Korea was more serious. There are only 3 schools with medical humanities coursework or related coursework, but only 2 professors with humanities majors and 1 professor with medical humanities major.

In this current situation, educational utilization of narrative medicine in Korean medical areas is evaluated to be still in its infancy than that area in the United States. Researches in narrative medicine or narrative-based education in Korean medical humanities classes have begun since 2006. Those researches are summarized as the following Table 1:

Table 1. Narrative Medicine Research in Korean Medical Areas.

\begin{tabular}{|c|c|c|c|}
\hline No. & Research Results & Educational Implications & Researchers \\
\hline 1 & \multirow{2}{*}{$\begin{array}{l}\text { Absence of educational goal } \\
\text { as a prerequisite of medical } \\
\text { humanities education }\end{array}$} & \multirow{2}{*}{$\begin{array}{l}\text { Necessity of curriculum and educational } \\
\text { model development, cultivation of } \\
\text { professors }\end{array}$} & Meng (2007) \\
\hline 2 & & & An et al (2008) \\
\hline 3 & $\begin{array}{l}\text { Three ways of writing } \\
\text { education }\end{array}$ & $\begin{array}{l}\text { Writing as an essence of education, } \\
\text { especially writing for communication }\end{array}$ & Shin (2006) \\
\hline 4 & $\begin{array}{l}\text { Characteristics of discussion } \\
\text { materials }\end{array}$ & $\begin{array}{l}\text { Necessity to reflect medical students' } \\
\text { characteristics }\end{array}$ & Ahn \& Jeon (2011) \\
\hline 5 & $\begin{array}{l}\text { Analysis of a class of } \\
\text { 'Writing for Healing' }\end{array}$ & $\begin{array}{l}\text { Necessary to redefine healing in terms of } \\
\text { holism and }\end{array}$ & Ban \& Yeh (2012) \\
\hline 6 & $\begin{array}{l}\text { Analysis of creative strength } \\
\text { and weakness of medical } \\
\text { students }\end{array}$ & $\begin{array}{l}\text { Necessary to develop curriculum based } \\
\text { on medical students' characteristics and } \\
\text { design-based thinking }\end{array}$ & Hyun (2013) \\
\hline 7 & $\begin{array}{l}\text { Three ways of writing } \\
\text { education }\end{array}$ & $\begin{array}{l}\text { Necessity of reflective, imaginative and } \\
\text { empathic writing }\end{array}$ & Hwang (2013) \\
\hline 8 & $\begin{array}{l}\text { Current status of medical } \\
\text { communication classes }\end{array}$ & $\begin{array}{l}\text { Necessity to develop those curriculum } \\
\text { and diversification of lecture contents }\end{array}$ & Lee et al (2015) \\
\hline 9 & $\begin{array}{l}\text { Analysis of poem writing } \\
\text { class }\end{array}$ & $\begin{array}{l}\text { Possibility of poem as a tool to } \\
\text { communicate between patients and } \\
\text { doctors and as a tool of treatment }\end{array}$ & $\operatorname{Kim}(2016)$ \\
\hline 10 & $\begin{array}{l}\text { Confusion of its educational } \\
\text { purpose, procedure and } \\
\text { contents }\end{array}$ & $\begin{array}{l}\text { Improvement of ethical problem-solving } \\
\text { competency based on critical thinking } \\
\text { and academic writing }\end{array}$ & Jeon \& Ahn (2017) \\
\hline 11 & $\begin{array}{l}\text { Application of Korean novel } \\
\text { literary text with illness } \\
\text { narrative to moral } \\
\text { imagination education in a } \\
\text { nursing school }\end{array}$ & $\begin{array}{l}\text { Meaningful growth of nursing students } \\
\text { as moral subject through narrative } \\
\text { medicine }\end{array}$ & Hwang \& Kim (2017) \\
\hline 12 & $\begin{array}{l}\text { Application of flipped- } \\
\text { learning- based class }\end{array}$ & $\begin{array}{l}\text { Possibility of flip learning as a new } \\
\text { teaching strategy and as a way to } \\
\text { strengthen competencies }\end{array}$ & Oh (2020) \\
\hline 13 & $\begin{array}{l}\text { Importance of self-reflective } \\
\text { writing and identity as a } \\
\text { 'listening doctor' }\end{array}$ & $\begin{array}{l}\text { Suggestion of } 3 \text { kinds of writings: } \\
\text { oneself, patients, and patients' family }\end{array}$ & Youm (2020) \\
\hline
\end{tabular}

Korea.

First, at the beginning stage, general directions of medical humanities education were explored in

Meng (2007) suggested general future tasks for medical humanities in Korea. He evaluated that the current status of Korean medical humanities was twenty years later than the United States. And he called for firstly setting up general educational purpose based on humanistic virtue, and then developing 
interdisciplinary curriculum and educational models, and finally cultivating medical-humanities-majoring professors and prepare a related system.

An et al (2008) analyzed the syllabi of medical humanities and social sciences classes in 10 medical schools. As a result, there was some commonality in 10 schools like emphasis on disease prevention, health improvement, medical ethics, medical regulation, professionalism, and community medicine. Future tasks were suggested as the clarification of educational goals in order to develop a core curriculum of medical humanities and social sciences in Korea and then the shared experiences of developing a well-designed curriculum with other medical schools for effective teaching.

Second, specific ways of narrative medicine or narrative-based education in Korea have been discussed afterwards.

Shin (2006) suggested the need for writing education for medical students. When considering Korean medical schools' conditions, the writing education in medical schools can be conducted in three ways as follows : writing as a study tool, writing focused on appropriate medical sentences, and writing for communication. The author suggested the third way of writing education in more realistic way to Korean circumstances.

Ahn \& Jeon (2011) analyzed the characteristics of discussion materials such as book and movie that promote student participation in discussions, satisfaction with student instruction, and tutor intervention in a medical university's medical humanities class in Korea. Research result said that differences in grades and the understanding of the discussion material should be considered when choosing discussion materials. Thus, it implies the necessary to develop medical humanities discussion's materials reflecting medical students' situations and characteristics.

Ban and Yeh (2012) provided cases of writing activity at ' $Y$ ' medical school. Writing activities were done in a part of medical humanities class or extracurricular activities class with independent writing class. Especially, a class of 'Writing for Healing' opened to pre-medical freshmen. Although the class aimed to help students identify and acknowledge internal diseases to lead a healthier life and eventually become positive and responsible health care providers, the term of healing was still vaguely defined in the medical class. The researchers suggested the necessary to approach healing in terms of holism.

Hyun (2013) analyzed creative strength and weakness of medical college students through TTCT (Torrance Tests of Creative Thinking), and thus said that those students had storytelling articulateness as a strength but lack of idea production or imagination and lack of understanding of other thoughts and inner image. Therefore, medical humanities curriculum needs to be developed on the basis of medical students' characteristics and design-based thinking.

Hwang (2013) suggested the utilization way of illness narrative in teaching medical humanities. First, reflective writing on medical care provider's own inner world or educational experience was the most necessary. Second, imaginative and empathic writing on patients' emotional condition and their context with a concrete plot was helpful. Third, parallel chart writing, which was developed by Rita Charon (2008), can be written by medical students or medical professionals with everyday language in order to understand the perspective of patients and externalize medical professionals' ambiguous emotions.

Lee et al (2015) examined the current status of medical communication classes of medical schools in Korea like the existence of those classes, course title, total hours, and institution. The result was that many medical schools in Korea are evaluated to be at the beginning stage of developing and operating the curriculum to teach medical communication. Thus, as the status was not systematic, the study suggested the need for seriously developing and operating curriculum focused on medical communication, and the need for diversification of lecture contents in Korea.

Kim (2016) said that writing poem may change pre-medical students' introspection and the experience could provide mechanism to practice clinical treatment for reducing pain of body and mind of the patients. According to the Kim's research and analysis for 88 students to participate poem and literature class in reading and writing poems during 4 semesters, positive awareness for poetry increased from $37 \%$ to $76 \%$, while negative awareness decreased from $46 \%$ to $11 \%$. Pre-medical students recognized that poems can be used as a tool to communicate between patients and doctors and when students become doctors, poems can be as a tool of treatment.

Jeon \& Ahn (2017) said that the reason for the difficulty in teaching medical ethics and professionalism in Korea lies in the confusion of its educational purpose, educational procedure and contents. The improvement of ethical problem-solving competency needs to be the core component in teaching medical ethics and professionalism. Therefore, the moral and ethical inference in medical ethics must be based on critical thinking and academic writing.

Hwang and Kim (2017) applied Korean novel literary text with illness narratives to moral imagination education in a nursing school. The education was meaningful to nursing students in that they can grow up to moral subject with serious thought and creative activity and self-reflection. The educational experience can be cognitive and emotional basis for health care providers. 
Oh (2020) said that there were not yet effective teaching and learning models to realize the purpose of medical humanities education. In this regard, exploring the possibility of flipped-learning to apply medical humanities classes, the study designed the class based on the ADDIE model consisting of five stages, analysis - design - development - execution - evaluation. And finally the study applied flipped-learning-based medical humanities class to ' $\mathrm{P}$ ' university's medical school and analyzed the recognition of learners.

Youm (2020) said that primary writing needs to be self-reflective writing as a process of understanding oneself first in order to understand one's own body and those of others. And then defining medical professional's identity as a 'listening doctor', the researcher said that writing needs to focus on listening. For this end, the educational content has been suggested as following three kinds of writings: writing about medical professional's own experiences with illness, writing about the situation of a patient as the main agent of sickness, and writing on a patient's family as the main agent of caregiving.

\section{A Case of narrative-medicine education in a medical school}

The 'I' University's medical school was established in 1984 in 'I' city with the third largest population in Korea. The medical school have cultivated approximately 50 medical doctors and 100 nurses a year. The medical school have employed a professor with medical humanities major and operated the curriculum of medical humanities. The curriculum of medical humanities consists of three stages and seven coursework as the following Table 2.

Table 2. Medical Humanities Education in a Medical School.

\begin{tabular}{|c|c|c|c|c|}
\hline Stage & Coursework & Education Content & \multicolumn{2}{|c|}{ Academic Grade } \\
\hline \multirow{2}{*}{1} & Patient-Physician-Society 1 & Life-Science-Ethics & \multirow{2}{*}{ Pre-medical $2^{\text {nd }}$ grade } & $1^{\text {st }}$ Semester \\
\hline & Patient-Physician-Society 2 & Communication Skills & & $2^{\text {nd }}$ Semester \\
\hline \multirow{3}{*}{2} & Patient-Physician-Society 3 & Medicine and Arts & Medical $1^{\text {st }}$ grade & $2^{\text {nd }}$ Semester \\
\hline & Patient-Physician-Society 4 & Medical History & \multirow{2}{*}{ Medical $2^{\text {nd }}$ grade } & $1^{\text {st }}$ Semester \\
\hline & Patient-Physician-Society 5 & Medical Interview & & $2^{\text {nd }}$ Semester \\
\hline \multirow{2}{*}{3} & Patient-Physician-Society 6 & Medical Ethics & \multirow{2}{*}{ Medical $4^{\text {th }}$ grade } & $1^{\text {st }}$ Semester \\
\hline & Patient-Physician-Society 7 & Career Exploration & & $2^{\text {nd }}$ Semester \\
\hline
\end{tabular}

As the coursework name 'Patient-Physician-Society (PPS)' means, that coursework focus on a variety of issues within the relationship between patient and medical professionals, between medical professionals and society.

At the first stage, the PPS- 1 cultivates those $2^{\text {nd }}$ grade pre-medical students to have ethical issues in life science areas like personal information protection, climate crisis, genetically modified organism, abortion, Dr. Hwang woo-suk scandal in human stem cell research, medical experiment crime by Japanese Army Unit 731, operation room's closed-circuit television, and so on. These are important medical ethics issues in Korea. And then the PPS-2 cultivates those students to have interpersonal communication skills in studying self-perception, cultural diversity, listening and responding, verbal and nonverbal communication.

At the second stage, the PPS-3 cultivates those first and second grade medical students to have empathic competence through arts like literature, visual arts, and cultural relics. Moreover, the PPS-4\&5 make those students to recognize medical professionalism human right sensitivity toward minority groups through western and Korean medical history, and to learn medical interview skills and practices in various medical cases.

At the third stage, the PPS-6\&7 cultivates those third and fourth grade medical students to seriously consider their roles as medical professionals with ethical knowledge and attitude before their graduation and entrance to medical fields.

\section{Conclusion and discussion}

The above researches don't describe everything of narrative medicine education but present overall picture in Korean medical schools. However, those researches imply future task of narrative medicine or medical humanities education in Korean medical schools, especially during and after Covid-19 pandemic era.

First, current education has generally emphasized on writing education in Korea. This trend seems to reflect a natural result from Korean medical humanities education's short history. Although writing is a core element of narrative medicine education, educators need to try other education areas beyond writing, other various means of expression beyond narrative (Hwang, 2020a). Narrative medicine curriculum can be developed with medium like drama, movie, music, etc. 
Second, existing tendency of narrative utilization focus mainly on acquiring patient's information and forming rapport with patients. In other word, narrative medicine has been not used as a critical tool to fundamentally reconsider the role of medicine and medical professionals but mainly used as a complementary tool for medicine (Hwang, 2020a). In this sense, narrative medicine needs to be much more sought as a critical means of medical education. Especially, medical humanities or narrative medicine needs to seriously consider the unprecedented health crisis like the current Covid-19 pandemic. Hwang (2020b) said that social justice of national immunity system or ecological system beyond the existing human-centered health perspective are requested to be seriously consider and responded as medical humanities and narrative medicine's issues. Thus, medical humanities education can raise up medical professionals with critical perspectives and alternative solutions to existing medical situations.

Third, medical narratives need to be educated and studied in bi-directional ways. Hwang (2020a) suggested the necessity to introduce specific education and research on how to connect closely patient's illness narratives and doctor's medical narratives, and to improve the existing medical customs like writing medical charts in clinical fields. Thus, medicine humanities education and research in Korea need to focus on narrative itself like narrative's therapeutic mechanism and effect.

\section{References}

Ahn, J. H. \& Jeon, W. T. (2011). Analysis of the characteristics of discussion materials that promote group discussion in the medical humanities. Korean Journal of Medical Education, 23(4), 253-261.

An, J. H., Kwon, I., Lee, S. N., Han J. J., \& Jeong J. E. (2008). Study on the medical humanities and social sciences curriculum in Korean. Korean Journal of Medical Education, 20(2), 133-144.

Ban, J., \& Yeh, B. I. (2012). Application of 'writing for healing' in premedical humanities education. Korean Journal of Medical Education, 24(3), 189-196.

Charon, R. (2008). Narrative medicine: Honoring the stories of illness. Oxford University Press.

Choi, K. J. (2020) 2020-1st semester online lecture excellent case guide book, 55-58.

Hwang, H. S., \& Kim, S. A. (2017). Moral imagination education using illness narrative literature. Korean Journal of General Education, 11(3), 153-183

Hwang, I. K. (2013). Teaching medical humanities through an illness narrative. Korean Journal of Medical Education, 25(2), 81-88.

Hwang, I. K. (2020a). Narrative in medicine, focusing on current status and tasks. Humanities Research, $45,435-464$.

Hwang, I. K. (2020b). Covid-19 and medical humanities: Medical humanities' history and tasks. Writers, $74,183-196$.

Hyun, E. (2013) Analyzing the creative strengths of college students majoring in medicine for developing 'medical humanities' based on design. Journal of Korea Design Knowledge, 26, 249-258.

Inha University's College of Medicine (2020). Introduction of the college: purpose of education. Retrieved March 1, 2021, from http://dept.inha.ac.kr/user/indexSub.do?codyMenuSeq=9505\&siteId=medicineeng

Jeon, D. S., \& Ahn, D. S. (2017). Teaching medical ethics and professionalism based on critical thinking and writing. Journal of Humanities, 67, 157-193.

Kim, J. H. (2019). Expansion of narrative medicine through re-reading and re-writing: Becoming physician-interpreter (Unpublished Doctoral Dissertation), Pusan National University, Korea.

Kim, S. L. (2016). A medical-humanistic study of poem and medical education. Cogito, 79, 348-374.

Kim, Y. S. (2011). Social and cultural expansion and transformation of storytelling. Seoul: Book Korea.

Kim, Y. S., \& Oh, Y. S. (2020). A qualitative case study on introducing the teaching model of narrative-based humanities therapy. Korean Education Inquiry, 38(1), 107-130.

Lee, I. W., Kim, C. S., Lee, H. S., \& Lee, W. S. (2015). A content analysis on a form and manner in medical communication subject: Focused on the medical schools in Korea. Communication Theories, 11(2), 104-141.

Meng, K. H. (2007). Teaching medical humanities in Korean medical schools: Tasks and prospect. Korean Journal of Medical Education, 19(1), 5-11.

Oh, H. J. (2020) A case study on application of flipped learning in medical humanities: Focus on instructional design and learners' perspective. Journal of Science Education, 44(2), 240-258.

Oh, Y. S., Kim, Y. S., \& Wang, G. M. (2018). Exploratory study on international research trend of narrative therapy. Journal of Literary Therapy, 48, 41-74.

RISS (2020). Research Information Sharing Service. Retrieved March 1, 2021, from http://www.riss.kr/index.do

Shin, S. K. (2006) The need for writing education for medical students and its direction. The Research in Writing, 2, 61-84

Youm, W. H. (2020). The direction and composition of medical writing. The Korean Journal of Literacy Research, 11(1), 301-325. 


\title{
RETHINKING THE OTHER FOR MULTICULTURAL EDUCATION - FOCUSED ON THE PHILOSOPHY OF BUBER AND LEVINAS
}

\author{
Seungeun Choi \\ Inha University/Research Professor (Republic of Korea)
}

\begin{abstract}
The number of foreigners residing in Korea exceeded 2.5 million for the first time ever. As the ratio of foreigners to the total population approaches $5 \%$, it is evaluated that Korea has actually entered a multicultural society. It is known that among the types of foreigners staying there are many young foreigners who visit Korea for the purpose of employment. The number of marriage immigrants was 16,025 , an increase of $4.3 \%$ from the previous year. Of these, $82.6 \%$ were women. Entering a multicultural society in a situation where empathy for each other is insufficient can lead to social conflict. In particular, in the COVID-19 pandemic, hostility toward foreigners is more prevalent, and hatred for strangers is increasing.

This study critically analyzes these social phenomena and seeks to raise the philosophical basis for multicultural education by establishing a concept with a new perspective on the other. This paper focuses on the philosophy of Buber and Levinas. By establishing 'I and You' as a meeting, Buber presented a new relationship with others. Meanwhile, Levinas emphasized human ethics and responsibility as the absolute and infinite being of the other.

According to Buber, in the world there is a relationship between 'I-You' and 'I-It', and in order to live a true life, you must establish a relationship between 'I and you'. The relationship between 'I and it' is a temporary and mechanical relationship where objects can be replaced at any time by looking at the world from an instrumental point of view. However, the relationship between 'I and You' is a relationship that faces each other personally, and the only 'I' that cannot be changed with anything and the 'You' that cannot be replaced exist in deep trust.

In phenomenology of otherness, Levinas intends to describe the encounter with the something outside the subject. The concepts of possession, distinctiveness and understanding are replaced by those of approaches, proximity, care and fecundity.

In Korean society, a policy that seeks to use foreigners as human resources and, especially in the case of marriage immigrant women, as a solution to a society with low birthrates along with the labor force, shows how society treats others. Therefore, multicultural education must rethink the existence and dignity of human beings through the perspective of the other as asserted in the philosophy of Buber and Levinas.
\end{abstract}

Keywords: Other, multicultural education, philosophy, Buber, Levinas.

\section{Introduction}

The number of foreigners residing in Korea exceeded 2.5 million for the first time ever. As the ratio of foreigners to the total population approaches $5 \%$, it is evaluated that Korea has actually entered a multicultural society. It is known that among the types of foreigners staying there are many young foreigners who visit Korea for the purpose of employment. The number of marriage immigrants was 16,025 , an increase of $4.3 \%$ from the previous year. Of these, $82.6 \%$ were women (Ministry of Justice, 2021). Entering a multicultural society in a situation where empathy for each other is insufficient can lead to social conflict. In particular, in the COVID-19 pandemic, hostility toward foreigners is more prevalent, and hatred for strangers is increasing.

This study critically analyzes these social phenomena and seeks to raise the philosophical basis for multicultural education by establishing a concept with a new perspective on the other. This paper focuses on the philosophy of Buber and Levinas. By establishing 'I and You' as a meeting, Buber presented a new relationship with others. Meanwhile, Levinas emphasized human ethics and responsibility as the absolute and infinite being of the other. 
Multicultural education is an idea, an educational reform movement, and a process (Banks, 1997). Multicultural education values different student cultures and prepares students to thrive in a diverse world. At its core, multicultural education fosters equality, justice, and equity, and it establishes the reality of philosophical ideals in classroom environments. In spite of this concept of multicultural education, aversion to difference is increasing in Korean society. In addition, human alienation, dehumanization, and self-loss, which become increasingly serious, seem like pathological phenomena in which communication is absent.

In Korean society, a policy that seeks to use foreigners as human resources and, especially in the case of marriage immigrant women, as a solution to a society with low birthrates along with the labor force, shows how society treats others. Therefore, multicultural education must rethink the existence and dignity of human beings through the perspective of the other as asserted in the philosophy of Buber and Levinas.

\section{Relationships in Buber's philosophy}

Buber's philosophy was built on existentialism. He said that the true existence only emerges from the human face-to-face, that is, the encounter, as an interaction between a free man and another man. The essence of Buber's thought is that through encounters, people are guided toward being human. "Humans bring a dramatic change in their lives due to the opportunity of meeting. Through these changes, human beings are transformed from beings as humans to beings that become humans (Buber, 1956)."

Buber's thoughts on the relationship between 'I-You' suggest the concept of community needed in modern society. He divided the two fundamental orders of the human world into a personal community in which genuine dialogue is based on the relationship of 'I-You' and a collective society in which a monopoly is formed based on the relationship of 'I-it'. He regarded humans as not as an isolated existence, but as an existence to meet and communicate.

Buber argued that humans are creators who shape their existence through relationships. Relationships are established in sincere dialogue, and dialogue makes it possible to meet personalities. It is a situation for self-discovery. Therefore, the relationship between 'I-You' is a relationship of a whole person and a personal dialogue. "Relationship in education is a pure conversation" (Buber, 1979). The composition and growth of character is the task that teachers and students want to achieve in one meeting place called education.

Through his thoughts on the relationship between 'I-You', Buber's philosophy goes beyond individual existentialism to present the relationship between humans and nature, between humans and humans, and between humans and mental beings as a prototype of the relationship. This is why human relational coexistence is important in a multicultural society. According to Buber (1979), human self-loss and atomization stem from the broken relationship between humans and humans. Humans are beings that cannot be objectified, and they must become 'I and You' that coexist as personalities. "Every true life is an encounter." A true community does not consist only of people having feelings for each other, but it begins with all human beings entering into a living interrelationship (Buber, 1979). In other words, what matters is the area of the relationship that is to be discovered or rediscovered.

\section{The other in Levinas' philosophy}

In the concept of 'I-You', the wall of self disappears, and relationships are formed in my essence. You cannot think of a relationship without "you' who fully affirms this point. The existence of "you" is a milestone in finding another existence, and the encounter is a priori existence or birth. In this way, humans are in a relationship even though they did not intend. In this context, Levinas perceives human beings not as subjects at all, but as "links of encounters", and recognizes me as being not as real, but as a category (Levinas, 1963). According to Levinas, the other is neither manipulated nor controlled. They are not trapped in the horizons of understanding or existence that Heidegger emphasizes. It is the other who is not under any category. In addition, the externality of the other is neither spatial nor conceptual (Levinas, 1997). In this way, Levinas's main philosophical concern is that it is inherently impossible to make the other a subject of understanding, and that the otherness must be preserved as it is.

The other exists as 'manifestation', that is, 'appearing'. At this time, the other appears through a face that 'shows the existence of another person in a single way.' Here, the face does not mean any expression or outline. The face contains infinite otherness implicitly. Responsibility is derived from the other, the face of the other, and the close relationship between me and the other (Levinas, 1979).

Levinas calls responsibility as the essential and fundamental structure of the subject and the condition of subjectivity. Responsibility refers to the responsibility of others, those who have nothing to 
do with me, and those who do not see me. Also, it is a responsibility that goes beyond my actions. I take the responsibility of the other. In this respect, the responsibility Levinas refers to is clearly distinguished from the self-responsibility or responsibility of conduct, which is fundamental in law. At this time, the other refers to the weak, the poor, the widow and the orphan above all else. For these other people I owe. I must respond to the request of the other as 'the first person'(Levinas, 1979). The point to note here is that, according to Levinas, my responsibility to the other is unlimited. In this respect, responsibility to the other is different from tolerance. Tolerance starts from the same person, at best, it only refers to limited liability. However, the other's face appeals for unlimited responsibility.

\section{Multicultural society and others}

The relational attribute of 'I-You' ultimately leads to the creation of 'Between-being (Zwischensein)' as a third concept. It refers to a communal existence formed by the relationship between 'I-You', which is considered the core of Buber's communicative thoughts (Rotenstreich, 1963).

This is not a real existence, but a relational communication thought by implying the meaning of a relational existence. Between-being is not another third entity between 'I and You', but it can be referred to as 'being together' or 'Between men (Zwischenmensch)', which is created by 'I and You' together. The 'I' who creates these between-beings must be a personal being. Thus, between-being can be defined as a mystical concept that creates a new relationship. Specifically, the existence between 'I and You' is formed by standing face to face (Marcel, 1963).

Levinas evaluates the between-being as belonging to a third being, not a creative center, not as a field of force with both a subject and an object. However, according to him, there is no independent existence, and it has a special transcendental property in which 'I and You' form a special encounter. In other words, between-being does not have a substantial concept of existence, such as the content of existence, the object representation of existence, or the existence that can be described, and implies the meaning of expressing existence as a whole (Levinas, 1963).

The important point is that human personal communication relationships do not exist in the inner world or the vast outer world of each human being, but are created between these humans. As an inter-being, the self becomes the subject by being in charge. The subject stands tall as an irreplaceable person, as the first person, as a being who is not swung by anything. I cannot deny this responsibility. The reason is that this responsibility is the highest dignity of the irreplaceable (Levinas, 1961). By taking responsibility for the other, the self finds the identity necessary to become an authentic subject. Only when ethical subjectivity is established can it become a condition for a multicultural society.

The fear that prevails in today's society is mixed with anger, criticism, and envy. Fear blocks rational thinking, poisons hope, and hinders constructive cooperation for a better future (Nussbaum, 2018). Hate for others begins with fear. We must free ourselves from fear of others and build solidarity together as members of a multicultural society.

In a multicultural society, solidarity with the other means that it is not simply an external solidarity through coexistence of various cultures, but an internal communication based on ethics and absolute responsibility toward others. This is because dynamic coexistence is possible when individual beings in various cultures go beyond acknowledging their differences.

\section{Conclusion}

Multicultural education is a process because its goals are ideals that teachers and administrators should constantly strive to achieve. A major goal of multicultural education is to help students from diverse cultures learn how to transcend cultural borders and to engage in dialog and civic action in a diverse, democratic society. From this goal of multicultural education, the issue of restoring humanity through the personal "encounter" of 'I and You' must go to the issue of humanity. Since this is a matter of education, it takes place when the true encounter between 'I and You' is emphasized in the current dehumanized education.

We cannot be totally indifferent to the needs of others. The reason is that the other is a necessary condition for the formation of my subjectivity. I cannot make me a whole subject unless I distinguish myself from what I am not. The question of who I am is bound to be an ethical matter. Because who I am is always influenced by what is outside me (Levinas, 1979). In the neoliberal system, Korean society tended to use multicultural members, especially marriage immigrant women, children of multicultural families, and foreign workers as human resources. We must rethink the dignity of all humans. In a multicultural society, all members are responsible for each other. We coexist through encounters in a conversational relationship between 'I and You'. For a sustainable multicultural society, we must become an ethical being responsible for others. 


\section{References}

Banks, J. A. (1997). Multicultural Education: Characteristics and Goals. In J. A. Banks \& C. A. M. Banks, (Eds.). Multicultural Education: Issues and Perspectives (3rd ed., pp. 3-31). Boston: Allyn and Bacon.

Buber, M. (1965). Between Man and Man, M. Friedman(trans), New York: The MacMillan.

Buber, M. (1979). I and Thou. W. Kaufman(trans.), New York: Charles Scribner's Sons.

Friedman (eds.), Martin Buber, Stuttgart: Kohlhammer Verlag, 119 134.

Levinas, E. (1961) Totality and Infinity: An Essay on Exteriority. A. Lingis (trans.), Duquense University Press.

Levinas, E. (1963). Martin Buber und die Erkenntnistheorie. In P. A. Schilpp and M.

Levinas, E. (1979). Time and the Other. R. A. Cohen (Trans.) Duquense University Press.

Levinas, E. (1997). Heidegger, Gagarin and Us, in: Difficult Freedom: Essays on Judaism. Seán Hand (trans.), The Johns Hopkins University Press.

Marcel, G. (1963). Ich und Du bei Martin Buber. In P. A. Schilpp and M. Friedman (eds.), Martin Buber, Stuttgart: Kohlhammer Verlag.

Marcel, G. (1963). Ich und Du bei Martin Buber. Schilpp and Friedman.

Ministry of Justice (2021). Monthly statistics on immigration·foreigner policy. Republic of Korea.

Nussbaum, M. C. (2018). The Monarchy of Fear: A Philosopher Looks at Our Political Crisis. Simon \& Schuster, Inc.

Roberts-Cady, S. E. (2009). Rethinking Justice with Levinas. In Essays on Levinas and Law. Palgrave Macmillan, London.

Rotenstreich, N. (1963), Gruende und Grenzen von Martin Bubers dialogischem Denken. In P. A. Schilpp and M. Friedman (eds.), Martin Buber, Stuttgart: Kohlhammer Verlag. 


\title{
THE TEACHER TRAINING DURING COVID-19 PANDEMIC: AN EXPLORATORY STUDY ABOUT ONLINE LABORATORIES QUALITY
}

\author{
Rosanna Tammaro, Iolanda Sara Iannotta, \& Concetta Ferrantino \\ Department of Human, Philosophy and Education Sciences (DISUFF), University of Salerno (Italy)
}

\begin{abstract}
The spread of novel Corona Virus and the resulting Covid-19 Pandemic has had a profound impact in our lives and most of daily activities have been upset. Negative effects crushed education and all around the world schools, universities and tertiary institutions had to shut down moving to Distance Learning. Distance Learning was in fact the global answer to continue educational activities and preserve students' right to education. The United Nations Organization for Culture and Education (UNESCO) reports that ten months after rising pandemic, more than 331 million students worldwide are affected by the Pandemic and in 28 countries the schools are still closed (updated 09.12.2020). During the months of the first contagion curve, only $15 \%$ of teaching activities were delivered remotely, globally, thanks to Distance Learning. More than 1.5 billion students worldwide are or have been touched by the closure of schools and universities due to the Covid-19 Pandemic.

Teachers and instructors world-wide had to find the best solution to fix the pedagogical challenge. For this reason, teaching strategies, methods and materials have been adapted to the online learning environment. Distance Learning refers to an electronic learning environment; generally, it is used if time and/or geographic conditions do not allow a direct contact between educators and students (King, Young, Drivere-Richmond \& Schrader, 2001). UNESCO (2002) asserts that Distance Learning includes learning process carried out separately in time and space, through artificial electronic or print media; this holds also for a part of the educational process. Distance Learning requires specific evaluation procedures throughout qualitative and quantitative methodologies, focusing the performance assessment and the learning process (Benigno \& Trentin, 1999).

This article is a part of a wider research that wants to investigate the students' experience about online Laboratory classes during Pandemic crisis. Based on a quantitative, non- experimental and ex-post-facto research, this article specifically investigates the strategies used during remote Labs students attended during the sanitary emergency. Data was collected through a no-tested research survey administered with an online free app. A voluntary response sample from 749 Single-cycle Primary Teacher Education students, from first year course to the fifth, attending university in one of the most important athenaeums in Southern Italy, at the end of their last second semester. Results from the closed-response questions show the use of a variety of strategies whose effectiveness should be assessed based on empirical evidence.
\end{abstract}

Keywords: Teacher training, distance learning, Covid-19, laboratory classes, quality.

\section{Introduction}

On March 11th, 2020, the World Health Organization (WHO) announced the COVID-19 Pandemic, caused by the spread of novel Corona Virus, as a public and international emergency. The COVID-19 Pandemic had been impacting many qualities of life and, the education processes. Schools shut down enforced by institutions has resulted in a rapid digitalization in the education practices. Distance Learning was the global answer to keep educational activities and preserve students' right to education. During the first months of the COVID-19 Pandemic, only $15 \%$ of teaching activities were delivered remotely, worldwide, using the only possible strategy, that is Distance Learning (UNESCO, 2020). Different Distance Learning strategies led uneven results, for which feedback is expected from specialist literature; in many cases, Distance Learning or e-Learning intensified digital divide and the Internet access. This kind of digital divide affects both the poorest and most disadvantaged countries, those where this condition is known and motivated by several problems of a social, economic, and political nature, but also those developed and industrialized countries, in which modern digital devices 
remain not used to carry on teaching and learning processes (Chetty, Aneja, Mishra, Gcora, \& Josie, 2017).

Online learning refers to an electronic learning environment that imposes certain responsibilities on students and teachers; in fact, the effective success of a distance learning action is strongly influenced by student readiness, learning management systems adopted, technological support and institutional commitment (Markova, Glazkova \& Zaborova, 2017). There is uncertainty in the specialist literature, and this vagueness affects teachers and educators in choosing this teaching method. Devotees of Distance Learning believe that learning at distance can be as effective, or even more, than face-to-face pattern (Allen, Mabry, Mattrey, Bourhis, Titsworth, \& Burrell, 2017) if content, teaching methods, communication, and learner support are considered in designing the learning project. On the other side, opponents denote concerns about students' online participation and feelings (misunderstanding, loneliness, frustration); these conditions could impact in their learning effectiveness and satisfaction (Markova et al, 2017). By reason of their peculiarities, distance learning actions also require specific evaluation procedures throughout qualitative and quantitative methodologies, focusing the performance assessment and the learning process (Benigno \& Trentin, 1999). Specialist literature also refers the uncertainty about how to teach (timing or methods), what to teach, the capacity of teachers and students, the teaching environment, and the implications for education equity (Zhang, Wang, Yang \& Wang, 2020). The use of Distance Learning by universities stressed concerns about the quality and the effectiveness of online courses compared to conventional educational patterns, independently from the present sanitary emergency.

Complications increase if we focus on Laboratory Instruction. In Italy, Single-cycle Primary Teacher Education degree programs provide opportunities for training with Laboratory methods, that are mandatory, to develop in the future teacher both knowledge and strategies based on students age, education, or cultural backgrounds. Ministerial Decree no. 249/10 regulates the requirements and methods of initial training for teachers which will be in service in kindergarten, primary school, and secondary school: the laboratory instruction qualifies the professional profile of future teachers, in conjunction with the disciplinary courses and the internship. The value of the practical path is expressed in the table proposed in the same Decree, which provides for the acquisition of no. 33 university formative credits (UFC) in the five years course. In future teachers training, the transition from theory to professional practice is one of the most relevant aspect (Calvani, 2011; Zecca, 2014). Pedagogical and didactics laboratories in the Single-cycle Primary Teacher Education degree program offer an opportunity to demonstrate consistency between theories and professional practices through fading.

\section{Design}

This study follows a quantitative, non-experimental, and ex-post-facto research design, with a survey approach, focused on the perceptions of the future teachers of primary education, about the organization of online Labs they attended, due to the sanitary emergency caused by Covid-19 Pandemic. Data was collected through a no-tested research survey administered with an online free app at the end of the second semester 2019/20, between the end of June and the first half of July 2020. The questionnaire design works on Google Form and the access link was shared to students in the official website of the Single-cycle Primary Teacher Education degree program and through students WhatsApp groups, thanks to the collaboration of students' representative. Data were collected through voluntary response sample: 749 Single-cycle Primary Teacher Education students, from first year course to the fifth, attending Labs classes at the University of Salerno, in their second semester, during the sanitary emergency. At the University of Salerno, the Scientific and Technical Committee, gathered for the crisis, decided to adopt Microsoft Teams for Distance Learning: the whole of the didactic offer have been supporting by this platform. Data collection was made thanks to an electronic, anonymous, self-administered questionnaire handed out through Google Form composed by 11 closed-ended questions and 4 open-ended questions. In this work the authors present the results of students' opinion about teaching strategies used in Distance Learning for Laboratory classes. The research question was presented as follows:

According to your experience, what do you think about the adequacy of the following teaching strategies in online laboratory classes:

- frontal lecture, in synchronous modality;

- guided explanation, with shared exploration of tools and apps;

- lecture with visual support;

- video lesson;

- individual work;

- group or pair work;

- problem based learning,

- project learning (individual or group work);

- flipped learning. 
The research question was catered throughout scaling with partial semantic differential (Likert scale).

\section{Results}

The $97.5 \%$ of all voluntary sample is female. Most students are between 18 and 23 years old $(64.5 \%)$; the other age groups are represented in the research as follows: $22 \%$ age group $24-29,7.9 \%$ between 30 and 35 years old and, $5.6 \%$ over 36 years. The voluntary sample well represents the different years courses of the Single-cycle Primary Teacher Education program. Indeed, Laboratory activities are planned from the first to the fifth year of course, with specific differences between pedagogical and didactics Labs. Results show that, for each year of the course, on average $20 \%$ of those enrolled in that year replied. In relation to the research questions, we believe that it is important to highlight that most of the students joined more than 1 online Labs. Precisely, 418 responding students attended 2 Labs, 119 students were present at 3 Laboratory activities and, even 32 responding students participated in 4 or more online Labs. All the voluntary sample responded the research question. The item has been proposed as follows: According to your experience, what do you think about the adequacy of the following teaching strategies in online laboratory classes. To the Single-cycle Primary Teacher Education students was asked to reflect on the following teaching strategies, assuming the use by the teachers in charge in the laboratory classes:

- frontal lecture, in synchronous modality;

- guided explanation, with shared exploration of tools and apps;

- lecture with visual support;

- video lesson;

- individual work;

- group or pair work;

- problem based learning;

- project learning (individual or group work);

- flipped learning.

Results show that students have recognized the different teaching strategies mentioned in the closed-ended question; responding students believe that frontal lecture, in synchronous modality was much used for the 39\% and often used for 30\%. About the guided explanation, which provide for shared exploration of tools, programs or useful apps for teaching and learning was always used for $17 \%$ of the responding sample.

Lecture with visual support (like .ppt presentation) was often used for 36\% and always adopted for $21 \%$ of the students. Consistently with the results about frontal lectures, in synchronous modality, video lessons were never used for $20 \%$ and rarely proposed for $21 \%$ of the responding sample. Individual work was required by the teachers of Labs: for 32\% was often commanded and, for another $32 \%$ was much required. Widely used amongst teaching strategies group and/or pair work: for 35\% of the responding students, it was proposed often and for $22 \%$ it was always used. Problem based learning, despite the literature indication, was not really introduced in Labs practice in Single-cycle Primary Teacher Education program: for $28 \%$ of the responding students, it has been used often. Project learning (individual or group work) was used often for $31 \%$ and always for $23 \%$ of the responding sample. To conclude, flipped learning was rarely adopted for $24 \%$ and never for $19 \%$ of students.

\section{Discussion and conclusion}

Distance learning generally has been being a strategy for vocational learning, for working students, for non-residents or individuals in remote regions, who are unable to be present at classroom lectures, as in the poorest and most disadvantaged countries. On the other hand, distance learning has become a well-known part of the world of education in the last year, due to the sanitary emergency. The Covid-19 Pandemic has upset the lives of all of us in different ways and, it revolutionized the education sector as well as fields such as health, economy, and tourism. Many countries around the world have temporarily closed educational institutions (schools and university) to control the spread of the Novel Corona Virus. Students around the world had to quickly adapt their learning strategies, based on specific cognitive styles, to distance education application (platforms, tools, etc.) even if they had no previous or sufficient experience. Similarly, instructors and teachers world-wide had to quickly adapt strategies, methods and materials based on the new learning environment. At the University of Salerno, in the Single-cycle Primary Teacher Education program it was the first experience of online learning for all the planned activities. Research quantitative results from the closed-response question revealed, as we have 
already said, that students have recognized the different teaching strategies. The percentage emerged by the analysis shows that teachers have work adapting strategies for distance Labs. Active teaching strategies were considered to differentiate the educational offer. Nonetheless, it should not be assumed that teachers' familiar with online learning environment will change easily from onsite to online learning model. In fact, despite strong points, online Laboratory class is still a challenge for policymakers, instructors, and stakeholders if the concerns about Covid-19 Pandemic will remain the same.

\section{References}

Allen, M., Mabry, E., Mattrey, M., Bourhis, J., Titsworth, S. \& Burrell, N. (2017). Evaluating the Effectiveness of Distance Learning: A Comparison Using Meta-Analysis. Journal of Communication, 54(3), $402-420$.

Benigno, V. \& Trentin, G. (1999) La valutazione nella formazione a distanza. In G. Trentin (Ed.), in Telematica e formazione a distanza: il caso Polaris (207-227) Milano: Franco Angeli.

Calvani, A. (2011). Principi dell'istruzione e strategie per insegnare. Roma: Carocci Editore.

Chetty, K., Aneja, U., Mishra, V., Gcora, N. \& Josie, J. (2017). Bridging the digital divide in the G20: skills for the new age. Economics - The Open-Access, Open-Assessment E-Journal, 68, 1-17.

King, F.B., Young, M.F., Drivere-Richmond, K. \& Schrader, P.G. (2001). Defining Distance Learning and Distance Education. AACE Review 9(1), 1-14.

Markova, T., Glazkova, I. \& Zaborova, E. (2017). Quality Issues of Online Distance Learning. 7th International Conference on Intercultural Education "Education, Health and ICT for a Transcultural World”, EDUHEM, 237, 685 - 691.

UNESCO, 2020. Retrieved October 04, 2020. https:/en.unesco.org/covid19/educationresponse/ globalcoalition.

Zecca, L. (2014). Tra 'teorie' e 'pratiche': studio di caso sui Laboratori di Scienze della Formazione Primaria all'Università di Milano Bicocca”. Italian Journal of Educational Research, 13, $215-230$.

Zhang, W., Wang, Y., Yang, L. \& Wang, Y. (2020). Suspending ClassesWithout Stopping Learning: China's Education Emergency Management Policy in the COVID-19 Outbreak. Journal of Risk and Financial Management, 13(55), 1-6. 


\title{
THEORY AND PRACTICE OF STORYTELLING WITH SCRATCHJR TO DEVELOP EARLY MATHS SKILLS
}

\author{
Annarosa Serpe \\ Department of Mathematics and Computer Science, University of Calabria (Italy)
}

\begin{abstract}
This paper seeks to contribute to the debate surrounding children and digital storytelling by focusing on its application in preschool to develop early maths skills. Starting from a literature review, the paper describes a brief relevant question of how storytelling and teaching programming can be mutually supporting and outlines the educational potential of this approach. At the crossroads between the examination of some pedagogical practices, the paper shows a modality of didactic work that is relevant and practicable for conducting digital storytelling activities in the preschool.
\end{abstract}

Keywords: Digital storytelling, early math skills, preschool, ScratchJr.

\section{Introduction}

The design and implementation of digital storytelling (DST) activities in preschool are part of the broad framework of the objectives outlined by the Piano Nazionale Scuola Digitale (PNSD - National Digital School Plan) as part of the broader programme initiated by the recent law reforming the education system, "La Buona Scuola" (The Good School), Law 107/July 2015. One of the main objectives of the PNSD is to promote and support students' skills in the efficient and effective use of technologies as well as to train teachers in the use of new models of didactic interaction that involve the involvement of technologies. In this direction, the objective envisaged by action \#7 of the PNSD is to promote of the implementation of 'innovative learning environments' in the schools where technologies have an enabling but not exclusive role: a sort of 'digital carpet' in which, however, imagination and 'doing' meet, combining tradition and future through didactic practices. In this perspective of transversal learning, didactic scenarios built around computational logic and thinking, manual and digital artefacts, serious play and storytelling find their natural home. This paper is part of this perspective and focuses on digital storytelling (DST) with ScratchJr as one of the possible resources that can be used in the preschool to develop early maths skills. Indeed, DST helps the teacher implement best practices in early childhood because it integrates knowledge across domains. Overall, language is an important component of both early literacy and early numeracy, so these are two important skill areas during the early childhood period. Not only are these skills critical in and of themselves in terms of early school success, they are also necessary building blocks for knowledge in other areas. Therefore, the purpose of this paper is to recommend the use of DST practices as an educational methodology to promote maths skills and support critical use of digital technologies in the preschool.

\section{Theoretical background}

Storytelling has a very important role in developing the narrative skills that are fundamental for a child's cognitive and emotional growth. Regarding the early developments of maths skills, in particular, storytelling is a favoured tool as it guides children towards learning general notions of logical concepts and favours the acquisition of a way of thinking which will later help them to approach mathematics as a way of doing, thinking and acting. The use of the storytelling approach in instructional applications dates back to earlier time. Stories have been tools preferred by teachers as they help children understand difficult and abstract subjects. For a long time, storytelling was employed spontaneously rather than as a deliberate and planned instructional approach in early childhood education (Coskie, Trudel \& Vohs, 2010; Philips, 2013). The understanding of the use of storytelling as an engaging and meaningful teaching approach in early literacy education began with a study by Egan (1985 and 1989) highlighting that teaching is best shaped in story formats because storytelling stimulates children's imagination which is a very powerful learning tool. 
Subsequent research studies noted that storytelling can nurture cognitive engagement, critical thinking, and story sequencing (Peck, 1989; Kim, 1999, Serpe 2013; Cremin, Flewitt \& Mardell, 2017). These researches have shown also that follow-up activities such as discussion, retelling, and topic-related activities (written, drama, oral) can further enhance literacy development. Today, with the use of technology, traditional storytelling has been replaced by digital storytelling (DST). Commonly, the DST refers to the process of developing a multimodal narrative (pictures, video, sound effects, music or text), using digital tools icons (Meadows, 2003; Robin, 2008; Brígido-Corachán \& Gregori-Signes, 2014). Put simply, the DST can be understood as the practice of inventing and telling stories through a combined use of a variety of languages: verbal, visual, sound and digital. DST is used at all levels of education from early childhood to higher education. Several studies have also generated qualitative evidence that DST has beneficial effects on encoding, visual perception, creative thinking, and fine motor skills (Kocaman-Karoğlu, 2015; Sylla, Coutinho, Branco \& Muller, 2015). For children the activity of DST opens up more learning opportunities because it helps them organize and express their ideas and knowledge in a distinctive and meaningful way (Robin, 2008). It even allows children younger than six to understand a new language and to enjoy a story through digital media, without knowing how to read it.

DST can therefore facilitate a constructivist approach to teaching and learning (Sadik 2008). Research literature shows that it can be considered a useful educational tool for using digital devices to support media literacy (Maureen, van der Meij \& de Jong, 2018). In addition to building on students' technological skills, DST encourages further educational outcomes because it increases student motivation and helps teachers build constructivist learning environments that encourage creative problem-solving based on collaboration and peer-to-peer communication. Additionally, DST can be used to facilitate integrated approaches to curriculum development and engage students in higher order thinking and deep learning (Dakich 2008). Consequently, as the literature review has revealed, DST can be used for different purposes due to its benefits to the educational process. In the relevant preschool literature, it is seen that DST activities have been used to determine pre-service teachers' current states and changes they have undergone in relation to technology (e.g. Callens \& Elen, 2010; Toki \& Pange, 2014; Kildan \& Incikabi, 2015; Yuksel-Arslan, Yildirim \& Robin, 2016), in maths activities (Pramling \& Samuelsson, 2008; Inan, 2015; Preradovic, Lesin \& Boras, 2016), and in other aspects. In preschool, the DST can be used as a powerful model for creating constructivist learning environments. Indeed, based on the pedagogical theory of constructivism, children's learning is an active and social process where they should discover and construct knowledge for themselves. DST has the potential to engage children in integrated approaches to learning with digital media.

The literature indicates that children are interested in making animation using the ScratchJr digital multimedia editing tool (Bers \& Resnick, 2015; Thompson \& Tanomoto, 2016; Serpe 2019).

ScratchJr is a visual programming language (VPL) designed to introduce coding skills to children aged 5-7. It builds on the VPL Scratch (Resnick, Maloney, Monroy-Hernández, Rusk, Eastmond, Brennan, ... \& Kafai, 2009) which uses interconnecting on-screen blocks to program character animations. ScratchJr maintains the creative programming elements of Scratch, which allow children to easily create interactive short stories and games. It has a user's library of projects, a main project editor, and tools for selecting and drawing characters and background graphics. The characters can be added to a scene, and are given behaviours by combining instruction blocks. The ScratchJr interface allows children to use blocks that control motion, looks, sound, character communication, allows children to use blocks that control motion, looks, sound, character communication, and more. When children open the ScratchJr app they are prompted to create a new project, open an existing project, or explore various learning resources. In the process, children learn early maths and literacy concepts and develop valuable problem-solving skills. Scratch's constructivist matrix allows children to become protagonists of their learning. It does this precisely because they are involved in interactive and meaningful experiences rather than in passive experiences where knowledge is transmitted directly from the teacher to the children. Scratch thus allows children to play the role of problem-solver (Ferguson 2011); at the same time, it allows teachers to demonstrate to children an active use of the digital tool by linking it to knowledge of the contents, problem-solving and creative thinking. Consequently, a VPL like ScratchJr offers new ways of teaching and learning processes in preschool. The paper fits into this theoretical framework and puts forward an activity to support the integration of DST in Early Childhood Education. This activity is taken from an action-research project realised by university and school working together - targeted to design scaffolds, trough micro-modules, for children to gain content knowledge in the areas of early literacy and early maths, as specified in greater detail in the introduction. 


\section{Methodology}

Following the theoretical framework, the researcher with the teachers designed the active learning environments based on the DST with ScratchJr tool. The DST planning aims to help children see and experience how mathematical ideas interconnect and build on one another to produce a coherent whole. Consequently, the components related to each phase of the authoring process have not been neglected (tellability, the initial scenario, Storyboard, discussing the scenario with children and recapitulation, voice insert, etc.). Given the specific characteristics of the A-R project, the main pedagogical goals can be briefly summarized as follows:

- use DST for stimulating mathematical learning through the identification of interdisciplinary connections among different fields of experience;

- $\quad$ scientific control of the conditions and procedures in the use of ScratchJr to practice maths and literacy content and other cognitive skills such as creativity, critical thinking, and problem solving;

- $\quad$ strengthen the skills profile of preschool teachers in the use of digital tools.

The didactic action saw the involvement of 26 children belonging to two sections of a traditional urban Calabrian preschool that has been collaborating for years with researchers from the University of Calabria in the field of initial and in-service teacher training. The systematic documentation of the entire A-R project was the subject of a thesis in Primary Education Sciences of the University of Calabria. The methodological-didactic scaffolding was structured in full respect of the biopsychic, social and cultural peculiarities of the children as well as their learning styles and rhythms. It is based on a series of concrete learning experiences - posed on individual, group and direct instruction by the teacher - exploiting various recurring moments of everyday life. Consequently, the educational-training paradigm followed was to carry out activities related to ideas and concepts first in a traditional way (without the use of technology) and then with a tablet, using the ScratchJr app based on the context and the didactic intentionality.

\subsection{DST with ScratchJr: Theater of numbers}

Number concepts become significant to children when they develop out of experiences that are functional in the world of those children. Here, below, we show a DST activity extrapolated from the micro-module 'Number sense' aimed at linking many types/quantities of concrete objects and actions to numbers. Specifically, the activity goals focused on:

$\circ$ the control of visual-motor coordination and fine motor skills;

○ to count accurately - first forward from 0 to 10 , then to count backwards;

o identify the positions of objects and people in space, using terms such as forward/back, up/down, right/left;

o experimenting with different and multidirectional languages through dramatization (traditional and digital).

On this basis, the activity with children was organized as follows: (1) the telling of a short story of numbers (zero to ten) to the children by the teacher; (2) conversation with the children (prompt questions); (3) transition from mental images to practice through different approaches which employ different and multidirectional languages; (4) reflection on the practical activities; (5) iconic, ideographic and graphic-symbolic representation; (6) theatre approach on combining hands-on activities with Scratch Jr and more traditional tools. For reason of space, only some extracts relating to the above-mentioned phases will be included. Fig. 1 shows a sequence of the traditional dramatization activity: the theatre with number-shaped puppets (made by children), the animation of the number 3 (the child animates the number puppet by saying/reciting 'I come after two and I'm three, no one is as perfect as me') and the animation of subsequent numbers.

Figure 1. Theatre of numbers - Traditional dramatization by children.
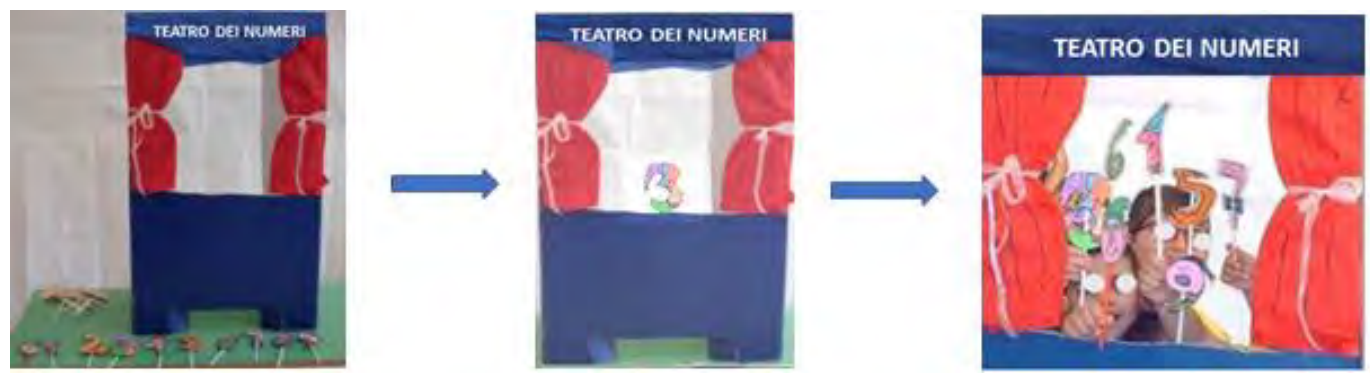

The theatre approach supports the children in the development of their narrative skills, not only with reference to the chronological sequence of narrative events, but also with the exploration of a child's own creative and expressive, personal and emotional, social dimension. Moreover, the theatre approach enables children to have full control of the story. 
At this point, the generalizations and the switch to greater levels of abstraction are aided by a tablet with the ScratchJr App enabled. Specifically, the children must create a project based on a real experience; in other words, it is a matter of representing stages related to the "Theatre of numbers" (Figure 2). Consequently, the elements of ScratchJr that must be brought into play when one thinks of a program as the result of a process of logical organization and structuring and as a means of communication are discussed. In this activity, the children are no longer able to act with their whole body because the perceptive-visual channel and the use of hand-eye coordination are mainly used. They have to invent a series of instructions in sequence to reach the goal (Serpe 2019).

Figure 2. ScratchJr project "Theatre of numbers".
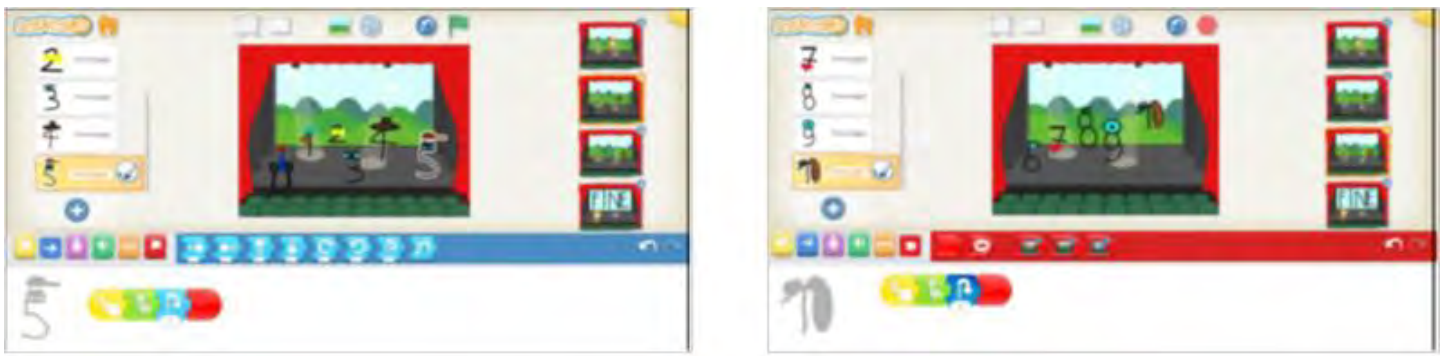

Working with ScratchJr is like working in a theatre where the action takes place on a stage where the sprites perform a script. In this way, the children have written their story without writing a single line of code and without knowing programming: simply by moving blocks to create sequences of behaviour of the individual characters. The children tell their story - Theatre of numbers- by creating a concatenation of coloured blocks that represent the elementary steps, or the instructions that describe them. Specifically, they have utilized the following blocks: Sound (green), Motion (blue), Triggering (yellow), and End (red).

\section{Assessment}

For the evaluation phase, an observation protocol was drawn up which stated the expected levels of competence, the indicators for checking and the achieved objective. This protocol was used by the teachers while the children were carrying out the activities. The choice was dictated by the need to obtain reliable results which were not influenced by possible expectations, rather than the somewhat confused recollections of the chidren's individual responses recorded at a later stage, as well as by the need to keep options open to unexpected behavior triggered by DST in the classroom. A qualitative rather than a quantitative reading brought to the fore the range of individual responses to the single classroom initiatives, in an effort to find the children's reaction to each suggested activity.

\section{Conclusion}

DST is a new pedagogical approach that has the potential to induce a basic shift in the learning process because it helps the children not only to read technology but turns them to active protagonists. The VPL ScratchJr is a tool very easy tool to use to create games, simulations, animated stories, maths experiments and animated presentations. It's fun to use because the children can work on digital literacy skills tailored to their developmental level, such as understanding and utilizing digital interfaces, non-linear navigation, critical thinking, problem-solving, cooperative learning, creative design and many others. Ultimately, DST assessment using ScratchJr makes children think creatively and it enhances their design skills, and, last but not least, allows children to start develop 21 st century skills.

\section{References}

Bers, M.U., \& Resnick, M. (2015). The official ScratchJr book: Help your kids learn to code. No Starch Press.

Brígido-Corachán, A.M., \& Gregori-Signes, C. (2014). Digital storytelling and its expansion across educational context. In A. M. Brígido-Corachán \& C. Gregori-Signes (Eds.), Appraising digital storytelling across educational contexts (pp. 13-29). Valéncia: Universitat de Valéncia.

Callens, J.C., \& Elen, J. (2010, May). Digital storytelling as a mediation tool to support in-depth reflection? In Global Learn (pp. 790-795). Association for the Advancement of Computing in Education (AACE). 
Coskie, T., Trudel, H., \& Vohs, R. (2010). Creating community through storytelling. Talking Points, 22(1), 2-9.

Cremin, T, Flewitt, R, \& Mardell, B. (Eds) (2017) Storytelling in Early Childhood: Language, Literacy, and Culture. London and New York: Routledge.

Dakich, E. (2014). Theoretical and Epistemological Foundations of Integrating Digital Technologies in Education in the Second Half of the 20 th Century. In Reflections on the History of Computers in Education (pp. 150-163). Springer, Berlin, Heidelberg.

Egan, K. (1985) Teaching as Story-telling: A Non-mechanistic Approach to Planning Teaching. Journal of Curriculum Studies, 17:4, 397-406.

Egan, K. (1989). Teaching as story telling: An alternative approach to teaching and curriculum in the elementary school. University of Chicago Press: Chicago.

Ferguson, D. (2001). Technology in a constructivist classroom. Information Technology in Childhood Education Annual, 2001(1), 45-55.

Inan, C. (2015). A Digital Storytelling Study Project on Mathematics Course with Preschool Pre-Service Teachers. Educational Research and Reviews 10 (10):1476-1479. doi:10.5897/ERR2015.2247.

Kildan, A. O., \& Incikabi, L. (2015). Effects on the technological pedagogical content knowledge of early childhood teacher candidates using digital storytelling to teach mathematics. Education 3-13, 43(3), 238-248.

Kim, S. Y. (1999). The Effects of Pretend Play and Storytelling upon Narrative Recall. Korean Journal of Child Studies, 20(2), 205-223.

Kocaman-Karoğlu, A. (2015). The changing nature of storytelling by means of technology in the instructional process: Digital storytelling. Educational Technology Theory and Practice, 5(2), 89-106.

Maureen, I. Y., van der Meij, H., \& de Jong, T. (2018). Supporting literacy and digital literacy development in early childhood education using storytelling activities. International Journal of Early Childhood, 50(3), 371-389.

Meadows, D. (2003). Digital storytelling: Research-based practice in new media. Visual Communication, 2(2), 189-193.

Peck, J. (1989). Using storytelling to promote language and literacy development. The Reading Teacher, 43(2), 138-141.

Phillips, L. (2013). Storytelling as pedagogy. Literacy Learning: The Middle Years, 21(2), ii.

Pramling, N., \& Samuelsson, I.P. (2008). Identifying and solving problems: Making sense of basic mathematics through storytelling in the preschool class. International Journal of Early Childhood, 40(1), 65-79.

Preradovic, N.M., Lesin, G.\& Boras D. (2016). Introduction of Digital Storytelling in Preschool Education: A Case Study from Croatia. Digital Education Review 30: 94-105.

Resnick, M., Maloney, J., Monroy-Hernández, A., Rusk, N., Eastmond, E., Brennan, K., ... \& Kafai, Y. (2009). Scratch: programming for all. Communications of the ACM, 52(11), 60-67. Retrieved from https://dl.acm.org/doi/fullHtml/10.1145/1592761.1592779 e

Robin, B. R. (2008). Digital storytelling: A powerful technology tool for the 21 st century classroom. Theory into Practice, 47(3), 220-228.

Sadik, A. (2008). Digital storytelling: A meaningful technology-integrated approach for engaged student learning. Educational Technology Research and Development, 56(4), 487-506.

Serpe, A. (2013). 'Doing Mathematics' in The Nursery School: I'll Tell You a Story. In L. Gómez Chova, A. López Martínez \& I. Candel Torres (Eds), ICERI2013 Proceedings (pp. 883-891). Valencia: IATED Academy.

Serpe, A. (2019) Programming with ScratchJr to create interactive Maths-Experiences in Preschool. In L. Gómez Chova, A. López Martínez \& I. Candel Torres (Eds), INTED2019 Proceedings, (2007-2016). Valencia: IATED Academy.

Sylla C., Coutinho C., Branco P., \& Muller W. (2015). Investigating the use of digital manipulatives for storytelling in pre-school. International Journal of Child-Computer Interaction, 6, 39-48

Thompson, R., \& Tanomoto, S. (2016). Children's Storytelling and Coding: Literature Review and Future Potential. In PPIG (p. 6).

Toki, E. I. \& Pange J. (2014). ICT Use in Early Childhood Education: Storytelling. Tiltai 66 (1): $183-192$.

Yuksel-Arslan, P., Yildirim, S., \& Robin, B. R. (2016). A phenomenological study: Teachers' experiences of using digital storytelling in early childhood education. Educational Studies, 42(5), 427-445. 


\title{
MOTIVATION IN FOREIGN LANGUAGE LEARNING: THE DYNAMIC INTERACTIONS OF MANY FACTORS
}

\author{
Christine Besnard \\ Glendon college, York University, Toronto (Canada)
}

\begin{abstract}
As all educators know so well, motivation is one of the most, if not the most, challenging aspect of language learning and teaching that they must deal with in their classes. We are therefore presenting a review of the last 10 years' literature on the major constituents of motivation, and on the intrinsic factors (anxiety, emotions, attitude, etc.) that have a deep impact on L2 learners' motivation.
\end{abstract}

Keywords: Motivation, anxiety, emotions, self-concept, personality.

\section{Introduction}

All language teachers will agree that motivation is one of the most, if not the most challenging aspect of language learning and teaching that they deal with in their classes. Indeed, they often wonder why they can motivate most, but not all of their students, despite their vigilance, efforts, and strengths as skilled language educators. Still, they are very aware that to learn well and efficiently, learners need to be motivated; they need to want to learn. (Ekiz et Kulmetov, 2016; Gardner, 2010).

We are therefore presenting a review of the last 10 years of literature on the major constituents of motivation, delving deep into this particularly rich issue.

First, it is important to understand that language learning differs from all other subjects as it is not limited to the learning of facts such as new words, new sounds, and new grammar rules; it also encompasses the discovering of new communities, new cultures and new mores. And in doing so, it triggers not only the learners' cognition but also their affect. It requires endless patience, discipline, perseverance, and self-efficacy from the learners as L2 learning extends over a protracted period of time (Kormos et al., 2011).

Motivation is a multi-faceted, complex and wide-ranging concept (Csizér et al., 2010; Ekiz \& Kulmetov, 2016; Gardner, 2010; Kormos et al., 2011) that encompasses the duration and intensity of effort learners are ready to invest, their attitude towards the L2 and the community that uses it, their desire to meet and interact with its members, and their interest in discovering the new language itself. Motivation is very dynamic as it fluctuates rapidly over time $(\mathrm{CaO}, 2014)$ and it is deeply influenced by multiple intrinsic factors. These include emotions, anxiety, self-perception, self-esteem, false beliefs, attitude, age, gender, willingness to communicate (Boudreau et al., 2018). It is also influenced by extrinsic factors such as teachers, families, peers, the learning environment, and the interactions with natives of the L2, etc. (Al-Hoorie, 2017 ; Csizér et al., 2010 ; Ekiz \& Kulmetov, 2016 ; Kormos \& Kiddle, 2013).

This particularly wide range of characteristics and factors explain why there exist so many individual differences among learners regarding their degree of interest, motivation, effort, perseverance, readiness to take risks, open-mindedness towards other people and cultures, active participation in their language classes, and ultimately, their willingness to communicate with the L2 whenever possible.

\section{Very brief history}

In 1959, the Canadian professors, researchers, and scholars Gardner and Lambert, became the first people to fully grasp the central and foundational role of motivation in the quality of language learning. From the beginning of the 1960s until today, research on this major concept is divided into 3 main periods: the socio-psychological period (1959-1990) lead by Gardner \& Lambert, the cognitive period lead by Dörnyei (1990-2015), and the educational period which we are in and which considers emotions and affect as being central to motivation. 


\section{Main characteristics of motivation}

Al-Hoorie (2017), Cao (2014) and Csizér et al. (2010) underline the dynamic and variational nature of motivation. Indeed, motivation is deeply and constantly influenced by variations in feelings of self-efficacy, self-confidence, as well as the level of interest and comfort generated by the learning environment that educators create.

\section{Emotional states}

Emotions or more accurately emotional states are very complex, as they are psychophysiological reactions to exterior stimuli which, in turn, trigger a large variety of behavioral reactions. The learning environment is particularly rich in such stimuli as teachers, peers, teaching techniques, corrective style, curriculum, and the overall atmosphere of the class have a constant and strong emotional impact on all learners of a same group. But as research has shown since the late 1990s, these stimuli trigger different reactions and behaviors among students, and greatly influence learning through a deep impact on their attentional, cognitive and memory capacities (Boudreau et al., 2018).

It is undeniable that emotions pervade communication and social interactions, and that the more positive they are in the language classroom, the better the learning This is why it is paramount to fully grasp the major role that enjoyment and anxiety play in the quality of language learning in an institutional environment, whether elementary, secondary, or post-secondary.

\section{Enjoyment}

Influenced by Maslow's theories on human motivation and in particular, by his hierarchy of needs, humanistic education in the 1980s considered that, in the realm of cognition, affect is as important as intellect, and that positive emotions are the best facilitators of good learning. Later, a number of researchers applied the main principles of positive psychology to the field of second language learning and teaching, and pointed out that indeed, students learn best when enjoying the whole learning process. Furthermore, Shao et al. (2013) mentioned that to best promote a positive attitude towards L2 learning, teachers need to be gifted with a strong emotional intelligence which keeps them attuned to their students' emotional states and needs. And Dewaele \& MacIntyre (2014) and Dewaele et al. (2016) wrote that the students' main sources of enjoyment in the language classroom are opportunities to succeed, interesting class activities, good teaching skills, and recognition from one's teachers and peers.

\section{Foreign language anxiety}

All researchers (Boudreau et al., 2018) agree that language anxiety is a negative emotional reaction which makes learners feel apprehensive and anxious when reading and writing in another language, or else made to talk and comprehend an L2 in front of their teachers and peers. Dewaele (2013) argues that language anxiety is particularly complex and multidimensional as it is triggered by the learners' self-perception, self-beliefs and self-regulation which, when they are negative, interfere with the learning process.

Language anxiety creates a barrier to the learners' full cognitive functioning by weakening their attention, and by making them doubt their ability to be successful. It interferes with the cognitive functioning of learners as their attention is constantly divided between the language task and the control of their anxiety. In fact, Boudreau et al. (2018) state that language anxiety is a strong predictor of success or failure in L2 learning. It mainly manifests itself through the fear of having to publicly communicate in the L2, the fear of a bad evaluation, and the fear of tests.

In the language classroom, the degree of anxiety that learners feel can depend on the number of languages they know, whether the L2 they study belongs to the same language family as their L1, and their culture. But it mainly depends on the teachers' teaching and corrective strategies, and on the classmates' judgments.

It is also worth mentioning that the effects of anxiety on the learners' motivation is considerable, as it prevents them from noticing and therefore benefiting from the teachers' corrective feedback (Rassaei, 2015). It also diminishes their willingness to communicate, it weakens their self-perception, self-concept, and self-confidence, and it prevents them from taking risks as they fear failure. Anxious language learners are not motivated, and try to avoid language courses as they often experience learned helplessness. 


\section{Self-perception, self-concept and self-confidence}

Today, it is widely recognized that the learners' perception of their own potential to learn a language has a profound influence on their motivation to learn it. If it is positive, then their motivation to keep trying will be high. But if, due to repeated failed experiences, their self-perception is negative, they will not be motivated to keep trying for fear of failing again (Dörnyei, 2009; Kormos et al.).

It is also worth mentioning that the more anxious students are, the more they tend to underestimate their own potentials (Dewaele et al., 2008). Good teachers can make a huge difference if they are guided by the principles of positive psychology and they are fully aware of the importance of giving all students, even the weakest and the most demotivated, opportunities to succeed.

While it is difficult to know if, because their self-concept and their self-confidence are low that their anxiety is high, or if it is because their anxiety is high that their self confidence and self image are low - everybody agrees that anxiety undermines motivation, and that it can be mitigated with the use of good teaching strategies.

\section{False beliefs}

Many researchers point out that, from an early age, students hold preconceptions about their own intelligence and their own capacities to succeed, along with false beliefs about the main constituents of good language learning. Here again, good teachers, who are aware of these kinds of challenges, can manage to dissipate such misleading beliefs with the help of discussions and the use of effective learning strategies.

\section{Attitude}

Dörnyei (2009) and Kormos et al. (2011) as well other researchers stressed that the learners' attitude towards the learned language and the community who speaks it has a profound impact on their motivation to actively study it in and out of school, to take every opportunity to communicate in it, and to embrace the native speakers and their culture with an open mind.

\section{Personality}

It is also interesting to wonder if the learners' personality has an impact on their motivation. But research on the issue is rather scarce. Nevertheless, a number of studies have focused on the link between neuroticism and language anxiety (Dewaele, 2013) and have discarded any link between psychoticism, extroversion and language anxiety (Dewaele, 2013). And because researchers like Dewaele (2002) mention that many anxious language learners are introverts who underestimate their own proficiency and are often reserved and less confident, it is tempting to conclude that they lack motivation due to a tendency to remain silent and talk less than their extroverted peers, who speak more and with more fluidity and ease. But this does not mean that introverts are less motivated, as when they write and read, they are as active and involved as the extroverts. Nevertheless, one cannot deny that the anxiety that many introverts feel, especially when asked to communicate in front of others, may make them appear unmotivated and uninterested even though it is often far from the truth.

Another personality trait that has an impact on motivation is perfectionism. Anxious individuals are quite often perfectionists (Dewaele, 2013), whose fear of making mistakes prevents them from taking risks. And yet, taking the risk of making mistakes is considered to be one of the best strategies good language learners use, as they recognize that using corrective feedback enables them to make progress.

\section{Willingness to communicate (WTC)}

WTC is the desire and initiative learners take to communicate in the L2. According to many researchers like MacIntyre et al. (2003), WTC depends mainly on the learners' apprehension of making mistakes, the perception of their own proficiency, and ultimately, on their self confidence.

In 2014, Cao pursued research on WTC by adopting a socio-cognitive perspective, and identified the influential factors such as integrative motivation, attitude, personality, emotions, gender, and age, to which she added culture, the desire to interact and communicate with the natives of the L2, and the learning environment (teachers, class procedures, peers, etc.).

Moreover, it is important to recognize that all these factors are highly dynamic and they interact with one another at all times so as to constantly impact the learners' motivation. 


\section{Age}

Although it has been long established that younger language learners have a clear phonological, a lexical and a morphosyntactic advantage over later L2 learners, it is less recognized that older learners can reach the same level of proficiency thanks to their greater cognitive maturity, their greater capacity for abstraction and their greater emotional self-regulation abilities (Pfenninger \& Singleton, 2016; Zhengwei \& Kerong, 2019).

But the impact of age on learners' motivation is multifactorial and depends not only on social, cognitive, developmental, linguistic, experiential, and psychological factors, but also on life circumstances (i.e. if you are an immigrant, etc.) and on the learning environment. And what is of particular interest is that in a formal setting, the group dynamic between learners has a major impact (Kormos et al., 2011).

But according to Pfenninger \& Singleton (2016), older learners at the secondary and post secondary levels tend to be more motivated, as they are likely to be more confident, less anxious, and hold a more positive attitude towards the L2 and the learning environment than younger learners from elementary school. Moreover, older learners tend to be more motivated to learn other languages, especially English, as they 'consume' a lot of music, TV programs, films, videos, Internet sites and social network platforms in the language.

\section{Gender}

Today, more and more researchers are interested in understanding why in Anglo-Saxon countries like Canada, Australia, the United States of America and the United Kingdom, at the middle and secondary school level, girls are more motivated than boys when studying certain languages (Kissau). These studies show that boys are as motivated as girls until early adolescence, but the longer they have to pursue the study of certain languages - like French in Canada - the less motivated and interested they become. On the contrary, with age, girls become more and more motivated in the study of such languages.

The above researchers found that girls' motivation is integrative, as they are interested in communicating with natives of the language they learn and in learning about their culture and mores. On the other hand, boys are more instrumentally motivated, and mainly view the practical advantages (i.e. a career) of knowing an L2.

Such major differences between boys and girls are largely due to society's and families' attitudes towards L2 learning, to the boys' perception of certain languages (like French) as being too feminine, to the lack of male language teachers, and to language activities which answer more to the needs and interests of girls.

Such an issue is all the more disappointing, as recent research clearly shows that boys' aptitudes for L2 learning are as good as girls' (Wucherer et Reiterer, 2018).

\section{Extrinsic factors}

Even though this paper does not focus on extrinsic factors such as teachers, families, peers, the learning environment, and interactions with the natives of the L2, they must also be taken into consideration, as they have a major impact on motivation (Al-Hoorie, 2017; Csizér et al., 2010; Ekiz \& Kulmetov, 2016).

\section{References}

Al-Hoorie, A. H. (2017). Sixty Years of Language Motivation Research: Looking Back and Looking Forward. SAGE Open, 7(1), 1-11.

Boudreau, C., MacIntyre P. D., \& Dewaele, J. (2018). Enjoyment and Anxiety in Second Language Communication: An Idiodynamic Approach. Studies in Second Language Learning and Teaching, $8(1), 149-170$.

Cao, Y. (2014). A Sociocognitive Perspective on Second Language Classroom Willingness to Communicate. TESOL Quarterly, 48(4), 789-814.

Csizér, K., Kormos, J., \& Sarkadi, A. (2010). The Dynamics of Language Learning Attitudes and Motivation: Lessons from an Interview Study of Dyslexic Language Learners. The Modern Language Journal, 94(3), 470-487. 
Dewaele, J. M., MacIntyre, P., Boudreau, C., \& Dewaele, L. (2016). Do Girls Have all the Fun? Anxiety and Enjoyment in the Foreign Language Classroom. Theory and Practice of Second Language Acquisition, 2(1), 41-63.

Dewaele, J., \& MacIntyre, P. D. (2014). The Two Faces of Janus? Anxiety and Enjoyment in the Foreign Language Classroom. Studies in Second Language Learning and Teaching, 4(2), 237-274.

Dewaele, J. (2013). The Link Between Foreign Language Classroom Anxiety and Psychoticism, Extraversion, and Neuroticism Among Adult Bi- and Multilinguals. The Modern Language Journal, 97(3), 670-684.

Dewaele, J., Petrides, K. V., \& Furnham, A. (2008). Effects of Trait Emotional Intelligence and Sociobiographical Variables on Communicative Anxiety and Foreign Language Anxiety Among Adult Multilinguals: A Review and Empirical Investigation. Language Learning, 58(4), 911-960.

Dewaele, J. (2002). Psychological and Sociodemographic Correlates of Communicative Anxiety in L2 and L3 Production. International Journal of Bilingualism, 6(1), 23-38.

Dörnyei, Z. (2009). Personality in Second Language Acquisition. Oxford: Oxford University Press.

Ekiz, S., \& Kulmetov, Z. (2016). The Factors Affecting Learners' Motivation in English Language Education. Journal of Foreign Language Education and Technology, 1(1), 1-21.

Gardner, R. C. (2010). Motivation and Second Language Acquisition: The Socio-Educational Model. (Vol. 10). New York, NY: Peter Lang Publishing, Inc.

Kissau, S. (2013). Gender Differences in Second Language Motivation: An Investigation of Micro- and Macro-level Influences. Canadian Journal of Applied Linguistics, 9(1), 73-96.

Kormos, J., Kiddle, T., \& Csizér, K. (2011). Goals, Attitudes, and Self-related Beliefs in Second Language Learning Motivation: An Interactive Model of Language Learning Motivation. Applied Linguistics, 32(5), 495-516.

MacIntyre, P.D., S. Baker, R. Clément et L. Donovan. (2003). Talking in Order to Learn: Willingness to Communicate and Intensive Language Programs. The Canadian Modern Language Review/La Revue Canadienne des Langues Vivantes, 59(4), 589-607.

Pfenninger, S.E. and Singleton D. (2016). Affect Trumps Age: A Person-in-Context Relational View of Age and Motivation in SLA. Second Language Research, 32(3), 311-345.

Rassaei, E. (2015). Oral Corrective Feedback, Foreign Language Anxiety and L2 Development. System, 49, 98-109.

Shao, K., Yu, W., \& Ji, Z. (2013). An Exploration of Chinese EFL Students' Emotional Intelligence and Foreign Language Anxiety. The Modern Language Journal, 97(4), 917-929.

Wucherer, B. V., Reiterer, S. M. (2018). Language is a Girlie Thing, isn't it? A Psycholinguistic Exploration of the L2 Gender Gap. International Journal of Bilingual Education and Bilingualism, 21(1), 118-134.

Zhengwei, P. and Kerong, Q. (2019). The Younger, the Better? A Multi-Factorial Approach to Understanding Age Effects on EFL Phonological Attainment. Journal of Language and Education, $5(1), 29-48$. 


\title{
THE DEVELOPMENT AND PILOTING OF AN INSTRUMENT TO MEASURE NATURE OF SCIENCE (NOS) UNDERSTANDING
}

\author{
Tarisai Chanetsa, \& Umesh Ramnarain \\ Department of Science and Technology Education, University of Johannesburg (South Africa)
}

\begin{abstract}
The study describes the development of an instrument, to measure NOS understandings of science teachers and a subsequent pilot study to test the instrument. The pilot measured NOS understanding of two teachers using a questionnaire that had been developed by the researcher. The objective of the study was to construct a questionnaire that could measure NOS understanding based on the family resemblance approach (FRA). The NOS is a construct that has been defined by various scholars and there exists multiple perspectives. For this study, two schools of thought defining the nature of science: the consensus view (CV) and the reconceptualized family resemblance approach to NOS (RFN) were considered. The CV has been widely accepted for years to represent the NOS through its tenets, and there exists reliable tools to document NOS. Based on the CV researchers developed an instrument, views of nature of science (VNOS), to document NOS understanding. In the past decade, scholars have challenged the CV of NOS and highlighted shortcomings in its tenets. FRA was developed that depicts science in a holistic system with dynamic interactions unlike the CV that represents NOS as independent tenets. From FRA, emerged RFN consisting of social and cultural categories that affect how science is done. The approach of RFN due to its holistic approach will be preferred in this study. The authors of RFN developed a RFN questionnaire to assess views about NOS using a Likert scale. Due to the limitations of the Likert scale, an open-ended approach is preferred in the qualitative analysis of views of NOS as is found in the VNOS form. To collect data on NOS understanding, the researcher compared VNOS and the RFN questionnaire and developed an integrated family VNOS (IFVNOS) questionnaire.

The IFVNOS questionnaire was administered in a pilot test followed by interviews to elaborate on responses. The responses were analysed by two coders and triangulated to ensure reliability. The responses were allocated codes to document NOS understanding, on a range from naïve to explicit understanding. The findings revealed that the IFVNOS questionnaire developed can be used as a tool to measure NOS understanding and more testing is required to assess reliability.
\end{abstract}

Keywords: Views, nature, science, family resemblance.

\section{Introduction}

This paper describes the development of an instrument to measure nature of science (NOS) understandings of science teachers and a subsequent pilot study to test the instrument. The NOS is a construct that has been defined by various scholars and there exists multiple perspectives. For this study, two schools of thought defining the nature of science: the consensus view by Abd-El-Khalick (2013) and the reconceptualized family resemblance approach to NOS (RFN) by Erduran and Dagher (2014) were considered. Based on these two schools of thought, the researcher developed an analytical framework, the integrated family views of nature of science (IFVNOS) and developed a questionnaire to assess views of NOS based on IFVNOS. The aims of the study are listed below.

\subsection{Aims}

- To design an instrument to measure views of NOS based on the consensus view and reconceptualised family resemblance approach to NOS

- To pilot the use of the instrument to measure views of NOS of in-service science teachers

\section{The Nature of science (NOS)}

Research shows that the nature of science (NOS) is a concept that is naively understood globally. Akerson, Abd-El-Khalick, and Lederman (2000) have shown that regardless of level of education, there is an international inadequate realization of what NOS is. The misconceptions of NOS could possibly be due to the fact that there does not exist one explicit definition of what NOS is. Rather it is a concoction of 
attributes and a combination of at least seven aspects as defined by Lederman (1998) known as the tenets of NOS, such as empirical; inferential; creative; theory-driven and tentative to name a few.

These tenets are widely accepted to be a representation of the consensus view of NOS and have been used as the framework for analysing NOS pedagogical views in students and teachers by Kruse, Easter, Edgerly, Seebach, and Patel (2017); and for the analysis of curriculum documents worldwide as conducted by Lederman (2007) to name but a few. Reliable and valid instruments for NOS analysis based on the consensus view have been developed and used by researchers over decades of years such as the views of nature of science questionnaire (VNOS) developed by Lederman, Abd-El-Khalick, Bell, and Schwartz (2002). It is for this reason of reliability and validity that the consensus view will contribute to formulating the framework used to analyse views of NOS in this study.

In more recent times, scholars have challenged the consensus view of NOS and highlighted shortcomings in its tenets as not encompassing economic, political, philosophical, social and financial systems of science as stated by Erduran and Dagher (2014). The family resemblance approach to science (FRA) has been developed to depict science in a holistic system with dynamic interactions. This view of science by Irzik and Nola (2010) adopted the generic definition of family resemblance coined by Wittgenstein in 1958. They proposed four categories of the FRA that reflect NOS as a) activities b) aims and values c) methodologies and methodological rules and d) products, which they substantiated had none of the shortcomings of the consensus view of NOS. Dagher and Erduran (2016) added categories of 'social organisations and interactions', 'political power structures' and 'financial systems' to FRA. This addition was made to highlight that science is impacted by societal and cultural factors. The FRA has a number of authors but the work of Erduran and Dagher (2014) will be considered in this study as their terminology appeals to science education and are applicable for science curriculum. RFN defines NOS using categories of aims and values; methods; scientific practices; scientific knowledge; social certification and dissemination; scientific ethos; social values; professional activities; social organisations and interactions; financial systems; and political power structures.

\section{Conceptual framework}

In designing the integrated aspects of NOS conceptual framework, the researcher analysed both the consensus view tenets and RFN categories. Ideally, the framework to be used in this study should comprise explicit statements such as those in the consensus view as the researcher has found these to be user friendly in content analysis of textbooks. This study forms part of a larger research aimed at improving NOS understanding amongst teachers through the use of textbook analysis. It was found that the consensus view makes use of explicit tenets descriptive of independent NOS aspects, whilst RFN represents a holistic interactive dynamic system of NOS categories. Research in RFN is limited and not widely spread at the time of writing this paper. There is, however, sufficient evidence and reliable sources to validate the use of its instruments in science education. Studies have been carried out in pre-service teacher education courses on NOS in Turkey using the RFN approach by Kaya, Erduran, Aksoz, and Akgun (2019) and findings from this study have contributed to the understanding of how NOS can be incorporated in science teacher education using RFN. The application of RFN to curriculum analysis is not widely spread at this time but has been used in analysing the content of USA and Turkey curricular by Kaya and Erduran (2016). FRA has also been used in investigating coherence about NOS in science curriculum documents of Taiwan as was conducted by Yeh, Erduran, and Hsu (2019).

The researcher has found that within RFN categories, tenets of the consensus view on NOS are embedded. In analysing RFN the researcher found that two categories of RFN have no consensus view tenet representation, that is in the scientific ethos category and social values category. These are defined as the norms that scientists employ in their work as well as in interaction with colleagues and values such as freedom, respect for the environment and social utility respectively. In the framework that is to be developed, it is necessary to represent these two RFN categories using keywords in order to match the format of the consensus view. Keyword analysis is the approach used by the authors of RFN, Kaya and Erduran (2016) when they conducted content analysis of Turkish curriculum statements. Keyword analysis involves the selection of indicative words from the descriptors of categories. For instance, to analyse the social certification and dissemination category, Kaya and Erduran (2016) used the words provided in the description of the category. The category is defined as the social mechanisms through which scientists review, evaluate and validate scientific information through, for example, the peer review systems of journals. Kaya and Erduran (2016) selected keywords such as "peer-review", "validate", "evaluation", as the representative words of the category. From the two categories of scientific ethos and scientific values not represented in the consensus view, the researcher developed the keywords "ethical practices" derived from the definitions provided by the two categories. Ethical practices as keywords have thus been included in the conceptual framework for this study. This framework has been termed the Integrated Family Views Nature of Science (IFVNOS) and comprises (from the CV tenets): empirical, inferential, creativity, tentative, theory-driven, methods, scientific knowledge, social dimension of science, social and cultural embeddedness of science, science vs pseudoscience and derived from RFN, ethical practices. 


\subsection{IFVNOS questionnaire}

To collect views of NOS of the participant teachers, the researcher made use of the views of nature of science questionnaire version C (VNOS C) developed by Lederman et al. (2002). VNOS (C) has been validated by its authors and there exists a high level of confidence in it thus making it an instrument of choice in this research. It has undergone an intensive validation process and revisions from VNOS (A) to VNOS (B) to this version of VNOS (C). The authors have provided crucial logistical and conceptual issues for consideration by researchers using VNOS $(\mathrm{C})$ to ensure its correct administration. The issues to be aware of input into increasing the validity of the research process by ensuring correct use of the instrument with minimal errors. VNOS(C) although valid and verified had shortcomings identified by the researcher because of its basis solely on the consensus view. The need then arose to incorporate aspects of the family resemblance approach into $\operatorname{VNOS}(\mathrm{C})$ that were found to be lacking in the consensus view.

The authors of RFN Kaya at al. (2019) developed a questionnaire to assess views about NOS reflecting the five RFN categories and incorporated into the questionnaire educational applications. The RFN questionnaire comprises seventy questions with five options of responses which are 'totally agree', 'agree', 'not sure', 'disagree', and 'totally disagree' from which respondents select one option. One of the limitations of this 5-Likert scale is that the opinion and alternative responses of the respondents is not captured. Kaya et al. (2019) acknowledge the oversimplification of the instrument for the nature of data to be collected and argue that their interest was in developing an instrument for RFN. In view of this oversimplification as noted above the author of this research opted for open ended questions extracted from the $\operatorname{VNOS}(\mathrm{C})$ questionnaire, numbers 1-9 below. Questions relating to family resemblance that were not represented in $\operatorname{VNOS}(\mathrm{C})$ were added to the questionnaire, numbers 10-12 below. This formed the integrated family views of nature of science (IFVNOS) questionnaire.

1. What, in your view, is science? What makes science (or a scientific discipline such as physics, biology, etc.) different from other disciplines of inquiry (e.g., religion, philosophy)?

2. Do all scientific disciplines such as physics, astronomy, biology and chemistry use the same scientific method? Explain your answer

3. Define what an experiment is. Does the development of scientific knowledge require experiments?

If yes, explain why. Give an example to defend your position. If no, explain why. Give an example to defend your position.

4. After scientists have developed a scientific theory (e.g., atomic theory, evolution theory), does the theory ever change? If you believe that scientific theories do not change, explain why. Defend your answer with examples. If you do believe that scientific theories do change: a) explain why theories change? b) explain why we bother to learn scientific theories? Defend your answer with examples.

5. Describe the purpose of theories, laws and models in producing scientific knowledge

6. Science textbooks often represent the atom as a central nucleus composed of protons (positively charged particles) and neutrons (neutral particles) with electrons (negatively charged particles) orbiting that nucleus. How certain are scientists about the structure of the atom? What specific evidence do you think scientists used to determine what an atom looks like?

7. Scientists perform experiments or investigations when trying to find answers to the questions they put forth. Do scientists use their creativity and imagination during their investigations? If yes, then at which stage of the investigations do you believe scientists use their imagination and creativity: planning and designing, data collection, after data collection? Please explain why scientists use creativity and imagination during their investigations. If you believe that scientists do not use imagination and creativity, please explain why. Provide examples if appropriate.

8. It is believed that about 65 million years ago the dinosaurs became extinct. Of the hypotheses formulated by scientists to explain the extinction, two enjoy wide support. The first, formulated by one group of scientists, suggests that a huge meteorite hit the earth 65 million years ago and led to a series of events that led to the extinction. The second hypothesis, formulated by a second group of scientists, suggests that massive and giant volcanic eruptions were responsible for the extinction. How are these different conclusions possible if scientists in both groups have access to and use the same set of data to derive their conclusions?

9. Some claim that science is infused with social and cultural values. That is, science reflects the social and political values, philosophical assumptions, and intellectual norms of the culture it is practiced. Others claim that science is universal. That is, science transcends national and cultural boundaries and it is not affected by social, political and philosophical values and intellectual norms of the culture in which it is practiced. If you believe that science reflects social and cultural values, explain why. Defend your answer with examples. If you believe that science is universal, explain why. Defend your answer with examples.

10. Scientists engage in professional activities such as attending conferences and doing publication reviews. Why do scientists engage in such activities?

11. Scientists work in organisations or establishments such as universities and research centers, how are they organized in these institutions? 
12. Teaching epistemic, cognitive, social and cultural values should be core components of the science curriculum. Do you agree or disagree with this statement? Provide a reason for your opinion.

\section{Methodology}

The pilot study to test the IFVNOS questionnaire and its readability, adopted a structural content analysis approach. Two participant teachers were purposefully selected based on availability, access to online teaching of either natural sciences, life sciences or physical sciences. Teachers were required to complete the IFVNOS questionnaire online. On receipt of each questionnaire, the researcher drafted an interview schedule aimed at clarifying aspects of the respondents ' answers that may not have been clear or were posing conflicting messages to an understanding of NOS aspects.

\subsection{Content analysis}

"Content analysis has been defined as a systematic replicable technique for compressing many words of text (or other meaningful matter) into fewer categories based on explicit rules of coding" (Krippendorff, 1980). The qualitative data collected from IFVNOS questionnaire and the interview for each teacher were coded for NOS aspects following Saldana`s coding techniques. According to Saldana (2009) a code serves to summarize or condense data rather than simply reducing it. NOS aspects were assigned to every response provided by participants, in some instances responses comprised more than one NOS aspect. IFVNOS responses and interview responses were assigned NOS aspects independently. The units of similar NOS aspects were then grouped together for analysis to allocate a rating describing the degree of explicitness or implicitness of the NOS representation.

\subsection{Scoring rubric}

Points are allocated by the researcher from a scale of positive three points, explicit representation, to negative three points, explicit naïve representation, based on Abd El-Khalick's scoring rubric (2013). A cumulative score ranging from -33 to +33 is then assigned to the NOS understanding of each teacher. The higher the cumulative score, the more explicit, informed and consistent is the representation of NOS.

\subsection{Reliability and validity}

To ensure reliability in content analysis, Abd-El-Khalick (2013) stipulates the use of more than one rater to achieve inter rater reliability of the findings. Two raters were used in this study and each one reviewed and analysed the data independently, assigning scores of NOS understanding to the units of analysis. There was complete agreement between the findings of the two raters indicating a high level of reliability of the findings. Conducting an interview post evaluation of IFVNOS responses and triangulation of findings from both questionnaires contributed to some level of validity in the findings.

\section{Findings}

The in-service science teachers were found to have an inadequate overall understanding of the nature of science. The cumulative possible score of NOS understanding of +33 represents an explicit and informed understanding. Although the teachers in some instances displayed an explicit, informed understanding of some NOS aspects, these scores were lowered by mixed understanding or naive understanding in other instances. The table below displays some quotations from teacher responses and corresponding scores allocated by the researcher.

Table 1. Excerpts of NOS responses of teachers and score assigned.

\begin{tabular}{|l|l|l|l|}
\hline Teacher & $\begin{array}{l}\text { Cumulative } \\
\text { score } \mathbf{3 3}\end{array}$ & Example of excerpts & $\begin{array}{l}\text { NOS } \\
\text { understanding }\end{array}$ \\
\hline $\begin{array}{l}\text { Physical } \\
\text { Sciences }\end{array}$ & +13 & $\begin{array}{l}\text { Scientific theories: "Theories do change, theories are developed on } \\
\text { knowledge that are known, but often limited. Theories cannot always } \\
\text { be proven wrong, but they can't be proven right either. The lack of } \\
\text { concrete evidence proving a theory right, means that a theory can } \\
\text { change. } \\
\text { Certain models have been adapted and changed, but older models can } \\
\text { be useful to explain certain aspects" }\end{array}$ & $\begin{array}{l}\text { explicit, } \\
\text { informed }\end{array}$ \\
\hline
\end{tabular}

\section{Discussion of findings}

The inadequate NOS understanding of the teachers is commensurate with findings by Govender and Zulu (2017) in the South African context. The small number of teachers used in the pilot does not provide enough indicative findings on the reliability of the instrument. The aim of the pilot was to test if 
IFVNOS can be used to capture views of NOS and this was achieved. IFVNOS will be used on a larger number of teachers forming part of a study to improve NOS understanding through textbook analysis and the reliability of the instrument can then be commented on.

\section{Conclusion}

This paper reported on the development of an instrument to measure views of NOS that merged the consensus view and RFN. The IFVNOS questionnaire was tested on two teachers to produce findings that are commensurate with results by other researchers, that the NOS is one that is naively understood by teachers in South Africa as found by Gwebu (2015), Govender and Zulu (2017). It can be concluded from the findings of the pilot that the IFVNOS questionnaire can be used to measure NOS understanding and that there is still a need for professional development programs to improve the NOS understanding of in-service teachers.

\section{References}

Abd-El-Khalick, F. (2013). Coding and scoring instructions. Nature of science textbook analysis methods.

Abd-El-Khalick, F. (2013). Target nature of science aspects. Nature of science textbook analysis methods, $1-2$.

Akerson, V. L., \& Abd-El-Khalick, F., \& Lederman, N. G. (2000). Influence of a reflective explicit activity based approach on elementary teachers' conceptions on nature of science. Journal Research of Science Teachers, 34(7), 673-699.

Bantwini, B., \& Kurup, R., \& Linneman, S. R., \& Lynch, P., \& Webb, P. (2003). South African science teachers 'perception on the nature of science. African Journal of Research in SMT Education, 7, 35-50.

Dagher, Z. R., \& Erduran, S. (2016). Reconceptualizing the nature of science for science education. Why does it matter? Science and education, 25, 147-164. doi:10.1007/s11191-015-9800-8

Erduran, S., \& Dagher, Z. (2014). Family resemblance approach to characterizing science. Reconceptualizing the nature of science for science education (pp. 19-40). Netherlands: Springer.

Govender, G., \& Zulu, D. (2017). Natural sciences junior high school teachers` understanding of the nature of science and its impact on their planning of lessons. Journal of Baltic Science Education, 16(3), 366-378.

Gwebu, M. I. (2012). The understanding of the nature of science among physical sciences teachers from the Badplaas circuit of the Mpumalanga Province (Master's thesis, University of Johannesburg, Johannesburg, South Africa). Retrieved from https://ujcontent.uj.ac.za/vital/access/manager/ Index?site_name=Research $\% 20$ Output

Irzik, G., \& Nola, R. (2010). A family resemblance approach to the nature of science for science education. Science and Education, 20(7), 591-607.

Kaya, E., \& Erduran, S. (2016). From FRA to RFN, or How the family resemblance approach can be transformed for curriculum analysis on nature of science. Science \& Education, 25, 1115-1133.

Kaya, E., \& Erduran, S., \& Aksoz, B., \& Akgun, S. (2019). Reconceptualised family resemblance approach to nature of science in pre-service science teacher education. International Journal of Science Education, 41(1), 21-47.

Krippendorff, K. (1980). Content analysis: An introduction to its methodology (2nd ed.). Thousand Oaks, CA: Sage.

Kruse, J.W., \& Easter, J.M., \& Edgerly, H.S., \& Seebach, C., \& Patel, N. (2017). The impact of a course on nature of science pedagogical views and rationales comparing preservice teachers in their first versus second experience. Science and Education, 26, 613-636. doi:10.1007/s11191-017-9916-0

Lederman, N. G., \& Abd-El-Khalick, F., \& Bell, R. L., \& Schwartz, R. S. (2002). Views of nature of science questionnaire: toward valid and meaningful assessment of learners`conceptions of nature of science. Journal of Research in Science Teaching, 39(6), 497-521.

Saldana, J. (2009). The coding manual for qualitative researchers. An Introduction to Codes and Coding (pp. 1-31). London: SAGE Publications.

Yeh, Y., \& Erduran, S., \& Hsu, Y. (2019). Investigating Coherence About Nature of Science in Science Curriculum Documents. Science \& Education, 28, 1-20. 


\title{
PROCESSABILITY APPROACHES TO RECEPTIVE THIRD LANGUAGE ACQUISITION: IMPLICATIONS FOR MULTILINGUAL CLASSROOMS
}

\author{
Helen Forsyth \\ Faculty of Education, Free University of Bozen-Bolzano (Italy)
}

\begin{abstract}
Existing research indicates a qualitative difference between Second Language Learning and Third Language Acquisition, and certain psycholinguistic and developmental aspects to multilingual learners merit investigation. The present paper examines stages in receptive learner acquisition of English as a Third Language at Italian-medium primary schools in South Tyrol in Italy employing a picture selection task and implicational scaling analysis. It highlights the role that processing approaches to acquisition proposing constraints on developmental readiness and cross-linguistic influence may play for the emergence of receptive competence in morpho-syntactic structures.
\end{abstract}

Keywords: Teachability hypothesis, processability theory, third language acquisition, receptive competence, multilingualism.

\section{Introduction}

An increasing proportion of the world's population is learning English as a third or, additional, language because of mass migration, globalisation and technological advances, or the presence of autochthonous minority languages. Inevitably, questions arise concerning decisions on didactic approaches to an eventual third language taken by schools in these regions (Cenoz \& Gorter, 2005). Research into bilingualism has found existing competence in two languages to create advantages for Third Language Acquisition (TLA), which benefits from more language learning experience (Golonka, 2010), the effects of bilingualism on cognition (Bialystok, 2009), and access to two linguistic systems (Cenoz, 2003). Competent users of two languages may also display more positive attitudes towards learning a third language potentially thanks to sociolinguistic factors (Brohy, 2001). From a psycholinguistic perspective, bilingual competence is said to feature non-linearity, individual variation, and interdependence (De Angelis, 2007; Jessner, 2008). TLA and multilingualism has emerged as a sub-field in its own right, separate to that of bilingualism, and has produced a variety of models and theories focusing on the role of cross-linguistic influence (Rothman \& Cabrelli Amaro, 2010), metalinguistic knowledge (Herdina \& Jessner, 2002), and the extent and nature L1 and L2 influence in TLA (Bardel \& Falk, 2007).

\section{Literature review}

A study of receptive acquisition from a processability perspective of morpho-syntactic structures in early stage third or additional language learners at primary school presents a little-explored means of investigating the proposed qualitative difference between Second Language Acquisition (SLA) and TLA. Processability Theory (PT) (Pienemann, 1998, 2005) is a cognitive approach to language acquisition that takes the theory-building capacity of the learner to be the driving force behind the acquisition of language competence, and seeks to explore the means by which linguistic skills become automatic, or procedural (Jordan, 2004). PT has its origins in the morpheme order acquisition studies carried out in the 1970s (Bailey, Madden \& Krashen, 1974; Dulay \& Burt, 1973), which took inspiration from studies on first language acquisition conducted in naturalistic settings (Brown, 1973; Cazden, Cancino, Rosansky \& Schuman, 1975). Researchers found certain morpho-syntactic structures to emerge in the same set order for both L1 and L2 learners regardless of input, creating the L1=L2 hypothesis (Jordan, 2004) - a phenomenon that was attributed to unknown mechanisms at the time. Attention was also turned to SLA learners of different native language (L1) backgrounds (Pica, 1983; Pavesi, 1986) with the aim of exploring whether second language (L2) learning could be a universal and predetermined process independent of the L1 variable. As attention was increasingly applied to L2 learning contexts, Pienemann devised the Teachability Hypothesis (TH), which seeks to provide 'a set of psycholinguistic background information on which teaching methods 
should be based. ' (Pienemann, 1989:76), and elaborated the broader framework of PT. The TH's treatment of the theory-practice interface has since informed teaching methodology and syllabus design, which previously tended to rely on intuitive ideas for grading levels of difficulty in materials. A substantial body of empirical evidence supports the TH (Ellis, 2008: Boss, 1996; Mansouri \& Duffy, 2005), and it continues to represent a theoretical model with strong predictive power for the acquisition of morpho-syntactic structures (Jordan, 2004).

\section{Premises of PT}

PT conceives L2 acquisition in terms of sequential progression through a series of stages, with Stage 1 comprising the processing skills that are first acquired, and Stages 5 or 6 the last skills to be acquired. The learner is said to pass upwards through the stages and activate the procedures in a cumulative fashion. Figure 1 (without numbered stages) illustrates the schedule for interlanguage production.

Figure 1. Developmental stages for L2 English morphology with examples. Source Di Biase et al. (2015)

\begin{tabular}{|c|c|c|c|}
\hline \multicolumn{2}{|c|}{ Processing Procedure } & Structure & Example \\
\hline \multicolumn{2}{|l|}{ S-BAR Procedure } & $\begin{array}{l}\text { e.g., subjunctive } \\
\text { marking in } \\
\text { subordination }\end{array}$ & $\begin{array}{l}\text { I suggest be eat less. } \\
\text { It's time yout left. }\end{array}$ \\
\hline \multicolumn{2}{|l|}{ Sentence Procedure } & $\begin{array}{l}\text { SV agreement; } \\
3^{\text {rd }} \text { person } s g-s\end{array}$ & Peter loves rice. \\
\hline \multirow[b]{2}{*}{ Phrasal Procedure } & NP Procedure & $\begin{array}{l}\text { phrasal plural } \\
\text { marking }\end{array}$ & $\begin{array}{l}\text { these girls } \\
\text { many dogs } \\
\text { three black cats }\end{array}$ \\
\hline & VP Procedure & $\begin{array}{l}\text { AUX + V: } \\
\text { have }+\mathrm{V} \text {-ed } \\
\text { MOD + V } \\
\text { be + V-ing }\end{array}$ & $\begin{array}{l}\text { they bave jumped } \\
\text { you can go } \\
\text { I am going }\end{array}$ \\
\hline \multicolumn{2}{|l|}{ Category Procedure } & $\begin{array}{l}\text { past - } t d \\
\text { plural -s } \\
\text { possessive 's } \\
\text { verb -ing }\end{array}$ & $\begin{array}{l}\text { Mayy jumped } \\
\text { my brothers narking } \\
\text { Mary's car } \\
\text { be eating }\end{array}$ \\
\hline Lemma access & & $\begin{array}{l}\text { single words } \\
\text { formula }\end{array}$ & $\begin{array}{l}\text { station bere } \\
\text { my name is Pim }\end{array}$ \\
\hline
\end{tabular}

In addition to those within the developmental dimension, certain structures display a degree of variation (Dyson, 2004) and thus belong to the variational dimension, which is said to be more responsive to well-timed instruction and free of the constraints affecting the teachability of developmental features (Pienemann, 1989).

\section{Reception (decoding) and production (encoding)}

Differences may arise between learner decoding (receptive) processing and encoding (productive) processing. On a chronological level, the general assumption in SLA/TLA is that comprehension emerges earlier than production of morpho-syntactic structures (Clark \& Hecht, 1983; Chondrogianni \& Marinis, 2012; Gass, 2017). Another aspect is the concept of separate workspaces for production and comprehension in the brain. Larsen-Freeman finds evidence for 'overlap between a comprehension grammar and a production grammar' (2002:282), while Levelt (1989) conceptualises language production and comprehension to involve two separate modules. These issues could lead to asynchronies that language teachers need to be aware of.

\section{Transfer}

Considerable evidence for cross-linguistic influence has been gathered from bilinguals and a variety of models have been elaborated for TLA, including the Cumulative Enhancement Model (Flynn et al., 2004), the Typological Primacy Model (Rothman, 2013), amongst others. It is reasonable to expect the possibility of transfer effects to be increased in tri- or multilinguals. The PT-aligned Developmentally Moderated Transfer Hypothesis (DMTH) (Pienemann \& Lenzing, 2015) addresses questions of transfer, which is said to be constrained by the capacity of the developing target language processor (Lenzing, 2021). 


\section{Study objectives}

Research questions guiding the cross-sectional study in question are the following:

1) In the groups tested, does receptive grammar develop in the same stages found for productive grammar and which are predicted by PT?

2) Do the L3 English study participants transfer features from their L1 and/or L2 to English? If so, under which constraints does transfer take place?

PT-related research has typically drawn on empirical productive learner data, leaving receptive learner data and reception-production interaction mostly unexplored (Ellis, 2008). This study attempts to operationalize the emergence of morphological structures in third language (L3) learners focusing on receptive data.

\section{Methodology}

The following six Category Procedure (Stage 2), one Phrasal Procedure (Stage 3) and two Sentence Procedure (Stage 4) phenomena lending themselves to testing learners' comprehension were selected:

Stage 2 Subject Verb Object (SVO), Plural (Plu), Negative (Neg), Genitive (Gen) or Possessive -s, Pronoun Subject (ProSbj) and Possessive Determiner (Poss)

Stage 3 Pronoun Object (ProObj)

Stage 4 Copula Verb Agreement (AgrC) and $3^{\text {rd }}$ person singular Verb Agreement (AgrV)

Instrument for observing emergence was the Early Language and Intercultural Acquisition Studies Grammar Test (ELIAS GT) versions A and B (Kersten, Piske, Rohde, Steinlen \& Weitz, 2010) - a picture selection task (3 multiple choice options: correct/incorrect/distractor). The two A and B testing sessions were administered 7 days apart to maximise the concentration span of the participants. The ELIAS GT relies on morpho-syntactic contrasts and measures learners' knowledge of nine morpho-syntactic structures by instructing them to match orally presented prompts containing a target structure with pictures representing the propositional content of this prompt (Buyl \& Housen, 2015). Each prompt is accompanied by three drawings: one representing the prompt, a second an error that contrasts with the prompt grammatically, and a third functions as a distractor that depicts a different propositional content to the prompt. Two intact, mixed-gender groups of 7-8 year olds (group 1, n=42), and 9-10 year olds (group 2, $\mathrm{n}=32$ ) attending an Italian-language primary school formed the sample. They receive 4 weekly lessons of English from in the first school year, at 5-6 years old. The population investigated displays endogenous bilinguality (presence of L2 community) for Italian and German, and English is an exogenous language (absence of L3 community) (Hamers \& Blanc, 2000). An emergence criterion of at least 5 out of $6(\geq 5 / 6)$ target-like responses was chosen to mark emergence of a production structure, classed as the "first systematic use" (Pienemann, 1984:191). Scores of $\geq 5 / 6$ and 6/6 responses were recorded for both groups. Implicational scaling, the preferred method of analysis in PT studies (Pienemann, 2005), which seeks to arrange the morpho-syntactic structures into a hierarchy whereby the emergence of one structure implies the previous emergence of one or more structures for each learner (Ellis, 2008), was used. A coefficient of scalability (c scal) was calculated to establish whether the data are truly scalable and unidimensional and can therefore support the PT hierarchy, with the lower threshold set at 0.60 (Hatch \& Lazaraton, 1991).

\section{Results}

The first and second matrices for each pair achieved different results in terms of scalability:

Matrix 1; $\geq 5 / 6$ correct $n=42$ (group 1): c scal 0.5000 (non-scalable)

Matrix 2; $\mathbf{6} / 6$ correct $n=42$ (group 1): c scal 0.66672 (scalable)

Matrix 3; $\geq 5 / 6$ correct $n=32$ (group 2): c scal 0.51875 (non-scalable)

Matrix 4; $\overline{6} / \mathbf{6}$ correct $n=32$ (group 2): $\mathrm{c}$ scal 0.74181 (scalable)

In both sample groups, the $\geq 5 / 6$ emergence criterion yielded non-valid scalability, while the $6 / 6$ emergence criterion category achieved the required validity. One particular deviation in the findings for the $\geq 5 / 6$ criterion was the mode (10 participants) for Matrix 3, whereby acquisition of the Stage 4 Copula AgrC took place before Stage 3 ProObj.

\section{Interpretation}

It appears that the more the responses display target-like accuracy, the more they adhere to developmental trajectory predicted for the PT Stages 2-4. There is some intra-stage variability, especially in the older group, who may be entertaining a wider variety of options for comprehension in their Hypothesis Space (Pienemann, Kessler \& Itani-Adams, 2011). Regarding transfer, German is typologically more similar to English than Italian (Hakansson, 2017) and overlaps more frequently than Italian in terms of morpho-syntax, as well as phonology, something that may play an important role in comprehension tasks. However, this study found that possible facilitative transfer from L2 German does not necessarily aid 
accuracy in the comprehension of certain structures such as the $3^{\text {rd }}$ person possessive determiner (Poss), indicating that learners were not at the developmental stage to benefit from facilitative transfer for this structure. DMTH-constrained transfer is said to occur only from Stage 3 of the PT hierarchy (Buttkewitz, 2018). Lower scores for Poss feature more in the younger sample group. There was evidence of learners making recourse to facilitative transfer from L2 German for the Gen ' $s$ morpheme and $3^{\text {rd }}$ person ProSbj, especially for the older group. This would support the DMTH, as older learners are more likely to have arrived at Stage 3 in the PT hierarchy.

\section{General teaching implications and future research}

There are a number of possible teaching implications deriving from PT-related research, which stresses the need for teachers to deliver lessons that respect learners' developmental readiness and to wait for one structure to be acquired by the class before moving on to the next, both for production and reception. Concerning teacher training, findings from PT-related studies can offer teachers increased awareness of their students' interlanguage development and orientation, consequently predicting and classifying nontarget-like language and adopting realistic expectations of achievement. Regarding methodology, formfocused instruction may take a developmentally moderated approach with the aim of determining the items to target at any given point in time, and successfully utilize findings from PT research via Developmentally Moderated Focus on Form (Di Biase, 2008). Task-Based Language Learning (Norris \& Ortega, 2000; Willis \& Willis, 2007) is highly compatible with PT and the TH because it may be geared towards classes involving different stages of development. Further research may reveal whether data collected within the PT framework for comprehension correspond with production data chronologically. Additional research would also be needed to examine the factors involved in the acquisition of variational features in multilinguals and elaborate guidelines for identification of these features, as well as testing the DMTH for other multilingual contexts. The formulation of explicit definitions of emergence for receptive comprehension, and the devising of self-paced reading/listening or eye-tracking tasks to target online processing would also be of value. Though the study outlined is purely descriptive, third language teachers in contexts with similar language constellations may be prompted to reflect on the architecture of the language processors of their multilingual students and consequently put any pedagogically-attuned predictions into practice.

\section{References}

Bailey, M. \& Krashen, S. (1974). Is there a 'natural sequence' in adult second language learning? Language Learning, 21(2), 235-43.

Bialystok, E. (2009). Bilingualism in development. Language, literacy, and cognition. $7^{\text {th }}$ printing. Cambridge: Cambridge University Press.

Boss, B. (1996). German grammar for beginners: The teachability hypothesis and its relevance to the classroom. In Sola, C. A., Rolin-Ianziti, J. \& Sussex, R. (Eds.) "Who's afraid of teaching grammar? Working papers in applied linguistics, 1, 93-103.

Brohy, C. (2001). Generic and/or Specific Advantages of Bilingualism in a Dynamic Plurilingual Situation: The Case of French as Official L3 in the School of Samedan (Switzerland). International Journal of Bilingual Education and Bilingualism 4(1), 38-49.

Buttkewitz, P. (2018). Acquiring English as a Third Language: A Processability Perspective (Doctoral dissertation, Universität Paderborn). Retrieved from https://digital.ub.unipaderborn.de/hs/content/titleinfo/2908115

Buyl, A. \& Housen, A. (2015). Developmental stages in receptive grammar acquisition: A Processability Theory account. Second Language Research, 31(4), 523-550.

Cazden, C., Cancino, H., Rosansky, E., Schuman, J. (1975). "Second Language Acquisition Sequences in Children, Adolescents and Adults". Cambridge, Mass.: Harvard University.

Cenoz, J. (2003). The additive effect of bilingualism on third language acquisition: A review. International Journal of Bilingualism, 7(1), 71-87.

Cenoz, J. \& Gorter, D. (2005). Trilingualism and minority languages in Europe. International Journal of the Sociology of Language. 171, 1.

Chondrogianni, V. \& Marinis, T. (2012). Production and processing asymmetries in the acquisition of tense morphology by sequential bilingual children. Bilingualism: Language \& Cognition 15, 5-21.

Clark, E. V. \& Hecht, B. F. (1983). Comprehension, Production and Language Acquisition. Annual Review of Psychology. 34, 325-349.

De Angelis, G. (2007). Third or Additional Language Acquisition. Multilingual Matters. Berlin: De Gruyter. 
Di Biase, B. (2008). Focus-on-form and development in L2 learning. In Kessler, J.-U. (Ed.), Processability approaches to second language development and second language learning (pp. 197-219). Newcastle: Cambridge Scholar Publishing.

Di Biase, B., Kawaguchi, S. \& Yamaguchi, Y. (2015). The development of English as a second language. In Bettoni, C. \& Di Biase, B. (Eds.), Eurosla Monograph Series, 3, 85-115. Amsterdam.

Dulay, H. \& Burt, M. (1973). Should we Teach Children Syntax? Language Learning, 23, 245-258.

Dyson, B. (2004). Developmental style in second language processing: A study of inter-learner variation in the acquisition of English as a Second language. (Doctoral dissertation, University of Western Sydney). Retrieved from https://researchdirect.westernsydney.edu.au/slandora/object/uws:817/datastream/PDF/view

Ellis, R. (2008). The Study of Second Language Acquisition (2 ${ }^{\text {nd }}$ ed). Oxford: Oxford University Press.

Flynn, S., Foley, C. \& Vinnitskaya, I. (2004). The Cumulative-Enhancement Model for Language Acquisition: Comparing Adults' and Children's Patterns of Development in First, Second and Third Language Acquisition of Relative Clauses. International Journal of Multilingualism,

Gass, S. (2017). Input, Interaction, and the Second Language Learner. New York: Routledge.

Golonka, E. (2010). The Influence of Prior Language Learning Experiences on Learning of Unrelated or Distantly Related Languages. Russian Language Journal, 60, Special Issue. American Councils for International Education.

Hakansson, G. (2017). The Typological Challenge in PT. Dyson, B. \& Hakansson, G. (Eds.), Understanding Second Language Processing: A focus on Processability Theory (Bilingual Processing and Acquisition (BPA), Band 4. Amsterdam: John Benjamins, 79-103.

Hamers, J. \& Blanc, M. (2000). Bilinguality and Bilingualism. Cambridge: Cambridge University Press.

Hatch, E. \& Lazaraton, A. (1991). The Research Manual. Boston, MA: Heinle \& Heinle.

Herdina, P. \& Jessner, U. (2002). A Dynamic Model of Multilingualism: perspectives of change in psycholinguistics. Multilingual Matters 121. Berlin: De Gruyter.

Jessner, U. (2008). Teaching third languages: Findings, trends and challenges. Language Teaching, 41(1), $15-56$.

Jordan, G. (2004). Theory Construction in Second Language Acquisition. Amsterdam: John Benjamins.

Kersten, K., Piske, T., Rohde, A., Steinlen, A. \& Weitz, M. (2010). Early Language and Intercultural Acquisition Studies (ELIAS). Multilateral Comenius Project funded by the EU.

Larsen-Freeman, D. (2002). Making sense of frequency. Studies in Second Language Acquisition 24: 275285.

Mansouri, F. \& Duffy, L. (2005). "The pedagogic effectiveness of developmental readiness in ESL grammar. Australian Review of Applied Linguistics, 28(1), 81-99.

Norris, J. M. \& Ortega, L. (2000) Effectiveness of L2 Instruction: A Research Synthesis and Quantitative Meta-analysis. Language Learning 50(3), 417 - 528.

Pavesi, M. (1986). Markedness, discourse modes and relative clause formation in a formal and an informal context. Studies in Second Language Acquisition, 8, 38-55.

Pica, T. (1983). Adult acquisition of English as a second language under different conditions of exposure. Language Learning, 33, 465-497.

Pienemann, M. (1984). Psychological Constraints on the Teachability of Languages. Studies in Second Language Acquisition 6(2), 186-214.

Pienemann, M. (1989). Is language teachable? Psycholinguistic experiments and hypotheses. Applied Linguistics, 10, 52-79.

Pienemann, M. (1998). Language processing and second language development: Processability theory. Amsterdam: John Benjamins.

Pienemann, M. (2005). An introduction to Processability Theory. In M. Pienemann (Ed.), Cross-linguistic Aspects of Processability Theory, 1-60. Amsterdam: John Benjamins.

Pienemann, M. (2015). An Outline of Processability Theory and its Relationship to other Approaches to SLA. Language Learning, 65(1), 123-151.

Pienemann, M. \& Lenzing, A. (2015). Processability Theory. In Van Patten, B. \& Williams, J. (Eds.). Theories in second language acquisition: an introduction, 159-179. New York: Routledge.

Pienemann, M., Kessler, J-U. \& Itani-Adams, Y. (2011). Comparing levels of processability across languages. International Journal of Bilingualism, 15(2), 128-146.

Rothman, J. (2013) "Linguistic and cognitive motivations for the Typological Primacy Model (TPM) of third language (L3) transfer. Timing of acquisition and proficiency considered". Bilingualism: Language and Cognition, 18(2), 179-190.

Rothman, J. \& Cabrelli Amaro, J. (2010). "What variables condition syntactic transfer? A look at the L3 initial state". Second Language Research, 26(2), 189-218.

Willis, D. \& Willis, J. (2007) Doing Task-based Teaching. Oxford: Oxford University Press. 


\title{
COGNITIVE AND LINGUISTIC SKILLS ASSESSMENT PROTOCOL: ADAPTATION AND VALIDATION FOR EUROPEAN PORTUGUESE
}

\author{
Inês Martinss ${ }^{1}$, Cristiane Lima Nunes ${ }^{1}$, Simone Aparecida Capellini ${ }^{2}$, \\ \& Graça S. Carvalho ${ }^{1}$ \\ ${ }^{1}$ University of Minho - Child Studies Centre CIEC (Portugal) \\ ${ }^{2}$ São Paulo State University LIDA (Brazil)
}

\begin{abstract}
Linguistic and Cognitive skills play an essential role in the development of communication, language and literacy. Therefore, their assessment of school children is crucial since it allows the child's cognitive and linguistic profile characterisation, according to the school year she attends.

This study intended to describe the adaptation and validation process of the instrument - Cognitive and Linguistic Skills Assessment Protocol. This Protocol was adapted from a Brazilian (Portuguese) version to a European Portuguese version to evaluate the cognitive-linguistic skills of school children $\left(1^{\text {st }}\right.$ to $5^{\text {th }}$ grade). It consists of two versions, the collective version and the individual version.

The collective version consists of writing, arithmetic, auditory processing and visual processing skills; the individual version consists of reading, metalinguistic, auditory processing, visual processing and processing speed skills.

After adapting the linguistic aspects (morphosyntactic and semantic), a pilot study was carried out to verify whether the instrument was well-adapted and easy to understand for the study's target population.

The sample consisted of a class for each school year, excluding children with special educational needs or intellectual/auditory deficits. A total of 75 children were evaluated: 12 children of the $1^{\text {st }}$ grade; 18 of the $2^{\text {nd }}$ grade; 15 of the $3^{\text {rd }}$ grade; 15 of the $4^{\text {th }}$ grade; and 15 of the $5^{\text {th }}$ grade. The results showed that the protocol was, in general, well adapted.

The instrument was then applied to a larger sample ( 2 classes per school year) in a total of 157 children (without special educational needs or intellectual/auditory deficits), and the data were processed in the statistical program IBM SPSS.

In general, the mean values were the expected ones in all subtests of the Protocol Collective Version and some tests of the Individual Version, from the $1^{\text {st }}$ to the $4^{\text {th }}$ grade, but not the $5^{\text {th }}$ grade, which showed non-expected mean values.

This work provided the possibility for developing the subsequent phase of the study, where percentiles will be calculated to obtain the standard/normalised values to classify children's performance as standard, above average or lower than expected.
\end{abstract}

Keywords: Cognitive-linguistic skills, validating, protocol, school children.

\section{Introduction}

The development of cognitive-linguistic competencies is fundamental for literacy development (Su et al., 2017). So, it is important that children, with the transition to the early years of schooling, have acquired the necessary skills to reach all stages of the school process, from the acquisition of reading and writing. Children should develop skills that allow them to associate, memorize, classify, interpret, compare elements (Ferreira \& Tabaquim, 2017) and develop phonological awareness, knowledge of alphabet letters (Salvador \& Martins, 2017; Caravolas et al., 2012) and the rapid appointment (Caravolas et al., 2012). Phonological awareness is essential in the literacy process because children have to associate a phoneme (auditory) with a grapheme (visual) in order to be able to read/write (Andrade, Andrade \& Capellini, 2014; Germano \& Capellini, 2015; Oliveira, Germano \& Capellini, 2016). Pre-school education plays a vital role in developing these skills (Moniz, 2009; Ferreira \& Tabaquim, 2017). It should be noted that during primary school, children learn to read/write but, from then on, reading/writing are the skills that allow the individual to learn new contents throughout their life (Oliveira \& Capellini, 2016) and promote their insertion in society (Bandini et al., 2014).

The identification of difficulties in cognitive-linguistic competencies, particularly in the first years of schooling, is important. After identifying difficulties, a specialized intervention can be done 
before significant perturbations can be manifested in the student's school performance (Navas, 2011; Nicolau \& Navas, 2015).

The choice of adaptation of this protocol is justified because there is a shortage of instruments that systematically and rapidly assess the cognitive-linguistic competencies involved in the learning process in Portugal.

\section{Objectives and instrument description}

This study intended to describe the adaptation and validation process of the instrument Cognitive and Linguistic Skills Assessment Protocol (CLSAP) (Capellini, Smythe \& Silva, 2012). This Protocol was adapted from a Brazilian (Portuguese) version to a European Portuguese version to evaluate the cognitive-linguistic skills of school children $\left(1^{\text {st }}\right.$ to $5^{\text {th }}$ grade). It consists of two versions, the collective version and the individual version.

The collective version consists of 5 subtests: (S1) writing the alphabet in sequence; (S2) copy shapes; (S3) mathematical calculation; (S4) dictation of words and pseudowords; and (S5) repetition of numbers in random order.

The individual version consists of 13 subtests: (S1) word reading; (S2) non-word reading; (S3) alliteration; (S4) rhyme; (S5) repetition of words; (S6) repetition of non-words; (S7) rhythm; (S8) syllabic segmentation; (S9) quick naming of figures; (S10) fast digit naming; (S11) visual memory for shapes (2 shapes to 5 shapes); (S12) discrimination of sounds; and (S13) repetition of numbers in reverse order.

Data were analysed using the statistical program IBM SPSS 25.

\section{Methods}

The CLSAP was adapted from Brazilian Portuguese, the original Protocol, to European Portuguese. In the adaptation of the CLSAP, author authorization was requested. Two types of adaptation were made: adaptation of the linguistic aspects of the text (direct adaptation of verb tenses, organization and sentence structure) and a lexical adaptation in specific tests. Given the differences between the vocabulary of Brazil and Portugal, it was necessary to do lexical exchanges in some specific tests. Some words were replaced by others, keeping, whenever possible, all phonetic and syllabic characteristics (number and syllabic constitution) (International Test Commission, 2017).

After completion of the instrument, a pilot study (pre-test) was carried out to verify that they were correctly adapted and easily understood by the target population (Almeida, \& Freire, 2008; Canhota, 2008).

After concluding the changes in the CLPAS, the protocol was used to assess children of a larger sample to determine the protocol standard normative values for the target population.

All data collection was carried out in two schools in a school group in the northern region of Portugal with convenience samples.

The samples included children without special educational needs or intellectual/auditory deficits.

It should be noted that written permission was requested from the director of the school group to carry out all data collection. The children 's parents/guardians were also informed about the investigation, authorizing their participation of their student in the study.

\subsection{Pilot study}

The CLPAS adapted version was applied to a class of each school year (from the $1^{\text {st }}$ to the $5^{\text {th }}$ year) to check whether the instrument was correctly adapted or if it would be necessary to make some improvement changes.

A total of 75 children were evaluated: 12 children of the $1^{\text {st }}$ grade; 18 of the $2^{\text {nd }}$ grade; 15 of the $3^{\text {rd }}$ grade; 15 of the $4^{\text {th }}$ grade; and 15 of the $5^{\text {th }}$ grade. The results showed that the Protocol was, in general, well adapted, and only three words were replaced in the whole Protocol.

The adaptation of the protocol underwent some vocabulary adjustments since most students made changes in their reading ( 1 word in subtest 1$)$ or were unaware of the meaning of the words presenting difficulties in their repetition (1 word in subtest 4 and 1 word in subtest 8 ). The substituting words keep the same number of syllables and syllabic constitution of the original word (disyllabic word: consonant $(\mathrm{C})$ vowel $(\mathrm{V})$ - consonant $(\mathrm{C})$ vowel $(\mathrm{V})$ vowel $(\mathrm{V})$; trisyllabic word: CV-CV -CVC; disyllabic word: $\mathrm{CV}-\mathrm{CVV}$ ). One must be careful to maintain the structure of the original words to ensure that the adaptation is as reliable as possible. collection.

With these small changes, the CLSAP was completed and ready for the next phase of data

\subsection{Main study}

The CLSAP final version was applied to a larger sample ( 2 classes per school year, from the $1^{\text {st }}$ to the $5^{\text {th }}$ year). Of the 205 evaluated children, six were excluded since they were not present in the joint 
evaluation session. Of the remaining 199 children, other 42 children were excluded because they had special educational needs or intellectual / hearing deficits.

Of the 157 children included in the study, 79 were girls and 78 boys, aged between 6 and 10 years. They were distributed as follows: 31 children from the $1^{\text {st }}$ year, 34 from the $2^{\text {nd }}, 31$ from the $3^{\text {rd, }} 31$ from the $4^{\text {th }}$ and 30 from the $5^{\text {th }}$ year. Mean, minimum and maximum values were calculated.

Table 1 shows that all subtests of the Protocol Collective Version, mean values are increasing from the $1^{\text {st }}$ to the $4^{\text {th }}$ grade, as expected, but not on the $5^{\text {th }}$ grade, which has a lower mean value.

Table 1. Results of Cognitive Skills Assessment Protocol (CLSAP) - Collective Version.

\begin{tabular}{|c|c|c|c|c|c|c|}
\hline \multirow{2}{*}{ Grades } & \multirow{2}{*}{ Numbers $(\mathrm{N})$ and Scores } & \multicolumn{5}{|c|}{$\begin{array}{l}\text { Cognitive and Linguistic Skills Assessment Protocol (CLSAP) } \\
\text { Collective Version }\end{array}$} \\
\hline & & S1 & S2 & S3 & S4 & S5 \\
\hline \multirow{4}{*}{$1^{\text {st }}$} & $\mathrm{N}$ & 31 & 31 & 31 & 31 & 31 \\
\hline & Min. & 10 & 2 & 2 & 4 & 4 \\
\hline & Max. & 26 & 4 & 8 & 31 & 7 \\
\hline & Mean & 23,19 & 3,29 & 5,16 & 15,10 & 5,35 \\
\hline \multirow{4}{*}{$2^{\text {nd }}$} & $\mathrm{N}$ & 34 & 34 & 34 & 34 & 34 \\
\hline & Min. & 9 & 2 & 4 & 16 & 4 \\
\hline & Max. & 26 & 4 & 18 & 37 & 9 \\
\hline & Mean & 23,91 & 3,65 & 9,65 & 26,18 & 6,06 \\
\hline \multirow{4}{*}{$3^{\text {rd }}$} & $\mathrm{N}$ & 31 & 31 & 31 & 31 & 31 \\
\hline & Min. & 20 & 3 & 8 & 21 & 2 \\
\hline & Max. & 26 & 4 & 19 & 37 & 10 \\
\hline & Mean & 25,42 & 3,77 & 15,32 & 31,42 & 7,19 \\
\hline \multirow{4}{*}{$4^{\text {th }}$} & $\mathrm{N}$ & 31 & 31 & 31 & 31 & 31 \\
\hline & Min. & 22 & 3 & 10 & 21 & 6 \\
\hline & Max. & 26 & 4 & 20 & 37 & 10 \\
\hline & Mean & 25,71 & 3,87 & 18,06 & 31,97 & 7,84 \\
\hline \multirow{4}{*}{$5^{\text {th }}$} & $\mathrm{N}$ & 30 & 30 & 30 & 30 & 30 \\
\hline & Min. & 21 & 3 & 13 & 20 & 5 \\
\hline & Max. & 26 & 4 & 20 & 38 & 9 \\
\hline & Mean & 25,07 & 3,77 & 17,47 & 31,83 & 7,20 \\
\hline Total & $\mathrm{N}$ & 157 & 157 & 157 & 157 & 157 \\
\hline
\end{tabular}

Similarly, through the subtests 1 to subtest 8 of the Protocol Individual Version, mean values are increasing from the $1^{\text {st }}$ to the $4^{\text {th }}$ grade, as expected, but not the $5^{\text {th }}$ grade, which has a lower mean value in subtests 2,6 and 7 .

Table 2. Results of Cognitive Skills Assessment Protocol (CLSAP) - Individual Version: Subtest 1-Subtest8.

\begin{tabular}{|c|c|c|c|c|c|c|c|c|c|}
\hline \multirow[t]{2}{*}{ Grades } & \multirow[t]{2}{*}{ Numbers $(\mathrm{N})$ and Scores } & \multicolumn{8}{|c|}{$\begin{array}{c}\text { Cognitive and Linguistic Skills Assessment Protocol (CLSAP) } \\
\text { Individual Version }\end{array}$} \\
\hline & & S1 & S2 & S3 & S4 & S5 & S6 & S7 & S8 \\
\hline \multirow{4}{*}{$1^{\text {st }}$} & $\mathrm{N}$ & 31 & 31 & 31 & 31 & 31 & 31 & 31 & 31 \\
\hline & Min. & 0 & 2 & 3 & 5 & 2 & 4 & 2 & 12 \\
\hline & Max. & 17 & 8 & 10 & 20 & 5 & 7 & 7 & 20 \\
\hline & Mean & 7,58 & 4,42 & 6,42 & 13,26 & 3,58 & 5,42 & 4,39 & 17,77 \\
\hline \multirow{4}{*}{$2^{\text {nd }}$} & $\mathrm{N}$ & 34 & 34 & 34 & 34 & 34 & 34 & 34 & 34 \\
\hline & Min. & 5 & 2 & 3 & 6 & 2 & 3 & 2 & 10 \\
\hline & Max. & 70 & 10 & 10 & 20 & 7 & 7 & 8 & 20 \\
\hline & Mean & 37,44 & 7,24 & 7,38 & 15,41 & 4,38 & 6,09 & 4,68 & 18,85 \\
\hline \multirow{4}{*}{$3^{\text {rd }}$} & $\mathrm{N}$ & 31 & 31 & 31 & 31 & 31 & 31 & 31 & 31 \\
\hline & Min. & 29 & 5 & 6 & 8 & 3 & 5 & 1 & 14 \\
\hline & Max. & 69 & 12 & 10 & 20 & 7 & 7 & 9 & 20 \\
\hline & Mean & 49,71 & 8,19 & 8,90 & 17,35 & 4,58 & 6,29 & 5,81 & 18,90 \\
\hline \multirow{4}{*}{$4^{\text {th }}$} & $\mathrm{N}$ & 31 & 31 & 31 & 31 & 31 & 31 & 31 & 31 \\
\hline & Min. & 37 & 6 & 5 & 9 & 3 & 4 & 4 & 13 \\
\hline & Max. & 69 & 10 & 10 & 20 & 7 & 7 & 9 & 20 \\
\hline & Mean & 56 & 8,23 & 9 & 17,97 & 5,26 & 6,61 & 6,52 & 19,26 \\
\hline \multirow{4}{*}{$5^{\text {th }}$} & $\mathrm{N}$ & 30 & 30 & 30 & 30 & 30 & 30 & 30 & 30 \\
\hline & Min. & 35 & 5 & 4 & 15 & 3 & 4 & 2 & 17 \\
\hline & Max. & 70 & 10 & 10 & 20 & 7 & 7 & 10 & 20 \\
\hline & Mean & 61,63 & 8,20 & 9,03 & 18,50 & 5,27 & 6,33 & 6,23 & 19,53 \\
\hline Total & $\mathrm{N}$ & 157 & 157 & 157 & 157 & 157 & 157 & 157 & 157 \\
\hline
\end{tabular}


Table 3 shows that in subtest 9 and 10 , de mean values decrease from $1^{\text {st }}$ to the $5^{\text {th }}$ grade, because the results of these subtests are counted in seconds. In subtests 11 and 12, there are no significant differences between the five grades. In general, in subtest 13, the mean value increases with schooling.

Table 3. Results of Cognitive Skills Assessment Protocol (CLSAP) - Individual Version: Subtest 9-Subtest13.

\begin{tabular}{|c|c|c|c|c|c|c|c|c|c|}
\hline \multirow{3}{*}{ Grades } & \multirow{3}{*}{ Mean (M) } & \multicolumn{8}{|c|}{$\begin{array}{l}\text { Cognitive and Linguistic Skills Assessment Protocol (CLSAP) } \\
\underline{\text { Individual Version }}\end{array}$} \\
\hline & & \multirow{2}{*}{$\begin{array}{c}\text { S9 } \\
\text { (seconds) }\end{array}$} & \multirow{2}{*}{$\begin{array}{l}\text { S10 } \\
\text { (seconds) }\end{array}$} & \multicolumn{4}{|c|}{ S11 } & \multirow[b]{2}{*}{ S12 } & \multirow{2}{*}{ S13 } \\
\hline & & & & 2 shapes & 3 shapes & 4 shapes & 5 shapes & & \\
\hline \multirow{4}{*}{$1^{\text {st }}$} & $\mathrm{N}$ & 31 & 31 & 31 & 31 & 31 & 31 & 31 & 31 \\
\hline & Min. & 29 & 72 & 1 & 0 & 0 & 0 & 17 & 2 \\
\hline & Max. & 67 & 179 & 2 & 2 & 1 & 1 & 20 & 4 \\
\hline & Mean & 45,55 & 106,85 & 1,71 & 0,97 & $\mathbf{0 , 2 9}$ & 0,13 & 19,58 & 3 \\
\hline \multirow{4}{*}{$2^{\text {nd }}$} & $\mathrm{N}$ & 34 & 34 & 34 & 34 & 34 & 34 & 34 & 34 \\
\hline & Min. & 25 & 58 & 0 & 0 & 0 & 0 & 15 & 2 \\
\hline & Max. & 51 & 129 & 2 & 2 & 2 & 1 & 20 & 6 \\
\hline & Mean & 36,32 & 82,44 & 1,53 & 1,03 & 0,29 & 0,09 & \multicolumn{2}{|c|}{$19,213,47$} \\
\hline \multirow{4}{*}{$3^{\text {rd }}$} & $\mathrm{N}$ & 31 & 31 & 31 & 31 & 31 & 31 & 31 & 31 \\
\hline & Min. & 25 & 48 & 1 & 0 & 0 & 0 & 17 & 2 \\
\hline & Max. & 55 & 110 & 2 & 2 & 1 & 2 & 20 & 7 \\
\hline & Mean & 36,77 & 71,90 & 1,61 & 1,06 & 0,52 & 0,42 & \multicolumn{2}{|c|}{$19,584,55$} \\
\hline \multirow{4}{*}{$4^{\text {th }}$} & $\mathrm{N}$ & 31 & 31 & 31 & 31 & 31 & 31 & 31 & 31 \\
\hline & Min. & 24 & 43 & 0 & 0 & 0 & 0 & 17 & 2 \\
\hline & Max. & 44 & 80 & 2 & 2 & 2 & 2 & 20 & 9 \\
\hline & Mean & 32,42 & 63 & 1,70 & 1,10 & 0,77 & 0,23 & \multicolumn{2}{|c|}{$19,675,03$} \\
\hline \multirow{4}{*}{$5^{\text {th }}$} & $\mathrm{N}$ & 30 & 30 & 30 & 30 & 30 & 30 & 30 & 30 \\
\hline & Min. & 22 & 43 & 1 & 0 & 0 & 0 & 19 & 3 \\
\hline & Max. & 42 & 81 & 2 & 2 & 2 & 2 & 20 & 7 \\
\hline & Mean & 29,43 & 54,80 & 1,93 & 1,33 & 0,53 & 0,40 & \multicolumn{2}{|c|}{$19,935,03$} \\
\hline Total & $\mathrm{N}$ & 157 & 157 & 157 & 157 & 157 & 157 & 157 & 157 \\
\hline
\end{tabular}

\section{Discussion/ conclusions}

After data analyses, it is possible to conclude that these results are, in general, expected. Mean values increase from the $1^{\text {st }}$ to the $4^{\text {th }}$ grade, excepting subtests 9 and 10 of the CLSAP Individual Version. In those subtests mean values decrease with schooling because the results of these subtests are counted in seconds instead of counting points. These results are justified by the fact of children at primary school are maturing, developing, improving their linguistic, cognitive (Nippold, 2006) and auditory processing skills (Krizman, et al., 2015) that allows them to develop literacy.

The exception is the $5^{\text {th }}$ grade, which has lower mean values in the CLSAP Collective Version and some subtests of the CLSAP Individual version (subtests 2, 6 and 7). Several reasons can explain these non-expected results: subtests with lower sensitivity to evaluate children of the $5^{\text {th }}$ year; heterogeneous classes (more students with lower results); unidentified students with special educational needs or intellectual/auditory deficits, among others.

Despite the non-expected results of the 5th grade, the CLSAP Protocol seems to be a reliable instrument that allows a screening evaluation of children from $1^{\text {st }}$ to $4^{\text {th }}$ grades, allowing the identification of children at risk of developing learning problems. A more exhaustive and individualized assessment can then be initiated, referrals to different health professionals, promoting a multidisciplinary investigation, confirming or ruling out diagnoses, and promoting an adjusted intervention to the child's needs.

The next phase of the study percentiles will be calculated to obtain the standard/normalized values that define a children's cognitive-linguistic profile, identify areas with normative values, and identify problematic areas in which the children obtained values lower than expected.

\section{References}

Almeida, L. S., \& Freire, T. (2008). Metodologia da investigação em psicologia e educação (5 $5^{\mathrm{a}}$ ed.). Braga: Psiquiúibrios Edições.

Andrade, O. V. C. A., Andrade, P. E., \& Capellini, S. A. (2014). Caracterização do Perfil Cognitivo-Linguístico de Escolares com Dificuldades de Leitura e Escrita. Psicologia: Reflexão e Crítica, 27(2), 358-367. doi:10.1590/1678-7153.201427217 
Bandini, C. S. M., Bandini, H. H., Motta, S. A. C., \& Souza, D. G. (2014). Emergence of Reading and Writing in Illiterate Adults After Matching-to-Sample Tasks. Paidéia (Ribeirão Preto), 24(57), 75-84. doi:10.1590/1982-43272457201410

Canhota, C. (2008). Qual a importância do estudo piloto? In E. E. Silva (Org.). Investigação passo a passo: perguntas e respostas para investigação clínica (pp. 69-72). Lisboa: APMCG.

Capellini, S. A., Smythe, I., \& Silva, C. (2012). Protocolo de avaliação de habilidades cognitivo-linguísticas. Marília: Fundep, Ed.

Caravolas, M., Lervåg, A., Mousikou, P., Efrim, C., Litavsky, M., Onochie-Quintanilla, E., Salas, N., Schöffelová, M., Defior, S., Mikulajová, M., Seidlová-Málková, G., \& Hulme, C. (2012). Common patterns of prediction of literacy development in different alphabetic orthographies. Psychological Science, 23(6), 678-686. doi:10.1177/0956797611434536

Ferreira, F. R., \& Tabaquim, M. L. M. (2017). Habilidades cognitivas de escolares do ensino público e privado: estudo comparativo de pré-competências para a aprendizagem acadêmica. Revista Psicopedagogia, 34(104), 126-136.

International Teste Commission. (2018). ITC Guidelines for Translating and Adapting Tests (Second Edition). International Journal of Testing, 18(2), 101-134. doi: 10.1080/15305058.2017.1398166

Krizman, J., Tierney, A., Fitzroy, A.B., Skoe, E., Amar, J., \& Kraus, N. (2015). Continued maturation of auditory brainstem function during adolescence: A longitudinal approach. Clinical Neurophysiology, 126, 2348-2355.

Nicolau, C. C., \& Navas, A. L. G. P. (2015). Avaliação das habilidades preditoras do sucesso de leitura em crianças de $1^{\circ}$ e $2^{\circ}$ anos do ensino fundamental. Revista CEFAC, 17(3), 917-926. Doi:10.1590/1982-021620157214

Nippold, M. (2006). Later language development: School-age children, adolescents, and young adults ( $3^{\mathrm{a}}$ ed.). Austin: Pro Ed.

Oliveira, A. M., \& Capellini, S. A. (2016). E-LEITURA II: banco de palavras para leitura de escolares do Ensino Fundamental II. CoDAS, 28(6), 778-817. doi:10.1590/2317-1782/20162016049

Oliveira, A. M., Germano, G. D., \& Capellini, S. A. (2016). Desempenho de escolares em provas de processo de identificação de letras e do processo léxico. Revista CEFAC, 18(5), 1121-1132. doi:10.1590/1982-0216201618523315

Salvador, L., \& Martins, M. A. (2017). Práticas de literacia familiar, competências linguísticas e desempenho em leitura no primeiro ano de escolaridade. Análise Psicológica, 1(34), 1-12. doi:10.14417/ap.1172

Su, M., Peyre H., Song, S., McBride, C., Tardif, T., Li, H., Zhang, Y., Liang, W., Zhang, Z., Ramus, F., \& Shu, H. (2017). The influence of early linguistic and family factors on literacy acquisition in Chinese children: Follow-up from age 3 to age 11. Learning and Instruction, 49, 54-63. doi:10.1016/j.learninstruc.2016.12.003 


\title{
MOTIVATIONAL POWER OF GAMIFICATION: THE EFFECT OF PLAYFUL LEARNING ON PSYCHOLOGICAL NEEDS OF SELF-DETERMINATION THEORY
}

\author{
Bahar Kutun ${ }^{1}$, Alke Martens ${ }^{2}, \&$ Werner Schmidt ${ }^{1}$ \\ ${ }^{1}$ Business School, Technische Hochschule Ingolstadt (Germany) \\ ${ }^{2}$ Fakultät für Informatik und Elektrotechnik, Universität Rostock (Germany)
}

\begin{abstract}
Gamification, i.e. the integration of game design elements into a non-gaming environment, aims to increase users' engagement and motivation to achieve their goals regarding a given task. It is placed at the border between formal and informal learning approaches. Motivational difficulties are well known in educational settings, especially in Computer Science, where strict formal content meets very playful computer gamers. Hence, we followed the approach of gamification to raise the motivation of learners in the field of Business Process Management (BPM) lifecycle. We developed a board rallye game, based on 16 game design elements. The core of the rallye game is to convey knowledge in a playful way. In order to be able to determine the effects of the rallye game on several aspects, e.g. knowledge transfer and (learning) motivation, we carried out field experiments with 57 students at the Technische Hochschule Ingolstadt and at the Hochschule Augsburg. In this paper the perspective of self-determination theory (SDT), that has found general acceptance in motivational research, is used to understand and analyze the motivational power of gamification.
\end{abstract}

Keywords: Gamification, game based learning, business process management, self-determination theory, knowledge transfer.

\section{Introduction}

Regarding Computer Science education, same as education in related fields, e.g. Business Informatics, we always observe similar scenarios: almost all students love to play computer games, almost all students love the idea of smartness and of working on mobile devices, working in groups and being creative. At the same time, quite a lot of students have serious problems with acquiring formal knowledge. The rule of thumb says: the more formal (e.g. mathematically formal) a content is provided in a lecture, the less the students are motivated to take up the approach. A while ago we have made a test with a quite demanding (role playing) gaming environment, where the players have to learn lots of rules before being successful in the game. We let the students compare the rules of this game with rules in theoretical computer science and they admitted that the formal rules in theoretical computer science are less complicated than the rules in the game. We discussed this topic. In the result, our discussion ended with something even psychologists have a problem to put their finger on: motivation! Students described that in the game they are eager to learn, as the rules are kind of "standing in the way" of playing, and simply have to be learned to succeed in the game. In contrast to that, the building blocks of theoretical computer science contain no motivational factor, as the students' insight regarding the goal is missing. They have the short term goal to pass the exam, but they are not able to see the long term goal, i.e. deep understanding of their field of work.

Based on this observation and related to our knowledge in eLearning, game-based learning and learning design for a new world, we decided to make an approach where we develop a game, where part of the task is to understand BPM. BPM lifecycle includes activities that consider the design of business processes from analysis to execution and monitoring. Business process modeling is one of the activities in the lifecycle. Business process models are a comparably easy tool to describe processes and generally, students are not overwhelmed by its complexity. Nonetheless, we know that quite a lot of students are not very eager to grasp the rules, the underlying meaning and functionality of the BPM, and that they often have a kind of barrier, which they are not able to overcome. Thus, our approach is to use a rallye game as cover for the BPM lifecycle basics. As all of our students are eager to play on the computer, we designed a setting, where the game itself is not computer based. By using this design, we wanted to make clear that the game-based approach is helpful by itself - and not based on the innovation hype of a new computer game. Investigations like this have been carried out e.g. by the well-known beer game. As we wanted to 
put a finger on the motivational factor, which we heavily discussed with our students (who also are not sure what exactly motivation is), we put together the following research questions: without?

RQ1: Is the increase in knowledge higher when learning with gamification than when learning

RQ2: Is the (intrinsic) (learning) motivation higher when learning with gamification than when learning without?

Regarding the aspect of investigating motivation in a non-psychological study, we based our work on the SDT. In the following, we describe the game and afterward give an insight into our evaluation, which took place with more than 50 students. Finally, we draw conclusions and give ideas for further research in Section 4.

\section{Game design and implementation}

\subsection{Rallye track design}

In order to facilitate a flexible and modular layout of the rallye track, we developed single track sections per learning content portion, e.g., per BPM cycle activity. Thus, the rallye game ensures that the amount and order of learning units to be played can be determined by learners and teachers. There are two variants of the single track sections: a section with a given route to follow and a section with the opportunity to choose from alternative routes. A complete rallye track can be built up by linking the single track sections to each other (see Figure 1). Each single track section consists of fields with various meaning: 5 learning fields (blue), 3 question fields of various difficulty (green $=$ easy, yellow $=$ medium, red $=$ difficult), 2 event fields (star) and 1 empty field (white, only in single track section with alternative routes).

Figure 1. Example for a complete rallye track with 7 single track sections.

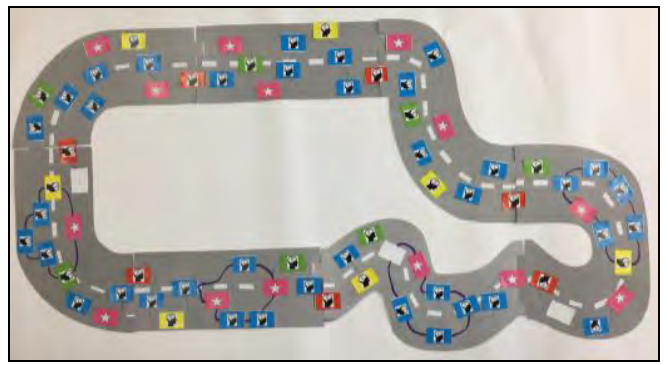

\subsection{Elements for knowledge transfer}

Since the BPM rallye aims to transfer knowledge in the field of the BPM lifecycle, elements for knowledge transfer are integrated into the game. For this purpose, we created 15 learning cards per BPM cycle activity. They include the learning content related to the BPM cycle activity and can be flexibly assigned to the single track sections. In order to check the learning content, we designed 18 control question cards per BPM cycle activity. On the front side are questions of various question types, e.g., open / closed questions or fill the gap questions. To give the players immediate feedback the answer of the question is printed on the back side of the control question card.

\subsection{Game design elements and SDT}

We have assigned the game mechanics (full list of game mechanics and their implementation in the game see Kutun \& Schmidt, 2018), to the SDT in order to identify their contribution to the satisfaction of the psychological needs (see Table 1).

Table 1. Matching game mechanics to the psychological needs.

\begin{tabular}{|l|l|}
\hline SDT & Game mechanics \\
\hline Need for autonomy & Customization \\
\hline Need for competence & $\begin{array}{l}\text { Badges, Clear goals, Competition, Countdown, Epic Meaning, } \\
\text { Feedback, Progression bars, Pyramid scoring, Quests, Ranking list, } \\
\text { Transparency of results }\end{array}$ \\
\hline Need for social relatedness & Epic meaning, Free lunch, Gifts \\
\hline
\end{tabular}

\subsection{Prototype and playing}

Based on the discussed game design we created a prototype. The components of the rallye game set are illustrated in Figure 2. 
Figure 2. Content of a rallye game box.

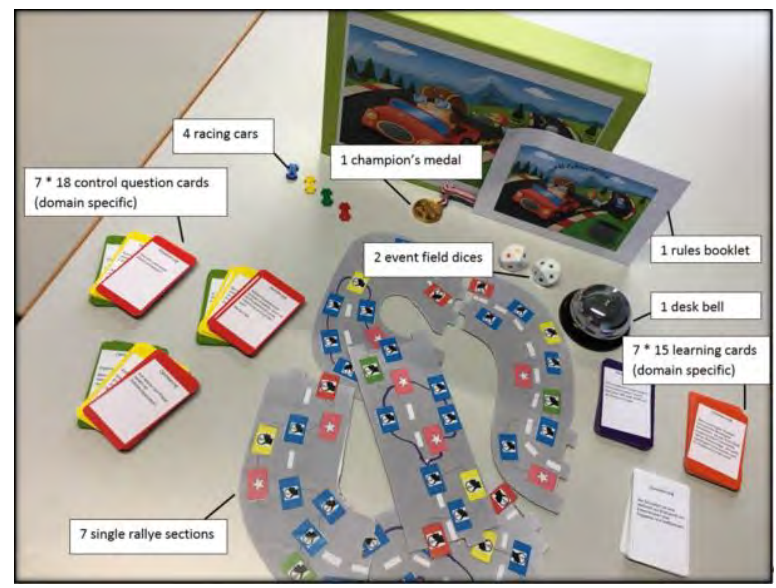

The players organize themselves in teams of 3 to 4 people. The teams create their own rallye track by determining the amount and order of learning content according to the teacher's instruction or to their own preferences. The youngest player begins playing. The game is played clockwise. The players move their racing cars field by field across the track and follow the instructions of the fields, e.g., drawing a learning or control question card. Learning content, control questions and their answers are read aloud, so that all team members can follow and discuss. If a racer reaches a question field, he may only proceed if he can answer the question correctly. The game ends when the first racer (winner) reaches the finish field.

\section{Evaluation and results}

After a successful technical test, in which the transparency of rules and rules booklet, as well as the playing time was checked, the game was tested and evaluated as part of a field experiment. We have determined the course of the field experiment as follows: first, the participating students were randomly divided into experimental and control group and in smaller teams of 3 to 4 within each group. To determine the current level of knowledge of the participants a knowledge test (pre) was carried out. The test included questions about the BPM lifecycle activities. All teams were asked to choose 3 BPM cycle activities and had a total of 60 minutes to play the rallye game or to study the lecture. Teams of the experimental group played the rallye game, while the teams of the control group were provided with a lecture script, which is usually used in the lecture to convey knowledge in the field of the BPM cycle. During this phase, a qualitative observation was made by the moderator / teacher. In order to analyze the increase in knowledge, we repeated the knowledge test as post-test after the field experiment. In a final step the students evaluated the field experiment. They assessed, whether the psychological needs of SDT could be met in the field experiment. Additionally, their statements with respect to flow experience or learning success were collected. The entire experiment took about 2 hours.

We carried out two field experiments in the described way. The first one took place in the course 'BPM' of the Bachelor's program 'Digital Business' at the Technische Hochschule Ingolstadt with 42 students. The second field experiment we conducted in the course 'BPM' of the Bachelor's program 'Business Informatics' at the Hochschule Augsburg with 15 students.

This paper presents the results of the knowledge tests (knowledge growth, see Figure 3 ) and the satisfaction of the psychological needs of SDT (see Figure 4).

Figure 3. Knowledge growth.

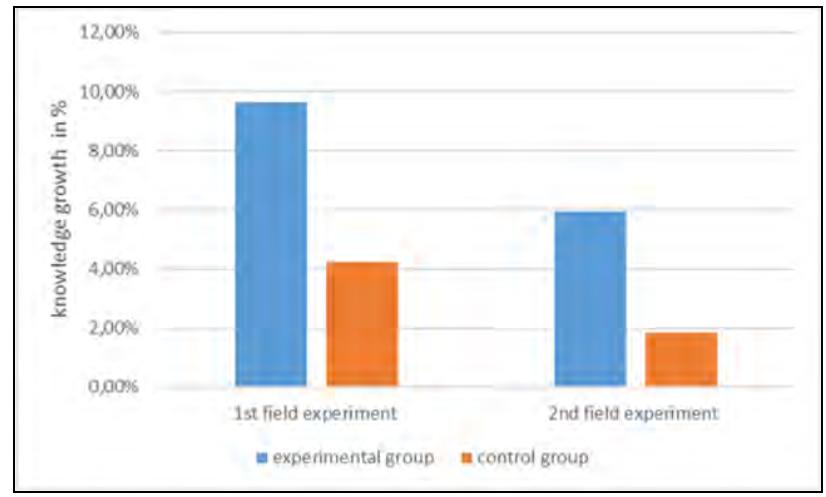


The knowledge growth is determined by comparing the pre and post knowledge tests. It is obvious that the experimental groups were able to achieve a higher increase in knowledge. Possibly this is due to the fact that the students in the experimental group have a higher (learning) motivation than the learners in the control group. This assumption will be investigated in more detail by analyzing the evaluation sheets.

With the rallye game an almost identical net effect could be measured in both field experiments. On average, the net effect of the rallye game was a $4.76 \%$ increase in knowledge. The time frame used for this was approximately 1 hour (= time to deal with the BPM cycle activities). This means learners could improve one grade within an hour. This grade level gain refers to a grading system with 10 levels from 1.0 (best) to 4.0 (= pass limit at 50\%). The results give some evidence for a positive answer to RQ1, i.e. that gamified learning can lead to a higher knowledge increase compared to traditional learning.

In order to analyze the satisfaction of the needs of SDT and thus to determine the (intrinsic) (learning) motivation, reliability analyses, significance tests and the measurement of the effect's strength were carried out. In addition, we conducted a single factor multivariate analysis of variance (MANOVA).

Figure 4 depicts the results of these validity checks for the first field experiment.

Figure 4. Satisfaction of psychological needs of SDT.

\begin{tabular}{|c|c|c|}
\hline & Dxperimental group & Control group \\
\hline \multicolumn{3}{|c|}{ Need for competence } \\
\hline $\mathrm{M}(\mathrm{SD})$ & 3,86 & 2,74 \\
\hline Chronbach's $\alpha$ & $\alpha=0,9 ;$ excellent reliability & \\
\hline F value & $F(1,40)=14,604$ & \\
\hline Significance level & $0,000<0,05$ & \\
\hline Effect strength & $\mathrm{d}=1,2 ;$ great effect & \\
\hline \multicolumn{3}{|c|}{ Need for social relatedness } \\
\hline $\mathrm{M}(\mathrm{SD})$ & 4,10 & 3,45 \\
\hline Chronbach's a & $\alpha=0,8 ;$ good reliability & \\
\hline F value & $\mathrm{F}(1,40)=5,784$ & \\
\hline Significance level & $0,011<0,05$ & \\
\hline Effect strength & $\mathrm{d}=0,8$; significant effect & \\
\hline \multicolumn{3}{|l|}{ Need for autonomy } \\
\hline $\mathrm{M}(\mathrm{SD})$ & 3,84 & 3,55 \\
\hline Chronbach's $\alpha$ & $\alpha=0,6 ;$ questionable reliability & \\
\hline F value & $F(1,40)=1,474$ & \\
\hline Significance level & $0,116>0,05$ & \\
\hline Effect strength & $\mathrm{d}=0,4$; small effect & \\
\hline
\end{tabular}

The significant effect on the basic psychological need for competence is reasonable, since the experimental group receives, for example, immediate feedback on answering control questions. Likewise, the feeling of social integration is higher in the experimental group due to the interaction with other players during the game round than in the control group. The fact that the control group can also meet the need for autonomy is probably due to the fact, that the students can make their own decisions regarding the reading sequence of the lecture notes for different BPM cycle activities.

For the 2nd field experiment, only evaluation sheets of the experimental group are available because the control group did not want to fill out the form. For this reason, the satisfaction of the psychological needs of SDT cannot be analyzed for the 2nd field experiment. However, the qualitative observation in both field experiments revealed a significantly higher level of commitment and fun in the experimental group.

According to the results of the analysis, the rallye game beneficially contributes to the satisfaction of the three basic psychological needs of SDT. Hence, RQ2, whether the (intrinsic) (learning) motivation is higher when learning with gamification than when learning without gamification, can also be answered positively. 


\section{Conclusion and future work}

We followed the gamification approach to develop a board game, which should support learning processes in the field of Business Process Management. We evaluated and tested the rallye game with two field experiments with university students. The experiences and feedback we collected indicate that the game is appropriate to transfer knowledge in a playful way. In addition, the results show that the rallye game can contribute to increase the (intrinsic) (learning) motivation of learners.

In order to extend empirical grounding the rallye game should be subject to further evaluation with several groups, e.g., employees in learning situations.

Based on the information on the evaluation sheets, it was also found that some students in the control group would rather participate in the experimental group and vice versa. For this reason, a field experiment can be carried out to analyze which effects occur when participants choose themselves the group in which they want to participate. Thus, the winner or loser problem can also be solved.

Based on the positive experience with the board game, it is interesting to find out whether the transfer of the concept to a digital version can also be successful. Therefore, there are plans to develop the rallye as a web-based game and analyze its effects on learning success and motivation.

Generally, we think that future learning will tend towards establishing more "fun" in the learning process. This can be reflected by a change in instructional methods, which might also contain the embedding of games or gamification aspects in the learning. Naturally, playful or game based learning takes place in children education, where it is a quite normal part of the instructional material. However, as soon as the child grows up, the perception is that learning, teaching and training have to be serious and no fun, to be accepted. Our impression is that a method mix is the most fruitful instructional design. Especially young students in their first years at the University are often missing the big picture. They know that they have to learn all the stuff provided by their teachers, but in quite a lot of cases, they don't understand why. As long as the big picture is missing, raising the motivation by e.g. choosing a game as one of multiple ways to mediate information can be fruitful, as our investigation shows. Regarding the idea of smart education, the integration of game, gamification, and serious learning seems to be the most promising - either in University as in school or high school setting.

\section{References}

Bartle, R. A.: Designing Virtual Worlds, Indianapolis: New Riders (2004).

Bartle, R. A.: Hearts, clubs, diamonds, spades: Players who suits MUDs, in: Journal of MUD research 1 (1), 19, pp. 1-28 (1996).

Björk, S., Holopainen, J.: Patterns in Game Design (Game Development Series), Rockland: Charles River Media (2004).

Deterding, S., Dixon, D., Khaled, R. and Nacke, L.: From game design elements to gamefulness: Defining gamification, MindTrek '11 Proceedings of the 15th International Academic MindTrek Conference: Envisioning Future Media Environments, pp. 9-15 (2011).

Deterding, S., Khaled, R. Nacke, L. and Dixon, D.: Gamification: Toward a definition, CHI 2011 Gamification Workshop Proceedings, pp. 12-15 (2011).

Hamari, J., Koivisto, J., Sarsa H.: Does gamification work? A literature review of empirical studies on gamification, Proceedings of the 47th Hawaii International Conference of System Sciences (HICCS); pp.3025-3034 (2014).

Kapp, K. M.: The Gamification of Learning and Instruction: Game-Based Methods and Strategies for Training and Education. San Francisco: Pfeiffer (2012).

Kutun, B. and Schmidt, W.: Rallye: Playful and Motivated Learning, EDULEARN18, pp. 735-741 (2018).

PRSH e.V.: http://www.prsh.de/2014/04/22/gamification-4-die-zielgruppe-als-spielgruppe/

Rosemann, H.: Arbeitshefte für Psychologie: Motivation: Motivationstheorien, Motivationsarten: Lern- und Leistungsmotivation, Aggression, Angst, Frustration, Konflikt und Widerspruch, Motivierung im Unterricht. Berlin: Polerz (1974).

Ryan, R. M., Deci, E. L.: Self-Determination-Theory: Basic Psychological Need in Motivation, Development and Wellness. New York: The Guilford (2017).

Schacht M, Schacht S.: Start the game: increasing user experience of enterprise systems following a gamification mechanism, in: Maedche A, Botzenhardt A, Neer L (Eds.) Software for people. Heidelberg: Springer, pp.181-199 (2012).

Schiefele, H.: Lernmotivation und Motivlernen. München: Franz Ehrenwirth, (1974).

Werbach, K., Hunter, D.: For the win: How Game Thinking can revolutionize your business, Philadelphia: Wharton Digital Press (2012). 


\title{
TEACHING SETSWANA PROVERBS AT THE INSTITUTION OF HIGHER LEARNING IN SOUTH AFRICA
}

\author{
Bridget Mangwegape \\ Department of Languages and Social Sciences, Central University of Technology (South Africa)
}

\begin{abstract}
The paper sought to investigate how first year University student's-teachers understand and instil appreciation of the beauty of Setswana language. Since the proverbs are carriers of cultural values, practices, rituals, and traditional poetry, they are rich in meaning, they can be used to teach moral values for the sake of teaching character building among the students and teaching Setswana at the same time. Proverbs contain values of wisdom, discipline, fairness, preparedness, destiny, happiness, and efforts. Proverbs are short sayings that contain some wisdom or observation about life and or role-play and to use a few of the proverbs to reinforce the meaning, using proverbs as a pedagogical strategy, the researcher has observed that student teachers find it difficult to learn and teach learners at school. Students-teacher's think and feel about how they conceptualize proverbs, how they define their knowledge and use of Setswana proverbs. The lecturer observed how the nature of proverbs are linked to the culture embedded in the language. In Setswana language there is a proverb that says, "Ngwana sejo o a tlhakanelwa" (A child is a food around which we all gather) which implies that the upbringing of a child is a communal responsibility and not an individual responsibility. Put in simple terms, a child is a child to all parents or adults, since a child's success is not a family's success but the success of the community. In doing so, the paper will explore on how student-teachers could make use of proverbs to keep the class interested in learning Setswana proverbs. As a means of gathering qualitative data, a questionnaire was designed and administered to student-teachers and semi-structured interviews were conducted with student teachers. The findings revealed that despite those students-teachers' positive attitudes towards proverb instruction, they did not view their knowledge of Setswana proverbs as well as the teaching of proverbs. The paper displays that proverbs constitute an important repository of valid materials that can provide student-teachers with new instructional ideas and strategies in teaching Setswana proverbs and to teach different content, which includes Ubuntu and vocabulary and good behaviour.

Proverbs must be taught and used by teachers and learners in their daily communication in class and outside the classroom in order to improve their language proficiency.
\end{abstract}

Keywords: Setswana language, proverbs, student- teachers, teaching and learning, Ubuntu.

\section{Introduction}

Setswana is an African language spoken in South Africa, Botswana, and parts of Namibia. It is the national language of Botswana, and one of the eleven official languages in South Africa. Proverbs constitute knowledge not only for African peoples but knowledge for the global public sphere (Dei, 2014: 50). Proverbs reflect human experience across cultures and languages, which contain folk wisdom tested throughout the time. In relation to language teaching, they can be used to teach, among others, speaking, writing, grammar, vocabulary, culture, and values. The use of proverbs can be carried out through Setswana culture and values. Teaching and learning Setswana becomes a vital effort as the Setswana student- teacher must exert his/her efforts to make his/her teaching interesting and his/her students have fun while they are studying, and to lead their students to a great success in learning the focus language. It is however important to note that, for student-teacher to apply strategies of teaching proverbs, he/she should bring in various techniques to his/her classroom to avoid monotony in class. To have a good start a student-teacher needs a strategy to teach proverbs in a very interesting approach that would have a feeling of pleasure during the learning process. Using Setswana proverbs could be an effective way to start a new lesson. When necessary, the student-teacher could compare two proverbs with a different context but serve the same meaning, for instance a Setswana proverb "Le aramele le sa go tlhabetse" (Make hay while the sun shines) and "Ngwana 
wa dikgomo ithute molodi, o gopole motlhang malata a ile". Son of a cattle-farmer do learn the (cattle-tending) whistling yourself, so that you can take over when your father's farm hands are gone.

Both meaning refers to the child to learn things while the parents are still alive. In this way proverbs are useful guideposts and could serve as interesting in the teaching and learning situation. The lessons learned from proverbs are diverse and of the greatest importance in the training of student-teachers. Evidently, proverbs have influence on teaching student-teacher how to part with knowledge when teaching learners at school. The need being the effectiveness of proverbs are that they are maxims, a wise saying based upon people's experience, and are reflection of the social values and sensibility of the people.

\section{Theoretical framework}

The theoretical importance of teaching - learning Setswana home language using proverbs is based on model theories that are founded on Education, schooling, cultural and instruction framework. Barlett Jere Whiting (2013), points out that a proverb is an expression which, owing its birth to the people, testifies its origin in form and phrase, expresses what is apparently a fundamental truth, that is a truism, in homely language. Furthermore, some proverbs have literal meaning as they are stated, other proverbs have figurative meaning which makes sense.

According to Calvins's Theory of Value, there is human value planted in learning and knowledge acquisition. The proverb if well taught by the student-teacher, with the right knowledge and skills should add moral and academic value in the learner and improve their performance not only in writing but also in life, in whichever context is presented, that is in and out of the class.

Proverbs are experiences, some of which have been learnt the hard way (Nyembezi, 1950). In a classroom situation they reveal what the learners and the student - teachers go through and their outlook to life. According to Ellis and Tomlinson (1980) and Mwanzi (1986) say that learner's accuracy in the use of Setswana depends on their ability to assimilate and use different integrated structures if well taught. Some proverbs have literal meaning as they are stated. Other proverbs have figurative meaning which makes sense.

Proverbs have been used as teaching tools for centuries to teach moral values and social skills. They may deal with mind, wisdom, experience, learning, and authority. They are indeed effective devices to communicate wisdom and knowledge about human nature and the world at large (Mieder,2004:146). Proverbs contain a truth in few words that relate to everyday life having a universal value, and they can be remembered easily. Considering the good values of proverbs to teach Setswana as home language, it is a good way to consolidate the learning of vocabulary, grammar, sentence patterns and moral values.

\section{Related literature review}

There is a strong link between proverbs and pedagogy, for instance, student-teachers would teach learners at school the norms and values of society and instil in them the concept ubuntu (humanness) which they believed would make children grow up and be responsible citizens. Manda (2009) points out that ubuntu the understanding. Ubuntu is one of several African approaches to a comprehensive understanding of the process of cultivating cohesion and positive human interaction with one another and with creation in daily life. However, ubuntu picks out the idea that human beings are radically interdependent, and that this interdependence entails a morally normative pressure toward generosity, hospitality, friendliness, compassion, forgiveness, reconciliation, consensus, and positive group-identification (van Niekerk 2013). Therefore, in teaching and learning, learners' exposure to certain proverbs can help in developing ubuntu in them. This can be seen through their behaviour, for example, respecting and treating one other with dignity and love. Onyebuchi Eze (2015) believes that the core of ubuntu can be summarised to mean that a person is a person through other persons "motho ke motho ka batho ba bangwe" This means that humanity is not embedded in a person solely as an individual but that it is also bestowed from one person to the next. We need each other, we create each other and sustain one another as humanity is a quality, we owe to each other (Mangwegape 2019).

According to Mangwegape (2019), there is an expression that reflects this notion of social inclusion or social acceptance, namely, "Moeng goroga re je ka wena" (welcome dear guest, so that through you we may have plenty to eat - a rough translation). This expression reflects the African people's perspectives about visitors or guests, that a visitor or a guest is an important person who arrives into the space of a host; that they deserve more than the host or the host's family in terms of warmth, compassion, empathy, and care. Therefore, a visitor or a guest is viewed not as a client, a competitor, a challenger, or an intruder in one's space but as someone who adds value, plenty, comfort, humour, and honour; someone through whom there would be plenty to eat because even the meagre reserves that had been hidden for so long would be unearthed. 
Some of these studies have employed questionnaires to uncover students' attitude to and/or experiences of the teaching and learning of proverbs. For instance, using a questionnaire, Hanz'en (2007) uncovered that teachers had a positive attitude towards using proverbs in Setswana language teaching.

\section{Research methodology}

The research design selected was qualitative approach which sought to establish the current knowledge and skills for the Setswana student-teacher in presenting lessons based on proverbs in Higher learning institutions. In this study, questionnaires and focus group interviews were developed by the research and used to collect data.

\section{Aim of the study and research questions}

The aim of the study is how student-teachers can make use of proverbs to keep learners interested in learning Setswana. Basically, proverbs reflect human experience across cultures and languages which contain folk wisdom tested throughout the time.

- What are the student-teachers' perception regarding the usage of ubuntu in proverbs?

- What are student-teachers' perceptions about the institution of higher learning Setswana teachers' practices in teaching proverbs in the lecture room?

- How do they think about their knowledge and use of Setswana proverbs?

\section{Sample}

The population of this study comprised 26 first year students, registered at the Higher learning institution of Central University of Technology in Setswana. The participants in this study were divided in groups for both first and second period of the study, and a questionnaire was developed for the Setswana student-teachers based on the objective of the study.

\section{Procedure}

The following steps were to improve the student-teachers teaching and learning:

Stage 1: Teaching proverbs

Student-teachers can be used to teach comparison between speaking, writing grammar, vocabulary, culture, and values.

Stage 2: Student-teachers can invite learners to make some comparison of proverbs that carry the same meaning.

Stage 3: Student-teachers should look for a strategy to teach proverbs in an interesting manner.

Stage 4: Culture and values can be carried out through the use of proverbs.

Stage 5: the philosophy of ubuntu can be used in the current issues of teaching character building,

Stage 6: Proverbs can be used in teaching character building as well.

\section{Ethical considerations}

The researchers observed ethical guidelines of seeking institutional permission, privacy, voluntary participation, and confidentiality of participant.

\section{Data analysis}

The researcher used qualitative method to analyse the data in this study. The questionnaire was designed to find answers to the research questions. For each proverb identified, detailed information about where language teaching, could be used to teach, among others, speaking, writing, grammar, vocabulary, culture, and values. Through the analysis the researcher identified the principle of ubuntu which they could be developed through their use. A focus-group interview took the form of a conversation with the intention that the researcher explores with the participants' views, ideas, beliefs, and attitude about teaching and learning of proverbs.

Student-teachers' perception regarding teaching and learning of proverbs in the classroom. lesson interesting.

$90 \%$ find it very interesting in the beginning of the lesson when the student-teacher makes the 
$60 \%$ Learners are going to look for books that entails Setswana proverbs to learn more about them. $70 \%$ of the learners enjoyed the usage of ubuntu in proverbs.

The results show that learners enjoyed proverbs that deals with culture and values.

\section{Results and discussion}

The results show that by understanding the meaning of proverbs, learners could name and explain the proverbs, others could list the key words that they associated with proverbs. The meaning of proverbs could be of great help to the learners since teaching and learning took place, student-teachers started giving lessons on proverbs, they demonstrated qualities of ubuntu and their exposure to proverbs is of significant to the nature of proverbs that are linked to the culture embedded in the language. It can be noticed that the learner's meaning mostly included some of the cultural and formal aspects of proverbs. Owing to the variety in the forms of proverbs, there is not an exact and inclusive meaning that can enable one to identify them with any uncertainty. Some of the meanings of the Setswana proverbs are not quite true, for instance the proverb that says, 'ngwana yo o thogokgolo o sira rraagwe', (the big-headed child obstructs his father's view). Here the truth could be challenged and questioned. Considering these findings, the meaning of proverbs presented to the student-teachers in teaching and learning need to be renewed and updated to provide a more accurate picture of proverbs in modern times.

\section{Conclusions}

Proverbs can serve as interesting in teaching and learning situation because they are meaningful, and they contain some good values that can be practiced in daily life. In relation to character building, proverbs bear some educational values which can be used to build the student-teachers character. Setswana proverbs as the crystallisation of collective wisdom are the core of Setswana. Based on the features of Setswana proverbs, a student-teacher can make use of instilling the concept of ubuntu which they believed would make children grow up and be responsible citizens. The student-teacher can use proverbs in teaching Setswana skills, or the linguistic components of Setswana.

\section{References}

Dei, G.J.S., 2014. African indigenous proverbs and the institutional and pedagogic relevance for youth education: Lessons from Kiembu of Kenya and Igbo of Nigeria. Journal of Education and Training, 1(1), pp. 1-28.

Eze, Michael Onyebuchi, and Thaddeus Metz. 2 (2015): "Emergent issues in African philosophy: A dialogue with Kwasi Wiredu. "Philosophia Africana: Analysis of Philosophy and Issues in Africa and the Black Diaspora, 17. 75-87.

Mangwegape, B.K., 2019. Reflections of Ubuntu principles in selected Setswana drama texts (Doctoral dissertation, University of the Free State).

Mieder, W., 2004. Proverbs: A handbook. Greenwood Publishing Group.

Taylor, A. and Whiting, B.J., 2013. A Dictionary of American Proverbs and Proverbial Phrases, 1820-1880. Harvard University Press.

Van Niekerk, J., 2007. In defence of an autocentric account of Ubuntu. South African Journal of Philosophy, 26(4), pp. 364-368. 


\title{
FACULTY \& STUDENT RETENTION: KEEPING OUR HBCU-UDC ALIVE DURING THE COVID-19 PANDEMIC
}

\author{
Arlene King-Berry, \& Carolene Eslyn Charles \\ Department Education, University of the District of Columbia (USA)
}

\begin{abstract}
There is a national crisis around recruiting and retaining students from HBCUs. The Journal of Blacks in Higher Education surveyed 64 of 100 HBCUs and found that only five of the schools surveyed graduated more than 50 percent of their students. The statistics are startling because HBCUs, some of which date to Reconstruction in the South after the Civil War (widely accepted as the period from 1865 to 1877), ostensibly was designed to improve an underserved community. Despite the large number of freshmen admitted each year to Historically Black Colleges and Universities (HBCU), a low number graduate (Tinto, 1993). It is, therefore, imperative that HBCUs implement strategies most likely to increase retention and persistence rates.

When it comes to taking a closer look at pedagogy and practice in teaching, the COVID-19 Pandemic has created innovative environments for faculty to assess the students. The new perspective has many faculties utilizing evidence-based practices regarding performance-based assessment and other innovative techniques to assess students learning. Online teaching \& learning and online assessment are likely to occupy a higher percentage of the future curriculum, which can be seen as a positive development for online learning.

A correlation assumed that university faculty satisfaction and fair promotion could have a positive effect on student retention and engagement with a comprehensive analysis of these studies. It is paramount to consider that not only was fundamental student engagement found of tremendous relevance, but the literature is evident that student engagement during the entire higher education experience also leads to higher student retention rates and increased institutional commitment (Burke, 2019).

This paper defines retention and persistence at HBCUs and presents the results of a systematic literature review that (a) identifies the challenges that impact student retention and persistence at HBCUs during the COVID-19 Pandemic and (b) delineates research-based practices/strategies recommended to address the academic, socio-emotional, and financial and health/wellness challenges of students attending HBCUs.
\end{abstract}

Keywords: Universal design, teaching strategies, HBCUs, retention, persistence COVID-19.

\section{Introduction}

Retention in higher education is typically defined as the continued enrollment of a student from the first year to the second year (Bean 1980, 1982; Cotton et al. 2017; Farrell 2009; Ishler and Upcraft 2005; Spady 1970; Tinto 1975, 1993). Persistence refers to the act of continuing towards an educational goal (e.g., earning a bachelor's degree). A study conducted by the National Clearinghouse Research center retention was defined as continued enrollment (or degree completion) within the same higher education institution in the fall semesters of a student's first and second year. Persistence, on the other hand, is continued enrollment (or degree completion) at any higher education institution - including one different from the institution of initial enrollment — in the fall semesters of a student's first and second year. (National Clearing House Research Center 2018).

The retention and persistence of minority students in HBCUs are especially critical given the historical context of HBCUs. HBCUs exist because of the United State's history of exclusion, segregation, and racism. With the end of slavery following the Civil War, African American citizens faced numerous challenges gaining access to higher education. Financial barriers and admissions policies made attendance at many colleges and universities nearly impossible for most African Americans. 
In general, the research presents a troubling picture of student persistence and retention. Fall 2017 entering college students aged 20 or younger had a persistence rate of 76.9 percent, down 2.1 percentage points from the Fall 2009 entering cohort. This group also showed the highest spread between persistence and retention rates, with about 15 percent, or one in seven students, enrolling in a different institution in their second fall term. Entering students 21 to 24 -years-old had a persistence rate of 57.6 percent. This data represents an increase of 3.5 percentage points over the Fall 2009 entering cohort. Students aged 25 or older at college entry had a persistence rate of 53.3 percent, a figure that has remained essentially flat across all cohort years shown here.

The outbreak of the COVID-19 virus forced a significant shift in university experiences for faculty and students that would have been unimaginable only months earlier. In March 2020, the Pandemic forced the closure of most U.S. university campuses, obliging millions of students to finish their semester via remote learning. The rapid pivot to remote learning required mastering new learning platforms and forms of communication. In addition, it required sudden and complete dependence on digital devices and steady internet connections. Although all students faced the challenges of adapting to novel conditions in the middle of a semester, not all students began that hasty transition on equal footing. (Katz, Jordan, \& Ognyanova, 2021). For example, students with disabilities were generally the last to gain access to eLearning platforms and forms of communication. Furthermore, the imposition of social distancing deepened the process of segregation and exclusion for individuals with disabilities and those from culturally and linguistically diverse groups.

\section{Design}

Criteria were developed to guide the final selection of articles. Following a review of six (6) textbooks, two were selected for inclusion in this review based on the following criteria: (a) the texts had recent publication dates (2018-2020); (b) they were among the most widely used in first-year experience courses and introductory special education courses, and (c) they provided up-to-date references and resources.

\section{Methodology}

Two questions were designed to gain a current perspective on the retention/persistence challenges of students attending HBCUs and the strategies for assisting them.

* Question 1: What challenges impact retention and persistence at HBCUs

* Question 2: What research-based practices/strategies reduce the impact of these challenges?

* Question 3: What teaching strategies will ameliorate the impact of COVID- on faculty and diverse learners?

With these research questions in mind, a systematic multi-step search for relevant literature was conducted. First, current textbooks used in the first-year experience and special education were reviewed to ascertain appropriate retention strategies. Second, a search for peer-reviewed journal articles was conducted on the ERIC system, using the keywords retention, retention strategies, COVID-19, first-year experience, HBCUs. Third, a Google Scholar search was conducted using the same keywords. These searches yielded critical information and numerous articles addressing the topics of concern. Anecdotal feedback regarding challenges and valuable strategies from the author's courses was also considered.

\section{Discussion}

\subsection{Challenges that impact student retention and persistence at HBCUs}

The review of selected literature revealed that myriad factors impact the retention and persistence of HBCU Students during the Pandemic. Academic, socio-emotional, and financial factors comprised three challenge categories most frequently cited as negatively impacting students' retention and persistence.

\section{1) Academic Challenges}

Research literature reviewed indicates that students from low socioeconomic backgrounds face several challenges to successful college/university matriculation. These challenges include low standardized test scores; inadequate study skills; and poor grades, unreliable internet, fluctuating governmental directives, unprepared faculty. Although all students faced the challenges of adapting to novel conditions in the middle of a semester, not all students began that hasty transition on equal footing. 
(Katz, Jordan, \& Ognyanova, 2021). Low-income students often come to college less academically prepared than their more advantaged peers, with troubling implications for racial achievement gaps.

As a result, universities wrestle with myriad problems in their attempts to manage the education of students with disabilities. They struggle to find creative ways and alternate solutions to providing needed services during the Pandemic while maintaining compliance with applicable laws and regulations (Kennedy, 2020). Teaching strategies and technology applications (Apps) congruent with the central principles of the Universal Design for Learning (UDL) educational framework have a vital role in addressing the educational needs of students and faculty during this difficult time. Thus, the purpose of the literature-based research described herein was to identify UDL-congruent teaching strategies and technology Apps that higher education personnel can utilize to deliver and support effective eLearning for students with various learning characteristics and challenges.

\section{2) Social-Emotional Challenges}

According to the literature reviewed, socio-emotional variables constituted a second major area of challenge for college students. Variables such as loneliness, stress, poor time management skills, problems at home, unsupportive social environment, substance abuse, negative encounters with the law, and other behavioral challenges were cited in relevant literature (Palmer, Davis, Hilton, 2009). Riddle (2017) maintained that time management, stress, and social problems were among the seven top challenges most first-year college students face.

\section{3) Financial Challenges}

Financial challenges play a significant role in the retention and persistence of college students, both directly and indirectly. For example, direct financial/economic challenges include a lack of monetary resources and regulations regarding students' eligibility to receive financial aid. However, financial concerns and obligations are often intimately linked to the college campus's lack of social and academic engagement (Richards \& Awokoya, 2012). Thus, by negatively impacting social and academic engagement, these challenges also indirectly impact student retention and persistence.

\subsection{Practices/strategies that address academic, socio-emotional, and financial challenges Academic Support Approaches, Practices, and Strategies}

This literature review yielded a wide variety of practices and strategies for addressing the academic, socio-emotional and financial challenges that impact student retention and persistence. Specifically, effectiveness data emerged regarding the following approaches, practices, and strategies.

Universal Design for Learning Principles (UDL). This inclusion principle provides a much-needed framework for meeting the needs of students regardless of cultural, linguistic, and ability diversity. UDL is a framework to improve and optimize teaching and learning for all people based on scientific insights into how humans learn. "Three essential elements of UDL are often considered when developing curriculum for learners with diverse abilities. These components are multiple means of representation, engagement, and expression." Gargiulo \& Bouck, (2020, p. 27).

Open Source Resources. This emerging technology is designed to promote proven pedagogical content using an open-source design wherein a university produces specific materials for students which they can access for free. Student performance and retention are enhanced by access to high-quality resources.

Learning Communities. Learning communities in the form of seminars, clusters of students taking two classes together, or professional studies groups are particularly successful for part-time students. Bombardieri (2018) credits three factors for the effectiveness of this approach with part-time students: (a) the relationships with other students that a learning community provides; (b) the community's connections to supportive resources such as mentoring and coaching; and (c) a more meaningful, satisfying academic experience than first-year students are likely to experience by taking only a couple classes at a time. 
Time Management Strategies. Time management - the way individuals manage the events in their life with regard to time - has been cited as one of the seven (7) top challenges first-year college students face (Riddle, 2017). King-Berry (2016) maintains that, much like money, time is both valuable and limited; it must be protected, used wisely, and budgeted. Based on her work with students attending an urban HBCU, King-Berry offers several strategies designed to start students on a productive time management journey: develop a Daily Log, establish priorities, ask for help, don't put off for tomorrow what one can do today, do not let external factors waste valuable time, regularly revisit priorities.

\section{$\underline{\text { Socio-Emotional Support Approaches, Practices, and Strategies }}$}

Welcoming Campus Climate. In order to improve retention, a welcoming campus climate for nontraditional students is imperative. Furthermore, HBCUs should ensure that many of the courses and programs geared toward nontraditional students are offered on their main campuses, rather than miles away in a branch location or a remote office (Palmer, 2009).

High-Quality Faculty. Gasman \& Arroyo (2019) suggest that faculty members may be "the most pivotal players for creating holistic institutional conditions that facilitate student success and student development," (p. 7). These authors maintain that students benefit greatly in their pursuit of higher education when an institution has a critical mass of faculty members who are exceptionally skilled in their content.

Mentoring. Student mentors can also contribute significantly to the success and well-being of new college enrollees. Often, peers are highly skilled at understanding students' unique challenges and can relate more closely than faculty and staff to these challenges, offering first-hand advice (Kahu, 2018).

Culturally Relevant Community-Based Curriculum. Culturally relevant pedagogy and instructional materials can play an essential role in HBCUs to systematically remove prejudices about race and class and honor students' diverse backgrounds. These curricula will serve as a source of pride and motivation for African American students, enhancing their educational experiences (Honoring Origins-Chiefs of Change, 2019).

\section{Economic/Financial Health and Wellness Approaches, Practices and Strategies}

Clear Health Care Options. As students grapple with the high cost of education, college/university students must determine whether a parent's insurance plan will adequately cover them. Myong (2019) has indicted four insurance options that college students have: (a) staying on their parents' plan, (b) choosing a student health plan, (c) choosing a marketplace plan, (d) qualifying for Medicaid. When students are admitted to a college or university, appropriate institutional personnel should discuss their insurance status with them and apprise them of their options.

Strategies for Sustaining Health and Wellness. It is incumbent on faculty advisors and health services personnel to ensure that incoming students are made aware of recommendations that can support the stamina, physical, mental and emotional well-being that will minimize health care costs and contribute to students' retention and persistence. Multiple sources, such as the National Society of High School Scholars, offer tips and recommendations for staying healthy in school.

\section{Conclusion}

Retention and persistence remain among the most significant challenges to the much-needed existence of HBCUs, especially during the COVID-19 Pandemic. To improve, HBCUs must respond aggressively and effectively to the academic, social-emotional, and financial challenges that negatively impact their students' ability to complete course requirements, receive passing grades, establish meaningful relations, and matriculate in accordance with their academic plan. Articles selected and presented in this literature review offered empirical strategies that can positively impact the retention and persistence of HBCU students regardless of their cultural, linguistic, or ability diversity if implemented. While much work remains to be done, hopefully, the information presented here will improve retention and persistent outcomes for HBCUs. 


\section{References}

Bombardieri, M. (2018.). A Promising Model to Boost Retention for Part-Time Students. Retrieved from: https://www.americanprogress.org/issues/educationpostsecondary/reports/2018/07/31/454239/promisingmodel-boost-retention-part-time-students

Gargiulo, R. M., \& Bouck, E. C. (2021). Special education in contemporary society: an introduction to exceptionality. Los Angeles: SAGE.

Gasman, M., Regla-Vargas, A., Sandoval, C., Samayoa, A. C., \& Nguyen, H. (2020), January 31). Contributions of Historically Black Colleges and Universities to the Production of Black Nurses. Retrieved from https:/www.healio.com/nursing/journals/jne/2020-2-59-2/\{5f097c28-ad33-4bfa9976-cc15dd4a7989\}/contributions-of-historically-black-colleges-and-universities-to-theproduction-of-black-nurses

Kahu, E., \& Lodge, J. (2018). Student Success. Retrieved from https://studentsuccessjournal.org/issue/view/69

Katz, V., Jordan, A., \& Ognyanova, K. (2021, February 02). Digital inequality, Faculty communication, and remote learning experiences during the Covid-19 pandemic: A survey of U.S. undergraduates. Retrieved February 12, 2021, from https://journals.plos.org/plosone/article?id=10.1371\%2Fjournal.pone.0246641

Kennedy, H. (2020, December 01). Special education in a pandemic: A legal and guideline summary for mediators and conflict resolution practitioners. Retrieved February 11, 2021, from https://www.mediate.com/articles/kennedy-spec-ed-pandemic.cfm

King-Berry, A. (2016). The Power of Time Management in Ensuring Success for Students from Traditionally Under-represented Groups in Higher Education. Process Education Conference Proceedings

Myong, E. (2019). Four ways for college students to manage their health-care costs. Retrieved from: https://www.cnbc.com/2019/09/03/four-ways-for-college-students-to-manage-their-health-carecosts.html

National Society of High School. (2018). 7 Tips for Staying Healthy in College. Retrieved from: https://www.nshss.org/blog/7-tips-for-staying-healthy-in-college/

NSC Research Center. (2019). Persistence \& Retention - 2017. Retrieved from: https://nscresearchcenter.org/snapshotreport28-first-year-persistence-and-retention/

Palmer, R. T., Davis, R. J., \& Hilton, A. A. (2009). Exploring Challenges That Threaten to Impede the Academic Success of Academically Underprepared Black Males at an HBCU. Journal of College Student Development, 50(4), 429-445. doi: 10.1353/csd.0.0078

Richards, D., Awokoya, J.T. (2012). Understanding HBCU Retention and Completion. Retrieved from: https://files.eric.ed.gov/fulltext/ED562057.pdf

Riddle, R. (2017, May 9). Top 7 Challenges Most College Freshmen Face. Retrieved from: https://www.youniversitytv.com/college-tips/top-7-challenges-college-freshmen-face/

Tinto, V. (2012). Completing College. Retrieved https://www.press.uchicago.edu/ucp/books/book/chicago/C/bo5514387.htm 


\title{
STUDENT TEACHERS' OPINIONS ABOUT USING AUTHENTIC MATERIALS AND TASKS FOR ACQUIRING ESTONIAN CULTURAL HISTORY
}

\author{
Kristel Ruutmets, Evi Saluveer, \& Mari Niitra \\ Institute of Education, University of Tartu (Estonia)
}

\begin{abstract}
According to the Estonian National Curriculum for Basic Schools (2011), students should value their cultural heritage. Therefore, schools should do everything to develop students' cultural awareness and knowledge. Despite the importance of the topic the curriculum does not specify how and where it should be taught and does not say which material to use. One possibility to address the problem is to use authentic materials and tasks. The latter offer numerous ways to learn about one's cultural history, and help to create a bridge between the classroom and real life. Authentic materials are not specifically created for pedagogic purposes while authentic tasks require students to learn, practise and evaluate material the same way as they would do in real life. The focus of the use authentic materials has so far been mostly on foreign language teaching and learning. However, they have a huge potential in acquiring cultural knowledge as they offer both current and historical information. The aim of the study was to find out future primary school teachers' opinions about the authentic materials and tasks used during the course "The Child in Estonian Cultural History". 25 first-year students who attended the course participated in the study. The data was collected from the students' written reflection and analysed qualitatively. The results revealed that the students understood the relevance of authentic materials and tasks in acquiring and appreciating one's cultural history. They believed that authentic materials and tasks enrich the teaching and learning process, and help to make connections to their everyday life. It also became evident that the students needed better instructions of how to find appropriate authentic materials and exploit them effectively in their future teaching career.
\end{abstract}

Keywords: Authentic material, authentic task, cultural history, students' opinions.

\section{Introduction}

The Estonian National Curriculum for Basic Schools (2011) defines value competence as one of the general competencies, which among others emphasises the ability to value students' connections to the cultural heritage of their country and nation. The latter refers to the spiritual and material cultural property transferred from previous generations to the next (Kuutma, 2007). Despite the importance of the topic, the curriculum does not specify how and where it should be taught and does not say which material to use. Authentic material could complement the traditional study materials used to learn about cultural history. What is more, according to the Estonian Occupational Qualification Standards for teachers (level 7) (2020), the obligatory competencies of a teacher include the ability to choose study materials suitable for the learning objectives and the level of the study group. In-depth consideration of the choice and objectives of the study material in teacher training is also recommended in the Estonian Report of 2018 OECD Teaching and Learning International Survey (Taimalu et al., 2020). In order for the students to develop an understanding of how to choose and assess study material in their future teaching careers, it is important for them to exploit authentic materials and the tasks based on them during studies.

The widespread definitions of authentic materials still relied upon come from years ago and they are predominantly related to foreign language learning. For instance, authentic materials can be defined as materials "which have been produced for purposes other than to teach language" (Nunan 1995: 54) or as texts which are "created to fulfil some social purpose in the language community in which it was produced" (Little et al., 1988: 27, referred to in Guariento \& Morley, 2001). Nevertheless, the use of authentic materials should not be limited to (foreign) language learning. They could successfully be exploited in various other subjects, especially considering the definition of the word "authentic" as genuine, real, true-to-life. According to Mishan (2005: 46), authentic materials are like 'treasure chests of 
cultural exploration', providing up-to-date and historical information that can be used to raise learners' cultural awareness. Hereby it is important to find material that relates to the learners' cultural background and helps to understand its nuances (McGrath, 2016). In addition to traditional authentic materials (e.g. newspapers, books, films), the digitalisation of cultural heritage gives access to various materials, such as archival documents, databases and other publications. Exposure to authentic materials could also be linked to non-formal learning environments (e.g. museums, archives, libraries) and meaningful real-life tasks. The connection to real life in authentic tasks has been emphasized by many researchers (Mishan, 2017, Mueller, 2018, Oliver, Herrington, \& Reeves, 2002, Richards, 2006, Tomlinson, 2017). Such tasks are communicative in nature, and have a specific context and purpose (Mishan, 2017, Richards, 2006, Tomlinson 2017). Of equal importance is the accompanying learning process where new knowledge is acquired by independent research (Nicaise, Gibney, \& Crane, 2000). Tomalin and Stempleski (1993) stress that displaying a cultural document or artefact in class is not enough. Students need to be taught how to find appropriate information in the material.

Considering the importance of authentic material in bridging the gap between classroom and real life and their role in acquiring knowledge about one's cultural history, the study aimed at finding out future primary school teachers' opinions about the authentic materials and tasks used during the course "The Child in Estonian Cultural History". Based on the aim the following research questions were formulated:

1. Which positive aspects did the students point out in relation to the use of the authentic materials and tasks in learning Estonian cultural history?

2. Which problems did the students describe in relation to the use of the authentic materials and tasks?

3. How did the students assess the experience of using authentic materials and tasks in relation to their future teacher careers?

\section{Method}

\subsection{Sample}

The sample included 25 first-year students of the curriculum of primary school teacher at the University of Tartu (Estonia), who completed the compulsory course "The Child in Estonian Cultural History" in spring 2020. The study was conducted during the course and participation in it was voluntary. While presenting the results, the students' names are not mentioned to guarantee their anonymity.

\subsection{Data collection and procedure}

Qualitative research, which enables to address questions about the experience and perspectives of the participants, was employed in the study. During the course the students had to complete three tasks: 1) a short presentation about a toy after a visit to Tartu Toy Museum; 2) an analysis of an autobiographical children's book; 3) research work based on interviewing a family member about their childhood. The tasks were based on the use of different authentic materials and enabled the students to learn more about Estonian cultural history. After completing the tasks in May 2020 the students had to write a written reflection based on open questions related to the research questions of the study. The average length of the reflection was $1.5 \mathrm{~A} 4$ pages.

\subsection{Data analysis}

Thematic analysis was used to analyse the results obtained from the students' written reflections. The analysis was carried out in several phases, suggested by Brown and Clark (2006). First, every author read and re-read some of the students' reflections, independently identified meaningful units (words, phrases, sentences) and labelled them with initial codes. Then, to increase the trustworthiness of the study, all the authors together reviewed the initial coding in all the reflections and in the case of differences in coding reached a consensus. Next, similar codes were grouped into potential sub-themes, which in their turn were categorised under main themes. Finally, the sub-themes and main themes were reviewed and refined according to the research questions.

\section{Results}

\subsection{Positive aspects in relation to the use of the authentic materials and tasks in learning Estonian cultural history}

When analysing the data, the following sub-themes were identified: attractiveness of the materials and tasks, and benefits of the tasks in learning cultural history. 
Attractiveness of the materials and tasks. In the case of the presentation of a toy after a museum visit, the students appreciated the informal environment and free choice of the toy the most. The toys were considered exciting and innovative material, which in the students' opinion helped to make a personal connection with their parents' and grandparents' past. The students found the task fun and stressed a good alternative to traditional learning in the classroom. Another positive aspect of the task was its simplicity. A number of the students also mentioned that they enjoyed listening to the fellow-students' presentations. The second task, the book analysis, received the most variable evaluations. The students had to choose an autobiographical children's book from the given list. Not all the students considered the book they chose interesting. However, those who did pointed out that it enabled them to draw parallels with their own childhood. They also appreciated the connections between the theoretical materials used during the course and themes exposed in the chosen books. An alternative way of learning history instead of memorising historic dates was mentioned a number of times. The third task - research about one's family member's childhood - was considered the most favourite task by the majority of the students. Aspects such as an interesting and exciting process, new information about the family member's past and emotional connections to their relatives were repeatedly mentioned. Based on the students' reflections it could be concluded that all the used authentic materials and tasks increased the students' interest in historical objects, events and related literature and helped to make connections between the present and the past.

Benefits of the tasks in learning cultural history. Several benefits of the tasks were named. The visit to the toy museum made the students realise the rich possibilities of such learning process. Despite the simplicity of the task, it helped to exemplify different historical periods. When it comes to the reading task, increased awareness in using a literary work and its usefulness in understanding historic events was highlighted. The autobiographies the students read enabled them to see the 'big picture' of the Soviet period. The task also gave inspiration for similar tasks to be used in their future career. The third task about a family member's childhood helped the students to understand the past in a wider historical context, putting their family history in the centre of the events. Comparing their own childhood experiences with those of their relatives was considered to be a valuable experience. The task inspired some of them to study their family history more thoroughly in order to write it down for the future generations.

\subsection{Problems described in relation to the use of the authentic materials and tasks}

The data analysis revealed the following sub-themes: problems related to the materials and problems related to the tasks.

Problems related to the materials. One of the problems brought out in relation to the first two tasks was making an informed choice. The variety of different toys made it difficult to focus on one particular toy. Limited information about a chosen toy at the museum exposition was also mentioned. Some students were dissatisfied with the chosen book and found it difficult to understand or boring. They said it was due to particular style and old-fashioned vocabulary. The lack of documented personal archives in some cases also complicated doing research on a family member's childhood.

Problems related to the tasks. The students reported little previous experience in analysing literary texts. Hence, they were worried about the tendency to retell the story instead of analysing it. While researching a family member's past, mainly practical problems were indicated, e.g. lack of family photos from a particular period, difficulty visiting elderly relatives during the Corona pandemic in spring 2020 , organisation of the working process and finalising the results. The students repeatedly stressed the need for more concrete instructions for analysing books and conducting research. Some students would have preferred indicative questions about each book and a clear structure and format of the expected outcome.

\subsection{The experience of using authentic materials and tasks in relation to their future teacher careers}

Using authentic materials and doing authentic tasks during the course enriched the students' understanding of different learning environments and materials. Most of the students claimed that they would certainly use similar tasks with authentic materials in their future teaching. They saw the former as a possibility to diversify the learning process and make subjects more attractive. On the other hand, students could add very few original ideas of their own. Watching and analysing old TV commercials, interviewing classmates, using Google Maps street views were suggested by some students. 


\section{Discussion and conclusions}

Authentic materials and tasks are important for learning about cultural heritage, both material and spiritual. They create perspective, help put details in a broader context, and develop a deeper understanding of certain historical periods. The connections made during the study process with one's personal life and family history motivate students and help to make learning meaningful. The relevance and cultural appropriateness of authentic materials and tasks as well as students' intrinsic interest in them have been stressed by several authors (e.g., Belet Boyaci \& Güner 2018, McGrath, 2016). The authentic materials used in the course "Child in Estonian Cultural History" and the tasks based on them were highly evaluated by the students. They were seen interesting and meaningful bringing variety to the traditional classroom. The students realised the tasks' "enriching potential in the learning process" (Black 2005: 158). In addition, the respondents also appreciated the variety and novelty of the tasks, and alternative learning environments.

However, it became obvious that the students are used to detailed instructions and felt uncertain when given more freedom in completing tasks that require improvisation and varied outcomes. At the same time, it is important that in completing authentic tasks students should be encouraged to construct their own responses (Mueller, 2018) rather than using existing algorithms (Oliver et al., 2002). The respondents' uncertainty about their work may be due to the results-oriented school system in Estonia. At the same time, it became evident that real-life tasks helped the learners to create meaningful connections with the past and place personal experiences in a broader context. In this way, history, which for many was previously related to memorising facts, acquired a new meaning. According to Tomlinson (2013: 27), foreign language teaching "materials which address the learner in an informal, personal voice are more likely to facilitate learning than those which use a distant, formal voice." The present study confirms the idea that authentic materials can have a much wider role in teaching and their use should not only be limited to language learning. The tasks gave students the confidence to use authentic material and related tasks in their future teaching. Teachers' experience during their studies creates a context for their further choices (Falk et al., 2006). Therefore, their insecurity about doing authentic tasks may influence their future decisions on the choice of appropriate materials and tasks.

Based on the findings of the study, the following recommendations can be made. Authentic materials are an inexhaustible source in acquiring knowledge. When used together with meaningful authentic tasks, they give learners a deeper insight into a studied topic. On the other hand, the teacher's role in using authentic materials and tasks should not be underestimated. Students should be helped to choose appropriate material and be equipped with concrete selection criteria. Also, samples of the expected outcome can be demonstrated by the teacher to give students a better understanding of the task. It is also important to develop student-friendly guidelines for using authentic materials that are relevant to the content of a particular subject. Such materials would offer future teachers useful ideas and techniques and encourage them to put these ideas into practice. As a result, more teachers would be motivated to use 'the real' (McGrath, 2016) in their lessons and courses.

\section{References}

Belet Boyacı, Ş. D., \& Güner, M. (2018). The impact of authentic material use on development of the reading comprehension, writing skills and motivation in language course. International Journal of Instruction, 11(2), 351-368. doi.org/10.12973/iji.2018.11224a

Black, G. (2005). The Engaging Museum: Developing Museums for Visitor Involvement. London \& New York: Routledge.

Brown, V., \& Clarke, V. (2006). Using Thematic Analysis in Psychology. Qualitative Research in Psychology, 3, 77-101.

Falk, J. H., Dierking, L. D., \& Adams, M. (2006). Toward a Usable Model for Understanding Learning in Museums. In S. MacDonald (Ed.), A Companion to Museum Studies (pp. 323-329). London, Blackwell Publishing.

Guariento, W., \& Morley, J. (2001). Text and task authenticity in the EFL classroom. ELT Journal, 55 (4), 347-353. doi.org/10.1093/elt/55.4.347

Kuutma, K. (2007). Kultuuripärand. In T. Jaago (Ed.), Argikultuuri uurimise terminoloogia e-sõnastik. Retrieved April 13, 2021, from https://argikultuur.folklore.ee

McGrath, I. (2016). Materials Evaluation and Design for Language Teaching (2 ${ }^{\text {nd }}$ edition). Edinburgh: Edinburgh University Press Ltd.

Mishan, F. (2005). Designing Authenticity into Language Learning Materials. Bristol: Intellect Books. 
Mishan, F. (2017). 'Authenticity 2.0': Reconceptualising 'Authenticity' in the Digital Era. In A. Maley \& B. Tomlinson (Eds.), Authenticity in Materials Development for Language Learning (pp. 10-25). Newcastle upon Tyne: Cambridge Scholars Publishing.

Mueller, J. (2018). Authentic tasks. Retrieved March 25, 2021, from http://jfmueller.faculty.noctrl.edu/toolbox/tasks.htm

National Curriculum for Basic Schools (2011). Riigi Teataja I, 14.01.2011. Retrieved April 29, 2021, from https://www.riigiteataja.ee/en/eli/524092014014/consolide

Nicaise, M., Gibney, T., \& Crane, M. (2000). Toward an Understanding of Authentic Learning: Student Perceptions of an Authentic Classroom. Journal of Science Education and Technology, 9(1), 79-94.

Nunan, D. (1995). Designing Tasks for the Communicative Classroom. Cambridge: Cambridge University Press.

Occupational Qualification Standards: Teacher, EstQF Level 7 (2020). Retrieved January 22, 2021, from https://www.kutseregister.ee/ctrl/et/Standardid/vaata/10824233

Oliver, R., Herrington, J., \& Reeves, T. (2002). Authentic activities and online learning. Retrieved March 27, 2020 from https://ro.ecu.edu.au/ecuworks/3900

Richards, J. C. (2006). Communicative Language Teaching Today. Cambridge: Cambridge University Press.

Taimalu, M., Uibu, K., Luik, P., Leijen, Ä., \& Pedaste, M. (2020). Õpetajad ja koolijuhid väärtustatud professionaalidena. OECD rahvusvahelise õpetamise ja opppimise uuringu TALIS 2018 uuringu tulemused (2). Tallinn: SA Innove. Retrieved from https://www.innove.ee/wpcontent/uploads/2020/04/TALIS2_kujundatud.pdf

Tomalin, B., \& Stempleski, S. (1993). Cultural Awareness. Oxford: Oxford University Press.

Tomlinson, B. (2013). Materials Evaluation. In B. Tomlinson (Ed.), Developing Materials for Language Teaching (2 ${ }^{\text {nd }}$ edition) (pp. 21-48). London, New Delhi, etc.: Bloomsbury Academic.

Tomlinson, B. (2017). Introduction. In A. Maley \& B. Tomlinson (Eds.), Authenticity in Materials Development for Language Learning (pp. 1-9). Newcastle upon Tyne: Cambridge Scholars Publishing. 


\title{
TRANSFER EFFECT OF $N$-BACK TRAINING: MATHEMATICAL IMPLICATIONS IN SCHOOL-AGE CHILDREN
}

\author{
Selma Boz \\ Department of Education, Eötvös Loránd University (Hungary)
}

\begin{abstract}
Working memory (WM) is the system which is used for short-term storage and where information about cognitive tasks is manipulated. One of the most important characteristics of WM is its limited capacity, which restricts cognitive performance. Despite of this limit in WM capacity, the efficiency of WM can be improved with WM training and this training effect can be transferred to performance on complex tasks, such as mathematical operations. Such training tasks are complex and necessarily include core processes and these measures, therefore, contribute to difficulty to design tasks and interpret the outcomes for specific changes gained from the training. For example, $n$-back tasks which are used in a wide range of research are based on core training. Since core trainings address the executive functions of WM and enhance the domain-general aspects, increasing performance on domain-general factors may promote both near and far transfer effects of training. In the current study, WM training will be constructed on the basis of the interference framework that characterizes individual differences in WM performance. The aim of this study is to explore individual differences in training and the way transfer effects occur, evaluating gains from Mathematics proficiency. An adaptive version of $n$-back tasks will be implemented for the proposed study, within WM load and interference lures. The study will be carried out with 40 school-age children between the ages of 9 and 12, and Solomon four group design method will be used to group them. $d$ ' (D-Prime) theory will be conducted in order to obtain detailed comparison between groups as well as interpretation of individual differences in processing of information.
\end{abstract}

Keywords: Working memory, n-back training, near transfer effect, far transfer effect, mathematics.

\section{Introduction}

The complex tasks in Mathematics (Math) include numerous cognitive processes and strategies which are necessary for Math skills. Accordingly, cognitive processes related to numbers and counting abilities are identified with working memory (WM) (Hubber et al., 2014) where information is stored and monitored, as well as manipulated (De Stefano \& LeFevre, 2004; Raghubar, Barnes, \& Hecht, 2010). However, the prominent feature of WM is its limited capacity (Baddeley, 2000). Therefore, a task can contribute to exceeding individual's available capacity (Just \& Carpenter, 1992), leading to poor performance in Math.

The main theoretical framework of this study has been offered to describe the basis of individual differences in WM capacity and to explain the functions of WM. In this framework, this paper presents a possible outcomes of how interference theory (Cowan, 2000; Oberauer, 2001) defines individual differences in WM performance along with $n$-back training and how trained, process-specific improvements in WM performance may affect mathematical improvements in school-age learners as transfer effects.

As a result of the training outcomes, this study may help curriculum designers to immerse training programs in Math curriculum to create more efficient teaching programs regarding children's individual differences.

\section{Theoretical background}

\subsection{Working memory}

It is conceded that working memory (WM) is a system which has a processing-oriented construct and supplies active processing and temporary storage of task-relevant information (Cowan, 1995; Oberauer, 2009). One of the most important characteristics of WM is its limited capacity, which contributes to restriction in cognitive performance. WM capacity is associated with performance on cognitive tasks. For instance, performance of individuals with greater capacity might be better than individuals with lesser 
capacity in cognitive domains (Conway, Jarrold, Kane, Miyake \& Towse, 2007). In accordance, understanding what constrains WM capacity is an important step toward understanding the reasons of individual differences in cognitive activities (Oberauer, Farrell, Jarrold \& Lewandowsky, 2016).

\subsection{Interference framework}

The limitation in WM capacity can be explained by interference between items and processes (Nairne, 1990; Oberauer \& Kliegl, 2006; Oberauer, 2009). According to this interference theory, WM is a limited-capacity system, but this limitation is ascribed to interference among memory representations and processes (Oberauer, 2009). In brief, when an individual faces a flow of information, his/her limit of capacity can be exceeded. This exceeding in capacity might lead to limitations to hold information in memory and to update those items during the processing of new information. It eventually becomes difficult to differentiate old information from the new one. The capability to resist interferences is required to accomplish complex tasks (Nigg, 2000). Here, interference control can provide a link between WM and information processing in Math. As an example, regarding Math settings, it is possible that interference will occur if a given problem is largely similar to a previously learned problem, resulting in all likelihood less retrieval capability (De Visscher \& Noël, 2014). Therefore, the efficiency of memory representations of Math problems, especially arithmetical problems, depends on previously learned problems (i.e. overlap theory) (Nairne, 1990).

Consequently, poor performance in WM is based on inadequate control of irrelevant information (Hasher and Zacks, 1988). It becomes unavoidable to recall irrelevant information instead of target items, if no longer relevant items cannot be suppressed (Palladino, 2006). On that occasion, while an individual is processing information, these relevant and irrelevant items induce competing for limited access in WM. $\mathrm{He} / \mathrm{she}$ must resist irrelevant information to remove them once they get access or give access in the first place in memory (Hasher, Lustig \& Zack, 2007; Unsworth \& Engle, 2007). Individuals who can manage this process with their skills of interference control perform better on higher-order cognitive tasks than individuals with poor control abilities (Unsworth, 2010; Friedman \& Miyake, 2004). Therefore, interference control is an essential construct of individual differences for cognitive abilities.

\section{3. $n$-Back training and transfer effects}

It is propounded that the efficiency of WM can be improved with WM training (Klingberg et al., 2005; Verhaeghen, Cerella, \& Basak, 2004; Westerberg et al., 2007). Due to the fact that WM plays a key role in various processes, as well as individual differences in cognitive performance, the main target about training studies is to recruit WM mechanism and transfer training effect to performance on complex tasks (Sternberg, 2008).

The decision about whether the training is effective depends on its transfer effects on to untrained tasks (Shipstead, Redick, \& Engle, 2010). Accordingly, WM training is considered to provide both near and far transfer effects (Barnett \& Ceci, 2002). Near transfer effect concerns with improvement in a related domain, such as WM scores, while far transfer effect relies on a measure that training can affect other related skills. Near transfer effect concerns with improvement in a related domain, such as WM scores, while far transfer effect is based on a measure that training can affect other related skills. The outcome of far transfer effect is significant to predict the efficiency of a training program, however near transfer effect might be devalued as a structure of practice effect if near transfer tests reflect similar outcomes to the training tasks (Klingberg et al., 2005). Additionally, the methods of WM training generally can be classified as "core training" and "strategy training", as revealed by Morrison and Chein (2011). This categorization is based on training targeting that serves either domain-general or domain-specific aspects of WM. Core-based training paradigms are conceived to target domain-general mechanisms and precisely aimed to embrace overall functions, such as maintaining, encoding and retrieval of information, not a specific type of information. Such training tasks are complex and necessarily includes core processes and these measures, therefore, contribute to difficulty to design tasks and interpret the outcomes for specific changes gained from the training. Since core trainings target executive functions of WM and enhance the domain-general aspects, increasing performance on domain-general factors may promote both near and far transfer effects of training. For example, $n$-back tasks which are used in wide range of research are based on core training.

In an $n$-back task, an examinee is subjected to stimuli such as letters or shapes appeared one on a computer screen at a limited time. In this task, the target is to decide whether the current item matches the one that was presented " $n$ " items prior. " $n$ " can be manipulated to increase or decrease the load in the WM system. During the task, the examinee needs to make a recognition decision on each item by accepting targets and rejecting distractors based on the $n$-back rule (Oberauer et al., 2007). In this manner, information is presented rapidly and there are only " $n$ " number of relevant temporal positions, incoming items are bound to the same temporal context as previous items and the WM system is required to resist interference from this previously relevant information. 


\section{Methodology}

The research will include 40 Turkish students in primary schools, between the ages of 9 and 12 years. These participants will be randomly divided into four groups, according to the Solomon 4-group design, the strongest design for treatment studies, and each group will be engaged in a different combination of experimental manipulations: the first group will receive the pre-test, the training, and the post-test; the second group will receive only the training and the post-test; the third group will receive the pre-test, no training, and the post-test, and the forth group will receive only the post-test. The training groups will receive 16 online training sessions.

To address the aim of the study related to differences in transfer of trained skills to Math tasks between the experimental and control groups, accuracy and reaction time will be collected from the adaptive $n$-back paradigm and Math proficiency tests via E-Prime Go Software. The experimental groups will be completing an adaptive $n$-back training with lures, which were developed in the Cognition and Language Laboratory at the Graduate Center of the City University of New York (Wadhera, Campanelli, \& Marton, 2018). Within these groups, effects of individual differences and effects of experimental manipulations of interference and set size level on $n$-back performance will be analyzed. Signal Detection Theory will be used by calculating $d$ ' regarding $n$-back performance over the course of training. Between the experimental and control groups, three categories of Math tests will be administered before and after the training period to determine transfer effects. Performance of two control groups will be compared to that of the experimental groups.

A battery of Math proficiency tests will be administered online to participants in a randomized order, with respect to their group assignments by using E-Prime Go software. Three different tests will be used to examine participants' Math proficiency: WM updating test, arithmetic test and word problem test. The purpose of this task is to measure far transfer of trained skills of interference control to performance on Math tasks. Firstly, a standardized Math proficiency measure will be used, that includes the WM updating test (Pelegrina et al., 2020) to assess children's abilities to solve arithmetic problems while storing previous results for future use in calculation. A series of arithmetical operations appear consecutively in two boxes across all tasks. Depending on the task, participants are required to retrieve information associated with the box, apply the operation and then substitute the result for the corresponding box. Secondly, the arithmetic test will be designed based on interference theory, in addition to the principles of competition and cooperation among neighboring arithmetic problems (Vergut \& Fias, 2005). For instance, doing operations with multi-digit numbers needs holding intermediate results (e.g. holding tens in mind and doing carry operation) to attain a correct answer. Lastly, the word problem test (Ng, Lee and Khng, 2017) will be developed according to interference theories, that will embrace irrelevant information which participants will not need while solving the problem. Here, the participants will encounter distracting or competing information while trying to maintain the task goal and their performance in differentiating relevant and irrelevant information will be evaluated for this task.

\section{Expected outcomes and limitations}

In this study, it is a key aspect to determine whether this training will improve the WM system, which are related to manipulation of memory representations and to resisting interference during processing, and to understand how this improvement can be transferred to participants' Math skills. The possible outcomes are described based on these aims.

The experimental training group will show more pre- to post-training improvement than the control group on the numerical operations of Math proficiency. Training will contribute to gains in a population of elementary level children with different levels of arithmetic ability (Kuhn and Holling, 2014). Additionally, retrieval processes during Math learning allows consideration of the benefits of an interference-based WM training to children's performance on Math.

The second set of expected outcomes will address the differences across groups on described transfer tasks. Participants in both training groups will perform significantly better on the interference condition than the two control groups. They will also show significantly better performance on numerical operation tasks than the two control groups, which will contribute to strong evidence for the role of WM interference control in Mathematical abilities in school-age children. Alternatively, if the training groups show similar performance with the control groups, this may reveal that training domain-general WM mechanisms is not enough and that Math-specific processes have to be trained as well in order to improve performance on Math tasks. In addition, if the training groups perform significantly better on numerical operation tasks than the control groups, this will mean that binding and updating mechanisms play a crucial role in interference control and also ability in Math. Lastly, it is expected that the training groups and the control groups perform similarly on the specific tasks of fractions, decimals and algebra because 
I do not expect immediate effects of the WM training on a complex Math task that incorporates several other mechanisms, such as task difficulties and Mathematical prerequisites.

In this study, data collection would have happened during the 2020 fall semester in elementary schools in Turkey. Each participant would be tested and trained in person within the control of the investigator at their schools. Due to COVID-19, the schools were closed in Turkey where all task completion was planned to be done and the data could not be collected during the planned period. Therefore, the original plan was adapted to online data collection, which the process has not started yet.

\section{References}

Baddeley, A. (1992). Working memory. Science, 255, 556-559.

Barnett, S. M., \& Ceci, S. J. (2002). When and where do we apply what we learn? A taxonomy for far transfer. Psychological Bulletin, 128, 612-637.

Conway, A. R. A., Jarrold, C., Kane, M. J., Miyake, A., \& Towse, J. N. (Eds.). (2007). Variation in working memory. New York: Oxford University Press.

Cowan, N. (1995). Oxford psychology series, No. 26. Attention and memory: An integrated framework. New York, NY, US: Oxford University Press.

Cowan, N. (2000). Processing limits of selective attention and working memory: Potential implications for interpreting. Interpreting, 5(2), 117-146.

De Stefano, D., \& LeFevre, J-A. (2004). The role of working memory in mental arithmetic. European Journal of Cognitive Psychology, 16(3), 353-386.

De Visscher, A., Noël, M.-P., (2014). The detrimental effect of interference in multiplication facts storing: typical development and individual differences. J. Exp. Psychol.: General, 143, 2380-2400.

Friedman, N. P., \& Miyake, A. (2004). The relations among inhibition and interference control functions: A latent-variable analysis. Journal of Experimental Psychology: General, 133, 101-135.

Hasher, L., \& Zacks, R. T. (1988). Working memory, comprehension and aging: A review and new view. In G. H. Bower (Ed.), The psychology of learning and motivation. San Diego, CA: Academic Press.

Hasher, L., Lustig, C., \& Zacks, R. (2007). Inhibitory mechanisms and the control of attention. In A. R. A. Conway, C. Jarrold, M. J. Kane (Eds.) \& A. Miyake \& J. N. Towse (Ed.), Variation in working memory (p. 227-249). Oxford University Press.

Hubber, P.J., Gilmore, C. \& Cragg, L. (2014) The roles of the central executive and visuospatial storage in mental arithmetic: A comparison across strategies. The Quarterly Journal of Experimental Psychology, 67(5), 936-954.

Just, M. A., \& Carpenter, P. A. (1992). A capacity theory of comprehension: Individual differences in working memory. Psychological Review, 99(1), 122-149.

Klingberg, T., Fernell, E., Olesen, P. J., Johnson, M., Gustafsson, P., Dahlstrom, K., et al. (2005). Computerized training of working memory in children with ADHD-a randomized, controlled trial. Journal of the American Academy of Child and Adolescent Psychiatry, 44(2), 177-186.

Kuhn, J.-T., \& Holling, H. (2014). Number sense or working memory? The effect of two computer-based trainings on mathematical skills in elementary school. Advances in Cognitive Psychology, 10(2), 59-67.

Morrison, A. B., \& Chein, J. M. (2011). Does working memory training work? The promise and challenges of enhancing cognition by training working memory. Psychonimic Bulletin \& Review, 18, 46-60.

Nairne, J. S. (1990). A feature model of immediate memory. Memory \& Cognition, 18, 251-269.

$\mathrm{Ng}$, J., Lee, K., \& Khng, K. H. (2017). Irrelevant information in math problems need not be inhibited: Students might just need to spot them. Learning and Individual Differences, 60, 46-55.

Nigg, J. T. (2000). On inhibition/disinhibition in developmental psychopathology: Views from cognitive and personality psychology and a working inhibition taxonomy. Psychological Bulletin, 126(2), $220-246$

Oberauer, K. (2001). Removing irrelevant information from working memory: A cognitive aging study with the modified Sternberg task. Journal of Experimental Psychology: Learning, Memory, and Cognition, 27(4), 948-957.

Oberauer, K. (2009). Design for a working memory. In B. H. Ross (Ed.), The psychology of learning and motivation: Vol. 51. The psychology of learning and motivation (pp. 45-100). San Diego, CA, US: Elsevier Academic Press.

Oberauer, K., \& Kliegl, R. (2006). A formal model of capacity limits in working memory. Journal of Memory and Language, 55(4), 601-626. 
Oberauer, K., Farrell, S., Jarrold, C., \& Lewandowsky, S. (2016). What limits working memory capacity? Psychological Bulletin, 142(7), 758-799.

Oberauer, K., Süß, H.-M.,Wilhelm,O., and Sander, N.(2007).Individual differences in working memory capacity and reasoning ability, in A. R. A. Conway, C. Jarrold, M.J. Kane, A. Miyake and J. N. Towse (Eds), Variation in Working Memory, (pp. 49-75), New York, NY: Oxford University Press

Palladino, P. (2006). The Role of Interference Control in Working Memory: A Study with Children at Risk of Adhd. Quarterly Journal of Experimental Psychology, 59(12), 2047-2055.

Pelegrina, S., Justicia-Galiano, M.J., Martín-Puga, M.E. and Linares, R. (2020). Math Anxiety and Working Memory Updating: Difficulties in Retrieving Numerical Information from Working Memory. Front. Psychol. 11(669).

Raghubar, K. P., Barnes, M. A., \& Hecht, S. A. (2010). Working memory and math: A review of developmental, individual difference, and cognitive approaches. Learning and Individual Differences, 20 (2), 110-122.

Shipstead, Z., Redick, T. S., \& Engle, R. W. (2010). Does working memory training generalize? Psychologica Belgica, 50, 245-276.

Sternberg, R. J. (2008). Increasing fluid intelligence is possible after all. Proceedings of the National Academy of Sciences, 105(19), 6791-6792.

Unsworth, N. (2010). Interference control, working memory capacity, and cognitive abilities: A latent variable analysis. Intelligence, 38(2), 255-267.

Unsworth, N., \& Engle, R. W. (2007). The nature of individual differences in working memory capacity: Active maintenance in primary memory and controlled search from secondary memory. Psychological Review, 114, 104-132.

Verguts, T. \& Fias, W. (2005). Interacting neighbors: A connectionist model of retrieval in single-digit multiplication. Mem Cognit. 33(1), 1-16.

Verhaeghen, P., Cerella, J., \& Basak, C. (2004). A working memory workout: How to expand the focus of serial attention from one to four items in 10 hours or less. [Article]. Journal of Experimental Psychology. Learning, Memory, and Cognition, 30(6), 1322-1337.

Wadhera, D., Campanelli, L., \& Marton, K. (2018). The influence of bilingual language experience on working memory updating performance in young adults. In. T. T. Rogers, M. Rau, X. Zhu, C. W. Kalish (Eds.), Proceedings of the 40th Annual Conference of the Cognitive Science Society, 2639-2644, Madison, WI. ISBN: 978-0-9911967-8-4

Westerberg, H., Jacobaeus, H., Hirvikoski, T., Clevberger, P., Ostensson, M. L., Bartfai, A., \& Klingberg, T. (2007). Computerized working memory training after stroke - A pilot study. Brain Injury, 21(1), $21-29$ 


\title{
SMART CV FOR LIFELONG QUALIFICATIONS CERTIFICATION BASED ON BLOCKCHAIN
}

\author{
Anastasios A. Economides, \& Maria Perifanou \\ SMILE lab, University of Macedonia (Greece)
}

\begin{abstract}
There is a need for fast, automatic, and trusted verification of a person's qualifications. This paper proposes the Smart CV (Curriculum Vita) that contains links to Blockchain-based certifications of the person's qualifications. Also, the paper proposes an architecture for the Blockchain-based Smart CV consisting of five layers: 1) Trusted certificate Issuers; 2) Trusted Distributed Ledgers; 3) Trusted management; 4) Smart CV; 5) Users. Educational institutes, accreditation organizations, public authorities, employers and others can cooperate to issue and accept these Blockchain-based certificates presented on a person's Smart CV.
\end{abstract}

Keywords: Accreditation, blockchain, certificates, lifelong education, qualifications certification.

\section{Introduction}

Currently, there are serious ethical problems in higher education with regards to copying and fake degrees (Børresen, et al., 2020). Most educational certificates are issued and stored as digital certificates, and they face security dangers and adulteration. Employers, teachers, university administrators, and other officials have serious concerns about the validity of these certificates and they do not trust them. In addition, when employers and recruiting agencies screen candidates' CVs (Curriculum Vita), they would like to fast and easily verify these candidates' qualifications. Therefore, there is a need for an automatic, trusted, open, and transparent solution for managing and verifying qualifications. This paper proposes the use of the Blockchain technology for qualifications' certification in education (formal, informal, and non-formal), employment, and other cases. It proposes a Smart CV linked with Blockchain-based certifications of the information included in it. It also proposes a model for the Smart CV as well as an architecture for the interactions of all entities involved (e.g., certificates' providers, public authorities, professional licenses providers, educational institutes, employers, persons) and the Distributed Pledges.

The blockchain is a security technology that has been applied in many sectors including education (Sharples \& Domingue, 2016). Blockchain technology can create new opportunities and challenges for knowledge and skills certification anytime and anyplace. It provides a decentralised trusted peer-to-peer infrastructure, which also supports identity management, openness, transparency, and accountability (Mikroyannidis et al., 2019). The blockchain is a long chain of linked blocks securely stored on every participating computer. Each block typically contains a link to a previous block, a timestamp and transaction data. The next block can only be added if the majority of participants agree on.

Blockchain technology has been used by various secure issuing and verification protocols. These protocols store metadata regarding the certificate issuer, the data issued, and the type of certificate. Blockcerts (MIT, 2020) is an open standard for creating, issuing, viewing, and verifying blockchain-based certificates. Individuals are able to possess and share their own official records. Arizona State University's Trusted Learner Network (TLN) (ASU, 2019) is a decentralized approach to securely recording, curating, and sharing learner's data. There are 12 principles of the TLN: 1) Stores learner achievements; 2) Safe and secure; 3) Always up-to-date; 4) Issued and maintained by the entity; 5) Presents current information first; 6) Records learner consent; 7) Shared only within the TLN; 8) Co-owned by the learner; 9) Open-source tools and APIs; 10) Identity and access management tools included; 11) Non-commercial use; 12) Network of networks. 
A certificate issuer (e.g., Universities, Certification and License providers) can add a block containing a certificate for a person in the blockchain. The data about the certificate are timestamped and securely stored in all participating computers. Anyone (e.g., the person, a teacher, an employer) having the cryptographic 'public key' can view these data. However, no one can change these data, even the original certificate issuer. The University of Nicosia used Bitcoin blockchain to issue and verify academic certificates (UNIC, 2020). Also, Sony Global Education (SGE) developed a blockchain-based system to record and reference educational data and digital transcripts from multiple educational institutions (SONY, 2017). SAP introduced TrueRec, a Blockchain-based digital wallet for storing professional and academic credentials (SAP, 2017). Whenever a new credential is issued through TrueRec, the user receives the credential and its digital fingerprint is recorded on the blockchain. When the user sends this credential to someone, the receiver can instantly verify its validity.

Rooksby \& Dimitrov (2017) developed an Ethereum Blockchain-based system to store student grades and to provide a cryptocurrency. Also, Skiba (2017) developed a Blockchain-based secure and trustworthy system to allow students to own their credentials from different universities. Similarly, Turkanović et al. (2018) as well as Gräther et al. (2018) developed platforms for certificate issuing, validating, and sharing. Furthermore, Mikroyannidis et al. (2019) proposed a Blockchain-based personal Learning Passport that contains Smart Badges from both formal and informal learning organizations.

This paper extends the traditional digital CV exploiting the Blockchain technology. In a CV, a person lists titles of his/her experiences and certificates acquired from various institutes, organizations, businesses, and employers. However, there is no guarantee for the accuracy of all these information. Blockchain technology can verify the integrity of a certificate, its timestamp, its issuer, and much more.

First, this paper introduces a Smart CV model. Then it introduces an architecture for all entities involved. Finally, it concludes and suggests future research directions.

\section{Smart CV}

A person's CV includes information regarding certificates issued by public and private authorities. These certificates include licenses, degrees, credentials, records, credits, test results, badges, awards, positions, experience, endorsements, recommendation letters, etc. A certificate is a proof (verification) that the person successfully passed specific thresholds or achieved specific outcomes or completed specific requirements. For example, a certificate may certify that the person participated in an activity above a specific level (e.g., above $80 \%$ attendance in the activity, or above $60 \%$ completed assignments in the activity), or that the person successfully passed a specific threshold in a specific activity (e.g., test, exam, work), or achieved a specific score, outcome, achievement, artifact, award, professional status, position, etc.

This paper defines Smart CV to be a digital CV containing the certifications for any information reported in it. In the same way a digital document may include web links to information in the Web, a smart CV include links to the corresponding certificates in one or more Blockchains. The validity of the Smart CV is provided by the Blockchain.

The next Figure 1 shows a Smart CV. For example, the certificate "DS Training Cert1" confirms that the person has "successfully" participated in the Digital Skills Training \#1 (e.g., Python programming). In parallel, the certificates "DS Cert1" and "DS Cert2" confirm that the person has successfully passed the exams for the Digital Skills certification \#1 (e.g., Certified Entry-Level Python Programmers- PCEP), and the Digital Skills Certification \#2 (e.g., Microsoft Technology Associate 98-381: Introduction to Programming with Python). All these certifications are officially issued by the appropriate authorities. In the Smart CV, there are links to the corresponding data in the Blockchains. Anyone holding the public key for a specific certificate can see it. So, the Smart CV owner can grant access to specific certificates to specific recipients.

Further granularity can be also incorporated in this Smart CV model. For example, the Smart CV can include the courses taken for the M.Sc. degree and all work done for each course (Figure 2). Also, it can include certificates for professional responsibilities and achievements in various jobs.

Finally, let us define an Open Smart CV. An Open Smart CV is a Smart CV that is Open to anyone, i.e., all information and certificates listed in this Smart CV can be accessed and viewed by anyone. In a partially Open Smart CV, only specific information and certificates are open to specific people or machines. The degree of its Openness depends on how much information is open to how many people or machines. 
Figure 1. An example of a Smart $C V$.

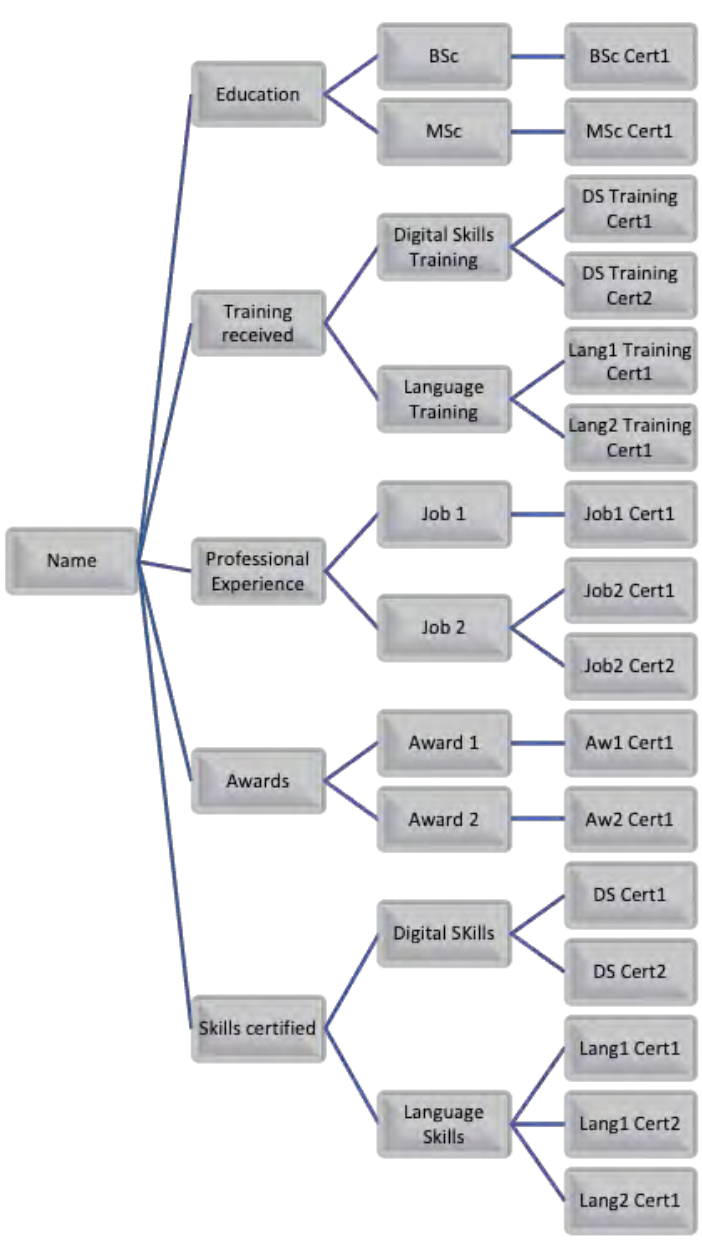

Figure 2. More granularity of a Smart CV example.

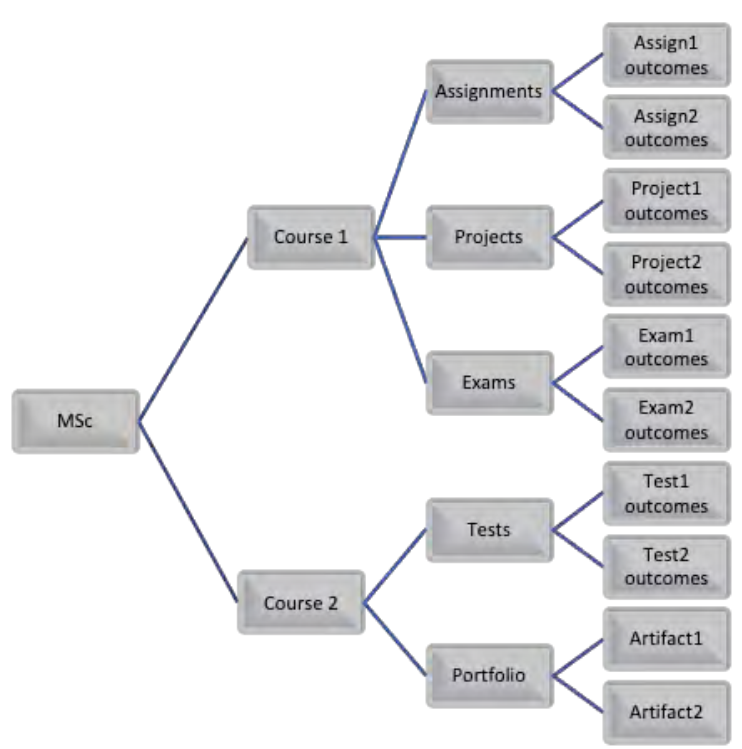

\section{Architecture}

In this section, the paper introduces an architecture for the Blockchain-based Smart CV (Figure 3). There are 5 layers in this architecture: 1) Trusted Certificate Issuers; 2) Trusted Distributed Ledgers; 3) Trusted Management; 4) Smart CV; 5) Users. 
Figure 3. Architecture of the Blockchain-based Smart CV.

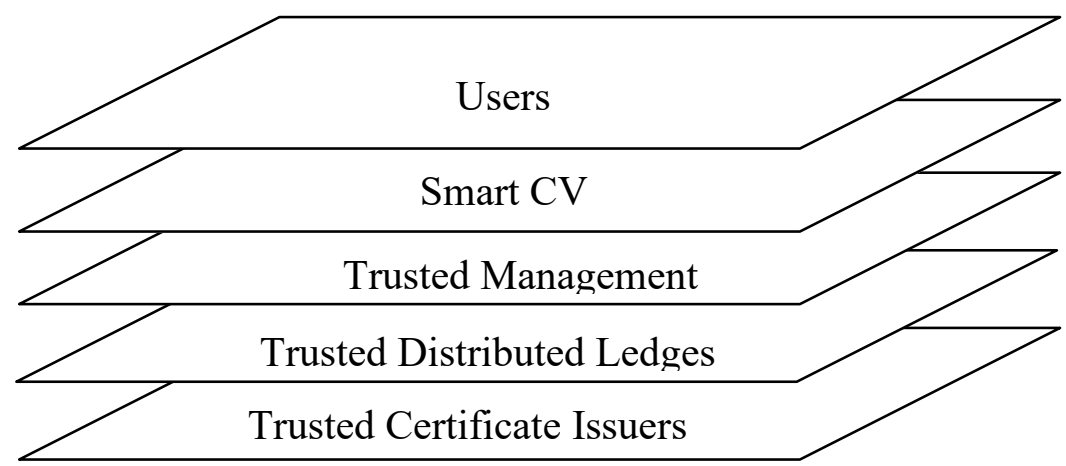

A Certificate Issuer can be any public or private authority that issues certificates (e.g., educational institute, accreditation or certification organization, employer, government authority, professional association, licensing authority). A User can be the person itself (the smart CV owner), any Certificate Issuer, and anyone who is interested in evaluating the person's Smart CV (e.g., educational institute, teacher, employer).

Figure 4. Interactions among Certificate Issuers and Certificate Users.

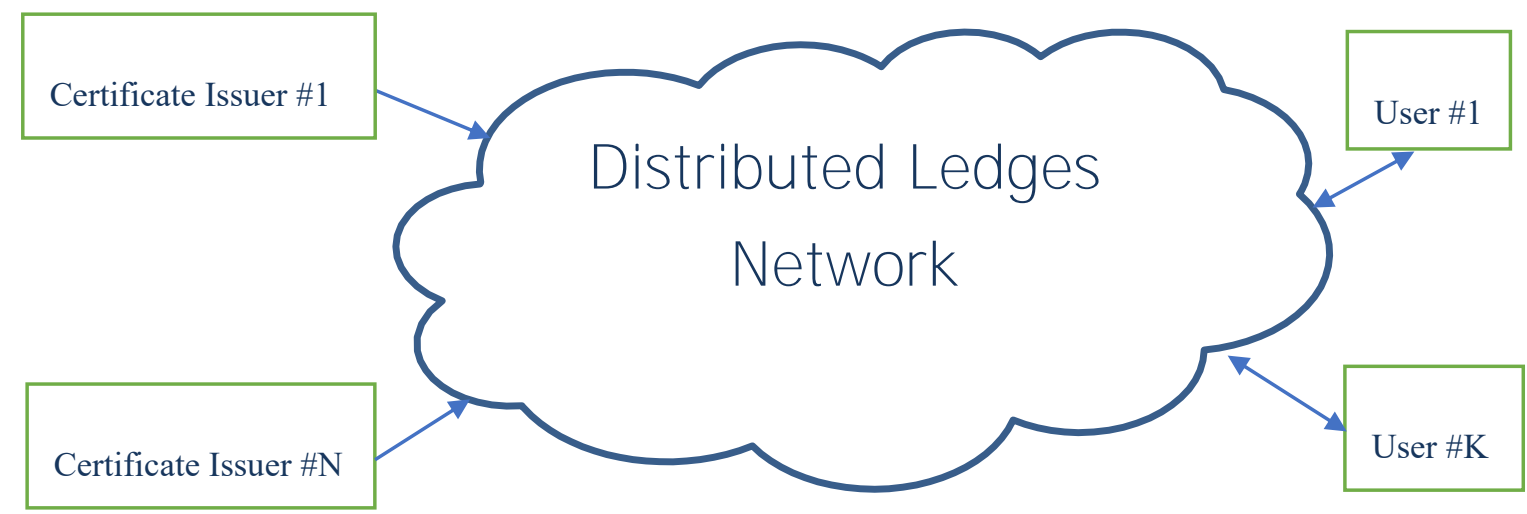

\section{Conclusions and future research}

Recently, there is an increase of fraud in the area of qualifications certifications. Fake certifications are submitted by candidate employees and students applying for a position, a scholarship or job. This paper proposes the Smart CV to fight this problem. A certification authority issues a certificate which is stored in a Blockchain. The Smart CV contains a link to this securely stored certificate. Anyone holding the public key for this specific certificate can see it. Educational institutes, accreditation organizations, public authorities, employers and others can cooperate to issue and accept these Blockchain-based certificates. The paper also provides an Architecture of the Blockchain-based Smart $\mathrm{CV}$ and the Interactions among Certificate Issuers and Certificate Users. Future research may try to implement this Smart CV with rear data.

\section{References}

ASU (2019). The Trusted Learner Network (TLN). Retrieved 12-12-2020 from: https://uto.asu.edu/initiatives/trusted-learner-network

Børresen, L. J., Meier, E., \& Skjerven, S. A. (2020). Corruption in higher education. Global challenges and responses. Series: Global Perspectives on Higher Education, Volume: 46, Brill Publ.

Chapman, D. W., \& Lindner, S. (2016). Degrees of integrity: The threat of corruption in higher education. Studies in Higher Education, 41(2), 247-268. 
Gräther, W., Kolvenbach, S., Ruland, R., Schütte, J., Torres, C., \& Wendland, F. (2018). Blockchain for education: Lifelong learning passport. In Proceedings of 1st ERCIM Blockchain Workshop 2018. European Society for Socially Embedded Technologies (EUSSET).

Grech, A., Camilleri, A.F., \& Inamorato dos Santos, A. (2017). Blockchain in education. Publications Office of the European Union, Luxembourg. ISBN 978-92-79-73497-7. doi: 10.2760/60649

Harris, J., \& Wihak, C. (2017). To what extent do discipline, knowledge domain and curriculum affect the feasibility of the Recognition of Prior Learning (RPL) in higher education? International Journal of Lifelong Education, 36(6), 696-712.

Kontzinos, C., Kokkinakos, P., Skalidakis, S., Markaki, O., Karakolis, V., \& Psarras, J. (2020). Decentralised qualifications' verification and management for learner empowerment, education reengineering and public sector transformation: The QualiChain project. Mobile, Hybrid, and On-line Learning (eLmL 2020), 51.

Lundvall, B. Å., \& Rasmussen, P. (2016). Challenges for adult skill formation in the globalising learning economy-a European perspective. International Journal of Lifelong Education, 35(4), 448-464.

Mayombe, C. (2017). An assessment of non-formal education and training centres' linkages with role-players for adult employment in South Africa. International Journal of Lifelong Education, 36(3), 339-358.

Mikroyannidis, A., Domingue, J., Bachler, M., \& Quick, K. (2018). Smart blockchain badges for data science education. In: 2018 IEEE Frontiers in Education Conference (FIE) (pp. 1-5). IEEE.

Mikroyannidis, Al., Third, Al., \& Domingue, J. (2019). Decentralising online education using blockchain technology. In: The Online, Open and Flexible Higher Education Conference: Blended and online education within European university networks, 16-18 Oct 2019, UNED, Madrid.

MIT (2020). Blockcerts - The Open Standard for Blockchain Credentials. Retrieved 12-12-2020 from: https://www.blockcerts.org/

Mohamedbhai, G. (2016). The scourge of fraud and corruption in higher education. International Higher Education, (84), 12-14. https://doi.org/10.6017/ihe.2016.84.9111

Müller, R., Remdisch, S., Köhler, K., Marr, L., Repo, S., \& Yndigegn, C. (2015). Easing access for lifelong learners: a comparison of European models for university lifelong learning. International Journal of lifelong education, 34(5), 530-550.

Rooksby, J., \& Dimitrov, K. (2019). Trustless education? A blockchain system for university grades. Ubiquity: The Journal of Pervasive Media, 6(1), 83-88.

SAP (2017). Meet TrueRec by SAP: Trusted digital credentials powered by Blockchain. Retrieved 12-12-2020 from: https://news.sap.com/2017/07/meet-truerec-by-sap-trusted-digital-credentialspowered-by-blockchain/

Sharples, M., \& Domingue, J. (2016). The blockchain and kudos: A distributed system for educational record, reputation and reward. In: European conference on technology enhanced learning (pp. 490-496). Springer, Cham.

Skiba, D. J. (2017). The potential of blockchain in education and health care. Nursing education perspectives, 38(4), 220-221.

SONY (2017). Sony develops system for authentication, sharing, and rights management using blockchain technology. Retrieved 12-12-2020 from: https://www.sonyged.com/2017/08/10/news/press-blockchain

Turkanović, M., Hölbl, M., Košič, K., Heričko, M., \& Kamišalić, A. (2018). EduCTX: A blockchain-based higher education credit platform. IEEE Access, 6, 5112-5127.

UNIC (2020). Blockchain Initiative: MSc in Digital Currency. Retrieved 12-12-2020 from: https://digitalcurrency.unic.ac.cy/about-the-program/ 


\title{
KNOWING TO EMPOWER: STUDY OF THE DIFFICULTIES OF THE INFORMAL CAREGIVER
}

\author{
Rosa Martins ${ }^{1}$, Francisco Almeida ${ }^{2}$, Susana Batista ${ }^{1}$, \& Nélia Carvalho ${ }^{1}$ \\ ${ }^{1}$ Higter School of Health, Polytechnic Institute of Viseu (Portugal) \\ ${ }^{2}$ Continuing Care Unit- ACREDITA (Portugal)
}

\begin{abstract}
The Informal Caregiver (IC) faces multiple difficulties in caring for the dependent person. Thus, the purpose of this study is to identify the levels and dimensions of the difficulties experienced by ICs in caring for the dependent person. Methods: Observational, cross-sectional, and descriptive quantitative study, using a non-probability convenience sample composed of 119 ICs from the Central region Portugal. The measuring instrument used included a sociodemographic data form and an Informal Caregiver Difficulties Assessment Scale (EADCI). Results: Moderate difficulties were mostly observed, which were higher in the dimensions caring for myself and activities of daily living. On the other hand, health status/ risk prevention and community and social resources, were assessed in a more positive way. Conclusion: These results indicate that ICs have difficulties at various levels of caring for the dependent person, strengthening the need to implement new strategies capable of responding to these challenges.
\end{abstract}

Keywords: Informal caregiver, difficulty, care, dependent person.

\section{Introduction}

The caregiver is defined by the International Classification for Nursing Practice (ICNP) as individual: assists with identification, prevention, or treatment of illness or disability, attends to the needs of a dependent (ICN, 2016). It is a key element in the rehabilitation process of the dependent person, since it will ensure the satisfaction of the patient's basic Activities of Daily Living (ADL's), after returning home.

The informal caregiver (IC) usually has different responsibilities, providing unpaid assistance to a dependent person. They perform tasks of daily living simultaneously with other activities related to health care, namely: taking medication, treating wounds, monitoring equipment, and others. These are usually family members or close relatives who provide partial or total care to the dependent person with self-care difficulties, facilitating his/her well-being and helping him/her in different tasks and ADLs. The current demographic changes, with an increasing weight of the elderly population, have translated into an increase in longevity, although not always in good health and without disability, which conditions the future guarantee to the accessibility, quality and sustainability of health care and the role of caregivers (Araújo \& Martins, 2016). The challenges posed by an aging population require efforts to assess the value of these invisible and growing care responsibilities, which puts increased pressure on caregivers across Europe (CÈS S, et al., 2019).

A study developed by Andrade, et al. (2019) showed an effective lack of training and support to the caregivers of dependent people, who experienced serious difficulties in providing continuity of care at home. It should be noted that $97.4 \%$ of the surveyed caregivers reported not having received guidance or training on care provision from the health team. Caring for dependent people is often associated with situations of overload that translate into physical, psychological, emotional, and even financial problems (Oldenkamp, et al., 2018). These constraints cause ICs to present a set of difficulties and "unpreparedness" that hinder their performance, leading them in many circumstances even to exhaustion. Therefore, and taking into account the difficulties reported by ICs, it is essential to identify the priority areas of intervention, in order to empower them to develop the provision of health care, while considering the levels of overload. The dimensions of care, often reported by ICs, are mainly associated with self-care, feeding, hygiene and comfort, dressing / undressing, mobilisations, transfers, use of sanitary equipment, and therapeutic management. Dixe et al. (2019), (Petronilho, 2016). However, it should be noted that the situation of the IC of a dependent person is unique and incomparable, and the caregiver's circumstances, family dynamics, and cultural aspects should be considered. In addition, there are cultural 
rules that impose the responsibility of caring, and, for this reason, informal caregivers experience difficulties differently. In this sense, it becomes essential to have access to an educational pedagogy, with support interventions according to their needs, empowering them to respond to new challenges, but for this, it is essential to know their real difficulties (Oldenkamp et al., 2018).

Thus, this research aimed to identify levels and dimensions of the difficulties experienced by informal caregivers in caring for the dependent person.

\section{Methods}

Observational, cross-sectional and descriptive study, with a quantitative nature. The sample used is a non-probability convenience sample composed of 119 ICs, from the central region of Portugal. Participant eligibility emerged from the following inclusion criteria: being the main informal caregiver of a dependent person for at least 6 months, being aged $\geq 18$ years and the dependent person having a dependence level with a Barthel Index Score $<90$. A questionnaire was used as a data collection instrument (DCI), composed of three sections: a first section with sociodemographic data, a second one with psychosocial context data, and a third one composed of a Scale of Assessment of the Informal Caregiver's Difficulties (AICD) built, validated and adapted to the Portuguese population by Martins \& Almeida, 2018. This Lickert-type scale is composed of 30 items, with four response options (1 minor difficulties, ... and 4 major difficulties) and grouped into four dimensions: activities of daily living (ADLs); health status / risk prevention; community and social resources; and caring for myself. Data were collected after permission was granted by the Executive Board of the ACeS Dão-Lafões. The procedures were performed in accordance with the ethical principles of the Declaration of Helsinki and were also authorized by the Ethics Committee of the University where the study was conducted, through Opinion No.22/2018. The statistical treatment was performed using the Statistical Package Social Science version 22.0 for Windows and was processed using descriptive statistics.

\section{Results}

The study sample included 119 informal caregivers, mostly females (83.2\%), aged between 19 and 87 years, with a mean of 60.14 years $( \pm 13.71)$ (see Table 1$)$.

Table 1. Distribution of the sample according to age and gender.

\begin{tabular}{c|ccccccccc}
\hline Gender & $\mathbf{n}$ & $\mathbf{\%}$ & Min. & Max. & $\bar{x}$ & DP & CV\% & $\frac{S k}{\text { Std. Error }}$ & $\frac{\boldsymbol{K}}{\text { Std. Error }}$ \\
\hline Female & 99 & 83,2 & 36 & 87 & 58,51 & 11,997 & 20,50 & 1,695 & $-0,782$ \\
Male & 20 & 16,8 & 19 & 84 & 68,25 & 18,496 & 27,10 & $-2,922$ & 1,731 \\
\hline Total & 119 & 100 & 19 & 87 & 60,14 & 13,711 & 22,80 & 0,081 & $-0,755$ \\
\hline
\end{tabular}

Caregivers are mostly $(78.2 \%)$ married or living in a consensual union and have completed secondary education $(52.9 \%)$ as an academic qualification. In professional terms, $32.8 \%$ of the ICs are still working (only 35.3\% are retired), working full-time, during daytime working hours (34.7\%), as employees and with a monthly income ranging between 500 and 1000EUR. The majority (65.9\%) of the ICs are wives and daughters of the dependent person, have been providing care for over 2 years $(61.3 \%)$ and approximately half $(50.4 \%)$ of the sample devotes 12 hours daily to care. The motivations behind caring are: caring for pleasure or own will (52.1\%), having no other alternative (34.5\%), and moral/religious obligation $(25.2 \%)$.

Table 2 expresses the difficulties expressed by the ICs: consequently, we found that the greatest difficulties are associated with the dimension caring for myself $(=56.08 \%, \pm 27.383)$, and the Activities of daily living $(=51.79 \%, \pm 27.215)$. Contrarily, the least difficulties are linked to Community and social resources $(=35.57 \%, \pm 25.918)$ and Health status and risk prevention $(=39.47 \%, \pm 26.117)$. The analysis of the participants' difficulties in global terms (global scale score) reveals significant levels of difficulties $(=46.04 \%, \pm 22.430)$, as we can see in Table 2 . 
Table 2. Difficulties of ICs per dimension and overall value of EADCI.

\begin{tabular}{|c|c|c|c|c|c|c|c|c|c|}
\hline Dimensions & n & $\%$ & $\underset{\%}{\text { Min. }}$ & $\underset{\%}{\operatorname{Max} .}$ & $\begin{array}{l}\bar{x} \\
\%\end{array}$ & $\begin{array}{l}\text { DP } \\
\%\end{array}$ & CV\% & $\frac{S k}{\text { Std. Error }}$ & $\frac{K}{\text { Std. Error }}$ \\
\hline $\begin{array}{l}\text { Activities of daily } \\
\text { living }\end{array}$ & 119 & 100 & 0,0 & 100,0 & 51,79 & 27,215 & 52,55 & $-0,500$ & $-1,959$ \\
\hline $\begin{array}{l}\text { Health status and } \\
\text { risk prevention }\end{array}$ & 119 & 100 & 0,0 & 100,0 & 39,47 & 26,117 & 65,64 & 2,108 & $-1,375$ \\
\hline Caring for myself & 119 & 100 & 0,0 & 100,0 & 56,08 & 27,383 & 48,828 & $-0,248$ & $-1,764$ \\
\hline $\begin{array}{l}\text { Community and } \\
\text { social resources }\end{array}$ & 119 & 100 & 0,0 & 100,0 & 35,57 & 25,918 & 72,865 & 2,189 & $-0,473$ \\
\hline Global Factor & 119 & 100 & 3,45 & 100,0 & 46,04 & 22,430 & 48,719 & 1,495 & $-1,198$ \\
\hline
\end{tabular}

In order to quantify the levels of difficulties by groups, we observed that $46.2 \%$ of the sample had moderate difficulties, $28.6 \%$ had low difficulties and $25.2 \%$ had high difficulties. The analysis by gender shows that men are positioned essentially (70\%) at moderate levels, while women are distributed across the different levels (see Table 3), with the statistical differences by gender being significant $(\mathrm{X} 2=7.617 ; \mathrm{p}=0.022)$ and confirmed by the adjusted residual values.

Table 3. Distribution of the sample by levels of difficulty, according to gender.

\begin{tabular}{r|cccccccc}
\hline \multirow{2}{*}{$\begin{array}{l}\text { GCs } \\
\text { ICnder }\end{array}$} & \multicolumn{2}{c}{ Female } & \multicolumn{2}{c}{ Male } & \multicolumn{2}{c}{ Total } & Adjusted Residuals \\
\cline { 2 - 10 } Difficulties & $\mathbf{n}$ & $\mathbf{\%}$ & $\mathbf{n}$ & $\mathbf{\%}$ & $\mathbf{n}$ & $\mathbf{\%}$ & Female & Male \\
\hline Reduced difficulties & 33 & $\mathbf{3 3 , 3}$ & 1 & 5,0 & 34 & 28,6 & $\mathbf{2 , 6}$ & $-2,6$ \\
Moderate difficulties & 41 & 41,4 & 14 & $\mathbf{7 0 , 0}$ & 55 & 46,2 & $-2,3$ & $\mathbf{2 , 3}$ \\
$\quad$ High difficulties & 25 & 25,3 & 5 & 25,0 & 30 & 25,2 & 0,0 & 0,0 \\
\hline Total & 99 & 100,0 & 20 & 100,0 & 119 & 100,0 & & \\
\hline
\end{tabular}

\section{Discussion of results}

The participant's sociodemographic characteristics are in line with other studies recently conducted in the Portuguese context and targeting similar populations (Martins et al., 2018; Andrade et al., 2019). This is a sample mostly composed of female informal caregivers, with a mean age of 60.14 years, with married marital status and with the second cycle of education as academic qualification, confirming the expected correlation with the statistical data published in Portugal by the National Statistics Institute (INE, 2019). The monthly income earned by the majority is around low values (500-1000). These data are in line with those of Matos, (2019); Martins \& Santos (2020) when they refer that there are groups of informal caregivers (mostly elderly) who are at the poverty line with very strong impacts on their quality of life. The sociodemographic profile of these ICs is characterized by being mostly women, relatives of the dependent person (wives and daughters), distributed by different professional situations (active, retired and unemployed), dedicating about 12 hours daily to care. Despite the change in gender attitudes and the rapid entry of women into the labour force in recent decades, women continue to play an important role in managing the home and caring for family members, even in situations in which they need to cumulatively exercise their professional activity, which has obvious implications in other areas, such as the reduction of leisure and social activities, leading to higher levels of overload, anxiety and stress (Costa \& Castro, 2016). However, characteristics, such as level of education, employment and socioeconomic status, present variations in different societies and countries. (Martins \& Santos (2020). A study conducted by Sequeira (2018) showed that the main reasons for assuming the role of caregiver are: own initiative, family decision, being the only person who could care, and request from the dependent person. Matos, (2019) also mentions that there are many reasons that lead ICs to assume this role, such as the obligation to care due to social norms, affective bounds, commitment, piety, or altruism. These data are in line with those of this study, since they conveyed: caring for pleasure or own will, having no other alternative and also the moral / religious obligation of retribution. 
Studies converge in highlighting the variability of feelings and difficulties expressed by ICs. It is known that the caregiver is unique, incomparable, involved in a family dynamic and is conditioned by cultural aspects (Hajek \& König 2016). Therefore, moderate difficulties were observed (for almost half of the sample) low difficulties and high difficulties for smaller groups. There is a clear difference between men and women as the former position themselves essentially at moderate levels, while women are distributed over different levels. However, the inequality of the sample has to be taken into account, as most of the participants are female and care for their relatives for longer periods and longer daily time. On the other hand, caring is constantly changing and should be considered as a permanent state of personal development, transformations and ontological self-understanding that leads to more positive perceptions (Oliveira \& Carraro, 2016).

It was also shown that the major difficulties are associated with the dimension caring for myself and the activities of daily living. These are data corroborate those of Dixe (2018), when he advocates that the daily routine of the ICs with extensive hours of care in assisting and supervising the ADLs of the dependent person is neglected in their self-care, leisure and/or social activities that remain in the background, making them vulnerable to the development of depression, stress and lower quality of life. Added to these difficulties, is the need to actively assist and supervise basic activities of daily living for long periods of the day and for which they feel they are not prepared (Martins, et al., 2018). In the opposite direction, the difficulties are smaller when the dimensions community and social resources and health status and risk prevention are associated. In fact, in recent years there has been a special attention to ICs, through greater awareness of the implementation of training programs and facilitating access to social resources (Petronilho, 2016). On the other hand, psychosocial predictors of the caregiver identified so far, include greater socio-emotional support, lower subjective burden, higher quality relationship with the dependent person and higher intrinsic motivation for caregiving (Greenwood \& Smith, 2019).

\section{Conclusions}

Informal care is a complex and dynamic process, which is constantly changing and should be analysed not only from the perspective of a standardized care model, but also based on the actions and difficulties experienced and felt by the caregiver.

The ICs present real difficulties of moderate level, with greater demands in assisting and supervising the activities of daily living and self-care. The dimensions related to community and social resources and also the health status and risk prevention are assessed in a more positive way, which may be associated with the development of communication and organizational skills, among other anticipatory care for caregivers' empowerment.

Therefore, it is important to understand in future studies, which are the predictors of the difficulties and lived experiences, but also of the positive motivations facilitating caregiving, since there are internal and external factors that may influence the well-being of the informal caregiver.

\section{References}

ACSS (2019). Administração Central do Sistema de Saúde, IP. Rede Nacional de Cuidados Continuados Integrados - onde estamos. Retrieved from https://www.arcgis.com/apps/ PublicInformation/index.html?appid=7874a58d37a248a481d567d85be88134

Andrade, L. M., Costa, M. D. F. M., Caetano, J. Á., Soares, E., \& Beserra, E. P. (2019). A problemática do cuidador familiar do portador de acidente vascular cerebral. Revista da Escola de Enfermagem da USP, 43(1), 37-43. http://dx.doi.org/10.1590/S0080-62342009000100005

Araújo, F. \& Martins, T. (2016). Avaliação dos cuidadores: considerações e orientações para a prática. In T. Martins, et al. (Org.), A pessoa dependente \& o familiar cuidador (pp. 113-130). Porto: Escola Superior de Enfermagem do Porto.

Bruggen, S. V., Gussekloo, J., Bode, C., Touwen, D. P., Engberts, D. P., \& Blom, J. W. (2016). Problems experienced by informal caregivers with older care recipients with and without cognitive impairment. Home Health Care Services Quarterly; Vol. 35: 1, 11-24. Retrieved from http://dx.doi.org/10.1080/01621424.2016.1145166

Costa, S. R. D. da, \& Castro, E. A. B. de (2016). Autocuidado do cuidador familiar de adultos ou idosos dependentes após a alta hospitalar. Rev Bras Enferm.; 67(6), 979-986. Retrieved from http://www.scielo.br/pdf/reben/v67n6/0034-7167-reben-67-06-0979.pdf

DGS (2015). Direção-Geral da Saúde. Plano nacional de saúde: revisão e extensão a 2020. Lisboa: Direção-Geral da Saúde. Retrieved from http://1nj5ms21li5hdggbe3mm7ms5.wpengine.netdnacdn.com/files/2015/06/Plano-Nacional-de-Saude-Revisao-e-Extensao-a-2020.pdf.pdf 
Dixe, M. A. C. R., Teixeira, L. F. C., Areosa, T. J. T. C. C., Frontin, R. C., Peralta, T. J. A., \& Querido, A. I. F. (2019). Needs and skills of informal caregivers to care for a dependent person: a crosssectional study. BMC Geriatrics; 19, 255, 2-9. Retrieved from https://doi.org/10.1186/s12877-019-1274-0

Greenwood, N., Smith R. (2019). Motivations for being informal carers of people living with dementia: A systematic review of qualitative literature. BMC geriatrics; 19(1): 169.)

Hajek, A., \& König, H. H. (2016). Informal caregiving and subjective well-being: evidence of a population-based longitudinal study of older adults in Germany. J Am Med Dir Assoc.; 17, 300-055. Retrieved from https://www.ncbi.nlm.nih.gov/pubmed/26705001

ICN (2016). International Council of Nurses. CIPE® Versão 2015 - Classificação Internacional para a Prática de Enfermagem. Genebra: ICN.

INE (2019). Instituto Nacional de Estatística. Estimativas de população residente em Portugal 2018. Lisboa: INE. Retrieved from https://www.ine.pt/xportal/xmain?xpid=INE\&xpgid=ine_destaques\&DESTAQUESdest_boui=354 227526\&DESTAQUESmodo $=2$

Martins, R., Rodrigues, A., Andrade, A., Albuquerque, C., \& Martins, C. (2018) Perception of informal caregivers on planning for the discharge of hospitalised elderly patients. Rev Enf Rol, vol. 41 $n^{\circ} 11-12$ (nov-dec) pp 193-197. http://hdl.handle.net/10400.19/5330

Martins, R., \& Santos, C. (2020). Capacitação do cuidador informal: o papel dos enfermeiros no processo de gestão da doença. Gestão E Desenvolvimento, (28), 117-137. https://doi.org/10.34632/gestaoedesenvolvimento.2020.9468

Matos, N. A. M. de (2019). Dificuldades do cuidador informal no cuidar da pessoa dependente. (Dissertação de Mestrado). Instituto Politécnico de Viseu. Escola Superior de Saúde de Viseu. Retrieved from http://repositorio.ipv.pt/handle/10400.19/5478

Oldenkamp, M., Bültmann, U., Wittek, R. P. M., Stolk, R. P., Hagedoorn, M., \& Smidt, N. (2018). Combining informal care and paid work: The use of work arrangements by working adult-child caregivers in the Netherlands. Health Soc Care Community; 26(1), e122-e131. doi: $10.1111 /$ hsc. 12485 .

Oliveira M.D., Carraro T.E. Cuidado em Heidegger: uma possibilidade ontológica para a enfermagem. Revista Brasileira de Enfermagem, 2016; 64(2): 376-380

Petronilho, F. (2016). Preparação do regresso a casa. In T. Martins, et al. (Org.), A pessoa dependente \& o familiar cuidador (pp. 73-93). Porto: Escola Superior de Enfermagem do Porto.

Sequeira, C. (2018). Cuidar de idosos com dependência física e mental. (2a ed.). Lisboa: Lidel - Edições Técnicas. 


\title{
WOMEN IN ENGINEERING, FACULTY OF ENGINEERING IN BILBAO
}

\author{
F. Javier Maseda Rego ${ }^{1}$, Itziar Martija López ${ }^{1}$, Patxi Alkorta Egiguren ${ }^{2}$, \\ Izaskun Garrido Hernández ${ }^{1}$ \& Aitor J. Garrido Hernández ${ }^{1}$ \\ ${ }^{1}$ Automatic Control Group (ACG), Institute of Research and Development of Processes, \\ Faculty of Engineering in Bilbao, University of the Basque Country (UPV/EHU) (Spain) \\ ${ }^{2}$ Engineering School of Gipuzkoa, University of the Basque Country (UPV/EHU) (Spain)
}

\begin{abstract}
The situation of women in the engineering world has different aspects. On the one hand, it can be stated that women are well received in certain areas of the technological world, and they are very integrated into academia. In other areas, such as the world of industrial business, recognition is more complex being those less open environments.

Last century, the woman who broke the taboo in Spain was the mayor of Bilbao and the first industrial engineer graduated in Spain in 1912, Pilar Careaga. By means of her public presence, her message could reach the general society, but as something exceptional. At the Faculty of Engineering in Bilbao, the first female Industrial Engineer was Pilar Ipiña, graduated in 1965. Fifty-three years had passed.

Women in Engineering, more than a century later, remain a clear minority. While it is true that the presence of women in engineering schools is socially fully accepted, it is no less true that many young women dismiss the possibility of approaching that world from an early age. The lack of benchmarks seems to be a clear factor. Many of the engineers who are being interviewed in the search for ideas to motivate girls and young women, end up seeing lacks of references when asked about it.

While the experience of being a woman in such a traditionally male field has lights and shadows, reflect of what can be seen in different referenced studies, a positive message must be transmitted, as this has been the experience of both engineering students and workers in academia or in the business world.

Proposing solutions to smooth out the differences in numbers between men and women in the world of Engineering and Science requires knowing the causes, in order to be able to carry out actions that lead to collecting women's talent and with the appropriate training give it all the value that can achieve, both in the improvement of society as a whole and in the personal development of each of them. The aim is to achieve real equal choice between women and men and put everyone at the service of a better society. Equality is theoretically achieved, but it can still be improved.
\end{abstract}

Keywords: Women in engineering, engineering education, gender.

\section{Introduction: The choice of studies, the influence of the family and social mobility}

During childhood and adolescence, school, high school and university are a very important source of references for children. The referents are a fundamental factor in the perception of what is appropriate or accessible for girls. However, these examples of women girls may want to look like should be close, not only important. A woman astronaut or Nobel laureate may be admirable, but she can be someone unattainable and therefore impossible to imitate. However, the teachers of physics and chemistry, technical drawing or mathematics are women; they can be a more influencing factor, for being an achievable goal, in the view that technology, engineering or science are girls' things (Ayuso, Baldassarri, Trillo, Aragüés, Masiá, Molina, Murillo, Cerezo \& Villarroya, 2019).

The family environment also plays a fundamental role when choosing the field in which to pursue higher education. Not discouraging girls with comments about the difficulty of science or engineering studies is very important not to take them away from a fascinating world where discoveries, pure research, and inventions are waiting for talent (Ayuso, Fillola, Masiá, Murillo, Trillo-Lado, Baldassarri, Cerezo, Ruberte, Marical \& Villarroya-Gaudó, 2020).

Actions are being developed from the university world and from professional associations to promote that female talent is not lost in these areas, and actions are being taken to explain all these possibilities to girls and young women, but it is no less important that the family and community is 
informed and aware. Girls have no problem with science or technology subjects, and it should be natural for them to enjoy those disciplines. Interesting readings about women in science and technology can bring not just girls, but families, closer to the world of science and engineering (Tietjen and Reynolds, 1999).

Social mobility could be defined as the movement from one social position to another. University studies in engineering are linked to social mobility, including possibilities of occupation, something important for equal opportunities for boys and girls. Continuing studies is even more differentiating for women than for men (Neglia, Tragodara, Paragulla \& Caceres, 2020).

In terms of probability of attaining higher education, Spain is in position 8 out of 20 European countries, and has improved through the last generations (CRUE, 2018). Among people from 45 to 59 years of age, the percentage of adults who attained higher education and whose parents did not have them is $16 \%$, and among those from 30 to 44 it improves to $21 \%$ (CRUE, 2018).

An important piece of information to assess the possibility of social mobility is the number of universities in Spain and their territorial distribution. There are 50 public universities and 34 private universities in Spain (CRUE, 2019). The geographical proximity favours that families can financially support that young people access university studies. From the data (CRUE, 2018), (CRUE, 2019) it can be extracted that the percentage of women who access higher education is larger than that of men.

Figure 1 shows a report on Public Universities in Spain (CRUE, 2019) about women first enrolment. The orange colour corresponds to ten of twelve bachelor's degrees of the Faculty of Engineering in Bilbao.

Figure 1. Women first enrolment in Public Universities in Spain.

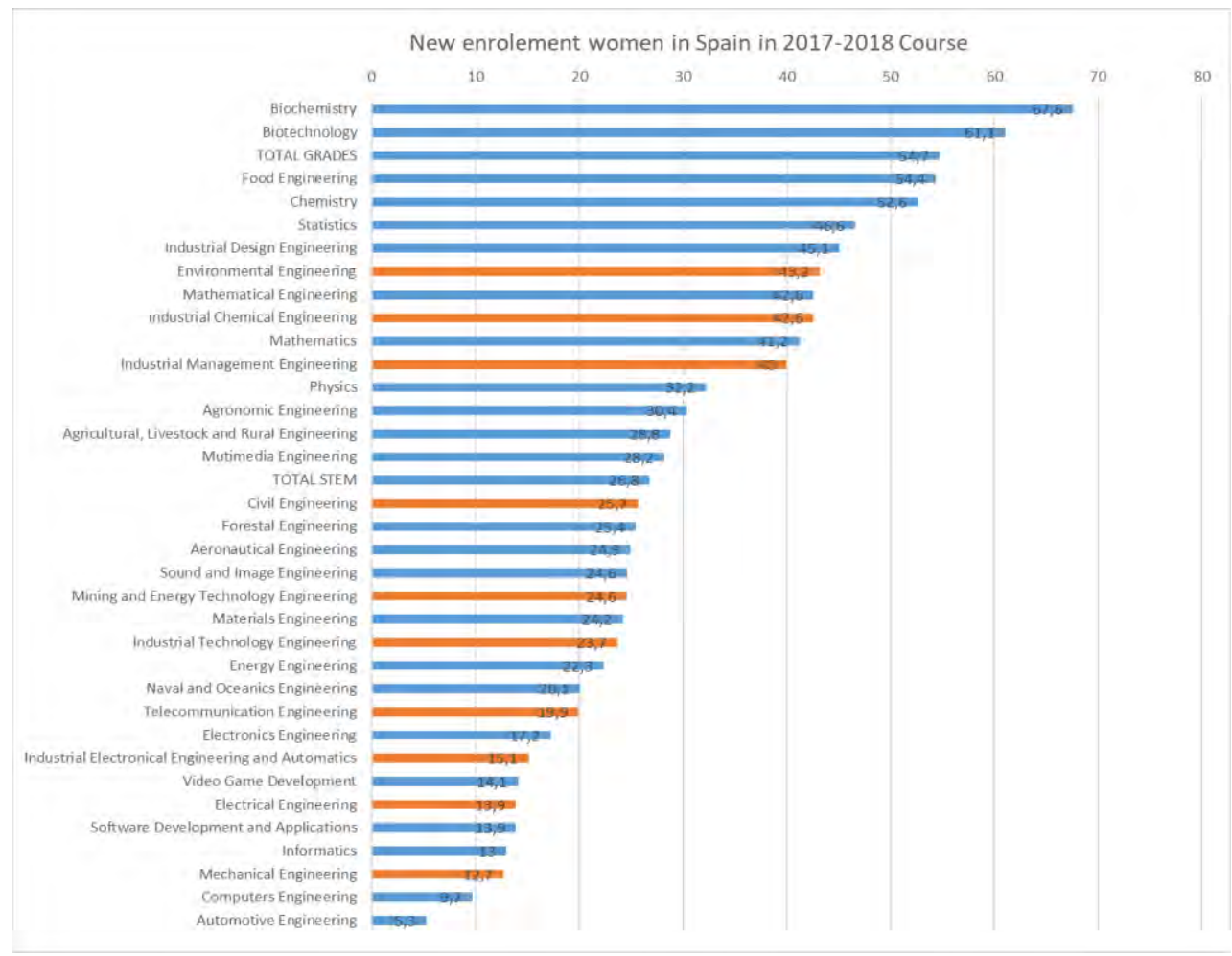

Reversing this trend and recovering women who like engineering fields is a social objective that will benefit everyone (De Carvalho Fernandes, Madeira, Da Gama Afonso, Da Silva Duarte, De Souza \& Peixoto, 2019).

\section{Women in academic world. Faculty of engineering in Bilbao}

Once women enrol on engineering studies at the university, even today, they are living in a very masculine environment. This is generally friendly and gender considerations are not carried over to the classroom. In the 1960s, 70s, or 80s, the female presence was testimonial but the student experience was generally satisfactory (Udén, 2002). Normality in dealing with teachers and classmates was the standard then and continues to be so today. No differentiating attitudes were perceived by gender, neither by the teaching staff nor by the peers. 
In the Faculty of Engineering in Bilbao in the 90s, 5 women and 95 men were in their sixth year of Industrial Engineering, Mechanical Degree. Considering 2014/15 to 2019/20 courses, 30 years later, the average ratio of enrolled women is $13 \%$.

The Faculty of Engineering in Bilbao has enrolled 4702 students distributed in their twelve engineering bachelor's degrees and eighteen master's degrees in 2019/20 course.

Figure 2 shows two blocks of graphics, the first one including gender distribution for the new incoming students of four bachelor's degrees and, at the second one showing the percentage of total new incoming women in the Faculty of Engineering in Bilbao. These graphics clearly confirm the reality of women in engineering degrees being a small proportion of the total students and the tendency does not improve along these years.

Figure 2. New incoming students in four bachelor's degrees and total new incoming women in the Faculty of Engineering in Bilbao, 2014/15 to 2019/2020 courses.
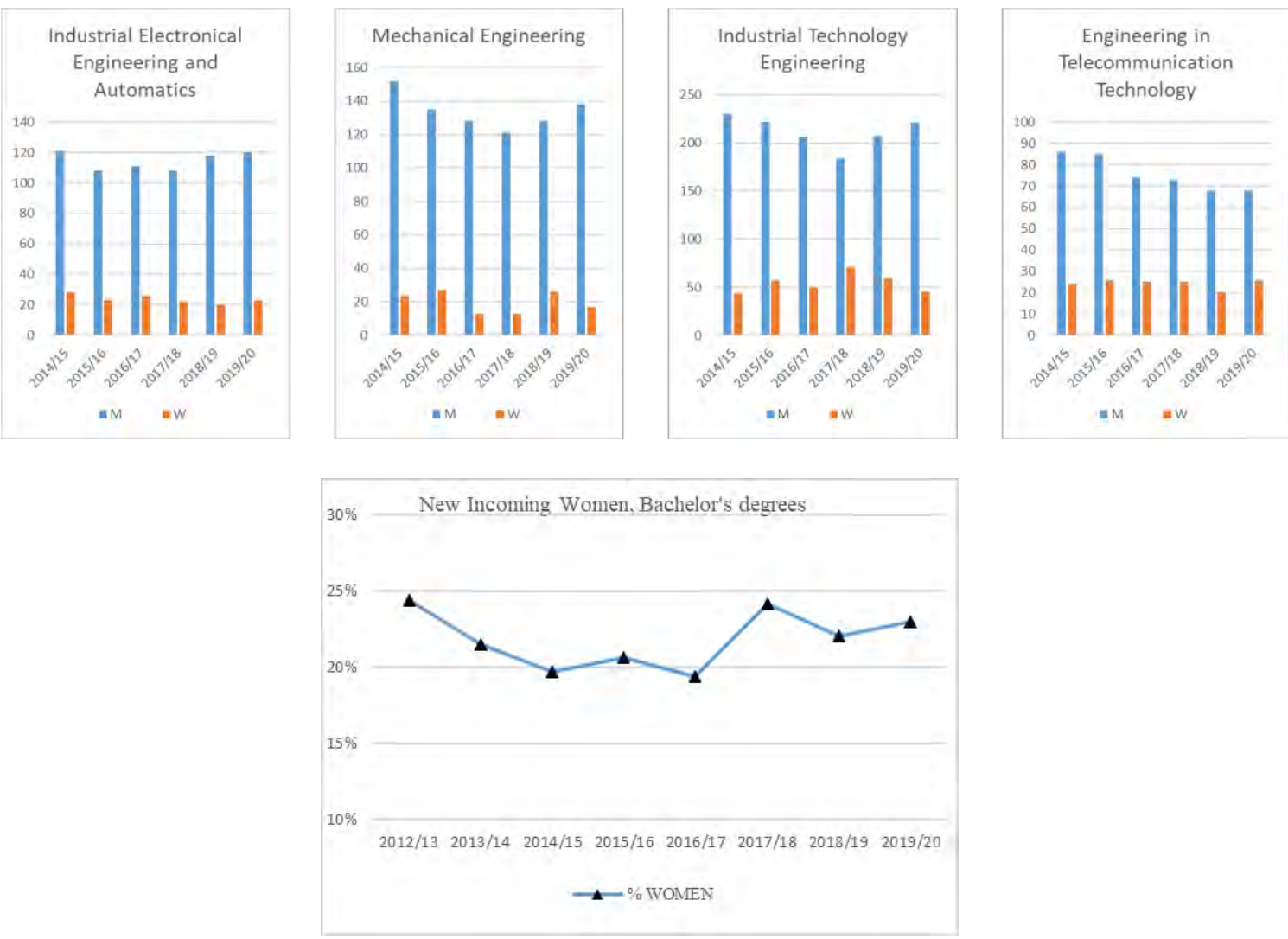

It is important to highlight that the dropout rate in the first year of undergraduate studies is lower among women, $18.1 \%$ compared to $23.2 \%$ for men (CRUE 2018). The percentage of credits passed compared to those enrolled, continues to be higher among women, $73.2 \%$ compared to $66.5 \%$ for men (CRUE 2018).

It seems clear, in view of the aforementioned data, that female engineering students are perfectly equipped for these studies. These data should reinforce the vision of young women, who could be deciding their studies and their professional future, that there is no objective reason that should separate them from their vocations (Mozahem, Ghanem, Hamied \& Shoujaa, 2019).

\section{The work environment and the glass ceiling}

The engineer professional career is a very flexible profession, being the knowledge fields in the careers highly diverse. In addition, the engineering graduate will be able to practice the profession after obtaining the title and without any additional requirement. These two circumstances allow the entrance in the work environment with certain easiness. Industry, academic, research, administration and business are different areas where engineers can develop their professional life.

Taking public universities and administration in Spain as example of women in different work positions, Table 1 shows the differences between men and women (Ministry of Science, Innovation and 
Universities, 2018). The results are revealing and this gender inequality could be extrapolated to other environments, especially taking into account that gender polices are regulated through different laws in the public administration. In the industry, data show similar differences (Fouad, Singh, Cappaert, Chang \& Wan, 2016).

Table 1. Ratio women/men in University and Governing institutions in Spain, 2018.

\begin{tabular}{|c|c|c|c|c|c|c|c|c|}
\hline & $\begin{array}{l}\text { Universities } \\
\text { in Spain }\end{array}$ & $\begin{array}{l}\text { Universities } \\
\text { in Spain }\end{array}$ & $\begin{array}{l}\text { Faculties } \\
\text { in Spain }\end{array}$ & $\begin{array}{l}\text { Faculties } \\
\text { in Spain }\end{array}$ & $\begin{array}{l}\text { Research } \\
\text { Institutes } \\
\text { in Spain }\end{array}$ & $\begin{array}{l}\text { Public } \\
\text { Institutions } \\
\text { in Spain }\end{array}$ & $\begin{array}{l}\text { Public } \\
\text { Institutions } \\
\text { in Spain }\end{array}$ & $\begin{array}{l}\text { Faculty } \\
\text { Engineering } \\
\text { in Bilbao }\end{array}$ \\
\hline & $\begin{array}{l}\text { Rectors/ } \\
\text { deans }\end{array}$ & Vice-rectors & $\begin{array}{l}\text { Faculty } \\
\text { directors }\end{array}$ & $\begin{array}{l}\text { Vice- } \\
\text { directors }\end{array}$ & Directors & $\begin{array}{l}\text { Grade D, } \\
\text { the lowest }\end{array}$ & $\begin{array}{c}\text { Grade A, } \\
\text { the highest }\end{array}$ & Lecturers \\
\hline Women & $2 \%$ & $39 \%$ & $27 \%$ & $47 \%$ & $19 \%$ & $58 \%$ & $25 \%$ & $34 \%$ \\
\hline Men & $98 \%$ & $61 \%$ & $73 \%$ & $53 \%$ & $81 \%$ & $42 \%$ & $75 \%$ & $66 \%$ \\
\hline
\end{tabular}

Higher studies provide a qualification that generally allows graduates to achieve quality employment. One of the objectives of the students is to have successful access to employment and data demonstrate that university education fulfils its purpose (Ministry of Science, Innovation and Universities, 2018). However, today there are still both a wage gap and a higher unemployment rate for women (Cadaret, Hartung, Subich \& Weigold, 2017). Many women still face the double challenge: that of moving up socially and that of breaking different barriers of inequality, like the 'pregnancy penalty' (Vella, 2020).

When analysing the impact that studying science or engineering has on female university graduates, one could say that there is good news. The higher the qualification, the better employment rate. In addition, the fields of engineering and science have one of the highest occupancy rates. Combining both factors, there are even more reasons to encourage women to choose these studies (Mills, Gill, Sharp \& Franzway, 2011).

Work environment is one of the most complex ones for women in engineering, as reaching management positions continues to be more difficult for women. Many highly trained and experienced women, including many not having children, have hit the named 'glass ceiling'. (Mozahem, Ghanem, Hamied \& Shoujaa, 2019).

\section{Conclusions and possible actions}

Exploring solutions in gender differences is a complex problem. Equitable representation of women is essential for the normalization of the female presence. It is necessary that female engineers are working to their abilities and developing their talents to make their presence natural, and in this way, they must reach decision-making positions.

In primary and secondary education, having female references in engineering fields helps normalize girls' vision of their possible choice of engineering or technology fields. Visibility of women who work in engineering and science must be promoted so that it is perceived as something natural and these options are chosen with the same spontaneity with which girls choose to be a doctor, a psychologist, or a teacher.

The fear of an insufficient professional projection after very demanding studies can also keep girls away from the world of engineering. Knowledge of the reality of labour insertion of women in the industry with a high professional category is also motivating.

It must be recognized that in order to change situations with great inertia like this one, actions must be taken to break the current imbalance.

\section{Acknowledgements}

This work was supported in part by the Basque Government, through project IT1207-19 and by the MCIU/MINECO through RTI2018-094902-B-C21/RTI2018-094902-B-C22 (MCIU/AEI/FEDER, UE). 


\section{References}

Ayuso, N., Baldassarri, S., Trillo, R., Aragüés, R., Masiá, B., Molina, P., Murillo, A. C., Cerezo, E., \& Villarroya, M. (2019). Integral Actions Towards Women in Engineering Recognition. IEEE International Conference on Emerging Technologies and Factory Automation (ETFA), 1836-1840.

Ayuso, N., Fillola, E., Masiá, B., Murillo, A. C., Trillo-Lado, R., Baldassarri, S., Cerezo, E., Ruberte, L., Marical. M. D., \& Villarroya-Gaudó, M. (2020). Gender Gap in STEM: A Cross-Sectional Study of Primary School Students' Self-Perception and Test Anxiety in Mathematics. IEEE Transactions on Education, doi: 10.1109/TE.2020.3004075.

Cadaret, M. C., Hartung, P. J., Subich, L. M., \& Weigold, I. K. (2017). Stereotype threat as a barrier to women entering engineering careers. Journal of Vocational Behavior, 99, 40-51.

CRUE Spanish Universities. (2018). La Universidad Española en Cifras 2016/17. Spain. Legal deposit M-40802-2018. https:/www.crue.org/publicacion/espanola-en-cifras/

CRUE Spanish Universities. (2019). La Universidad Española en Cifras 2017/18. Spain. Legal deposit M-3628-202, ISBN 978-84-09-18182-7. https://www.crue.org/publicacion/espanola-en-cifras/

De Carvalho Fernandes, M. R., Madeira, V. R., Da Gama Afonso, H. C. A., Da Silva Duarte, K., De Souza, A. L. L., \& Peixoto, A. (2019). A Study on the Support for Women in Engineering Courses. IEEE Global Engineering Education Conference (EDUCON), 1237-1240.

Fouad, N. A., Singh, R., Cappaert, K., Chang, W., \& Wan, M. (2016). Comparison of women engineers who persist in or depart from engineering. Journal of Vocational Behavior, 92, 79-93.

Mills, J. E., Gill, J., Sharp, R., \& Franzway, S. (2011). Getting it together: Feminist interdisciplinary research on women and engineering. Women's Studies International Forum, 34, 13-19.

Ministry of Labour, Migration and Social Security. (2018). La situación de las mujeres en el mercado de Trabajo 2018. NIPO: 854-19-050-9. http://www.mitramiss.gob.es/es/sec_trabajo/analisis-mercadotrabajo/situacion-mujeres/situacion_mujer_trabajo_2018.pdf

Ministry of Science, Innovation and Universities. (2018). Cientificas en Cifras 2017, Estadísticas $e$ indicadores de la (des)igualdad de género en la formación y profesión científica, NIPO: 057180822.https://www.ciencia.gob.es/stfls/MICINN/Ministerio/FICHEROS/UMYC/Cientificas cifras_2017.pdf

Mozahem, N. A., Ghanem, C. M., Hamied, F. K., \& Shoujaa, R. E. (2019). Women in engineering: A qualitative investigation of the contextual support and barriers to their career choice. Women's Studies International Forum, 74, 127-136.

Neglia, L. F., Tragodara, K. S. C., Paragulla, J. V., \& Caceres, M. R. C. (2020). The presence of women in the Engineering Programs of the University of Sciences and Humanities. Motivations, permanence and monitoring. IEEE World Conference on Engineering Education (EDUNINE), 1-4.

Tietjen, J. S., \& Reynolds, B. (1999). Women engineers bridging the gender gap. International Symposium on Technology and Society - Women and Technology: Historical, Societal, and Professional Perspectives, 206-210.

Udén, M. (2002). The Impact of Women on Engineering: A study of Female Engineering Students' Thesis Topics. International Journal Engineering Education, 00, 1-7.

Vella, H. (2020). Leaving women to hold the baby: The real reason for the gender gap? Could addressing the 'pregnancy penalty' with equal parental leave policies for both mothers and fathers be a catalyst for retaining more women in the engineering and technology sector?. Engineering \& Technology, 15 (1), 52-55. 


\title{
CREATING LOVEMARKS THROUGH STUDENTS OF PUBLIC UNIVERSITIES IN IRELAND
}

\author{
Javier Casanoves-Boix ${ }^{1}$, Ana Cruz-García ${ }^{2}, \&$ Maurice Murphy ${ }^{2}$ \\ ${ }^{1}$ Department of Marketing, Valencian International University / Valencia (Spain) \\ ${ }^{2}$ Department of Marketing, Munster Technological University / Cork (Ireland)
}

\begin{abstract}
This research was carried out to examine the role of educational brand capital applied to public universities in Ireland. To this end, the main contributions in the literature related to the study of brand capital and its application in the Irish educational sector were analyzed, identifying which variables determine brand capital in this sector. Once a suitable model was established, an empirical study was realized using a sample of 423 valid responses from students at the two main public universities in Cork (Ireland). The results obtained will show the repercussion of each variable of the brand capital relative to the determining variables (brand awareness, brand image, perceived quality, and brand loyalty), while laying the foundation for university managers to develop marketing strategies adapted to maximize the building of educational brand capital.
\end{abstract}

Keywords: Marketing, brand capital, higher education, public universities, Ireland.

\section{Introduction}

The number of organizations with an affinity to generate efforts towards brand creation is increasing, which is considered one of the most important assets (Kaynak, Salman, and Tatoglu, 2008). Thus, it is essential to study those attitudes of consumers that can favour (or disadvantage) their relationship with the brand (Batra, Ahuvia, and Bagozzi, 2012). In recent years, and due to the high demand that consumers have acquired in their purchase decision-making, the experience of use and consumption is a key piece to detect the perceptions of customers with the brand and, at the same time, maximize their loyalty to it (Henao and Colorado, 2017).

At the university level, since the twentieth century, the pressure to conform teaching and research to the economic, technical, and administrative demands of the moment have been emphasized, seeking to design appropriate solutions to satisfy an increasingly demanding market (Morín, 2018). Thus, today's universities develop their activity in a highly competitive and complex environment, seeking to increase the offer of studies in the region in which they operate and even overcome it through the international offer thanks to the virtual modality (García and Pelekais, 2012). In that sense, Manes (2008) considers that it is necessary for every university to incorporate a marketing area in its process, seeking to maximize business opportunities. Thus, and according to Durán and Parra (2014), the university marketing strategy, whether in the public or private sphere, is considered key to improving the service offered in an increasingly demanding client, while helping to create diversity and compete in increasingly heterogeneous markets.

Focusing our attention on the role that public higher education plays in Ireland, the Higher Education Authority (HEA) indicates that today there are 24 higher education institutions, divided into 9 universities, 11 Institutes of Technology, and 4 institutions considered as "other colleges". Thus, according to White (2001), the increase in students from the 1960s to the present has been one of the most relevant phenomena. O'Connor and White (2011) consider that some of Ireland's universities have achieved good status internationally.

Parallel to this, brands have evolved over time to become a life experience for consumers, having acquired emotional importance that is reflected in the satisfaction of the people who buy and consume it (Camacho, 2008). Everything builds or destroys a brand, and this continuous and indefinite process over time must feed on all the actions that the company (or educational institution) directs to its public, as well as the interactions and experiences of the public with it (Olins, 2008). Thus, and taking into account that the market is increasingly complex and competitive, every educational center must aim at generating marketing and brand strategy adapted to the new consumer reality (Llorente, 2019). Within this process, 
the student becomes a key piece within the system, as in many cases they are considered clients (Sarrias, 2018). And, applying branding to the higher education sector, the student has a high impact on the university brand capital maximization process (Casanoves, Küster, and Vila, 2017).

In this framework, the objectives of the present research were to (1) establish which are the most determinant variables of brand capital in the higher education sector, and (2) decipher which are the most outstanding variables by university students in Ireland. Thus, and after reviewing the seven major proposals on brand capital models in the literature (Farquhar, 1989; Aaker, 1992; Keller, 1993; Faircloth, Capella, and Alford, 2001; Yoo and Donthu, 2001; Delgado and Munuera, 2002; Buil, Martínez and De Chernatony, 2010), we have considered four elements that are identified by these authors and were also deemed to be of importance in previous studies. These are: (1) brand awareness, (2) brand image, (3) perceived quality, and (4) brand loyalty.

To sum up, the realization of the present research supposes a scientific advance in the discipline of marketing; although there has been specific research into brand capital and the variables that compose it (Colmenares and Saavedra, 2007), it is considered that research does not presently exist that thoroughly analyses the perception of brand capital through the opinions of university students in Ireland. It can also help university managers because based on the results obtained on the significance of each of the variables of the educational brand capital and they can generate appropriate strategies to maintain or improve it.

\section{The perception of brand capital among public university students in Ireland}

After reviewing the seven main proposals on brand capital models made by the literature, four elements have been considered that shared by the authors, and taking into account the importance given in previous studies, we understand that their contribution to brand capital is key. These are: (1) brand awareness, (2) brand image, (3) perceived quality, and (4) brand loyalty. Each one of them is detailed below.

\subsection{Brand awareness}

In the specific field of education, several authors (Toma, Dubrow, and Hartley, 2005; Brewer and Zhao, 2010; Pinar, Trapp, Girard, and Boyt, 2014) find that branding in higher education is a very important variable for universities, in order to generate greater preference for consumption in educational services and, therefore, increase sales. In other words, greater brand awareness will mean greater brand equity. In view of the above, it is possible to raise the first research hypothesis: H1. The perception of brand awareness influences the perception of brand capital among Irish public university students.

\subsection{Brand image}

In the specific field of education, several authors (Hamann, Williams and Omar, 2007; Waeraas and Solbakk, 2009; Guzmán, Abimbola, and Whisman, 2009) have shown that the image of the brand in public and private universities is a very valuable asset for organizations, and effective and rapid measurements of the image transmitted to target audiences must be carried out since this perception may be different in both areas. This image, as it improves, will lead to increases in the brand capital of the university institution whose image is favored. In view of the above, it is possible to raise the second research hypothesis: $\mathrm{H} 2$. The perception of brand image influences the perception of brand capital among Irish public university students.

\subsection{Perceived quality}

In the specific field of education, several studies (Peltier, Schibrowsky, and Drago, 2007; Chen, 2008; Pinar, Trapp, Girard, and Boyt, 2014) show that the quality perceived in private and public higher education is a variable that also depends on the fact that it is up to educational institutions to obtain greater satisfaction from their users. Quality, therefore, is another key source in the configuration of the brand capital of the university institution, insofar as higher perceived quality will translate into greater brand capital. In view of the above, it is possible to raise the third research hypothesis: H3. The perception of perceived quality influences the perception of brand capital among Irish public university students.

\subsection{Brand loyalty}

In the specific field of education, several papers (Brown and Mazzarol, 2009; Paswan and Ganesh, 2009; Rojas, Vasquez, Kara and Cerdá, 2009) highlight the relevance of brand loyalty in the higher education sector, which implies that this variable is very important in generating educational brand capital. Audiences that are more loyal contribute to increasing brand equity. In view of the above, it is 
possible to raise the fourth research hypothesis: H4. The perception of brand loyalty influences the perception of brand capital among Irish public university students.

In view of the above, Figure 1 shows our proposed theoretical model designed to defend the present investigation.

Figure 1. Theoretical model proposed for the present research.

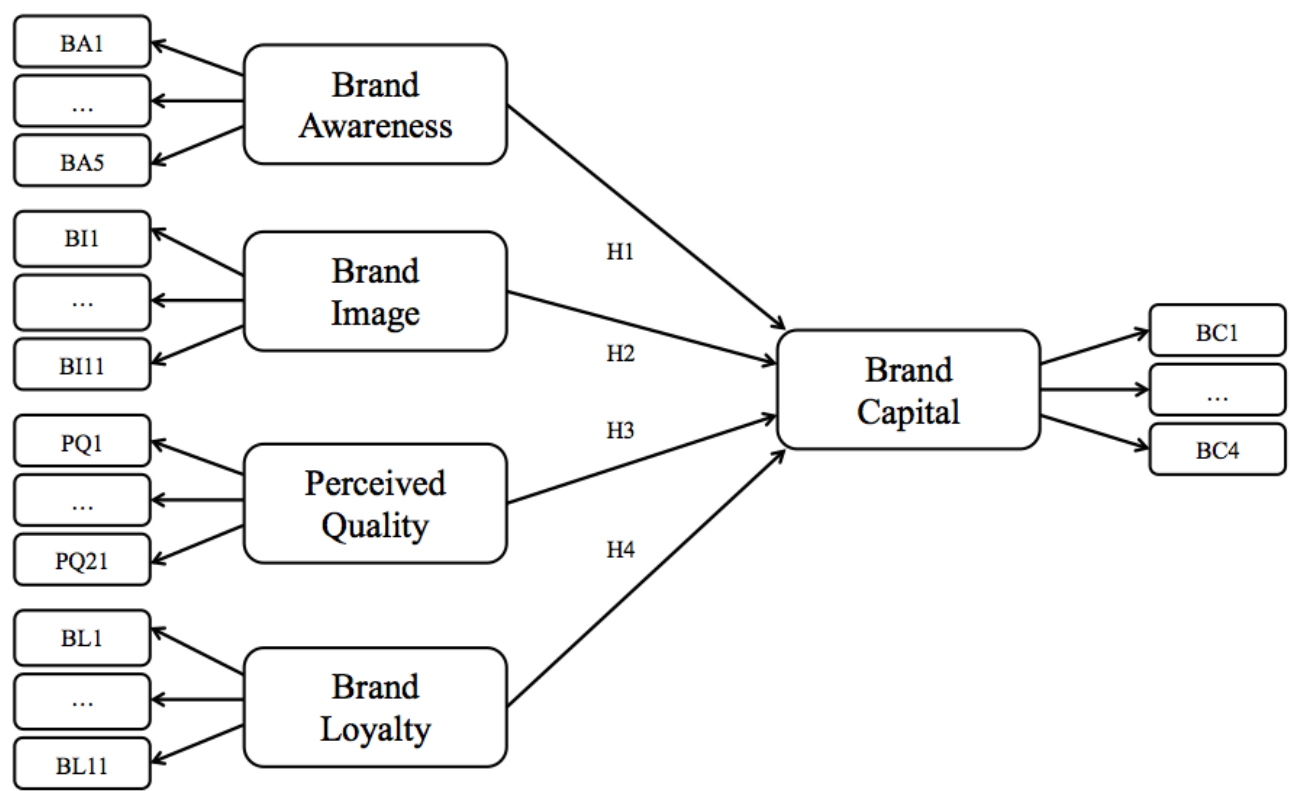

\section{Methodology}

In order to corroborate the established hypothesis, we conducted empirical research quantitative in nature, by means of a survey in the English language aimed at a group of 423 students from the two main public universities in Cork (Ireland).

Grade 5 Likert scales were used to measure the concepts of (1) brand awareness, (2) brand image, (3) perceived quality, and (4) brand loyalty. These scales are based on the measurement scales proposed by Aaker (1992) and Keller (1993) and were adapted to our field of study, higher education. The techniques for data analysis were based on descriptive statistics and multivariate analysis, using as a working tool SPSS v19 for Windows for descriptive techniques of data and SmartPLS 2.0 for executing multivariate techniques.

\section{Conclusions}

As a work in progress, it should be noted that we are currently in the analysis phase, through the application of different methods of analysis depending on the information to be obtained, distinguishing between (1) psychometric characteristics of the measuring instrument, divided into an analysis of the quality of the items and the validation of the scales; and (2) hypothesis testing, using a Structural Equations Modeling (EQS).

Once we finish this, we will document the conclusions and business implications for each variable proposed for our brand capital construct (brand awareness, brand image, perceived quality, and brand loyalty). With this, we will discuss the limitations of our research as well as future research, in order to open a new way for the scientific community.

\section{Acknowledgments}

This work was made possible by funding from Munster Technological University (Ireland).

\section{References}

Aaker, D. A. (1992). The value of brand equity. Journal of business strategy, Vol. 13(4), pp. 27-32.

Aldás, J. (2013). Partial least squares path modelling in marketing and management research: An annotated application. In Quantitative modelling in marketing and management (pp. 43-78). 
Batra, R., Ahuvia, A., \& Bagozzi, R. P. (2012). Brand love. Journal of marketing, 76(2), 1-16.

Brewer, A., \& Zhao, J. (2010). The impact of a pathway college on reputation and brand awareness for its affiliated university in Sydney. International Journal of Educational Management.

Buil, I., Martínez, E., \& De Chernatony, L. (2010). Medición del valor de marca desde un enfoque formativo. Cuadernos de gestión, 10, 167-196.

Camacho, J. (2008). El valor de la marca; Brand Equity. Página electrónica de Nielsen México. [en línea] Disponible en: http://mx. nielsen. com/press/Elvalordelamarca BrandEquity. shtml (consulta: diciembre de 2009).

Casanoves, J., Küster, I., \& Vila, N. (2017). Student loyalty as a key variable to build university brand capital. ESIC Market. Economic \& Business Journal, 48(3).

Chen, L. H. (2008). Internationalization or international marketing? Two frameworks for understanding international students' choice of Canadian universities. Journal of Marketing for Higher Education, 18(1), 1-33.

Colmenares, O. A., \& Saavedra, J. L. (2007). Aproximación teórica de la lealtad de marca: enfoques y valoraciones.

Delgado, E., \& Munuera, J. L. M. (2002). Medición del capital de marca con indicadores formativos. Investigación y marketing, (75), 16-20.

Durán, S., \& Parra, M. (2014). Diversidad Cultural para promover el desarrollo de habilidades sociales en educación superior. Revista Cultura, Educación y Sociedad, 5(1), 55-67.

Faircloth, J. B., Capella, L. M., \& Alford, B. L. (2001). The effect of brand attitude and brand image on brand equity. Journal of Marketing Theory and Practice, 9(3), 61-75.

Farquhar, P. H. (1989). Managing brand equity. Marketing research, 1(3).

García, J., \& Pelekais, C. (2012). La Dirección estratégica como factor potenciador de la Gestión del Conocimiento en Universidades Privadas: una perspectiva desde los Centros de Investigación. Material mimeografiado Jornadas del Centro de Investigación de Ciencias Administrativas y Gerenciales. CICAG. Universidad Dr. Rafael Belloso Chacín.

Guzmán, F., Abimbola, T., \& Whisman, R. (2009). Internal branding: a university's most valuable intangible asset. Journal of Product \& Brand Management.

Hamann, D., Williams, R. L., \& Omar, M. (2007). Branding strategy and consumer high-technology product. Journal of Product \& Brand Management.

Henao, L., \& Colorado, L. (2017). Calidad de servicio, satisfacción y antecedentes de la lealtad hacia las empresas de telecomunicaciones en Colombia. XXII Congreso Internacional de Contaduría, Administración e Informática. Ciudad Universidad. Ciudad Méjico.

Kaynak, E., Salman, G. G., \& Tatoglu, E. (2008). An integrative framework linking brand associations and brand loyalty in professional sports. Journal of Brand Management, 15(5), 336-357.

Keller, K. L. (1993). Conceptualizing, measuring, and managing customer-based brand equity. Journal of marketing, 57(1), 1-22.

Llorente, C. (2019). Marketing educativo: Captación y fidelización de alumnos. ESIC Editorial.

Manes, J. M. (2005). Marketing para Instituciones Educativas. Buenos Aires: Ediciones Granica S.A.

Morín, E. (2018). De la reforma universitaria.

O’Connor, P., \& White, K. (2011). Similarities and differences in collegiality/managerialism in Irish and Australian universities. Gender and education, 23(7), 903-919.

Olins, W. (2008). The brand handbook. Thames \& Hudson.

Paswan, A. K., \& Ganesh, G. (2009). Higher education institutions: Satisfaction and loyalty among international students. Journal of Marketing for Higher Education, 19(1), 65-84.

Peltier, J. W., Schibrowsky, J. A., \& Drago, W. (2007). The interdependence of the factors influencing the perceived quality of the online learning experience: A causal model. Journal of Marketing Education, 29(2), 140-153.

Pinar, M., Trapp, P., Girard, T., \& Boyt, T. E. (2014). University brand equity: an empirical investigation of its dimensions. International Journal of Educational Management.

Sarrias (2018). School marketing: como vender más siendo un centro de enseñanza. Profit Editorial.

Toma, J. D., Dubrow, G., \& Hartley, M. (2005). The Uses of Institutional Culture: Strengthening Identification and Building Brand Equity in Higher Education. ASHE Higher Education Report, Volume 31, Number 2. ASHE Higher Education Report, 31(2), 1-105.

Wæraas, A., \& Solbakk, M. N. (2009). Defining the essence of a university: Lessons from higher education branding. Higher education, 57(4), 449.

White, T. (2001). Investing in people: Higher education in Ireland from 1960 to 2000. Institute of Public Administration.

Yoo, B., \& Donthu, N. (2001). Developing and validating a multidimensional consumer-based brand equity scale. Journal of business research, 52(1), 1-14. 


\title{
THE IMPACT OF COVID-19 ON RESIDENTIAL CARE SERVICES FOR CHILDREN: A CALL FOR FAMILY-BASED APPROACH IN ALTERNATIVE CARE
}

\author{
Lucia Carriera, Chiara Carla Montà, \& Daniela Bianchi \\ "Riccardo Massa" Department of Human Sciences for Education, University of Milano-Bicocca (Italy)
}

\begin{abstract}
Children's rights and needs are at the center of the United Nations 2030 Agenda for Sustainable Development, where education is viewed as crucial for providing the opportunities for sustainable, peaceful and equitable coexistence in a changing world. Alternative care settings are educational contexts (Tibollo, 2015) that deal with children in vulnerable conditions (UN General Assembly, 2010). For this reason, they can be considered as a sort of "field test" or "magnifying glass" on how the progress in striving to the implementation of the goals is proceeding - no one must be left behind. The 2020 global pandemic provoked an external shock to current socio-economic dimensions of sustainability. Education has been one of the most struck systems - let's think of the 1,6 billion learners that have been affected by school closures (UNESCO, 2020).

With this global framework in mind, the contribution aims at offering a pedagogical reflection on the impact the Covid-19 pandemic is having on children living in residential care centers (RCC).

Worldwide, many RCCs, following the ongoing global pandemic, have been closed with the consequent return of children to their families of origin (CRIN, 2020). This process of deinstitutionalization, however, has not been overseen by rigorous monitoring, leading to increased risks of violence for children. This urges authorities to take carefully planned measures with respect to deinstitutionalisation in light of the COVID-19 pandemic (Goldman, et al., 2020). But Covid-19 is not only a health risk for children in RCCs. Because of the complex impact that the pandemic has had on the lives of children, on one side care responses are required, and on the other psycho-social and educational ones are also crucial (SOS Villaggi dei Bambini Onlus Italy; Save The Children, 2020). In Italy, for example, special guidelines have been drawn up to mitigate the spread of the virus within residential structures, that sometimes are overcrowded (Istituto superiore di sanità; SOS Villaggi dei Bambini Onlus Italia, 2020). In addition, tools have been provided to support the mental health of the children and adolescents that are deprived of opportunities for socialization given the closure of schools. In some cases they are isolated within the services themselves to mitigate the risk of the spread, causing a limitation in the possibility of seeing people outside the institution as their parents.

Covid-19 underlines the urgency of promoting family-based alternative care for children. In particular, this paper aims to read through a pedagogical lens, the European scenario of residential services for children, to explore the impact of Covid-19 in these services; and to promote a family-based approach in alternative care preventing the risk of institutionalization in children welcomed.
\end{abstract}

Keywords: Alternative care, children, covid-19, de-institutionalisation, family-based approach.

\section{Introduction}

The United Nations Convention on the rights of the Child -UNCRC- (1989) emphasizes the right and importance of growing up in a family but, in certain exceptional cases -following the principle of the best interest of the individual child-, as stated in Article 20, it may be needed to resort to alternative care settings, amongst which residential care centers (UN General Assembly, 1989):

«1. A child temporarily or permanently deprived of his or her family environment, or in whose own best interests cannot be allowed to remain in that environment, shall be entitled to special protection and assistance provided by the State.

2. States Parties shall in accordance with their national laws ensure alternative care for such a child. 3. Such care could include, inter alia, foster placement, kafalah of Islamic law, adoption or if necessary placement in suitable institutions for the care of children. When considering solutions, 
due regard shall be paid to the desirability of continuity in a child's upbringing and to the child's ethnic, religious, cultural and linguistic background» (UN General Assembly, 1989, p.6).

In most European UNCRC signatory countries, residential care centers (RCC) are part of the child protection system, that aims at defining a general, legal and practical framework for interventions aiming at protecting children. Residential care centres may be defined as a "broad class of settings where children live full-time, with a view to protecting them from the risks of living with their own families who have been deemed - at least temporarily - unable to adequately cater for their development. Furthermore, residential care settings are invested with an "educational mission", they put in place a nurturing environment for predisposing a personal change in children who have experienced adverse conditions by changing the quality of care and environment in which they live in (Biffi \& Montà, 2020, p.173). These aspects are also emphasized by the United Nations 2030 Agenda for Sustainable Development, that sees educational environments as crucial for providing the opportunities for sustainable, peaceful and equitable coexistence in a changing world.

RCCs aim at pedagogically organizing elements such as space, time, language, body, symbols, all elements that put together characterize the educational experience (Tibollo, 2015), in order to promote the human flourishing of children in particularly vulnerable conditions. For this reason, they can be considered as a sort of "field test" or "magnifying glass" on how the progress in striving to the implementation of the goals is proceeding (Montà \& Sommaruga, 2019).

\section{Family-based approaches in alternative care}

The 2020 global pandemic provoked an external shock to current socio-economic dimensions of sustainability. Residential care settings have been impacted on in different ways as the latest studies report.

The report Transition from Institutional Care to Community-Based Services in 27 EU Member States" declares that:

«In times of the COVID-19 pandemic and lockdowns, (...) the negative aspects of institutionalisation are increasingly blatant and only tend to aggravate with the congregation of a large number of people in one building, and the deprivation of social contacts». (Šiška J, \& Beadle-brown, J., 2020, p.3).

Children in RCCs live in close proximity to each other, unavoidably in close contact (Wang J. et al., 2020) so specific regulations have been drafted to mitigate the risk of contagion within residential facilities. In some cases, children, in fact, have been isolated within the services themselves to mitigate the risk of the spread, causing a limitation in the possibility of seeing people outside the institution as their parents and peers. To this end, in Italy, for example, tools have been provided to support the mental health of the children and adolescents that are deprived of opportunities for socialization (SOS Villaggi dei Bambini Onlus Italia, 2020). When thinking of RCCs as a "magnifying glass" of sustainable development-as they deal with children in vulnerable conditions, the pandemic has exacerbated structural issues within them mining the progress towards the SDGs. RCCS, in fact, are often considered as the last resort and, due to the dominant culture of risk management and protection, high caseloads, the burden of paperwork, the lack of adequate staffing, work modes tend to be procedure-driven and often child unfriendly rather than based on a pedagogical model able to provide a nurturing environment for the flourishing of children's capabilities (Beckett et al., 2007; Horwath, 2010; Winter, 2009). The pandemic put children's health at great risk and, with the aim of protecting them, their needs-rights, that are already in a fragile position, have been definitely "locked-down"-let's think of individualised interventions, respect for the child's well-being and rights, taking into account children's opinions and preferences (UN General Assembly, 2009; Eurochild, 2012).

If on one side children have been locked down in RCCs, on the other side it is RCCs that have been closed down, leading to the return of children to their families of origin. This might seem to be an important step towards the de-institutionalisation process, a fundamental goal in the child protection system (Eurochild, 2020). However, studies (Wilke, N. G., Howard, A. H., \& Goldman, P. (2020) point out that this process of return to biological families of origin has been very sudden and, above all, has not been adequately supervised. In addition, due to measures to contain the risk of the Covid-19 infection, children cannot count on the crucial support of schools or even on in-person visits for family monitoring. Although policies emphasise the importance of ensuring that children remain with their birth families, this return process is very fragile and potentially risky and deserves to be strategically structured and implemented. Some of the main concerns related to this failure to monitor the de-institutionalisation process, listed by the literature, are 1) unresolved antecedents to placement, 2) lack of pre-placement preparation, 3) poverty and unemployment, and 4) education for children and caregivers (Wilke, N. G., Howard, A. H., \& Goldman, 
P., 2020, p. 3). The ongoing global pandemic has further amplified the fragilities of many families, potentially expanding the risk of vulnerability for children in the child protection system.

In this contribution, in line with the current literature on the topic, we suggest to refer to a "family-based approach" when thinking about the deinstitutionalisation process. We have illustrated how potentially risky it is to send children back to their families of origin without adequate intervention and monitoring strategies. In this paper with "family-based approach", we refer both to the work with families of origin and also to a form of alternative care (Save the Children, 2009).

With regard to the first definition, literature for years has been pointing out the importance of firstly, investing in prevention to strengthen parental responsibility, empower the most at risk families and avoid an escalation of problems that will lead to institutionalisation (Eurochild, 2012). For example, by investing in a wide range of services to address problems that arise at different stages such as: family planning, prenatal care, preventing abandonment at birth, early childhood services, out of school programmes, after school care, specialised services and financial support for children with special/ complex needs and so on (Eurochild, 2012, p.18).

When, as reported in this paper, the removal has already taken place, the reunification of the child with the family of origin should be gradual, and also anticipated by continuous communication between the family of origin and the child. This transition should also be accompanied by a supportive strategy, also through networking with services or organisations that have implemented similar programmes and could facilitate this process (Wilke, N. G., Howard, M. H., \& Pop, D., 2020).

Another crucial dimension highlighted in the literature is the need to mitigate the precedents that led to separation from the family of origin, prior to the child's return, including supporting families through economic resilience programmes for example -especially in a period such as the Covid-19 one (Wilke, N. G., Howard, A. H., \& Goldman, P., 2020).

At last, we briefly take into consideration the second definition of "family-based approach" citing Save The Children's report Keeping Children Out of Harmful Institutions. Why we should be investing in family-based care, that defines this approach as:

«A form of alternative care that involves a child living with a family other than his/her birth parents. This includes kinship care, foster care, adoption, kafala (an Islamic form of adoption), and supported child-headed households». (Save the children, 2009. p VI).

This kind of an approach requires, amongst others, specific selection and training for substitute families, the presence of a legal and policy and procedural framework, standards of care planning, professional monitoring and inspection services, technical support from social services (Save the children, 2009).

\section{Conclusion}

When thinking about RCCs as a "magnifying glass" of sustainable development, whose lens has been additionally brought into focus by the Covid-19 pandemic, we suggest the following points of attention.

The first one refers to adopting a "family-based approach" when working with families both in prevention terms - to avoid displacement of children - and in support terms - to empower families for children's return. During the pandemic the return process has not been pedagogically planned, putting at risk children's rights and their human flourishing, in other words the educational intervention that was taking place within the RCC. Moreover, the families of these children, already in vulnerable conditions, have been suddenly and without adequate support been asked to exercise their parental functions in the midst of a global crisis.

When thinking of RCCs, often considered as a last resort and overwhelmed by procedural and organisational issues, we can note that the pandemic has exacerbated these aspects by overemphasizing protection and limiting the rest of children's rights - locking down children in the institutions and adopting ridged sanitary protocols. For this reason, it is urgent to think of these institutions as a pedagogical dispositive (Tibollo, 2015) able to put the child's needs-rights at the heart, through a personalised educational plan - able to consider the return into the family of origin right from reception.

Finally, it is high-time to think and plan of a "family-based approach" intended as an ensemble of forms of alternative care to RCCs, to limit the risks of institutionalization. 


\section{References}

Beckett, C., McKeigue, B., \& Taylor, H. (2007). Coming to conclusions: social workers' perceptions of the decision making process in care proceedings. Child \& Family Social Work, 12(1), 54-63.

Biffi, E., \& Montà, C. C. (2020). Documenting Children in Alternative Care Services: Transitional Spaces Between 'Being Spoken for' and 'Speaking for Oneself'. In M. Alasuutari, H. Kelle, \& H. Knauf (Eds.), Documentation in Institutional Contexts of Early Childhood: Normalisation, Participation and Professionalism (pp. 167-183). Retrieved 18.02.2021, from https://doi.org/10.1007/978-3-65828193-9 9

CRIN (2020). Children in Out-of-Home Care: Lessons from the Pandemic. Retrieved 18.02.2021, from https:/home.crin.org/readlistenwatch/stories/children-in-out-of-home-care-lessons-from-thepandemic?rq= $\operatorname{covid} \% 2019$

Eurochild. (2012). De-institutionalisation and quality alternative care for children in Europe: Lessons learned and the way forward. March, 1-27.

Goldman, P. (2020). The implications of COVID-19 for the care of children living in residential institutions. The Lancet, Child and Adolescence Health, 4(6).

Horwath, J. (2010). See the practitioner, see the child: The framework for the assessment of children in need and their families ten years on. British Journal of Social Work, 41(6), 1070-1087.

Jennifer C. Davidson, Ian Milligan, Neil Quinn, Nigel Cantwell \& Susan Elsley (2017) Developing family-based care: complexities in implementing the UN Guidelines for the Alternative Care of Children, European Journal of Social Work, 20:5, 754-769. doi: 10.1080/13691457.2016.1255591

Montà, C., \& Sommaruga, S. (2019). Children's Participation within Alternative Care Settings: First Findings from a Narrative Literature Review. ECER 2019 Hamburg-The European Conference on Educational Research. Emerging Researcher's Conference. 'Education in an Era of Risk-the Role of Educational Research for the Future'.

Save The Children (2020). Proteggiamo i bambini. Whatever it takes. L'impatto della pandemia sui bambini e sugli adolescenti in Italia e nel mondo. Retrieved 18.02.2021, from https://s3.savethechildren.it/public/files/uploads/pubblicazioni/proteggiamo-i-bambini-whatever-ittakes.pdf

Save the Children. (2009). Keeping Children Out of Harmful Institutions Keeping Children Out of Harmful Institutions. Keeping Children out of Harmful Institutions: Why Should We Be Investing in Family-Based Care.

Šiška J, \& Beadle-brown, J. (2020). Transition from Institutional Care to Community-Based Services in 27 EU Member States: Final report. Research report for the European Expert Group on Transition from Institutional to Community-based Care. Retrieved 18.02.2021, from https://deinstitutionalisationdotcom.files.wordpress.com/2017/11/report-fo-the-ad-hoc_2009.pdf

SOS Villaggi dei Bambini Onlus Italy (2020). SOS Villaggi dei Bambini e COVID-19: Linee guida per il contenimento e mitigazione del rischio COVID-19 in comunità. Retrieved 18.02.2021, from https://www.sositalia.it/getmedia/40df5a82-df7d-4d30-82bd-0ee07ca59e81/LINEE-GUIDA-PERIL-CONTENIMENTO-E-MITIGAZIONE_SOS.pdf

Tibollo, A. (2015). Le comunità per minori. Un modello pedagogico: Un modello pedagogico (Vol. 12). FrancoAngeli.

UN General Assembly (2010). 64/142. Guidelines for the Alternative Care of Children. 53(53), 1-23.

UN General Assembly. (1989). Convention on the Rights of the Child. United Nations, Treaty Series, 1577, 3. Retrieved 18.02.2021, from https://www.refworld.org/docid/3ae6b38fo.html

UNESCO (2020). Global monitoring of school closures caused by COVID-19. Retrieved 18.02.2021, from https://en.unesco.org/covid19/educationresponse.

Wang, J., Yang, W., Pan, L., Ji, J. S., Shen, J., Zhao, K., Ying, B., Wang, X., Zhang, L., Wang, L., \& Shi, $X$. (2020). Prevention and control of COVID-19 in nursing homes, orphanages, and prisons. Environmental Pollution, 266. Retrieved 18.02.2021, from https://doi.org/10.1016/j.envpol.2020.115161

Wilke, N. G., Howard, A. H., \& Goldman, P. (2020). Rapid return of children in residential care to family as a result of COVID-19: Scope, challenges, and recommendations. Child Abuse and Neglect, 110. Retrieved 18.02.2021, from https://doi.org/10.1016/j.chiabu.2020.104712

Wilke, N. G., Howard, M. H., \& Pop, D. (2020). Data-informed recommendations for services providers working with vulnerable children and families during the COVID-19 pandemic. Child Abuse \& Neglect. Retrieved 18.02.2021, from https://doi.org/10.1016/j.chiabu.2020.104642.

Winter, K. (2009). Relationships matter: the problems and prospects for social workers' relationships with young children in care. Child \& Family Social Work, 14(4), 450-460. 


\title{
CONSIDERATIONS OF TALENT MANAGEMENT IN RETENTION OF ACADEMICS IN THE NATIONAL UNIVERSITY OF LESOTHO
}

\author{
Theressa Madzingesu Zengeya ${ }^{1}$, Gregory Alexander ${ }^{2}$, \& Desiree Pearl Larey ${ }^{3}$ \\ ${ }^{I}$ Sol Plaatje University (South Africa) \\ ${ }^{2}$ Central University of Technology (South Africa) \\ ${ }^{3}$ University of the Free State (South Africa)
}

\begin{abstract}
The aim of the study was to examine the contribution of talent management practices at the National University of Lesotho in the retention of talented academics. The university has immense competition within the local, regional and international labour market. It is threatened by high mobility and low retention of highly qualified staff, which has affected the quality of learning, especially postgraduate programmes. The study employed Bourdieu's social theory and Adam's theory of equity as a theoretical lens to understand talent management practices to retain talented academics. Bourdieu's theory was used to offer insight on the various forms of capital, and how the capitals could be instrumental in the design and implementation of talent management practices in order to increase retention of talent in universities. In this study 'talent' is used to refer to holders of doctorates, associate professors and professors or researchers of new information and theories and inventors of new technology with great potential to make a significant impact on the university's productivity. A literature review was undertaken to examine how the social theory of Bourdieu, particularly the conversion of different kinds of capital (symbolic capital) are used by the university to recognise the value of talented academics in order to retain these academics. Following a qualitative methodology and purposive sampling, data was generated through semi-structured interviews and document analysis to advance a critical and interpretive understanding of the perspectives of talent management from both management and talented academics in the university. Thematic analysis was used to synthesise the data. The data from fourteen (14) participants composed of management and academics revealed that, though the university is implementing talent management practices, it does not have an official and structured talent management program, which is imperative in retaining academics. This study concludes by advocating the design and implementation of a formal, contextual and structured talent management framework, in consultation with all key stakeholders, in order to increase retention of talent academics in the National University of Lesotho.
\end{abstract}

Keywords: Equity theory, Bourdieu's social theory, talent management, talented academics.

\section{Introduction}

The aim of the study was to examine the contribution of talent management practices at the National University of Lesotho (NUL) in the retention of talented academics. Khoreva and Kostanek (2019) found that most Talent Management (TM) studies targeted Human Resource (HR) practitioners who may have a different interpretation than any other groups in firms, hence the keen to survey academics who are beneficiaries of TM practices in universities. Higher education institutions are facing some difficulties and challenges in attracting qualified staff, particularly in the areas of safety and security, workloads and conflicting opinions (Mohammed, Hafeez-Baig \& Gururajan, 2018). Higher education institutions are based sturdily on the attraction of experienced staff to fill crucial positions (Mohammed, Hafeez-Baig \& Gururajan, 2018). There is no clear conception of TM and how it impacts on retention (Mensah, 2015), in practical terms, hence organizations implementing TM may not understand the mechanism through which TM improves employee retention and how this translates into organisational brand name (Mensah, 2015). The construct "talent" and "talent management" lack theoretical vigour and standardized definition (Ansar \& Baloch, 2018; Damarasri \& Ahman, 2020) hence the existence of inconclusive debate among scholars. Despite this focus and attention, various researchers noted that talent management literature continues to be under-explored (Collings \& Mellahi, 2009; Garrow \& Hirsh, 2008; Hoglund, 2012; Lewis \& Heckman, 2006; Reilly, 2008; Yarnall, 2011). Collings and Mellahi (2009) noted that the literature of talent management remains unclear about the concept as a whole especially in terms of its definition and 
theoretical boundaries. In addition, from the practitioner's perspective, Yarnall (2011) posited that institutions, such as public universities (NUL) are implementing talent management without careful considerations to the consequences of such application neither on the talent pool nor on the remaining employees.

\section{Theoretical framework}

This study draws insights from Adam's equity theory and Bourdieu's cultural capital theory in an endeavour to establish the effectiveness of talent management within a university context in an attempt to retain the highly talented academics. According to Armstrong (2009:328), equity theory states that individuals compare their job inputs (physical and mental ability) and outcomes (rewards) with those of others internally and externally, and then respond to eliminate inequalities, sometimes by leaving the organisation. According to Swanepoel, Erasmus, Wyk and Schenk (2011:478), in order for universities to encourage highly talented members to stay, rewards system, training, and promotion opportunities must provide sufficient returns. There should also be a perceived equilibrium when employees compare own institution rewards with what is received by their counterparts performing comparable jobs in other or similar institutions. According to Nenty and Bioa (2013:7), promotional criteria should be clearly stated in the university's promotion guidelines and reflect equity.

Bourdieu's work sees the education structures of industrialised communities as functioning to validate class inequalities. According to Sullivan (2002:144), Bourdieu's theory states that fundamental powers are embedded in all forms of capital (cultural capital, social capital, economic capital and symbolic capital) that are observed and acknowledged as legitimate. Cultural capital is seen as forms of cultural knowledge, competences or dispositions or intellectual acquisitions that equips the individual with appreciation for or skills of a specific subject area or field of study, Bourdieu (1993:7). These may be educational qualifications that one holds, for example, certificates, diploma, degrees, publications etc. Cultural capital is accumulated through a long process, learning through the family, society or formal institutionalised educational process.

\section{Methodology}

This study adopted a qualitative research approach. A total of 14 participants were interviewed in this study (3 university management representatives, 3 professors, 4 associate professors and 4 doctoral holders). Informed consent was obtained from all the participants to audio record the interviews and participants were informed of anonymity and confidentiality applied to the research process, de Vos, Strydom, Fouché \& Delport, (2002). Authorisation to conduct this research at the National University of Lesotho was granted by the institutional authorities. Data from the transcribed interviews was thematically analysed where similar categories of data were grouped into themes in order to make sense and find meaning of the data.

\section{Analysis and Discussion of Findings}

The data from the 14 interviews points that in order for talent management to be effective, there should be perceived equity between one's educational investment and their rate of returns in terms of economic and non-economic compensation. The following are some of the themes that emerged from the data which will be discussed briefly:

\subsection{Theme 1: Retention allowance}

All participants seemingly agreed that though there was no written retention strategy at the university, the organisation had made an effort to put in place a $10 \%$ retention allowance of basic salary for talented academics. Participant C4: "As an associate professor, the university offers me 10\% allowance of my basic salary on a monthly basis. It is a permanent feature to encourage me to stay. However, the allowance has been eroded by inflation since salaries have been stagnant for a long time." While the academics suggest for the university to do review the allowance upwards, management expressed that: The University acknowledges that the allowance had been overtaken by inflation, but because of the shoestring budget from the government that the university is working with, it may not be possible to increase the allowance from 10\%. If the financial situation of the university improves anytime, there could be a possibility to raise the percentage, (Participant M2). This comment concurs with Mgaiwa (2018:3), that a major challenge, especially in government universities, is that the greater part of compensation is financed from the state budget, which could be limiting for designing lucrative reward systems. This leaves the university with a major challenge to think creatively in terms of seeking other sources of income apart from 
the government subventions and redesign competitive compensation structures in order to increase the retention allowance to where academics feel appreciated and acknowledged as the valuable assets of the university.

\subsection{Theme 2: Extension of retirement age for highly talented academics}

Extended retirement age was one of the retention strategies that most of the professor participants expressed with excitement as most of them were towards retirement. One professor (Participant C5) noted that: "Two years ago (2017), council approved extension of retirement age for associate professors and professors to be moved from 65 to $70-71$ according to individual strength. This has helped to retain professors since most of them are towards retirement." From the interviews, this came as a big relief to most talented academics as one participant $\mathrm{C} 2$ explained: When I turned 60, I felt I was now at the best stage of my career where I am a seasoned researcher, ready to mentor junior academics but knowing that I was going to retire in a few years was affecting me. This came as a big relief for me and to my career. This is contrary to what Brewster (2008:129) observes that, some universities have 55-60 years as the retirement age which means the universities lose the best talent when they are at the climax careers with the opportunity to best service to the university through their accrued years of teaching and research experience. Consequently, extension of retirement age was one of the major issues that all talented academic would put serious consideration on as it affected the closure of their careers and any policy that send them to retire early may have deterring factors on retention.

\subsection{Theme 3: Allocation of resources}

Bourdieu's theory is of utmost importance to university management to understand that for a university to remain relevant concerning research, it has to put some groups of academics ahead of others in some points, (Bourdieu (1984). This was motivated by one of the professors (Participant E2) commenting on the limited funds for conferences: "In my opinion, because the university has limited funds, more funds should be allocated to senior academics, who are professors and doctorates so that we keep abreast with other professors in other universities in terms of research. In other universities, senior and junior lecturers are not allocated the same amount for research. Research grants should be allocated according to seniority. Lack of research leads to academic degradation". On the contrary, one of the participants (C6) had this view: "I think the research funds are enough for me because I do not even have the time to do research because of my workload and I have only claimed the research funds once since I started working at the university in 2004. " From the responses, the university could support talent's career advancement by contributing towards sustainable research through provision of opportunities of building social capital through attendance of conferences and research collaborations with other academics in the higher education arena. This could contribute immensely towards self-actualisation of academics as research is one of the key factors towards one's career growth and promotion.

\section{Conclusion}

Since talent is a multidimensional construct, the TM practices at NUL need to be initiated to address the social, educational, economic and cultural capital of the talented academics in an equitable manner in order to increase retention and gain a competitive advantage. The study reveals that designing and implementing a formal, contextual and structured talent management framework, in consultation with all key stakeholders, has potential to increase retention of talented academic in universities. The TM program should be exclusively designed and implemented in consideration that those with higher educational qualifications expect to be high on the economic and social hierarchy as a form of recognition and appreciation. Although suggestions about talent management practices such as: competitive economic rewards, challenging work, open communication, allocation of resources, recognition of achievement and more have the potential to improve talent retention, there has to be perceived equilibrium internally and externally between talent's cultural capital and rate of returns in order to increase retention. A correct balance of inputs and commitment from all stakeholders (management, talent and government) in the design and implementation of talent management yields positive results in increasing talent loyalty to the organisation. In most cases, they will decide to quit or exit environments with restricted academic freedom. Therefore, it is of paramount importance that all the talent management practices aim to address the needs and preferences of talent, individually and collectively in order to achieve both individual and organisational goals. 


\section{References}

Ansar, N. and Baloch, A., 2018. Talent and Talent Management: Definition and Issues. IBT Journal of Business Studies (JBS), 14(2).

Armstrong, M., 2009. Armstrong's Handbook of Human Resource Management 11th Edition. London: Kogan Page

Bourdieu, P. 1984. The social space and the genesis of groups. Theory and Society 14:723-744.

Bourdieu, P., 1986. The forms of capital. In Richardson, J. (ed) Handbook of Theory and Research for the Sociology of Education. New York: Greenwood.

Collings, D.G. and Mellahi, K., 2009. Strategic Talent Management: A Review and Research Agenda. Human Resource Management Review, 19(4), 304-313.

Damarasri, B. N. and Ahman, E., 2020. Talent management and work motivation to improve performance of employees. Dinasti International Journal of Education Management and Social Science, 1(4), 490-498.

Drew, G.M. 2006. Balancing academic advancement with business effectiveness. The dual role of senior university leaders. International Journal of Knowledge, Culture and Change Management, (6), 117-125.

Gallardo-Gallardo, E., Thunnissen, M. and Scullion, H., 2020. Talent management: context matters.

Khoreva, V. and Kostanek, E., 2019. Evolving talent management patterns and challenges in Russia and Kazakhstan. Baltic Journal of Management

Lewis, R. E. and Heckman, R.J., 2006. Talent management: A critical review. Human resource management Review, 16(2), 139-154.

Mensah, J. K., 2015. A "coalesced framework" of talent management and employee performance. International Journal of Productivity and Performance Management.

Mgaiwa, S. J., 2018. The Paradox of Financing Public Higher Education in Tanzania and the Fate of Quality Education: The Experience of Selected Universities. Hong Kong: SAGE.

Mohammed, A.A., Hafeez-Baig, A. and Gururajan, R., 2018. Talent management as a core source of innovation and social development in higher education. Talent Management as a Core Source of Innovation and Social Development in Higher Education, 1-31.

Nenty, J. and Biao, I., 2013. The professor within the context of African Universities. Contemporary Journal of African studies, 1(1), 1-20.

Sullivan, A., 2002. Bourdieu and Education: How Useful Is Bourdieu's Theory for Researchers? The Netherlands' Journal of Social Sciences, 38(2), 144-166.

Swanepoel, B., Erasmus, B., Wyk, V. M. and Schenk, H., 2011. South African Human Resource Management for the Public Sector. $2^{\text {nd }}$ Edition. Cape Town: Juta and Co Ltd.

Thunnissen, M., Boselie, P. and Frutier, B., 2013. A review of TM: Infancy or Adolescence? The International Journal of HRM, 24 (9), 1744-1761. 


\title{
HIGHER EDUCATION: SUSTAINING THE FUTURE OF STUDENTS DURING A PANDEMIC
}

\author{
Naziema Jappie \\ Centre for Educational Testing for Access \& Placement, University of Cape Town (South Africa)
}

\begin{abstract}
The COVID-19 challenge is unprecedented; its scale still is not fully understood. Universities in the South Africa do have plans in place to continue the academic year in 2021 but have no idea to what extent education will resume to normal face to face activity. Although the future is unpredictable, given the uncertainty in the epidemiological and economic outlooks, universities have to ensure quality and sustainability for the medium and long-term implications for teaching, learning, the student experience, infrastructure, operations, and staff.

Amongst the range of effects that COVID-19 will have on higher education this year, and possibly into future years, admission arrangements for students is one of the biggest. It is also one of the most difficult to manage because it is inherently cross sector, involving both schools and higher education. There is no template in any country of how to manage education during the pandemic. However, there are major concerns that exist, in particular, regarding the impact on learners from low income and disadvantaged groups. Many are vulnerable and cannot access the digital platform.

Post 1994, the South African government placed emphasis on the introduction of policies, resources and mechanisms aimed at redressing the legacy of a racially and ethnically fragmented, unjust, dysfunctional and unequal education system inherited from apartheid. Many gains were made over the past two decades especially, in higher education, two of which were access and funding for the disadvantaged students to attend university. However, the pandemic in 2020 disrupted this plan, causing the very same disadvantaged students to stay at home without proper learning facilities, poor living conditions or no access to devices and data. The paper argues that the tensions and challenges that dominated the Covid-19 digital educational reform have resulted in a significant paradigm shift focused on out of classroom experiences as expressed in the new ways of teaching and learning and possibly leaving certain groups of students behind.

Consideration is given to three broad areas within higher education in South Africa. Firstly the current dilemma of teaching and learning, secondly, the access or lack thereof to the digital platform and challenges facing students, and the thirdly, the issue of admission to higher education.

All three areas of concern represent the degree to which we face educational disruption during the pandemic.
\end{abstract}

Keywords: Access, digital learning, equality, sustainability, teaching.

\section{Introduction}

The Coronavirus, COVID-19 challenge is unprecedented. The complexity and instability of the education system was put to test and educational leaders had to make decisions that would have to take all matters into consideration. Schools and universities had to shut their doors and stop teaching and learning, students had to vacate their accommodation on campuses and return home. Most affected were foreign students who could not leave due to travel restrictions and had to find alternate accommodation. Education was brought to a complete halt - universities became empty shells, little ghost towns. Universities in South Africa are still closed in 2021, with very few classes that being conducted face to face. For now, teaching online is predominant and no one knows when normal activities will resume. But even though the higher-education sector does not have all the answers, given the uncertainty in the epidemiological and economic outlooks, they have questioned the medium- and long-term implications for teaching, learning, the student access to digital platforms and new admissions. This paper highlights the important issues that arose in higher education during the peak of the pandemic and includes some observation of the desktop research findings conducted by JET Education Services on Governance and Management-Higher Education Response to Covid-19. 


\section{Methodology}

The desktop research took place under exceptional circumstances, where face-to-face interviews and focus groups were impossible but where websites could be used to gather information and data for debate and discussion. The researchers adjusted to these new circumstances by flexibly and creatively investigating and categorising the varying responses by higher education institutions to the pandemic and the lockdown, in the process also drawing upon their own ideas and individual experiences. The research team consisted of 11 participants from a range of South African higher education institutions; they consisted mostly of young researchers and were accompanied by a team lead, a co-researcher and a reviewer.

Team meetings were held during the month of April using Google Hangouts as well as WhatsApp. There were also one to one discussions between the team lead and individual participants. The initial meeting set the scene for the work and divided the areas of interest among the participants. Each researcher was given a timeframe within which they were to complete the task given to them and submit their work on the Google platform created by JET. Report for theme 8 can be viewed at www.jet.org.za.

\section{Observations}

\subsection{Impact on teaching and learning}

The only certainty is uncertainty. However, given the mission, and operations of universities, they needed to examine all the possibilities across the institutions and the implications for teaching and learning. During the pandemic, it was envisioned that most students will complete the 2020 academic year online, and the class of 2020 will graduate virtually. Although the year was extended into 2021, some students were allowed to return to class for the second semester, especially if they were in their final year or needed to conduct laboratory work. However, restrictions remained for some international students and those who could reside in student accommodation were given resources to continue their studies.

Even this relatively optimistic outlook was likely to pose significant challenges to higher education. As South Africa decreed total strict lockdown from the COVID-19 pandemic in March 2020, the number of universities rapidly switching to emergency remote learning soared. However, few of the institutions were well prepared for this sudden, disruptive move, whilst others had a late start to the academic year. (Bevin et al, 2020). Much scrambling and improvisation occurred as the leadership, teaching staff and administrators made great strides to implement broad-based online remote teaching. University core task teams worked long hours to secure laptops for disadvantaged students and data from service providers to ensure that all students had the resources that they needed for the remote teaching to take place.

Remote or online teaching and learning is not the norm at South African universities. Staff and students had to reimagine the classroom virtually and engage without any face to face interaction. There was definitely a need for capacity building among academics so that they were sufficiently trained to offer virtual teaching. Some universities struggled with financing the systems for online learning. The system is extremely expensive, with a license fee of R4 million per year, said the DVC Academic Prof Crafford. Another challenge with regard to online learning is the issue of policies for facilitating teaching and assessment online. Minister Nzimande noted that only $20 \%$ of technical and vocational education and training (TVET) colleges can afford online education. (Timeslive, 2020). Many universities do not have the policies thus creating the need for serious policy development and implementation for the new normal. The national department of education (DHET) offered support for student in financial distress to ensure their stability in learning and mindset.

This pandemic exposed the inequalities and disparities in the higher education across the world and South Africa is no different. Universities began creating well-designed, sophisticated solutions for remote teaching/online learning but did not think seriously think about ways of addressing the issues for those who don't have access to internet even though they have been given data and laptops. The penny only dropped when the students complained. Increasingly, the more resourceful universities partnered with internet providers and governments to overcome this critical challenge by negotiating zero-rated access to specific educational and information websites, whilst other, less resourceful universities, desperately tried to remain financially sustainable. The scramble to teach remotely is one of the key challenges facing staff and students of a number of universities. Many higher education institutions have students from lower-socio economic backgrounds who do not have access to internet due to affordability. There was also a recognition that living conditions of many students are unconducive to learning, with overcrowded homes, insufficient amenities that would make it impossible for them to function suitably (USAF, 2020). 
It was vital and necessary to seriously seek alternative means and approaches in order not to leave behind students with little or no access to electronic communication. The painful reality of the digital divide in South Africa had to be strategically and systematically managed: reaching out to 'marginalised' students must be a national priority in this time of crisis. The shift to the "new normal" had to be sector wide with an emerging paradigm of how to reimagine education post COVID-19. The Universities South Africa (USAf) board members stated that majority of students are not ready to switch completely to online learning (USAF, 2020). Members engaged in a robust debate over the impact of the pandemic on the academic programme. While some reported a $90 \%$ readiness to deliver classes online, and some even declare that they were prepared to resume classes online from the as early as 1 April 2020, others urged a serious introspection over how the sector might ensure that all of its students were able to study, virtually (USAF, 2020).

\subsection{Quest for admission - Class of 2021!}

High school grade 12 learners in their final year, seek admissions to universities. With Grade 12 students back to school, a sense of optimism has grown, as well as prospects for a fresh start at university in 2021 and possibly 2022. But the calamitous, impact of COVID-19 on every facet of societal normality, means that the class of 2020 will have a variety of additional challenges to overcome should they want to study further.

COVID-19 will have an enormous impact on higher education, possibly for years ahead, especially on admission arrangements for incoming students. It is also one of the most difficult to manage because it involves both basic education i.e. schools and the higher education sectors. There is no template of how to deal with this and each country is doing the best they can. In South Africa in particular, there are major concerns regarding the impact on learners from low income and disadvantaged groups. (Atherton, 2020)

The principles and values enshrined in the SA Constitution, the Higher Education Act of 1997, and the White Paper for Transformation (1997) address the legacy of racial, gender, class and other forms of social discrimination imposed by apartheid. Matsepe et al (2020:437) show that universities tend to privilege students from rich or affluent communities while neglecting talented and potentially good students from marginalised groups, particularly those from under-resourced township and rural schools. In the reading is shows that the problem has shifted largely from race to one of social class due to an overemphasis on narrow conceptions of merit that cannot be reconciled with equity and social justice concerns. If this is the case under normal circumstances what then, is the impact on these marginalised students during the pandemic and will this create an opportunity for universities to rethink their admissions policies so that students from marginalised backgrounds have equal opportunity to enter higher education?

While there is sufficient evidence that most institutions agreed on the need to embrace the "no student left behind" motto, they have to address current social injustices, given the intensity of competition among institutions, and develop admission strategies that will allow the marginalised students access to higher education. The pandemic exacerbates the situation for disadvantaged students to benefit previous admissions policies, they require comparable skills, knowledge and resources with students from affluent backgrounds who have the ability to engage with technology and are able to learn remotely or online. Whilst admissions criteria for SA universities differ from one another, no clear policy pathway that informs and regulates the selection and admissions were established sector wide during this pandemic. Each university has made adjustments to suit their own needs.

3.2.1. Dangling a carrot! - Dealing with admissions. There is a serious concern that the health issues and the economic consequences from the pandemic will result in more students declining admission offers. For this reason, I believe that some universities will be likely to offer students funding or scholarships in an effort to get them to enrol. It is clear that 2021 is a competitive year for student enrolments will be intense. At the end of the day it will be up to students and their parents as to what is the best possible solution for 2021. If a family is affected economically from COVID-19, they may appeal for additional financial aid. The National Student Financial Aid System (NSFAS) provides financial assistance to students who must meet the financial qualification criteria for funding. That is, they must have a combined gross family income of up to R350 000 per annum, as assessed and verified by NSFAS. It is not clear how many households reached this baseline due to COVID-19, since income earned for many families will differ from that of 2019 if parents have lost their jobs and the income has declined. For the 2020 financial year, NSFAS received a record number of first-time applications $(543,268)$ by the 30 November 2019 closing date (compared to 428,929 the previous year) from across the country, with the vast majority of applicants submitting applications online. 


\section{Uncertain futures - It's a matter of time!}

Finally, the challenges facing South African higher education is linked to the wider challenges facing South Africa: poor economic growth, high youth unemployment and the paralyzing effect of the political crisis surrounding the ANC leadership and government. While the South Africa state may have the resources - financial and technical - to map a way forward for the higher education sector, its ability to implement are severely constrained by political leadership and insufficient capacity. (Tjønneland, 2017).

Whilst this pandemic is disruptive and provides little hope it is important to be creative and adaptable to the next normal. Students may not be able to engage as much with staff within the universities, their academic success remains an important factor. Students can learn more about programmes offered by universities by utilising the online platform and resources. Engaging in on line extra-curricular activities within your own spaces following the health protocols can give students the edge to showcase their commitment to learning outside of a formal classroom setting. Leadership skills is a key factor that most universities love to see. Taking initiatives and leading, demonstrating leadership is crucial to post school education. Students must be encouraged to volunteer for social services and engage with communities.

Many students have given consideration to other factors like should they leave their home town, what about the fees if teaching is online and they don't receive a campus experience they have been looking forward to. Most residences at universities have to also rethink how they cater for students ensuring that they adhere to all the COVID protocols. This also means that two students cannot share one room, raising the cost of accommodation for the student. A number of universities have pushed back their application deadline to August and September 2020.

Because of the economic consequences of coronavirus, many students may have to abandon their first choice university to attend one that is more affordable. In addition, a university closer to home would be a more viable choice especially because of fewer accommodation that will be available. (Massa, 2020) Taking these factors into consideration, universities are likely to admit more students than they did last year because they expect that more of their admitted students will ultimately opt to stay closer to home.

Whether to stray from a university choice in these uncertain times is a decision that students and their families must make. At some point - likely long before this entering class graduates from college the pandemic will be over and life as we knew it will return. Parents and students should make this decision carefully, of course, and should consider what is in the student's best interest going forward in a post-COVID world.

How much do we know about the implications for student enrolment, equity, and experience? In a disruptive situation, the main impact will be on persistence, as students will struggle to adapt to online teaching and learning especially those who have not had any access to online teaching. Universities with insufficient methods of creating a captive online experience could be in a less desirable situation is students are dissatisfied with their digital offerings and decide to go elsewhere. Students may wait until the normal campus life begins and therefore many students may take a gap year.

In terms of equity, lower-income students will suffer disproportionately. They are less likely to have the resources, such as laptops and high-speed internet access, to enable them to succeed in an online-learning environment. The most crucial challenge is one of financing their education if they cannot access NSFAS nor can they get bursaries from companies due to the lack of profits during this pandemic year. What of the student campus life and experience, being at home with a laptop or tablet and listening to a lesson is not the same as socializing and going to classes on campus.

When nothing seems normal, and everyone is fighting the pandemic, managing admissions and knowing how to navigate a student experience is daunting. University administrators and academics have to be compassionate and understanding. Students coming to the university for the first time in 2021/22 may be fearful of facing the uncertainty. But if we want to create futures for the incoming class of 2021 and beyond, then a value driven leadership is important to create an environment of care and engagement. After all universities are hubs for innovative thinking and reimagining the future, and in doing so giving opportunities to the leaders of tomorrow. 


\section{References}

Atherton, G, (April, $\left.4^{\text {th }}, 2020\right)$. Admissions and equity challenges for HE post COVID- 19 retrieved on March, 152021 from https://www.universityworldnews.com

Bevins, F., Bryant, J.,Krishnan, C and Law, J. (April, 2020). Coronavirus: How should US higher education plan for an uncertain future? With American campuses largely empty of students, higher-education leaders need to shift their thinking to what happens next. Retrieved on February, 20. 2021 from www.mckinsey.com

Booysen, S. (Ed.). (2016). Fees Must Fall. Student Revolt, Decolonisation and Governance in South Africa. Johannesburg: Wits University Press

Cloete, N, Goedegebuure, L, \& Gornitzka, A. (Eds.). (2016), Pathways through higher education research - a Festschrift in Honour of Peter Maasen, Oslo: Department of Education, University of Oslo

Council on Higher Education, (2016). South African Higher Education Reviewed. Two Decades of Democracy, Pretoria: CHE.

Erasmus, Z. (2010). Confronting the categories: Equitable admissions without apartheid race classification. South African Journal of Higher Education, 24 (2), 244-257.

Gibbon, T, (Ed.). (2014), Driving Change: The Story of the South Africa Norway Tertiary Education Programme, Cape Town, African Minds

Illanes, P and Sarakatsannis, J (2020). Although most students have gone home, colleges and universities still have decisions to make. An integrated nerve center can help. Retrieved on March, 30, 2021 from www.mckinsey.com

Makinana. A. 21 April 2020. Academic year likely to spill over into 2021: higher education ministry. Retrieved on March, 17, 2021 https://www.timeslive.co.za/politics/2020-04-21-academic-year/

Massa,R. (April, 2, 2020) 5 ways that the coronavirus will change college admissions this fall. Retrieved on March, 24, 2021 from https://theconversation.com/5-ways-that-the-coronavirus-will-changecollege-admissions-this-fall-135152

Matsepe D, Michael Cross and Samuel Fenyane (2020). Equity in Admissions Policies of Undergraduate Students in Post-Democracy in Selected South African Universities. International Journal of Criminology and Sociology, 2020, 9, 437-445

Tjønneland, E.N. (2017) Crisis at South Africa's universities - what are the implications for future cooperation with Norway? (CMI Brief vol. 16, no. 3, 4 p.) Bergen: Chr. Michelsen Institute

USAf Board Meeting. (April, 1, 2020). Business continuity in the face of COVID-19 dominates the agenda of the USAf Board of Directors' meeting. Universities South Africa. Retrieved on February, 18, 2021 from www.usaf.ac.za 


\title{
ENABLING TRANSFORMATIVE INCLUSIVE LEARNING PEDAGOGIES OF PRESERVICE TEACHERS IN MULTICULTURAL HIGHER LEARNING CONTEXTS
}

\author{
June Palmer ${ }^{1}$, Rantsie Kgothule ${ }^{2}$, Gregg Alexander ${ }^{1}$, \& Edwin de Klerk ${ }^{3}$ \\ ${ }^{1}$ Postgraduate Studies in Education, Central University of Technology, Free State (South Africa) \\ ${ }^{2}$ School of Education Studies, University of the Free State (South Africa) \\ ${ }^{3}$ School of Education, Sol Plaatje University (South Africa)
}

\begin{abstract}
Several studies echo the role of participation and interaction in learning activities as crucial to valorise all students equally. Inclusive pedagogy should recognize the disputed nature of inclusive education and the subsequent unpredictability in teaching practices as a means of identifying students requiring additional learning support particularly amid the COVID-19 pandemic. Such variability raises significant questions about the nature and value of educational provision, around the globe, but particularly in the South African multicultural higher learning context. Having applied a transformative learning methodology this paper explores the influence of inclusive learning pedagogies in shaping preservice teachers' repertoires in multicultural higher learning contexts. The findings suggest that transformative learning promotes specific practices such as trusting relationships within the learning context and an appreciation for diversity and inclusivity, opportunities for critical reflection, shared and collective learning, and transformative leadership development. Ultimately, when circumstances permit, transformative preservice teachers move toward a frame of reference that is more self-reflective, integrative and inclusive of experience. In conclusion we suggest that stakeholders in higher education contexts consider creating institutional spaces for preservice teachers to change their frame of reference in approaching their own teaching and learning repertoires in transformative and inclusive ways.
\end{abstract}

Keywords: Multicultural higher learning context, preservice teacher, Inclusive learning pedagogy, transformative learning theory.

\section{Introduction}

In shaping learning, preservice teachers' knowledge of inclusive practice and employing transformative learning practices become all important. Sustaining preservice teachers' commitment to inclusive practices through teacher leadership while enabling them to identify barriers to learning and catering to the learning support needs of their learners are some of the key aspects HEIs should address. This paper supports the 4IR requirement of "accelerating workforce reskilling" (Penprase, 2019) by (1) promoting the increase of tech-enhanced and online and education within Higher Education Institutions (HEIs), (2) educating students with varied learning experiences, and creating platforms within their learning environments to accommodate innovative technological skills that may improve the learning experiences of all learners. More importantly, these settings should adequately (3) prepare preservice teachers to thrive in learning amid global pandemics through transformative learning modalities such as merged modes of teaching and optimization of online and flipped courses. In so doing, it will ensure more resourceful knowledge settings that can adjust to the multiplicity of student training needs to give more modularity and flexibility of educational programmes.

As such, this paper addresses the question: How may HEIs prepare preservice teachers to implement transformative learning pedagogies to become transformative change agents in multicultural higher learning contexts? 


\section{Theoretical framework}

In this progressively globalised education environment, HEIs have an obligation to ensure that students are not only taught about local or national issues, but that they obtain knowledge about educational trends around the globe, improve their critical intellectual abilities to enable them to have a purposeful role in extremely multifaceted and challenging societies. In this paper, the latter notion fits well into our thinking of applying transformative learning (TL).

TL signifies "developing leadership attributes and its purpose is to produce enlightened change agents" (Frenk et al. 2010, 6). Thus, the result of transformative learning aims at ensuring that individuals have more inclusive insights of the world, the capability to distinguish between various information regarding society, better openness to various viewpoints, and the capacity to incorporate diverse scopes of individual experience into significant and all-inclusive relationships (Mezirow, 1991). TL theory envisions that HEIs will ensure that students apply critical thinking, contest their own expectations, and assist them develop open and inclusive perceptions (Banks \& Banks, 2004).

To this end, TL requires that HEIS involve students (and preservice teachers in particular) "in mentorship, leadership or community development programs to apply their perspectives, intercultural skills, and global knowledge to make them more inclusive, discriminating, open, reflective, and emotionally able to change" (Mezirow, 2003, 58-59). In so doing, HEIs may help students to, "develop their power to perceive critically the way they exist in the world with which and in which they find themselves; they come to see the world not as a static reality, but as a reality in process and transformation" (Freire, 1970, 83).

\section{Discussion: Our point of departure}

Figure 1. Preservice teachers' as transformative change agents.

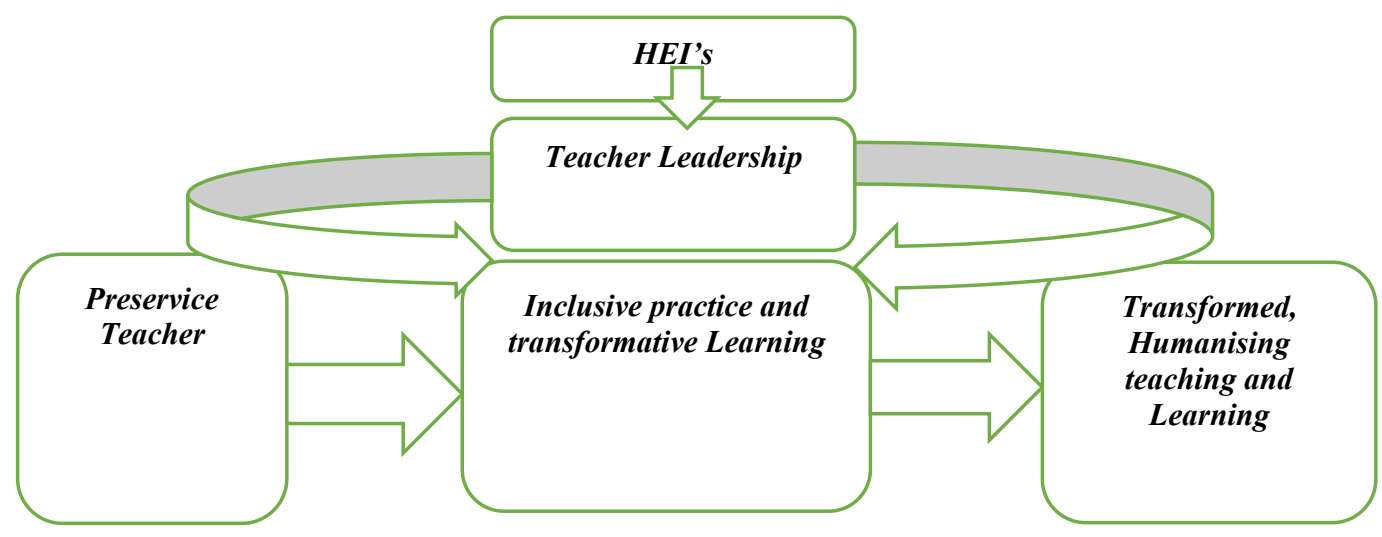

For decades, TL was regarded as something more empowering, thoughtful and more critical than other practices of learning. The potential of TL is that it helps individuals to critically move beyond those apparently self-evident conventions that governs individual thinking, actions and feeling that have been unquestioningly adopted through education and socialization (Hoggan, Mälkki \& Finnegan, 2017). According to Kasworm \& Bowles (2012), a significant intervention strategy to support transformative learning may be indicated as, "the development of self-reflection, an emotional capability to openness, and critical disjuncture" (p. 392). For preservice teachers in HEIs, the aforementioned intervention strategy may include a deliberate improvement of self-reflection through inter alia, thoughtful journals, articles, blogs, or experimental activities such as role-playing aiming to solve confusing problems, engaging in cultural experiences that requires that attention be given to issues such as privilege, race, class, power and gender. Consequently, Kasworm and Bowles's (2012) intervention strategy may be regarded as significant because it may assist learners to scrutinize their expectations, worldviews as well as previous experiences.

These strategies, we contend, are some of the salient features to developing preservice teachers as competent teacher leaders. In enhancing leadership ability, HEIs should acknowledge the learning support needs of preservice teachers to equip them to hold a frame of reference that is enabling in the way that they approach their own teaching and learning repertoires in transformative and inclusive ways. This paper proposes that inclusive practice in HEIs may be successfully accomplished by: 


\subsection{Increasing online and tech-enhanced teaching within HEIs}

Covid-19 necessitated a rethinking of teaching within HEIs, implying that the physical classroom is not accessible in the case of challenges such as pandemic outbreaks (Mpungose, 2020). A turn to online teaching has become more than just an option and may be regarded as an instrument that can make teaching practices more flexible, innovative and student-centred (Dhawan, 2020).

Significantly, HEIs are familiar with online technologies which they only needed to expand because they were not starting from scratch with new and uncontested technological solutions (Czerniewicz, 2020). This implies that HEIs are required to not only increase their online and tech-enhanced pedagogical approaches, using technology more aptly and design teaching strategies suitable for particular situations, but also being mindful that technological choices will be formed in ways that will mirror prevailing variances, viewpoints and discourses (Murgatrotd, 2020 as cited in Ali, 2020).

An increase in tech-enhanced teaching opportunities will allow HEIs to look at the productive side of online learning technologies, thus bringing out innovations and digital developments. Thus, whilst HEIs are positioned to design flexible programs which may be technologically more accessible, students may get opportunities to practice technology (Huang et al., 2020). Fundamentally, the use of more tech-enhanced approaches may improve adaptability, critical thinking abilities as well as problem-solving skills, whilst HEIs may reap the benefits of time and location flexibility. When HEIs accelerate the speed of technology repetition and optimise practical application of online teaching, students from various backgrounds can be taught in innovative and inclusive ways (UNESCO, 2020).

\subsection{Teaching students with diverse backgrounds}

Globally, HEIs should be united in the promise to guarantee equitable and inclusive education as well as to support constant learning opportunities for individuals from different backgrounds (United Nations [UN], 2016). In this regard, HEIs have the daunting task accommodate and integrate social and cultural diversities, to ensure that thoughtful cultural approaches are embedded in their practices and to monitor and improve such practices in this respect (Feldman et al., 2018). Despite the afore-mentioned challenges, HEIs should play a strategic part in constructing a more sustainable and inclusive learning and teaching environment so that students (and preservice teachers in particular) are well prepared to appreciate and embrace diversity, grow inclusive learning settings and address several forms of segregation or relegation in scholastic settings (Cretu \& Morandau, 2020).

Initial Teacher Education Education programmes in HEIs should, therefore, equip preservice teachers with the required information, abilities, approaches and standards (Coates, Harris \& Warring, 2020) and use frames of reference, previous knowledge and diverse experiences to make learning opportunities more applicable and actual (Walton \& Rusznyak, 2019). Consequently, the construction of an inclusive social-emotional environment that may assist students to be more comfortable to express individual thoughts and experiences, specifically because they have contrasting cultural backgrounds and attainment levels (Harriott \& Martin, 2016).

\subsection{Preparing preservice through transformative inclusive learning modalities}

The reality of diversity in schoolrooms globally has been identified as, "One of the most challenging developments within education" (Lancaster \& Auhl, 2013, 363). In response to such an observation, HEIs have to provide an answer to this encounter by providing preservice teachers with the information necessary to promote transformative inclusive practices so that they will be able to teach in diverse classroom settings. The strength of a transformative inclusive pedagogy lies in its power to reduce the disparity of opportunity to learn, whilst it supports the ability to teach (Florian, 2015). In essence, HEIs should train preservice teachers how to enact transformative inclusive learning pedagogies in an ever-changing world. This paper uses a view by Florian and Black-Hawkins (2010) to explain that transformative inclusive learning pedagogies,

"seek to embed equitable access and opportunity for success within the classroom and curriculum. It is underpinned by a shift in pedagogical thinking from an approach that works for most learners existing alongside something different for those (some) who experience difficulties, towards one that involves providing rich learning opportunities that are sufficiently made for everyone" (p. 826).

The above explanation is applicable to the current online digital spaces that HEIs find themselves. For instance, it is imperative that HEIs consider the developing scope of digital technologies (Janssen et al. 2013, p. 474), requiring a constant reflection on preservice teachers' skills and desires and where required plan for professional learning opportunities in response to fast fluctuating educational settings. One way in which HEIs can prepare preservice teachers through transformative inclusive learning pedagogies is to teach them effective digital literacy skills, implying that they are taught a set of abilities to access the internet, discover and manage digital information and engage with virtual 
communication and information networks (Gilster, 1997 as cited in Falloon, 2020, 2450). Arguably, an understanding of digital and online information may be regarded as an inclusive view of digital literacy (Falloon, 2020).

Another way in which HEIs may prepare preservice teachers is to offer transformative learning opportunities which may stimulate the improvement of proficiency and confidence in new roles and relationships that may enable preservice teachers to bring about change in their learning and working environments (Tsimane \& Downing, 2020). For instance, HEIs can train preservice teachers how to use imaginative skills in that they learn how to create brainstorming situations and work as generators of new information and knowledge regarding inclusive practices (Llewellyn, 2016).

\section{Conclusion}

This paper asked the question: How may HEIs prepare preservice teachers to implement transformative learning pedagogies to become transformative change agents in multicultural higher learning contexts? We answered this question through our arguments that HEIs should strengthen their support to preservice teachers by empowering them how to utilise transformative inclusive learning pedagogies. We recommend that HEIs regard innovations and digital developments, the use of prior experiences and frames of reference, as well as digital literacy skills as ideal tools to prepare preservice teachers so that they will be ready to apply transformative inclusive learning pedagogies in the multicultural learning contexts within which they may function in the future.

\section{References}

Ali, W. (2020). Online and Remote Learning in Higher Education Institutes: A Necessity in light of COVID-19 Pandemic. Higher Education Studies, 10(3), 16-25.

Banks, J., \& Banks, C. (2004). Handbook of research on multicultural education. San Francisco, CA: Jossey-Bass.

Cheng, W., Cheng, Q., Yin, X., Zhuang, R., Berrada, K., Burgos, D., Chan, C., Chen, N. S., Cui, W., Hu, $X$. et al. (2020). Handbook on facilitating flexible learning during educational disruption: The Chinese experience in maintaining undisrupted learning in COVID-19 outbreak. Beijing: Smart Learning Institute of Beijing Normal University.

Coates, J.K., Harris, J., \& Waring, M. (2020). The effectiveness of a special school experience for improving preservice teachers' efficacy to teach children with special educational needs and disabilities. British Educational Research Journal, 46(5), 909-928.

Cretu, D.M., \& Morandau, F. (2020). Initial Teacher Education for Inclusive Education: A Bibliometric Analysis of Educational Research. Sustainability, 12(12), 4923. Retrieved March 24, 2021, from: https://doi.org/10.3390/su12124923

Czerniewicz, L. (2020). What we learnt from "going online" during university shutdowns in South Africa. Retrieved March 24, 2021, from: https://philonedtech.com/what-we-learnt-from-goingonline-during-university-shutdowns-in-south-africa/

Dhawan, S. (2020). Online Learning: A Panacea in the Time of COVID-19 Crisis. Journal of Educational Technology Systems, 49(1), 5-22.

Falloon, G. (2020). From digital literacy to digital competence: the teacher digital competency (TDC) framework. Education Technology Research and Development, 68, 2449-2472.

Feldman, A., Altrichter, H., Posch, P., \& Somekh, B. (2018). Teachers investigate their work (3rd ed.). London \& New York: Routledge.

Florian, L. (2015) Inclusive Pedagogy: A transformative approach to individual differences but can it help reduce educational inequalities? Scottish Educational Review, 47(1), 5-14.

Florian, L., \& Black-Hawkins, K. (2010). Exploring inclusive pedagogy. British Educational Research Journal, 37(5), 813-828.

Freire, P. (1970). Pedagogy of the Oppressed, trans. Myra Bergman Ramos. New York: Continuum.

Frenk, J., Chen, L., Bhutta, Z.A., Cohen, J., Crisp, N., Evans, T., \& Kistnasamy, B. (2010). Health professionals for a new century: transforming education to strengthen health systems in an interdependent world. The Lancet, 376(9756), 1923-1958.

Harriott, W.A., \& Martin, S.S. (2016). Using culturally responsive activities to promote social competence and classroom community. Teaching Exceptional Children, 37(1), 48-54.

Hoggan, C., Mãlkki, K., \& Finnegan, F. (2017). Developing the Theory of Perspective Transformation: Continuity, Intersubjectivity, and Emancipatory Praxis. Adult Education Quarterley, 67(1), 48-64.

Huang, R. H., Liu, D. J., Tlili, A., Yang, J. F., Wang, H. H., Zhang, M., Lu, H., Gao, B., Cai, Z., Liu, M., 
Janssen, J., Stoyanov, S., Ferrari, A., Punie, Y., Pannekeet, K., \& Sloep, P. (2013). Experts' views on digital competence: Commonalities and differences. Computers \& Education, 68, 473-481.

Kasworm, C., \& Bowles, T. (2012). Fostering transformative learning in higher education settings. In E. Taylor \& P. Cranton (Eds.), The handbook of transformative learning: Theory, research, and practice (388-407). San Francisco, CA: Jossey-Bass.

Lancaster, J., \& Auhl, G. (2013). Encouraging Pattern Language Development in a Preservice Inclusive Education Course: A Comparative Study. International Journal of Disability, Development and Education, 60(4), 363-381.

Llewellyn, S. (2016). Crossing the invisible line. De-differentiation of wake, sleep and dreaming may engender both creative insight and psychopathology. Conscious Cognition, 46, 127-147.

Mezirow, J. (1991). Transformative dimensions of adult learning. San Francisco, CA: Jossey-Bass.

Mezirow, J. (2003). Transformative learning as discourse. Journal of Transformative Education, 1(1), 58-63.

Mpungose, C.B. (2020). Emergent transition from face-to-face to online learning in a South African University in the context of the Coronavirus pandemic. Humanities \& Social Sciences Communications, 7(1), 1-9. Retrieved March 29, 2021, from: https://www.nature.com/articles/s41599-020-00603-x

Penprase, B.E. (2019). Accelerating Workforce Reskilling for the Fourth Industrial Revolution an Agenda for Leaders to Shape the Future of Education, Gender and Work. World Economic Forum: Geneva

Tsimane, T.A., \& Downing, C. (2020). Transformative learning in nursing education: A concept analysis. International Journal of Nursing Science, 7, 91-98.

UNESCO. (2020). COVID-19 Educational Disruption and Response. Retrieved March 24, 2021, from: https://en.unesco.org/covid19/educationresponse/

United Nations. (2016). Sustainable development goal 4: targets and indicators [webpage]. New York: UN. Retrieved March 29, 2021, from: https://sustainabledevelopment.un.org/sdg4\#targets

Walton, E., \& Rusznyak, L. (2019). Cumulative knowledge-building for inclusive education in initial teacher education. European Journal of Teacher education, 43(1), 18-37. 


\title{
BRANDING IN PRIVATE UNIVERSITIES AT EL SALVADOR: BRANDS THAT THE PUBLIC FALL IN LOVE WITH
}

\author{
Javier Casanoves-Boix ${ }^{1}$, Ana Cruz-García ${ }^{2}$, Pablo Pinazo-Dallenbach ${ }^{1}$, \\ \& José Ricardo Flores-Pérez ${ }^{3}$ \\ ${ }^{1}$ Department of Marketing, Valencian International University / Valencia (Spain) \\ ${ }^{2}$ Department of Marketing, Munster Technological University / Cork (Ireland) \\ ${ }^{3}$ Department of Marketing, José Simeón Cañas Central American University / San Salvador (El Salvador)
}

\begin{abstract}
This research was carried out to examine the role of educational brand capital applied to private universities in El Salvador. For this purpose, the main contributions of the literature related to the study of brand capital and its application in the educational sector were analyzed, identifying which variables determine brand capital in the higher education sector. Once a suitable model was established, an empirical study was realized through a questionnaire in digital format, using a sample of 381 valid responses from undergraduate students from a private university in San Salvador (El Salvador). In order to validate the proposed construct, structural equation modeling will be applied, using SPSS v.19 and EQS 6.2 as working tools. The results obtained will show the repercussion of each variable of the brand capital relative to the determining variables, which are: brand awareness, brand image, perceived quality, and brand loyalty.
\end{abstract}

Keywords: Marketing, brand capital, higher education, private universities, El Salvador.

\section{Introduction}

From the 1990s to the present day, it is possible to appreciate an important trend towards the diversification of higher education, which has benefited the private university while discouraging the development of the public university model (Ortíz and Rúa, 2017). Thus, the contribution of private higher educational institutions is vital to satisfy the needs of an increasingly globalized and internationalized society (Johnson, Adams Becker, Estrada \& Freeman, 2015). And this, added to the apogee of research on teaching and learning of management and business from the XXI century (Díez, 2018) and, especially, to the need to pay more attention to research in educational management, in order to add relevant value to the business world (Adler and Harzing, 2009).

With this, and given that universities are operating within dynamic and challenging environments, the marketing strategy becomes a priority to ensure strong recruitment and retention of students and teachers (Asaad, Melewar, Cohen and Balmer, 2013). There is consensus that understanding the university brand and its clear development and communication provides great value for universities (Duesterhaus and Duesterhaus, 2014). Therefore, the strategic management of the brand becomes a key piece within the educational sector and, especially, in higher educational institutions (Rauschnabel, Krey, Babin and Ivens, 2016).

Following this line, Küster (2012) considers that higher education also provides an interesting and important context for marketing research, since universities around the world are increasingly oriented towards marketing strategy and students are, increasingly considered as potential customers. Thus, it seeks to obtain results in terms of value, effectiveness, and long-term benefits, which have been very important in the business world through the achievement of competitive advantages and the conquest of a wide segment of the international market. In other words, it seeks to generate a feeling of love for the brand by consumers and thereby improve sales figures (Esteban, Ballester and Muñoz, 2014).

Focusing our attention on the role that public higher education plays in El Salvador, their National Education System indicates that today there are 20 private universities in the country. Thus, according to Ávalos (2010), the country has had in recent years a considerable increase in university students, as well as improvements in infrastructure and the appearance of new private universities. 
Thus, Yamada, Castro, Bacigalupo, and Velarde (2013) consider that private universities require more research regarding their brand capital, mainly due to the excessive importance that has been given to maximizing income money from customers and the low weight of quality in services provided. Thus, the brand constitutes a key strategy to achieve the purchase preference of potential customers, although it is true that its management is difficult (García and Bergantiños, 2001). Thus, and according to Retamosa (2018), the need to build an educational brand to differentiate itself from the aggressive competition and to cover more student market share and talent attraction is revealed. Therefore, any brand that has a significant capital value can considerably lengthen the life of an organization and transform, in the eyes of consumers, the products/services offered into pure gold (Casanoves, 2017).

In this framework, the objectives of the present research are to (1) establish which are the most determinant variables of brand capital in the higher education sector, and (2) decipher which are the most outstanding variables by private university students in El Salvador. Thus, and after reviewing the seven major proposals on brand capital models in the literature (Farquhar, 1989; Aaker, 1992; Keller, 1993; Faircloth, Capella, and Alford, 2001; Yoo and Donthu, 2001; Delgado and Munuera, 2002; Buil, Martínez and De Chernatony, 2010), we have considered four elements that are identified by these authors and were also deemed to be of importance in previous studies. These are: (1) brand awareness, (2) brand image, (3) perceived quality, and (4) brand loyalty.

To sum up, this research represents a scientific advance in the marketing discipline since to date, although there have been specific investigations of brand capital and the variables that comprise it, there are very few investigations that exhaustively analyze the perception of brand capital through the undergraduate students of a private university in El Salvador.

\section{The perception of brand capital among private university students in El Salvador}

After reviewing the seven main proposals on brand capital models made by the literature, four elements have been considered that shared by the authors, and taking into account the importance given in previous studies, we understand that their contribution to brand capital is key. These are: (1) brand awareness, (2) brand image, (3) perceived quality, and (4) brand loyalty. Each one of them is detailed below.

\subsection{Brand awareness}

In the specific field of education, several authors (Brunzel, 2007; Brewer and Zhao, 2010; Mourad, Ennew and Kortam, 2011; Furey, Springer and Parsons, 2014; Pinar, Trapp, Girard and Boyt, 2014) find that branding in higher education is a very important variable for universities, in order to generate greater preference for consumption in educational services and, therefore, increase sales. In other words, greater brand awareness will mean greater brand equity. In view of the above, it is possible to raise the first research hypothesis: H1. The perception of brand awareness influences the perception of brand capital among private university students in El Salvador.

\subsection{Brand image}

In the specific field of education, several authors (Cervera, Schlesinger, Mesta and Sánchez, 2012; Williams, Williams and Omar, 2013; Denegri, Etchebarne, Geldres, Cabezas, and Herrera, 2014; Alwi and Kitchen, 2014; Hemsley, Melewar, Nguyen and Wilson, 2016) have shown that the image of the brand in private and public universities is a very valuable asset for organizations, and effective and rapid measurements of the image transmitted to target audiences must be carried out since this perception may be different in both areas. This image, as it improves, will lead to increases in the brand capital of the university institution whose image is favored. In view of the above, it is possible to raise the second research hypothesis: H2. The perception of brand image influences the perception of brand capital among private university students in El Salvador.

\subsection{Perceived quality}

In the specific field of education, several studies (Chen, 2008; Hasan, Ilias, Rahman and Razak, 2009; Calvo, Levy and Novo, 2013; Sultan and Yin Wong, 2013; Pinar, Trapp, Girard and Boyt, 2014) show that the quality perceived in private and public higher education is a variable that also depends on the fact that it is up to educational institutions to obtain greater satisfaction from their users. Quality, therefore, is another key source in the configuration of the brand capital of the university institution, insofar as higher perceived quality will translate into greater brand capital. In view of the above, it is possible to raise the third research hypothesis: H3. The perception of perceived quality influences the perception of brand capital among private university students in El Salvador. 


\subsection{Brand loyalty}

In the specific field of education, several contributions (Paswan and Ganesh, 2009; Conejeros, Leonor, Rojas, and Segure, 2010; Schlesinger, Cervera and Calderón, 2014; Montoya, Torres, Berrio and Montoya, 2020) highlight the relevance of brand loyalty in the higher education sector, which implies that this variable is very important in generating educational brand capital. Audiences that are more loyal contribute to increasing brand equity. In view of the above, it is possible to raise the fourth research hypothesis: H4. The perception of brand loyalty influences the perception of brand capital among private university students in El Salvador.

In view of the above, Image 1 shows our proposed theoretical model designed to defend the present investigation.

Figure 1. Theoretical model proposed for the present research.

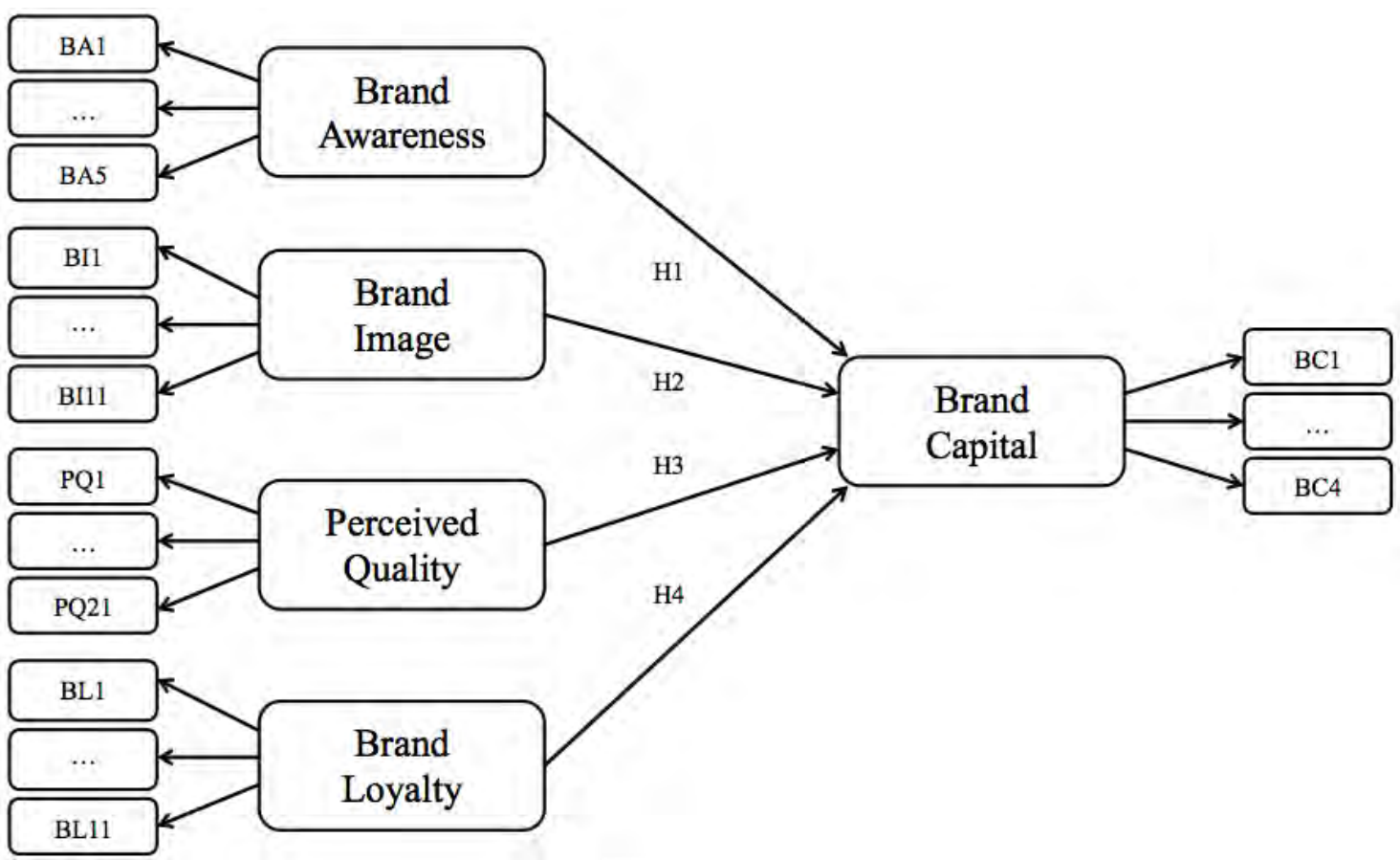

\section{Methodology}

In order to corroborate the established hypothesis, we conducted empirical research quantitative in nature, by means of a survey in the Spanish language aimed at a group of 381 undergraduate students from one private university in San Salvador (El Salvador).

Grade 5 Likert scales were used to measure the concepts of (1) brand awareness, (2) brand image, (3) perceived quality, and (4) brand loyalty. These scales are based on the measurement scales proposed by Aaker (1992) and Keller (1993) and were adapted to our field of study, higher education. The techniques for data analysis were based on descriptive statistics and multivariate analysis, using as a working tool SPSS v19 for Windows for descriptive techniques of data and EQS 6.2 for executing multivariate techniques.

\section{Conclusions}

As a work in progress, it should be noted that we are currently in the analysis phase, through the application of different methods of analysis depending on the information to be obtained, distinguishing between (1) psychometric characteristics of the measuring instrument, divided into an analysis of the quality of the items and the validation of the scales; and (2) hypothesis testing, using a Structural Equations Modeling (EQS).

Once we finish this, we will document the conclusions and business implications for each variable proposed for our brand capital construct (brand awareness, brand image, perceived quality, and brand loyalty). With this, we will discuss the limitations of our research as well as future research, in order to open a new way for the scientific community. 


\section{Acknowledgments}

This work was made possible by funding from Munster Technological University (Ireland).

\section{References}

Aaker, D. A. (1992). The value of brand equity. Journal of business strategy, Vol. 13(4), pp. 27-32.

Adler, N. J.; \& Harzing, A.-W. (2009). When Knowledge Wins: Transcending the Sense and Nonsense of Academic Rankings. Academy of Management Learning \& Education, 8(1), 72-95.

Alwi, S. F. S., \& Kitchen, P. J. (2014). Projecting corporate brand image and behavioral response in business schools: cognitive or affective brand attributes? Journal of Business Research, Vol. 67(11), pp. 2324-2336.

Asaad, Y., Melewar, T. C., Cohen, G., \& Balmer, J. M. (2013). Universities and export market orientation: An exploratory study of UK post-92 universities. Marketing Intelligence \& Planning.

Ávalos Guevara, B. É. (2010). Análisis histórico del desarrollo académico de la Universidad de El Salvador 1950-2003 (Doctoral dissertation, Universidad de El Salvador).

Brewer, A., \& Zhao, J. (2010). The impact of a pathway college on reputation and brand awareness for its affiliated university in Sydney. International Journal of Educational Management, Vol. 24(1), pp. 34-47.

Brunzel, D. L. (2007). Universities sell their brands. Journal of Product \& Brand Management, Vol. 16 No. 2, pp. 152-153.

Buil, I., Martínez, E., y De Chernatony, L. (2010). Medición del valor de marca desde un enfoque formative. Cuadernos de Gestión, pp. 10.

Calvo, C., Levy, J. P., \& Novo, I. (2013). Perceived quality in higher education: an empirical study. Marketing Intelligence \& Planning, Vol. 31(6), pp. 601-619.

Casanoves, J. (2017). Fundamentos de Branding. Claves para construir una marca poderosa. Profit Editorial.

Cervera, A., Schlesinger, W., Mesta, M.A., y Sánchez, R. (2012). Medición de la imagen de la universidad y sus efectos sobre la identificación y lealtad del egresado: una aproximación desde el modelo de Beerli y Díaz (2003). Revista Española de Investigación en Marketing ESIC, Vol.16(2), pp. 7-29.

Chen, L. H. (2008). Internationalization or international marketing? Two frameworks for understanding international students' choice of Canadian universities. Journal of Marketing for Higher Education, Vol. 18 No. 1, pp. 1-33.

Conejeros, S., Leonor, M., Rojas, H., y Segure, M. (2010). Confianza: un valor necesario y ausente en la educación chilena. Perfiles educativos, Vol. 32(129), pp. 30-46.

Delgado, E., y Munuera, J. L. (2002). Medición del capital de marca con indicadores formativos. Investigación y Marketing, Vol. 759, pp.16-20.

Denegri, M., Etchebarne, M. S., Geldres, V., Cabezas, D., y Herrera, V. (2014). Personalidad de marca de las carreras de ciencias empresariales: un análisis comparativo entre universidad pública y privada. Trabajo presentado en la XLIV Asamblea Anual del Consejo Latinoamericano de Escuelas de Administración (CLADEA), Noviembre, Guayaquil.

Díez, F. (2018). Dónde estamos: Una introducción a la educación en los negocios. Journal of Management and Business Education, 1(1), 1-10.

Duesterhaus, A., \& Duesterhaus, M. (2014). Attributes of successful university brands in the USA. Journal of brand strategy, 3(2), 169-183.

Esteban, A. A., Ballester, M. E. D., \& Muñoz, J. P. (2014). ¿ Quién ama a las marcas? Determinantes personales y de consumo. Revista Española de Investigación de Marketing ESIC, 18(1), 2-16.

Faircloth, J. B., Capella, L.M., \& Alford, B. L. (2001). The effect of brand attitude and brand image on brand equity. Journal of Marketing Theory and Practice, pp. 61-75.

Farquhar, P. H. (1989). Managing brand equity. Marketing research, Vol. 1(3), pp. 24-33.

Furey, S., Springer, P., \& Parsons, C. (2014). Positioning university as a brand: distinctions between the brand promise of Russell Group", 1994 Group, University Alliance, and Million+ universities. Journal of Marketing for Higher Education, Vol. 24(1), pp. 99-121.

Garcia, M. J., \& Bergantinos, G. (2001). Los componentes del valor de la marca: una aplicación empirica en el segmento alto del mercado automovilistico. Revista Europea de Dirección y Economia de la Empresa, 10(2), 161-78. 
Hasan, H. F. A., Ilias, A., Rahman, R. A., \& Razak, M. Z. A. (2009). Service quality and student satisfaction: A case study at private higher education institutions. International Business Research, Vol. 1(3), pp. 163.

Hemsley, J., Melewar, T. C., Nguyen, B., \& Wilson, E. J. (2016). Exploring brand identity, meaning, image, and reputation (BIMIR) in higher education: A special section, pp. 2019-3022.

Johnson, L., Adams Becker, S., Estrada, V., \& Freeman, A. (2015). NMC Horizon Report: 2015 Higher Education Edition. Austin, Texas: The New Media Consortium.

Keller, K. L. (1993). Conceptualizing, measuring, and managing customer-based Brand equity. Journal of Marketing, Vol. 57, January, pp. 1-22.

Küster, I. (2012). El Docente Universitario desde una perspectiva de mercado: Influencia en el rendimiento del estudiante. Alicante: 3 ciencias, pp. 1-118.

Montoya, I. A., Torres, J. A. S., Berrio, S. P. R., \& Montoya, A. (2020). Lovemark effect: analysis of the differences between students and graduates in a love brand study at a public university. Innovar, 30(75), 43-56.

Mourad, M., Ennew, C., \& Kortam, W. (2011). Brand equity in higher education. Marketing Intelligence \& Planning, Vol. 29(4), pp. 403-420.

Ortíz, J. M., y Rúa, A. (2017). Gestión de la calidad y diseño específico de los procesos de admisión en el sistema universitario español: Estudio de caso en una universidad privada. REICE. Revista Iberoamericana sobre Calidad, Eficacia y Cambio en Educación, Vol. 15(1), pp. 87-106.

Paswan, A. K., \& Ganesh, G. (2009). Higher education institutions: Satisfaction and loyalty among international students. Journal of Marketing for Higher Education, Vol. 19(1), pp. 65-84.

Pinar, M., Trapp, P., Girard, T., \& E. Boyt, T. (2014). University brand equity: an empirical investigation of its dimensions. International Journal of Educational Management, Vol. 28(6), pp. 616-634.

Rauschnabel, P. A., Krey, N., Babin, B. J., \& Ivens, B. S. (2016). Brand management in higher education: the university brand personality scale. Journal of Business Research, 69(8), 3077-3086.

Retamosa, M. (2018). University Branding: capital de marca universitario desde la perspectiva de sus grupos de interés (Doctoral dissertation, Universidad de Castilla-La Mancha).

Schlesinger, W., Cervera, A., y Calderón, H. (2014). El papel de la confianza, la imagen y los valores compartidos en la creación de valor y lealtad: aplicación a la relación egresado-universidad. Revista Española de Investigación en Marketing ESIC, Vol. 18(2), pp. 126-139.

Sultan, P., \& Yin Wong, H. (2013). Antecedents and consequences of service quality in a higher education context: a qualitative research approach. Quality assurance in education, Vol. 21(1), pp. 70-95.

Williams, R. L., Williams, H. A., \& Omar, M. (2013). The Marketing Impact of the Principles of Renaming Within a Higher Education Service Organization. American Marketing Association.

Yamada, G., Castro, J. F., Bacigalupo, J. L., \& Velarde, L. (2013). Mayor acceso con menor calidad en la educación superior: algunas evidencias desde las habilidades de los estudiantes. Apuntes: Revista de Ciencias Sociales, 40(72), 7-32.

Yoo, B., \& Donthu, N. (2001). Developing and validating a multidimensional consumer-based brand equity scale. Journal of business research, Vol. 52(1), pp. 1-14. 


\title{
TRANSFORMATIVE LEADERSHIP IN MULTICULTURAL SCHOOLING CONTEXTS: A CRITICAL REFLECTION OF IN-SERVICE TEACHERS' PRACTICES AND SCHOOL MANAGERS' ROLES
}

\author{
Rantsie Kgothule ${ }^{1}$, June Palmer ${ }^{2}$, Gregg Alexander ${ }^{2}$, \& Edwin De Klerk ${ }^{3}$ \\ ${ }^{I}$ School of Education Studies, University of the Free State (South Africa) \\ ${ }^{2}$ Department Postgraduate Studies in Education, Central University of Technology (South Africa) \\ ${ }^{3}$ School of Education Studies, Sol Plaatje University (South Africa)
}

\begin{abstract}
In exercising their power and authority, School Management Teams (SMTs) should engage in transformative leadership which commences with interrogations regarding social justice, democracy and social responsibility. According to Freire's philosophy of education it is further expected of SMT members to support and shape the belief that autonomy is a condition arising from the responsible engagement with decision-making; that we are 'unfinished' in our development as human beings; and that we are responsible for the development of a critical consciousness as a necessary condition of freedom and the creation of democratic and equitable learning spaces. In a transformative leadership context, authority must inform all critical practices of pedagogical intervention and goal setting should support in-service teacher's autonomy, self-worth and develop their potential and the level of intrinsic motivation to flourish in inclusive school settings. This paper reports on a qualitative pilot study conducted with SMT members and teachers in the Northern Cape Province of South Africa to gain their insights regarding their roles as leaders in devising mechanisms to invest in radical democratic principles and the promotion of inclusive school practices. The key findings indicate that the SMT's role require that they interrogate their frame of reference and transform their thinking in terms of social justice in multicultural school settings and create opportunities for in-service teachers to develop professionally and use digital technology creatively to enhance teaching and learning. As a force for transformation, we conclude that transformative leadership may be a catalyst to engage school leaders and teachers in individual and combined processes of awareness of inclusive practices and action.
\end{abstract}

Keywords: Transformative leadership, school management teams, autonomy, inclusive practices.

\section{Introduction}

Multicultural education provides teachers and SMTs with opportunities to work with different school populaces and attain justice within societies discernible by disparities based on ethnicity, language, religion, gender and socioeconomic status (Banks, 2004). Teachers and SMTs should actively integrate programmes which would speak to diversity to assist learners to improve their academic performance and promote their overall development as human beings (Pourdavood \& Yan, 2020). Transformative leadership may be a pathway to change outcomes for learners in multicultural school settings (Shields \& Warke, 2010; Theoharis, 2007).

Transformative leadership requires that action be taken to redress inequalities and to guarantee that learners have equal opportunities to develop optimally, to be treated with dignity and to improve their competences (Shields, 2014). Inequities unfavorably impact on the learning and success of learners (Shields \& Warke, 2010) and calls for inclusive practices to be applied to learning by advocating for traditionally marginalized learners. Inclusive Education was a focal point during the approval of the 1994 Salamanca statement at the World Conference on Special Needs Education: Access and Quality, organized by UNESCO in Spain. The conference formally approved inclusive education as the furthermost active way of ensuring that everybody enjoys equal education opportunities (UNESCO, 1994). As socially just agents, transformative leaders ought to proactively and meticulously contest the political and social issues that perpetuate inequities in schools (Skrla, McKenzie, \& Sheurich, 2009). This study, therefore, poses the question: What are the roles of SMT members and teachers in devising mechanisms to institute radical democratic principles to promote inclusive school practices? 


\section{Literature review}

\subsection{Transformative leadership as catalyst for transforming multicultural schools}

Multicultural schools are representative of opinions and behaviors that respect and acknowledge the existence of different groups in society, recognizes and values their socio-cultural dissimilarities, and encourage and allow for a continual involvement within an inclusive cultural setting (Rosado, 2020).

Transformative leadership (TL) seems to be ideal in terms of teachers' practices and principals' roles in leading schools in multicultural contexts. Montuori and Donnely (2018) assert that transformative leadership invites individuals to take responsibility in asking what kind of world they would like to create through their interactions, opinions and beliefs, and link it to the ideal school environment. This implies that TL may be regarded as driving force which should inspire individuals to be more creative, interconnected and more personal - principles that embody individuals' desired ideals and allow them to make an influence that mirrors their ethics, expectations, and anxieties (Montuori, 2010). Consequently, TL steers attention to leadership in multicultural contexts in that it may assist teachers and principals to make positive contributions to development in schools (Vora et al., 2018).

\subsection{Developing teacher autonomy and inclusive learning spaces}

As transformative leaders, the role the senior management teams (SMTs) in schools should be develop teacher autonomy and create inclusive teaching and learning spaces as ways to lead in multicultural school contexts. In so doing, SMTs should foster the development of autonomous, socially answerable and critical conscious individuals, "within a vision of education as (inter)personal empowerment and social transformation" (Vieira, 2006, 23 as cited in De Klerk, 2014, 195). Teacher autonomy should prepare in-service teachers to independently and disparagingly reflect on the privileges and power of prevailing cultures, their individual space within schools, and to analyze issues of multiculturalism to construct equal and inclusive learning spaces through their teaching practice (Alismail, 2016).

One way in developing inclusive learning spaces is to foster numerous opportunities for engagement, that is, providing flexible and diverse platforms for distinct learning, teamwork and collaboration (Holeton, 2020). An inclusive, learning-friendly classroom (ILFC) invites, encourages, and teaches all learners irrespective of their linguistic, intellectual, gender, emotional or social characteristics. An ILFC is, therefore, a space in which teachers understand the significance of diversity and plans such that all learners are treated similarly (Salahuddin, 2017).

\subsection{Promoting inclusive practices for transformative leadership professional development}

To promote inclusive practices, Education White Paper 6 highlights that professional development should be based on, "the development of effective leadership in policy, administration and programme implementation, the establishment of management information systems, and the development of competencies" (Republic of South Africa [RSA], 2001, 28). Interpreting the stipulation in RSA (2001), the intention of inclusive practices for transformative leadership professional development should be aimed at improving the skills, attitudes, understanding and performance of teachers [and SMTs] in terms of understanding key strategies critical to achieving success (Salahuddin, 2017).

Inclusive practices for transformative leadership professional development are needed to support an inclusive environment in multicultural school contexts in which diverse team members are respected for their efforts to ensure a sense of belonging and appreciation for distinctiveness (Ashikali, Groeneveld $\&$ Kuipers, 2020).

\section{Theoretical Framework}

This paper explores in-service teachers' practices and school managers' roles in multicultural schooling contexts through the lens of transformative leadership theory (TLT) (Shields, 2011; 2016). This theory critiques practices by offering greater individual achievement as well as "a better life in common with others" (Shields, 2011, 5). TLT is beneficial all stakeholders, with attention paid to issues of academic attainment, language, culture, beliefs and gender (Theoharis, 2007 as cited in Shields \& Hesbol, 2020). Consistent with TLT, the afore-mentioned issues have relevance to multicultural schooling contexts in that it requires transformative leaders to make calculated and informed decisions, take risks and manage multiculturalism, whilst displaying a sense of culture and accountability (Shields, 2011).

We were aware that the application of TLT (Shields, 2011, 2016) requires that we should be cognizant of possible risks of analyzing data in such a way that it would affect the explanation thereof (Evers \& Wu, 2006). Having said this, we were deliberate to prudently ground the data in a practical inferential system (Evers \& Wu, 2006) focusing on teachers' practices and school managers' roles in multicultural school contexts. 


\section{Methodology}

\subsection{Setting and participants}

The data for this pilot study was collected from an ex-model C multicultural Afrikaans public primary school with 324 learners from Grades $\mathrm{R}$ to 7 with 08 teachers and 05 assistant teachers. The assistant teachers perform duties from Gr R-4, and the school is situated in a rural area in the Northern Cape Province of South Africa. Participants included two teachers, one head of department and the principal of the school. The principal, HoDs and teachers received an introductory email before we started with the process of data collection, providing information about the study. We requested that they complete the interview document through email. The email comprised information about privacy, start and end dates, as well as a link to the semi-structured interview schedule. The participants expressed their willingness to be part of the research study as they believed that it would benefit them because involvements of this kind may encourage development within the school. Participants completed the interview schedules electronically and emailed it back to the researchers. The analysis of the data focused on the answers provided in the interview schedule and the content of the participants' responses in line with the research question.

\subsection{Qualitative pilot study}

Qualitative pilot studies used in research are reduced forms of larger studies, also referred to as viability studies, and the pre-testing of a specific research tool (Baker, 1994). The pilot study is used to evaluate the feasibilities of the main study in respect of its application as well as usefulness and frequently contains an evaluation of resources, such as costs and time, for the main study (Gudmundsdottir \& Brock-Utne, 2010). Our pilot study aims to yield practical information about the main study to be conducted and to gain participants' insights regarding their roles as transformative leaders in devising mechanisms to invest in radical democratic principles and the promotion of inclusive school practices in multicultural schools.

\section{Discussion}

The discussion will be based on reviewing the research findings, showing how it relates to the literature review as well as our research question. The school will be referred to as School A, teachers as $\mathrm{T} 1$ and $\mathrm{T} 2$, the head of department as HoD and the principal as P1.

We started the interview by asking the question: How is learner inclusivity addressed in your school? A teacher responded thus: I can say that we really include them in everything that we do. And it was good to strengthen issues regarding differentiation. In this regard, we gave activities in line with the cognitive abilities of our learners and even provided opportunities for re-assessment where necessary [T1]. When probed to provide some of the corrective and supportive strategies teachers have put in place to assist learners in their learning to promote individual progress, behaviour, and social-emotional development during the COVID-19 pandemic, a teacher indicated: Learners who struggled were given opportunities to redo activities. I also sent motivational messages to parents via WhatsApp to encourage learners when they must complete activities. The parents appreciated this [T2]. Salahuddin (2017) agrees that to ensure the success of inclusive practices and build a country's social capital, individuals such as parents and teachers as well as communities must work together.

Teachers further elaborated on the platforms that are created for learners to identify and challenge injustices, express their feelings about how to improve their learning experiences within the school by indicating: I requested parents to allow their children to send me messages on their WhatsApp. This worked quite well and I experienced that communicating with them made them feel good. I also had a WhatsApp group with parents and many a times I read messages where parents give guidance to other parents and how they motivate each other [T2].

Upon probing the participants about the leadership style of the SMT and the creation of developmental opportunities for teachers to show leadership they mentioned: We had regular updates from the SMT on our staff's WhatsApp group. They would alert us about teaching and learning programmes on the radio and television. They also held regular Zoom meetings with us and we received emails. They used these platforms to keep us in the loop regarding educational developments [T1]. Teachers are encouraged to attend departmental workshops and courses and partake in virtual training [T2]. The teachers reported receiving a lot of support and professional inspiration from their leaders who encourage them to lead and innovate in their classrooms while contributing to the development of their colleagues and the school. When teachers are enabled to be autonomous and can take a leadership role themselves, they acquire professional confidence that fosters effective teaching practice (De Klerk, 2014; Wayne \& Youngs, 2003). 
SMT members were probed on some of the issues and challenges that COVID-19 has brought and the types of inequalities that the pandemic has highlighted in the school. Due to anxiety and stress, some parents withdrew their learners from school and some of the learners only attended school when they wished to do so. It was difficult for learners to follow teaching and learning programmes because most of them do not have a television or even a computer at home. I mean, technology and the use thereof are a huge problem within our community [P1]. Determining exactly how much the COVID-19 pandemic has impacted on curriculum delivery, may be difficult and an accurate assessment may only be made once teachers and learners return to schools and the extent to which the gap between disadvantaged children and their peers has changed. Although schools' closings have undoubtedly contributed to slow the spread of COVID-19, the use of virtual education platforms, as a substitute for face-to-face classes, is challenging and firstly impact learners from disadvantaged backgrounds (Teymori \& Fardin, 2020).

To the question on how learning support is offered to learners with disabilities and online teaching strategies, an SMT member responded in the following way: This was difficult and we could only provide parents with necessary material to ensure that some of teaching and learning would take place at home. We decided to only assess learners in terms of work already completed in order not to burden them with unfamiliar things. This really help and ensured that learners progress at a good pace, we are very aware of the fact that many learners struggle academically [HoD]. We provided learners with containing learning activities which were collected after completion [P1]. Significantly, transformative leaders promote an inclusive vision by eliciting, "elicit high performance because they strongly believe in the abilities of their constituents" (Kouzes \& Posner, 2012, 276). This conviction (Kouzes \& Posner, 2012), when combined with leadership resources and support, validates trust that transformative leaders have in their teachers and senior management team members, and builds collegial trust in return.

SMT members were probed on how their leadership assisted in the execution of actions to promote teaching and learning to mitigate COVID-19 and inclusiveness in the school. The principal indicated: I allowed teachers to work independently, ensure that they would feel in charge of their own teaching practices. I also developed a reporting template on which they would provide information about learners' progress and completion of activities. They understood that the idea was not to check on them, but that mechanisms were put in place to ensure that all learners got equal opportunities to learn [P1]. Transformative leaders thus stimulate innovative personal qualities, strengthening individuals' creativity, unlock intellectual abilities and encourage participative leadership (Abdelrahman \& Kelly, 2019).

The current pandemic offers unprecedented challenges, but also opportunities: although the usual way of teaching, learning and school leadership have been disturbed, spaces have been created to reimagine instruction approaches as well as leadership abilities.

\section{Conclusion}

This pilot study was conducted to acquire knowledge regarding transformative leadership in multicultural schooling contexts. The responses from participants (teaches and SMT members) revealed that the development of inclusive learning spaces is imperative in transforming, motivating and enhancing diverse platforms for learner development. Successful inclusion practices not only accentuate the significance of leaners in the classroom, but it also highlights the quality of their experiences and their academic attainment in terms of curriculum content. Teachers and SMT members play a fundamental role in ensuring that inclusive practices are regarded as fundamental in education. Based on the findings the pilot study yielded, we were able to adapt our interview schedules and improve the research design which will inform the larger study we are undertaking.

\section{References}

Abdelrahman, Z., \& Kelly. L. (2019). The role of CEO transformational leadership and innovation climate in exploration and exploitation. European Journal of Innovation Management, 22, 84-104.

Alismail, H.A. (2016). Multicultural Education: Teachers' Perceptions and Preparation. Journal of Education and Practice, 7(11), 139-146.

Ashikali, T., Groeneveld, S., \& Kuipers, B. (2020). The Role of Inclusive Leadership in Supporting an Inclusive Climate in Diverse Public Sector Teams. Review of Public Personnel Administration, 2020, 1-23.

Baker, T.L. (1994). Doing social research (2nd ed.). New York, NY: McGraw-Hill.

Banks, J.A. (2004). Teaching for social justice, diversity, and citizenship in a global world. In The Educational Forum, 68(4), 296-305. 
Bennis, W., \& Nanus, B. (2007). Leaders: Strategies for Taking Charge. 2nd Edition. New York, NY: Harper-Collins.

De Klerk, E.D. (2014). Teacher autonomy and professionalism: A policy archaeology perspective. M.Ed.-dissertation. Bloemfontein: University of the Free State.

Evers, C.W., \& Wu, E.H. (2006). On generalising from single case studies: Epistemological reflections. Journal of Philosophy of Education, 40, 511-526.

Gudmundsdottir, G.B., \& Brock-Utne, B. (2010). An exploration of the importance of piloting and access as action research. Educational Action Research, 18, 359-372.

Holeton, R. (2020). Toward Inclusive Learning Spaces: Physiological, Cognitive, and Cultural Inclusion and the Learning Space Rating System. Retrieved February March 17, 2021, from: https://er.educause.edu/articles/2020/2/toward-inclusive-learning-spaces

Kouzes, J., \& Posner, B. (2012). The Leadership Challenge (5th ed.). San Francisco, CA: Jossey Bass.

Montuori, A. (2010). Transformative leadership for the 21st century. Reflections on the design of a graduate leadership curriculum. ReVision, 30(3-4), 4-14.

Montuori, A., \& Donnely, G. (2018). Transformative Leadership. In J Neal (ed.). Handbook of Personal and Organizational Transformation (pp. 1-32). San Francisco, CA, USA: Springer International Publishing.

Pourdavood, R.G., \& Yan, M. (2020). Becoming Critical: In-service Teachers' Perspectives on Multicultural Education. International Journal of Learning, Teaching and Educational Research, 19(2), 112-135.

Republic of South Africa. (2001). Education White Paper 6. Building an Inclusive Education and Training System. Pretoria: Government Printer.

Rosado, C. (2020). What makes a school multicultural? Retrieved February March 17, 2021, from: http://www.edchange.org/multicultural/papers/caleb/multicultural.html

Salahuddin, S.F. (2017). Building inclusive learning friendly classrooms: need of the hour. International Journal of Reflective Research in Social Sciences, 1(1), 10-13.

Shields, C.M. (2011). Transformative leadership: An introduction. In C.M. Shields (Ed.), Transformative Leadership: A Reader (pp. 1-17). New York, USA: Peter Lang.

Shields, C.M. (2014). "Ethical leadership: a critical transformative approach". In C.M. Branson C.M. \& S.J. Gross (Eds.), Handbook of Ethical Educational Leadership (pp. 24-43). New York, NY: Routledge.

Shields, C.M. (2016). Transformative leadership in education: Equitable and socially just change in an uncertain and complex world (2nd ed.). New York, NY: Routledge.

Shields, C.M., \& Hesbol, K.A. (2020). Transformative Leadership Approaches to Inclusion, Equity, and Social Justice. Journal of School Leadership, 30(1), 3-22.

Shields, C.M., \& Warke, A. (2010). "The invisible crisis: connecting schools with homeless families". Journal of School Leadership, 20(6), 789-819.

Skrla, L.E., McKenzie, K., \& Sheurich, J.J. (Eds). (2009) Using equity audits to create equitable and excellent schools. Thousand Oaks, CA: Corwin Press.

Teymori, A.N. \& Fardin, M.A. 2020. COVID-19 and Educational Challenges: A Review of the Benefits of Online Education. Ann Mil Health Sci Res. (In Press): e105778

Theoharis, G. (2007). Social justice educational leaders and resistance: toward a theory of social justice leadership. Educational Administration Quarterly, 43(2), 221-258.

UNESCO. (1994). The Salamanca Statement and Framework for Action on Special Needs Education. Adopted by the World Conference on Special Needs Education: Access and Quality. Salamanca, Spain: UNESCO.

Vora, D., Martin, L., Fitzsimmons, A.R., Pekerti, A.A., Lakshman, C., \& Raheem, S. (2018). Multiculturalism within individuals: A review, critique, and agenda for future research. Journal of International Business Studies, 50(6), 1-26.

Wayne, A. \& Youngs, P. (2003). Teacher characteristics and student achievement gains: A review. Review of Educational Research, 73(1), 89-122 


\title{
ENHANCING EDUCATORS' CREDIBILITY IN INTELLIGENT LEARNING ENVIRONMENTS
}

\author{
Mario Mallia Milanes, \& Matthew Montebello \\ Department of Artificial Intelligence, University of Malta (Malta)
}

\begin{abstract}
The deployment and use of Artificially Intelligent tools and techniques has proved to be effective and convenient, rendering them highly popular and desirable within any application. The benefits that such smart services provide are increasingly becoming popular within virtual learning environments as educators and learners continue to revert to such online portals during the academic process of higher education programmes. However, numerous educators have been sceptical of the inferences made by the machine learning techniques that implicitly at the background of the learning environment are monitoring the learner and collecting data to optimize the educational process as well as the learning experience. In an effort to enhance such a credibility we present an intelligent learning environment that justifies its decisions and propositions through an explainable interface that tracks back its conclusions to reasonable and plausible justifications. In this paper we present our research work together with our experiences in developing and deploying such a ground-breaking concept.
\end{abstract}

Keywords: Artificial intelligence in education, intelligent learning environment, learning analytics, eXplainable AI.

\section{Introduction}

The use of Artificial Intelligence (AI) to the educational domain has been investigated for a number of years (Montebello, 2018a) and a plethora of AI techniques have been employed to add-value to the online learning environment (Montebello, 2014) especially in an effort to personalise the learning experience (Montebello, 2016a), as well as, provide essential learning analytics (Haniya, et al., 2019). The benefits documented (Montebello, 2018b) coupled with the added effectiveness measured (Montebello, 2017a) are clear indications that AI can play an important role in education, supplementing educators while empowering them at the same time. However, numerous educators have been sceptical of the inferences made by the machine learning techniques that implicitly at the background of the learning environment are monitoring the learner process through which the learners can benefit. These same automated systems are programmed to collect masses of learner-generated data while interacting the virtual learning environment (VLE) and processed intentionally to be employed in further optimising the educational process as well as the learning experience. The educators' credibility of an AI-enhanced VLE effects the eventual adoption and deployment of such virtual environments, and thereby it is of utmost important that the educators become the prime advocates who support and take full advantage of the added-value provided by the technology. One way to have educators onboard is to not only provide them with supplementary resources and automated information that assisted them in their task to educate, but to include them as collaborators within the intelligent process as the underlying intelligent learning environment transparently justifies each step of its academic decisions and pedagogical propositions. This can be done through an explainable interface that keeps tracks of every step in the process and presents them back to justify its conclusions to the same educators in a reasonable and plausible manner. Such a technique is referred to as eXplainable AI (XAI) where the intelligent system provides a full trace of how it reached specific inferences thereby demystifying the 'black box' concept of current systems that provide no rational or comprehendible way of how specific educational decision had been reached or how the learning environment provided the additional value to the educational process through the analysis of the data generated by the learners themselves.

The rest of the paper is organised as follows. In the next section the background information related to use of AI within an education context together with the employment of XAI to justify the entire process is provided to assist the reader understand better the rest of the paper. Section 3 presents the proposed 
intelligent learning environment enriched by the justifications provided by the XAI for educators to better understand and appreciate the additional academic assistance. We close the paper with some future directions and number of conclusions accumulated through our experiences in developing and deploying such a ground-breaking concept.

\section{Background}

The use of technology within an educational context has always been regarded as a natural combination (Luckin, Holmes, Griffiths, \& Forcier, 2016) that both learners and educators benefitted from. Furthermore, the integration of artificially intelligent techniques (Montebello, 2017b) within the educational process provided added-value to supplement the benefits that educators fruitfully deliver on a day-to-day basis. The use of artificial intelligent (AI) techniques to personalise a specific user's experience is an established research domain within the computer science domain (Cawsey, Grasso, \& Paris, 2007), whereby various Machine Leaning (ML) techniques are available (Degemmis, 2003) to generate a specific user profile that is used to customise a variety of environments, like information over the World-Wide Web (WWW) while searching (Montebello, 1999), e-Commerce servics (Goy, Andrissono, \& Petrone, 2007), healthcare consumers (Cawsey, Grasso, \& Paris, 2007), and mobile phone guides (Kruger, 2007). In education this same concept is also possible by generating a student learning profile that is used to customise the entire educational process, as documented by Brusilovsky and Milla (2007). The use of generated digital learner profiles through the use of AI and in particular ML has employed to personalise the learning environment in various scenarios (Montebello, 2014). Numerous notorious learner profile generators are employed to generate a learner profile that can be used to personalise the learning process (Schiaffino \& Amandi, 2009). However, one typical concern with automatic profile generators is the inability to produce a profile at the very beginning of the process when no previous information about the learner is available. This problem commonly referred to as the 'cold start' effect (Ortega, Hernando, Bernal, \& Bobadilla, 2012) can be easily and quickly addressed by adopting the explicit collection of learner interests and needs at the beginning of the process, and eventually employ automatic profile generation from then onwards. This is possible by the process whereby students trigger off the profile generation by initially providing explicit information during registration whereby they are given the space to declare their specific academic qualities, descriptions or educational characteristics, together with interests and needs that can be employed to generate a much more accurate profile. This initial explicit method generates enough information and momentum for the automatic method to seamlessly take over the process and effectively generates a learner profile that can be productively used to personalise the content, the process, the supplementary educational materials, as well as the learning environment itself (Montebello, 2019). Such a generated profile encapsulates as much as possible the comprehensive learner characteristics that deal with knowledge, interests, and educational needs. In this respect a learner profile is considered a collection of inferences about information concerning a student that one is not able to observe (Zukerman \& Albrecht, 2001). The main use of the learner profile is to adapt and personalise the learning process as well as the content and the delivery of the educational material.

Another technology being employed in the proposed system is a technique to justify and explain the artificially intelligent decisions derived from the various ML techniques employed. The demand for more information that is provided to the end user has been documented (Murdoch, Singh, Kumbier, Abbasi-Asl, \& Yu, 2019) providing the need and advantage of having a rational explanation of how such conclusions have been reached. The classic closed or black box philosophy of how traditional software operates does not offer any kind of justification that can alleviate and assist the credibility of the user (Gilpin, et al., 2018) especially in circumstances that directly affect their educational future or of those around them. If AI is to be employed ethically and optimally, especially in a support role, the end user, a learner or even an educator, must be kept in the loop and given the facility to follow on conclusions reached. Such a functionality would assist learners and educators alike to gain trust in the back-end system that is assisting them within the virtual learning environment. One of the main inhibitors of progress to explainability is the lack of consistency and measurement metrics (Preece, Harborne, Braines, Tomsett, \& Chakraborty, 2018). Currently two eXplainable A.I. methods (XAI) are predominantly being employed to provide additional value to the artificially intelligent services provided. The embedded approach to explainability (Arrieta, et al., 2020) is the first XAI technique being employed, whereby the feature to explain the process forms part of the ML algorithm itself. This means that previously developed ML techniques will need to be adapted and re-coded to accommodate the tracing and reporting of additional information to end users in a way that they will be able to analyse the internal working of the ML algorithm and comprehend the rationale behind the output provided. This output that is provided to add value to the learning experience is required to be padded with human-readable instructions which facilitate understanding (Gilpin, Testart, Fruchter, \& Adebayo, 2019). The second XAI technique that is commonly 
referred to is the post-hoc approach to explainability whereby the rationale behind the AI decisions inferred are applied retroactively. The advantage in this case is that current ML models can still be employed and eventually compile an explanation as a result of applying that specific ML technique. IN this way traditional ML techniques employed within recommender systems are provided with a clear and detailed justification of the decisions the model arrived at. Such an outcome is clear enhancement on previous implementations (Paez, 2019), as XAI managed to convert dry and meaningless responses into significant and informative sources of information providing much needed credibility in the intelligent underlying virtual learning environment.

\section{Intelligent learning environment}

An intelligent learning environment that was developed as part of research project (Montebello, 2016a) to provide personalised e-learning services is being upgraded to include XAI functionalities. The supplementary added-value will provide much needed justifications of the customisation provided together with clear rationale of all the decisions and propositions provided by keeping track of the inferences made. The enhanced personal learning environment (Figure 1) is meant not only to tailor the virtual learning environment by providing a personalised learning experience, but also to justify the lateral recommendations and suggestions provided together with simple justifications that the learner can understand and come to terms with what the underlying ML functionality is providing. Over and above these explicit XAI occurrences, the educator who administers the learning environment is provided with an interface to control and oversee the personalisation process both of the content and the academic process. This provides the opportunity for educators to understand the customisation process while strengthening their credibility in the artificially intelligent backend and the holistic learning process provided by the intelligent virtual learning environment.

Figure 1. Upgraded Personal Learning Environment.

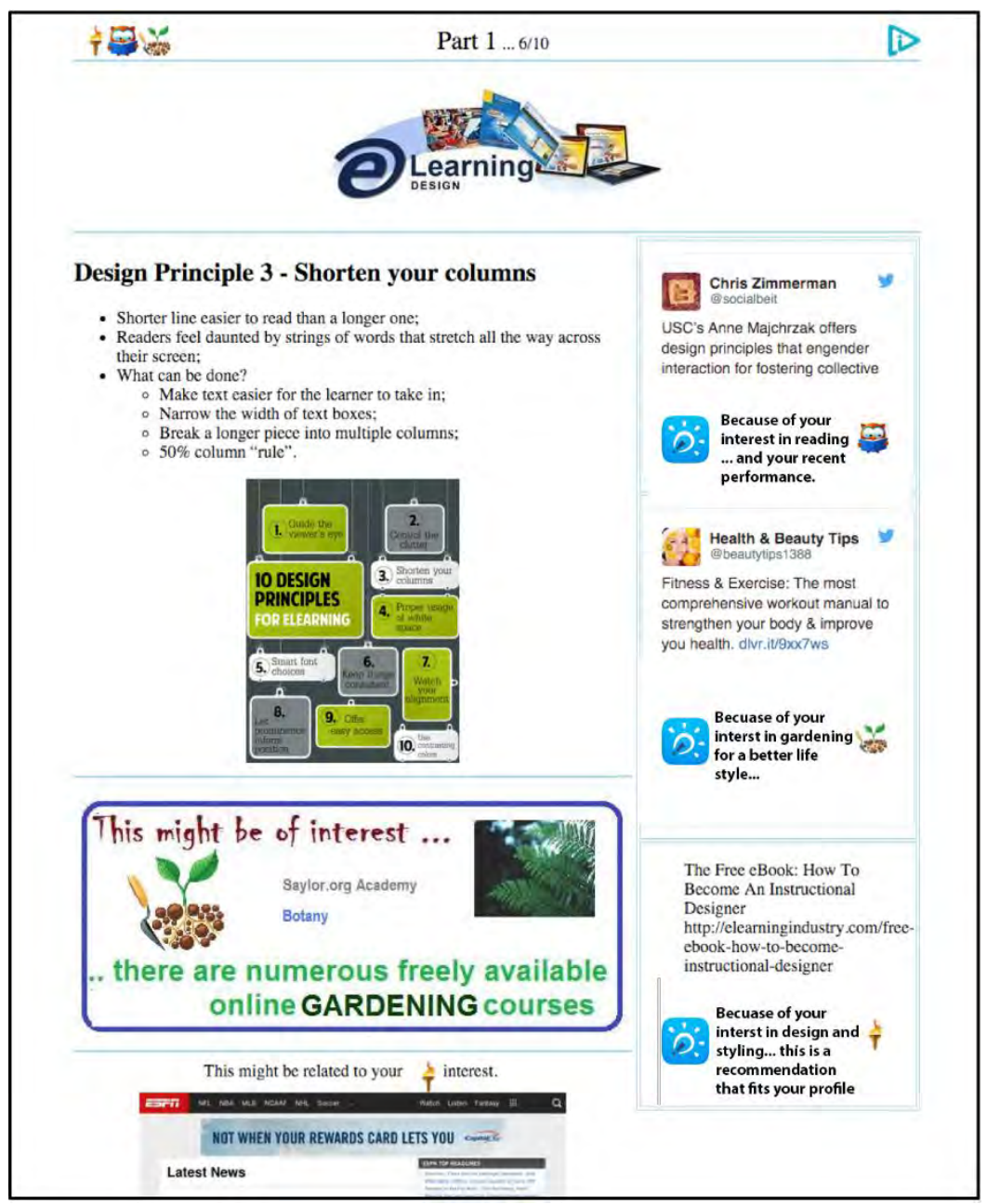




\section{Future Work}

A number of potential avenues will be ensued to further enhance the educators' credibility in the intelligent learning environment as additional XAI functionality is integrated within the proposed backend system. A look-ahead feature to map out a road map of an optimised learning process based on numerous success stories that fall within the same cluster as the specific learner will encourage both the learner and the educator as it provides an explicit rationale based on the individual learner portfolio that has been accumulated and employed to generate both the learner profile and the academic plan. Additionally, the inclusion of an XAI assistant within the virtual learning environment that can seamlessly accompany the learner over multiple devices will enhance the effectiveness and then overall success of the AI added-value while strengthening the output created by the underlying ML techniques that have additional learning data based on the real learning analytics accumulated. The same assistant will interact with the educator's interface to provide additional information to substantiate the inferences performed. Furthermore, the justified integration of social networks and the inclusion of certified crowdsourcing will provide additional content that will deliver a richer learning experience whereby the underlying AI functionality will have even more data to work on and better assist the learner. The XAI component will still provide the proposed functionality with the added-value of applying the smart techniques on richer content that will raise the overall learner experience and educator credibility.

\section{Conclusion}

In this paper we proposed the integration of eXplainable Artificial Intelligence (XAI) functionality within an intelligent learning environment that was already enriched by Artificial Intelligent (AI) techniques and Machine Learning (ML) technologies to customise and personalise the Virtual Learning Environment (VLE). The rationale at the basis of our enhanced intelligent VLE is aimed at enhancing the learners' and educators' credibility on the functionality provided by the underlying intelligent environment by providing explicit justifications and simple explanations of the decisions and propositions inferred by the ML algorithms that are processing the unique data generated by the individual learners. The XAI interface tracks back its conclusions to generate reasonable and plausible justifications that are communicated back to the end users, learners and educators. We presented our research work, as well as, proposed additional enhancements to the intelligent VLE by taking further advantage and extracting richer benefits that eventually strengthen the use of AI in education in an effort to take e-learning to the next level.

\section{References}

Arrieta, A., Díaz-Rodríguez, N., Del-Ser, J., Bennetot, A., Tabik, S., Barbado, A., ... Herrera, F. (2020). Explainable Artificial Intelligence (XAI): Concepts, taxonomies, opportunities and challenges toward responsible AI. Information Fusion, Vol 58, 82-115.

Brusilovsky, P., \& Milla, E. (2007). User Models for Adaptive Hypermedia and Adaptive Educational Systems. In P. Brusilovsky, A. Kobsa, \& W. Nejdl, The Adaptive Web (pp. 3-53). Heidelberg: Springer.

Cawsey, A., Grasso, F., \& Paris, C. (2007). Adaptive Information for Consumers of Healthcare. In P. Brusilovsky, A. Kobsa, \& W. Nejdl, The Adaptive Web. Heidelberg: Springer.

Cawsey, A., Grasso, F., \& Paris, C. (2007). Adaptive Information for Consumers of Healthcare. In P. Brusilovsky, A. Kobsa, \& W. Nejdl, The Adaptive Web. Heidelberg: Springer.

Degemmis, M. (2003). Extraction of User Profiles by Discovering Preferences through Machine Learning. In M. A. Kioptek, S. Wierzchon, \& K. Trojanowski, Intelligent Information Processing and Web Mining. (pp. 69-78). Zakopane, Poland: Springer.

Gilpin, L., Bau, D., Yuan, B., Bajwa, A., Specter, M., \& Kagal, L. (2018). Explaining explanations: An overview of interpretability of machine learning. 5th International Conference on Data Science and Advanced Analytics, (pp. 80-89). IEEE.

Gilpin, L., Testart, C., Fruchter, N., \& Adebayo, .. (2019). Explaining Explanations to Society. ArXiv abs/1901.06560.

Goy, A., Andrissono, L., \& Petrone, G. (2007). Personalization in E-Commerce Applications. In P. Brusilovsky, A. Kobsa, \& W. Nejdl, The Adaptive Web (pp. 485-520). Heisdelberg: Springer.

Haniya, S., Tzirides, O., Georgiadou, K., Montebello, M., Kalantzis, M., \& Cope, B. (2019). Assessment Innovation in Higher Education by Integrating Learning Analytics. 3rd International Conference on Education and Distance Learning. Barcelona: ICEDL. 
Kruger, A. (2007). Adaptive Mobile Guides. In P. Brusilovsky, A. Kobsa, \& W. Nejdl, The Adaptive Web (pp. 521-549). Heidelberg: Springer.

Luckin, R., Holmes, W., Griffiths, M., \& Forcier, L. (2016). Intelligence Unleashed - An argument for AI in Education. London: Pearson.

Montebello, M. (1999). Personalised Information Retrieval over the $W W W$, Ph.D. Thesis. Cardiff: Cardiff University.

Montebello, M. (2014). Enhancing the Effectiveness of E-Learning through the combination of Personal Learning Portfolios and Social Networks. 7th International Conference on Education, Research and Innovation (ICERI 2014). Seville, Spain.

Montebello, M. (2016a). Personalised e-Learning. Sheffield, UK: Ed.D. Thesis.

Montebello, M. (2016b). Enhancing e-learning through the merging of e-portfolios, social networks and artificial intelligence. 10th International Technology, Education and Development Conference (INTED2016). Valencia.

Montebello, M. (2017a). Measuring E-Learning Effectiveness Using a Three-Way Comparison. 19th International Conference on e-Education and e-Learning (pp. 921-926). Boston: (ICEEEL), Boston, USA. International Science Index, Educational and Pedagogical Sciences.

Montebello, M. (2017b). Next Generation e-Learning. 5th ACM International Conference on Information and Education Technology (pp. 150-154). Tokyo: ICIET.

Montebello, M. (2018a). AI-Injected e-Learning - The Future of Online Education. Switzerland: Springer.

Montebello, M. (2018b). Assisting Education through Real-Time Learner Analytics. 48th IEEE Annual Frontiers in Education (FIE) Conference (pp. 133-139). San Jose, California, USA: FIE.

Montebello, M. (2019). Ambient Intelligent Classroom - Beyond the indispensable educator. Switzerland: Springer.

Murdoch, W., Singh, C., Kumbier, K., Abbasi-Asl, R., \& Yu, B. (2019). Interpretable machine learning: definitions, methods, and applications. ArXiv, abs/1901.04592.

Ortega, J., Hernando, F., Bernal, A., \& Bobadilla, J. (2012). A collaborative filtering approach to mitigate the new user cold start problem. Knowledge-Based Systems, 225-238.

Paez, A. (2019). The Pragmatic Turn in Explainable Arti cial Intelligence (XAI). Minds and Machines, 29(3), 441-459.

Preece, A., Harborne, D., Braines, D., Tomsett, R., \& Chakraborty, S. (2018). Stakeholders in Explainable AI. ArXiv abs/1810.00184.

Schiaffino, S., \& Amandi, A. (2009). Intelligent user profiling. Artificial Intelligence, LNAI 5640.: IFIP, 193-216.

Zukerman, I., \& Albrecht, D. (2001). Predictive statistical models for user modeling. User Modeling and User-Adapted Interaction, 11(1-2), 5-18. 


\title{
EXPLORING THE IMPLEMENTATION OF TEACHER LEADERSHIP IN LESOTHO HIGH SCHOOLS
}

\author{
Lieketseng Lethole ${ }^{1}$, June Palmer ${ }^{1}, \&$ Edwin de Klerk ${ }^{2}$ \\ ${ }^{1}$ Postgraduate Studies, Central University of Technology, Free State (South Africa) \\ ${ }^{2}$ Education Studies, Sol Plaatje University (South Africa)
}

\begin{abstract}
Whilst teacher leadership is an evolving concept with a potential that has yet to be realized, the fostering of teachers' leadership growth remains a sustainability element in education worldwide. Teacher leadership for sustainability indicates a fresh and extended consideration of leadership emphasising sustainability principles and providing leadership that transforms the school environment while engaging in collaborative efforts to do so. Located in the interpretive paradigm, this qualitative study sought to elicit the views of Heads of department (HoDs) and District Education Managers (DEMs) in Lesotho high schools to explore the views they consider most relevant in developing teacher leadership skills to ensure leadership succession as sustainable practice. The findings reveal that to achieve sustainable teacher leadership, there is a need to withdraw from a top-down hierarchical model of leadership towards more flexible, transformative, and empowering approaches to leadership. Furthermore, in order to maintain sustainable teacher leadership, HoDs and DEMs must be innovative in providing reflective plans for professional development that can sustain teachers throughout their careers and foster learning environments that are healthy for teachers, learners, and the school. The study recommends that school leaders should mobilise the leadership expertise of teachers in their schools in order to create more chances for transformation and capacity building. Sustainable teacher leadership can help bring about great improvements in a school, including extending the scope of leadership beyond what the HoDs and DEMs cannot achieve alone, and building their relationship capacity to become collaborative change agents.
\end{abstract}

Keywords: District education manager, school management team, sustainable teacher leadership, teacher leadership.

\section{Introduction}

Teacher leadership focuses on learner advancement and signifies a leadership model which is focused on the concepts of professional cooperation and encouraging the teacher to be actively involved in development opportunities as well as decision-making to sustain school leadership (Makoelle \& Makhalemele, 2020). Significantly, enhancement in leadership sustainability may contribute to the changing roles of leaders within the school environment.

Makoelle and Makhalemele's (2020) study in South Africa point out that the importance of sustainable teacher leadership and teachers' involvement in decision-making processes show comparisons between how they theorise and enact leadership and the techniques used by teachers internationally. In South Africa, however, it is absolutely clear that the governmental dialogue of teacher leadership remains a critical matter which impact on teachers' thoughts of teacher leadership and how it is to be enacted.

The problem of teacher leadership in Lesotho high schools has not been adequately addressed. Whilst teachers in Lesotho schools typically fulfil the role of learning facilitators aiming at improving learners' academic achievements, they simultaneously contribute to the schools' development (Perumal, 2015). In Lesotho, mistrust of teachers towards their schools' leaders exists as leaders are sceptical of the capability teachers possess to carry out certain tasks entrusted to them. Consequently, teachers become demotivated and the level of commitment wanes. It is typically these sustainability factors that the researchers wish to explore in this study. To address the problematic of teacher leadership, the current study provides recommendations on how to sustain leadership aimed at providing direction to Lesotho high schools in developing teachers as leaders.

This paper addresses the central question: What are the sustainability factors that influence teacher leadership practices in Lesotho high schools? 


\section{Conceptual framework}

A conceptual framework informs the direction of the research. Whilst a conceptual framework contains the significant variables, features or concepts and presumes connections among them (Miles \& Huberman, 1994), it also provides an indication on how to explore the research problem and signposts how the variables in the study are connected (Ravitch \& Riggan, 2017). The conceptual structure in Figure 1 provided the authors with guidelines to teacher leadership practices.

Figure 1. Teacher Leadership Conceptual framework (created by authors).

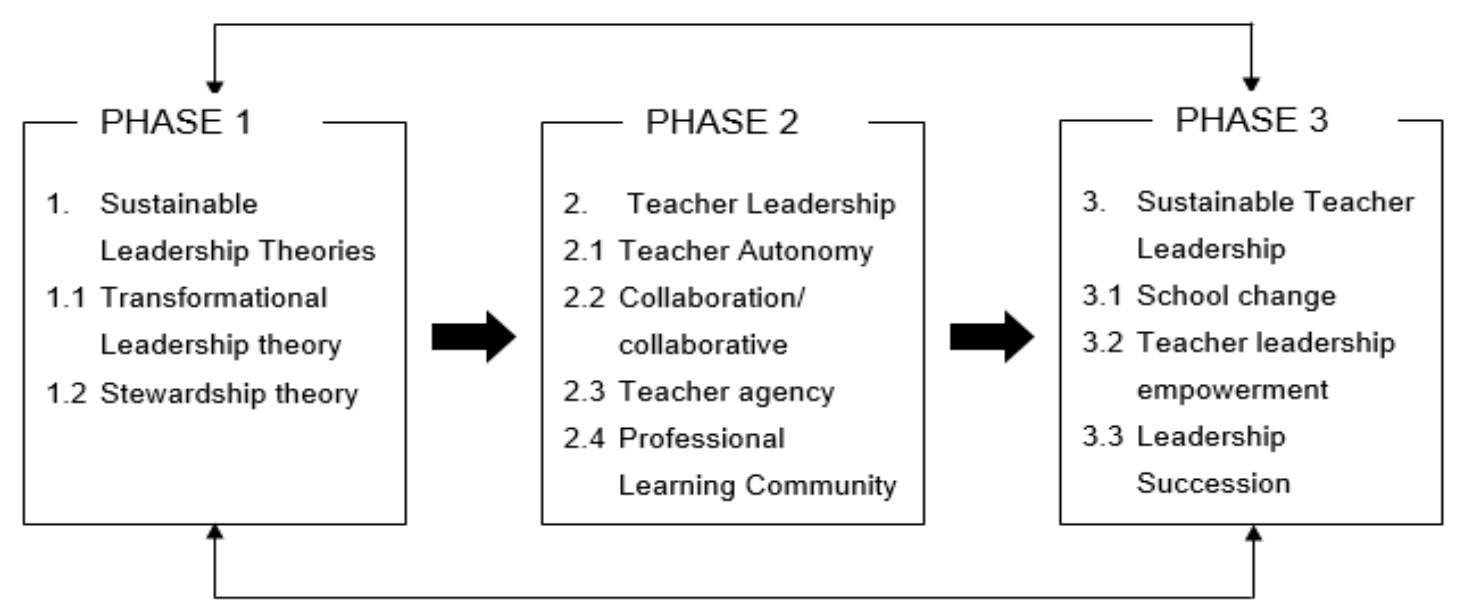

The development of teacher leadership is enhanced when teachers are afforded opportunities to raise their voices on matters such as the establishment of PLCs, decision-making as well as ensuring professional autonomy (Sfakianaki et al., 2018). Sustainable teacher leadership includes three aspects. First, school change requires a shifting from the traditional autocratic approach to the transformational approach by actively working with stakeholders to sustain leadership and to improve the school (Olujuwon, 2013). Second, teacher leadership empowerment aims at enhancing teacher leadership opportunities by building capacity in terms of abilities, skills and expertise whereby teachers partake in decision-making and the management of the school (Peterlin, Pearse \& Dimovski, 2015). Third, leadership succession can be regarded as a process of finding and growing future leaders who will replace current leaders, in order to sustain continuous successful leadership over time in schools (Al-Zawahreh, Khasawneh \& Al-Jaradat, 2019)

In this study, the researchers contend that, in order to sustain leadership in schools, HoDs and DEMs should work collaboratively with a shared vision to.

\section{Methodology}

This research employed a qualitative methodology to acquire knowledge of how sustainable teacher leadership is practised in designated schools in the Berea and Maseru districts from the perspective of Heads of Department (HoDs) and District Education Managers (DEMs). Researchers are positioned to obtain more information about the social world they are learning about, through involvement with an emphasis on the individual (Denzin \& Lincoln, 2011). The collected data was in the form of words, providing for a more transparent approach, without the use of mathematical information (Creswell, 2011). The qualitative approach was suitable for this study because of its importance in emphasising the existing experiences of HoDs in Lesotho schools.

\section{Participants and sampling}

In this study, purposive sampling was used to identify the participants. This technique implies that the chosen participants share more or less particular similar characteristics and can, therefore, offer essential information desirable for this research study and suitability to advance the aim of the study (Maree, 2011, Mouton, 2011). Eight HoDs and two DEMs were selected to participate in the study in four schools in the Berea district and four schools in the Maseru district of Lesotho. 


\section{Data collection}

The HoDs and DEMs were requested to engage with the researchers by means of in-depth individual semi-structured interviews. The aim was to elicit the feelings and experiences of HoDs and DEMs of the nature and practice of leadership succession and teacher leadership in their schools. Denzin and Lincoln (2011) assert that semi-structured interviews are suitable where researchers primarily focus on procedure or difficulty, as it delineates the lines of inquiry by means of open-ended questions (Maree, 2011).

\section{Data analysis}

Codes and thematic analysis were used to analyse the data. Coding involves a careful scrutiny of the recorded data, breaking it down into sections and then dividing it into important logical units (Maree, 2011). Moreover, coding is usually used in the occurrence of a pattern or data repetition (Saldana, 2016). Thematic analysis was done by categorising mutual themes in answers, for example, looking at the differences and similarities in answers by grouping the data, searching for significant patterns and then arranging it according to themes and content (Sutton \& Austin, 2015).

\section{Discussion of findings}

The participants were adamant that factors influencing teacher leadership in Lesotho High Schools mainly centred around decision-making and autonomy.

\subsection{Sub-theme: Shared in decision-making}

Darling-Hammond, Hyler and Gardner (2017) mention that the development of teachers, growing their full potential and leading themselves effectively, should be regarded as the core of being a leader. To achieve the goals of a school, principals need to be efficient in leading learning and teaching processes to be regarded as transformative leaders (Faupel \& Sü $\beta, 2019$ ). DEMs reveal that they work together with principals to discuss the vision of the school. DEMB reiterates,

"I think it is important to do so because it enables everyone to come up with new ideas and views

that provide a genuine conclusion which helps schools to always remember what they want to achieve at the end. Principals especially should not work alone".

Working in collaborative teams allows transformation to take hold in an organization when the leaders empower others, disperse leadership and models collaboration and its practices (Admiraal et al., 2019). Relationships are simultaneously fostered which may enable teachers to address struggles across leadership and shift their experience of working in an isolated environment to one of supporting collaborative efforts. DEMM indicates,

"Trust is a real issue in schools. Some principals are autocratic. To involve stakeholders develops an environment of trust by allowing the voices of the stakeholders to be heard and their issues to be known".

Participants HoDA, HoDB, HoDC, HoDE and HoDG stated that there is a need to strengthen school values, mutual trust and respect to co-create a satisfying and interconnected school environment that is ideal for school improvement. In this way teachers may embrace the practice of deliberating their duties and difficulties with each other and devote time conversing what knowledge they can acquire during workshops in the pursuit of innovative ideas (Admiraal et al., 2019). HoDF and HoDH indicated that HoDs and DEMs should support a healthy environment with open communication channels so that teachers may assist each other and participate in school-wide decision-making. HoDE made the following statement in this regard:

"The close relationship between stakeholders is common in my school, we prepare scheme of work with subject teachers whereas, with HoDs it's is once a year while we do not meet the DEMs at all".

\subsection{Sub-theme: Teacher autonomy}

Teacher autonomy is important for the creation of a unique learning situations where the diverse learning needs of learners can be addressed. Notably, teacher autonomy is an informally created process, where support and development teams can facilitate and share autonomous learning, different pools of knowledge, equal power and teaching experience (Edwards \& Gammell, 2016). However, teachers demonstrate their teaching abilities according to the designed curriculum which restricts their autonomy (Wermke et al., 2019). Participants (DEMB and DEMM) indicated that teachers who require autonomy are the ones that seem independent and who ensure that teaching and learning take place without any prescribed 
instruction from authority. DEMM elaborated, stating:

"They plan on their own and ensure that the delivery of the curriculum within their classes is done properly. They also ensure that every work that has been done is done as required. As a result, these teachers require more support to function optimally".

Participants DEMM and DEMB further revealed that they encourage teacher autonomy, but within academic constraints, such as compiling reports at the end of the lesson and evaluating them, after which they are afforded opportunities to develop their individual self-sufficiency. This implies that teachers should engage in peer observation aiming at developing the self and others. Teachers should be dynamic in balancing the desire to make choices grounded on their individual capability with the encouraging effects of teamwork. Consequently, DEMB confirmed stating that:

"Minimum guidelines should be set while classes should be monitored and guidance provided in order to produce good results as a team. However, teachers should not always be told what they should do. Sometimes it is for them to decide."

Organizational success requires a focus on aspects of teacher autonomy such as responsibility, capacity and freedom in carrying out their professional activities (Wermke \& Forsberg, 2017). In addition, they require creating a collaborative learning environment such as empowering teachers to share knowledge. HoDA and HoDE mentioned that teachers have freedom because they participate in different departmental meetings to make suggestions regarding innovations in terms of implementation plans for learning. They do have freedom although they communicate it with the principal. Stating thus,

"Our principal allows us to decide in our departments concerning different materials that we need but at the end of the day we have to report to him" (HoDE). Adding to this, HoDB, reported, "As a head of department, I want to believe that my responsibility is limited especially in my department because the principal is the one who makes conclusions". HoDD, explained further by stating that, "I do not think I have that much autonomy because most of the things are done by the principal" and HoD4 elaborated, "For example, if we want to hold a debate with other schools if the principal does not give us a time to do that, we end up not doing it because is the one who has the final word".

Leaders must trust teachers' capacity to carry out responsibilities and tasks and, in so doing, reinforce teacher autonomy, because autonomous teachers work with their learners openly in an attempt to stimulate learning whilst fostering accountability. Autonomous teachers continually search, in collaboration with their learners, for better reactions to diverse difficulties unavoidably arising in re-interpreting and developing their learners (Wang \& Wang, 2016).

\section{Recommendations}

Training programs for teachers as leaders may be considered the first step in addressing the leadership imperative. The Ministry of Education and Training (MoET, 2009) in Lesotho and denominational educational secretaries may provide professional development training programs and short courses focusing on principals' and teachers' leadership development such as seminars and online refresher courses (Moodley, 2014). Schools (in collaboration with the MoET, 2009) could train teachers and leaders on developing tailor-made approaches to sustain teacher leadership in schools. This is a crucial interchange as some leaders are not trained in leadership, so it is difficult for leaders to assist teachers in leadership skills, even to empower themselves and others (MoET, 2009).

Fostering positive school change and improvement through continuous professional development, demonstrate improved instructional practices for example, the use of ICT, and creates cooperative working practices such as relationship-building and networking with teachers (Loh \& Ang, 2020; Sun \& Leithwood, 2012).

Additionally, such programmes should focus on the value of PLCs, as the quality of education relies heavy on principals and teachers continuously renewing their professional knowledge and skills, in order to sustain leadership and maintain improved learner performance throughout the school. DEMs must aid SMTs and teachers in areas of management and administration, such as arranging in-service courses, providing national publications and materials, as well as providing administrative assistance from the MoET (2009), both nationally and at district level (Gale, 2014).

\section{Conclusion}

The data emanating from the in-depth interviews were subjected to thematic analysis and a main theme was presented. The findings were verified from the quotations from the interviews, as well as from the relevant literature. It is imperative that DEMs and HoDs foster collaborative, team-based, teacher leadership practices in schools in the quest for ensuring leadership succession. The findings confirm that 
teacher leadership is significant for teacher leaders to facilitate learning and teaching and building effective PLCs to enhance the schools' functioning. As a result, it provides an opportunity for a school leader to create a wider path and inclusive opportunities for sustaining teacher leadership.

\section{References}

Admiraal, W., Schenke, W., De Jong, L., Emmelot, Y., \& Sligte, H. (2019). Schools as professional learning communities: what can schools do to support professional development of their teachers? Professional Development in Education, 2019. Retrieved March 22, 2021, from: https://www.tandfonline.com/doi/pdf/10.1080/19415257.2019.1665573?needAccess=true

Al-Zawahreh, A., Khasawneh, S., \& Al-Jaradat, M. (2019). Green management practices in higher education: The status of sustainable leadership. Tertiary Education and Management, 25(1), 53-63.

Creswell, J.W. (2011). Educational research: Planning, conducting, and evaluating quantitative. Upper Saddle River, NJ: Prentice Hall.

Darling-Hammond, L., Hyler, M.E., \& Gardner, M. (2017). Effective Teacher Professional Development. Palo Alto, CA: Learning Policy Institute.

Denzin, N.K., \& Lincoln, Y.S. (2011). The SAGE handbook of qualitative research. Thousand Oaks, CA: Sage.

Edwards, B. \& Gammell, J. 2016. Building strong school leadership teams to sustain reform. Leadership, 45(3), 20-23.

Faupel, S. \& Sü $\beta$, S. (2019). The Effect of Transformational Leadership on Employees During Organizational Change - An Empirical Analysis. Journal of Change Management, 19(3), 145-166.

Loh, R.C.Y., \& Ang, C.S. (2020). Unravelling cooperative learning in higher education: A review of research. Research in Social Sciences and Technology, 5(2), 22-39.

Makoelle, T.M., \& Makhalemele, T. (2020). Teacher leadership in South African Schools. International Journal of Management in Education, 14(3), 293-310.

Maree, K. (2011). First steps in research. Pretoria: Van Schaik Publishers.

Miles, M., \& Huberman, A.M. (2017). Qualitative data analysis. Thousand Oaks: Sage Publications.

Ministry of Education \& Training (MoET). 2009. Circular Notice No 4 of 2009. Lesotho.

Moodley, S. 2014. Exploring the role of leadership and management in school-based Teacher-professional development (Doctoral Dissertation). Edgewood: UKZN.

Mouton, J. (2011). How to succeed in your master's and doctoral studies. Pretoria: Van Schaik.

Olujuwon, T. (2013). The challenges of teacher leaders in Nigerian public secondary schools. Paper presented at the 58th Assembly of the International Council on Education and Teaching, Bangkok, Thailand.

Perumal, J.C. (2015). Critical pedagogies of place: Educators' personal and professional experiences of social (in) justice. Teaching and Teacher Education, 45, 25-32.

Peterlin, J., Pearse, N.J., \& Dimovski, V. (2015). Strategic decision making for organizational sustainability: The implications of servant leadership and sustainable leadership approaches. Economic \& Business Review, 17(3), 273-290.

Ravitch, S.M., \& Riggan, M. (2017). Reason \& rigor: How conceptual frameworks guide research (2nd ed.). Thousand Oaks, CA: SAGE Publications, Inc.

Saldana, J. (2016). The coding manual for qualitative researchers ( $3^{\text {rd }}$ ed.). London, UK: Sage.

Sfakianaki, E., Matsiori, A., Giannias., D.A., \& Sevdali, I. (2018). Educational leadership and total quality management. Investigating teacher leadership styles. International Journal of Management in Education, 12(4), 375-392.

Sun, J., \& Leithwood, K. 2012. Transformational school leadership effects on student achievement. Leadership and Policy in Schools, 11(4), 418-451.

Sutton, J., \& Austin, Z. (2015). Qualitative Research: Data Collection, Analysis, and Management. The Canadian Journal of Hospital Pharmacy, 68(3), 226-231.

Wang, Y., \& Wang, M. (2016). Developing learner autonomy: Chinese university EFL teachers' perceptions and practices. In R. Barnard, \& J. Li (Eds.), Language learner autonomy: Teachers' beliefs and practices in Asian contexts (pp. 23-42). Phnom Penh: IDP Education.

Wermke, W., \& Forsberg, E. (2017). The changing nature of autonomy: Transformations of the late Swedish teaching profession. Scandinavian Journal of Educational Research, 61, 155-168.

Wermke, W., Olason Rick, S., \& Salokangas, M. (2019). Decision making and control: Perceived autonomy of teachers in Germany and Sweden. Journal of Curriculum Studies, 51, 306-325. 


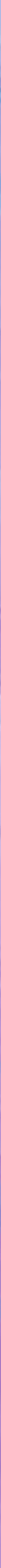





\title{
THE LEARNINGS OF THE BASIC EDUCATION TEACHER
}

\author{
Joana Paulin Romanowski \\ Programa de Pós-Graduação, Centro Universitário Uninter (Brazil)
}

\begin{abstract}
The research has as object of study the learning of basic education teachers in order to identify the learning of basic education teachers in their professional performance that contribute to their teacher education. The survey was conducted through a questionnaire using the Lickert scale answered on the google forms platform. 370 teachers from all regions of Brazil participated in the research. The study references are based Zeichner (2008), Martins (2009, 2016). In the analysis of the answers, the highest index of the scale was considered for the indication of the percentages. None of the answers obtained a $100 \%$ indication of the highest index on the scale. The responses with the highest number of responses were grouped into the following categories: teachers learn in (i) collective teaching practice and management in the school space; (ii) in their own teaching practice; (iii) with the reflection of its practice; (iv) in courses, lectures and (v) by conducting individual studies. The responses with the lowest index refer to learning: in informal spaces, on the internet and with the parents of their students. The most valued responses refer to learning: sharing problems; of ideas and opinions about education; planning classes in collaboration with school teachers; teaching together with another teacher in the same class; insertion of new teaching methods and innovations; they participate in school coordination councils where new possibilities are discussed and in many situations they read, consult; they prepare and develop workshops at the school to support teachers at the school and other schools. Teachers emphasize as a strong possibility of reflection and investigation their practice in the act of teaching and learning by reviewing the experiences: contradictions between the ideas about teaching and how they are put into teaching practice; when the teacher describes his practice to other people. By examining his experiences in practice, observing the strengths and weaknesses, and in reflections on his own beliefs and conceptions about teaching, the teacher has the opportunity to change his practice. The conclusions indicate that the teacher's practice contributes to his education.
\end{abstract}

Keywords: Teaching practice, teaching, basic education, teacher education.

\section{Introduction}

This article presents a research carried out by the Education, Technology and Society Research Group, of the Education and New Technologies Graduate Program at UNINTER and has as its object the study of the educational practice carried out in the school in the perspective of the informal formation of the teacher. The investigation assumes to understand the relations of the teaching action with the sociocultural interferences in the daily life of this practice and the implications with the teacher formation. The analysis process takes practice to, from there, understand the relationships that guide it. The resulting theory is an expression of this practice (Martins, 2009, 2016). $m$ the object of study is the formation of the teacher in informal interactions.

The study of the processes of training, learning and development of the teaching professional has been a constant in educational research. The concepts of "teacher learning", "professional teacher development", "teacher training" or even "teacher change" have generated lines of research whose results are shown in different manuals published by the AERA (American Educational Research Association) and by prestigious publishers.

\section{Objectives}

The research aims to answer the question: How do teachers learn in a society that connects? More specifically, we aim to: learn how the learning processes are carried out by 21 st century teachers, in a connected society that offers alternative non-formal and informal ways to improve teachers' professional knowledge. To answer these objectives, the methodology collected qualitative data obtained through a questionnaire answered by teachers. 


\section{Methods}

For data collection, the questionnaire was made available on Google Forms and teachers from kindergarten, elementary and high school from cities in different regions of Brazil were invited. The questionnaire contains questions related to the identification of participants and questions about teaching learning. All questionnaire data were grouped and categorized. The distribution of participants by city, from the largest to the smallest, expresses the involvement of participants from capitals, medium-sized cities and cities in the interior. Curitiba is the city with the largest number of participants: 374 participants from the regions answered the questionnaire: Midwest 24; northeast 46; north 9; southeast 66; south 225. Regarding the degree of course of the participants, the data express that 4 teachers are graduated in medium level without graduation and the remaining 370 with graduation in licentiate courses. As for the type of institutions in which teachers are linked, there is a smaller number in private non-profit institutions.

\section{Discussion: Teachers' learning of teaching}

In carrying out this research, the concepts of "teacher learning", "professional teacher development", "teacher training" and "changing teaching practice" are considered. Among the authors who discuss the issue are considered: Gatti et all (2009), Martins (2016), Romanowski, Prates and Martins (2020); Romanowski, Saheb and Martins (2020); Romanowski, Cartaxo and Martins (2018), in addition to Gitomer and Bell, (2016); Loughran and Hamilton, (2016).

In the systematization and organization of responses, groupings were established considering the content of the questions answered, as follows: (i) learning in collective teaching practice and management in the school space; (ii) learning in their own teaching practice; (iii) learning from reflective practice; (iv) learning in other informal and collective spaces; (v) learning on the internet; (vi) teaching learning with interactions with parents; (vii) learning in courses, lectures; and (viii) learning by conducting individual studies.

Learning in collective teaching practices: The teachers participating in this research express that they learn intensively in the school space through the interactions of discussions about the practice in a collective way such as: sharing with fellow teachers the problems that arise in the school routine; when together with other teachers they try new teaching methods; at coordination council meetings at school; in the development of innovation projects in the school and when they prepare and develop workshops to exchange experiences. Hargreaves (2004) postulate that the school presents itself as a space for collective learning in a process of interaction of teachers' experiences.

Learning in your own teaching practice and reflection of its practice: In this grouping are numerous manifestations of learning by teachers in their own practice, as stated by Martins (2016, p. 36): teachers create alternatives to carry out their work practice. In this research, they were indicated as learning situations in their own practice, as the teachers point out, "I learn when" I adapt my way of teaching to the specificities of the content; I have my own experiences, with new teaching strategies; I analyze and try to understand why the wrong answers my students give to my questions; I reflect on my own beliefs and conceptions about teaching; I analyze the reactions of students in the class; and others.

Internet learning: Research and consultations on the internet assume an increasingly incisive incorporation and gained greater visibility during the pandemic caused by COVID 19, as pointed out by research by Romanowski et all (2020). Thus, teachers indicate learning in searches on the internet and social networks for content and resources for classes, with readings on education in journals, videos of teachers, consultation of websites, blogs, etc. teachers, with participation in courses and specializations in distance learning. During the pandemic due to the health crisis caused by Covid 19, internet learning intensified. In Brazil, this process of classes held remotely by applications with Zoom, Meet, Teams, in which teachers and students were present during the class, but distanced in space, was called remote classes.

Learning by conducting individual studies and courses: Conducting individual studies favors learning when reading educational journal articles, about the content of the taught material, in manuals in manuals and books on Education. Teachers indicate that they carry out individual research, favoring their professional development. The indication that they carry out studies is intense in their responses and there is evidence of the search for updating the knowledge on which teachers teach classes, such as reading: scientific articles, specialized books, psychopedagogy, on the stages of cognitive development and forms of human being learning, philosophy, where they seek to broaden their vision and understanding in several areas. 


\section{Conclusions}

It is noteworthy that the data collected favored the analyzes that, in comparison with the studied authors, can be highlighted:

(i) the collective process of developing intergroup research. This practice points out practice points out possibilities of favoring the exchange between researchers and areas of knowledge in the perspective of interdisciplinarity in order to expand scientific collaboration, deepening the discussion and analysis of the issues and problems investigated. This practice of conducting research in partnership favors a new academic culture, overcoming individualism and moving towards more collaborative practices as indicated in Martins (2016);

(ii) The contributions of informal training express an intensification of the valuation of teaching practice itself as a contribution to the process of teacher training. The realization of the action itself, without due reflection, confines itself to the act of carrying out the action, therefore, a contribution of teaching performance, in which training dispenses with reflection, as highlighted by Zeichner (2008). That is, it is by reflecting on the action that it is possible to understand this action.

(iii) The evidence expressed in the training provided by collective interactions, mainly in the school space, from meetings to conversations, as observed in Gohn (2008) and Trilla (2008). Teachers are increasingly making the transition from isolation, from individualization to the strengthening of teacher collectives by constituting communities, even though teachers continue to investigate and study to improve their professionalization.

(iv) Individual studies carried out based on the search for readings of the materials with which they work in the daily teaching and learning process. In the teachers' records, this effort that encourages the improvement of their training through these self-training initiatives is valued.

(v) Regarding the internet as a source of consultation for teachers. This informal consultation that contributes to the training process, both in consultations in repositories of articles and texts, as well as in social networks.

These notes favor understanding that the process of teacher training in the current context is expanded by the possibilities of formal training with an intensified offer in courses, lectures and events and that it enriches itself with the situations made possible by informal training.

Nowadays, with the increase of access to new sources of knowledge provided by digital media, by the valorization of collective training and informal and non-formal training, new perspectives of teacher professionalization are being guided.

We emphasize that this expansion by bringing contributions to teacher education, paradoxically, raises the demands for better professionalization of teachers, which is presented for research as issues to be investigated. The demands for improving teaching practice have been expanded, but working conditions remain precarious.

\section{References}

Gatti, B. A.; Barreto, E. S.; Andre, M. E. D. A. (2011). Políticas docentes no Brasil: um estado da arte. Brasília, DF: UNESCO.

Gitomer, D.; Bell, C. (Eds.) (2016). Handbook of Research on Teaching. New York: AERA.

Gohn, M. da G. (2011). Educação não-formal e cultura política. 5. ed. São Paulo: Cortez.

Hargreaves, A. (2004). O ensino na sociedade do conhecimento: a educação na era da insegurança. Porto Alegre: Artmed.

Loughran, J., Hamilton, M. L. (2016). International Handbook of Teacher Education. Singapore: Springer.

Martins, P.L. O. Pesquisa-ensino na formação inicial de professores e a interlocução com a educação Básica: princípios e metodologia. In: Romanowski, J. P.; Martins, P. L. O., Cartaxo, S. R. M. (Org.). Práticas de formação de professores: da Educação Básica à Educação Superior. (2016) Curitiba: Champagnat, v. 1, p. 01-20.

Martins, P.L. O. (2009). A didática e as contradições da prática. 3. ed. Campinas -SP: Papirus.

Romanowski, J. P.; Saheb, D.; Martins, P. L. O. (2020). Demandas para a formação dos professoresda educação básica no Brasil. Educatio- Revue scientifique. Education Chrétienne, v. 10.

Romanowski, J. P.; Prates, S. C.; Saheb, D.; Martins, P. L. O. Cartaxo, S. (2016). Práticas de formação de professores da Educação básica à Educação Superior. Curitiba: PUCPRess, p. 71-84

Romanowski, J. P.; Prates, S. C.; Martins, P. L. O. (2020). Aprendizagem da Docência para a educação básica em comunidades de prática. Revista Faeeba, v. 29, p. 61-77, 2020.

Trilla, J. A educação não-formal. In: Arante, V. A. (2008). Educação formal e não formal: pontos e contrapontos. São Paulo: Summus, 2008, 167p., p. 15-58.

Zeichner, K. M. (2008). Uma análise crítica sobre a "reflexão" como conceito estruturante na formação docente. Educ. Soc. [online]. 2008, vol.29, n.103, pp.535-554. 


\title{
WHAT DOES A STUDENT OF A TEACHING DEGREE LEARN APART FROM SUBJECTS?
}

\author{
Carolina Falcón Linares \\ Department of Education Sciences, University of Saragossa (Spain)
}

\begin{abstract}
Awareness of emotional experiences, vicarious learning and values, in relation to teaching profession, had emerged as a core of interest in previous research. This case study aims to activate awareness of future teachers in several ways. It is about developing critical reasoning about learning from a complexity perspective: (a) training the ability to contextualize learning with their personal beliefs and values, (b) improving strategies to transfer it, and (c) accompanying construction of professional judgment.

The intervention is carried out during two academic years with students of Teaching Degrees in Saragossa (Spain). Learning goals and evaluation are maintained, but teacher-student and peer communication styles are modified. The key to the new methodology is to strengthen the personal and professional narrative in coherence with the subjects. It is a priority that students feel synergies between what they learn, their vicarious knowledge, their emotional memory and the vocation for teaching.

After each semester, discussion groups have been held, obtaining 14 hours of video recording, with the oral narrative data of 215 students divided into groups of 5 . Three emerging categories have been obtained (professional vision, professional development and appreciation of teaching action), and nine subcategories have been defined on a second phase of the analysis.

During university education, there are memorable teachers who motivate action and career leadership, others who go unnoticed, and some who perform a negative influence. The reason is, first, in the unconscious inference of their pedagogical models; and second, in the feelings that have emerged during the time shared with them.
\end{abstract}

Keywords: Preservice teacher education, case study, affective pedagogy, vicarious learning, teacher beliefs.

\section{Introduction}

A great challenge for those who want to be teachers is the familiarity of the work they anticipate to do. Teaching can seem like a natural process, and many people choose teaching because they feel they have an affinity for it or because they consider it a simple profession. The familiar is perceived as attractive and affordable on many occasions. Lortie (1975) explained this pattern as the power of observational learning: the experience that pre-service teachers have had in their lifetime as students. This "learning" confers on them a very solid baggage of vicarious knowledge of which, on the other hand, they are not aware (Shaughnessy and Boerst, 2018). The study by Lortie (1975) underlines the importance of becoming aware of the knowledge and assumptions that students bring to the training process, focusing mainly on practical intuition and beliefs. From the professional experience of the author of this work, it is also necessary to direct conscious reflection towards the values and affective processes that have been linked to vicarious knowledge throughout the academic life (Falcón and Arraiz, 2020).

In a study carried out in the context of training in health sciences, students participate in activities to recognize professional styles based on what they observe in their university professors and in practices tutors. The qualitative description highlights the selective and conscious attention towards the observed roles, better memory strategies and motivation to imitate the observed exemplary models. The powerful impact of awareness of direct and vicarious learnings on professional vision is evident in this research (Horsburgh and Ippolito, 2018).

Regarding teacher training, progress is being made in educational innovation that includes reflective processes on the competencies to be acquired during university training and on the strategies that teachers can implement in this regard (Alsina, Batllori, Falgàs and Vidal, 2019; Domingo and Gómez, 2014; Schrand, Jones and Hanson, 2018; Steenekamp, Van der Merwe and Mehmedova, 2018). 
But there is no solid theoretical framework regarding the communication process that can best activate these processes within university classrooms, despite the fact that the activation of learning from the educational relationship is considered the key factor in performance, above any other didactic strategy (Hattie, 2008). Research is also lacking on the heuristics that students build during their learning regarding teaching models and on how motivation to imitate the best is generated.

The heuristic concept is complex because it involves cognitive, social and emotional construction. But, above all, because it involves learning from experience and the personal elaboration of meanings that include the unconscious imagination. People imagine when they remember and, as well, people use their memory when they imagine. This statement is one of the main conclusions of the study by Conway and Loveday (2015), in which autobiographical memory and the unconscious construction of heuristics emerge as the key factors in the vicarious learning of teaching models.

Research is lacking regarding the processes of awareness about vicarious learning, its integration with training and its transforming power with a professional sense. This case study develops and evaluates a teaching innovation that aims to raise the level of awareness of students during their training process. It is about developing critical reasoning about learning from an upper perspective, applying the three strategies of the analytical-critical method of Schwartz and Sharpe (2010): (a) the ability to contextualize an educational situation and understand it from their beliefs and values, (b) the necessary skills and strategies to make adaptations, and (c) the management of appropriate experiences to make decisions. The objectives are: $1^{\circ}$ ) Foster conscious learning and critical reflection on vicarious experiences with teaching models, in the context of the subject. $2^{\circ}$ ) Know how students live the learning process, how they express themselves about it and what is their assessment of having experienced the subject.

\section{Design and method}

A case study is designed through a teaching innovation program and its qualitative evaluation. The teaching innovation has been developed since 2017 to 2019 with 243 students. Subjects belong to the Degrees of Teacher in Early Childhood Education and in Primary Education, in the first and second year.

Maintaining the usual contents and activities, a communicative model has been adopted focused on the development of narratives by the students. From day one, students have been encouraged to produce individual and group written and oral stories. Strategies for deconstruction of their narratives and critical reconstruction have been worked out from the awareness of new plausible factors of inclusion in their arguments. Imagination games, chained questions and debates have been carried out to activate the recognition of the professional heuristics that they build during the course. The purpose has been to generate conscious learning regarding the contents of the subjects within the framework of their life stories. For example, after performing an activity (case resolution, PBL, visual map, etc.), students analyze it regarding the following variables: direction, sense, value, transfer and integration.

For data collect, students have participated in discussion groups. The topic is the description, interpretation and feeling of the learning process, acquired competences and personal transformation. The activity has been recorded on video outside the classroom, without observation of the teacher or the rest of the group. Videos have been sent to the teacher, as part of the assessment portfolio, which increases their interest and security regarding the privacy of what they relate. Not all students have authorized the use of their videos for research, so about 14 hours of narrative data have been analyzed, corresponding to 215 students.

\section{Results}

Narrative data are analyzed following the Grounded Theory of Bartlett and Payne (1997). After the extraction of significant fragments, they are grouped into conceptual nodes and assigned to different categories. At the end of the analysis, built with NVivo 10, three macro-categories emerge (C1, C2 and C3) which, in turn, include nine subcategories at the second hierarchical level.

Students reflect on their vision of the teaching profession $(\mathrm{C} 1)$ specifying what is the model of a good teacher for them. They explain how they understand different models from their personal history and their feelings. They dialogue and debate about the meaning of the training they are acquiring and how they want to practice in their professional future. This category is divided into: $(\mathrm{C} 1,1)$ Hermeneutical vision of the teaching profession, $(\mathrm{C} 1,2)$ Humanistic vision of the teaching profession and $(\mathrm{C} 1,3)$ Personal identification with a professional model.

The second macro-category is defined as the development of the teaching profession (C2) and shows how they begin to develop their professional identity. They express how some processes help them to be aware of the received influences and to build a career plan. The best rated are the creative openness 
of some activities, practical experiences and simulations, personal tutorials and discussions. This category is divided into: $(\mathrm{C} 2,1)$ Identification of a teacher functions, $(\mathrm{C} 2,2)$ Awareness about professional identity and $(\mathrm{C} 2,3)$ Integration of knowledge from critical reflection.

Third, the assessment of teaching action (C3) is defined, which includes very diverse contributions on the reflective method based on awareness. The work of linking theory, practice and previous experiences is recognized. And it is appreciated that dynamic and participatory communication processes have motivated learning and deepening outside the classroom. The three subcategories are: $(\mathrm{C} 3,1)$ Positive: experiential and memorable formative experience, $(\mathrm{C} 3,2)$ Negative: resistance to change and uncertainty about the assessment and $(\mathrm{C} 3,3)$ Satisfaction and motivation focused on new challenges.

\section{Conclusions}

Implicit learning about the profession, with which students enter the Faculties of Education, conditions any future reflective intervention and their own professional identity. It is the baseline on which to start projecting the necessary skills to be good teachers, overcoming the fallacy of believing that they begin teachers training when they come to the Degree. Guided reflection on teaching models has made it possible to integrate past, present and future in the learning process of the subjects (Shaughnessy and Boerst, 2018). That is, students have acquired a professional vision of their vicarious learning, becoming aware of how past and present experiences are integrated with new knowledge and serve to design the future career project.

Teaching role has been the main object of reflection and change regarding communication, attitude in class and in tutoring. Sensitive and vocational learning has been enhanced, adopting horizontal democratic relationships with students. The most valued of the communicative model implemented is the way to stimulate authentic and personalized participation, activating student learning, instead of just facilitating it (Hattie, 2008). But it is unknown what long-term effects the intervention aimed at causing the conscious emergence of vicarious knowledge, beliefs, emotional experiences and values may have. The next phase consists of expanding the design to a study with a larger sample, which also includes longitudinal and quantitative data.

\section{References}

Alsina, Á., Batllori, R., Falgàs, M. y Vidal, I. (2019). Marcas de autorregulación para la construcción del perfil docente durante la formación inicial de maestros. Revista Complutense de Educación, 30(1), 55-74.

Bartlett, D. \& Payne, S. (1997). Grounded theory. Its basis rationale and procedures. In: McKenzie, G., Powell, J. \& Usher, R. (eds). Understanding Social Research: Perspectives on Methodology and Practice (173-195), London: Falmer Press.

Conway, M.A. \& Loveday, C. (2015). Remembering, imagining, false memories and personal meanings. Consciousness and Cognition, 33, 574-581.

Domingo, A. y Gómez, M.V. (2014). La práctica reflexiva. Bases, modelos e instrumentos. Madrid: Narcea.

Falcón-Linares, C. y Arraiz, A. (2020). Construcción de la identidad profesional docente durante la formación inicial como maestros. Revista Complutense de Educación, 31 (3), 329-340.

Hattie, J. (2008). Visible Learning: a synthesis of over 800 meta-analyses in education. London: Routledge.

Horsburgh, J. \& Ippolito, K. (2018). A skill to be worked at: using social learning theory to explore the process of learning from role models in clinical settings. BMC Med Educ, 18, 156.

Lortie, D. (1975). Schoolteacher: A sociological study. Chicago, IL: University of Chicago Press.

Schrand, T., Jones, K. \& Hanson, V. (2018). "Reflecting on Reflections": Curating ePortfolios for Integrative Learning and Identity Development in a General Education Senior Capstone. International Journal of ePortfolio, 8(1), 1-12.

Schwartz, B. \& Sharpe, K. (2010). Practical wisdom: The right way to do the right thing. New York, NY: Riverhead Books.

Shaughnessy, M. \& Boerst, T.A. (2018) Uncovering the Skills That Preservice Teachers Bring to Teacher Education: The Practice of Eliciting a Student's Thinking. Journal of teacher education, 69(1), 40-55.

Steenekamp, K., Van der Merwe, M. y Mehmedova, A.S. (2018). Enabling the development of student teacher professional identity through vicarious learning during an educational excursion. South African Journal of Education, 38(1). 


\title{
INTERDISCIPLINARY AND INTERSECTORAL DOCTORAL EDUCATION DESIGNED TO IMPROVE GRADUATE EMPLOYABILITY
}

\author{
Tara Cusack ${ }^{1}$, Nicola Mountford ${ }^{2}$, Minna Isomursu ${ }^{3}$, Guido Giunti Garcia ${ }^{3}$, \\ Dimitris Filos ${ }^{4}$, \& Ioanna Chouvarda ${ }^{4}$ \\ ${ }^{I}$ School of Public Health, Physiotherapy and Sports Science, University College Dublin, (Ireland) \\ ${ }^{2}$ School of Business, Maynooth University (Ireland) \\ ${ }^{3}$ University of Oulu (Finland) \\ ${ }^{4}$ Laboratory of Computing, Medical Informatics and Biomedical Imaging Technologies, \\ School of Medicine, Aristotle University of Thessaloniki, (Greece)
}

\begin{abstract}
Typically, less than half of doctoral graduates will be employed in academia immediately after graduation, with less than 10\%-15\% achieving a long-term academic career. This leaves $85-90 \%$ of $\mathrm{PhD}$ graduates seeking employment outside the academic setting, for example in industry and government. The objective of the CHAMELEONS study (CHampioning A Multi-sectoral Education and Learning Experience to Open New pathways for doctoral Students) is to develop innovative educational interventions that shape more adaptable, entrepreneurial, and employable graduates, ready to meet the challenges of the future. Stakeholders from the connected health industry, clinical care, charities, patients, patient representatives, government, recent doctoral graduates, and academics were invited to participate in a "World Cafe" participatory method for collecting qualitative data. Owing to the COVID-19 health situation this took place via Zoom. Analysis of the results revealed 4 key learning objectives for doctoral graduates to: 1. Develop networking and communication skills. 2. Understand user centred research design. 3. Market research capacity and research skills. 4. Build an understanding of themselves and others. This led to the development of three bespoke doctoral modules: 1. Forging relationships: Building and Sustaining your Doctoral Network; 2. Managing the Project: Keeping on Track with an Eye to the future; Module 3: Starting your Career: Future Proofing your Career and Getting a Job. These modules are available to doctoral students across five European Universities.
\end{abstract}

Keywords: Intersectoral, interdisciplinary, doctoral, education, participatory.

\section{Introduction}

Ten years from now, jobs will be more knowledge and skills-intensive than ever before. Demographic, socio-economic, and technological change together are having "a near-simultaneous impact on employment and need for new skill sets, requiring an urgent and concerted effort for adjustment" (World Economic Forum, 2016). Currently less than $20 \%$ of all doctoral graduates stay in academia with the remaining $80 \%$ seeking employment outside the academic setting, for example in industry and government (Euraxid, 2021). It would appear, therefore, that these graduates possess many of the required skills for purposeful employment outside academia. A gap has been identified, however, in that current doctoral curricula do not foster big thinkers and creative problem-solvers, graduate attributes that society needs (Bosch, 2018). There is a growing need to re-imagine a $\mathrm{PhD}$ education that incentivises doctoral students to engage with research consumers, not only within their discipline, but also, across other disciplines and sectors to have real social impact for an improved society. At a professional and research level, international, interdisciplinary and inter-sectoral networks are on the increase. Such collaborative doctoral programs can assist the knowledge society in finding innovative ways of approaching the world's problems by asking creative questions and finding creative solutions within multiple employment contexts (Mountford, Coleman, Kessie \& Cusack, 2020). To date, there is a lack of research in the area of the interdisciplinary, inter-sectoral doctoral education and the question remains: how do we best design these programmes to ensure that the $\mathrm{PhD}$ students' develop into big thinkers?

This paper presents the results of a module design process within the CHAMELEONS project (CHAmpioning a Multi-sectoral Education and Learning Experience to Open New pathways for doctoral Students). CHAMELEONS (2021) is a European Union Horizon 2020 research and innovation project which aims to design, deliver and evaluate a range of interdisciplinary, intersectoral and international modules that will broaden $\mathrm{PhD}$ graduate skills, improve their employability in both academic and non-academic environments and which will equip them to solve societal challenges in the area of 
connected health. CHAMELEONS was based upon previous work which examined the perceptions of interdisciplinary and intersectoral doctoral students engaged in EU funded Marie Curie Fellowships (Mountford et al., 2020) and the other which examined how interdisciplinary education could be used in the area of connected health (Chouvarda, Mountford, Trajkovik, Lončar-Turukalo, \& Cusack, 2019). The project consortium consists of ten partners from five European countries. Five are academic institutions, Maynooth University (Ireland), University of Oulu (Finland), University of Porto (Portugal), Aristotle University of Thessaloniki (Greece) and University College Dublin (Ireland). The remaining partners include an Irish non-profit patient representative organisation: Irish Platform for Patient Organisation Science and Industry), a Portuguese charity, Santa Casa da Miscericórdia da Amadora; a Spanish SME, Salumedia Labs; and a Spanish healthcare educator, the Andalusian School of Public Health.

\section{Objectives}

The overall aim of CHAMELEONS was to develop a range of interdisciplinary, inter-sectoral and international modules which are designed to broaden the skills of $\mathrm{PhD}$ graduates and improve their employability in academic and non-academic environments. The modules would enable students to develop fundamental and advanced research skills, business skills and knowledge while enhancing and further developing their emotional intelligence.

\section{Methods}

Stakeholders in the design process included representatives from the following: academia, industry, charities, health, patient representative organizations, expert patients, an education technologist, an expert in ethics, recent $\mathrm{PhD}$ graduates, and current $\mathrm{PhD}$ students.

The curriculum design workshop employed a "World Café" participatory design (Lo, Weinhardt $\&$ Sieber 2020). Under usual circumstances the design workshop would have taken place in a large room with a number of large round tables. The round table layout is considered to resemble a café. At each table there would be a nominated scribe, and this individual remains at the table throughout the workshop. Following discussion of the topic allocated to that table for the specified length of time the group moves to the next table. However, the scribe remains behind and updates the next group on the work already completed. The reasoning underpinning the rotation of the group is to build on the ideas and thoughts of the group which has gone before. This process enables a comprehensive discussion and debate of the issues at hand. Owing to the global pandemic it was not possible for this workshop to take place in a face-to-face environment, therefore breakout rooms in Zoom were used instead to mimic tables. In terms of the development/design workshop the groups within each table/breakout room were asked to focus on questions related to one of the following topics: Communication; Research Methods; Business Skills; Emotional Intelligence, Professional Development; Self-Care. These topics were chosen as they had emerged from a systematic literature review (Leniston \& Mountford, 2021) and surveys of current and recent doctoral graduates and doctoral programme coordinators (Kosvyra, Filos, Mountford, Cusack, Isomursu \& Chouvarda, 2021) all undertaken as part of CHAMELEONS. The workshop participants were asked to identify learning needs and strategies which might be used to achieve this learning. Data was recorded by each of the scribes and collated by the workshop lead. The data was categorised, examined and discussed at a series of smaller post workshop meetings. The purpose of this was to distill the essence of the workshop and to develop learning strategies mapped to the results of the workshop.

\section{Results}

Analysis of the workshop results revealed four desirable module learning outcomes. On successful completion of the module the students would be able to: 1. Develop networking and communication skills; 2. Understand ethical user centred research design; 3. Market their research capacity and research skills; 4 . Build an understanding of themselves and others. In order to address these learning outcomes the module was designed for delivery over five days with an intervening weekend. The module was entitled "Forging relationships: Building and Sustaining your Doctoral Network". Each day was dedicated to a particular topic and was led by one of the primary investigators in this project. Day 1 addressed communication; Day 2 Building Skills and Profile; Day 3 Understanding themselves and mapping their careers; Day 4 User centred design and Day 5 was a distillation of learning. Each day included interactive sessions which enabled students to network with potential employers, developing sessions relating to research skills, and personal development and reflection. The module will result in the award of five (5) European Credit Transfer System credits (ECTS). Assessment was designed to "fall from" the learning process whereby students presented their reflective learning together with developing a group presentation for delivery on the final day. The second and third modules, Managing the Project: Keeping on Track with an Eye to the future and Starting your Career: Future Proofing your Career and Getting a Job are currently being developed. They will be developed against the backdrop of previous work and the module one evaluation. 


\section{Discussion/conclusions}

This paper presents a framework by which stakeholders may come together to co-design a doctoral educational intervention. Co-created curricula are becoming increasingly important in a bid to keep pace with emerging new areas of employment for graduates across contemporary society. Engaging stakeholders is key to ensuring that doctoral education fosters the development of graduates who are "fit for purpose" in this fast-changing world. The skills attained during doctoral education, for example problem solving, project management, information literacy, innovation, entrepreneurship etc. are essential in a modern world seeking to be at the cutting edge of solving societal problems. Enabling graduates to create sustainable networks beyond their doctoral education is important for professional development.

Owing to Covid 19 travel restrictions the first module was rolled out via Zoom in April 2021. Discussion with the students on the final day of the module took place using Miro (an online collaborative tool https://miro.com). Following preliminary examination of student feed-back a number of key observations can be made. The students highly valued the opportunity to network and appreciated the speakers' and team's interdisciplinarity, despite the fact that it took place online. This may be heightened by the requirement to work remotely for over a year. The intervening weekend in the middle of the module proved to be important in order to give the students time to reflect upon their learning and begin to examine how their new skills could be integrated into their existing knowledge. The research skill development was highly valued. The module assessment (reflective submissions and end of module presentations) clearly demonstrated how the learning had enabled them to tap into and develop their emotional intelligence.

This project continues to develop, it is an iterative process underpinned by a systematic review conducted as part of the CHAMELEONS project, together with surveys of recent doctoral graduates and doctoral programme leads. The development continues to be informed by the students who participate in the module. CHAMELEONS continues to strive to meet its commitment to develop a range of interdisciplinary, inter-sectoral and international modules which are designed to broaden the skills of $\mathrm{PhD}$ graduates and improve their employability in academic and non-academic environments.

\section{Acknowledgments}

This project has received funding from the European Union's Horizon 2020 research and innovation programme under grant agreement No 873105.

\section{References}

Bosch G. (2018) Train PhD Students to be Thinkers not specialists. Nature 554, 277. Doi: 10.1038/d41586-018-01853-1

CHAMELEONS Consortium (2021) Retrieved April, 28, 2021 from https://www.chameleonsproject.eu/

Chouvarda I., Mountford N., Trajkovik V., Lončar-Turukalo T., Cusack T. (2019) Leveraging Inter-Disciplinary Education to secure the future of Connected Health Research in Europe. Journal of Medical Internet Research. 21 (11), e14020. doi:10.2196/14020

Kosvyra A., Filos D., Mountford N., Cusack T., Isomursu M., Chouvarda I. (2021) PhD courses and the intersectoral experience: a qualitative study. Paper for presentation at HEAd'21, Valencia, 2021 (In press http://headconf.org).

Leniston, N., and Mountford, N. (2021) Born or made - can interdisciplinary and intersectoral doctorate education create institutional entrepreneurs? A systematic review. Paper for presentation at HEAd'21, Valencia, 2021 (In press http://headconf.org).

Lo, K., Weinhardt, M., Siebe, S. (2020) The "World Cafe" as a Participatory Method for Collecting Qualitative Data. International Journal of Qualitative Methods. 19: 1-15. doi.org/10.1177\%2F160940692091697

Mountford, N., Coleman, M., Kessie, T., \& Cusack, T. (2020) Interdisciplinary doctoral research networks enhancers and inhibitors of social capital development, Studies in Higher Education, 45:12, 2558-2573. doi:10.1080/03075079.2019.1623768

Vitea Realising the Potential of Researchers. Euraxind. Retrieved April, 30, 2021 from https://www.vitae.ac.uk/researcher-careers/euraxess-uk-career-developmentcentre/euraxind/euraxind-project-background

World Economic Forum. (2016). The Future of Jobs, Global Challenge Insight Report, Retrieved April, 30, 2021 from http://www3.weforum.org/docs/WEF_Future_of_Jobs.pdf 


\title{
IMPORTANCE OF DIGITAL COMPETENCES AND ATTITUDES TOWARD RESEARCH IN MEXICAN TEACHERS
}

\author{
Pedro José Canto Herrera, Hugo Salvador Flores Castro, \\ \& Sergio Humberto Quiñonez Pech \\ Faculty of Education, Autonomous University of Yucatan (México)
}

\begin{abstract}
The aim in our study was to determine the importance of digital competences and attitudes regarding research to teachers, according to various variables such as gender, age, and level of studies. A questionnaire was used to gather information from 28 teachers at the Escuela Normal de Educacion Primaria "Rodolfo Menéndez de la Peña", in México. The questionnaire was developed based on Aldana y Joya (2011), and the GIDU-EDUTIC/IN research group from the Universidad de Alicante. The questionnaire comprises 48 questions on the importance of digital skills and 50 questions on attitudes towards research. All questions use a Likert scale with 5 answer options. Cronbach's Alpha was used to determine the reliability of the instrument. It was found that the questions related to the importance of digital competence an alpha equal to 0.912 and for the questions of attitudes towards research an alpha equal to 0.854 . It was found that teachers considered important the five digital competences dimensions. It also was found that they considered that creativity and innovation as the most important dimension and the use and access of information as the less important. The participant teachers' attitudes towards research were more neutral. It was found that the cognitive dimension was the one with the highest score, while the behavioral dimension the one with the lowest score. It is concluded that training needs are detected to improve their digital skills and their attitude towards research, the need for further research on the effect is perceived that could have for the development of research groups in this institution.
\end{abstract}

Keywords: Digital competences, attitudes, attitudes toward research, teachers, Mexican teachers.

\section{Introduction}

In the literature it is possible to see many studies on the importance of teachers' digital competences and teachers' attitude towards research. Over the last few decades, the concept digital competence has been used more frequently and are increasingly discussed (Spante, Soflova, Lundin and Algers, 2018). In addition, the scientific production about digital competence is a relevant topic at international level due to the growing interest of researchers in this area of study (Rodríguez and Martínez, 2018).

According to Spante and others (2020), digital competence is defined as the confident and critical use of Information Society Technology (IST) for work, leisure, and communication; It includes the use of computers to retrieve, assess, store, produce, present and exchange information, and to communicate and participate in collaborative networks via the Internet. Today's teachers are expected to integrate digital technologies to improve the quality of their learning-teaching activities (Guillén, Mayorga, Bravo and Escribano, 2020).

Research attitudes play an important role in the whole process of research (Khan, Hussain and Khan, 2018). Aldana and Joya (2011) define attitudes as an enduring and persistent organization of beliefs that predispose one to react preferentially in a certain way. In the last ten years there have been many studies related to the attitude towards research. One of them was developed by Khan, Hussain and Khan (2018), who reported a positive disposition towards scholarly activities, viewed themselves as researchers, felt professional satisfaction in research activities, and showed a positive attitude towards research activities.

In Mexico basic education teachers are formed by Escuelas Normales, universities also offer educational programs that are studied with the main expectation of occupying, upon graduation, a teaching position.

The following research questions are addressed in this study: 1) What is the opinion of teachers regarding their digital competences? \& 2) What is the teachers' attitude regarding research? 


\section{Method}

In this quantitative study, a cross-sectional survey model was used. The cross-sectional survey model is a research model which aims to know individuals' opinions on the subject being examined at a given time (Fraenkel, Wallen and Hyun, 2014).

\subsection{Population}

The population consisted of 33 teachers who worked at the Escuela Normal Rodolfo Menéndez de la Peña at the time the instruments were applied. Of the total number of teachers, 28 answered the digital competences questionnaire and 29 answered the questionnaire on attitudes towards research.

\subsection{Instruments}

Two questionnaires were developed to collect information from teachers: Digital competencies questionnaire, and Attitudes towards research questionnaire: the digital competencies questionnaire was developed based on the DigComp framework, and the GIDU-EDUTIC/IN research group from the Universidad de Alicante. The questionnaire is organized in 48 statements, using a five-choice Likert-type scale with answers ranging from "Not important at all" to "Very important". The instrument considers five factors with respect to the assessment of digital competencies: technological literacy (11 items); access to and use of information ( 8 items); communication and collaboration ( 8 items); digital citizenship ( 8 items); and creativity and innovation (13 items). The questionnaire of attitudes towards research was designed based on the questionnaire adapted from Aldana and Joya (2011), is organized into 50 statements and, like the previous questionnaire, uses a Likert-type scale, with responses ranging from "Strongly disagree" to "Strongly agree". The instrument considers three factors of the construct: affective (20 items), what the subject feels, the emotions that the research produces in him/her; cognitive (10 items), what the subject knows or thinks he/she knows about the research; and behavioral (20 items), what the subject does or is willing to do with respect to the research.

Cronbach's Alpha was used to determine the reliability of both instruments. It was found that the questions related to the importance of digital competence an alpha equal to 0.912 and for the questions of attitudes towards research an alpha equal to 0.854 .

\section{Results}

\subsection{Teachers' opinion on digital competences}

All the teachers said they had a computer, only one of them said they did not have internet; in the aspect of hours spent with the computer per week, one of them used it one hour or less $(3.6 \%), 14(50 \%)$ used it more than one hour and up to five hours, 7 (25\%) used it more than five hours and up to twenty hours and the remaining 6 teachers $(21.4 \%)$ used it more than twenty hours. Regarding the development of their subject with computer support, 27 out of 28 teachers stated that they use it.

Regarding the type of training, they have received in the use and handling of computers, only one teacher stated that he had not received any type of training, 96.4\% stated that they had received basic computer knowledge, $82 \%$ on the use of programs (word processing, presentations, spreadsheets) and $64 \%$ on the learning of specialized software in their area of study. In addition to the previous question, 8 teachers reported receiving less than 10 hours of ICT training, 10 teachers reported receiving between 10 and 20 hours and one teacher reported receiving more than 20 hours.

Figure 1. Mean obtained in the dimensions of the questionnaire "Digital Competencies".

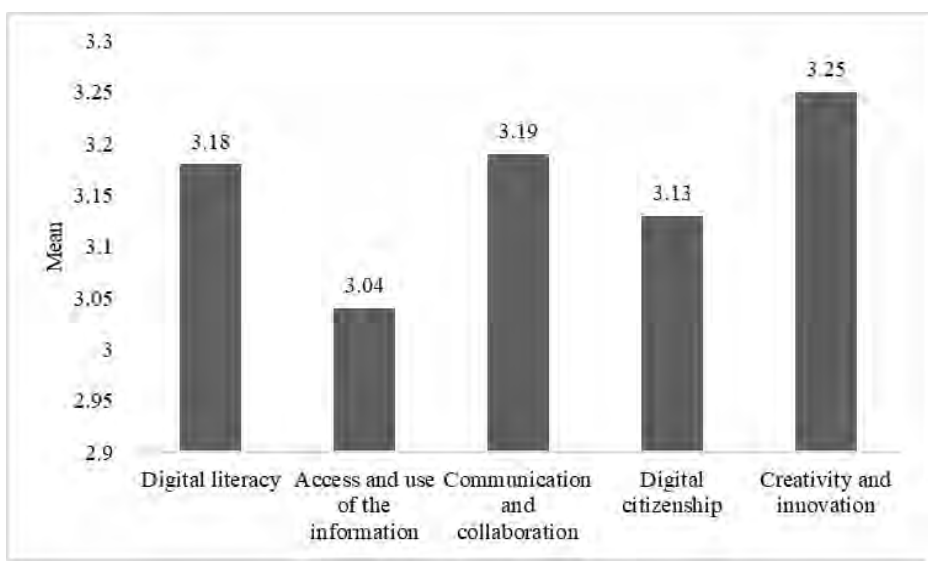




\subsection{Teachers' attitudes regarding research}

In general, teachers showed a positive/low attitude towards research. In addition, as shown in Figure 2, a better attitude was found in the cognitive dimension and a lower attitude in the behavioral dimension. With respect to the latter dimension, four statements had a significantly low score: "I often find myself consulting scientific information" with a mean of 1.86; "To do research it is necessary to be methodical" with a mean of 1.62; "Research contributes to the recognition of institutions" with a mean of 1.86; and "Research, teaching and social projection have no relationship" with a mean of 1.31 .

Figure 2. Mean obtained in the dimensions of the questionnaire "Attitudes Towards Research".

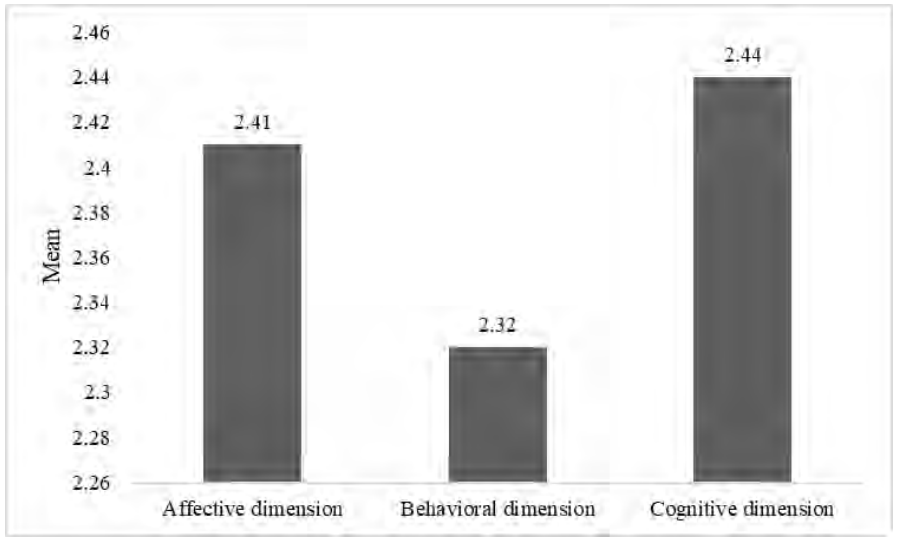

\section{Discussion and conclusions}

The results of the study regarding teachers' attitudes towards research coincide with the results reported by Aldana and Joya, 2011; being that in those studies it was found that the interest that teachers might have in developing their research competencies do not have the desired impact on their attitudes.

From the analysis of the results obtained from both questionnaires, it is possible to point out, in the aspect of the assessment of digital competencies, that the teachers of the Escuela Normal have the tools to develop their digital competencies and have received training for their development, which translates into the high levels they say they have of digital competencies, particularly in terms of creativity and innovation.

\section{References}

Aldana, G. M. and Joya, N. S. (2011). Actitudes hacia la investigación científica en docentes de metodología de la investigación. Tabula Rasa, 14, 295-309.

Aldana, G. M.; Babativa, D. A.; Caraballo, G. J. and Rey, C. A. (2020). Escala de actitudes hacia la investigación (EACIN): Evaluación de sus propiedades psicométricas en una muestra colombiana. Revista CES Psico, 13(1), 89-103.

Cebi, A. and Reisoglu, I. (2020). Digital competence: A study from the perspective of pre-service teachers in Turkey. Journal of New Approaches in Educational Research, 9(2), 294-308. doi: 10.7821/naer.2020.7.583

Fraenkel, J. R.; Wallen, N. E. and Hyun, H. H. (2014). How to design and evaluate research in education ( $9^{\text {th }}$ ed.). London: McGraw Hill.

Guillén, E. D.; Mayorga, M. J.; Bravo, J. and Escribano, D. (2020). Analysis of teachers' pedagogical digital competence: Identification of factors predicting their acquisition. Technology, Knowledge and Learning, 1(18). https://doi.org/10.1007/s10758-019-09432-7.

Rodríguez, A.M. and Martínez, N. (2018). La competencia digital en la base de Scopus: Un estudio de metaanálisis. Revista de Estudios y Experiencias en Educación, 2(2), 15-24.

Spante, M.; Soflova, S.; Lundin, M.; and Algers, A. (2020). Digital competence and digital literacy in higher education research: Systematic review of concept use. Cogent Education, 5, 1-21. https://doi.org/10.1080/2331186X.2018.1519143. 


\title{
SELF- AND PEER-ASSESSMENT TO ENHANCE STUDENT ENGAGEMENT IN UNDERGRADUATE GROUP PROJECTS
}

\author{
Dermot Kerr, \& Sonya Coleman \\ School of Computing, Engineering and Intelligent Systems, Ulster University (UK)
}

\begin{abstract}
Group projects are an important part of undergraduate computer science learning because of their role in developing working skills which are vital for professionals in the computing industry. While group projects offer many potential learning benefits there is no guarantee that the development of working skills will be achieved. In fact, group projects introduce their own stresses and strains for students due to the need to share the workload as fairly as possible, in how individual contributions are measured and recognised, the effect this has on individual performance, and ultimately how this contributes to the student's success in the course. Group projects which are not designed, supervised and assessed in a way that promotes meaningful teamwork and collaboration can lead to failure. In this paper we demonstrate practical use of the WebPA system to allow students to perform self- and peer-assessment to effectively measure individual contributions within group projects. The impact of the tools in supporting and measuring performance is validated through quantitative student feedback where we demonstrate significant student engagement in the assessment process and student satisfaction in mark allocation.
\end{abstract}

Keywords: Peer-assessment, self-assessment, group projects, computer science, WebPA.

\section{Introduction}

The concept of peer-assessment (also known as peer review) has been used in education and beyond for many years. It provides a transparent mechanism through which students can critique and provide summative feedback to their fellow students on their work. Additionally, this may encourage students to take an independent approach to their own personal learning. For example, self and peer assessment encourages students to engage with the assessment criteria and also to reflect on their own performance as well as the performance of their fellow students. This is considered by many as an important process as developing and providing peer feedback to other students also assists students in developing critical thinking skills and objective evaluative judgements based on the assignment criteria. Additionally, beyond that it provides students with an opportunity to develop lifelong and transferable skills in assessing and providing feedback to others, in home life, education and the workplace. Moreover, it equips students with the skills and self-awareness to self-assess and improve their own work.

Peer assessment comes with its own challenges, both in terms of giving and receiving peer feedback. Some people will naturally be severe in their assessments and some students will respond badly to that, sometimes causing them to question the value of their work. Additionally, people can be wrong when it comes to the assessment of another's work. Therefore, this should be overseen by a lecturer or person responsible for the course delivery. However, one of the advantages of peer assessment is that it provides students with deep learning and a deeper understanding of the assessment process. In order to allow students to properly assess the work of their peers, they need to acquire a thorough understanding of the assessment criteria and the assignment itself; this naturally promotes a deeper learning (Hughes, 1995). As a consequence, this deep learning and self-evaluation can have a significant impact on their subsequent performance (Brown 1994; Falchikov 2007). Peer assessment also has clear benefits for teaching staff. It has the potential to reduce the workload of assessment marking by placing some responsibility on students and help to alleviate the pressures associated with large classes and other difficulties. However, this is only achieved if significant effort is attributed to designing the peer assessment at the beginning; in order to make it work successfully, the students must understand what it is, why its being carried out and how it will work. This paper analyses student feedback on the use of Web-PA to attribute weighted marks to individual group members for a group assessment in a UX course. In general, the students considered the use of Web-PA as fair and equitable. 


\section{Methodology}

The study is based on a group project for undergraduate students studying Computer Science, Software Engineering and Information Technology. All students were enrolled on a 12-week second year module on the topic of UX and user interface design. Students were divided into groups of four through a process of student self-assigned groups, with any remaining students assigned to groups by the lecturer. In the study presented here there were 120 students in the cohort resulting in 30 student groups. The groups were tasked to develop a user interface to solve a real-world problem using one of ten provided scenarios. Each scenario asked the students to develop a web-based user interface for a desktop or mobile device. The overall aim of the group project was to develop core competency and confidence in client-side web development while appreciating the need for user-centred design (Monk, 2000). Essentially, this requires the students to understand the intended users, their needs, and the context of their actions - only then is the actual system design considered in terms of what it should look like, and how the design should be based on real people, with real tasks and needs. User-centred design is a hands-on process that requires student groups to identify actual users (stakeholders), conduct a focussed discussion on the tasks they are trying to complete, and thoroughly understand the context and environmental constraints of their work. Students will then base their initial design solutions on the outcome of such discussions although the first designs are likely to be rough drafts and problematic. Students are expected to work in groups to identify potential user-related issues by using a strategy that enables continuous evaluation of the proposed design. It is essential for students to work as a group to appreciate both user and business needs and apply and reflect on user-centred design techniques as part of their learning experience. Group work facilitates the development of transferable skills that are essential in employment, such as compromise, cooperation, negotiation, delegation, etc. Students also learn from each other. Students have different ideas and contributions on the requirements, design and implementation stages; this combined input is essential to appreciate user-centred design. Once students have completed their projects they are subsequently tasked to self- and peer-review the other members of their group using 5-point criteria that was defined by the students during the semester.

\subsection{Web based peer review}

Assigning a single mark to a group project is often a worry for undergraduate students. A common perception is that individuals working on the project are not given the credit they deserve for their contributions, and group members who don't put in effort receive the same marks as those who have contributed strongly. Peer assessment permits better grading of a student's abilities against a range of important transferable skills that they will have to demonstrate as graduates, such as communication, leadership, presentation skills, working as part of a team, etc. Completing the peer-assessment is a key aspect of learning as it ensures students reflect and assess their group peers' abilities as well as their own abilities.

The selected peer assessment system, Web-PA, was developed in Loughborough University as a web-based system for both self and peer assessment (Willmot and Crawford, 2004). It has been used across a number of faculties at Loughborough for several years. Web-PA can handle large classes of students and has been previously described in detail by the authors (Willmot and Crawford, 2004). It provides an easy way by which individuals can be assigned a proportion of the overall project mark based on information provided by individual members of the groups. Web-PA allows the teaching staff to establish a number of criteria against which each group member marks themselves (self) and each of the other group members (peers). This is typically completed at the end of a project but could also be carried out at prescribed times throughout the project lifetime. Students can enter data in confidence and the system calculates a variation factor (called the Web-PA factor) for each individual member of the group based on the normalised total score. The teaching staff marks the group project submission in the normal manner and this mark, or part of it, is weighted by the calculated variation factor for each individual. In the case when all group members score equally, the Web-PA factor $=1.0$, therefore all members achieve the unmodified team mark. There is some early evidence of higher levels of student satisfaction with respect to group work since Web-PA was introduced (Gatfield, 1999).

\section{Evaluation}

A questionnaire was designed for the students with a purpose of gathering quantitative feedback on the use of the Web-PA system for self- and peer- assessment. In general, the students considered Web-PA a fair means of calculating weighted factors for individual contributions. In total 37 students completed the questionnaire, and the key results are presented in Figure 1. In Figure 1(a) we can see that $>75 \%$ students agreed or strongly agree that Web-PA was a good approach to peer assessment. Figure 
1(b) illustrates that approximately $72 \%$ found the assessment to be fair and reasonable and we believe this satisfaction rate can be attributed to the use of Web-PA. It should also be noted that satisfaction can be anecdotally measured by general student satisfaction of the module during the staff-student consultative process; many less queries and issues with the group assessment were raised.

Figure 1. Quantitative evaluation of survey responses to two categories: (a) "I found the assessment fair and reasonable"; (b) "I found the Web-PA assessment a good way to evaluate my own and others' contribution to the project".

(a)

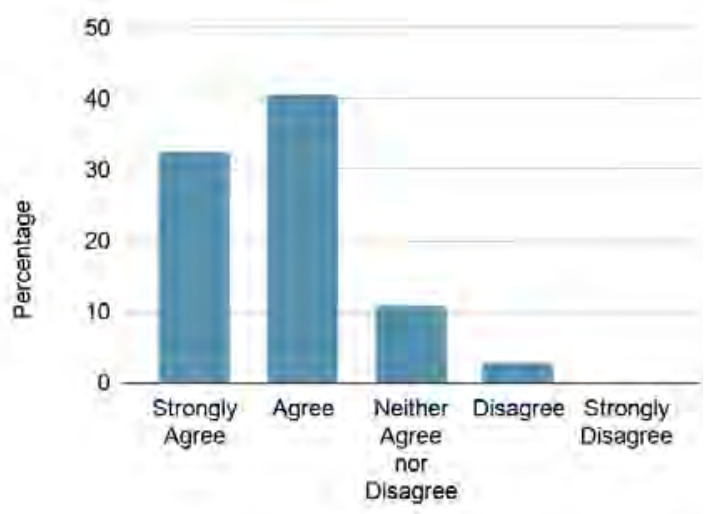

(b)

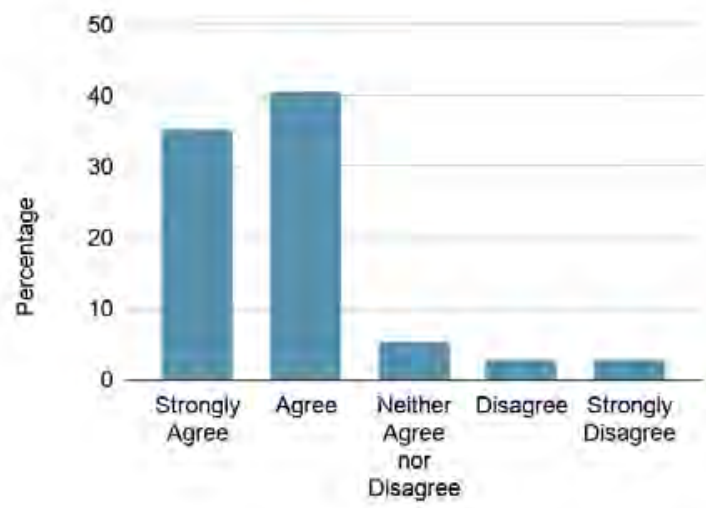

\section{Conclusion}

When students contribute to their marking criteria research has shown that student learning is enhanced. The criteria used must be clear and transparent for your students in order for them to assess the work of their peers. This process of peer and self-assessment supports the students in learning to understand what is meant by high quality and they can also learn from their peers that there may be different approaches to successfully completing an assignment. This peer assessment was conducted with second year students, such skills will be transferable to their placement and final years and will ideally lead to increased course engagement. Peer assessment can provide frequent and relevant formative feedback that students can act upon in a valuable way.

Peer assessment is an excellent way to encourage students to actively participate in group activities. As the students get the opportunity to mark each other and therefore be evaluated by others which prevents them from 'hiding' in a group. This increased engagement naturally improves the learning and teaching experience for the students, ensuring that they fulfil all module outcomes. The student feedback on this approach was very positive and the modules marks, and attendance illustrated an improvement over previous years. Therefore, this will be used in the UX module in the forthcoming year.

\section{References}

Brown, S. Rust, C. \& Gibbs, G. (1994). Strategies for Diversifying Assessment in Higher Education. The Oxford Centre for Staff Development, Oxford. Oxonion Rewley Press.

Falchikov, N. (2007). In: Rethinking Assessment in Higher Education (Boud, D. \& Falchikov, N., eds.), pp. 128-144. Abingdon. Routledge.

Gatfield, T. (1999) Examining student satisfaction with group projects and peer assessment. Assessment and Evaluation in Higher Education, 24 (4), 365-377.

Hughes, I E (1995) Peer assessment of student practical reports and its influence on learning and skill acquisition. Capability, 1, 39-43

Monk, A., (2000), June. User-centred design. In International Conference on Home-Oriented Informatics and Telematics (pp. 181-190). Springer, Boston, MA.

Willmot, P., Crawford, A., R. (2004) Online peer assessed marking of team projects. Proceedings of the International Conference on Engineering Education, ICEE 2004, Paper WA7/4, Gainesville, Florida, USA, October 2004, 1-7. 


\title{
MOOCS AS A TOOL FOR VIRTUAL UNIVERSITY ORIENTATION
}

\author{
Ilaria Merciai, \& Ruth Kerr \\ Federica Web Learning, Centre for Innovation, Experimentation and Diffusion of Multimedia Learning, \\ University of Naples Federico II (Italy)
}

\begin{abstract}
The Covid-19 era, and its enforced transition of all teaching and learning activity to the online space, is potentially leading to reduced university enrolment rates. International student enrolments are predictably down due to travel restrictions and concerns about student safety, but even at home the same trends are being observed. One of the conversations around this issue is the value-for-money question in relation to a perceived reduction in the quality of the overall student experience when the networking opportunities of on-campus life and study are taken away. A further question is the level of digital readiness of staff and school-leaver students, and whether they are able to deal successfully with preparation for final-year school exams, university choice, and for university entrance tests in remote learning. Federica Web Learning, the University Centre for Research Innovation and Dissemination of multimedia and distance learning, has long been making the case for MOOCs as a valid tool for virtual orientation. In the current climate, MOOCs can provide chunks of ready-made quality learning content for use as the asynchronous component in today's hybrid online courses, meaning that the time teacher and class spend in plenary, in video-conferencing, can be devoted to discussion and more in-depth analysis of the learning objectives. The MOOCs can be specially chosen from the growing range on offer from university providers around the world: some provide remedial content in problem subjects and topics; some offer specific exam preparation content and others offer university orientation, or study skills.
\end{abstract}

Keywords: MOOCs, university entrance, hybrid models, digital readiness.

\section{Introduction}

2020 has been dubbed the second year of the $\mathrm{MOOC}^{1}$. When 150 million learners were forced online due When 150 million learners were forced online due to the global pandemic from March 2020 onwards, the major MOOC providers saw a massive surge in user numbers across the board, registering an overall increase of over 110 million enrolments, 35 million of which went to Coursera (Shah D., 2020). Federica Web Learning, with its federica.eu platform ${ }^{2}$, was no exception, registering an average of 330 new users every day in 2020 , and a $300 \%$ increase compared to the previous year. By the end of 2020 , according to Class Central (Shah D., 2020) there were 16,000 MOOCs from 950 universities, covering subjects in 13 broad disciplinary areas, but the in-demand skills relating to technology and business still represented $40 \%$ of all courses. The disciplines that enjoyed the biggest increase during the pandemic were personal development, health and medicine, especially information relating to COVID-19, and foreign languages (Shah D., 2020). The message from Providers like Futurelearn ${ }^{3}$ and LinkedIN Learning (McKeever, 2020) was that online learning represented an advantageous use of free time during the lockdown, and when furloughed, in terms of personal growth and learning new skills in readiness for a return to work (Coughlan, 2020). However, in countries with a large, existing MOOC offer, and national governance, like China for example, MOOCs played a significant role in an institutionalised transition to remote learning, for schools as well as universities (McAleavy, Gorgen, 2020). The courses were used countrywide as quality interactive content within a video-conferencing live session framework, or as asynchronous content in an online flipped classroom delivery mode. The major MOOC providers, like

\footnotetext{
${ }^{1} \mathrm{https}$ ://www.classcentral.com/report/the-second-year-of-the-mooc

${ }^{2}$ https://www.federica.eu

${ }^{3} \mathrm{https}$ ///www.futurelearn.com/courses/collections/boredom-busters
} 
Coursera $^{4}$, edX $\mathrm{X}^{5}$ and Futurelearn, encouraged this type of MOOC use through various initiatives, including discounted access, free certification and special for-credit schemes with partnering institutions. Although high school teachers and students may well have been part of the growing MOOC audience in this period, there are very few figures available that attest to the precise learner demographic. Specific examples that we have include the preparatory mathematics course on the federica.eu platform ${ }^{6}$, which is designed to aid students in their evaluation of the appropriateness of different degree courses and, more specifically, to support preparation for university entrance tests. This course saw an increase of 25,000 new enrolments on the pandemic edition.

\section{Existing MOOC orientation initiatives}

In a period of forced distance learning, it could be imagined that the orientation process of choosing the right degree subject at the right university, which requires high levels of self-awareness as well as good search skills to find the available choices, is even more complex for school-leavers when they lack the in-person support of their teachers and peers. However, MOOC initiatives that specifically aim to support students in bridging this school to university gap, are still relatively few. The FUN platform published a new cluster of 25 orientation MOOCs from "Is this faculty for me?" and "How to adapt successfully to University Study" to "Careers in Cultural Heritage". Futurelearn also offers courses in the university application process in the UK and "Getting ready for academic success". The Federica Web Learning metaMOOC initiative is one of the few to provide comprehensive access to the classrooms of degree courses in 12 disciplinary areas, offering a general overview of subject matter, level of difficulty, and an insight into the specific teaching style. Across the globe, HE Institutions have launched various initiatives to "weather the recruitment crisis" (Basken et al., 2020), especially where international student fees are an important segment of the funding. In Italy, where enrollment numbers for 2020 were higher than expected but saw students applying to institutions close to home (Vatalaro, 2020) - to reduce costs and for personal safety - a growing number of online Orientation Days and Webinars in 2020 have tended to promote the single institution rather than objectively support students in their university choice or preparation. In line with providing this support, Federica Web learning has established a navigation button on its home page - one of only three specific areas - to target the Orientation audience directly and to guide them to the content specifically developed with their needs in mind.

\section{Society needs skilled citizens}

In an epoch in which the need for a broad range of high-level skills is required by a digital knowledge society and the jobs market, the need for a minimum Bachelor's credential is equally high (Selingo, 2014, 2017). This is especially true in Italy, where the figures regarding numbers of graduates and numbers of NEETS ${ }^{7}$ (OECD, 2020) - compare unfavourably with the rest of Europe. This coincides with a period marked by decreasing student enrolment rates, both internationally and at home. Both factors serve to highlight the potential usefulness of an increased specific online offer for orientation.

A further relevant consideration is the growing body of literature that points to the fact that online and varied forms of hybrid (Perez-Sanagustin et al., 2017) and hyflex (Beatty, 2019) learning are here to stay. Despite problems like the digital divide, and a certain lack of digital preparation on the part of some teachers, recent surveys, including our own - jointly created and administered by IPSOS Italy and Federica Web Learning (Reda, 2020), and targeting 1200 university students throughout Italy - highlight the advantages of quality online learning, in terms of flexibility, inclusion, greater opportunities for personalised and community learning from a student perspective, and cost-effectiveness, scalability and research-based provision, from an institutional perspective. The offer of a well-managed digital infrastructure that covers all aspects of student life from orientation to exams, from learning to mentoring and counselling will probably be increasingly important to tomorrow's students.

\footnotetext{
${ }^{4}$ https://blog.coursera.org/coursera-together-free-online-learning-during-covid-19

${ }^{5} \mathrm{https}: / /$ www.edx.org/covid-19

${ }^{6} \mathrm{https}: / / \mathrm{ms}$.federica.eu/enrol/index.php?id=3

${ }^{7}$ In Italy a national plan proposal "Memoria del Ministro Franco sulla Proposta di piano nazionale di ripresa e resilienza [Commissioni congiunte 5a, 6a e 14a Senato della Repubblica V, VI e XIV Camera dei deputati] - 08 marzo 2021" has been disseminated. Retrieved from: https://www.mef.gov.it/ufficio-stampa/articoli/2021_2023-Daniele_Franco/Audizione-del-Ministro-Franco-sulla-Proposta-dipiano-nazionale-di-ripresa-e-resilienza-Commissioni-congiunte-5a-6a-e-14a-Senato-della-Repubblica-V-VI-e-XIV-Camera-deideputati-08-marzo-2021/
} 


\section{Conclusion}

The effectiveness of a MOOC based orientation strategy was already explored in our previous contributions (Merciai, Kerr, 2019; Merciai, Kerr, Melchionna, 2021), where we set out the three-pronged strategy that Federica Web Learning now employs: a classic orientation based on clarification of content and method for specific degree courses; academic preparation for university entrance exams; vocational preparation aimed at raising self-awareness to manage the changes that the move from school to university represent.

The pandemic forced educational institutions to deliver their teaching and learning in remote, and those institutions who already had online courses, digital content or structured learning pathways available, as well as staff with experience of multimedia delivery, were obviously in a better position to deal with the physical closure of schools and campuses. And this is true for the stages of student orientation too. As various forms of hybrid learning look set to remain, post-covid, it is important that guidance for final-year school exams, university choice, and for university entrance tests succeed in a digital learning format too, so that growing numbers of school-leavers not only enroll on the university degree courses that society needs, but also stay the course and graduate successfully.

\section{References}

Basken P., Bothwell E., McKie A., Matthews D., Ross J. (2020). Which nations will weather the storm on international recruitment? Five key recruiting nations' crisis measures on international student recruitment compared and analysed. Retrieved February 25, 2021 from https://www.timeshighereducation.com/news/which-nations-will-weather-storm-internationalrecruitment

Beatty B. J. (2019). Hybrid-Flexible Course Design, EdTech Books. Retrieved February 25, 2021 from https://edtechbooks.org/hyflex

Coughlan S. (2020) Coronavirus: Furloughed workers offered online skills training. Retrieved February 25, 2021 from https://www.bbc.com/news/education-52447539

J.J. Selingo J. J. (2017). The Future of the Degree: How Colleges Can Survive the New Credential Economy, in The Chronicle of Higher Education Special Report, Washington D.C., The Chronicle of Higher Education.

McAleavy T., Gorgen K. (2020) Education Development Trust. Retrieved February 25, 2021 from https://edtechhub.org/wp-content/uploads/2020/04/research-best-practice-pedagogy-remoteteaching.pdf

McKeever V. (2020). Not working due to lockdown? Here's how to keep busy and learn new skills. Retrieved February 25, 2021 from https://www.cnbc.com/2020/04/08/coronavirus-heres-how-tokeep-busy-and-learn-new-skills-on-furlough.html

Merciai I., Kerr R. (2019). MOOCs as a Key Strategy for University Orientation in Education and New Developments 2019, ISSN: 2184-044X ISBN: 978-989-54312-5-0 2019, pp. 286-90.

Merciai I., Kerr R., Melchionna G. (2021), Moocs For Bridging The School - University Gap, in Education Applications \& Developments VI. Being printed.

OECD. (2020). Education at a Glance. Retrieved February 25, 2021 from https://www.oecd.org/education/education-at-a-glance

OECD. (2020). OECD Employment Outlook 2020. Worker Security and the Covid-19 Crisis. How does Italy Compare. Retrieved February 25, 2021 from https://www.oecd.org/italy/EmploymentOutlook-Italy-EN.pdf

Perez-Sanagustin M., Hilliger I., Alario-Hoyos C., Delgado Kloos C., Rayyan S. (2017) H-MOOC framework: reusing MOOCs for hybrid education, in « Journal of Computing in Higher Education », 29, pp. 47-64.

ProjetSUP on FUN platform. Retrieved February 25, 2021 from https://www.mooc-orientation.fr and https://www.fun-mooc.fr/news/25-mooc-dorientation-sont-disponibles-sur-fun

Reda V. (2020). Generazione Greta. In De Notaris D., Melchionna G., Reda V. (a cura di). (2020) Didattica digitale. Chi, come e perché. Salerno editore. ISBN: 8869735354, p. 136.

Shah D. (2020). By the Numbers: MOOCs During the Pandemic. Retrieved February 25, 2021 from https://www.classcentral.com/report/mooc-stats-pandemic

Vatalaro F. (2021). Università, le previsioni erano nere come la pece. Ma forse le cose non vanno poi così male. Retrieved February 25, 2021 from https:/www.ilfattoquotidiano.it/2020/09/15/universita-leprevisioni-erano-nere-come-la-pece-ma-forse-le-cose-non-vanno-poi-cosi-male/5930702/ 


\title{
HERITAGE AND ART EDUCATION THROUGH THE SCREEN. FILLING THE SPACE BY PERFORMATIVE METHODOLOGIES
}

\author{
Alessandra De Nicola \\ Interdepartmental research Centre for Cultural and Artistic Heritage Bi-PAC, \\ University of Milano-Bicocca-Universidad Católica de Murcia UCAM (Italy)
}

\begin{abstract}
Long before the pandemic, museums started to invest, experimenting with some performative practices (Bishop 2006; Lista 2006) as a method and tool to foster access and participation of different audiences to their heritage. Since the advent of the \#culturequarantine, in which most of the educational activities have taken place through a digital space, care and attention to gesture and space have become a key to respond effectively to the needs of educators and users. After an initial phase of rejection and disorientation, teachers, educators and trainers had to find new answers. The aim of this contribution is to describe some of these answers looking at methodologies coming from the field of choreographic and performance research. The argumentation will pass through the narration of some international proposals, three action research experiences accomplished with museum educators and schoolteachers, through which it was possible to observe how the needs and requirements changed as the lockdown conditions changed. The outcome of the research, which took about one year, is the reconsideration of the body as a mediator of the educational and training experience. On the one hand we see the "body as archive" for new knowledge, on the other hand, the space of digital educational activities is reified, thanks to this new role of the body.
\end{abstract}

Keywords: Heritage and art education, distance education and elearning, learning space, performance, challenges and transformations in education.

\section{Introduction}

This contribution is part of a wide-ranging, long-term research project that investigate the practices and methodologies of research in the performing arts for a new approach to heritage education. Over the years we have witnessed numerous research projects that have contributed to a paradigm shift in mediation and, consequently, in the fruition of cultural heritage (De Nicola, 2020). This change consisted of moving from a frontal narration, carried out by an expert who had a passive audience in front of $\mathrm{him} / \mathrm{her}$, to put the cultural object at the centre, as the subject from which the experience of fruition is born. Involving the public in a meaningful experience, that sees the cultural object as the source for the acquisition of new knowledge, was the necessary step to initiate the second paradigm shift, i.e., the active participation of the different audiences through the workshop or interpretative techniques and methodologies. In this way, the alliance between school and museum was significantly created; to paraphrase the words of John Dewey (1938), museums became "the alembics of knowledge". A great contribution to these revolutions comes from the relationship that has been created, in contemporary times, between artistic production and the public (Bishop, 2006): starting with the DADA proto performances/happening, the work of art exists and is meaningful only concerning its audience. Museums, exhibition spaces and some landscapes characterised by cultural heritages, have long seen performative actions as a valid response to the growing demand for participation in the creation of meanings by the public (Bal 2011; Jackson, Kidd 2011). The \#quarantineculture phenomenon, due to the pandemic accelerated a process of revisiting practices that had already been ongoing in the cultural sector for some decades. More than ever in the uncertainty surrounding the pandemic, museums sought to keep culture alive by producing new contents or offering a safe means for audiences to discover or rediscover, in surrogate digital form, cultural heritage assets from geographically nearby or faraway. This mirrored a pattern that has already been observed during emergencies such as environmental disasters or brutal acts of terrorism, whereby cultural heritage assets serve as key identity markers for communities actively seeking to re-establish their identities. It is at times of crisis such as these that the public perceives the 
heritage assets held in museums as a key resource with the power to reinforce the local community. The first point to be made is that access to a computer and a good Internet connection alone were enough to support a wide range of formats, including webinars, performances, distance meetings, podcasts and radio art. Since the advent of the \#quarantineculture, in which most of the educational activities, in museums and schools, have taken place through digital space, care and attention to gesture and space have become a key to respond effectively to the needs of educators and users. After an initial phase of rejection and disorientation, teachers, educators and trainers had to find new answers.

\section{The educators' point of view, methodological aspects}

Some of these responses sought through the management of: a training course with 27 museum educators from the municipality of Milan - May/June 2020 (2 questionnaires); a training course for 22 teachers with Pirelli Hangar Bicocca and performer Marcella Vanzo - November 20/ January 21 (2 questionnaires); a training course with 27 museum operators from all over Italy January 2021 (1 focus group). The observation of the general data to have a broader point of view took place through the collaborative platform Politeaching: dai docenti e per $i$ docenti, consigli per una didattica efficace ai tempi del coronavirus (from teachers and for teachers, tips for effective teaching in the times of coronavirus) created by the Politecnico di Milano, where teachers from all over the world share techniques, methodologies and perplexities. Fundamental was the investigation into the experience of Italian teachers during the COVID-19 health emergency by The Italian Educational Research Society (Lucisano, 2020). All the experiences and data collected show three orders of problems: 1. an increase in working time linked to the need to restructure teaching. 2. The problems related to the management of learning environments and the difficulties in involving students. 3. The evaluation of students' work was one of the most difficult aspects. The present paper worked on point 2. Cooperatively, we searched with teachers and educators for solutions to produce a meaningful relationship beyond the screen. The first point from which we started was the work on the search for feedback, trying to recover some of the structured achievements in educational practice (Ani, 2009; Rowe, 2011). Many teachers saw the almost obsessive search for students' feedback as the only way to achieve a participatory lesson/workshop. Thus, we propose to use the scientific method, starting from the observation of natural objects and their reproduction using different media and techniques, we tried to restore centrality to the experience of art (Dewey, 1938), understood as a dynamic and vital practice, beyond the screen. Only after the experience, in their concrete space, it was possible to create a debate, so, to have significant feedbacks. The other, fundamental step was to restore centrality to the body. It was only possible thanks to the involvement of artistic practice and methodologies deriving from performance. We have tried to close the distance by rethinking the concept of discipline. The path forward has been one of contamination between disciplines and methodologies, drawing heavily on informal learning. Thinking about Jacques Derrida, we implemented a process of deconstruction, a fundamental theoretical element of performance practice.

\section{Body and performance}

Following Merleau-Ponty, the body is made of the same flesh as the world. The body is the mediator that overcomes the non-objectivity of space and time. A response to the fear of accessing a territory that we are no longer able to dominate, which leads us to a stiffening, incapable of proposing problems and finding solutions, as educational practice provides. According to Gilbert Simondon's thought, regarding the individual concerning the technique, the definition of the individual foresees a subdivision into distinct and closely related phases: physical, vital (biological), psychic and collective. The first sees the body and its boundaries as the first step to get in touch with reality. Paraphrasing Derrida, it is only when boundaries are defined, starting from experience, that the subject becomes aware of one's possibilities and succeeds in overcoming the limits imposed by external subjects to achieve new knowledge. The activities proposed during the different experiences worked in this direction, trying to reactivate all the senses (the voice, no longer the teacher's alone, but everyone's; touch as a tool to rediscover three-dimensionality, the laptop frame as a limit to be broken through the body's movement in space) to fill the digital space and at the same time restore the centrality of the educational experience, in which the body becomes both the mediator of the experience and the archive of newly acquired knowledge (Gamelli, 2006; Hooper-Hill, 2007; Lepecki,2010). Similarly, in addition to the experienced workshop practice, we would like to point out how many cultural realities have proposed professional performances as a means of keeping the relationship with the public warm. At the Pinacoteca di Siena, the project Capolavori in Ballo (Masterpieces in Dance) by MOTUS: a multimedia work and a performance in which dance combined with art to show some lesser-known aspects, often details, of the masterpieces conserved in the Pinacoteca. At the Gagosian, on the occasion of the exhibition "Anselm Kiefer: Field of 
the Cloth of Gold, Hugo Marchadand and Hannah O'Neil danced to Florent Melac's choreographies, leading the spectator to ideally walk through the landscape created by Kiefer's works. Movement succeeds in giving a third dimension to wheat fields or threatening skies. Le Grand Palais de Paris, closed to the public for works until 2024, is shown through "La Ronde" the work created by Boris Charmatz. \#dancinbo "la danza e danza a Bologna" was a television format in which the city of Bologna is told through dance in places of art, architecture and monuments. During Black lives matter, the Tate Gallery broadcast on its social channels the performance by Enam Gbewonyo set to music by Liz Gre in which the fusion of sounds and movements created "an ode to Blackness and response". It was a work inspired by Lynette Yiadom Boakye's painting "Stillness", exhibited at the time. By the éreale project, on YouTube, the Royal Museums of Turin remained engaged with their audiences through a video in which dancers, acrobats, fencers and opera singers acted in the emptiness and silence of the rooms, describing and interpreting them.

\section{Conclusions}

The outcome of this paper is the reconsideration of the body as a mediator of the educational (Gamelli,2006; Hooper-Hill, 2007) and training experience. On the one hand, we see the "body as archive" (Lepecki,2010) for new knowledge, on the other hand, the space of digital educational activities is reified, thanks to this new role of the body. The instrument of this new relationship with the real is the performative practice, through a process of deconstruction as opposed to the traditional educational practice that sees in the structure and systematization of the contents, one of the central aspects. Distance learning has transformed the educational space into a digital space in which the possibility of temporal displacement between the source of the educational activities and the recipient has made the educational experience less authentic. The possibility of choosing between synchronous and asynchronous modes, the condition of a space mediated through all technological apparatuses have led to a further loosening of the educational relationship. If in pedagogical practice and research, the environment is considered a third educator (Malaguzzi, 1993), and anchoring the topics of the lessons to everyday life, to the search for the so-called reality tasks, is a necessity of didactic and educational activities, the question underlying this article is what definition of reality we can give to this type of educational activities. The answer lies in proposing short activities linked to experience involving all the senses, bringing the body back into the world, into every day of our teaching beyond the screen.

\section{References}

Ani, A. (2019). Positive feedback improves students' psychological and physical outcomes. Indonesian Journal of Educational Studies, 22(2),134-143

Bal, M. (2011). Exposing the Public. In S. Macdonald (ed.) A Companion to Museum Studies, Chichester: Blackwell, 525-542.

De Nicola, A., Garcia Sotile, M.E., \& Gomez Lozano, S. (2020). Research and creations between art-architecture to enhance the urban heritage through an educational process. AusArt Journal for Research in Art.8 (2), pp. 25-37.

Dewey, J. (1938) Experience and education. New York, NY: Kappa Delta Pi

Frey, B. S., Kirshenblatt-Gimblett.B. (2002) The Dematerialization of culture and the Deaccessioning of Museum Collections. In Museum International 54 (4) 58-63

Gamelli, I (2006) Pedagogia del corpo. Roma: Universale Meltemi.

Hooper-Greenhill, E. (2007), Museum and education purpose, pedagogy, performances. New York: Routledge.

Jackson, A.,Kidd, J. (eds) (2013). Performing Heritage: Research, practice and innovation in museum theatre and live interpretation, Manchester: Manchester University Press.

Lepecki, A. (2010a). "The Body as Archive: Will to Re-enact and the Afterlives of Dances." In Dance Research Journal 42(2): 28-48.

Lucisano, P. (2020) Doing research with teachers. The first results of the national SIRD survey "A comparison of the approaches to distance learning adopted in Italian schools in the period of the COVID-19 emergency". Lifelong Lifewide Learning VOL. 17, N. 36, pp. 3-25

Rowe, A. (2011). The personal dimension in teaching: Why students value feedback. The International Journal of Educational Management, 25(4), 343-360.

Simondon, G. (1989). L'individuation psychique et collective, Paris: Aubier. 


\title{
CREATING A VIRTUAL STUDY ABROAD EXPERIENCE TO RUSSIA
}

\author{
Jay Woodward ${ }^{1}$, \& Michelle Kwok ${ }^{2}$ \\ ${ }^{I}$ Department of Educational Psychology, Texas A\&M University (United States of America) \\ ${ }^{2}$ Department of Teaching, Learning and Culture, Texas A\&M University (United States of America)
}

\begin{abstract}
COVID-19 has drastically altered our world. Though travel is halted, global education does not have to stop. We used this time to reconceive the notion of study abroad and designed a study abroad program that could be facilitated virtually and enhanced with face-to-face classroom interaction. We were inspired to embark on this journey for several reasons. First, the realities of the pandemic create risks associated with international travel. Second, international experiences need to be more accessible-more students should be able to participate in global education, even if they do not have the means or ability to do so. We present our design considerations in building and implementing this virtual study abroad program. As part of the design, we partnered with VEXA (Virtual Experiences Abroad), a Moscow-based company that built the online interface and facilitated the interactions between our students and Russian citizens, including visits to a Russian Orthodox Church, the Bolshoi Ballet theater, and elementary and middle schools. We also brought elements of Russian culture to life through face-to-face experiences including a live cooking session with a Russian chef, discussions with a Russian Orthodox priest, and a ballet lesson with a company member of the Bolshoi theatre. These types of experiences facilitated group discussions and social interaction opportunities, crucial for establishing relationships. Overall, our main goal was to reconceive the traditional notion of study abroad while garnering results that would match the transformational gains that global education provides.
\end{abstract}

Keywords: Study abroad, technology, multicultural education, global education.

\section{Introduction}

Although COVID-19 has restricted travel, it has also by necessity inspired imagination and the adoption of new strategies and technologies to think beyond what is implausible and conceive what is possible about study abroad programs. Although borders are closed, global education initiatives do not have to cease. Furthermore, as the internet is quickly changing how we communicate with one another, the concept of "travel" needs to be re-examined. Sensing a gap, the authors used this time to reconceive the notion of study abroad and generated an international program that could be facilitated virtually and enhanced with face-to-face classroom interaction.

A semester-long virtual study abroad course was developed that sought to expand the boundaries of global education while reaching students who wouldn't otherwise be afforded the opportunity to travel. This course, which was initially offered in the Spring of 2021, was produced in partnership with VEXA, Virtual Experiences Abroad, a Moscow-based company that provided the interface and facilitated the interactions between students and Russian citizens. A number of modules and live experiences were created for the virtual study abroad; including 1) language and communication; 2) people and practices; 3) societal institutions; and 4) culture and the arts.

\section{Literature}

In a review of literature analyzing how universities across the world prepare their graduates for entrance into the 21 st century workplace, Briguglio (2010) states that "although the number and variety of graduate attributes developed by universities may differ, the theme of preparing students for operating in global scenarios is seen repeatedly in higher education literature, with competencies in intercultural communication a priority" (p. 10, emphasis added). But how are these competencies structured or achieved? The conventional means of programming is through a standard study abroad experience (Anderson \& Lawton, 2015). In study abroad programs, students are situated in an unfamiliar culture that compels them to pay close attention to and rapidly develop strategies to communicate ideas across 
cultures as well as formulate a perspective of their own culture. According to the "Open Doors" report issued by The Institute of International Education (2020), in a typical year, U.S. institutions send nearly 350,000 students abroad. However, the reality is that the pandemic has restricted movement, and halted international travel. Global engagement, in its most traditional form, has been grounded.

The expansion of both the domains and audiences of a traditional study abroad experience is at the heart of this course design. First, international experiences need to be more accessible - more students should be able to participate in global education, even if they do not have the means or ability to do so (Whatley \& Raby, 2020). In a recent article released by The Chronicle of Higher Education, it was reported that just $2 \%$ of undergraduates study abroad; a small percentage of the overall college population (Fisher, 2021). But diving into the breakdown of that number further reveals a disparaging and discouraging pattern. The International Coalition for Global Education and Exchange (Artis et al., 2021) reports that racial or ethnic minority students represent less than one-third of study abroad participants even though their proportional representation in the U.S. college population approaches one-half.

Compounding this further is that the "cost of participating in study abroad programs can be a serious impediment for many students" despite a clear desire to study abroad (Amani \& Kim, 2018, p. 680). Findings by Stroud (2010) reinforce this notion further by indicating that aside from cost, fear of discrimination was also a salient influential factor as well. Deterrents and barriers to participation not only pertain to ethnic and racial minority students, but also non-traditional students as well. Another factor could be family obligations and responsibilities, with students who are employed having to endure financial hardships to take time off, and no guarantee they will have a job when they return (Amani \& Kim, 2018, p. 680). Therefore, our course design is based in equity, in that it will allow students, for whom study abroad might not have been a possibility, the chance to experience the transformational learning that these opportunities provide.

\section{Course design}

The course itself was initially designed with intercultural communication as a key focus. The course began on the topic of communication; starting with the Russian language itself. Students learned the Cyrillic alphabet, and quickly applied their knowledge to introduce themselves and hold short conversations with Russian language teachers. From the module on language, students were taken through cross-cultural experiences across a variety of societal institutions. For example, students explored the Russian Orthodox Church, where they were able to draw distinctions between their own theological perspectives and predominant perspectives in Russia, accentuated through interviews with Russian Orthodox clergy and viewing of artifacts used in worship. Students were led on a private tour of the Faberge Museum, learning about the history of Faberge as well as traditional costume of that time. Students also engaged in cultural exchanges with elementary and high school-aged children in which they shared about daily life and traditions across the US and Russia.

We also brought elements of Russian culture to life through experiences that allowed for collaboration and enhanced a sense of community in our group (Ritz, 2011). These included engaging in a live cooking session with a five-star Russian chef to make a traditional meal. Students were also challenged to learn ballet from a Russian ballerina and hear about her training regime. From there, students gained a behind-the-scenes look into the Bolshoi Ballet, where students were able to see snippets of rehearsals and converse with company members.

\section{Methods of assessment}

The main measurement tool built into this course provides quantitative and qualitative data to show how students have grown as a result of participating in this virtual abroad experience. Students took two norm-based assessments pre- and post-course: 1) the Global Perspectives Inventory (GPI), and 2) an Intercultural Development Inventory (IDI). The GPI measures cognitive, interpersonal, and intrapersonal gains as a result of studying abroad. Students were classified on subscales related to 1) Knowing; 2) Knowledge, 3) Identity, 4) Affect, 5) Social Responsibility, and 6) Social Interactions. A t-test for mean differences will determine if students demonstrate significant change on any of these aspects as a result of participation. The first iteration of this course is currently being completed, so we do not yet have data to reflect pre-post changes.

The second instrument, the IDI, assesses intercultural competence. Student answers to the IDI will give them quantitative data as to their perceived orientation (PO) towards other cultures (where they think they are) along with their developmental orientation (DO) towards other cultures (where the instrument assesses them to be) and the resulting developmental gap. The continuum that the IDI rates students on is a 5-point continuum that ranges from Denial (limited capability for understanding and responding to cultural difference) all the way to Adaptation (shifting one's own cultural perspective and changing behavior in culturally appropriate ways). Data from the IDI shows that only $3 \%$ of individuals 
fall into the Denial category and only $2 \%$ will ever achieve Adaptation. The majority of individuals fall in the middle, and a goal of this virtual study abroad is to engage students in "needle moving" experiences.

When students complete the IDI, their results are presented to them in a debriefing session to provide them key insights into how they make sense of cultural differences. They are then presented with a series of choices and options to systematically increase their intercultural competence and close the gap between their (DO) and (PO) by working through a customized Intercultural Development Plan (IDP). The IDP is tied directly to the results from the IDI and is set up to allow students to gain insights concerning identified intercultural challenges they might be facing and identify personal intercultural competence development goals that are important for them to progress through during the semester.

\section{Preliminary findings}

Although we do not have pre-post data to report, individual student reflections do reveal the impact of this virtual study abroad course. Student reflections reveal how powerful the live interactions were. In of the live experiences, we rented a local restaurant and live-streamed in a Russian chef to teach us traditional dishes. The owner and chef of the local restaurant also supported us during the lesson. This experience made a strong impact on one of our students, who recalls:

FANTASTIC experience and nothing less. I have never experienced something like this in my college career that went so in depth and beyond a picture on a slide show. I will remember this experience until I can't remember anything anymore! Honestly, when I look back on college I KNOW this will be one of the first things to come to mind every time. Why? We don't get experiences like this normally, so I am SO appreciative that we had this opportunity. It was engaging, it was immersive, it was awesome to learn directly from a professional Chef who was courteous enough to spend the time teaching us! When I signed up for the study abroad, honestly, this was the type of experience I was hoping for!

Live experiences such as this one helped students feel immersed in a different culture, without ever having to leave town.

Another student foregrounds the importance of personal reflection on their growth. In the following, the student reflects on being encouraged to engage in cultural activities outside of class time.

Seeking out unique and challenging activities to spur my development was really great, especially outside the classroom environment. However, taking the time to really reflect on what I participated in, examine the impact it left on me, and how I can take that moving forward was something I was truly appreciative of.

In addition to building interactive virtual and live experiences, we made sure to provide consistent avenues for students to engage in self-reflection as well as reflecting on their role(s) in the different spaces and cultures they participate in. It is through the purposeful programming of these activities and assessments that we aim to demonstrate participant growth and the achievement of positive learning outcomes in future semesters. Moving forward, our plan is to deepen course content and enrich live experiences to promote further intercultural awareness and communication.

\section{References}

Amani, M., \& Kim, M. M. (2018). Study abroad participation at community colleges: Students' decision and influential factors. Community College Journal of Research and Practice, 42(10), 678-692.

Anderson, P. H., \& Lawton, L. (2015). Student motivation to study abroad and their intercultural development. Frontiers: The Interdisciplinary Journal of Study Abroad.

Artis, R. C., Book, C. L., Clinton, J., Lucas, J. S., Pellow, J. P., \& Whitehead, D. M. (2021). Advancing Global Stability and U.S. National Security through Peaceful Exchange. Retrieved from https://static1.squarespace.com/static/5e947e0237a0b6041f0cd80a/t/6064b5b69341cc22bb8a8c08/ 1617212872956/TIC-WhitePaper_3-21_web.pdf

Briguglio, C. (2007). Educating the business graduate of the 21st century: Communication for a globalized world. International Journal of Teaching and Learning in Higher Education, 19(1), 8-20.

Fisher, K. (2021, April 1). The year without study abroad. Retrieved from https://www.chronicle.com/article/the-year-without-study-abroad?cid=gen_sign_in

Ritz, A. A. (2011). The educational value of short-term study abroad programs as course components. Journal of Teaching in Travel \& Tourism, 11(2), 164-178.

The Institute of International Education (IIE). (2020). Open doors report. New York, NY.

Whatley, M., \& Raby, R. L. (2020). Understanding Inclusion and Equity in Community College Education Abroad. Frontiers: The Interdisciplinary Journal of Study Abroad, 32(1), 80-103. 


\title{
NEW ACTIVE METHODOLOGIES FOR CRITICAL LEARNING IN THE FIELD OF BIOCHEMISTRY OF HUMAN NUTRITION
}

\author{
Catharina Merchante ${ }^{1}$, David Posé1, Fernando Gallardo ${ }^{1}$, Mar Quiñones ${ }^{2}$, \\ Juan Antonio Gálvez ${ }^{3}$, \& Beatriz Martínez-Poveda ${ }^{1}$ \\ ${ }^{1}$ Department of Molecular Biology and Biochemistry, University of Málaga (Málaga, Spain) \\ ${ }^{2}$ Department of Physiology, University of Santiago de Compostela (Santiago de Compostela, Spain) \\ ${ }^{1}$ Department of Education and Academic Training, My Scientific Company (Spain)
}

\begin{abstract}
Background: The teaching of the subject "Biochemical Basis of Human Nutrition" of the Degree in Biochemistry is based on the premise that students apply the knowledge acquired in previous courses concerning biochemistry and metabolism. However, for many topics covered in this subject, not rigorously application of this knowledge has been detected, existing influences derived from non-expert information available in the media. To a large extent, this problem lies in the fact that nutrition is a topic widely covered in the media, although often in a generalized, incomplete and not very rigorous way.

Methodologies: In this project we proposed students to apply a critical view on nutrition-related information available in the media, with special emphasis on the hottest topics, such as transgenic foods and Mediterranean diet. For this purpose, we designed two strategies: (1) a mini-workshop activity in connection with the subject "Food Biotechnology" focused on the use of transgenic foods; (2) involving students in the creation and management of a web page aimed at dealing with topics related to nutrition, worked from two approaches (informative and scientific). For the development of these activities, students were assigned to different working groups and information about the knowledge of the students in the topics was collected in pre- and post-activity tests. In this way, we involved students in real activities of expert search and screening of information, in order to communicate it in different environments.

Results: The project was developed during two academic years, involving students from two successive promotions (30 students in the first year and 39 in the second year). The activities proposed within the project were voluntary, and the percentage of adherence to them was $100 \%$ in both cases, indicating the high degree of acceptance among the students. We created a website (www.lawebnatural.com) in the context of this project. In the activities aimed at researching and writing articles on specific topics within the web page environment, questionnaires were carried out prior to the development of the activities to evaluate the degree of knowledge that the students had about the topics to be worked on in the activities. The implementation of post-activities questionnaires showed an improvement percentage of $85 \%$ in the knowledge of the topics. The elaboration of graphic material on transgenic foods for the mini-workshop activity, was another profitable activity contributing to a better understanding of the topics.

Conclusions and implications: The use of these dynamics concerning the active participation of students in creative tasks based on information search improves the quality of learning. The choice of current topics in nutrition awakens the students' critical spirit, as they confront their pre-established ideas about these topics with the new knowledge acquired.

Findings: This communication is derived from the Educative Innovation Project PIE19-068, funded by University of Malaga. Websites were supported by funds from My Scientific.
\end{abstract}

Keywords: Nutrition learning, web page creation, critical learning, nutrition topics.

\section{Introduction}

During the course of the Degree in Biochemistry, students progressively acquire many concepts about biochemistry and metabolism, reaching a deep knowledge of them after the first courses. The passage through compulsory subjects common to both Mentions, such as Fundamentals of Biochemistry, Experimental Biochemistry I and II, in the first course, and Regulation of Metabolism in the second course (in addition to other subjects specific to each of the Mentions) ensures that in higher courses 
students can apply the conceptual bases necessary for the acquisition of new knowledge in more applied fields. In the particular case of Biochemical Basis of Human Nutrition (BBHN), an elective subject of the last course of the degree, students must integrate this knowledge by directing it to the concept of human nutrition.

Unlike other topics handled during the degree, nutrition is nowadays on everyone's lips. In the media we always find news related to nutrition (specific sections within morning programs, advertisements and news spread through social networks...). We can say that nowadays nutrition is a topic that is widely handled by the general population and not only by experts. This fact has a positive side, as it raises awareness of certain bad habits or informs about good practices related to nutrition. On the other hand, the generalization of nutrition in so many non-specialized contexts can be a great risk: the excess of information can eventually lead to misinformation (Varela-Mosquera, \& Varela-Moreiras, 2017).

During the teaching of the BBHN course, current concepts arise that arouse great interest but that are very much associated with the "vox populi" controversy, and in many cases the students themselves who participate in the course use arguments that are not well contrasted and do not properly integrate the expert knowledge they have acquired during the degree. This has been particularly observed in concepts related to transgenic foods, despite being a topic they have worked on in different subjects. In order to solve this tendency regarding this and other "hot-topics" related to nutrition, we propose 3 objectives focused to encouraging critical thinking in the students and also to explore the use of popular media as a motivational tool for students.

\section{Design}

The present work has been applied to two groups of students (30 and 39 students), enrolled in the subject BBHN during two successive academic years (2019/2020 and 2020/2021). The activities developed were offered on a voluntary basis. The proposed methodology (described in Methods section) was applied during the 4 months of the course, and included the development of different learning methodologies: (1) organizing a mini-workshop format activity in connection with the subject Food Biotechnology, in which the two groups of students assume roles of critical transmitters/receivers of information (focused on the use of transgenic foods); (2) involving students in the creation and management of a web page aimed at dealing with topics related to nutrition, worked from two approaches (informative and scientific). In this way, we intend to involve students in real activities of expert search and screening of information, in order to communicate it in different environments. Questionnaires were prepared about different topics in nutrition, in order to evaluate before and after the training actions, the students' previous knowledge and their general impressions about them. These questionnaires served as a tool to measure the impact of the actions on learning.

\section{Objectives}

1. To encourage a critical view of "hot-topics" related to human nutrition. Biochemistry.

2. Create spaces for communication between subjects of the different Mentions of the Degree in

3. Motivate student participation in outreach media beyond the scope of the subjects.

\section{Methods}

\subsection{Selection of "hot-topics"}

A brainstorming activity was carried out in class, in which students suggested topics related to nutrition that are usually treated in the media or generate doubts in the students themselves as to their veracity or scientific basis. Concepts related to Mediterranean Diet and transgenic foods were included in these topics.

\subsection{Search for information}

Working groups of 3-4 students were established and "hot-topics" were assigned to each group ( 2 topics/group). A dynamic was carried out in class oriented to the search for information in specialized databases (MedLine, Scopus...) or in web pages of official organizations or agencies of international prestige that offer accurate information on topics related to nutrition (FAO...). 


\subsection{Screening and use of the information}

Once the information was compiled, each group screened it, selecting the essential information related to each topic. This activity was carried out by the working groups outside the classroom, and a summary of the essential points and the basic bibliography was elaborated and sent to the teachers for their supervision. The groups of students used the selected information for the elaboration of (1) a poster in congress format. The work was mainly synthetic, since it was essential that all the information collected was structured in an orderly, visual and understandable way to a receiver who does not have much knowledge about the topic. (2) two informative texts referring to each of the two assigned topics. One of the texts was treated from a scientific point of view, explaining in detail the biochemical/metabolic/physiological bases of the topic worked on. The other text was elaborated in a more informative format, trying to convey to the reader the essential ideas about the topic worked on, but without falling into technicality. In total, each group elaborated 4 texts, two scientific and two informative, about the two topics assigned to them. These articles were included in the section of contents in a web page created for the subject.

\section{Results and discussion}

The activities proposed within the project were voluntary, and their adherence to them was an indicator of the students' interest in doing other types of activities to complement lecture attendance. In the two consecutive courses in which they were carried out, the percentage of adherence was $100 \%$, indicating the high degree of acceptance among the students. Moreover, the number of students enrolled in the BBHN course increased by $30 \%$ (from 30 to 39 students) in the second year since the project was launched, from which it can be inferred that the course had an increase in the degree of acceptance among students, since BBHN is an elective subject.

We created a website (www.lawebnatural.com) in the context of this project. The students worked on the different topics, in their more scientific vision and in their divulgative version, within the context of this web page, creating content that in turn motivated their work in the subject and their knowledge of the topics covered. The existence of an open work environment on the Internet, with the possibility of visualization that their work entailed, motivated the students to research the subjects, demonstrating a high degree of adherence to the tasks, with very positive perception.

The elaboration of graphic material on transgenic foods for the mini-workshop activity, and its subsequent sharing by the students, improved their knowledge on this specific topic, which had not been previously worked on in any subject of the Degree in Biochemistry taken by them. Questionnaires were carried out prior to the development of the activities to evaluate the degree of knowledge that the students had about the topics to be worked on in the activities, and were completed with questionnaires carried out afterwards. As a result, an average improvement percentage of $85 \%$ was achieved, demonstrating that the work carried out by the groups of students improved their knowledge of the topics worked on.

\section{Conclusions}

The use of these dynamics that depart from the classic master class model demonstrate that the active participation of students in creative tasks based on information search improves the quality of learning. The choice of current topics in nutrition for the development of the tasks awakens the students' critical spirit, as they confront their pre-established ideas about these topics with the new knowledge acquired.

\section{References}

Varela-Mosquera, G, \& Varela-Moreiras, G. (2017). Introducción a la historia de la nutrición. In A Gil Hernández \& F Sánchez de Medina Contreras (Eds.), Tratado de nutrición, Tomo I (1-18). Editorial Médica Panamericana ISBN:.978-84-9110-190-1 


\title{
BLUEPRINTS FOR CHANGE: WHAT MULTICULTURAL EXPERIENCE OFFERS INSTRUCTORS OF PRE-SERVICE EARLY EDUCATION TEACHERS
}

\author{
Michelle Henault Morrone ${ }^{1}$, \& Yumi Matsuyama ${ }^{2}$ \\ ${ }^{1}$ Department of Human Care, Nagoya University of Arts and Sciences (Japan) \\ ${ }^{2}$ Nihon Fukushi University (Japan)
}

\begin{abstract}
This research is part of a long-term study focused on the redesign of pre-service early teacher education based on observations of schools that use a multicultural inclusive model. The Swedish school highlighted in this research provides a case study in how international standards are appraised by education stakeholders (researchers, educators, the local community, etc.) and then transformed into curricula in local practice. The key to this Swedish approach is the emphasis on democratic values in education. This gives the educators at the preschool in question a traditional "Swedish" basis for their progressive efforts to rise to the challenges presented by their multicultural student body, challenges they meet by creating a warm and welcoming atmosphere for all members of the school community, students, teachers, and parents alike. The goal is to make each person feel valued and included in the educational process. The emphasis is on inclusivity for all, whatever their background, religion or socio-economic status. The approach of the Ringmuren Forskolan is presented as a potential model for institutions that have the responsibility of preparing pre-service teachers for their work in an increasingly multicultural world.
\end{abstract}

Keywords: Multiculturalism, pre-service, inclusivity, preschool.

\section{Introduction}

Sweden has long been considered a champion of human rights in the wider world. However, a dramatic increase in immigration to Sweden in the late $20^{\text {th }}$ and early $21^{\text {st }}$ century has given Sweden's human rights concerns a new domestic focus. Sweden itself is now increasingly a multicultural society in which human rights issues are no longer mainly matters of foreign policy. Since at least the beginning of this century, Sweden has found itself having to deal with problems of equity and inclusiveness that were almost entirely outside the historical experience of what had been an extremely insular and homogenous society. Rising to the challenge, Sweden has managed to develop a strong consensus that "multiculturalism is understood as active efforts to make public institutions more inclusive and hospitable to ethnic and religious diversity." (Borevi, 2013). This essay will focus on this inclusive hospitality toward newcomers as it has manifested itself in the public institution of the school. In particular, we will describe how one school at the socio-economic margins benefits from the commitment of its leaders to ideals of multicultural inclusivity.

\section{Ringmuren Forskolan, Uppsala Sweden}

This preschool is a public school on the woodsy outskirts of Uppsala, the fourth most populous municipal area in Sweden. A preschool or Forskolan in Sweden, is for children from ages one to five. The neighborhood served by Ringmuren Forskolan has a high percentage of immigrants from a diverse mix of cultures. The parents are from Turkey, Syria, Iran, India, China, and Somalia, as well as from EU countries such as Greece, Spain, Poland, and the UK, among others. The school has between 100 and 120 children speaking 24 different languages, in addition to Swedish. Some children with autism and visual impairment are also enrolled at the school. Ringmuren Forskolan is perhaps somewhat typical of the most diverse schools in Sweden but such an extreme degree of diversity is by no means typical of Swedish schools. The principal said she hoped that through the school experience newcomers can participate in notions of freedom espoused in Swedish democracy. This democracy, she went on to say, was similar to 
what Dewey first wrote about in his book on this topic at the beginning of the progressive movement. It was based on equity.

Principals Inger Björklund and Yvonne Möller explained that they addressed the unique challenges of this school by first collaborating with Cecilia Caiman, a Stockholm University researcher. She helped them work towards the creation of a curriculum that addresses the following question: "How can we follow children's fascination, inquiry and storytelling about nature's life and death?" The principals then received the assistance of curriculum development managers Erik Andersson, an Uppsala University graduate student, and Anna-Karin Backelin, to develop a workable school plan that would attempt to answer that question. Once the school mission was formulated and submitted for review by the Uppsala local government, the actual establishment of the school could begin with the support of local government funds.

The school is founded on the idea that the recognition of children's rights can help contribute to a hopeful and sustainable future. The school's mission statement, which is entitled "Learning for Sustainable Development," sets forth the school's commitment to children's rights, democratic values and sustainability:

- The promotion of democracy and values that strengthen children's rights, inclusion and relationship creation

- Organization of the learning environment in relation to sustainability and other objectives of the curriculum

- Projecting a design approach with a focus on processes and cooperative learning

$\circ$ The right of children to a close relationship with the natural world, and the cultivation of careful actions to create sustainable habits

- A caring approach to the environment gives materials longer life

(Ringmuren Forskolan Mission Statement, 2019)

So how do these ideals manifest themselves in practice? We will outline a few distinctive characteristics of the school's unique curriculum in action.

\section{Design}

From the outside, the school building is a nondescript structure of the sort typically used for Swedish schools. It is inexpensively but solidly built and has no architectural pretentions. It is entirely utilitarian. Upon entering, the first thing one notices about the school is its carefully planned layout. Rooms flow into rooms, and certain areas are marked off for exclusive purposes. There are quiet spaces for each age group and also for teachers. These spaces suggest a strong Reggio Emilia influence. Overall the school design makes clear that children are at the center of the educational enterprise.

\section{Learning rooms}

Learning spaces are designed (aesthetically, too) for each level of development. Developmental spaces provide what research has shown to be comfortable, appropriate places for learning at each stage of a child's development. So, for one-year olds, there is a room for the senses, one with water and plants, one with an opportunity for creative play, and a room to experiment with lights of different colors. Children are free to roam the rooms of interest to them. Each room's space is small---only 3 or 4 children can enter at most. Teachers note what interests an individual child and talks to them about it, urging them to express themselves when they are ready. At the age of two, as the senses and body develop, a room offers a variety of light, sound, and sensory (sand, water, soft items) opportunities, as well as for storytelling and increased interaction with the natural environment and creative construction. By the time children are three, they are experimenting more with the outside natural environment, with the art studio, as well as with the indoor garden and atrium, where they experiment with growing things and also, observing decay. A magic room provides children with the chance to play with optical illusions (IT based) as the teacher helps them understand how these are formed. Logic and mathematics, as well as small-scale digital construction takes place here. At four, the student spends more time on reading and working in the studio and textile room. A basic understanding of science-biology physics, and chemistry - is learned, and some things related to technical-analog and digital sound and movie production are introduced. Finally, at five years old, students are using the Sustainable Room for experiments in light, growth, and the experience of the decay (death) of natural things like mushrooms or apples. This is further discussed in the communication room where language and mathematics, as well as 
pattern construction is encouraged. The day the author visited, a selection of various pipes was on a table so the children could learn about wind and where it comes from. Blowing into the tubes, one of the teachers explained, first helped them understand that the wind was also within their bodies, thus connecting the inner wind with outside nature. Finally, wind was related to the energy windmills the children sometimes see in the countryside.

\section{Teacher instruction/cooperation}

The main teacher/developers, full-time teachers, part-time helpers as well as class helpers, meet regularly to discuss the projects, problems, and outcomes of their teaching objectives. The management teachers like Erik, well schooled in pedagogy, engage the other teachers by offering them ideas for projects derived from research programs. They also work to integrate teacher-driven ideas for activities into the curriculum as it is being formed. The immediate community of parents is also welcome to participate in a number of cultural events that highlight the neighborhood's diversity. Mothers and fathers, both, could be seen at the school during the author's visit. One father was outdoors watching the four-year olds as they did a wood construction project using real hammer and nails. (Surprisingly, there were no accidents and no apparent concern that there might be). Inger explained warmly and proudly that Erik and the other development manager work hard to involve all the staff and parents democratically in decisions about the curriculum and to listen to their concerns, and that everyone has a voice in the creation of the school.

Another important inclusive action can be seen in the cloakroom where parents come to pick-up and drop off their children. Here, a mini-lending library of books is placed close to where shoes and coats are kept. This encourages sharing, and also, helps parents far from the city library to read free-of-charge books that may otherwise be difficult to obtain.

\section{Conclusion}

Many educators believe that ideally children should start their education by allowing their natural curiosity to lead them toward a love of learning in an environment of peers that is open and accepting. But education is not just about children in isolation. It is also about teachers and parents, and how they contribute to the learning environment. When they are invited to participate and contribute in an atmosphere of respect, no matter whether they are full or part-time teachers, or even helper parents, the school community benefits. In the case presented here, the inclusive hospitality and deep concern for the creation of a learning community owes much to the passion and commitment of the principals and main teachers who created a vision and a mission for their school, and then worked to build a curriculum on that foundation.

The commitment to curriculum development based on a progressive pedagogy was an impressive aspect of Ringmuren Forskolan. Equally impressive was the care teachers took to ensure that their curriculum was suited to their students and that no teacher or helper was denied a voice in generating the ideas necessary to make the school a dynamic learning place. This inclusion of different perspectives illustrates the degree that democratic values and consensus are valued in Sweden, and it is this aspect of Swedish society and culture that may be the most important value this school can pass on to its largely immigrant population of students and parents. "Each person counts," as the teachers often say. The teachers are committed to making multicultural education an inclusive education, feeling that education for a sustainable future does not make sense if it is intended only for certain groups within society, whether they are privileged or underprivileged. After all, in the end each child, whatever his or her background, inherits a shared future.

\section{References}

Borevi, K. (2010). Dimensions of Citizenship: European Integration Policies from a Scandinavian Perspective., in Bo Bengtsson, Per Strömblad and Ann-Helén Bay (eds.). Diversity, Inclusion and Citizenship in Scandinavia. Newcastle upon Tyne: Cambridge Scholars Publishing.

Borevi, K. (2013). Understanding Swedish Multiculturalism, in Debating Multiculturalism in the Nordic Welfare States. London: Springer.

Dewey, J. (1916). Democracy and Education. New York: Macmillan Press.

Essen, G. (2018). Systematiskt kvalitetsarbete. Stockholm: Text and Kultur AB.

Stoudt, A. (2021). The Reggio Emilia Approach. Retrieved May 23, 2021 from https://www.scholastic.com/teachers/articles/teaching-content/reggio-emilia-approach/ 


\title{
SCHOOL LEADERSHIP AND TEACHERS' IMPLEMENTATION OF CURRICULUM REFORM IN TAIWAN: MEDIATING EFFECT OF TEACHERS' ORIENTATION
}

\author{
Chun-Hung Cheng, \& Mei-Ju Chen \\ Department of Education and Learning Technology, National Tsing Hua University (Taiwan)
}

\begin{abstract}
In response to the global education development trend, Taiwan had officially launched the Competency-based Education Reform in 2019. Although school leadership has been linked to teachers' changes, the relationship's underlying mechanism remains unclear. Thus, we aimed to examine the mediating effect of teachers' orientation toward curriculum changes on the relationship between school leadership and teachers' implementation of reform. In October 2020, we conducted a questionnaire survey on teachers in 53 elementary and middle schools among six counties/cities in Taiwan. Among 506 valid responses, 345 teachers are women $(68.2 \%)$ and 161 are men $(31.8 \%)$. We adapted the Education Reform Scale developed by Ramberg in 2014. The dependent variable was "Teachers' Implementation of Curriculum Reform (3-item)". The main predictors included "School Leadership (4-item)" and "Teachers' Orientation toward Changes (3-item)". Each item was responded to on a 6-point scale from strongly disagree to strongly agree. We used SPSS PROCESS macro to conduct the mediation analysis. After controlling for teacher's characteristics, the regression model showed that school leadership is positively associated with teachers' implementation of reform $(\beta=0.450, \mathrm{p}<0.001)$. After adding teachers' orientation in the model, the association of school leadership with teachers' implementation of reform attenuated but remained statistically significant $(\beta=0.286, \mathrm{p}<0.001)$. Teachers' orientation showed a significant indirect effect on the association between school leadership and teachers' implementation of reform $(\beta=0.164$; Bootstrap $95 \% \mathrm{CI}=0.105$ to 0.227 ). This study suggests that teachers' orientation toward curriculum changes partially mediates the relationship between school leadership and teachers' implementation of the Competency-based Education reform.
\end{abstract}

Keywords: Competency-based education, curriculum reform, school leadership, teachers' orientation, Taiwan.

\section{Introduction}

In response to the global education development trend (Chappell, Gonczi, \& Hager, 2020; Cheng, 2017; Fullan, 2015; Moon, 2007), Taiwan has officially implemented the Competency-based Education Reform in 2019. This education reform was focusing on "competency" for elementary school to high school students (National Academy for Educational Research, 2014). The competency-based interdisciplinary curriculum is at the center of this reform, and the new curriculum is expected to cultivate students' ability to confront challenges and solve problems (Chen \& Huang, 2017; Henri, Johnson, \& Nepal, 2017).

However, whether teachers can implement changes in teaching methods following the new curriculum guidelines is still unknown. Also, although school leadership has been linked to teachers' changes, the relationship's underlying mechanism remains unclear.

\section{Design}

This study was a cross-sectional questionnaire survey design. 


\section{Objectives}

The objectives of the present study were to: (1) examine the relationship between school leadership and teachers' implementation of curriculum reform, and (2) examine the mediating effect of teachers' orientation toward curriculum changes on the above relationship.

\section{Methods}

We conducted a questionnaire survey on teachers in 53 elementary and middle schools among six counties/cities in Taiwan in October 2020. The content of the questionnaire included the Education Reform Scale developed by Ramberg (Ramberg, 2014). The outcome variable was "Teachers' Implementation of Curriculum Reform (3-item, Cronbach's $\alpha=0.867)$ ". The independent variable was "School Leadership (4-item, Cronbach's $\alpha=0.867$ )" and the mediator was "Teachers' Orientation toward Changes (3-item, Cronbach's $\alpha=0.867$ )". Each item was responded to on a 6-point scale from strongly disagree to strongly agree. We used the model 4 of SPSS PROCESS macro to conduct the mediation analysis.

\section{Results}

Among 506 valid responses, 345 teachers are women $(68.2 \%)$ and 161 are men $(31.8 \%)$. There are 264 elementary school teachers $(52.2 \%)$, and 242 middle school teachers $(47.8 \%)$. Regarding the teachers' implementation of reform, most teachers responded that they had been implemented curriculum changes, and those who responded they did not implement changes were $4.7 \%$ to $7.1 \%$. The multiple linear regression model (Table 1) showed that school leadership is positively associated with teachers' implementation of reform (Model 2, $\beta=0.450, \mathrm{p}<0.001$ ) after controlling for teacher's characteristics and other covariates. After adding teachers' orientation in the model, the association of school leadership with teachers' implementation of reform attenuated but remained statistically significant (Model 3, $\beta=0.286$, $\mathrm{p}<0.001)$. Teachers' orientation showed a significant indirect effect on the association between school leadership and teachers' implementation of reform $(\beta=0.164$; Bootstrap $95 \% \mathrm{CI}=0.105$ to 0.227$)$.

Table 1. Multiple linear regression model of teachers' implementation of reform.

\begin{tabular}{|c|c|c|c|}
\hline \multirow{3}{*}{$\begin{array}{l}\text { Outcome } \\
\text { Independent variable (ref) }\end{array}$} & \multirow{3}{*}{$\begin{array}{c}\begin{array}{c}\text { Model 1 } \\
\text { Teachers' Orientation }\end{array} \\
\beta\end{array}$} & \multirow{2}{*}{\multicolumn{2}{|c|}{$\begin{array}{cc}\text { Model 2 } & \text { Model 3 } \\
\text { Implementation of Curriculum Reform }\end{array}$}} \\
\hline & & & \\
\hline & & $\beta$ & $\beta$ \\
\hline School Leadership & $0.279^{* * *}$ & $0.450^{* * *}$ & $0.286^{* * *}$ \\
\hline Teachers' Orientation & & & $0.588^{* * *}$ \\
\hline Male & -0.005 & -0.002 & 0.001 \\
\hline Educational attainment & $0.099^{*}$ & 0.029 & -0.030 \\
\hline Background & $-0.089^{*}$ & -0.063 & -0.011 \\
\hline Teaching School & -0.084 & -0.026 & 0.023 \\
\hline Years of service & $-0.102^{*}$ & -0.032 & 0.028 \\
\hline \multicolumn{4}{|l|}{ Position (Mentor) } \\
\hline General & 0.082 & -0.014 & -0.062 \\
\hline Administration & 0.090 & 0.068 & 0.015 \\
\hline \multicolumn{4}{|l|}{ Area (Taichung City) } \\
\hline Hsinchu City & 0.100 & 0.067 & 0.008 \\
\hline Hsinchu County & -0.002 & -0.022 & -0.021 \\
\hline Miaoli County & -0.036 & 0.022 & 0.043 \\
\hline Changhua County & -0.031 & 0.006 & 0.025 \\
\hline Nantou County & 0.007 & 0.004 & -0.001 \\
\hline \multicolumn{4}{|l|}{$\begin{array}{l}\text { Teaching experience (less than } 1 \\
\text { year) }\end{array}$} \\
\hline $1-2$ years & -0.017 & 0.016 & 0.026 \\
\hline 2 or more years & $0.112^{*}$ & $0.132^{* *}$ & 0.066 \\
\hline
\end{tabular}




\section{Discussion}

This study found that school leadership was associated with teachers' implementation of the Competency-based Education reform. Also, teachers' orientation toward curriculum changes partially mediates the association. Most countries have recognized Competency-based education, and it is also the common goal of education for everyone (Arguelles et al. 2000, Cheng, 2017; Fullan, 2015; Salganik \& Rychen, 2003; Wu \& Chan, 2018). To keep up the pace with the world for Taiwan's education, all educators must devote themselves to competency-based education reforms (Chen \& Huang, 2017).

This research shows that school leadership can directly influence teachers' implementation of curriculum reform. Through school leadership's overall planning of curriculum and teaching, teachers can make curriculum planning and implementation changes. Therefore, to make the reform influential, school leaders and their teams must have clear curriculum plans and measures so that teachers can implement them in practice. At the same time, this study also pointed out that the willingness of teachers to participate in reform will be affected by school leadership. In other words, if school leadership fails to play the role of leading teachers and makes teachers willing to join the school in reforms, the effectiveness of change will be reduced. Therefore, school leaders and their teams must develop curriculum and teaching and reach a consensus with all the members in school to make the reform works.

\section{Conclusion}

This study suggests that teachers' orientation toward curriculum changes partially mediates the relationship between school leadership and teachers' implementation of the Competency-based Education reform. To realize teachers' implementation of curriculum changes, we recommend that the school leadership should work with teachers to build stronger connection between school leadership and teachers. At the same time it is necessary to reach a consensus with all the members in school to push the reform forward.

\section{References}

Chappell, C., Gonczi, A., \& Hager, P. (2020). Competency-based education. In Understanding adult education and training (pp. 191-205). Routledge.

Chen, H.-L. S., \& Huang, H.-Y. (2017). Advancing 21st century competencies in Taiwan. National Taiwan Normal University, 1-21.

Cheng, K. (2017). Advancing 21st century competencies in East Asian education systems. Center for Global Education. Asia Society, 2, 26.

Fullan, M. (2015). The New Meaning of Educational Change, Fifth Edition. Teachers College Press.

Henri, M., Johnson, M. D., \& Nepal, B. (2017). A Review of Competency-Based Learning: Tools, Assessments, and Recommendations. Journal of Engineering Education, 106(4), 607-638. https://doi.org/10.1002/jee.20180

Moon, Y. (2007). Education reform and competency-based education. Asia Pacific Education Review, 8(2), 337-341. https://doi.org/10.1007/BF03029267

National Academy for Educational Research (2014). Curriculum Guidelines of 12-Year Basic Education_General Guidelines. New Taipei City: National Academy for Educational Research. https://cirn.moe.edu.tw/WebContent/index.aspx?sid=11\&mid=9900

Ramberg, M. R. (2014). What Makes Reform Work?-School-Based Conditions as Predictors of Teachers' Changing Practice after a National Curriculum Reform. International Education Studies, $7(6), 46-65$.

Salganik, L. H., \& Rychen, D. S. (2003). Key competencies for a successful life and a well-functioning society. Cambridge, MA; Toronto: Hogrefe \& Huber. Retrieved from http://books.google.com/books?id=GK63AAAAIAAJ

Wu, P. C., \& Chan, J. C. (2018). Reflecting on the perspective transformation of competency-based education. J. Educ. Res. Dev, 14, 35-64. 


\title{
A MOTOR INTERVENTION TO PREPARE LEARNING TO WRITE
}

\author{
Natalie Lavoie ${ }^{1}$, \& Émile Lebel ${ }^{2}$ \\ ${ }^{1}$ Department of Education, University of Quebec in Rimouski (Canada) \\ ${ }^{2}$ Kinesiologist, Rimouski (Canada)
}

\begin{abstract}
Writing is a complex activity that requires the automation of graphomotor skills. Unfortunately, 10 to $30 \%$ of primary school students have difficulty at this level, which impairs the development of writing skills. It therefore seems judicious to intervene in kindergarten to support motor precision as well as visuomotor capacities, considered as prerequisites for writing by many researchers. The purpose of this study was to investigate the effect of motor training on visuomotor integration, motor precision and handwriting performance (speed and readability) in 5-year-old children. According to a quasi-experimental design (pretest, post-test with control group), 34 children participated in an intervention in subgroups, twice a week for 6 weeks. The mean and standard deviation were calculated for each of the tasks performed. Statistical tests ( $t$ test) were then carried out. The results show that the children in the experimental group improved their motor precision as well as their graphomotor skills compared to those in the control group. This project provides new insights into the benefits of working on basic skills in preparation for learning to write and will equip teachers on how to guide and support graphomotor skills before entering first grade.
\end{abstract}

Keywords: Motor intervention, handwriting, kindergarten.

\section{Introduction}

Writing is a complex activity that requires the automation of graphomotor skills in order to trace organized sets of letters. Difficulties at this level would impair the development of writing skills (Karlsdottir \& Stefansson, 2002). It is therefore important to find new ways to facilitate this learning from kindergarten since the ability to control the motor gesture has an impact on the fluidity of writing (readability and speed) (Danna \& Veley, 2015).

Handwriting is described as a perceptual (related to the shape of the letter) and motor skill (related to the movement producing the letter trajectory) which requires motor precision (control and coordination of the musculature of the hands and fingers) as well as visuomotor abilities (coordination between visual perception and finger movements), considered as prerequisites for writing by many researchers (Feder et Majnemer, 2007). Problems with any of these underlying components could lead to inefficient letter formation (Schneck et al., 2012) and on the ability to produce one's first name (Puranik \& Lonigan, 2012). Several studies have underlined the effectiveness of intervention programs that target these components among young students (Bazyk et al., 2009) but most of them were conducted in first grade or among children with disabilities. So, the purpose of this study was to investigate the effect of motor training on visuomotor integration, motor coordination and handwriting performance (speed) of general education kindergarten students (5-year-old children).

\section{Method}

\subsection{Participants}

According to a quasi-experimental design (pretest, post-test with control group), four kindergarten classrooms participated in the study: school 1: 2 intervention classrooms $(n=34)$; school 2: 2 control classrooms $(n=25)$. All kindergarten were invited to participate in this study. Signed parents ssente were obtained for all study participants. Consent was also obtained from school principals and teachers. For ethical reasons, the teachers of the control classrooms received the training program after the study period was complete. 


\subsection{Measures}

Visual-motor skills (VMI) and motor coordination (MC) were assessed with two tasks of the Beery-VMI, short form (Berry, Berry \& Buktenica, 2010). This test captures how visual perception and finger-hand movements are coordinated during handwriting. For the first task, the VMI, participants had to copy geometric forms. They get a point for each form completed correctly (max. score: 21). In the second task, the MC, participants traced a geometric form by connecting the dots without crossing the double-lined path. They had five minutes to complete as many as possible (max. score: 30 ). The raw score for the two tests were converted by age into a normalized score. Handwriting performance has been verified by a first name (FN) writing task (speed). Children had to write their first name as fast as possible, ensuring every letter was readable. The number of letters produced per second was calculated.

\subsection{Intervention}

Experimental group- In order to improve the motor skills required when writing, a training program was deployed. The intervention was supervised by a trained student in Kinesiology who went to the experimental classes. The program consists in 12 sessions (twice a week) each lasting for $30 \mathrm{~min}$. (total intervention time $=12$ hours). Each training session follows a well-defined plan, made up of 4 steps: 1- 5-min warm-up; 2- 10-min muscle building; 3- 10-min coordination activities; 4- 5-min cool-down.

The intervention was provided in sub groups (on average 8 students per group) in quiet, private rooms at the schools.

Control group- The children in this group received no intervention and attended their normal classroom activities. They participated in both pretest and posttest evaluation sessions at the same time as the children in the intervention groups.

\subsection{Data collection}

Data were collected a week before (pretest: February) and after training (posttest: April) using the same assessment battery. All data were collected by two students who were trained in administering the assessments. The children were met individually, in a room outside the classroom. The average duration of the meeting was around 15 minutes.

\subsection{Data analysis}

Two paired sample student t-tests were used to analyze mean differences in the pretest, posttest, and gain (posttest-pretest) scores for the control and experimental groups. A significance level of 5\% was used to determine statistically significant results.

\section{Results}

Before the start of the intervention, the scores of the experimental group and those of the control group were comparable on the three tests (VMI. MC, FN) ( $p>.05)$. After the intervention (T2), the results all improved for the experimental group while for the control group they increased only on the FN (decrease on the VMI and on the MC). Despite this progression of the experimental group, the differences between the groups are not significant.

However, we can observe, for the VMI, that the initial score of the experimental group (99.80) is slightly below the average of the standardized scores established for this test, i.e. 100, while that of the control group (101.44) is above (Table 1). At T2, we observe that the scores have tilted. That of the experimental group went above (102.62) while that of the control group slipped below (99.80).

Table 1. Mean (SD) Pretest and Posttest.

\begin{tabular}{lllll} 
& \multicolumn{2}{l}{ Intervention group $(n=34)$} & & \multicolumn{2}{l}{ Control group $(n=25)$} \\
& T1 & $\mathrm{T} 2$ & $\mathrm{~T} 1$ & $\mathrm{~T} 2$ \\
& $M(S D)$ & $M(S D)$ & $M(S D)$ & $M(S D)$ \\
\hline VMI (visuo-motor) & $99,80(11,31)$ & $102,62(6,22)$ & $101,44(6,19)$ & $99,80(11,31)$ \\
MC (motor coor.) & $103,63(10,00)$ & $105,53(10,26)$ & $101,52(9,35)$ & $100,64(11,28)$ \\
FN (handwriting) & $0,33(0,15)$ & $0,38(0,16)$ & $0,32(0,17)$ & $0,36(0,18)$ \\
\hline
\end{tabular}

Secondary Analysis

Another way to observe the results is by determining individual progress made by children. The difference between the pretest and the posttest was calculated for each child to observe changes in their level of performance. It is observed that $35,3 \%$ of the children in the experimental group improved on the three tests while only $12 \%$ of those in the control group progressed. 


\section{Discussion}

The finding that experimental group improved from pretest to posttest suggests a positive practice effect may have occurred, although the results are not significant, after a relatively short period of intervention. These results did not support the findings of some studies who found significant improvements after an abbreviated intervention period (Ohl et al., 2013) but are consistent with the findings of others who have found insignificant improvement in scores (Ducharme-Lapointe, 2005). Thus, the duration of the intervention should be reconsidered in order to obtain significant results. The small sample size may also account for the failure of the results to reach statistical significance. For the VMI, the experimental group went from a score below the normalized mean established to a score above, showing an evolution at a rate exceeding that of maturation. This result therefore suggests that improvement is not only linked to maturation but also to intervention. Various studies indicate that the score obtained on the Berry VMI is an important indicator of writing skills (Ziviani \& Wallen, 2005), hence the relevance of offering children a motor program before entering first year.

On the first name writing task, both groups show a stable production speed. Frequent writing practices in the natural context of the classroom contribute to the development of better motor control (Danna \& Veley, 2005) and are necessary for benefits to be observed when writing the first name. The program alone therefore could not influence the production speed. In addition, the relatively short time between the pretest and the posttest could also explain that the results of the two groups remained stable. A longer period seems essential for the integration of letters in memory and for a faster production of them (Vander Hart et al., 2010). It is interesting to note that already more than a third of the children who have benefited from the program would have the necessary skills to begin learning to write letters, hence the relevance of the experienced program.

\section{Conclusion}

Effectiveness of the intervention was not demonstrated in this study. However, the results are encouraging since already after 6 weeks progress can be observed. This program could be integrated into the activities of the kindergarten class to enhance the content relating to the development of graphomotor skills. Thus, children could start the first year better prepared. Eventually, it would be relevant to experiment the program over a longer period, with a larger sample.

\section{References}

Bazyk, S., Michaud, P., Goodman, G., Papp, P., Hawkins, E. \& Welch, M. A. (2009). Integrating occupational therapy services in a kindergarten curriculum: A look at the outcomes. American Journal of Occupational Therapy, 63, 160-171.

Beery, K. E., Beery, N. A. \& Buktenica, N. A. (2010). The Beery-Buktenica Developmental Test of Visual-Motor Integration ( $6^{\text {th }}$ ed.). Minneapolis: NCS Pearson.

Danna, J. \& Velay, J.L. (2015). Basic and supplementary sensory feedback in handwriting. Frontiers in Psychology, 6(169). doi: 10.3389/fpsyg.2015.00169

Ducharme-Lapointe, A. (2005). Les habiletés préparatoires à l'écriture: programme d'intervention novateur en ergothérapie. Mémoire de maitrise, Faculté de médecine, Université Laval, Québec.

Feder, K.P. \& Majnemer, A. (2007). Handwriting development, competency and intervention. Developmental medecine and child neurology, 49(4), 312-317.

Karlsdottir, R. \& Stefansson, T. (2002). Problems in developing functional handwriting. Perceptual and motor skills, 94(2), 623-662.

Ohl, A.M., Graze, H., Weber, K., Kenny,S., Salvatore, C. \& Wagreich, S. (2013). Effectiveness of a 10-Week Tier-1 Response to Intervention Program in Improving Fine Motor and Visual-Motor Skills in General Education Kindergarten Students, American Journal of Occupational Therapy, 67(5), 507-514.

Puranik, C.S. \& Lonigan, C.J. (2012). Name-writing proficiency, not length of name, is associated with preschool children's emergent literacy skills. Early Childhood Research Quarterly, 27(2): 284-294.

Schneck, C., Shasby, S., Myers, C. \& DePoy Smith, M.L. (2012). Handwriting Without Tears versus Teacher-Designed Handwriting Instruction in First Grade Classrooms. Journal of Occupational Therapy, Schools \& Early Intervention, 5(1), 31-42

Vander Hart, N., Fitzpatrick, P. \& Cortesa, C. (2010). In-depth analysis of handwriting curriculum and instruction in four kindergarten classrooms. Reading and Writing, 23, 673-699.

Ziviani, J. \& Wallen, M. (2006). The development of graphomotor skills. In A. Henderson \& C. Pehoski (Ed.), Hand function in the child: foundation for remediation (p.217-238). St-Louis, MI: Mosby Elsevier. 


\title{
ORGAN DONATION: AN EDUCATIONAL PACK FOR HIGH SCHOOL STUDENTS
}

\author{
Styliani Kapsali, Vasiliki Sapountzi, Alexandra Nestora, \& Lefkothea-Vasiliki Andreou \\ Department of Biological Applications and Technologies, University of Ioannina (Greece)
}

\begin{abstract}
Blood, bone marrow and organ donation is a major issue that concerns all of us. Even though 18 is the age of eligibility to become a donor, awareness should be raised earlier through education. To this end, and given that this issue is marred by prejudice and misconceptions, we developed an educational pack, aimed at senior high school students, which may be delivered in the context of a biology or sociology course. The proposed teaching intervention follows a three-fold approach: (1) First, students are educated on monoclonal antibodies and relevant biotechnology tools and their role in organ transplantation via a board game, (2) Second, we promote empathy using a free writing exercise that employs art prompts and audiovisual material, (3) Third, we assign students with research projects that involve building questionnaires, collecting and analyzing data and producing a science poster to be posted on the school website. Importantly, the aim of this proposed intervention is to educate and to raise awareness while students build on their research, technology and writing skills.
\end{abstract}

Keywords: Organ donation, science literacy, research thinking, active learning, secondary education.

\section{Introduction}

As the famous quote of Bonnie Arbon goes, "You are a piece of the puzzle of someone else's life. You may never know where you fit, but others will fill the holes in their lives with pieces of you." (https://helphopelive.org/). Recent studies have shown that there is a rise in organ donation demand. More specifically, in the United States of America a new patient will need a transplant every ten minutes (Bastani, 2020), as opposed to every fifteen minutes ten years ago (Abouna, 2008). It is therefore crucial that this issue is effectively communicated as it involves awareness, empathy, and social cohesion, thus reflecting social culture (Parker et al., 2009). Nevertheless, controversy and misconceptions surround organ donation (Morgan et al., 2008). In the present micro-scenario, we aim to promote awareness in an interdisciplinary educational approach.

\section{Methodology}

Subject: Biology, Sociology - Topic: Organ donation - Age group: high school students and young adults - Time: 90 minutes.

\subsection{Educational goals}

Through this educational pack we aim to: (1) Educate students on biological and biotechnological topics relevant to organ donation, (2) Introduce students to blood, bone marrow and organ donation procedures, (3) Introduce students to pre-writing strategies, (4) Alleviate students' writing apprehension, (5) Encourage artistic expression, (6) Introduce students to research thinking and methodology, (7) Improve students' research and collaboration skills, (8) Raise awareness on health issues, (9) Promote empathy and highlight the social benefits of volunteering, (10) Familiarize students with complicated and sensitive science and social issues, (11) Promote science, technology and visual literacy, (12) Practice interdisciplinary (i.e., Biology, Sociology, Art, Research), critical thinking and active learning educational approaches. 


\subsection{Materials}

(1) IT room with Internet access, (2) Laptop, (3) Projector, (4) Speakers, (5) A4 paper sheets, (6) Printer, (7) Printing material for the board game activity.

\subsection{Procedure}

The present micro-scenario has been developed to educate and raise awareness on the topic of blood, bone marrow and organ donation. The teaching intervention spans over two teaching hours. In the first phase, we discuss science topics related to donation by means of an educational board game. During the second phase, the students engage in art and research activities. We conclude with self-reflection and an evaluation of the proposed lesson.

2.3.1. 1st Phase (time: 45 min). 1st micro-activity (time: $45 \mathrm{~min}$ ). Introduction to biology and biotechnology topics concerning organ donation using an educational board game activity.

1. Warmer: We project Sir Robert Lechler's TEDxLondonBusinessSchool talk entitled "The future of Organ Donation" (https://www.ted.com/talks/robert_lechler_the_future_of_organ_transplants). We prompt students to discuss their feelings and thoughts on the talk transcript.

2. Next, students are divided into groups of 3-5 people. Students are randomly assigned to groups with the help of a Random Sequence Generator algorithm (https://www.random.org/sequences/).

3. We explain to students that they will engage in an educational board game activity, namely "Make life last!". The game pertains the following topics: monoclonal antibodies, the antigen-antibody relationship, organ/tissue preservation, organ, bone marrow and blood donation \& 3D organ printers/nanobiotechnology.

4. We hand to each group the following: a packet of double-sided cards, an answer sheet, a pack of double-sided colored badges.

5. We explain the game rules to the class: once a group has written down the answer to a card, the team can move their respective question badge on the gameboard. The team that first reaches the finish line having answered all questions is the winning team. The winning team can choose the destination of the next field trip, decide who the next guest speaker of the class will be or pick an organization of their preference for the class to visit.

Note to the instructor: The cards have been designed using a Google Docs Slides template (https://www.google.com/slides/about/) and are loosely based and inspired by Science Museum "Who am I?" flashcards (https://learning.sciencemuseumgroup.org.uk/resources/talking-points-cards/). The game materials can be found online at the "Make life last!" designated Google Folder (https://drive.google.com/drive/folders/1JEVjGSPQAmImPxUZTrsJ8jjHYMKJE1uG?usp=sharing). The teacher should print out the cards in advance of the lesson as well as the answer sheets and the badges. The gameboard can be designed to the teacher's preference using an online application such as "Board Games Maker" (https://www.boardgamesmaker.com/) or "The Game Crafter" (https://www.thegamecrafter.com/). Alternatively, the board can be hand-crafted, or a line-up of colored boxes may be used instead.

2.3.2. 2nd Phase (duration: 45 minutes). 2nd micro-activity (duration: 20 minutes). Empathy on the issue of organ donation is promoted by means of a free writing exercise that involves art prompts. Students are thus introduced to pre-writing strategies and artistic inspiration is employed to alleviate writing apprehension, i.e., writing-related stress.

1. A discussion is held on students' feelings and attitudes towards writing. We explain that stress-related writing, namely writer's block, is a common problem that may be alleviated through pre-writing strategies, such as free writing (Andreou et al., 2018).

2. Students are handed out blank, white sheets of paper. We explain to them that they will engage in a free writing activity where a series of art prompts, pertinent to the topic of organ donation, will be projected. Following each prompt, they will be asked to write freely and non-stop, without planning or attention to structure or editing.

3. First, an excerpt of the video "Transplant" (03:42 - 06:42), of the art project by the same name (http://www.transplantproject.com/video), by artists Tim Waiwright \& John Wynne is projected. Following the video, and in response to it, the students are instructed to write freely and non-stop for 3 min. Trigger warning: the video contains a still of a bloody cloth and a sound with a high pitch.

4. Second, the video art "Tunnel" (https://www.vasileiadereli.com/copy-of-solo) by artist Vasileia Dereli is projected (duration 02:53). Students are again requested to write for the next three minutes. Trigger warning: contains an agonizing scene of skin stretching that some may find disturbing.

5. Finally, the painting "A French underground hospital at Verdun" (https://wellcomecollection.org/works/nuy2gd3t) by Ugo Matania is projected while the music piece "The 
firebird" by Igor Stravinsky is reproduced (duration 03:30) (https://www.youtube.com/watch?v=wWQa8ZdAeIM\&ab_channel=LondonSymphonyOrchestra-Topic). Students are again requested to write.

2.3.3. 2nd Phase (duration: 45 minutes). 3rd micro-activity (duration: 25 minutes). Introduction of students to research thinking and methodology via a science poster activity. Students collect data concerning organ donation and communicate their findings.

1. We instruct students to run a Google Scholar search (https://scholar.google.com/) using organ transplantation as a search term. We ask them to study the results returned and explain to them that the site is a repository of reliable science and research publications.

2. Students are instructed to work in groups and come up with ten questions exploring the social aspects of organ donation, e.g., common misconceptions. We then ask them to build their questionnaires on Google Forms (https://www.google.com/forms). The questionnaires will be later posted on the school website so that data for a sociological study may be collected.

Homework project \#1: Students are handed-in instructions on how to run a basic descriptive statistics analysis on their data. Note for the instructor: This activity could be a joint project with their Math instructor. With regards to data analysis, useful instructions may be drawn by the dummies.com website (https://www.dummies.com/software/microsoft-office/excel/how-to-use-excels-descriptivestatistics-tool/).

Homework project \#2: Students are requested to build a science poster on Canva (https://www.canva.com/el_gr/) so to effectively present and communicate their research findings. For their posters, we instruct them to use copyright-free images from repositories such as the Wikimedia Commons (https://www.wikimedia.org/).

3. We ask students to self-reflect on the learning outcomes of their engagement with the activities described in the present micro-scenario. We then hold a plenary discussion on the educational intervention.

\section{Discussion}

Organ donation is a topic somehow overlooked in education; however, it has been shown that when part of the curriculum it promotes understanding and health literacy (Siebelink et al., 2017). This may be due to the interdisciplinary, complicated, and sensitive nature of the issue. Also, creating a safe space in class (Holley \& Steiner, 2005) is substantial for the topic to be discussed and analyzed. In the present micro-scenario, we propose an educational pack for high school students. The relevant science topics are communicated via an educational board game that we have constructed for the purposes of this project. Empathy is raised by means of art and writing. Finally, the social aspects of organ donation are investigated though research posters. The effectiveness of the proposed educational pack should be further investigated in terms of the learning outcomes and the student experience.

\section{References}

Abouna, G. M. (2008). Organ shortage crisis: problems and possible solutions. Transplantation Proceedings, 40, 34-38.

Andreou, L.-V., Aletra, V., Athanasopoulou, G., \& Psarropoulou, C. (2018). Good practices in teaching English for scientific purposes to Biology students in higher education. INTED2018 Proceedings, 7174-7183.

Bastani, B. (2020). The present and future of transplant organ shortage: some potential remedies. Journal of Nephrology, 33, 277-288.

Holley, L., \& Steiner, S. (2005). Safe space: student perspectives on classroom environment. Journal of Social Work Education, 41, 49-64.

Morgan, S. E., Harrison, T. R., Afifi, W. A., Long, S. D., \& Stephenson, M. T. (2008). In their own words: the reasons why people will (not) sign an organ donor card. Health Communication, 23, 23-33.

Parker, J., Saklofske, D., Wood, L., \& Collin, T. (2009). The role of emotional intelligence in education. In Assessing emotional intelligence (pp. 239-255). Boston, MA: Springer.

Siebelink, M., Verhagen, A., Roodbol, P., Albers, M., \& Van de Wiel, H. (2017). Education on organ donation and transplantation in primary school; teachers' support and the first results of a teaching module. Plos One, 12. 


\title{
PERSONAL PERSPECTIVES THAT MATTER
}

\author{
Stephanie Kamai \\ Education Divsion, University of Hawai 'i, West O'ahu (USA)
}

\begin{abstract}
The purpose of this paper is to contribute to the existing literature about the theoretical and practical aspects of lesson study and its usefulness in preservice teacher reflectivity. Lesson study is a professional development model that began in Japan and is used in schools and universities among educators in many different parts of the world. Collaborative research lesson study, a variation of lesson study that maintains essential elements of lesson study used in Japan, has been used with preservice teachers at a small university in Hawai'i. This paper seeks to highlight the differences and suggests areas of study for further consideration.
\end{abstract}

Keywords: Lesson study, collaboration, groupwork, inquiry, reflection.

\section{Introduction}

There are five steps in lesson study: goal-setting, lesson planning, research lesson, post-lesson discussion and reflection (Fujii, 2016). On the surface these steps appear easy to follow. After experimenting with lesson study for four years, it is clear that our program uses some essential components of lesson study but is restrained due to the limitations inherent to teacher preparation for undergraduate students. Preservice teachers have limited teaching experience, authority and influence in a school. CRLS is not done school wide. CRLS is carried out one preservice teacher at a time in one classroom. The focus for our program is to provide preservice teachers with an experience that will reinforce collaboration, inquiry, and reflection through Collaborative Research Lesson Study (CRLS). Lesson study begins with a research question that is the result of careful consideration regarding student performance.

\section{Lesson study theory in practice}

The CRLS process begins with creating groups of similar grade level considerations and common field placement assignments. The groups meet on the first day of the semester and establish norms for groupwork (Cohen \& Lotan, 2014) and discuss what they have learned about their school community, the students in their classrooms, and a learning challenge they have learned about from their mentor teacher or observations they have made. Mentor teachers may have already provided suggestions for an instructional or pedagogical strategy the school plans to use to address the learning challenge. Groups who stay in dialogue (Patterson, K., Grenny, J., McMillan, R., \& Switzler, A., 2002) experience success in moving to the next step and begin to form communities of practice which becomes the process that gives the group an identity (Wenger, 1998).

A key component during this phase of lesson study is for preservice teachers to anchor their ideas and wonderings with a research question [Fujii, 2016]. This phase is messy and can be frustrating. They are working on several tasks at the same time. They might be researching the learning challenge itself, school curriculum, and/or pedagogical and instructional strategies without having a clear theme or focus. Conceptualizing the research question can be a daunting task but a crucial step that informs their progress. If the research question is written without fully understanding the discussions, the groups will go off course.

Eventually, preservice teachers agree on a lesson to teach to a group of students in one of their classrooms. One preservice teacher agrees to teach the lesson while the other group members observe. Observers agree to take notes on predetermined areas that they believe will provide rich data. The mentor teacher and content specialist is invited. The primary purpose of observing practice in lesson study is to fine-tune instructional improvements and assess progress on how classroom students are responding to 
the lesson. Observations focus on collecting evidence related to what teaching and learning looks like when the action plan is implemented. A question I ask preservice teachers to think about when finalizing the lesson plan before teaching the lesson is: Based on what you know about your students, what misconceptions might they have? This question typically generates a change to the lesson and alternative ideas to use if the situation arises during the actual lesson. I encourage preservice teachers to think on their feet, this preparation helps them to feel more confident.

Noteworthy to the CRLS process is a post lesson debrief session. This process typically takes 2-4 hours and focuses on the students, not the teacher. What were students saying? What questions did student ask? How do we know students were engaged? What were students doing when they were not participating? Debriefing the session in this way encourages preservice teachers to naturally reflect on what the teacher was doing at the time while focusing on students. The group then evaluates student work and makes some interpretations about the results. Preservice teachers are asked to provide a rationale for the changes they would make the next time they teach the lesson.

A final group paper that documents the entire project throughout the semester is submitted. Students summarize their lesson study project and share the results at a public presentation at the end of the semester. The lesson study paper documents the lesson project that students grapple with during the semester. It is a messy and ambiguous endeavor that captures the complex nature of the teaching process. For many students the demand can be daunting. The public presentation, pre COVID, was held in a local school. Some principals offered professional development credit for teachers who attended the lesson study presentation. Student presentations reflected the arduous task of writing the paper. After working on the paper for several weeks, they were ready to present what they did, smoothly.

Finally, preservice teachers submit a Personal Perspectives narrative at the end of the semester. The general prompt asks them to reflect on the lesson study process. The perspectives of preservice teachers who participated in those in-between spaces (Hyatt, 2015) during the lesson study process are intended to shed light on the areas of lesson study that are meaningful to them and the value of the student teaching experience. Their perspectives are

\section{Lesson study as a reflective activity}

Student teachers complete a personal reflection to a general prompt that asks them to reflect on the lesson study process. Myers conducted a study of preservice students and found that reflection is a complex skill and future teachers should be taught how to reflect before actually beginning the lesson study process (2012). Chassels \& Melville posit that the lesson study has benefits and challenges for inservice and preservice professional development. The authors state that, "The benefits include the development of teacher candidates' new insights into the needs of students, an increased awareness of different teaching strategies, and the importance of collaboration. The challenges are mainly focused on the issue of time and school administrative structures that impede teacher collaboration" (2009).

Lesson study or Jugyou kenkyuu originated in Japan but has been implemented and studied in the United States. The research on lesson study highlights the many systems in place where educators are trying out the lesson study professional development model (Lewis, Perry \& Murata, 2006). Teachers develop curriculum, write student learning objectives that align with state and national standards, assess student performance, and modify instruction and learning activities in order to accommodate each learner.

CLRS is quite different from lesson study in Japan. I argue that the structural components (Takahashi, A. \& Yoshida, 2004) adds value to our program and, perhaps in other parts of the world, (Doig, Be. \& Groves, S., 2011) needs reflection about ways in which CRLS can contribute to the existing research on its impact on preservice teachers.

\section{Conclusion}

When teaching professionals are focused on the strengths and possibilities that exist, and when they grapple through these tasks collaboratively and reflectively, an inside-out strategy occurs that honors the wisdom, experience, and sensitivity of classroom teachers (Jarvis, et.al, 2017). Lesson study is a valuable way for preservice teachers to gain authentic experiences with collecting data, setting goals and measuring student learning in preparation for the realities of their practice as beginning teachers. Lesson study is a process that honors teachers and the wisdom and instincts they individually and collectively bring to student learning while learning more about their craft.

A call for more research into what and how student teaching experiences contribute to preservice learning is needed. This paper presented a snapshot of the Collaborative Research Lesson Study used at one university. Research that will recount preservice teachers experiences about their engagement in the process, the problems and consequences that happen, as well as what is most significant to them is ongoing. 


\section{References}

Chassels, C. \& Melville, W. (2009). Collaborative, reflective, and iterative Japanese lesson study in an initial teacher education program: Benefits and challenges. Canadian Journal of Education, 32(4). 734-763.

Cohen, E.G. and Lotan, R. A. Designing Groupwork: Strategies for the Heterogeneous Classroom 3rd Edition, Teachers College Press; 3rd edition (2014). 256 pgs.

Doig, B and Groves, S. (2011). Japanese Lesson Study: Teacher Professional Development through Communities of Inquiry. Mathematics Teacher Education and Development, Vol. 13(1). 77-93.

Fujii, T. (2014). Implementing Japanese Lesson Study in Foreign Countries: Misconceptions Revealed. Mathematics Teacher Education and Development, 16(1).

Fujii, T. (2016). Designing and adapting tasks in lesson planning: a critical process of Lesson Study. ZDM Mathematics Education, Springer, 48. 411-423

Hammerness, K., Darling-Hammond, L., Bransford, J. et.al, (2005). How teachers learn and develop. In L. Darling-Hammond and J Bransford (Eds), Preparing Teachers for a Changing World: What Teachers Should Learn and Be Able to Do (358-389). San Francisco: Jossey-Bass.

Hyatt, J. (2015). Reflective Communities: Mentoring teacher candidates during the (in)between spaces of the practicum. Journal of Social Theory in Art Education, 35.

Jarvis, R., Dempsey, K., Gutierrez, G., Lewis, D., Rouleau, K., \& Stone, B. (2017). Peer coaching that works. McREL International. Denver: CO.

Lewis, C., Perry, R., \& Murata, A. (2006). How should research contribute to instructional improvement? The case of lesson study. Educational Researcher, 35(3), 3-14.

Myers, J. (2012). Lesson Study as a Means for Facilitating Preservice Teacher Reflectivity. International Journal for the Scholarship of Teaching and Learning, Vol. 6(1).

Patterson, K., Grenny, J., McMillan, R., \& Switzler, R. (2002) Crucial Conversations: Tools for Talking When Stakes are High. Mc-Graw Hill Contemporary. New York: New York.

Takahashi, A and Yoshida, M. (2004). Ideas for Establishing Lesson-Study Communities. Teaching Children Mathematics, 10(9).

Takahashi, A. and McDougal, T. (2016). Collaborative lesson research: maximizing the impact of lesson study. ZDM - Mathematics Education, Springer, 48. 513-526.

Wenger, E. (1998). Communities of practice: Learning, meaning, and identity. Cambridge: Cambridge University Press. 


\title{
CO-CONSTRUCTING A LEARNING EXPERIENCE TO APPROACH MENTAL ILLNESS IN THE CLASSROOM: A TEACHING MICRO-SCENARIO
}

\author{
Anastasia Karamolegkou, Christina Diamantopoulou, Georgia Koutentaki \\ \& Lefkothea-Vasiliki Andreou \\ Department of Biological Applications and Technologies, University of Ioannina (Greece)
}

\begin{abstract}
Social distancing, isolation, stress, and fear in the times of the COVID-19 pandemic are factors that trigger or exacerbate mental health conditions. Further to this, mental health literacy is particularly relevant to secondary education as puberty is a common age of onset of mental disorders. Nevertheless, the topic is somewhat overlooked due to teaching challenges that involve potential emotional triggers, the complex and sensitive nature of the issue, as well as a limited pool of educational resources. Here, we propose a teaching micro-scenario that addresses the topic of mental health literacy via an interdisciplinary approach that promotes active learning. First, students are introduced to the neurobiology of mental disorders by means of engaging with interactive audiovisual materials and a 3D brain simulation. Then, students work on their statistics skills by calculating estimates on affected populations including the school community. Finally, art and creativity are employed to explore healing and public health. The evaluation of the proposed learning intervention is achieved in the form of plenary discussion.
\end{abstract}

Keywords: Mental health literacy, secondary education, active learning, interdisciplinary education, STREAM.

\section{Introduction}

The COVID-19 pandemic has had a negative impact on the mental health of the young (Ye, 2020). Further to this dire outcome of home-confinement and social alienation, young adolescents are already at an increased risk as more than half of mental illnesses have their onset before the age of 14 (Kessler et al., 2007). Therefore, it is imperative to promote mental health literacy (Bjørnsen, Espnes, Eilertsen, Ringdal, \& Moksnes, 2019) in secondary education. Having said that, educators face challenges in the form of personal triggers, the emotional weight and complexity of the topic (Reinke, Stormont, Herman, Puri, \& Goel, 2011), as well as a lack of a good grasp of relevant educational resources (Andrews, McCabe, \& Wideman-Johnston, 2014). The present micro-scenario proposes an interdisciplinary approach (Osman, Hiong, \& Vebrianto, 2013) aiming at informing students about mental illnesses and increasing empathy by highlighting the social stigma. Furthermore, STREAM (Science Technology Reading Engineering Arts Mathematics) approaches such as the present intervention are deemed effective (Ververi, Koufou, Moutzouris, \& Andreou, 2020) at boosting science, technology and art literacy by means of active learning and involvement (Wood, 2009).

\section{Methodology}

Subject area: Biology, Neuroscience, Psychology, Art - Topic: Mental health literacy - Age group: teenagers and young adults - Duration: 90 minutes.

\subsection{Educational goals}

Through this teaching approach we aim to: (1) Promote mental health literacy, (2) Educate on 6 common mental illnesses in terms of the following aspects: neurobiology, incidence \& prevalence, signs \& symptoms, causes, and treatment, (3) Call attention to alarming patterns of behavior amongst teenagers that may be linked to mental illnesses, e.g. eating disorders, (4) Identify misconceptions related to mental 
illnesses, (5) Inform on the impact of stigma on people with mental illnesses, (6) Boost science, technology and art literacy, (7) Introduce research thinking, (8) Encourage artistic expression, (9) Apply a STREAM interdisciplinary approach to mental health issues, (10) Implement co-constructivism in the class by boosting student initiative, collaboration, active learning and peer learning.

\subsection{Materials}

(1) Laptop, (2) Projector, (3) Speakers, (4) IT (Information Technology) room with Internet access, (5) Student Tablets.

\subsection{Procedure}

The proposed intervention comprises IT-enhanced micro-activities concerning mental health and spans over two teaching hours. In the first hour, we use a two-fold approach: First, we educate students on 6 common mental illnesses and then students work on relevant incidence data. In the second hour, students employ art as a motivation for further research and learning on the topic and they also produce their own pieces.

2.3.1. 1st Phase (time: 45 min). 1st micro-activity (time: 30 min). Educating on the topic of mental illnesses by means of interactive Web 2.0 platforms and audiovisual material.

1.Warmer: We project a TEDx video (excerpt 06:54-11:08) that involves the stigma a woman living with schizophrenia has endured (https://youtu.be/xbagFzcyNiM).

2. Students are instructed to visit the Genially platform (https://www.genial.ly/). The link provided involves interactive images on 6 common mental illnesses (namely, schizophrenia, eating disorders, depression, bipolar disorder, obsessive compulsive disorder, post-traumatic stress disorder). The uploaded material has been produced by the authors for the purposes of the present teaching micro-scenario (https://view.genial.ly/6049100a42ac330d8f4cc5bb/interactive-image-interactive-mentalhealth). Students explore the material and subsequently a plenary discussion is held.

3. We then direct students to the "Mental Health" page on the website "Our World in Data" (https://ourworldindata.org/mental-health). Students are requested to explore the site and collect information on the global, national and gender-prevalence statistics concerning mental illnesses. As a homework activity, we ask students to produce relevant estimates based on the school population using the "Part, Whole and Percentage" page on the GeoGebra platform (https://www.geogebra.org/m/knxczufb\#material/vmbuztsg).

2.3.2. 1st Phase (time: $45 \mathrm{~min}$ ). 2nd micro-activity (time: $15 \mathrm{~min}$ ). In this activity, students are prompted to explore brain simulations to familiarize themselves with brain structures and to gain a better understanding of how those are involved in mental illnesses.

1. Students are instructed to explore the 3D Brain app (https://play.google.com/store/apps/details?id=org.dnalc.threedbrain). The app contains interactive brain structures with information on the links between brain regions and mental illnesses.

2. Additionally, we ask students to use an interactive brain model, provided by the BrainFacts.org website, where they gain a more realistic view of the brain (https://www.brainfacts.org/3dbrain\#intro=true).

2.3.3. 2nd Phase (time: $45 \mathrm{~min}$ ). 3rd micro-activity (time: $30 \mathrm{~min}$ ). Approaching mental illnesses through an art-combo activity.

1. Warmer: Students watch a 3-video compilation (08:12) by Button Poetry (https://youtube.com/playlist?list=PLEXLmEyYScFU2Ra_KPXXALA7AOodjIInI). The compilation consists of 3 poems by the respective individuals: a woman living with depression who attempts to communicate her feelings to her mother, a man with obsessive-compulsive disorder who shares his experience of heartbreak, and a woman who has faced eating disorders, narrates the obstacles she has encountered during her recovery.

2. We initiate a discussion about well-known people that have publicly shared their stories on dealing with mental illnesses. Then, we show students Tate Modern (https://www.tate.org.uk) entries of artwork from artists that have lived with mental illnesses such as Edvard Munch and Vincent van Gogh.

3. Importantly, students are then asked to design their own artwork in the form of web-based posters on a virtual canvas provided by the Glogster platform (https://edu.glogster.com/). Students are requested to draw material and inspiration for their multimedia, interactive posters from the sources explored in previous steps and activities (e.g., the BrainFacts.org website provides a screenshot tool where they could produce pictures of brain domains etc.). Additionally, we explain to students that they 
may also use copyright-free images from online repositories such as WikiMedia Commons (https://commons.wikimedia.org/wiki/Main_Page). Their finished digital art collages are presented in class at a later time point.

2.3.4. Evaluation (time: $15 \mathrm{~min}$ ). A plenary discussion is held on the scope of the lesson. In the discussion, we urge students to brainstorm on ways to raise awareness on mental health or to promote empathy on the individual and societal levels (e.g., performances, podcasts, talks etc.). Before leaving class, students are requested to answer a Google Forms (https://www.google.com/forms/about/) questionnaire evaluating learning outcomes (https://docs.google.com/forms/d/e/1FAIpQLSdsDFp8AjiVxckIK4_PMyCDXMAB1fsrV_o_3

pahokSYm5NWWA/viewform?usp=sf_link). The questionnaire has been produced for the purposes of the present micro-scenario. As a Going-Further activity, students may be asked to produce original single-act plays that tap on the issue of mental illnesses.

\section{Discussion}

The relationship between mental health literacy and the well-being of adolescents has recently been pointed out (Bjørnsen et al., 2019). Interestingly, relevant investigation has shown that even shortterm interventions negate misconceptions and are effective in increasing mental health literacy (Pinfold, Stuart, Thornicroft, \& Arboleda-Flórez, 2005). We propose an educational micro-scenario aimed at high school students that is in line with the theory of co-constructivism (Reusser \& Pauli, 2015). The micro-activities are IT-enhanced (Andreou, 2019) and thus suitable both for distance-learning as well as face-to-face settings. Finally, in this study, a questionnaire has been designed to determine the learning outcomes of the proposed intervention, therefore an investigation will show the effectiveness of the micro-scenario.

\section{References}

Andreou, L. V. (2019). Remembrance Day: A micro-scenario-based teaching of English as a foreign language employing micro-activities in a digital environment. INTED2019 Proceedings, 7533-7542. doi: 10.21125/inted.2019.1833

Andrews, A., McCabe, M., \& Wideman-Johnston, T. (2014). Mental health issues in the schools: Are educators prepared?. The Journal of Mental Health Training, Education and Practice.

Bjørnsen, H. N., Espnes, G. A., Eilertsen, M. E. B., Ringdal, R., \& Moksnes, U. K. (2019). The relationship between positive mental health literacy and mental well-being among adolescents: Implications for school health services. Journal of School Nursing, 35(2), 107-116.

Kessler, R. C., M., A., Anthony, J. C., De Graaf, R., Demyttenaere, K., Gasque, I., \& Unstun, T. B. (2007). Lifetime prevalence and age-of-onset distributions of mental disorders in the World Health Organization's. World Psychiatry, 6, 168-176.

Osman, K., Hiong, L. C., \& Vebrianto, R. (2013). 21st Century Biology: An interdisciplinary approach of Biology, Technology, Engineering and Mathematics education. Procedia - Social and Behavioral Sciences, 102, 188-194.

Pinfold, V., Stuart, H., Thornicroft, G., \& Arboleda-Flórez, J. (2005). Working with young people: the impact of mental health awareness programs in schools in the UK and Canada. World Psychiatry, 4, 48-52.

Reinke, W. M., Stormont, M., Herman, K. C., Puri, R., \& Goel, N. (2011). Supporting children's mental health in schools: Teacher perceptions of needs, roles, and barriers. School Psychology Quarterly, 26(1), 1-13.

Reusser, K., \& Pauli, C. (2015). Co-Constructivism in Educational Theory and Practice. International Encyclopedia of the Social \& Behavioral Sciences: Second Edition, (Vol. 3, pp. 913-917). Oxford, UK: Elsevier.

Ververi, C., Koufou, T., Moutzouris, A., \& Andreou, L. V. (2020). Introducing robotics to an English for academic purposes curriculum in higher education: The student experience. In 2020 IEEE Global Engineering Education Conference (EDUCON) (pp. 20-21). IEEE.

Wood, W. B. (2009). Innovations in teaching undergraduate biology and why we need them. Annual Review of Cell and Developmental Biology, 25, 93-112.

Ye, J. (2020). Pediatric mental and behavioral health in the period of quarantine and social distancing with COVID-19. JMIR Pediatrics and Parenting, 3(2). 


\title{
TELECAREER: ANTECEDENTS AND CONSEQUENCES OF STRATEGIC CAREER BEHAVIOURS ON IBERIAN TELEWORKERS
}

\author{
Joana Carneiro Pinto \\ School of Human Sciences, Catholic University of Portugal (Portugal)
}

\begin{abstract}
This paper aims to present the state of the art, objectives, methodology and expected results of a project that investigates the nature, causes and consequences of the use of strategic career management behaviours in an Iberian sample of teleworking adults. Specifically, our purpose is to analyze the strategic behaviours - authenticity, balance and challenge - according to the Kaleidoscopic Career Model developed by Sullivan and Mainiero (2008). The role of self-efficacy beliefs, the desire for career control, and perceived organizational support, as antecedents of those career behaviours, will be assessed, as well, as the consequences of their use on perceived career control, objective and subjective career success, and career satisfaction. The aim is to develop an explanatory model of career management for Iberian teleworkers, with implications for the design of human resource development programmes in organisational contexts. It is an innovative project on the international scenario, by the target population on which it focuses, but also by the combination of the selected career variables.
\end{abstract}

Keywords: Strategic career behaviours, human resources management, teleworkers, empirical model.

\section{State of the art}

Over the past fifty years, behaviours and attitudes of personal control over one's career have been considered a consequence of vicissitudes affecting the world in general, and organizational life in particular. Several authors have argued that these behavioural dynamics should be seen as normative in relation to working life, since they express the progressive desire for personal control over career outcomes (King, 2000; Sullivan \& Mainiero, 2008; Viannen, et al., 2008). In this sense, the interest for the study of strategic behaviours on career goals has been increasing (e.g., Greenhaus, et al., 2010; Kossek, et al, 1998).

According to the Kaleidoscopic Career Model (Sullivan \& Mainiero, 2008), there are three strategic career behaviours: (i) authenticity, alignment between own values and those of the organization, (ii) balance, between professional and non-professional responsibilities; and, (iii) challenge, stimulus at work and career progression opportunities. Each worker, throughout his/her career/life, invests more or less in each of these behaviours, depending on the career objectives he/she has defined. In relation to teleworkers, these behaviours are expected to be even more pertinent, given the proactive and autonomous role expected from them, not only in the redefinition of their professional roles and responsibilities, but also in terms of their career decision-making (Raghuram, Wiesenfeld \& Garud, 2003).

Strategic career behaviours have been associated with desired personal and professional results, such as the perception of success (Sturges, et al, 2002), the perception of control over career goals (King, 2000), wage increase (Lau \& Pang, 2000; Raabe, Frese, \& Beehr, 2007), career/work satisfaction (King, 2000; Lent \& Brown, 2006; Raabe, et al, 2007), and life satisfaction (King, 2000). Research also indicates that socio-cognitive factors (e.g., beliefs of self-efficacy, perception of support and barriers to achieving goals; King, 2000; Kossek, et al., 1998; Lent \& Brown, 2006; Raghuram, et al, 2003), and perceived organizational support (e.g., Desrosiers, 2001) are motivators for strategic career action.

Despite this important set of studies, there is still a narrow understanding about the relationships between these variables. Moreover, the conclusions from these studies have applicability, mostly, in "traditional" workers. Although official statistics do not exist, with the lockdown due to the Corona virus, it is estimated, that in Portugal and Spain, a great number of workers have been developing their activity through teleworking in the past few months. And, it is possible that, in a near future, some companies will adhere more easily to this type of work regime. But, teleworkers, in general, believe that teleworking impairs their advancement towards the desired professional goals (e.g., McCloskey \& Igbaria, 2003). Human resources departments will benefit from the findings of this project, as they will be able to develop personal career development programs that give workers back a sense of power and control over their career goals and thus stimulate greater adherence to the reality of telework. 


\section{Objectives}

This study aims to characterise the nature of career management strategies and to develop and empirically test an integrative model that explains the causes and consequences of the use of such strategies for Iberian teleworking adults. In this sense, the following specific objectives are pursued: (a) To characterize the use of behavioural processes (authenticity, balance and challenge) of career management by Iberian teleworking adults; (b) To test existing causal relationships between beliefs of self-efficacy, desire for control over career goals, and perceived organisational support, and the use of career management strategies; (c) To test existing causal relationships between the use of career management strategies and perceived control over career, objective and subjective career success and career satisfaction; (d) To test the impact of sociodemographic variables of the teleworking adults on the causes, behaviours, and consequences of using kaleidoscopic career management strategies; (e) To derive implications of the data for the development of theory on personal career control and to outline methods of promoting career strategies for teleworkers, considering that the idea of "out of sight" may mean "out of mind" in terms of career progression, is seen as one of the main reasons for professionals to be resistant to joining the telework regime.

\section{Methodological work plan}

The implementation of the work programme will take place in three phases.

1st phase: Literature review to update knowledge that will focus on the use of behavioural processes aimed at influencing career results, using referential and full text bases, with access to national and international studies. And, contact, information sharing, and associated work, with international and national researchers who can give more contributions to this research.

2nd phase: Conducting the empirical study, i.e. the study of the measurement model, by collecting data from an Iberian sample of teleworking adults. According to the defined hypothetical model, three antecedent variables contribute to the use of the strategic behaviours of the kaleidoscopic career model. Thus, it is expected that beliefs of self-efficacy (a) desire for control over career goals (b) and perceived organizational support (c) determine the three career management behaviours (authenticity, balance and challenge). But it is also expected that perceived organizational support (d) will influence self-efficacy beliefs and career satisfaction (e). As well, self-efficacy beliefs are expected to influence subjective career success (f). In turn, it is expected that the use of authenticity, balance, and career challenge behaviours will determine four consequential ones, namely perceived career control (g), objective career success (h), subjective career success (i), and career satisfaction (j). Amongst these, perceived career progress influences career satisfaction $(\mathrm{k})$, and objective career success influences both perceived career progress (l) and career satisfaction (m). The possibility of socio-demographic variables affecting the nature, causes and consequences of the use of this type of career strategies is also anticipated (see figure 1). The evaluation of the variables will be carried out using questionnaires (quantitative data). In addition to the measures, information regarding the research and the response procedure will be provided and participants will be informed about the ethical procedures. The evaluation protocol will be placed on an international dissemination platform for studies to facilitate the data collection process.

Figure 1. Kaleidoscopic Career Model: antecedents e consequences on teleworkers.

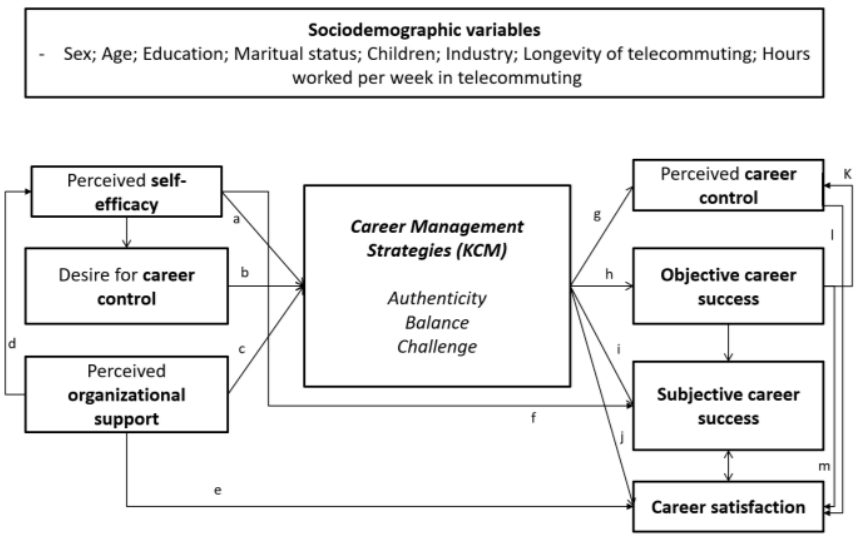

3rd phase: The results of the measurement model are analysed, interpreted, and disseminated. Data will be entered into a database and processed through Structural Equation Modelling (SEM) procedures for the purpose of testing the hypothesised conceptual model. We will analyse the significance of the hypothesised trajectories and assess the overall quality of the model's adjustment to data. The results obtained will contribute to the expansion of the theory of personal control in the career, with 
implications for the design of methods to promote career strategies in organizational contexts, specifically oriented to Iberian teleworkers. In general, the aim will be to contribute to the identification and creation of strategies through which HR departments can support these workers to acquire, train, and develop a set of skills that increase the probability of achieving their career/life goals even in a telework situation.

\section{Expected results}

Despite the important set of studies that we present in the state of art, there is still a narrow understanding about the relationships between the variables included in this study. Moreover, the conclusions from these studies have applicability, mostly, in "traditional" workers. Although official statistics do not exist, with the lockdown due to the coronavirus, it is estimated, that in Portugal and Spain, a great number of workers (about four out of 10) have been developing their activity through teleworking in the past few months. And it is possible that, in a near future, some companies will adhere more easily to this type of work regime. The previous prejudice associated with teleworking has changed due to the pandemic. And, in an economy that will certainly be very fragile, telework may give the necessary boost, within what is possible, to the economy. But, teleworkers, in general, believe that teleworking impairs their advancement towards the desired professional goals. This project will be immensely useful in understanding how people use their personal resources so that they can continue actively in career development. This has never been done more intensely and actively than in these times. With this project we can inform those who work with workers (Human Resources Departments), to promote goals aligned with a more satisfactory career management, and capable of empowering workers in their decision making. On the other hand, from this restructuring of the world of work and telework, new career opportunities arise within the career counselling itself, new challenges, which can only be mitigated when investigated.

\section{References}

Desrosiers, E. I. (2001). Telework and work attitudes: The relationship between telecommuting and employee job satisfaction, organizational commitment, perceived organizational support, and perceived co-worker support.

Greenhaus, J. H., Callanan, G. A., \& Godshalk, V. M. (2010). Career management. Sage.

King, Z. M. E. (2000). The development and initial test of a theory of career self-management (Doctoral dissertation, Birkbeck (University of London).

Kossek, E. E., Roberts, K., Fisher, S., \& Demarr, B. (1998). Career self-management: A quasi-experimental assessment of the effects of a training intervention. Personnel Psychology, 51(4), 935-960.

Lau, A., \& Pang, M. (2000). Career strategies to strengthen graduate employees' employment position in the Hong Kong labour market. Education+ Training.

Lent, R. W., \& Brown, S. D. (2006). Integrating person and situation perspectives on work satisfaction: A social-cognitive view. Journal of Vocational Behavior, 69(2), 236-247.

McCloskey, D. W., \& Igbaria, M. (2003). Does" out of sight" mean" out of mind"? An empirical investigation of the career advancement prospects of telecommuters. Information Resources Management Journal (IRMJ), 16(2), 19-34.

Raabe, B., Frese, M., \& Beehr, T. A. (2007). Action regulation theory and career self-management. Journal of Vocational Behavior, 70(2), 297-311.

Raghuram, S., Wiesenfeld, B., \& Garud, R. (2003). Technology enabled work: The role of self-efficacy in determining telecommuter adjustment and structuring behavior. Journal of Vocational Behavior, 63(2), 180-198.

Sturges, J., Guest, D., Conway, N., \& Davey, K. M. (2002). A longitudinal study of the relationship between career management and organizational commitment among graduates in the first ten years at work. Journal of Organizational Behavior: The International Journal of Industrial, Occupational and Organizational Psychology and Behavior, 23(6), 731-748.

Sullivan, S. E., \& Mainiero, L. (2008). Using the kaleidoscope career model to understand the changing patterns of women's careers: Designing HRD programs that attract and retain women. Advances in Developing Human Resources, 10(1), 32-49.

Van Vianen, A. E., De Pater, I. E., \& Preenen, P. T. (2008). Career management: taking control of the quality of work experiences. In International handbook of career guidance (pp. 283-301). Springer, Dordrecht. 
WORKSHOPS

( 



\title{
RADICAL PRESENT AND REFLEXIVE CONNECTIONS. DIDACTICAL APPROACHES TO ALIENATED SPACES
}

\author{
Nushin Hosseini-Eckhardt ${ }^{1}$, \& Leicy Esperanza Valenzuela Retamal ${ }^{2}$ \\ ${ }^{1}$ Fakultät für Erziehungswissenschaft, Psychologie und Bildungsforschung, Technische Universität \\ Dortmund/Academic Councilor (Germany) \\ ${ }^{2}$ Theater Pedagogy (Germany-Chile)
}

\begin{abstract}
Our starting position is the observation of disappearing public spaces and due to that an increasing alienation in social structures (the global pandemic situation having accelerated this). From two different fields of pedagogy (philosophy of education and performative arts) we aim to set up didactical approaches that give a counterbalance to those tendencies. Especially growing possibilities and challenges of digital formats lead us to a pedagogy of the "Radical Present". On the basis of our previous theoretical research and practical work in schools and workshops we want to discuss and apply concepts and methods of "Reflexive Connections" and „Whole-Body-Performances" as ways of initiating experiences in pedagogical settings. Anyone who shares the interest of finding ways of connection as a joint democratic idea is welcome to participate e.g. teachers, graduate students, masters or doctoral students, researchers and others (8-12).
\end{abstract}

Keywords: Radical present, reflexive connections, spaces of empathy, „, soft eyes “, experience.

\section{Coping with alienated spaces}

Watching tendencies of fragmentation via (digital) social bubbles, alienation from politics up to narratives of post democratic times, altogether being boosted by biased algorithms and the present distanced living and learning in the pandemic situation, our didactical project 'zooms' in on the concepts of the "Radical Present" and "Reflexive Connections". To us as a theatre pedagogue and a philosopher of education it is a professional urge to work on theoretical concepts, didactical methods and pedagogical settings that give balance to those tendencies of alienation.

\section{Forms of the radical present}

The aim of this research is to find methods and concepts for pedagogical spaces of connection and reflection: with oneself, with each other and as a co-existence in a democratic community. We understand these as key aspects to deep learning and "Bildung" based on theories of John Dewey, Maurice Merleau-Ponty, Max Horkheimer/Theodor W. Adorno and Homi K. Bhabha.

Our pedagogical foundation is based on John Dewey's idea of democracy not only being a form of government, but furthermore "a primarily mode of associated living, of a conjoint communicated experience" (Dewey in Bohnsack 2003:11). This idea is banal and complex at the same time. As it refers to the mode of humans as social beings, but also to the complex structures of difference. The dialectics of alienation and connection are, due to this a core aspect in the process of learning as enrichment.

The French philosopher Maurice Merleau-Ponty stresses out the body as a phenomenon that materializes the past, present and future. Our concept of the 'Radical Present' derives from the combination of the body as a chiasmatic entity, but also from its fragility and mortality that points out the immediacy of any perception and cognition (see Merleau-Ponty 1966: 3-18, 91-96).

With the concept of "hybridity" the cultural theorist Homi K. Bhabha uses from a postcolonial perspective almost arty approaches to topics of difference and negotiation as a mode of empowerment. The radicalness of his works is to be seen in the way Bhabha shows the connection between even paradoxical and asymmetrical power relations through the fragility and vulnerability of the human body and mind. Bhabha directs the view to ways of resistance and empowerment through cultural, aesthetic, and linguistic methods and strategies (see Bhabha 2002 and Hosseini-Eckhardt 2021:207). 


\section{Ways of reflexive connections}

The didactical approaches of the "Radical Present" and "Reflexive Connections" are based on three main criteria:

1. Working on human-personal relations in spaces of empathy

Through exercises of re-knowing and observation, we seek to build a time-space where knowing someone else is related to understanding from where (which perspective) we observe him/her. Sometimes we just need to hear a common story of his/her life, to start to empathize and recognize ourselves in an-other.

\section{Initiating experiences}

From a theatrical and performance pedagogy point of view, we can say that the purpose is not to "teach something" but to initiate "experiences".

Every action, such as walking in a room or describing an object, are opportunities to re-discover how we learn, who we are in a particular group of people or at a specific moment in time.

\section{Exercising philosophical watching: "Soft Eyes"}

Connecting these 'here and now' situations to abstract levels of community and society by practicing 'reflective watching'.

\section{Methods of whole- body- performances}

Based on the above concept this workshop will apply hybrid methods. This means a combination of experiments with "Body Performance" such as exercises of "Philosophical Reflections" for present and digital formats.

1. Here and now (1 min of your lifetime with yourself)

For the introduction we apply methods of the choreographer Mary Overlie, inventor of the "six viewpoints" which is a structure for dance improvisation in time and space. It involves the awareness to work with: "Space, Shape, Time, Emotion, Movement and Story” (Bogart, Anne \& Landau, Tina:2014).

2. Radical empathy (3 min of your lifetime with another person)

The methods of the Radical Present are somatic (soma/body-mind) and are based on working with the previously mentioned "here and now" situations and then put them in function to another. That is to listen and try to understand someone from one's radical present. On this occasion we will tell a corporal story -from of ourselves, -from our bodies. A moment of the radical empathy arises when e.g. a story is connected to a corporal experience and is communicated that way. Through this joint corporal aspect (shared vulnerability) others will be able to make a new kind of perception of this story and may even find an empathetic approach to the other person.

3. Physical imagination (Be in the body of someone else)

After listening to another person's story, we will do an experiment concerning empathy. We will try to put ourselves in the body of another person. Using our imagination we will narrate and present the story we were told to others as if it were our own story.

This experiment seeks the recognition of fragilities that bind us together as human beings.

4. Why (Philosophical reflexions of the Radical Present as a consciously experienced time):

"Soft eyes"

- What do I see when I look at something?

- What distracts me?

- How do I widen my view for a broader context? 


\section{Experience of dependence}

To cope with alienation we need to take seriously the paradoxical condition that people are individuals and at the same time seek connection. For that we explore pedagogical potentials of the Radical Present in order to initiate conscious experiences of one's own dependence on- and responsibility for others.

\section{References}

Ahrens, Sönke. (2011). Blickdehnübungen für emanzipierte Zuschauer. Die Lehren aus The Wire. In Zahn, Manuel \& Pazzini, Karl-Joseph (Eds.), Lehr-Performances. Filmische Inszenierungen des Lehrens (p. 164-173). Wiesbaden: VS Verlag für Sozialwissenschaften.

Bhabha, Homi K. (2000). Die Verortung der Kultur. Tübingen: Stauffenberg Verlag.

Bogart, Anne \& Landau, Tina. (2014). The Viewpoints Book. London: Nick Hern Books, The Glasshouse.

Bohnsack, Fritz. (2003). John Deweys Konzept von "Demokratie" als erfülltem Leben. In Bohnsack, Fritz (Ed.), Demokratie als erfülltes Leben (p.11-25). Bad Heilbrunn/Obb.: Verlag Julius Klinkhardt.

Dewey, John. (2000). Erfahrung und Denken. In John Dewey. Demokratie und Erziehung. Eine Einleitung in die philosophische Pädagogik (p.186-203). Weinheim/Basel: Beltz Verlag.

Horkheimer, Max. (1985). Begriff der Bildung. In Horkheimer, Max, Gesammelte Schriften. Band VIII: Vorträge und Aufzeichnungen 1949-1973 (p.409-420). Frankfurt a.M.: Fischer Verlag.

Hosseini-Eckhardt, Nushin. (2021). Zugänge zu Hybridität. Theoretische Grundlagen- Methodenpädagogische Denkfiguren. Bielefeld: Transcript Verlag.

Kallnbach, Siglinde. (2006). Performance - der perforierte Begriff-. In Lange, Marie-Luise (Ed.), Performativität erfahren (p.21). Berlin: Schibri - Verlag.

Menghini, Adalisa. (2016). The Art of Movement. In Hentschel, Ulrike (Ed.), Theater lehren. Didaktik probieren (p.68). Strasburg (Uckermark): Schibri - Verlag.

Merleau-Ponty, Maurice. (1966). Phänomenologie der Wahrnehmung. Berlin: Walter de Gruyter \& Co. 


\title{
PRINCIPLES FOR HOW WE TREAT EACH OTHER: EQUITABLE CONVERSATIONS IN OUR EDUCATIONAL AND PERSONAL SPACES
}

\author{
Jennifer Sanguiliano Lonski, Laurinda Lott, \& Hank Van Putten \\ Peace and Justice Institute, Valencia College (USA)
}

\begin{abstract}
Educators have the unique opportunity to promote equity, change, and social justice ideals to an entire generation. Through daily lessons, classroom norms, and beliefs, classroom teachers can disrupt inequity among students. The Peace and Justice Institute (PJI) at Valencia College has worked with approximately 140 educators through the week-long PJI Teachers Academy over the past three years. This workshop explores the basis of the PJI philosophy, the Principles for How We Treat Each Other: Our Practice of Respect and Community Building (PJI Principles), and discusses social justice practices and norms that research indicates support equity and inclusion in the classroom. This workshop will begin with a brief introduction to the Peace and Justice Institute and the presenter backgrounds. Research has indicated that the practice of reading the PJI Principles aloud, discussing them with members of the community, and focusing on application impacts the way we communicate with each other in our personal and professional spaces. In this session participants will read the PJI Principles aloud, hearing the voices of their online community as they discuss the implications of a standard set of norms. Following the initial reading, the presenters will dive deeper into three of the principles, working with participants to explore practical applications of the PJI Principles. With the understanding that social change towards equity and justice can begin with teachers and their classrooms, this workshop will conclude with research regarding personal and professional change related to the PJI Principles. This presentation is open to all participants.
\end{abstract}

Keywords: Equity, inclusive, social justice, education.

\section{Introduction}

Education does not only instruct students on various content areas, but serves as the introduction to societal norms, beliefs, and expectations through curriculum, lessons, and daily interactions. In this way, classrooms and schools can either reproduce social inequity, or act as disruptors of inequity. In order to serve as the latter, educators need to be equipped with the tools requisite to provide a socially just and inclusive education. The Peace and Justice Institute (PJI) at Valencia College has hosted the Teachers Academy for the past three years, working with 140 educators across 40 schools. While focusing on educators, the Teachers Academy is a part of the larger Peace and Justice Institute that has the mission of "Making a difference by intentionally engaging in practices and principles that explore, advocate, and honor the dignity of self, others, and the earth. (Peace and Justice Institute, 2021). PJI has supported local communities for the past 12 years, including development opportunities for nonprofits, city employees, the faith community, police departments, as well as the faculty, staff, and students at Valencia College.

At the core of the PJI philosophy is a series of thirteen Principles for How We Treat Each Other: Our Practice of Respect and Community Building (the PJI Principles, see Table 1). During PJI and Teachers Academy sessions, participants read and discuss the Principles, and apply them to their personal and professional context. Primary, secondary, and higher education institutions alike have implemented the PJI Principles as norms in their classrooms and community. Throughout the course of two research projects, including a doctoral dissertation, Teachers Academy alumni expressed the importance and significance of the Principles in their personal and professional practices (Sanguiliano Lonski, 2020, Sanguiliano \& Mack, 2020). One Teachers Academy alumni, a second-grade teacher, shared in an interview that the most impactful portion of the professional development was

The PJI Principles ... especially number 10, "When things get difficult, turn to wonder." I encourage the students to listen and think before they speak. They may not agree with their friend, but their friend may be going through a difficult time, maybe dad had to go out of town, maybe they didn't have breakfast, could be a million different scenarios. Stop and turn to wonder. How can you help your friend? Principle 10 will change everything! 
When asked about the PJI Principles, a high school teacher explained, "You can always use them. You can use them when you are disciplining or when you're disappointed, or when something nice happens, you can use some with your praise...", while another stated, "I think the most important thing are just the Principles. Because if you do nothing but instill the Principles for How We Treat Each Other, you're going to be fine." Repeatedly, teachers discussed the importance of the PJI Principles in their classrooms, a paradigm shift from the traditional focus of classroom management and educational professional development (Sanguiliano Lonski, 2020).

Table 1. The PJI Principles How We Treat Each Other: Our Practice of Respect and Community Building.

1. Create a hospitable and accountable community. We all arrive in isolation and need the generosity of friendly welcomes. Bring all of yourself to the work in this community. Welcome others to this place and this work, and presume that you are welcomed as well. Hospitality is the essence of restoring community.

2. Listen deeply. Listen intently to what is said; listen to the feelings beneath the words. Strive to achieve a balance between listening and reflecting, speaking and acting.

3. Create an advice free zone. Replace advice with curiosity as we work together for peace and justice. Each of us is here to discover our own truths. We are not here to set someone else straight, to "fix" what we perceive as broken in another member of the group.

4. Practice asking honest and open questions. A great question is ambiguous, personal and provokes anxiety.

5. Give space for unpopular answers. Answer questions honestly even if the answer seems unpopular. Be present to listen not debate, correct or interpret.

6. Respect silence. Silence is a rare gift in our busy world. After someone has spoken, take time to reflect without immediately filling the space with words. This applies to the speaker, as well - be comfortable leaving your words to resound in the silence, without refining or elaborating on what you have said.

7. Suspend judgment. Set aside your judgments. By creating a space between judgments and reactions, we can listen to the other, and to ourselves, more fully.

8. Identify assumptions. Our assumptions are usually invisible to us, yet they undergird our worldview. By identifying our assumptions, we can then set them aside and open our viewpoints to greater possibilities.

9. Speak your truth. You are invited to say what is in your heart, trusting that your voice will be heard and your contribution respected. Own your truth by remembering to speak only for yourself. Using the first person "I" rather than "you" or "everyone" clearly communicates the personal nature of your expression.

10. When things get difficult, turn to wonder. If you find yourself disagreeing with another, becoming judgmental, or shutting down in defense, try turning to wonder: "I wonder what brought her to this place?" "I wonder what my reaction teaches me?" "I wonder what he's feeling right now?

11. Practice slowing down. Simply the speed of modern life can cause violent damage to the soul. By intentionally practicing slowing down we strengthen our ability to extend nonviolence to others - and to ourselves.

12. All voices have value. Hold these moments when a person speaks as precious because these are the moments when a person is willing to stand for something, trust the group and offer something they see as valuable.

13. Maintain confidentiality. Create a safe space by respecting the confidential nature and content of discussions held in the group. Allow what is said in the group to remain there.

\section{Primary objective}

The primary objective for this session is to identify ways the PJI Principles for How We Treat Each Other enhance our personal and professional lives. This workshop is not intended to be a substitute for the 40-hour PJI Teachers Academy professional development session. The weeklong Teachers Academy explores a myriad of topics beyond the Principles including an in-depth analysis of personal beliefs, privilege, and biases, before addressing curricular concerns, understanding Adverse Childhood Experiences (ACEs), inclusive and social justice education, restorative practices, and equity in education. The current workshop serves as an introduction to the PJI Principles, and the beginning of a discussion of equity in educational and personal spaces. 


\section{Workshop design}

This workshop will begin with an introduction of PJI, PJI Teachers Academy, and the presenters. To best replicate the PJI experience, participants will be asked to read the full text of the PJI Principles aloud. It is through hearing the PJI Principles read by different members of the community that the impact and gravity of each Principle can begin to be fully embraced. After reading the principles aloud, the participants will be divided into breakout rooms for moderated discussions on the applications of the PJI Principles in educational, professional, and personal spaces. The presentation will conclude with the breakout sessions rejoining as a centralized group to share highlights from their discussions. The presenters will also review recent research related to PJI Teachers Academy.

\section{References}

Peace and Justice Institute. (2021). PJI Principles How Se Treat Each Other. Retrieved January 18, 2021, from https://valenciacollege.edu/students/peace-justice-institute/who-we-are/principles.php

Peace and Justice Institute. (2021). Who We Are: Our Vision. Retrieved January 18, 2021, from https://valenciacollege.edu/students/peace-justice-institute/who-we-are/

Sanguiliano Lonski, J. (2020). Social Justice, Inclusive Education, and Teacher Agency. (Doctoral dissertation). Retrieved from https://stars.library.ucf.edu/etd2020/281

Sanguiliano, J., \& Mack, R. (2020) A Look Inside: The Peace and Justice Institute Academy for Teachers' Influence on Participant Professionals. Peace and Justice Institute Journal, 10(2), 8-11.Retrieved January 18, 2021 from: https:/valenciacollege.edu/students/peace-justiceinstitute/resources/documents/pji-journal-vol10no2-interactive.pdf 


\section{AUTHOR INDEX}

Adegoke, O.

280

Agreda Montoro, M.

Aina, A.

Albu, A.

Albuquerque, $\mathrm{C}$.

Aldinah, S.

Alexander, G.

$155,163,172,182,601,610,620$

Alkorta Egiguren, $\mathrm{P}$.

Al-Mahdi, O.

462,588

Almeida, B.

231

Almeida, F.

482

Amante, $\mathrm{S}$.

Andreou, L.-V.

Antunes, A.

Arame, $\mathrm{M}$.

Araneda-Guirriman, C.

Armie, M.

Arnold, M.

Arredondo-Hidalgo, M.

Baetens, J.

Batista, S.

Beg, A.

Bembich, C.

Besnard, C.

Beukes, J.

Bianchi, D.

Biffi, E.

Bonnet, $\mathrm{M}$.

Bosco, A.

Boz, S.

Brasili, S.

Caldera González, D.

Cámara-Estrella, A.

Campos, N.

Canto Herrera, $\mathrm{P}$.

Capellini, S.

Cardona-Moltó, M. C.

Cardoso, J.

Carmo, S.

Carriera, L.

Carvalho, G.

Carvalho, N.

187

250

64

482

344

673,679

482

294

121

270

376

167

420

583

44

23

534

348

69, 597

69

424

434

573

486

167

319,329

49

646

549

265

339

192

597

549
Casanoves-Boix, J.

593, 615

Castellano-Almagro, R.

187

Ceschi, A.

226

Chanetsa, $\mathrm{T}$.

539

Charles, C.

563

Chen, M.

363

Chen, M.-J.

667

Cheng, C.-H.

667

Chiner, E.

265

Choi, S.

299

Choi, S.

521

Chouvarda, I.

643

Coleman, S.

649

467

Costa, A.

344

Costa, C.

344

Coutinho, E.

344

Crovetto, C.

214

Cruz-García, A.

593, 615

Cunha, M.

49, 482

Cusack, T.

643

111

Cysneiros Filho, G.

334

D'Alessio, A.

304

Da Milano, C.

111

da Silva, N.

294

Daimon, $\mathrm{T}$.

214

De Barca, P.

$610,620,630$

de Munnik, M.

231

655

De Nicola, A.

344

Delplancq, V.

434

Di Carmine, F.

236

Di Martino, V.

679

Diamantopoulou, C.

319, 329

Díaz-Pareja E.

64

Dima, F.

506

Domazet, M.

396, 496

Dominguez-Perez, D.

396, 496

Dominguez-Vergara, N.

8,578

Economides, A.

245

Ehrhardt, L.

511 
Estrina, T.

141,429

304

640

Falcón Linares, C.

Fernández, J.

Ferrantino, C.

Fidalgo, S.

Filos, D.

Flores Castro, H.

Flores-Pérez, J.

Fojcik, M.

Forsyth. H.

Frolli, A.

Gallardo, F.

Gálvez, J.

Gamper, L.

Gao, S.

Garcés Mancero, F.

Garcia, G.

García-Vera, V.

Garrido Hernández, A.

Garrido Hernández, I.

Gillain, R.

Goda, Y.

Gómez-Puerta, M.

Gostimir, M.

Grandits, P.

Grigsby, M.-R.

Guida, M.

Gupta, A.

Gutiérrez Albán, L.

Hájková, P.

Han, X.

Handa, J.

Hanesová, D.

Hass, A.

Hațegan, C.

Hathazi, A.

Hazy, C.

Hernández Espino, A.

Herreros, T.

Hosseini, Z.

Hosseini-Eckhardt, N.

$\mathrm{Hu}, \mathrm{Y}$.

Huang, A.

Hui, V.
Iannotta, I.

Kerr, R.

610,620

Kgothule, R.

44

309

299, 309

Kim, Y.

563

406

429

290

126

391

679

554

411

79,457

658

275

324

74

601

670

444

197

670

371

630

146

59

319, 329

434

690 
Lopez Garcia, P.

Lott, L.

Louw, J.

Mai, V.

Makura, A.

Malach, J.

Mangwegape, B.

Mantshiyane, N.

Martens, A.

Martija López, I.

Martínez-Gómez, M.

Martínez-Poveda, B.

Martins, I.

Martins, R.

Maseda Rego, F. J.

Masoabi, C.

Matoti, S.

Matsuba, R.

Matsuyama, Y.

Mavuru, L.

Medina, J.

Membrive, V.

Merchante, C.

Merciai, I.

Meyer, M.

Migone, $\mathrm{P}$.

Milanes, $\mathrm{M}$.

Mjånes, J.

Mkhwanazi, N.

Mokhothu, K.

Mokoena, A.

Mollo, P.

Montà, C.

Montebello, M.

Morais, B.

Morrone, $\mathrm{M}$.

Motloung, A.

Mountford, N.

Moutsios-Rentzos, A.

Mpisi, A.

Murphy, M.

Myers, M.

Narváez Ríos, M.

Nechita, A.

Nestora, A.
Niitra, M. 568

Nolka, E.

116

Nthejane, L.

217

Nugroho, A.

358

Nunes, C.

549

Ochoa-Luna, J.

358

Ogegbo, A.

250, 280

Oh, Y.

516

Oliveira, I.

344

Olson, K.

159

Opić, S.

506

Ortega-Tudela, J.

319, 329

Ortiz-Colón, A.

187

Palmer, J.

Pap-Szigeti, R.

Peens, S.

$610,620,630$

Pereira, J.

150

Perifanou, M.

344

Perini, M.

8,578

226

Petolicchio, A.

334

Phindane, $\mathrm{P}$.

136, 381

Piergallini, R.

486

106

615

682

420

245

275

661

401

661

646

$84,93,102$

501, 539

376

39

344

434

424

187

637

126

568

568 
Sandell, E.

Sapountzi, V.

Sarmiento, K.

Sartori, R.

Savona, A.

Schmidt, W.

Schumacher, S.

Seloma,P.

Sepúlveda-Páez, G.

Serban, I.-L.

Serpe, A.

Setlalentoa, W.

Shapir, B.

Shih, S.

Silva, C.

Sofianopoulou, C.

Sondlo, A.

Sorzio, P.

Souto, L.

Stadler-Altmann, U.

Stanley, C.

Strongoli, R.

Szigeti, M.

Talaş, D.

Tammaro, R.

Tammaro, R.

Tandzegolskienè, I.

Tarantino, A.

Toda, M.

Tommasi, F.

Török, E.

Trifu, R.

Truyen, F.

Tsai, H.

Tseng, H.

Twarog, S.

Valenzuela Retamal, L.

Van Der Putten, S.

Van Putten, H.

Van Zyl, P.

Varney, P.

Vicherková, D.

Vlada, M.

Ward, M.
529

172, 381

146

363

192

116, 511

501

23

192

353

358

236

205

314,415

525

334

74

201

294

226

177

314, 415

420

363

13

429

687

88

690

182

424

452

64

366
159

44

673

Werdina, L. 429

Williams, T.

172

673

141

Winschiers-Theophilus, $\mathrm{H}$.

358

226

Wizel, M.

97, 260

Wolf, S.

424

472

Wong, $\mathrm{T}$.

79

554

Woodward, J.

658

353

Zabeli, N.

290

93

Zengeya, T.

601

121

Zhou, G.

429

221

Zhubi, A.

285 